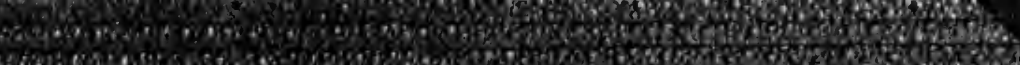

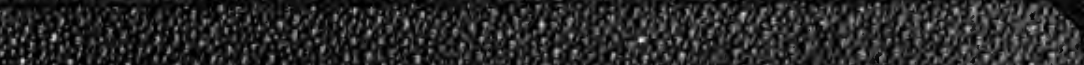

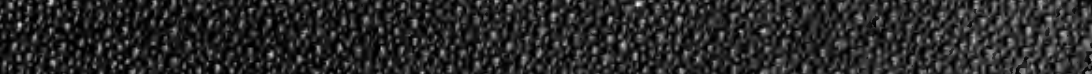

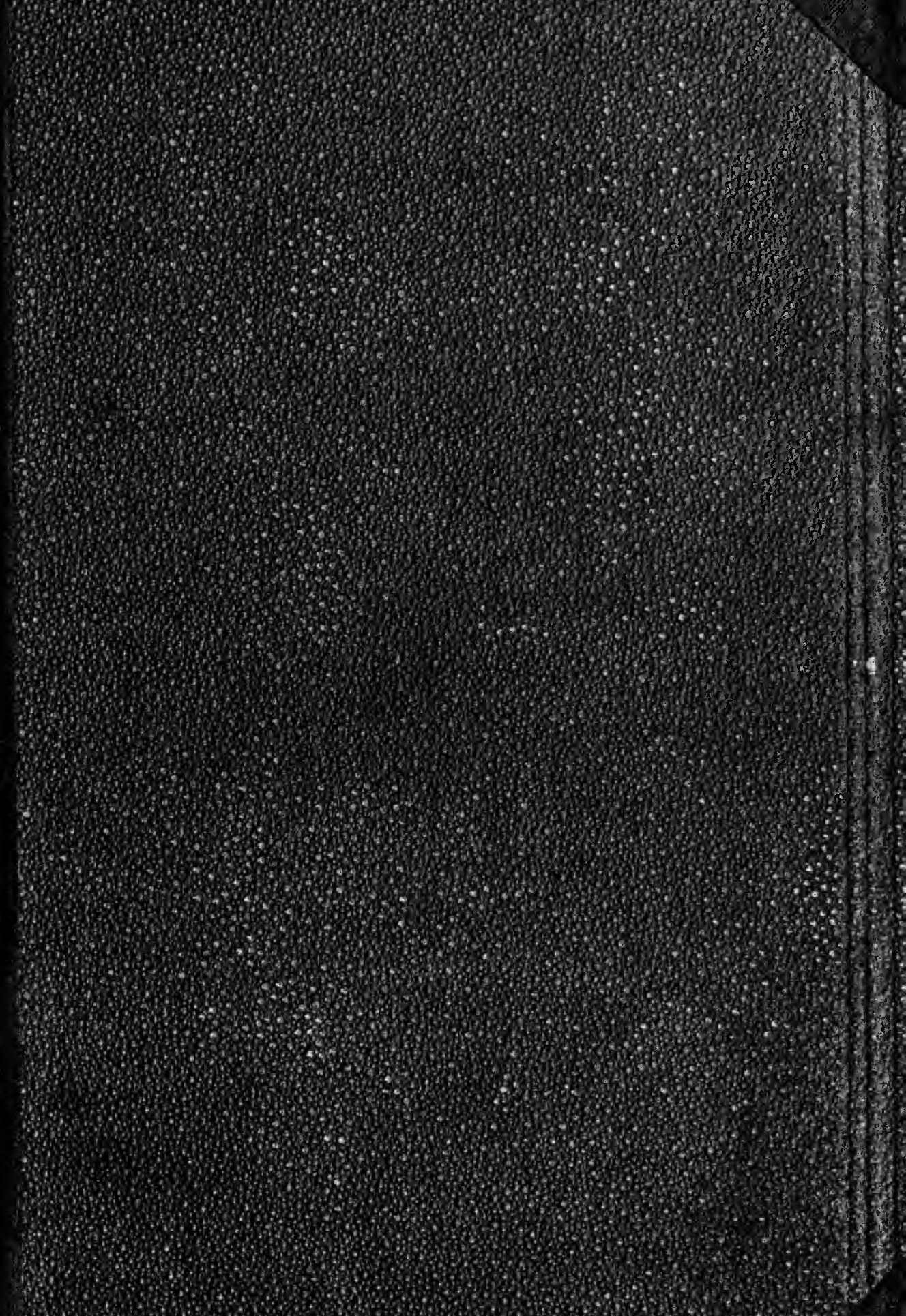




Digitized by the Internet Archive in 2007 with funding from Microsoft Corporation 


\section{PRACTICAL TREATISE}

ox TIIE

\section{DISEASES OF WOMEN.}

$B Y$

\section{T. GAILLARD TIIOMAS, M.D.,}

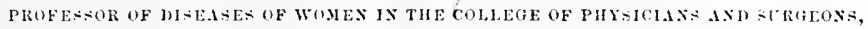
SEW YORK ;

PRESIDIST OF TIF AMERICAN GYXEOLOMICAL SOCIFTY FOR 1 TiS:

VICE-PRESLEST (IF TIE SEW YORK ACAIENY OF MLUICISE:

SLRARONTOTHE NEW YORK STATE WOMAN'S HOEPITAL;

PREAIJEST OF THE MLDICAI. BOARD OF THE NIESERY ASD CHJLD' HOSPIT.L, NEW YORK;

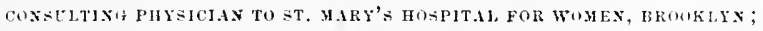

HOSORARY FELLOW OF TIFE OBFTETRIC.AL SUCIETY OF LOXDUN :

CORRESPOSDIXIA FELLOW OF THE OBATETRICAL SUCLETY OF BLRLIX,

OF THE MLDIC.AL SOCHETY OF LIMA,

ASI OF THE OBSTETRICAL SOCIETY OF PHHAADELPHA;

HOSORARY MEMBER OF THE SOLTII C.IROLAS. MEDHCAL ASSOCIATION A.L OF THE

LOLISVILLE OBSTETRICAL SOCIETY.

FIFTII EDITION,

ENLARGED AND THOROCGHLY REYISED.

CONTAINING TWO HUNDRED AND SIXTY-SIX ENGRAVINGS ON WOOD.

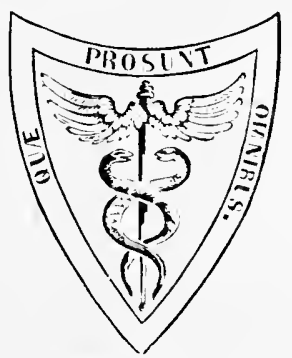

P H I L A D E L. P II I A :

IIEXRY C. LEA'S SON t CO.

1880 . 
Entered according to Act of Congress, in the year 18s0, by II ENRY C. LEA'S SON \& CO. in the Ofice of the Libraitian of Congress. All rights reserved. 


\section{TO \\ JOHN T. METCALFE, M.D., \\ SEW YORK.}

MY DEAR DOCtOR:

I venc.te to you the fifth as I have done the four previous editions of this work. If its merits have grown with time as steadily as our friendship has done, I shall feel fully satisfied with the results of my lahor:; and if it reeeive from my professional brethren only a tithe of such kinduess as that for which during a quarter of a century I have been indebted to you, I sliall be grateful indeed.

Sincerely your friend,

T. GAILLARD THOMAS. 



\section{PREFACE TO TIL FIFTH EDITIOX.}

Twelve years have elapsed since the publication of the first edition of this work. In that time four successive editions have appeared, and its author, recognizing the great adrances which during that period have been made in gynecology f fully appreciates the fact that a text-book which aspires to meet the demands of 1880 must of necessity be very different from one which was offered to supply those of 1868 . He has devoted two years of labor to the enteavor to bring this edition to the level of the present state of the science of which it treats; with what success the reader will judge.

That many new views, new methods, and new remedies which have of late years been lauded in gynecology pass ummentioned will at once be apparent. The author's object has been to write a practical work, not an encyclopedia; to record views and methods which recommend themselves on account of their merit, not merely of their novelty. So rapidly do new things present themselves in this active department of medicine, howerer, that it must be stated that some innovations which apparently possess merit have been left ummentioned because sufficient time has not elapsed for their trial.

To the medical profession in America the author would express his sincere thanks for numberless acts of kindness, 
encouragement, and courtesy, which have stimulated his ambition to improve a work which has met their generous endorsement and lightened the labor which has attended his efforts.

The kindly reeption of previous editions of this work in Europe, as eridenced by its translation into German, French, Italian, and Spanish, has given the author sincere gratification, and he avails himself of this opportunity of thanking the translators for the very careful manner in which they have performed their work, and the uniform courtesy which they have shown to him.

Upon two points he would ask the lenient judgment of his readers: first, the mechanical contrivances for the treatment of flexions of the uterus, which should be honestly tried before being judged; and second, the diagrams illustrative of the perineum and its injuries, which to one who has not carefully considered the subject may appear exaggerated.

For the index of this erlition, which the author regards as a good type of what an index should be, he is indebted to his triend Dr. S. Beach Jones.

NEW Yonk,

294 Fifth Arenue, Sept. $26,1880$. 


\section{0 N T E N T S.}

\section{CIIAP'TER I.}

IItetorical Sketch of Gracology

\section{CIIAP'TER II.}

The Eriology of Lterise Disease

Neclect of Exercise and Physical Development . . . . . . . . 4. 43

Excessive Development of the Nervous System . . . . . . . 4.)

Inproprieties of Dress . . . . . . . . . . . . 45

huprudence during Menstruation . . . . . . . . . . . 47

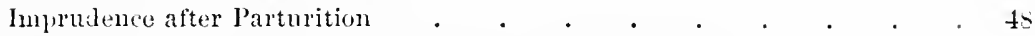

Non-recognition or Neglect of Injuries due to Parturition . . . . . 4s

Prevention of Conception and Induction of $A$ bortion . . . . . . . 50

Marriage with Existing Lterine Disease . . . . . . . . 51

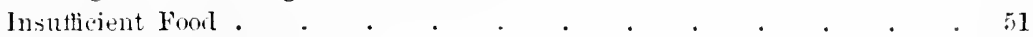

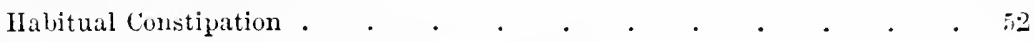

\section{CILAPTER III.}

Gexenal Cossineratioss upon Uterixe Patiology and Treatiext . . 54

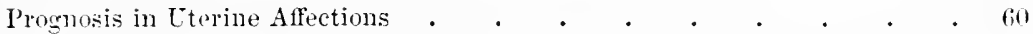

Reasuns for the Frequency of Failure in the Treatment of Cterine Diseases . 61

\section{CHAPTER IV.}

(iexeral Cossmeratioss tpox some of the most Importaxt Tuerapeltic

REsorRCES OF GYNECOLOGY . . . . . . . . . . . 66

(ieneral System of Diet and Exereise , . . . . . . . . 66

Pessarios . . . . . . . . . . . . . . . . 6 . . . .

Precautions to be Observed in Operations . . . . . . . . . . . 70

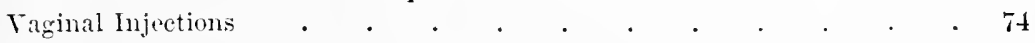

The Tampon . . . . . . . . . . . . . . . . .

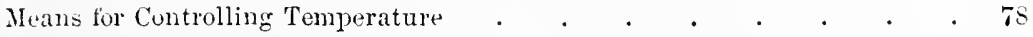

\section{CHAPTER V.}

Diagosis of tile Diseases of the Female Gexital Orgaxs . . . . . E

Rational Signs of these Diseases . . . . . . . . . . . . . 82

Nimagrment of Patient dnring Plysical Exanination . . . . . St

Neans of Physical Diagnosis . . . . . . . . . . . . . . . . . . . . . .

Anæsthesia . . . . . . . . . . 87 


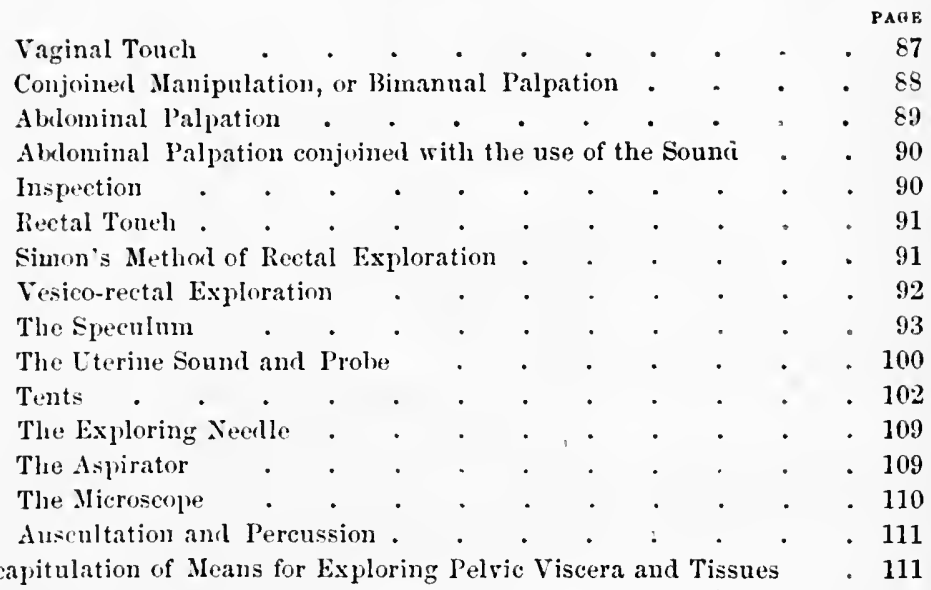

\section{CIIAPTER VI.}

Cosgexital axi Isfantile Malformatoss of tue Female Sexcal Organs - 112

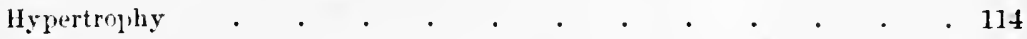

Abence and liulimentary Development of the Cterus and Ovaries . 115

Congenital Misplacement of the Uterus _ . . . . . . . . . 119

Alsence and Rudimentary State of the Ovaries . . . . . . . . 119

Alsence and Rudimentary State of the Vagina . . . . . . . . 119

Anomalies of Cterine Development during Childhood . . . . . . 119

\section{CIIAPTER VII.}

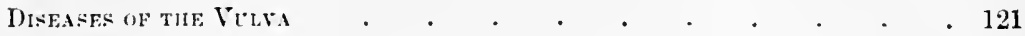

Sormal Anatomy . . . . . . . . . . . . . . 121

Vulvitis . . . . . . . . . . . . . . 122

l'urulent Vulvitis . . . . . . . . . . . . . 122

Follicular Vulvitis . . . . . . . . . . . . . . . . 124

Cyst and Alscess of the Vulro-raginal Glamess . . . . . . . 126

Eruptive lisuases of the lulva . . . . . . . . . 128

Phlomemons Inflammation of the Labia Majora . . . . . . . 129

liupture of the Bulls of the Vestibule . . . . . . . . . 130

loukmal lfemorrlage . . . . . . . . . . . . . . 130

Purinulal Henatowel.. . . . . . . . . . . . . . . . 131

l'udendal II ruia . . . . . . . . . . . . . . 134

IIyllocele . . . . . . . . . . . . . . 136

\section{CIIAPTER VIII.}

P'ruritus Vulrip . . . . . . . . . . . . . . . 138

$11 y$ yerathesia of the Vulva. . . . . . . . . . . . . . 145

[rritable lrethrial carmule . . . . . . . . . . 147

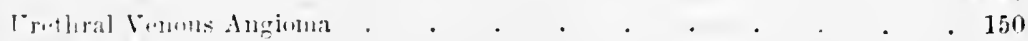

Prolapiselretlire . . . . . . . . . . . . . 150

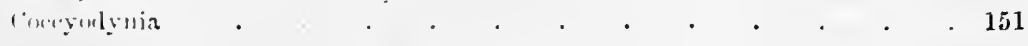




\section{('IIP'TER IX.}

P.in:

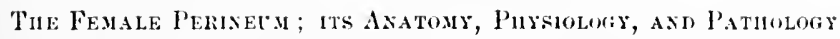
1.54

\section{CIIAP'TER X.}

Prollape of Vagisi, Bladder, Rectum, and Istestines . . . . 168

I'rolapise of the Vagina

Cystecele, or Prolape of the Bladider . . . . . . . . . 172

Rectocele, or l'rolapse of the Reetum . . . . . . . . . . 17:

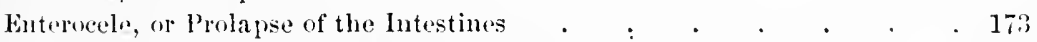

Treatment of Vagrinal Prolape and IIernice. . . . . . . . 17t

Colporhaphy or Elytrorrhapliy . . . . . . . . . . . 176

\section{CIIAPTER XI.}

Screical Mfaxs Amapted to Restoration of tue Perineal Body . . . 182

Varieties of lerineal laceration . . . . . . . . . . 180

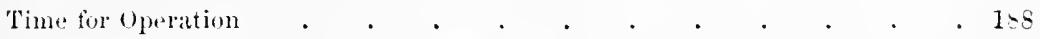

T'reatment of Cases which have Cicatrized . . . . . . . . . . 160

Gperation for Partial Rupture . . ‘. . . . . . . 102

Operation for Complete Rupture . . . . . . . . . . 192

CIAPTER XII.

Vagrisuls

\section{CIIAPTER XIII.}

Vacisitis

Simple Vaginitis

Specific Varinitis or Gonorrluea

Gramular Vaginitis

\section{CIIAPTER XIV.}

Atresia of the Gexital Tract axn Retextion wituin it of Mexstrital blood

AND OTHER Fletes . . . . . . . . . . . . . 200

Atresia of the Cterus. . . . . . . . . . . $\mathbf{2} 21$

Atresia of the Vagrina. . . . . . . . . . 224

Operative Procedures . . . . . . . . . . . . . 229

\section{CHAPTER XV.}

Fintil.e of the Female Gexital Organs . . . . . . . . 233

Erinary Fistule . . . . . . . . . . . . 233

Vesico-raginal Fistula . . . . . . . . . . . 233

Uretho-raginal Fistula. . . . . . . . . . 2034

Vesico-nterine Fitnla . . . . . . . . . . 234

Vesicu-utero-ratginal Fistula . . . . . . . . . . 234 
Treatment . . . . . . . . . . . . . . . . . . . 245

Cauterization . . . . . . . . . . . . . . . . 245

suture . . . . . . . . . . . . . . . . . . 245

Sims's Operation : . . . . . . . . . . . . . . 246

Simon's Operation . . . . . . . . . . . . . . . 252

Elytroplasty . . . . . . . . . . . . . . . . . . . 258

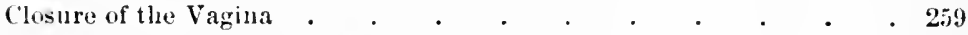

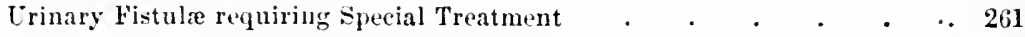

Vesico-uterine Fistule . . . . . . . . . . . . . . 261

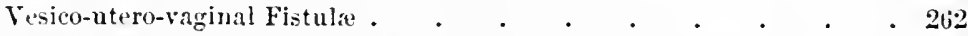

Fistula with Extensive Destruction of the Base of the Bladder $\quad . \quad$. 262

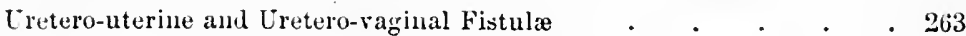

\section{CHAP'TER XVI.}

Fecal Fistlle . . . . . . . . . . . . . 265

Entero-raginal Fistula . . . . . . . . . . . . 267

simjle Vaginal Fistule . . . . . . . . . . . 267

\section{CHAPTER XVII.}

Acte Exdonetritis

\section{CIIAPTER XVIII.}

Chrosic Cervical Exdometritis

\section{CIIAPTER XIX.}

Curosic: Conporpal Exmonetrits

Injections into the Cterine Cavity

\section{CIIAPTER XX.}

Areolar Hyperplasia of the Lteres-The so-called Curosic PareachinaTul's METRITL

\section{CIIAPTER XXI.}

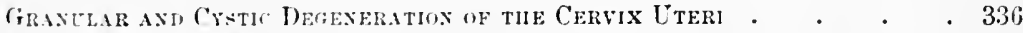
(iranular D)egeneration of the Corvix . . . . . . . . . 337 Cystic or Follienlar bereneration of the Cervix . . . . . . . 342

\section{CIIAPTER XXII.}

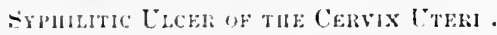

CIIAPTER XXIII. 


\section{CHAPTER XXIV.}

Lacerition of the Cervix Uteri .

\section{CIIAPTER XXV.}

Gexemal Cossiderations tpox Displacenexts of tile Uteres 363

\section{CIIAPTER XXVI.}

Aecext and Descext of the Uteres . . . . . . . . . . . 381

Ascent of the Uterus . . . . . . . . . . . . . . . . 351

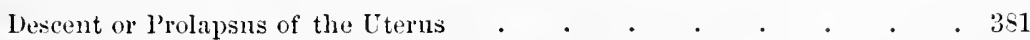

Methorts of Replacing the Uterus . . . . . . . . . . . . 394

Iethorls of Sustaining the Uterus . . . . . . . . . . 395

Pessaries . . . . . . . . . . . . . . . 401

\section{CHAPTER XXVII.}

Anterior Displacenients of the Utert's . . . . . . . . . 405

Antecersion . . . . . . . . . . . . . 405

Antetlexion . . . . . . . . . . . . . . 410

Treatment of Anterior Displacements . . . . . . . . . . 413

Heans for Reduction . . . . . . . . . . . 413

Means for Retention of the Cterus in Position . . . . . . . 417

P'essaries . . . . . . . . . . . . . 420

Operation for Irreducible Cervical, Corporeal, or Cervico-corporeal Flexion . $\quad \$ 29$

\section{CHAPTER XXVIII.}

Posterior Displacemexts of the Utercs . . . . . . . . 432

Retroversion and Retroflexion . . . . . . . . . 432

Methols of Reduction . . . . . . . . . . . . . 435

Neans for Retaining the Uterus in Position . . . . . . . . 442

Pessaries . . . . . . . . . . . . . 445

Laterotlexion $. \quad . \quad . \quad . \quad . \quad . \quad . \quad . \quad . \quad . \quad . \quad .452$

\section{CHAPTER NXIX.}

INYERSiON OF THE UTERTS . . . . . . . . . . . . 453

Methols of Checking IImorrhage, the Ltarns being left in sitü . . . $\$ 62$

Methods of lieplacing the Lterus . . . . . . . . . . 463

Gradual Reduction . . . . . . . . . . . 465

Rapil Reduction . . . . . . . . . . . . . . 467

Metlods of Amputating the Lterns . . . . . . . . . 4 47

CIIAPTER XXX. 
CHAPTER XXXI.

Pelic Peritonitis

\section{CHAPTER XXXII.}

Pelvic Abscess

Methods of Operating .

Neans for causing closure of the sae

\section{CIIAPTER XXXIII.}

Pelvic Hexatocele

Methods of Operating

\section{CIIAP'TER XXXIV.}

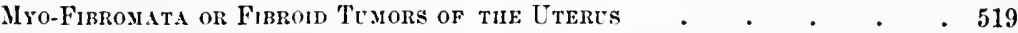

Palliative Treatment . . . . . . . . . . . . 528

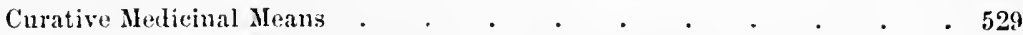

Curative Surgical Procedures _ . . . . . . . . . . . 532

Laparotomy . . . . . . . . . . . . . . . . 545

Hethods of removal of the Cterus . . . . . . . . . 548

\section{CIIAPTER XXXV.}

Crsto-fibromata, or Fibro-crstic Tranos of tile Uteres

\section{CIIAPTEI XXXVI.}

Uterine Polyt

Palliatios Treatment

Curative Treatuent

\section{CIIAPTER XXXVII.}

Sarcoma avi ADexoma of the Uthers.

CIAP'TER XXXVIII.

Cancer of the Ltemes: 


\section{CHAP'TER XXXIX.}

PARP

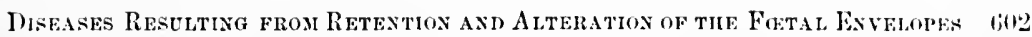
Eterine Moles . . . . . . . . . . . . . . 6012 Cystic begeneration of the Chorion, or Cterine Hydatids . . . . . 604

\section{CIIAP'TER XL.}

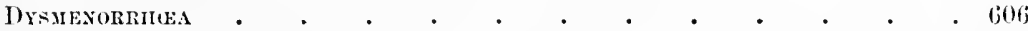

Neuralgic Dysmenorrhoi . . . . . . . . . . (6ill

Congestive or Inflammatory Dysmenorrhoea . . . . . . . . 611

Oistructive Dysmenorrhœa . . . . . . . . . . . 613

Membranous Dysmenorrhea . . . . . . . . . 620

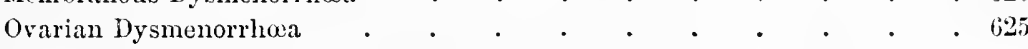

CIIAPTER XLI.

Mexorkitagia and Metrorrilagia.

\section{CIIAPTER XLII.}

A MExorRhuei

\section{CILPTER XLIII.}

LETCORRIIEA

\section{CHAPTER XLIV.}

STERILITY $6+8$

\section{CIIAPTER XLV.}

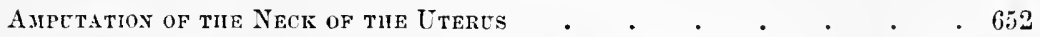

Operation by Bistoury or Scissors . . . . . . . . 654

Operation by Ecraseur . . . . . . . . . . . . 654

Operation by Galvamo-Cantery . . . . . . . . . . 655

\section{CIIAPTER XLVI.}

Diseases of pHe Ovaries

Absence

Imperfect Development

Atrophy

Ovarian Apoplexy

Displacement

Ovaritis

Acnte Oraritis

Chrome Ovaritis 


\section{CHAPTER XLVII.}

Ovariax Tumors

Carcinoma . . . . . . . . . . . . . . . . 673

Fibroma or Fibrous Tumor . . . . . . . . . . . . . 675

Cysto-Carcinoma . . . . . . . . . . . . . . 676

Cysto-Fibroma or Cysto-Sarcoma . . . . . . . . . . . 677

Dermoid Cysts . . . . . . . . . . . . . . . 679

Colloid Degeneration . . . . . . . . . . . 680

\section{CIIAPTER XLVIII.}

Ovarian Crsts ayd Crstomati

Cysts of the Broad Ligaments

Parasitic or Hydatid Cysts

Tubal Dropsy

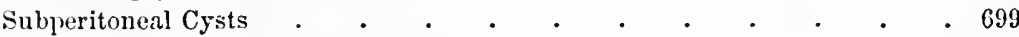

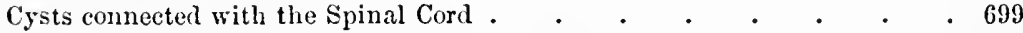

Aspiration . . . . . . . . . . . . . . 715

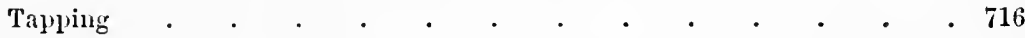

\section{CHAPTER XLIX.}

Ovaniotouy

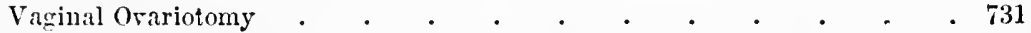

Abdominal Ovariotomy

\section{CHAPTER L.}

Ö̈PHORECTOMY

\section{CIIAPTER LI.}

Diseases of the Faldoplas Tebes

\section{CIIAPTER LII.}

Extha-teteme l'reginary

CIIAPTER LIII. 


\section{LIST OF ILLUSTRATIONS.}

Fu.

1. Ancient valrular specula (Scultetus)

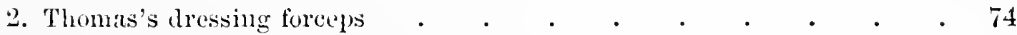

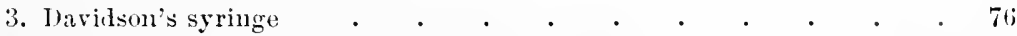

4. Vacrinal syringe nozzle, with reverse current . . . . . . . 76

5. Sims's serew for remoring a tampon . . . . . . . . . . . . . 78

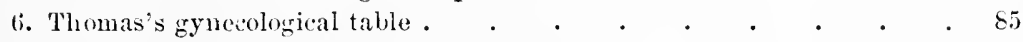

7. Themas's gynecological table. . . . . . . . . . . . . . . 86

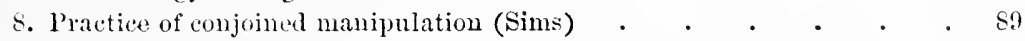

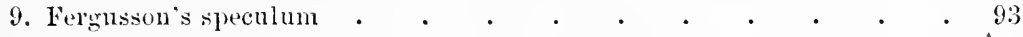

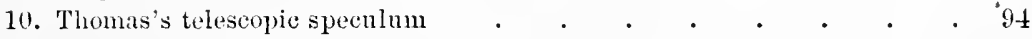

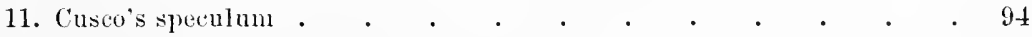

12. Howard's modification of Cusco's speculum . • • • • • • • • 95

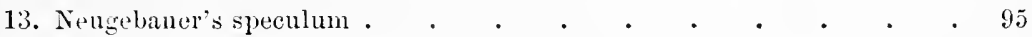

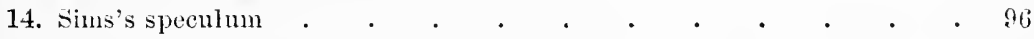

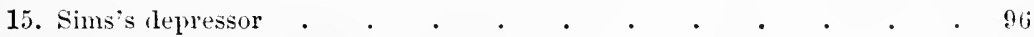

16. Nott's speculum closed . $\quad . \quad$. . . . . . . . . . . . 97

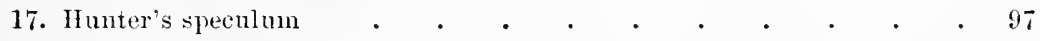

18. Thomas's modification of Sims's speculum • • • • • • • • . 97

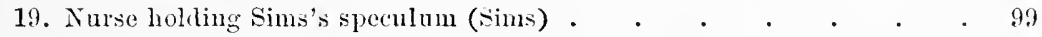

20. Position of woman in examining with Sims's speculum (Leblond) • 99

21. Soumls of Simpson and sims compared . . . . . . . . . 101

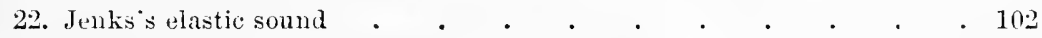

23. A sponge-tent, with thread passing through it . . . . . 103

24. A sea-tangletent . . . . . . . . . . . . . 104

25. A tupelo tent before and after introduction and expansion . . . 10.)

26. Tenaculum for fixing the uterus . . . . . . . . . . . . . . 106

27. Introluction of a tent (Sims) . . . . . . . . . . . . . . . . . 106

25. Dieulatoy"s aspirator . . . . . . . . . . . . . . 109

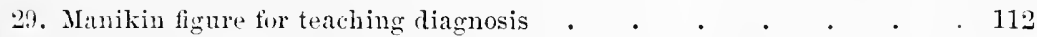

30. Conlescence of Hüllerian ducts in a foetal sheep (I. Müller) • • . 113

31. A. S., aged 4 years and 9 months. Nenstruated regularly from the age of 21 montlis . . . . . . . . . . . . . . . . 114

32. Bow-shapul rudiment of uterus (Nega) . . . . . . . . . . . . 115

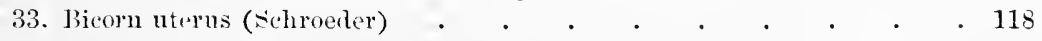

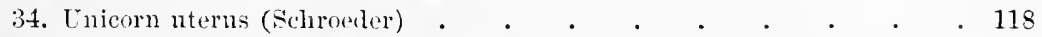

35. 1)uble uterus (from specimen in possession of author) . . . . . 118

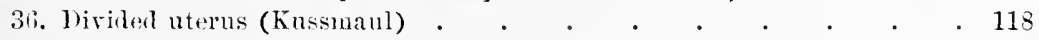

37. Development of Graafiun vesicles (Kuss. Pliysiology) . . . . . 119

38. Follicular vulvitis (luguier) . . . . . . . . . . . . 125

39. Plesus of veins of the restibule (Kobelt) . . . . . . . . . 130 
FI6.

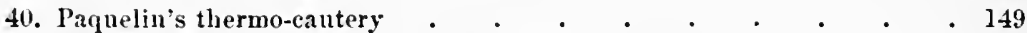

41. Diagram ordinarily used for representing the perineum . • • • 156

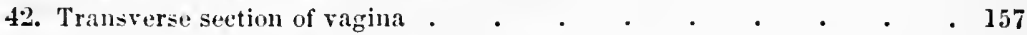

43. Normal relation of the pelvic viscera $. \quad . \quad . \quad . \quad . \quad . \quad . \quad 158$

44. Sehematic diagram of perineal buly . . . . . . . . . . 160

45. The same, perineal body removed . . . . . . . . . . . . 160

46. The perineal hody destroyed, the rectal wall descends . . . . . 161

47. The perineal body destroyed, both rectal and vesical walls descend . 161

45. An elastic rol when bent yields towards its convex surface . . . 162

49. An elastic rod with double curres yields in opposite directions . . 162

50. An elastic strip, with decided convex curve below, will rery decidedly $y$ yeld in the direction of lower arrow . . . . . . . . . . . . 163

51. Sins is operation for colporrhaphy (Sins) . . . . . . . . . 178

52. Sins s nperation. Slrape of denudation and position of uterus . . 179

53. Emmet”s operation : first step . . . . . . . . . . . 179

54. Emmet's operation : second step . . . . . . . . . . . . . 179

万. Oroid denudation, with sutures passed . . . . . . . . . . 180

56. Periueal boly perfect; both vaginal walls sustained . • . . 183

57. Perineal bolly removed by rupture; loth vaginal walls robbed of support 184

5. Perinetun improperly repaired . . . . . . . . . . . 185

59. Thomas's tooth forceps . . . . . . . . . . . . . 191

60. Slightly curved scissors . . . . . . . . . . . . . . . . 191

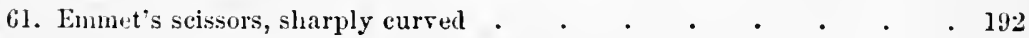

62. Profile view of perineum . . . . . . . . . . . . . . 192

63. Sehematic view of part to be denuded . . . . . . . . . . . . 193

64. Dunulation for repair of perineum (Savage) . . . . . . . . 194

65. One of the blecding triangles which are to be ereated . . . . . 195

60. The two bleserling triangles alout to be united $\quad . \quad$. . . . . 195

67. Show's surface denuded and sutures in position . . . . . . . 197

G.. Profile view of recently closed perineum, sutures in place . . . 198

69. Methor of securing the ends of the sutures (Emmet) . • • • . 198

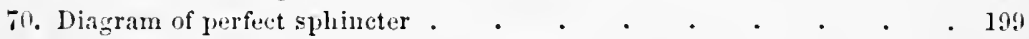

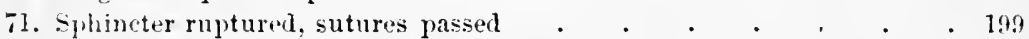

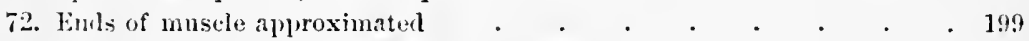

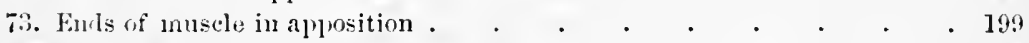

74. Sclumatic diagraun showing the ruptured lowel . . . . . . 201

75. Surface denuderl in complete perineal rupture, and first two sutures in

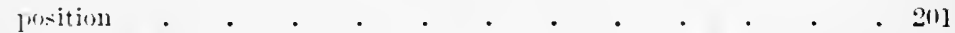

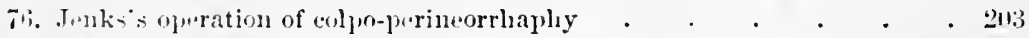

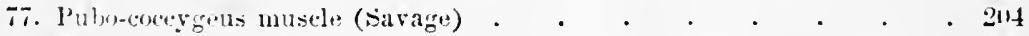

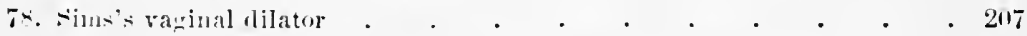

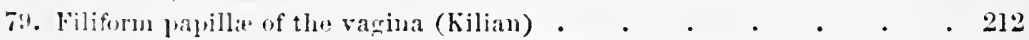

so. Epitlulimu in all stages of development, in simple raginitis, 200 diamearrs (T. Smith) . . . . . . . . . . . . 214

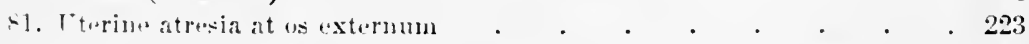

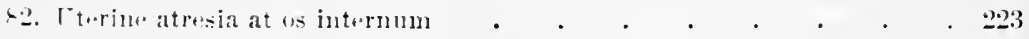

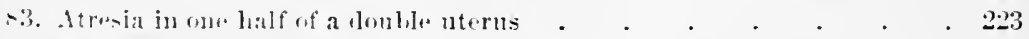

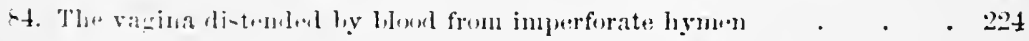

Vacina amd uterus both distended with blood in consegluences of an in-

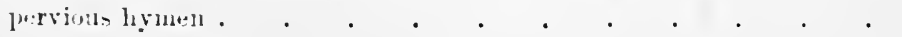


86. Varieties of urinary fistulie . . . . . • . . . . . 234

87. Curved scissors . . . . . . . . . . . . 246;

88. Bistoury for paring edges of fistula . . . . . . . . . 24;

89. Paring the elges (Wieland and Dubrisay) . . . . . . . 247

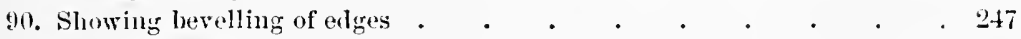

91. Sims's sponge-holder with handle nine inches long . . . . . 24)

92. Needles held in forceps. . . . . . . . . . . 24!

93. Conrse of the neelle . . . . . . . . . . 245

94. P'assing the neelle (Wieland and Dnbrisay) . . . . . . 249

95. Twisting the sutures . . . . . . . . . . 250

96. Fulcrm for supporting wire while it is twisted . . . . . . 250

97. Fork with blunt points to aid the passage of sutures . . . . . 250

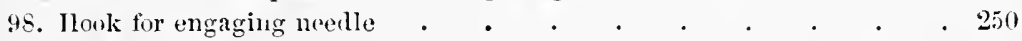

99. Sntures twisted (Wirland and Dubrisay) . . . . . . . 251

100. Sims's catheter, old style . . . . . . . . . . . . 251

101. Sims's catheter, new style . . . . . . . . . . . . . . 251

102. Simon's position for vesico-vaginal fistula (Simon) . . . . . 253

103. Vivifying the edges of the fistula (Simon) . . . . . . . 255

104. Sutnres in position (Simon) . . . . . . . . . . . . 257

105. Obliteration of the vagina (Simon) . . . . . . . . 260

106. The cervix is slit to expose the fistula above, and sutures are passed . 261

107. Anterior lip of fistula united to anterior lip of cervix (Simon) . . $\mathbf{2 6 2}$

108. Anterior lip of fistula nnited to posterior lip of cervix (Simon) . . . 242

109. Examination for fecal fistula. . . . . . . . . 266

110. The dots represent the site of chronic cervical endometritis . . . .

111. Villi of canal of the cervix uteri, covered by cylindrical epithelium and containing looped bloodvessels, one hundred diameters (T. Smith) • 276

112. Syringe for removing cervical mucus . . . . . . . . 2st

113. Rod eight or nine inches long, wrapped with cotton . . . . . 255

114. Budl's elastic probe . . . . . . . . . . . 286

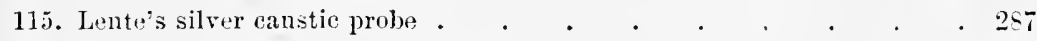

116. Lente's cup for fusing nitrate of silver . . . . . . . . . 2 2 .

117. Silver probe with cotton wrapped around it and thread attached . . $28 s$

118. Sins's curette, representing the angles at which it may be bent . . 28?

119. The dots show the site of corporeal endometritis . . . . . 290

120. Wylie's cervical speeulum, with probe passing throngh it . . . 299

121. Molesworth's donble canula and bulb syringe for injecting the uterine earity . . . . . . . . . . . . 306

122. Showing the site of cervical hyperplasia . . . . . . . . 321

123. Showing the site of corporeal hyperplasia . . . . . . . . 321

124. Buttles's spear-pointed searificator . . . . . . . . 333

125. Hard rubber cylinder for dry cupping the cervix uteri . . . . . 334

126. Cystic degeneration of the eerrix . . . . . . . . . . 343

127. Rècamier's curette . . . . . . . . . . . . . 350

128. Sims's steel curette . . . . . . . . . . . . . . . . 350

129. Thomas's wire curette . . . . . . . . . . . . . . . . 350

131. Emmet's enrette forceps . . . . . . . . . . . 351

131. Bilateral laceration to vaginal junction . . . . . . . . 356

132. Bilateral laceration to vaginal junction, with hyperplasia of cervical walls 
Fit.

133. Double tenaculum separating the flaps of a unilateral laceration (Emmet). . . . . . . • . . . . . 357

134. Multiple or stellate laceration of the cervix (Emmet) . . . . . 357

135. Lacerated cervix denuded, and strip of undennded surface left to act

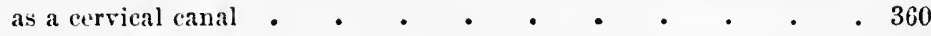

136. Sutures passerl after denudation of cerrix . . . . . . . 361

137. Sntures twisted and bent downwards against the wall of the cervix . 362

138. The regions of the abdomen and their contents. Edge of costal cartilages in dotted ontlines (Gray) . . . . . . . . 367

139. Normal position of the uterus . . . . . . . . . . . . 368

140. Diagram representing the uterine axis in the three degrees of prolapsus 383

14]. Skirt-supporter . . . . . . . . . . . . 397

142. Waist with buttons for support of skirts . . . . . . . . 397

143. The action of the diaphragm, the parts in normal condition $\quad . \quad 400$

144. The action of the diaphragm, the parts deformed by tight and heary clothing . . . . . . . . . . . . 400

145. Cutter's prolapsus pessary in position . . . . . . . 403

146. Cutter's prolaysus pessary . . . . . . . . . . . 403

147. Thomas's modification . . . . . . . . . . . . 403

145. The degrees of anteversion . . . . . . . . . . . . 409

149. Antetlexion . . . . . . . . . . . . . . . 411

150. Yormal axis and the three varieties of flexion . . . . . . 411

151. Elliot's uterine repositor . . . . . . . . . . . . 415

152. Jennison's sound . . . . . . . . . . . . 415

153. Nillerslie Wallace's spring tent . . . . . . . . . . 416

154. Ablominal pad of wood or cork . . . . . . . . . . 418

155. Abdominal supporter . . . . . . . . . . . . . 418

156. The perineal body destroyed, both rectal and resical walls descend . 419

157. Thomas's anteversion and anteflexion pessary . . . . . . . . 421

15x. Thomas's anteversion pessary, with fixed projection . . . . . . 421

159. Thomas's anterursion pessary as it appears in the vagina . . . 422

160. The same instrument in position . . . . . . . . . . 422

161. The same instrument as it appears on removal . . . . . . 422

162. Thomas's anteversion and anteflexion pessary . . . . . . 422

163. Thomas's elastic pessary for anterior displacements . . . . 422

164. Anteversion pessary supporting uterus . . . . . . . . 423

165. Cutter's 'T-pessary for anterior displacements . . . . . . . . 423

1tit. Thomas's molification of Cutter's pessary . . . . . . . 423

167. Graily Hewitt's anteversion pessary . . . . . . . . 424

168. Fowler's pessary for anterior displacements . . . . . . 425

169. Anteflexion pessary supporting intra-nterine stem . . . . 428

171. (ilass stem supporterl by dise pessary . . . . . . . . 428

171. Camplell's soft-rubber spring-stem pessary . . . . . . 429

172. Silhenatic diagran, showing the ereation of new uterine axis . . 430

173. Sims's knife. . . . . . . . . . . . . 431

17.t. P'osterior snetion of the cervix (sims) . . . . . . . . . . . 431

175. lietroversion of the uterus . . . . . . . . . . . 433

176. ketrotlexion . . . . . . . . . . . . . 433

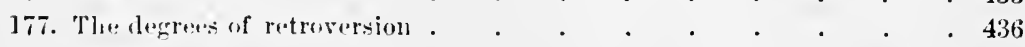

17. Sins 's uterine repositor . . . . . . . . . . . 440 
204. Cup and stem for making continuous pressure in replacing the inverted uterus . . . . . . . . . . . . 465

205. Replacement of nterus by dilatation throngh abdomen . . . 470

206. Rapid reduction by White's method . . . . . . . 471

207. Partially restored uterus sustained by closure of os externum (Emmet) 472

208. Lines representing the root of the pelvis . . . . . . 490

209. Peritoneal hematocele (Barnes) . . . . . . . . 513

210. Subperiton'al hematocele (Emmet) . . . . . . . . 513

211. Uterine fibroma. Oblique longitudinal section of muscular cell-bundles (Billrotll) . . . . . . . . . . . 522

212. Nolesworth's cervical dilators . . . . . . . . . . 534

213. Incision of cervix by Paquelin's knife for the accomplishment of dilatation

214. Areling's polyptome

215. Nélaton's forceps.

216. The écraseur, straight and curvel

217. The écrasenr at work

218. The spoon-saw

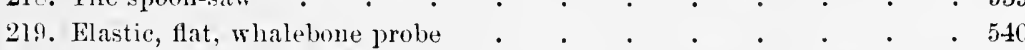

220. Attachment of fibroid in Mrs. A.'s case . . . . . . . 542

221. Diagram representing the tumor imbechled in the posterior wall of the nterus

222. Thomas's clanu, open . 
FIli.

225. Cellular polypus

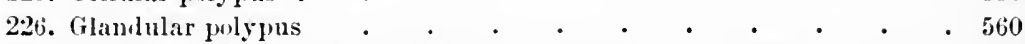

227. A submucous tibroid being gradually transformed intoa fibrous polypus 560

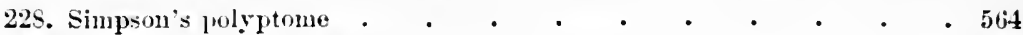

209. Hicks's wire rope écraseur . . . . . . . . . 565

230. Cancer of mamma ; stroma and cells (Billroth) • • . . . 576

231. Connective tissue framework of cancer of mamma. Brushed-out alcohol

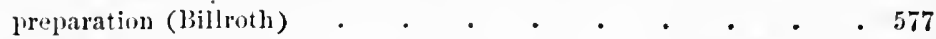

232. Flat epithelial cancer of cheek. Glandular ingrowth of rete Matpighii into connective tissue (Billroth) . . . . . . . . . 578

233. Tranverse section of a vegetating epithelioma (Virchow) . . . 581

234. Vegetating epithelioma (Simpson) . . . . . . . . 583

235. Forceps for amputating the cervix . . . . . . . . 593

236. Cervix amputated and parts above cut out . . . . . . . . 594

237. Simon's scoop . • • • • • • • • • • . . 595

235. Cystie degeneration of chorion (Boivin and Dugès) . . . . . 605

23\%. Priestly's dilator for the cervix . . . . . . . . . . 616

240. Schultze's dilator. . . . . . . . . . . . 617

241. Simpson's hysterotome . . . . . . . . . . 617

242. Stohlman's hysterotome . . . . . . . . . . . 618

243. White's hysterotome . . . . . . . . . . . . 618

244. Iysmenorrhoal membrane (Coste) . . . . . . . . 624

245 . Thomas's wire curette . . . . . . . . . . 634

246. Syringe for dry cupping the cervix . . . . . . . 640

247. Galvanic pessary . . . . . . . . . . . . . 641

24. Vaginal leucorrhoa under the microscope (Smith) . . . . 644

24:. Cervical leucorrho a under the microscope (Smith) . . . . . 645

250. Conolilal cervix (Sims). . . . . . . . . . . . 650

251. Byruets galrano-caustic battery . . . . . . . . . 655

252. Nicrescopic appearance of ovarian fiuid (Drysdale) . . . . . . 689

253. Tubal dropsy (Homper) . . • . . . . . . . . . 698

254. Spencer Wells's trocar . . . . . . . . . . . . . 719

255. Spencer Wells's trocar . . . . . . . . . . . . 719

25t5. Bozman's securing apparatus . . . . . . . . . 731

257. Emmet's trocar and canula for tapping cysts . . . . . . 737

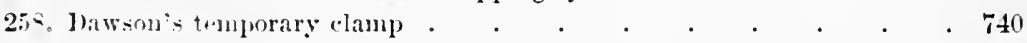

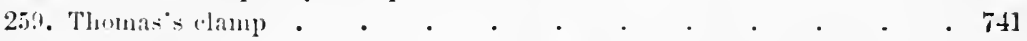

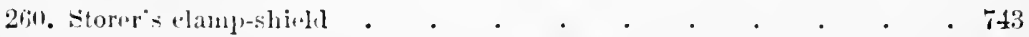

261. Thomas's Irainage tule of metal, vulcanito, or glass . . . . Tt6

262. Record of temperature in a case of ovariotomy . . . . . . T4?

2133. Recoril of temperature in a case of ovarintomy . . . . . . 750

264. Inecorl of temprature in a cast of ovariotomy . . . . . . 750

265. Kihlues: forrerert . . . . . . . . . . 753

26fe. Tubal dropsy (buivin and bugès) . . . . . . . . T6t 


\section{DISEASES OF WOMEN.}

\section{CHA P'TER I.}

\section{HISTORICAL SKETCH OF GYNECOLOGY.}

At the present day, when so much attention is being paid to the diseases peculiar to women, it becomes almost necessary that a chapter upon the history of the subject should precede others of a more practical character in a systematic work. A knowledge of what has been accomplished in reference to any subject, and what was known concerning it in previous ages, cannot fail to interest the student, and render lim more capable of appreciating recent advances. In this way, too, a taste for the study of ancient literature may be inculcated, and many a useful hint, many a suggestive statement may be met with which will germinate for the common good. Some of the most valuable contributions to modern gynecology will be found to be foreshadowed, or even plainly noticed, by the writers of a past age, and afterwards entirely overlooked. As examples may be cited, the use of the uterine sound, sponge-tents, dilatation of the constricted cervix, and even the speculum itself. Indeed, we need not seek in ancient literature for illustrations of this fact, for nowhere conld a more striking one be found than that of so valuable a procedure as Sims's operation for vesico-vaginal fistula being fully described in every detail in 1834 , and so completely forgotten in twenty years as to be accepted as entirely new at the end of that time.

There can be no doubt that a knowledge of medicine was possessed by the ancient Egyptians, whose literature has only within the last century been opened to profitable investigation. Until 1799, all concerning it was enshrouded in darkness. At that time a French engineer, while throwing up earthworks at Rosetta, discovered an insignificant looking stone, which has since furnished the wanting key, its inscription being written in Greck as well as in the ancient hieroglyphics. Since then valuable papyri hare been, thanks to the researches of De Sacy, Akerblarl, and Champollion, fully and satisfactorily deciphered. The data thus obtained 
earry the knowledge of medicine back to a period previous to 3000 years before Christ, and evince an attempt at rational treatment, Egyptologists declare, which surpasses that displayed by the early Greeks. The "papyrus of Berlin," the earliest record of medicine, is singularly free from superstitious doctrines and use of charms in the treatment of disease, which at a later period crept in. Pliny informs us that in the times of the Ptolemies a medieal school was established at Alexandria, and dissections of the human body legalized. The Egyptians appear to have been especially skilful as oculists, and it is probable that attention was paid to the diseases of women, for among the six medical books in the collection Thoth, consisting of forty-two volumes, one devoted to this subject is particularly mentioned. Some modern Fryptologists have even stated that among the hieroglyphics the shape of the uterus can be recognized. But Egyptology is certainly to-day only in its first infancy. Hope that the future may bring forth a great deal more than the past has done with reference to it may be further founded upon the fact that Herodotus distinetly announces that specialties existed among this primeval people. " Ilere," says he, "each physician applies himself to one disease only, and not more. All places abound in pliysicians; some for the eyes, others for the head, others for the teeth, others for the parts about the belly, and others for internal diseases."

From Biblical literature, which is so abundantly at our command, we learn almost as little upon our subject; and from the time of Moses, about 1,500 B.C., to that of Hippocrates, 400 B. C., testimony of precise knowledge upon it is almost entirely wanting. This is the more astonishing when we bear in mind that in the Talmud are found evidences of a great deal of knowledge concerning the Casarean section and other subjects in obstetrics; that in the books of Moses we find intelligent reference to the hymen and menstruation; and that in the New Testament we see St. Luke, a physician of the time, recording the fact of "a woman laving an issue of blood twelve years, which had spent all her living upon plysicians, neither could be liealed of any," etc.

Although we know so little concerning the knowledge possessed upon this subjert hy those who preceded the Greeks in civilization, we eamuot doult that they did much to instruct the latter in this as in other departmonts of learning. Ilistory everywhere records the faet that the Greeks were instructer by the Eryptians, as the Romans subsequently were ly the Greeks.

With our present knowledge of the literature of the most ancient eivilizations, we must alnit that with the writings of the Greek sehool, founded by Hippocrates, commences the history of gyneeology. Three rolumes were written upon the subject by authors contemporaneous with Hippo- 
crates. They have ordinarily been attributed to him, lunt Dr. Francis Alams, the translator of the works of Ilippocrates for the Sydenlanu Society, feclares them to be, "ancient but spurious, whose author is not known." In these books the subjects of metritis, induration, menstrual disolders, displacements, ete., are discussed. Aretaus, Galen, Archigenes, and Celsus, who probably lived in the first and second ecenturies, all treated of gynecology ; the first describing the vaginal touch, the varieties of lencorrhoa, and ulceration of the womb: while the second makes the first allusion on record to the speculum vagina, as being a distinet instrument from the speculum ani, and the third gives a description of periuterine cellulitis which shows him to have been at least familiar with the fitct that the tissues immediately connected with the uterus were liable to suppurative inflammation, the purulent products of which discharge themselves through the vagina or reetum.

Soranus, the younger, made important contributions to gynecology. He was edueated at Alexandria, and went to Rome in the year $220 \mathrm{~B}$. C., where he wrote his celebrated work De Utero et Pudendo Muliebri. II is the oldest historian of medicine, and the biographer of Hippocrates. Ilis accurate descriptions of the sexual organs were much admired. He takes pains to assure his readers that he dissected the human cadaver, and not monkeys, as did Galen and others. He compared the form of the uterus to a cupping-glass, showed the relation of this viscus to the ilium and sacrum, and made known the changes which the os undergoes during pregnancy. Ile attributes procidentia to a separation of the internal membrane of the uterus, speaks of the sympathy which exists between the womb and the mammary gland, and describes the hymen and clitoris. He uncterstood digital exploration and the use of the uterine sound and vaginal speculum. Many of the ancient writers confounded the uterus with the varina; he distinguished the one from the other very clearly. Soranus likewise differentiated pregnancy from ascites and solid tumors, and laid stress upon the absence of tympanites and fluctuation in solid tumors as a means of distinguishing them from aseites, in which they are present.

From this time for centuries, there is abundant evidence that the study of the subject was pursued with vigor, but so many of the works of the authors of those periods exist only in fragments, and so many are strongly suspected of being fietitious, that we pass them over to stop at the faithful compilation of Aëtins, who flourished at Alexandria in the sixth century after Christ. His works, compiled in the great library at Alexandria, contain a digest of what was known and done by his predecessors and contemporaries, and offer the fullest and most reliable evidence concerning

1 I am indebted to the library of the New York Hospital for an opportunity of fully consulting this and other rare works which were accumulated by the late Dr. John Wation. 
the knowledge of those times. In quoting him, and his immediate successor, Paulus Egineta, who was also a compiler, though a far less conscientious one, I must be understood as recording, not the views of these individuals, but those entertained by physicians who lived from the time of Hippocrates to the time of their writing, a period of about one thousand years.

In his 16 th book Aëtius treats of the diseases of women in such a manner as to leave no doubt as to his laving had a thorough knowledge of many disorders and means of investigation and treatment, which, being rediscovered thirteen hundred years afterwards, have, in many instances, been regarded by us as entirely new. Thus he speaks of the speculum, sponge-tents, peri-uterine cellulitis, medicated pessaries, raginal injections, caustics for ulcers of the cervix, dilatation of the constricted cervix, a sound for replacing the uterus, ete.

As I have already stated, Soranus before Christ, and Galen in the second century, speak of the speculum vaginæ; but Aëtius still more clearly mentions it, and gives rules for its introduction, which are copied almost verbatim by Paulus without acknowledgment. The use of sponge-tents he very fully describes, telling of their mode of preparation, and even advising that a thread should be passed through them for removal, and that a succession of them should be employed till complete dilatation is accomplished.' The importance of injections, the douche, hip-baths, and application of caustics for ulcers of the cervix, he also dwells upon, and advises the dilatation of a constricted cervix by means of a tin tube. The variety of vaginal injections in use among the Greeks was as great as that of to-day. As astringents, pomegranate rind, galls, plantain, rose oil, alum, sumach, etc., were employed ; and as emollients, linseed, poppies, barley, etc., exactly as we use them now. They relied to a great extent upon the use of medicated pessaries in the cure of ulcerations and inflammatory engorgements, employing wool covered with wax, or butter nixed with satfiron, verdigris, litharge, ete. Octarius Horatianus even goes so far as to adrise a mixture of arsenie, quicklime, and sandarach in very foul uleers. In aldition to injections and pessaries, Aëtius mentions the use of vapor. medicated or simple, conducted to the cervix by means of a reed passed up the vagina.

The nse of a uterine sound, passed into the uterus and employed as a repositor, is likewise alluded to by this anthor, in a passage where he alvises that displacements of the uterus should be corrected specillo et digito.

I'anl of Agrina, who suceeeded Aëtius, alludes distinctly to the speeulum at :n instrument in greneral use before his time. "If, therefore," says he, "the ulceration be within reach, it is detected by the dioptra; but if 
deep seated, by the discharges." And again, "The person using the speculum should measure with a probe the depth of the woman's vagina, lest, the tube of the speculum being too long, it should happen that the uterus be pressed upon."

It is curious to see how, even in many minor matters, the ancients anticipated discoveries which our contemporaries have brought forward as entirely new. For example, the air-pessary, made so popular in France and other countries by Gariel, is described and recommended by the Greeks. Colombat ${ }^{1}$ declares that, "The aneient Greek physicians made use of pessaries like those just mentioned (air pessaries), of the form and length of the male organ, which is the reason why they are.called

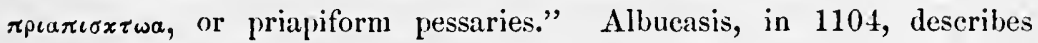
herpes uterinus; and uterine hemorrhoids are alluded to by Paulus Egineta ${ }^{2}$ in this explicit manner: "Hemorrhoids form about the mouth and neek of the uterus, which will be discovered by the speculum." And thus it is with so many other modern suggestions, that the student of ancient medieal literature is most willing to admit the truth of the proposition, formulated by Aristotle over two thousand years ago, that " probably all art and all wisdom have often been already fully explored and again quite forgotten."

The learning of the Greek School was appropriated by the Roman, which was an offshoot from it, as the writings of Celsus, Aspasia, Moschion, and Antyllus abundantly testify. But the knowledge of the schools of Greece and Rome was destined to be scattered abroad. At the period of the subjugation of Egypt and the destruction of the celebrated library at Alexandria by the Saracens, A. D. 640, it passed as a trophy of war into the hands of the Moslem invalers. "In a few centuries the fanaties of Mohammed had altogether changed their appearance," says the learned Draper." "When the Arabs conquered Egypt, their conduct was that of bigoted funatics; it justified the acensation made by some against them, that they burned the Alexandrian library for the purpose of heating the baths. But scarcely were they settled in their new dominion, when they exhibited an extraordinary change. At once they became lovers and zealous cultivators of learning." The physicians of Alexandria were greeted by them as instructors, and from the seed thus planted sprang the Arabian School. With other information, of course, they gained that pertaining to gynecology, but, the Mohammedan laws forbidding the examination of women by one of the opposite sex, the study languished in their hands; and although Rhazes, Avicenna, and their successors copied from Greek writers upon it, a want of zeal, due to want of personal observation and

1 Diseases of Females, Meigs's translation, p. 152.

2 Sydenhan Society's erlition, vol. i. p. 645.

3 Intellectual Development of Europe, p. 285. 
experience, allowed a retrograde movement to occur which left the subject enveloped in darkness for centuries afterwards. Albucasis, one of the last of this school, flourished at the end of the eleventh century, and after him, although from time to time writers of greater or less merit on diseases peeuliar to women appeared, nothing worthy of special note occurs, exeept the occasional allusion to the speculum, which had evidently fallen almost entirely into disuse.

We lave then sufficient data to warrant the belief that the physicians who flourished from the foundation of the Greek School of Medicine, 400 years before Christ, to the dispersion of the Alexandrian School by the Saracens, 640 years after Christ, were well informed in gynecology, and were familiar with means of investigation which were subsequently lost, or ceased to be appreciated. They fully sustain the statement of the English translator of the works of Hippocrates, that "they furnish the most indubitable proof that the obstetrical art had been cultivated with most extraordinary ability at an early period."

It must not, however, be supposed that the knowledge of the ancients was of the same exact and scientific nature as that which has prevailed sinee the modern introduction of the speculum. He who seeks in this literature for distinct and lucid pathologieal data will surely meet with disappointment. They did not sufficiently separate inflammations of the puerperal and non-puerperal uterus, confoumled affections of that organ with those of the pelvic areolar tissue, and made no distinctions between cliseases of the mueous membrane and parenchyma, nor the morbid states of the neek and body. Among their remedies were numerous articles which to-day we regard as inert or even injurious, as pigeon's dung, woman's milk, stag's marrow, etc.; and Aëtius and Paulus seem to have been as partial to the "grease of geese" as our lower classes are at present. To make amends for this many a valuable and suggestive thought may be grleaned with reference to diagnosis and treatment. This has certainly been proved by our experience of the past, and we have no evidence to warrant the belief that these rich mines have yet been exhausted.

The learning of the Arabians was in time, like that of the rest of the world, gradually enshrouded by the ignorance and superstition of the period termed the "Dark $\Lambda$ ges." During that time many of their writingrs, ats well as those of the Greek and Rioman schools, were destroyed or lost; but as society emerged from the darkness which overshadowed its intelligence, we see the thread at onee taken up and followed, though langnidly and without vigor, to the beginning of the nineteenth century.

Towart the millde of the seventeenth century we find rery special and tull allusion made to the speculum and its uses by Ambrose Paré and Sicultetus; the instrument being well represented by diagrams, with descriptions attacherl.

"Fig. 1," says Scultetus, " is an instrument which they call "speeulum 
ani, vagina et nteri,' in that by its help ulcers of the rectum, vagina, and uterus mat be seen, to be carefully observed, accolding to their extent and kind."

Aëtius and Paulus evidently knew of a tubular speculum, since they say, "lest the tube of the speculum be too long," etc.; but Scultetus, as

Fig. 1.
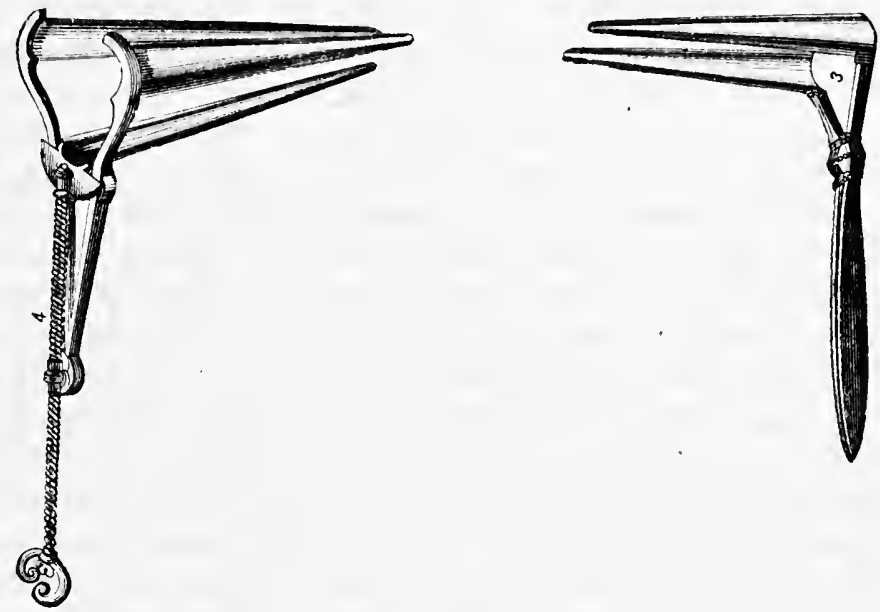

Ancient valvular specula. (Scultetus.)

already shown, figures a bi-ralve and quadri-valve, closely resembling those in our hands at present. It is worthy of mention, in this connection, that there is now preserved, in the Museo Borbonico at Naples, a bivalve speculum which was removed from the ruins of Pompeii.

It has already been stated that Aëtius makes reference to a sound for replacing the uterus. This is by no means the first notice of this useful instrument, for it is repeatedly mentioned by Hippocrates. One of six passages from writings imputed to him, I translate from the work of Monsieur T. Gallard."

"Treatment for rendering fertile a sterile woman; attention is directed to that part which consists in replacing a displaced neck of the uterus.

"Just after the patient has taken a bath and a fumigation, open the uterine moutl and replace it at the same time, if necessary, with a sound of tin or learl, at first small in size, then larger, if it passes, until the difficulty seems remedied; dip the sound in any emollient preparation which may be thought best, and which should be rendered liquid by meltingr."

2 Hippocrates Eurres Complètes. Tome vii. p, 379. 
A recent biographer of Harvey ${ }^{1}$ remarks, "That the older writers looked upon the vagina and uterus as one organ, and when they spoke of the forner, they either ealled it 'uterus' or 'cervix uteri.' What we now call the cervix uteri, they called the internal cervix ; and, as far as my reading goes, no operative procedure upon this part of the womb, when in its unimpregnated state, had ever been attempted before Harvey invented his dilator, and used intra-uterine injections of sulphate of iron."

If the passage recently quoted does not carry conviction that the manipulations recommended have reference to the neck of the uterus and not to the vagina, the following, from the same souree, will do so :-

"Treatment $t^{2}$ of cases in which the seminal fluid is not retained on account of an imperfection of the uterine orifice.

"In those cases in which seminal fluid escapes immediately after intercourse, the cause is in the mouth of the womb. They should be treated thus: if the orifice is very much contracted it should be dilated with small bits of pine wood and lead." We cannot suppose that in cases in which intercourse was praeticable any contraction below the os externum uteri could exist, rendering such dilatation necessary.

Professor Simpson ${ }^{3}$ asserts that among the ancients the sound was resorted to only for dilatation of the cervix, and not for exploration and measurement. The specillum mentioned by Aëtius was employed for reposition, while Hippocrates advises the use of a sound hollowed out on one side, and corered by medicated ointments: this, "the operator introduces into the uterine orifice, and pushes onwards so as to make it enter the interior of the uterus. When the medicinal substance is melted, the sound is withdrawn." In 1657 , a probe, used as we now employ the uterine sound, and intended especially for uterine exploration, was actually described by Wierus, ${ }^{5}$ and alluded to by Hilken, Cooke, and others. In 1771 it was employed by Levret for measuring the length of the uterine cavity in hypertrophy of the cervix, and subsequently as an aid to diagnosis by Chambon, Vigorous, and Desormaux.

As we pass in review the ehief works which appeared upon our subject in the eighteenth century, we find frequent mention of the speeulum, which is spoken of as a matter of course in the treatment of uterine affections, and yet was evidently not so employed as to render it really a valualle aid in diagnosis or treatment. This constitutes one of the most rurious episodes met with in the history of any discovery with which we are acquainted. A most simple and useful instrument was not only well known in aneient times, and subsequently fell into disuse, but fell

\footnotetext{
1 Obstet. Journ. Great Britain and Ireland, vol. i. p. 26.

2 (rallarl, op. cit., p. $116 . \quad 3$ Obstet. Works.

4 (iallard, op. cit., p. 116.

5 I). H. (. Wright, Diseases of Women, Eng. edl, rol. i. p. 135.
} 
into disuse without having ever been really forgotten. It was described by snccessive writers up to the nineteenth eentury in language as distinct as words could make it; and yet not only diel they who read, but they who wrote it, not comprehend its meaning or appreciate its significance. Like the Indians possessed of the diamond, all saw and yet none valued. Iow eould Ambrose Paré, for example, writing in 1640, have indicated its use more clearly than when he tells us, in chapter xix., that ulcers of the womb may be recognized, "by the sight, or by putting in a speculum?" In a copy of his works, in the library of Prof. W. A. Hammond, the word speculum is italicized in this sentence. Scultetus, as we have seen, not only described, but figured the instrument in 1683 .

In 1761, Astruc, " Royal Prof. of Physic at Paris," in describing occlusion of the vagina and obstruction to the menstrual flow, says: "There is nothing more required than to examine the vagina by introducing the finger into it, rubbed previously with oil or pomatum; but, if that be not suflicient, a speculum uteri may be used, or some other more simple instrument for dilatation, in order to be able, by means of the dilatation of the vagina, to judge by the sight of what the tonch could not decide."

In 1801, forty years after this, Récamier is supposed by many to have invented the speculum. Most assuredly it was not for the invention, but for the regeneration of an instrument which had been curiously lost sight of, that the world was indebted to this great man, who was really the founder of the modern school of gynecology. Guided by the advice found in many works which his library must have contained, works with which to suppose him not to liave been perfectly familiar would be to cast a slur upon his medical reseurch, he employed a speculum vaginæ in 1801 . Like his predecessors, he did not appreciate the great results which were to flow from it ; nor does he appear to have regarded himself as having invented it. It was not until 1818 that he introduced it to the profession, and gave $\mathrm{i}^{+}$its place as a valuable addition to science. Can any one suppose that it conld have required seventeen years of experimentation and study for a man with the talent of Récamier, to have applied this simple and useful instrument to purposes of utility? Is it not more likely that the experiencs of seventeen years taught him the full value of the instrument? 'The credit which belongs to Récamier is not that of an inventor, but that which is equally great, of having recognized the value of what was well known, but not appreciated by his predecessors and contemporaries.

Even before this fortunate revival, as the eighteenth century approached its close, the glimmer of the new era which was about to dawn could clearly be detected in the advanced views which were promulgated by Garangeot and Astruc in France, and Denman, John Clark, and Hamilton in England. The early part of the nineteenth century found the field occupied chiefly by Sir Charles Clarke and Dr. Gooch in England, and 
Récamier and Lisfrane in France. These were not the only eminent writers of that time, but they were unquestionably those who ehiefly moulded professional opinion.

Even at that period gynecologists divided themselves into two parties, which may be said to have coalesced only within the last decade. In England the feeling was strongly in favor of regarding the loeal disorder as the result and not the cause of concomitant constitutional derangement; while in France the uterine disease was viewed as the main element, and the general eondition regarded as dependent upon and resulting from it.

The great advantages of the speeulum secured its rapid adoption in France. More slowly it forced its way, in spite of many prejudices, in Great Britain, and before a great many years had passed, it was, throughout the eivilized world, placed upon an enduring basis as one of the many boous bestowed by medicine upon liumanity. The way being opened for investigation by this instrument, new aids to diagnosis and treatment were rapidly brought forward. In 1826, Guilbert read before the Academy of Medicine of Paris an essay proposing the application of leeches to the cervix. In 1828, Samuel Lair read before the same body a paper in which he counselled the use of the uterine sonnd, which lad never been utilized. In 1832, M. Melier presented an essay, in which he offered two new suggestions in the treatment of uterine diseases-one, injections into the earity of the cervix; the other, local applications through the ragina by dossils of lint saturated with astringents, nareoties, ete. His views are quoted extensively by French writers, and Nonat says that the author reeognizes, "aree une franchise qui l'honore," that Boyle, Chaussier, Guillou, and others had a short time before him used similar means. Very euriously neither Melier nor lis commentators mention that both these suggestions are made and fully elaborated by $\Lambda$ struc, in his excellent article upon "Lleers of the Lterus." Ife describes these applications of medicated charpie very earefully, remarking that it is advisable to "tie a thread to every pledget, in order to draw it out again when it is proper to renew the dressing." And he not only advises injeetions of water, impregnated with different substances, into the cavity of the womb, but also the juices of plantain, houseleek, nightshade, etc. "For," says he, "as it is of consequence that these injections should enter into the uterus, where the uleer hats it: seat, it is proper they should be made by a professor of midwifery, ealable of introdueing skilfully the end of the canula into the orifice of the uteris," etc.

At this time arose the question as to cancer of the uterus, whether it wats the loral manfestation of a general blood state, or the result of an inflammatory engorgement long neglected ; a question which exeited warm divinsion, and bronght forth the most opposite views.

The anbition of leceamier was not satisfied with exposing the cervix utrit to view. Ile hat the bollness to explore the cavity of the body of 
the organ, almost establishing the use of the sound, and even, by means of a species of scoop called a eurette, ventured in certain eases to scrape its investing mucous membrane. In addition he described, through one of his students, pelvie cellulitis, and gave the first intimation which modern observers have had of the possibility of pelvic hematocele.

'The impulse given by Récamier to gyneeology cannot be overestimated, for the instrument which he had rediscovered, and the merits of which he had appreciated, was destined to remove it from the field of speculation and theory, and to place it in that of exact science. From about the year 1820 , it began to attract general attention, and to receive the endorsement of the profiession.

The subject at that time received more notice in France than in any other country, and for the next twenty years Lisfranc, Boivin, Colombat, l'Heritier, Imbert, and others enricled its literature and advanced its interests. But it was not until towards the end of that time that any really remarkable arlvance was effected. Then it was that Kiwisch, in Germany, Hugnier, in France, and Simpson, in Great Britain, took the lead in their respective countries.

It has been already stated that from the earliest period of medicine the uterine sound had been reconmended, and that in the seventeenth, the eighteentl, aml the nineteenth centuries this recommendation had been repeated. In spite of this it had never become an instrument of practical value, and even after 1828 , when Lair recommended it, it fell entirely out of notice. By a curious coincidence Kiwisch, Simpson, and Huguier, without concert or communication with each other, about the same time urged its adoption, and by vigorous efforts foreed it upon the attention of all interested in gynecology as a diagnostic means of inestimable value. Before this time the sound was practically unknown; after it, it lield its place as one of our most valuable diagnostic resources.

The labors of Récamier marked an era in gynecology. One scarcely less important was effected by those of Simpson, who, appearing in the field about the year $18+3$, created an enthusiasm for the department, and gave an impulse to it by the vigor and originality of his writings, and the brilliancy of lis contributions. His articles, indeed, first incited the study of uterine displacements in Great Britain, and to his efforts may be traced, in great degree, the interest which has been of late years aroused in that country with reference to uterine patlology. Until this time the subject had attracted very little attention there, and advanees which had been made in it were due almost entirely to French pathologists. It is true that the excellent work of Sir Charles Clarke exister ; but that warm and zealous interest which has since resulted in so much benefit to gynecology had not then been excited. But Prof. Simpson was not alone in this work. Di. J. H. Bennet, of London, at that time a young physician, who had for some years served as interne in the hospitals of Paris, returned to his 
own country imbned with the views which Récamier and Lisfranc had disseminated among a large circle of followers. In 1845, the first edition of his work on Infiammation of the Uterus appeared, and it is safe to assert that no work of modern times, written upon any subject connected with our profession, has exerted a more decided and profound influence. Taking up the matter with a vigor and energy which foreed attention, if not conviction, he produced an undeniable impression upon the profession, not only in his own country, but in Germany, France, and America. The chief points insisted upon in his work are these: 1. That inflammation is the chief faetor in uterine affections, and that from it follow, as results, displacements, uleerations, and affections of the appendages. 2. That menstrual tronbles and leueorrhoea are merely symptoms of this morbid state. 3. That in the vast majority of eases, inflammatory action will be found to confine itself to the eervical eanal, and not to affeet the cavity of the body. 4. The propriety of attacking the disease in its habitat by strong causties.

It is now over a quarter of a century since the appearance of the first edition of Dr. Bennet's work, and since during that period his views have been freely canvassed and veliemently opposed, since too his own experience has ripened and he has had abundant time for more mature refleetion, it must be a matter of great interest to know to what extent his opinions have been modified. In the London Lancet appears the abstract of a paper read by him before the British Medical Association in 1870, which serves to contrast his more recent with his former views.

The purport of this paper will be best given in the rectpitulation by which the author concludes it :-

" 1 . I consider that, under the influence of mechanical doctrines pushed to an extreme, uterine displacements are by many too much studied per se, independently of the inflammatory lesions that complicate and often oceasion them. 2. That the examinations made to aseertain the existence of inflammatory complications are often not made with sufficient care and minuteness, as evidenced by the fact that I enstantly see in practice cases in which inflammatory lesions have been entircly neglected, and the secondary displacements alone treaterl. 3. That inflammatory lesions are often the principal cause of the uterine displacements through the enlargement and increased weight of the uterus, or of a portion of its tissues, which they occision. 4. That when such inflammatory conditions exist, as a rule they should be treated and cured, and then time given to nature to absorb morbid enlargeinents before mechanical means of treatment are resorted to."

Soon after the appearance of Dr. Bennet's work, a discussion sprang up between its author on one side, and Drs. Robert Lee, West, and Tyler Smith on the other, with reference to the true character of ulecration of the neck; Dr. Bennet supporting the view that the eervix is often affected l,y inflammatory ulceration, and his opponents denying it. The import- 
ance which he attached to the matter may be appreriated from the following quotation. In reviewing the state of uterine pathology in Great Britain, as illustrated by the standarl work of Sir Charles Clarke, he says : "Various forms of cancerous ulceration are carcfully described, but the very existence of inflammatory ulceration is not inentioner. Now, when we reflect that, as I shall hereafter show, in nearly five cases out of six of confirmed uterine disease, in which eluronic discharges, mucons, puriform, or sanguinolent, or other well-marked uterine symptoms are present, there exists inflammation or inflammatory ulceration of the cervix, it is easy to conceive how erroneous must be the views respecting uterine pathology, of a medical school ignorant of so vitally important a ciremustanee."

The last edition of Dr. Bennet's work was published in 1861, and a quotation of the views held by him in 1870 shows that they were essentially unaltered. Yet I believe that I am correct in saying that the great majority of the progressive gynecologists of our time sustain the views which are opposed to his. I find myself to-day endorsing the action of Sir Charles Clarke in publishing a work on diseases of women " in which the very existence of inflammatory ulceration is not mentioned," or is mentioned only for the purpose of disputing its validity.

One great advance which was effected by the work of Dr. Bennet was the placing upon a surer basis than it had yet oceupied, the differentiation of engorgement and induration from commencing eanecr of the neck.

It would be well, before proeeeding further, to consider very briefly the different pathological views which from this time, and even somewhat betore it, were offiered to the piofession, and more or less generally adopted.

They may be thus enumerated :-

1st. That inflammation is the starting-point of most of the affections of the uterus, and that a large number of evils follow this morbid state as results.

2d. That uterine disorder is dependent upon a constitutional derangement, and would yield without other treatment than that directed to the removal of the general condition.

3d. The view of Dr. Bennet, which is similar to the first mentioned, with this additional point, that metritis generally limits itself to the neck, and only exceptionally affects the body.

4th. The view of Dr. Tyler Smith, that leucorrhoa arising from glandular intlammation in the corvix is the cause of granular derangement of this part, and of subsequent engorgement.

5th. The view that uterine disorders often, if not generally, commence in displacement, which is a primary and not a secondary condition, and that to relieve the train of morbid symptoms, this, its exciting eause, should be first remover.

6th. The view that uterine disorder is commonly the result of ovarian 
inflammation, which reacting on the womb is the prime mover, in many cases, of its morbid states.

I have no inteution of fully diseussing here the merits of these theories, but will limit myself to a few words conneeted with each.

The theory mentioned first in this enumeration is the oldest on record, the writers of the Greek School, even, adopting it. Thus Paulus Frgineta heads his chapter on the subject, "Inflammation of the uterus and elange of its position." One of the symptoms of such inflammation he consilers to be retroversion of the uterus. In the beginning of the preserit century this was generally acepted in France. Lisfranc and Récamier adopted it, and it was transferred to, and advocated in, Great Britain by the writings of Dr. Bennet.

The views of this last author, appearing as they did at a time when the field of uterine pathology was almost entirely uneultivated, and charaeterized as they were by a great deal of persuasive force, produced in this conutry a marked impression. As to myself I am foreed freely to confess that since the publication of the first edition of this work my opinious with regard to them have undergone a material alteration. This alteration has resulted not from theoretical reasoning, but from careful and candid investigation and experimentation at the bedside. I lave come to regard the belief of Dr. Bennet in inflammation as the great moving eause, the common factor, in the production of nterine diseases, as an error. And as my views have thus altered with reference to pathology, they have, necessarily, likewise changed with reference to treatment. It appears to me that the time has arrived when many who formerly accepted the opinions of Dr. Bennet will be prepared to arlmit the fact that his treatment is too serere; his use of eaustics too heroic; and his neglect of artificial support to the displaced uterus too decided. No one could have accepted his views more cordially than I did. They were seductive by reason of their simplicity, and plausible from their apparent rationality. Careful observation at the bedside, in as large a field as could be desired, has led me to feel that evil, rather than good, resnlts from an adherence to them. Feeling this, I slatl strive in the work which I am now undertaking so to modify my statements as to meet what I regard as the true requirements of the sulj.ject.

Let us lowever hear in mind, while venturing to criticize the views and fmactice of Dr. Bennet, that seience is progressive, and that what was good a funarter of al century ago has simply given place to what is better. If, with all the lights of mokrm pathology, we stood now where Dr. Bunnet stoul when he wrote, the diseredit would have been with 11 ; it is not with him that we do not do so. Howerer others may differ from him, no candiel mind can deny the obligation under which he has placed his hrethren by arousing their attention and directing their investigations into proper channels. 
No one ean devote himself to the practical study of uterine discases withont being impressed with the strong gromuls whieh exist for the maintenance of the second of the theories mentioned. No grave nterine tronble atlects the system for any length of time without reacting to a greater or less extent upon the general health. The nervous system becomes groatly disordered, the functions under its infnence are badly pertormed, and derangement in hematosis is the invariable result. As the local discase often approaches stealthily, and may exist for a length of time without exciting suspicion, what is more natural than that many should view it as one of the numerons results of the general depreciation? These three facts, however, which will constantly repeat themselves, as often, I may say, as favorable eases offer for testing the question, will, I think, very generally lead to a distrust of the doctrine: 1st, the fact that uterine disease and constitutional derangement existing together, a cure can rarely be effected by general means alone: 21, that the uterine affection being removed, the general state is at once improved; and $3 \mathrm{~d}$, that those general conditions which prostrate the vital forces to the last degree, as, for instance, tubereulosis, uræmia, scurvy, leucocythamia, etc., destroy life without ever showing, unless as an exception to a rule, uterine discase as a consequence.

The constitutional depreciation of a woman will, however, sometimes prove a predisposing cause of local disease. As granular degeneration under the eyelids will arise from this cause, so will a kindred condition often occur on the cervix uteri, yet both will require local as well as general treatment. The enfeebled woman is more liable to subinvolution, passive congestion, and displacements, after delivery, than the strong; and inflammation of the glands of the cervix is a well-known result of plithisis pulmonalis, tertiary syphilis, and ancmia.

The theory of Dr. Tyler Smith I lay before the reater in his own worls: "It is my conviction, notwithstanding, that in the majority of cases in which morbid states of the os and cervix are present, cervical lencorrhœa, or, in other words, a morbitly augmented secretion fiom the mucous glands of the cervical canal, is the most essential part of the disorler, and that the diseased conditions of the lower segment of the uterus, which have been malle so prominent, are often secondary affections resulting from the lencorrhoal malady." This theory was by no means a new one when adranced as above mentioned, for Lisfranc ${ }^{2}$ mentions it thus: "Observation proves that leucorrhoea can in the first place cause uterine engorgements, and that later it may be kept up by them; it occasions them often."

Lisfranc, however, says "often," while Dr. Smitl says, "in the majority of cases." But even before Lisfranc it had attracted attention, for

1 On Leucorrhcea.

2 Clin. Chirurg., vol, ii. p. 303. 
Paulus Egineta gives "defluxion" as one of the causes of "ulceration of the womb." 'That an acrid leucorrhoal discharge will create abrasion of the os, follicular vaginitis, urethritis, pudendal inflammation, and pruritus, no one will deny. We see a similar irritation occurring on the upper lip in nasal catarrh in children, which sometimes spreals as an eruption over the whole face. The leucorrhoa regarded by Dr. Smith as the primary disease is, however, only a symptom of cervical endometritis, which may disorder nutrition in the deep tissues of the cervix, and result in enlargement and induration. The views of Dr. Smith were brought fortl at a time when Dr. Bennet was pressing the theory of inflammation as the keystone of uterine pathology, and in combating the idea of parenehymatous inflammation, he recorded the important fact that the morbid state described under that name is very often preceded by, and results from disease taking its rise in the mucous lining of the canal. Dr. Smith's position was maintained with all that ability and force which have rendered him so popular as an author amongst us in America, and the influence of his writings upon uterine pathology can be, at present, clearly traced in this country.

In the year 1854, a discussion, which soon assumed extensive proportions and elicited great warmth, arose in the Academy of Medicine of Paris, with reference to the treatment of uterine displacements. M. Velpeall stood fortl as champion of the view which is here expressed in his own worls. "I declare, nevertheless, that the majority of the women treated for other affections of the uterus have only displacements, and I aflirm that, eighteen times out of twenty, patients suffering from disease of the womb, or of some other part of this region, those for instance in whom they diagnose inflammation (engorgements), are affected by displaceinents." In this and subsequent discussions he was upheld by some of the most eminent practitioners of Paris, and by many the view then expressed is still alluered to. No one of experience will question the fact that a disorder of position of the uterus will often result in subsequent disorder in nutrition and sensibility. Every one must have repeatedly met with cases in which the reposition and support of a displaced uterus have at once dissipated a collection of symptoms which by many would have been attributed to inflammation of the mucous lining or parenchyma. Every one must have found in many cases the relief of a displacement, which was regarded as only an: unimportant concomitant of the morbid state, result in complete cure. But admitting this is merely arlmitting the propriety of regarding displacement as one of many nutoward influences which may disoreler the innervation, circulation, and nutrition of the uterus ; not making it the chict factor in the prorluction of uterine diseases.

The prinary importance of displacement was long ably maintained in

$$
1 \text { op. cit., p. } 1 ; 24 .
$$


this country by the late Prof. IIugh I. IIodge, of Philadelphia, amel the adlerents of this theory are numerous.

The most signal instance of its aloption which las recently occurred is that of I)r. Graily IJewitt, of Lombon. While he does not nake displacement absolutely essential as a primary factor of uterine disease, and limits his belief in its agency almost entirely to flexions or deformities of shape, the inportance which he attaches to such displacements may be gathered from the following quotations from the third edition of his valuable work upon the diseases of women.

“a. Paticnts suffering from symptoms of uterine inflammation (or, more properly, from symptoms reterable to the uterus) are almost universally fouml to be aflected with flexion or alterations in the shape of the uterus of easily recognized chalacter, but varying in degree.

. b. The clange in the form and slape of the uterus is frequently brought abont in consequence of the tissues of the uterus being previonsly in a state of musual softness, or what may be often correctly designated as chronic inflammation.

"c. The flexion once produced is not only liable to perpetuate itself, so to speak, but continues to act incessantly as the cause of the clironic inHammation present."

In a certain number of cases very grave and annoying symptoms of uterine disease will be found due to chronic ovaritis, an affection in which treatment is so ineflicient that every practitioner must dread to meet it. The symptoms of uterine disease being present, an exploration of the pelvic organs is made. No uterine disease of any kind is found to exist, but prolapsed into Donglas's cnl-de-sac are found the ovaries, large, tender, and tumetied. In other cases uterine disease will be found coexistent with enlargement, tenderness, and displacement of ovaries, and the practitioner indulges the hope that so soon as the uterine disorder shall be cured the orarian trouble will disappear. Such a sequence, however, does not oceur, and he recognizes, to his disappointment, that what he recrarded as a secondary matter is jeally one of primary importance. For this reason no examination of the pelvic viscera should be considered complete which does not involve a careful investigation of the state of the ovaries.

For many years a thorough sceptic as to the frequency of ovarian disorder as a cause of the ordirnary symptoms of uterine disease, I am now convinced of $j$ ts truth, and in few cases do I give more guarded prognoses than in those in which I find one or both ovaries enlarged, tender, and molapsed.

Since the year 1850 , when he published his well-known work upon the subject of Orarian Inflammation, no one has been a more constant or consistent adrocate of the claims of ovarian pathology upon the notice of the gynecologist than Dr. Tilt, of London. At a meeting of the London Obstetrical Suciety, in April, 1873, he recapitulated his views, and it 
cannot fail to be a matter of interest to see how time and experience have affected them. The positions which he originally took were these: 1 st. That the recognized frequency of inflammatory lesions in the ovaries and in the tissues that surround them is of much greater practical importance than is generally adnitted. 2k. That of all inflammatory lesions of the ovary those involving destruction to the whole organ are very rare, whilst the most numerous, and, therefore, the most important, may be ascribed to a disease that may be called either chronic or subacute ovaritis. 3 d. That, as a rule, pelvic diseases of women radiate from morbid ovulation. 4tl. That morbid ovulation is a most frequent cause of ovaritis. 5th. 'That ovaritis frequently causes pelvie peritonitis. 6th. That blood is frequently poured out from the ovary and the oviducts into the peritoneum. 7 th. That subacute ovaritis not unfrequently eauses and prolongs metritis. $8 \mathrm{th}$. That ovaritis generally leads to considerable and varied disturbance of menstruation. 9th. That some ehronic ovarian tumors may be considered as aberrations from the normal structure of the Graafian cells.

Dr. 'Tilt pointed out that althongh these views, when promulgated, had been adversely criticized by Drs. Rigby, West, Bennet, and Churchill, they were now to a great extent accented, and that they have been amply demonstrated both clinically and microscopically by Aran, Bernutz, Gallarl, Négrier, and Siredey. I would emphatically dissent from his $3 \mathrm{l}$ postulate, which $I$ regard as entirely too sweeping an assertion, but with the remaining eight I fully agree.

Of late years rapid advances have been made in the surgical treatment of the diseases of women. Under the lead of Simpson, Wells, Brown, and Keith, in Great Britain ; of Simon, Esmarch, Ulrich, Hegar, Spiegelberg, and Schroder, in Germany ; and of Sims, Atlee, Emmet, Peaslee, Dunlap, Agnew, and Kimball, in the United States; operations for ovariotomy, the eure of ruptured perineum, vesico-vaginal fistula, constriction, or tortuosity of the cervix, prolapsus uteri, laceration of the cervix, ete., lave been perfected and are now constantly practised.

During the last quarter of a century three men have led the profession in the surgical portion of this department, and by their originality done a great deal to ereate what exists to-day; Sins in America, Baker brown in England, and Sinon in Germany. Before their period anesthesia was unknown and their predecessors lacked its aid. For them it oflered its rare arbantages, and they hat the genius to make good use of them.

Both the science and art of gynecology have been greatly advanced by the pathologieal researches of the German seliool. To-day confessedly in advance of all other nations in the study of pathology, the laborious, conscientious, aud persevering scholars of that country are altering and improving our views in reference to this subject, while contributions of great fractial value are eoming forth from them to enrich our literature. Among these nay be especially mentioned those by Kiwiseh, Hennig, 
Waldeyer, Simon, Spiegelberg, Martin, Scanzoni, Klob, Schreder, Veit, and Sehultze.

It is a great sonree of pleasure to me before closing this sketch to be able to record the faet that Ameriea has not been wanting in her contribution towards the progress of this branch of medicine. While the intrests of erynecology were, during the early part of the present century, adranced in other lands by those whose names have been mentioned, in America they were pressed upon the attention of the profession and assiduously cultivated by three able advocates, all, singular to relate, from the same eity,-Dewees, Meigs, and IIodge. Each of these observers bronght to his work the most signal ability and enthusiasm, and, having abuurant opportunities, as public teachers and writers, of disseminating their views, they each exerted a decided influence upon the mind of the profession. To the last of these gentlemen the profession throughout the world is more deeply indebted for means of properly sustaining the uterus by pessaries than to any one else who has ever labored in this field, and we see in onr lay his determined opposition to the phlogistic theory of uterine disorders rapidly gaining advocates amongst the ablest and most philosophical in our ranks.

From this country have emanated, as contributions to this important department of medicine, anasthesia, ovariotomy, the revival of the method by which raginal fistule have been made amenable to systematie treatment, and which since the time of Gossett had been entirely forgotten; aml last, but by no means least, the introduction into ordinary practice of Sims's methods of exploring the pelvic viscera.

I have elsewhere called the results of the labors of Récamier and Simpson eras in the progress of this department. I now venture so to style those of Marion Sims. In doing this I make no reference to the improvements inaugurated by him in the treatment of injuries to the genital organs; my allusion is to the great advantages which now flow and are to flow from the invention of his speculum, which exposes the uterus by a new principle, and opens the way to a more complete examination of that organ. Récamier marked an era by improving our powers of diagnosis in exposing the cervix uteri; Simpson another, by opening to investigation the body of the uterus; and Sims a third, by rendering both investigations more simple, complete, and satisfactory.

There is no more certain way of appreciating the effeet of light than by witlıdrawing it and marking the degree of darkness which results. If all that Sims has done for gynecology were suppressed, we shonld find that we had retrograded at least a quarter of a century.

The ordinary specula in we before the discovery of Sims's, simply separate the raginal walls mechanically, and thus expose the uterus. Sims's instrument, on the other hant. elevates the posterior vaginal wall, which allows the entrance of air to distend the whole passage, the woman lying 
on her side in such a manner that the cavity can be probed with the most perfect ease, and applications made to the fundus. I am fully aware that many will differ from me in this opinion, but being entirely free from prejudice in favor of this instrument, or against the ordinary varieties, I maintain it fearlessly, feeling confident that time will prove it to be correct. No one who has not tested the two methods of examination is really entitled to an opinion upon the point, and I cannot doubt the conclusion of him who has done so faithfully and intelligently.

It may very pertinently be asked how I reconcile this opinion with the facts that with the exception of Emmet in his reeent work, and myself, no other writer of a systematic treatise on gynecology recommends this method of exploration in preferenee to that by the cylindrical speculum in daily practice; that few, if any, of the gynecologists of Great Britain or the continent of Europe employ it to the exclusion of the old plan in ordinary cases; and that even in this eity, where the personal advocacy of Sins himself and the wide-spread influence of the Woman's Hospital which he has founded are felt, only a score of practitioners do so, most of whom are conneeted with this hospital. My explanation of the faets is this : to employ Sims's speculum efficiently considerable experience with it is necessary. One who has not practised with it so as to become skilful will find it far less useful than the cylindrical and valvular specula in orlinary use. I feel sure that most of those who have tried it and cast it asisle, exeept for operations on the vagina or uterus, have attributed their own shortcomings to an instrument the use of which they had not mastered. Again, it is necessary to have an assistant, and highly desirable to have a practised assistant, to hold the speculum. None of the substitutes for such an assistant have ever proved or, I think, will ever prove effectual. For this reason also the use of this instrument has not become more generil.

It is becoming customary, with those who practise gynecology as specialists in this city and employ this speeulum, to see their patients almost universally at their offices, and to have in attendance a trained nurse who manages both patient and instrument during examinations. One practising in this manner places himself, I am confident, on a vantage ground, which ean seareely be imagined by him who clings to the old methods of (xploration. 'The experience required, lowever, to use this speculum with alvantage, and the disalvantage of its requiring the aid of a nurse, will prevent its universal or even very general aloption. I do not believe that the practitioner who sees very little of uterine disease will ever employ it. But there are at present many who are studying and practising gynecology extensively and scientifically. It is to such that these remarks are especially adlressedl.

In stating all this thus plainly and positively, I am by no means ignorant of the eriticism to which I expose myself from an overwhelming and 
most influential majority. I confess that even to me the slow advance made by Sims's speculum, as an instrument for every-day use, has been a matter of great surprise. Familiarized, lowever, by years of practice with both methods of examination, and prejudiced in favor of neither, I calnot doubt the result. The assertion of its rights by the new method will give an impetus to the advance of gynecology which in some degree it has eren now effected.

I cannot elose this part of my subject without appealing to those working in this department who are willing to test the matter, in the following manucr. Learn the use of 'Sims's speculum, not by personal labor and experiment, but from one who is fully master of it; have at your disposal a trained nurse, and persevere with the method for three months, and you will endorse the statement as to the vantage ground which you will oceupy, which just now appears so exaggerated to you. Nothing is easier than to attack upon paper such a position as that which $I$ lave here assumed; nothing more tempting than a half humorous, half sareastic review of it. But the question is one of too great moment to be thus dealt with. All earnest workers in our ranks are in seareh after truth, not striving to prove themselves right; all wise men are eager to avail themselves of improvements in their calling, not to find warrant for hugging what is old.

Although the scope of this chapter will not admit of the mention of all the works which have recently appeared upon this subject, I cannot refrain from mentioning one which comes to us offering, among other valuable contributions, one of the most important pathological facts, and with it its corresponding surgical resource, which the last half century has yielded. The work is the highly original and valuable one of Dr. Thomas Addis Emmet, of New York; the prathological contribution which, even if this eminent author had done nothing else to lay his profession under obligation, woukl indelibly write his name upon the records of gynecology, is the diagnosis and treatment of laceration of the cervix uteri. No one contribution to this department which has been made in the period mentioned has exerted a more marked influence upon uterine pathology than this is now doing, and will do in the future. None will have more influence in abolishing useless and hurtful therapentical resources.

During the past thirty years a decided effort has been made all over the civilized world to introduce into medicine a remarkable innovationthe opening of its doors to the entrance of women as practitioners. The prevalent and very just sentiment, that the gentle and sympathetie nature of woman would, in this department of labor, find an appropriate field of action, at that period began to be clearly expressed, and the urgent demand which was made by progressive minds in different comtries has at the present day been fully met. This has not been accomplished without opposition. 'The usual adverse striving of narrow and non-progressive minds has not been wanting to retard the advance of the movement, but 
in spite of this, with an almost unprecedented rapidity when its magnitude is considered, it has arrived at assured success.

The connection of woman with the practice of medicine is a matter of no recent date. The sentiment which fosters it now has existed in an undeveloped state from the earliest ages. Aëtius makes mention of the writings and practice of Aspasia, who was a doctress at Rome about the third century, and copies extensively from her upon ulceration and displacements of the womb. Paulus Egineta is, for some of his chapters, indebted to Cleopatra, fragments of whose writings he has preserved for us. He evidently quotes her with respect, and credits her with what he borrows. In the thirteenth century an Arabian woman, Trotula by name, published a treatise, in which she mentions that many Saracenic women practised the art of obstetrics at Salerno. In later times, during the seventeenth and eighteenth centuries, women were graduated as Doctors of Medicine in the Italian Universities, and as such enjoyed great consideration. In 1732, La Dottoressa Laura Bassi graduated at Bologna, and filled the ehair of Natural Plilosophy for six years. In the last part of the eighteenth century, Madouna Mazzonlina lectured on anatomy at Bologna, while others of lesser note filled positions of minor importance. To the women of Arabian civilization the department of obstetrics was entirely surrendered; for so great were the sensuality and libertinism of the Saracens, that the Mahommedan laws prohibited the attendance of males upon females; and thus their whole treatment, except in extreme cases, devolved upon the midwires.

In France a portion of the work of medicine has long been allotted to "Sages Femmes" or midwives, and the names of Mmes. La Chapelle and Boivin, who lived in the last part of the eighteenth and the beginning of the nineteenth centuries, come to us clothed with great authority.

The demand of our time then is not that woman may practise medicine, but that she should have every opportunity which that time offers her to prepare herself for the work. Many have doubted, and upon excellent grounds, the ability of woman to cope with man in this field of labor, for there is no resisting the evidences of history, that, in spite of opportunities and incentives, female practitioners have failed in time past, not only to alvance, but even to maintain the integrity of the art intrusted to their hands. The experience of the future may contradict that of the past ; but even its doing so will offer no good reason for despising the lesson which the past has left on record. As futile would it be, however, to resist the orrwhelming "logic of events," and to shut our eyes to the fact that the "woman movement" has conquered for itself in medicine a position which entitles it to consideration and respect.

The opportunity which is now oflered to woman for retrieving what has becen lest in former ages is certainly all that the most exacting of modern reformers could require. The prejudice which for years existed against 
her in this connection appears to be, in this country and in Europe, almost entirely cradicated. In many of the most ancient and eminent of the universities of Europe they are free to matriculate, and in most of the largest cities both of Europe and America female medieal colleges exist. In this eity, some of the most able of our junior teachers are engaged in instruction in the Female Medical College, and many of the most eminent and conservative of the senior members of the medical profession have aecepted positions as consultants to the hospital attached to the college. Female practitioners are frecly met in consultation in general practice, and the Comty Medical Society, one of the two representative associations of the city, : 1 hnits them to its ranks as members. The general and sincere feeling of the progressive and most prominent members of the medical profession here is unquestionably this, to allow to females a fair opportunity to enter the field of medicine, and strive to establish their ability to perform its arduous functions, however much they may doubt the suceess of the enterprise. All appear willing to intrust the solution of the problem of woman's fitness for the duties of medicine to time, the great crucible of human theories.

"The burning question," says J. R. Chadwick, in an excellent review of this subject, "is no longer, shall women be allowed to practise medicine? They are practising it; not by ones or twos, but by hundreds; and the only problem now is, shall we give them opportunities for studying medicine before they avail themselves of the already acquired right of practising it?" Admitting that this question is justly put, can any one wishing well to humanity and to seience venture to array himself on the negative side?

An innovation in general surgery which bids fair to be one of the greatest improvements which has ever been effected in that art has been reserved for our time-the establishment upon a systematic basis of antiseptic surgery. No departments of surgery will feel, indeed are now feeling, the influence of this more deciledly than those of gynecology and obstetrics. The great evil from which they have suffered is septicxmia, and this it is the special object of Listerism to prevent and overcome. Not only does this method offer great advantages in ovariotomy, in all its details except the use of the spray it may with the greatest adrantage be applied to all operations within the pelvis.

I am so often consulted by recent graduates as to the works which they should make the basis of a library upon gynecology, that I feel that I may render a service by the following list. Only such works are reeorded as will prove of absolute service to the active practitioner who seeks knowledge chiefly upon practical points :-

Sonat-Maladies de l'Utérns, 1 rol.

Aran-Maladies de l'Utérus, 1 rol.

Becquerel-Maladies de l'Utérus, 2 vols. 
Blatin et Nivet-Maladies des Femmes, 1 vol.

West-Diseases of Women, 1 vol.

Tilt-Uterine and Ovarian Inflammation, 1 vol.

Bennet-On the Uterus, 1 vol.

Simpson-Diseases of Women, 1 vol.

IIewitt-Diseases of Women, 1 vol.

Churchill-Diseases of Women, 1 vol.

Byford-Medical and Surgical Treatment of Women, 1 vol.

Sims-Uterine Surgery, 1 vol.

Baker Brown-Surgieal Discases of Women, 1 vol.

Tilt-Uterine Therapeuties, 1 vol.

Seanzoni-Diseases of Females, 1 vol.

Meigs-Diseases Peculiar to Females, 1 vol.

Bedford-Diseases of Women and Children, 1 vol.

Colombat-On Females (annotated by Meigs), 1 rol.

Ashwell-Diseases of Women, 1 vol.

McClintock-Diseases of Women, 1 vol.

Courty-Maladies de l'Utérus et de ses Annexes, 1 vol.

IIodge-Diseases Peculiar to Women, $1 \mathrm{vol}$.

Klob-Pathologieal Anatomy of the Female Genital Organs, 1 vol.

Speneer Wells-On Diseases of the Oraries.

Kiwisch-On Diseases of the Ovaries, 1 vol.

Wright-Diseases of Women, 1 vol.

Emmet-On Vesico-Tagiual Fistulæ, 1 vol.

Duncan-Parametritis and Perimetritis, 1 vol.

Duncan-Fecundity, Fertility, and sterility, 1 vol.

Athill-Diseases of Women, 1 rol.

Gallard-Léçons Clinique sux les Maladies des Femmes, 1 vol.

Peaslee-Ovarian Tumors, 1 vol.

Atlee-Ovarian Tumors, 1 vol.

Barnes-Treatise on Diseases of Wromen.

Goodell-Clinical Iectures on Diseases of Women, 1 vol.

J.el)lond-Traité Elementaire de Chirurgie Gynecologique, 1 vol.

Schrueder-Diseases of Female Sexual Organs, 1 vol.

Tait-Diseases of Women, 1 vol.

Fmmet-Principles and Practice of Gynecology, 1 vol.

IIegar and Kaltenbach-Die Operative Gynäkologie, 1 vol.

Skene-Diseases of the Bladder and Urethra in Women, 1 vol.

Mary Putuam Jacobi-The Question of Rest for Women.

Martineau-Traité Clin. des Affice. de l'Utérus.

The following joumals are now devoted to this subject:-

Centralblatt für Gynecologie.

Anmales de finnecologie.

Obstetrical Jourmal of Great Britain and Ireland.

Amrrican .lomrual of Obstetrics and Diseases of Women and Children.

Obstetric Gazette.

Archiv für Gynaikologie. 


\section{II A P T E R II.}

\section{THE ETIOLOGY OF TIE DISEASES PECULIAR TO WOMEN.}

Ix investigating the causes of the diseases peculiar to women I shall especially refer to those which are active in this country. In doing this I desire to avoid all comparison between the frequency of such affections liere and abroal, for in the absence of statistical evidence such an attempt would necessarily prove futile. My chief reason for giving myself the limits lerein prescribed is my desire to base the views advanced in this chapter entirely upon personal observation, to offer to the reader not the conventional doctrines prevalent upon the subject of which it treats, but those views which have impressed themselves upon my own mind as ralid and valuable. With this object in view, it is manifestly easier to write of habits and influences which come under one's daily observation and connect themselves with the experience of his daily life.

I shall divide the causes to which I shall draw attention into predisposing and exciting, premising their enumeration by the announcement that I do not propose to mention all of the former which are active, but to limit myself to those which are most prominent, and which are to a great degree aroidable. Others, such, for example, as inherited constitutional rices, will be spoken of in connection with special diseases as they come under notice. Considering very fully the predisposing causes, I shall give merely an enumeration of the chief exciting ones, leaving the fuller consideration of the latter also for chapters deroted to special affections.

If we compare the present state of women in refined society over the world with that of the working peasants of the same latitudes, or with the North American squaws, or the powerful negresses of the Southern States, we can with difficulty believe that they all sprung from the same parent stem, and originally possessed the same physical capacities. Observation proves that women who are not exposed to depreciating influences can compete in strength and endurance with the men of their races, and in savage countries they are sometimes regarded as superior to them. In the lower orders of animals this equality is still more marked. The mare endures as much as the horse, and some of our most celebraterl racers have represented the female sex. The lioness is fully as dangerous to the hunter as her more majestic consort, and the bitch proves as untiring in the chase as the most muscular $\log$ in the pack.

From all these facts we may logically argue, that the human female, if 
properly developed and placed beyond causes which militate against her physical well-being, would be in no great degree the inferior of the male. This position I now assume, and maintain that the customs of eivilized life lave depreciated lier powers of endurance and capacity for resisting disease. My eflorts will be directed to an endeavor to point out what these habits and influences are. I do not, of course, advanee the statement that uterine diseases are unknown among uncivilized women, for I lave too often seen prolapsus, retroversion, granular degeneration, and kindred disorders anong the former slaves of this country to do so. These affections were, however, rare among them, and not exceedingly common, as they are amongst our white women, and even when they existed, they did not so profoundly affect the constitutions of those suffering from them. As I shall hereafter point out, injuries inflicted by parturition play a most important role in the cansation of these disorders. To such injuries as laceration of the perineum and eervix, disorders of involution, ete., the savage woman is unquestionably liable, and their occurrence would entail upon her the same evils which would result from them in the civilized. Yet how much less liable to their occurrence is the strong, well-developed, muscular frame of the former than the delicate sensitive organization of the latter? And even if exposed to the baneful influence of these accidents, how much more able is she to resist their depreciating influences ! Tliere are in this city to-day thousands of poor women who go through with the labors of their lives of drudgery with the uterus, vagina, and portions of the bladder and rectum in the condition of complete prolapse, the first two organs entirely, and the last two in great degree, outside of their bolies. How differently would the refined woman of a higher spluere be affected by a similar condition, and how utterly wretched would her life ordinarily be rendered!

In a woman of robust frame, healthy nerrous system, and perfect blood state, who lives a rational and carefully regulated life, an accident, occurring at larturition, luring menstruation, or at any time disconneeted with these trying periods, may produce serious disease. But in such a woman accidents are much less likely to occur, and even if they did so would produce much less serions consequences than in one in whom the predisposing causes of disease of the genital system had for a lifetime, and even longer, for hereditary influences are powerful for evil in this comnection, prepared the way for the easy establishment of pathological conditions.

Those influences which, growing ont of the plyysically depreciating luabits of eivilized life, tend most decidedly to develop a predisposition to direises of the female genitalia may thus be enumerated :-

Norglect of out-door exereise and physical development.

Orerwork of hrain, and exeessive development of nervous system.

Inproprieties of llress.

Imprudence during menstruation. 
Imprudence after parturition.

Non-recognition or neglect, on the part of the obstetrician, of iujuries due to parturition.

Prevention of conception and induction of abortion.

Marriage witl existing disease of genitalia.

Insuflicient food.

Ilabitual constipation.

Neglect of Exercise and Physical Development. - There can be no doubt of the faet that, as a general rule, in the higher walks of life throughout the civilized world, the female, from infancy to old age, takes much less exercise than the male, and in the Cnited States, owing to peculiarities of climate, this disproportion is probably more marked than in the countries of Europe. It is true that the last decade has seen a most gratifying improvement in this respect, and that the practice of outdoor anusements, such as rowing, bowling, archery, walking, croquet, horseback exercise, ete., has become much more general.

This, however, is greatly confined to the inhabitants of eities and to very young women, and even among these it must become much more general than it is to-day for it to produce the results which may in time be expected from it. The female by nature is as a rule much more inclined to a sedentary life than the male, and as her occupations keep her indoors she is apt, whether living in city or country, to lose all taste for out-door amusements, and to confine herself to the close, heated air of inhabited apartments. Among our farming population, where all the out-loor work is done by the males, the women commonly take less exereise in the open air than do those in our cities, and much of their time is spent in rooms heated by stoves which cook the air and render it dry and unwholesome.

In spite of the improvement we have mentioned, in our eities will, today, be found hundreds of ladies who do not walk a mile a day for weeks together, and many more who have never engaged in any exercise which called forth the action of other muscles than those employed in the quietest locomotion.

But nowhere is the neglect of early physical development more marked than in our boarding-schools and female seminaries, where every hour of the day from six in the morning to nine at night is allotted by rule to some special task. Instead of the girls being eneouraged to engage in outdoor pursuits calculated to create muscular power, they are reared in the belief that such pastimes are hoydenish, unbecoming, and fit only for rough boys. Their hours of leisure are occupied by reading, music, drawing, or some similar light task, and an hour's walk every day is regarded as a degree of exercise quite suffieient for the requirements of health. By this plan the mind is constantly kept in the thraldom of control, and chafes under the depressing intluence of a never-ending surveillance. A set of 
romping school-girls could as profitably laugh by rule as really enjoy and improve by exercise under the eye of an instruetress or professor of calisthenics. It is not the mere bodily exertion which is of benefit, lut the total mental relaxation, the exhilaration and the abandon which aceompany it. The prisoner working for eiglit hours on the treadmill does not profit by it as the firee and happy equestrian or oarsman does by oneeighth the time of exereise.

One of the most important results of exercise is the increase of the peripheral circulation. This increases cutaneous exhalation, and tends to equalize the eireulation. The woman who neglects it is peculiarly prone to excessive uterine and ovarian congestion at menstrual epochs, and to sluggish cireulation in these parts at all times. It is this fact which explains the excellent results attainable in cases of uterine and ovarian disease from the use of passive motion by the Swedish movement cure, the Turkish bath, surf bathing, and other methods which create turgescence of the cutaneous capillaries, and exalt metamorphosis of tissue in the periphery of the body. One of the most valuable and beneficent means of treating these diseases that $I$ know of is the use night and morning of a warm sponge-bath of water strongly impregnated with salt, followed by thorough friction with a rough towel and calisthenic exercises for five or ten minutes.

Excessive Development of the Nerrous System.-The necessity for a due proportion existing between the development and strength of the nervous and muscular systems has always been recognized, and has given rise to the trite formula, "mens sana in corpore sano," as essential to health. Lnfortunately the restless, energetic, and ambitious spirit which aetuates the people of the United States, has prompted a plan of education which by its severity creates a vast disproportion between these two systems, and its effects are more especially exerted upon the female sex, in which the tendeney to such loss of balance is much more marked than in the male. Girls of tender age are required to ajply their minds too constantly, to master studies which are too diffieult, and to tax their intellects by efforts of thought and memory which are too prolonged and laborious. The results are, rapid development of brain and nervous system, precocious talent, refined and cultivated taste, and a fascinating viracity on the one latul ; a morbid impressibility, great feebleness of museular system, and marked tendency to disease in the generative organs, on the other.

That this statement of the arlvantages which are gained and the price which is paid for them is perfectly true, no American practitioner will denly. But the mere existence of the fact is not the most melatneholy feature of the case; it is far more painful to see mothers listening to it, almitting its truth, and yet ealmly and dispassionately choosing to make the trial, as we see them doing constantly. 
When the day arrives in which our young growing girls are exlueated physieally with the assiduity and system now bestowed upon their mental culture; when mothers desire to see their laughters grow up strong, weIl developed, muscular women, and not merely highly edueated and aceomplished valetudinarians, one of the most prolific of the predisposing callses of disease of the genital organs will have disappeared. No amount of mental laber, no degree of mental culture will fit a woman for the physial duties of wife and mother, or render her eapable of bearing children competent to resist the inroads of disease.

In a woman developed by this pernicious system, the physiological congestion of the pelvie organs attending orulation produces pain which is known as " neuralgie dysmenorrhoa ;" ovulation becomes irregular and abnormal, favoring the development of subacute ovaritis; the normal hypertrophy of the uterus consequent upon utero-gestation slowly and imperfectly passes off, subinvolntion often remaining; while the enfeebled muscular supports of the leary organ allow it to lapse from its position and assume that of flexion or version.

Timproprieties of Dress. - The dress adopted by the women of our times may be very graceful and becoming, it may possess the great adrantages of developing the beauties of the figure and concealing its defects, but it certininly is conducive to the development of uterine diseases, and proves not merely a predisposing, but an exeiting eause of them. For the proper pertormance of the function of respiration, an entire freedom of action should be given to the ehest, and more especially is this needed at the base of the thorax, opposite the attachment of the important respiratory nuscle, the diaphragm. The habit of contracting the borly at the waist by tight elothing confines this part as if by splints; indeed it accomplishes just what the surgeon does who bandages the chest for a fractured rib, with the intent of limiting thoracic, and substituting abdominal respiration.

As the diaphragm, thus fettered, contracts, all lateral expansion being prevented, it presses the intestines upon the movalule uterus, and forces this organ down upon the floor of the pelvis, or lars it across it. In addition to the force thus exerted, a number of pounds, say from five to ten, are bound around the contracted waist, and held up by the hips and the abdominal walls, which are rendered protuberant by the compression alluded to. The uterus is exposed to this downward pressure for fourteen hours out of every twenty-four; at stated intervals being still further presierl upon by a distended stomach.

In estimating the effects of direct pressure upon the position of the uterus, its extreme mobility must be constantly borne in mind. No more striking evidence of this ean be cited than the fact, that in examining it by Sims's speeulum, if the clothing be not loosened around the waist, the 
cervix is thrown so far back into the hollow of the sacrum as to make its engagement in the field of the instrument often very difficult, and that attention to this point in the arrangement of the patient will at once remove the diflieulty. While the uterus is exposed by the speculum, it will be found to ascend with every expiratory effort, and descend with every inspiration; and so distinct and constant are the rapid alterations of position thus induced, that in operations in the vaginal eanal the surgeon can tell with great certainty how respiration is being affected by the anasthetic employed. An organ so easily and decidedly influenced as to position by such slight causes must necessarily be affected by a constriction which, in autopsy, will sometimes be found to have left the impress of the ribs upon the liver, producing depressions corresponding to them.

Corseting, lacing, and the wearing of tight and heavy clothing, also prodace a deleterious effect in quite another way. Pressure against the abdominal and thoracic muscles, and orer the diaphragm, produces in them a partial paresis. This impairs abdominal as well as thoracic respiration, to a great extent comnteracts the important retentive power of the abrlomen over the pelvic viscera, and allows the influence of gravitation, which before was by that means antagonized, to catuse displacement. This result of a pernicious liabit cannot be too thoroughly appreciated or too much insisted upon. So prominent is it in etiology that I might well have considered it under the head of exciting causes. By the direet influences of pressure just considered, and the paresis of thoracic, abdominal, and diaphragmatic muscular fibres now alluded to, the abdominal viscera press upon the growing uterus of the young girl, and the fundus being bent towards the eervix, one uterine wall develops much more rapidly than the other, and at puberty the menstrual effort finds itself interfered with by closure of the cervical canal, and an origin for uterine disease is created thercby.

To a woman who has systematically displaced her uterus by years of imprudence, the act of sexual intercourse, which, in one whose organs maintain a normal position, is a physiological process devoid of patholorical results, becomes an absolute and positive source of disease. The axis of the uterus is not illentical with that of the vagina. While the latter las an axis coincident with that of the inferior strait, the former las one similar to that of the superior. This arrangement provides for the passage of the male organ below the cervix into the posterior cul-rle-sac, the cervix thus escaping injury. But let the uterus be foreed down, as it is by the frewaling styles of fashiomable dress, even to the distance of one inch, and the natural relation of the parts is alterel. 'The cervix is directly injured, and thus a physiological process is insensibly merged into one prometive of pathologieal results. Ilow often do we see uterine disease ocem just after matrimony, even where no excesses have been eonmitted. It is not an excessive judulgenee in eoition which so of ten produces this 
result, but the indulgence to any degree on the part of a woman who has distorted the natural relations of the genital orans.

But this is by no means the only method by which displaecment of the uterus may induce disease of its struetures. It disorders the eireulation in the displaced organ, and produces passive congestion and its resulting hypertrophy, prevents the free eseape of menstrual blood by pressing the os against the vagina, creates flexion, causes friction of the cervix against the floor of the pelvis, and stretches the uterine ligaments and destroys their power and eflicieney.

These facts should be carefully borne in mind by the physician who attempts to relieve nterinc displacements by the use of pessaries. If he merely replaces the displaced organ and relies for its support upon a pessary, he will often fail in accomplishing the desired result. He is striving at great disadvantage with a short lever power against the weight, not of the uterus alone, but of the super-imposed viscera pressed downwards by several pounds of clothing, which add their weight at the same time that they constrict the waist and substitute abdominal for thoracic respiration. 'Thus employed the pessary will often give great pain, and so injure the parts upon which it rests as to necessitate removal, and the practitioner will find himself cut off from one of his most valuable resources. Should he, on the other hand, before employing a pessary, remove all constriction and weight from the abdominal walls, apply a well-fitting abrominal supporter over the hypogastrium so as to aid the exhausted abdominal muscles in their work, keep the displaced and congested uterus out of the cavity of the pelvis by a tampon of medicated cotton, or bring gravitation to his assistance by the position of the patient, he will ordinarily at the end of a week be able to employ with great adrantage the same pessary, which at first seemed to accomplish evil and not good.

Imprudence during Menstruation is a prolific source of disease. Some women, through ignorance, many through recklessness, and a few from necessity, go out lightly clad in the most inclement weather during this period, and many suffer in consequence from violent congestive dysmenorrhoa, and of ten from endometritis. Every practitioner will meet with a certain number of eases of uterine disease which have this origin, and run on for years, ending, perhaps, in parenchymatous disease, which may prove incurable.

During a period in which the ovaries and uterus are intensely engorged, in which the surface of the ovary is broken through by the escaping ovule, and the nervous system is in an unusual state of exeitability, ordinary prudence would suggest that the body should be well covered, that the congested organs should be left at rest, and that exposure to cold and moisture should be sedulonsly aroided. I need not say that these rules are commonly negleeted; and in evidence of the fact I will venture the 
assertion that, on this very day, the thermometer $15^{\circ}$ above zero, the skating pond of our park contains scores of delicate and refined women who are showing a disregard of them by their presence there.

The immediate result of exposure during menstruation is most commonly inflammation of the mucous membrane of the uterus. Such an inflammation once exeited will often go on for years and in time end in parenchymatous disease, entailing in its progress dysmenorrhœa, sterility, pelvic pain, and gastric disorders, which impair digestion and nutrition. Many cases, too, of pelvic peritonitis, cellulitis, and hematocele develop at this trying period of congestion and nervous exaltation.

Imprudence after Parturition.-No sooner does fixation of the impregnatel ovum upon the uterine surface occur than a surprising stimulation is exerted upon the fibre-cells forming part of the uterine parenchyma, which grow with rapidity, enlarging the organ, pari passu, with the requirements of its increasing contents. After the expulsion of the embryo, either at full time or at any period of pregnancy, the fibres thus developed undergo a fatty degeneration and absorption, which has received the name of involution. This process occurs rapidly after abortion, but after labor at term it requires six weeks for its full accomplishment. In order that it may proceed with normal rapidity and certainty, perfect rest is essential; and the woman who rises too soon, and resumes her usual occupations, while the lochial discharge is still existing, risks the results of interference with it. Besides this, the uterus is much heavier than usual, and the additional danger of the induetion of displacement is ineurred by too early exertion. Lastly, the mucous membrane lining the cavity of the uterus is for some time after parturition in an abnormal state, and is feculiarly liable to disease from exposure to cold and moisture. A very valid oljection may be mate to this view, that in the lower walks of life women rise after labor, and attend to their duties with impunity on about the ninth day, and yet enjoy a marked immunity from uterine affeetions. This is true; but let it be remembered that they are unaffected by the influences to which I have alluded as calculated to enfeeble and deteriorate their grenerative systems.

Another influenee connected with parturition, which develops itself much more decidedly among the ligher than the lower classes, is the pernicions habit of tiglit bandaging. For three or four weeks after delivery the unrse eommonly applies two folded towels over the enlarged uterus, and by powerful compression by a bandage forces the organ backwards into the hollow of the sacrum. This is supposed to preserve the comeliness of the figure, and the reputation of many at nurse rests mainly upon the thoroughness with which she develops an influence that is fruitful of evil in divplacing an enlarged uterus in a woman who for a fortuight at least lies chiefly upon her back. That a well-fitting bandage, only tight enough 
to give support, applied after delivery, proves a source of comfort to the woman, I am not disposed to deny. In this way I always employ one. liut I feel very sure that a great deal of superstition attaches in the lying-in room to this appliance, both as a means of preventing deterioration of the figure, and post-partum hemorrlage. Uterine contration should bo seeured by rital, not mechanical means, and no amount of compresion by a bandage will cause the over-distended abdominal muscles, skin, fasciae, and areolar tissue to return to their original condition. Not only should tiglit bandaging be avoided after delivery, the position should be sys. tematically chamged at intervals from the dorsal to the lateral decubitus. I an convineed that uterine displacement is one of the most fruitful causes of subinvolution. As, during the six weeks or two months succeeding delivery, the process of retrograde metamorphosis, called involution, progresses, the uterus, under untoward influenees, many of which are developed by the routine management of the lying-in chamber, becomes displaced. This results in impeded venous return from its tissues; the process of involution is cleeked; and months or years afterwards the patient, being forced to apply to a physician, is informed that she has suffered and is suffering from metritis of a chronic character of which displacement is a complication or result.

Every practitioner frequently hears that some lady has been injured for life "because she was not properly bandaged at her last confinement," and either doctor or nurse, possibly both, are severely censured for the eulpable neglect. Too often such censure is listened to in silence, and the party supposing herself injured is allowed to hold the same opinion still. It is the duty of every physician to inform those coming under his influence as to the futility of trusting to the obstetric bandage, or, if he cannot conscientiously do so, to review his opinion upon the subject, and see whether lis own confidence is not misplaced.

Non-recognition or Neglect of Injuries due to Parturition.-When it shall become the duty of the cbstetrician, as it surely soon will do under the influence of advancing knowledge, before relinquishing the care of the recently delivered woman, to inform himself thoroughly as to the existence of laceration of the cervix or perineum; when the false and vicions doetrine of undervaluing and ignoring these grave accidents is silenced forcver; and when a neglect of their early repair by surgical resort shall be regarded as a flagrant obstetrical dereliction; then the number of women affected by pelvic disorders will become suddenly and wonderfully diminished. The time for this is now at hand, and the profession everywhere should raise its voice in a matter of preventive medicine as important as that relating to the infections diseases.

So, too, is the time at hand for the complete obliteration of a prevalent idea in the public mind, that the functions of the obstetrician ordinarily 
consist in watching by the parturient couch, receiving the coming clild, and creating harmony and good feeling by well-turned compliments and blandness of manner. This popular idea has caused and causes now many a tender husband, who, were he about to select a coachman, would carefully inquire as to his capacity for an important trust, to confide his wife at the most delicate period of her existence to the hands of one notoriously incompetent. These are the practitioners who, day after day, year after year, send forth women with lacerated cervices, and ununited perineums, to furnish to the gynecologist in the future cases of uterine engorgement, leucorrhoea, prolapsus, and other displacements, and cystitis, and a long list of pathological states which will cling to them for life, sapping their usefulness, and destroying the happiness of their houselolds.

\section{Prevention of Conception and Induction of Abortion.-Means estab-} lished for the accomplishment of the first of these ends are often productive of uterine disorder. This will not be wondered at when the harsliness of some of them is borne in mind. The workings of nature in this, as in all other physiological processes, are too perfect, too accurately and delicately adjusted, not to be interfered with materially by the clumsy and inappropriate measures adopted to frustrate them. The practice is becoming exceedingly common, as every physician is aware, so common, indeed, that in the older portions of this country, unfortunately, it must be said, in the more civilizel and educated, it is by no means usual to meet with large families of children.'

The fact is not an agreeable one to deal with, and the facts which $I$ am citing may prove unacceptable to many of my countrymen, but it is one which is rapidly assuming proportions which must influence the future population of our country. It is useless to ignore it. If an evil is to be eralicated, the first step towards such a consummation is its recognition, and what class of men can more immediately and more effectually grapple with this one than plyysieians?

With these statements we leave this unattractive subject to deal with another, which, from its importance, cannot conscientiously be passed over in silence. Statistics slowing the frequency of criminal abortion never lave been, and never will be written, for the crime creeps stealthily, beneath the scrutiny of society. That this criminal practice constitutes a prolific source of uterine disease no one engaged in gynecology can for a moment doubt. So impressed with this fact are the physicians of the Cnited States that some years ago, at its meeting in New York, the

1 Able pajers npon this subject appear in the Boston fiynecological Jonrnal from

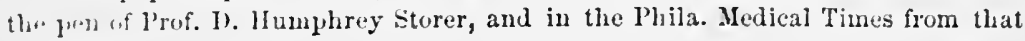
of l'rof. W'm. Goodell. 
Ameriean Medical $\Lambda$ ssociation offered a prize" for a "short and comprehensive tract for circulation among females, for the purpose of enlightening them upon the criminality and physical evils of forcel abortions."

Murriuge with Existing Uterine Disease.-It is a common practice with physicians to recommend marriage as a cure for uterine lisease. There are a suflicient number of abnormal conditions which childhearing cures to mike the practice appear legitimate, but a vast deal of harm frequently results from it. A constricted ecrvix which causes dysmenorrhoa, a pure endometritis of neck or body, or an inactive state of the ovaries which results in amenorhoca, may be relieved by the parturient act; but displacement, peri-uterine celuulitis or pelvic peritonitis, will very often produce evil results after labor, and very generally return with renewed violence as soon as involution has been accomplished. The advice is too often given empirically, and, like all such counsel, is hazardous in its results. My experience leads me to fear a return of such conditions after childbearing, even in a patient whom I considered cured at the time of marriage.

Insufficient Food.-Many diseases of the uterus are established, and a still larger number perpetuated, by impoverished blood and the disordered nerve state dependent upon spanæmia. So well known is this fact that a generous diet commonly constitutes an important element of treatment, and its result in improved hematosis is hailed as the harbinger of approaching improvement. 'The tone of the uterus, that is its muscular strength and power of resistance, is decidedly affected by want of sufficient nutrient material, and flexions are a frequent consequence, as Dr. Graily Hewitt has ably pointed out; engorgement of the mucous membranes of the uterus, Fallopian tubes, and vagina, are favored by the same influence; and it is beyond doubt that a feeble, atonic state of the uterine ligaments is engendered and kept up by it. To no nation in the world is a full supply of the most nutritious food so attainable as to the inhabitants of the United States. And yet it is no exaggeration to maintain that the American woman, except in our cities, is at least half starved. She suffer's not from an enforced but a voluntary starvation, which however none the less impoverishes her blood and impairs her nerve power. Let any one travel through our farming regions and examine closely the women with whom he meets, and he must admit that the robust, buxom, florid lass and matron is the exception; the pale, lank, and emaciated, the rule.

1 The prize thus offered was awarded to Prof. II. R. Storer, of Boston, for an able essay, entitled "Why Not?" 
These women are not overworked, for this country knows no hardworked peasintry. They are under-fed, however, from their eradles to their graves. It must be remembered that it is not merely material introduced into the stomach which nourishes the body, but the introduction of material capable of making blood of good quality which does so. The eating of salt fish and meats in place of fresh, the drinking of large amounts of tea in place of milk and malt liquors, and the eonsumption of incaleulable amounts of the noxious and inevitable pie of the Eastern States in place of bread and nutritious puddings, will never answer the requirements of nutrition until the laws which govern that process are altered.

The Ameriean travelling in Great Britain is always struck by the large amounts of nutritious food, of malt liquors, and of the products of the dairy which are consumed as well as by the amount of time given to their consumption, and very often lie plumes himself upon the more elegant habits of his own country. In vain do we look among our women for justification for such self-congratulation, and most earnestly would we urge an imitation of customs which would greatly improve our own condition.

IIabitual Constipation.-A large proportion of women who, after puberty, marriage, and maternity, suffer from uterine disease do so in consequence of deformities of the uterus developing between the period of infancy and that of womanhood. One of the most frequent and obstinate of these is cervical anteflexion. In this state the body of the uterus does not alter its position, but the eervix is bent sharply forwards, ereating a stricture at or near the os internum uteri, and causing obstruction to the eseape of fluids from the uterus and interference with its venous circulation. The habit of allowing large, hard masses of fecal matter to remain not only for days but for a week at a time in the rectum, as many women do, contributes largely to the oceurrence of this detormity in the soft, pliable, growing uterus of girlhood.

Alone it is suflicient to bend the uterus and give it the shape of a gourd, but, combined with pressure from alove by tight, heavy clothing constricting the waist, it is not astonishing that it very often produces this common disorder of the shape of the organ. Once produced it is a condition which pretty surely results in endometritis, dysmenorrhaa, and sterility, and it is one rarcly remediable except by resort to surgery.

Let me present a picture, simple and unexaggerated in its iletails, of millions of our women who are exprosed to the baneful influencrs which $I$ have endeavored to portray. The woman is flat-chested, slightly roundshoulderenl, and thin almost to emaciation. Her hands and feet are cold, and her facies is not one suggestive of hilarity or buoyncy of spirit. Anceulate the thoracic organs, and a slight hasic murmur will be heard over the heart, and the respiration will be found fecble and inefficient. 
Tell the patient to inflate the lungs fully, and the effort is so poor an one that it is seen at once that a full inspiration is a rare matter with her. She eraves such stimulants as tea, and desires as food articles which are sweet. The bowels are almost invariably constipated, and an examination of the skin shows that it is inative, and that its vessels are not filled with red blood, but shrumken and atonie.

She is nevertheless in excellent health, does a large amomint of work in her house, and jerhaps for a long lifetime fulfils all the requirements of her existence. So she willingly allows her daughters to follow in her footsteps. And yet how thoroughly is this woman fulfilling every indieation which is necessary to eause her to fall an easy prey to disease of the sexual organs as to that of any other organ in the body!

The interdependenee of the various physiological processes one upon the other is very striking. Primary nutrition keeps the blood in healthy state, respiration keeps it in active eirculation, and action of the muscles stimulates and makes perfect the flow through the eapillary vessels of the skin, liver, kidneys, and all the other organs of the body. Derangement in any one of these proeesses creates disorder in others. Imporerished blood entails imperfect circulation, defieient respiratory effort furthers this, and an inactive state of the muscles tends to production of local hyperamia by allowing blood stasis in the deeper parts of the body. All this renders excretion inefficient, and the nerve centres soon feel the benumbing influence of a slow toxamia. It is evident that the influenees which I have mentioned tend very decidedly to disorder the system in this way.

This completes the list of those influences which, in my estimation, most markedly predispose to disease of the female genitalia in the Cnited States. In reviewing them I trust that I have not spoken in a tone of exaggeration of any one of them.

There are two points in this connection which I would earnestly insist upon, and concerning which $I$ feel that the medieal profession is greatly at fault. The first is the prevalent idea that there is in woman an inherent tendency to disease of the sexual organs, that she is born to these affections "as the sparks fly upwards," and that an entire immunity from them is a licky circumstance which is rather a eause for surprise. The second is the belief that, these disorders being contracted, not from avoidable but from inevitable causes, the woman herself is not responsible for then. Once falling a victim, she immediately puts herself under the eare of a physician, and then very likely follows a lengthy and tedious course of local treatment.

Surely one of the highest duties of the physician is to disseminate correct riews upon these points; one of his greatest derelictions endorsing them by tacit consent.

I shall deal very cursorily with the exciting causes of these diseases, for 
the reason already given. I would not, indeed, have alluded to them here were it not that the opportunity for enumerating them in this conneetion appeared to be too important a one to be lost.

The ehief of these may thus be tabulated:-

1st. Injuries inflieted by parturition-e.g., laceration of eervix and perineum; pudendal and sub-peritoneal hematocele; and inversion of the uterus.

2d. Derangements of involution-e. g., subinvolution of uterus, vagina, perineum, and uterine ligaments; superinvolution of uterus; fungoid degeneration of the endonetrium; retention of futal envelopes; displacements of the uterus.

31. Congenital and infantile anomalies in shape, proportions, and position of genitalia-e.g., flexion; undeveloped state of cerrix, of body of uterus, or of both; eontractions of cervical eanal; absence or imperfect development of ovaries, and similar imperfections of the vagina.

4th. Sudden violent and unaceustomed efforts producing flexions, versions, and prolapse.

ith. The development of neoplasms in connection with any of the genital organs-e. g., fibroids or eysts of the uterus, vagina, or ovaries; adenoma, sarcoma, eancer, etc.

6th. Deposits of lympl throughout the pelvis from general peritonitiseausing displacements of uterus and ovaries; ovarian engorgement and neuralgia; congestion of all the pelvic organs.

7 th. Loeal treatment, and examination by sounds, tents, etc.-causing peritonitis, septicamia, and cellulitis.

stl. Contamination by gonorrhoal or syphilitic virus_causing endometritis, salpingitis, pelvic peritonitis, and development of syphilitic abrasions and neoplasms.

3th. Means adopted for prevention of eonception and production of eriminal abortion_eausing endometritis, granular degeneration, pelvic peritonitis and cellulitis, fungoid degeneration of endonetrium, septicamia, and retention of the fuetal envelopes.

\section{II A P'T E R I I I.}

GENERAL CONSIDERATIONS IPON ITERINE PATHOLOGY AND TREATMENT.

LAt us suppose that a woman, born of a mother who has transmitted to her a rather feeble constitution, lives such a life as to expose herself to enfeblement of the nerve power, imporerishment of the blood, and local 
disorders of the eireulation, from the predisposing eauses mentioned in the last chapter. These alone are sufficient to establish in her disease of the sexual oryans; or, if they do not do so, one of the exciting causes enumerated may supervene, and, falling upon well-prepares gromut, the seeds of disease thus sown thrive luxuriantly. Let us consider the patholugical steps by which the various pelvic diseases peculiar to her sex are de veloped.

Notining more decidedly retards the progress of gynecology, lowers it as a special study in the eyes of the sister departments, and fans the dying flame of a prejudice with which it has been able successfully to contend only during the past half century, than the unsettled state of uterine pathology. In general medicine, in surgery, and in all other special departments, the study of pathology is made the keystone of the arch which supports them; and observers seem willing to agree as to fixed principles concerning it. In gynecology, this whole subject presents the melancholy aspect of uncertainty and dissension. Many of its votaries, insteat of taking broad and strong views, become the partisans of some special dogma or theory, which is warmly attacked by others who hold some view equally narrow, incomprehensive, and exclusive.

As a result of this state of pathological confusion among the leading minds deroted to the department, every newly-fledged specialist feels warranted in elaborating and maintaining a theory of his own; or, in attaching himself to one of the many which present themselves for his choice.

All must admit that to this department to-day as many able, zealous, and industrious laborers are devoted, as to any other in medicine. Why should such a body weaken its influence by adherence to dissentient and partisan views? Why is one impelled to entertain the view that inflammation of the parenchyma plays the important part of moving canse in uterine disorders; another that displacements of the uterus do so; another that the chief trouble consists in an irritation or hyperæsthesia in the uterine nerves; another that catarrhal inflammation of the uterine mucous membrane is the origin of most of its disorders; while still another attributes to the inefficient restoration of the uterus after the structural elanges due to utero-gestation, the most important role? To one who calmly and dispassionately eonsiders the subject, not in the study, but by the bedside, and who goes to it with a mind free from prejndice, and eager for the discovery of truth, it appears to me that it must in time become evident that truth lies not in any one of these theories, but is to be found to a certain extent in each. No pathologist elaims that hepatic, or cardiac, or renal disease has always the same pathological origin; why shonld any one expect to find for uterine disorders a nuiversal pathogenie factor?

At wo period in modern times lats this department been so favorably and respectfully regarded, by the science of which it is a part, as at pre- 
sent. Now, then, has the time arrived when every one of its well-wishers should strive to obliterate all factions and parties, to free it from dogmas and narrow views, and place it where it should always have stood, upon the broad platform of an enlightened pathology.

That the uterus should perform its functions efficiently and naturally, it is essential, 1st, that its innervation and circulation should be normal; $2 d$, that its structure shonld be unaltered in character and proportions; and $3 \mathrm{~d}$, that no decided and permanent change should have occurred in its position. An abnormal state, developing in connection with any one of these essential conditions, may derange the functional powers of this important viscus, and demonstrate itself by symptoms which produce greater or less discomfort to the woman. When, as very often happens, the first evil produces others, until at last all three conditions are interfered with, the gravity of the symptoms increases with simultaneous increase in their number and varicty. Sometimes the first link in the cliain of morbid action is an altered condition of the nerves governing circulation, some general or local condition reffecting itself upon these regulators of nutrition; as a consequence, an aflux of blood takes place to the uterine mucous membrane, and its vessels hecome distended, and in time dilated. This lasts for a variable time, when the second link is furnished in this manner: an excessive degree of nutrition is supplied to the subjacent connective or areolar tissue of the organ, and its size and weight increase. Then the third link rapidly develops itself. The uterus now being heavier than normal, its natural and hitherto sufficient supports are insuflicient for its maintenance in position, and it descends in the pelvis, sometimes so as to alter the direction of its axis, and protrude between the labia majora; at other times its axis is not changed in its descent, and then the cervix, striking against the curved surface of the sacrum, is bent forwards so as to offer an obstruction to the escape of menstrual blood; at others, the fundus falls forwards, laterally, or backwards, either bending upon the neck, or by its displacement forcing this part out of position likewise. Then appear, as symptoms of this threefold disturbance, leucorrhoa, hackache, dysmenorrhoa, difficulty in locomotion, and the long list of discomforts to which women thus affeeted are liahle.

This, however, is hy no means alweys the sequence of events. Sometimes the uterus anlarged by utero-gestation does not return to its original small size. but remaining large and heary. it falls from its place in consefunene, and this disorder of position reacts upon the other two conditions which I have stated are essential to health_-normal innervation and circulation, and an unaltered state of the structure of the organ.

Agaili, a nterus may be in a perfectly normal state in every respect, when suddenly it becomes retroverted. As a consequence, innervation and cirentation are at once disturbed, congestion occurs. a hypergenesis of tissue gradually takes place, and thus what was originally merely a dis- 
placement becomes a eondition of eongestion, enlargement, and chronic eatarrh.

The position which I assume, with reference to the pathologieal series which may result in confirmed uterine disease, is this: that the pelvie organs of a woman who has hitherto been in perfeet health may become gradually or suddenly diseased by one of the three following abnormal developments in the uterus: 1 st, disorder in innervation and circulation; 2d, ehange in quantity of comnective or musenlar tissue; $3 d$, change in position. I assume, furthermore, that, the first here mentioned being the primary lesion, the second and third may result from it; that, the second being the primary lesion, as in subinvolution or the development of neoplasms, the first and third may result from it; and that, the third primarily showing itself in a perfeetly healthy organ, the first and second may be its eonsequences.

Let us now proeeed one step further. Those primary pathologieal conditions which most eommonly produce disorder in the three elements which I have mentioned, may be said to constitute the espeeial factors of uterine disease. What are they?

1st. Catarrhal inflammation of the lining membrane.

2d. Prolonged congestion of uterine tissues.

3d. Excessive growth of connective or museular tissnes.

In the beginning one only may exist, uterine eatarrh, for example; in time this may induce another, congestion in the parenehyma; and still later, this excessive blood supply may result in a third, hypergenesis of connective tissue. Whatever then tends to induce and keep up any one of these three morbid states, tends direetly to the establishment of confirmed uterine disease, and the consideration of this point brings us to the investigation of the individual pathologieal ageneies which ordinarily produee such a result.

1st. In the very large majority of cases of uterine disease, the first link in the morbid ehain is subinvolution, which produces as direet consequenees, passive congestion, hyperseeretion by lining membrane, menstrual disorders, displacements, sterility, and interferenee by pressure with neighboring organs.

2d. A certain number of eases is produeed by disordered uterine eireulation and innervation, the results of displacement of the uterus, either as a whole or by bending of itself upon its axis. Such displacement or distortion induces passive eongestion, hypergenesis of tissue, dysmenorrhoea, sterility, and endometritis.

31. A certain number of eases arises from primary catarrhal inflammation of the lining membrane of the uterus itself. This, eommeneing as an entity, results in hypergenesis of tissue, displacements, menstrual disorders, and sterility. 
4th. In a number of cases by no means small, the circulation, innervation, and size of the uterus are interfered with by obstruction to the escape of menstrual blood. Such obstruction distends the uterine cavity by the inprisoned menstrual discharge, inflames its lining membrane, and results in leucorrhoa, dysmenorrhwa, hematocele, and flexions.

5th. In some cases the uterus is, by sympathy with diseased ovaries, kept in a condition of exalted innervation and deranged circulation, which, in time, eventuates in congestion of the whole organ and hypersecretion by the mucous lining. As consequences of these states, there appear as symptoms, leucorrhoa, menstrual disorders, displacements, sterility, etc.

6th. The development of benign or malignant growths, consisting of hyperplasia of one or more of the uterine elements, often deranges the innervation, circulation, and proportionate weight of the uterus, and results in displacements, sterility, menstrual disorders, leucorrhœa, pelvic pains, mechanical interference with surrounding organs, etc.

7th. The uterus, although not primarily affected, may become displaced and congested from interferenee by contracting lymph, exuded in contact with it and over its surface, as a consequence of pelvic peritonitis. Such displacenent and congestion may result in excessive growth of tissue and endometritis.

8th. Discase not only of the neck but of the body, and not only of the mucous membrane but of the proper tissue of the organ, is often induced by laceration of the eervix, which results in eversion, and the exposure of a large and vulnerable surface to friction and injury during coition and exercise.

$9 t h$. The genital organs are often kept in a state of erethism and hyperamia by a neurosis, such as vaginismus, or a point of intense nerrous excitement, such as fissure of the anus, which may develop into absolute discasce.

Let the pathologieal state which establishes the disorder be what it may, after it has continued for some time and its instrumentality lats resulted in fixed discase, the following symptoms develop as eharaeteristic of such discase: lencorrhua ; menstrual disorders; pain in back, loins, and pelvis; sterility; lysteria or nervous symptoms; gastric, intestinal, and vesical derangements, etc. They are confined to none, but in time mark all.

'That congestion constitutes one of the pathological steps in the proeess is beyond question; but how short-sighted, how superficial, to make it a sole factor, to declare it to be "fons et origo"!

With these facts before him, the sturlent may well ask, how any logical mind could consent to adhere to an exelusive pathologieal doctrine, ignoring or denying others of unquestionable importance and significance? It hat:, I think, heen done hy confoumding eause and effect. He whose nind is hampered by the theory of inflammation will find it in every case of long standing, in the mucous membrane, for congestion of this produces 
hypersecretion; and in the parenelyma, heanse hypermutrition in this part has resulted in hypergenesis of tissue. The utems is large, tumefied, secreting excessively, and tenter to the tonch; all these prove for him "inflammation" to exist. In the great majority of cases in which a diseased uterus is examined after it has been in an abnormal condition for a long time, the following physieal signs will be diseovered :-

1st. The uterus will be larger than normal.

2l. Catarrh of the lining membrane will exist.

31. The vaginal face of the cervix will be in a gramular condition.

4 th. The uterus will be displaced.

5th. The ovaries will be found slightly enlarged and sensitive.

Ilere are five theories offering thenselves for adoption, and in a conclave of five consultants, each might hold an unassailable ground, and each might possibly be right. But, as no one has the key to the progressive development of the conılex condition, no one can prove himself so. Aceording to my observation, the analysis of this collection of morbid states, which most frequently furnishes the key to their solution, is this :-

Involution of the uterus was interfered with some years before, and subinvolntion existed for a while, and gradually resulted in areolar hyperplasia ; this soon resulted in displacement, which impeded venous action; from this, a uterine catarrh arose, which exeoriated by its diseharge the vaginal tace of the cervix; from this cause, combined with friction, granular degeneration took place; and the irritation transmitted by this complication of irritating influences ereated enlargement and sensitiveness of the ovaries.

I say, that, according to my experience, the most common fictor of this series is subinvolution; but $I$ do not say that it is the universal factor. It may be that all these lesions arose from congestion dne to retroversion which has been negleeted, and has long prevented free venous return. Or, perchance, the large granular surface, whieh has been ealled an "inflammatory ulcer," is an eversion of the cervical mucous membrane due to rupture of the cervix, which occurred five years ago in parturition, and has kept up nervous irritation and hyperamia, which have resulted in all these "signs of inflammation."

Impressed by the fact that, with many of the physical and rational signs of inflammation, the enlarged, sensitive, and engorged uterus is not inflamed; one prarty has endeavored to cut the gordian knot by styling the anomalous state one of "irritability." But the term was badly chosen, and its introduction has aceomplished more of confusion than of simplifieation, nor have the profession generally been willing to accept a name

1 If pertrophy signifies excessive growth or enlargement of a tissue already existing: hyperplasia signifies the development of new tissue. 
signalizing the nervous condition alone for a state characterized by congestion, hypergenesis of tissue, and coincident, probably resulting, nervous exaltation.

But, it may be asked, is not this eondition of enlargement of the uterus after all a state of inflummation, of chronic metritis, however it may have arisen? I answer, no more a condition of chronic inflammation than is the enlargement of the tonsils which lasts for years in children; or than the tenter, enlarged spleen, the ague cake of malarial poisoning; or than the enlarged testicle of syphilis. I do not deny the name and character of inflammation to suppurative tonsillitis or quinsy, to the orchitis of gonorrhea or even to that very rare disease splenitis, which sometimes ends in suppuration. Let the unprejudiced reader reply to this question from his own observation: does the state of the uterus which we are considering most resemble the former or the latter of these pathological states? I cannot doubt his reply.

These remarks apply not only to the partisans of the dogma of inflammation, but to those of all the others which have been adopted. He who wishes to sustain his views and his party by finding displacement will almost always do so, for a heary uterus, which was in normal position in the beginning, generally falls from its place in time; he who looks for uterine catarrh will likewise be gratified, for a congested mucous membrane always gives forth an excessive secretion; and even he who will be satisfied with nothing but ovarian disease will often be able to sustain his theory, for chronic uterine disorler is very apt to affect in time these organs, which are so intimately in sympathy with the uterus.

Prognosis in Uterine Affections.-There is no organ of the body the diseases of which offer greater difficulties in prognosis than those of the uterus. So much depends upon the habits of the patient, the injurious influences to which she is exposed, and the faithfulness with which she follows out the directions of the physician, that often very little can be predicted, very little promised with any certainty. The error into which the incautious jractitioner is most likely to fall is that of predicting a cure at too early a period, and fixing some definite time for its accomplishment. The patient may declare that she and her friends will be satisfied even if the limit be fixed not by months but by years, nevertheless she is desirous of knowing when she may confirlently expect a cure. The answer to this (puestion, not in the lesser interest of the practitioner, but in the greater one of the patient, must often be, that no such time can possibly be determined uron. In some cases it becomes necessary to state further that not only is the time but the certainty of complete cure doubtful; that local treatment will cause pain, may result in danger, and may absolutely ageravate the existing symptoms.

Another point which influences prognosis is this: in the management of uterine diseases it is of primary importance that the praetitioner should 
enlist the interest and co-operation of his patient. Should she be aptthetic with regard to the result, or even, having begun treatment with enthusiasm, become disaffeeted from any cause, his duties will probably prove irksome, anmoying, and fruitless. For this reason he should be eautious in urging with too great earnestness the adoption of local treatment.

In view of this, and the additional fact that treatment may extend over months before a cure is effected, the physician should avoid all resources which by their uncleanliness or disagreeable nature may disgust a refined patient, or make her rather willing to bear her disease than the means adopted for its cure. If such means will be very likely to give relief, they should of course be employed; but if, as is the case with many of them, their eflicaey be extremely doubtful, they should not be insisted upon. For example, if a lively, fastidious lady were called upon, for the relief of "ul endometritis which is not in itself very annoying, to forego society and spend most of her time in bed, to fill the vagina daily with a semi-solicl mass of powdered linseed after the method of Mélier, to rub mercurial ointment over the hypogastrium, and have a weekly application of leeches around the anus, she would probably in time get tired of the treatment, and lapse into the very state of apatly to which $I$ have alluded.

There is one class of eases in dealing with which I should especially recommend that perfect frankness be observed. It may be represented by a patient who has been persuaded by husband, mother, or friends, contrary to her wishes, to submit to treatment. She utterly repels the course to be alopted, is sure that it will do her no good, is unwilling to fultil the directions left her for daily guidance, but yields, under the assurance of her advisers that the treatment will be free from discomfort, give no pain, and will surely cure her in a few weeks. The physician, for the sake both of his patient and himself, should avoid joining in this deception. Stating the facts fully to her, telling her of the danger which neglect will involve, and of her duty under the circumstances, he should apjeal to her reason, and decline to take charge of her ease until she really desires his services.

Reusons for the Frequency of Failure in the Treatment of Cterine Diseases.-That some uterine affections of non-malignant type are incurable cannot be denied; but even putting these out of consideration, the fact is notorious that the local treatment of these diseases is not as successful in its results as we could wish. I now propose an investigation into the causc's of this want of success. It appears to me that the most apparent and most constant of them may this be summed up:-

Imperfeet diagnosis ;

Erroneous progncsis;

Inefficient or inappropriate therapeutics;

Inattention to general management. 
Imperfect Diagnosis. It is not rare to meet with instances in which physicians have, for months, treated eases of uterine disease concerning the nature of which they not only did not have a correct theory, but had no theory at all. Under these cireumstances the most general practice is to pass, about once a week, a solid stick of nitrate of silver up to the os internum, not to cure cervical endometritis, for that has never been suspected, but to do the best one can in the way of treatment, when he does not know the nature of the disease which he treats. I lave no inclination to attribute this always to any intentional laxity of morale, but rather to indecision and aversion to creating a disagreeable issue with the patient. It is, however, impossible to deny the fact that such a course will sometimes be p'irsued by those who, in the case of a diseased eye or infiamed knee-joint, woull not hesitate to confess, with the utmost frankness, their uncertainty and need of assistance. With uterine, as well as all other diseases, the diagnosis must be properly made before treatment can prove curative; and in this field of practice, fully as much as in others, honesty and sincerity should guide the practitioner. He who practises deception here, is surely no less culpable, althongh far more likely to escape detection, than the charlatan who makes it a rule of life.

Erroneous Prognosis.-Fren if the diagnosis and treatment be correct, an erroneous prognosis as to time of cure may so sap the confidence of the patient as to send her to other counsel. And now she may run the gauntlet of theories and therapeutics. Her first attendant having recognized endometritis with resulting displacement, the second may treat the displacement alone, as the origin of luer symptoms. Passing into the hands of a third, she may be told that to elieck her profuse leucorrhea would be to cure her disease. which the fourth miglit eontradict, with the assertion that the uterine disorder was only a complication of ovaritis, which was the fourtain of all her difficulties.

Inefficient or Inappropriate Therapeutics may cause failure in eure even when a proper diagnosis and prognosis have been made. At times a course of local alteratives may be persevered in when the disease demands more general treatment. At others it is neeessary to extend treatment into the eavity of the body, and not of the neck alone; and at others still, to perform a trifling surgieal operation to remove a difficulty which, unless removed, may keep up the disease indefinitely.

The best results in the management of these affections will not follow a direct resort to treatment of the most prominent existing disease, but will very often be obtained by removal of its cause, or the alleviation of its complieations. Let me make my meaning elear by some examples. The liysician examines and finds endometritis to exist with its usual symptoms, leucorrhua, fain, menstrual disorlers, ete. This affection may be the result of an antecedent displacement. If it be so, replacing and retaining in position the displaced organ should be the first step in treatment, 
as it was the first step in diseased action. Causa non sublata tollitur non effectus, is as trne as the converse proposition. Again, a patient has menorrhagia and prolonged nenstruation, with a long, contracted cervix IIteri. Obstruction to the realy escape of menstrual blool often so alters the lining membrane of the body of the uterus as to create these disomlirs. If the pinysician treat the symptom, he will surely fail in curing it, while suceess will attend his efforts if he remove the obstruction which prevents the uterus from emptying itself.

So also with the complications which are excited by nterine disorders. A patient is affected by cervical endometritis that in time produces hyperplasia, which by increasing uterine weight displaces the uterus. That organ lying upon the floor of the pelvis is injured by locomotion and coition, its lower segment is bathed in purulent leucorrhoea, and great pelvic pain annoys and laarasses the patient. If the practitioner expects to cure her, let him, at the same time he treats the primary disease, the endometritis, relieve a set of complications which, unless removed, will cause repeated relapses as often as he approaches the accomplishment of his end.

One more example may be cited before concluding these remarks. A displacement of the uterus exists, and the practitioner knows that it has been due to one of two influences, either increase of uterine weight, or loss of uterine support. Which was primary he cannot determine, for at the time of his examination botl exist. To effect a cure it would be the part of 'wisdom not to limit treatment to one, but simultaneonsly to treat both by giving artificial support, and diminishing uterine weight. Without being able to say which is the original disease and which the complication, he should endeavor to relieve both at the same time. And here, unfortunately, the patient is liable to come in contact with the personal prejudice of her attendant; he does not approve of pessaries. Why? Because he has seen them do great damage! Yet he does approve of splints, of the catheter, of anasthesia, and of opium! Very likely he has not given an hour to the investigation of this important subjeet in his whole professional career. How often do patients come to those specially treating these diseases, after years of treatment from such prejudiced practitioners, with anteversion, retroversion, or slight prolapse, and, obtaining immediate relief, ask in surprise the significant question, why was this not done long ago?

'The surgery of gynecology is new, and like every new and decided improvement it has been abused by indisereet and frequent resort to it in cases not requiring other than medical treatment. This has aroused a prejudiee against it in the minds of many excellent conservative men. Nevertheles, it must be apparent to every progressive gynecologist that the future advances of this department are to depend in great degree upon surgrery, that the gynecologist of the future must necessarily possess sur- 
gical attainments, and that he who ignores this patent fact will surely prove unequal to the task which he mudertakes. The day is not far distant when a gynecologist without surgieal ability will be as impossible as an oplithalmologist is to-diay, and much evil resilts at present from the existenee of the contrary state of things. It is impossible to estimate how many thousands, I would even say millions, are now and have been for years under treatment for various uterine disorders who could in a month be restored to health by trachelorrlaj, hy ; how many wearing pessaries for a lifetime for posterior and anterior displacement could in the same time be permanently relieved by perineorrhaphy; and how many suffering lengthily from the discomforts reflected from anal fissure would be immediately relicved by stretching the sphincter ani.

Every man is loath to acknowledge incapacity to patients who believe him to be possessed of all medical seienee; and in some of these cases, for years the patient is allowed to bear suffering, ineonvenience, and expense by reason of the vanity and incompeteney of her plysician. In other eases the practitioner is not aware of the facts whieh are liere stated, and he errs without fallt, for these views are not generally known and accepted. That they will be, however, is as sure as that "truth is strong and must prevail."

Inattention to General Management and IIygiene.-The statement which we often meet with, that the majority of the cases of uterine dis. ease require no loeal treatment whatever, is a fallacy, based either upon strong prejudice against one of the most important modern improvements in medicine, or upon want of experience in such cases. But too much stress cannot be laid upon the advantages to be derived from constitutional treatment and the general management of these eases. We too often fail to insist upon rest, cessation of marital intereourse, quietude after applications to the uterus, and other points, a negleet of which may exert a powerful influence for evil, and frustrate the effects of all that is done by local means.

Astrue begins his directions for treating uterine uleers by advising-

"To charge the patient to abstain from all kinds of exercise, and to keep constantly laid down on a longr seist.

"It is for the same reason fit, in the case of a married woman, that she should lie separately from her husband.

"They should for the same reason guard against all the passions of the nind that may agitate it, as grrief, uneasiness, and anger, ete."

This advice, given over a century ago, is often neglected to-day, and tor much roliance placed upon local means, and upon them alone. Every one who has had experience in the treatment of these disorders must have been struck with surprise at the wonderful improvement exerted upon cases, which have long resisted local means, by a sea-voyage, a visit to a watering-place, a course of sea-bathing, or a few months passed in the 
commtry. Not only is this improvement manifest in the general state of the patient; it slows itself locally, also, and in some cases complete recovery may be thus attained. The same fact is aqually noticeable in old ulecrs of the leng focal means, the eflicacy of which in such cases no one donbts, having failed in produeing good results, entive recovery is eflected by means, such as those alluded to, which act upon the constitution.

I remember having hat this very decidedly impressed mpon my mind by the following case: I had for honths been treating a delicate lauly for marked retroversion with cervical endometritis and hyperplasia, the results of an old subinvolution. Suddenly her friends made np their minds to visit the Iloly Land, and she was eager to accompany them, and applied to me, not for permission, but assent, for she had evidently determined to go before consulting me. A great part of the journey was to be made on horseback at a very slow gait, and I really feared that she would be made very ill by it. 'To my surprise, however, she rapidly improved, and returned to this comntry better than she had been for years. And yet upon examination I found the uterus still out of position, and granular degeneration of the cervix still existing, though much improved.

It should not be forgotten by the gynecologist that chronic local disease is often caused by a general depreciation of the system. In some eases the lumgs madergo ehronic pnemmonic consolidation, which often goes on to phthisis; in others, chronic corneitis or granular lids occur; while, in others still, cervical endometritis marks the altered constitutional eondition. When such a result takes place, the two states continue to react one upon the other. The depraved system increases the loeal disorder to which it has given rise, and the irritation, kept up by the latter, agrgavates the degree of the former. This being true, it would evidently be irrational to treat one of the two existing pathological conditions without having due regard to the other. Some cases of endometritis, however, occur in women who are apparently in good loalth, and are usually the consequences of parturition or abortion. But cervical, and even corporeal endometritis, the latter of which may go on to gramular degeneration, will generally be found to have engrafted themselves npon a depreciated system.

The following case is illustrative of this view. Dr. Alfred E. M. Purdy bronght to my office, for examination, a patient who had two uteri and two distinct vagine. As I proeeded to examine, he stated that the right uterus was affected by granular degeneration. I discovered, however, that both were thus discased. Dr. Purdy had not examined for some weeks, and, during this period, the general state which had produeed disease in one uterus had effeeted the same change in the other. It may with justiee be objected that both may have been produced by a local cause. None such eonli be discovered, the patient having been cxposed to no local influenees which-had not existed for years previously. 


\section{H A P T E R I V.}

\section{GENERAL CONSIDERATIONS LPON SOME OF TIE MOST IMPORTANT THER APEUTIC IRESOURCES OF GYNECOLOGY.}

IT is not my intention to devote a chapter here to the general consideration of the ordinary therapeutical resourees of this department, but, as some of the most important of these should be especially considered and deseribed, I prefer to do so here, rather than seatter them in a desultory manner throughout the work where some of them might escape notice.

At the same time that the judieious practitioner should avoid routine, he should not allow himself to confound in his mind the two terms routine and system, and, while no two cases should be treated exactly alike, a general plan will apply with greater or less exactness to many.

General system of diet and exercise for restoring the depreciated nerve and blood state ordinarily attendant "pon the pelvic diseases of women.

$A$ s a rule these cases require a general tonie plan of treatment. There are, however, a few exceptions to the rule, such, for example, as cases in which the neurasthenia and spanamia so universal as conseguences have not as yet arisen, because the patients lave not been long enough exposed to the pathological condition.

The following are the directions which I give to patients for a general plan:-

1. While you are under treatment, renember that a great deal will depend upon your cordial co-operation and intelligent endearor to carry out instructions.

2. Eat fresh animal food three times a day, and as much other nutritious food, such as brearl, erushed wheat, potatoes, rice, ergs, ctc., as you can.

3. Between breaktast and the mid-rlay meal, the mid-day and evening meal, and upon retiring at niglit, drink a tumbler of milk, or a teacupful ot beef tea, or of mutton or chicken broth.

4. Every morning upon rising, and every night upon retiring, take a sponge bath of warm water strongly impregnated with table salt, about a teacupful to an ordinary basin of water. Then rub thoroughly and briskly with a rough towel: the knitted tape towel is the best.

5. After each bath exercise for ten minutes briskly with dumb-bells, the rowing machine, or light calisthenic rods, breathing during this time freely and as deeply as possible.

6. Endeavor to sleep for nine hours every night, and, for one hour at 
mill-day every day remove the onter clothing, lie quietly in bed, ramain cutirely withont oecupation, and if possible sleep.

7. IIave an action by the bowels once in every twenty-four hours. If constipation exists, take a tablespoonful of this preseription every morning on waking, in a half tumbler of cold water-

$$
\begin{aligned}
& \text { R.-Wagnesia Sulph. } 3 \text { iv. } \\
& \text { Ferri Sulph. 3:s. } \\
& \text { Acidi sulph. Dil. } 3 \mathrm{ij} . \\
& \text { Aquæ, Zxvj.-M. }
\end{aligned}
$$

8. During menstruation keep very quiet, and at all times avoid violent muscular exertion and fatigue.

9. Use every night and moming a copious vaginal injection of very warm water, by the method explained to you.

10. Be sure that the clothing be loosely worn, and that all weight of skirts be carried upon the shoulders and not upon the hips.

It is tiresome for a practitioner seeing a large number of new patients daily to repeat these directions to each. IIe is very apt too, even if willing to assume the labor, to forget some of them, and, even if he do not, the patient is very sure to do so. It is therefore very useful to have them printed upon a slip of paper, so that a copy may be carried home for reference and future guidance.

Of course, in addition to these, special cases will require particular prescriptions, and directions as to use of stimulants, etc. If the patient is to wear a pessary too, I am in the habit of giving another list of directions having special reference to the management of this, which will be given in connection with that subject.

Pessaries._Uterine pessaries hold a prominent position among surgical appliances, as a means of procuring palliative and curative results. Like all other mechanical means which are powerful for good, they are capable of doing a great deal of harm. Were I asked at the present monent whether I believed that in the aggregate they accomplished more good or evil, I should be forced to give a doubtful reply, great an advocate as I am of their use. Their injurious conseguences I would attribute, not to the instruments themselves, but to the improper manner in which they are rery often used, and the carelessness with which they are allowed to remain in sitĥ without observation. It splints were applied to broken bones and never examined until union was effectel, their utility would soon become doubtful. Pessaries should be carefully watched, for they sometimes create cellulitis, peritonitis, and vesico-, recto-, and utero-varinal tistulax. In some cases they have been known to pass completely out of the vagina, into the rectum or bladder. Some years ago a case entered the service of Prof. L. A. Sayre, of the Bellevue Hospital Medical College, presenting very obseure symptoms of uterine disease. Examination proving that some foreign substance existed in utero, Prof. Sayre dilated 
the eervical canal, and extracted a globe pessary which had migrated from the vagina into the uterus, and been retained there for a length of time.

Whatever pessary be employed, it should sustain the displacel nterus without creating pain or disconfort. Should any such inconvenience be produced, it should be at once remored, for the most violent cellulitis and peritonitis may result. While a pessary is kept in the vagina, cleanliness should be secured by daily vaginal injections, and at intervals, not exceeding two months, it should be removed, examined, and reintroduced.

One of the difficulties attending the use of these instruments in general practice, unquestionably arises from the faet that a great deal of experience is necessary before any one can use them with certainty of accomplishing good results. But another is due to the practitioner having only a small supply from which to choose. He who habitually employs this means should have at his disposal a large and varied assortment, and should possess sufficient mechanical ingenuity to mould and adapt these to the special requirements of cases which may present themselves. The rulcanite pessary may be given any shape after being heated, and metallic ones may be readily moulded by the fingers.

Whether a suit for malpractice has ever arisen on account of injury done by a pessary, I cannot say, but I can easily imagine such a source of litigation. Every practitioner should bear in mind, that injury done by a pessary does not argue ignorance on the part of its introducer. When one removes, as every gynecologist must often do, a pessary from a position in the pelvis in which it has become imbedded, and finds, as its result, a ragged, ulcerative tract existing, he is very apt hastily to conclude that the instrument wats improperly applied. This is by no means always true. I have repeatedly removed pessaries under these circumstances, which had been introluced by the most competent gynecologists. Ilow common it is to find a pessary which one has carefully introdued, turned complietely upside down at the end of a week. The migratory and evolutionary performances of the vaginal pessary are truly wonderful. These facts being recognized and admitted by all, the evilent deduction is that it is unjust, as it is unprofessional, to expose to a patient, at the expense of an absent colleague, every lesion which these dillicult instruments have created. To tell a patient that the instrument she wears has male a deep uleer in the vagrina, is to tell her that her attending physician has been grilty of a gross blunder; for "uleer," in the popular nind, means anything that is frightful in the way of lesion, from erythema to carcinoma. And although the statement is literally true, he who makes it knows that the same aceident has happened to himself many times, that a week of rest will entirely efface it, and that no real damage has resulted to the patient from its occurrence. It camnot be denied that even in our day there are those in our profession whose minds have not yet become disen- 
thralled from the prejunlice against gynecology which existed up to a half century ago. These too often foreret that the observance of professional ethies should rise superior to the promptings of an illiberal sentiment, of which every day is proving the injustice and fallacy. It is at matter not of courtesy, but of professional honor, to protect the interests of a brother practitioner, as far as the patient is concerned; much more so, where the gurstion concerns his reputation with the public upon whose esteem his neefulness depends.

Some years ago a case in point occurred to me, which was so instructive in this connection that I venture to detail it. $\Lambda$ larly called upon me for treatment for anteversion, after having been for some montlss under the care of an advertising charlatan of this country. Upon removing a very coarse and elumsy retroversion pessary, I found a deep and ragred ulcer which had penetrated by its lower extremity into the tissue intervening between the ragina and bladder. It was deep, large, and ragged. The temptation was very strong to expose the user of this instrument, and to make the uleer the text of a discourse upon the employment of ignorant pretenders by the public, but upon second thought I refrained, put the patient upon appropriate treatment, and, as she lived out of town, directed her to return in three weeks. At the end of that time she came back, and, as the ulcer had healed, and all vaginal irritation had disappeared, I inserted an anterersion pessary, and sent the patient home, directing her to see me again in a week, as that proved to be the earliest moment at which it wonld be practicable. In a week she returned, and to my mortification I found that pressure of the uterus upon the pessary had ereated a large and ragged ulcer. The only difference between that created by myself and by the eharlatan was, that mme was a little the larger and more vieions in appearance.

It is this very danger which now makes me so scrupulous about examining an anteversion pessary repeatedly during the first ten days of its sojourn in the vagina.

In spite of all its attendant evils, the use of the pessary is, as I have said before, one of the nost important points in gynecology, and every practitioner of that art should make it a faithful, special, and constant sturly. I confess that when I am told, as I sometimes am by physicians, that they never use pessaries, because they are so strongly prejuliced against them, the question always arises in my mind, then how and why do you treat uterine diseases? How pessaries can be dispensed with is to me one of the unfathomable mysteries of gynecological practice. And why any one should practise an art and ignore a means which, properly mastered, constitutes one of the most powerful and reliable of its resources, is equally incomprehensible.

I think it an excellent plan for the physician who has inserted a pessary to give to the patient some such written directions as those which follow, 
urging her, in case of troulle from the instrument, to refer to and closely abide by them.

1st. You are wearing a pessary. If it give you pain, pass your finger into the ring which you will feel and draw it away. Do not mind a little discomfort in doing this, but do it without fail.

2d. If after this you suffer pain, go to bed and send for a physician.

31. Every night and morning put one or two gallous of hot water in a tub, sit over this, and with the "Davidson's syringe" syringe out the ragina for five minutes. The water should be as warm as you can comfortably bear it.

4th. Wear your clothing as loosely as possible, using "skirt supporters," and not wearing tight corsets.

5th. Keep the bowels regular, securing one action every day.

6th. Aroid, as much as possible, going up stairs, lifting heary weights, using the sewing machiue, and riding in a rough vehicle.

7th. Lie down for an hour at midday every lay, and keep very quiet at menstrual periods.

8 th. Remember that attention to these directions will have an important influence on your recovery.

Precautions to be uniformly observed in operations upon the sexual organs of the female, for prevention of septicamia and pyamia.

One of the greatest achievements of modern pathology has been the discovery of the agency of certain families of lowly organized nomads and micrococei in the production of diseased states which the humoral pathology of the olden time had traced to the blood. Although the subjeet, born only twenty years ago, is still in its infaney, a great deal has already been accomplished in reference to it, and it is not too much to hope that the path has been struck which is lestined to lead to an elucidation of "contagion,"-"the pestilence," as IIoly Writ expresses it, "that walketh in dirkness." Those who were ehiefly instrumental in establishing our knowledge upon this point are Virelow, Rindfleisch, Recklinghausen, Hueter, Vogt, and Klebs.

During the last ten years the subject has reeeived great attention, and diphtheria, septicamia, pyæmia, malignant pustule, scarlet fever, variola, and, according to Letzcrich, whooping-cough are classed among liseases due to fungi or micrococei. The only ones of the affections which specially concern us are pyamia and septicamia, which, although many dissent from the view, it is very generally agreet originate in the introluction into the bloor of bacteria of the rorl and globular variety. These, being alsorbed by bloodressels and lymphatics upon a wounded surface, are distributed throngh the system, cansing decomposition of the blood, and resulting in septicamia, pyamia, septic emboli, thromboses, and localized inflammations.

L pon theoretical grounds a pathological discovery of this peculiar 
lind would have been naturally expected to emanate from the pathological laboratories of Germany. But for Great Britain was reserved the honor of utilizing the seductive theory. Lister, of Scotland, batsing his researches upon the facts just mentioned, endeavored with wonderful success to prevent the entrance of bacteria into the blood during and just after any suddenly oecurring solution of continuity. These products of the vegrable world may be encountered anywhere, but are especially met with in hospitals and other places where the sick are erowded together; for example, upon the walls, floating in the air, upon the hands of surgeons or assistants, upon instruments, ligatures, sutures, dressings, bandages, and sponges.

To be secure then against the entrance of bacteria into the open vessels of wounds, the greatest eare must be exereised. Prof. Zweifel, ${ }^{1}$ of Erlangen, once performed an operation for closure of a vesico-vaginal fistula, and lost his patient from septicxmia on the twelfth day. Antiseptic measures had been carefully observed, and he was at a loss to account for the accident, until he examined by the microscope the eatgut used for suture. This, although kept in carbolized oil, he found filled with bacteria, which he thought were thus introduced into the economy.

Not only are instruments, needles, thread, etc., to be carefully disinfected, the room in which an operation is performed should always be carefully cleansed and disinfected likewise. The experiments of Pasteur ${ }^{2}$ prove that the germs of such organisms as micrococci, bacteria, etc., are everywhere present in the air, especially in that of hospitals, whieh likewise contains floating in it pus globules and spores of epiphytic parasites which emanate from diseased organisms. In 1865 Broca had the walls of St. Antonio Hospital sponged, and in the liquid expressed from the sponges le detected pus globules. In 1861 Eiselt, of Prague, plaeing an instrument analogous to Pouchet's aëroscope between two beds of a ward occupied by thirty-three children suffering from purulent ophthalmia, distinctly detected the presence of pus globules floating in the air. Nepreu, of Paris, had one square metre of wall in the surgical ward of La Pitié sponged, and discovered in the liquid expressed micrococci in large amounts, several micro-bacteria, epithelial cells in small number, several pus globules, several red globules, and, lastly, irregular blackish masses and ovoid bodies whose nature was unknown.

It is against the agency of these poisons that cleanliness as striet as it is possible to make it, eireulation of pure air in the chamber of the patient, and all the antiseptic measures so fortunately introduced by Lister seem to guard.

In boracic, sulphurous, and carbolic acids, and other chemical com-

1 Centralblatt für Chir., No. XII. 1879.

2 Rérue Méd. de l'Est, lévue de Therap., No. 23, 1874. 
pounds, have been found septicide agents capable of destroying these lowly organized germs. Of these Lister has found carbolic acid to be the best up to the present time; and, by thoroughly cleansing instruments, hamds, dressings, and sponges, and by saturating not only them, but the atmosphere coming in eontact with the abraded surfaces, with carbolized water, he has so completely closed every avenue of bacterial approach that sepsis and its consequences have been to a great extent prevented.

Should the theories of Lister prove to be true, and they certainly promise so to do, surely the fact will not be disputed that no one of his predecessors has accomplished more brilliant results for practical surgery than he. Enless we are greatly in error, thousands of lives have already been saved by his eflorts, and who ean estimate what the future will bring forth? His methods niay all be changed, and the use of the spray may pass away, but the grand principle, the pivotal truth which he has given us, will probably live forever.

Let the gynecological surgeon keep constantly before his mind the fact that uncleanliness goes hand in hand with bad, and cleanliness with good surgery. Simple as this agency seems, it is the sole one upon which rests the greatest advance of modern surgery. Emmet says, truly, "many a woman's death warrant is earried under the nails of her surgeon." Many years ago a humorons medical writer, half in jest, elevated the tonguescraper to a place of dignity in the treatment of dyspepsia. The nailbrush, in serious earnest, deserves such a position as a prophylactic of lymphangitis and septicemia.

It is a well-authenticated fact that the scratch of the lion, tiger, et id genus omne, even when very insignificant, proves dangerous throngh erysipelas and lymphangitis, which are very apt to ensue. The elaws of these predatory carnivora are constantly cliarged with decaying animal matters, the accumulation of years, and they infect the wounds which they make as the lancet of the vaceinator, the poisoned arrow of the Indian, or the nails of the uncleanly surgeon do.

Nowhere is eleanliness of such primary importance as in obstetrics and surgery. In every (xploration, every, even the most trivial, operation in gynerology and obstetrics, Lister's methods, execpt the spray, shomd be strictly observed, and in all grave operations the spray too should be employed.

The following rules slould always be observed in operating on the fumale genitalia :-

list. Before and after every operation wash all instruments in very hot carbolized water, and during every operation kecpall instruments immersed in earbolized water. This should especially be observed in regard to needles and sutures.

2d. In all laparotomy operations pursue Lister's antiseptic method fully. 
31. Where the spray is not employed, always bathe denuded surfaces, both belore and alter apposition by suture, with carbolized water.

4th. Always destroy sponges used in an operation which admits of the possibility of these being contaminated by septic fluids, and when they are employed a second time always have them immersed previously in boiling carbolized water.

5th. Alter all operations upon the uterus bathe or spray the vaginal portion of the organ with carbolized water, and tampon lightly for twentyfour honrs with antiseptic cotton. This being removed, syringe the varina with earbolized water at short irtervals.

6th. After all operations on the pelvic organs syringe the vagina with carbolized water as often as onee in every eight hours.

7th. After all operations quiet pain and nervous excitement by opium.

8th. Before all grave operations give a full dose of quinine, ten to fifteen grains.

9th. Before every operation let the operator and his assistants eleanse and disinfect their hands as if they felt sure that septic material attached to them.

10th. Aroid even trivial operations, unless good reason for doing otherwise exist, for a few days belore and after menstruation.

'That a strict observance of all these precautionary rules will uniformly prevent the development of lymphangitis, septicamia, and peritonitis, I neither believe nor maintain. That it will do a great deal towards diminishing the fiequency of these accidents, I am entirely convinced hy observation and experienee. That they are of valne $I$ feel sure. That they are not essential is fully proved by the successful results, which we daily see around us, of operations practised with entire disregard of every one of them.

Even in ordinary examinations of the uterus the antiseptie idea should always be kept in mind. The plan which I follow, therefore, is this : Every day my oflice nurse pours boiling water upon all the instruments ordinarily employed, such as speculum, probe, sound, tenaculum, depressor, etc., washes them earefully with soap, and rubs them bright with a substance ealled electro-silicon. They are then kept immersed in earbolized water during examinations. After every examination the instruments used are again washed with soap, rapidly rubbed bright, and immersed in a fresh suply of carbolized water. After every examination the examiner's laands are carefully washed with soap in very warm water, the nail-brush freely used, and just before another examination they are rinsed in the earbolizerl water in which the instruments are brought in. The fingers and all instruments introduced either into the vagina or uterus are lubrieated witl earbolized raseline, carbolie soap, or soft soap thoroughly carbolized. In these examinations absorbent cotton, held in a pair of dressing foreeps 
like those shown in Fig. 2, should be made to replace sponge, which is so much more likely to carry contagion from one patient to another.

Fig. 2.

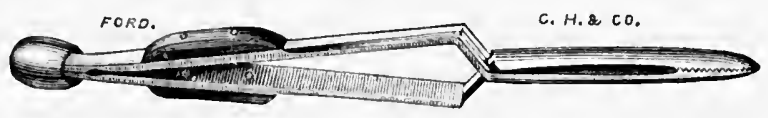

Thomas's dressing forceps.

That patients are at times injured by want of proper hygienic precautions on the part of gynecologists, I feel assured by personal observation. That the contamination of women through their criminal ignorance or carelessness is not much more frequent, is a matter of unceasing amazement to me. Every gynecologist should feel two things very sincerely with reference to his daily system of examinations. 1st. That he would be willing to have his own female relatives exposed to all the risks of contagion to which he exposes his patients; and 2d. That he would at any time willingly submit his methods to the eritical investigation of a jury of his peers as far as concerns cleanliness and hygiene.

After operations where it becomes necessary to have the bladder evacnated by the catheter, the precaution should always be observed of dipping the catheter in carbolized water and smearing it with carbolized oil or vaseline before its introduction. A neglect of this often results in prolonged vesical trouble which might readily have been avoided.

Vaginal Injections.-There is no agent in the treatment of diseases of the pelvic viscera which possesses greater value than this, and yet none which has been used from time immemorial in a more unsystematic and desultory manner. Until the appearance of Scanzoni's work, now over twenty years ago, very small amounts of fluid were used, not nearly enongh to wasl out the vaginal canal thoroughly, and the little piston syringe employed for the purpose, and holding only about an ounce, was utterly insuflicient. Scanzoni taught us the important lesson that copious vagiual injections should always be employed where this method was resorted to, and gave us several very excellent plans for using them. This was an important step in adrance. Since that time Emmet has done a great deal to systenatize the matter, and introduced a method which I shall lay before the realer. IIs method is hased upon the following deductions :-

1:t. 'That no patient can use raginal injections etlieiently herself', but must lave them alministered hy another.

2I. That for them to be effectual the patient must lie upon the back with the hips elevated.

8t. That a copious flow over the vaginal surface of water varying in temperature from $100^{\circ} \mathrm{F}$. to $110^{\circ} \mathrm{F}$. is most appropriate for all cases in which congestion exists. 
It l. 'That cold water thus employed is hurtful by causing first vaseular contraction and afterwards dilatation, while hot water proluces first expansion and then contraction.

"The injection," says he, " can be better given to the patient after she is mulressed for the night and in bed. She shonld be placed near the edge of the bed with the hips elevated as much as possible by the bedpan, and a small pillow under her back, the lower limbs being flexed. Iler body must be covered, to protect her from cold, and her position made perfectly comfortable; whenever the bed is a sof one, for the purpose of keeping the hips elevated, a broad board should be placed under the pan to prevent it from sinking into the bed from the weight of the patient. The vessel of hot water is placed on a chair by the bedside, and the nurse passes the nozzle of the syringe into the vagina, over the perineum, directing it along the recto-vacrinal wall until it has reached the posterior cul-de-sac. The water must be thrown in, at first, very carefully, until the vagina has become distended."

In hospital practice there is no method as good as this carried out in all its details, but in private practice every one must see the difficulties which will attend it. Dr. Emmet says, that "few women are so situated as to be unable to get some one to administer the injections properly." I should alter the sentence, making it read "f'ew women are so situated as to be able ;" for a lady does not like to call upon a servant to perform so delicate a task for her, nor is she willing either to impose it upon an equal or to bear the heavy expense of having a professional nurse visit her daily. Under these circumstances I employ the following plan. The patient places a pillow upon the elge of her bed and an empty tub upon the floor under it. She then covers the pillow by a piece of India-rubber cloth which drapes into the tub. Then, putting two chairs one on each side and a little in front of the tub, she places a small table in front of these, and upon this another chair. Upon the chair which stands on the table a tub containing about two gallons of lot water is now put, near the bottom of which has been inserted a spigot to which a long rubber tube is affixed, which ends in a vaginal nozzle. The patient now lies upon the bed, the pelvis elevated by the pillow, places her feet upon the chair, covers her limbs with a shawl or blanket, touches the spring, an ordinary clothes-pin makes a good one, which controls the flow, and the water bathes the vagiua, and running out is conducted by the India-rubber cloth into the tub.

IIere the only articles purchased are the tub with the spigot and tube attached, and a yard of India-rubber cloth, which are inexpensive. The patient will have everything else in her chamber, and very little trouble attaches to the method, which is certainly an efficient one.

While I admit the great value of Emmet's method, I do not by any means admit his postulate that " not the slightest advantage is received from then (vaginal injections) when administered with the patient in the upright 
posture, or, as is the usual method, while seated over a bidet." Thus administered they are less eflectual than in the method deseribed, but still they do a great deal of good. While a patient is travelling, or in eases where injections are required only for cleanliness, they may be relied upon to do very good work, and I, therefore, describe the method of employing them. Placing in a tub from one to two gallons of water, at as high a temperature as proves comfortable to the patient, she may sit over it upon a board placed across it, or upon a stool placed in

'FIG. 3.

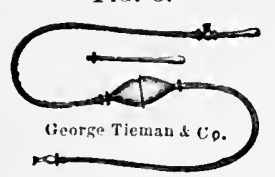

Davidson's kyringe. it, and inject the water by means of a syringe. The most convenient syringes for the purpose are the Essex and Davidson's. Both of these are provided with a stem about five inches long, which being introduced into the vagina and carried up so as to touch the cervix, throws, when the ball of the instrument is compressed by the disengaged hand of the patient, a steady stream against it. By this means a stream of warm water is made to pour over the eervix for from twenty to thirty minutes, according to the anount of fatigue which the use of the instrument causes the patient.

Warm water is the best, as it is the simplest, most attainable, and cleanest of all the emollients which can be used for this purpose. But it may easily be medicated by the addition of laudanum, half' an ounce to the gallon; infusions of linseed, poppies, hops, bran, slippery elm, starch, hyoscyamus, conium, or farina; or by the addition of glycerine, one ounce to the gallon, lime-water or tar-water, both of which last are often very soothing to vaginitis that may exist as a complication.

A few worls are essential in reference to the nozzle which should be used in giving these injections. No anount of care will prevent the in-

FIG. 4.

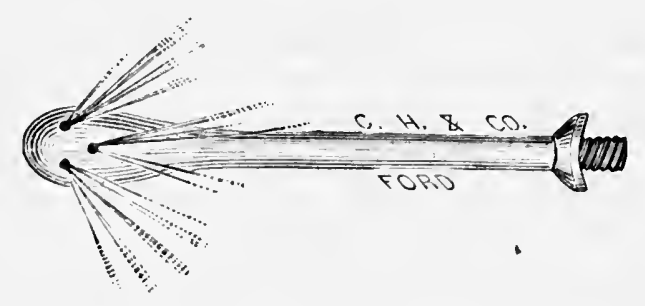

Taginal syringe nozzle, with reverse current.

jection of fluid into the uterine eavity unless the nozzle be properly constructed. Sometimes where the cervix is lacerated or the cervical eamal dilated the patient will earry the instrument directly into the os externum and project a large amount of fluid into the uterus such an accident is followed by violent uterine contraction, and the probable passage of a por- 
tion of the liquid into and perhaps through the Fallopian tubes, and this often results in a degree of pain which almost cattses collapse, and sometime's even in pelvic peritonitis. This accident ean always be prevented by having the nozzle of the syringe male with a reverse eurrent as represented in the diagram. I have for many years employed those marle of hard rubber, and it seems to me that in view of the fact that serious accillents sometimes follow the use of nozzles with direct jet, the precaution of reversing the current should always be observed by instrument makers.

The Tampon.-Had Sims's method of uterine examination done nothing else than lead to the proper method of using the vaginal tampon, it would have done by that alone a vast deal of good. Before its introduction the use of the tamyon was a painful, uncertain, and inefficient hemostatic method. Since the use of Sims's speculum it has become an easy, painless, scientific, and most effectual method for preventing and cheeking hemorrhage from the non-pregnant uterus. The operator in gynecology who does not understand the modern method of tamponing the vagina, and who still relies upon the introduction by the fingers of a "kite-tail tampon," a silk handkerchief, pieces of cotton, or this combined with sponge, etc., surely does great injustice, both to his patient and himself, and courts hemorrhagean evil which might easily be avoided.

In speaking of the vaginal tampon a recent writer ${ }^{1}$ says : "It is a barbarous, slovenly, unseientitic proceeding, and is generally based upon incompetence and instigated by terror. If hemorrhage be issuing from a closed os, it may be plugged with a sponge tent, in order that the source may be afterward reached. But if the cause of the hemorrhage be known and be irremorable, the treatment should be to inject the uterus with acetic acid, or even with some salt of iron, though the latter is a proceeding accompanied by terrible risks." I quote this to say how entirely I dissent from it. The tampon properly applied is not only a simple, cleanly, and painless procedure; it is safer, more eflicient, and more scientific than the alternatives here suggested.

The patient being placed upon a table upon the left side, Sims's speculum is introduced and held by an assistant, while with sponges or rolls of eotton the surgeon removes from the vagina all mucus and blood elots which may exist there. Upon a plate near him have been placed a number of thick disks of carbolized cotton, some soaked in solution of persulphate of iron one-third to water two-thirds, or in a saturated solution of alum or eopper, and others simply saturated with water. All superfluons fluid has been squeezed out by pressing these disks between cloths. Taking up in the dressing forceps one of the disks which has been saturated with an astringent, the surgeon packs this behind the neck of the uterus, then alongside of this he places amother, holding the first one well 
in place, meantime, by a rod of whalebone, or other similar substance, until the secont is placed. In this way piece after piece is packed away until a collar is placed aronnd the neck of the uterus which extends to a level with the os externum. Then this part is covered with more astringent cotton, which is packed into place and held there by pressure from a rod, and simply wet cotton is packed $n$ pon it until the ragina has been filled to within an inch of the vulval, when a piece of soft dry cotton is made to hold the more efficient upper tampon in position. The lower portion is now carefully pushed away from the urethra, and, a dry soft towel being laid over the rulva, a $\mathrm{T}$ handage is applied.

Such a tampon is a safe liemostatic agent. After operations upon vagina, vulva, or cervix, it proves a most certain preventive of hemorrhage. As a means for eheeking hemorrlage, already fully established, it has no equal in value in gynecological surgery.

When it is necessary to remove this tampon, which may be left in position for twenty-four or even thirty-six hours, two methorls present themselves. First, the speculum may be gradually introdueed, and each piece of cotton as it becomes visible be caught by a tenaculum and pulled out until the last piece is remeved. Second, the position of the patient being unaltered, one finger is passed up until the cotton is touched; then the screw, represented in Fig. 5, is slipped along it, and by a few turns imbedded in the mass. Traction is then made and a portion of the tampon

Fig. 5.

is removed. After this another piece is eanght and drawn away until the vagina is emptied. In cases in which it is desirable not to move the pationt for fiar of fitigning her, and where no seeond tampon is to be applied, this ingenions instrument answers an excellent purpose.

Means for controlling the temperature after operations, and during pathological conditions developing in gynecology.

The most careful observation and a large elinieal experience have led me to the conclusion that one of the most momentons problems in theraprotics eonsists in keeping the animal heat within proper bounds. In my opinion one of the most important impressions which shonld gain firm foothold in the mind of every practitioner is this: Prolonged highte tempereture kills. In many diseases, surh, for example, as septicamia, typhus and typhoid fever, peritonitis, sunstroke, scarlet fever, ete, it is commonly the chief and mest immediate factor by which a fatal isste is produced ; in many others it is a prominent, though not the chief, agent which "xhatusts the vital forees; while in others still, such as chronic brain 
diseases, dysentery, eaneer, ehronic cardiac diseases, ete., it is no factor at all.

It for a week a very high temperature has been allowed to contime in any ease, death will very likely result from this continuance at at later period of the disorder, even if at the end of that time it be lowered and kept within proper boumds. The vitality of the blood has been impaired; the muscular and nerve tissues supplied by the depreeiated fluid are altered, and the structure of important organs elanged in character; and these unfortmiate occurrences lead on to death. In a lengthy case of typhoid fever the temperature being allowed to remain for three or four weeks at or near $104^{\circ}$, it becomes lower by the self-limitation of the disease. At that time pnemonia or some other complication develops, and the patient dies. Under these cireumstances death is regarded as having been due to an matroidable complication; but, if the blood state had not been steadily depreciated by the antecelent month of high temperature, the complication would very likely not have occurred.

A child passes through the first eight or ten days of scarlet fever with a temperature at or near $105^{\circ}$, and then succumbs to cerebral exlaustion, secondary meningitis, or pneumonia. Had the pathologieal conditions created by ten days of a temperature of $105^{\circ}$ not been allowed to oceur, these secondary manifestations might have been avoided. To elicit all the beneficent results which control of temperature can produce, such control must be exercised: (a) throughout the course of the disease from its beginning to its end; (b) by means which do not disorder digestion or exhaust the strength; (c) by means which are eertain, systematie, and always attainable.

These remarks apply to the whole field of medicine, but in no department of it have they greater force than in that which especially engages our attention. The diseases which the gynecologist most dreads, to which the largest number of his patients sucemmb, and consequently with which in his daily labors he has most frequently to cope are two, which destroy life in great degree by exhausting the vital forces by high temperatureperitonitis and septicamia. Give him control over these and the most melancholy part of his daily functions would be obliterated! Arm him with the means of closing the broadest gateway through which the fatal issues of these affections may enter, and the consummation so deroutly to be wislred is more nearly to be attained than it could be in any other way.

The day is, I think, not far distant when it will beeome a cardinal rule in the treatment of every disease to maintain throughout its course the temperature at or under $100^{\circ}$. In my own practice that day has alrearly arrived. As I have already said, observation and experience have fixed the fact which I am liere upholding in my mind as one of the most important in the whole field of therapeutics. I am as thoroughly convineed 
of its truth, and $I$ as sincerely believe in it as I do in the efficacy of the cinchona salts in malarial diseases.

Its value was elearly pointed out years ago by Curry of England, and some may regard it as an evidence arverse to its claims that it was soon obliterated from the professional mind. 'This objection, weak in itself, is ammililated by the fact that Cury, at the same time and with a like futility of result, urgel the claims of the greatest medical discovery of the last century, one which, from the standpoint of utility to medicine and through it to humanity, equals in importance vaccination and anasthesia-clinical thermometry.

As the method for accomplishing control of temperature is fully described under the head of ovariotomy, I shall not allude further to it here, but refer the reader there.

\section{II A P T E R V.}

DIAGNOSIS OF THE DISEASES OF THE FEMALE GENITAL ORGANS.

TuE diagnosis of the diseases of the pelvic viseera of the female offers many obsurities, and frequently foils the most careful and capable practitioners. With the ntmost caution, assisted by the most practised skill, no one can avoid occasional crrors, while in the experience of those not possesing these qualifications, they must be frequent and glaring. The only safeguard which can be established against their occurrence, and the only guarantee which can be obtained for success in prognosis and treatment, is the thorongl mastery of the subject which is now to engage us.

It is not rare for one making a special study of gynecology to find those less familiar with it committing errors of diagnosis, or, what is more common, arriving at no conchsion, in cases which are perfectly simple and present no ohscurities whatever. When meeting such instances in the practices of intrlligent men. I have been struck by the fact that the source of diflienlty is almost always the same. The failure of diagnosis has not been due to their having drawn incorret eonelnsions from diagnostic means, but to their not having brought these means fully into action. and lroperly applied then to the solution of the case in hand. In many instances, nterine disease heing snspreted, the physician employs varinal tonch. and follows it by the speculum. If the os and ervix be diseased, J11: is slleressful in diagnosis ; but if not, he beromes diseouragred, forgetful of the fiset that rectal touch, the uterine probe, dihatation by tents, conjoimed manipulation, and other means should be resorted to, and that, withut appraling to these, even the most skilful diagnostieian would be 
as helpless as himself. There are means at our command for exploring every tissue within the pelvis-the uterus, the ovaries, the areolar tissue, etc.; and until they are brought into service earefully, systematically, and thoronghly, no one ean feel that he has done justiee to his powers of alignosis, ol allowed himself full opyortunity for drawing correct eonclusions. Skill in diagnosis must be obtained at the bedside, but for that sehool to be mate profitable, the student must have a thorough familiarity with the theory of the means of investigation which he is there to apply. Ilaving mastered these, let him in an obscure case develop them one after the other, slowly, carefully, and thoughtfully, until he has arrived at a diagnosis, or at the fact that he is unable to make one even after having availed himself of all the resources at his command.

Let ne illustrate this by a supposititious case. An inexperienced examiner discovers upon vaginal touch that the vagina is oceupied by a large tumor. If he rest satisfied with this method of exploration, and without reflection adopt the idea that the case is one of fibrous polypus, he may commit a grave error. The most skilful of gynecologists could not deeide by touch alone, and would be, almost as much as he, exposed to error if he relied upon it. All the means which the experienced diagnostician can bring to his aid are likewise at the service of the inexperienced; and if the former stand in need of their assistance, surely the latter much more deeidedly requires it. Let him then ask himself this question, although he may feel absolutely positive, altogether certain, that he is dealing with a fibrous polypus: what else may this be? At once the answer will come, it may be a case of prolapsed uterus, or of inversion of the uterus. It is important that he should know which it is, and usually it is quite easy to decide.

Drawing down the tumor, he examines by inspection and touch, and seeks the os externum, up which to pass the sound. It is not anywhere to be found, and moreover the tumor is larger below than it is above. The case is not one of prolapsus, and he feels that his diagnosis of polypus is surely correct. If it be a polypus which occupies the vagina, the uterus should be abore it. He now practises conjoined manipulation, but to his surprise this organ is nowhere to be felt. This may be due to lis want of experience, and he examines further with the sound, endearoring to pass it alongside of the neck of the tumor, and into the uterine eavity. He is surprised again, to tind that it is arrested at the neek of the tumor, around which he now passes his finger, and finds it closed everywhere by a gutter of circular eharacter existing about an inch above the lips of the dilated os. The case now looks like one of inversion, but he is not sure, for sometimes adhesive inflammation attaclies the walls of the cervix to the neek of the polyus. Are there any means by which he may settle this (fuestion positively? By conjoined manipulation he thinks that he 
feels a ring or circle over the abdominal face of the tumor, and gradually he pushes his fingers into it, and becomes positive of its existence.

Now placing the patient upon the back he passes one finger into the rectum and a sound into the bladder and approximates them above the tumor. He finds no uterus intervening, and his diagnosis is made; the case is one of inversion of the uterus. This is his diagnosis, that is, his deduction carefully and philosopluically drawn from the premises presented to him, by the best means at his disposal. Let him resort to all these means, and success will usually be his. But, it may be suggested, he is not as familiar with these means as a more experienced man is. Practically, I agree that he is not; but why is he not theoretically? Are they not recorded and fully explained in all his works on gynecology? What is demanded of him is not experience, not wisdom; but a faithful and earnest effort to arrive at the truth by simply employing means which science places at his disposal.

These remarks of course apply with equal force to every condition in which a diagnosis is required. Let it be a constant habit to demand of one's self, after admitting a suspicion as to the nature of the disease, what else could present the physical appearances which exist? Having carefully considered this, let the various means of differentiation at command be fully tested. Then if an error of diagnosis creep in to damage interests entrusted to his charge, the mortified diagnostician may console himself with the reflection that at least he has exerted himself to the utmost of his ability to avoid it, and not fallen into a trap set for him by carelessness, indolence, or incompetency.

It must not be forgotten, however, that certain rare and exceptional cases will occasionally occur, the diagnosis of which will baflle the skill and experience of the most cautious and conscientious. Take, for example, the following : a patient aged sixty-two years had a movable abdominal tumor which was examined by a number of physicians. She died suddenly, and autopsy revealed extra-uterine pregnancy, a child weighing four and a half pounds lying loose in the peritoneal carity. Or this : ${ }^{2}$ a tumor is discovered in the pelvis; the patient dies from some cause disconnected with it, and it is found to be a displaced kidney. But such cases are rare. The careful and intelligent diagnostieian will very generally be successful.

\section{Rational Signs.}

In the examination of a patient suspected of having uterine disorder no direct or suggestive questions should be asked, but the symptoms should be drawn forth by encouraging and properly directing her narrative of her casc. Certain signs, which we call "rational," from their appealing to

2 N. Y. Med. Record, Feb. 1st, 1872, p. 539.

2 Braithwaite's Retrospect, part 37. 
our reason and not to our senses, such as pain in the hearl, back, and limbs, incustrual disorder, leucorrhoil, impeded locomotion, derangement of the digestion, and nervous manifestations, will lead as to suspect the genital olgans, and may even convince us of the existence of discase there. Cienerally, however, they result in the adoption of other and more certain means of diagnosis, which are termed "physical."

Every one will, after due experienee, adopt some system by which his examination of patients will be expedited, and the certainty of arriving at a correct diagnosis be increased. The plan which I consider best adapted to these eurls is that which follows :-

1st. The personal history, age, etc., of the patient should be obtained.

2d. The duration of the illuess should be fixed.

3d. The history of the attack from commencement to date should be elicited.

4th. The present state of the patient should be ascertained.

In obtaining the history of the disease, no leading questions have thus far been asked ; the patient has told us what she herself has observed. Her evidence leads us to suspect some special disorder, and then we proceed thus :-

5th. Direct questions are put with the intent of testing the correctness of the suspicion which the patient's story has exeited.

6th. Physical means are brought to the corroboration of the diagnosis by rational ones.

Forms, either written or printed, such as that which follows, will not only save a vast deal of time and trouble, but give uniformity to histories taken, so that after a number of them have been accumulated they may be collated with reference to special points, or preserved for personal reference or publication.

$$
\text { C.ISE, No. }
$$

Date,

Name Age Married?

No. of children No. of abortions Time since last pregnancy Age at which menstruation appeared

Duration of present illness Symptoms during its course 
Present condition as regards

$\begin{aligned} & \text { Menstruation, }\left\{\begin{array}{l}\text { Regularity } \\ \text { Amount } \\ \text { Pain }\end{array}\right. \\ & \text { Leucorrhoa, } \quad\left\{\begin{array}{l}\text { Charaeter } \\ \text { Amount } \\ \text { Constancy }\end{array}\right. \text { ( Loeality } \\ & \text { Pain, } \text { Iegree }\end{aligned}$

Incomotion

i Degree

Other symptoms.

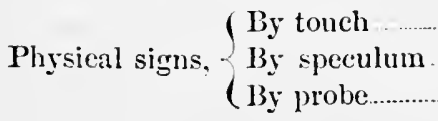

Diagnosis

Treatment

It will be observed that I have not enumerated the various rational signs generally attendant upon uterine affections, but merely the means for drawing them forth. Their special mention will be reserved for the study of particular affections. If the evidence elicited leaves any of the pelvie viscera under suspicion, this is verified or removed by means which are more positive and reliable from the faet that they address our senses.

It will further be seen that the headings of my table are not numerous, nor the table itself lengthy or exhaustive. My belief is that the ehief reason why such tables are not more generally employed is that they are so long and so filled with non-essential items as to become tedious and impraeticable. This table is that which I employ in daily practice. I find that when filled out it gives all the salient points in my cases, and these are all that $I$ desire ordinarily to preserve.

Maxagenext of Patiext dering Pirsical Exaninatiox-Before eommeneing the consicleration of physical signs, I slall make a few remarks upon a subject of great importance in this connection, namely, the management of the patient luring the examination. As Dr. Sims has tanglit us, she should never, unless it be impossible to do otherwise, be examined upon a bed or sofa, lut upon a table corerel with a blanket, shawl, or rug of some kind, and provided with a small pillow. 'The facility thus given for thorough investigation is very great, and the avoidance of the sinking of the body into the soft bed repays most fully the extra trouble which it causes to make the change. It may be said that many larlies will strongly object to the exposure ineident to getting upon a table. This is not so; a little persuasion will orreome such objections at once, and the increased exposure is in reality imarinary, for the table is to all intents a bed, and a sheet for covering the person gives all desirable pro- 
tection. Shonld it be necessary to employ a bed, the leaf of a dining-table or a wille board should be slipped across the mattress under the upper sheet and covering, and a latrd surface will thus be presented for the paticrit to lie upon, which will obviate, in great degree, the objections to the bed otherwise arranged.

The patient should always lie upon her back in a first examination, with the elothing loose around the waist, the knces drawn up, and the abdominal walls relaxed. A sheet should be spread over her so as to eonceal the entire person. The table having been previously turned to a window admitting a strong light, a chair should be placed at its foot for the examiner, and at the right side of it another, upon whieh has been arranged a basin of warm water, soap, and a towel.

$A$ variety of tables for these examinations in the physician's office are now before the profession. I here present that wheh I employ both in office and hospital practice. For the eylindrical speculum it presents the advantages of an ordinary table; for Sims's speculum, a great many more.

Fig. 6.

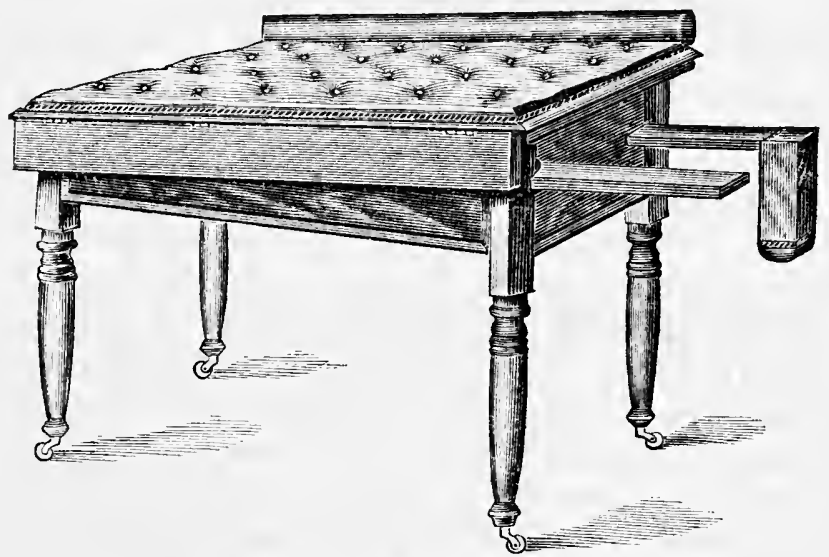

Thomas's gynecological table.

Fig. 6 represents the table prepared for an examination on the baek; a pillow supports the head, the buttocks are slightly elevated, and the fect rest upon the projecting pieces. When this examination is completed, the patient stands upon the chair or stool recently occupied by the examiner, and the table is changed for examination with the speculum in Sims's position, as shown in Fig. 7. The top of the table is now elerated at one side so that it slants deeidedly to the other. The ankles of the patient, resting one upon the other, are supported by the projecting pad upon the end of the foot-piece. The other foot-piece has now been pushed into the body of the table. This position, by gravitation, throws forwards the viseera, 
and thus aids in rendering the action of Sims's speculum more perfeet. It will be observed that the slanting surface of the table is now supported by the hinged piece which in Fig. 6 lies as a flap along the side of the table, but in Fig. $\tau$ is turned up.

FIG. 7.

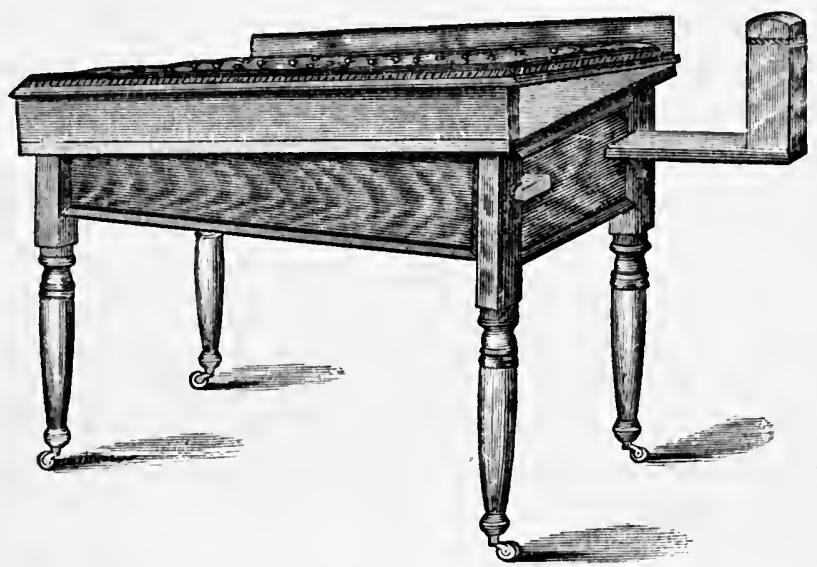

Thomas's gynecological table.

\section{Means of Physical Diagnosis.}

I shall enumerate and consider these in the order in which they will generally be employed in a case requiring the aid of all of them for its elucidation :-

1. Anxsthesia.

2. Vaginal touch.

3. Conjoined manipulation.

4. Abdominal palpation.

5. Abdominal palpation conjoined with use of the sound.

6. Inspection.

7. Rectal touch.

8. Vesico-rectal exploration.

9. The speculum.

10. The nterine probe and sound.

11. The elastic sound.

12. 'Tents.

13. 'The wire loop.

14. The exploring needle.

15. The aspirator.

16. The microscope.

17. Auscultation and Percussion. 
Andestriesia.-This shonld not be resorted to nuless there be some special indication for it. Should the patient be intractable, delirious, or a malingerer; should the investigation involve much severe pain ; or should there be some tonic spasm of the muscles as an element of the discase, as is the case in spurious preguancy and phantom tumors, it affords an ail to diagnosis of great value, and should never be neglected. When we are forced to examine a virgin who is very sensitive, and opposed to the investigation, it is sometimes advisable, for without it a diagnosis is frequently impracticable. One even of large experience is of ten greatly surprised by the results of two consecutive examinations, the one without and the other with anasthesia. The second not only corrects the shortcomings of the first, but throws a flood of light where obscurity existed before.

Vaginal Toucu.-This, which will bo the first exploratice measure to which the examiner will resort, constitutes one of the most important at his command. It will reveal much or little, as it is praetised slowly and thoughtfully, or hastily and as a matter of routine. In making it the index finger of either hand may be employed, and when it is desirable to reach as far up the pelvis as possible, the index and middle fingers may be used. During this examination the patient should invariably be laid upon the back, with the legs flexed and the buttocks very near the edge of the table. The observance of this position is of great importance, as vaginal touch should in every ease be combined with abdominal palpation, to which union the name of conjoined manipulation or bimanual palpation has been applied.

The index finger of one hand, being introduced into the vagina, the other fingers being flexed into the palm and the thumb laid upon them, passes directly to the eervix uteri, assuring the investigator, as it goes, of the perviousness of the vaginal canal. Upon reaching the os, this part is carefully examined with reference to size, eonsistency of lips, and character of discharge; a patulous os, with soft, velvety sides eovered by a glutinous secretion, admonishing him of the existence of inflammation of the os and cervical canal. The cervix should then be examined with reference to location, size, and density. This being done, the finger should be slid along its posterior surface into the recto-nterine space, and the presence of any hardness or tumefaction there be noted. Should such be found, it will probably be due to one of these canses . retroflexion or retroversion of the uterus, uterine enlargement, a fibrous tumor, scybalæ in the rectum, inflammatory products, the result of peri-uterine cellulitis or peritonitis, a prolapsed ovary or ovarian tumor, or an hematocele. Should no tumor be diseorered, but the line of resistance given to the finger be found to disappear at the vaginal junction with the uterus, it may be inferred 
with moderate certainty that at this point none of the above mentioned conditions exist.

This space being explored, the finger should then be passed anteriorly, and swept upwarl and forward along the base of the bladder toward the sympliysis pubis. Any hardness diseovered here will probably be due to anteflexion or anteversion of the uterus, a fibrous tumor, stone in the bladder, uterine enlargement, or possibly cellulitis.

The state of the ovaries should then be tested by lateral pressure, and the eondition of the pelvic areolar tissue and walls by firm pressure in all directions.

In certain rare and obseure cases, such, for example, as those in which a diagnosis of large tumors in the vagina is very diffieult, it becomes necessary to introduce the whole hand into the ragina. This procedure, which should be resorted to while the patient is anrsthetized, must be practised with the greatest caution. Otherwise injury may be done to the parts about the vulva, and a large and carelessly managed hand may produee rupture of the vagina.

One manceure, by which touch of the parts lying elosely in contaet with Douglas's cul-de-sac is much facilitated, still remains to be mentioned. Where small tumor's exist behind and disconnected with the uterus, or where enlarged and prolapsed ovaries are to be sought for and examined, an excellent result is of ten obtained by placing the patient in Sims's left lateral position, and passing the index and middle fingers of the right hand as high up as possible, their palmar surfaces looking towards the posterior wall of the vagina. By this method $\mathbf{I}$ have repeatedly detected enlarged and slightly displaced ovaries which in the dorsal decubitus had entirely escaped observation.

Conjomed Maxiplation, or Bmaxua Palpation.-As the preceding examination consists in tonching organs above the pelvic roof for the most part, and which are generally quite movable, it is evident that its results are diminished by ascent of these parts as they are pressed upon. To bring them more fully within the reach of the finger in the ragina, and to prevent their retreat, ahdominal palpation should invariably be combined wirh vaginal tonch. While the latter is being performed by the index finger of one latml, the other land should be placed on the abromen, and hy it the uterus be made to descend, so that even its upper parts may become accessible. This will enable the examiner to sweep the finger in the vagina over the posterior, anterior, and lateral surfaces of the organ, and deteet the presence of any enlargement, sensitiveness, or abnormal growth there. Fig. 8 represents this.

But not only should the walls of the uterus be thus explored : the rolume, shape semsitiveness, and regularity of surface of this organ, as well as of the oraries, the hroad ligaments, anterior vaginal wall, and bladder, 
shonkl likewise be ascertained. To aceomplish this with reference to the uterus, let the finger in the vagina be placed under it-anterior to the cervix if it be in normal position or anteflexerl, posterior to it if it be retroflexed-and the organ will be distinctly felt resting between it and the tingrers which depress the abdominal wall. lisy the same methot the other parts mentioned should be examinet. Conjoined manipulation is of great

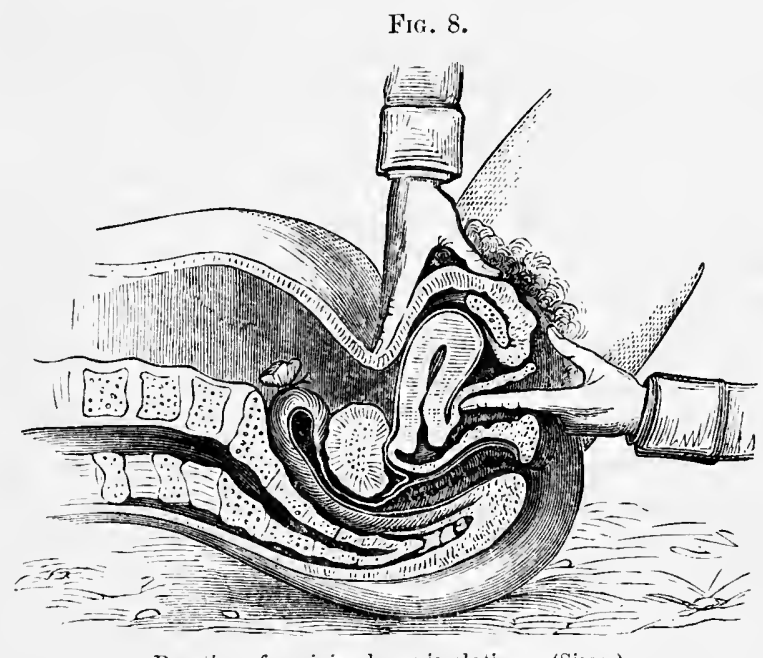

Practice of conjoined manipulation. (Sims)

importance; indeed no examination can be considered eomplete without it. By a neglect of this seemingly trifling precaution I have known the existence of large tumors, and even of pregnancy quite advaneed, entirely ignored. Some time ago a physician sent to me from a distance a case which he supposed to be one of prolapsus uteri, from the fact that the uterus was low in the pelvis, never suspecting for a moment the existence of two fibrous tumors, each the size of a foctal head, which depressed the displaced organ.

Were I ealled upon to mention the most important method of diagnosis at the disposal of the gynecologist, not excepting the speculum and sound, or even the two of them together, I should unhesitaringly select conjoined manipulation. It is less generally known, and much less generally appreciated than it deserves to be.

Not only may this method be practised by combination of vaginal touch with abclominal palpation: it may likewise eonsist of the combination of the latter with rectal touch, by one finger, or by the introduction of the hand after Simon's method.

Andonisal Palpatiox.-The practice of bimanual palpation will have assured the investigator of the presence of any tumors which may 
exist in the pelvis. Should such have been discovered, a further examination will, of course, at once be entered upon to ascertain their size, shape, attachments, and eontents. In this exploration both hands are employed externally, and by them firm pressure is made and the abdominal walls depressed, so that by grasping the masses their characters may be appreeiated. By this means the diagnostician deeides as to the solidity or fluitlity of tumors, their sensitiveness to pressure, the presence of foctal morements, and other points of equal importance.

Ainonixal Palpation conjolxed with the cse of tme Socxd.I shall very soon speak of the uterine sound in relation to its ordinary and more legitimate funetions. Here $I$ allude to it only as a means of rotating the uterus in the pelvis in order that the hand pressed upon the abdomen nay separate it from enlargements in the abdomen. This method of investigation is of so great value, and appears to me so little appreciated and so rarely practised, that $I$ wish to draw especial attention to it. Let us suppose: that a tumor occupies the pelvis or lower portion of the abdomen, and it be desired to determine how close a relation exists between it and the uterus. The sound being passed to the fundus, the patient lying upon the back, it is made to rotate the uterus. The left hand, which is unoccupied, is now placed on the abdomen, so as to become cognizant of movements in the uterus and tumor. If both move equally, their connection is intimate; if the uterus move freely and the tumor but little, it is less marked; while if the tumor remains stationary during rotation of the uterus, there is probably no connection, or one only by lengtly honds of union.

Again, in cases where palpation and conjoined manipulation fail to map out the position of the uterus on account of obseure pelvic tumors or great obesity of the woman, lifting the organ by the sound and rotating it under the fralm laid upon the abdomen, is a raluable resource.

Lastly, in cases of supured fibrous polypus where one fears to operate lest an inverted uterus may have misled him, although the passage of the sound alone makes him almost sure as to diagnosis, it gives confilence to feel the uterine body rolling under the land laid over the ablomen, for it is not an unheard of occurrence for the sound to pass through the uterine walls and enter the peritoneum.

I would urge this procelure, as a rule, in the examination of abdominal and pelvic tumors. Indecel, in a large number of such catses, a necglect of it will allow of errors in diagnosis, which, by its adoption, might have been aroided.

Ixipertox.-A great dral may he learned from the inspection of discascul growths about the vulva, or ostium vagina, and of tumors in the vagina. which may be drawn down between the labia, and valuable information may be gained concerning abdominal enlargements by this means. 
For example, the shape of an ovarian eyst is globular and protuberaut, white that of an abdomen affected by ascites is flat and bulging at the sides ; the form of a mono-eyst is ustally grlobular, while that of a polyryst is commonly irregular; the development of a preguant uterus is regrilar and symmetrical; that of a solid tumor of the uterus often irregular and unsymmetrical.

Recral Toucu.-Should anything have heen discovered upon either uterine wall to make further light ujon the state of these parts desirable, or should symptoms have presented thenselves which excite suspicion of the presence of some morbid growth, the index finger of one hand should be carried far up into the rectum, and, if necessary to enable it to reach the posterior uterine wall, a tenaculum should be fixed in the cervix, and by gentle traetion the organ drawn down. Generally, however, suffieient depression will be accomplished by firm pressure over the hypogastrium with the other hand, the tips of the fingers pressing the uterus towards the floor of the pelvis; or both of these means may be combined by bringing to our aid the hand of an assistant. Those who have not employed this method systematically must have a faint idea of the great facility which it gives for exploration of the lower portion of the posterior wall and recto-uterine space.

Prof. Simon, of Heidelberg, some years ago greatly modified the method of exploring the pelvic viscera of the female through the rectum. IIs method is thus put into practice:-

1st. The patient is anasthetized and placed in an exaggerated lithotomy position; the knees being thrown upwards so as to flex the thighs sliarply.

21. The sphineter ani is thoroughly stretehed, and first the fingers and then the hand cautionsly introduced. In certain very rare cases an ineision, involving the sphineter, is made through the posterior raphe of the anus. For diagnostic purposes this is very sellom refuired.

3d. The fingers are then separated and a careful examination of the pelvic organs is made.

4 th. Should it be found neeessary to invade the parts above the level of the sacrum, three or four fingers are introduced into the sigmoid flexure, so that we may "reach above the umbilicus without in the least injuring the intestines or peritoneum, and, the upper portion of the rectum and sigmoid flexure being extremely movable, can pal pate the whole abdomen as far as the lower edge of the kidney."

It was asserted that by this means a positive diagnosis could be made of many diseased states of the uterus, ovaries, rectum, and sometimes even of the kidneys; that hy it the examiner is enabled to hold the ovaries betwen the thumb amd finger and appreciate their size, consistence, and smootlness; to discover tumors of the uterus no larger than a cherry ; to 
ascertain the length of the pedicle of an ovarian cyst, and the freedom from attachments of the cyst itself; and in a case of renal cyst to learn that the tumor has no connection with the pelvic organs.

Such is Simon's methorl of rectal exploration. In an edition of this work published six years ago, I advocated it, basing my views chicfly upon the assertions of its originator, and to a limited extent upon personal experience. To-day with fuller experience I maintain that, except in a very few rare cases, it should be expunged from the list of explorative measures in gynecology. That in certain exceptional cases it may have to be resorted to, I do not deny ; but even in these it should be employed with the greatest caution, and be regarded in the light of a serious operative procedure. It is attended by too great danger of laceration of the wall of the intestine, and cramps the hand so as to give too little explorative power in proportion to the risk run to warrant a frequent resort to it.

Several cases are now on record in which its employment in the hands of careful and skilful practitioners has terminated fatally. The danger is greatly increased where several examiners succed each other in exploration. The carlier examinations stretch and weaken the tissues, and the later lacerate them. For this reason it should be made a rule that only one exploration should be made, and that that should last only a short time.

$\Lambda$ great deal more can be accomplished by the introduction of the hand exe(p) the thumb, alter streteling the sphincter anj, than by the old method of introducing only one or two fingers.

Should any substance lie in the recto-raginal space, its character may be accurately appreciated by what has been styled, by Dr. Tilt, the "double touch," which consists in introducing the index finger into the rectum and the thumb into the vagina, and then approximating them. Or the index of one hand may be introduced into the ragina and that of the other into the reetum.

Vesico-rectal Exploration.-This consists ordinarily in passing a atheter or sound into the bladder, and pressing it towards the index finger in the rectum. Its scope is not extensive, but for some purposes no other method answers the sane end, as, for example, for the following :-

Appreeiating the size of the uterus in very fat women;

Detecting alsence of the uterus;

Differentiating inversion from jolypus.

Thro only difference between this method and conjoined manipulation consists in the attempt to grasp the uterus between the finger and sound insterd of between the fingers of the two hamb. Who the originator of this ingenious nethod is I eamnot say. By Mr. C. F. Weiss it is attributed to Malgaigne. 
This method may be practised in still another manner; that proposed by Noeggerath. It consists in dilatation of the urethra by graduated dilators, the introduction of the index finger of one hand into the bladier and that of the other into the rectum or vagina, and the approximation of these so that the uterine walls, anterior, posterior, and lateral, ean be carefully and thoroughly examined. This method, like that of Simon, should be resorted to only in obseure and diflieult cases not suseeptible of elucidation by other means.

Tire Speculy.-This is by no means our most valuable diagnostie resource. Too great a reliance upon it as such is calculated to diminish the physician's powers for arriving at a correct conclusion in obseure cases. Unquestionably the greatest benefits derived from the speculum demonstrate themselves in the therapeutic department of this subject. As a diagnostic means it is inferior to vaginal and reetal touch combined with abdominal palpation, and chiefly aids us in this field by opening the way to the proper use of the nterine probe, which constitutes one of the most reliable methods at our command for appreciating the condition of the eavity of the uterus. Let any one who is surprised at the statenent, which many will be, reflect as to what can really be seen even in aggravated cases of disease, except malignant, granular, and eystic degeneration of the cervix. The position of the uterus, the presenee of a foreign body in its cavity, the condition of its surrounding tissues can none of them be learned from the sense of sight.

All vaginal specula may be classified under two heads, cylindrical and valvular. Of the first variety cylinders of metal, porcelain, ivory, and wood are in general use. None of these compare in elegance, eleanliness, and utility with that of Dr. Fergusson, of London, which consists of a tube of glass coated with quicksilver, and covered by India-rubber, which is thoroughly varnished. This instrument is represented in Fig. 9.

\section{FIG. 9.}

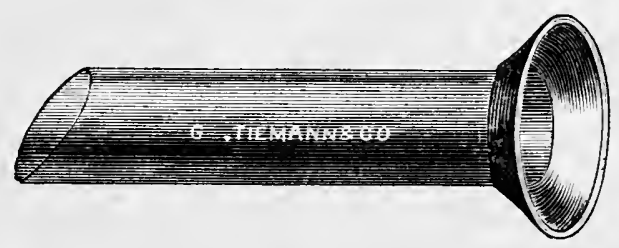

Fergusson's speculum.

Objections which attach to all cylindrical instruments are the following: to suit all eases they must be from five to six inches long, which renders probing the uterus through them impossible, and prevents applications from being carried to the fundus; it is not possible to examine through them 


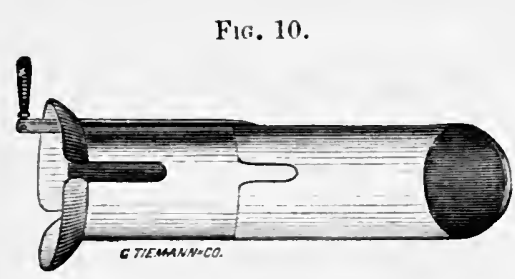

Thomas's telescopic speculum.

by touch; and in anterersion it is difficult to get the cervix into the field. The instrument represented in Fig. 10 obviates many of these difficulties by accommodating itself to the length of every vagina, so that the shoulders come just between the labia.

It consists of two thin metallic tubes, one of which slides within the other. To the inner tube are attached, at the mouth, wings which sustain the labia, and the outer tube ends in a tip which is either straight or curved. It is called the "telescopic speculum," from its mechanism, and measures, when not extended, along its shorter side two and a half inches, along the opposite, three. When extended, it is as long as the ordinary cylindrical specula. On both surfaces, upper and lower, are two fenestrx, which admit of elevating or depressing the probe in cases where flexion or version exists, and its handhe must be much lowered. A downward curve may with advantage be given to the longer lip. This curve looks at first both odd and useless; but upon experiment it will be found to answer a very useful purpose. In cases where the uterus is normal in position it will not depress the cervix too much, while by turning it up when this part lies imbedded in the hollow of the sacrum the examiner will be enabled to lift it and engage

Fig. 11.

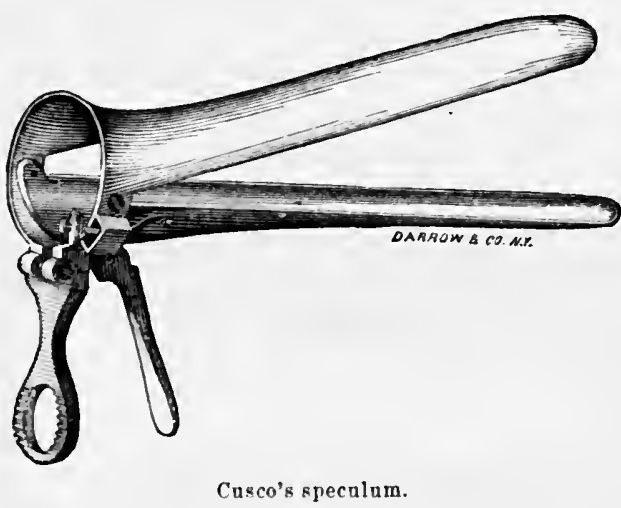

it in the field of the speeulum. When fully introduced the wings at the month of the instrument support the labia, and thus no superfluous portion extends beyond the vulva.

Of valvular specula the biralve of Ricord, the trivalve of Ségalas, and the quadrivalve of Charrière have long been popular. No instrument of 
this variety with which I am acquainted equals that of M. Cuseo, Fir. 11. It is compact, easily introluced, and shows the cervix very charly.

A great many modifications of Cusco's speculum are now in use. Indeed so great is the variety of modifieations of this and of Sims's instru-

Fig. 12.

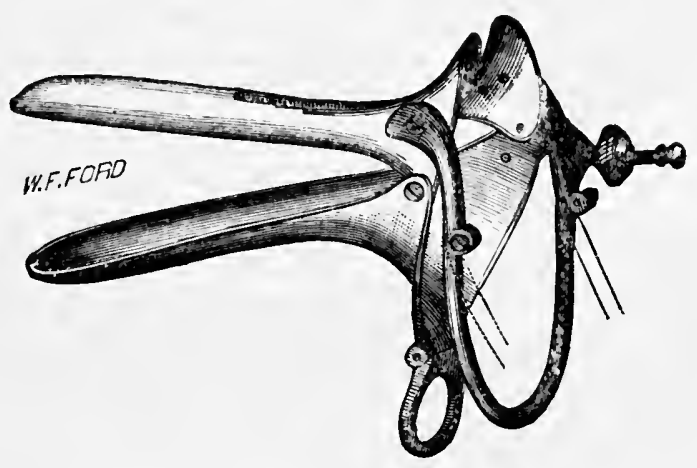

Howard's modification of Cusco's speculum.

ment that the speculum seems destined to vie with the obstetric forceps in the number of its variations. Fig. 12 represents Dr. IIoward's modifieation of Cusco's speculum, a very good representative of its class.

Of all the specula thus far mentioned I have spoken from personal knowledge. The next I show upon faith alone. It is the speculum of Prof. Neugebauer, of Warsaw, which is so highly commended by some of the most eminent gynecologists of Great Britain that I bring it before the reader upon their authority. The diagram here exhibited shows this instrument somewhat modified by Dr. Barnes, of London, and as presented by him before the London Obstetrical Society.

All valvular specula, how-

FIG. 13.

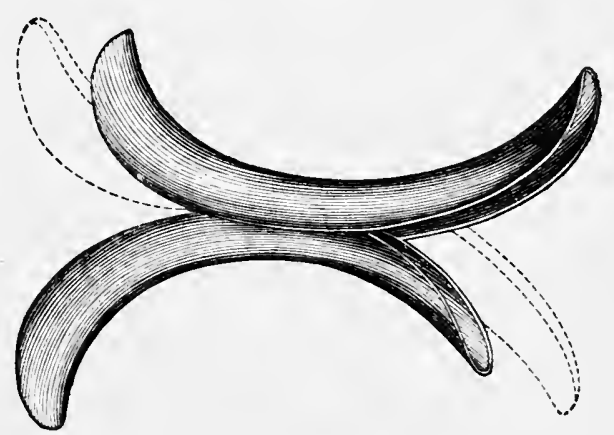

Neugrebauer's speculum. ever, present these great disadvantages. It is difficult to avoid prolapse of the vaginal wall between their branches, and in removing the instrument these are liable to be painfully pinched. If, upon introducing and expanding their branches, the os uteri is exposed, all goes well ; but if it is not in the field, these instruments are awkward and unwieldy in overcoming the difficulty; indeed, in many cases, the speculum must be with- 
drawn and reintroduced to accomplish the result. They have one great advantage over the cylindrical specula, namely, their introduction is attended by much less pain. Should the case be one of a multipara, a cylinder may be introduced without pain, but in a nullipara, or virgin, this is often caused.

Like the eylindrical, the valvular specula in general use do not as a rule admit of probing the uterus and making applications to the fundus.

FI.. 14.

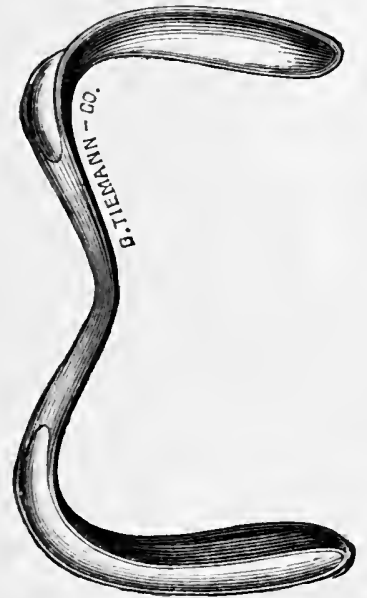

Sims's speculum. I do not deny that in some cases it is possible, nor that by persererance a skilful operator may succeed in effecting these objects in many instances, but it is usually so difficult that the general practitioner will not find such specula available for these ends.

FIG. 15.

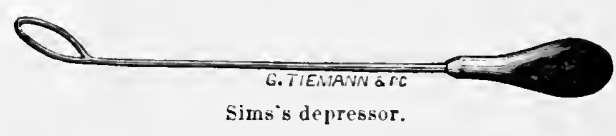

Sims's speculum, Fig. 14, which is in reality a bivalve, obviates all these difficulties in the most complete and satisfactory manner. In exposing the uterus it develops a principle not brought into action by any other variety, the dilatation of the vaginal canal by air, which enters on account of the position of the patient and gravitation of the pelvic and abdominal viscera. I have stated that this instrument is a bivalve speculum; the upper valve is constituted by the blade of the speculum itself, and the lower by the depressor, represented in Fig. 15, which acts upon the anterior wall.

The facility which Sims's instrument gives for exploration and treatment is very great, so great. I think, that the practitioner devoting himself to gynecology who does not avail himself of it, loses as great an advantage as the anseultator would forego in not bringing to his aid the double stethoscope of 'amman. But unfortunately this instrument presents such disadrantages that it can never eome into general use. In the lands of those attending a suflicient number of eases of uterine disease to give them skill in manipulation and opportunity for thoroughly familiarizing themselves with it, it will always fill a large place, but in general practice it will not do so. It eannot be employed without an assistant, and not only so, a skilled assistant is necessary for it to be of real value. This fact has incited many to alter Dr. Sims's original model so as to combine its allantages in instruments free from the objections which have been mentioned. $A$ few of these I lay beforc the reader. 
When the posterior vaginal wall is lifted by Sims's speculum, the anterior must be depressed by an instrument held in the other hand. Thus both hands are oecupied, and the operator is bereft of power to proceed. The olject of the alteration is to liberate one hand in order that the further steps of the examination maly be proceeded witl.

Dr. Nott's speculum (Fig. 16) does this by depressing the anterior vaginal wall by two short arms. These at the same time keep the blade of the speculum itself in place, and thus either one or both hands are free for making applications to the uterus, probing its earity, or whatever else may be reculuired.

Fig. 16.

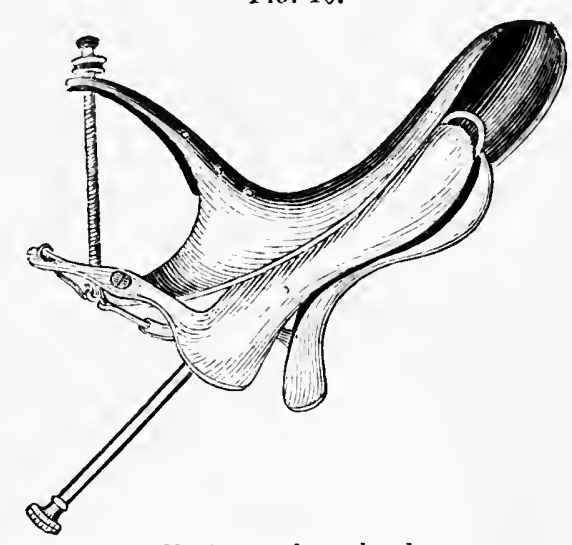

Nott's speculum, closed.

The speculum of Dr. J. B. Ilunter (Fig. 17) is simply Sims's speeulum, with its blades bent inwards so as to enable the examiner to fix it in a support which is attached to the table and acts as a mechanical assistant. The speculum being thus fixed keeps its position perfectly, and the examiner with both hands free, proceeds in his investigation, employing the depressor as when an assistant aids him. To make this arrangement effectual some practice is necessary, but with that it will prove an exeellent one.

FIG. 17.

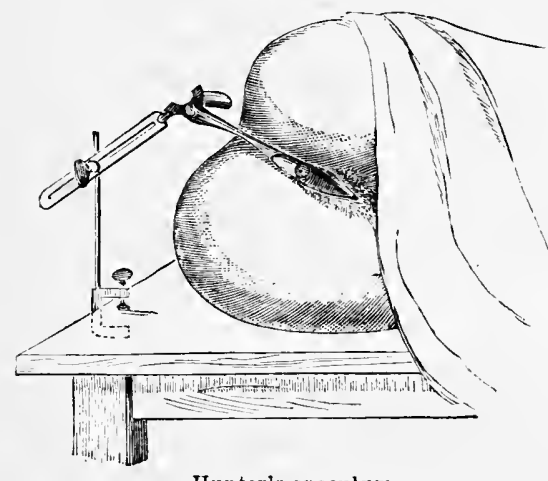

IIunter's speculum.
Fig. 18.

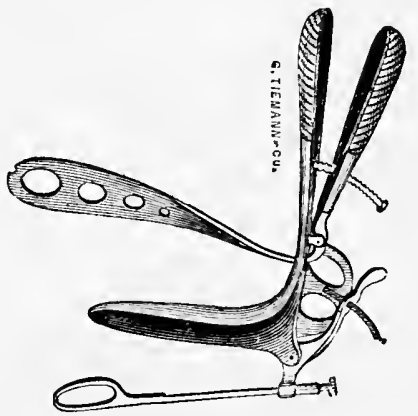

Thomas's modification of Sims's speculum.

The instrument represented in Fig. 18 clasps the sacrum; one blade, $a$, the speculum itself, being placed within the ragina, and the other, on the outer surface of the sacrum. Their anproximation by the left hand ele- 
vates the posterior vaginal wall, and the handle is held by one hand. The anterior wall is then depressed by the depressor, and thus one hand is left free. This instrument appears complicated in a diagram, but in reality it is by no means so. For a long time I employed it without the sacral piece. Some even now prefer it thus, thongh the fatigue which it causes to the left arm in lifting the posterior vaginal wall and perineum, constitutes an objection to it.

Method of Introducing Valvular and Cylindrical Specula.-The patient being placed in position on the back, as already explained, and the speculum, probe, and whatever other instruments are to be employed, laid in a basin of warm water at the bedside, the physician seats himself in a chair, or if a low bed be used instead of a table, kneels or sits upon a stool. The finger, having been thoroughly lubricated with soap or carbolized vaseline, is passed up, and the location of the cervix ascertained. The speculum, similarly lubricated, is then passed in this way ; if the eylindrical instrument be used, the perineum is depressed by its tip, and it is very slowly and gently insertel and carried to the cervix; should one of the valvular varieties be employed, it is inserted elosed, and expanded after reaching the cervix.

Introduction of Sims's Speculum and its Varieties.-In this method of examination the element which commands success is not the use of the instrument, but the position of the patient. If the position recommended by Sims be attainel, exposure of the cervix will be easy; if a similar but not identical attitude be substituted, the examination will prove entirely unsatisfactory.

The object of the position is to allow the alulominal viscera and walls to gravitate, so as to draw the anterior wall of the vagina forwards, in a direction opposite to that impressed upon the posterior wall by the speculum. To accomplish this the patient must be not on her batek, nor on her side, but in a position between the two. This is well represented in Fig. 19. The left arm must be drawn behind the patient so as to let her rest on the left side of the chest, and the right leg be so flexed as to let the right knee lie just above the left.

When the patient is arranged, the correctness of the posture may be tested by noting that the lower trochanter is not just opposite the upper, but nearer to the examiner by two or three inches. I am thus partieular in describing this position, first, because it is diflicult for one maccustomed to its employment to place his patient properly in it; and, second, because upon its perfect attainment depends the snceessful use of Sims's speculum. The patient heing in position, the speenlum is introduced, the posterior vaginal wall elevated by it and the anterior depressed by the depressor, Fig. 15, held in the other hand, or by the mechanical depressor represented in Fig. 1n. 
One reason why the great alvantages of Sims's speeulum are not more generally recognized and acknowledged is unquestionably to be found in

FIG. 19.

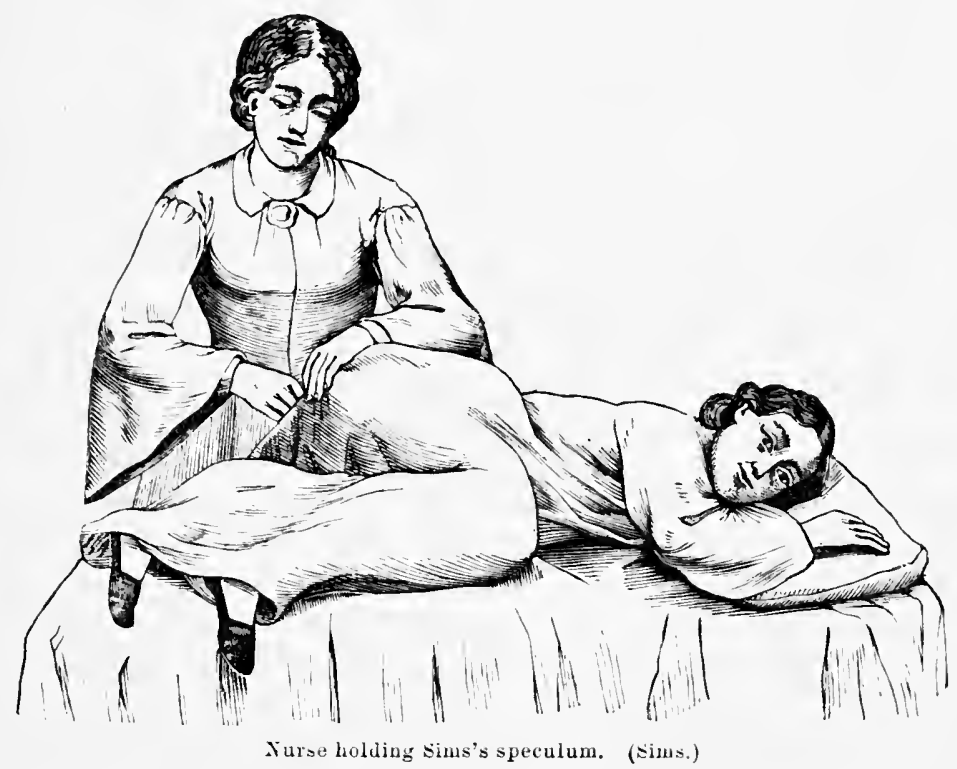

the fact that the patient is not properly arranged before its introduction. To impress this fact and to show how faulty the arrangement of the ja-

FIG. 20.

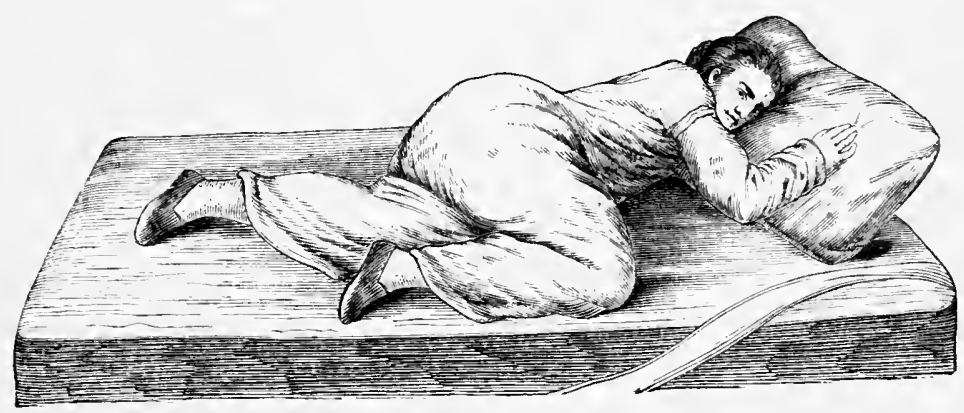

Position of woman in examining with Sims's speculum. (Leblond.)

tient may be, I introduce a diagram from a recent and very excellent French work upon gynecological surgery.

No diagram could better represent how the woman should not be placed than this. 
The Uterine Souxd._I'his valuable diagnostic means, although to a certain extent known in ancient times, was more recently recommended in 1828 by Samuel Lair.' It was not however adopted upon his reeommendation, and it was not until about the year 1843 that it was generally aceepted. At this time its elaims were simultaneously urged by Simpson of Eslinburgh, Intuier of Paris, and Kiwisch of Prague, working without eoneert. It matters little to which of them belongs the eredit of having been the first to eonceive the idea of the regeneration, to Simpson certainly belongs that of having forced it upon the attention of the profession and established its value by clinical evidence.

The instruments in general use are those of Simpson, Valleix, Huguier, and Kiwisch, which resemble each other closely in prineiple, each consisting of a stiff metal rod divided into quarter inches and bent so as to pass in the axis of the healthy uterus. The method of their introduction is this: the index finger of one hand being introdueed into the ragina and placed against the cervix, the sound is by the other slid upon its palmar surface to the os, passed into it, and by depression of the handle gently alvanced to the fundus. If the uterus be in its normal position, and the somd be used by a skilful hand, the operation is not difficult. But it is not the healthy uterus which we are generally ealled upon to explore. If the organ be displaced, the difficulties and dangers attending the employment of the sound are considerable, as may be julged of from the following quotations :-

Beequerel ${ }^{2}$ says: "But its employment is attended with such diffieulty that it requires all the skill of an adroit and experienced practitioner, and we dreal seeing it popularized among young plyssicians of little skill and experience." Nonat ${ }^{3}$ declares that, "on account of the accidents which sounding may excite, it should only be resorted to with great eantion and in those eases where its neecsity is clearly shown." Scanzonit candidly acknowledges that, "in the first place, the uterine sound is hy no means so harmless as has been asserted," and then goes on to sum up the evils which may result from it. But I will not quote more; this suflices to show how the diflieulties and dangers to which 1 have alluded are regarded by some of the best authorities of our day.

The fitets which may be ascertained by the sound are these:-

1. The capacity of the uterus.

2. The existence of growths within it.

3. Deviations of the conrse of its callal.

4. Differentiation of displacements from uterine tumors.

5. The mobility of the uterus.

1 Samucl Lair, "Nouvelle méthele de traitement des ulcères, ulcerations et engorgenent de l"utérus," 1825.

2 Malalies de l'uterus.

3 Maladies de l'utérus.

4 Diseases of liemales, Am. ed. 
The great importanee of these facts with reference to diagnosis is evident, and one would suppose that an instrument revealing so much would be universally employed. Sueh, lowever, is not by any means the casce. By adepts it is commonly resorted to, but in general practice will be found many, indeed a majority, who do not employ it from fear of its results, the diffieulty of its introduction, and uncertainty as to its revelations.

1)r. Sims has, however, furnished us witlı a new instrument and method for probing the uterus, which acts upon an essentially different prineiple from that formerly employed, and makes the investigation so simple and void of danger, that I strongly recommend its adoption.

Fig. 21 represents the sounds of Simpson and Sims, for the purpose of contrasting then. The first is a strong, muyielding staff, composed of German silver, and as large as a No. 3 catheter.

The second is not a sound, but a probe, only a little larger than the ordinary surgical probe, composed of pure silver or copper, and perfectly pliable.

Mode of Probing the Uierus. - While the woman lies on her back, the examiner, by vaginal touch, carefully ascertains the position of the uterus, by passing his finger, first into the fornix vaginæ, over its posterior face, and then along the lase of the bladder, over its anterior wall. This gives him Fig. 21.

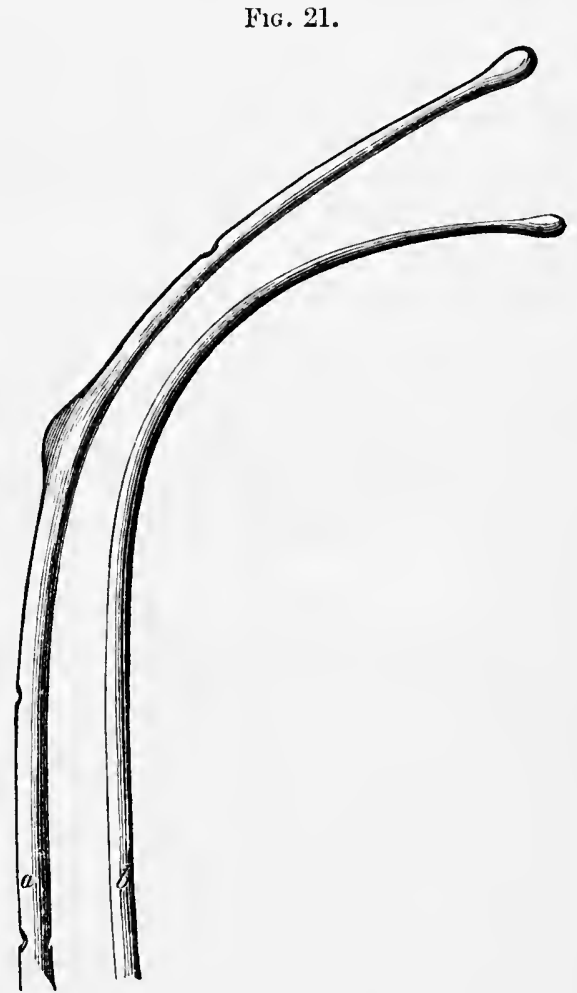

Sounds of Simpson and Sims compared. a definite idea of the direction of the eanal along which he is to pass lis probe, and without it he should never essay the procedure. The speculum is then introduced, the patient being turned on the left side. The examiner then takes tha probe, and with his fingers gives it the exact curve which he supposes the uterine canal to have, and gently endeavors to pass it in. Should he firil, he withdraws the instrument, alters the curve slightly, and makes other attempts until he succeeds, which will be very soon if he has used this method so often as to have given himself experience. Every effort at introduction is made as cautiously as if the 
probe were passing into the larynx instead of the womb, and no force whatever is exerted. Suecess is attained by properly curving the probe, and by that alone. Sometimes the infleetion given to it must be the are of a small eirele; at others a sharp angle; sometimes the instrument is left perfeetly straight; in fact every variety of direction may be given it. In a certain set of rare cases, even a spiral twist is required.

This employed, the uterine probe becomes a means of verifying a diagnosis which las been made by touch, and is certainly safe, easy of introduetion, and painless. It may be used in all eases exeept pregnancy, doing no injury even in endometritis, so gentle is its entrance into the inflamed eavity.

No one can dispute the faet that having been passed it performs the chief functions of the sound, proelaiming the course, lengtl, and capacity of the uterine canal.

As the practitioner grows in skill in the practice of conjoined manipulation, that most raluable and reliable of all his means of diagnosis, he will less and less frequently find a resort to the sound or probe necessary. In the vast majority of his eases he will by that means so clearly determine all that the sound or probe could reveal, that he will feel satisfied without further investigation.

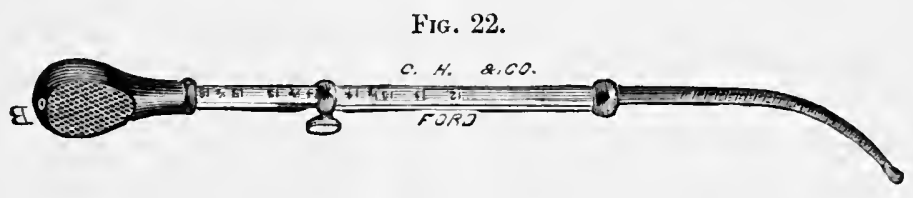

Jenks's elastic sound.

Some eases of enlarged uteri, with or without the presence of submucous fibroids, require the use of an elastie sound for their full exploration. For this purpose sounds of gum elastic and whalebone have been employed. A very excellent elastie somnd of metal has been devised by Dr. E. W. Jenks, of Chicago, and an exceedingly ingenious one by Jenison, which will be elsewhere represented.

Texts.- Before the time of Récamier, the cavity of the uterus was a space entirely closed to investigation and local therapeuties, unless the os were greatly dilated by disease. lle not only aspired to an accurate knowlenge of its affections, but boldly applied his remedies directly to the diseasul surface; and, in cases of intra-uterine granulations, scraped off the discatsal mucous coat with the curette. Even to him, however, the diagno is of liseases within the cavity, when the os was closed, was an imposibility, and for the means of combating this difficulty we are again indubted to Dr. Simpson, who, in 1814 , placed the use of sponge-tents among the most important of our resources for diagnosis. 
The object for which they are employed is the dilatation of the cervical eanal, in order that the cavity of the body may be examined by touch or sight, and that treatment may be applied in cases of polypi, gramulations, fibrous tumors, hydatids, removal of the products of conception, etc.

Vatrions substances have been recommended for the mannfacture of tents, only two of which have thus far come into general nse, compressed sponge and the laminaria digitata, or sea-tangle.

The practitioner sloukl no more think of preparing his own spongetents than his extracts or tinetures. They are now made by those who possess much more skill and experience than himself, and by procuring them from these manufieturers the interests of both himself and his patient will be subserved. They should be steeped in a solution of carbolic acid

Fig. 23.

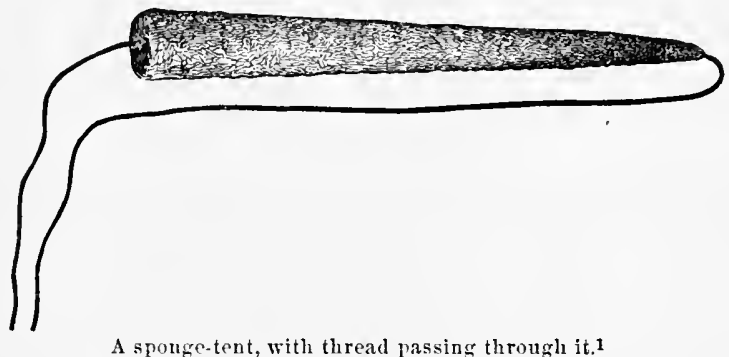

A sponge-tent, with thread passing through it.1

as an antiseptic, and may be medicated with iodine, zinc, copper, or other substances. The cord attached to a tent should always pass through it, and out at its upper extremity. A neglect of this simple precaution has repeatedly allowed a tent to break upon its removal, and one-half to remain in the eavity of the body of the uterus.

Preparation of Sea-T'angle Tents.-In 1862, ${ }^{2}$ Dr. Sloan, of Ayr, Scotland, first recommended the use of this substance for dilating the cervix uteri. The laminaria is an aquatic plant found upon various parts of the Atlantic coast of Europe and America. That found in the Bay of Fundy, I am informed by Messrs. Tiemann \& Co., is far superior to any other with which they have experimented. 'This plant, when saturated with moisture, swells to three times the bulk which it has when thoroughly dried. In its moist state a long piece of it is perforated at both extremities, in order that it may be hung up and allowed to dry, al weight being attached to the lower end so as to stretch it and make it straight. When dry, this is cut into pieces from two to two and a half inches long and made

1 The extremities of this thread should of course be tied together.

2 Glasgow Mled. Journ., Oet. 1862. 
perfectly smooth and round by a knife, a piece of glass, or sand-paper. 'Tiemann \& Co. prepare them very beautifully by turning in a lathe.

Dr. Greenlaalgh, of London, has improved these tents by having them perforated from one extremity to the other, so as to make them tubular instead of solid. Thus prepared

FIG. 24.

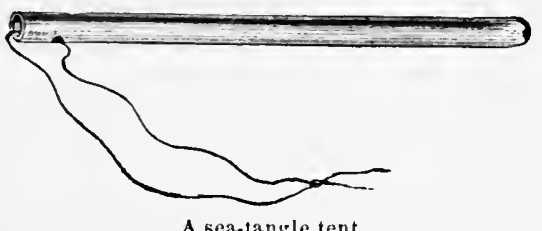
they will dilate much more rapidly and completely. One of Dr. Greenhalgh's tents is represented in Fig. 24.

The advantages of these tents over those made of sponge consist in their ereating. no fetor, and presenting no animal matter

for absorption. Their disalvantages are their requiring a longer time for expansion, their being kept in the cervix with greater difficulty, and offering a larder substance to the walls of the cavity of the uterus.

The late Dr. Nott, who experimented extensively with them, arrived at couclusions very much in their favor, as will be seen from an examination of his deductions which I here place hefore the reader.

"1st. Where moderate dilatation is required, the laminaria is preferable to the sponge-tents.

"2d. If placed in warm water, just before introduction, for a few minutes, they become flexible, coated with mucilage, are easily eurved to suit the cervieal canal, and may be inserted with the utmost facility.

"3d. From their smoothness and softness they are removed without force, and produce no abrasion or irritation.

"4th. They may be medicated with morphia, iodine, or anything soluble in water, but do not absorb aleoholic solutions or glycerine. After being so charged. they may be dried and kept for use an indefinite time.

"5th. They do not become putrid, and therefore poisonous, as do spongetents. and may therefore be retained twenty-four hours or more with impunity.

"(ith. The black. ovoid laminaria, from the Bay of Fundy, is much preferable to the other varieties yet brought to our markets, and free from the objections made to laminaria by some writers.

" 7 th. The laminaria will be found of great benefit in obstructive dysmenorlurea, if introdued a few days before the menstrual period, and also in cases of uterine catarbh connected with contracted cervix; they prepare the way well, too, for all intra-uterine medication. In either case, if softened in liot water before introduction, they rarely produce any pain or irritation.

"sth. It is better to insert several small tents than one large one, as the small ones expand more rapidly than the large ones."

The last point here mentioned is one of great importanee in their use, and for its recognition we are indebted to Dr. Kidd, of Dublin. IIe thus 
speaks of it. "When the uterine tissues are relaxed by hemorrlagn, a fine tent can be passed at once through the whole length of the cervix and on to the fundus, and by a little care a number of fine tents can be packed alongside of one another in the canal, when at single large one, thougl not nearly of the size of the bundle so formed, could not be passed at all. 'The first tent introduced serves as a guide to the others, and when they absorb fluid and swell out, they not only dilate the os internum as much at the os externum, but also the cavity of the uterus itself.",

Of late Dr. G. E. Sussdorff; of this eity, has recommended the nse of tents made of wood of the tupelo or nyssa, a tree growing thronghout the Southern States. Upon his recommendation I commenced the use of these tents, and have been so much pleased with them as to have for the past year employed them very generally. 'They do not upon absorption of moisture expand as much as sponge, but they make up for this defect by

Fig. 25 .
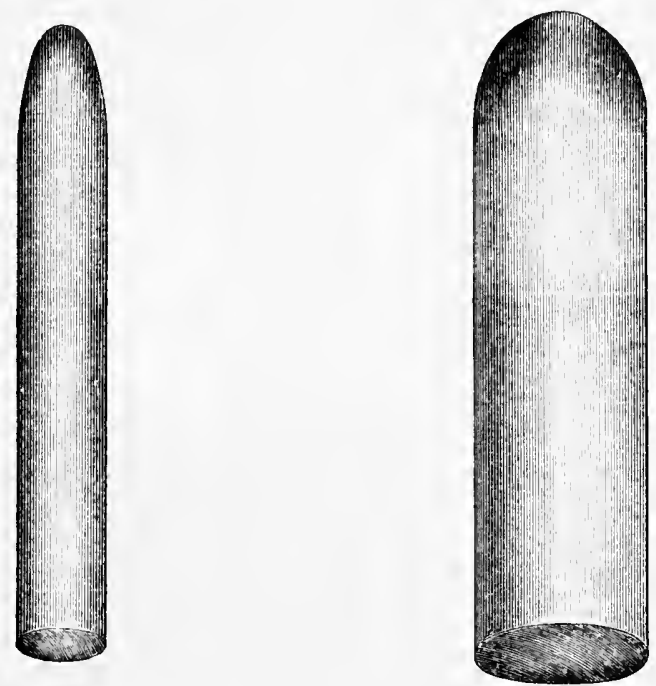

A tupelo tent before and after introduction and expansion.

myieldingly maintaining their inereased size after expansion which sponge fails to do. Fig. 2.5 represents one of these tents before introduction by myself, in a case of a patient suffering from a submucous fibroid, and the same npon removal at the end of twenty-four hours. The figures are of natural size.

The tupelo tent has, I feel sure, a brilliant future before it. While it will not entirely supersede sponge, it will in a great many cases replace it. Mode of introducing Tents.-If the uterus be low in the pelvis and its 
neck dilated, a tent may be held in the bite of any pair of uterine dressingforeeps and slipped in without the speculum, the woman lying on the back. In ordinary cases they should be introduced through the short cylindrical, or one of the varieties of Sims's speculum. The introduetion is most easily accomplished with the last in all cases, and in some it can only be

Fig, 26.

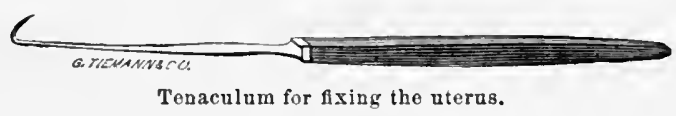

effected with it. Before the introduction of the tent the ragina should be syringed out with carbolized water, and the tent, having been lubricated with carbolized vaseline or gelatum petrolei and grasped by a pair of forceps, is directed in coincidence with the nterine axis as aseertained by the probe, and gently pushed through the cervix, as represented in Fig. $2 \overline{7}$.

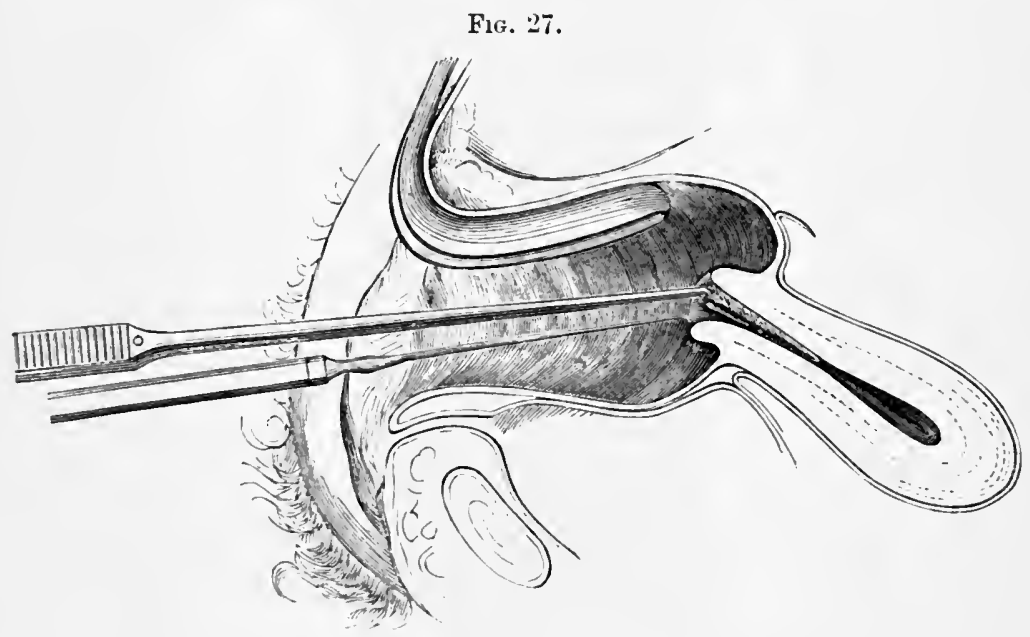

Introduction of a tent. (Sims.)

After this the vagina should be syringed ont with carbolized water, a mass of carbolized cotton packed against the cervix so as to exclude atmospheric air and keep the tent in place, and the woman be directed to remain in bed until it is removed.

Its removal is accomplished, through the speculum, after removal of the cotton and syringing with carbolized water, in from twelve to twenty-four hours, with the same foreeps by which it was introdnced, or by traction upon the threal attached to it, the patient lying upon the back.

Drungers. - There is always danger in dilating the cervix by tents, though it is by no means so great as to make one hesitate in employing them, for the cases which demand them are often urgent ones, and they 
serve a purpose not attaimable by any other means. It is much to be regretted that practitioners have not shown more alacrity in publishing infortunate results from the use of this method of exploration and treatment. IIad all the fatal cases which have resulted from accidents due to tents been faithfinly recorded, the list would now be a long one, and it would be greatly lengthened by a record of all the instances in which tedious, exhausting, and dangerous disease has thus been excited. It may then be asked whether it is right to recommend a method accompanied hy so mueh danger. The same line of argument applies to this question, which does to so many similar ones in medicine. Great dangers attend the use of amastheties, of nareoties, and of other means which are in daily use, but the proportion of accidents occurring from their use is small althongh the aggregate is large; and the good which they effect is so great that their evils must be condoned.

In my own practice I have met with four fatal cases resulting from the use of tents. In one they were employed to remove a foctal shell which had been retained for two months and was destroying the patient's life by septicamia; in the others the cervix was being dilated for the removal of fibrous polypi, the hemorrhage from which had greatly exlausted the patients. One of these women lied from tetanus, one from peritonitis, one from an orerwhelming and sudden attack of septicæmia, and one from sloughing of a fibroid and chronic septicamia.

Some time ago I was called in consultation to the bedside of a lady who was dying of general peritonitis, which had arisen one week after the removal of a sponge-tent employed for dysmenorrhoa by her physician, who was a most careful and competent practitioner. Dr. Braxton Hicks says, "I have seen a case end fatally where there had been dilatation a week previous; mental shock suddenly lighting up the inflammation and extending it to the peritoneum." Besides these cases I have seen, as every other gynecologist has who has employed this means to any extent, a number in which the following affections have been excited by tents: pelvic peritonitis, peri-uterine cellulitis, septicemia, endometritis, and hematocele.

This is the record of my own practice, and my observation of that of many of my friends whose results I have had an opportunity of seeing exactly agrees with it. Let it be remembered that many of the operations of gynecology are performed after dilatation of the cervix by tents. A fatal result ensuing is commonly attributed to the operation. With my experience I camot doubt that the preparatory dilatation is accountable for it in many cases.

In view of the great suddenness with which the dangerous symptoms which follow the use of tents develop themselves, I confess myself greatly at a loss to account for the method by which they establish the morbid train. My impression is that the tent establishes a lymphangitis or angeiolencitis in the abundaut network of uterine lymphaties, and that 
from this sonrce, as in cases of dissecting wounds, a rapid advance of inflammation takes place to neighboring parts. In this way the peritoneum and pelvic areolar tissue are reached; in this way septicæmia develops itself. How else could these parts become affected in the course of twelve or twenty-four hours? Even if a septic endometritis were established which reached the peritoneum through the Fallopian tubes, peritonitis would be the invariable result, which is not the ease, and the development of this would probably be less rapid.

This subject is one of so great importance that $I$ deem it best before leaving it to enumerate certain rules which should always govern the practitioner who resorts to this valuable, but at the same time unquestionably hazardous, method of diagnosis and treatment.

1st. In the introduction of a tent no force whatever should be employed. Should that first essayed not pass the os internum easily, it should be at once withdrawn, and either bent so as to follow more accurately the course of the cervical canal as ascertained by the probe, or exchanged for a smaller tent.

24. A tent should nerer, under any circumstances, be introduced at the physician's office and the patient allowed to go home with it in utero. Such practice is hazardous in the extreme. Even when introduced at the patient's home she should at once be confined to the recumbent posture and kept perfectly quiet. The tent should be eovered with carbolized vaseline.

3d. The practitioner slould always investigate as to the previous existence of chronic pelvie peritonitis or cellulitis, two of the most common of the diseases of women. Should they have existed, tents should be carefully avoided. In most of the instances in which I have seen dangerous results follow their use, one of these conditions had previously existed and been excited into activity by them.

4 th. A tent should never be allowed to remain in the uterus more than twenty-four hours, and if it be eompatible with the accomplishment of the desired result, it should be removed in twelve hours.

5th. Just hefore and just after removal of a tent, the vagina should be washed out with an antiseptic fluid, and if any pain, cliilliness, or discomfort follow the removal, opium should be freely administered and perfect quietude enjoined.

6th. After removal of a tent, the patient should be kept in hed for at least twenty-four hours, and ncrer allowed to travel before the expiration of four or five days.

I am fully aware that these precantions will be incredulously received by those practitioners who have habitually, and with impunity, inserted tents at their offices, and sent the patients home with directions to remove them, hy means of the cord, on the next day. But it is the duty of every conscientions man to give weight to the experience of others. If it were 
essential for every praetitioner to lose one patient from this or any kindred eanse before regarding it as really dangerons, the number of fatal atses would necessarily grow very large.

The Exploming Nefole-Dy means of a long, delicate needle, or very narrow tube, constituting a canula for a trocal the size of a small knitting-needle, the contents and characters of tumors in the pelvis may be ascertained. These instruments are not employed in treating cysts, but are required only to remove sufficient fuid to anmomee the character of the contents of the tumor. Sometimes a tumor, supposed to be solid and irremediable, is thus proved to be amenable to treatment.

'Tine Asrirator.-To whom belongs the eredit of originating this method of evacuating the fluid contents of tumors or cavities 1 am unable to say. M. Courty alludes to it as a method of emptying orarian cysts in use ten years before the appearance of his work, and mentions the instruments employed for that purpose by Buys, Monro, Guérin, and Boinet. To M. Dienlafoy, of Paris, certainly belongs the eredit of systematizing and popularizing it to such an extent that it must be looked upon as a great resource, not only for diagnosis, but treatment of many of the morbid states with which the gynecologist is ealled to deal.

This method consists in the introduction of very slender, long needles perforated by a capillary tube, into tumors in regard to the characters of

FIG. 28.

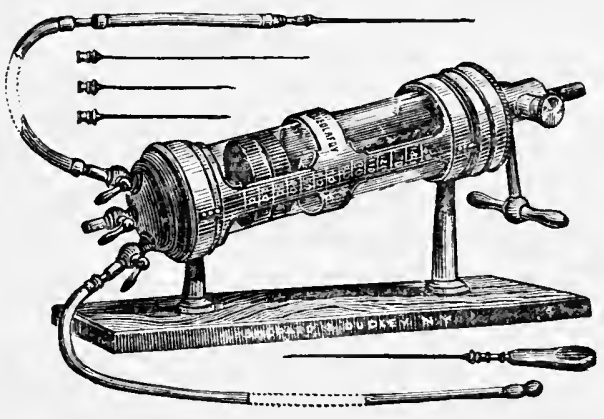

Dieulafoy's aspirator.

which it is desired to decide; connecting these by gutta-percha tubes with a glass cylinder in which a powerful piston plays very aceurately; and ereating a vacuum in this by drawing the piston mpwards. Powerful suetion is thus exerted upon the material in the eavity penetrated by the needle, and, if it consist of fluid not too tenacious to flow through so small a needle, it passes through the tube and enters the cylinder. Fig. 28 exlibits the most recent modification of Dieulafoy's aspirator. Such instru- 
ments, very perfectly construeted, ean now be obtained of the instrument makers of this eity.

One great advantage possessed by this instrument consists in the fact that the needles are so delicate that the intestines, the bladder, solid tumors, or even important secernent organs may be penetrated without great danger. The sac imprisoned in intestinal hernia, the large intestine distended by gases, the bladder threatened with rupture by impassable stricture, have all been tapped by it with impunity.

Before passing the needle into the tissue of a tumor or other growth it should always be inmersed in lot carbolized water and thoroughly cleansed.

Should the operator not have this instrument at his disposal, the same principle may be applied to diagnosis by the use of the ordinatry hypodermie syringe, as suggested by Dr. II. F. Walker, and suflicient fluid obtained for chemical and microscopical examination.

This method of exploration nay be applied to all pelvic and abdominal tumors, witl the best results.

In the use of the aspirator too mucl eare cannot be observed as to eleansing the needles before introducing them. 'The fluid of ovarian eysts is often withdrawn by them, then the needle used is carelessly washed, put aside, and again used at the intinite risk of contamination of another patient. Not only should the needles be scrupulously cleansed after, but before being used; and immediately before introduction they should be dipped in a carbolized solution.

Tun Microscople-The nicroscope will often prove useful as an aid in diagnosis in determining the malignant nature of certain morbid growths, the character of produets of inflammation, the comnection of intra-uterine growths with eonception, the purulent nature of uterine leucorrhea, and the deleterious effeets of uterine discharges upon the zoosperm in the production of sterility. In several cases of obstinate metrorrhagia dependent upon an unaseertained cause, I lave been able, through eervieal dilatation and the use of the curette, to obtain material suffieient for a positive diagnosis of sarcoma or eaneer of the body, by this instrument. One case has come to my knowledge in which many of the symptoms of eaneer of the boly existed, but in which the error in liagnosis thus created was eorreted hy a removal of a portion of the supposed morbil growth and examination by the microseope. By this instrument the substance was pronounced to be not cancer but sponge, and further investigation proved that one-half of a sponge-tent had remained in the borly of the uterus for several months. A similar case has been reported to me, in which a piece of eotton was longr retained, giving rise to very anomaloms symptoms. A portion beingr removed, the microseope revealed its true nature. 
Of late, Foulis and Thornton have pointed out the important fact that examination of the abdominal effusion acconpanying cancer of the ovaries reveals the cancer-cell, and leads to a correct diagnosis; and I)rystale has proved the great value of the mieroscope in examination of ovarian fluids and the determination of the diagnosis by them.

Ausclitation and Percussion.-The important assistance of auscultation and pereussion in mapping out the size of tumors, determining pregnaney, diflerentiating this from ovarian cysts, etc., is so evident as merely to require a passing mention.

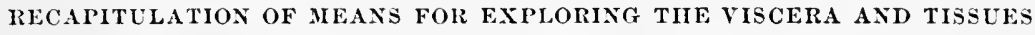 OF THE PELVIS.}

1st. Iugina and Cervix-

Vaginal touch;

Siglit, through the speculum ;

Conjoined manipulation.

2u. Outer Surfuce of the Literus-

Vaginal and rectal touch, while the organ is brought within reach by hypogastric pressure or the tenaculum;

Conjoined manipulation; .

Tesico-rectal exploration;

Simon's method.

3ı. Carity of Cervix and Body-

Tents, followed by introduction of finger.

The uterine probe and sound.

Removal of substance by curette and use of microscope.

4th. The Ovaries, Broad Ligaments, Pelvic Peritoneum, and Pelvic Areolur Tissue-

Vaginal touch;

Rectal touch ;

Simon's method;

Conjoined manipulation ;

Abdominal palpation ;

Auscultation and percussion;

The exploring needle;

Ilie aspirator.

It is so difficult for a teacher to give instruction to a class upon the subject of diagnosis of the diseases of women that I am inducel by that consideration to give a representation of a manikin tigure which has given me great satisfaction in this connection.

This figure is made of thick board, painted to resemble the human female, the legs being articulatel, and the whole fixed to a table like that represented in Figs. 6 and 7 . Upon the part representing the trunk all 
the abdominal, thoracic, and pelvie organs are painted except the uterus. In place of this a peg or pivot is fixed, and upon this uteri, of all shapes and sizes, flexed, with tumors, enlarged, inverted, etc., may be fixed to

Fig. 29.

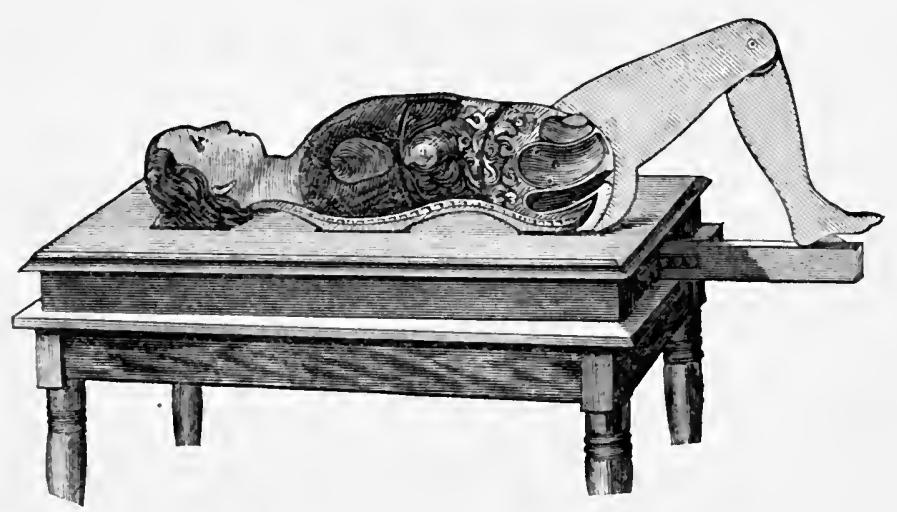

Manikin figure for teaching diagnosis.

illustrate cases presenting themselves clinically. After examination on the back, the figure is placed in Sims's position, the table elevated at one side, and the speculum and sound are employed. The sense of sight is made to supplement that of hearing, and instruction is made clearer by this means.

\section{CHA P T ER VI.}

\section{CONGENTAL AND INFANTILE MALORMATIONS OF THE FEMALE SEAUAL ORGANS.}

M.xy cases of disase are due to congenital malformation of the ovaries, or uterus, or to deformities arising from arrest of or disproportionate development during girlhoot. $L_{p}$ to the period of puberty the uterus, ovaries, and vagina are unimportant organs in the female economy. At that time they rapilly develop and immediately assume most important relations. During their period of insignificatice, even if the most striking malformation exist, it produces no evil result, and, unless some aceidental cireumstance reveal it, is not recognized or even suspected. Puberty arrives, the girl beeomes a woman, and all is changed. Upon the efficient performance of the functions of ovulation and menstruation are, for the mext thirty-five or forty years, to depend in great degree the health, the usetnluess, and the happiness of the woman. 
Preparatory to the performance of these functions the pelvic viscera have been steadily though very slowly developing, and now with great suddemess an important duty is thrown upon them. If during uterine life their development has been defective, or if during the period intervening between birth and puberty they have either not suflieiently grown or hase grown in sueh a manner as to be misshapen, then are they incompetent to the performance of the duties required of them, and certain diseased conditions are the result.

I shall consider only the most inportant of these, and it must be borne in mind by the student that their importance must not be estimated by the posibility of their relief. The recognition of the fact that a pathological state is irremediable and that treatment for it is unalvisable is always a matter of as great moment as the aseertaining that a more fortunate state of attairs exists. In all departments of medicine, but especially in gynecology, treatment which accomplishes no good necessarily tends to the protuction of evil.

Development of Generative Organs.-In the lumbar regions of the futus, before the end of the second month, the anatomist Wolff discovered two bodies, each consisting of a large number of tubes elosed at one extremity and by the other opening into a common excretory canal. These have since been known as the Wolffian bodies, and from them essentially spring the male internal organs of generation, but not so the female. At the inner border of each Wolffian body lies a germ which, remaining unehanged until the second month, develops into the ovary of one side, while the Wolflian borly gradually becomes atrophied.

From the inner sides of these deseend two ducts, called the duets of Miiller, which passing dowuwarls side by side unite at a point just below one where the urethra of the foctus begins to show its rudimentary formation. At about the end of the second month, these ducts begin to approach each other more nearly at a point in the pelvis, and, gradually coaleseing and their inner walls disappearing, the ragina and cervix, and, at at later period, the corpus uteri are created. The upper portions of the ducts passing off to each side obliquely eonstitute in the future the Fallopian tubes. Fig. 30 will show the coaleseence of the Miillerian ducts in the foxtal sheep).

FIG. 30.

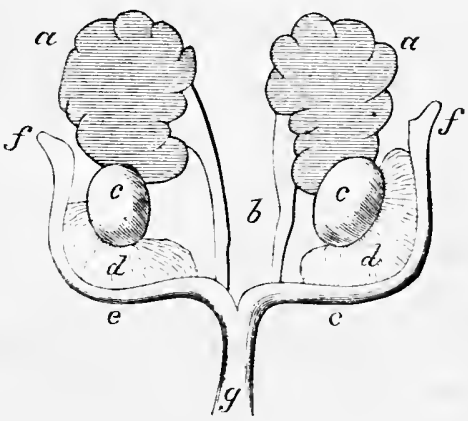

(ivaluscence of Müllerian ducts in a fotal sherl. (I, Müller.)

A rudimentary vagina, Fallopian tubes, and uterus are thus formed, and gradually go on to full development during the rest of fuetal life. Any 
arrest of development affecting the ducts of Müller, any imperfection of them, or any failure in coalescence of the two ducts, even when fully developed, inevitably gives rise to malformation or deformity. Some of these produce grave consequences at puberty; others are so wanting in result that the functions of the woman are healthily performed in spite of them. Their very existence even may never be revealed, or be discovered only by accident towards the end of or after menstrual life.

The rarieties of congenital malformation of these parts which I shall consider are the following:-

Hypertrophy of the uterus.

Absence or rudimentary state of uterus, ovaries, or vagina.

Enicorn and bicorn uterus.

Double and divided uterus and vagina.

Congenital misplacement of the uterus.

Hypertrophy may affect the foetal uterus and ovaries, and as a result the child be born with this organ and the external genitalia as fully dereloped as they should normally be at puberty. In these monsters by excess of

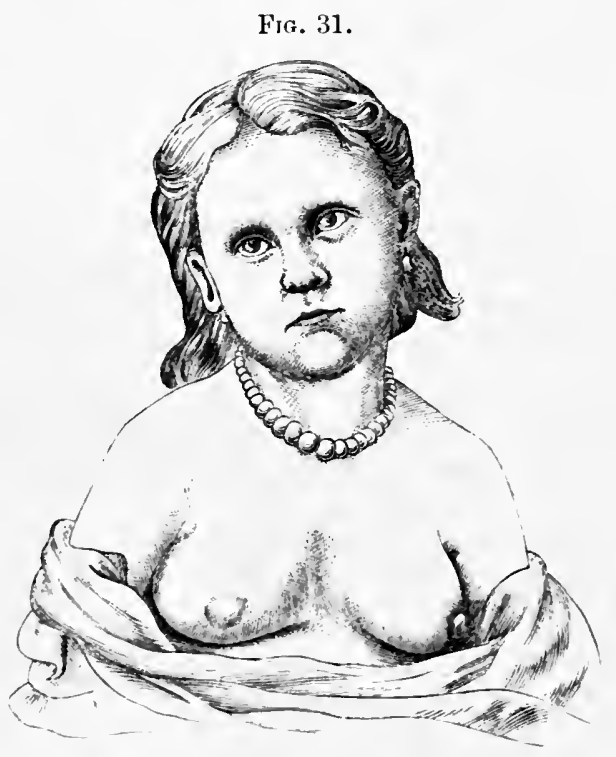

A. S., aged 4 years and 9 months. Senstruated resularly from the aro of 21 months.

development, the most remarkable sexual precocity sometimes shows itself. Intances are recorded in which menstruation began at birth or within a month after, anf one case of undoubted anthenticity is reported in which, menstruation beginning at two years, parturition at full term oecurred when the mother was only eight. Fig. 31 represents a girl whose case was brought to my notice some years ago. 
I have seen another "asc in which menstruation began at cight months and continued regularly.

Absence, and Rudimentury Development, of Uterus and Ovaries. - At times an entire failure, not only of coalescence but of development, ocenrs in Miiller's ducts. The Fallopian tubes, uterus, and ragrina are all absent, and very often in such eases the ovaries likewise. In other cases the uterus is absent, while the vagina, Fallopian tubes, anel ovaries are developerl, coalescence of the ducts having failed while development above and below las occurred.

Entire absence of the uterus, tubes, and ovaries, as proved by postmortem examination, not by physical exploration during life, is of so rare oecurrence that some pathologists have doubted its existence. When it occurs it usually does so in infints who suffer from want of development of the lower latf of the boly. It must be borne in mind that sometimes rulimentary uterine horns exist which, in a physical examination, cannot, even by the most practised touch, be distinguished from portions of the oviduets and ovaries. In some cases of undoubted rudimentary uterus only a slight nodular harl- * ness can be discovered where FIG. 32. the uterus should be, which feels like an argregation of areolar tissue only. 'There can be little doubt that these cases are clinically often elassed with those of absence of the uterus.

The rudimentary uterus is often accompanied by a similar condition of the ovaries, vagina, and even the mamme and external genitalia. In such cases the vagina will often be found as a cul-de-sac neasuring only one

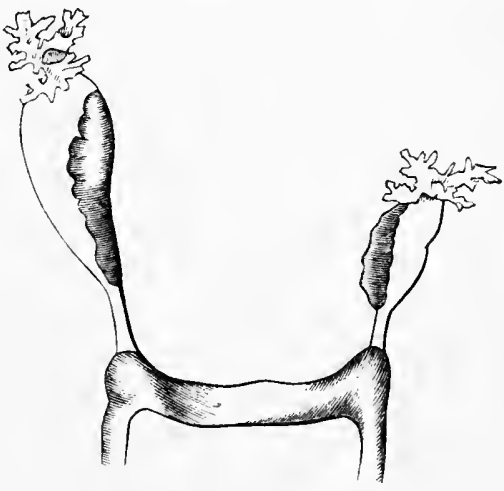

bow-shaped rudiment of uterus. (Yega.) or two inches. 'This, however, under sexual efforts long and perseveringly continued, often undergoes great elongation and development. When this fails the urethra sometimes undergoes dilatation, and, being penetrated by the virile organ, acts as a viearious vagina.

The rudimentary uterus usually alpears under one of these forms: a thin membranous expansion spreats from the extremities of the Fallopian tubes and round ligaments towards the vagina; a round, harl, two-horned solid body marks the site of the uterus; a flattened, erescentic line of tissue occupies the site of the uterus, extending across the pelvis with its convex surface looking upwards; the cervix being entirely wanting, the semblance of a body is present without a eavity ; the body with cornua exists, but without perforating camal ; or, lastly, the cornua exist with cavities 
within them, while the body and cervix uteri are both very rudimentary in their development.

Since the days of modern gynecology, this anomaly has been found to be of not very rare occurrence; previous to that period many cases went undetected because uninvestigated. The attention of the physician is usually drawn to their existence by the fact that the girl arriving at sixteen or seventeen years has never menstruated, and her relatives have become apprehensive; or marriage is anticipated, and the girl or her mother, unwilling to assume its responsibilities while mystery exists with reference to so important a subject, desires investigation; or the girl, suffering from uterine enlargement, the result of retention of menstrual blood, is aceused of illegitimate pregnancy and is brought for the physician's decision of the matter; or, worse than all, marriage has been contracted, the husband not having been candidly dealt with, sexual intercourse has been found to be impossible, and he brings his wife for examination.

In such eases the physieian's duty, if he be cognizant of the facts before marriage, is too clear to require mention. So grave does the law regard a fraud of this kind that it is considered a sufficient ground for divorce. The physician may likewise be consulted, as I myself have twice been, as to the propriety of inarriage, the man knowing perfeetly the imperfections of his proposed wife, and appreciating that not only are menstruation and conception impossible but sexual intereourse likewise. As long as the laws of physiology hold true, so long will it be the duty of the medieal adviser to oppose under such cireunstances the contraction of a tie which must, unless the husband be more or less than mian, prove, in a short time, al source of sorrow and disappointment.

The evils which result from this distressing anomaly of sexual development are not merely the remote and contingent ones just mentioned; there are others which are almost inherent to it. These are absent in the must deeided eases of want of derelopment, and present in those which are less complete. Thus if uterus, ovaries, and vagina be really absent or decidedly rudimentary, the woman may patsi a long life if she does not contract marriage, not only without suffering, but without knowledge of her imperfection. If, however, a eomplete atresia exists in the lower portion of the uterus only or upper portion of the vagina, while the ovaries are suficiently developed for ovulation to occur, menstrual blool eollects, distemls the uterine cavity, sometimes regurgitates through the tubes, or ruptures them, or furnishes material for septic absorption.

Such cases sometimes termmate fiatally from these causes, and not ramely from the results of surgieal procedures aldopted for their relief. They will be elsewhere considered in reference to this aspect of the sulject.

Where the utrous is almost or entirely absent and the ovaries present, the most aggravated derangements of the nervous system, hysteria, epilepsy, 
and mental disorders sometimes show themselves. In such a case seen in consultation by Drs. Peaslee, Emmet, and myself, extirpation of the ovaries was decided upon and performed by Dr. Peaslee. Unfortunately the result was a fatal one. In a similar anomaly mentioned by 1):play, a post-montem examination gave mecuivocal evidences of ovulation. Repeated small hematoceles must, of course, have been the consequener, as neither oviducts nor uterus existed.

The question of treatment in such eases turns entirely upon the propriety of the surgical resource of opening a free passage through the atresie cervix uteri or vagina, for the eseape of menstrual blood alrealy imprisonerl, or for that which may be in the future exeited to flow by therapeutic means adopted for that purpose. Before adopting and, as is equally important, before discarding these, a thorough exploration should al ways be made, and the manifold dangers of the operation, together with its decided chances of fitilure, should be carefully considered. A great deal of unwarrantable surgery has been indulged in in such cases from neglect of these two duties.

Physical Examination of such Cases.-The patient should be anasthetized, and placed upon the back upon a table, and the legs flexed by two assistants. Then, the splineter ani being gently stretched, the index and middle fingers of the left hand should be carried far up the rectum, and conjoined manipulation carefully practised for detection of the uterine borly. To this may be alded the approximation of the posterior wall of the blatlder to the fingers in the rectum by a sound in the bladder, or, if necessary, by resort to introluction of the index finger of the right hand through the urethra in eases diflicult of decision. There are no other means of physical exploration at our command, but these, intelligently practised, are very reliable if preceded by anesthesia, as they should always be.

But he who in these eases relies for his decision upon physical signs alone will surely be misled; rational ones are of equal importance as a guicle to surgical interference. A large hard fibrous mass may be found in the position of the uterus, and yet the grave operation for atresia vagine might not be advisable. If menstrual blood is discovered imprisoned; it a distinct period of exeitement or maliase marking ovulation can be traced; or if the otherwise perfect development, goot health, and slight obstructive deformity which exist, all point to the probability that the hard mass in the site of the uterus is that organ with fair degree of develoument, the patient should be encouraged to submit to operation. If, on the other land, there be no trace of accumulated menstrual blood ; no evidences of an ovular nisus; and none by plysical means of distinct presence of a mass in the uterine site, he who resorts to operation is exposing his patient to an unwarrantable risk. 
Unicorn, Bicorn, Double, and Divided Lterus._Sometimes the Müllerian ducts develop into the two halves of the uterus, but, coalescing

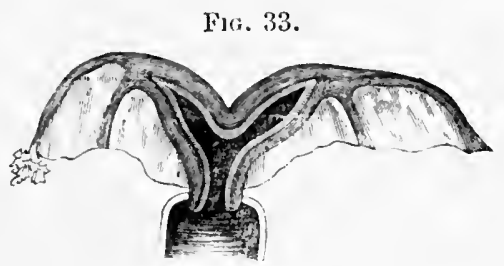

Bicorn uterus. (Schroeder.) badly, or the walls dividing tube from tube not being obliterated by absorption, deformities of less gravity than those just mentioned may result. One horu alone may develop while the other fails to do so ; both horns may develop but unite only at the cervix; or both horns may develop, and although they coalesce perfectly their internal walls may not disappear, and thus a septum remain which divides the cavity into two.

Fig. 34.

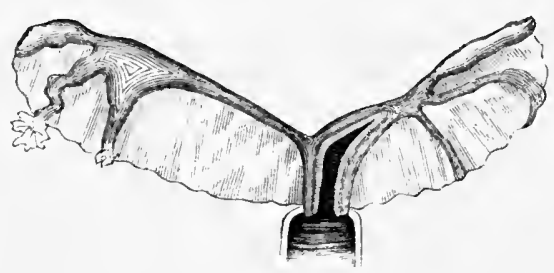

lonicorn ulerns. (Fohroeder.)

The aecompanying figures will give a very good idea of these deformities by arest of development.

Firi. 35.

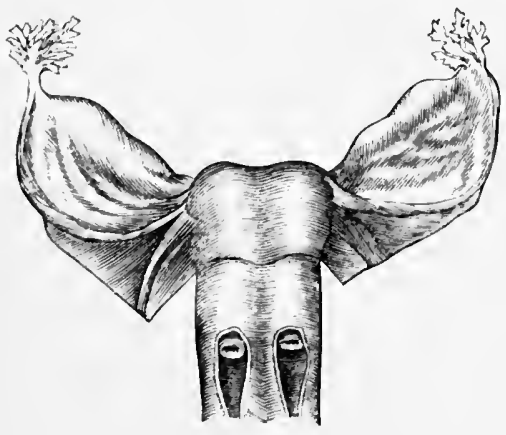

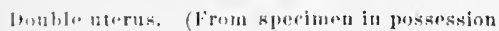
ot inthor.)
FIg. 36.

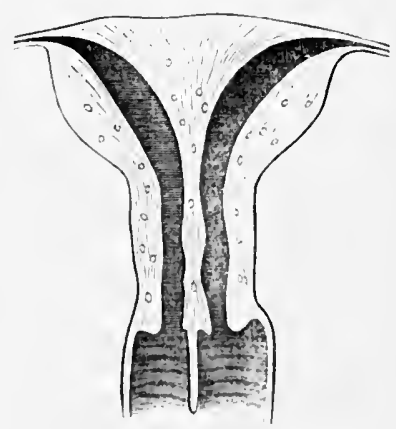

Wivided utrus. (Kussmanl.)

Somm of thene deformities create great diffieulties in diagnosis and curi(11: problems in pluysiology : such, for example of the former, as cases in which mrnitrual blool becomes imprisoned in one dilated uterus while 
the other remains cmpty ; and of the latter, instances in which a child is born at full term from one uterine eavity, and in two or three months another from the other, or in which a white and mulatto child, the oflspringr of ditlerent fathers, are produced at the same parturient act.

Ordinarily these malformations produce no evil, and it is probable that only a very small proportion of them come to the knowledge of the patient or physician. They repuire no treatment.

Congenital Misplacement of the Uterus.-Bometimes the uterus is placed, hy reason of its peculiarity of development, obliquely across the pelvis, inchining to one or other side; or, one lalf developing more decidedly and rapidly than the other, a congenital latero-flexion exists; or, the fundus being flattened, what is called the anvil-shaped uterus results. The chief importance of the recognition of these states is connected with prognosis and the futility of treatment for their removal.

Absence and Rudimentary State of the Ovaries.-The ovaries, as well as the uterus, may be either not developed at all or very imperfectly so. These organs arise about the end of the sccond month of foctal life from a germ at the side of the Wolflian bodies. As they develop, the outer covering dips in, as shown in Fig. 37, to make the Graafian follicles, which contain the ova, the discharge of which at stated periods constitutes the great function of these glands

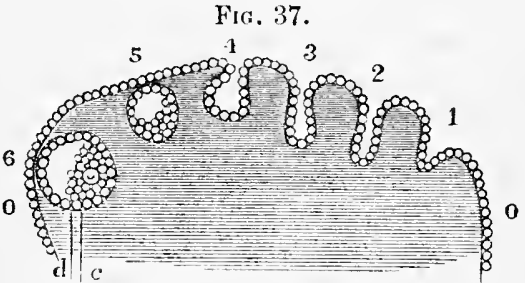

Development of Giadian vesicles. (Küss.

Physiology.) and the characteristic feature of the female sex. Sometimes these organs contain few if any follicles, and are incompetent to their duty in the economy. The results of this arrest of perfect development are amenorrhwa and sterility, which usually prove entirely rebellious to treatment.

The activity with which this reduplication, and formation of follicles goes on, may be judged of by Sappey's' statement that Kölliker counted in a fortal ovary more than six thousand.

Absence and Rudimentary State of Vagina.-Like the uterus the vagina is created by union of the Müllerian ducts, and like it also is subject to a variety of malformations, due to an arrest of development or failure of complete union. The chief of the anomalies thus ereated are diminutive, rudimentary, unilateral, and atresic vagina. Some of these are productive of no evil consequences and require no treatment; others will be considered under the heads of Atresia Vagina and Retention of Menstrual Blood.

Anomalies of Uterine Derelopment during Childhood.-Whe uterus is 
an organ which varies greatly at different pcriods of life in size and shape. In the foctus, the girl at puberty, the nulliparous woman, the multiparous, and the old woman who has lived beyond the menopause, it is a different organ in these respects. In the first the neck is disproportionately large, in the second the body and neek gralually become equal in size, in the third the size of the body preponderates, in the fourth the carity of the body enlarges and the os externum changes its shape, and in the fifth a general physiological atrophy occurs, which diminishes the size of the whole uterus, though affecting the body somewhat more than the neck.

It is the changes, and the anomalies which mark them, occurring between birth and the establishment of puberty, which are now to receive attention. During this time the uterus very slightly develops until puberty is reached, when the rapid development of that period shows itself especially in this organ. During childhood the uterine body is bent forwards, an anteflexion existing. This gradually passes off, leaving only a slight antecurvature, to last through life, as the changes of puberty eause the uterine walls to become dense and resistant. At puberty, as Boivin and Dugés pointed out, and as Cusco' more particularly insisted upon, one wall sometimes devclops rapidly, while the other correspondingly undergoes atrophy. Anteflexion, or more rarely retroflexion, is the result, and the first menstrual eflort is attended by pain and obstruction. Any influence which presses the abdominal viscera down upon the uterus while yet this organ is soft and yielding tends to develop this anomaly, which has received the name of congenital flexion.

Again, the foetal uterus with its disproportionately long neck may disappear, and still the organ, now well proportioned, may not undergo development at puberty, but may remain small and unprepared for its coming functions. 'This constitutes the incompletely developed uterus of Kiwisch, Rokitansky, and Seanzoni, the pubesecnt utcrus of Puesch, and the congenital atrophy of other writers.

This condition is marked by tardy occurrence of menstruation, and by a feeble, irregular, and seanty discharge; a marked tendency to complete amenorrhora existing.

Fortunately a good deal of benefit, under these circumstances, often results from treatment caleulated to attract nervous influence and nutrition to the deficient organ. The most reliable of these are the eautious and systematic use of small tents, the employment of an intra-uterine galvanic stem, a current of electricity passed through uterus and ovaries, and the complete establishment of the general health by exereise and tonic treatneent.

In some of these cases the most unfortunate results show themselres in connection will the nervous system. In two cases I have seen epilepsy, 
and in one mental imbeeility, which seemed to be clearly traceable to the abscince of sexual development.

Even when no general symptoms show themselves, the undeveloped condition which characterizes these eases to a certain extent incapacitates the female for the duties of' wife and mother.

\section{II A P T E R VII.}

\section{DISEASES OF TIIE VULVA.}

Normar Anatomy.-The vulva is the elliptical opening which exists at the distal extremity of the vagina, and comprises the mons veneris, lahia majora and minora, clitoris, meatus urinarius, vestibule, fossa navicularis, fourehette, and hymen.

Labia Majora.-From the mons veneris, which consists of adipose tissue corered by skin in which exist numerous hair-bulbs, two folds of integument pass downwards to unite at the fourchette. These are ealled the labia majora. Externally they are covered by skin, which contains seattered hair-bulbs, but on their inner surfaces their eovering is mucous membrane, whieh is studded with sebaceous follicles, the secretion of which is unctuons and semi-solid. These glands are remarkably large, reaching, according to E. Klein, ${ }^{1}$ a diameter of 0.5 millimetre. They open immediately upon the free surface.

Within, the labia are filled with adipose tissue, a portion of which is inclosed in saes, of which one arises from each external abdominal ring and extends downwards towards the fourchette. To these Broca hats given the name of dartoid saes.

The Clitoris.-Beneath the superior commissure of the labia juts forward a little erectile organ, which is analogous to the penis of the male, and receives the name of clitoris. It is covered by mucous membrane, consists of erectile tissue, and arises by two rami, one of which is attached to each ramus of the pubes. Like the male penis, this little organ is proviled with a prepuce and frenum.

Labia Minora.- These consist of two folds which, arising at the elitoris, pass downwards and disappear abont laalf way between the two eonmissures. Like the clitoris they are formerl of ereetile tissue eovered orer by mucous membrane, and an attentive examination discovers upon their surfaces a large number of glands, whieh seerete a sebaceous material.

The Fossu Navicularis and Vestibule are merely spaces intervening;

1 Stricker's Manual of Histology. 
the first, between the perineum and vagina; the second, between the meatus and clitoris. They are both covered by mucous membrane, and the latter is studded with follicles.

The Hymen is a thin veil consisting of a double fold of mucous membrane, which in part closes the ostium vagina. When ruptured its remains can be distinctly discovered, sometimes not at all diminished in bulk, upon the walls of the vagina.

Passing over the clitoris, to which it is attached, and running downwards on each side of the vulva so as in part to cover the bulbi restibuli, will be found a musele, which is, I think, very generally regarded as the sphincter vagina. Savage denies that it, the bulbo-cavernous nusele, has any such influence, the true sphincter vagina being the pubo-coceygeus muscle, which is seen by dissection within the pelvis, arising from the inner surface of the pubic bones. Descending on the sides of the vagina some of its fibres pass between it and the rectum to meet others from the opposite side in the perineum. Another set go behind the rectum, and uniting with similar ones from the opposite side, intermix with its circular fibres to make the internal sphineter. The remaining fibres, still more outward, are inserted in the sides of the coccyx.

\section{Vulvitis.}

7) finition.-Vulvitis is the name applied to inflammation of the mueous membrane lining the vulva. Affecting all of this structure, the surface covered by epithelium and the glands imbedded in it, the inflammatory action sometimes extends through the submucous tissue into the proper structure of the parts underlying it, ereating tumefaction, pain, and sometimes even suppuration.

Tarieties.-Authorities differ with regard to the elassification of its varieties.

That which appears most appropriate is the following:-

$$
\begin{aligned}
& \text { Purulent vulvitis; } \\
& \text { Follicular vulvitis. }
\end{aligned}
$$

There is a variety of the affection also which is styled gangrenons, but it is so entirely confined to children that its consideration here would be out of place.

\section{Purmlent Vulvitis.}

This variety of the affection may be either of non-specific form, or a true gonorrhora of the vilva. The former is in many respects analogons to bilanitis in the male, while the latter resembles very elosely speeific inflammation in other mucous membranes of the body. 
Causes. - It may result from

Vaginitis, specifie or simple;

Want of cleanliness;

Injury, or friction from excreise;

Eruptive disorders;

Onanism;

Chenical irritants;

Excessive venery.

Symmtoms. - The parts are red, swollen, hot, and at first dry. Then a free flow of pus takes place which bathes the whole surface and stains the linen of a yellow hue. In addition to these signs of active inflammation, superfieial uleers will be found seattered over the parts affected, and in rare eases patches of diphtheritic membrane will be seen adhering to them. At times the neatus urinarius becomes affected, and painful micturition, with scalding and heat, is eomplained of. At others the most intense pruritus affects the vulva, and the patient, in endeavoring to obtain relief, may contract the habit of masturbation. Should the inflammation extend to the vagina, the symptoms of vaginitis will also show themselves, and by a similar extension to the bladder those of cystitis may develop. In severe cases febrile action, with thirst, heat of skin, and general discomfort, is present, but this is not usually the case.

The pus which is discharged, always in the specific form of the disease, and very generally in the non-speeific, gives forth a disagreeable odor, and is usually so irritating in its nature as to excoriate the inner surfaces of the thighs when it comes in contact with them. Should this material, even in the non-specific form of the affection, be carelessly brought in contact with the conjunctive, a severe form of purulent ophthalmia is excited. The late Professor Bedford gave me the account of a case in which coition under such circumstances gare rise to a urethritis in the male, which was made the basis of a suit for divorce. He was applied to as a medical expert, and found upon examination that non-specific purulent vulvitis, uneomplicated by vaginitis or urethritis, existed.

Course and Termination.-Even without treatment it is probable that the affection would always be recovered from in time; but it would run a lengthy and tedious course, and perhaps give rise to complications which wonld be productive of greater evil than the original disorder. When properly treated, it generally runs a rapid course and is readily cured.

Treatment.-If inflammatory action be excessive, the patient should be kept in bed, upon low diet, and the bowels freely acted upon by saline catharties. Emollient applications should be made constantly to the in. flamed part, and cleanliness serupulously observed. The patient should be directed to bathe the vulva freely with warm water three or four times daily, and to apply a warm poulnice of powdered linseed, slippery elm, or 
grated potato. To the poultices may be added with advantage a solution of acetate of lead and tincture or powder of opium.

As soon as the acute action has subsided, the lead and opium wash should be kept in contact with the parts, by dossils of lint soaked in it and placed between the labia. It is thus compounded:-

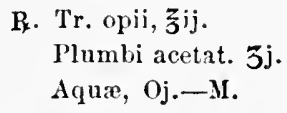

At a still later period the diseased surface should be painted over several times a day with a solution of persulphate of iron and glycerine, one part of the former to eight of the latter. Should the disorder not be entirely eradicated by this treatment, the vulva may be painted over onee in every forty-eight hours with a solution of nitrate of silver, ten grains to the ounce of water, and kept constantly powdered with lycopodium, bismuth, or stareh, until recovery is complete. Should pruritus attend the latter stages of the disorder, a wash composed of one scruple of carbolic acid to one pint of water will be found useful.

\section{Follicular Vulvitis.}

Definition and Synonyms.-It has been already stated that in the mucons membrane lining the vulva, nore especially in that covering the labia majora, labia minora, and vestibule, numerous follieles exist. Presenting themselves as solitary glands, they are classified under the three following heads-muciparous, sebaceous, and piliferous. In ordinary purulent vulvitis, these, as component parts of the diseased membrane, are implieated in the morbil action. Sometimes, however, they alone are aflected by disease, when the name of follicular vulvitis or vulvar follieu. litis has been applied to the condition. Any or all of the varieties of glands just mentioned may be diseased, and authors have given special names to the varieties, so that a list whieh would eomprise them all would le a long one. As examples may be mentioned papillary, pruriginons, erythematous, sebaceous, granular vulvitis, ete.

We may avoid tediousness of detail, and at the same time rum no risk of being lel into crror, by classing all forms of inflammation affecting the solitary grlands of the vulva under the head of follicular rulvitis; provided that we bear in mind that all the varieties of glands may be simultaneonsly affected, or that one set alone may be diseased, the others remaining healthy.

Crunses._This form of vulvitis may be indueed by the following influences:-

Pregnancy ;

Nieglect of cleanliness ;

Vaginitis;

Exanthemata;

Eruptions on the volva. 
Symptoms._-There are burning, itehing, and heat in the vulva, with increase of glatudular secretion. At times the secretion is exessively oflensire and irritating in character.

The urethra frequently becomes inflamed at its vulvar extrenity, and scalding in the passage of urine results. The volva may become so sensitive to tonch, that eflorts at sexual intercourste exteite vaginisuns, which thus constitutes a symptom of the disease.

Physicul Signs.-If the muciparons follicles be chiefly atfected, the nuncous membrane of the vulva will be found intensely red in spots or prateles, which are slightly elevatel. These are most commonly found on the elges of the lower vaginal ruga, the nymphite, and the carunculas. They sometimes resemble the swollen villi upon the tongue, and bleed upon slight irritation.

Should the disease have affected chiefly the sebaceous and pilife-

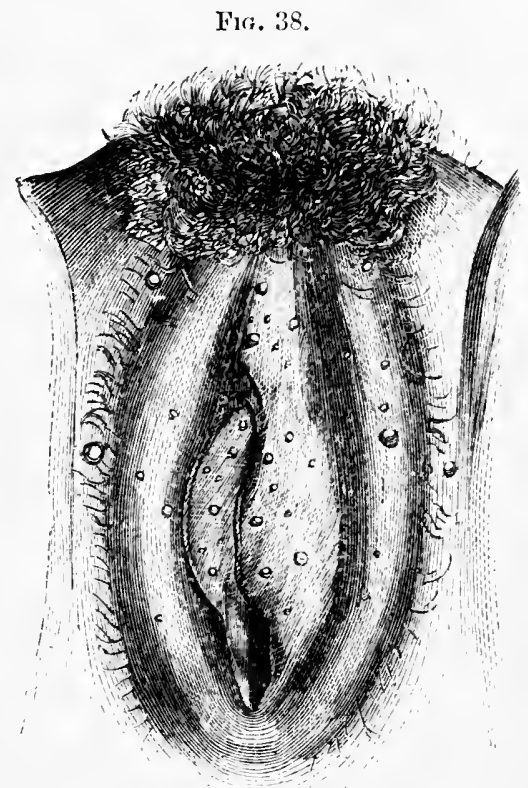

Follicular vulvitis. (Huguier.) rons glands, little, red, rounded papilla will be found on the surfaces of the labia majora and minora, and the base of the prejuce of the clitoris. After a while a trop of pus will appear in the apex of each, which is soon discharged, and the distended follicle shrivels. Beneath the labia ninora a semi-fluid mass of offensive secretion will generally be found, which will, it not carefully removed, conceal the follicles underlying it.

Cunre and Duration.-CIt' this disorder occur during prearnancy, it may disippear at its conclusion. In sone case's it becomes so severe, and produces such annoying symptoms, that abortion is induced by it. It it exist in the non-pregnant state, and be not appropriately treated, it may continue for an unlimited time and establish urethritis, not only in the patient, but in her husband. This fact should be especially recollected, tor a suspicion of want of chastity may be excited in the mind of the husband, and serious domestie difficulty result.

Treatment.-Follicular vulvitis should be treated upon the same principles as the purulent form ; by repeated ablution, warm poultices, sedative washes, and lucal alteratives, especially the persulphate of iron and nitrate of silver. Dr. Oldhan, who wats one of the first to enlighten the profes- 
sion in regard to this affection, placed great confidence in the following prescription :-

R. Acidi hydrocyanici dil. $\mathbf{z}^{\mathrm{ij}}$.

Plunbi diacetatis, $Э \mathrm{j}$.

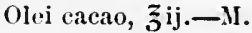

S. Apply after washing the parts with cold water.

The elironic form of this affection, which is fortunately rarely met with, constitutes a really formidable and uncontrollable disease. In the American Journal of Obstetries will be found a remarkable instance of it reported by D)r. B. F. Dawson, which, as typical of that form of the disorder, is worthy of espeeial notice. The patient, aged sixty years, had suffered from follicular vulvitis sinee the age of sixteen, and after consulting numerous practitioners in vain, had, on account of the intolerable itching attending the disease, been indueed to resort to opium for comfort, until in time she had become a confirmed opium-cater. At the time when the history was given, the following was the condition of the vulva: "On parting the labia, which had to be done with the utmost gentleness, as the patient suffered and flinched at every at tempt, the mucous membrane of the labia, as well as the fourebette, was found completely covered over by a thick cheesy substance, of a dirty cream color, which emitted a peenliarly offensive odor." This condition had proved so entirely rebellious to treatment, that removal of the entire mucous covering of the vulva which was the site of the diseased glands hat to be resorted to.

\section{Cyst and Abscess of the Vulvo-Vaginal Glands.}

Anatomy.-.Just anterior to the lyymen, or the carunenlas myrtiformes, will be found on cach side a little opening, sufficiently large to aduit a small probe or bristle. This opening leads through a canal three-fifths of an inch long, which is the excretory duct of a eonglomerate gland which has recrived the name of vulvo-vaginal gland. These glands are found, one on each side of the ostium vagina, between the vagina and the ascending branch of the jschium, from which they are distant three-tenths of an inch, and lie in entact with the transverse artery of the perinenm. The fact that they are sepanated from the vagina by an aponeurotis prolongation, lie between the superficial and middle layers of the ischio-pubic fitscial, and have the myielding ischium on one side, accounts for the compiete confinement of pus forming in them, and its not heing discharged by the rectum or vagina. They were described by Duveney, Barthelinus, Morgagui, and their immediate suecessors, but in time, very singrularly, thry were forgotten. In 1811, MI. Inguier, of Paris, redsecribed them fully, and threw much light upon their diseased conditions.

Sometimes, their montls becoming occiuded by adhesive inflanmation, their secretion is retainesl, and they undergo great cnlargement and dis- 
tention. At other times suppurative inflammation is set up and abseess is the result.

Canses.-The causes of inflammation of these glands are very much the same as those of vulvitis, of which, indeed, this aflection is often a conconitant disorder.

Symptoms.-There are heat about the rulva, pruritus, and fain upon tonch. 'The mouth of the luet is red, and the finger pressed over the site of the gland diseovers a hard, painful, and perlaps fluctuating tumor about the size of a small hen's exg. Very often the first intimation of the existence of the disease is given by pain during the sexual act, or upon manipulation.

Differentiation.-An alsecess of this gland is generally readily distingruished from a cyst by the presence of the ordinary signs of inflammation, or, when cystic distention exists without inflammation, the locality of the round mass rolling slightly under the finger without tenderness will make the diagnosis elear. From phlegmonous inflammation of the labium najus it will be known by its distinct, globular, and limited outline, the former affection being diffinse. Furuncles are entirely too superficial to create confusion in diagnosis.

Course and Duration.-This disease is one of no great moment, and its natural temdency is to recovery. Its usnal duration is fiom two to three wecks, and the inflammatory process may terminate either by resolution or by suppuration. Should the latter oceur, the pus may be discharged through the duets of the gland, or in the furrow between the labia minora and majora. In some cases, however, the gland becomes filled with a honey-like matter, and exists as a cyst for months, and even for years.

Treatment.-When inflammation affects the cyst wall, an emollient poultice or cooling and anodyne lotion should be kept applied to the vulva, and rest slould be prescribed until suppuration has oceurred. Then, if pain be very severe, the accumulated pus nay be evacuated, by means of a lancet, near the month of the gland or at any other point where fluctuation is most distinct. If pain be not severe, the eracuation of the pus maly be left to nature.

When retention of the contents of the gland has created a cyst unattended by suppuration, or when frequent return of suppurative action remders a madical procedure necessary, it has been adrised to extirpate the gland. This is a bloody operation, as the transversus perinei artery is apt to be severed. In all my experience I have never found extirpation necessary, and have practised in its stead the procedure which I shall now describe.

Catching up the mucons membrane over the sac, I cut out with scissors an ellipse. This exposes perfectly the wall of the sac, which is punctured by the tenaculum, so as to allow the escape of a small amount, say one third, of its contents. The sac wall is now lifted by the tenaculum, and an 
elliptical piece is eut out of that also. This prevents elosure and secures drainage. The eavity is now filled with earbolized eotton, which in thirtysix or forty-eight hours is removed.

\section{Eruptive Diseases of the Vulva.}

The skin and mucous nembrane making up the vulva may, like the same structures in other parts of the body, be affeeted by eruptive disorders of various kinds. It is not my intention to enter with any minuteness into the eonsideration of these diseases, for whieh I refer the reader to any of the modern works upon dermatology, but merely to note the fact that they may oceur upon this part, and mention the leading eharacteristics of the most frequent of them.

Any eruptive disorder which may elsewhere affect the skin or mucous nembrane of the body may show itself on the vulva. The following list includes those which are most commonly met with and most frequently eall for diagnosis and treatment:-

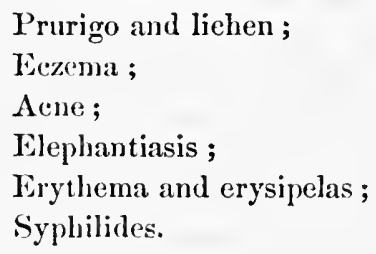

$\Lambda s$ is the ease elsewhere with prurigo, that of the vulva presents large, seat tered papules, very irritating and generally having their apiees bereft of cuticle. Lichen shows more numerous papules, which rest upon a thickened and somewhat indurated cutaneous base. Pruritus vulva is the mo:t prominent symptom of these maladies. So intense is the irritation of the vulva established by them that vulvitis is the consequence, the disease then being styled pruriginous vulvitis.

In eczema the surface is red, heated, and covered by little vesieles, which breaking, give forth a serous fluid. The eruption confines itself elicfly to the cutaneous surface, the mucons lining being less affeeted. It may pass off rapidly as an acute disorder, but sometimes there are successive crops of vesicles which exhaust the strength of the patient, in consequenee of the nervous excitement and irritability whiei the disease induces. In many cases of diabetes and vesico-raginal fistula, this allection constitutes an exeedingly annoying and even painful complication.

Aene consists in engromerment of the sebaceous follicles studding the labial faces; not in ative inflammation, which would bring the case under the head of follicular valvitis, but in engorgement by their own retained secretion.

Elephantiasis of the labia differs in nothing from that of other parts. The aftection is very rare. Kiwisch records one ease in which both labia increased in size, so as to equal the head of a man, and to fall nearly to 
the knees. The parts affected by it are the labia majora and minora, the clitoris, anó the perineum.

Erythena and erysipelas are simply accompanied by graver symptoms when they aflect the genital organs than when they develop on the skin elsewhere.

Syphilis in secondary and tertiary form may affect the labia, ereating hypertrophy, ulceration, and all the evils which it excites in other parts.

'These disorders ereate the ordinary symptoms of vulvitis, and hence they are commonly confounded with it. Pruritus vulva is one of their most constant signs, and the itehing which it produces often first attracts attention to their presence.

Treatment.-Little need be said here of treatment, for it should be guided by the rules which govern the management of the same cutaneous disorilers in other parts of the body. The general health should be carefully attended to; change of air advised; and tonies and alteratives, such as iron and arsenic, preseribed in combination, the first, with colombo, or the second, with the tinetures of cinchona, or gentian. Local treatment should consist in the maintenance of strict cleanliness by bathing the diseased parts freely in tepid water, and the pruritus, which invariably exists and leads to scratching, should be relieved by lotions containing acetate of lead, opium, borax, or a small amount of creasote or carbolic aeid.

\section{Phlegmonous Inflammation of the Labia Majora.}

The areolar and adipose tissues, which in great degree make up the bulk of the labia majora, are very frequently the seat of inflammation and abscess. The disease is excited by irritating vaginal secretions, vulvitis, direct injury, and the peculiar blood state which results in the development of furuncles and carbuncles.

Symptoms.-In the first stage there is active congestion, which in the second produces luardness and teusion from effusion of liquor sanguinis into the areolar tissue. The third stage consists in the breaking down of this mass by the process of suppuration and formation of an abscess. The pus which is thus created is usually very offensive from propinquity to the rectum and vulva.

The diagnosis is generally very easy. Attention is directed to the part by heat, pain, throbbing, difficulty of locomotion, and exquisite sensitiveness upon pressure. Upon physical exploration one labium is found very much swollen and quite hard and tender. Although it is usually easy to distinguish this disease, care must always be taken to differentiate it from labial hernia, displacement of an ovary, pudendal hematocele, oedema labiorum, and vulvitis. As this point will engage our attention elsewhere, it requires no further mention here.

Treatment.-The treatment should consist, in the first stage, in the application of cold and sedative lotions, low diet, saline cathartics, and 
perfect rest. One of the best local applications will be found to be the lead and opium wash. As the second stage advances the process of suppuration, which is now inevitable, should be encouraged by poultices, and as soon as pus is distinctly discoverable it should be evacuated by puncture. Early opening is advisable, because the tissues obstinately resist natural eracuation, and the accumulation may pass upwards towards the abdominal ring through the dartoid sac.

\section{Rupture of the Bulbs of the Vestibule.}

Anatomy.-If an incision be made by a scalpel through the skin and its subjacent adipose tissue, around the vulva, and all the tissues making up that part be dissected off, a reticulated plexus of large veins will be found beneath the labia called the pars intermedia and bulbi vestibuli. These extensire channels for blood have been represented by Kobelt, as shown in Fig. 39.

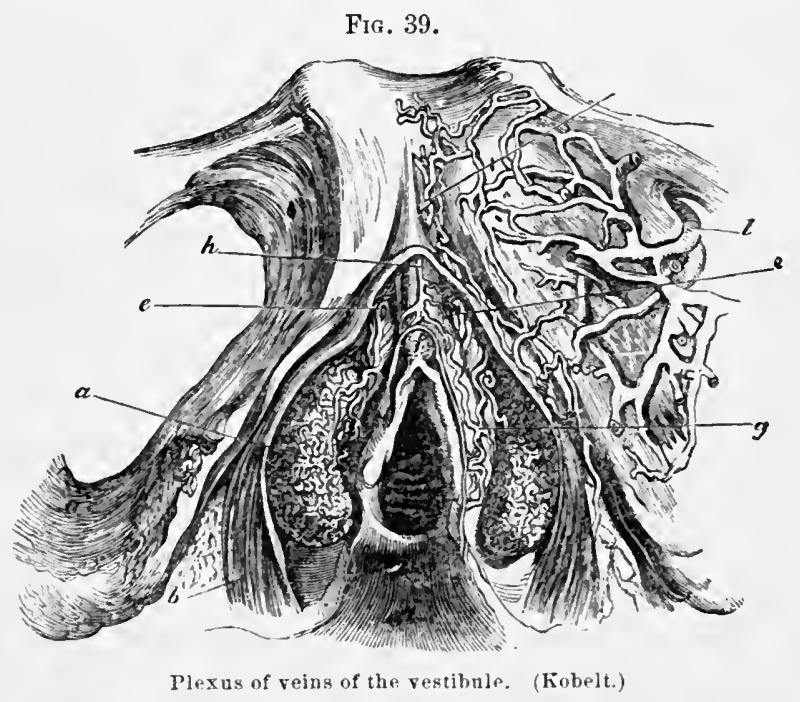

Any influence which causes a rupture of these vessels must produce one of two effects: if there be a corresponding rupture of the skin, a free hemorrhage will oceur, known as pudendal hemorrhage; if not, the blood pouring out into the areolar tissue, surrounding the womded plexus, will soon form a coagulum, constituting a bloody tumor, which has received the name of thrombus or pudendal liematocele.

\section{Pudendal Hemorrhage.}

Especial attention was called to this condition by Sir James Simpson,' who, in 1850 , recorded from his own experience, and that of others, a

1 Obstet. Works, vol. i. p. 277, Am. ed. 
number of instances in which from a very slight rupture of one labium fatal hemorrlage took place. Ile declared that criminal cases had repeatedly occurred in Scotland, in which women, both pregnant and nonpregnant, had suddenly died from pudendal hemorrhage, arising from rupture of the bulbs of the vestibule. Suspicion of injury, at the hands of the husbands or neighbors, had been entertained in most or all of the instances referred to.

The accident is a rare one. But two instances have come under my notice, one occurring in consequence of puncture of the labium by a stick, the woman falling in crossing a fence; the other the result of a similar puncture by a piece of china, from the breaking of a pot de chambre. Both these cases readily yielded to the recumbent posture, and the application of cold and styptic compresses. A very interesting case, the details of which I camot now find, was published some time ago in one of the journals of the day. A lady, standing upon a chair to mount a horse, slipped and fell, so as to cause the sharp extremity of one of the upright pieces to puncture one labium. Bleeding was profuse, and so obstinate as to require several attempts at checking it before it was finally controlled. This was in the end accomplished by a tampon in the vagina and firm compression by a $\mathrm{T}$ bandage.

Cuuses._-The great predisposing causes are pregnancy, varicose condition of the reins, and a large pelvic tumor.

The exciting causes are-

$$
\begin{aligned}
& \text { Great muscular efforts; } \\
& \text { Blows rupturing the labium; } \\
& \text { Incisions or punctures. }
\end{aligned}
$$

Symptoms. - The hemorrhage that announces the accident will lead to a physical exploration, which will at once reveal the nature of the lesion.

Treatment.-The nature of the accident being once recognized, the control of the flow will not usually be difficult. If it be not effected by cold and astringents, such as ice, the persulphate of iron, or tannin, the vagina should be filled with a firm tampon of cotton, a folded towel applied as a compress over the vulva, and a $\mathrm{T}$ bandage made to press this forcibly against the borly. Should this plan fail, the wound should be enlarged by incision and filled with pledgets of cotton saturated with solution of persulphate of iron; then the tampon should be applied in the vagina and a compress carefully adjusted by means of a $\mathrm{T}$ bandage. It is difficult to conceive of any case occurring in the non-pregnant woman which could resist this method if effectually employed.

\section{Pudendal Hematocele.}

Definition and Synonims.-The term thrombus, derived from the Greek $\theta$ porßow, "I coagulate," and which is used synonymously with hema-

1 Prof. Simpson records a case due to straining at stool. 
toma and sanguineous tumor, is that which is generally applied to this condition. I have preferred the appellation of pudendal hematocele, given to the disorder by Dr. A. H. McClintock, from its pointing out the similarity between it and pelvic hematocele, which resembles it in pathology, and because the term thrombus is now commonly applied to the coagulation of blood in a bloodvessel.

A pudendal hematocele is a tumor formel by a mass of clotted blood effused into the tissue of one labium, or the areolar tissue immediately surrounding the wall of the vagina.

History.-As early as 1554 , the disease was mentioned by Rueff, of Zurich, and in 1647 , Veslingius is said by Dr. Merrimen to have noticed it. It attracted the attention of Kronauer, of Basle, in 1734, and subsequently that of Levret, Boer, Audibert, and others. ${ }^{2}$ In time it passed somewhat out of notice, until the researches of Deneux, ${ }^{2}$ in 1830 , drew attention to it in more recent times. It is generally alluded to by authors only as one of the results of pregnancy and parturition, though it is incontestably proved that it may occur in the non-pregnant and even in the virgin state. Velpeau records an instance in a girl of fourteen years, who had not yet arrived at puberty, and declares as the result of his experience, that "thrombus culra occurs almost as frequently in non-pregnant women as in those who are in labor." He declares that he has, in the course of one year, observed six cases in the non-pregnant woman; and in his whole experience he has met with twenty instances of the affection.

$\Lambda$ the same time that I defer to the statement of so reliable an authority as Velpeau, I must express surprise at it. The aceident in the puerperal woman is not very rare, but my experience would lead me to regard it as extremely so in the non-puerperal, sinee in a practice of twenty-seven years I lave met with but four eases. These occurred as direct results of injuries done to one labium by a severe blow, and resembled very elosely the same accident which occurs so often around the eye. Another fact which adds to my surprise is this: in connection with this subject $I$ lave carefully examined the current medical literature of the day, and, although it teems with reports of this affection as a complication or sequel of labor, I find few reports of instances in the non-pregnant woman. Nevertheless, as I am in this work strictly avoiding the study of the diseased states constituting the eomplications and sequela of labor, I shall specially consider that form of the affection which oceurs in the non-puerperal state.

Puthology.-The pathology of this eondition is similar to that of pulendal hemorrhage, which has just received notice, for both are results of rupture of the bulbs of the vestibule. In that which we are now consilering, the effused blood, instead of pouring away, collects in the tissue

1 Velpeau, Dict. de Méd., rol. xxx.

2 Sur les Tumeurs sanguines de la Vulve et du Vagin. 
of one labium, under the vagina, or even in the areolar tissue of the palvis, and forms a coagulum. It bears to pudendal hemorrhage the same relation which a simple fracture bears to one of compound character.

Rupture of a branch of the ischiatic or pudic artery may, during labor, likewise produce a bloody tumor, ${ }^{1}$ but this should not be treated of under the technical head of pudendal hematoeele, for it would really constitute a case of sub-peritoneal hematocele.

Mode of Development. - When a large vessel has been injured, a tumor, perhaps the size of an orange, is suddenly discovered at the vulva. At other times the tumor is quite small, not larger than a walnut. The extent of the laceration likewise governs the rapidity with which the tumor forms after the injury has been inflicted. In some instances a slight flow slowly continues until compression from the clot checks it. When the aecident occurs in the non-pregnant state, the amount of blood effused is generally less extensive than in pregnancy, and is usually confined to the rulva.

Cuuses.-The causes are similar to those of pudendal hemorrhage, namely :-

Muscular efforts;

Blows injuring the labia;

Punctures by small instruments.

Symptoms.-The symptoms are usually a sense of discomfort, with pain and throbbing, and if the effusion reaches the urethra, there is obstruction to urination. The patient or attendant will often first recognize the fact that something abnormal has occurred by the sense of touch, practised without a suspicion as to the nature of the real difficulty.

Differentiation. ${ }^{2}$ - Care must be observed not to confound this affection with-

\section{Abscess of the labia; \\ Pudendal hernia; \\ Inflammation of vulvo-vaginal glands ; \\ CEdema labiorum.}

The mere anmouncenent of the possibility of error in diagnosis is all that is necessary, for the physical characteristics, mode of development, and rational signs of these affections are so different from those of pudendal hematocele, that examination will always settle the point with certainty.

Prognosis.-If the sanguineous collection be small, it will, especially in

1 Meigs"s Treatise on Obstetries, 5th ed., p. 94.

2 I have ventured to use this term in place of "differential diagnosis," giving it the signification which it has in Natural History, instead of that which belongs to it in Mathematics. This use is sanctioned by Worcester; and Agassiz speaks of the "differentiation of species." Its cognate verb is equally necessary and convenient. 
the non-pregnant state, generally disappear spontaneously. If, however, it be large, and if the patient have recently bęen delivered, thiere are always two dangers to be apprehended. The lesser of these is hemorrhage; the greater, purulent infection through the walls of the cyst, or the formation of an extensive abscess, which may produce the same result. These may follow in the non-puerperal form of the affection, but the danger of both is mueh less great than in the puerperal, where the ressels of the part are largely distended, in consequence of excessive growth, and where the blood state is one of hydremia and hyperinosis.

Natural Course.-Should the tumor be left to itself, it may be absorbed in a short time and leave no trace; in five or six days it may burst and discharge; the clot may become encysted, and remain indefinitely in the tissues; or the irritation of the clot may create suppurative inflammation, and abseess of the labium be the consequence.

Treatment.-Should the tumor be small, and not excite much pain, a cooling lotion of lead and opium should be applied, the patient kept quiet, and the evacuations of the bladder and rectum regulated, in the hope that absorption will take place. As soon as evidences of phlegmonous inflann. mation around the tumor appear, suppuration and discharge should be encouraged by poultices. When the tumor is large, and experiment has demonstrated that it will not undergo absorption, it is advisalble to evacuate the blood-clot by incision. This should be done by means of a bistoury, upon the mucous face of the labium majus, the patient being placed under the influence of an anæsthetic. After an incision has been made, one finger should be inserted and the clot turned out of its nidus. If hemorrhages ensue, the sac should be thoroughly washed out with a solution of the persulphate of iron, and pressure exerted. Should this not check it, pledgets of lint soaked in this astringent should be passed into the sac, and, if necessary, counter-pressure exerted per vaginam by a tampon of cotton. In case no hemorrhage should follow evacuation of the cavity, no raginal tampon should be employed, nor should the empty sac be filled with cotton. A better plan under these circumstances would be to wash out the eavity thoroughly with a weak solution of carbolic acid in water, for the more eertain avoidance of septicxmia and of phlegmonous intlammation.

\section{Pudendal Hernia.}

Anatomy.-By some anatomists it is stated that the round ligaments of the uterus ('nd in the mons veneris; but this view is incorreet. $A$ nore careful dissection traces them through the internal abdominal rings, along the inguinal canals, to the labia majora, where they are lost in the dartoid sacs, described by liroca as passing through these folds. The labia majora are unquestionably the analogues of the scrotum of the male, and the round ligaments correspond to the spermatic cords. Into the inguinal 
canals these ligaments are attended by a prolongation of peritoneum which lat received the name of the canal of Nuck. This ordinarily becomes obliterated at full term of foetal life, but not always. When it remains pervious, the formation of inguinal hernia is favored.

Definition.-Down one of the inguinal canals, by the side of the round ligament, a loop of intestine, and sometimes a portion of the mesentery, an ovary, the bladder, or the entire uterus, may pass, as inguinal hernia oceurs in the male.

The faet that this disease is by no means frequent, makes its recognition the more important, for were the practitioner not aware of the possibility of its oceurrence, the intestine might be wounded, under the supposition that the labial enlargement was due to abscess, or distention of the vulvo-vaginal glands.

Causes.-The displacement may be produced by violent museular efforts, or blows, or falls, as in the male.

Symptoms.-Strangulation of the intestine with its characteristic signs may occur, according to Sir Astley Cooper and Scarpa, ${ }^{1}$ although it is very rare. The hernia may usually be overcome by taxis. In one case with which I met, reduction was extremely difficult, and could only be accomplished by prolonged effort. When the intestine becomes prolapsed, no strangulation existing, a sense of discomfort, upon bending the body or even upon walking, directs the patient's attention to the affected part, and leads her to apply to the physician. By him the nature of the case will at once be suspected, from the peculiar gaseous or airy sensation yielded to the touch. Certainty of diagnosis will be arrived at by absence of all signs of inflammation or odema, the detection of impulse upon coughing, and resonance upon pereussion, and the possibility of diminishing the volume of the tumor by taxis and position. There are no very great difficulties attending the differentiation of the disease. The danger is that the possibility of hernia at this point may be forgotten, and deductions drawn without considering it. Although the probability of error be not great, the appalling nature of the accident in which it would result, warrants the relation of the following ease, which is illustrative of its possibility. A patient called upon me with the following history: she had had an abscess just below the external abdominal ring, which, after poulticing, had been evacuated by her physician, a aout a month before the time of her visit to me. After this, she had felt well until a week before, when, after a muscular effort, the pain had returned with all the original signs of abscess, and these had continued, although she had painted the part steadily with tincture of iodine, as she had been directed to do in case of such an occurrence. Being in great haste at the moment, I examined the enlargement while the patient was standing, and under a recent cica- 
trix, which was painted with iodine, I diseovered what I supposed to be a reaccumulation of pus. As the patient eame to me in the absence of her physician, merely for the evacuation of this, I placed her in the reeumbent posture, and, lancet in hand, proceeded to operate. But, to my surprise, I discovered that change of posture diminished the size of the enlargement. This excited my suspicions, and I found that a recent hernia had oceurred under the old cicatrix.

Treatment.-The patient having been placed upon the back with the hips elevated by a large cushion, or, as is better, by elevation of the foot of the bed or table upon which she lies, the tumor should be grasped, compressed, and pushed up the canal, down which it has descended, until it returns to the abdomen. Then a truss, so arranged as to press upon the inguinal canal, should be adjusted, and worn with a perineal strap, to keep the compress of the instrument sufficiently low down to effeetually close the point of exit. Should strangulation have occurred, and return of the prolapsed part by taxis prove impossible, the case will require the surgical operation for that condition, for a deseription of which the reader is referred to works on general surgery.

\section{Hydrocele.}

Definition and Frequency._-This affection, which consists in a collection of fluid in the inguinal canal, around the round ligament, is one of such rarity in the female that its very existence is commonly ignored, and mention of it is rarely made by systematic writers. ${ }^{1}$

Anatomy.-It has been already stated that the labia majora of the female are analogous to the scrotum of the male, and that the round ligaments, which are analogous to the spermatic cords, do not end in the mons veneris, as was formerly supposed, but passing downwards enter the labia majora and distribute their filaments within the dartoid sacs, whieh extend like glove-fingers downwards towards the fourchette. The interesting and valuable artiele of M. Broca upon this snbject will be found quoted at length in Crureilhier's Anatomy. The peritoneal covering of these ligaments usually extend to the inguinal canals, but occasionally in young subjects it is prolonged through a portion of the canal constituting the canal of Nuck." In adults this is ordinarily obliterated, and henee the rarity of hydroeele and hernia in the female. Sometimes it remains permanently open, when not only may the intestines descend, but even the orary may pass down, making an attempt to enter the dartoid sacs and imitate the entranee of the testes into the scrotum.

Pathology.-The affection which we are now eonsidering is the result of excessive secretion on the part of this serous nembrane, which, by the

1 Scanzoni's work upon Diseases of Women contains an account of it.

2 Cyclopedia of Anat. and lhys., Supplement, p. 706. 
fluid collected within it, is distended laterally and downwards. Should the ablominal opening of such a sae remain pervious, the fluid thus collecting could readily be forced upwards as in the same aflection in the male, but if that opening has become impervious, the fluid becomes sacculated and such return is impossible. So rare is this affection that I offer no apology for the introluction of the following instance of it, ${ }^{1}$ reported ly Dr. E. P. Bennett, of Danbury, Connecticut.

"In an extensive practice of over forty years, but one single case has come under my observation. This ease occurred recently in a young married female residing in Putnam County, and was mistaken by a surgeon of some eminence for a case of inguinal hernia, who endeavored to reduce it, but failing to do so, pronounced it adherent, and irreducible, and advised to let it alone. That such a mistake should have been made is not at all surprising, as it was a lydrocele of the round ligament coming down through the inguinal canal, and occupying exactly the place of inguinal hernia, and closely resembling one. She subsequently came under my care, and upon inquiry I learned that about five years since a small tumor had made its appearanee, which had slowly and steadily increased in size until it had attained its present size, which was about as large as a turkey's egg. It had not been painful, was not attended with abdominal disturbance, had never receded when recumbent, and gave to the touch a feeling of flud contents instead of the doughy feel of hernia, and I therefore thought that, whatever it might be, it was not hernia; and, upon closer inspection, I diagnosed hydrocele of the round ligament, although it was not diaphanous. So sure was I of a correct diagnosis that I at once proposed an operation, to which she readily consented; and, with the aid of a professional brother, who coincided with me in my diagnosis, I proceeded to eautiously lay open the sac, when we found, to our great satisfaction, that we had not blundered in our opinion. The serous contents of the sac having been evacuated, I injected it with a saturated tineture of ioline, and she speedily recovered without the supervention of a single unpleasant symptom. This case is only important from its rarity, and the fact that most physicians are not aware that hydrocele can, or ever does, occur in the female; and my object in writing this article is not to record any remarkable achievement in surgery, but to call the attention of physieiaus to this subject, and thereby prevent mistakes which might be attended with disastrous results."

A pamplilet has been published upon the subject by Dr. Hart, of this city. In it he details an operation for hernia performed in a case of hydrocele from a mistake in diagnosis. The fluid of the hydrocele being evacuated, the wound was closed by silver suture, and the patient recovered. He declares that the disease is mentioned by Aetius, Paré, Scarpa, Meckel, and Poland.

Differentiation.-The greatest circumspection should be observed before a diagnosis of this rare malady is arrived at. The sense of fluctuation,

1 N. Y. Med. Record, Nov. $15,1870$. 
with entire absence of symptoms of inflammation, the absence of resonance on percussion, and the ordinary signs of hernia, the existence of translucency, and the gradual development of the tumor without pain or constitutional exeitement, would all be reasons for suspecting it. But, before ultimate measures are adopted for its cure, a very ine exploring needle, such, for example, as that of the ordinary hypodermic syringe, should be passed in, in order that the contents of the sac may be carefully examined.

Should the character of this fluid not assure us that hernia exists, the smallest needle of the aspirator should be introduccd, and all the fluid drawn off. Even where hernia exists, such a procedure has been found to favor return of the sac, and to do no harm by rendering it subsequently pervions.

Treatment.-The diagnosis being made, the treatment should consist in evacuation by means of the aspirator, and, if cure do not follow this, in the injection of tincture of iodine in addition, which may be done by revers- . ing the action of the same instrument.

\section{II A P'T E R VIII.}

\section{PRURITUS VULVAE.}

Definition.-This affection consists in irritability of the nerves supplying the vulva, which induecs the most intense itching and desire to scratch and rub the parts. Although not itself a disease, it is always so important, and often so obscure a symptom, that it requires special notice and investigation.

Pathology.-It has just been stated that it consists in disorder of the nerves supplying the vulva. It matters not whether this be a true neurosis or one secondary to some other pathological state, the great element of pruritus vulva is nervous irritability or hyperasthesia. That it is often excited by irritating discharges and eruptive disorders there can be no question. Whether it ever depends upon idiopathic nervous hyperesthesia, as some suppose, is doubtful. I have never met with an instance in which it appeared to do so.

Mode of Development and Course.-In the beginning, the irritability and tendency to scratch are sometimes very slight, so as to annoy the patient very little and give her but trifling uneasiness. Sometimes they exist only after exertion in warm weather, upon exposure to artifieial heat, or just before and after menstruation. The disorder is aggravated by the 
connter-irritation which it demands for its relief. The rubbing and scratehing that are practised cause an afflux of blood, render the skin tender and its nerves sensitive, and in time greatly angment the evil by produeing a papular eruption. The disease and the remedy which instinct sugrests, reaet upon each other, the first requiring the second, and the second aggravating the first, until a most rebellious and deplorable condition is developed. It would be difficult to exaggerate the misery in some of these cases. The patient is bereft of sleep by night, and tormented eonstantly by day, so that society becomes distasteful to her, and she gives way to despondency and depression. The itehing is generally intermittent, in some cases occurring at night, in others only at certain periods of the day. In two eases that $I$ have met, the patients were free from all irritation except at night, when the disturbance and nervous anxiety became so intense as to prevent sleep, exeept when large doses of opium were given. Loss of sleep, the use of opium, and the nervous disturbance incident to the disease, often prostrate and exhaust the patient to an astonishing extent.

This disorder is to some degree paroxysmal, any influence which produees congestion of the genital organs aggravating it very much. Lying in a warm bed, sexual intercourse, eating and drinking, more especially highly seasoned food and stimulating beverages, and the act of ovulation, all produce this result. Its duration has no limit; months, and even years, sometimes passing before relief is obtained.

Although the term "pruritus vulvæ" is that ordinarily applied to it, it must not be supposed that the irritation is always coufined to the vulva. It often extends up the vagina, to the anus, and down the thighs. In pregnant women I have repeatedly known it to spread over the abdomen. It may be asked why such a state should be styled "pruritus vulvae?" These extensions are merely complieations of the original malady which really deserves that name, and are due to eontamination, by scratching, with an ichorous element which constitutes, as I believe, the prominent exeiting cause of the trouble.

Causes. - Every practitioner dreads to meet with an agravated case of pruritus vulve, for he knows how obstinate the malady commonly proves. The only reasonable hope of controlling it must rest in viewing it strietly as a symptom, and striving to diseover and remove its cause. No fixed prescriptions, however much lauded for their efficacy, should be relied upon. The primary disorder should be sought for and cured, in the hope of removing that one of its results which is most pressing in its demands for relief. Should the case have progressed for some time, it will often be found impossible to deeide as to its cause, for the scratehing induced by it will frequently establish a cutaneous disorder, the conneetion of which with the pruritus, whether as cause or effect, will be doubtful. 
The predisposing eauses of pruritus are the following :-

Uterine, vaginal, or urethral disease;

Pregnaney;

Depreciated general health ;

Habits of indolence, luxury, or vice;

Uterine or abdominal tumors;

Want of cleanliness;

Constitutional syphilis;

Severe exercise in one of sedentary habits.

It will be observed that most of these influences are those which predispose to the development of abuormal secretion by the mucous membrane lining the genital tract. Such excessive and deranged secretion I believe to be in the great majority of cases the immediate, exciting cause of the nervous irritation. That there are other causes, it will be seen that I admit, but to treat this condition successfully, I am convinced that special reference must be had to this element. He who simply keeps in view the local trouble, in the majority of cases will be striving merely against the branches of an evil, the root of which consists in the ichorous material, which bathes and excoriates the terminal extremities of the nerves of the vulva and vagina.

In all the instances of pruritus vulve that $I$ have been able to examine early enough to determine as to the etiology, I have found one of the following conditions to exist as the apparent cause of the hyperesthetic condition of the nerves:-

1st. Contact of an irrituting discharge-

Leucorrhoca ;

Hydrorrhica;

Discharge of cancer;

Dribbling of urine;

Diabetes.

2d. Local inflammation-

Vulvitis;

Urethritis;

Vaginitis;

$\Lambda_{\text {plithous ulcers. }}$

3d. Local irritation-

Eruptions on the rulva;

Animal parasites;

Onanism;

Vegetations on the vulva;

Vasenlar urethral earuneles;

Growth of short, bristly hair on mucous fice of labia.

Of all these, leucorrhea is the most frequent cause. This symptom of uterine disorder fortunately produces pruritus only as an exception to a 
rule. Under certain eircumstances it appears to possess peculiarly irritating and excoriating qualities, which, even when the flow is insignificant in anount, will exeite the most intolerable itching. This feature is most commonly observed in the discharge attending pregnancy; and in that of senile endometritis, which covers the vagina with bright red spots, and gives it a glazed look like serous membrane. In an exeeedingly obstinate case, oceurring in a woman of seventy years, the leueorrhceal diseharge was so small in amount that the patient was not aware of its existence, nor did I appreeiate its connection with the disorter until I discovered aceidentally that the only relief which could be obtained followed the application of a wad of cotton against the cervix uteri. In every case of pruritus the vaginis should be carefully investigated for evidence of leucorrhoe, unless some other suffieient cause is apparent. In the same manner the other discharges mentioned may cause nervous irritability in the vulva.

It is not, howerer, usually vaginal leucorrhœa which produces the result; it is much more eommonly due to the diseharge arising from cerrical or corporeal endometritis, and the obstinacy of these affeetions accounts to some extent for that of the secondary one.

I have so often found diabetes aceompanied by this symptom that I always examine the urine in obscure cases. It is by many attributed to the constitutional agency of the disease. The marked relief afforded by the systematie use of the catheter has led me to think otherwise. My impression is that the pruritus is probably not connected with the constitutional effects of the disease upon the nerves, but with the direet and local influence exerted by the disordered secretion.

Local inflammation, by the discharge which it exeites and the itching which attends it, is very evidently ealeulated to give rise to pruritus; and yet cases thus established are not the most rebellious with which we meet.

Any form of eruption upon or around the vulva may, and usually does, excite itching. Eezema, prurigo, liehen, and many others, may do so here as they do elsewhere, and the natural warmth of the part, formed as it is of folds of tissue and covered by hair which is thiekly interspersed with sebaceous and piliferous glands, makes them the more likely to prove aetive in eausing it.

Animal parasites of two varieties may give rise to it, the pedieulus pubis and the acarus scabiei. The first exeites through irritation a liehenoid eruption, while the second produces seabies, or itch.

One of these causes will generally be found to have given rise to pruritus vulve, but it is only in originating the difficulty that it will prove active. Very soon secondary influenees, as eruptious, exeoriations, ulcerations, and increased discharges, the results of scratching, superadil themselves as anxiliary agents, and keep up the disorder.

Treatment.-It has been stated that the first effort of the practitioner 
should always be to diseover the disease of which the pruritus is a symptom, and then to endeavor to remove it by appropriate means. Should leueorrhœa be the eause, the uterine or vaginal affection which gives rise to it should be treated. Should an eruptive disorder be found to be the source of the difficulty, the measures which would be advisable for this affection elsewhere developed, laxatives, baths, ehange of air, tonies, and arsenic, would be equally beneficial here.

But this alone will not be sufficient. While eradication of the misehief is thus attempted, palliative means must be vigorously adopted for the sake of present relief. Should the case be regarded, upon careful investigation, ats due to eontaet of an irritating fluid with the nerves of the vulva, perfect cleanliness should be secured by three, four, or, if necessary, a larger number of sitz baths daily, and the vagina should, at the time of taking each bath, be syringed out with pure or medicated water. The irritated surface should be protected by unetuous substanees, or inert powders, such as bisnuth, lycopodium, or starch, from the injurious contaet, and in ease the diseharge eomes from the uterus, a wad of cotton should be placed daily against the cervix uteri to prevent its eseape to the vulva, or, as is better, after a thorough use of the vaginal donche the vagina should be thoroughly tamponed daily with eotton saturated with glycerine to which has been added horax or acetate of lead, two drachms to the ounce. Of this plan, which I should mention does not confine the patient to bed, I can speak in high terms. While it protects the vulva from iehorons discharges, it does not prevent ablution and applications to the point of maximum irritation. A very useful vaginal injection, and wash for the vulva, under these eircumstances, is the following:-

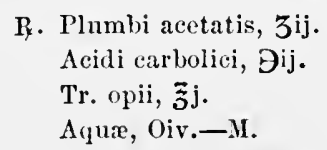

'This may relieve itching for a time, until removal of the eause of the symptom is accomplished.

In ease the pruritus is the result of a local inflammation, this should be treated as elsewhere recommended, by poultices of linseed, potato, or slippery elm, to which have been added a proper amount of lead and opium; or fomentations of lead and opium wash, or poppy-heads may be used in their stead. If vaginitis or vulvitis be present, great relief will often be obtained by painting the lining membrane of the diseased part over with a strong solution of nitrate of silver, or by touching the whole surface very lightly with the solid stick, and then using the tampon of cotton and glycerine.

Should an cruptive disorder be the exeiting eause, it should, as already stater, be treated upon general prineiples. Meantime temporary relief may be obtained by painting the surface of the vulva over with a solution 
of nitrate of silver, or the use of the ungt. creasoti, ungt. chloroformi, or ungt. atropia of the U. S. Dispensatory. Dr. Simpson advises an infinsion of tobaceo, and Dr. J. C. Osbor'n, ${ }^{1}$ of $\Lambda$ labama, in an interesting article upon the medicinal use of this drug, declares that he always resorts to a strong deeoction of it as a wash for the vagina and vulva in this affiection, and for the anus in "prurigo podicis." According to the latter gentleman the local sedative effects of tobacco are very useful in the control of prurigo. My own experience agrees with his.

Aithough the fact will probably not prove one of practical value, it is certainly one of interest that cases have recently been reported in which smoking tobacco has appeared to relieve pruritus. $A$ s an illustration I quote the following: "Mrs. W., a woman of nervous temperament, became pregnant a few months after her marriage. In addition to the usual deraugement of the alimentary eanal, she soon experienced a severe itching all over her body. 'The skin was of a perfectly normal appearance; the pruritns, however, eaused lier great exeitement and soon produeed nervous spasms. For several weeks every possible external and internal remedy was used in vain. A decoction of walnut leaves gave her some relief when in the seventh month of pregnancy. Then a violent pyrosis and neuralgia of the dental nerves supervened. In order to alleviate the latter, she was advised by her husband to try the effect of smoking, when the pain as well as the itching and pyrosis disappeared immediately. Mrs. W. smoked one cigar every evening until she was prematurely delivered by a fright, after $8 \frac{1}{2}$ months.

"Fourteen months afterwards, Mrs. W. again became pregnant, and was again affected in thie fourth month of pregnancy with pruritus followed by pyrosis. She did not immediately resort to smoking, from the dislike of this habit, until the evil increased, when the smoking of one cigar again renlered her perfectly comfortable."

No local application las acquired a more universal popularity in the treatment of pruritus vulva than solutions of corrosive sublimate. The following fornula is a good one of its kind:-

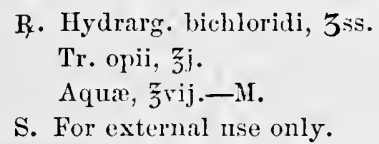

Should eczema or lichen have produced inflammatory action in the skin and subcutaneous areolar tissue, poultices, etc., should be employed, as it' local inflammation were the cause of the affection.

While these palliative and curative means are being adopted, sleep should be secured by preparations of opium, or one of its substitutes,

\& Tribune Med., Jan. 31, 1869; Wiener Med. Wochenschrift, No. 22, 1869. 
codeine, chloral, hyoscyamus, or chlorodyne. At the same time the general state of the patient should be improved by vegetable and mineral tonics, good food, and fresh air. In some cases more benefit will arise from the use of iron, the mineral acids, and sea-bathing, than from any other means.

In certain cases dependent upon chronic raginitis, or chronic endometritis which has resulted in raginitis, the disorder will be found to be rather "pruritus vagine" than "pruritus vulva," and under these circumstances the severity of the local and general disturbance may be very great. In such cases I hare found great benefit from the frequent use of copious vaginal injections of warm infusion of bran. The patient, in the semirecumbent posture, with the nates over a tub containing three or four quarts of this, with from six to eight drachms of laudanum, and one to two drachms of acetate of lead dissolred in it, should inject the vagina freely for from ten to fifteen minutes, and this should be repeated four or five times a day. After a short time the soothing and alterative influence which it exerts will show itself so decidedly that less assiduous attention to the disorder will be demanded.

In the same way infusion of tobacco and solutions containing borax, lead, alum, zinc, or earbolic acid will be found to be very valuable remedies. They should be used very freely, and after previous cleansing of the vagina by pure water. One great difficulty in the treatment of the disease consists of the inefficient manner in which raginal injections are practised by patients. This should be guarded against by explieit directions, and the use of the means suggested hereafter in connection with that subject.

The following preseriptions bave obtained a reputation for the treatment of pruritus; and I know by experience that they deserve it:-

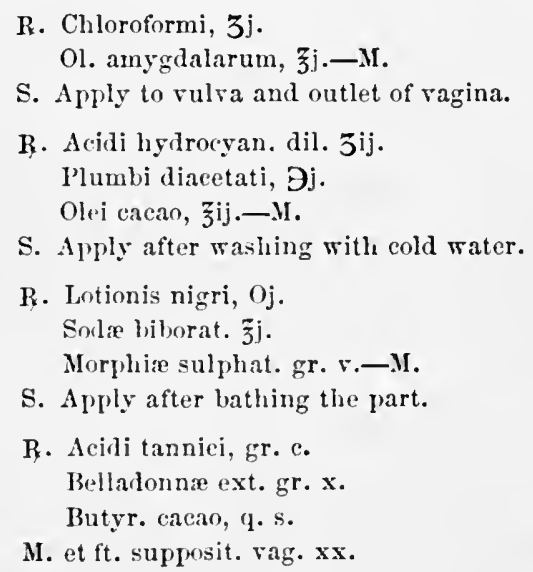

S. Apply after washing with cold water.

R. Lotionis nigri, $\mathrm{Oj}$.

Solle biborat. jj.

Morphise sulphat. gr. v.-M.

S. Apply after bathing the part.

R. Acidi tanniei, gr. c. Belladonna ext. gr. $x$.

Butyr. cacao, q. s.

M. et ft. supposit. vag. $\mathrm{xx}$.

S. Let the patient plase one in contact with the cervix uteri, every night, after thoroughly syringing the vagina. 
Where diabetes exists as a cause, the patient should bathe the parts after urination, and be instrueted to keep the vulva thoronghly covered and protected by one of the ointments aheady mentioned.

Where the pedieulus pubis is fomml to exist, mild mercurial ointment should be applied ; and for the acarus scabici, sulphur ointment will be fomml suffieient as a parasiticide.

When the itching is loeated in the skin of the mons veneris and surrounding parts, rubbing it freely with a moist stick of nitrate of silver is often of great serviee.

The following preseription I have never employed, but it is highly recommended by good authority :-

\section{B. Zinci sulpho-carbolat. $\mathbf{3 j}$.} Aquæ destillat. 亏亏ij.

S. After careful bathing use as a wash once or twice a day.

Where short, bristly hairs are found growing from the inner or mucous surface of the labia majora, great relief follows depilation. Each hair should be seized by forceps, the operator using a magnifying glass, and jerked from its place.

Dr. Stevens, of Cincinnati, reports excellent results from the use of undiluted sulphurous acid as a wash applied freely to the vulva. He declares that prompt relief is in that way attainable.

\section{Hyperæsthesia of the Vulva.}

Definition.-CThe disease which I proceed to describe under this name, although to all appearances one of trivial character, really eonstitutes, on accomnt of its exeessive obstinacy and the great influence which it obtains over the mind of the patient, a malady of a great deal of importance. It consists in an excessive sensibility of the nerves supplying the mucous meinbrane of some portion of the vulva; sometimes the area of tenderness is confined to the vestibule, at other times to one labium minus, at others to the meatus urinarius; and again a number of these parts may be simultaneously affected. It is a condition of the vulva closely resembling that hyperasthetie state of the remains of the hymen which eonstitutes one form of vaginismus. In two cases I have seen the whole surface of the rulva, exeept the labia majora, affected by an excessive sensibility which extended along the urethra.

Frequency.-This disorder, although fortunately not very frequent, is by no means very rare. So commonly is it met with at least, that it becomes a matter of surprise that it has not been more generally and fully described.

Puthology.-It is not a true neuralgia, but an abnormal sensitiveness; "a plus state of excitability" in the diseased nerves. No inflammatory action affects the tender surface, no pruritus attends the condition, and 
physical examination reveals nothing except occasional spots of erythematous redness scattered here and there. The nerve state appears identical with that which sometimes develops in the scalp, and on parts of the cutaneous surface. The slightest friction excites intolerable pain and nerrousness; even a cold and unexpected current of air produces discomfort ; and any degree of pressure is absolutely intolerable. For this reason sexual intercourse becomes a source of great discomfort, even when the ostium ragine is large and free from disease. It is this difficulty which generally first causes the patient to apply to a physician for relief.

Causes.-The predisposing causes appear to be the period of life near or at the menopause, the hysterical diathesis, or a morbid mental state characterized by tendency to depression of spirits. As exciting causes I have found chronic vulvitis and irritable urethral tumors to exist in some eases, but in others no cause whatever has been apparent.

Symptoms.-I lave said so much on this subject, under the head of definition, that $I$ have little more to add. The patient applies for relief because the act of sexual intercourse is painful, and because in the sensitive spot there is always a degree of discomfort, which is increased by bathing the part, or eren by the friction incident to walking. $\mathrm{L}_{\mathrm{p} \text { pon }}$ questioning lier, it will be observed that her mind is disproportionately disturbed and depressed by this. In some cases it seems to absorb all the thoughts, and to produce a state bordering upon monomania.

Differentiation. - It should be distinguished from irritable urethral tumor and vaginismus, which will be readily accomplished by inspection and touch.

Treatment.-The treatment of this condition is most unsatisfactory. I have met with a number of cases of marked eharacter, and in not one was complete relief given by treatment. Whether they subsequently recovered I camnot say, but they certainly were not cured while under my observation. In one case, which I saw with Dr. Metealfe, the sensitive area was the vestibule, and to this we applied nitric acid so as to destroy the mucous membrane completely and followed this up by local sedatives, but to no purpose. In another, which I attended with Dr. Sims, he removed portions of the latbia minora and of the rulvar mucous membrane, without suecess. In another ease I dissected ofl all the sensitive tissue, which was quite extensive. This patient, the wife of a clergyman, left me well, and was greatly rejoiced; but, in six months, I received a letter from her declaring that she was worse than before the operation. The treatment which I would recommend from my experience is this : to send the patient away from home where, in addition to enjoying change of air, seene, and surroundings, she would live absque marito; to put her upon the use of frenfral tonies, as arsenic, strychnine, quinine, and iron ; and after having cured : any local exciting disease, like vulvitis or urethral vegetations or tumors, to make frequent ablutions with warm water and apply sedative 
and ealmative substances in the form of lotions or ointments. As examples of these, I would mention opium or its salts, earbolie acid, chloroform, bellalonna, and iodoform. Sometimes benefit seems to result from strong solutions of alum, tannin, and similar agents.

My observation of the results of causties and the knife is not such as to inspire me with confidence in them.

\section{Irritable Urethral Caruncle.}

This affection has, likewise, received the names of vascular tumor, and irritable vaseular excrescence of the urethra.

Just at the edges of the meatus urinarius, and, sometimes, along its walls for some distance, little vascular tumors develop themselves, which render this eanal very irritable, and in this way produce a great deal of discomfort.

Pathology.-According to Wedl ${ }^{1}$ they consist of hypertroplied papilla, which, as they enlarge, are aceompanied by excessive growth of areolar tissue. They are extremely vascular, eapillary vessels of eonsiderable size being found within them, ramifying in transverse sections, very mueh like the vasa vorticosa of the ehoroid. Dr. Reid, ${ }^{2}$ of Edinburgh, declares that they are richly supplied with nervous filaments. These two anatomical facts account for two corresponding elinical observations, that they bleed very freely and readily, and that they are almost as sensitive to the touch as a neuroma. Sarage styles these curious growtlis "pseudo-angiomata," and asserts that within them, cystic cavities, probably the remains of urethral glands, are occasionally found, filled with mucus.

Causes.-Of the etiology of this affection nothing is known. It develops in the young and old; the married and single.

Symptoms. - The patient eomplains of pain upon sexual intercourse, in passing urine, in walking, and upon the slightest contact of the clothing. Sleep is disturbed by these means, and by the inerease of sensitiveness engendered by the warmth of the bed. As a consequence, she becomes nerrous, hysterieal, and greatly depressed in spirits. Her whole thoughts often become fixed upon this one painfully absorbing topic, and a most wretchel mental state is at times produced. Of course these grave results occur only in very aggravated eases; but, even in minor ones they are present in slight degree.

Dr. T. F. Cock informed me of a ease in which a patient became so much depressed from this eause that she eommitted suieide, and I have a similar statement of another ease from a non-professional souree. In the latter, the time had been appointed for remoral of the growth when the patient destroyed her life. I should be sorry to leave the impression, that mental alienation of grave eharacter is likely to develop from these little

1 Pathological Anatomy.

2 Simpson, Diseases of Women, p. 276. 
growths; it is not. A eertain degree of it is very apt to be met with; and, in rare eases, where the suffering is very great, it sometimes becomes excessive. To convey some idea of the amount of pain induced by urination in some eases, I quote the following: "I was told by a shepherd's wife, who had one of these sensitive caruncles at the orifice of the urethra, that, whenever she was obliged to pass water, she was in the habit of going to some distance away from her cottage, in order that she might moan and seream unheard, and not distress her family with the sound of her cries, so intense and intolerable was the suffering which at such times she experienced.""

Physical Signs._-The patient being placed upon the back with the thighs flexed and the knees separated, inspection shows, at the meatus urinarius, a florid, vascular growth, varying in size from that of a cherrystone to that of a pigeon's egg. Scanzoni declares that they may grow to the size of a goose's egg. Sometimes, instead of one, quite a number may be found, of small size, extending around the meatns or up the canal. Where the canal itself is invaderl, the eases are always very difficult of cure, on account of the difficulty in reaching the morbid developments.

Differentiation.-_There are but two conditions with which $I$ have ever known the disease confounded. One is prolapsus urethra or eversion of the mucous membrane of the canal; the other syphilitie growths of warty character. From the first a careful examination will readily distinguish it, and when the second exists similar developments will be found upon other parts of the vulva. Besides neither of these conditions is nearly so annoying and painful as that which we are considering.

Course and Duration. - It is impossible to say how long these growths will continue to exist when not interfered with. I have known them last for years without continuing to develop, but retaining a small size, and being always excessively sensitive and annoying.

Progrosis. - In case a single large caruncle exist, an almost positive promise of relief may he lield out from its removal; but where a number of small, fungous, warty growths surround the meatus and extend up the urethra, cure is extremely diffienlt, for no sooner are they removed than the morbid process of development rapidly produces more. Another dis. conraging feature of these cases is this, a nerrous hyperssthesia is engendered hy the growth, which lasts long after its removal. It behoores the operator in such cases always to be guarded in his promises, at the same time that he urges interference as the only hope for relief in the present, and safity from increased trouble in the future.

Treatment.-Before operating the patient should be thoroughly anæsthetized and placed upon the back, with the thighs flexed and the knees widely separated. The labia being then separated by an assistant on each 
sile, the tumor should he seized near its base by foreeps, pulled towards the operator, and its attachment cut by seissors. Very free hemorrhage may vecur. To control this, the raw surface should be wiped dry and thoronghly tonched with fuming nitric acisl, a stick of nitrate of silver, or the atual cautery.

This operation may be very niecly performed by galvane-cautery, if an instrument be attainable. By this means not only is hemorrhage prevented, the base is also thoroughly cauterized, which is a great sateguard against return of the growth.

Where the urethra has been invaded it should be thoroughly stretched by little retractors introduced within it, and held by assistants, and the growths thus exposed be eut off by scissors, or scraped from their attachnents by a steel curette. After removal, their bases should be very cau-

Fig. 40.

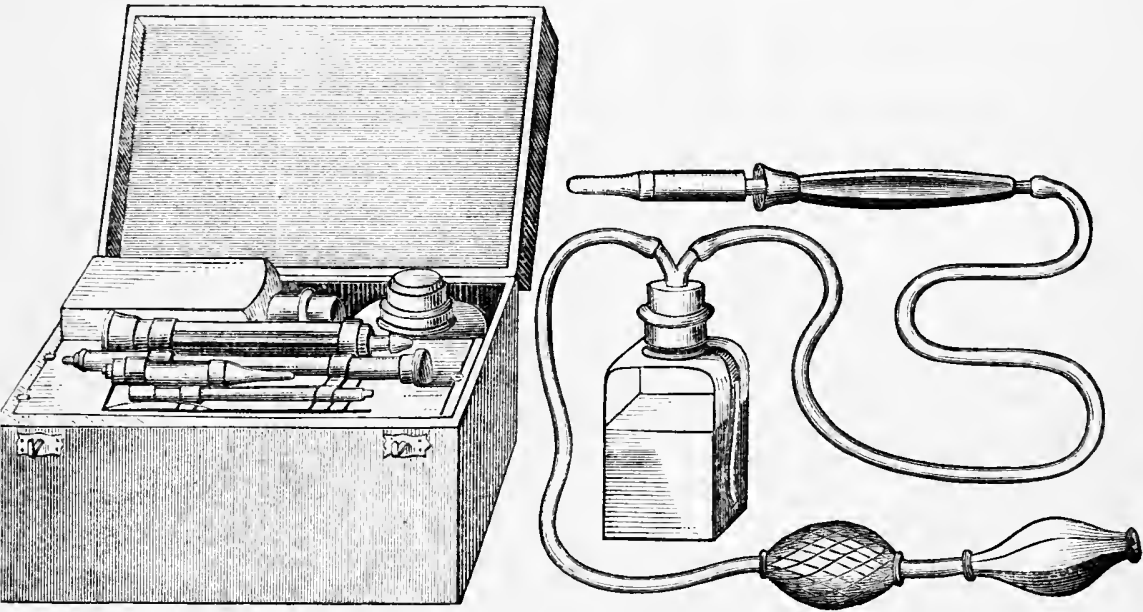

Paquelin's Thermo-Cautery.

The apparatus consists of a hollow handle, insulated with wood, to protect the hands from the heat. It is furnished with three movable, hollow, platinun cauteries; into these, after they have been heated to blackness in the tlame of a spirit lamp, a blast of benzine rapor is introduced by means of a Richardsun's spray bellows, which at once raises them to and maintains them at a state of vivid incandescence. The heat thus produced can be kept up for an indefinite time by slighlly compressing the bellows occasiunally.

tiously touched with nitric acid, or, what is still better as preventive of return, the actual eautery. A few years ago the actual cautery was an instrument so unnanageable and difficult of employment that it wats rarely used for slight operations. Now, thanks to the genius of 2I. Paquelin, whose instrument is shown above, it is used as easily as the stick of nitrate of silver. 


\section{Urethral Venous Angioma.}

This is a disease affecting the urethro-vaginal tubercle or anterior half of the urethro-vaginal septum. It sometimes attains large size, and projects between the labia. From irritable carunele or vascular excrescence it can be differentiated by its want of sensitiveness.

It appears, says Sarage, ${ }^{1}$ to be due to venous eongestion, analogous to that giving rise to priapism.

Its treatment is identical with that of urethral earuncle.

\section{Prolapsus Urethræ.}

This accident, which has likewise been described as procidentia and eversio urethre, consists of prolapse of the urethral mucous membrane, with proliferation of the underlying connective tissue. It is not commonly met with, but at times produces considerable irritation of the urethra and bladder, and leads to an erroneous diagnosis of irritable caruncle. I have met with it only in adults of enfeebled constitution and advanced age; but Guersant, in the Rérue de Thérapeutique, declares that he has seen fifteen cases in little girls between two and twelve years of age. Diagnosis is easy. A roseate projeetion encircles the meatus, which is sensitive and liable to bleed. The only diseases with which it could be confounded are, irritable earunele, urethral polypus, and renous angioma. From all these it ean realily be differentiated by carreful examination, which shows that it entirely surrounds the meatus, while they do so only in part. The extreme sensitiveness of irritable caruncle is not a differential sign which can be relied upon, for I have seen prolapse of the urethra develop this symptom very decidedly.

It may for some time exist without symptoms, but usually soon creates diffieult and painful micturition, pruritus vulva, and leucorrlwal discharge.

Treatment._-The simplest method of treatment is to seize the prolapsed circle with tooth-forceps, the patient being anesthetized, draw it down with very little force, and cut it off with curved scissors. The resulting hemorrhage will readily be controlled by applying a pledget of lint or cotton, saturated with a solution of persulphate of iron, one-third of the full strength, against the raw surface, and making pressure by the finger for some minutes. Should it be decmed neeessary to continue it longer, this may be done by a $\mathrm{T}$ bandiage.

If great vaseularity leads to fear of hemorrhage, the ingenious method of Sequin may be adopted witl advantage. This consists in introdueing a female catheter into the bladder, and ligating the prolajred part to it so as to strangulate it entirely. The catheter is left in sitû until released by sloughing off of the ligated part 
In one case I drew down the prolapsed tissue, passed a double silk ligature through its base, and tied the two halves. The cure was perfect.

$\Lambda$ better operation than either of these would be encircling the prolipsed tissue, which should be well drawn down, by the galrano-canstic wire, removing the mass in this way, and keeping a catheter in the blander tor some llays if necessiry.

Should obstinate hemorrlage follow any of these operations upon the urethra or vulva, a tirm vaginal tampon witl a $T$ bandage used so at to press its lowest portion against the bleeding surfice will readily control it. The former presses the urethra npwards and the labia outwards, while at the same time it gives a firm, fixed point, against which direct pressure by a $\mathrm{T}$ bandage and compress may be made. It possesses more real value than all the other means, usually mentioned for the control of such hemorrhages, combined ; such, for example, as Monsell's salt, the actual cautery, strong acids, ete. The vulva is so exquisitely sensitive that the patient is apt to rebel against these, and in audition they often fail in accomplishing the result.

\section{Coccyodynia.}

Definition and Frequency.-This affection consists in a morbid state of the coccyx, or the muscles attached to it, which renders their contraction, and the consequent movement of the bone, very painful. It is of frequent occurrence, numerous cases having been observed, since attention has been called to it, by practitioners who saw it previously without regarding it as a special disorder.

History.-Coccyodynia was first described, in 1844 , by the late Dr. Nott. Under the name of neuralgia of the eoccyx he described a case which fully embodies the symptoms and treatment of the affection by surgical resouree. ${ }^{1}$

Although Dr. Nott gave every detail with which we are now familiar, as to the symptomatology and treatment of this affeetion, the subject was nearly forgotten until the year 1861, when it was again deseribed, almost simultaneously, by Simpson, of Scotland, who gave it its name, ${ }^{2}$ and Scanzoni, of Germany. We have in this another instance, of which so many exist, of the complete oblivion into which a few years may cast a valuable eontribution to science. Surely in such a case he who revires what is forgotten deserves as much eredit as he who originally made the discovery.

Anatomy.-The coccyx serves as a point of attachment for the greater

1 X. O. Med. Journ., May, 1844.

2 In Prof. Alexander Simpson's edition of Sir James Simpson's posthumous volume on Diseases of Women, the name coccygodynia is used. In his Clinical Lectures, published in Philadelphia, 1863, the name which I here employ appears. 
and lesser sacro-sciatic ligaments, the ischio-coceygei muscles, the sphincter ani, levatores ani, and some of the fibres of the glutei muscles. These are thrown into activity by certain movements, as rising from the sitting into the standing posture, the act of defecation, etc., and in such acts the existence of the disorder which we are considering is revealed.

Pathology.-The peculiar pain which characterizes this disease has, according to my experience, a variety of causes; I have removed one coccyx in which a fracture with dislocation, received in early life, which caused it to jut in at a right angle to the sacrum, was its source; another in which, as in Dr. Nott's case, just recorded, caries existed; while in still a third no abnormal condition could be discovered. In such cases as the last, the pain which characterizes it is probably due to a lyyper-sensitive state of the fibrous tissues surrounding the coceyx, or of that making up the tendinous expansions of the muscles. This may at times be, as I'rof. Simpson has suggested, of rheumatic character; but it appears to me that it is very generally a neuralgic state, due to uterine or ovarian disease, of which coccyorlynia is a frequent consequence.

As a rule, so long as the bone is uninflueneed by contraction of the muscles attached to it, no pain is experienced, but as soon as contraction produces motion it is excited.

Causes.-It occurs most frequently in women who have borne children, but it is by no means confined to them. I have on two occasions met with it in young, unmarried ladies, and IIerschelman reports two cases in children from four to five years of age.

Its chief causes are the following:-

Blows or falls upon the coccyx.

Injuries inflieted by parturition.

The influence of cold and exposure.

Uterine and ovarian disease.

IIorseback exercise. (")

In a case mentioned by Courty the patient had the peculiar habit of sleeping with the buttoeks uncovered, and the sacrum pressed against the wall. In nine of Scanzoni's cases the condition followed parturition; in five, the use of the obstetric forceps; and in two, lorseback exercise was the only cause ascertainable.

Symptoms.-The paticnt, upon sitting down, rising, making any effort, or frasing feces through the rectum, experiences severe pain over the cocryx. In some cases this is so severe as to cause the greatest dread of sudien or violent movement. In others, the patient is unable to sit, on aceount of the discomfort caused by pressure on the bone. The most trying process is that of rising from a low seat, and, to accomplish this, the suflerer will obtain all the aid that is praticable, by assistance with the

1 Scanzoni, op. cit. 
hands, which will be placed as auxiliary supports upon the edges of the chair or stool upon which she rests.

Differentiation._.'The only conditions with which this may be confounded are painful hemorrhoids, fissure of the anus, and a spasmodic condition about the museles of this part, due to asearides in the reetum. From these a careful and thorough pliysieal examination will always readily distinguish it.

Prognosis.-Coceyodynia often lasts for years, annoying and distressing the patient, but never to any degree depreciating her health or constitutional state. If left to nature it may wear itself out, but it is probable that it would generally remain for a long time if not relieved by art.

Treatment.-Before any plan of treatment is adopted, care must be taken to discover whether the disorder is seeondary to uterine disease or anal fissure. If it be so, the primary disorders, and not their results, should receive attention.

If the coccygeal disease be primary, blistering, the use of morphia by the hypodermic method, and the persistent use of the galvanic current will often effect a cure. While they are being tried, the use of iodoform as a reetal suppository may be with advantage employed together with all general means calculated to improve the tone of the nervous system.

Should these means do no good, and the patient's condition demand relief, recourse shonld be had to one of two radical methods of cure, section of the diseased muscles, or amputation of the bone to which they are attached. The first, placed at our disposal by the late Prof. Simpson, consists in severing the attachments of all the coccygeal muscles; the second, in extirpating the coccyx itself, after the plim of Dr. Nott.

The first operation may be performed subcutaneously by an ordinary tenotomy knife. This is passed under the skin at the lowest point of the coceyx, turned flat, and earried up between the skin and cellular tissue until its point reaches the sacro-coceygeal junction. Then it is turned so that in withdrawing it an incision may be made which entirely frees the cocryx from muscular attachments. The knife is then introduced on the other side so as to repeat the section there. As is usually the case in subcutulueons operations, no hemorrhage occurs unless some large vessel be injured. I have resorted to this procedure but once, when I found it exceedingly difficult of accomplishment, and it proved an entire failure in giving relief:

In fat women subcutaneous section of the mnscles attached to the coccyx is by no means so easy a matter as one would suppose who has not made the experiment. Under these circumstances the operation is simplified and rendered more certain by making an incision down upon the coccyx, lifting the exposed extremity of this bone with the finger, and then with a pair of scissors severing the muscles. This procedure is both 
easy of performance and certain as to result ; that is, supposing that it is resorted to in a case really demanding it.

Should detachment of the muscles fail, as it will do if the bone be diseased, an incision should be made over the coccyx, the bone laid bare by severance of its attachments, and the whole of it removed by a pair of bone forceps, or disarticulated by the knife as practised by Dr. Nott in the case alrealy mentioned. By one of these procedures cure can be confidently promised, and as neither is attended by danger, our resources in this affection maly be regarded with great satisfaction.

Many slight cases of coceyodynia occur, however, which pass away with time and palliative treatment. The gynecologist should take care that operation is not resorted to too early.

Tumors of considerable size may spring from the external organs of generation. Thus we may lave tumors resulting from hypertrophy of the clitoris, or of the nympha, lipoma of the labia majora, and cystic tumors of large size growing by a pedicle from the same site. Malignant disease also frequently attacks these organs, where it runs its usual course: differing in nothing from its career in other locations.

We have now considered the most important of the diseases of the rulsa. To treat of them all would be to devote a larger space to the subject than a work of this character could afford. Certain important pathological conditions of the hymen would be treated of here were it not that they will receive notice under the head of retention of menstrual blood.

I have usually considered in this connection rupture of the perineum, but as a very obvious advantage, which I feel sure the reader will appreciate, attends haring that subject succeed prolipse of the ragina, bladder, and rectum, I have transferred it.

\section{H A P T E R IX.}

TIE FEMALE PERINEUM: ITS ANATOMY, PHYSIOLOGY, AND PATHOLOGY.

$A$ CiBEAT deal of the diversity of opinion concerning the propriety of the repair of the ruptured perineum, as well as of the difficulty attending the comprehension and performance of the operation, is, I think, due to an inenrect understanding of the anatomy of this part. While the anatomy of the male perineum has been conscientiously studied, that of the fermale has been singularly neglected, and this neglect has reflected a 
decided influence upon the knowledge of its physiology, pathology, and surgery.

The conventional methor of dealing with the anatomy of the female perineun is to pronomee it the floor of the pelvis; the space extending from the inferior commissure of the vulva to the ants, and composed of skin, cellular tissue, aponenrotic union of muscles, and the mueous membrane of the vagina. Tyler Smith begins his remarks upon this suljjeet with these words, "To the obstetrieian the anatomy of this part is matter of great interest," and yet he gives such a deseription of it as I have stated above, and represents it by an illustration showing the union of the spluineters of the anus and vagina, ete. I'layfair, in his late excellent work, dismisses the subject, which he pronounces one "of great obstetrie interest," with less than eight lines, just three more than Leishman lias allotted to it, and four more than it receives in Meadows' Manual of Mislwifery.

Upon such topics French writers are usually quite minute and full ; but Cazeaux deals with the female perineum, in his "Traite de l'art des Aceouehements," in three lines and a half, and Joulin does not mention it.

A few words now as to some of our own authors. Meigs, who deseribes the fourehette quite at length, does not describe the perineum at all, nor is any mention made of its anatomy by Bedtord, Byford, or Miller.

Obstetrie writers may defend this omission by the assertion that they do not write of anatomy but of obstetries, and that the student should come to them informed upon this subject. Let us, then, turn to the writers on anatomy upon whom our students at present rely. Cruveilhier, one of the most accurate and exhaustive writers upon gross anatomy, after describing quite fully all the external organs of generation, limits his remarks upon the female perineum to an enumeration of its muscles and fiscix, saying not one word of its functions, its shape, or its important relation to the pelvie viscera. Wilson and Gray, after enumerating the organs of generation in the woman, say nothing of the perineum. But Holden ${ }^{1}$ promises better things. On the middle of a page, in large letters, appear the words, "The Dissection of the Female Perineum;" then follows a study of all the external organs of generation, and nowhere appears one word about the perineum which he started out to disseet, except an allusion to its vessels; and for these the reader is referred to the male perineum.

Even if the plea which I have mentioned were arailable for obstetrieal writers, it would not be so for those upon gyneeology, and yet in not one systematic treatise does any deseription of this organ appear, exeept In the last edition of my own, and that is, I regret to say, very imperfect indeed. A vast deal is said about the eauses of rupture and methods 
of cure, but nothing about the meehanies, the physiology, the philosophy, if I might be allowed the pluase, of this important organ, which is ealculated to make the student otherwise than superficial with reference to the subject.

So far as my knowledge extends, we owe to Dr. Savage, of London, the demonstration of the fact that the perineum or perineal body is, in the female, a triangular wedge composet of fascia and areolar tissue, which fills the space intervening between the backwarl curve of the rectum and the forward curve of the vagina. Long before his writing, sections of frozen bodies had been made, showing this anatomical fact; but he, I believe, first named this triangle the "perineal body" and drew our attention to its significance and uses.

The diagram ordinarily employed to convey to the student an idea of the anatomy of the perineum and the relations of the pelvic organs of the female is that represented in Fig. 41.

Fig. 41 .

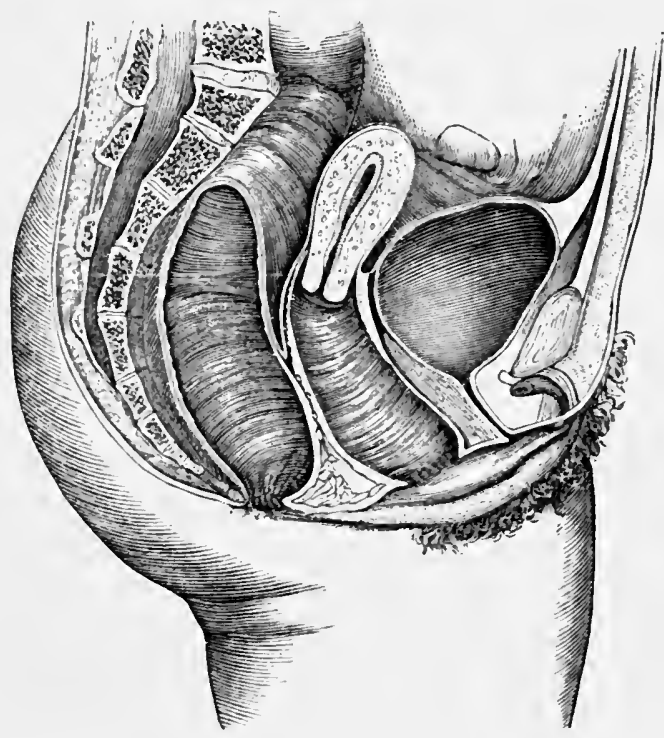

Diagram ordinarily used for representing the perineum.

This certainly portrays a state of things which never exists, unless artificially produced, and listorts the reality to such an extent as to be productive of absolute evil, yet this is the diarram employed by Gray, Wilson, and many others, and even to-day it is quite commonly copied into works dealing with this subject in a special manner.

It is, I think, incumbent upon the obstetrical and gynecological writer to give to the student at correct idea of the perineum. It alpears to me 
that the anatomy and uses of a part should be simultaneously described, if any practical utility is to arise from the deseription. P'resent to the student a hypothetical, supposititious diagram of the female perineum-such as that seen in Fig. 41-and one can readily look with charity upon his regarding it as a part of little importance, and pardon the young pantitioner who talks flippantly aloout the triviality of its rupture, and is alyathetic at the bedsile as to prevention of the accident.

In the living and, indeed, in the dead body, the vagina never gapes, as represented in this diagram, and never so distorts itself unless distended by some foreign body which separates wall from wall. It no more stands distended without some snch influence than the urethra does when undistended ly a sound or catheter. The normal vagina is a collapsed canal, and its anterior wall rests directly upon the posterior, and is sustained by it. 'The gentle passage of a small cylindrical speculum, the patient lying upon her back, or of a small Sims' speculum as she lies upon the side, will make this fact quite evident. To the finger gently passed up it is FIG. 42. made equally apparent.

Henle has marle a study of the vagina by transwerse section, and represents it by the following diagram :-

IIere the anterior and posterior walls are seen lying directly and closely in contact.

Fig. 43 represents my idea of the true relations of the vagina, bladder, uterus, reetum, and perineum to each other. At first sight it resembles closely Dr. Savage's diagram, but examination will show that it differs materially from it in these respects-the uterus is lower in the pelvis, more inelined forwards, and the vagina, instead of consisting of a canal with a single eurve from behind forwards, presents a double curve: first, a decided one, from behind forwards, and second, a very slight one, from above downwards and backwards. It is the result of careful observation at the bedside for years, with special reference to this point, and I cannot doubt that every one examining upon the living subject with referenee to the position of uterus, bladder, and rectum, and the shape and direction of the raginal canal which it portrays, must admit its accuracy. One thus examining is apt to regard the perineal body as exaggerated; but the prominence given to this is fully endorsed by Savage, and it must be borne in mind that this represents a perfect and typical organ, unimpaired, as it so often is, by influences which will soon be considered.

Here the perineum is represented in all its importance of function and essential bearing upon the maintenance of a proper relation of surrounding parts. Instead of appearing as a flat surface consisting of skin, areolar 
tissue, and tendinous expansion of muscles filling the space intervening between the anus and rulva, it is seen as the "perineal body." Triangular in shape, composed of strong and elastic connective tissue, it is bounded upon its superficial face by the plane ordinarily described as the female

Fig. 43.

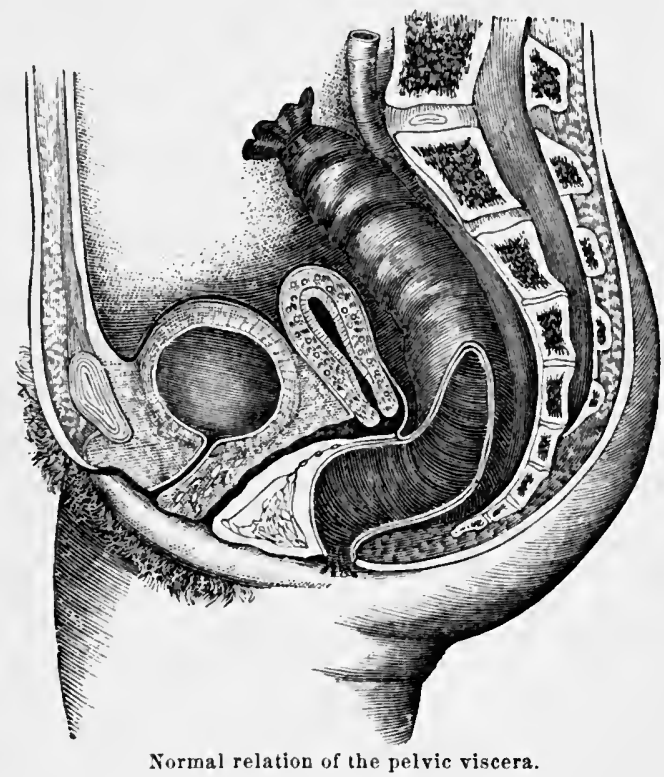

perineum. It is a coneavo-convex triangle. Its anterior side, very slightly convex, sustains the inferior wall of the vagina, while its posterior side, decidedly concave, supports the anterior wall of the reetum, which naturally arches forwards to fill its coneavity, and prevents its prolapsing into the vagina and out of the vulva.

At its upper portion, the vagina, it will be observed by reference to the diagran, forms a depression which reeives the cervix uteri which rests within it, impinges upon the rectum, and is to a eertain extent sustained by the shelf-like aetion of the tissue at the junetion of the upper and lower vaginal enrves. All this is faet, not theory, and all of it can be verified at the bedside by an unbiased investigator.

If the perineal body just described be regarded merely from a mechanical point of view, as an inactive mass of tissue, its influence in the coordination of pelvie support may well be doubted. Let it be remembered that it rests inferiorly upon a set of museles whose union occurs at the space between the anus and vulva. The contraction of these throws the perineal boly forwards and upwards, presses it against the anterior wall of the vagina, and thus makes of it an aetive agent in giving support. In 
some cases this action is so strong as to become abnormal and to canse dysparenaia, or to render coition entirely impracticable. So marked is this at times that the perineal body has to be cut through hy the knife to overcome the diffieulty.

We are now prepared to appreciate the functions of the female perinenm or perineal body ; for I feel that the whole triangle must be described as the female perineum, if we ever intend to ineuleate true, rational, and reliable precepts as to management of this part during labor, and in reference to uterine displacements. Its functions are the following: 1st, it snstains the anterior wall of the rectum, and prevents a prolapse of this, which would incvitably drag downwards the upper vaginal concavity, and with it the cervix uteri, and destroy the equilibrium of the uterus; $2 d$, it sustains the posterior vaginal wall, and prevents a prolapse of this, which would allow of rectocele; $3 \mathrm{~d}$, upon the posterior vaginal wall rests the anterior, upon this the bladder, and against the bladder the uterus; all of which depend in great degree for support upon the perineal body; 4 th, it preserves a proper line of projection of the contents of bladder and rectum, and this prevents the occurrence of tenesmus, a frequent cause of pelvic displacements.

Remove this triangle, and the relations of the pelvic viscera are liable to grave distortion; as the removal of the keystone of an areh of masonry would effect the same result in the structure which it supports. The change is not immediate or so striking, for there we deal with inelastic and brittle substances, here with elastic and resilient ones; there with parts unattached to outside supports, here with those attached through the areolar tissue of the pelvis to its bony walls. Let me show the keystone action of the perineum by means of two schematic diagrams, which considerably exaggerate its dimensions.

The triangle in black in Fig. 44 represents the perineal body in exaggerated form, and shows its action as the keystone of an arch, the sides of which are made up of the anterior rectal and posterior vaginal walls which rest upon it and are sustained by it. Fig. 45 shows the effect of removal of this. Now no longer do the parts which rest against it receive support, and their immediate tendency is to fall downwards and outwards. I now remove these exaggerated diagrams and show the eflect of destruction of the perineal body by others.

As the posterior vaginal wall prolapses, it is followed by the anterior rectal wall; this effices the superior vaginal depression and drags directly upon the eervix uteri which descends likewise. As the anterior wall descends, it is followed by the posterior wall of the bladder, this to a certain extent by the whole organ, and this, being attached to the uterus, by it likewise.

Previous to the establishment of this abnormal relation of the pelvic viscera to each other, the bladder was, by its apposition with the uterus, 
a means of anterior support to it. Now it not only ceases to perform this useful function, but becomes an absolute and direct tractor upon it.

FIG, 44.

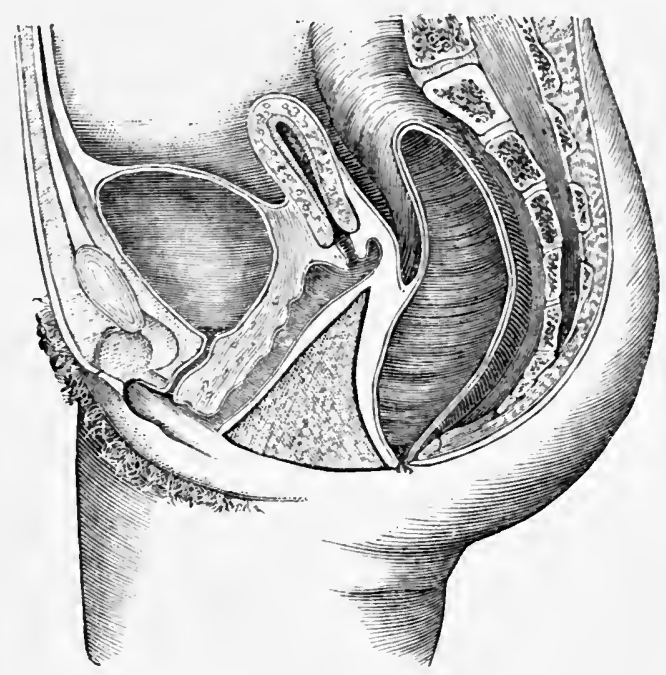

Schematic diagram of perineal body.

FIg. 45.

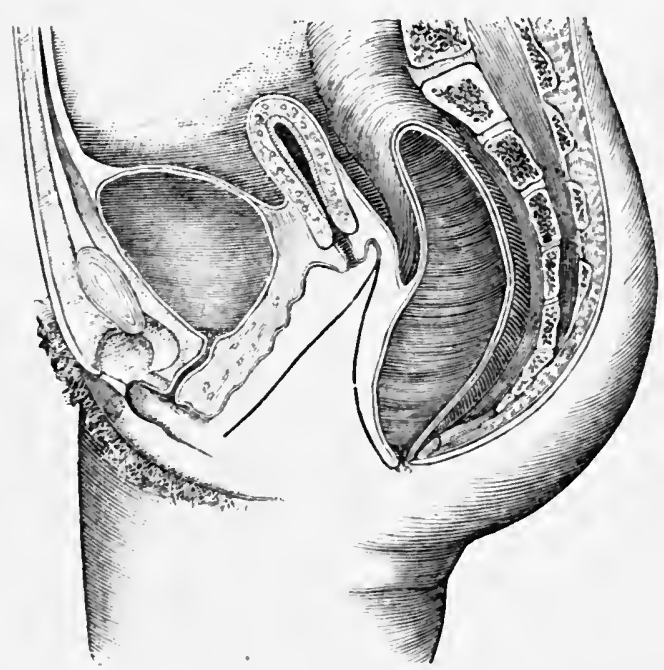

The same, perineal body removed.

It may be objecterl that the keystone in this case is an inverted one, and that therefore the comparison does not hold good. But this is not a 
valid eriticism, for the inverted keystone is attached above, and therefore has an action which it would not otherwise possess.

Fis. 46 .

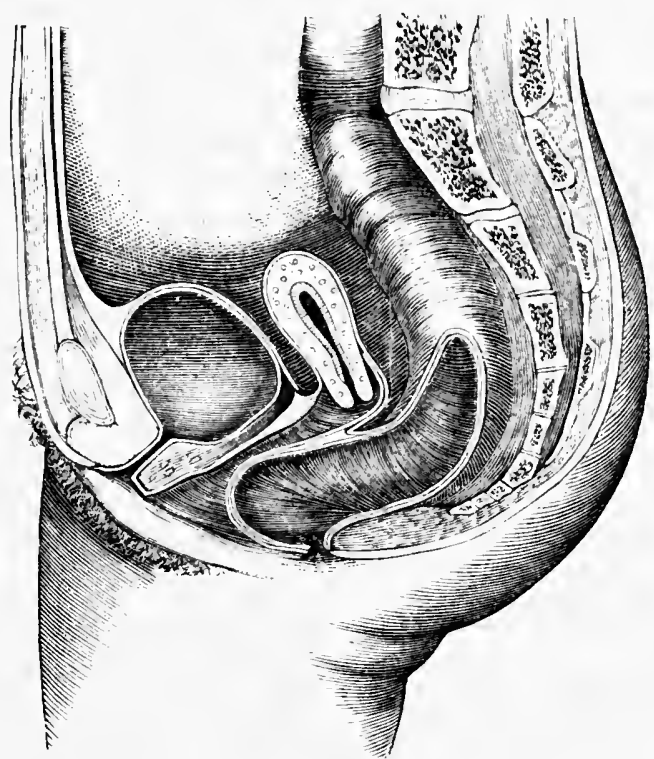

The perineal body destroyed, the rectal wall descends.

FIG. 47 .

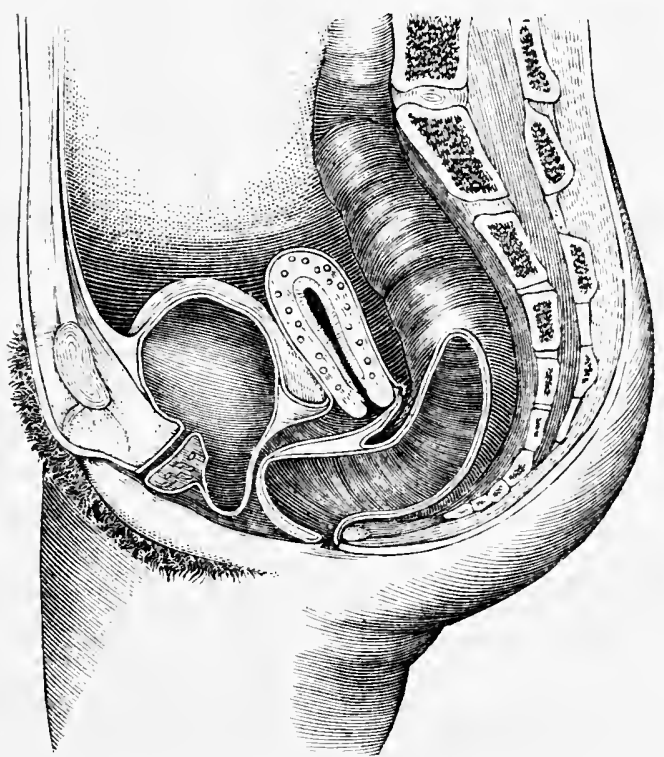

The perineal body destroyed, buth rectal and vesical walls descend. 
I now proceed to point out another mechanical prineiple involved in the support of the pelvie viscera and afforded by the anatomical arrangement of these parts. An examination of Fig. 43 will show that the posterior vaginal wall is decidedly concave in its upper half, and very slightly con vex in its lower. Let us examine first the mechanism of the upper half, and then of the lower. Take a strip of steel or whalebone (Fig. 48), put one end (A) upon a table, and giving it the shape of the letter $\mathrm{C}$, make pressure upon its upper end $B$, and the elastic band will always yield in one direction-towards its convex surface-in the direetion shown by the arrows.

FIG. 48.

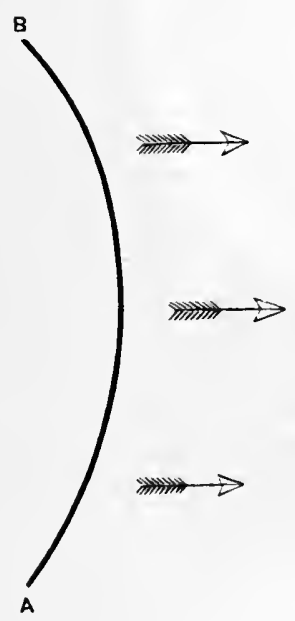

An elastic rol when bent yields towards its convex surface.
FIG. 49.

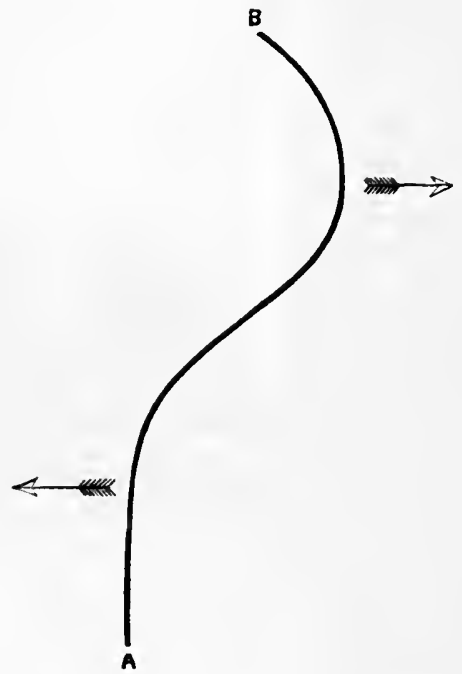

An elastic rul with donble curves yields in opposite directions.

Now change the shape of the elastic strip, so as to give its lower half a slight anterior eurve in a direction opposite to that of the upper, and make presure as before. The upper half will yield towards its convex surtace, in the line of the arrows (Fig. 49); but not so the lower. This will yiehl towards its convex surface and in an opposite direction.

Now apply this to the posterior vaginal wall under the influence of presure. The upper encave portion will yield towarls the rectum, and receive support from it and other structures resting in the hollow of the sacrum. The lower, slightly convex portion will tend to fall forwards, andl. if the pressure be exaggerated, downwards. But in a normal state of the parts, the anterior vaginal wall and hadder arrest this tendeney and the posterior wall is enplported.

Let us carry this a little further and see what the effect of destruction of the perineal body would be. The condition shown in Fig. 49 is then 
greatly racugrerated, an absolute $S$ being created, and the lower portion of that being withont support from the blather, whicts is no bonger in (on)tale with it, prolapse beeomes almost inevitahle. Fig. 30 will demonstrate: this.

liut it must not be supposed that gravitation is the only influenet? which, under these circumstances, disturbs the relatims of the pelvie vistera. 'Two otlee influences ald themselves to those just mentioned to still farther foree downwards the anterior and posterior vaginal walls. Prolapse of blatkler and recum distort the line of extrusion of the eontents of these viseera, and thus to more tration upon the parts above, elirect expulsive power is brought to bear. And now, too, the nterus, dragged downwards from its position by the heavy vagina and still heavier blatder, adds its weight as an influence calculated to increase the existing tendency to prolapse of all the viscera of the pelvis. It falls downwards, forwards, or backwards, offering an instance of some one of those uterine displacements which we so often meet with, and which cause practitioners so much annoyanee and pationts so much discouragement.

One approaching the subject in this way is prepared to comprehend the significance of the destruction of this boty, and to appreciate the effect which its withdrawal would exert upon the relations of the pelvic vis"ra. Appreciating the important

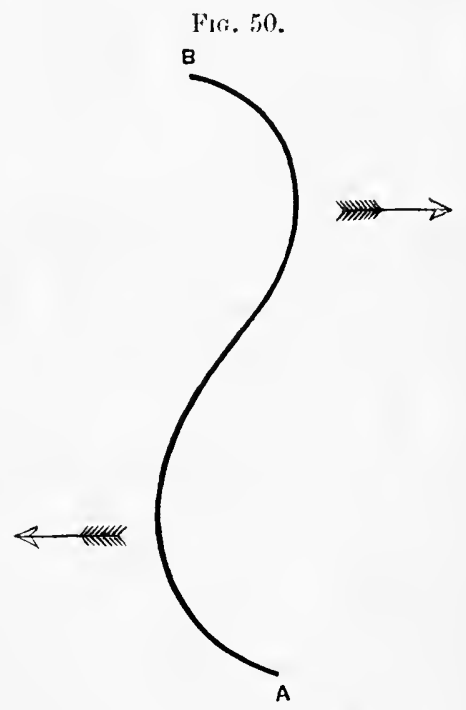

An plastir strip, rith decided eonvex curve beluw, will very decidedly yield in the direction of lower arrow. relation of the little studied and little recognized triangular perineal hody, le recognizes in it a wedge turned base downwards and acting as the keystone of an arel upon the integrity of which depends the support of organs which, deprived of its co-ordinating mechanical influence, would tend to fall downwards, bringing with them other parts which they in turn sustain. Let us row inquire what those influenees are which commonly disable this wedge or keystone, and render it ineficient and wortlless. The perineal body may lose its tonicity and efticiency trom the following calses :-

1st. From constitutional feebleness.

2d. From feebleness the result of prolonged orerdistention.

31. From subin rolution.

4th. From senile atrophy.

5tl. From laceration. 
In a very few cases, in girls of weak, delicate fibre, the perineal body will, withont other assignable cause, be found to be totally worthless and entirely incapatble of performing its functions. Such eases are not eommonly met with, but they do unquestionably exist, and every pratitioner of large experience must have met with them. In such cases, the virgin vagina presents to the finger the characteristics of that which has given birth to children, and not only vaginal walls but perineum are extraordinarily relaxed.

Either in the virgin, the nulliparous married woman, or the multipara, the uterus, from increase of its own weight, or from suddenly applied pressure from above, may become sudhenly or gradually completely prolapsed. When such prolapse occurs, and the uterus for a long time remains between the labia, the perineal body, by orerdistention, loses its power, and after restoration of the uterus to its place remains entirely enfeebled. This condition is likewise produced by inversion, the presence of a large fibrous polypus, or the wearing of large, globular pessaries.

As utero-gestation advances, not only does the uterus grow with the growth of the fetus: the vagina, uterine ligaments, mamma, and perineum likewise undergo a physiological hypertrophy, whieh continues till delivery. After this has taken place, that retrograde metamorphosis, styled involution, may fail in any or all of these parts, which then remain large, lax, and wanting in contractile power. This failure may affect the perineum, in eonsequence of a laceration more or less profound, and the absorption of septic material subsecquently. Or it may oecur, as subinvo. lution of other parts often does, without assignable eanse. I am not aware that this condition attracted any attention, as connected with the perineum, until $I$ called attention to it in this work some years ago. As to its existence there can be no doubt, and it certainly produces evil iesults which are seareely less striking than those resulting from laceration. The difficulty of accounting for complete loss of power, as evidenced by extreme relaxation of the perineum, will be reeognized in the literaturs of this sulject by an attempt to explain the condition by supposing that in such cases the perineal borly has been sundered from above without any laceration having been inflietsel either upon its mucous or cutaneous surface. 'This is a very convenient way of solving the problem, but until proof' of this theory is given, its validity may well be questioned.

Subinvolution often affects vagina and perineum simultaneously, and although the latter appear to be nornal in size, and uninjured by the parturient process, it is found loose, atonic, and feeble. The anterior vaginal wall and bladder sag downwards for want of support, and the posterior vaginal wall and reetum protrude over the ineflectual perineal barrier. Instances of this pathological condition are very common, and uterine displacement, as a result of it, will be frecquently seen.

Cares of complete uterine prolanse in very old women, in whom both 
uterns and vagina have long mudergone senile atrophy, are not by any means rare. Here the uterus does not deseend primalrily, but an absorption of the adipose tissue, which is stored away aromm the vagina, and serves as a support for it, ocenrs ats the decadence, of advancing age shows itself, and a perineum hitherto strong becomes ineflicient and inactive.

linpture of the perineum may simply be described as a splitting of the perineal body. Laceration in the first degree splits the triangle, one side of which is covered by the vagina, only for a short distance; one in the second degree splits it to its centre; while those in the thind and fourth divide the triangle entirely through, and at once remove the keystone from its place in the areh.

Destruction of the power and function of the perineal body, more frequently than anytling else, induces anterior and posterior displacements of the uterus and prolapsus in its three degrees. Removal of the perinenm does not take away support from the uterns, but it alters the shape and removes the supports of the vagina, and causes it to drag upon and displace the uterus as a direct tractor.

A curious phenomenon, which oceurs in about one out of a liunared eases of destruction of the power of the perineal body, while in itself not important, serves to show how markedly the relations of the pelvic organs are in this way impaired. I allude to entrance of air into the vagina. While the pelvic organs are in normal condition, the cluse apposition of the vaginal walls, already alluded to, entirely excludes the spontaneous entrance of air, and at once expels it if forced in. Let the perineal body be entirely exhausted, however, and ecrtain positions assumed by the woman draw air into the eanal, which subsequently escapes with a disagreeably explosive sound. This occurrenee has been described ${ }^{1}$ under the names of garrulitas vulva or flatus vaginalis, and deserves some attention, in view of the fact that it alarms patients who are at a loss to account for it, and mortifies them by its happening at untoward times.

So intimately are gynecology and obstetrics connected, in reference to this subject, that a few words upon its relations to the latter will not be inappropriate. It is no exaggeration to say that a very large proportion of female diseases take their origin in the mismanagement of the lying-in chanber. If this be so, and no gynecologist will deny it, to the obstetrician the importance of the perineum in this connection cannot be exaggerated. Its rupture furnishes one of the most fruitful sources for the absorption of septic elements, and I do not hesitate to say that thousands of women suffer throughout their lives from uterine displacements, engorgements, and vesical and rectal prolapse in consequence of injuries inflieted upon it during the parturient act. To an imperfect eomprehension of the anatomy

1 Ses an essay by Löhlein: Zeitschrift für Geburtshülfe und Gynäkologie, Bal. v. IIft. 1 . 
and functions of the perineum $I$ attribute, in great degree, the improssicn entertained by many preatitioners that, in spite of all that is said, its rupture, so long as it does not involve the anal sphineter, is a matter of little moment. 'This dangerous dogma' — which, in my mind, renders him who entertains it an unfit person to be intrusted with the grave responsibilities of the lying-in chamber-is always based upon the fact that such a furatitioner has seen many perineums ruptured during labor, and even withent interferente on his part has, to use the conmon phrase, "heard nothing of them atterwards." But such a loose method of drawing deduetions is hazardous as well as unphilosophieal. How do they who draw them know how many eases of septiexmia which have oecurred in their practice have been due to the exposure of lymplaties and bloodvessels to the entrance of septie poison, or low many eases of uterine displacement, or vesical and rectal prolapse, treated by themselves or others, have been the remote consequences of perineal lacerations, regarded at the time of their occurrence as of no importanee? If septic poisoning destroy his patient, the medical attendant perhaps attributes her death to "puerperal fever," that hydra-headed monster of the lying-in elamber, which he i: satistied that neither he nor any other practitioner could have prevented. To account for remote troubles oecurring years afterwarls is equally sim1) in his philosophy, for has not the patient lifted heary weights, or fillen, or does not the displaced and congested uterus present suffieient signs of "clironic metritis" to offer this as a seapegoat?

Let us suppose that the perineum bas been torn during labor down to the sphincter ani muscle. In this accident the vagina is always torn, though the grare conseguences attending that aceident when oeeurring in the upper half of the canal, are here prevented by the intervention of the triangle of dense dastic tissue which exists between the ragina and the rectum. An immediate consequenee is the exposure of an extensive raw surfuce indisposed to heal by first intention, richly supplied with blood and lymph vessels, and quite near to chains of lymphatic glands, intrapelvic and inguinal. Over this surfice the flow of an ichorous, fetid, and semi-putrid animal fluid must, in spite of the greatest preeantions, steadii. fass for from two to three weeks; a fluid consisting of lecaying and flaking decidna, disorganized blood, and quantities of mueo-pus. The wonder is, uot that septicamiat aceurs io often under these circumstances, but that so many cases eseatpe it, where everything spems so perfectly arranged to favor it. Let one imagrine a wound an inch deep and an inch and a half long, made in the thigh mear the groin, or on the arm near the axillat. and bathed esery hour of the day with the lochial discharges of a parturient woman! Would he regard the occurrence of lymphangitis, phlebitis, and

1 Ses upon this stabject an mxpellent paper in rol. iv. of the Am. Gynecological Suciety's Trans., by Lr. J. Taber Johnisol. 
erysipelats as being unlikely consequences? Amb yet this is what oecurs to every lacerated perineum; the wound thus trated being in no mannel protected against the evils incilent to such exposure.

If cases of decided laceration of the perineum were elosely followed up from the lying-in room to the end of life, and all the evils which immediately and remotely arise from this aceident intelligently noted, the list. would be a long one; all not, of course, showing themselves in every case, but some oceuring to one woman and some to another. It may be thus presented:-

Septicamia.

Anterior and posterior uterine displacement.

P'rolatisus.

C'ystocele.

Rictocele.

Chronic eystitis.

Chronic rectitis.

Cterine engorgement and hyperplasia.

Subin rolution of uterus and vagina.

Destruction of power of uterine ligaments.

Development of a tendency to abortion.

Impairment of sexual gratification to the male.

Nemalgia affecting the site of rupture.

Presented thus, this array may appear unnecessarily formirlable, but there is not one pathological condition mentioned which practical men will feel inclined to question the oceurrence of, as a consequence of puerperal laceration of the perineal body.

As for me, I freely confess that, at the moment of labor, I would rather have a patient sustain a fracture of the radius than a laceration of the perinenm down to the sphincter ani. The broken bone wonld cause pain, sleeplessness, nervousness, and perhaps fever: but it would not expose the patient to the same danger of septicania, or of subsequent uterine, vaginal, rectal, and resical displacement.

$\Lambda$ decided laceration having occurred, if the obstetrician be a man who has familiarized himself with the anatomy and pliysiology of the perineum, it is difficult to understand how he can dombt the propricty of early closure of the wound, both as immediately preventive of septicamia, for for fortyeight hours, during which the healing process seals together the freshly-cut surfaces, the uterine discharges are innocuous, and as remotely preventive of all the evils which have just been enmmerated. Should the operation prove a success, the gain to the patient will be great; if it prove a failure, no evil will have been done.

That there are sonces of failure for immediate operation inherent to the condition itself cannot be denied; but equally fruitful sources for it are to be found in ignorance of the anatomy of the part to be repaired, the 
performance of the operation lurriedly and without system, and the fact that the obstetrician has cultivated no capaeity for sirgery.

This question may here be very pertinently asked: If in the non-puerperal state the perineum should be severed eompletely down to the sphineter ani musele, would prolapse of raginal, reetal, and vesical walls neeessarily oceur? No; not necessarily; though in time probably. On three oceasions I have done this for the delivery from the vagina of very large tumors, and to test the question, I have delayed closure of the perineum. In no case did prolapse ocenr. And why did it not do so when it so commonly ensues upon rupture of the perineum in labor? Because laceration of the perineum during labor or abortion is very commonly the cause of subinvolution of vagina and perineal body. The former remains a large, lax, uncontracting bag; the latter, a yielding, unresisting mass of adipose tissue and skin.

Even after labor, prolapse of these parts does not always ensue upon rupture, even though the sphineter ani and posterior vaginal wall, for some distance up the rectum, be involved. In spite of the accident, involution goes on, the strength of the raginal walls is recovered, and they are sustained, although their shape and direction are altered, and they lack the support of the perineal body. But such an oceurrence as this is the exception and not the rule, and in spite of many such the rule stands unquestionable.

\section{CHA P T E R X.}

PROLAPSE OF VAGINA, BLADDER, RECTUM, AND INTESTINES.

\section{Prolapsus of the Vagina.}

TuE remarks made in the preceding ehapter being distinetly borne in mind, it will be easy for the student to get a eomprehensive idea of prolapse of the pelvic viseera as a consequence of lisability on the part of the perineum, and the subject may be dealt with much more eursolily than it could have been without them.

It might upon very valid grounds be maintained that prolapse of the vagina, or rectum and blaller are so intimately connected with prolapsus uteri, that this chapter should have been united with that upon the latter condition. I have especially avoided this course, for the reason that $I$ wish to direct the realer's attention partienlarly to prolapse of the vagina as a primary condition, one often long existing without uterine lescont, and very freguently preeding that state as a causative influence. For any repetition which may occur in the two chapters, I offer 110 apology, in vew of the great importance of both subjects. 


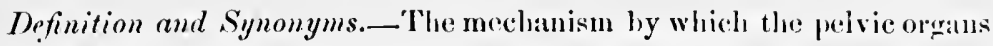
of the female are krept in their proper positions, and relations to ale h other, oflers, in its simplicity and perfection, an excollent rexample of that adaptation of means to an end which is so often repeated in the animal economy. The uterus is so sustained that when necessity reguires it, mot only in pregnancy hut under a number of other circumstanees, it may rise or fall, or tilt backwards or forwards, while the rectum, bladrler, and lowest layer of small intestines are kept in place and allowed to distend and empty themselves without material change of relation.

When the tone of the walls of the vagina is impaired and they ponch into its own canal so as to fall downwards towards the vulva, the condition is called prolapsus. As, however, this results in descent of the uterus, small intestines, bladler, and anterior wall of the rectum, it is often included under the names of prolapsus uteri, eystocele, enterocele, or rectocele. As considemble diversity of opinion exists concenning the nature of prolapsus vargina, it is necessary for us, before proceeding, to comprehend its definition with perfect elearness. By some it is maintained that hernia of neighboring viscera into the vagina should not be included under the head of prolapsus, which, as Colombat declares, is an "inversion of the internal lining membrane, causer by infiluation of the cellular texture that unites the mucous to the subjacent membranes." By others it is believed that true prolapse is impossible without simultaneous displacement of one or more of the surrounding pelvic organs. All admit, of course, that in such an exuberant development or hypertrophy as that which occurs during pregnancy, a portion of the canal may be forced out of the vulva, but this is not what is ordinarily meant by the term prolapsus vagina. Dr. Savage' expresses himself thus upon the point: "Prolapse of the ragina alone, or prolapse of the vaginal mucous membrane alone, are two affections which, anatomically considered, would seem impossible."

It is an important question whether there ean be jrolapse of the vagina without rectocele, cystocele, or uterine prolapse. The anterior or upper wall of the vagina is closely bound to the base of the blatder and the front of the cervix uteri, and by means of the utero-sacral ligaments it is indirectly attached to the sacrum. This wall aids in support of the uterus, bladter, and small intestines. The posterior wall is not so firmly bound to the rectum, though the adhesion at the extremity of the uterorectal pouch of peritonem is quite strong. At the perineal septum, a point a short distance above the vulva, and just at the upper edge of the perincal borly, the muscular walls of the vagina pass off to attach themselves to the ischio-pubic rami. At that point the canal is eonstrieted by the pubo-coccygeus, the true sphineter vagina muscle. The mucous mem- 
brane of the canal jasses down to the fourchette. These anatomical arrangements account for the fact that prolapse of the vagina without simultaneous displacement of one or more of its surrounding viscera is exceelingly rare, and that when it does oceur as a distinet disease it is very generally found to affect only the posterior wall. I have met with no case in which the anterior wall has decidedly prolapsed without coincident descent of the bladder, but I have seen repeated instances of prolajse of the posterior wall without alteration of the position of the reetum.

Pathology.-Any influence which impairs the natural tonicity and strength of the raginal canal, renilering it abnormally voluminous and lax; which alters its natural shape and the incurvation of its walls; or which destroys its lower buttress or support, will tend to induce this aftection. As pregnancy and parturition combine most, and often all of these, they very generally furnish both predisposing and exciting causes. The development of the vagina, and increased weight of the uterus dependent upon the former, and the distention of the canal and enfeebling of the sphincter muscle ineident to the latter, all unite in favoring prolapsus. As the fibre cells, which constitute the nascent state of the uterine muscular fibres, develop, so as to make of the insignificant non-pregnant uterus the powerful organ which expels the child at full term, so do those of the vagina, the Fallopian tubes, and the uterine ligaments. By the proeess of involution which diminishes the size and weight of the uterus, these parts likewise return to their original dimensions. Those influences which arrest this important process in the uterus, resulting in subinvolution, likewise affect it in the other parts mentioned, and render them atonic and feeble.

Prolapsus vagina is very rare, except in those who have borne ehildren, althongh it may oceur. Sir Astley Cooper met with it in a girl, aged serenteen, who was arlmitted into Guy's Ilospital, for supposed prolapsus uteri, and Prof. Meigs' mentions that Dr. Mutter, of Plibalelphia, saw it occur in a child six months old in consequence of a convulsion.

Canses.-From what has just been said the following canses will naturally suggest themselves as those most likely to produce this displacenent :-

Violent efforts of the abdominal muscles ;

Reprated parturition;

Senile atrophy of vaginal walls ;

Rupture of prineum ;

Previous listention by tumors;

Long-continued varginitis ;

Subinvolution of the ragina and perinenm.

Of all these causes the last is the most frequent, inore especially when 
it accompanies, as it often does, partial rupture of the perinem. Next in frefuency stand senile atrophy and absorption of surromuling anlipase tisiste.

It is evident that all act either by debilitating the power of the vacrinal walls hy more mechanical distention, by specifically rohbing them of their tonicity, or by renoving the buttress ananint which the canal rests at the rulvis.

Terieties. - The displacement may be of two forms, acute and clironic. 'Tle power of the eanal may be overeome by a violent effort, a fit of conghing, nterine or abdominal contractions, or similar acts, which with great suddenness, foree the contents of the abdomen dewn mon the pelvie viscera. This occurrence, which is very rare, is generally accompanied by sudden descent of the uterus, or occurs soon after parturition. The ordinary form of the affection is that in which hy the slow and steady action of one or more of the causes enumerated, the resistance of the vagina is gradually overcome, and little by little a fold is forced downwards towards and through the vulva. 'The first variety is the result of a few minutes' efforts; the second, that of montls, or even years of morbid action. Prolapse of one wall, partial prolapsus, as it has been styled, is often lost sight of in view of the hernia of the bladder, rectum, ot small intestines, which accompanies it. Hence eystocele, rectoecle, and enterocele may be regarderl as complications of the affection.

Course, Duration, and Treatment.-A sudden attaek of prolapsus being overeome by proper means, and the patient kept quiet, may disapprear, and not return; but in that variety which occurs gradually there is no limit to the duration of the disease. Generally, the physician is not ealled until it has existed for a long time and become chronic. The most important results of the condition are prolapse of the uterus, bladder, and rectum, one or more of which are almost sure to ensue.

Progmosis. - The prognosis as to cure will depend upon the degree and duration of the malady. It is always, whatever be its extent, susceptible of considerable relief by surgical means, but generally proves ineurable by those of medical eliaracter.

Symptoms. - Should displacement of the ragina exist alone, that is, without ereating hernia of surromeling organs, the patient will complain of a sense of discomfort in the ragina, with a tendency to bearing down, as if to expel some foreign boly ; a feeling of heat, fulness, and throbbing of the vulva; a certain amount of pelvic nneasiness in walking or making aly muscular effort, and a tendeney to become fatigued, if the condition be one of acrorawated character. Physical exploration will reveal the presenee of a tumor between the labia, which touch will demonstrate to contain no lipuid, and yet not to be solid in its nature. Sometimes the mueous membrane covering it is excoriated, ulcerated, and purple in color ; at other times it will be smootl, shining, tough, and covered by parement 
epithelium. A simple vaginal prolapse of any extent is, as has been stated, quite rare. When it does occur it generally affects the postinior wall, but prolapse, accompanied by hernia, is more commonly found to affect the anterior wall, cystocele existing. Should the case be complicated by vesical or rectal prolapse, the symptoms just enumerated will present themselves with the addition of others dependent upon disturbance of the functions of the part which forms the hernia. In one case the prominent symptoms will point to the bladder; in another, to the rectum; and, in very rare instances, to the small intestines.

As the treatment of prolapsus vagina is, with slight modifications, the same for uncomplicated and complicated cases, it will be considered after the subject of vaginal herniæ has been diseussed.

\section{Cystocele, or Prolapse of the Bladder.}

Cystocele, or vesico-vaginal hernia, consists of descent of the bladder towards the vulva, so as to impinge upon the raginal canal. When the anterior wall of the vagina, which is closely adherent to the bladder, the base of which it in part sustains, ceases to afford the required resistance, the bladder, partly under this influence and partly under that of traction, deseends and forms a small pouch in the vagina. This is at first very small, but gradually it increases, until at last it forms a decided tumor, which protrudes between the labia majora. The pouch thus created becomes filled with urine, which, in the ordinary act of micturition, cannot be evacuated, from its being contained in a species of diverticulum. This undergoes decomposition, free ammonia is formed, and cystitis or vesical catarrh is established, which annoys the patient by pain, heat, vesieal tenesmus, and scalding in urination. Should any doubt exist as to the character of the tumor felt in the vagina, a curved sound or eatheter may be passed into it through the urethra for the settlement of the question.

It is an interesting question whether cystocele is ever the cause instead of the result of prolapse of the vagina. It is probable that it may be so in very rare cases, thongh such a connection between the two affections must le incommon, since the former generally occurs in women who have borne children, and this been exposed to influences which tend to climinish vaginal resistance. Seanzoni ${ }^{1}$ is convinced that the vesical prolapse is sometimes primary, and due to irregular spasmodic contraction of the fibres of the borly of the blamler while the neek remains firm. This forces the urine to the fundus, which dilates and undergoes displacement.

\section{Rectocele, or Prolupse of the Rectum.}

Rectucele, or recto-vaginal hernia, vecurs in a manner similar to that by which the bladder descends. The posterior wall of the vagina not only 
ceasing to give proper support to the anterior wall of the rectum, but dragreing it obliquely downwards, this forms a ponch which soon fills with feeal matters. The feces, becoming hard, and, in corsecquence, irritating, create mucous inflammation and discharge, with tenesmus, obstinate constipation, and hemorrhoids. The tumor thus formed will sometimes epual in size a man's fist, and protruding over the perineum give some difliculty in diagnosis from its size and solidity. This difficulty will at once disalppear upon rectal exploration and the use of an enema of ox gall and warm water. In one instance I saw a patient contined to bed for three or four moutls from one of these sacculated accumulations of feces, under the supposition that cellulitis existed, which by effused lymph harl completely blocked up the pelvis. It may be supposed that such an error will rarely be met with, yet the case which I lave just mentioned occurred to a practitioner of great experience and ability.

\section{Enterocele, or Prolapse of the Intestines.}

Enterocele, or entero-vaginal hernia, consists in descent of a portion of the small intestines into the pelvis, so as to encroach upon the viginal canal. Such a descent usually occur's in this manner: a loop of intestine resting in Douglas's cul-rle-sac stretches this serous prolongation, and, advancing between the rectum and ragina, pushes the posterior wall of the latter before it so as to form a tumor at the vulva. In a similar manner it is stated that the intestine may advance between the bladder and uterus and depress the anterior vaginal wall, but this must be rare, as authors of extensive experience assert that they have never met with it.

Enterocele is not an aceident likely to produce evil results unless it occur during labor, when strangulation may take place. Even at this time such a complication is very rare, for the free passage afforded the displaced intestine lack to the abdomen will almost always preclude this difficulty. Dr. Meigs ${ }^{1}$ relates a case occurring during labor, in which the progress of the parturient process was ehecked by a large mass of intestines until he succeded in reducing the hernia. He says, with reason, that in such a case strangulation or contusion was to have been feared.

One very momentous aspect in which these hernia must be riewed is in relation to puncture of vaginal tumors, oceurring during labor, for ascertaining their contents. No such explorative means should be resorted to without careful differentiation of vaginal hernia of all deseriptions, and especially of that of which we have last spoken. The peculiar s'nsation to the touch, of a tumor filled with air, a resonant sound upon percussion, the detection of peristaltic movements, and careful exclusion of all other forms of tumor which might appear under the circumstances, will serve to avoid error. When it is borne in mind that vaginal tumors 
are very near the inflated intestines, and that they often yield to the touch an airy sensation, it will be appreciated that great caution is necessary in arriving at a diagnosis. Even when the investigator feels positive in his diagnosis, it is always advisable to test the question by capillary puncture and aspiration. Should an intestine be punetured by the little noedle employed, no evil will result.

The following case illustrates the dangers and possibilities of erroneous diagnosis in these eases :-_

A widlow :et. 52, mother of twelve children, the last born twelve years ago. A year since she suffered from prolapsus uteri, whieh was replaced. Patient presents, on examination, a swelling about three inches long, reddish-blue in eolor, protruding between the labia majora, covered with granulations and pus. Diagnosis-Polypus of the uterus; operation for removal. After suffering severe pain in the ahdominal regions for several hours, death ensued. Autopsy-In the pelvis was found a half pound of liquid blood. Eterus and ovaries atrophied. A portion of the great omentum and a piee of the transverse colon were carried away with the mass. In the posterior wall of the vagina, was an opening about $5 \mathrm{~cm}$. in liameter. $24 \mathrm{em}$. of omentum and $10 \mathrm{~cm}$. of the colon were excised.

Treatment of Vaginal Prolapse and Hernice.-Should the accident have occurred suddenly, reduction should at once be accomplished, and the reurrence of the displacement prevented by appropriate means. The bladder and reetum being evacuated, the patient should be placed in the knea-chest position, and, the fingers being well oiled, stealy pressure should be exerted in eoincidence with the axis of the inferior strait, until the prolapsed part is returned to its place. In the case of enterocele alrearly referred to as treated by Prof. Meigs, the patient was placed upon the left side, and taxis being practised, the mass suddenly slipped above the superior strait, into which the next uterine contraction forced the ehild's head. To prevent a relajıse the pelris should be elevated, the patient kept perfectly quiet, tenesmus, if present, relieved by the use of opium, and the vagina constrieted by astringent injections.

lint sudden cases of vaginal prolause and hernia are very rarely met with. It is usually those whieh have slowly and gradually established themselves that we are called upon to treat, and these are always obstinate aul rebellious. The means at our command for overconing such cases are the following :-

1st. Local astringents and tonics;

21. Development of retentive power of the abdomen;

31. Supplementary support ;

4th. Surgical proceelures.

The first of these may be effectual in slight eases, but in those of graver

1 Centralblatt für Chir., May 3, 1879, p. 303 ; Hosp. Gazette. 
character they will prove insuflicient. The toue and strength of thr vagina may be temporarily restored by the use of injections of larers: amomits of water medieated with tannin, alum, or zinc, employed night and morning. 'The patient shonld be sent during the summer to a watering-place, where sea-bathing and injections of sea-water into the vagina may be employed. A very excellent result will also sometimes follow the use of vaginal suppositories eontaining one of the astringents mentionerl.

'Too much stress cannot be laid upon the influence of the abelomen in sustaining the pelvic viscera. An impairment of its foree by want of exereise, and the pernicious habit of disabling the power, and impering the function of the diaphragm and chest nuscles, by tight lacing and the wearing of heavy clothing, is one great cause of their displacement. Improvement in this respect, by removal of the depreciating influenees mentioned, and recovery of lost power by appropriate exercises, is a matter of great moment. But this will be left for consideration under the heal of Cterine Displacements.

Supplementary Support._-In stout women an abdominal bandage with perineal pad, by relieving pressure from above may accomplish a great deal of good when combined with complete removal of all constriction and weight of clothing about the waist. In thin women it accomplishes nothing.

The vaginal pessary, an instrument of decided value in all the displacements of the uterus, does little or no good here. In many cases no pessary which rests upon the walls of the ragina can be retained within the distended eanal; in others none ean be found capable of resisting the lownward pressure; while in all increase of dilatation and atony is effected by them. It is true that for a time applarent goorl results from them, but the hope to which this gives rise is very generally delusive, and very socn they must be abandoned. The function of a raginal pessary is to support the uterus; not to sustain the vagina. In some cases an exception will be found to this rule in Cutter's cup pessary or some similar instrument supported by an external attachment. Here sutficient power is afforded for support of the uterus at a high point in the pelvis, which mechanically puts the lax vagina on the streteb and prevents its prolapse together with that of the bladder and rectum. This instrument will be shown in connection with prolajsus uteri.

Surgical Procedures. - Of these there are three which may prove effectual. If a ruptured perineum seem to produce the want of support, the operation of perineorhaphy may be all that will be necessary. This is described in the next cliapter. Should this not be sufficient, colporrhaphy should be jerformed upon the anterior or posterior vaginal wall, as one or the other seems most at fault; and, should even this not relieve the condition, the remaining wall should be likewise diminished in extent by the same procedure. 
Almost all, except the most aggravated eases, which are accompanied by great hypertrophy in the vaginal walls, will yield to these three proeedures, alone or combined.

Colporrhaphy or Elytrorrhaphy.'-The idea of constrieting the vagina so as to diminish its calibre, and by this to remove the traction exerted by its fall upon rectum, bladder, and uterus, long ago suggested itself to the minds of surgeons. In 1823, M. Romain Gérardin made the suggestion before the Medical Society of Metz, but the operation does not appear to have been essayed, for the writer with a great deal of patriotic zeal states, in a subsequent essay upon the subject, ${ }^{2}$ that "his desire harl been to put beyond controversy the origin of the operation, and to preserve for French surgery the priority of its conception, if not of its execution." While this surgeon was felicitating his country upon the conception of an idea, Dieffenbach, in Germany, and Heming, in England, proved its practicability by absolute performance. Dieffenbach probably operated as early as 1830 , as a report of his having done so was published in June, 1831. In November, 1831, the late Dr. Marshall IIall, of England, published a case, in which at his suggestion it lad been performed by Dr. Heming, the translator of Boivin and Dugès on the Diseases of the Uterus, witlı complete suceess. Subsequent to this period it was performel, with various modifieations, by Fricke, Scanzoni, Velpean, Roux, Stolz, and others; the operation always consisting in "the removal of a band of vaginal nucous membrane and union of the two lips of the wound in such a manner ats to diminish the calibre of the vagina. . . . . Dieffenbach refers to a great number of women who were conpletely eured by the procedure. . . . . . Fricke out of four cases cured three." ${ }^{3}$ Julging from these quotations, it appears that the operation has been known and practised for a long time on the continent of Europe, especially in Germany. In England it had not been resorted to up to the year 1565 , it we may judge from the statement of Dr. Sims that, after a diseussion "pon an esiay presented by himself to the Lundon Obstetrical Society in that year, Mr. Speneer Wells ealled his attention to the operation of Mr. Huming, already referred to, with the assertion that "at least one casc had been successfully" operated upon."

The operation, probably for reasons which I shall mention hereafter, had fallen entirely into disuse when Dr. Sims revived it in 1s.8s, with certain modifications. His operation, which I shall soon describe, differs very essentially from that adopted by his predecessors, and should in

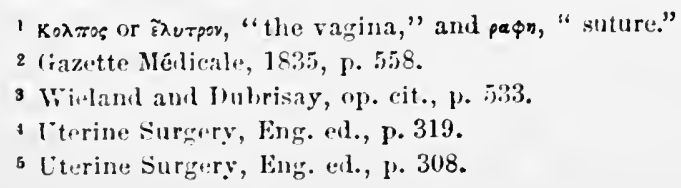


justice he regarded as the parent of the numerous, I had almost said inmmerable, molifications of it which have since appeared.

It is a mischievous error to describe this operation as one performed for prolansus uteri. That that displacenent is one of the complications often existing as a consequence of prolapse of the vargina is true, but the operation is often neeessary when vagina, bladker, and rectum alone aro seriously involved. 'The traction exerted by the descent of these visecra is frequently the cause of uterine displacements of various linds, and that being removed by the operation, the consequent displacement disappears. But the student must remember that colporrhaphy is the legitimate surgical resource for loss of power and displacement of the ragina. To take a different view is to obscure the subject, and to substitute a purely enpirieal for a seientific and rational arrangement.

This error is based upon the belief that the ragina is a uterine support, and that its prolapse allows of deseent of the pelvic viscera; not that it daags them down by its own inherent tractile power. Some writers describe two operations for narrowing the vagina, one for the cure of prolapsus uteri, and another, both being for anterior elytrombaphy, for prolapsus vesica! This is surely a useless and mistaken technicality. Whatever supports vagina, bladder, or rectum takes away direct traction from the uterus, and allows other influences, the retentive power of the abdomen chief among them, to keep the uterus in position. Carl schroder' strikes the true key-note of this subject when he declares that "the only cireumstances under whieh we may expeet a satisfactory result from this operation are when the vaginal prolapse was the primary one."

Sims's Operation of Colporrhaphy._-'The patient, being put under the influenea of an anasthetic, is laid upon a table, upon the left side as for an ordinary speculum examination, and Sims's largest speeulum introduced. A eurved sound, with forked tenaculum points, is fixed in the eervix uteri and made to cause a fold in the anterior vaginal wall, as shown in Fig. 51 .

The parts being steadied by this instrument, the operator, by means of two tenacula, folds over the opposite walls of the vagina so as to decide where union is to be effected. Ilaving settled this point, the mucous membrane is hooked up by a tenaculum several lines above the meatus and cut by curved seissors. The tenaculum lifting the piece thus cut, and when necessary bejng again attached to the mucous membrane, the ineision is carried upwards so as to cut ont a strip extending to one side of the cervix. Then another furrow is eut in the same manner on the other side.

The sound being renoved, and the cervix pulled down by a small tenaculum, the two transcerse lines of denulation, shown in Fig. j2, nearly uniting the two arms of the $V$, are male. 
Sutures of silk are then inserted after the plan employed in raginal fistula, and by them silver sutures are drawn into position. The passage of sutures should be commenced at the apex of the triangle and continued upwards.

FIG. 51.

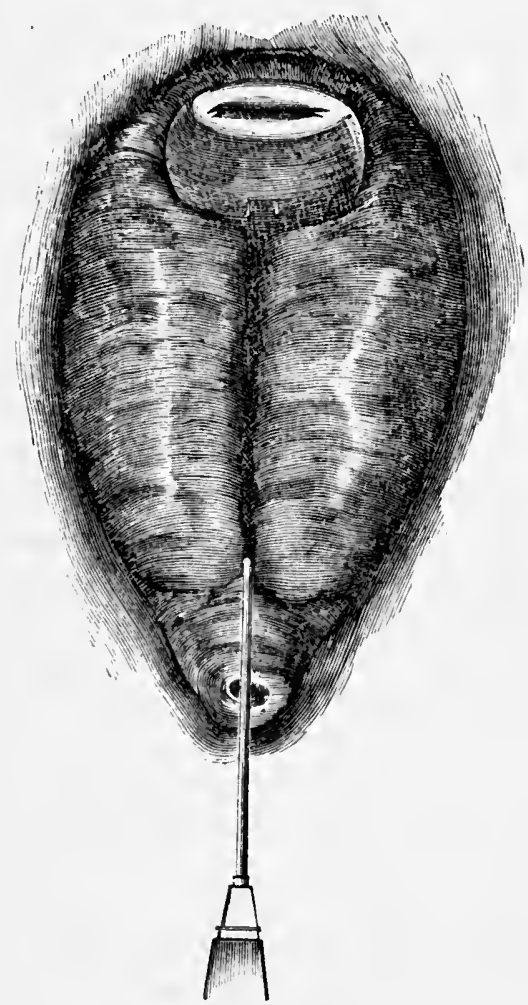

Sims's operation for colporrhaphy. (Sims.)

The after treatment consists in perfect quietude in the lorizontal posture, frequent removal of nrine by a catheter, and the production of constipation by the use of opium. The lower sutures may be removed in ten days, and the upper in a fortnight. The patient should be kept in the recumbent posture for two or three weeks, and cautioned against immolerate muscular cflort for some time afterwards.

Dr. Einmet, finding that the pouch left posterior to the uterine neck by this procedure was sometimes entered by the eervix, improved the operation by extending the transverse denudations so as to make them meet. Ile lias sines the introduetion of this procedure still further simplified it, in the following manner. At the commenecment he catches up with a truaculum a patch of mucous membrane at the proper distance to one side of the cervix, and snips this out with seissors. On the other side he does 
the same thing, and also on the posterior wall of the cervix. IIe then patsies a wire suture so as to bring all these denuded points together, firce to face, and twists the wire so as to fix them. 'The result is that the

Fin. 52.

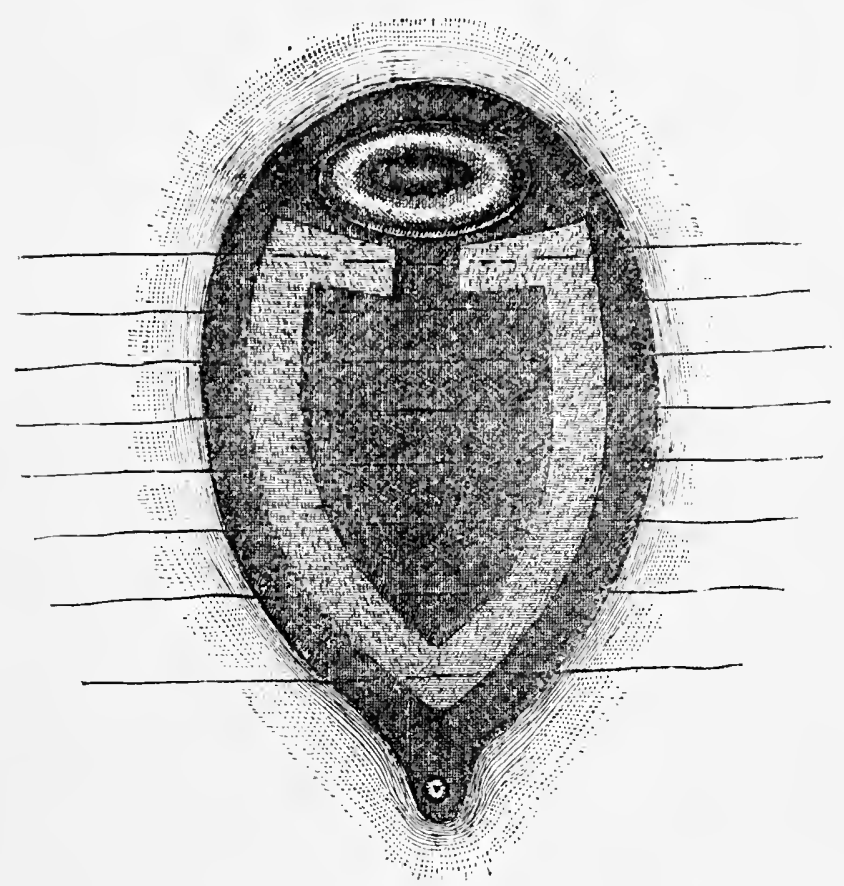

Sims's operation. Shape of denudation and position of uterns.

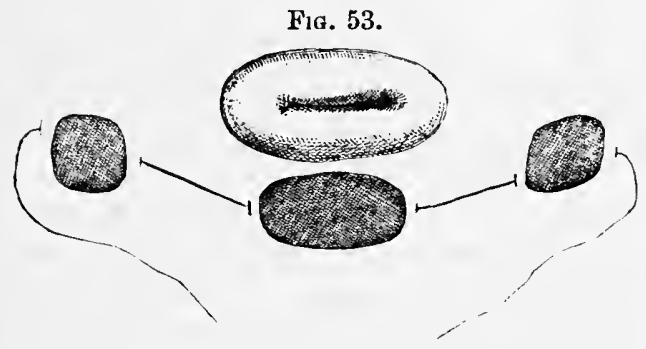

Emmet's operation : first step.

folding of the vagina accomplished by the sounr, as shown in Fig. 51, occurs without the use of that instrument. Catching up a piece of mueous membrane on the vaginal fold of each side with the tenaculum, he now
Fia. 54.

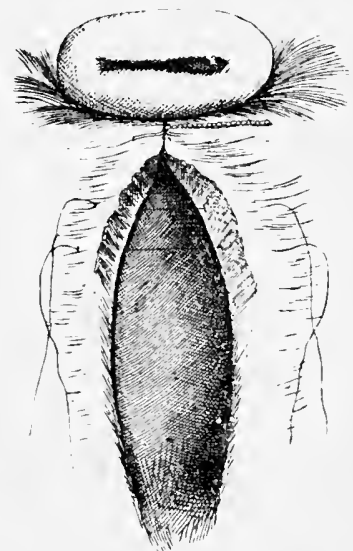

Emmet's operation : second step 
cuts it out and at once passes a suture, and thus he proceeds, step by step, a voiding a great flow of blood, and opposing the abraded surfaces immediately, accurately, and without danger of passing the sutures so that they will not be symmetrical.

As I have already mentioned, there are numerous modifications of this operation, but I shall mention only two more, one for elytrorrhaphy upon the posterior wall, or posterior elytrorrhaplyy; the other for the anterior operation.

The preuliarly shaped triangle of Sims is by no means necessary for this operation. Any tigure which results in constriction of the vaginat wall will remove traction from the uterus and keep the vagina from prolapsing. Thus Hegar turns the apex of the triangle up, and the base down. while others resort to variously shaped denudations. One of the simplest for both posterior and anterior wall is an ovoid figure, the whole of the extent of which is denuded. This form dates back as far as Dieffenbach. It is slown in Fig. 5.5.

Fig. 55.

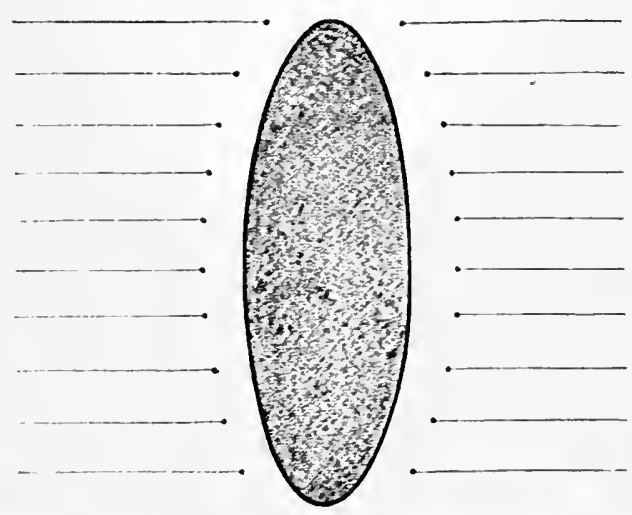

Ofal denudation, with sutures passed.

This operation is easier of performance than the two preceding ones, and gives a stronger and more perfect union of tissurs which is less likely 10 yieh to pressure. When it is performed noon the anterior wall the patient should lie as in Sims's operation just described; when upon the pesterior wall, upon the bark, the thighs flexerl upon the abdomen, and the lateral walls of the vagina retracted by right angled retractors held by assistants. Sinon's operation of "pesterior colporrhaphy" is only a modification of this.

Very generally both anterior and posterior elytrorrhaphy are entirely inperfect resourees unless combined with perineorrhaphy, and the latter 
is often very alvantageonsly united with these under the name of elytrop'rineorthaphy or colpo-perineorrhaphy.

I now proceed to deseribe an operation which has accuired considerable reputation in Franee, and which seems to have at future before it. It is thit of M. Léon Le Fort, and is thus described by him.'

"The uterus being entirely outside of the vulva, without reducing it, I make on the anterior wall of the vagina, the patient lying on the back, four incisions, cutting out a portion of mucous membrane which yields me a raw surface about six centimetres long by two wide upon the part nearest to the vulva. Then, lifting towards the abdomen the prolapsed uterus so as to see the posterior face of the tumor, I make on this part a raw surface similar to that on the anterior wall. That being done, $I$ in part replace the uterus so as to bring the extremities of the two raw surfaces in contact where they are nearest the uterus. I then apply on the transverse border three sutures, reuniting longitudinally the anterior and posterior walls of the ragina; I then proceed to the reunion of the lateral borders by passing from each side a silver thread, traversing the border of the anterior freshened surface, then the corresponding border of the posterior freshened surface. A thread being placed in a similar mamer on the opposite side and at the same level, it is sufficient to tie these sutures to increase by the apposition of the opposite raginal walls the reduction of the uterus. This reduction is completed gradually as the sutures are put in place, and, when the two raw surfaces have been mited throughout their extent, the reduction is complete. The threads which have served as sutures for the transverse border nearest the uterus, being hidden in the depth of the vagina, are difficult of access when after several days union is effected; therefore it is wise to give to these threads sufficiently great length in their twisted part, in order to seize them easily when they become free after section of the part embraced in these loops."

That the operation of elytrorrhaphy has effected excellent results, there can be no doubt. The journals of the day contain numerous reports of cases successfully operated upon by slight modifications of the methods here described. Its disadvantages are, that it is a very tedious process, difficult of performance for one not familiar with this kind of surgery, and liable to failure even if' carefully and thoroughly accomptished. Further than this, it is unquestionable that in a large number of cases expansion of the vagina recurs in time in spite of it. Scanzoni² goes so far as to say that the operation always fails. After employing it thirteen times he says: "From the results obtained in our own cases, we can by no means pronounce favorably on these operations." Courty salys, in speaking of the operation, "The majority of surgeons to-daly regard as useless a method

1 Le Blond, Traité Elémentaire de Chir. Gýn., p. 496.

2 Op. eit., p. $159 . \quad 3$ Mal. de l'Ltérus, p. 748. 
of treatment, which is likewise not devoid of danger." A reviewer of the New York Medical Journal" says: "We have now unde: our charge, a patient operated upon nine years ago by Sims's method; in a year the cicatrices thad given way, and the procidentia returned. Three years ago, she was operated on twice by Emmet's method; in little more than a year the bands gave way, and her condition was worse than before, for the vagina was so deformed by the cicatrices that it became impossible to adjust a pessary." I sliall not, however, strive to accumulate evidence of this kind; I have offered this merely to sustain my statement that there are certain disadvantages attaching to the procedure.

In spite of all this my experience with the operation, combined, be it understood, with perineorrhaphy, leads me to place a very high estimate upon its merits, and to regard it as meeting a difficulty in many cases tor which no other resource is offered either by medicine or surgery.

\section{II A P T E R XI.}

SLRGICAL IEANS ADAPTED TO RESTORATION OF THE PERINEAL BODY.

TuE pathological conditions treated of in the two preceding chapters are so directly connected with loss of power in the perineal body that the surgical procedure adapted to the restoration of that part very naturally comes next under consideration.

I beg the reader to observe that the operative procedure about to be described is not limited to the cure of laceration of the perineum. It is appropriate to the restoration of the perineal borly which las lost its power and fimetion from any eause-rupture, subinvolution, senile atrophy, constitutional debility, or prolonged overdistention. The indication is to fill the triangular space created by the anterior curve of the posterior wall of the vaginat and the posterior curve of the anterior wall of the rectum with a dense, resisting body, which will fit into the space, support the walls just mentioned, and act an the keystone of an areh which directly or indirectly sustains the hladder, the rectum, the uterus, and the intestines above. This is the comprehensive and broad view which should be taken of the operation, and npon its thorough appreciation and aceeptance mneh will depend which is to follow.

All that is said as to the importance and treatment of destruction of the perinemu in this chapter is based npon the facts stated in Chapter IX. 
Bofore reading this the student is, therefore, urged to peruse that. Without that this would be superficial and imperfect; by its aid it will become much more thorough and eomprehensive. In spite of the fulnoss with which the subject is dealt with there, I deen a slight recapitulation of salient points alvisable licre. In toing this I offer no apology for repetition of former statements, for I am an alvocate of the plan of a popular teacher of the French language who instructs by "répétition sans cesse."

Anatomy.-Proceeding in elose proximity with each other towards the pelvic ontlet, the vagina and rectum diverge at a point above the perineum: the one arching forwards in eoincidenee with the pelvie curve, the other slightly backwards towards the eoecyx. In this way an irregular triangle is created, of which the base is the skin between the fourchette aul anus, one side the posterior vaginal wall, and the other the anterior wall of the rectum. 'This space is filled by a body, having the union of musenlar tendons as its base, and which is itself composed of fibro-elastie tissue. One of its sides resting upon the rectum, the other gives strength, elasticity, and firmness direetly to the posterior wall of the vagina; while this wall, being by it pressed against the anterior or upper vaginal wall, sustains it and the bladder which lies upon it. Figs. 56 and 57 will show

FIG. 56.

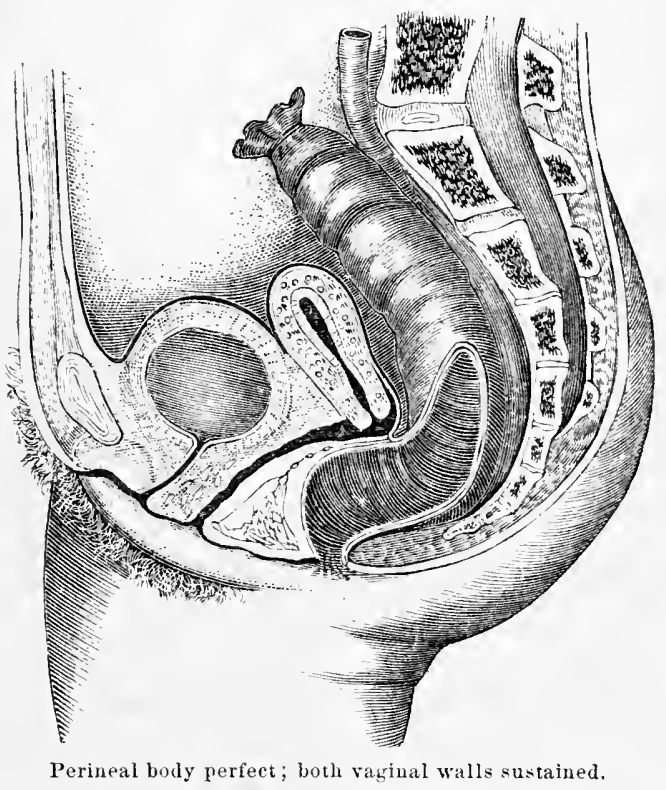

the relations of the perineal body and the effect of its removal upon the vaginal walls. The anterior or upper wall, after its removal by rupture, lacks support and falls downwards, prolapse of this wall oeeurring, with 
cystocele. The normal direction of the posterior wall is also destroyed. Instead of its arching forwards, with a gentle curve, towards the vulva, its lower portion runs like the letter $S$, to the anus. The result of this change of direction, with the coincident loss of support from the strong, elastic perineal body, is to create a sagging forwards, and soon prolapse of this wall follows that of the anterior, and uterine displacement is a consequence.

It may with some justice be remarked that Fig. 57 represents the perineal body, not simply exhausted but split through, as can only be done by laceration. It is true that in other conditions of loss of power there is an appearance of a perineum left, but it is the semblance of a departed power, and the diagram must, in such cases, to a certain extent, be regarded as scliematic, referring to absence of function rather than of tissue.

Fig. 57.

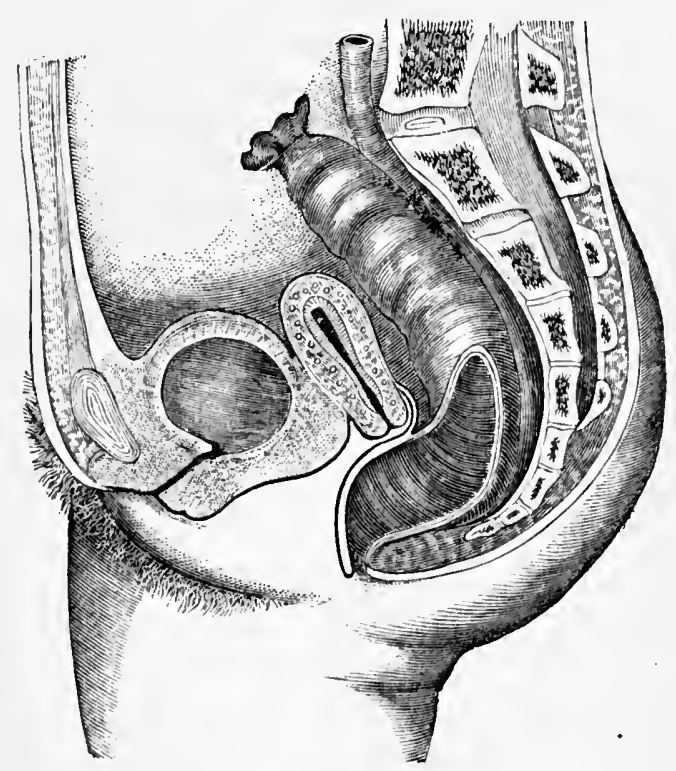

Perineal budy removed by rapture; buth vaginal walls rolbed of support.

When a woman with a normal perineum is placed npon the hack, and the finger of the exaniner is passed into the vagina, as it passes over the perineal body it will be firmly pressed against the upper vaginal wall. Gon the withrlawal of the finger, the separated walls will he observed to come in contact at once by the rising of the posterior wall. It the perineal boly have lost its power, no snch upward pressme is found to exist, and the vaginal walls are discovered to be in less close contact.

After operation for restoration of the destroyed periueum, an examination of this kind should be marle. If the upward pressure of the perineal 
body is found to be suflicient to bring the posterion in contact with the anterior vaginal wall, the object of the operation has been attained. It it do not so, both walls will lack support, in spite of the fact that the superficial perineum, the base of the perineal triangle, las been united and appears perfect. The latter result will deceive the patient, and may deceive the surgeon, with false hopes. The former will alone give futme immunity from the dangers of vaginal prolapse and its consequences.

Fir. 58.

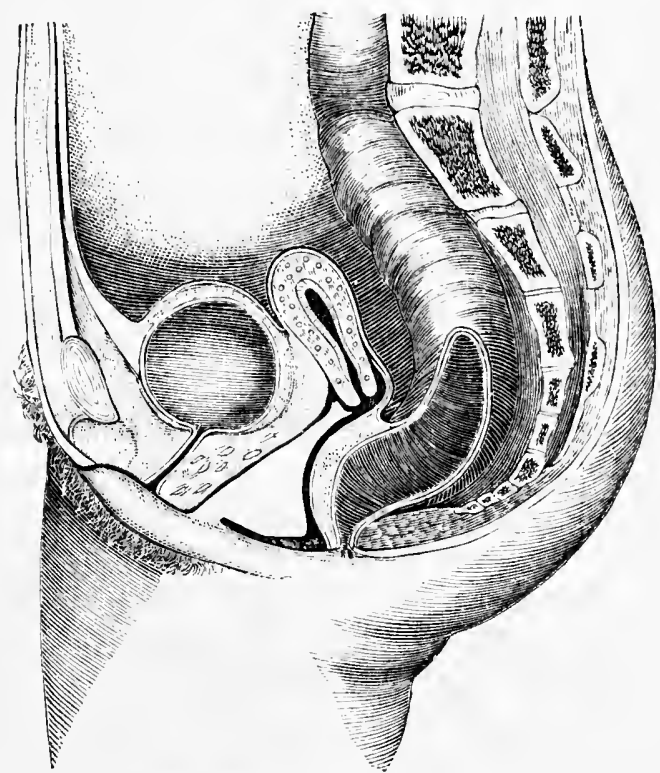

Perineum improperly repaired; perineal body not restored to place; vaginal walls not sustained.

Those influences which destroy the power of the perineum and render it incapable of its important functions are the following :-

Constitutional feebleness ;

Prolongerl overdistention ;

Senile atrophy;

Subinvolntion ;

Laceration.

All these, with the exception of the last, have bet'n considered with sufficient fulness in Chapter IX.; laceration requires more careful study here.

It being now understood that the repair of a perinenm the power of which has been destroyed from any of the causes mentioned is to be conducted upon exactly the same principles as those which apply to the operation for laceration, I slaall use this accident as a means of illustrating it and confine my remarks to it during the rest of this chapter. 
Varieties of Perineal Laceration._-All cases may be classed under two heads :-

Complete and Partial Rupture.

These include the following degrees of destruction :-

Superficial rupture of the fourchette and perincum, not involving the sphincters ;

Rupture to the sphincter ani ;

Rupture through the sphincter ani;

Rupture throngh the sphincter ani and involving the recto-raginal septum.

Complete rupture presents such serions discomforts as a consequence, that partial rupture is by many riewed as a trivial circumstance. So it is by comparison, but so likely is it to be followed by prolapse of one or both vaginal walls that it should never be undervalued. As soon as such prolapse occurs, uterine, vesical, and rectal troubles become almost inevitable.

The evils resulting from partial rupture are by no means insignificant, but they are more remote and more tolerable than those which follow complete. When the sphincter ani is torn through, and still more markedly when the rectal wall is ruptured, incontinence of feces and rectal gases occurs to such an extent as to embitter the life of the unfortunate patient. The consequences of rupture of the perineum may thus be presented:-

Subinvolution of the vagina;

Prolapsus vagine with cystocele or rectocele;

Prolapsus uteri ;

Incontinence of feces and intestinal gases;

Prolapsus recti.

The first three of these may result from both varieties of rupture, complete and incomplete. The last two attend only the former. Even when the two passages are laid into one, it is sometimes surprising to see how little the patient may suffer; but generally, under these circumstances, her condition is truly deplorable. Fecal matters and gases jass without control, and the uterus, vagina, bladder, and rectum tend so strongly to descent, that exercise, muscular efforts, or tenesmus produce weariness, felvic pain, and traction upon the broad ligaments. In some instances, so great is the disturbance of function, that the unfortunate woman finds herself an ohject of disgust to her associates and even of loathing to her hushanil.

Subinvolution of the vagina is rarely alluded to as a consequence of rupture of the perineum; but I see the two conditions too of ten coexistent to regard it as a mere coincidence. "The muscular walls of the vagina," says saragre. "are not separable into coats or layers. Two-thirds of the thickness of the vagina, varying from 2-3 lines above to $5-6$ below, is make un of this muscular portion; the inner third consists of a dense, 
ecllular lining membrane, inseparably united to it." The elastie, contratctile elements of this catnal are identical in strueture with uterine fibre; and development oeeurs in them as in those of the uterus umber the stimulus of gestation. A retregraule metamorphosis likewise aflects thrm subsequent to labor. $\Lambda$ s this process is often interfered with in the uterus by rupture of the cervix, so is it in the vagina by rupture of the perineum. Let any one appeal to his own experienee for the frequency of subinvolution of the vagina as a concomitant of rupture of the perineum. It may be objected that the latter often results from difficult and patticularly from instrumental delivery, which may produce both conditions. An examination into the histories of eases will refute this ; the result is often produed when the labor has been very rapid and unaided. It may again be suggested that prolipse of the ragina, a consequence of the rupture, excites excessive growth in its walls; but the two things coexist where perineal rupture has not resulted in vaginal prolapse, almost as often as where it has done so.

C'uuses._. The power of the perineum may be destroyed by a number of influences, for whieh the realler is referred to Chapter IX. of this work. For laceration of the perineum there is but one cause-parturition.

Minute details upon this subject, and upon means which should be adopted for prevention, will be found in works upon obstetries. All that it is neeessary to state here is that parturition is the great exeiting eause of the accident, and that it is almost never met with in nulliparous women, except after removal of large tumors per vaginam, and then it is usually of little moment.

Prognosis._In an incomplete case of slight claracter, where the fourehette and only a small portion of the perineal body are involved, no evil usually results. Laceration of this eharaeter and to this extent is the rule in first labors, and not the exception. It requires no interference, and is so insignificant in consequence, that it is not included under the subdivisions which I have nentioned. Even the first and second degrees of laceration which I have tabulated are often produetive of no evil, and may, unless eareful inspection be made, pass unrecognized by both physician and patient. But this is the exception and not the rule.

The third degree is always an accident of gravity ; while the fourth represents the most serious form of the eondition. 'The greater the injury the less likely will be spontaneous recovery, and the more probable the complieations and results which have been mentioned.

Natural History of Perineal Laceration.-It is the general impression, and one which I formerly shared, that any laceration which does not entirely sever the sphincter ani may unite by first intention without surgical treatment, and that none which eonverts the two passages into one will do so. Even, however, when the rupture has been complete, it has been asserted that spontameous cure has taken place. For example, 
Pen' once affirmed that he had seen a woman thus injured, and who passed her feces involuntarily, entirely recover. De la Motte declares that thirty years afterwards he met and examined Peu's patient in Normandy, and found that no recovery had occurred. Observation at the bedside has led me to question whether union by adhesion of the lips of these wounds ever occurs spontaneously. Very certain am I that in my own experience I have never seen one do so. Let the limbs be bound together ever so elosely, the inevitable passage of lochial material between the cut surfaces prevents union by first intention. Repair is effected by granulation, and is often very good, but it is never perfect. I am not prepared to say that the statement is absolutely and universally true, but $I$ believe it to be so as a general rule, that a lacerated perineum left to nature for repair is never afterwards as perfect as it was before the occarrence of the injury or as it usually is after proper repair by surgical means.

How then is it, it may be asked, that so many women who suffer from laceration of the perineal body do not suffer from the consequences which have been mentioned? First, because, if the laceration does not interfere with raginal involution, it often does no harm, or at least not for many years, when its conneetion with displacements is entirely forgotten; and second, hecause the imperfect repair effected by gramulation is commonly sufficient to answer all purposes.

I am fully aware that many will be found who will positisely affirm that they have seen even lacerations in the third and fourth degrees entirely repaired by first intention. "False facts," says Cullen, "are more dangerous than false theories." This I strongly suspeet, though, as I have stated, I cannot assert, to be one. The ostium vagina just after delivery $i$, in its overdistended and always slightly lacerated condition, with folds of redundant vagina pressing down upon it, a most deceptive part. I have myself often been deeeived as to serious laceration just atter delivery, and I have frequently seen others similarly misled. A prolific field is thus open for error to the superficial and inexperienced examiner, who, having mistaken a slight laceration for one of aggravated eharacter, and finding that repair hats been eflected by nature, asserts in future that he hats known spontaneous recovery even after most extensive destruction of the perineum.

Should the case really be a serious one, however, and the practitioner onr who believes that nature will in all probability repair the aceident and restore the perincal body to its important functions, a golden opportunity will be lost, and the patient in all likelihood remain as sulterer in consequence.

Time for Operation.- $\mathrm{C}_{\text {pon }}$ this point authorities difler willely, some urging immediate ation, some advising delay until the effects of parturition have entirely passed away, while others compromise the matter by

1 Velpeau, Traité de l'Art des Aecouchements, vol. ii. 1. 639. 
giving preference to the plan of waiting a fow days only. To the first class betong baker brown, Demarquay, Samzoni, Simon, amb othere of equal weight. Shanzoni thus clearly perints ont the anlvantage of airly interference: "The operation should be performed just aftor the dolivery, bealuse it is more likely that the bleeding lips of the womm will then mite, and becanse, vivification of the edges not being neeessiry, the procedure is simpler and less dangerons." 'The worst cases of the accident with which we meet generally follow instrumental o: namual telivery, and when the diseovery of its oceurrenee is mate the patient will nsually he in a profomm anasthetic sleep. Every operator should be prepared, under sneh eireumstances, to attempt repair of the injury, for, if he suecedd, the patient will be saved much suflering, white failure will not in any wise depreciate her condition. For this reason no ease of obstetrical instruments should be considered complete which has not in it needles and sutures for performance of this operation. I have commonly resorted to inmediate operation, and the result of my experience leads me always to alopt it, unless the sphincter ani and recto-vaginal wall be so profoundly implicated in the laceration as to make the operation a serious and lengthy one, or necessarily to insure the passage of lochial discharge between the lips of the wound. Among those who are opposed to immediate interference are Roux and Velpeatt; while Nélaton, Verneuil, and Maisonnenve advise delay for a few days, when all hemorrhage will have ceased and the edges of the wound be covered by gramulations. ${ }^{\prime}$ There are three circumstances which tend to defeat the success of immediate operation. First, it is often performed by one not habituated to its peformance; and, being practised upon a woman who, having just been delivered, is exposed to the danger of post-partum liemorrhage, and surrounded by anxions friends, it is likely to be finisled too hastily. Second, the lochial discharge, eoustantly passing over the lips of the wound, is very likely to enter and prevent mion. Third, the operator having been tanght to regard the perineum as the superficial layer of tissues intervening between the fourchette and anus, closes this by correspondingly superficial sutures, leaves the upper portion of the perineal body open, creates a pouch for the acemulation of putrefying materials, and leaves the anterior vaginal wall and bladder withont support in the future.

My advice and practice with regard to this point are decidedly to give the patient the benefit of the donbt and to elose the rupture at once. If failure follow, however, never, muless there be some special reason for so doing, attempt another operation before the results of partnrition have entirely passed away. This will not be before the lapse of two months from the time of delivery; just after delivery there is a reason for operating which has passed away in a fortnight.

1 Wieland and Dubrisay, French 'Trans. of Churchill on Dis. of Women. 
As I have elsewhere already remarked, it is my conviction that a very large number of cases of uterine disease take their origin in the lying-in ehamher, and a large proportion of these in unrepaired eases of lacerated perineum. When immediate operation becomes the rule of obstetric practice, the number of cases of disease thus occurring will at once and very decidedly diminish.

lint the full results of immediate operation will never be exhibited until the obstetrician studies the anatomy of this part, and learns how to approximate its entire divided surface by sutures carried up to the highest point at which solution of continuity has occurred.

Treatment of Cuses which have Cicatrized.-The operation which is now grenerally adopted in these eases, and which has received the name of perineorraphy, consists in vivification of the edges of the lips of the womd and their approximation by sutures. Although the accident for which this procedure is instituted was described by the ancients, no surgical means of eure were ever advised for it until the time of Ambrose Paré. He advised the suture, and was followed in its use by his pupil Guillemeau. Subsequently it was employed by Delamotte, Saucerotte, Trainel, Noel, and others. Dieffenbach employed it successfully, adding to the operation oblique lateral ineisions involving the skin and areolar tissue, for the purpose of relieving tension upon the parts brought together by suture.

Ahout the year 1832, Roux, of Paris, obtained the most brilliant results from the operation, and probably its elevation to the position of a reliable surgieal procedure was due more to his achievements than to those of any other individual. He employed the quilled suture, and eured by it four out of the first five eases operated upon. Although such success was obtained in France at this period, we find English writers, as late as $18.5^{2}$ and $1853,{ }^{1}$ doubting the efficacy of sutures, and advising that assistance should be limited to aiding the efforts of nature. Of late years great advances have been made in the operation by Mr. Brown in England; Verneuil, Langier, Demarquay, and others in France; Langenbeck and Sinm in Germany; and Sims, Emmet, Agnew, and others in the United State.

To no department of gyneeology does there attach more surgical rublish which needs a thorongh elearing away than to perincorraphy. It has attionled a fruifful tield for attempts at originality and innovation; suceessive investigators too often seeming to strive not so much for simplicity ats for some peculiarity of procedure which they could eall their own. Sitripued of this, the operation is a simple one, and, under the influence of advancing anatomical knowledge, has reached a point at which operators may -tand in unison. Among the methods which I think should at present be cast aside as etlete material, I would cite the use of the quill 
suture, cutting the tissue alongside of the prinemm, cutting the sphinetrer ani, dissecting flaps from the neighboring cutaneous surfices, and many others. Let the operator fully understand what he sets ont to aceomplish, which is by no means always done in a surgieal procedure, and he will readily appreciate that the simplest, easiest, and surest method of doing this is the best. Let lim, on the other hand, have in his mind a dim, uncertain knowledyre of what he desires to acemplish, and let him fill lis mind with the details of the speeial plan of this or that operator, and he will be led to adopt complicated and uncertain proeedures.

In description 1 shall adhare to no one partieular and exact methorl, but deseribe that combination which I have selected as best in my own practice.

P'reparation of the Patient.-The general health should be earefinly investigated. If it be bad, the operation shonld be delayed, and the patient put upon tonics and placed under the best hygienic cireumstances. For a week before operation, the bowels should be kept lax by some mild eathartic, in order that after that time eure shall not be jeopardized by the coming down of scybalie, which have not been removed by a cathartic given twenty-four hours before operation. This point is one of a great deal of moment, and should not be overlooked. In cases of eomplete rupture it is better even to give a fortnight to the fulfilment of this indication. A compound cathartic or compound aloetic or rhubarb pill may be given every twelve hours, or a saline cathartic at the same intervals. Free alvine evacuation, not hypereatharsis, is what is required. During this time the ragina should every night and morning be thoroughly syringed out with warm water to remove secretions and quiet local irritation.

Instruments and Appliances needed.-These will consist of a long handled eurved scissors; a bistoury with narrow blade; a tooth forceps and

FIg. 59.

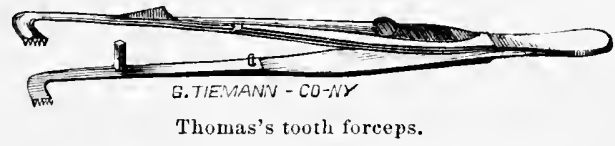

Fig. 60 .

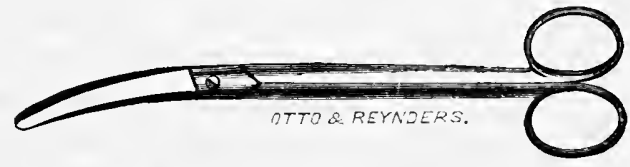

Slightly curved seissors.

tenaculum; one doven small sponges (size of a wahut), fixed in handles ten inches long; artery foreeps; silk ligatures; and straight darning needles, threaded with silk, which is double and tied at the eve of the needle by as small a knot as possible. A basin of water should be in readiness to 
receive the bloody sponges, and a pitcher, bucket, or other reservoir at land to supply more when this is to be changed. The instruments should be kept immersed in earbolized water, with which the parts should be freely bathed.

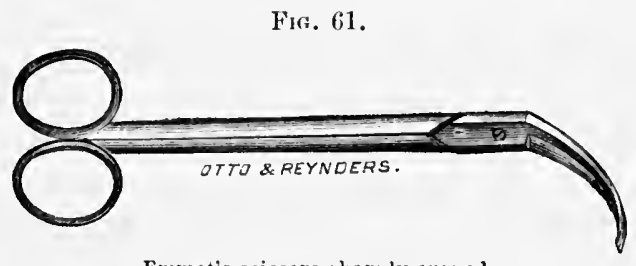

Emmet's scissors sharply curved.

Operation for Partial Rupture.-It is a matter of great surprise to me that no distinct separation should be made by writers between the descriptions of operations for partial and complete rupture. The first is a procedure in which the merest tyro should succeed. The seeond is one of the most delicate and uneertain operations in gynecology, in which even the most skilful may fail. I feel sure that evil has arisen from confounding a simple and difficult procedure, and shall make a wide difference between them.

The operation for partial rupture has for its sole object the restitution of the perineal body. That for complete rupture has for its main object the restoration of the power and functions of the sphineter ani. After the main object of the second operation has been attained, that of the first should claim attention.

Before describing these operations, I would say a few words upon division of the splineter ani. I have operated a great many times for rupture of the perineum, and cannnot recall a case of final failure; thus far I have never eut the sphincter. My experience, confirmed by that of many others, leads me to indorse Dr. Sarage's

FIti. 62.

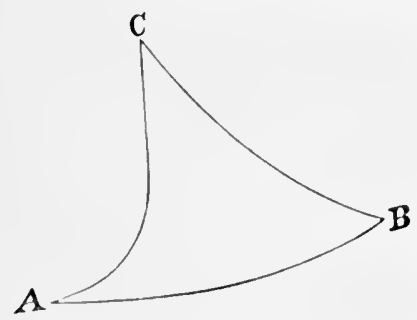

P'rufile viow of porincinen. A re, recial wall. A $B$, rutanouse surface. IB $C$, vaginal wall. (barvin.) statement, that "the success of" operations for the elosure of perineal lacerations is obvionsly not promoted by the division of the surerficial anal sphineter."

Let the operator keep elearly in mind the shape and dimensions of the body which he is about to restore. It is a triangle with apex above and hase below. Two surfaces of this shape are to be vivified and held face to face by sutures. That is the whole operation.

First part of the Operation.-The patient, dressed for beal, shonld be placed upon a table before a window admitting a strong light, in the position for lithotomy, and put under the 
influence of ether. Four assistants will be serviceable, although three would answer the purpose. One of these should adninister the anarsthetic, one should hold each knee, and a fourth should attend to the duty of handing the required instruments to the operator, and washing the sponges as they become bloody. 'The assistants, lifting the feet from the table and flexing the thighls so that the edges of the tibia will be horizontal, should hold the knees elasped under the arins and steady the feet with the hands of the same side, while the unocenpied hands of the other side retract the labia and expose the ruptured part. These directions should be observed by the assistant holding the right knee; he who holds the left should do so with the right arm, clasping it with this and retracting the labium with the right hand, while with the left he sponges the woumd with sponges held in long handles, which do not cause his hand to obstruct the operator's view. It will at first appear that it would be difficult for one assistant to do all this. Let him who thinks so try it, and he will find that it is not so, and that such arrangement of his aids will be greatly to his advantage. This operation, like so many others in surgery, often fails, or at least drags heavily in its progress, from the want of a suflicient number of assistants, to each of whom is allotted an especial duty.

All being now ready, the index and middle fingers of the two assistants who hold the knees are fixed upon the labia by the operator, and, the degree of traction which they are to practise being regulated, the operation is begun.

Seizing the tissue just above the anus with tooth forceps or a tenaculum, a strip of mucous nembrane is removed from the posterior vaginal wall and from the original site of the perineal body upwards as fitr as it is proposed to extend to the rectal side of the triangular denunation to be created on each side. Fig. 63 will show this very well. The furrow just alInded to will extend from D to $\mathrm{B}$. It should always be carried to the point where the normal curve of the posterior vaginal wall is altered in its course, by loss of perineal power, and begins to take an excessive and abnormal curve, the whole wall being now slaped like S. One great object of the operation is to change the shape of this wall of the vagina from A B D to A B C. Before this is done, pressure upon it will cause the lower portion of the $\mathrm{S}$ to sag forwards. After it is done the whole wall under pressure from above downwards will be supported by the sacrum and the tissues Fig. 63.

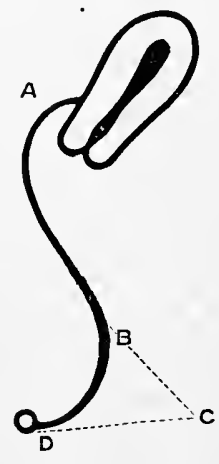

Schematic view of part tu be denuded. which lie upon it for its upper curve, and by the perineal body for its lower.

The rectal side of the new perineal triangle then is created by denudation of the posterior vaginal wall. If the base or rectal side of this trian- 
gle does not involve the posterior raginal wall, what does it inrolve? This was the original site of the perineal body. Its anterior or vaginal side was originally ingina, and the posterior vaginal wall now prolapses

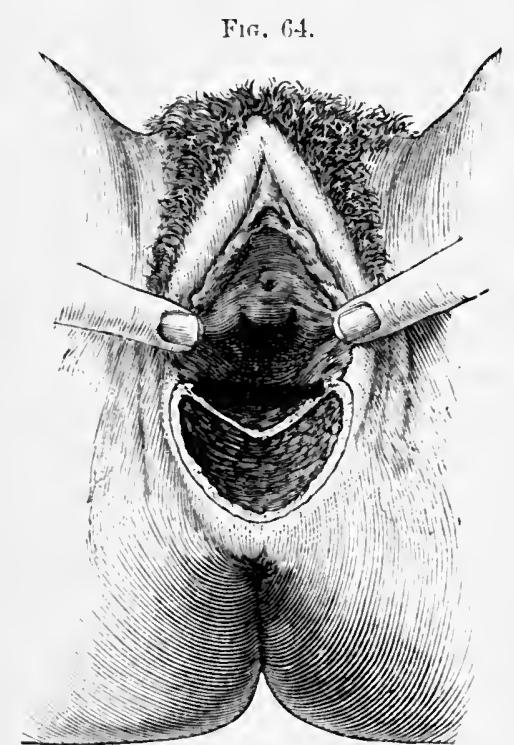

Denudation for repair of perineum. (Savage.) and usurps the place of this body. Baker Brown's operation for rectocele' consisted of a colpo-perineorrhapliy based upon this fact, and every one who has closed a perineum since his time, and not limited himself to a mere episiorrhaphy, has performed the same. Mr. Brown was rery soon followed by Savage, who gives the accompanying diagram.

Savage says that his plan "includes in the resection all the redundant ragina at its ano-vulvar margin, in the first place; and in the second, the removal of a triangular portion of vaginal mueous membrane, the middle angle extending to some distance upwards along the posterior wall of the vagina," etc. He then declares

that it "causes the posterior segment of ragina to approach the pubis so as to offer an effectual obstacle to the prolapse." This method of operating was the natural and inevitable outcome of an effort to replace the perineal body, and every operator making this attempt performed more or less perfectly colpo-perineorrlaphy.

In reference to the origination of the present operation of perineorrhaphy, or at least as regards all its essential features, it may be stated that the credit of making it a colpo-perineorrhaphy and remlering it a remedy for rectocele belongs to Baker Brown. A reference to his work will put this beyond question, as he represents the operation in a diagram with this descriptive statement, "Operation for rectocele." Ilis operation combined all that is esiential in that which is now, witil little modification, generally accepted. Since lis publieation of it, no one las materially altered it, except Marion Sims, who performed the important function of stripling the procedure of certain superfluities, like section of the sphineter and the nise of quills, which were not merely useless, but absolutely hurtful.

We have now formed what is to be the base and line of union of two triangles, which meet upon the furrow just created. Now cateling up the 
tissue on the inner side of one labium majus, about midwaty between ne'atus and anus, another furrow is cut extending town to the anal origin of the first furrow, and another is then carried from the point selected on the labium backwarls to the upper or vaginal "xtremity of the basic furrow. A triangular space, covered by mucous membrane, mappel out by three bleeding furrows, will be left, as shown in Fig. 6.5.

('A. furow extending from anus ny) the vagina (the rectal side); C B, furrow extending from anus to point millway up labium majus (cutaneons side); B A, furrow extending from point on labium to vaginal extremity of rectal furrow (vaginal side). Now the tissue in the unabraded triangle $\mathrm{D}$ is removed by temaculum and seissors, as little tissne as possible being eut away, and a bleeding triangle is left. The opposite sile is similarly treated, and the result is two such triangles placed base to base upon the line $\mathrm{C}$ A. The doubling orer of these npon each other, and the

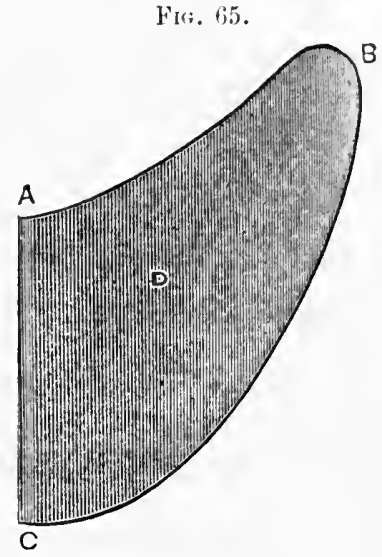

One of the bleeding triangles which are to be created. securing them in contact by suture, constitute the second part of the operation, as slown in Fig. 66.

$$
\text { His, } 191 \%,
$$

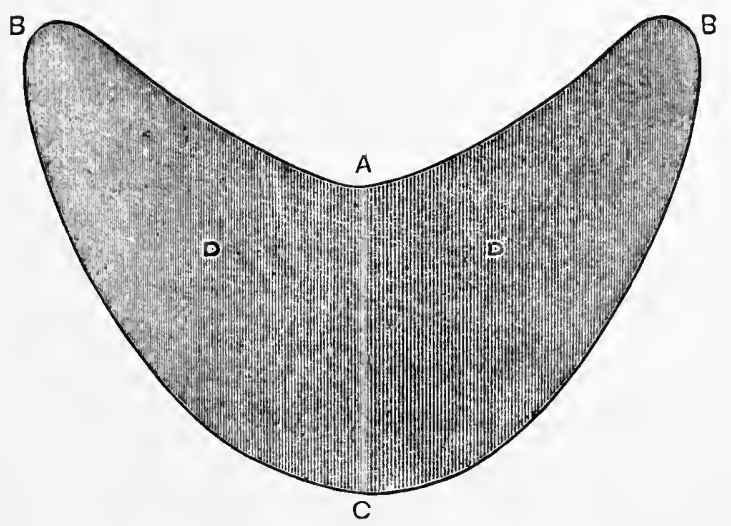

The two bleeding triangles about to be uniterl.

If the stulent will cut two triangles shaped like Fig. 6.j out of thin bourl and unite them by linen pasted upon both sides, so that it will act as a hinge, he will be able immediately and perfectly to comprehent hoth the frst and second steps of the operation. It is in that way that I have best suceeeded in explaining them in didactic lectures. 
In performing the first part of the operation, I very commonly begin on one side and eut successive strips across until the whole surface is pared; but the method which $I$ have mentioned simplifies the procedure, and after adopting it once for the complete understanding of the operation the operator may afterwards do otherwise.

This part of the operation may be performed by the knife, but it is done more expeditiously and with less hemorrhage by the scissors, as Emmet has so justly pointed out. Prof. E. W. Jenks, of Chicago, has proposed another method of denudation which will be found described in an interesting article by him in the American Journal of Obstetrics and Diseases of Women and Children. ${ }^{1}$ This consists in the introduction beneath the mucous membrane of a pair of sharp-pointed scissors by which, without for a moment removing them, he by rapid snips separates the membrane from its attachment and remores it with great rapidity and little loss of blood. All the denudation done is effected in this manner.

Dr. Albert Smith, of Philadelphia, has employed in these cases and recommends the use of a large dentist's burr ${ }^{2}$ with cutting flanges, which is made to revolve rapidly by a treadle which dentists now so commonly employ. By this the surface is rapidly, thoroughly, and bloodlessly denuded of its mucous covering.

The whole surface having been pared, the operator stops and carefully examines to see if any arteries are spouting, and if any undenuded surfaces still remain. If he find the former he twists them, and, if necessary, ties them with very delicate silk ligatures, which he cuts short; if the latter he catches them with the tenaculum, and with the bistoury cuts them away.

The first step of the operation is now finished. The operator should not hasten to the second, for the tissues should be exposed for a while that he may be assured against hemorrhage. Sutures should never be applied until all hemorrhage bas been cliecked.

$2 d$ part of the Operation.- Now taking in the needle-holder a round, curved or straight needle, about two and five-eighths inches long, which will cause less hemorrhage than the needle with cutting edges, armed with a doubled silk threar, giving a loop about eight or ten inches long; he inserts it opposite the lowest external angle of the vivified triangle, which would be a little above the level of the anus, and makes it pass across the middle of the united bases of the triangles, over the rectum, and emerge at a corresponding point on the opposite sidc. This suture is nowhere visible within the ragina, for it lies embedded in the tissues lying over

1 Am. Journ. Obstet., rol. xii. \o. 11, p. 1879.

2 This instrument was first used by myself in the operation for vesico-vaginal fistula, but shortly afterwaris Dr. Snith, without a knowledge of the fact, employed it in this procedure. 
the rectum. It may be passed by one sweep, or, if this prove dillieult, maly be drawn out at the midlle of its eourse, and reinserted. This suture is twisted at its extremities and left in position, and, another being taken, it is inserted above the first, and made to pass throngh the tissines at a higher point of the vivified surfice. Guided by the finger in the rectum, it is k"pt embedded in the recto-vaginal septum, and energes at a point on the other side corresponding to that of entrinee.

This, like its predecessor, I am in the habit of concenling in the tissues, so that alter its jassage it is nowhere visible within the vagina. I believe that an embedded suture excites nuch less irritation on the denurled surfice, and aets less like a seton upon it than an exposed one. In this way sutures of silk are passed, and by them those of silver are inmediately drawn into place, about one-third of an inch apart, and inserted at a 'fuarter or half an inch from the edges of the wound. All these are concealed from view except the last one or two, which should pass under the upper angles of the triangles, and catching up the vaginal tissue at the highest point of the denullation should bring them all together.

At each side of the perineal triangle thus formecl, two pockets may be created in which putrid materials may collect. 'To aroid this great eare should be taken to eonceal the sutures espeeially at these points. Denudation should likewise be most earefully practised there.

For the details, as to the method of drawing the wires into place and twisting them, the reader is referred to the article on Vesico-raginal Fistula. After the plin there deseribed, he

FIG. 67.

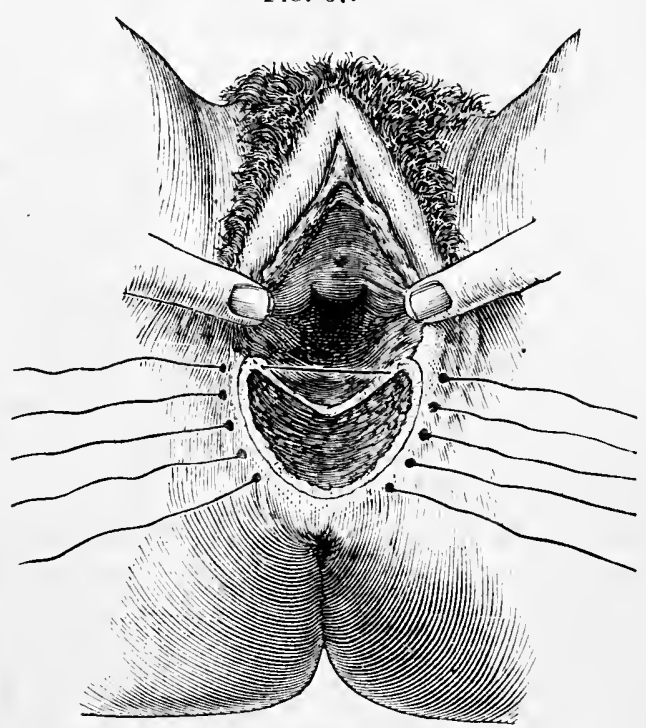

Shows surface denuled and sutures in position. twists them one after the other from below npwards. If it appear necessary, superficial sutures are then passed between the deep ones to approximate the eutaneous surface more eompletely.

At the risk of being eonsidered prolix, I offer still another diagram giving a profile view of the sutures in position, and pressing one triangle against its opposite. The sutures will be seen to run bick and pass through 
the posterior vaginal wall, dragging this forward as a background or base to the two opposed triangles now to become an artificial perineal body.

The sutures should not be eut short but left about two inches long, then twisted together and secured by a small piece of India-rubber tubing, after a plan suggested by Emmet and shown in Fig, 69. The patient is then put to bed; the knees are bound together; the dorsal or lateral decubitus preserved; the urine drawn by catheter every six hours; the vagina kept clean by syringing with tepid water; and the diet made nutritious, though mild and unstimulating. On the eighth or ninth day, the sutures should all be removed, and on the next, the bowels should be aeted on by a saline cathartic, great eare being observed to prevent tenesmus.

FIG. 68 .

Fig. 69.
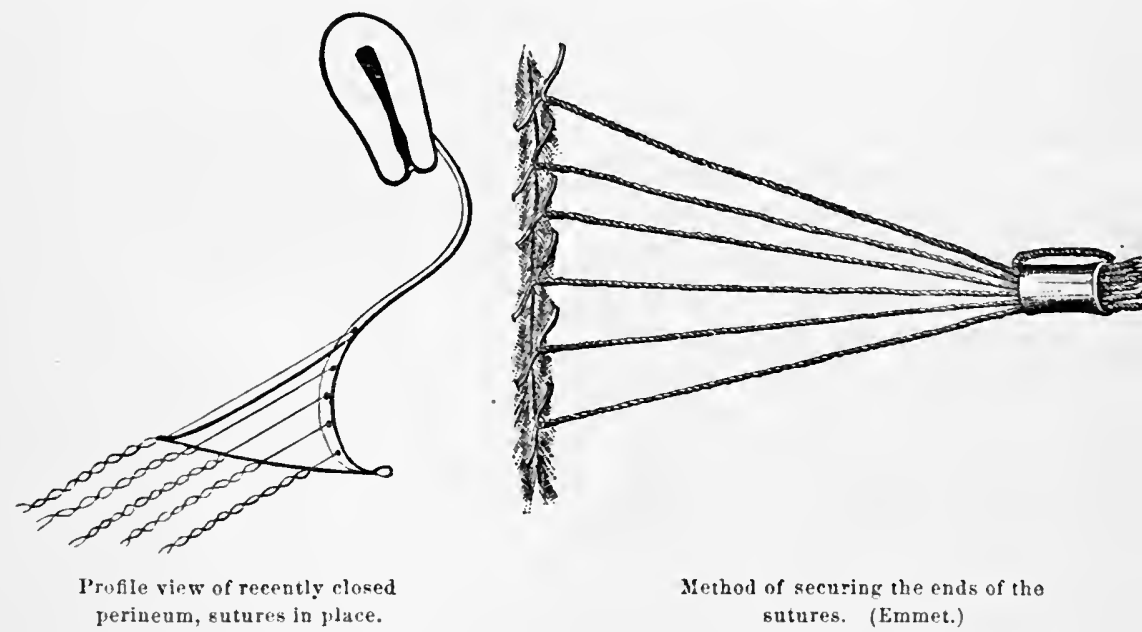

Method of securing the ends of the sutures. (Emmet.)

Operation for Complete Rupture._Complete perineal laceration always involves rupture to a greater or less extent of the anterior wall of the rectum. If rupture of the bowel extend for more than from one inch to an inch and a laalf above the upper edge of the sphincter ani, it is better to close it by a primary operation consisting of vivifying its edges and uniting them down to the anus. After union of these parts, closure of the perineum may be practised. If the bowel be not injured above an inch and a half from the sphincter, one operation will suffice to close the whole. I would not be understood at making this a dogmatic rule, but merely one which approximates the line of conduct which I deem best.

The sole object of the operation for partial rupture is restoration of the perineal body. The oljocts of the operation for complete rupture are; first. restoration of the sphineter ani muscle to all its power and functions; seeond, elosure of the rectal opening; and third, restoration of the perineal body. What constitutes the main object in the first operation, is the 
least important of those striven alter in the second. The operator must then appreciate that mere closure of the rent in the genital fissure is not what is desired. IIe may gatin this, and not benefit his patient in the leatst, for incontinence of feces and gases may continue. Success involves always complete union of the ends of the severed muscle and complete closire of the rent in the bowel. To secure these the ends of the muscle, spreal out and expanded, must be curled up and approximated, and the rectovarinal septum must be drawn up and united to them. With these facts in view, clearly defined and appreciated, the diffieulties of the operation greatly diminish. To no one are we so mueh indebted for their demonstration and illustration by practieal results, as to Dr. Emmet, of this city, who, in 1873, wrote a valuable paper upon the subjeet, giving a clear exposition of the peeuliar action of this aceident upon the sphineter ani and of the best method of restoring it to its normal shape and functions.

Let Fig. 70 represent the perfeet sphincter, Fig. 71 will show it ruptured and spread out, with the point of insertion and exit of the needles.

Fili. 70 .

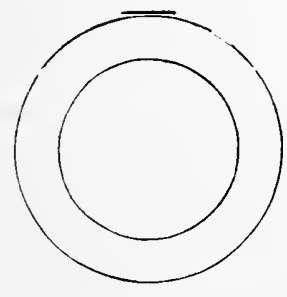

A

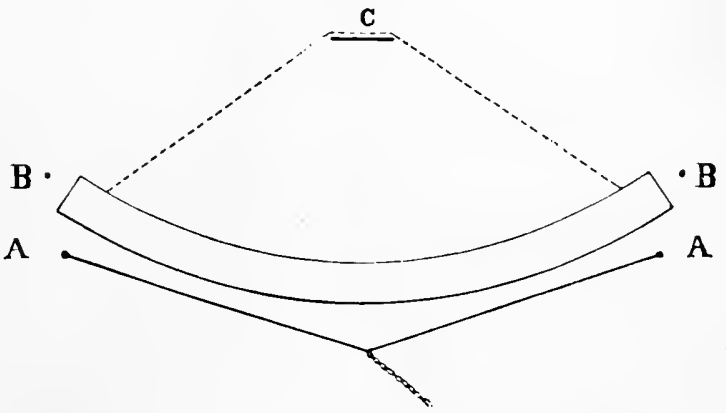

Fig. 72 .

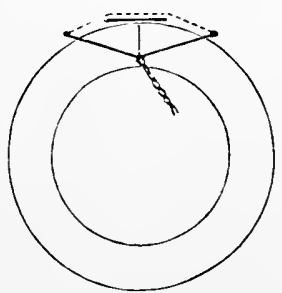

Fig. 73 .

The dotted line shows the course of the metallic sutures embedded in the tissue. It will be seen that the remaining recto-vaginal wall is a fixed point, and that as the wire is twisted, the ends of the muscle are elevated, and the three points approach each other as shown at c. As the twisting goes on, these points come nearer and nearer together as seen in Fig. 72, until at last they unite as shown in Fig. 73 . 
Should the first needle be inserted and drawn out above the end of the broken musele, as shown in $\mathrm{B}$ B, Fig. 7 , the tissue at this point will be approximated, and the ends of the muscle brought close together, but absolute and complete union will not have been at tained, and loss of function will still exist. The first suture is the important one, and must eatch

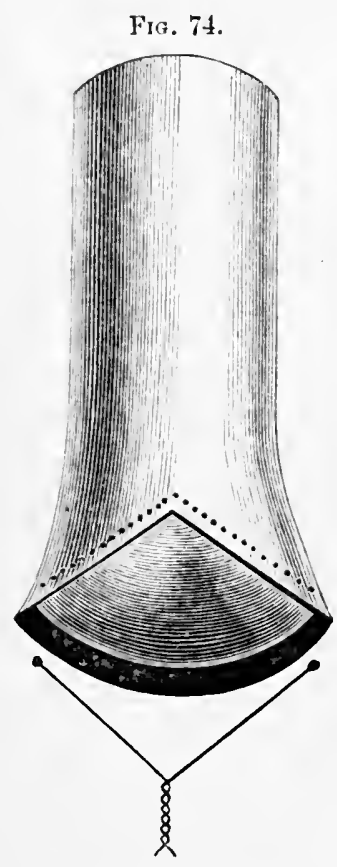
the ends of the broken and expanded musele so as to lift them upwards into contact with each other and with the recto-vaginal septum.

In vivifying the parts before insertion of the neelles the two lateral triangles representing the perineal body split in two are denuded, and

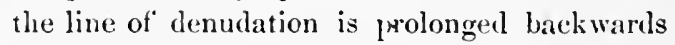
along the edge of the recto-vaginal septum. 'The border of the reetal mueous membrane at the extremities of the broken musele as far as the upper end of the rent in the bowel is the guile for doing this.

Fig. $7 t$ is a schematic diagram showing the ruptured bowel, the expanded muscle at its anal extremity, the insertion and exit of the needles, and the comrse (dotted lines) of the embedded sutures. The line of denudation is marked out by the course of these sutures.

The rectal rent presents itself to the operator as an imperfect, isosceles triangle, apex above and base below. The two lateral borders of this are the parts to be vivified. The two basic angles are on a lower plane than that of the apex, and are less fixed in their position. As the three angles are acted upon hy the constricting influence of the encireling suture, as this is gralually twistel, the two movable basie angles are elevated to the plane of that of the apex while the latter is by taction drawn down to meet them. Coincidently the denuded sides of the triangle are, of eourse, approximaterl, and thus the rectal opening is eompletely elosed.

To slum up this part of the subject, the rule for passing the first suture consists in the introluction of the needle as low down as the lower alge of the anns. F'om this point it passes upwards through the recto-vaginal sepum, completely ancireles the rectal rent, and eomes out alongside of the lower edge of the anus on the opposite side.

Lent the readere reter to $\mathrm{Fig}$. 75 and he will appreeiate that a suture which takes this course, like the string at the mouth of a bag, puckers the open fats, draws them into apposition, and controls the action of the sphineter. The two conditions which we have to fear as sourees of failure after this 
operation are, first, recto-vaginal fistula, and second non-union of the sphineter. This method, to a great extent, secures us agatinst both. 'The subsequent steps of this operation are the same as those of that for partial rupture.

I lawe in a large experience with this operation fitiled four times. As it is from oul past failures that we must learn to avoid failure in the future, I shall strive to give the realer the benetit of ny experience. In two of $\mathrm{my}$ four eases perfect union was obtained, but the rectum was found, in spite of the fact that in both patients eatharsis liad been kept up for a week, filled with large, hard, seybalous masses. 'This ereated violent tenesmus, and destroyed the newly formed perineum.

In the third case a large, bulbous, rectal plug lad been lelt in place, and its removal ruptured the united extremities of the muscles, leaving Fig. 75.

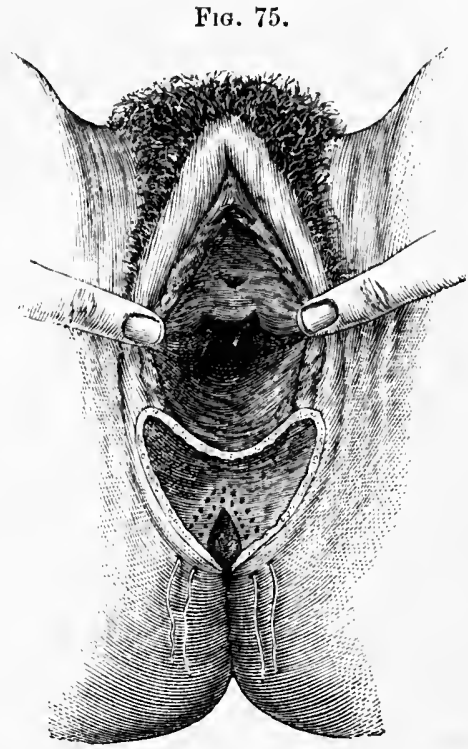

Surface denuded in complete perineal rup. ture, aud first two sutures iu position. the perineum whole.

In the fourth case the nurse in using the syringe for a rectal injection unquestionably passed its nozzle repeatedly between the lowest suture and that just above it, leaving a central opening in the perineum, which constituted a recto-perineal fistula, the sphincteric union remaining perfect.

Upon the experience thus obtained, I have predicated the following rules of practice, which $I$ invariably observe and strongly recommend :-

1st. When about to operate for complete perineal laceration, give two entire weeks to complete evacuation of all scybalous misses from the intestinal eanal. This tract, it must be remembered, is twenty-five feet long, and keeps fecal masses stored up in it for months. Do not practise hypereatharsis, but let the patient have two medicinal evacuations in every twenty-four lours. This may be done by giving one compound rlubarb or compound cathartic pill every eight, twelve, or twenty-four homrs, according to the patient's susceptibility to catharsis.

2d. During this time feed the patient freely upon animal food and animal broths, wheat, potatoes, and other nutritious articles of diet.

3d. During the first four lays after operation sustain her entirely, though thoroughly, upon strong animal broths alone, aroiding milk especially, which creates seybala of hardened casein. The reliance upon milk for avoidance of scybala is a mistake. 
4th. Keep the bowels constipated for four days after operation-till primary union takes place. At the end of that time they should be acted upon by a gentle laxative or enema.

5th. If a reetal tube be employed, let it be one of small size.

6th. Should an enema be used, let the physician himself administer it, unless the capacity of the nurse be above suspicion.

Every surgeon must admit that no detail is too insignificant for his personal attention, which is eapable of turning the balance in favor of or against the success of an operation which he has performed.

I have already stated that sometimes the rectal rent is so extensive that it cannot be elosed by the same operation as that by which the perineum is elosed. Under these eircumstances, which I have encountered several times, colporrhaphy should be first performed, and immediately or at a later period perineorrhaphy. The sutures may be passed by a suture with a needle at each extremity from the ragina into the reetum, and be left hanging from the anus, or they may be left in the vagina.

It is often necessary to perform two operations, one posterior colporrlaphy and the other perineorrhaphy, at the same time, for fear of discouraging the patient by too frequent resort to operation. Under these eircumstances a long ovoid denudation should be extended up the vagina towards the cervix, and the edges brought together by catgut or silk-worm gut suture, and then perineorrhaphy should be performed. The perineal sutures being removed on the eighth or ninth lay, the animal sutures may be left in the vagina to undergo absorption. This prevents the straining of the new perineum necessary for removal of silk or silver sutures.

For this purpose, Jenks, ${ }^{1}$ after denuding a tongue-shaped extension up the posterior vaginal wall, approximates the raw surface by catgut sutures, runs down upon each of these a perforated shot, passes down upon this a piece of hard rubber tubing two and a lualf inehes long, and puts at the end of this another shot which he compresses firmly. Upon removal of the compressed shot, the tube, uncompressed shot, and suture can all be readily withdrawn. Fig. 76 shows this part of Jenks's ingenious operation.

After closnre of the perineum, should the patient tolerate it, a rectal tube may be introdneed oceasionally for the escape of air from the bowel, or in place of this a large catheter may be kept in reeto, thongh this is not necessary.

Great danger of separation of the lips of the wound, even when perfeetly united, ocenrs on the occasion of the first alvine evacuation, when seybalous masses are ajt to pass and to tear the newly united parts asunder. As I have stated, I have twiee had this happen in my experience in operations performed in private practice. To prevent this unfortumate ocenrence, some keep the bowels acting daily from the time of operation. Formerly I kept them constipated until removal of the sutures; now, in consequence 
of the accidents to which I have allurled, I arlopt the plan which Giranville Bantock condorses in an excellent monograph mon this operation, that of keeping the bowels quiet for three or fom days, and then acting upon them by laxative enemata.

FiG. 76 .

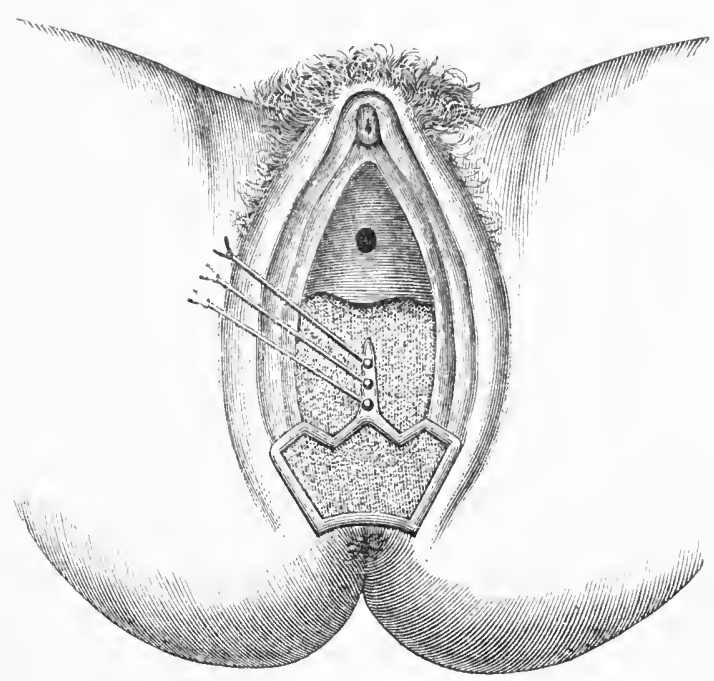

Jenks's operation of colpo-perineorrhaphy.

I variety of substances are now used as sutures in this operation. The Germans, following the lead of Sinnon, still cling to silk; in Eingland and America, Sims's silver wire is rery generally used; but some follow the adviec of Lister in employing catgut, while Bantock lias a strong bias in faror of the gut of the silk-worm.

\section{I A P E R XII.}

\section{VAGINISUICS.}

Definition.-This affection consists in a peculiar sensibility or lyyperasthesia in the nerves of the vaginal nucons membrane at the site of the liymen, which upon irritation are supposed to prodnce spasmodic contraction in the sphincter vagine muscle.

Frcquency._- Taginismus is of frequent occurrence, and will often be met with in practice. It las received little notice heretofore, not because

I On Rupture of tise Fenule Perineum. London, 1875. 
of its rarity, but because the attention of practitioners has not been specially directed to it. Dr. Sims declares that during twenty-four months he met with it seventeen times, and during four years I saw thirteen wellmarked eases.

History.-The fact that sueh a condition occurs and becomes a morbid state of considerable importance was known to Dupuytren, Roux, and Burns, ${ }^{1}$ of Glasgow. They not only described it, but adopted an operative proeedure which has since been revived, and is even now by many regarded as the most reliable method of cure. Their views did not apparently attract much attention, nor was their import really appreciated until, at a later periol, they were insisted upon by Professors Simpson and Scanzoni. Between August, 1861, and October of the same year, it was described by Debout, ${ }^{2}$ Miehon, and IIuguier, and just afterwards by Marion Sims, who applied to it the appellation which I lave adopted. By these authors, incision, subcutaneous or through the mucous membrane, was recommended, in imitation of earlier investigators, after less severe measures have failed of effecting a cure. Since the time last referred to, the affection has been allotted a space in the various systematic text-books which have appeared upon gynecology.

Anatomy and Pathology.-It is, I think, very generally accepted as at fict that the bulbo-eavernosus musele wlich passes over the clitoris and forms a figure-of- 8 with the sphincter ani is the constrictor raginx. Dr. Salvage denies this positively, declaring that " the constriction of the raginal ring is produced by the pubo-coccygeus nuscle." This is a broad and powerful muscle situated within the pelvis just above the point at which

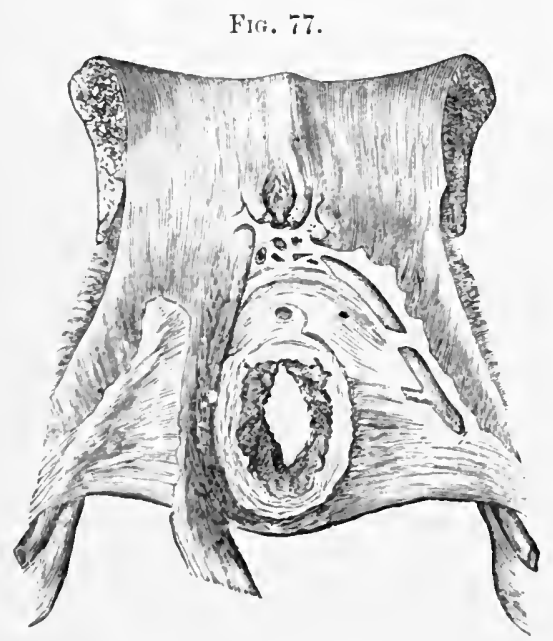

Pubo-cocrypuns muscle. (Savage.) the vaginal walls branch off to seek their osseous attachment. Arising from the inner surface of the pubic bones its fibres take various courses; its median fibres descend by the side of the urethra and vagina, some of them turning in between the vagina and reetum to neet similar fibres from the opposite side in the perineal looly; another more out ward serics, turning in beneath the rectum, intermix with fibres of the other side; while the remaining fibres still more outwarl are inserted into the silles of the coceyx. Fig. 77 shows a portion of this muscle.

1 Simpson, Clin. Lec. Dis. of Women.

2 Bul. Gén. de Thérap. Mléd. et Chir., 1561. 
Certain morbid states produce so great a degree of irritability in the nerves supplying the vulva and lower part of the vagina, that upon contact with foreign bodies a spasm occurs in this and in neighboring nuseles, which constitutes the disease that now engages us. The attention of some has been chiefly fixed upon the nervous condition, the pubic nerve being, accorling to them, the seat of the difficulty, while others have especially regarded the resulting muscular spasm. It is curious to perceive how, from diflerent standpoints, both parties were led to the same surgical resource.

Causes.-This affection bears to the vagina the same relation which blepharospasm does to the eyelids, or laryngismus to the larynx; and, like those affections, is not ordinarily a primary disorder, but one which results from some special loeal cause. It may arise from excessive nervous irritability affecting the whole system, as is often seen in hysterical women, or be produced by some local disorder of apparently insignificant character. P'rof. Willard P'irker ${ }^{1}$ reports a case which was due to an irritable caruncle of the meatus not larger than a flaxseed, removal of which resulted in cure. In other words, it may be an idiopathic affection, or symptomatic only of some other disorder.

The recognized causes of the disease are-

The hysterical diathesis;

Excoriations or fissures at the vulva;

Irritable caruncle of the meatus;

Chronic endometritis or vaginitis;

Pustular or vesicular eruptions on the vulva;

Neuromata ;

Fissure of the anus; ${ }^{3}$

Hyperasthesia of the remains of the hymen;

An abnormally rigid perineum;

Disproportionately large size of male organ.

Professor Seanzoni in August, 1868, published his views upon this subject. During the preceding three years he had seen thirty-four marked cases, due chiefly, he thought, to violent efforts at sexual intercourse, practised upon women having small vaginas and well-developed hymens. Scanzoni found that twenty-five of his thirty-four patients had various functional and organic difficulties, which in twenty cases lad come on after marriage; in eleven, there was congestive dysmenorrhoa; in one, amenorrhoa had existed for three years; in thirteen, there was chronic metritis ; four had either ante- or retroversion; in one, there was perimetritis; in seventeen, chronic uterine catarrh ; in fonrteen, vaginal catarrh ;

1 Bul. N. Y. Acad. Med., rol. i. p. 439.

2 Simpson, Med. Times and Gaz., 1857, vol. i. p. 336.

${ }^{3}$ H. Dewees. Baker Brown. 
in one, anteflexion; in two, retroflexion; nine had urinal difficulties; one had inflammation of the right Bartholin's gland; in fourteen, there were symptoms of anamia; and in seventeen, of hysteria. Although the sexual act could not be fully completed, conception was not entirely impossible, as out of the thirty-tour cases two had conceived; in the other thirty-two, sterile marriages had existed from one to eleven years. This sterility was not due to want of sexual desire, but arose entirely from spasin involving all the museles of the pelvis, which also rendered examination, either by the touch or speculum, impossible without the use of an anæsthetic. ${ }^{1}$

Some of the canses which I have enumerated produce vaginismus by direct irritation of the nerves of the vaginal mucous menbrane; others, by ereating a discharge which indirectly establishes the same condition.

Dr. William Neftel, of this eity, has recently published some very interesting observations upon the influence of lead poisoning in ereating this neurosis. He records four rery striking cases, having this as a canse, and in one, the vaginismus was the symptom which incited an examination for poisoning by lead. 'These cases were successfully treated by electricity.

Symptoms and Physical Signs._The patient will generally complain of excessive pain upon sexual intercourse, the mere attempt at which will throw her into a state of nervous trepidation and apprehension. 'This and sterility will probably be all that will have attracted her attention, though in some cases a marked tendency to spasm will have been noticed upon sudden changes of position, or washing the genital fissure. One or more of these symptoms call for a physical exploration, when the following facts will be recognized. As soon as the finger is brought into contact with the site of the lymen, the patient will probably spring from her place, complain of agonizing pain, and evince great nerrous disturbance. Should the examiration be persisted in, introduction of the finger will be found to be almost impossible, and if it be forced into the canal, a violent muscular contraction will be pereeived. If, instead of the finger, a canel's hair brush or a feather be employed, severe pain and contraction will follow even this applieation to the surface.

Differentiation.-There is no other affection with which this can be confoumled. All that it will be necessary to deeide concerning it will be, whether it is an illiopathic or a symptomatic disorder.

Course and Juration.-In its duration it is unlimited. Cases are recorded in which it lasted for twenty-five and thirty yoars, and unless relieved by art, it will probably, in its worst forms, become a permanent condition. In its less severe type, and more particularly when lependent upon some othor diseased stite, it may often be relieved by mild means, or pass awily witlout treatment.

Prognosis._" From personal experience," remarks Dr. Sims, "I cau

1 New York Metl. Journal, vol. ix. p. 181. 
eonfidently assert that I know of no disease capable of prorlucing so mueh momappiness to both parties to the marriage contract, and I am happy to state that I know of no serious tromble that ean be so easily, so safely, and so certaiuly curecl."

The experience of Seanzoni, 'Tilt, and others, who have adopted an entirely diflerent treatment from that pursned by the last-mentioned author, and who depreate the use of the knife, learls them to the same farorable eonchsion. In my own experience I have met with no ease in which I have not been able to give relief, either by operative interference, or by the complete removal of the disease of which this condition was a symptom.

Treatment.-Careful seareh should be male, before the adoption of treatment, for the cause of the affeetion. Should this be discovered, hope may be entertained that its removal will effect a cure. Should no cause be discovered, or its treatment not be followed by recovery, the general state of the patient shonld be altered and improved by exercise, change of air and scene, vegetable and mineral tonies, sea bathing, and cheerful society. Riding on horsebaek las been especially advised, but rowing, bowling, walking, or any other exercise which develops the system and improves the tone of the nervous organism, will probably answer as well. Local treatment calculated to soothe the excited vaginal nerves should then be resorted to. The free use of vaginal injections containing laudanum, creasote, or acetate of lead is sometimes productive of good. Dr. Peaslee thought highly of an ointment eomposed of two grains of atropine to an ounce of lard. This alkaloid, or the extracts of opium, belladonna, hyoseyamus, or stramonium, may be incorporated in an ointment or in

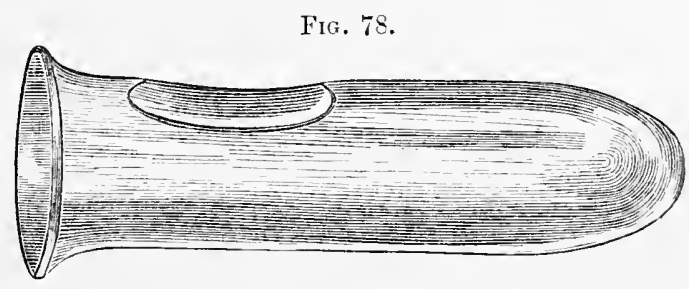

Sims's vaginal dilator.

suppositories, and applied freely to the sensitive part. In some cases suppositories containing from five to ten grains of iodoform prove very beneficial. At the same time the glass tube represented in Fig. 78 should be gently inserted into the vagina, and kept there for as many hours a day as practicable. Its presence will tend to benumb the nervons sensibility, distend the vagina, and produce a tolerance of foreign bodies. During this treatment the patient should live apart from her husband. This plan of treatment, simple as it is, combined with eopious vaginal injections 
used night and morning for the complete removal of irritating discharges, as well as for their own direct sedative effects, will often prove effectual and avoid the necessity for a surgical procedure of some gravity.

That the operation proposed by Dr. Sims for the cure of this condition is effectual, there can be no doubt. I have myself resorted to it in a large number of very aggravated cases, and in all with perfect success. But there has been for some time in the minds of many gynecologists a growing distrust of the neeessity of a resort to a procedure, which is reported in one case to have resulted in fatal henorrhage. In many cases, even of grave eharacter, it has been proved that by distention of the vagina, either with the fingers or by expanding instruments, and subsequent maintenance in the canal of a vaginal plug, cure can be accomplished as perfectly and even as rapidly as by the cutting method. Two eminent authorities, Scanzoni and Tilt, have especially advocated this plan and opposed the operation of Sims. Their views, as reported in medical journals, I here place before the reader.

"Of more than 100 cases that have fallen under Scanzoni's observation, in times past, he has been completely successful in the treatment of all to which he was able to give his personal attention, without in a single case having recourse to the knife. The first condition of success is complete sexual abstinence; for the first three or four days, a tepid sitz-bath should be used night and morning; warm local bathing, with aq. Goulardi, or the same applied with lint, several times a day. Defecation must be regulated, and friction from motion carefully avoided. After a few days, the sensibility of the parts will be so much allayed that a solution of arg. nit. $x-x x$ grs. to $\overline{\text { j.j }}$ of water, may be applied with a brush. After about eight days' continuance of this treatment, vaginal suppositories of ext. belladonna and cacao-butter may be placed behind the hymen, and in contact with it, daily. These remedic's, either alternately or simultaneously, must be continued until every trace of intlammatian has disappeared, and the normal sensibility is restored. Generally two or three weeks will be required to attain these objects. Then dilatation must be commenced; but for this purpose sponge-tents are nseless. A graduated series of glass conieal specula are best adapted to this object. After the first slightly painful attempt, the patient generally will be able to introduce it with facility, and it may be allowed to remain from one-half to one hour. Even when the hymen remains, it will not be necessury to incise it, as dilatation can be eflected without recourse to that measure. At first, the dilator may be used every two or three days, then every day or twice a day for two or three hours, gradually increasing the size of the dilator until the object shall have been attainol. which in some instances may require an instrument admitting dilatation, as that of Segalas. Sitz-baths, belladonna. and pencilling with nitrate of silver may be required from time to time, and the cure will usially be completed in from six to eight weeks. It will be seen that, althourh the tratment of sims is attenled with an equally satisfactory result, it is of a much more serious character than the treatment adopted by Scan- 
zoni ; and, after the operation, the success of the treatment depends generally upon the subsequent dilatation. The time required, moreover, is nearly the same by either process."

1)r. Tilt takes the same position in deprecating resort to the knife and giving preference to forcible distention. He anasthetizes his patient, and introrlueing both thumbs, back to back, forcibly distends the ostium vagina for five or six minutes. He then keeps a large vaginal plug in sitû by a $\mathrm{T}$ bandage for a number of days. This anthor lays especial stress upon the necessity, already alluded to, of first removing any existing uterine or vaginal disease, in the hope of simultaneously curing the secondary tronble, before having recourse even to the process of distention.

Shonld these means fail, the operation of removal of the hymen and section of the perineal body may be practised. It will be observed that I do not say of the sphincter vagina muscle. This is certainly not severed to any extent ; and it is highly probable, if we aecept Dr. Savage's anatomy of it, that its fibres are nowhere involved in the section. My impression is, that Sims's operation accomplishes two things : first, ablation of the hymen often removes nerves which are in a condition of hyperæsthesia; second, section through the perineum enlarges the ostium vagina, and thus removes an obstacle to intereourse.

If $I$ be correct in this, we have here an instance of the injury done by theorizing with reference to a subjeet which should be put beyond doubt by anatomical demonstration on the eadaver. No one would have done mischief, if told to enlarge the ostium vaginæ by section; many have causerl serious hemorrhage by endeavoring to sever the bulbo-cavernosus muscle, which good authorities declare to be no sphincter at all.

Sims's Operation.-The patient having been anæsthetized, and placed on the back, upon a table, the remains of the hymen are entirely excised by a pair of curved scissors. The slight hemorrhage resulting from this will soon cease under the application of a compress wet with ice-water, or of a solution of the persulphate of iron.

The index and middle fingers of the left hand are then passed into the ragina, so as to put the fourchette on the stretch. By means of a scalpel a deep incision is then made on the right of the mesial line, terminating at the raphe of the perineum. A similar incision is then made on the other side, the two being united at the raphé, and extended to the perineal integument and through its upper border. Each of these incisions will extend from about half an inch above the upper border of the sphincter (meaning evidently the bulbo-cavernosus), to the perineal raphé, thus passing across the muscle, and measuring nearly two inches.

After this, the vaginal dilator is placed in the canal, and worn for two hours in the morning, and three or four in the evening, according to the 
tolerance for it which is manifested. Fig. 78 represents the glass vaginal dilator, which is three inches long, slightly conical, open at one end and closed at the other, and varying in size from an inch to an ineh and a half in diameter. This instrument is kept in place by a 'T bandage, and should be worn for two or three weeks.

Burns's operation, more recently endorsed and practised by Sir James Simpson, rests, it appears to me, upon too weak a basis to warrant its use. It consists in section of the pudie nerve, which Sir James says " may be exposed by eutting through the skin and fascia, at the side of the labium and perineum; beginning on a line with the front of the vaginal orifice, and carrying the ineision back for two inches. The nerve, being blented with cellular substanee, is not easily seen in such an operation; but it may be divided by turning the blade of the knife and eutting through the vagina to its inner coat, but not injuring that. It may be more easily divided by cutting from the vagina. Slitting merely the orifice of the vagina will not do ; we must carry the incision fully half an inch up from the orifice, and also divide the mueous membrane freely in a lateral direction." Now let the reader examine Savage's plate, showing the pudic nerve, and he will see, that to sever it "by cutting from the vagina," the incision would have to be earried as far as the ramus of the ischium on each side, where it lies in direet contact with the pudic artery.

No one can examine a diagram showing the course of this nerve without strongly suspecting, that its section is an operation which has existed in the mind of the operator, and never really been performed upon the living being.

Upon what then did this procedure rest for its good effects? L Lon the same basis as that for the supposed section of the sphineter; severance of the tissues at the ostium ragine and consequent enlargement of the entrance to the ragina.

The practice which I should recommend in vaginismus, with the light which we at present have for onr guidance, is the following:-

1st. Remove existing uterine, ovarian, vaginal, urethral, or reetal disease, if any ean be discovered; insist upon the patient's living alsque marito; let her use copious vaginal injections of warm water twice daily; use the local anodynes mentioned by rectal or vaginal suppository, or throw into the vagina, every night, by means of a syringe, a pint of fluid, in which are dissolved twenty grains of ehloral; have a plug inserted into the vagina by the patient and retained for several hours every dity; give such tonics as quinine, stryehnine, and iron freely ; and, if it can be accomplished, let the patient have a change of air and scene, and indulge in sea bathing.

21. Should this plan fail, anirsthetize the patient, and by means of the blates of a trivalve or quadrivalve speculum, distend the ostium vagina 
thoroughly; follow this by the use of the vaginal plug, and resort to the muats above given for locally soothing and generally sustaining.

3.1. Shouh this method likewise fail, anasthetize the patient; remove the hymen by seissors, a simple proeedme; incise the perineal body exactly as it is torn in parturition, introtuee the phog, and keep it in sith for a week, removing it and cleansing it daily. After this, let the patient nse it herself, and follow out the directions given under my tirst eaption.

The act of parturition would be very likely to remove this condition entirely, but unfortmately one of the most constant of the results of vaginismus is sterility. This arises from the fact that sexual intercourse is so painful that it is imperfectly performed, or, as is more commonly the case, all efforts at overeoming the obstacle to it cease, and the woman lives a single life. Should this state of things be found to exist, the patient may be thoronghly anasthetized, in the hope that complete connection, accomplished under these circumstances, may result in pregnancy.

\section{CHAPER XIII.}

\section{VAGLINITS.}

Definition and Synonyms. - The mucous membrane lining the vagina is subject to inflammatory action, which receives the name of vaginitis. It is the same disease which by certain authors has been described under the titles of blemorrhoea and blennorrhagia.

Anatomy of the Vagina.-The vagina is a canal formed of strong, muscular elements and lined by mucous membrane. At its upper extremity it is attached to the cervix uteri, with which it unites at a variable point, but usually midway between the os internum and os externum. This cunal consists of three coats: 1 st, an outer eoat, formed of tibrous and elastic tissue; $2 \mathrm{l}$, a middle coat, formed of unstriped muscular fibre and fibre-cell, which are subject like the same structures in the uterus to great hypertroplyy during utero-gestation; and, 3d, an inner coat or lining mucous membrane, composed of connective tissue and elastic fibre, and covered over with squamous epithelium. The 31 extends to the fourchette; the 1 st and $2 \mathrm{~d}$ spread out at the upper portion of the perineum, making the perineal septum, and attach themselves to the ischio-pubic rami. Its general form has been aptly likened, by Dr. Savage, to that which would be assumed by a flexible tube if shortened to nearly half its 
Fie. 79.

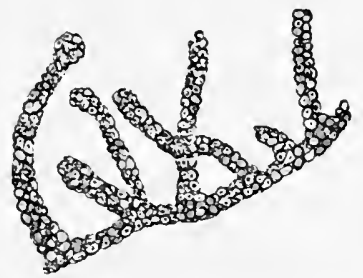

Filiform papilla of the vagina. (Kilian.)

length by a cord passed from end to end through one of its sides. The ridge thus formed is called the anterior column of the vagina, and marks the vesico-vaginal septum. It is about two inches long, while the posterior wall, the posterior column, as it is called, is twice that length. The anterior column, or cord, which shortens the vagina, puckers its investing mucous membrane and throws it into folds or rugie, which run transversely towards the posterior column. This mucous membrane is studded with papillæ, which are covered by pavement epithelium. The papillæ of the vagina, which were first fully described by Dr. Franz Kilian, were regarded by him as having for their function the transmission of sensation. He represents them as being thread-like and filiform, as shown in Fig. 79.

Much discussion has occurred among anatomists as to the presence of mueiparous glands between the folds of the raginal mucous membrane, some asserting and others as positively denying their existence. The researches of Huschke, Jarjavay, Jamain, Farre, and other eminent investigators, enable us to aceept their existence as an undocibted fact, though it is curious that Charles Robin' and Sappey lave been mable to discover them. The vagina may then be said to be lined by a mucous membrane which is covered by epithelium, and thrown into folds which are studded by projecting, filiform papilla, between which lie numerous muciparous follicles.

Varieties of Vaginitis. - Vaginitis assumes three forms, which differ from each other sufliciently to require separate investigation. They are denominated as follows :-

Simple raginitis ;

Specific vaginitis;

Granular vaginitis.

Prof. Ilidebranlt, of Germany, has recently described another variety which he styles "adhesive" for the reason that its chief characteristie is to produce athesions between the ragina and uterus. It occupies the upper third of the vagina: the mucous membrane bleeds readily; and the discharge is thick, creamy, and sanguinolent.

\section{Simple Vaginitis.}

Definition.-This variety of vaginitis consists in inflammation of the mucons membrane of the valginal canal from some eanse other than gonorrhacal contagion. 
Varieties.-It may exist in acute or chronic form, either of which types may appear originally or be the result one of the other. The ar'ute form may be exeited by some special eause and rapidly pass into the clironic; or, originating as a low grade of inflammation, the disease may at any time take on the characters of virulence and acuity. 'Two subdivisions of simple vaginitis, the recognition of which at the bedside constitutes an important point, are, primary and secondary. Sometimes the disease exists as a prinary lesion, but very commonly it depends upon the exeoriating properties of a fluid discharged by the mucous membrane of the uterus. Under these circumstances no treatment addressed to the raginal surface will effect a cure, for even if the disorder existing there be removed, it must inevitably return so long as the cause which originally produced it remains.

Causes.-In the great majority of instances this affection, more particularly in its chronic form, depends upon a discharge from the uterus, to which it is secondary. It may, however, arise from any of the following exciting influences:-

Exposnre to cold and moisture;

Injury from pessaries or coition;

Disordered blood states, as those of phthisis and the exanthemata;

Retained and putrefying secretions ;

Chemical agents ;

Parturition.

After matrimony the acute form is not unfrequently excited, and in prostitutes, whose occupation involves an abuse of sexual intercourse, it is quite common.

A bit of sponge, or other substance which retains the natural secretions, left in the vagina until putrefaction occurs, will often induce the affection, and three of the most virulent eases that I have ever seen were caused by contact of a solution of chromic acid with the raginal walls in making an application to the uterus.

Pathology.-At the commencement of the disease, the mucous nembrane of the ragina becomes highly vascular and its arterioles are distended. There is a rapid moulting of epithelium, so that abrasions often exist, and at times follicular ulcerations and diphtheritic deposits make their aplearance. Sometimes, though rarely, the epithelium lining of the vagina is thrown off entire, constituting a cast or mould of the eanal very similar in character to the dysmenorrhoeal membrane which is occasionally expelled from the uterus.

In very severe cases the inflammatory action passes down into the submucous tissues, and a true phlegmonous process is established which may result in abscess. For a period varying from fifteen to thirty hours after the inception of the disease, the natural secretion of the part is checked; 
then pus of acrid and offensive character pours forth freely, which, in a week or ten days, is replaced by muco-purulent material. This discharge is found to consist of serum, large numbers of epithelial cells, pus, bloodglobules, and an infusorial animalcule called the trichomonas vaginalis by M. Domné, who first described it. By some the last has been regarded as ciliated epithelium separated from the uterus, but it is probably an animalcule which exists in vaginal mucus of unhealthy character. MI. Donté at first regarded it as characteristic of specific vaginitis, but subsequently renounced the view.

Symptoms._Acute vaginitis manifests itself by the following symptoms :-

A sense of heat and burning in the vagina;

Aching and weight at the perineum;

Frequent desire for micturition;

Profuse, purulent discharge of offensive character;

Violent pelvic pain and throbbing;

Excoriation of the parts around the vulva.

In the chronic form the disease shows the same symptoms, though with much less sererity. In very mild cases, only a slight itching or burning sensation is experienced, with discharge of the leucorrhœal matter.

Physical Signs. - When the inflammation is acute the labia are found swollen and tense, the mucous membrane of the vaginal canal red and

Fig. $\varepsilon 0$.

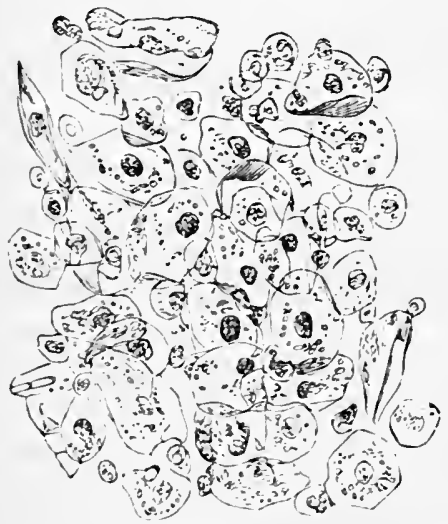

Epithelium in all stares of development, in simfil: vagiuitis. 2z diauelers. (T. suith.) covered with pus, and the animal heat very much increased. Introduction of the finger produces great pain, and often cannot be tolerated. As the labia are separated a flow of fetid muco-pus is discharged. If the canal be explored by means of the speculum, its surface will be found congested, while at numerous points abrasions, and perhaps follicular ulcerations, will be noticed. The inflammatory appearances of the vagina will be seen to have extended to the cervix uteri, and very generally from the os will be found to hang a plug of mucus secreted by the irritated, or even inflamed, Nabothian follicles.

Prognosis. - In its acute form it usually runs its course in about two weeks. In the chronic form it lasts for an indetinite time, often subsiding into ordinary vaginal lencorrhea, or rather into a state of which this is the only prominent symptom. 
Differentiution._-Simple vaginitis may be confounded with_-

Gonorrhu'a; ;

Endonutritis;

Pelvic abseess;

Giamular degeneration of cervix.

From the first the differentiation is always difficult and frequently impossible. The means by which it may sometimes be accomplished will be mentioned in the artiele relating to Specific Vaginitis. From the three remaining affections it is realily distinguishable by the speculum and vaginal touch. An error will be committed only when the practitioner is not mindful of the possibility of its occurrence, and draws his conclusions from insuflicient data. I have seen two cases of profuse and obstinate va ginal discharge regarded as the result of vaginitis, which were in reality produced by pelvic abscesses that emptied their contents into the upper part of the canal. An element in such cases calculated to mislead a superficial examiner is the fact that vaginitis does really exist to a limited extent as a result of the purulent flow from the abscess. This remark likewise holds true in reference to endometritis and granular degeneration.

Complications. - Vaginitis sometimes produces violent urethritis, and less frequently results in endometritis, Fallopian salpingitis, and pelvic peritonitis.

\section{Specific Vaginitis, or Gonorrhoea.}

Definition.-This variety of the affection consists in inflammation of the vulva, vagina, and urethra, arising from a specifie contagion which is transmitted by a yellow, purulent discharge.

Puthology.-The purulent material which is the contagious element, after remaining for some time in contact with the vaginal walls, excites in their investing nucous membrane an active hyperomia which results in heat, swelling, pain, and an ichorous and abundant purulent secretion. This inflammation may be simulated by simple acute raginitis, but its most characteristic features are usually excited by the contagious infiuence just alluded to. The discase may affect all the localities above mentioned at the same time, but very often it is limited to the upper part of the vagina, to the vulva, or to the urethra. In some eases it is for a length at time concealed in the vaginal cul-de-sac, no other part of the vagina being affected. This fact explains, says Alphonse Guérin, ${ }^{1}$ how women apliarently healthy transmit gonorrhoa.

Cuuses.-As there is but one cause for scarlet fever, for measles, and for variola, namely, absorption of a specific poison or contagious material, so is there, it appears to me, but one cause for gonorrhca. It is true that simple acute vaginitis may simulate gonorrho'a so closely that the 
most experienced observer will be foiled in diagnosis, but this fact does not prove the diseases to be identical. The poison of gonorrhœa produces inflammatory results as a certain consequence of contact; the causes of acute raginitis produce them as an accident which probably in a different state of the patient's system would not have occurred. ${ }^{1}$

Symptoms.-The symptoms of this variety of vaginitis differ very little, indeed in many cases not at all, from those of the simple acute form. They may be thus enumerated:-

Heat and burning in the vagina;

Aching and sense of weight at the perineum;

Frequent desire for mieturition;

Sealding in the passage of urine;

Profuse purulent leucorrhoca of offensive character;

Violent pelvic pain and throbbing;

Excoriation of the parts around the rulva.

Physical Signs._-The vulva, ragina, and urethra will be found swollen, tense, red, and hot. In the beginning they are unnaturally dry, but very soon a profuse secretion bathes them with a creamy pus, sometimes streaked with blood. Should the affection have exerted its influence chiefly upon the vulva, pruritus, excoriation, and intense heat will be observed. Should the urethra be chiefly $\mathrm{cr}$ solely diseased, instances of which are reeorded by Rieord and Cullerier, the most violent sealding upon the passage of urine will especially annoy the patient.

Differentiation.-It will be seen, from what has been already stated, that the differentiation of this disease from simple acute raginitis must be extremely difficult. In many cases it is impossible, for there are no signs which can be regarded as positively conclusive. The trichomonas raginalis, once supposed by Donné to be pathognomonie of speeific raginitis, is now known to exist in the pus of that which is simple; and urethritis, formerly viewed as diagnostic by many, is sometimes a complication of the simple form and is sometimes absent in the speeifie.

The following are the symptoms which should lead us strongly to suspeet the specific nature of a case:-

Great virulenee and acuity in development ;

Development in a woman previously free from vaginal diseharges;

Marked urethral complication;

Copious purulent discharge;

Transmission to the male from coition.

Although it is true that in many cases these ssmptoms will render us

1 This riew is denied by many of the best authorities, who regard gonorrhora as haring nothing specifie about its nature. At the sane time that I have no wish to ignore the opinion with which mine contlicts, I hare preferred to give my ow imrressions without discussing the matter. 
certain in our conclusions, in many others they will exist in cases certainly of non-specific character. I have on two oceasions seen them all attend calses of vaginitis, excited by aecidental contact of chromie acid with the vaginal walls.

Course, Duration, and Termination.-The duration of the disease will depend in great degree upon the character of the treatment arlopted. Unler a proper management even a severe case may often be cured in from two to three weeks, but if neglected, it may continue for months and perhays years. The morbil action passing up into the uterus may exist as an cndometritis long after the vaginal trouble has disappeared; or it may pass into the bladder and excite eystitis ; or down their narrow ducts into the rulvo-vaginal glands.

D). Noeggerath, in 1873, published a remarkable paper on " Latent Gonorrhoe in the Female Sex," in which he declares, that certain morbid phenomena in the female organs, which have hitherto been considered as separate, and treated independently, possess a common basis from which they collectively and separately take their origin-this being nothing more nor less than gonorrhœa. "I have," he says, "undertaken to show that the wife of every husband, who, at any time of his life before marriage, has contracted a gonorrhoa, with very few exceptions, is affected with latent gonorrhoea, which sooner or later brings its existence into view through some one of the forms of disease about to be described. . . . I believe I do not go too far when I assert that of every 100 wives who marry husbands who have previously had gonorrhœa, scarcely 10 remain healthy; the rest suffer from it or some otlier of the diseases which it is the task of this paper to describe. And, of the ten that are spared, we can positively affirm that in some of them, through some accidental cause, the hidden mischief will sooner or later develop itself."

The diseases to which this author refers as remote consequences of latent gonorrhœa are perimetric inflammations, both acute and chronic, ovaritis, and catarrh of the genital tract. These when once excited are, he declares, incurable, and render the life of the female one of misery and danger. 'These women rarely become pregnant, or, if they do so, either miscarry or bear only one child. To sustain this assertion he gives the statistics of 81 eases, of which 31 only became pregnant. Of the 31 , only 2:3 went to full term; 3 were prematurely delivered, and 5 aborted. Of the 23 who went to full term, 12 had one child each during married life; 7 lad two children each; 3 had three; 1 had four; and among the 23 women there were five abortions. He asserts that althongh apparently cured, gonorrlixa may exist both in the male and female an entire lifetime in a lateut form, which may at any monent burst forth into acute gonorrhoal inflammation, or excite serious uterine or periuterine inflammation.

1 Die Latente Gonorrhce im Weiblichen Geschlecht. Bonn. 
Since the appearance of these views I have consitered this subject very carefully. While I admit, that even years after a gonorrhœea has been considered cured some lurking infectious element dammed up perhaps behind a stricture may transmit the disease, I have failed to get evidence of the truth of Dr. Noeggerath's assumptions as to the universality of such transmission of disease. Were they true indeed, it appears to me that a healthy woman would be a rare exception to a very general rule.

Complicutions.-The complications of gonorrloea in the female are numerous and important. The disorder sometimes becomes an exeedingly grave one, and, in some instances, destroys life. It may induce the following results :-

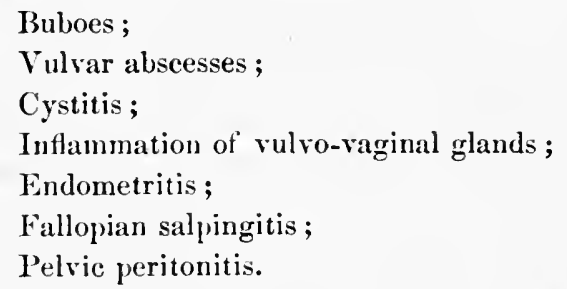

Buboes ;

Vulvar abscesses;

Cystitis ;

Inflammation of vulvo-vaginal glands;

Endometritis ;

Fallopian salpingitis ;

Pelvic peritonitis.

Mr. Salmon, ${ }^{1}$ who first drew attention to inflammation of the vulvoraginal glands as a result of the disease which we are considering, declares that it is quite common.

The passage of the disordered action into the uterus, through the tubes, and into the peritoneum is the most dangerous of all its consequences, and produees great risk to life from the pelvic peritonitis which it excites.

\section{Granular Vaginitis.}

Definition and Synonyms._-This variety of vaginitis was first described by Ricord, under the name of Psorolytrie. In 1844, M. Deville, ${ }^{2}$ a pupil of Ricord, desgribed it fully, and it was subsequently treated of by Blatin, Guérin, and others, under the names of papular, glandular, and granular vaginitis.

Puthology.-By these writers it was regarded as an hypertroply of the muciparous follicles, lying embedded between the ruga of the vagina. This hypertrophy, it was thought, was generally the result of pregnaney, though it was admitted that it might arise from simple or specific vaginitis. Many recent writers deny the existence of this variety of vaginitis, and view it only as an hypertrophy of vaginal papilla, the result of the forms of the affection already mentioned. Thus Dr. Bumstead. ${ }^{3}$ in speaking of gramulations found in the vagina as a result of vaginitis, says, "They have been erroneously regarderl by Dr. Deville ats peculiar to the vaginitis of

\footnotetext{
1 Bumsteard on Veneral lis., p. 172.

2 Archiv. de lled., 4th series, t. $v$.

3 Op. cit.
} 
pregnant women." Scanzoni ${ }^{1}$ and West $^{2}$ loth deny its existence, and upon the same ground, viz., the fact that Mandl and Kölliker have discovered very few mucous follicles in the vaginal mucous membrane. When, however, in opposition to the negative fact that these exerllent observers, supported by Robin and Sappey, have not discovered these glands, is arrayed the positive fact that Ilusehke, Jamain, Richet, Beequerel, Guérin, and others have done so, the gromuls for denial must be admitted to be insufficient. Even if sueh evidence of the propriety of almitting this variety of vaginitis did not exist, elinical research would corroborate the truthfulness of the deductions of M. Deville.

The disease is characterized by hemispherical granulations, about as large as half a millet-seed, scattered thickly over the mucous membrane of the vagina and over the cervix uteri. This variety of the disease appears to bear the same relation to simple vaginitis that follicular vulvitis does to the purulent form of that affection. I once saw a case of granular raginitis, so striking in its features that the attending physician had expressed to the patient's family his fears that malignant disease was developing. IIe became at once convinced of his grave error, when shown a description of the disease which really existed, and with which he had never before met. Although I believe in the validity of this variety of vaginitis, I must declare that $I$ have rarely met with it out of the condition of pregnancy.

Causes.-The glandular hypertrophy which gives to the disease its eharacteristic features and name, generally results directly from pregnancy, though it may be produced by either simple or specific vaginitis. Some women suffer from it in successive pregnancies.

Symptoms.-It demonstrates its presence by the symptoms already recorded as characteristic of simple and specific raginitis. With these, pruritus vulvæ and a lichenous eruption about the pubes are apt to appear. As farturition comes on and puts an end to pregnancy, it usually disappears, very often without any treatment whatever.

Treatment of Vaginitis.-The treatment of the various forms of this disease is so similar that it may be described under one head, modifications being suggested for those cases which have assumed a subacute or chronic aspect. If the case be one of acute character, the patient should be kept perfectly quiet in bed, and loeomotion and sexual intercourse strietly interlicted. Pain should be relieved by opiate or other anodyne suppositories placed in the rectum, and febrile action prevented or combated by mikd, unstimulating liet and refrigerants. Every fifth or sixth hour the patient, placing under the buttocks a bed-pan, upon which she lies, and between the thighs a vessel of warm water, should, by means of a syringe,

1 Distases of Females, Am. ed., p. 529.

2 Diseases of Women, Eng. ed., p. 640. 
throw a steady stream against the cervix uteri for fifteen or twenty minutes, or even for a longer time. The methods most appropriate for syringing the vagina are fully described in chapter four. The bowels should be kept in a lax condition by saline catharties, and the ardor urinæ relieved by the use of alkaline diuretics. Should inflammatory action run very high, and much pain be experienced, great benefit will be derived from the free administration of opium, which should be given until complete quiescence of the nerrous system is accomplislied.

When the severity of the symptoms has been relieved by this combination of general and local means, Sims's small speculum should be passed, the cervix and raginal walls eleansed with absorbent cotton, the whole canal washed over with a solution of nitrate of silver, $\exists j$ to $\bar{z} j$ of water, and a tampon of carbolized cotton soaked in glycerine applied, so as to prevent all contact of the opposing walls. This should be renewed once in every twenty-four hours. But lengthy renewal will not be found necessary, for cure will, as a rule, very soon occur.

\section{CHA PTER XIV.}

\section{ATRESIA OF TIIE GENITAL TRACT AND RETENTION WITHIN IT OF MENSTRUAL BLOOD AND OTHER FLUIDS.}

Definition and Synonyms.-The term atresia, derived from a, privative, and tpaw, "I perforate," signifies an imperforate condition, and should in its strict import be limited to complete closure of an aperture or canal. Any obliteration or occlusion which is so extreme as to remove the case from the class of strictures, and yet is not complete, should be styled stenosis. The genital eanal of the female may be imperforate at the vulva, in the vagina, or in the canal of the uterus itself.

Any one of these atresia may act as a barrier to the eseape of monstrual blood, and create a dangerous retention of that fluid with coincident overdistention of the vagina, uterus, and Fallopian tules, which may become so excessive as to cnd in rupture, peritonitis, and death. As this is the chief relation in which they are to be considered, it seems best to sturly the varieties of atresia under one head.

Congenital atresia never attraets notice until puberty has arrived, and then an examination is instituted on account of non-ippearance of the menstrual flow, the presence of an abdominal tumor caused by uterine or vaginal distention, or the suspicion of pregnancy, some of the prominent signs of which are present unler these circumstances. Acquired atresia is suspected for the same reasons. 
In general terms it may be stated that the higher up the atresia be, the greater the danger arising from its existence. Thus, an atresia of the hymen is the least dangerous of all; one as high as the os intermum uteri the most so. The reason for this is evillent: the former has above it, for acconmodation of retained fluid, the distensible vagina and cervical canal; the latter has only the uterus itself. Then, too, distention of the vagina produces less marked influence upon the Fallopian tubes than that of the uterus. Distention of the latter does not, it is now thouglit, cause a reflux through the tubes, but creates a species of vicarious menstruation from their walls. This gives rise to hremato-salpinx, which so often ends in rupture of the tube that that accident should be feared as one of the most deciderl dangers connected with the condition.

This tubal rupture may occur in two ways: first, sudden emptying of the uterine contents creates uterine contraction which at once extends to the muscular fibres of the tubes, and rupture is the result; or, previous peritonitis having fixed the tubes, descent of the uterus drags upon them so powerfully as to cause their rupture, or laceration of the false membranes which hold them.

It must not be forgotten, however, that, although it is an exception to the rule, vaginal atresia may cause distention of the uterus and tubes by gradually dilating the uterine tract, and before every operation this effect should be considered.

\section{Atresia of the Uterus.}

Definition and Frequency.- This consists in closure of the canal of the cervix so that no fluid can escape. In its partial form, that of stenosis, it is by no means rare, but fortunately complete atresia is decidedly so.

Virieties.-Uterine atresia may be either congenital or acquired. When it is congenital it may exist at the os internum, at the os externum, or involve the whole cervical canal. Sometimes the cervix is exceedingly small while the body is greatly distended by fluids.

When the condition is acquired, it may also be limited to one or both ora or involve the whole extent of the camal. The causes which most commonly induce it are the following:-

The use of canstics;

Cervical endometritis;

Irritation from neoplasms in the canal;

Senile atrophy ;

Sloughing after parturition;

Amputation of uterine neck;

The use of the steel curette.

The first of these is a very common cause of severe stenosis, and sometimes produces even complete atresia. The second, involving the Nabothian follicles, sometimes ends in adhesive inflammation. 'The third 
I have scen produce the condition in three cases. The fourth is so very common in old age that Hennig declares, that, out of one hundred women who had passed fifty years of age, about twenty-eight, over a quarter, suffered from it. The fifth and sixth are often met with as eanses, and the seventh I once had occur in my own practice.

Results.- It might at first thought be supposed that uterine atresia occurring after the menopause would be, as it usually is before puberty, a matter of no moment. As a rule this is so, but there are exceptions to both rules. In the old woman a watery secretion sometimes takes place, giving rise to hydrometra; suppurative action may occur, creating pyometra; and decomposition of the imprisoned fluid gives rise very rarely to a development of air, physometra. Very rarely hydrometra is found before puberty and hamatometra in old women.

The evils which result from uterine atresia are-

\section{Hiematometra ; \\ Hrmatosalpinx; \\ Hydrometra.}

And the consequences of these, if they be left uninterfered with, may be-

Peritonitis ;

Pelvie hæmatocele;

Rupture of the vagina, uterus, or tubes;

Septicemia.

Prognosis. - Whatever course be pursued, in a patient suffering from uterine atresia with retention of menstrual blood, the prognosis is necessarily a grave one. Non-interference may, and probably sooner or later will, end in the development of one of the aceidents just recorded. Surgical interference, on the other hand, is attended by the dangers of rupture of the tubes, laceration of the false membranous attachments, and the development of septicamia from the admission of air to the distended uterine cavity.

Dingnosis and Differentiation.-It is sometimes exceedingly difficult to differentiate retained menstrual blood in the uterine tract from fibrous tumors, malignant growths, ovarian cysts, hematocele, and pregnancy. The rational signs which enable us to do so are these: in all but the last, menstruation is commonly increased, while here it is suppressed ; the tumor is surely uterine and not ovarian, retro-uterine, or ante-uterine; it has come on slowly, and not suddenly as the tumor of hrmatocele does, and at every monthly epoch an increase of inconvenience is noticealle from its presence. Phyiral sirns yield more important results still. If an attempt be made cautiously to pass the uterine sound or probe, the cervical canal will be found to be closed. This constitutes the erucial test.

The diagrams, Fins, 81 and $8 *$, show the varietics of hematometra occurring in cervical attresia. 
Fig. 83 presents an instane of atresia in one of the uteri in a case of double uterus, the other being free to perform all its functions.

FIG. 81.

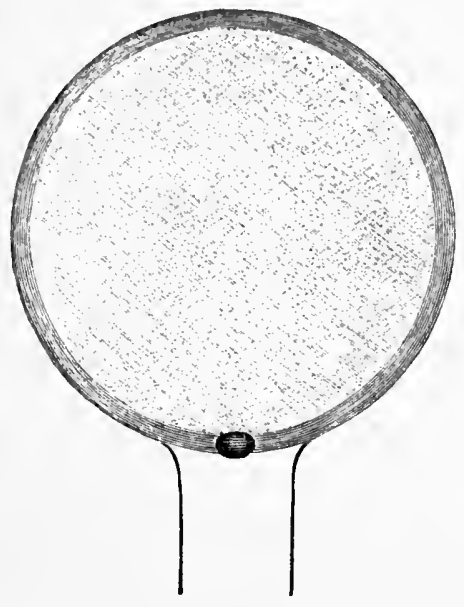

Uterine atresia at os externum.
Fis. 82.

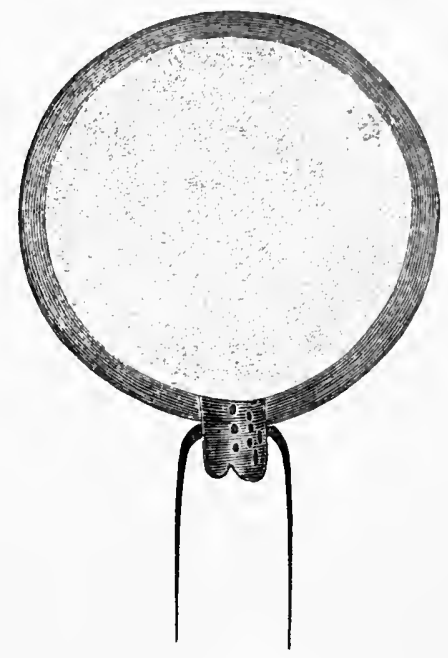

Uterine atresia at os internum.

In the last case menstruation would be regular, the uterus be suseeptible of recognition by conjoined manipulation and the passage of the sound to Fic. 83.

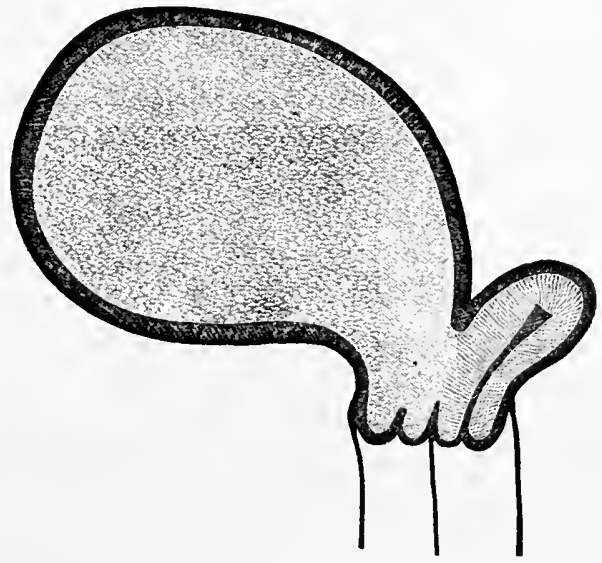

Atresia in oue-half of a double uterus.

the fundus, while one half of the abnormally developed organ would present the large tumor seen in the diagram. Diagnosis would be possible here only by very careful conjoined manipulation. 


\section{Atresia of the $\mathbf{V}$ agina.}

Like the uterus the ragina is in foctal life ereated from the approximation and amalgamation of the Müllerian duets npon the median line. In the former a great variety of congenital malformations are the result of arrest of development of these parts. So is it also with the latter; the chief of its anomalies being double, unilateral, diminutive, and rudimentary vagina, or no vestige of it may exist. The condition which is now to engage our attention may be due to such congenital arrest of development or to accidental eauses developing after adult life has been reached.

IIistory.-Hippocrates ${ }^{1}$ refers to this condition as a result of labor; Aristotle speaks of the accidental and congenital varieties; Celsus devotes a chapter to it, and it claims attention, as we come down to subsequent times, from Aetius, Avicenna, Lanfrane, Wierus, Ruysch, Mauriceau, and Roonhuysen. Heister and Boyer advanced our knowledge of it, but it was left for the daring enterprise of Dupuytren, Amussat, and Debron, to place its cure among the achievements of modern surgery.

FIG. 84.

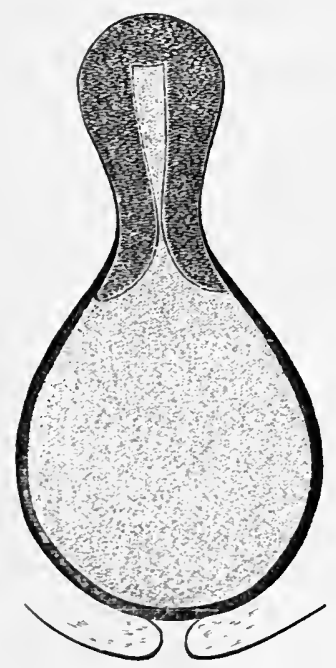

FIG. 85.

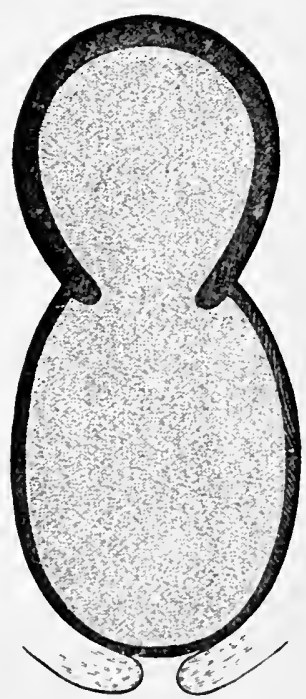

The vagina distended by blood from imper. forate lyymen.
Vagina and uterus both distended with blood in conseguence of an impervious hymen.

Firieties.-There may be no trace of the canal, the alucts of Miiller serming to have failed ontirely to develop; there may be a dintinct fibrous cord marking the site which it should have occupied, some slight develop-

1 Puesch, be l'Atrésie des Voies Gén. de la Fennme. 
ment appearing to have occurred; development may exist for some distance "1p the canal, failure having taken place above; or one Müllerian rluct has developed in part above and another below, giving two cul-ele-sacs separated from each other by impervious tissue. The whole canal is not rarely well developed, while the hymen guards its ontlet as an unyielding and completely closed obturator nembrane. The last of these vaginal atresiae, and, fortunately, the most frequently met with, is depicted in Figs. 84 and 85 .

Not only is the operation for relief in sucl a case much more simple than in other varieties of atresia, the uterus is usually not involved in the dilatation and the danger of trouble after operation is not so great.

Puthology. - As a result of injury from mechanical, chemical, or pathological ageneies, a vagina once fully developed may close from adhesion of its walls; its calibre may be diminished by absolute removal of its component structures in consequence of ulceration or sloughing; or the other parts of the female grenital system may go on to full development while this is arrested in its growth and remains a fibrous cord instead of a distensible canal.

Causes.-The following special causes may be enumerated as productive of it:-

Impervious hymen;

Arrest of development of vagina;

Prolonged and difficult labor ;

Chemical agents locally applied;

Mechanical agencies exciting inflammation;

Sloughing, the result of impaired vitality ;

Syphilitic or other extensive ulcerations.

One of the cases which have come under my observation resulted from syphilis; several from prolonged labor; one from the accidental passage of a sharp bit of wood up the vagina; another from retention of the foetal body fis two hours after delivery of the head; and one from a tampon of cotton saturated with persulphate of iron. Among the causes of sloughing from impaired vital force should be especially mentioned the continued and eruptive fevers, typhus fever, scarlatina, variola, etc.; and choleria as a catuse of the accident is referred to by M. Courty. Dr. Trask, of Astoria, N. I., has written an excellent article upon this subject, his conclusions being based upon thirty -six cases, of which fifteen were due to prolonged latbor.

Symptoms.-The disorder will demonstrate its existence only by incapacitating the vaginal canal for its important functions, copulation and trausmission of menstrual blood. Should it oceur in one too young or too old to require such functions from the vagina, no suspicion will be aroused as to its existence. The notice of the practitioner will generally be called to the patient by amenorrhuea or by an inability to perform the act of 
coition. Should the menstrual hemorrhage have taken place, a large amount of blood will generally be found confined above the constricted part of the canal, and violent contractions will have demonstrated the efforts which the parts have made to expel the accumulation. Besides these, no other rational signs will show themselves, but they will be sufficient to urge upon the attendant the necessity for a physical exploration.

Physical Signs.- The patient being placed upon the back, and vaginal touch attempted, entrance of the finger into and up the vagina will be found to be impossible. Investigation will prove that this is not due to vaginismus, or adhesion of the labia majora, and rectal touch will, in cases involving the vagina, usually discover that canal ruming up the pelvic eavity as a fibrous cord, though sometimes no trace of it will be found.

Results. - From the mere occlusion of the vagina there is no immediate or direct derangement. But in cases where menstrual blood is poured out by the vessels of the uterine mucous nembrane, and is accumulated at each monthly epoch in the portion of the canal above the stricture, or in the uterus, which is dilated by its retention, rupture of these organs or of the Fallopian tubes may occur; discharge from these tubes into the peritoneum may take place, and pelvic hæmatocele be the consequence; or the retention of the menstrual flow may produce all those nervous and cerebral symptoms so characteristic of sueh an occurrence.

Irognosis. - The prognosis of these cases, as regards the possibility of removal of the abnormal state, will depend upon the extent and completeness of the obliteration and destruction of tissue. The smaller the amouut of vaginal tissue found by rectal touch and examination by a sound in the bladder to exist, and the more complete and extensive the adhesion of the vaginal walls, the more closely will the case resemble one of entire absence of the vagina. The prognosis as to permanent cure will greatly depend upon the patient. If she be a woman of good sense and perseverance, and kecp up, after operation, distention by the vaginal plug, not for months, but for years, the result is often a very good and permanent one. If, on the other hand, she ignores the risk attendant upon the cessation of its use, contraction will probably recur. During the process of making a canal between the bladder and rectum, one of these viscera is very ant to be cut into, or the peritoneum may be opened at the fornix vagine. If a depot of menstrual blood be reached and evacuated, death is by no means rare from septicemia, purulent absorption, or a septic endometritis which ends in lymphangitis, or in salpingitis and peritonitis.

The prognosis is greatly governed, too, by the variety of atresia with which we deal. Occlusion due to impervious hymen warrants a very favorable proguosis; that arising from accidental causes, likewise; that from congenital cause in which the utcrus and ragina can be distinctly discovered as existing, a less favorable one; while that due to absence of vagina and uterus, as far as clinical observation can verify the fact, a 
well-nigh hopeless one. In other words, the more complete the absence of vaginal tissue and that of other organs of the pelvis, the more untavorable will be the prognosis as to recovery from surgical interference.

Should deformity of the external genitals exist, the uterus not be liseoverable, and no signs of distress at menstrual epochs show themselves, it may be concluded that the case is one of absence of the vagina, and not of eomplete atresia. But, thanks to the boldness of Amussat, even absence of the vagina does not preclude the possibility of establishing an artificial eanal. The importance of the differentiation consists in the fict that the surgeon should in such a case be doubly cautious and eircumspeet in his efforts, and guarded in his prognosis. It may at first thought appear that in ease there be no evidence of the existence of uterus or ovaries, and no inconvenience be experienced from retention of menstrual blood, it would not become necessary to resort to an operation to render the vagina pervious. But so great is the unhappiness often resulting from incapacity of the woman for the sexual act, that this beeomes a resson for her to demand the resources of art, and a valid ground for interference on the part of the surgeon. If no such demand is made for surgical interference, it would, in such a case as that just depicted, be an unwarrantable procedure. Not only is the patient exposed to danger without sufficient indication; she is thus exposed for the opening of a canal which has a marked tendency to close completely.

The rule with reference to operation for atresia due to congenital elosure or absence of the vaginal canal itself should, it seems to me, be this: it shouhl be resorted to $(a)$ if menstrual blood be imprisoned; $(b)$ if a uterus can be distinctly discovered and the patient be suffering from absence of menstruation; $(c)$ if the neeessity for sexual intercourse be imperative: it should be avoided unless demanded by one of these considerations.

Treatment.-To surgery alone can we look for any hope of recovery or of safety in cases of atresia of the female genital eaml. I shall treat of this part of the subject, as it applies to all varieties of atresia-uterine, vaginal, and their subdivisions. It is evident that, to do justice to it, operative interference must be described as applying to the following cases :-

1st. Where there is atresia of the uterine neck.

$2 d$. Where there is atresia of the hymen alone.

3 d. Where the vaginal canal is closed only for a small portion of its eourse.

4th. Where there is eomplete closure or entire absence of the ragina.

Where there is Atresia of the Lterine Neck.-The operator should decide, by careful conjoined manipulation, as to the degree of uterine distention which exists above the cervical closure. If this be slight, the obstruction may at once be overcome; if it be very decided, it will be 
safer to draw off the fluid gradually, in order to aroid violent uterine contractions, which may, as Barnes ${ }^{1}$ suggests, force fluid from the cavity of the uterus through the tubes, or affect the tubes by sympathy, or by sudden dragging downwards. Let us suppose that the uterine tumor is quite large; the patient should be placed in Sims's position, and, his speeulum being introduced, the cervix uteri should be caught with a tenaculum, and the point at which puncture is to be practised carefully selected. 'The smallest needle of Dieulafoy's aspirator should be, with the tube of the instrument attaclsed to it, fixed upon this point, and then, the vagina being filled with carbolized spray, it should be passed into the uterus and the blood drawn off by suction. When the uterine tumor is diminished about one-third, the needle should be rapidly withdrawn and the ragina tamponed with carbolized cotton, saturated at the moment of use with carbolized water.

This tampon may be left in place for forty-eight hours and then removed, and in a week or two, as seems best to the operator, this process of gradual withdrawal of the retained menstrual blood may be repeated, until the uterus has become small and nearly empty. Then, or at once, in case the uterus be not originally much distended, the operation for cure of the atresia may be practised. The following method I have resorted to in two cases with excellent results, and it appears to me to recommend itself on account of its simplicity and safety. The patient being arranged as for aspiration which has just been described, under a very slight carbolized spray which does not obscure vision, the cervix should be steadied by a tenaculum and a long exploring needle passed into the uterine carity. The sense of resistance overcome, and the escape of a drop of blood will assure the operator of his success in reaching it. Then putting into the gutter of the needle a delicate tenotome, he pushes it upwards to the required distance to open the canal. This section is repeated on the other three sides, the eavity of the uterus is syringed out with carbolized water very gently forced from a small syringe; a small glass plug is inserted in the cervix, and the vagina tamponed as after aspiration.

Where Iaginal Atresia is due to closure by a Diaphragm or by the Hymen.-_The same rule of practice should be observed, and the same antiseptic precautions adopted. If gradual evacuation be resorted to and septic fever begin to develop, recourse shonld at once be had to the rapid method. Gradual evacuation should be accomplished exactly as in uterine atresia, for it is always safe to conelude that with vaginal distention there is probably uterine. Section of the hymen may be practised in two ways : first, by passing the exploring needle, sliding a knife up its groove and making a free crucial incision; second, by catching the bulging septum, as P'ueseh has adviserl, and cutting out a large circular piece. 
After the oceluding septum las been destroyed, the cavity ahove should be freely syringed out with carbolized water, and Sims's glass vatuinal pling introduced.

Where there is entive Closure or Absence of the Tagina.-In the first ease a lard, fibrous cord will mark the position of the vagina; in the second no indication of it will be found, and a eanal must be crcated between rectum and bladder, out of a space oecupied by areolar tissue. Should aceumulation of menstrual blood have occurred, the operation will prove mucl easier than if it las not, for its greatest difliculty consists in finding the cervix uteri, and in cases of accumulation this is an easy matter.

The other operations for atresia become insignificant when compared with this one, which as Courty well observes especially calls for an "alliance of caution with skill."

Before operation, if there be any doubt as to the presence of the uterus or as to its size or position, the hand, except the thumb, may be introduced into the rectum, after stretching the sphincter, and a full and satisfactory exploration made.

If on account of great obesity it be found impossible to appreciate by conjoined manipulation the extent of tissue existing between the bladder and rectum, and consequently in the course in which the vagina is to be opened, or perhaps absolutely constructed, the urethra may be rapidly distended by sounds so as to admit the finger to the bladder. Then the index and middle fingers of the right hand being carried up the rectum, and the index of the left introduced into the bladder, this important point may be ascertained.

Before operating, the patient should be anæsthetized, and the bladder and rectum emptied of their contents. She should be placed in the lithotomy position upon a table before a good light, and the operator should have four assistants at lis disposal.

The operation may be performed by two methods: that of Dupuytren (1818), which eonsists of breaking a passage by the finger, cutting obstructions which eannot thus be overcome, and syringing out the cavity afterwards, the whole operation being finished at one sitting; and that of Amussat (1832), which consists of working with the finger and dull instruments, overcoming resistance by pressure rather than by incision, and completing the operation not in one but in severai sittings.

Dupuytren's Operation.-Barnes ${ }^{1}$ expresses a decided preference for this over Amussat's operation. and my experience leads me to agree with him. Courty ${ }^{2}$ thus deseribes Dupuytren's procedure :-

"The procedure devised by Dupuytren, about the year 1817, consists in the combined use of a eutting instrument and tearing of the cellular

1 Diseases of Women, p. 212, 2d Am. ed.

2 Mal. de l'utérus, p. $3 § 1.18 b 6$. 
tissue. It is accomplished in a single sitting, and appears to me preferable to the preceding one (Amussat's).

"The following is the description of it, with the modifications which $\mathbf{M}$. Puesch has added :-

"After having arranged the woman in a convenient position, the bladder is emptied by means of a male catheter which is given to an assistant who holds it turned upwards. It is not rernoved during the operation except where the obliquity of the part would render it tronblesome. The inlex finger of the left hand is then carried into the intestine as far as possible, in order to serve as a guide for the bistoury and at the same time as a protection to the rectum. After these preliminary steps the operator, placed between the thighs of the patient, makes a transverse incision at the centre of the obstacle, or in the vulvar orifice if the ragina is completely wanting; if the cellular tissue is lax, he can tear with his finger, the sound, or the handle of the bistoury the vesical and rectal walls till lie reaches the tumor; if it is tense or too resistant, the surgeon dissects by gentle efforts, separating the tissues with the handle or the finger rather than cutting them, and, if it be necessary, breaking them down at the edges with a button bistoury. In cach case he proceeds slowly and carefully, stopping from time to time to examine with the finger and be certain at what distance those organs are situated which it is necessary to avoid. When the canal which has been reopened will admit the index finger easily, and when a more distinet pereeption of fluctuation announces the proximity of the sanguineous collection, the operator is warranted in plunging a trocar into this, and the pouring out of a syrupy, brown liquid, like the lees of wine, will show that the end has been reached. The pressure upon the uterus is then stopped, a large part of the fluid is allowed to flow away through the canula, and then, substituting for this instrument a perforated sound, the operator increases the size of the opening by numerous incisions upon its sides and thus renders certain the final result. Afterwards he carries a gum-elastic sound into the nterine cavity, and throws through this, but with very little foree, several injections of warm water. The dressing having been finished, the parts are sponged and dried, and the patient is placed in a bed protected by cloths so as to prevent the betling from being soiled by the mueous and sanguinolent discharges which flow during the first days."

Aimussat's Operation.- The labia being retracted by the fingers of two assistants, holding the thighs, the finger of a third,' who kneels by the side of the operator, is introdneed into the rectum, with its palmar surface looking backward. A steel sound is then passed into the bladder, which the :tsistant, on the left of the woman, holds in the right hand. At this moment, this assistant holds the woman's knee under his left arm, retracts

1 The arrangement of assistants is my own. 
the labium by his left hand, and holds the sound in his right hand. 'The sound he must press upon gently, so as to let the operator's finger recornize its presence as it works its way up the vagina. By means of a pair of curved scissors, condueted up to the point of obliteration upon one finger, the tissue between the urethra and rectum should then be very cautionsly eut, in a transverse direction, and the finger introduced into the opening made. This is really almost all the cutting which should be done; the rest should be accomplished chicfly by the finger. This, by the sense of touch, tells the operator exactly how near he approaches the somnd in the bladder on one side, and the finger in the rectum on the other. To one who has not tried this plan, the facility with which the atherent vaginal walls may be separated, or a new tract torn through the tissues, will be surprising. Now and then, the application of the scissors or of a curved, probe-pointed bistoury will become necessary, but every such necessity constitutes an element of danger.

As the operator approaches the regions around the cervix, he may become bewildered as to its position. Under these circumstances, let him make pressure by his unoccupied hand, over the hypogastrium, so as to force the hard cervix down upon his finger, or stop and make a careful exploration by conjoined manipulation, two fingers in the rectum and one hand over the abdomen. Haring thus reassured himself he may proceed.

However the operation for atresia be performed, there is always great danger of relapse, and unless special means be adopted for maintaining the perviousness of the canal, it will probably occur. To prevent this unfortunate result the French operators, ${ }^{1}$ to whom we are indebted for most of our surgieal resources in this difficulty, used bougies wrapped with linen, tampons of lint, and India-rubber bags filled with air; but we have a much cleaner and more effectual means for doing it, in the glass vaginal pluy of Sims.

It menstrual blood have been imprisoned above the strictured portion of the vagina, the canal should, for a fortnight after operation, be kept scrupulously clean by injections of tepid water practised twice a day. If the uterus and tubes have been distended by retained fluid, the cavity of the former should, just after the operation, be carefully washed out with tepid water very slightly impregnated with carbolic acid, tincture of iodine, or Labarraque's solution of soda, as advised by Courty. The patient should then be kept as quiet as possible in the recumbent posture, and slightly under the influence of opium.

The period at which operation should be resorted to for congenital atresia is a subject of importance. Velpeau advocates operating in infancy, but Peusch, Boyer, and others regard the age of puberty and ap-

1 Courty, op. cit., p. 386. 
proach of menstruation as a more appropriate time. Should the menopause have arrived, no operation will be called for, unless hydrometra exist or marital relations demand it.

It should not be forgotten that delay in interference is often very disastrous during the period of menstrual activity, for lives have, in numerous instances, been destroyed by rupture of the Fallopian tubes, and even of the uterus itself, as seen by Peuseh. This observer drew his conclusions from 258 eases of atresia, in 18 of which rupture of the Fallopian tubes from distention by menstrual blood oceurred. In one instance of atresia, I saw an hamatocele the size of an infant's head result from discharge of blood from the tubes into the peritoneal cavity. It is possible that the mental emotion of the patient, and leer struggles during the operation, may account for the escape of blood into the peritoneum as noted by Bernutz. Hence, every effort should be made to avoid these, by complete anasthesia, and care should be taken not to allow of pressure upon the uterus either intentional or accidental.

In cases in which vaginal and uterine atresia liave existed together, and the uterus only is distended by blood, there can be no good reason urged for completing the removal of both atresia at one sitting. It is far safer to secure complete liberation of the uterine neck, and perviousness of the vaginal canal, unless delay be absolutely dangerous, and then, after the dangers arising from this procedure have passed away, to perform the other operation. Certainly, combining the two would not diminish the danger of either, while delay would not ordinarily increase the risk in any way, since the closure of the cervix is so complete as entirely to exclude the admission of air.

Lefort has advised and practised the creation of a new vagina by electrolysis. The following is the description given of the procedure by Le Blond in his admirable treatise upon Gynecological Surgery. 'The operation rests upon the fact that a mild continuous current of electricity passing through tissues by means of a metallic pole destroys them. "M. Lefort employs for the purpese a cylinder of boxwood, the extremity of which ends in a copper bulb connected with the negative pole of a pile of Morin elements in sulpliate of copper. The circuit of the pile is established by applying a metallic plate communicating with the positive pole on the stomach with the interposition of compresses soaled in a solution of sodium chloride. The appraratus is put in position only at night. At the end of a short time the existence of a canal of seven or eight centimetres in depth is found to exist, then when the uterine neek is reached the menstrual flow oecurs freely." I have no experience in this method, but le Blond speaks with confidence coneerning it, and gives it preference over the surgieal procedures which have been detailed.

1 Traité Elementaire de Chirurg. Gynecol. Paris, 1878. 


\section{II A P T E R X V.}

FISTUI. OF THE FEIALE GENITAL ORGANS.

Definition.-As a result of certain trammatic and morbid processes, the continuity of the vaginal and uterine walls may be destroyed and communication established with adjacent viscera. To the tracts or passages thus opened, the name of fistula has been given.

Varieties.-These communications eonnect the vagina or uterus with some viseus in inmediate proximity, for the natural outlet of which they act viearionsly, or with some neighboring part, as the peritoneum, the vulva, or the pelvic areolar tissue. Their varieties have received the following descriptive appellations :-

Urinary Fistula.

Vesico-vaginal fistula;

Urethro-vaginal fistula;

Vesico-utero-vaginal fistula;

Vesico-uterine fistula;

Uretero-uterine fistula ;

Uretero-vaginal fistula.

Fecal Fistula.

Recto-vaginal fistula;

Entero-vaginal fistula;

Recto-labial fistula.

Simple Vaginal Fistula.

Peritoneo-vaginal fistula;

Perineo-vaginal fistula;

Blind vaginal fistula.

\section{Urinary Fistulæ.}

Trinary fistule may oceur on any part of the anterior surface of the genital canal intervening between the vulva and fundus uteri. Fig. 86 displays the points at which they are psually observed.

Vesico-Vaginal Fistula (2) is a communication between the bladder and vagina, either at the trigone or the bas-fond, which may involve only enough tissue to admit a small probe, or entirely destroy the vesico-raginal wall. Such an opening may be oval, angular, elliptical, or linear in shape, 
and its borders may be thick or thin, soft or indurated, rough or smooth, pale or vaseular.

Urethro-Vaginal Fistula (1) resembles that just mentioned, except in the fact that the destruction of tissue which has produced it involves the wall of the urethra, and not that of the bladder.

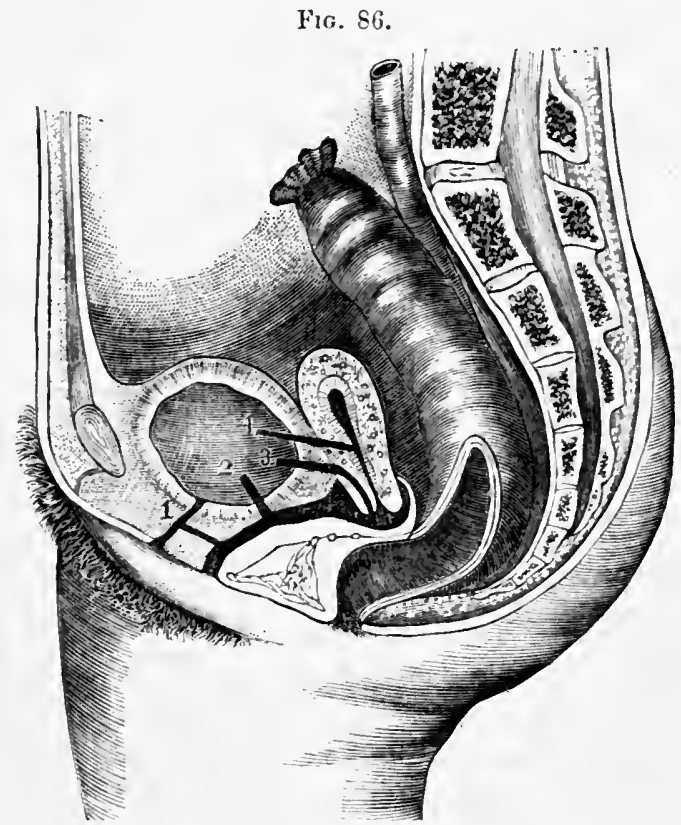

Varieties of urinary flstula: 1. Trethro-vaginal fistula; 2. Vesico-vaginal fistula; 3 . Vesicoutero-vagiual fistuta; 4 . Vesico-uterine fistula.

Tesicr-Lterine Fistula (t) are those in which there is a direct communication between the bladder and uterus above the point of raginal attachmont. The vagina is consequently not involved, and the urine passing into the uterus escapes at the os.

Iesico-C'tero-Vaginal Fistula (3) are those in the production of which a lesion occurs in both uterus and vagina, as is imperfectly shown by (3). At the vaginal junction there is a perforation of the bladder, but this does not penetrate to the cavity of the uterus. $A$ canal is created in its wall, and through this the urine escapes into the vagina. The last two forms of fistula were first accuratedy described by Jobert, who made of the last, two varieties, superficial and deep.. In the first a canal is channelled out on the verical surface of the cervix uteri; in the secont, the cervix is to a greater or less extent destroyed by the process of sloughing, and through it the urine passes. In the first form the lesion is chiefly vesical and uterine, the vargina not being much injured; in the other it affects three 
organs, the bladder, the uterus, and the vagina. All these forms of tistulat may thus be grouped into classes:-

1st Class. 'Those involving the urethra.

2d Class. Those involving the base of the bladder.

$3 \mathrm{~d}$ Class. 'Those involving the uterus.

4th Class. 'Those involving the ureters.

In some cases, however, multiple fistula exist, and no special classification cau be made.

Cavses.-Any influence which is capable of destroying the continuity of the vacrinal walls, either by mechanical, chenical, or vital action, would of conrse give rise to this condition. Those which are found in actual practice to have proved most commonly efficient, are the following :-

1st. Prolonged or very severe pressure;

2d. Direct injury ;

3d. Ulceration or abscess.

Pressure, which is more frequently a cause than any of the others mentioned, is generally produced by the child's head remaining too long in the pelvis during labor. This is beyond all doubt the most prolific source of the accident, though it may also attend a rapid labor in which the vagina has been pressed against some point of the pelvis with great violence. Such pressure produces sloughing of the part of the vagina receiving it, and at that spot a deficiency of tissue in future exists, which constitutes a fistula. The process of sloughing occurs from pressure of the factal head, exactly as a bedsore takes place in one who lies for too long a time in the same position, the sequence being, disturbed and retarded circulation, impaired nutrition, and local death. Or a puerperal raginitis may be established, which runs a violent course, and may end in sloughing after several weeks' duration.

An involuntary flow of urine usually announces the existence of a tistula within three or four days after delivery, though, when it is the result of injury inflicted by instruments employed in delivery, it may oceur inmediately. On the other hand, the separation of the slough, which will entail deficiency of tissue and its results, may not take place until much later, when perhaps all fears are allayed, and the case is regarded as progressing favorably. Jean Louis Petit reeords one case developing its symptoms after a month; Jobert one in which on the twenty-second day after delivery the slough was found at the mouth of the vagina; Adler, of Iowa, one in which after twenty-nine days the slough was only partially separated; and Agnew, of Philadelphia, another, in which it separated on the twenty-first day.

Other agencies which may create fistula, but which have been rarely noticel to do so, are pessaries, stones in the bladder, fecal accumulation, ete. 
Direct injury may produce the accident by contusing or lacerating the vaginal walls, as may oceur during delivery by the forceps or craniotomy. That these operations when carelessly or unskilfully performed may produce a fistula, no one will pretend to deny, but there can, with the evidence now recorded, be no doubt that they have often been credited with unfortunate results which were in reality due to tardiness in their employment. Very often, where a labor has been allowed to be prolonged in the second stage until the vitality of certain points in the vagina las become irremediably impaired, and the process of sloughing has been already inaugurated, subsequent delivery by forceps or craniotomy has been regarded as producing fistula. Under such circumstanees the real morbid agency, prolonged and violent pressure, is lost sight of, and the more palpable agents, the instruments employed, are viewed as the source of the aceident. The truth with reference to this point should be well understood by every practitioner, for unless it be so, an incompetent person may shield himself from merited blame by casting censure upon a consulting physician by whose efforts the lives of both mother and child have been saved, or a skilful operator may suffer unjustly in a suit for malpractice.

In a report upon this subject by Mr. I. Baker Brown to the Obstetrical Soeiety of London, in 1863, the following statements are made: "With regard to the causes of vesico-raginal fistula, of the 58 eases admitted into the London Surgical Home, 47 were over 24 hours in labor, and 39 were as much as 36 hours or more; 7 were two days ; 16 were three days; 3 were four days; 2 were five days; 2 six days; and 1 seven days.

"In the whole number of eases instruments were used in 29, exaetly one-half, and in 4 only of these was the labor less than twenty-fonr hours, and with seven exceptions the patient had been thirty-six hours or more in labor before instruments were used.

"Of the 58 eases, in 24 only the injury happened at the first labor; in 7 at the second; in 5 at the third; in 4 at the fourth; in 6 at the fifth; in 2 at the sixth; in 5 at the eighth; in 1 at the ninth; 1 at the thirteenth; 1 at the fifteenth; and 2 not mentioned."

"From the foregoing statisties it is evident that the cause of the lesion is protractel labor, and not the use of the instruments or deformity of the pelvis."

"As a necessary derhetion from what las been stated, it follows that vesico-raginal fistula would seareely if ever oecur, if a labor were not allowed to become protracted ; and this is a point for the careful consideration of practitioners in midwifery." The experience of Dr. Sims ${ }^{2}$ is confirmatory of that of Mr. Brown. Emmet, whose authority in this

- Obstet. Trans., vol, v. p. 23.

2 (iarduer's lotes to Scanzoni, p. 503. 
matter is very ligh, gives the causes of 179 eases, ${ }^{3}$ and 171 of the 13 mber originated in childbirth.

It may be said in a general way then that the cause of minary fistulie in the female is parturition, a few exceptions to the rule oecurring; that protracted labor is very generally productive of them; and that the prompt use of instruments is, as a rule, preventive of them.

It is a curious fact that, when for the relief of chronic eystitis a vesicovaginal fistula is intentionally ereated by the knife, it is difficult to keep it open. In spite of the occasional introduction of the somul for this purpose, sneh openings obstinately heal of their own accorl, so that it becomes necessary to place a species of button or stud in the opening to prevent an issue which, under these circunstances, is undesirable. This case seems parallel with that of perforation of the tympanum, which, being effected by an instrument, heals rapidly; while the closure of an opening, the result of disease, is usually impossible.

Abont thirty years ago Dieffenbach ${ }^{2}$ recorded a case of vesico-vaginal fistula, the cause of which had been the presence of a stone in the bladder, complicating labor; and Baker Brown mentions another instance of this kind in 1861.

Ulceration or Abscess. - The vaginal walls may be eaten through by cancerous, syphilitic, or phagedenic ulcers, or a communication may be established by an abscess opening into the vagina and into a neighboring viseus or part. In one case $I$ found, in the autopsy of a woman who had died from a profuse diarrhœa, in which the feces had passed by the vagina, a communication created by abscess between the caput coli and that canal.

Cancerous disease often destroys the vesico-vaginal septum, but as these fistule are irremediable, and attend upon a rapidly fatal disorder, they attract little attention in themselves. Lastly, eertain diseases producing deficieney of nutrition, as, for example, the continued fevers, may cause sloughing of the vaginal walls or phagedenic ulceration.

Srmptoms.-The prominent symptoms and signs of urinary fistula may be grouped under three heads : first, those furnished by a characteristic discharge; second, those arising from the irritant action of such discharge upon the part over which it flows; and, third, those afforded by physical examination.

Sometimes the escape of urine is so excessive as to preclude the necessity of a discharge per vias naturales: at others the excretion is partly

1 Principles and Practice of Gynecology. The author gives in his tables 202 cases, but I subtract 23 which were intentionally produced for removal of stone and cure of cystitis. Evidently these are not admissible in the study of Etiology.

2 Iferl. Record, vol, i. 321 . 3 op. cit. 
evacuated by the natural and partly by the vicarious outlet. This symptom shows at times eccentric variations. When the fistula is seated in the urethra, the bladder may be distended withont loss, which may take place into the varina during micturition. Sometimes while in the horizontal posture the escape will cease, the anterior vesieal wall being pressed by the intestines against the bas-fond so as to elose the opening; and in other cases, where the fistula is above the orifice of the ureters, the flow will take place while the patient lies, and cease when she stands.

The passage of excrementitious material through a eanal and over a tissue not intended by nature to tolerate it, produces inflammatory aetion, pruritus, eruptions, and excessive irritability. In urinary fistula the vulva and thighs are usually red, excoriated, and covered by a vesicular eruption. The vagina is sometimes covered by urinary concretions, and a highly offensive orlor emanates from the patient's body.

The general health is very likely in time to give way, and hysteria, ehlorosis, and graver disorders often show themselves.

Pinsical Sigrs.- If the fistulous orifiee be a large one, even a superficial examination by touch, the patient lying upon her back, will generally serve to reveal the nature and extent of the lesion. It is different, however, with very small fistula, which will sometimes elude the most careful investigation. For their detection Sims's speculun should be employed, and in many cases it will be found advisable to place the woman in the knee-elbow position, instead of that on the side, before its introduction, and to have the buttocks and labia pulled apart by the hands of assistunts. Even this mothorl is not effectual in revealing the opening if it he very minute. Under these cireumstances the bladder should be injected with water, and its escape into the ragina earefully watched for. Sometimes, by this means, a eapillary opening, just at the junction of the vagina and cervix, will be deteeted. Kiwisch, Meyer, Veit, and others have used for this purpose water colored with substanees whieh will impart a bright tinge to it. Infusion of cochineal, madder, or indigo may be thus employed. The opening being once deteeted, the probe and funger will realily reveal the course, extent, and terminus of the tract.

Complcatroxs.-The complications which these fistula develop are varginitis, vulvitis, strieture of urethra and vagina, and sometimes entometritis and periuterine inflammation. The most constant and important of these is the formation of bauds, which contract the ragina, and which oftun require severance bufore operative proeedure can be practised.

Proficosis.-Previons to the year 1852, the prognosis of all eases in which the orifice acted as a vicarious outlet, for example, vesico-raginal, recto-vaginal, and vesico-utero-vaginal fistula, was eminently unfavorable, 
for they very rarely undergo spontancous recovery, and the means of cure at our command up to that time were uncertain and full of discouragement. In 1860 , 1)r. Sims' stated, "Of' 261 cases of vaginal fistula (vesical and reetal) 216 have been permanently cured by the silver wire suture, 36 are curable, and 9 incurable. Every case is curable when the opreation is practicable, provided there is no constitutional vice to interfore with the powers of union. Success is the rule, failure the exeeption."

The enlarged experience of the profession has fully corroborated these assertions, made twenty years ago, and it may now be accepted as a true statement as to the prognosis of all fistula of the female genital organs except cases of vesico-uterine fistula, in which the point of rupture is out of reach of surgical interference.

Histonr.-The history of this subject dates back only to the sixteenth century, when attention was called to it, and a plan of treatment proposed by Ambrose Paré. Before the discovery of the forceps, the accident must have been one of very frequent occurrence, for then powerless labor was not under the control of the obstetrician, except by resort to a set of badly constructed instruments for craniotomy, which in themselves presented serious dangers of laceration. The symptoms which mark its existence are so palpable and distressing that it does not require a physician to diagnosticate it, and no case of any gravity could liave escaped notice. And yet, curious to relate, there are few diseases to which woman is liable, which have received so little notice at the hands of the ancients. Even pelvic cellulitis and other affections, which have but lately attracted attention from the physicians of our day, are distinctly allnded to by the writers of the Greek school; but this one, so annoying, so destructive of happiness, and so urgent in its demands for relief, has received scarcely any mention. It is true that Hippocrates makes some slight allusion to involuntary discharge of urine following difficult labors, but his remarks upon the condition are meagre and unimportant.

I do not elaim to have made a full examination of the writings of the Greeks and Romans with reference to the subject, but base the statement which I have advanced chiefly upon the fact that the two great compilers of their periods, Aëtius and Paulus Egineta, make no mention of it. The work of Aëtius upon diseases of women (Tetrabiblos IV.) is made up of quotations from Soranus, Aspasia, Galen, Philumenus, Archigenes, Leonidas, Rufus, Philagrius, Asclepiales, in fact of all worthy of note, whose writings were stored in the Alexandrian Library, which was the seat of his labors. By none of these is mention made of the affection. The works of Paul of Egina, enriched as they have been by the copions notes of Dr. Adams, their translator, are equally silent; and the researehes of 
those who have examined the writings of the $\Lambda$ rabians record no discovery of any deseription of it at their hands. At any rate, it is quite certain that no contributions to the treatment of the diffieulty were made by the writers of the Greek, Roman, or Arabian sehools.

Beginning at the seventeenth century, I will allude only to those who have male some adrance in tratment, and not endeavor to record the names of all who have reported emres, or alvised procedures which have not been of subsequent utility.

Before proceeding with the historical sketch which ensues, I would draw the attention of the reader to two interesting facts which it will demonstrate. It will be seen that for centuries steady, persevering, and systematic efforts lave been made to render this revolting malady curable, and that, as hats often been the case in other great discoveries, the minds of several investigators pursued the same course until at last success was reached. After a discovery has been made it is always easy to point out the elements upon which it rests for its success, and even to follow the process of reasoning by which each in turn was supplied. There can be no donbt that the three elements necessary for successful treatment of the lesion which we are considering, were-

1st. A means for exposing the fistula to view and manipulation;

2d. A suture which would remain in place without causing inflanmation;

3d. A means of disposing of the urine during the process of eure.

From the time that Paré suggested a plan of treatment, it will be noticed that surgeons bronght these three means of cure to their aid. But they employed them separately, some using one of them, some another, and others still combining two. It was not, however, till the time of Gosset, in 1834 , that the three were combined by the same operator.

In 1570, Ambrose Pare proposed the elosure of vesico-vaginal fistula by a retinaculum. In 1660, Roonhuysen, of Amsterdam, used a speculum, through which he pared the edges of fistula and united them by a needle. In 1720 , V(xlter, of Wurtemberg, advised a needle, needle-holder, suture by silk or hemp, and a catheter. In 1792, Fatio, of Basle, operated by twisted suture, flacing his patients in the lithotomy position. In 1804, Dessant used a raginal plug and catheter in the blalder. In 1812, Naegele, of Wurtemberg, searified the edges by seissors, used needles to approximate them, and employed the interrupted suture. In 1817, Schreger of Germany, placed the patient on the abdomen, scarified the edges, and used interrupted suture. In 1825, Lallemand, of France, applied nitrate of silver to the edges of the fistula, and approximated them by a "sonde érigne" passed throngh the bladder, and, of fifteen cases, cured fonr. In 1829, Jonx, of France, tried twisted suture with metallic bars and ordinary threal. In 1834, Gosset, of London, conbined the kneeellow position, levator perinei speculum, metallie sutures, and eatheter 
permanently kept in the blatler. In 1836, Beaumont employed the quilled or elamp suture. In 1837 , Jobert de Lamballe resorted to autoplasty, transplanting a piece from the labia, buttocks, or thighs. In 18:38, Wutzer, of Bonn, placed his patients on the abdomen, pareel the edges of the fistula, and approximated them by inseet needles and figure-of- 8 suture. To expose the fistula the perineum was held up by a hook and the labia drawn aside by assistants. In 1839 and 1840, Hayward, of Boston, U. S., reported three cases eured by vivifying the edges and elosing with silk suture. This surgeon introduced a notable improvement, and aided in the final suecess by vivifying not only the borders of the fistula but the neighboring vaginal surfaces. In 1844 , Chelius ${ }^{2}$ placed his patients in the knee-elbow position. In 1846, Metzler, ${ }^{3}$ of Prague, employed the levator perinei speculum, perforated balls the size of shot, the knee-elbow position, gilded needles, and a permanent eatheter. In 1847, Mettaner, of Virginia, employed the catheter and leaden sutures with such suecess that he was led to make the following statement: "I am decidedly of the opinion that every case of vesico-vaginal fistula can be eured, and my suceess justifies the opinion." In 1852, Jobert de Lamballe adopted his method, styled " réunion autoplastique par glissement," which consisted in giving suflicient vaginal tissue for union, by eutting transversely through the vagina, at its junetion with the uterus, in a line with the fistula. In 1852, Miurion Sims, ${ }^{4}$ of the United States, combined the three essentials for success; the speeulum, the suture, and the eatheter, and placed the operation at the disposal of the profession.

The discoveries to which he laid special elaim were these :-

1st. A method by which the ragina could be distended and explored;

2l. A suture not liable to excite inflammation or ulceration;

3l. A method of keeping the bladder empty during the process of eure.

Entering the field almost as early as Sims, Simon, of Germany, greatly aided in systematizing the operation, and has been seeond to no one else in improving it.

From a study of the literature of this subject it is made as evident as written testimony can make any history of the past, that not only did several investigators combine two of these elements of sucess in their operations, but that two, Gosset, in England, and twelve years afterwards Metzler, in Germany, absolutely combined all three. It is also made equally evident that they either failed to recognize the importance of what they had attained, or did not impress its value upon others so that humanity could profit by it. Dr. Gosset's procedure is thus described in his own words in the first volume of the London Lancet, page 346 .

"Having placed the patient resting upon her knees and elbows, upon

1 Med. Gaz., Dec. 3d, 1836, p. 355.

3 Schuppert on Ves.-Vag. Fistula, p. 41.

16
2 Agnew, op. cit., p. 15.

- Anner. Journ. Med. Sci., 1852. 
a firm table of convenient height covered with a folded blanket, the exterual parts were separated as much as possible by a couple of assistants, so as to bring the fistula, which was immediately above the neck of the blatler, into view. I seized with a hook the upper part of the thickened elge of the bladder which surrounded the opening, and proceeded with a spear-shaped kuife to remove an elliptical portion, which included the whole of the callons lip surrounding the fistula, the long angle of the ellipsis being transversely. This was readily effected; but, in consequence of the very contracted state of the parts, the next steps of the operation were with difficulty executed; and I should not have sueceeded in passing the sutures, had I not used needles very much curved, and a needle-holder which I could disengage at pleasure, the necdles being withdrawn with a pair of dissecting forceps after the holder was removed. In this way three sutures were passed; and afterwards, by twisting the wire, the incised edges were brouglut into contact and retained in complete apposition until they had firmly united. One of the sutures was removed at the end of the ninth day, the second at the end of the twelfth day, and the third was allowed to remain until three weeks had elapsed. After the operation the patient was put to bed and desired to lie on her face, an elastic gum catheter, having a bladder secured to its extremity for the reception of the urine, having been introduced and retained by means of tapes. She had not the slightest discharge of urine through the vagina after the operation, which completely succeeled in restoring the healthy functions of the part. 'The advantages of the gilt wire suture are these: it excites but little irritation, and does not appear to induce ulceration with the same rapidity as silk or any other material with which I am acpuainted; indeed, it produces scarcely any such effect, except when the parts brought together are much stretched. You can, therefore, keep the edges of a wound in close contact for an indefinite lengtl of time, by which the chances of union are greatly increased. I lave used it now in very many operations, as after extirpation of the breasts, tumors of various kinds, and for bringing the lips together after the removal of a cancerous growth, in all of which cases it answered extremely well."

The method of Metzler was published in the Prague Viertel Jahresschrift for 18.16, under the title of "Pathology and Treatment of Crinary and Vesico-Vaginal Fistulas, with a method of treatment easily executed and completely snccessful." I transeribe his article from the brochure of 1)r. Sichupert already alluded to.

"To perform the operation successfully, it is of much importance to latr-1st, a speculum, serving as a dilator of the vagina. Sueh an instruneit consists of a grooved conical blade, five aml a half inches long, three inches wide at the anterior part, one-half an inch wide at the posterior. 'lhe ond of the speeulum is bent under at at riglit angle, and profected with woor for the handle. The instrument is best when male 
of silver, and polished to refleet the light on the parts to be operated npone 2.l, an alparatus consisting of perforated clamps, gilded nowlles, and an instrument called 'Rosenkranzwerkzeng, eonsisting of perforated balls of' the size of large shot, by which the elamps are held in contatet. After the patient is placed on her linees and elbows, the dilator is introduced into the vagina and given to an assistant, who in holding it presices it anainst the rectum. The elges of the fistula are then pared ofl, which may be aceomplished with enrved seissors. One line and a half from the mueous membrane of the vagina and half a line from the edge of the bladiler have to be cut off; the needles are then applied, and the wound held in coaptation by the elamps; a female eatheter is introduced into the bhalder by the urethra, and the catheter fastened by a 'T bandige."

From what has been said thus far it would appear that Dr. Sims wats forestalled in all the rletails of the discovery by which he has rendered vaginal tistulat eurable. To a eertain extent this is unquestionably true, but only as regarils the theory of the matter. Before his publications the mitortunate women, whose lives were rendered miserable by fistula through the vaginal wall, were virtually almost as hopelessly affected at they were before Gosset and Metzler appeared in the field.

Velpeau, in 1839, thus speaks of cure of these fistulis: "To abrate the borders of an opening, when we do not know where to grasp them; to shut it up lyy means of needles or thread, when we have no point apparently to secure them; to act upon a movable partition placed between two cavities, hidden from our sight, and upon which we can scarcely find any purchase, seems to be calculated to have no other result than to canse muecessary suffering to the patient." Vidal de Cassis says: "I do not believe that there exists in the science of surgery a well-authenticated, complete cure of vesico-raginal fistula." Malgaigne, ${ }^{3}$ in $185 \mathrm{t}$, says: "But the truly rational method, that which at present offers the greatest facility and eflicacy, and the only one which should be applied in all cases of tistula of large size, is the suture by the procedure of Jobcrt."

Wutzer reported the following as the statisties which he had collected:4 "20 cases of vesico-vaginal fistula were subjected to 48 operations-among which were elytroplastie, episioraphie, cauterization, sutures, interrupted or twisted, and both-and only two eured!"

This was the real state of science with reference to this opprobrium chirurgice when Marion Sims, by combining and utilizing the three essentials for suecess, gained it, and rendered the operation practicable for all surgeons. It must not be supposed that he availed himself of the results obtained by his predecessors. All that he attained was arrived at by hard and original labor. Indeed, no one can read his address upon "Silver

1 Operative Surgery.

3 Nanuel de Mod. () perat.
2 Patholngie Externe.

- Med. Record, vol. i. p. 322 . 
Sutures in Surgery," delivered before the New York Aeademy of Medicine, in 1857 , without being struek by his want of fimiliarity with the antecedent literature of the subject of his discourse.

I would not be understood as claining for America in this matter more than she really deserves-the establishment of the method of cure upon a firm and certain basis. To claim more than this would be to ignore the plain teaching of history. To France belongs the inception; to England the glory of having absolutely made the discovery, although she did not appreciate the fact; to Germany, next to America, the credit of having specially andanced and perfected reliable operative procedures. In that country to-day, by the method of Simon, suceess even in the gravest cases has become the rule and failure the rare exception.

Since the first publication of Sims's method, numerous modifications of it have been put into practice both in this country and Europe, and Dr. sims himself has altered his plan of operating very much. The principle which he demonstrated is, however, the same, and the modifications of the operation all act in developing it.

In this country, the operation is commonly performed, not by specialists alone, but by practitioners in every walk of the profession, and, thanks to the extreme simplicity of Sims's procedure, it is no longer looked upon ats a diflicult undertaking, requiring special skill and experience. It is at the present day certainly very difficult to appreciate the statement of a physician" of Ireland, that " he unfortunately lad the opportunity of seeing a great number of fistulas, and a great number of operations, and his experience hatd been that the vast majority of them proved unsuccessful."

Means for Obtaining a Natural Cure.-Within a few days after delivery the olstetrician is generally made aware of the existence of vesicovaginal fistula ly a steady and involuntary dripping of urine. As soon as this is evident a Sims's stationary eatheter should be placed in the bladder, the vagina frequently syringed ont with warm water to lessen inflannatory action, and the patient kept in the abdominal decubitus, in order that a repair of the injury may he accomplished by the efforts of nature. This is all that can be done at this time, for it is too early to resirt to suture, and the lochial discharge would be interfered with by a tampon intended to aid in the eure. The operation ly suture shonld not be undertaken before the immediate results of parturition have passed off and the fistula has assumed a permanent size and character.

'Remarks by Dr. Cronyn before the Surgical Society of Ireland, March 15, $1 \leq 72$. 


\title{
Treatment.
}

The methods at our command for curing, or, where cure is impossible, obviating the inconveniences clue to fistulae of the female urinary apparatur, are-

\author{
1st. Cauterization ; \\ 21. Suture; \\ 31. Elytroplisty; \\ 4 th. Ocelusion of the vagina or uterus.
}

\section{Cuuterizution.}

This onee farorite methoul of treating all varieties of these fistula has now very deservedly fallen into disuse under the influence of improved methots by suture. Malgatigne probably gives this means its proper place when he declares that it should be employed only in those cases where the fistulit is scarcely perceptible. Even in such cases Sims's operation is far preferable, and cauterization should be employed only where some special circumstance, such ats want of skill or of the proper instruments, forees the operator to resort to it. The performance of it is very simple. Sinn's speeulum being passed so as to expose the fistulous spot, its borders should be thoronghly touched with a pointed stick of nitrate of silver or the actual cantery. This should not be repeated before the slough created las separated, and an opportunity been allowed for granulation to fill up the opening.

To cheek the flow of urine through the fistulous orifice and support the raginal and resical walls during the process of granulation, a small tampon of cotton, a Gariel's air pessary, or a glass vaginal plug should be kept in the vagina, and, to prevent distention of the bladder, a sigmoid catheter slould be permanently retained.

\section{Suture.}

Preparation of the Patient.-No operation in surgery more urgently demands a good constitutional condition, as an element of success, than this. Should the patient's health not be good, and lier blood-state be abnormal, a visit to the country, exercise, and fresh air, with vegetable and mineral tonies, will do a great deal towards avoidance of failure. At the same time the vagina should be regnlarly syringed with warm water to overcome local inflammation, and insure cleanliness. Should the disorder which cansed the destruetion of the vaginal wall have produced as a complication cicatricial bands in the canal, these should be cut, from time to time, and allowed to heal orer a glass vaginal plug, and if contraction have taken place in the urethra, it should be overcome by bougies. Before the time of the operation the bowels should be thoroughly eracuated by a cathartic, and on the day of its performance very little 
fool should be taken, for fear that the long-continued use of an anesthetic might produce vomiting, which would tear out the sutures.

Sims's Operation.- This operation may be divided into three parts :1st. Paring the entges of the fistula ;

21. Passing sutures through them;

31. Approximating them and securing the sutures.

The patient, being placed upon a table two and a half by four feet, whieh is covered by tolded blankets, is brought under the influence of an anasthetic, and placed in the following position. She is made to lie on the left sile, with the thighs bent at about right angles with the pelvis, the right a little more thexed than the left. The left arm is placed belind her back, and the chest brought flat down upon the table so that the stermm may tonch it. The assistant who is to bold the speculum, which is then introdneed, does so with the right hand, while with the left he elevates the right side of the nates. The table should be so arranged that a bright and steady light may fall into the vagina, which being then fully distended, will be seen throughont its extent, except where it is obscured by the spreculum.

The operator, having near him all the instruments, etc., which lie will repuire, places his assistants thus: one holds the speculum, another administers the ansesthetic, and a third stands reatly at his right hand to remove the blool aceumulating in the vagina, by means of sponges, in the sponge-hellers, Fig. 91, which are rapidly washed in a basin of water that stamels by his side, to be used again. A fourth assistant, if attanable, may be well employed in handing the instruments as they are required. All being ready, lie proceeds with the first step of the operation.

I'uring of the Edges of the Fistula.-The alge of the fistula, at the point which is deemed most diflicult of access and manipulation, is caught by the tenaculum, or with what I mueh prefer, the tooth forceps, shown

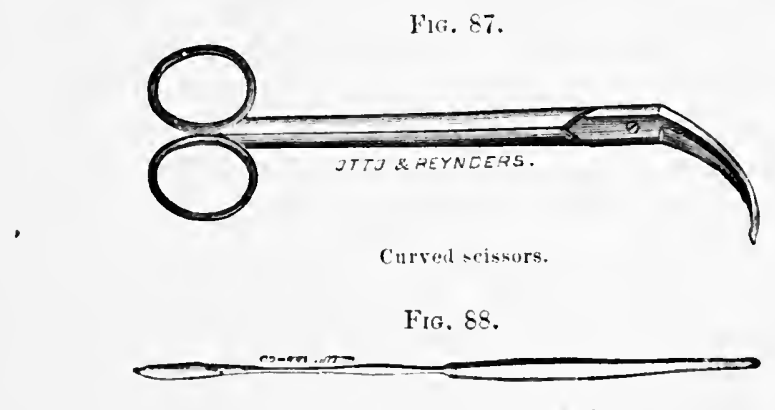

Bistoury for paring edges of fistula.

in Fir. 59, and herele up. Then with a pair of long-handled scissors, Fir. s. al a kuife, ligg. sr, a strip is cut, extending from the mucous mem- 
brane of the bladder to that of the vagina, care being taken not to wound the former.

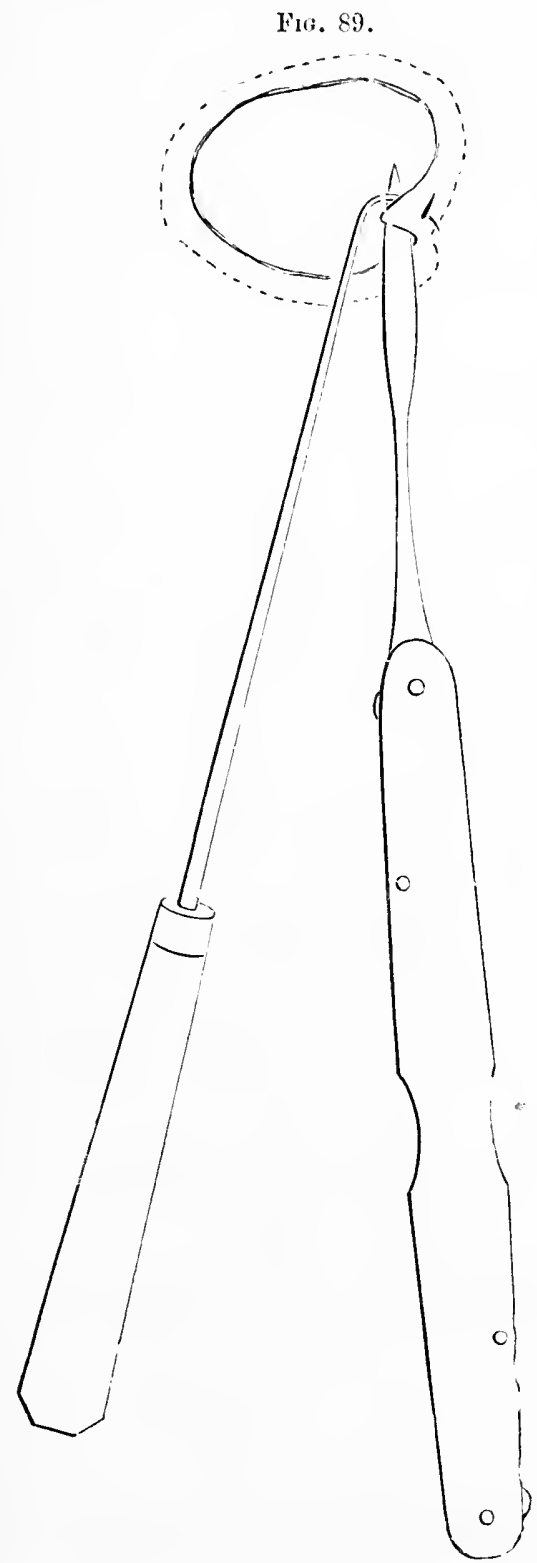

FIG. 90.

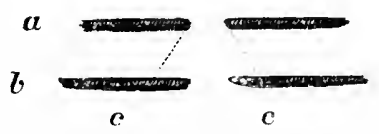

slowing bevelling of eilges. $a$, vesical border; $b$, vaginal burder; c $c$, incision.

Fig. 91.
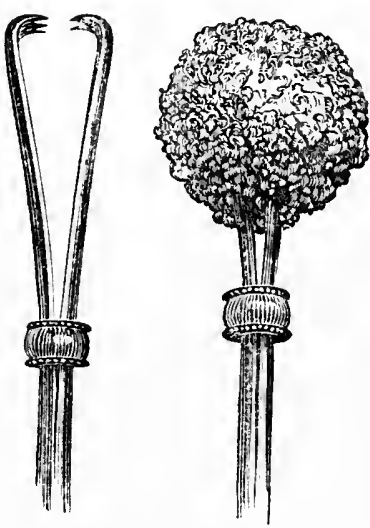

Sims's sponge-holder with handle nime isches long.

Paring the edges. (Wieland and Dubrisay.)

Another portion of the edge is then seized, and remored like the first. The wound thus left slıould be one bevelled from the vesical surface out- 
warls, and great eare should be observed to rimove the entire border, for upon this suceess depends.

It is of great moment that suffieient tissue should be removed, and that the amount taken on the vaginal surbice should be greater than that near the vesieal. I'rot. simpson makes this point very clear by the following language: "Enter the point of your kuife into the vaginal mucous membrane at some distane from the fistula; then transfix with your knife the elge of the fistula to the extent you intend to remove it, and bringing it out at the resieal border, carry it right and left fairly round the opening, so as, if possible, to bring ont a complete eircle of tissue."

The abraled surface, fiom the edge of the fistula to the point of vaginal section. should measure at least four lines, one-tlind of an inch, while abowe, it shoukd just touch the vesical border, not invading its mueous membrane. 'This is male evident by Fig. 90. During this part of the operation the sponges, held in long-handled sponge-holder's, will have to be firely resorted to, but the bleeding generally soon ceases, and the operator may proceed to the second step.

Pussing the Sutures.-The sutures are passed by means of slightly enred necelles held in a pair of strong foreeps, Fig. 92, made for the purpose. In some cases the metallic thread, made of annealed silver, which is employed, may be passed at once, but usually silk threads are first patserl, amb the silver sutures are attached and drawn through. Dr. E. Cutter recommends a very ingenions method for avoiding the necessity of threading the netelle, and thus having a piece of silver wire folded over so as to interfere with its fassage through the tissues. He welds the wire firmly to the needle so that no obstruction exists at the point of union. A number thus prepared are in realiness for each operation.

'The needles which we employ in the Woman's Hospital are about three-quarters of an inch long, round, slightly eurved, and without eutting ederes anywhere. Dr. John T. IJodgen, of St. Louis, has invented a neeflle which serves an excellent purpose. It is a very small, straight, short nexde, with a point like that of a troear. This passes readily thromgh the tissues, and to it is attached a delicate silk thread which earries the silver wire, the bent end of which is rubbed down very small by sand-paprer. The noefle, held in the grasp of the needle-holder, should be pasted at the angle of the wound which is most diflicult of access, half an inch from the alge of the incision, amd bronght ont at the resieal -urfacr. but not involving its murous lining. Fig. 98 represents the point of entrance and axit of the meedle.

'The print of the needle having passed out, it is engaged by the small, blunt hook lig. 9s, until it can be seized and drawn through by the 
needle foreeps. Then it is plungerd into the other lip and drawn out half' an inch from the elge of the incision. The ents of the silk suture are

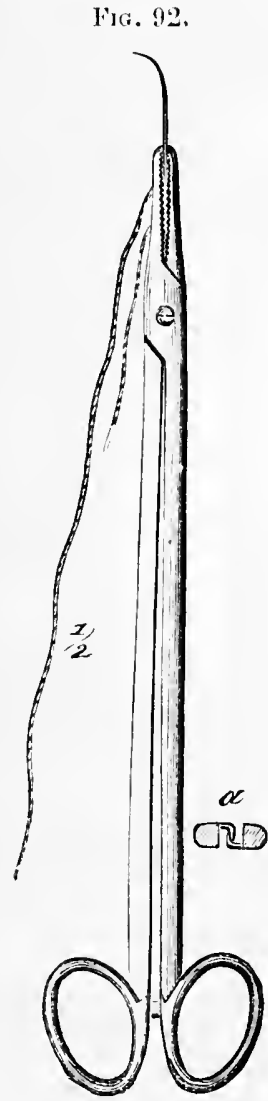

Jeedles held in forceps. lic. 93.

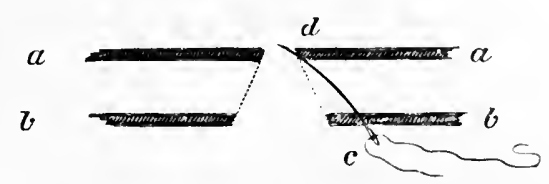

Course of the needle. a, vesieal horiler; b, varinal border; $c$, point of entrance of needle; $d$, point of exit of needie.

FIG. 94.

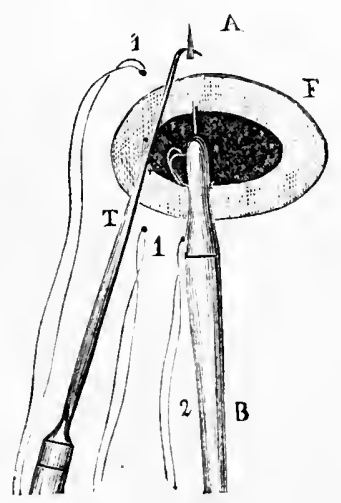

Passing the needle. (Wieland and Dubrisay.)

then given into the charge of the assistant holding the speculum, and another is passed in the same way at the distance of one-sixth of an inch from the first. In this way a sufficient number are passed to elose the fistula, Fig. 95.

During this procedure the edge of the fistula is to be fixed by the tenaculum, and should firm, opposing force be needed to make the needles pass, it may be given by that instrument.

When the needle is seized by the forceps and pulled so as to make the thread follow it, some opposing force is needed, or the thread might eut throngh the tissues. This foree is offered in the speeies of fork represented in Fig, 97, which is put as a fulcrum under the thread at its point of exit, and made to sustain and draw it through.

A bit of silver wire about twelve inches long is attached, by bending 
its extremity, to the first silk suture, and by the use of the fork just mentioned, the silk thread is drawn through so as to make the wire replace it.

F16. 95 .

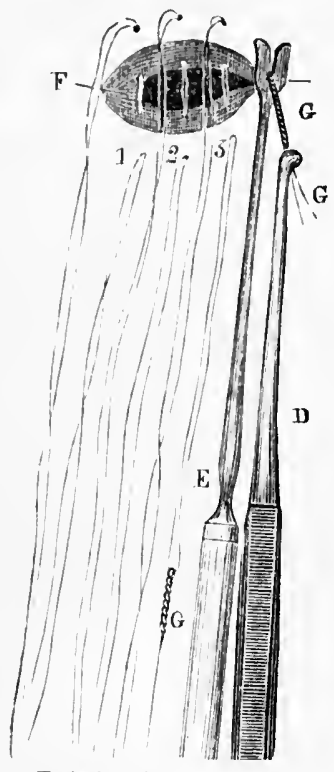

Twisting the sutures,
Figs. $96,97,98$.

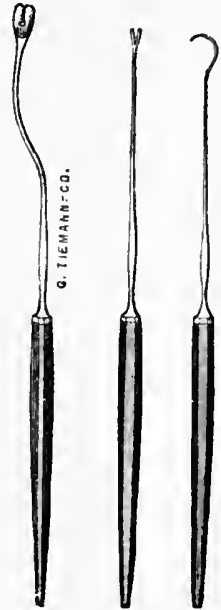

Fulcrum for supporting wire while it is twisted. Fork with blunt points to aid the passage of sutures. Hook for engaging needle.

'The silk is then cut off, the silver suture put aside, and the operator proceeds to replace each silk thread in the same way. This being accomplished, the intruments are then changed in order to effect the twisting of the sutures.

The ents of the silver sutures being drawn together hy the fingers, and the edges of the wound earefully approximated, each thread is slightly twisted so as to keep the whole in apposition. Then the ends of the first suture are seized in the bite of the foreeps, Fig. 95 , slipped into the fulcrum, Fig. 96, and torsion is made so as to elose the wound completely at this point. In this way the sutures are twisted one after the other, rare being taken not to carry the torsion so far as to strangulate the tissues engatged in the constrieting loop. Each suture is then clipped by at pair of scissors, about half an inch from the elge of the fistula, and by means of foreepls presied flat against the vaginal wall so als not to wound the opposite surtace.

The bladder should then be syringed ont to remove all blood which may lave accumulated there; for, if a large clot should be retained in this visene, it maty canse severe vesieal tenesmus, and smaller ones may borek un, the month of the catheter, which is to be kept in place permanently, and call for its repeated removal. 
The patient is then placed in bed by the assistants, an opiate is administered, and a Sins's sigmoid catheter is passed into the bladder and left

F). 99.
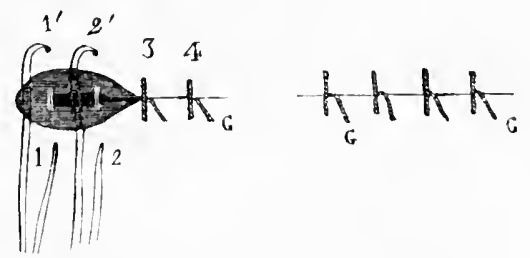

sutures twinted. (Wieland and Dubrisay.)

there. The mouth of this instrument projects beyond the vulva, so that under it a small china dish may be placed, which will reeeive the urine ats it passes through.

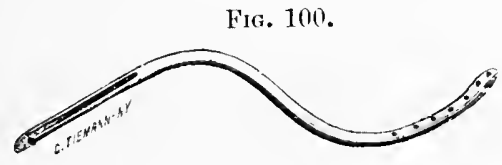

Sims's catheter, old style.
Fig. 101.

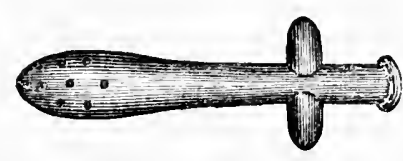

Sims's catheter, new style.

Dr. Sims ${ }^{1}$ has recently modified his catheter as represented in Fig. 101. To this a rubber tube is attached which acts as a siphon.

The nurse should examine the catheter every two or three hours to be certain of its pervionsness, and to remove the urine which collects in the receptacle placed under it.

Onee in every twenty-four hours the vagina should be syringed out with tepid water, or with this and white castile soap, or any similar detergent; but the bladder requires no further washing than that mentioned, except in cases of vesieal tenesmus. The bowels should be kept constipated by opium. The diet should be governed by the same rules which guide us in the management of patients under other surgical operations. It should be nutritious and unstimulating.

In from eight to fourteen days the sutures should be removed. Dr. Sims declares that, "it is unnecessary to allow the wires to remain longer than the eighth day;" but others, calculating upon the innocuousness of metallic substances in the tissues, have left them longer. In two of Dr. Schuppert's cases a leaking was detected when the bladder was injected on the sixth and seventh days, which had disappeared entirely on the twelfth, when the sutures were removed and the cure was found complete.

To accomplish the removal of the sutures, the twisted end of one of them should be seized by a pair of forceps and drawn upon gently until 
the edge of the loop emerges from the tissues in whieh it has been embedded. Then the blade of a pair of scissors should be inserted into the loop and one side cut, atter which a little traction will remove the suture.

An examination may then, with great caution, be instituted to ascertain whether sueess or fiilure has attended the operation. A visual examination will generally determine this. Sloould there be any doubt, the bladder may be filled very cantiously with tepid water to settle the question as to the entire closure of the fistula. Sometimes one operation fails to cure, althongh it diminishes the size of the fistula very much, and subsequent operations must be resorted to. It may be necessary to repeat these very frequently before suecess is attained.

The operation of Dr. Sims has been variously altered in all its steps, so that now the number of modifications is quite great, so great, indeed, that it would be out of the province of a work like this to mention them in detail. In his earlier operations Dr. Sims employed the quill suture, which he called the clamp suture, but a tendency on the part of the little metallic bars, which he used in place of quilis, to produce ulceration, induced him to resort to the interrupted suture.

Other methods have been suceessfully employed by Bozeman, Agnew, Baker Brown, Simpson, Simon, and others. For fear of being uselessly prolix, I shall describe but one of these, that of Simon.

Among other attempted improvements, Dr. Startin and M. Matthieu, of Paris, have invented hollow needles, through which the silver threads 'an be passed without first passing those of silk. Extended experience witl tubular needles leads ine to the conviction that they are at once the most ingenious and worthless appliances which can be employed.

Simon's Operation.-No one, with the exception of Marion Sims, has labored more earnestly, or achieved more for this operation than Prof. Gustav Simon, of IEeidelberg. Succeeding Dieffenbach, Wutzer, and Metzler, who had themselves aecomplished a great deal in advancing the intcrests of the operation by suture, he steadily labored with the means at his commind, and, even before he became acquainted with the improvements mate by Sims, hal aequired a great degree of skill in treating resico-vaginal fistula. 'To regard him as an imitator would be mujust. II. Was withont question a coincident discoverer.

'The rhief features of Simon's operation are these:-

1:t. I le repudiate's silver wire as a suture superior to fine silk.

2.l. Il employs an exaggerated lithotomy position in place of the left latraral position.

inl. Insteal of avoiding the mueous membrane of the bladder, he intentionally involves it in his abrasion.

4th. IIr uses no stationary eatheter, and has the urine drawn only during the first twenty-four hours, and this not always.

5th. He: allows the bowels to be evacuated whenever nature prompts it, 
und does not diet the patient nor confine her to bed. At times he eren permits outdoor exercise in twenty-four hours after the operetion in farorable cases.

I prefer to describe his procedure as far as prosible in his own words. 'The following resume of his nothod is male up from his work upon "The? Operation for Vesieo-vaginal Fistula," published in 1862.

"P'osition of Putient.- There are three positions, in general nse, for the patient in operation for vesico-raginal fistula: (1) The back, as in operation for stone; (2) the knee-elbow ; and (3) Sins's position, which is a modification of the latter. "I use neither of these, lut prefer the breechback position (Steiss-Riickenlage), which has all the advantages of those mentioned, withont their disadvantages. It consists in this, that the patient, lying on her back, is put in a position which is almost exactly similar to the knee-elbow josition. The breech is so elevated that it is somewhat above the level of the abdomen and breast. 'The thighs are

FIG. 102 .

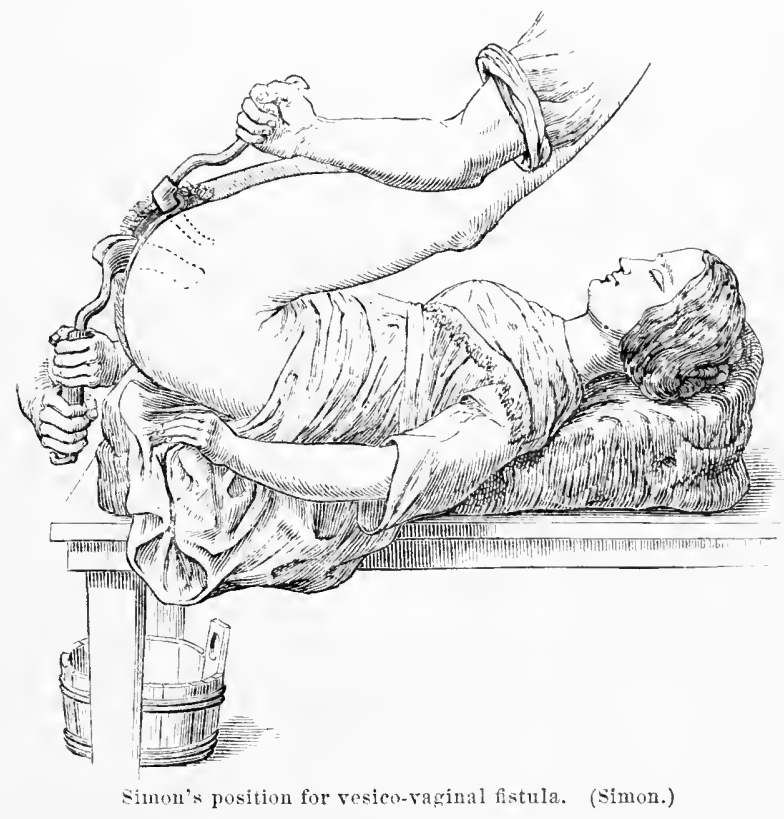

bent back towards the belly and the sides of the chest, so that the breech is the most projecting part. The lags are either flexed at the knee, or extended over the sides of the chest. The vulva is above and to the front. The head is supported by a pillow. If the fistula is seated very high in the vagina, the thigh must be drawn as far as possible upwards; if the fistula is, however, very near the vaginal outlet, we are not obliged to elevate the breech so much, and have no need, therefore, of flexing the 
thirh so foreibly. I have called this, in distinction to the ordinary back position, the ". Steiss-riickenlage ;" becanse in it the breech (Steiss) is the most projecting part, and presents itself in a mamer very similar to the breech presentation of the fieus.

The advantages are:-

1:t. 'The field of operation is clear, we are not obliged to operate between the thighs.

2d. The assistanee can all be given from the side, without hindering the operator.

Bd. It allows the use of several specula and the side retractors, to expand the vagina on every side.

$4 \mathrm{~h}$. It is quite as well borne as the ordinary back position.

ith. It almits of chloroform narcosis.

If the fistula can be brought down entirely with perfeet ease, I bring it directly to light. If, however, there is the least difficulty in moving it, (as in the majority of eases), I operate with the specula and retractors, with the fistula in situ. I always prove this by seizing the uterus with a hooked-foreep (Musenx) and pulling it gently down, before I operate with the specula and levers. I have improved Jobert's method of seizing the cervix with the forceps by passing two threads through the cervix, thus getting rid of an instrument which is very much in the way. Sims constructed a gutter-shaped speculum for expanding the fistula, which has left all other specula in the background. He used four sizes. It is shaped like Neugebauer's (1856), except that instead of ending in a sharp elge, it is romoled out at the end. I have found the use of this speculum in many difficult eases absolutely insufficient, and, in the majority of cases, it only answers the purpose by the aid of other instruments to expand the vacrina. I use, therefore, not this speculum alone, but also a flat-shaped swerulum to hold $u$, the other vaginal wall and also side levers (shaped like retractors), to hold back the labia and sides of the vagina. All these instruments are fixed in long handles, eurved at the end, in order to get the'n ont of the way, and to give the assistant a firm grasp.

Always use the widest specula possible, Sims's are not wille enough. I have had two sizes more made.

In adlition to these I often use long-handled hooks to srize the edges of the fistula. I always cut the cord-like contractions of the vagina, and laveroven ent the varinal folds which were in the way.

\section{Virifying the Edges.}

All operators have tried to give a large surface for union without enlarering the womml. They have done this by enting at the expense of the vagina, leaving the edges of the bladder intact. Aecording to my ob-rvations and experience, I give the preference to a deep, funmel-shaped incision of the edges of the fistula similar to the incision in plastic opera- 
tions in any other part of the body. The incision must brearried to the healthy tissue and all the cicatricial tissue extirpated.

It extends quite through the walls of the septum to the vesieal mucous membrane, and sometiuses through it.

In this way is formed a steep, fimnel. shaped wound, with its point in the bladder, and its base in the vagina, and its edges from 6 to $8 \mathrm{~mm}$. thick.

Fra. 103.

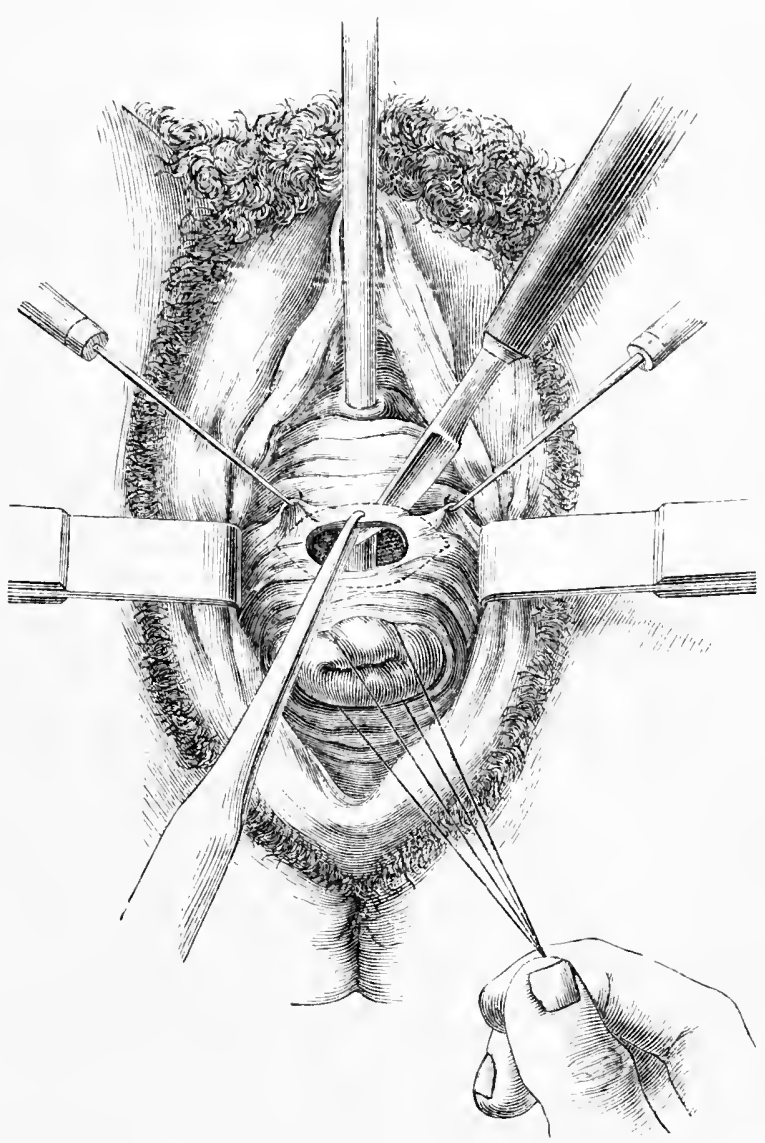

Vivifying the ederes of the tistula. (Simon.)

Although other anthors wish to avoid as much as possible the enlarging of this defect, it is exactly here only where mion can take place by first intention, that I strive to have the edges as free from cicatricial substance, and as prone to union as possible; and, even in the largest fistula, I do not refrain from this repeated paring off the edges, even to making the 
defect very much larger, until the union is aceomplished. And, even if with the best preparation of the edges, the mion does not take place, and we meet with entire want of suceess, the woman loses no more urine than hefore.

Sometimes I ent the resieal mucous membrane, and sometimes avoid it, hut place little weight on that.

The alvantages elaimed are:-

1st. By the deep funnel-shaped incision all cicatricial substance will be certainly cleared away.

21. The edges are more prone to union, as they unite in a natural manner. colge to edge, and not with a flat surface on the same; the nerres, vessels, ete., thus continue on in the normal direction.

:1. The very wille edge is unnecessary, as only the upper edges unite in any easer.

th. If union does not take place the first time, a second attempt is more likely to sueceel, with the thick edges, than where, with already thin edgres, these must be bevelled off still more and made thinner.

ith. The idea that eatarrh is more likely to follow this form of incision is unfounded.

\section{Uniting the Edges of the Wound.}

Wethod of Uniting.-There have been a great number of methods of hringing the edges together; all of which aecomplish their purpose, but are more complicated than the method I published in 1854, which, with some modification, I Iave used ever since.

In order to meet the indication for uniting, I use either one or two rows of fine silk sutures tied in the ordinary manner.

In larese fistula, where a great degree of relaxation is necessary, in order to bring the elges into exact union, I use my so-called double suture, consisting of two rows, one the 'relaxing, the other the 'uniting.' In small or in slit-shaped fistula, I use only one, the uniting row. In the double suture, one row, placed very deep and wide, appronches the tissues surrounding the fistula, to the line of union, thus relaxing the colges; while the other, placed between the stitches of the first, holds firmly the edges, and thus promotes the most exact union. When only one is userl, it is the miting row, and placed in the same manner as here described. Of course, aich row of sutures supplements the other in its actions.

butl, rows are placer very deep, even, in many eases, through the vesiall mucous membrane. 'They thus bring the edges of the wonnd, in their whole thickness, in the elosest union, and withstand greater traction than if they only seized a lart of the edges. The sutures are 1-1 $\frac{1}{2}$ lines apart. 'The point of entrance of the threals is, in the relaxing suture, some dis- 
tance from the edge, in the uniting, quite near. I consider it of very little importanee, whether the suture goes through the vesical mucous

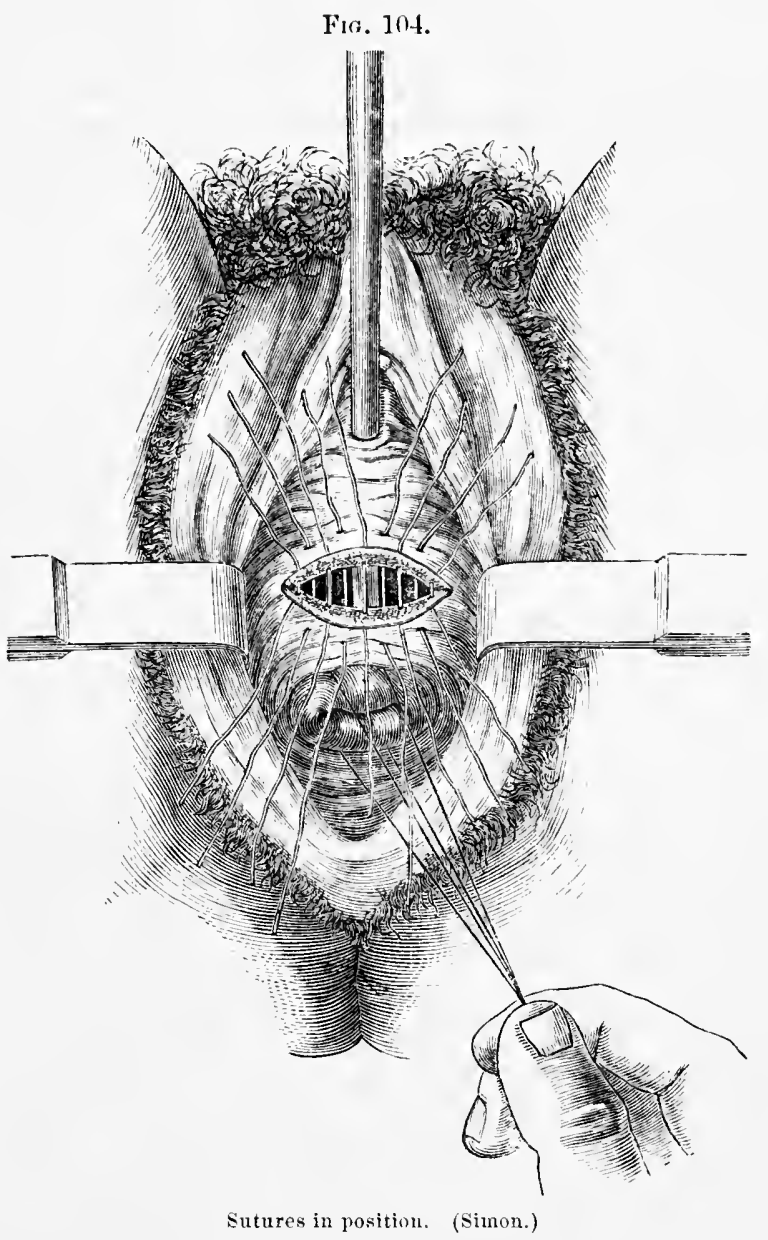

membrane or not. It is only necessary to be careful that this membrane does not get between the edges of the wound.

\section{After-Treatment.}

1st. From a series of observations, I conelude that neither on the wound nor on the new cicatrix does the urine lave any injurions influenee, and neither hinders the union by primary intention nor loosens a once formed cicatrix.

2d. From another series of observations, I have learned that the healing is not interfered with by a degree of distention, which could eome in 
a normal filling of the bladler, provided, only, that the wound is perfectly freshened and united.

In most cases the permanent retention of the eatheter only does harm.

Each of these deductions is drawn from a number of appropriate cases.

Upon these conclusions then is based my after-treatment, which up to the removal of the stitehes is entirely unimportant. Those minute directions, the carrying out of which is so tedious both for the patient and physician, are all laid aside. The patient is permitted to take any position she chooses. She passes her water, as soon as she feels the need, either in a bed-pan, or, if she object to that, in the sitting or knee-elbow position. Only in a few cases, where the patient is not in a condition to pass water spontancously, is the catheter used every three or four hours. On the fourth or fifth day an attempt is made to remove the stitches, and this is repeatel on the following days. On the eighth day, the patient is allowel to have her bed, even if all the stitches are not out.

To avoid passages from the bowels, with straining, on the first eiglit days, a fluid diseharge is recommended. If irritation of the bladder ensue, morphine, one-eighth grain per dose, should be given, and daily warm injections into the vagina, but not into the bladder, should be employed.".

Prof. Simon ${ }^{2}$ reports the following results : "Of 118 fistula occurring in 10.5 patients, there were $10 \pm$ fistula in 92 patients cured completely (a latcre cure is counted in under the first eategory); 5 fistula in 5 patients almost entirely closed; 2 patients with 3 fistula diseharged as ineurable; 6 patients died."

In the description of Simon's method here given, the words of the autlor have been employed as much as possible, and now, in concluding my account of it, I proceed to express my opinion as to its value as compared with that of Sims. In a very few rare cases of extensive destruction of the base of the bladder in women who are exceedingly obese, it answers a better purpose than that of Sims; but, as a rule, it is difficult to appreciate how any one who has tried both ean consider the former as comprable to the latter. Indeed it may justly be said that Sims's methorl leaves o little to be desired that all others are completely overshadowed by it.

Elytroplasty.-This operation was published to the profession by Jobert de Lamballe, ${ }^{3}$ in 1534 , and was subsequently altered and improved by Velpeau, Gerily, and Leroy d'Etiolles. It consists in dissecting a flap from one luttock (Jobert), or the posterior wall of the vagina (Velpeau and leroy), and fixing it by sutures into the orifice of the fistula, the bor-

1 This resume has been prepared from l'rof. simon's work by Dr. MI. D. Mann.

2 Am. Journ. Obstet., rol. ii. p. 241.

3 Bull, de l'Acad. de Méd. de Paris, t. ii. p. 145. 
ders of which have been previously pared. It rescmbles the operations of rhinoplasty performed upon the face, but is unfortunately wen more dificult than they, and calls for such great manual dexterity as to preelude its frequent adoption. Velpeau, by making two parallel, longitudinal incisions in the vagina, dissected up the intervening tissue and stitched it to the edges of the fistula.

Leroy prolonged these incisions to the rulva, dissected up the intervening flap, and, rolling this upon itself, applied its under or bleeding surfice against the fistula.

Elytroplasty is still employed sometimes where great destruction of tissue has taken place at the base of the bladder, but the difficulties and uncertainties attending it, together with the fact that more simple and efficient methods for dealing with this class of cases are at comuand, have rendered a resort to it very rare.

To one unaceustomed to the treatment of fistula, it would appear that the larger the fistula the more difficult would be its cure. This is not so; some of the most difficult cases will be found to be those in which the opening is so small as to be discerned with difficulty. In these cases I would strongly recommend the following plan. Introduce into the bladder a large steel somd, and by its extremity make the fistula to project towards the vagina; then cut away the tissue surrounding the fistula so as to let the sound pass freely into the vagina. Sutures may then be passed, and the enlarged fistula cured.

\section{Closure of the Vagina.}

This procedure is resorted to in despair of accomplishing the cure of the fistula, and in the hope of relieving the patient from the intolerable annoyance attendant upon an involuntary and constant discharge of urine. It does not. of course, equal in efficiency closure of the vesical fistula, since it involves the necessity of the urine being retained in the raginal canal, which is injured by its presence, and is proposed only for those cases in which, from extensive destruction of tissue, no hope of closure by suture or elytroplasty ean be entertained. By it the vagina and bladder are rendered a common receptacle for urine and menstrual blood, the only adrantage gained consisting in the fact that they may be retained and discharged at will through the urethra which remains open.

Closure of the vagina may be accomplished by two operations, episiorrhaphy and obliteration of the canal. The first, which consists in paring the inner surfaces of the labia majora and miting them by sutures so as to cause their complete adhesion, originated with Vidal de Cassis, who performed it in 1833. The operation is exceedingly simple in its steps, but a very minute opening almost invariably remains just mier the meatus through which a little urine exudes. This very nearly invalidates the 
success of the method, for even a slight escape renders the patient uncomfortable.

The second consists in paring, not the labia, but the vaginal walls. Strips of mucous membrane being thus taken away, the bleeding surfaces are brought in contact by suture, and the bladder is kept empty by a catheter until union has oceurred. This procedure, a far more valuable and reliable one than that of Vidal, was first performed by Simon, who has applied to it the name of " Kolpokleisis," or cross obliteration. Prof. Simon's first operation was performed in 1855, and since that time he declares that it has been resorted to in Germany in over fifty cases with complete success, and many cases suffering from incontinence of urine due

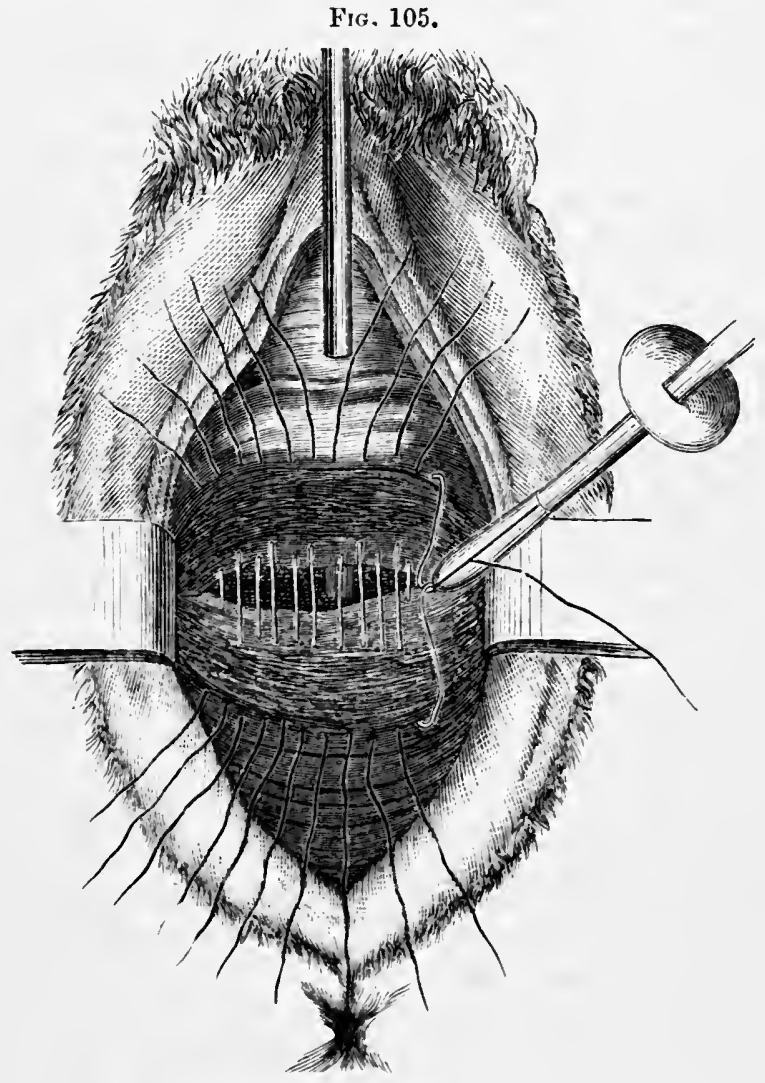

Ohliteration of the vagina. (Simon.)

to great loss at the base of the bladder have been entirely reliever by it. Ite places a very high estimate upon the operation, as the following extract from a published letter from him to Dr. Bozeman of this city will 
"The reason why I have proved the validity of my claims of priority at such lengths, is simply this, that in my opinion kolpokleisis is the most inportant plastic operation which in the last decennia has originated from one single man. The operation of vesico-vaginal fistula by uniting the borders of the defect is indeed, in its present perfection and precision, a mueh more important acquisition than kolpoklcisis, and probably the greatest achieve. ment of our century in plastic surgery ; but it has not been carried to that perfection by a single man, but, on the contrary, operators of all nations hive contributed their share to it. The 'uranoplastie' of our ingenious comtryman-von Langenbeck-could alone be placed by the side of kolpokleisis, as fur as the safety of the performance and its immediate success are concerned. It would rank higher still on account of its more frequent occurrence, if its benefit for the voice in increasing its purity could be secured in all or the majority of cases. But as in many cases this result is not obtained at all and in others only incompletely, kolpokleisis must be considered the more important operation, as in all eases it fully answers its purpose. This operation, which I invented at the time when the obliteration of the vulva, proposed by Vilal, proved inefficacious in re-establishing continence of urine, has already been performed more than fifty times with complete suceess. Through it many patients with incurable defeets of the bladder have been freed of the most intolerable suffering, viz., incontinence of urine. I have myself succeeded in eighteen cases in effecting perfect obliteration, and every German surgeon who practises the art of euring vesico-vaginal fistules has recorded one or more successful cases of that kind."

In his earlier operations, Prof. Simon confined this procedure to the lower section of the vagina, but he now obliterates the canal just below the loss of substance.

\section{Urinary Fistulæ requiring Special Treatment.}

In the great majority of instances no other plan of treatment than the suture is necessary. There are, however, some cases of urinary fistula in which the application of the suture is difficult, or even impossible. These will now engage our attention.

\section{Vesico-uterine Fistula.}

Jobert first pointed out the proper method for reaching these. His plian is not at present employed, but that now regarded as most reliable is only a modification of it. It consists in slitting "p the anterior lip of the uterus mitil the fistula is reached, vivifying its edges, and passing sutures directly through the cervix, as represented in Fig. 106 , so as to approximate the walls of the cervix and the lips of the fistula.

In case the fistulous orifice be so high as to be

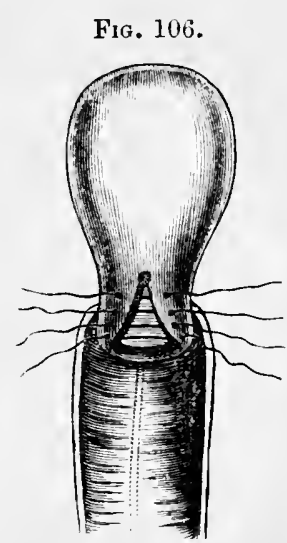

The cervix is slit to expose the fistula above, and sutures are passed. 
considered beyond reach, the only remaining resource is to close the os uteri externum by suture, and allow menstruation to occur through the bladder.

\section{Vesico-utero-v"aginal Fistula.}

For these the plan of vivifying the anterior lip of the os, and thus making the uterine tissue subservient to closure of the fistula, is peculiarly

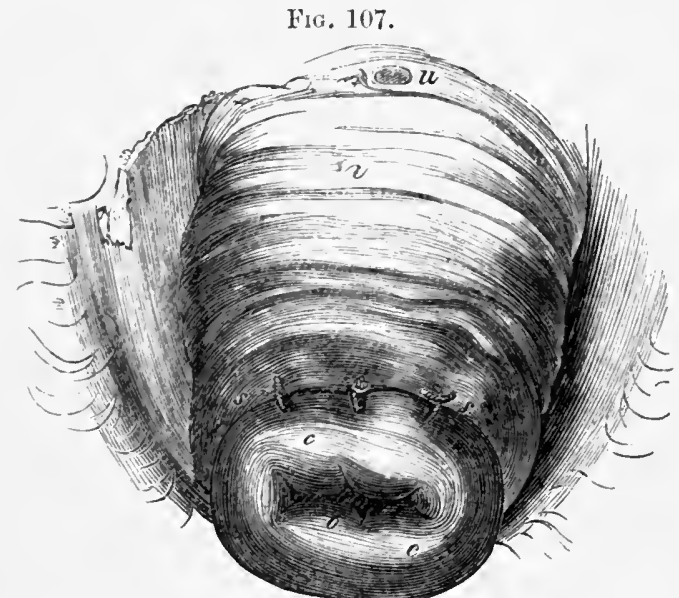

Anterior lip of flstula united to anterior lip of cervix. (Simon.)

applicable. The operation, represented at Fig. 107, is similar to tlaat for orlinary vesieo-vaginal fistula, the only differenee being that one lip of the fistula is made of the vivified cervix uteri.

In case the anterior lip of the uterine neek be so completely destroyed

FIG. 108.

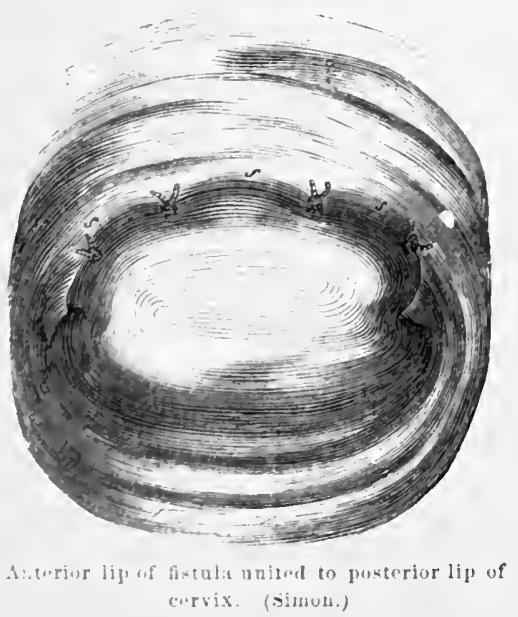
that it cannot furmish the requisite tissue for this purpose, the vagina may be united to the posterior lip so as to throw the cervix into the bladder. Menstruation will alterwarls occur into that viscus, and the blood thus accmunlating be discliarged with the urine.

\section{Fistula with Extensive Destruction of the Base of the Bladder.}

It has already been mentioned that elytroplasty and kolpokleisis offer resources in these ases. To Dr. Bozeman, however, we are indehted for still another procedure, the first step of which consists in 
dragging the uterus down daily for weeks before the operation by means of " p pair of forceps by which the neck is seized. In this way the uterus is male to approximate the vulva. 'Then one lip of the cervix, being viviferl, is bronght into contact with the extremity of the remains of the vesico-vaginal septum, and firmly united with it by suture.

'lo facilitate this procedure, the eervix may with great alvantage be slit to the vaginal junction, drawn forward and made to fill the space left vacant by the sloughing of the vagina.

\section{Uretero-uterine and Uretero-vaginal Fistulæ.}

In addition to the varieties of urinary fistula mentioned here, eertain rare instances of union between the ureters and vagina or uterus lave been recorded. A striking example of uretero-uterine fistula may be fomd detailed in the Dietionnaire de Médecine, vol. xxx., by M. Bérard. It is not only interesting in itself, but as displaying the method by which the diagnosis may be arrired at is worthy of speeial mention. Regarding it at first as a vesico-uterine fistula, from the fact that urine was diseharged from the uterus, he arrived at a different diagnosis from these facts:-

1st. The urine flowed steadily from the cervix when the bladder was empty.

2d. The urine thus flowing was limpid, unlike that from the blatler.

3d. 'The patient being kept seated over a vessel for two hours so as to preserve all the urine flowing per vaginam, a catheter was passed into the bladder and the amount removed exactly equalled that which hat escaped vicuriously.

th. Injeeting the bladder with fluid colored by indigo, the urine passing per vaginam remained limpid.

5th. A somd being passed into the uterus and another into the bladder, their points could not be brought into contact.

Uretero-uterine fistula is by no means common; only one instance is mentioned by Dr. Emmet in his reeent work as laving oceurred in his extensive experience. Dr. W. H. Baker, ${ }^{1}$ of Boston, has recently published an interesting ease, which was eured by disseeting up the ureter which encled at a point near the meatus urinarius, making an opening near the neck of the bladder, turning the ureter into this, and then closing the raginal wound.

Dr. Henry F. Camplell, ${ }^{2}$ of Georgia, reports an interesting case of uretero-vaginal fistula which he eured by this simple procedure: passing a small bistoury up the ureter, he slit its anterior wall, the knife passing

1 N. Y. Hed. Journal, Dec. 1878.

2 Amer. Journ. Med. Sciences, Jan. 1880. 
into the bladder. He then elosed the raginal surface of the cut thus male with silver suture. The patient rapidly and entirely recovered.

$\Lambda \mathrm{n}$ exceedingly interesting instance of this variety of fistula is mentioned by Zweifel, of Erlangen, in which he removed the kidney of the diseased sile with a successtul result. The right kidney which was left proved quite suflicient for the wants of the eeonomy.

There are eccentric and rare forns of fistula which I have not men tioned in my enumeration. For example, 1 have met with a case of vesico-abdominal fistula. Eight days after the operation of ovariotomy, about one pint of urine began to pass daily throngh the abdominal opening, the lower angle of which had been kept open for washing out the peritoneum. That the fistula was resical and not ureteral was proved by the escape of eolored fluid through the abdominal wound when injeeted into the bladder. This patient entirely recorered, and the fistula healed of itself.

Where a larger extent of denuded surface is required than ean be obtained by laring the edges of fistula, Langenbeek and Colles have resorted to the following plan. Splitting the edges of the fistula, they have separated the two flaps thus produced, and bringing the opposing raw surfaces together, have secured them by suture.

\section{I'reutment of Long, Tortnous, Capillary Sinuses remaining after Operation by Suture.}

Sometimes fistnle situated near and involving the neck of the uterns will be eured in great part by suture, and yet, at one or both extremities of the original opening, long, eapillary sinuses will remain, whieh, running a tortuous course, reach the bladder and render the operation a failure. Inder these eircumstances it is almost impossible to pare the edges of theses tracts by kuife or seissors, and the cautery which has been generally used fur them commonly fails to eure them. For these I lave adopted with the most satisfactory results the following plan. Ilaving a dentist's burr made with eutting flanges, instead of dull ones, such as are usually employed, it is titted to the ordinary dentist's treadle; as the burr is made to revolve rapidly by the action of an assistant's foot, it is passed up and down the sinns to be elosed several times until the operator feets that the entire eanal is thoronghly demuded. Then by curved needles, deep sutures are pasied approximating its vivified walls.

liy this means I have eured several fistule situated just in eontact with the cervix uteri, which wonld have been exeedingly difficult of cure by any other methorl. It has the advantage of being very expeditious, and I wonld urge its elaims in this class of cases. 


\section{CHAPTER XVI.}

\section{FECAL FISTULA.}

Definition.-These, which are much less frequently met with than urinary fistula, consist in communications establislied between the ragina or vulva and some part of the intestinal tract.

Vurieties._They may be recto-raginal, entero-vaginal, or recto-labial; the first being the most common, and the seeond the rarest of the varieties.

Canses.-The canses which produce them are almost illentical with those which result in urinary fistulie, viz. :-

Prolonged pressure ;

Direet injury ;

Ulceration or abseess.

The first of these may produce them, as it does those occurring on the anterior vaginal wall, by creating an intense inflammation which results in sloughing, or the intensity of the pressure may be so great as rapidly to destroy the vitality of the part. Sueh pressure is most frequently the result of difficult parturition, but in rare cases it may arise from badlyfitting pessaries or scybalous masses in the reetum.

Direct injury by instruments used in delivery, or others employed for removal of impacted feees, may evidently produce them.

Ulceration or abscess muel more firequently produces fecal than urinary fistulie. For the recto-raginal variety strieture of the reetum is a fruitful souree, the stricture producing a retention of fecal matters which exeites ulceration that may extend to the raginal canal. An abscess between the vagina and rectum may cause a communication between the two, or burrowing towards one labium may open there and connect this part by a traet with the rectum. In the same mammer a purulent eollection has been known to make a junction between the caput coli and ragina. Lastly, syphilitic and cancerous ulceration may open a ehannel between the intestinal and vaginal canals.

Symptoms._-The most promintent, of ten the only symptom which will attract the patient's attention, will be a discharge of oflensive gas or fecal matter by the vagina. The amount which escapes will of course be governed by the size of the fistula, but the annoyanee dependent upon the accident will hot be so, for even the smallest quantity will be suffieient to render the patient utterly wretehed by the offensive odor to which it gives rise. 
Physical Signs. - The patient being placed upon the back, touch should be practised upon all the surface of the ragina. If the fistula be one of any magnitude, this will at once discover it. If not, careful exploration by the speculum will almost always do so. Sims's speculum shonld be introduced under the symplysis so as to lift the anterior wall of the vagina while the lateral walls atre held aside by spatula. Should visual exploration not reveal the opening, the rectun may be filled with tepid water colored with cochineal or indigo, and its escape carefully watched for.

Prognosis._Fecal fistulae are more likely to be spontaneously recovered from than those of urinary eharacter, from the faet that they give passage to gaseous and semi-fluid exeretions, and not to an irritating fluid which is constantly dribhling away and keeping the fistulous walls from uniting. But even these are rarely recovered from unless surgical aid be brought to their relief.

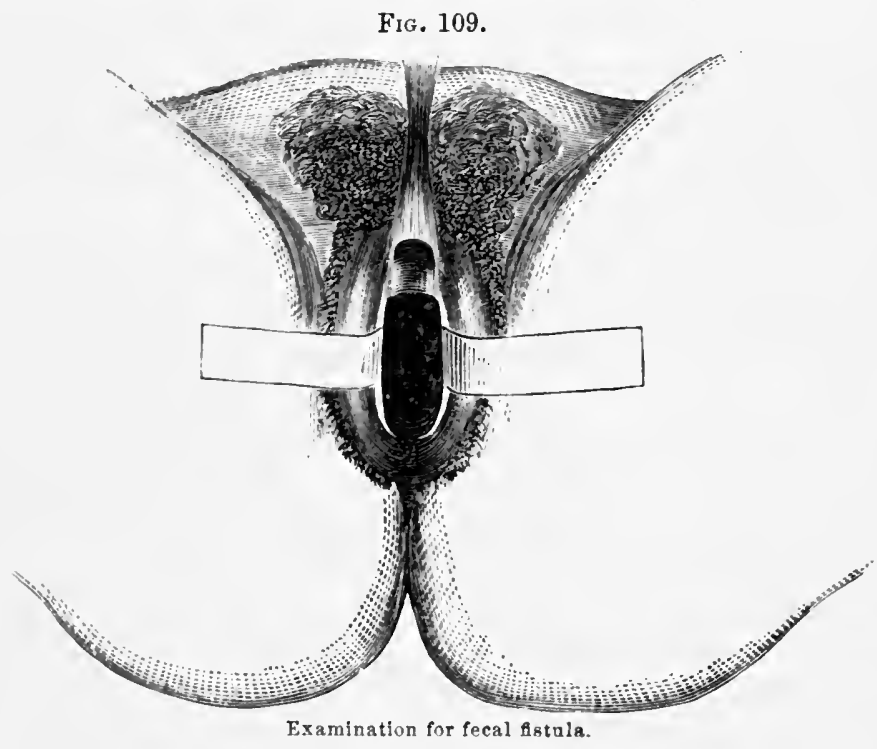

Treatment.-Recto-vaginal and recto-labial fistule should always be treated by suture.

This is practised upon the same plan as that which is followed in verien-vaginal fistula, with these exceptions, that the patient is placed in the prestion allopted in operating for stone, and that the speculnm is so inerted an to alevate the anterion instead of the posterior vaginal wall. linfore opration, the sphineter ani nusele should al ways be paralyzed by thorongle stretehing by the fingers, and after it a rectal tube should be rutained, muless very annoying to the patient. After the operation, too, the rectum. which should have been thoroughly amptied by enema before it, flonld be kept jerfectly cquiet by opiates for ten or twelve days. When 
evacuations are first permitted, laxatives shonld be employed in order to avoid tenesmus, which might destroy the union of the lips of the fistula.

In one case of recto-vaginal fistula $I$ have introduced the speculum into the rectum, and elosed the fistula on the rectal surface. The facility with which the operation was performed was surprising. Should the fistula exist only a short distance above the sphineter ani, the best methor of treatment is to eut completely through the perineal body, vivify carefully, and close the wound.

\section{Entero-Vaginal Fistulæ.}

Entero-Taginal Fistula, which consists in a fistulous tract between some part of the intestinal canal above the rectum, and the vagina, is rare, and when existing should be looked upon as an artificial anus, the closure of which would be attended by danger. If the opening be direet and there be no tract leading from one canal to the other, this would not be the case, but if a tract exist, the elosure of its raginal extremity would probably result in abseess excited by fecal matters passing out of the intestine.

\section{Simple Vaginal Fistulæ.}

Definition.-Under this head are grouped those forms of fistulous connection with the vagina which do not act as vicarious outlets for any neighboring organ, as, for example, peritoneo-raginal, perineo-vaginal, and blind fistula.

Peritoneo-vaginal Fistula has been rarely met with. When it does occur it is attended by danger of descent of the intestine into the vagina, and entrance of fluids and air into the peritoneal cavity. One reason for its rarity is probably the fact, that, no excrementitious substance passing through it, it very generally disappears without becoming ehronic. Should it not do so, no annoyance would arise from its existence, and it would be susceptible of immediate cure by suture.

Perineo-vaginal Fistula may result from partial closure of a ruptured perineum leaving a small orifice near the sphineter ani, or from penetration of the presenting part of the fotus through the perineum. It may be readily eured by incision, ligature, cauterization, or injection, after the plan just pointed out in eonnection with feeal fistulx.

Blind raginal Fistula are those which lead to a purulent collection in some part of the pelvis. They will be fully treated of when considering pelvic abseesses, and nothing need be said of them here further than to mention the prineiples upon which their treatment rests: 1st, dilatation of the fistulons traet by tents or incision ; $2 \mathrm{~d}$, exerting an alterative ation on the walls of the abseess by iodine, iron, nitrate of silver, water, etc. ete. 


\section{II A P T E R X VII.}

\section{ACUTE ENDOMETRITIS.}

I FREELY confess that the arrangement of no subject treated of in this work has caused me more perplexity, and is offered to the reader with greater hesitancy, than that which relates to the divisions of endometritis. Having personally no theory to sustain in reference to the matter, my sole desire is to present the subject in the manner which will best aid in its comprehension, assist the practitioner at the bedside, and favor a future advance in its pathology.

Thronghout the literature of gynecology admissions will everywhere be found of the fact that endometric inflammation limits itself to the neck, the body, or even, according to one authority, ${ }^{1}$ to the fundus of the uterus, and yet the two varieties of the affection are treated of as one, and one author" even goes so far as to assert that "the facility for locating its limit exclusively to cervix, body, or fundus rests only in the brain of the theorist." Barnes treats of the whole subject as "endometritis," yet, with claracteristic candor, he says, "it appears to me that attention has been too strictly fixed upon the visible changes in the cervix and os uteri; and that, thus engrossed, the mind has been closed against the less telling evidence of changes in the body of the uterus."

All things being carefully eonsidered, I have thought it best to alhere to the arrangement which follows, guarding the reader against the idea that any facility of differentiation, any dogmatic certainty of conclusion is claimed in reference to the matter. The arrangement simply seems to me, for many reasons, that which best meets the requirements of the present and favors the prospects of the pathology of the future.

The varieties of inflammation of the lining membrane of the uterus nay be clearly expressed in the following manner:-

$$
\text { Endometritis } \begin{cases}\text { Acute } & \left\{\begin{array}{l}
\text { General. } \\
\text { Cervical. } \\
\text { Corporeal. }
\end{array}\right. \\
\text { Chronic }\left\{\begin{array}{l}
\text { General. } \\
\text { Cervieal. } \\
\text { Corporeal. }
\end{array}\right.\end{cases}
$$

I Dr. Routh's article on "Fundamental Endonetritis."

2 Ur. T. A. Emmet, op. cit. 
Synonyms.-Aente endometritis has been treated of under the names of acute uterine leucorrho:a, acute uterine catarrh, acute internal metritis.

Frequency.-Acute inflammation of the lining membrane of the uterus is a condition which occurs quite frequently. Often running a rapid conrse, however, and ending in recovery or in chronic disease, it pasies unrecognized in many cases. In this way I would explain many of the cases of suppressio mensium and congestive dysmenorrhoa, which we so often find ending in chronic disease. And thus also would I account for the profuse and painful attacks of leucorrhoa oceurring with exanthematous ferers, and lasting for a length of time after they have passed off. It is very generally stated that acute metritis is seldom met with except as a sequel of parturition, and I agree in the statement as applying to parenchymatous inftammation, but it does not apply to endometritis, which often proves the source of sudden menstrual disorder and the cause of violent lencorrhoea.

Iarieties._The morbid process may affect the lining membrane of the cervix or of the body alone, or it may attack the whole uterine mucous tract, its selection of site being governed by its cause. Thus, that form which immediately follows parturition or abortion, or results from gonorhora, is likely either to affect the whole mucons tract or the cervical canal alone; while that which is due to sudden checking of the menstrual flow is more likely to be confined to the body.

Causes._The canses of acute endometritis are the following :-

Direct injury;

Cold from exposure during menstruation ;

Constitutional disease of septic or asthenic character;

Vaginitis, specific or simple;

Excessive venery;

Suppression of menstruation.

Examples of direct injuries which may produce acute endometritis are the introduction of the uterine sound or the intra-uterine pessary, the employment of tents or the application of chemical irritants, surgical operations, and intemperate coitus.

It is, probably, in some instances, through the instrumentality of this disease that those cases of fatal peritonitis which result from tents, sounds, and intra-uterine pessaries occur. Inflammatory action is first set up in the lining membrane of the uterus, and thence swiftly passes through the Fallopian tubes to the peritoneum.

Specific vaginitis or gonorrhoca will sometimes pass up into the cervix and body of the uterus, and out through the Fallopian tubes, creating pelvic peritonitis of most violent character. Even simple vaginitis, when of very severe form, may produce endometritis, though this is by no means common.

The peculiar blood state, attending upon and forming an element of 
measles, scarlatina, variola, and roseola, and exerting its influence on all the mucous linings of the body, will sometimes result in general endometritis, and the hemic condition resulting from phthisis not rarely does so. Kiwisch has stylerl this, "inetastatic constitutional catarrh."

Exposure to cold and moisture, great mental anxiety, or any other influence which suddenly checks the menstrual flow, not infrequently produces this disease. At the moment of exposure suppressio mensium, or congestive dysmenorrhoa, may take place, and from that tine endometrit is may exist. When we consider that such a sudden check of menstruation will sometimes result in hematocele of fatal character, it is certainly not to be womlered at that it may likewise produce the disease of which we are speaking.

Excessive venery, even where no violence is done to the uterus, may produce it by the prolongation of intense congestion of the organ kept up by this act.

Symptoms.-The disease demonstrates its presence in the non-puerperal uterus without any very violent symptoms.

Ordinarily the patient complains of pain, weight, and dragging in the pelvis: pain in the back, groins, and thighs; burning and pricking in the vagina, and resical and rectal tenesmus. After four or five days there is usually a discharge of a viscid liquid, which in eight or ten days becomes creany, purulent, and perhaps bloody; tympanites and sensitiveness upon pressure, and uterine tenesmus or "bearing-down pains," show themselves in sevre eases, and at times, though rarely, there is active diarrhoa due to reflex irritation of the rectal nerves. Should the fluid discharged from the vagina be allowed to eome in contact with the skin of the rulva, abdomen, or thighs, an intense cutaneous irritation is established, which may go on to excoriation and the development of pruritus of aggravated character. In two eases I have seen prurigo thus excited which spread over the entire horly. If the reaction of this purulent discharge be examined into, it will sometimes be found to be aeid and at other tines alkaline. The explanation of the fact is this: the discharge from the uterus is alkaline and that from the vagina acid. If the irritating uterine fluid have established, as it very generally does, vaginitis, the acid secretion from this source orercomes the alkalinity of that from the other. If, on the other land, no severe vaginitis exist, the discharge from the uterus presents its orlinary alkaline features.

I'lysical Signs. - C pou examination by touch the os uteri is found Eaping. the ecrvix swollen and very sensitive to pressure, the boty slightly enlargerl, and the whole orean lower than normal in the pelvis. Throngh the flembun the cervix is found to look swollen, adematous, and red, aur form the ponting os pours forth either a elear, albuminous-looking 1]uil, muco-pus, or long tenacious shreds of cervical mucus. All exploratims of the utcrus should, as a rule, be avoiden. 'The probe, if used at 
all, should be employed witl the greatest cantion, and never unless passed through the speenlum. The sound as ordinarily used should not be thought of. Probing will discover great sensitiveness throughout the uterine eavity, and the slightest touch upon the fundus will canse the discharge of at few drops of blood. Indeed, so great is the engorgement that even the introduction of the speeulum will often cause blood to flow from the cervix.

Bimanual examination will diseover the uterine body enlarged, and tender upon pressure, so that one who judged hastily, and without sufficient knowledge of the suljeet, would be very apt to diagnosticate with great positiveness acute parenchymatous metritis. There ean be no doubt that many of the reported cases of that affection have been nothing more that instances of this form of endometritis.

Differentiation.-CThe only diseases with which this would with any probability be confounded are, periuterine cellulitis, pelvic peritonitis, and aeute vaginitis. In the first two of these, constitutional disturbance is generally more marked and excessive than in this; they are often preceded by ehill, and usually by more intense febrile action, and greater elevation of temperature. This, however, is not universally true. The last is very generally attended by a lesser degree of general disturbanee. No positive conclusion can usually be arrived at without physical exploration, which in pelvie inflammation will discover fixation of the uterus, hardening of periuterine tissue, and excessive tenderness when parts other than the uterus are compressed by conjoined manipulation. It will generally be noticed that in cellulitis and peritonitis there is no great increase of uterine or vaginal discharge.

Pathology.-In its first stage acute endometritis consists in an intense and active hyperemia of the mueous lining of the uterus, whieh is red, swollen, œulematous, and softened. Its surfice is spotted, Scanzoni deelares, from congestion of the capillary network around the mouths of the utricular follicles. When the second stage las set in, the cavity of the uterus is found to contain an excess of mueus or creany-looking pus, which may be more or less mingled with blool. If the eervix be involved in this inflammatory engorgement, the mucous membrane of its vaginal portion participates markedly, as an examination by the speculum will prove.

In the mueus just mentioned the microscope reveals the presence of thousands of cells and sometimes entire easts of the utricular follicles.

"Ordinarily," says Seanzoni, " acute eatarrh of the mucous membrane of the uterns is accompanied by a congestive swelling of the muscular substanee of the womb, and most generally it is possible, particularly in the most internal layers of the organ, to see with the naked eye, that the 
ressels are gorged with blood. There ordinarily result from it an infiltration and a softening, which are much greater in the layers of the parenchyna of the uterus nearest to the mucous membrane. Hence, these alterations of tissue which are characteristic of acute parenchymatous metritis ordinarily accompany catarrh of the mucous membrane, when this has attainet a high degree of intensity." "The whole substance of the uterus," says Klob," "generally appears to be increased, and its tissue more vascular and succulent, especially in the layers nearest the mucous membrane."

Acute endometritis very rarely shows itself before puberty.

Complirations.-Its complications are acute metritis, urethritis, vaginitis, rulvitis, cystitis, salpingitis, pelvic peritonitis, and varions eruptive disorlers. the results of scratching excited by pruritus vulva.

The first of these complicating conditions is of so much moment as to repuire special consideration.

The time has, I think, arrived when, with our present light upon the subjeet, acute parenchymatous metritis should be given a suborlinate place in pathology instead of the prominent one which it formerly occupied. With reference to its frequency as a primary affection, many conflicting statements will be found. This arises partly from the fact that some latve written of it without making any distinction between the forms occurring in the puerperal and non-puerperal states, while others have confined their remarks, as is here done, to the disease in the latter condition; partly from endometritis, active congestion from suppressio mensium, and peritonitis and cellulitis having been mistaken for metritis; and in great fart from the difliculty of gaining post-mortem evidence, the disease generally being recovered from. As a complication of inflammation of the internal mucous or external serons covering of the uterus, parencliymatous inflammation is universally almitted. As a pathological entity, lowever. I question whether any well-authenticated case of this affection is on recorl. The descriptions of the disease which are given in recent works. such, for example, as those of Courty, Gallarl, and Scamzoni, each of whom devotes considerable space to it, appear to me to have come down to us as a matter of literary tradition rather than of clinical research.

While searching for a case of pure uneomplicated metritis, I have seen numbers of eases which were regarled by others as of this cliaracter, and guite a number which I viewerl as such until enlightened by post-mortem or other evidence. Iiokitansky" declares that, " in acute inflammation of this frogalu, gencrally the lining membrane of the uterus is affected primarily, and that this is scarcely ever the case with the uterine tissue, as

1 Path. Anat. Fomale Sec. Organs, American ed., p. 231.

2 Jatlobloy Anat. 
far as can be demonstrated by the pathological anatomist, with the exception of the reaction following tramatic influerces, espeeially of the varinal portion."

In his recent work Klob takes still stronger ground as to the existence of uncomplicated metritis, and asserts that never having met with an instance of the disease, he is forced to describe it upon the authority of others.

Some practitioners are prone to regard every case of inflammatory action in the pelvis, accompanied by great tenderness over the uterus, as metritis. Such cases are much more frequently due to pelvic cellulitis or peritonitis, which are by no means rare affections, or to active congestion, caused by suppression of the menses or excessive coition. After parturition, either at term or premature, true metritis does occur not unfrequently, but this variety does not eoncern our present investigation. As regards that form which we are considering, I feel convinced that, if the experienced practitioner will put aside his preconeeived views and interrogate the results of his observation, he will find, if he has his attention aroused to the frequency of the diseases which simulate it, that he has met with this affection very rarely.

Course, Duration, and Termination.-Acute endometritis, when occurring in the non-puerperal state, may, without treatment even, go on to reeovery, generally lasting from a month to six weeks, and perhaps passing throngh its whole course without its existence having been diagnosticated. It sometimes ends in the chronic form of mueous inflammation, or cren in slight hyperplasia, the superficial, subjacent, comnective tissue becoming affected. It is doubtful whether any severe case of endometritis runs its conrse without being to a greater or less extent complicated by a slight degree of parenchymatous disorder. As alrealy stated, the disease may end in ehronic endometritis or in recovery. It may, likewise, end in death; inflammatory action spreading along the Fallopian tubes and causing salpingitis, whieh, by resulting in free purulent discharge into the peritoneum, may establish inflammation there.

Prognosis.-In spite of all these possibilities the prognosis is always farorable if the patient take ordinary eare of herself and yield to a judicious plan of treatment.

Treatment.-The diagnosis having been elearly made, treatment should be at once established. Complete rest of mind and body should be regarled as essential points. In serere eases, the patient should be kept perfectly quiet upon her back in bed, and not allowed to leave it or to assume the sitting posture even to satiffy the ealls of nature. Opium should be freely given by mouth or rectum for the production of perfect nerrous quiescence and for the relief of pain. In severe cases one grain

1 Path. Anat. Fenale Sex. Organs, American ed., p. 231. 
of powdered opium or its equivalent of morphia should be administered every third hour. This drug, I feel sure, not only acts as a sedative to the nerrous system, and a quieter of pain ; it absolutely modifies the inflammatory process by its influence upon the nerves. The bowels, unless constipation exists, should not be acted unon by cathartics, and ordinarily no other medicine than opium should be administered. Over the hypogastrium a soft, warm poultice of powdered linseed slould be placed and covered by oiled silk. This need not be renewed oftener than once in twelve hours, for the oiled silk will preserve its warmth. The patient should not be annoyed by leeches or cups. Even if high febrile action show itself, this can be readily controlled by appropriate administration of tineture of veratrum viride. The diet should be rery simple, and should consist of fluid food chiefly, as milk, beef-tea, etc. A condition of intestinal quietude should be encouraged, and therefore such food as involves the elimination of a small amount of excrementitious matter should be allowed. By these means motion in the abdominal cavity may be lessened, and rest be assured to the diseased part. As soon as free secretion of muco-pus begins to slow itself, the vagina should be gently syringed out three times daily with copious injections of very warm water. For the proper accomplishment of this the patient should turn so as to lie across the bed, in the French obstetric position, on the back, with the buttocks over the edge of the bed, which has been protected by Indiarubber cloth, cach foot being supported by a clatir. A nurse, then placing between the thighs a tub containing three or four gallons of water, should pass the nozzle of at Dilvidson's syringe up to the cervix, and for fifteen minutes project against it a steady stream. All examination by speculum, probe, and, after a diagnosis lats been made, even by the finger, slould be arvided unless some special indication demand it. Astringent injections and all vaginal applications should be avoided. The affection which we are treating is located in the uterus, not in the ragina, and such applications merely annoy the patient and aggravate the disease. The warm injections which hare been alvised act as ponltices or fomentations to the whole internal surface of the pelvis, at the same time that they insure cleanliness to the vagina and remove from it a fluid which, if lett there, might axeite varinitis. Under this plan of treatment the patient shonld be kept until recosery, or until we are admonished by time that the diseas hats passed into its chronic form and requires different remedies.

To one aecustomed to the advice to apply leeches to the cervix or perinemun pass the speenlum, and apply solid nitrate of silver to the eervical canal, inject the vagina with solutions of persulphate of iron, keep the bowrols com-tantly active by saline cathartics, etce, this plan may appear tor ind flicient to be relied upon. Of any one entertaining this doubt I womll ask a trial and comparison of the two methods hefore he arrives at a derision which will gulde his future practice. If his experience agree with mine, I do mot doubt the resulting verdict. 


\section{CHAPTER X VIII.}

\section{CHRONIC CERVICAL ENDOMETRITIS.}

Wrex inflammation of acute character affects the uterus, it has a marked tendency to invade the entire organ, and to involve both eervix and body, but with clnonic inflanmation this is not the ease. Being of a lower grade of intensity, it more strietly confines itself to the mucous membrane and limits itself to the body or cervix. Such limitation is, however, neither universal nor absolnte, sometimes subjacent parts being more or less implicated, and at others the mueous membrane of the entire organ being simultaneously and equally involved.

Definition.-By the term chronie cervical endometritis is meant ehronic inflammation of the mucous membraie, extending from the os internum to the os externum, as represented by the dots in Fig. 110.

FIG. 110.

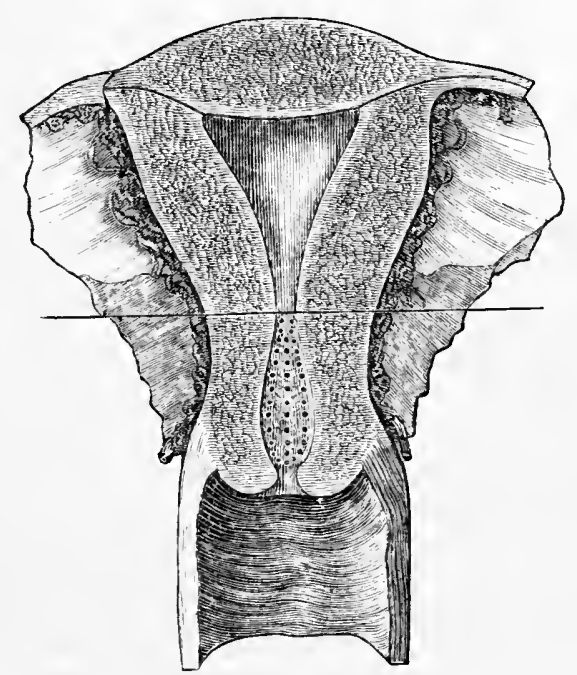

The dots represent the site of chronic cervical endometritis.

Frequency.-Of all diseases of the genital system of the female this is without doubt the most frequent, and, although not in itself a malady of dangerous eharacter, may prove the starting point for some of the most serions and rebellions of uterine disorders. Exposed as the cervix uteri 
is to injury during coition, laceration from parturition, and irritation from walking, riding, and lifting, it is not surprising that its complicated investment should frequently become the seat of disease.

This afleetion too is a frequent source of menstrual disorders, and very commonly produces sterility.

Synonyms.-It has been descrilsed under the names of cervical catarrh, cervical leucorrhoa, and endo-cervicitis.

Anatomy of the Cervical Mucous Membrane.-The cavity of the cervix uteri is a fusiform canal, measuring about one inch and a quarter, beginning at the os internum above and enling at the os externum below. On the anterior and posterior walls of the cervix are ridges, from which folds are given off which are arranged with regularity, and run obliquely upwarls and outwarls, to end in other indistinct lines on the sides of the canal. 'This arrangement of mucous membrane las received the name of arbor vitee.

butween these folds numerous mucous glands are seen, which are called by some the grands of Naboth.' Dr. Tyler Smith² estimates that at well-

Fig. 111.

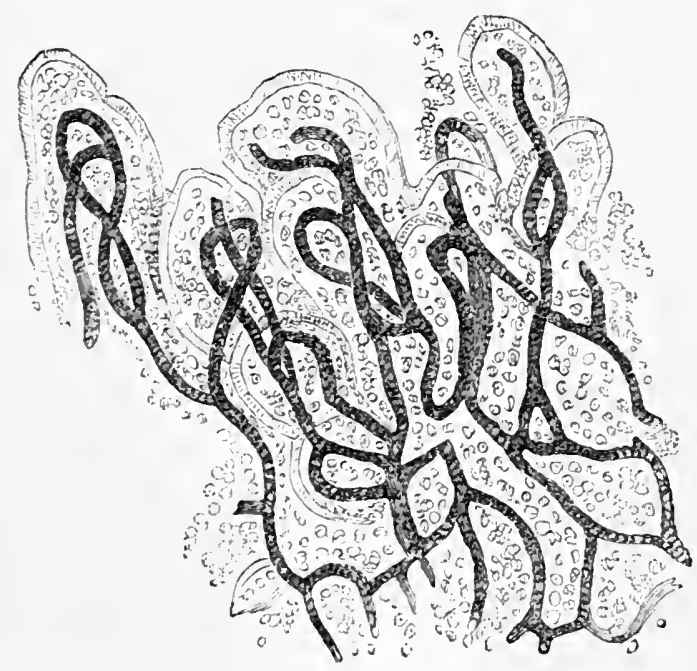

Vill of canal of the errix nteri, coverel by eylindrical efithelium and containing looped bloodvensels. One hundred dismeters. ('T. Smith.)

A.releped virgin cervix probably contains at least ten thousand of these follicles. The mucous membrane forming these folds or ruga is covered

1 A freat deal of curiosity attaches to the nature and function of these glands. Some recard th" Vabothian glands as iclentical with the nuciparous follieles, otlers

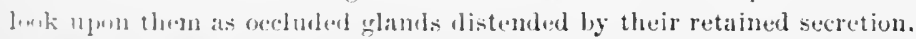

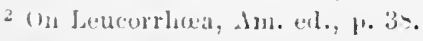


orer by eylindrical and ciliated epithelinm and studded by villi, which are found in eonsiderable numbers upon the larger rugae and other parts of the mucous membrane. (Fig. 111.)

'The natural secretion of the cervical canal has been shown by M. Ionné to be alkaline, mnlike that of the vagina, which is aeill.

Pathology.-Cervical endometritis consists in inflammation of all this structure and consequent alteration of its condition. The mueous glands are especially involved in the morbid action, the disease chiefly consisting in glandular inflammation. The glairy mucus which is secreted in large amount as one of its symptoms is the characteristic discharge of these structures. Looked at with a strong glass in post-mortem examinations of this disease, they are seen enlarged and elevated, and, according to Aran, ${ }^{1}$ their mouths may be seen very much dilated. In some eases it becomes complicited by granular degeneration. The villi or papillae, especially those on the vaginal face of the eervix, become diseased. At first there is a loss of the normal supply of epithelium, which produces a slight and very superficial abrasion. This becomes in time more distinct and marked, from destruetion of the rilli themselves over spaces of greater or less extent. If this process of destruction should go on and affect the deeper tissues, a true ulcer would be formed, and no one would ever have denied the name of ulceration to the existing condition, but it does not thus progress. In time an hypertrophy occurs in the villi, which increase in size, projeet like so many hairs from the surface, and give to the os and eerrix an appearance which has caused the term granular degeneration to be applied to it. This state affeets the raginal portion of the cervix chiefly, but may extend up the canal.

Another pathologieal state, which is occasionally met with as a complication of cervical endometritis, is an eversion of the os and lower portion of the canal to such an extent as to keep up inflammation there by the friction of the membrane, thus exposed, against the floor of the pelvis. Some very obstinate eases are due to this eondition.

The diseased mucous membrane pours forth with great actirity large amounts of thick, tenacious mucus, which is loaded with epithelium and sometimes tinged with blood.

Predisposing Causes.-It is a matter of some moment that the etiology of this affection should be studied under two heads-predisposing and exciting. The former includes :-

Natural feebleness of constitution;

The existence of a caclexia, as tuberculosis or scrofula;

Imporerishment of the blood from chlorosis or other cause;

Prolonged mental depression;

Insufficfent nutriment ; 
Excessive lactation;

Frequent parturition ;

Subinvolution ;

Styles of dress which depress the uterus;

Want of exercise and fresh air.

These influences pither act injuriously upon the nerrous system, and thus interfere with the cireulation and nutrition of the lining membrane of the cervix ; or by directly disordering the vessels and nerves of the uterus render it ready for the establishment of disease by some cause which would have exerted no baneful eflect upon a woman in perfect health.

It may naturally be asked why some of these influenees should especially produce this disease. My answer is, that they do not do so. Sonetimes they cause chronic pneumonia ; at other times granular eyelids; at others follicular faucitis; and again at others chronic cervical endometritis.

Erciting Causes._C Chief among these may be enumerated :-

Displacements of the uterus, especially flexions;

Excessive or intemperate coition;

Tlie use of intra-uterine pessaries;

Puerperal endometritis ;

Acute non-puerperal endometritis ;

Exposure or fatigue affecting a subinvoluted uterus;

Efforts at production of abortion and prevention of conception ;

Vaginitis, specific or simple;

Obstructive dysmenorrlicea ;

Cervical polypi ;

Laceration of the cervix.

Many other causes might be enumerated : but these will suffice to show the nature of those influences which act as excitants of the risease. Many of those mentioned would fail to produce it in a uterus which had not been prepared for their action by depreciating constitutional conditions. When treatment is established for the cure of the disease, if it he inaugurated and pursued without regard to the predisposing causes, it will often prove inefficient or futile in cases which would yield to a plan that showed a reegnition of their importance. Appreciating higlly, as I do, the value of loeal tratunent in uterine affections, were $I$ in the management of the disease limited entirely to one kind-local or general-I do not hesitate to say that I would infinitely prefer the latter. A renoval fiom a city to the country, the use of mineral and vegetable tonies, plenty of good, nutritious food, the observance of regular hours, the systematie practice of exercise in the fres air, and the pleasures of cheerful society, will. I fiel confilent, do far more for the patient than a weekly visit to thr oflice of a plysician and the reception of the most appropriate local tratment which sciener can afford. But better than eitler plan is the julieious combination of the two. They should go hand in hand. My 
wish is to keep prominent the faet, that of the two the general treatment is the more important in the disease which now concerns us, as it is in many others which we shall come to consider.

Symptoms._Cervieal endometritis may exist for a length of time without presenting any symptoms of sufficient gravity to warn the patient of its presenee. Even a leucorrhoa, which is somewhat abundant, often fails to attract her attention. 'The answer to a question as to its existence will often be a negative one in cases in which the practitioner will, by the speculum, discover a considerable anount in the vagina. In the great majority of cases the liscase will soon announce its existence by some or all of the following signs. The first symptom which will attract attention will probably be dragring sensations about the pelvis. These will soon be foilowed by pain in the back and loins, which will be very much increased by exercise or muscular efforts. Then a more or less profuse leucorrhoa will be noticed, the discharge as it issues from the vulva resembling boiled stareh or thiek gum-water, and often irritating the vulva and vagina to such an extent as to produce inflammation in them. Menstrual disorders may now show themselves. The discharge may be either too scanty or too profuse, too frequent or too infrequent, and to a certain extent painful; sometimes, though not often, decided dysmenorrhoea will exist.

Usually before the disease has existed for a long period, the constitution of the patient will slıow signs of becoming implicated. She will become nervous, irascible, moody, and often hysterical. Her appetite will diminish and digestion grow feeble, so that impoverished blood will soon be observed as a result of imparired nutrition. With some or all of these signs of the existing disorder, the patient may continue for a length of time without suffering from others of more annoying or graver character. Complications may, however, rapilly develop themselves; eystitis, cervical hyperplasia, and vaginitis coming on and proving exceedingly troublesome. At times pain during sexual intercourse constitutes a prominent sign of cervical disease, but it belongs rather to cervical hyperplasia than to endometritis, the former having added itself as a complieation to the latter, and thus produced the symptom. Sometimes nausea, and even romiting, present themselves as symptoms, and these, together with the digestive disorder before mentioned, produce a deterioration in the nutrition of the patient.

Although these symptoms are enough to make us confident of the existence of uterine disorder, they by no means furnish reliable grounds for a positive diagnosis. This can be arrived at only by physical exploration.

Physical Signs.-The patient being placed upon her back, and the finger of the examiner introduced into the vagina, the os uteri will probably be found in its usual position in the pelvis, for the weight of the uterus is not increased, the connective tissue not being involved. The os 
may be somewhat enlarged and its lips slightly puffed, or it may be roughened on aecount of granular degeneration. Sometimes, however, severe cervical emlemetritis may exist without any enlargement of the os, or any trace of abrasion or gramular degeneration. If the finger be placed under the cervix and that part raised by it, pain will be complained of, though not to any great extent. 'This will be most marked opposite the os internum. Noother affirmative sign can be elicited by this means, and the sieculum should then be used. By this the os will be seen to be in the condition just described, and from it will be found to exude a long string of tongh, tenacious nueus which will closely resemble the white of egg. If entangled by a small mass of cotton attached to the end of a whalchone rol, it will be found to be so viscid and resisting that it cammot be drawn from the canal. It will resist even a stream of water thrown with some foree upon it, and very often is removed only after several efforts by this or other neans. 'The cervix will usually be found to be sonewhat enlarged. Its tissue may present a swollen, puffed appearance, or be intensely rerl as if in a state of granular degeneration, which will upon close inspection be found to be due to removal of its investing epithelimn and the occurrence of hypertrophy of the villi. Should this condition exist, it will afford relief to the mind of the inexperienced gynecologist, for the diagnosis of the ease will be clear. But another state of things may be discovered which will leave him in doubt. Upon removing the plug of olstructing mucus, he may discover no evidence of disease. The os is no larger than it should be, its tissue is not reddened, no degeneration exists, in fact nothing is found explaining the backache, nervousness, impaired nutrition, and frofuse lencorrhoea which led lin to alvise and urge the examination. The case is simply one of cervical endometritis which affects the glands of the canal withont having produced granular degeneration.

It is often a matter of great difficulty to decide whether endometritis is confined to the neck or extends througl this part into the body. In many eases a certain comclusion is impossible. The evidences by which it may be usually arrived at are these: in the former ease the neek alone is found enlarged and temler to touch, conjoined manipulation, and the probe; in the latter, the boly al shows these signs of implieation of its tissues in the morbirl action. The discharce resulting in the former is nore thick, trnacious, and diffienlt of removal than in the latter variety. Iastly, the constitutional symptoms attending the latter are ordinarily graver than thes: [reated by the former.

Conrse, Inuration, and Termination.-Cervical endometritis is not a self-limiting distaser, and consequently its duration will depend upon circumstances which control its progress. It may unquestionahly disalplear withcut molixal aid. Any alterative influence which exerts a complete clange in the economy, as, for instance, parturition, entire alteration of the habits 
of life, or some change equally decided, sometimes results in a cure. But it is certainly safe to say that, unchecked, it frequently passes, in multiparous women, into cervieal hyperplasia, which wonld probably draw in its train displacement, and all the long list of ailments which make the lives of women sutfering from uterine disease so burdensome.

Prognosis. - The prognosis of this affection will depend upon the degree of glandular disease accompanying it. If the mueus which marks inflammation of the glands be slight in amount, and not very tenacious in chatracter, whatever be the extent of coincident gramular degeneration, the prognosis is farorable. When, on the other hand, there is little granular disease, and a large amount of thick, resisting mucus hangs from the cervical canal, the prognosis, according to my experience, is very loubtful, and sometimes lopeless, unless very ralical measures be adopted. If every practitioner will look back into his experience, he will see that in all serere cases he las either been forced to resort, for their cure, to measures which absolutely destroy the diseased glands, or that the patients in time, wearied of his insnccess, have gone for treatment elsewhere. Let it be remembered that $I$ allude now only to rery serere cases where the glands are profoundly involved. In regard to such, I feel sure that the experience of others must agree with mine.

Even in minor cases great cantion should be observed as to fixing the time at which recovery will take place. Even in the mildest case which has lasted for some time, from four to six montlss will probably elapse before perfect curc can be accomplished, and even after this a relapse will be very likely to occur unless preventive measures be adopted and strictly adhered to.

Treatment.-The disease consisting in cervical endometritis, the efforts of the practitioner should be directed to producing an alterative influence upon a mucous membrane which is in a condition of chronic inflammation, and the avoidance of all influences which may cause it to spread to arljacent tissucs. These ends will be best accomplished by the following means:-

General regimen;

Emollient applications;

Alterative applications;

Ablation or destruction of the diseased glands.

General Regimen._-"The first care of the practitioner," says Sir Charles Clarke, "should be to remove, if possible, the causes of the disease. . . Women who live in a moist atmosphere, who keep bad hours, who spend much of their time in bed, or who inhabit hot rooms (being generally weak women, and having a relaxed ragina), will be apt to be affected by the complaint." All such unfarorable circumstances should be modified. If any depressing influence, such as lactation, any liabitual discharge, or 
any cause for mental anxicty, be discovered, it should be carefully removed, and, the patient, unless absolutely plethoric, be put upon the use of vegetable tonics, the mineral acids, and preparations of iron. The functions of the alimentary canal should be constantly supervised. The diet should be mild and unstimulating, but most nutritious. No system of starvation should be entered npon, for the tendency of the disease is to the production of spansmia, and this we should combat. A course of full diet is, on the contrary, often decidedly indieated; for, as I have elsewhere remarked, women commonly depreciate the vital forces by an unintentional starvation. Lnter these circumstances $I$ am often in the habit of preseribing the following course: the patient is directed to eat fresh animal food, eggs, butter, wheat, etc., three times a day at regular meal times. Then between breakfast and the midday meal to take either a tumbler of fresh milk, half a tumbler of cream, or a teacupful of beef-tea, and to repeat this fluid but highly nutritious repast between the midday and evening meal, and again when retiring at night. It is surprising to sce how of ten patients will rapidly improve in all their functions under this course. The digestion will improve and constipation disippear or become greatly ameliorated, and under the improvement in the tone of the nervous system sleep will become more profound and refreshing. All spices and stimulating condiments should be avoided. Every day, unless some special contraindication exist, the pationt should take fresh air and exercise, by carriage or on foot for a time, which should be limited by the eircumstances of the particular case. If she should be unable to do this from any cause, she should be thoroughly protected, and pure air, even in winter, be allowed to circulate freely in her chamber, all the doors and windows of which should be opened for two or three hours daily. This plan, which is suggested by Prof. Byford, of Chicago, I have found a most excellent one. The bowels shonld be kept regular by saline cathartics, and the skin in proper state by occasional baths. Care must be observed not to depreciate the strength by catharsis, and, to prevent this, a ferruginous tonic may be advantageonsly combined with a cathartic, as in the following mixtures :-

R. Magnesize sulphatis, 弦.

Ferri sulphatis, gr. xvj.

Acidi sulphurici dil. $3 \mathrm{j}$.

Aquæ, Oj.-.II.

On: ounce (two tablespomfuls) in a tumbler of iced water every morning upon rising.

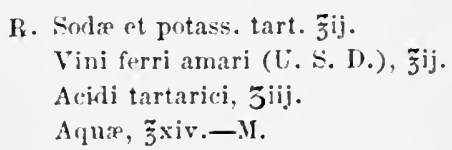

One ounce in a immbler of iced water ever morning upon rixing. 
Should one draught not be sufficient, two or even three may be taken daily, for the result will prove tonic and reparative as well as cathartic.

If mnch disturbance of the nervous system shonld exist, the bromide of potassium in doses of five to ten grains, three times a day, will be found very useful.

The appetite and digestion are so often impaired that special attention will generally have to be directed to alleviation of that collection of symptoms which are gromed under the head of dyspepsia. The stomach sympathizing with the nterus does not perform its functions with vigor; the gastric juices appear to be wanting or inefficient, and fermentation of the food often takes the place of digestion. Under these cirenmstances I can recommend from lengtlyy experience with it the following digestive tonic:-

\author{
B. One rennet, washed and chopped. \\ Sherry wine, $\mathrm{Oj}$. \\ Macerate for twelve days, then decaut, filter, and add- \\ Dilute nitro-muriatic acid, $3 \mathrm{ij}$. \\ Tinet. of $n u x$ vomica, $3 \mathrm{ij}$. \\ Subnitrate of bismuth, $3 \mathrm{ij}$.
}

One tablespoonful in a quarter of a tumbler of water before each meal.

This prescription combines the tonic properties of nux vomica and the peculiar alterative influences of bismuth, with a fluid which resembles the gastric juice. In many cases of habitual indigestion I have obtained from it the best results.

Emollient Applications. - The cervix should be irrigated every night and morning, by warm water thrown against it. To the water may be added chloride of sodium, glycerine, boiled starch, infusion of linseed, slippery elm, or tincture of opium. The irrigation shonld be so planned as to last for ten or fifteen minutes without fatiguing the patient or proving a source of annoyance to her. The methods for doing this are so fully described elsewhere that they need not be repeated here.

In many cases of this affection of not very aggravated character, and which have not advanced to the production of granular degeneration or hyperplasia, if this plan of general tonic treatment and soothing injections be faithfully carried out, all complaints will cease on the part of the patient, and a cure be gradually effected. Should this result not be attained, or should the disease be discovered at the first examination to have profoundly involved the cervical glands, resort must be had to applications to the diseased surface through the speculum.

In cases in which the lining membrane of the cervix is in a condition of granular degeneration, and the mucous glands are very little affected, cure can be almost as readily accomplished as where the same granular disease exists on the vaginal face of this part. But such cases will be treated of under the caption of "Granular Degeneration of the Cervix ;" 
they do not properly come under consideration at the same time with the more obstinate disease of the glands. To make this statement more elear; cervical endometritis consists of glandular inflammation, which is sometimes complicated by granular degeneration. In some cases the glands are very slightly diseased, while the villi of the canal are decidedly so; these come under consideration rather as "Granular Degeneration," which will be treated of elsewhere, than as true endometritis.

Alterative Applications. - It will be found that cervical endometritis, existing in a canal the os externum of which is contracted, will always prove much more difficult of cure than in one where this part is dilated. The degree of dilatation will generally be found to exert a marked influence over the tractability of the case. When then it is discovered that the disorder does not disappear under the influence of time, and the sim. ple measures already mentioned, as one of ordinary eatarrh, it is always advisable to dilate this part before proceeding with more decided measures. If this be neglected, and the practitioner satisfy himself with prassing through the constricted orifice, nitrate of silver, ioline, pencils of zinc, alum, iron, etc., once or twice a week, no good whatever will result. After months or even years of treatment, he will discover that the mild means whieh he has adopted have left the disease uncontrolled; or that the severe ones have increased contraction of the os, which renders menstruation difficult and painful.

The best and simplest method for overcoming the difficulty is to snip the external fibres of the os by scissors for an eighth of an inch, touch the raw surfaces thus made with nitrate of silver or solution of persulphate of iron to prevent union, and keep plugs of carbolized cotton in the canal for a week. Should there be any objeetions to this procedure, which is painless, free from danger, and effectual, the same thing may be imperfectly accomplished by repeated dilatation by metallic sounds, or by the use of a tent of sea-tangle or sponge. The use of a tent which dilates the os extrmum, not passing within the os internum, is to a great extent free from the dangers attaching to those which invade the body. The os ex-

FIG. 112. •

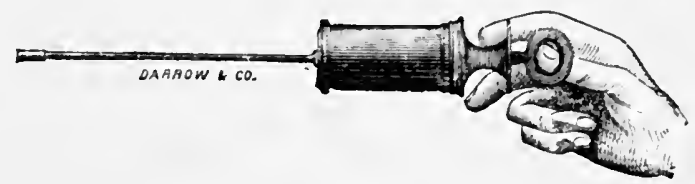

Syringe for removing cervical macus.

trinum having been dilated by one of these methods, the first if there be 111) special (bljection to it, so that free escape of the secretion of the muciparous glands may occur, the canal must be thoroughly cleansed. Unless this be systematically done it will be imperfectly accomplished, and the 
thick, tenacious material will completely shietd the diseased gland and neutralize any chemical agent before it ean reach them. 'Tlo: most oflicient means for removing this phug is the syringe represented in lig. 112. It is a syringe of hard rubber, two inches in eirenmference, holding an ounce, and so arranged as to be worked with one hand, the index and middle fingers surrounding the neck, and the thumb retracting the piston. L pon the extremity of its long pipe is slipped a bit of gutta-pereha tubing, the firee portion of which projects half an inch. 'This free portion readily enters the cervix, and goes up to the os internum. When introduced, the piston is powerfully retracted, the mucous plug is sucked in, and the cervix is left entirely clean.

Where the material which covers the os is purulent or starchy, and not tenacions, a stream of water may be projected from this syringe against the ecrrix, and the whole be removed by suction; or this may be done by a small pledget of carbolized cotton wrapped around a staff of whalebone, hickory, or bamboo, eight incles long, as thick as a pipe-stem, and tapering towarl its extremity. Should the first pledget become saturated, it can realily be slipped from the staff" and another wrapped in its place, or several rods may be prepared and kept ready for use.

FIG. 113.

Rod eight or nine inches long, wrapped with cotton.

When the characteristic plug of tenacious mucus is present, there are but two methods which entirely remove it : one is the exhausting syringe; the other the use of a dry sponge as large as a raspberry fixed in a longhandled sponge holder, or held in long dressing forceps such as those shown in Fig. 2, and passed into the cervical canal and rotated so as to entangle the thick mucus. The sponge should be thrown away afterwards, for the repretition of its use might convey disease from one patient to another. A supply of such small pieces of sponge should be kept at hand, in order that a new one may be used for each patient. After having been cleansed by one of these methods, the cervical mucous membrane is exposed, and applications can be made to it witl some prospect of their coming in contact with the diseased glands embedded in the jungle of convolutions which constitute the arbor vita. A neglect of the systematic removal of this material, I believe often prevents cure, and lience I am so minute in reference to what may appear an insignificant point.

It is a fact, universally admitted in every department of therapeutics, that certain substances of greater or less strength as escharotics have the property, when applied to inflamed mucous surfaces, of so modifying the morbid action existing in them as to diminisl its intensity and in time to clicek its progress. It is upon this principle that chronic inflammations 
of the fauces, urethra, bladder, and many other mucous surfaces are treated, and it is equally applicable to the part which we are considering. Alterative and escharotic substanees may be applied to the lining membrane of the cervix uteri in the following ways: by painting solutions over the canal by a brush or dossil of lint, by touehing the whole diseased area with drugs in solid form, or by leaving them for varying lengths of time in contact with the walls of the eanal in a solid form, or upon cotton which has been saturated with solutions of them.

Should the case be one of short standing and of no great degree of severity, the cervical canal should be thoroughly painted over with the compound tincture of iodine, a strong solution of nitrate of silver, glycerine saturated with tannin, or a saturated solution of carbolic acid. This may be done by using a brush of pig's bristles, which is far superior to one of camel's hair ; or, by wrapping cotton around a delieate probe of silver or whalebone and saturating this with the solution. Emmet's silver or Budd's vulcanite probe answers an excellent purpose.

FIG, 114.

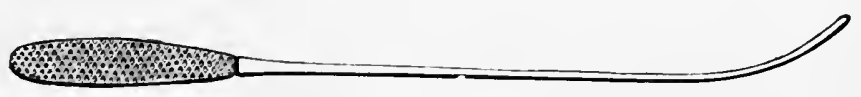

Budal's elastic probe.

Should the practitioner prefer to use a solid caustic, the nitrate of silver may, with great advantage, be employed, though the means generally adopted for applying this substance are inefficient. If a straight stick of lunar caustic be fixed in a quill or held in the grasp of a pair of foreeps and passed into the os, by no possibility can the procedure aceomplish what is desired. It may cauterize, and will probably do so with ohjectionable thoroughness, a guarter or half an inch of the lower portion of the canal; but how can it be expeeted to go upwards for an ineh and a guarter and come in contact with the whole surface inflamed, a surface remarkable for its inequalities and convolutions? Sir Benjamin Brodie many years ago, according to Dr. Barnes, of London, alvised fusing nitrate of silver and allowing it to cool upon the tip of a probe for eauterizing sinuous tracts; and Chassaignae, of Paris, applied the same substance to the eavity of the womb by coating platinum wires with it. Dr. F. D. Lente, of Cold Spring. N. Y., has experimented extensively in referenee to this subject, and the result of his investigations lats been to furnish the profession with the best and most reliable of all the means at our command for applying solid lunar caustic to the mucous lining of the uterus. Other methods which have been suggested and employed are these: the use of Lallemand's porte-canstique; leaving a pellet of nitrate of silver in the uterine cavity to dissolve; carrying up a small piece held in a delicate wire casing, etc.; but none of these compare with 1)r. Lente's, 
which is thus practised. $\Lambda$ probe, somewhat similar to the ordinary uterine probe, is warmed and then dipped in a little platinum cup that contains nitrate of silver which has been fused over a spirit-lamp. Removing the probe after dipping it, and waving it for a few seconds, a film of the nitrate will be found to have eovered its tip. It may then be again dippet, and the process repeated until a sufliciently large pellet is mate to cover the end of the instrument. Figs. 115 and 116 represent the probe and cup.

FIG, 115.

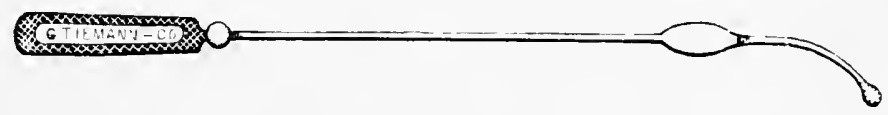

Lente's silver caustic probe.

FIG. 116.

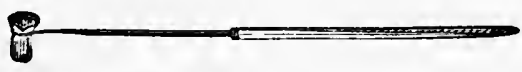

Lente's cup for fusing nitrate of silver.

The cervical canal having been cleansed of mucus, and its direction learned by the ordinary probe, Lente's probe is passed up and rubbed against every part of its investing membrane, and dipped as carefully as possible into its convolutions before removal.

After such an application, a stream of water should he projected against the cervix, and a pledget of eotton, which has been freely saturated with glycerine, with a bit of thread attached, should be placed against it. By means of the thread this may be removed by the patient in twelve hours.

The walls of the cervical canal may also be thoroughly eauterized by the introduction and retention of Braxton Hicks's crayons of sulphate of copper, iron, zinc, or alum east in a mould of the length and size of the camal. The gelatine crayons of Chamberlain also answer very well. They are introrluced into the cervieal canal and kept in sit $\hat{u}$ by a roll of cotton. The zinc points may be allowed to dissolve, as they give no pain in doing so. Those of iron, alum, and copper should have a thread attached by which the patient may remove them when they eanse discomfort.

Alteratives in combination with cocoa-butter may be made into suppositories two inches in length, and left in the cervical canal. Into these cervieal suppositories may be introduced zinc, copper, iron, lead, or bismuth, with opium, conium, or hyoscyamus.

Fig. 117 represents an instrument, originated by Dr. Sims, which consists of a silver probe surmounted by a slide, by means of whieh a roll of cotton soaked in any medicated solution may be left within the eervical eanal.

Two inches of the probe are wrapped with cotton whieh is soaked with 
the solution selected, and then passed into the cervical canal so as to be engaged within the os internum. The roll of medicated cotton is then slid

FIG. 117.

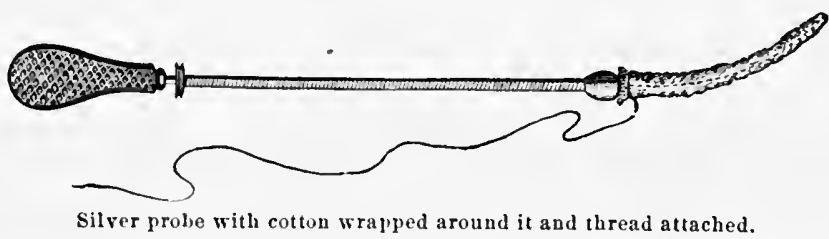

off by the slide and retained within the eanal, while the probe is withdrawn. In twelve hours the patient makes traction upon the thread attached to the cotton and it is removed.

Destruction and Ablation of the Diseased Glands.-As every gynecologist must have found out by annoying experience, there are cases of this affection which prove incurable by any and all of these means. They are instances not of granular disease, but of aggravated inflammation of the mucous follicles. It is in these cases that a long, glairy, and extremely tenaeious plug of mueus is seen hanging from the os externum, which it is often found almost impossible to remove eompletely. Month after month they tax the ingenuity and perseverance of the practitioner, and at the end of his efforts they seem as aggravated in character as they were betore. Under these cireumstances but one resource remains, that is to fulfil the indieation which is so often elsewhere adopted in surgery, to destroy or remove the habitat of a disease which is not susceptible of eure. This laas been done by some, by the use of potassa fusa and the actual cautery, but against both I wouk strongly advise, for they produce a great deal of subsequent eicatricial contraction. Dr. John Byrne intorms me that he introdnees with good effect an electrode of the galvanic cantery, which fits the canal, to the os internum, and then by establishing a eurrent makes it white hot. I know nothing of the plan personally.

One of the best chemical agents for destroying the glands is fuming nitric acid. This should be carefully applied to the canal by means of a film of cotton wrapled around the silver probe, after the caual has been thoronghly cleanser. After its use, a stream of cold water should be thrown by the syringe against the cervix, and a wad of cotton saturated with glyeerine applied. In ten days or a fortnight a slongh of the cervical nucous membrame will take place, after which the surface should be painted over twice a week with a solution of nitrate of silver $\exists \mathbf{j}$ to water $\tilde{\tilde{j}} \mathrm{j}$.

Another good caustic is a saturated solution of chromic acid, which, though not nearly as powerful as the nitric acil, answers very well.

These are the only agents which I would reeommend for this purpose. Nitrate of silver is not suthiciently powerful, and potassa fusi and the actual cautery are too destructive in their results. 
In alluding to these cases Dr. West' says: "I am disposed to think, however, that in the most obstinate cases it may be expedient to alopt a suggestion of M. Inguier, of which I have but small experience, though I have followed it with benefit on two or three oceasions. He is accustomed to searify the interior of the cervical canal with a small, curved, narrowbladed, blunt-pointed bistoury before introducing the caustic. 'The previous scarification exposes the more deep seated follicles, which would otherwise altogether eseape the action of the remedy; and, while $\mathbf{M}$. Huguier states that he las never known any mischief follow this proceeding, he has by its repetition two or three times effected the cure of cases that resisted every other mode of treatment."

In these very obstinate cases I have repeatedly resorted to a surgical procedure which accomplishes the removal of these glands, and which I lave never seen followed by subsequent contraction or inflammation.

This consists in the application of the cutting steel curette, represented in Fig. 118, so forcibly as to remove the arbor vita and mucous glands

Fig. 118.

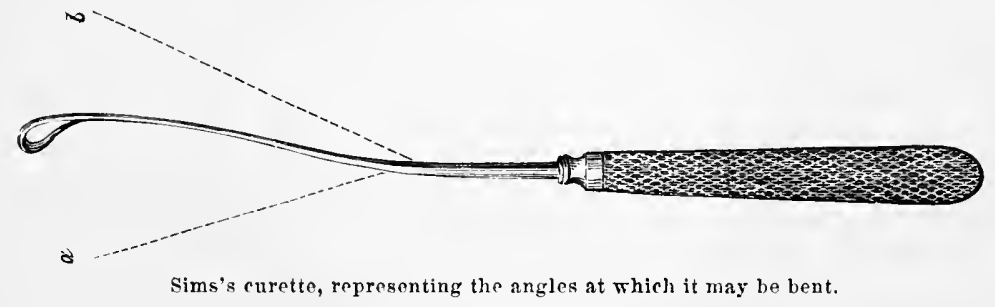

from the os internum to the os externum. Sometimes a second operation in two or three weeks after the first has been necessary, and sometimes even a third. By this means I have succeeded in curing some most obstinate cases which had resisted cure by all other means except the destruetive canstics to which I have alluded. The use of this method should be looked upon as an operation, and the patient guarded just as carefully against inflammation as she would be after section of the neck or any kindred procedure. I am fully aware that there are many who will at once characterize this procedure as harsh and unnecessary, but as I feel certain that it is neither, and as $I$ have lad experience enough with it to know that it meets the requirements of a class of cases which are incurable by other means, I strongly press its elains to a fair trial. This operation is not parallel with the application of the eurette to the body of the uterus for vegetations. It consists in what is equivalent to amputation of the glands, and is the counterpart of removal of the follicular surfaces of the tonsils when chronic inflammation of the follicles proves incurable. Extended experience with it in these otherwise intractable cases leads me to preserve my appreciation of its value. 


\section{CHA P TER XIX. \\ CHRONIC CORPOREAL, ENDOMETRITIS.}

LIKE the cervix, the body of the uterus is liable to ehronic inflammation confined to its lining mueous membrane. This receives the name of chronic corporeal endometritis.

Symonyms._This disease has been described under the names of cndometritis, uterine catarrh, uterine leucorrhoa, and internal metritis. The precise seat of the affection is pointed out by the dots in Fig. 119.

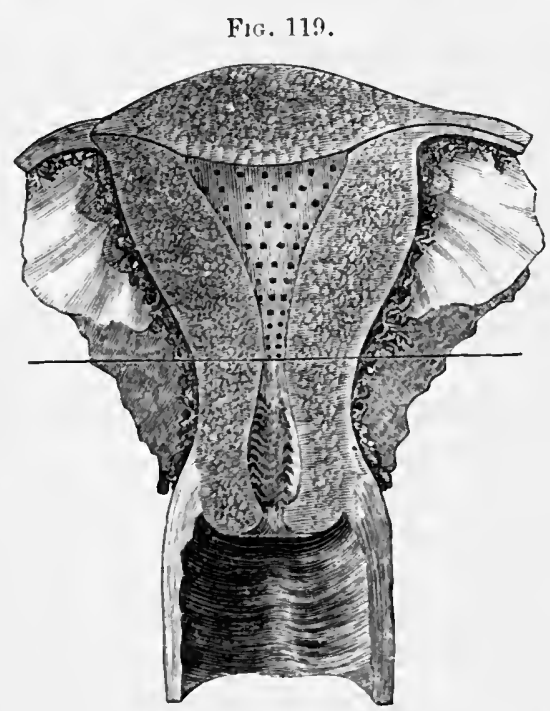

The dots show the site of corporeal endometritis.

Frequency._Few points in uterine pathology lave ereated more discus. sion of late years than this. Some excellent atthorities, following the lead of Dr. Henry Bemnet, regard it as of rare oecurrence, while a large majority eunsider it quite common. "Internal metritis," salys Aran, " is more frequent, nevertheles, in spite of all that has heen said to the contrary, in the eavity of the borly than in the cavity of the neck of the womb;" and this opinion is concurred in by Dr. West and others. To slow how unsettled this point is in the present state of pathology, let me

1 Mal. de l'Utérus, p. 40 . 
eontrast with this statement that of Prof. Byford, ${ }^{1}$ of Chicago, in his execllent work on Medical and Surgical Treatment of Women : "Inflammation limited to the cavity of the body of the uterus is not common, but I an cquite sure that I have met with at leatst two instances." While Dr. Byford's experience furnishes him but two instances, Dr. 'Tilt gives the statisties of fifty cases of which he has kept notes, and Klob declares the disease to be quite common.

The more industriously the student of gynecology interrogates the literature of this subject, the more unsettled are his conclusions likely to be, and unfortunately his own investigations, however carefully conducted, will often fail to enlighten him in the individual cases with which he meets, for the differential diagnosis between cervical and corporeal endometritis is often very difficult. My own opinions upon this important point I shall state freely, unbiassed by those of authors for whom I entertain the highest respect, but whose conclusions conflict with what I have earefully observed at the bedside.

The most frequent locality of uterine inflammation is that portion of the uterus below a line running across it through the os internum. The portion of the organ above this line, however, is much more eommonly affected by inflammatory disease than is stated by Dr. Bennet. During eighteen months I met, in private practice alone, nine well-marked and unquestionable cases, and with several more in which I could not satisfy myself as to the exact limit of the disease. The lining membrane of body and cervix may be sinultaneously affected, but this is the exception and not the rule; generally we find one or other portion of the organ the seat of disease. In making this last assertion I am fully aware of its importance, and of the fact that it will be dissented from by a great many. But feching eonvinced, as I do, that upon its non-recognition depends a certain amount of the obscurity attending the differentiation of disease of the neck and body, $\mathbf{I}$ wish to fix the attention of the reader upon it.

Anatomy.-If the mucous membrane of the uterus be examined with a lens, it will be seen to be studded with minute openings somewhat similar to the mouths of the glands of Lieberkiuhn in the intestines. These are the mouths of long, curling follicles, which project by their closed extremities downwards towards the parenchyma of the organ. They are lined by delicate epithelium, their lining membrane consisting merely of involutions of that of the uterus. These glands are of two kinds: the simple, which are unbranched tubes; and the compound, which have several branches. Besiles these glands there are intermixed with them mucous erypts, which sometimes beeome distended so as to form the so-called " channel polypus."

between these glands ramify numerous eapillaries, which dip down and 
form a network about their mouths so superficial that they are sometimes seen by a strong glass completely uncovered, and even projecting like villi into the cavity.

Pathology._Corporeal endometritis is, like the same affection in the cervix, a glandular disease. The utricular follicles are the seat of disorder, and it is to the exaggeration of their secretory function that is due the uterine leucorrhou which constitutes one of its prominent symptoms.

The post-mortem appearances of the mueous membrane are these: it is found to be swollen, soft, pale, and smooth, or covered over with granulations. In cases which have lasted very long, the utricular glands are in great numbers obliterated, or, atrophy having taken place at their mouths only, their secretions are retained, and they are distended into cysts. In time the mucous membrane is replaced by a thin layer of connective tissue, which is covered not by eylindrieal or ciliated epithelium, but by what resembles that of basement character. At times small mucous polypi are found in the eavity, while at others, a closure of the os internum uteri having been effected by adhesion, hydrometra exists.

I have had three opportunities for examining post mortem into the pathology of this disease. Two of these eases were presented to the Obstetrical Society of this city. In these instances the condition described by Scanzoni was most evident. The uterine cavity was found considerably enlarged, its walls diminished in thickness, and in one instance they were pronounced by Dr. J. B. Reynolds, after microseopical examination, to be in a state of fatty degeneration. The uterine neck was in every case found healthy both as to parenchymatous and mucous structure, and the enlarged body displaced by anterior or posterior flexure. The mucous lining of the body was in two eases quite smooth, and to a great extent deprived of epithelium; while in the third it was roughened, and presented points where the enlarged bloodvessels created a number of reddish spots. But enlargement of the uterine cavity is not always present; it marks chronic cases, and will not be recognized in those of recent origin. It is highly probable, too, that in eases of recent origin the pathological appearances which have been here deseribed would not be found to exist, but in place of them a thickened, congested, and florid appearance would present itself:

I'rognosis.-The prognosis of chronic inflammation of the uterine body is always grave with reference to cure. Even if the case be not of very serious character, and have lasted only a short time, the possibility of rapid recovery is doubtful, while, if it have continued for a number of years, it will often prove incurable. Scanzoni' says, with a candor which does him honor: "As for ourselves we do not remember a single ease where we have been able to eure an abundant uterine leucorrhou of several years' standing." In most cases a certaiu amount of amelioration may be

'Scanzoni, Diseases of Females, Am. ed., p. 202. 
effected even when they are of long standing; in a certain number trated early, eure may unquestionably be accomplished; while in a great many, nothing whatever, either in the way of cure or of relief, can be obtained, and the patient, after passing from physician to physician, settles down into a carefial mode of life, resolved to ceasc treatment and bear as best she may an evil which she has learned to regard as incurable.

The symptoms of a favorable and unfavorable case of corporeal endometritis may be thus contrasted :-

Progxosis is Fayorable witen

The case is of recent standing ;

The discharge is of mucts or blood; Dysmenorrheal shreds are not cast off ; Patient naturally of strong constitution ; Comective tissue is not affected ;

Dimensions of cavity are not increased;

Nervous system is not involved;

Patient near menopanse.
Prognosis is Uxpayorable whex

The case is of long standing;

The discharge is purulent;

Dysmenorrhœal shreds are cast off;

l'atient naturally of feeble constitution ;

Connective tissue is affected ;

Dimensions of cavity are decidedly increased ;

Nervous system is involred;

Patient not near menopause.

Predisposing Causes.-It has been noticed most frequently to have developed itself in women showing a tendency to the following conditions:-

Scrofula;

'Tuberculosis ;

Spanamia ;

Exhaustion from parturition;

Exhaustion from lactation;

Great and prolonged nervous depression.

Exciting Causes.-These may be enumerated as follows :-

Exposure during menstruation ;

Sudden checking of the menstrual flow;

Obstruction to escape of menstrual blood;

Abortion and parturition ;

Cervical endometritis ;

Acute endometritis, puerperal or not;

Subinvolution ;

Displacements causing great eongestion ;

Chronic pelvie peritonitis ;

Abuse of sexual intereourse :

Injury from sounds or intra-uterine pessaries, and injuries resulting from attempts to produce abortion;

Certain hemic conditions, as those aceompanying phthisis and the exanthematous diseases ;

Tumors in the uterine cavity or walls;

Vaginitis, specifie or simple. 
It is quite elear how either of the first two causes, in cheeking hemorrhage from the eongested mucous lining of the uterine body, may at once induce the first stage of the disease. They generally result in the acute variety, which passes off rapidly, but which sometimes ends in the chronic form.

Obstruction to escape of menstrual blood is a very fruitful source of the affeetion. The menstrual blood, if it pour at once into the vagina, remains fluid from allmixture of an acid mucus secreted by the lining membrane of that canal; but if it be imprisoned in the uterine cavity, where only an alkaline mueus exists, it very soon becomes elotted. These clots are too large to pass through a cervix of normal dimensions, and, of course, cannot escape from one unnaturally constrieted. Their presenee in the uterine earity, together with that of blood which they imprison, in time exeites contraction, by which they are expelled. This repeated dilatation anil contraction eannot last long without exciting inflammation in the mucous membrane of the uterus. Such an obstruction may have as its cause a small polypus which acts as a ball valve at the os internum, congenital or acquired narrowness of the cervical canal, or uterine flexion.

The parturient process is a very frequent source of the disease, especially where the undeveloped placenta is prematurely separated from its uterine connection. Where, in a prolonged labor, the early evacuation of the liquor amnii leaves the irregular outline of the body of the clitd pressing against the uterine investment for many hours, sueh a sequel might result.

Of cervical inflammation as an exciting cause Dr. Bennet ${ }^{1}$ thus expresses himself : "It" (corporeal endometritis) "appears, however, to be generally met with in practice as the result of the lengthened existenee of inflammatory disease of the cervix and its cavities. The inflammation gradually progresses along the cavity of the cervix until it reaches the os internum, and passes into the uterus." I have already stated my dissent from this view, although, at the same time, I admit that it may be correet.

Aeute endometritis may, instead of subsiding entirely, very naturally run into this disease.

Subinvolution of the uterus keeps up a eonstant tendency to hyperomia of the parenchyma which affects the mucous membrane. As a complieation of this condition corporeal endometritis is more commonly observed than as a consequenee of all the other causes combined.

Pelvic peritonitis disturbs the position, the innervation, and the cireulation of the uterus, and proves a fruitful souree of endometritis.

The effect of sexual intereourse as a eausative influence is frequently observed soon atter marriage, the first connubial approaches exciting 
uterine congestion with greater or less intensity. Dr. 'Tilt' renarks with reference to it: "It is useless to disguise the fact, connection hats a downright poisonous influence on the generative organs of some wonen." I camnot believe that the Almighty has ordained a function as essential to the perpetuation of our species which has a downright poisonous influence on the generative organs of a healthy woman. And yet, to a certain extent, the statement is correet, for upon a woman who has enfeebled her system by habits of indolenee and lnxury, pressed leer nterus entirely out of its normal place, and perhaps goes to the nuptial bed with some lurking uterine disorder, the result of imprudence at menstrual epochs, sexual intercourse has indeed such an influence. The taking of food into the stomach exerts no injurious influence on the digestive system, but the taking of food by a dyspeptic who las abused and injured the organ may do so.

Injuries from sounds, etc, act so evidently in exciting inflammation as to need only mention.

Certain conditions of the blood sometimes produce acute corporeal endometritis, which, as already stated, may pass into the form under consideration. As a complication of the exanthematous diseases, endometritis is well known, and its occurrence with phthisis has been noted by Dr. Gardner in the American edition of Scanzoni. Every practitioner must have noticed it in connection with that affection.

Tumors in the cavity or walls of the uterus very generally produce this disease in consequence of the congestion of the mucous membrane which they cause.

Vaginitis of non-specific character may, and of specific form often does, pass by continuity of structure into the neck and body of the uterus. The latter has in these cases in my experience not only affected the body, but the Fallopian tubes, resulting in peritonitis.

Symptoms.—The symptomatology of corporeal endometritis constitutes one of the most unsatisfactory and obseure subjects in the entire field of gynecology. At times its symptoms are so slight and at others so misked and obscure, that the disease often runs a lengthy course without exciting the suspicions of either physician or patient. Its effects upon the constitution also differ most maccountibly in different cases. Sometimes the disease will continue for ten, fifteen, or twenty years, producing profuse lencorrhcea, menstrual disorders, and nervous derangement, and yet result in no amnoyance so grave as to cause the patient to seek medical aill. At others it accompanies or excites areolar hyperplasia, which induces displacement and causes pain on locomotion, sexual interconse, and the passage of feces through the rectum ; or results in an ichorous discharge, which creates the annoying symptoms of vaginitis, eystitis, or pruritus 
vulra. The chief symptoms which usually present themselves in a case of mucous inflammation of the uterine body are-

Leucorrhœa ;

Menstrual disorders;

Pain in the back, groins, and liypogastrium;

Nervous disorders;

Tympanites ;

Symptoms of pregnancy ;

Sterility.

Profuse lencorrhoea of glairy character is one of the chief signs of the affection. This when very tenacions and thick is the product of the cervical glands, but the lining membrane of the uterus likewise secretes a similar fluid, differing from it chiefly in possessing the qualities mentioned in a very much less marked degree. But uterine leucorrhœa differs from cervical in other particulars; it is often more or less mixed with blood so as to have a rust-colored appearance, especially for a fortnight after menstruation. This, Dr. Bennet ${ }^{1}$ looks upon as being " as characteristic of internal metritis as the rust-colored expectoration is of pneumonia." It is a reliable and valuable, though by no means a universal, sign. Sometimes the menstrual discharge is regarded by the patient as greatly prolonged, when in reality it is this blood-stained leucorrhœa which follows the process of menstruation, that gives rise to the belief. In some instances the discharge is milky, and at others, and these are the most rebellious cases, perfectly purulent. There is a variety of corporeal endometritis which occurs in old women who have long ceased to menstruate, in which a watery or creamy pus is secreted. These cases are often accompanied by the most wearing and harassing pruritus vulve.

IIenstrual disorders are rarejy absent. The discharge is sometimes too profuse, even lasting throughout the month and constituting menorrhagia, or it is very seanty, and shows a marked tendency to cessation.

Where the connective tissue is entirely unaffected, menorrhagia may occur without pain, but this is not common, for that tissue is often simultaneously involved and dysmenorrhora coexists. Sometimes in these cases, an exfoliation of the entire lining membrane of the cavity of the uterine body occurs at the menstrual periods. This has received the name of the dysmenorrhoal membrane, and is by some regarded as an evidence of chronic corporeal endometritis.

Pain in the back, groins, and hypogastrium is generally present, and at times a burning sensation over the symphysis pubis proves a sonree of great disconfort.

Nervous symptoms of greater or less severity generally show themselves before the discase has lasted long. The patient complains of neuralgic

$$
1 \text { op. cit., p. } 76 .
$$


headache, especially over the crown, hysterical symptoms, with sarhess, tendency to weep, and a feeling of intense isolation and incapacity for any mental effort.

Meteorism is a very common symptom, the connection of which with inflammation of the uterine nucous membrane is not, at first glance, clarar. It is probably due to disorder of the nervous influences governing peristalsis and giving tone to the intestinal muscular tissue, which proceeds to such an extent as to result in accumulation of gases in the canal. In the same way this affection may induce constipation, which is often one of its most obstinate accompaniments.

Symptoms of pregnancy of ten exist in connection with the disease, and sometimes mislead the physician. Nausea and romiting are by no means invariably present, but are valuable signs. They appear to result from this disease as they do from occupation of the uterine cavity by the product of conception. Sometimes, in addition to these, there are darkening of the areola of the breasts, and enlargement and sensitiveness of the mamnary glands. When to these are added abdominal enlargement, from tympanites and irregularity of menstruation, it will be perceived how easily an error might be made.

Sterility is so commonly a result of endometritis that it should be considered as one of its signs. Very often it has been the only symptom that has led to an investigation of the state of the uterus which has determined the existence of the disease. The affection does not, however, preclude the possibility of conception; it only diminishes the probability.

Physical Signs. - The plysical signs are neither numerous nor reliable. Those of real value only will be mentioned. The uterine probe passed into the cavity will often show the length of the uterus to be greater than it would be in health, and create more discomfort than in a healthy uterus. Upon conjoined manipulation, two fingers being placed in the fornix vagina, and the fingers of the other hand made to depress the anterior wall of the abdomen, sensitiveness will usually be found in the body of the organ. The recognition of the absence of cervical disease, while at the same time there are profuse uterine leucorrhœa and the other symptoms recorded, will lead us strongly to suspect corporeal endometritis. Lastly, dilatation of the os internum may be taken as a corroborative sign.

Course, Duration, and Termination.-This disorder often lasts for years ; in the case of a nulliparous woman coufining itself to the mucous membrane; in that of a woman who has borne children gradually exciting congestion and exuberant growth in the subjacent parenchyma. This is the most frequent result exerted upon the parenchyma, but it may be affected in two ways: 1st, a hyperplasia, or excess of nutrition, may occul' ; $2 d$, an aplasia, or want of nutrition, may take place, and dilatation and distention eventuate. 
Complications.-The most ordinary complications met with are displacement, vaginitis, granular degeneration of the cervix, and pruritus vulva.

Treatment.-Special attention should be given to sustaining and improving the general health of the patient, which will often show a marked tendency to depreciation. Good cliet, fresh air, systematic exercise, and avoidance of all eircumstances calculated to depress the spirits or harass the mind, should be recommended. If practicable, ehange of air and scene should be brought to our aid, and the patient be sent occasionally to some suitable watering-place or country resort. The healthy condition of the nervous and sanguineous systems will be fostered by these measures, and should medicinal tonics be required, iron, the mineral acids, quinine, the bromide of potassium, or nux vomica may be administered. All rich ancl highly spiced food should be avoided, and the patient should be gnarded against habits of indolence and luxury which tend to exhaust the nervous strength.

The uterus should be placed at rest by removal of pressure upon the fundus by elothing, limitation of marital intercourse, avoidance of violent and intemperate exereise, and if necessary, by a sustaining pessary. Should absolute displacement exist, it should be carefully reetified; should laceration of the cervix exist, it should be repaired; and in case uterine enlargement or subinvolution be present, ergot in small doses should be systematically administered.

Applications to the Cterine Cavity.-Upon theoretical grounds direct applications to the diseased endometrium would hold out a brighter promise of cure in these cases than any other plan of treatment, and during the past quarter of a century it has become the conventional habit to recommend them. In this habit I have shared until eloser observation and enlarging experience during the past five years have led me to become sceptical as to the utility of the course. Observation and experience have so changed my own practice that I find myself very rarely resorting at present to applications above the os internum uteri. That they may become necessary in certain cases $I$ do not at all deny; but I maintain that they should not be habitually resorted to: 1st, because they very generally fail in curing the disease; and, $2 d$, because they are by no means voill of danger.

That a certain number of cases of pelvic peritonitis and cellulitis are created by these applications all must admit. In spite of this fact their use would be deedledly indicated were their results very promising. But in my experience their results are not promising, and for this reason I have given up their general use. I shall nevertheless describe the methorls by which sucli applications should be made as fully as possible.

liecamier was the first who harl the boldness to eauterize the cavity of the nterus, which he did by means of nitrate of silver in an ordinary 
porte-caustique. The practice thus introduced was continued and spread abront by Robert, Richet, Trousseau, Maisonneuve, and others, and to-diay is still commonly resorted to. There are four methods by which it may be practised: 1st, by the use of solutions painted over the surface; $2 \mathrm{~d}$, by ointments left to melt in utero; $3 \mathrm{l}$, by injections of fluid into the cavity of the body; 4th, by solid caustics. In commencing treatment the practitioner should see that the cervical eanal is well opened, in order to admit the free escape of fluids from the cavity ahove, and the application of substances through it from below. This perviousuess, if it do not exist, should be secured by the use of dilators before the local treatment is proceeded with. If the uterus be found sensitive to vaginal and reetal touch, the patient should remain in bed for some days before the first application is made, the bowels be kept actire by mild saline purgatives, and warm baths or hip-baths with copious vaginal injections employed. If the operator use the ordinary long, cylindrical speculum, he will in the majority of cases fail to accomplish the end in view, reaching the fundus uteri, for through such an instrument, it is always difficult to penetrate so high into the cavity. If, however, he uses the Sims speculum, or one of its modifications, or a short, cylindrical instrument, he will succeed without effort or delay. The instrument being introduced and the cervix cleansed by the speculum syringe, the operator very gently passes through the cervical canal a small and delicate cervical speculum. That shown in Fig. 120 is one of the best of its kind.

Having previously wrapped the silver or hard rubber probe with a film of cotton, he now passes this up to the fundus. This removes a good deal of mucus from the cavity which wonld otherwise have neutralized the caustic introduced. Removing the cotton from the probe, he wraps another piece around it, or, as is better, uses another probe already wrapped, and, dipping this into the fluid caustic which he has determined to use, he passes it

FIG. 120.

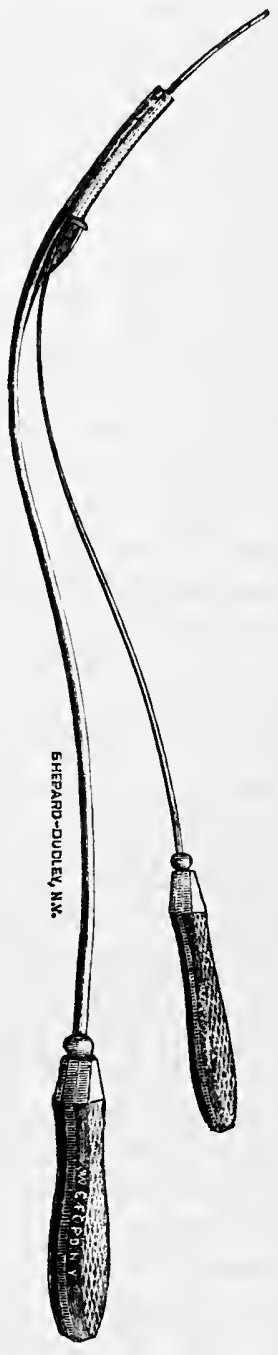

Wylies's cervical speculum, with probe passing through it. directly to the fundus and gently moves it over the surface. This should not be repeated, for the astringent aetion of the caustic makes repetition difficult, and if properly done the first time it will be unnecessary. After 
this the patient should go to bed and remain perfectly quiet, until the next day at least, and if any discomfort exist, for several days.

In place of the cotton-wrapped probe, the painting of the uterine surface may be very thoroughly accomplished by the use of a small brush of pig'sbristles dipped in the solution, and passed through the cervical speculum.

'The alteratives which may be thus employed are :-

Solution of chromic acid $3 . j$ to $z_{j} \mathbf{j}$ water;

Solution of nitrate of silver $\mathrm{Gj}_{\mathrm{j}}$ or $3 \mathrm{ss}$ to $\overline{3} \mathrm{j}$ of water ;

Compound tincture of iodine $\bar{\xi}$ ss to $\xi_{\text {ss }}$ of glycerine.

Saturated solution of sulphate of zinc ;

Saturated solution of sulphate of copper;

$C . S . D$. solution persulphate or perchloride of iron with equal parts of glycerine.

Solution of chloride of zine $3 \mathrm{j}$ to $\boldsymbol{\zeta}_{\mathrm{j}}$ water ;

U.S.D. muriate tincture of iron $3^{\mathrm{ij}}$ to $\zeta_{\mathrm{j}}$ water ;

Saturated solution of carbolic acid.

Lse of Ointments. - The application of ointments to the lining membrane of the uterus is so inconvenient and disagreeable a process that I cannot recommend it. It possesses no special advantages. It is proceeded with in much the same manner as that of fluids, except that a different instrument is, of course, necessary for their introduction. One which answers the purpose very well is the invention of Dr. F. D. Lente. It consists of a syringe with a silver tube attached. The ointment to be employed is put into the syringe by a spatula, and, the tube being introduced into the uterine cavity, the piston is pushed forward and the ointment is forced out. 'The following are the ointments which are generally thus employed, though any others-as lead, bismuth, ealomel, iodine, etc. -might be substituted :-

R. Argenti nitratis, $3^{\mathrm{ij}}$;

Belladonnæ ext. $\mathbf{3} \mathbf{j}$;

Ungt. spermaceti, $\mathrm{O}^{\mathrm{ij}}$.-M.

R. Plumbi acet. $3 \mathrm{ij}$.

Morph. sulphat. gr. iv ;

Butyr. cacao, žss ;

Ol. olivæ, q. s.-M.

The Application of Alteratives of Solid Character to the Endometrinm. -Substances of solid character which will melt under the influence of the heat of the body may be introduced into the uterine cavity in the form of suppositories or pencils. The pencils of zinc, copper, alum, or iron mentioned in the last chapter may be thus employed, or suppositories marle with cocoatbutter. or according to Becquerel's formula, may be used instead. Hecquerel's formula is the following :-

\footnotetext{
R. Tannin, 4 parts ;

Gun tragacanth, 1 part ;

Bread crumb, q. s.
}

One to be gently pusled into the uterine cavity and allowed to melt, every four days. 
Upon first trying an intra-uterine suppository or pencil of a certain strength, I should advise that a threal be always attached to it in order that it may be removed by the patient in case of pain. After testing in this way, the thread may be dispensed with, but, as a preliminary precaution, its necessity is great. Cases are met with in which a few drops of water in the eavity of the uterus will eanse pain, and I have seen the cantions introduetion of the uterine sound canse violent epileptiform convulsions. Should such a result follow the introduetion of a medicated peneil whieh has slipped out of reach, the position of the introducer would be an unfortunate one.

Injections into the Uterine Cavity.--'The subject of intra-uterine injection has often eome very prominently before the profession, and been fully and ably disensserl. Many eminent authorities have pronouneed in its favor, and reported hundreds of eases in whieh they have employed it with impunity and benefit. In the praetices of many it is, indeed, a routine method of treating eorporeal endometritis. While the evidence whieh has been addlueed proves that with proper precautions this means of medication is robbed of its chief dangers, it likewise makes it evident that in eareless, inexperienced, or unskilful hands it carries with it manifold and serious perils.

This method of treatment is not a new one, as many have appeared to think, but one of the oldest on record. It is eertainly a suspieious eireumstance that, employed, as it has been at rarious periods, during 2000 years, it should have, even at our day, as many opponents as it now numbers arrayed agaiust it. It may be suggested that the neeessity for allowing escape of the injeeted fluid has been only reeently reeognized, and that therefore the safety of the method has been only of late secured; but this is not so, for in 1833, Hélier, of France, employed a double canula construeted on the same prineiple as that of some to whieh I shall soon make allusion. In this conneetion it may not be unprofitable to take a rapid survey of the listory of the subject. For most of my tacts $\mathbf{I}$ am indebted to an exhanstive article by Dr. J. Colnheim, ${ }^{1}$ of Berlin, and translated by the late Dr. Kammerer, ${ }^{2}$ of this eity. Intra-uterine injeetions were employed and adrised "by Hippoerates, B.C. 400, for the purposes of washing out bits of retained plaeenta and medieating the surface affected by catarrh. They are likewise advised by Paulus Egineta, and, as we come down to later times, by Sylvius, Montanus, Ambrose Paré, Bottoni, Roderic a Castro, Mereurialis, Ludovie Mercatus, and Astrue. Otto, a translator of Astrue into German, in a note expresses the opinion that the fluid does not ordinarily penetrate into the uterine cavity, being prevented by the os internum, and says that "he

1 Beitrage zur Therapie der Chronischen Metritis. Berlin, 1868.

2 Amer. Journ. Obstet., vol. i. p. $37 \pi$. 
knows of cases in which the use of the above 'beautiful remedies' was followed by attacks of severe uterine eolie." The method was again advised by Wenceslaus, Collingwood, Berends, and Steinburger, and opposed with apparently equal warmth by Frank and Hourmann. The latter author drew attention to the dangers of the method by reporting a case of severe metroperitonitis, which resulted from a simple injection giren for lencorrhoa; and inmediately following his case three fatal ones were reported, two in Bretonneau's wards and one in Nélaton's. At a still later period they have been recommended by Récamier, Velpeau, Ricord, Kennedy, Retzius, Routll, Sigmund, Mattlews Duncan, Tilt, Brann, Martin, Courty, Nott, Kammerer, and others, and been opposed by Oldham. Mayer, Bessems, H. Bennet, Gosselin, Depaul, and others. Cases of violent nterine colic, accompanied by great prostration, feeble and rapill pulse, faintness and coldness of extremities, are repeatedly recorded even by the adrocates of the method; and peritonitis, ovaritis, and salpingitis, which lave been recovered from, have been met with as results of the practice by Hourmann, Leroy d'Etiolles, Landsberg, Oldham, Pédelaborde, Retzius, Becquerel, Noeggerath, myself, and others. Fatal cases of peritonitis have oecurred to Bretonneau, Nélaton, Gubiau, Noeggerath, Von IIaselberg,' Jobert,' and others. A case of sudden death from entrance of air into the veins has been met with by Bessems, ${ }^{3}$ who, in post-mortem examinations, "found air-bubbles in the rena cava and heart." Another case ending thus sudienly is reported by Dr. Warner, ${ }^{4}$ of Boston, as occurring at the Charity Hospital of St. Louis, where "a small quantity of water injected into the uterus occasioned immediately death. This result was evidently from shock." I do not find any statistical records fiom Dr. Simpson upon the subject, but the general impression left upon his mind concerning the method is thus plainly stated :5 "But, mark you, never think or dream of throwing liquids into the interior of the uterus by means of any injecting apparatus, for severe and fatal inflammations are very likely to ensue. Such a result may perhaps be caused by the fluid running along one or other patent Fallopian tube, and escaping into the peritoneum; more probably it maty be due to laceration of the mucous membrane and entrance of the fluid into one of the uterine veins; but however it may be produced, the consequences of injecting fluid into the cavity of the womb are so often dangerous and datrly, that the practice has now been given up, I believe, by all accoucheurs." In this passage he alludes to injections into the non-puerperal uterus for dysmenorrhea. Becepuerel ${ }^{6}$ reports the practiee as applied to

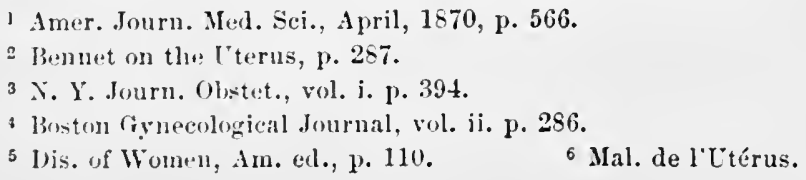


six cases of uterine eatarh. "In one case only, the catarrl was diminisherl of the remaining five, three could be saved only by energetic antiphlogistic treatment, the effects of the injection being exceedingly severe." Noeggerath reports four cases treated by injections; in the first ease, cure was happily effeeted ; in the second, cure was accomplished, but serions and protracted symptoms followed; in the third case, netroperitonitis was set up, but controlled; and in the fourth case the patient diexl.

There are two considerations in connection with this subject which must not be lost sight of. One of them is thus stater by Dr. Ilenry Bennet: "This accident" [fatal peritonitis, due, as he thought, to passage of fluid through the Fallopian tubes] "would probably have oceurred much oftener than it has done in the hauds of French practitioners, were it not that the natural coarctation of the os internum must have generally prevented the fluid injected from penetrating into the uterine carity." The other is this, that many cases of peritonitis, some fatal and others not so, which have been due to it have not been reported. One of the former and two of the latter have come to my own knowledge.

The explanation formerly given of the aceidents which may follow this procedure, was very maturally the penetration of fluid through the Fallopian tubes into the peritoneum. But, although this does occasionally oecur (see Von Haselberg's case as an example), it has been proved by experiment upon the dead body, as well as by observation of the practice upon the living, that there is a resistance on the part of the tubes which ordinarily prevents it. Experiments to test this matter have been carefully conducted by Vidal, Klemm, and Hennig, and all with the same result. It is probable that entrance is resisted successfully by tubes which are healthy, but that dilatation and atony from salpingitis would render the patient liable to the accident.

The deduction which the evidence elicited forces upon us is self-evident, namely, that at the same time that this method of treatment systematically and carefully resorted to is a valuable resource in endometritis, it is attended by many and great dangers. While it is proved that with eertain precautions, and in the hands of one skilled in manipulations of this charaeter, intra-uterine injeetions may usually be employed with safety and profit, it is equally manifest that a certain number of deaths have been due to them, and that they are frequently followed by excessive pain and grare constitutional symptoms when the essential precautions are neglected. I should strongly recommend the general practitioner who is unfamiliar with the treatment of uterine disorders to avoid their use entirely, except in cases of uncontrollable hemorrhage, in which the eervix is well dilated and no flexure of the uterus exists. When he is induced to essay this plan in the treatment of corporeal endometritis, let him bear 
in mind that the possibility of easy eseape of the fluid injected is not an advantige merely, but an essential for safety.

One very recent advocate of intra-uterine injections with a great deal of naïveté makes the following statement :-'

"Thongh most frequently women do not suffer any pain when injections, even of a strons solution of caustic, are made into the womb, yet it sometimes happens that symptoms which give great alarm to inexperienced persons do occur. The patient suddenly eries out, complains of violent eolies, of pain in the womb like that of labor; the abdomen becomes swollen, the face becomes pale, the extremities eold, the pulse small, and the patient is thrown into a state of great depression. These symptoms are sometimes accompanied with great trembling of the limbs and vomiting.

"I have related a case of this kind at the end of this memoir. Such a train of symptoms is undoubtedly alarming in appearanee, but is not followed by any fatal result."

I confess to sharing the feelings of those inexperienced persons who are greatly alarmed at the development of "such a train of symptoms," for that it is alarming not only in appearance, has heen more than abundantly proved by the oceurrence of death in a number of cases.

The experiments of Vidal, Hennig, and Klemm force us to admit that passage of fluid through the Fallopian tubes is not as likely an occurrence from intra-nterine injeetions as one would suppose it would be from theoretical reasoning. Colınheim, to whose admirable résumé of this sulject I am so much indebted, appears to regard them as conclusive. To my minl they are very far from being so. It is important to note that experiments performed on the eadaver are usually applied to healthy uteri and undilated tubes, while the gyneeologist employs these injections in cases where the endometrial mucous membrane is inflamed, and the Fallopian tules very often clilated in consequence. Is it not likely that a disease which overeomes the sphineterie action of the os internum uteri would likewise have a similar effect upon that of the metro-salpingian orifiecs? Post-mortem examination proves this to be the ease. Then there are a number of eases on recorll in whieh such immediate inflammatory results followed in the peritoneum, that there can be little doubt as to the occasional relation as cause and effect. Take for example the report of a case by Pédelaborde, in L'Union Mélicale for 1850 , in which, " three minutr:s after an injection of a decoetion of walnut leaves, severe uterine pains ensucel, and in a few hours were followed by acute peritonitis." A similar in-tance occurred to myself from injection of solution of persulphate of iron. Lastly, in a fatal case oceurring to Von Haselberg, the metal iron was detected by ehemical tests in one tube. If in a uterus free from diseare, whether in the cadaver or the living subject, a syringe be carried up

1 Gantillon on Lterine Catarrh, pamphlet, 1871. 
to, but not through, the os internum, and an injection made, the fluid will not enter the cavity of the body-and why? Because eorporeal endometritis has not destroyed sphineteric action at the os internum. liat in cases of endometritis, where that action is destroyed, a paralyzation laving been effected there by disease, how different is the case! Under such circumstances patients are often unable to use vaginal injections, for the reason that the fluid at once passes into the eavity of the body, and proluces violent uterine colic.

These cases are, I claim, precisely parallel, and ignoring the fact upon which I lave here laid so much stress is not only invalidating experiments made to throw light on a point of clinical importance; it is absolutely perverting them to the production of evil.

The medicinal substances which have been thus employed have varied very much with the views of different practitioners. Velpeau employed concentrated solutions of nitrate of silver; Ricord from two to three parts of tincture of iodine to one hundred parts of water; Evory Kennedy twenty to thirty drops of nitrate of mercury; while Sigmund resorts to solutions consisting of half a drachm of nitrate of silver, one drachm of sulphate of copper, one drachm of iodide of potassium with nine grains of iodine, two drachms of chloride of zine, or three drachms of perchloride of iron, to three ounces of water. Hennig employs pure warm water for a time, then water slightly tinctured with iodine, and lastly, pure tincture of iodine or solutions of silver; Fürst, one drachm of nitrate of silver to two of water; Martin, of Berlin, five grains of aluminate or sulphate of copper to six ounces of distilled water; and Kammerer used ten to twenty clrops of concentrated solution of chromic acid; Lugol's solution of iodine and iodide of potassium, or pyroligneous acid, in weak solution; or ten grains of sulphate of zinc to one ounce of water.

Beforc leaving this subject I will embody in a series of propositions the most important facts connected with it.

1. Intra-uterine injections may produce death even when simple and unirritating fluids are employed, by peritonitis due to absorption of the fluid and subsequent phlebitis ; passage of fluid into the peritoneum; endometritis (?); or by sudden entrance of air into a vein.

2. Even when no such dire result takes place, they may set up severe uterine colic, with tendency to eollapse, from hysterical neuralgia, violent uterine contractions like "after-pains," or intense irritation of uterine and tubal mucous membrane.

3. These dangers may be to a great extent aroided by attention to certain rules, which here follow :-

a. Never injeet the uterine eavity except with the certainty that the injected fluid can rapidly escape. Therefore always, unless the os internum be very much dilated, precede the injection by use of a tent, and always use a syringe insuring immediate reflux. 'The metlod for employ- 
ing uterine injections is very simple, but should always be practised with great system and eaution. A single tube of silver or elastic material like a catheter, with eyes at the side, may be used, provided the little syringe which projects the fluid be immediately removable so that the means of ingress may at once become the means of egress. We may, however, still more certainly insure egress by another instrument. The necessity for return of the injected fluid is so great that canulie with double canals or a canal and gutter have been constructed with especial reference to this. One of the most effectual and safest of these is the instrument shown in Fig. 121.

F1G. 121.

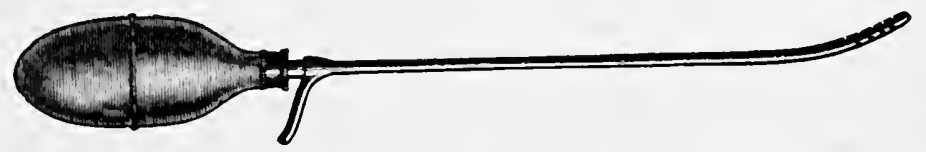

Molesworth's donble canula and bnlb syringe for injecting the uterine cavity.

When the India-rubber bulb is squeezed, the fluid which it contains escapes from holes in the end of the canula, and at once returns through another tube which lies alongside of it. Then, as the compression of the bulb ceases, a vacuum is ereated which sucks back every superfluous drop.

b. The best substances for injection are tincture of iodine, nitrate of silver, sulphate of soda, pyroligneous acid, carbolic acid, and sulphates of zinc, copper, or iron in weak solution. It is best always to begin with the use of weak alkaline injections of warm water, not only to see how tolerant the uterus will prove to the process, but because in the experiments of Klemm on the cadaver, in three out of eighteen cases, blue ink injected through a narrow os with moderate force penetrated the renous system of the uterus and broad ligaments without apparent laceration. After toleranee has been tested, stronger solutions may be used.

c. Always use solutions at a temperature of at least $85^{\circ}$ to $90^{\circ}$.

$d$. Wash out the cavity with warm fluid before using the stronger application; and in injecting always be sure that there is no air in the syringe, and never eject the fluid which it contains with force.

$e$. Never employ this method in a sharply flexed uterus before replacement, never just before or after a menstrual period, and never when pelvic peritonitis or periuterine cellulitis las recently existed.

$f$. After the use of this plan let the patient lie down until all sense of discomfort has passed, and confine her to bed and give opium freely on the first appearance of pain.

4. In uterine colic the most certain and immediate relief will follow the use of morphia by the hypodermic syringe. Astruc advised the addition of narcotics to injected solutions for the prevention of the accident. 
5. Lastly, although this plan of treatment, robber of many of its danger's by the precautionary measures liere alvised, may be comparatively safe in the hands of specialists skilled in nterine manipulations, it will always remain a hazardous method for the general practitioner who lacks such skill and who employs instruments not entirely suited to the purpose.

It may now be asked, sinee I oppose the habitual praetice of carrying applieations above the os internum uteri as well as that of injecting the uterine cavity, what course $I$ do advise and adopt in the management of this affection. $\Lambda$ s I have already stated, I would recommend careful attention to the general state, removal of displacements, cure of laceration of the cervix, extirpation if possible of any existing neoplasm, and, if uterine enlargement exist, the free use of ergot. To favor the free escipe of mucus from the uterine cavity I would see that the cervical eanal be dilated. And now if improvement did not occur I would apply the dull wire curette freely over the whole surface. In speaking of the pathology of corporeal endometritis, it was stated that the diseased membrane in time develops upon its surface fungoid granulations, mucous cysts, and mucous polypi. These secondary conditions often result in metrorrhagia or menorrhagia. Not only does the gentle application of the little wire curette without cutting edge accomplish the removal of these, it produces, when thoroughly applied, an altered state in the entire endometrial membrane, breaks distended bloodvessels, and often accomplishes a great deal for the relief of the disease. In cases of endometritis engrafted upon subinvolution and accompanied by hemorrhage, it is especially applicable. But its beneficial results depend, I feel sure, upon the fracture of tortuous and distended bloodvessels, and it is chiefly for this purpose that I use it.

The use of the dull wire curette does a greater amount of good in these cases at the expense of less risk than the applications just mentioned, and I infinitely prefer it.

\section{CH A P T E XX.}

\section{AREOLAR HYPERPLASHA OF THE UTERUS-THE SO-CALLED CHRONIC PAREACIYHATOUS METRITIS.}

Definition and Nomenclature.-One of the most common pathological combinations which confronts the gynecologist is that which $I$ here endearor in as concise a manner as possible to picture. A patient calls upon 
him for relief of backache; pelvie pains; dragging sensation about the loins; "bearing-down pains;" leucorrhcen; menstrual disorder, tending chiefly to excessive flow; throbbing sensation about the uterus; general feeling of despondeney; malaise and weakness ; and irritability about the bladder and rectum. All these rational signs pointing to the uterus as the probably delinquent organ, a physical exploration is made, and furnishes the following results: the uterus is usually discovered to be in the condition of descent, retroflexion, or anteflexion; it is voluminous, tender to the touch, and evidently engorged with blood; from the cervical canal a lencorrhoal matter pours; the probe carried to the fundus finds it tender, and ereates the flow of a little blond; the cervix is often in a conlition of granular or eystic degeneration; and a low grade of vaginitis exists.

To this pathological combination the more superficial diagnostician will often apply a name which announces one only of the existing conditions; as, for example, uterine catarrh, ulceration of the cervix, or retroversion or prolapse. The more reflective and intelligent examiner will ordinarily group the coineident morbid states together under the name of " ehronic metritis."

The latter would be fully sustained in his position by authority as abundant as it is orthodox, for by systematic writers, since the days of Récamier, this uterine state.has been described as one of "chronic parenchymatous metritis." Only within a very recent period have the pathologists of the German sehool begun to question the validity of this conclusion, which, taking its origin in France, was spread through England and America ehiefly by the writings of Dr. IIenry Bennet. According to this view the following pathological changes were believed to be those resulting in the condition just described. In the first stage the parenchyma was regarded as gorged with blood, a state of active congestion existing. This was supposed soon to pass into the second stage, consisting in an effusion of lymph, when, unlike a similar process in other parts, the morbid action ceased, or rather did not advanee, and unless relieved by treatment, continued stationary for a length of time. The third stage of inflammation in other parts, that of suppuration, was admitted to oceur rarely liere, or in the parenchyma of the body, but in time all inflammatory action ceasing, the cervix remained large and indurated without sensitiveness, or the effused lymph might be absorbed, and great diminution in size oecur with induration. Were this really the case the condition would constitute one of inflammation, even if we restricted ourselves in the use of that ambiguous term to the narrow and precise limits prescribed by Dr. J. Inghes Bennett, when lie says, "It should be applied only to that perverted alteration of the vaseular tissues, which produces an exudation of the liquor sangunis; it is this exudation alone which can be held to unequivocally characterize an inflammation." 
Examined more recently, however, by the more certain and less theoretical processes of motern science, all this lats come to be looked upon as erroneous. Cases which were formerly regarded as instanees of inflammation on aecomnt of the existence of enlargenent, congestion, and tenderness upon pressure, the microseope now proves to have been instances of excessive growth of the connective tissue of the uterus, with congestion, and resulting hyperastlesia of its nerves.

It may result from thee entirely different pathological states: first, from interference with retrograde metamorphosis of the puerperal uterns from any eanse; second, from congestion long kept up by mechanical causes, such as displacement; third, from a formative irritation or state of hypernutrition excited by endometritis, or the existence of fibrous tumors. Whatever be the originating pathological condition, that which results and which we are now considering consists in hyperplasia of connective tissne as its most marlied feature, and of congestion and nervous hyperasthesia as important accompaniments.

It is true that some progressive writers still cling to the name chronic inflammation, and apply it to hyperamia resulting in hypergenesis or hypertrophy of connective tissue, but this is by no means the signification which is ordinarily given to the term. Indeed, with reference to the uterus, so vague and unsatisfactory is the appellation chronic metritis, that there is no knowing what idea one who uses it really intends to convey. He who has in the library and at the bedside been perplexed and disheartened by the constantly recurring uncertainty which it has induced, will have learned to appreciate the feeling which prompted two cminent pathologists, Andral and J. Hughes Bennett, to propose that the vague term "inflammation" should be expunged from our nomenclature. 'To quote the worls of an accomplished writer of this eity :-

"The entity inflammation, fallen from its high and palmy state, is hanging by its eyelids as a pathogenic factor in most of the organs of the boly ; its last resting place seems to be the womb, and here still it has a good foothold. Why should uterine pathology alone be eumbered by an outworn theory?",

It is not an entirely correct statement that this pathological doctrine originated in France. Upon the revival of gynecology in that country by the labors of Récamier, it likewise revived and assumed important proportions. But the theory of parenchymatons inflammation as explaining this condition is as old as the seience of medieine itself, and it certainly is a peculiar conmentary upon it, that now, in the most advanced period that the seience has ever known, the retention of it not only results in doubt, uncertainty, and seepticism, but absolutely creates controversial discussion, and forms sects and factions, where all should be united for the common good. "All must momn," remarked the late Professor Hodge, "over a discrepancy of opinion which bears so directly on the treatment 
of such painful and distressing maladies." "We eannot but believe," says Meredith Clymer, "that the time is not far off when this rexed but important question will be re-opened, and examined in a fair-judging, and not peremptory and dogmatic spirit, uninfluenced by prejudice, prescription, or tradition; and that, measured by a new standard, and settled by the requirements of a more enlightened knowledge of the laws of life, present differences will be reeonciled, hostilc opinions conciliated, and the angry" voice of adverse factions be heard 'not any more forever.'"

Everywhere throughout the recent and progressive literature of gynecology, the foreshadowing of the advancing change in views with regard 'to this subject will be recognized. The pendulum, swung too far by the hand of Dr. Henry Bennet, is making its inevitable return. That it may stop on safe middle ground must be the hope of all. "Tlue determination of blood to a part here noticed, characterized by dilatation of the arteries, with increased flow of blood through the eapillaries, must be distinguished from the congestion of inflammation, characterized by the accumulation and stagnation of red and white corpuseles in the vessels, tending to be abnormally adherent to each other and to the vessels," says Dr. II. G. Wright, "quoting from Dr. Aitken. "Tested by this standard," that of Dr. J. IIughes Bennett, already quoted, says Dr. Graily Hewitt, ${ }^{2}$ "the uterus is certainly very little liable to 'inflammation;' exudation, and transformations of such exudations, purulent and otherwise, similar to what may be witnessed in other organs of the body, being very rarely witnessed in the parenchyma of the uterus. The morbid proeesses with which we are familiar as affecting the tissues of the uterus are for the most part alterations of growth, irregularities in growth, slight modifications, in fiact, of the processes which follow each other in due sucecssion in the natural condition of things. The word 'inflammation,' used in Dr. J. IIuglies Bennett's sense of the word, ecrtainly fails to convey an adequate idea of the modifications observed under sueh eireumstances." "Diffuse growth of connective tissue," says Klob, " constitutes the so-ealled induration, hitherto considered as a result of parenchymatous inflammation of the uterus. . . For reasons mentioned, I would also advise a disuse of the term "chronic inflammation." In a discussion upon chronie metritis before the New York Academy of Medicine, Dr. Noeggerath limited the disease to "growth of the eellular tissue both of the body and neek, oceurring only during the puerperal state." Dr. Peaslee preferred "t" call the disease under consideration eongestion, rather than inflammation, because it las none of the events of inflammation ;" and Dr. Kammerrer expressed the view that "chronic inflammation of the substance of the non-puerperal uterus is never met with; what has been deseribed as

1 Teturine Disorders, p. 218.

3 op. cit., 1. 129.
2 Dis. of Women, p. 363.

- Med. Record, No. 92, p. 475. 
such is hypertroply of connective tissue, resulting from long-continued hyperamia."

These views, which among men who are in the advanee in gyneeology are rapidly gaining ground, are not sustained by analogieal reasoning, but by anatomieal proof. I know of nothing which will more surely convince the realer of the necessity for an alteration in our nomenelature eoneerning this eondition, than a perusal of Scanzoni's article upon it. This author, after heading his ehapter, "Chronie Parenehymatous Inflammation of the Womb," goes on to say: "The nature of the disease would then be, in an anatomical point of view, an hypertrophy of the cellular tissue." Certainly the "anatomieal point of view" is an important one, and it is supported by what we observe from a elinieal stand-point.

So mueh evil hats arisen for pathology and treatment from the use of the term chronie metritis, and so elear a demonstration has been made that the condition so ealled is not one of true inflammation, that some other appellation is not only desirable, but has beeome absolutely essential. It is incontestable that there is a peculiar condition that affeets the uterus which is eharacterized by distention of bloodvessels from vital or meehanieal cause; effusion of the serum of the blood; and hypergenesis of conneetive tissue. To denote this state, gyneeologists have long required a name, for medical nomenelature is as necessary as it is faulty. Lisfranc felt this need when he styled it "engorgement ;" Hodge when he entitled it "irritable uterus ;" Bennet when he ealled it " metritis;" and others also have acknowledged the necessity, Klob, for example, in "habitual hyperamia" and "diffuse proliferation of eomneetive tissue," and Kiwiseh in "infarctus."

'The appellations infarctus, engorgement, and hyperamia only convey a partial idea of the truth ; they only announee one element of the condition-eongestion; while that of irritable uterus ignores all structural chauge in announcing another element-nervous hyperasthesia. At the same time that the phrase " diffuse proliferation of eonnective tissue due to hyperamia," which is employed by Klob, clearly defines the pathologieal condition, it is too long and burdensome to answer the purpose of a name to be conventionally employed. It there be a term now in existence which does really eonvey the idea truly and completely, it should surely, in the interests of pathology and treatment, as well as out of eonsideration for the overburdened student of medical nomenclature, be employed in preference to the adoption of a new one. Enlargement of an organ dne to formation of new eells similar to those of the tissue in which they are developed, has been stylerl by Virehow, hyperplasia, in eontradistinction to hypertrophy, whieh consists in increase of size from distention of cells already existing. As the condition of the uterus now under consideration 
is one arising from over-excitation of the vaso-motor and excito-nutritive nerves, a "formative irritation," as Klob styles it, and resulting in a numerical hypertrophy, it appears to me that the term areolar hyperplasia would more correctly designate it than any other with which $I$ am acquainted. With a sincere desire to lessen and not to increase the labors of the student and the perplexities of the gynecologist, I shall therefore replace the confusing term chronic metritis, by that of areolar hyperplasia of the uterus.

That the term is faultless, I do not claim. To one unaccustomed to it, it must even appear peculiar. I have merely to ask for it a favorable eonsideration on the grounds that it is faithfully descriptive of the condition to which it is applied, and that a decided necessity for some such term exists.

In a very fair, critical review ${ }^{1}$ of the third edition of this work, the reviewer remarks that this name "involves the notion that the connectivetissue elements alone hypertrophy, and disowns the muscular element as the one most readily provoked to increase. We do not deny that, in the disease in question, there is hyperplasia of connective tissue, or, at any rate, of non-muscular elements ; but we must aver our belief that concomitantly there is increase in the muscular elements also." $\Lambda t$ first glance, this appears to be a very strong point of objection; but I think that even the writer himself will, upon more careful examination of the views of patlologists, agree that they look upon the proliferation of areolar tissue as always the characteristic or highly predominant feature of the condition, and regard muscular growth as an insignificant accompaniment only. For obvious reasons it is impossible for me to quote largely to sustain this position, and I confine myself to the statement of Professor Klob, who, in speaking of this condition, expresses himself in the following terms: "The whole uterine connective tissue sometimes proliferates either without aecompanying increase of the muscular substance, or, if this does occur, the connective tissue predominates to such an extent that the muscular sulstance is comparatively of not much account."

It is true, that, while most who have investigated this subject hare fouml, like Klob and Scanzoni, a great preponderance of connective tissue, and an insignificant increase of museular elements, some have declared that the muscular structure is greatly hypertrophied. One reason for this variance of opinion is this : the most prolific source of areolar hyperplasia, the so-called chronic metritis, is interference with insolution of the par. turient uterus. What begins as subinvolution ends, in time, in a condition ordinarily styled chronic metritis. He who examines early will

1 lirit. and Foreign Medico-Chirurgical liev., Jan. I873.

2 In the Anerican translation of Klob the rendering is not this; but Dr. Kimmirer. the translator, informed me that that passige is not correct, but that this is. 
probably find a greater amount of muscular elements than he who does so later ; and let it be remembered that by continental writers, with one exeeption, ${ }^{1}$ no recognition is made of subinvolution as a discase distinct firom what Chomel styled it, post-puerperal metritis. In this waty I reconcile the researches of Llob, whose statement I have quoted, with those of Finn, ${ }^{2}$ who reports the following observations, mate at the Institute of Pathological Auatomy in St. Petersburg:-

"1. The normal disposition of the single nuscular fibre, as well as of the muscular bundle, remains unchanged.

"2. The muscular fibres do not change in quality, neither is their fatty degeneration a pathognomonic sign of this disease.

":3. The muscular fibres are always extended in both their lenerth and breadth above their normal standard, but more so in the former direction.

"4. The number of fibres is always largely increased.

" 5 . The amount of connective tissue in the latter stage of the disease is always relatively diminished, but absolutely cularged, so that the increase of bulk of the uterus is mainly caused by the hyperplasia of the muscular tibres, the augmentation of the connective tissue influeneing it but little."

If the disease really consists in a proliferation or hypertrophy of the areolar or comnective tissue of the uterus, and not in chronic inflammation, it would certainly be advantageous to apply to it some name which would signify that fact. "Areolar hyperplasia" ${ }^{3}$ expresses this fact concisely, and hence I have employed it.

Puthology of Areolar Hyperplasia.-The vast majority of cases are due to interference with that retrograde metamorphosis oceurring in the puerperal uterus, styled involution. To comprehend the pathology of cases thus arising, it will be necessary to consider the physiology of that process as well as the pathological conditions which may affect it.

It is only within the last quarter of a century that we have understood the process by which the uterus, an organ measuring three inches, in the short space of nine months enlarges so as to contain a clild or even two or three children, and then within two months after delivery, undergoes so rapid an absorption as to return to its original size. The credit of elucidating the subject belongs chiefly to Germany, for it is to Virchow, Franz Kilian, Ileschl, Kölliker, and Retzius that we are most indebted.

The important pathological fact that arrest in or disturbance of this process constitutes a condition of disease emanated from Sir James Simpson, who, in 1852, published the first article which drew especial attention to it. His article was entitled, "Morbid Deficiency and Morbid Excess

1 II. Courty.

2 Am. Journ. Obstet., rol. i. p. 264.

3 IIypertrophy signifies excessive growth of the elements of a tissue already existing; Iyperplasia signifies the development of new tissue. 
in the Involution of the Uterus after Delivery." Since that time, the condition which now engages us has become generally recognized as a uterine state of great frequency and moment.

'To fully comprehend this part of our subject it is necessary to bear in mind the component parts of the healthy uterine parenchyma. It consists of five elements: 1st. Fusiform fibre cells, or, as they are termed, the smooth museular fibres; $2 \mathrm{~d}$. Round and oval nuclei, which are supposed to be elementary fusiform fibre cells; $3 \mathrm{~d}$. Amorphous or homogeneous connective tissue, which permeates the parenchyma and binds together the fibre cells and nuclei; 4th. Fibrillated connective tissue or white fibrous tissue; and 5 th. Elastic fibrous tissue. These elements, together with nerves, bloodvessels, and lymphatics, make up the tissue of the uterus, which is covered by a serous membrane externally and a mucous membrane within.

No sooner does this structure feel the stimulus of conception than it develops rapidly, partly by growth of already existing structures and partly by new formations. The round or oval nuclei rapidly develop into fusitorm cells, and these as rapidly grow into colossal cells which grow longer and more powerful as pregnancy advances. "A new formation of muscular fihre also takes place,"' the connective tissue elements grow proportionately, and the bloodvessels enlarge.

Parturition occurs, and almost immediately a retrograde evolution begins to restore the uterus to its original constituency. The fully developed fibres undergo a fatty degeneration; the fat thus formed is absorbed, and the organ rapidly diminishes in size and weight. This fatty degeneration affects the organ after the fourth day subsequent to delivery, and, according to IIeschl, the commencement of a new formation of muscular fibres is recognized in the fourth week after labor, in the form of nuclei and caudate cells. At the end of the eighth week the uterus las returned to its normal state.

Certain untoward influences may retard or check this process, and the uterus remain flably and large, when it is said to be in a state of subinvolution, or arrested retrograde evolution.

Thus far we have been dealing with facts thoroughly ascertained by histological investigations and fully established by evidence yielded by the mieroseope. But from this point the pathology of subinvolution is not so satisfaetorily settled. Prof. Simpson declared that the disease was due to the fact that "this retrograde metamorphosis of the uterus has not taken place during the puerperal month, or lats taken place only to such an imperfect degree that the uterus is of the size we usually see it have at the ent of the first week or so after delivery;" but he entered, if I may julge from the posthumous volume of his work upon Diseases of Women,

1 Arthur Farre, Cyc. Anat. and Phys., article Lterus. 
upon no detailed aceount of the existing pathologieal defect in the orran. Since his writing, it appears to have been agreed upon that this consists of persistence of the museular fibres, charaeterizing pregnancy, in a state of fatty degeneration. Thas Dr. Wright ${ }^{1}$ says, "Pathologically it closely eorresponds with that state of the heart structure so almirably described by I) . Rielaard Quain, and commonly known as fatty degeneration." Dr. West ${ }^{2}$ expresses himself thus: "Though fatty degencration of the tissues takes place, yet the removal of the useless material is but imperfeetly accomplished, while the elements of the new uterus are themsclves, as soon as produeed, subjeeted to the same alteration." I search in vain the literature of the pathology of this subject for a basis for these hypotheses. That literature is seanty in the extreme as yet, and the subject awaits extended researehes before we can speak intelligently of it. The day has passed, however, when we ean let probabilities in pathology pass current for facts.

'The best, indeed I may say the only detailed account of this eondition studical by the microseope, which I have been able to obtain, is one by Dr. Snow Beek, ${ }^{3}$ of London. "The enlargement of the uterus did not depend so much upon an inerease in the size of the contractile fibre-cells, as upon an inereased amount of round and oval globules, with amorphous tissue in the uterine walls. . . . The essential eondition of the organ consisted in the elements of the different tissues retaining a portion of the natural enlargement consequent upon impregnation. But this enlargement was more dne to the increased size and amount of the soft tissue present in the walls of the uterus, as well as at the internal surface, than to the increased size of the contractile fibre-cells." Marked congestion existed, the bloodvessels being large aud forming a complete and continuous system with the eapillary network on the inner surface of the uterus. No allusion to preponderance of museular fibres is anywhere made, and no mention of fatty degeneration oceurs.

The condition of the uterine eavity is important. It is always inereased in size, the glands of the cervix are usually enlarged, and upon the lining membrane of the cavity fungoid growths are commonly developed.

This is all that ean with positiveness be said of the pathology of the early periods of subinvolution in the present undeveloped state of the subject.

The uterus, the study of the tissues of which gave Dr. Beck's results, measured $3 \frac{1}{2}$ inches in lengtll, $2 \frac{1}{4}$ inches across the fundus, the walls were $1 \frac{3}{8}$ inches thick, and the uterine canal was 3 inclies deep.

As time passes the uterine walls diminish in size, their tissue grows less

1 Uterine Disorders, p. 221.

2 Dis. of Women, 3d Eng. ed., p. 89.

3 London Obstetrical Trans., vol. xiii. 1) 239. 
vascular, the bloodressels become smaller, and the uterine cavity assumes smaller dimensions. But the organ does not assume its original size; it remains large, dense, firm, and sensitive; for years presenting the characteristic appearances of the so-called chronic parenchymatous metritis. Although taking an entirely different view of the pathology of chronic metritis, Dr. West signalizes almost the same fact in the following words: "It must, however, be at once apparent, that after inflammation has passed away, its effects may remain in the larger size and altered structure of the womb, and that the very nature of these changes will be such as to render the repair of the damaged organ both unlikely to occur, and slow to be accomplished, and must leave it in a condition peculiarly liable to be aggravated during the fluctuation of circulation, and alternations of activity and repose, to which the female sexual system is liable." This is just the state to which I allude at the commencement of this chapter, as one existing years after labor, and which, attended by congestion, displacement, catarrh, and granular degencration, is styled chronic metritis. It is, I think, this state which most frequently furnishes instances of areolar hyperplasia to the microscope.

Let any one faithfully and patiently watch a case of subinvolution for a year or two with reference to this point as I have repeatedly done, and I cannot doubt that he will have the same evidence which makes me so strong in my present belief. Lastly, let it be remembered, that by the French school no condition of arrest of development is recognized as accomnting for it; these are cases of "post-puerperal metritis," metritis, aceording to M. Gallard, without symptoms, "ehronique d'emblée."

Does any one claim that between this condition and chronic metritis a difference should be made? Let him tell me by what means he can at the bedside distinguish one from the other, and I may agree with him. There are no means for such differentiation. If the uterus be very large and the patient reeently delivered, the case is termed subinvolution by English writers; if its dimensions have diminished, years have elapsed since parturition, and the almost universal accompaniments of the condition, leucorrhrea, gramular degeneration, and displacement, be present, it is styled clironic metritis.

Arrest of involution of the puerperal uterus is an occurrence of very great frequency. It constitutes the chief cause of all chronic uterine disorders, and for this reason its importance cannot be overestimated. Until this subject receives the attention which it deserves, the present confusion as to the causes, pathology, and general features of chronic metritis, which lelps to weaken uterine pathology, must continue.

is a very general rule, areolar lyperplasia, the so-called chronic metritis, is a conseguence of subiniolution. This constitutes the explanation 
of the fact that so large a number of women with uterine affeetions refer their illnesses to child-bearing, and that so many who are well nutil that process remain invalids afterwards. Go back to the commencement of all eases of uterine disease, and a very large proportion will date from parturition. These liyperplastic or subinvoluted uteri were those which chiefly furnished Lisfranc's cases of "engorgement," which Jobert " melted down" with the actual cantery, and which hundreds to-day are treating by powerful caustics as parenchymatous metritis. The question may be asked, do I myself not blister, apply leeches, and even amputate the cervix in these cases? The element which sustains the disease is an excessive supply of blood; to diminish this is to strike at the root of the evil. In areolar hyperplasia I blister lightly, to exert an alterative influence upon the nerves; for the relief of coincident congestion, I leech occasionally, as I would for hyperamia elsewhere; and I amputate, as I would do the enlarged tonsils; but nowhere would I treat the condition as inflammation.

The only apology which I offer for enlarging still further upon this part of my subject, is contained in the fact that $I$ regard it as one of the most important points in the whole of uterine pathology. Even by Parisian writers, who above all others have been wedded to the theory of chronic inflammation, the dependence of a peculiar form of so-called chronic metritis upon disordered involution las been recognized. "The commencement of chronic metritis," says Gallard, " "is so insidious, that it is often diffieult to determine its date in each particular case. So rare are cases of true acute metritis which, in perpetuating themselves, become chronic, that it is generally admitted that the disease is, to a certain extent, chronic from its commencement. Nevertheless, I consider this passing of acute into chronic metritis as much more frequent than most authors think . . . Aran, after having contested this, was forced to recognize, as the origin of the greatest number of cases of chronic metritis, acute metritis following parturition. This acute stage often passes unnoticed among the sequela of libor, scarcely disturbed by slight febrile movements, which excite no suspicion of uterine inflammation so long as they do not present themselves with the alarming symptoms so characteristic of puerperal metritis. Here we see arise a condition'whieh Chomel with his eminently judieious and practical mind was obliged to distinguish from this serious disease by giving it a particular name, that of post-puerperal metritis." . . . . "This inflammation, which surprises the uterus before it has finished the work of involution which would reduce it to its normal size, finds in the histological features of this organ cireumstances most favorable as well for its development as its perpetuation and its passage into the chronic stage."

If this passage be read with the key which I here offer, it becomes 
plain low a condition arises insidiously after labor without the symptoms of inflammation, and yet ends in what is generally called chronic metritis; how a state due to parturition differs so widely from ordinary puerperal metritis, that a new distinetive appellation is required for it ; how metritis appears to commence in ehronic form; how Aran found this latent, undemonstrative, acute disorder the "souree of the majority of eases of chronic metritis;" and how, in spite of the obscurity of early symptoms, M. Gallard is forced to believe that the chronic disease does follow an acute puerperal metritis, the development of which is obscured by the sequela of labor. The supposed acute metritis, without symptoms to announce it, which is conjured up to sustain an untenable theory, was really an arrest of retrograde metamorphosis; the chronic metritis, which was afterwards found to exist in full development, with a commencement so obscure that it must have been "clironique d'emblée," was this same condition passing or having passed into areolar hyperplasia. At this time its slowly retrograding muscular fibres have, to a great extent, passed away, but its connective tissue continues exuberant, and the uterus remains large, swollen, tender, and heavy.

Compared with interference with involution, all other pathological influences become comparatively insignificant as causes of this condition; nevertheless they must receive due weight. The tissue of the virgin uterus presents a structure unfavorable to this disorder. 'That of a uterus once affected by gestation offers a more propitious field for its development.

Displacement of the uterus at first results in passive congestion, this being kept up, hypergenesis of connective tissue takes place. Fibroids, whether they be submucous, subserous, or mural, keep up a constant nervous irritation that induces hyperemia, which proves the first step towards this afiection. In a very important essay, Rouget ${ }^{2}$ proves the uterus to be an erectile organ, as richly supplied with a network of vessels as such organs always are, and very subject to active physiological congestion. It is certain that such a kind of hyperemia attends ovulation, and it is highly probable that sexual congress las a similar result. From this it will appear how prolongation of the molimen menstruationis, and excessive indulgence in sexual intercourse, especially near menstrual epochs, may produce evil consequences. ${ }^{3}$

As cardiac diseases and abdominal tumors, which interfere with venons return througl the vena cava, produce blood stasis and odema of the feet, of the labia majora, and of the parts about the vagima, so do they result in the same way in the uterus. Klob declares that this purely passive con-

1 Gallard, op. cit.

2 Rouget-Récherclies sur les Organes érectiles de la Femme.

${ }^{3}$ Scauzoni calls attention to the fact that it is met with in prostitutes. 
gestion is calpable of indueing hypernutrition and hypertropliy of the connective tissue. ${ }^{1}$

It has been already said that in aente endometritis the hyperarmia attending the disease ordinarily extends to the parenclyymatous layers immediately adjacent to the discased mueous membrane, and that in chronic endometritis there is often in the submucous connective tisste an absolute hypertroply. In some cases the process passes into a diffuse proliferation of the connective tissue of the entire uterine wall. 'Thus as a result of eervical endometritis we sometimes find cervical hyperplasia resulting, and so with the disense in the carity of the body. As I have already stated, where the uterine parenchyma has never undergone that physiologieal hypertrophy and retrograde metamorphosis attendant upon utero-gestation, endometritis will eontinue for a long periorl withont exeiting hyperplasia; but where such changes have ocenrrel, the more loose and permeable texture offers itself as an easier prey to the morbid process. Thus cervieal endometritis will continue for years in a virgin without any apparent enlargement of the structure of the neck, while such a result soon follows in a woman who has borne children. This fact has not attracted special attention, and yet it is a point which every practitioner must recognize, when it is brouglt to his attention, as one which is faniliar. Under these circumstances the enlargement is not due to anything absolutely eonnected with parturition. Parturition has been the predisposing cause; endometritis the exciting.

A very striking illustration of this affection due to non-puerperal causes is related by Dr. West, whose observation seems to have led him to very similar conclusions with mine. "Some years ago," says he, "I saw a lady, aged forty-three, who, during thirtcen years of married life, had never been pregnant. She had always menstruated painfully, and rather profusely; and both these ailments lad by degrees grown worse, and this especially during the last few montlis. She complained of a sense of weight and dragging immediately on making any attempt to walk, and induced even by remaining long in the sitting posture. . . . Menstruation was rery profuse, accompanied by diseharge of coagula, while at uncertain interrals during its continuance most violent paroxysms of uterine pain came on. On examination the enlarged uterus was distinetld felt above the symphysis pubis, as large as the doubled fist, and per varginam the whole organ was found much enlarged, and mueh heavier than natural; the cervix large and thisek, but not indurated; the os uteri small and circular; and the hymen was entire." He goes on to say: "Whenever the uterus is exposed to unusual irritation, it increases in size; not necessarily, nor I believe generally, as the result of inflamma- 
tion, but because the organ is composed of formative material, which excitement of any kind will call into active development."

In the first stage of the disease, the hypertrophied areolar tissue is congested, containing absolutely more blood than normal, and the whole of the affected part, neck, body, or entire uterus, is greatly increased in size and weight. As time passes, the second stage of the disorder supervenes, and an opposite state of things is set up. Klob describes it in these words: "The parenchyma on section appears white or of a whitish-red color, deficient in bloodressels, from compression of the capillaries by the contraction of the newly formed connective tissue, or from partial destruction ol obliteration of vessels during the growth of tissue; the firmness of the uterine substance is also increased, simulating the hardness of cartilage, and creaking under the knife." 'This constitutes a true selerosis ${ }^{1}$ of the uterus.

Every practitioner must have met with eases in which a large, red, engrorged, and soft uterus, examined after an interval of several years, lias been found, to his surprise, to have become small, densely hard, white, and anamie, and its cavity diminished in size. Such an olgan removed. from the body cuts like fibrous tissue, and appears when cut almost as dense and bloodless.

In leaving this important and interesting part of my subject, let me sum up what has been said, in a few words :-

1st. The condition ordinarily styled chronic metritis consists in an enlargement due to hypergenesis of its tissues, especially of its connective tissue, which induces nervous irritability, and is accompanied by congestion.

2d. Decidedly the most frequent source of this state is interference with involution of the puerperal uterus. A very large proportion of the cases of so-called chronic parenchymatous metritis are really later stages of subinvolution.

31. Areolar hyperplasia is often induced in a uterus which has once undergone the development of pregnancy, by displacement, endometritis, and other conditions inducing persistent hyperæmia.

4th. The same influences may possibly produce it in the nulliparons uterts, most frequently they do so in the neck, but such a result is exceedingly infrequent.

5 th. However produced, the condition is one of vice of nutrition engendering liyperplasia of connective tissue as its most striking feature, and, although attended by many of the signs and symptoms of inflamnation, it in no way partakes of the eliaracter of that process.

It las been maintained by some that acute puerperal metritis extends

1 The term sclernsis was, I beliere, first applied to this condition by skene, of lBrocklyn. Subsequently Gallard likewise employed it. 
itself into the ehronic metritis of the non-puerperal state, and this form of the aflection has been tifferentiated from subinvolution. I have seen no evidence of the correctness of this view, nor do I believe that any such distinction can be male at the bedside.

Course and Termination.-The length of time which this condition may last is very uncertain. After the connective tissue once becomes thoroughly affected by the disease, it rarely returns to its original condition, but so complete is the relief which may be afforded the patient by removal of those concomitant conditions that attend upon it and increase the discomforts which are due to it, that she will often for years imagine herself well. Very suddenly, however, imprudence during menstruation, the act of parturition, over-exertion, or some other influence creating congestion, will produce a relapse which will convince her of her error. It is astonishing to what an extent enlargement of the cervix as a result of areolar lypperplasia will go. Sometimes this part will equal in size a very small orange, and, filling the vagina, will compress the rectum to such an extent as to interfere with its functions. Uninterfered with by art the disease has no fixed limits. 'The increase of uterine weight which it induces usually results in lisplacement. This increases already existing congestion, and the patient suffers, until the menopause at least, from endometritis, granular cervix, and the ordinary-symptoms of displacement.

Fig. 122.

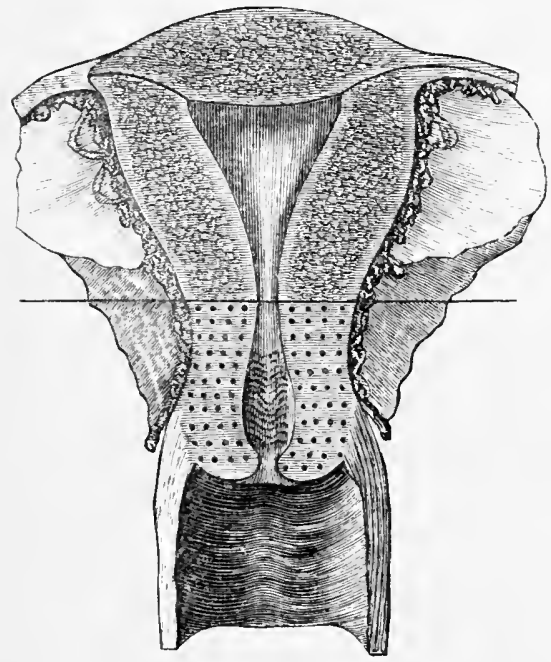

The dots represent the site of cervical hyperplasia.
FI. 123.

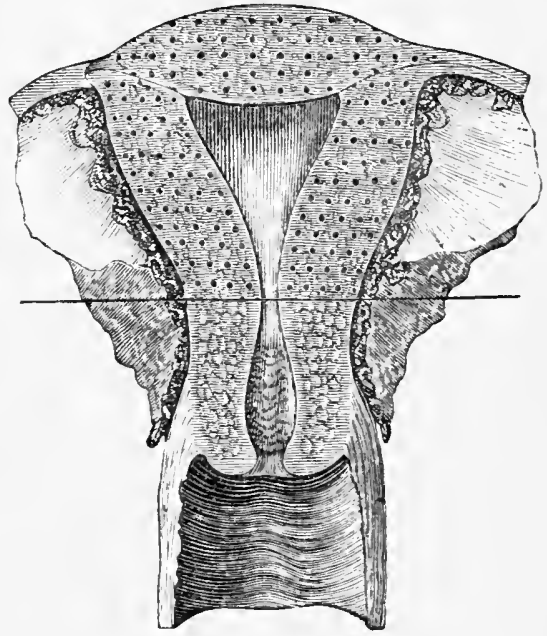

The dots represent the site of corporeal hyperplasia.

In some cases contraction of the exuberant tissne occurs, and uterine atrophy with its accompanying symptoms takes place.

Vurieties.-Whatever be its cause, areolar lyperplasia may affect the 
entire uterus; it may limit itself to the neek, extending from the os externum to the os internum; or it may affect the body from the os internum to the fundus. The habitat of hyperplasia limited to the cervix is represented by Fig. 122, while Fig. 123 represents that of the corporeal variety.

Whether arising from imperfeet involution or from non-puerperal eauses, this limitation to cervix or body will be frequently observed. Dr. West ${ }^{2}$ alludes to the eervical variety as "one in which the enlargement is limited to the neck of the womb, and sometimes even inrolves only one lip, generally the anterior. In the latter ease it is usually consequent on childbearing, and perhaps is, strictly speaking, rather the result of a partial deficiency of involution of the uterus than the effect of a generie hypertrophy of the part." This fact was first announced in Great Britain by Dr. Evory Kennedy.

Frequency.-This affection is one of great frequency, and as it was formerly universally regarded as chronic parenchymatous metritis, this is one great reason why inflammation of the structure of the uterus was thought to be so common. This fact makes its careful study a matter of great moment to the gynecologist. I do not hesitate to declare that, he who fully masters it and thoroughly appreeiates its frequency and influence will possess a key to the management of numerous cases which would in vain be sought for elsewhere.

As I have before remarked, interference with that retrograde metamorphosis of the puerperal uterus which is now styled involution is in the great majority of eases its cause. Surprise may for this reason be exeited by the assertion that of all forms of the affection, the cervical variety is the most frequent. The reason for this is to be found in the facts that cervical endometritis, which in multiparous women proves a not infrequent source of the disorder, is more common than the kindred affeetion of the boty; that the cervix is peculianly exposed to mechanical injury from eoition, friction against the vaginal walls, and laceration, oceurring during parturient distention; that after ehildbearing the connective tissuc at this point is looser and more permeable than that of the body; and that when involution is retarded for some months and then is accomplished, it sometimes takes place in the body, but fails to do so in the neek from that exposure to injurious influences which has just been alluded to.

The body of the uterus is so completely removed from eontact with mechanical agencies outside of the abdomen that this part of the organ, as a!rendy stated, is not so frequently affected by hyperplasia as the corresponding tissue of the cervix. Still it is ly no means unfrequently diseased. $A$ large number of cases of obstinate uterine disorders oceurring as a remote result of parturition are really of this nature, and the displacements, rebellious leucorrhua, and other concomitant evils which characterize them, 
are merely symptoms of this affection or of some of its resulting complieations. An important fact connected with this state is that where hypertrophy of the connective tissue exists, transient attacks of active congestion frequently occur and excite acute symptoms. These pass away, leaving the basis of the affection in its original state, again to return with all the signs of relapse. And thus a series of short but severe exacerbations gon on developing themselves in the ordinary course of an attack of the disoriler.

\section{I'redisposing Causes._-These may be enumerated as-}

$A$ depreciation of the vital forees from any cause;

Constitutional tendency to tubercle, scrofula, or spanomia ;

Parturition, especially when repeated often and with short intervals;

Prolonged nervous depression ;

A torpid condition of the intestines and liver.

Nulliparity secures, to a very great extent, an immunity from the disease, aml multiparity constitutes a most important predisposing cause. This fict arises not merely from its being, as it often is, an immediate consequence of the parturient act, but from the peculiar tissue changes of utero-gestation rendering the uterus prone to its development. "Frequently," says Klob, " this proliferation of connective tissue is developed after repeated deliveries in rapjd succession without any previous or existing inflammation, . . . and sometimes is developed in consequence of the puerperal condition." Its " eauses must be sought for in habitual hyperamia;" consequently whatever state gives a tendency to this must be regarded as a predisposing cause, while one which induces and perpetuates it must be looked upon as exciting. The woman who has never been preguant is much less liable to areolar hyperplasia thin she whose uterus has undergone the tissue changes of utero-gestation. Nevertheless, in very rare and exceptional cases, I think that she may suffer from it. In the whole of my experience I have seen but two or three cases, and the diagnosis in these is based upon clinical evidence alone.

Here let me guard the reader against a fallacions argument which is often used in reference to this matter. As areolar hyperplasia is rarely seen except in women who have borne children, it is said that it is always the result of interference with involution. This is incorrect. A woman bear's a child, has no post-partum tronble, and goes through uterine involution perfectly. A year or two afterwards she has endometritis. This in time produces areolar hyperplasia with its usual symptoms and physical signs. The same kind and degree of endometritis in a nulliparous woman would lave lasted for years without parenchymatous complication. In the former case the endometric disease existed on ground farorable to hyperplasia, because an important predisposing cause existed. In the latter sucl predisposition was wanting. 
The exciting causes are tlie following :-

Over-exertion after delivery ;

Puerperal pelvic inflammation;

Laeeration of the cervix uteri;

Displacements ;

- Endometritis ;

Neoplasms;

Cardiac disease;

Abdominal tumors pressing on the vena cava;

Excessive sexual intercourse.

After delivery many of both these sets of causes are developed by the pernicious system of management which nurses frequently adopt. The nerve and blood states of the woman are depreciated by starvation, impure air, and disturbance of sleep by attention to the wants of a child, while the enlarged uterus is forced into retroversion and the congestion which it induces, by a very tight bandage, rendered still more hurtful by a thick compress over the uterus. The praetitioner who regards delivery of the placenta as the end of the third stage of labor furnishes a marked predisposing cause. The third stage of labor consists in complete and permanent contraction of the uterus, and may not be accomplished for hours after the expulsion of the placenta. No obstetrieian has done his duty who leaves his patient before its accomplishment.

Symptoms.-It is impossible to present the symptoms of this condition entircly separated from those of complications which very eommonly attend it, such, for example, as displacement, laceration of the cervix, ovarian congestion, granular cervix, etc. These states of course produee symptoms of their own which mingle with those of the main disorder. The symptoms then, which are due to areolar hyperplasia and its almost inevitible complications, are the following. It the cervix alone be affeeted there are-

Pain in back and loins;

Pressure on bladder or rectum;

Disordered menstruation;

Difficulty of locomotion;

Nerrons disorder;

Pain on sexual intercourse;

Dỵspepsia, headache, and langnor ;

Leucorrhica.

If the affection be general or corporeal, graver symptoms manifest themselves. ${ }^{1}$ Chief among these are-

I It must not be snpposed that all these symptoms occur in all or eren in the majority of cases. In many cases few, and in some almost noue of them will be recnstrized. 
A dull, leavy, dragging pain through the pelvis, much increated ly locomotion ;

P'ain on defecation and coition ;

Dull pain beginning several days before menstruation, and lasting during that process;

Pain in the mamma, before and during menstruation ;

1)arkening of the areola of the breasts ;

Nausea and romiting;

Great nervous disturbance;

Pressure on the reetum with tenesmus and hemorrhoids;

Pressure on the blardder with vesical tenesmus;

Sterility.

Physical Signs of Cervical Hyperplasia._Vaginal touch will generally discover that the uterus has descended in the pelvis so that the cervix will rest upon its floor. The cervix will be found to be large, swollen, and painful, and the os may admit the tip of the finger. If the finger be placed under the cervix and it be lifted up, pain will usually be complained of, and if it be introduced into the rectum so as to press upon the cervix as ligh as the os internum, it will often reveal a great degree of sensitiveness. Under these circumstances the direction of the uterine axis will generally be found to be abnormal. The cervix will in some cases have moved forwards and the body backwards, or the opyosite change of place may liave occurred.

Physical Signs of Corporeal Hyperplasia.-If two fingers be carried into the vagina and placed in front of the cervix so as to lift the bladder and press against the uterus, while the tips of the fingers of the other hand be made to depress the abdominal walls, the body of the uterus will, unless the woman be very fat, be distinctly felt, should the organ be anteflexed. Should it not be detected, let the two fingers in the varina be now carried behind the cervix into the fornix vaginæ, and the effort repeated; if the uterus be retroflexed or retroverted, or even in its normal place, it will be detected at once. By these means we may not only learn the size and shape of the organ, but its degree of sensitiveness. This may likewise be accomplished to a certain extent by rectal touch. The uterine probe may then be introduced, the cavity measured, and the sensitiveness of the walls carefully ascertained.

A point which shonld be settled before the diagnosis can be considered complete will be, whether the cervix alone is affeeted, or whether its enlargement is only a part of a general uterine development. To determine this question, two means are at command: first, the examiner, introducing one or two fingers under the body of the uterus, and depressing the abdominal walls by the other hand, so as to clasp the fundus, ascertains whether it is larger than it should be, or of normal size and free from sensitiveness. 
He then passes the uterine probe into the cavity of the body, and measures it. If the uterine carity be inereased in size, the evidence is in favor of the disease having extended to the tissue of the body. Should its size be normal, this is probably not the case. This sign is not, however, to be entirely relied upon.

Differentiation.-When the whole uterus is affeeted, or the body of the organ alone is enlarged, the diseases with which areolar lyperplasia may be confounded in its first stage, are :-

\section{Preguancy ; \\ Neoplasms; \\ Periuterine inflammations.}

From these a careful differentiation should be made; for if in error, the practitioner would not only fail in giving relief, but, in some cases, might do great injury. For example, an examination by the probe might produce abortion, or so aggravate periuterine inflammation, as to eause serious and alarming consequences. The introduetion of the probe or sound should, for this reason, be praetised with great eaution, and only when good reason exists for supposing pregnancy and periuterine inflammation albsent.

Between pregnancy and endometritis with eorporeal hyperplasia, there is a chance of error in tiagnosis; for in both there are enlargement of the breasts, darkening of the areola, enlargement of the uterus, derangement of the nervous system, and nausea and vomiting. In the one, however, menstruation does not eease, there is no kiesteine in the urine, there is great sensitiveness of the body of the uterus, and an abundant leucorrhoca. Dr. Tilt has drawn espeeial attention to this important fact, in eonneetion with endometritis: "When most of the symptoms of early pregnancy are present," says he, "withont menstruation being suspended, in comparatively young women, internal metritis may be suspeeted."

Fibrous growths in the uterine walls will sometimes, from the peculiar symmetry of their development, eonpletely mislead us, giving uterine enlargement, leueorrhea of bloody character, ete. I have now in ny possession a uterus in the anterior wall of which a fibrous tumor, equal in size to a goose's cgge, gives upon superficial examination all the appearanees of engorgement and hypertrophy of uterine tissue with anteflexion and endometritis. In the same manner polypoid growths or submueous fibroids might give trouble in diagnosis. Lnder such eireumstances reliance would have to be placed upon the use of the sound, conjoined manipulation, and tents, together with the rational signs.

Perinterine inflammations fix the nterus, ereate harlness and swellings in the iliac fosse and pouch of Douglas, and sometimes produce purulent discharges.

Sometimes, suspicion of scirrhous eaneer in an early period being entertained, it becomes necessary to decide between its existence and that of 
the sceond stage of areolar liyperplasia or sclerosis. Scanzoni doubts the possibility of deciding, but it appears to me that the investigator will usually sueceed in doing so, by the following eomparison of signs and symptoms :-

\section{In Cerricul Selerosis.}

The patient shows no cachexia.

There is tendency to amenorthos.

The history usually points to parturition.

It has been preceded by symptoms of uterine enlargement.

The cervix feels like dense fibrous tissue.

The borly is perhaps inplicaterl.

A sponge-tent softelss the tissue.
In Scirrlous Cancer.

She often dues.

There is tendency to hemorrhage. It does not.

It lias not.

It feels almost like cartilage.

It is very rarely so.

It leaves it hard and dense.

Prognosis.-The prognosis in hyperplasia of the entire uterus or of the body alone is unt:avorable with regard to complete cure, though highly favorable with reference to great relief of symptoms and to danger to life. Should the patient be approaching the menopause, it is possible that, after the functions of the utcrus cease, atrophy may occur and relief be obtained. But one cannot be sure even of this, for the monthly discharge may give place to metrorrlagia, or all the symptoms may continue in spite of the menstrual cessation. Under a course of local treatment, combined with one conducted with special reference to the general system, hope may always be held out that, although restoration of the uterus to its normal condition maly not be effected, the evils resulting from the complications of this disease can be so fully controlled that comfort will be obtained. When the neck of the uterus alone is affected, a favorable prognosis may always be made, for here there are fewer grave complications to be encountered; such, for example, as corporeal endometritis, menorrhagia, etc. The diseased part is likewise more accessible to local treatment, and is also a much less sensitive and important part of the organism ; I might indeed almost say a less important organ, so distinct are the uterine body and neck physiologically and pathologically. As I latve elsewhere stated, the prognosis will depend in a great degree upon the patient. If she be unwilling to sacrifice her inclinations and pleasures, but half fulfil the directions of the attending physician, and clandestincly expose herself to prejudicial influences, the treatment will accomplish nothing. In the case of a reasonable patient, who appreciates what is at stake, and is anxious to regain her health, it may be regarded as favorable.

Complications.-Areolar hyperplasia may give rise to many and serious complications, as, for example, displacements, cystitis, rectitis, cellulitis, endometritis, menstrual disorders, hysteria, dyspepsia, ovarian disorders, ete. 
The question has been raised by Dr. Noeggerath as to the causative influence of this disease in the production of eancroid affections. In an essay real before the New Tork Acadeny of Medicine in 1869, he reported six cases which he regarded as due to the "transformation of the tissue aflected with chronic metritis into epithelioma or cauliflower excrescence." The object of the essay was "to prove that the tissue of the uterus affected with chronic metritis is apt to be transformed into papillary epitheliona." My experience has never furnished me with a case illustrative of the correctness of Dr. Noeggerath's opinion. It certainly cannot be an ordinary sequence of events, for the subject long ago attracted attention, and $I$ know of no recent author who takes similar ground. Klob's opinion is expressed in these words: "What has been said by various authors on the relations of diffuse growth of connective tissue to the development of carcinoma must be considered as a mere hypothesis."

Treatment.-Let me urge upon the practitioner, as a rule to be observed in every case, before treatment is adopted for this disorder, to examine for and remove, if discovered, the five following complications which very often accompany areolar hyperplasia, and establish symptoms which greatly increase the evils attending it. So important do I consider them, that I give them decided prominence.

1st. Laceration of the cervix uteri, which creates intense nerrous irritation, both immediate and reflex, and consequent uterine congestion and neuralgia.

2d. Displacement of the uterus, whieh results in vascular engorgement, dragring upon uterine ligaments, mechanical interference with surrounding larts, and difleculty in locomotion.

3d. Fungoid degeneration of the endometrium, which results in profuse leucorrlocal and bloody discharges.

4th. Granular and eystic degeneration of the cervix, which proluce nervous and vascular derangement of the uterus, leucorrlivea, and menorrluagria.

5th. Varginitis, which is excited by the discharge dependent upon engoroment of the culometrium.

IIe will be most successful in the treatment of areolar hyperplasia who most assiduously searches for and cures these complicating conditions before addressing remedies to the main affection.

Laceration of the eervix, and exposure of the delicate walls of the cervical canal to friction against the vagina, is so frequently not only a concomitant circumstance but, I think, a cause of this condition, by interfering with involution, that it should always be looked for. Let it not be supfosed that at mere visual inspection will reveal its existence. It will often

1 It must lwe noted that klob alludes to careinoma, while Noeggerath limits his statenent to epitheliona. 
fail to do so while the red and excoriated ecrvical walls are being for tong periods treated for so-called uleeration by eaustics and alteratives. To t $\cdots t$ the question, a tenaculim should be fixed in each labium cervieis, and these should be approximated so as to present to the eyes of the examiner the perfect cervix as it existed before the aceident. Once discovered, the inner surfaces of the torn lijs should be thoroughly pared and bronght together by suture. Such an operation will often have a most happy eflect upon the uterine disorder; nervous irritability will disappear, and nutrition beeome greatly improvel by removal of this focus of irritation.

If displacement exist, great benefit will be obtained from support rendered by means of a light and well-fitting pessary, the elastic ring of Ieigs if there be merely direet descent; Hodge's double lever or one of its varieties if there be retroversion; or an anteversion pessary if the uterus lave fallen forwards. In some cases the benefit derived from these instruments will be the chief, perhaps the only relief which we can bestow, and even where we eannot eure the disease we may by their use render lite much more agreeable by the alleviation of diseomfort.

If evidences of fungoid growths on the endometrium exist, the whole carity should be gently scraped by the wire-loop curette, and this source of leucorrhœa, metrorrlagia, and uterine congestion taken away.

At the same time that $I$ have elsewhere urged that too great importance should not be given to granular and eystic degeneration of the cervix, I would not ignore the fact that, once established, they become a sourec of irritation, and thus of uterine engorgement. They should by all means be treated and removed.

Vaginitis is secondary to uterine catarrh, which is a very common accompaniment of hyperplasia. It should be treated by the ordinary means elsewhere indicated, and a recurrence prevented by relief of the endometrial disease.

The subject carefully analyzed presents itself in this way. If the abnormal condition, which has created areolar hyperplasia, has passed away, this eondition is not in itself the source of many disagreeable symptoms. No woman thus affected feels perfeetly well, but she is often sufficiently confortable to be able to perform all her duties in life. But the uterus thus diseased is peculiarly liable to certain complicating conditions which have just been mentioned, and these create a great deal of discomfort by production of pains in the back and loins, nervousness, lencorrhera, and menstrual disorders. These symptoms are then in a great degree, as I stated in giving the symptomatology of hyperplasia, due to the complications of the disorder, and not to the disorder itself. In other words, sustain a lyperplastic uterus, keep it free from displacement, granular and cystic disease of the cervix, and uterine eatarrh, and the patient will be so comfortable as, in most instanees, to feel satisfied with her eondition. Sometimes this is all that we can accomplish. The mere fact of aceom- 
plishing these results will, however, do mueh for the cure of the disease itself. Relief of displacement favors free venous return and prevents congestion which feeds and perpetuates hyperplasia. Cure of uterine catarrh and of gramular and cystic degeneration of the cervix removes two great causes for hyperamia of mucous and submucous tissues. The means employed for the relief of these symptoms even do more, they tend by their own direet influence to alter the morbid state of the nerves of the part, to diminish the calihe of bloodressels under their control, and thus to eheck exeesive mutrition and secretion.

All complications being removed, the practitioner has now to deal with a lirge. heary uterus, the tissue of which is exuberant, the bloodvessels enlarged, and the nerves in a condition of hyperasthesia.

Let me enumerate the indications to be met by a few leading propositions.

1st. Fverything possible should be done to prevent congestion, and remove that already existing.

2d. Every attention should be given to the restoration of the general sr:tem, especially the blood and nerve states.

3d. All weight slould be taken from the large and heary uterus.

4th. Nervous hyperestliesia should be relieved by every means in our power.

The means for furthering these ends may thus be presented :-

Rest ;

General treatment;

Depletion ;

Emollient vaginal injections;

Alteratives.

Rest.-The patient should be instructed to take much less exercise than usual, to lie upon her bed or lounge for an hour every day about mid-day, and to be especially quiet during menstrual periods. It is as a general rule highly improper to confine her to bed, for many women become restive under the confinement, and suffer both in mind and body, the sanguineous and nervous systems being impaired by want of fresh air. If the connective tissue be so much affeeted that the cervix is very painful upon pressure, absolute rest upon the back may beeome necessary, but my impression is that deprivation of fresh air and exereise ordinarily does more harm than is compensated for by the advantages arising from quietude. Every day she should go, unless deterred by some special callse, into the open air, and a limited amount of exereise should be ineuleated ats a means of keeping up the general health.

Within a few years Dr. Weir Mitehell has introduced a plan for treating eases of neurasthenia which consists of complete rest. The patient is for a period varying from six weeks to three months kept as quiet, upon 
her back in bed, as if she were a marble statue; or rather, I should say, as far as volumtary motion is concerned. She is fer? by an attendant who is eonstantly by her side, and is not allowed even to lift her arms from the bed. Meantime she is very thoromghly nourished by milk, aminal broths, malt, cod-liver oil, egros, and other nutritious substances, every two or three hours ; while cutaneous action is excited, peripheral circulation kept at a maximum of aetivity, metamorphosis and elimination increased, am muscular strength fostered, by manipulation, passive exercise, electricity, and kneading. The moral faculties are likewise supervised; hysterical symptoms are controlled by moral suasion, judicious neglect, and an earnest appeal to the reason of the patient; and the mind is male to feel the influence of alienation from home influences by entire seclusion from firiends and relatives.

I can of course only allude to this plan, which observation leads me to set a very high estimate mon in the treatment of special cases, and would refer the reader for further details concerning it to the writings of Dr. Mitchell, ${ }^{1}$ and to an exeellent article by Dr. William Goodell. ${ }^{2}$

The uterus slould be placed at rest as much as possible. Its natural tendency under these circumstances is to fall from its position; consequently all pressure should be removed from its fundus by wearing the clothing loose, sustaining the weight of the skirts by attaeling them to the upper garments, so as to have the shoulders bear the burden, and uncompromisingly abolishing the corset.

At the same time a system of exereises should be practised by the patient calculated to develop the power of the abdominal and thoraeic muscles and thus restore or increase the retentive power of the abdomen. These will be alluded to in detail under the head of displacements of the uterus.

Abdominal bandages are very unpopular with many practitioners, who believe that they absolutely do harm. I believe otherwise, and regard them as great adjuvants, not in keeping up the uterus, but in supporting the super-imposed viseera, which, pressed downwards by tight elothing, and badly supported on aecount of the relaxation of the abdominal walls, fall directly upon the fundus. There is a great variety of abdominal supporters. I have no favorite, for one will aceomplish the end in a woman of a certain figure which would be inappropriate for another. That one should be selected whieh absolutely accomplishes the end in view, namely, sustining the riscera and supplementing the weakened muscles of the abdomen.

Sexual intercourse often produces bad results in an organ which is so prone to congestion, and great infrequency and eaution should be enjoined with reference to it.

1 Fat and Blood, and hor to make them.

2 Nerve tire and womb ils, Lessons in Gyuecology. 
By combining all these means we do all in our power to place the hyperplastic uterus at rest as we would a fractured bone or enlarged testicle.

General Treatment.-The diet should be plain and unstimulating, but at the same time nutritious, and in every way calenlated to maintain the normal state of the blood. Should spanamia exist, ferruginous tonies, alone or combined with regetable tonies, should be administered. The bowels should be kept in a perfectly normal state, and the skin active. Specific remedies lave been, and are still, employed by some practitioners for diminishing the size of the uterus. Of most of these $I$ doubt the effieacy. During the state of enlargement, that is, before contraction of the exuberant tissue has oceurred, ergot, kept up for a considerable time, produces good results. By its power of exciting contraction of the uterine tissue it diminishes hyperamia, and lessens the bulk of the uterus.

European writers speak in high terms of the alterative influences of the various watering-places and baths of the Continent, as those of Marienbad, Schwalbach, Brieknau, and Kissingen, in Germany, and of Saint Sauveur, Barréges, etc., in France. None of these equal in reputation the waters of Kreuznach in Germany, the curative property of which is supposed to depend upon the bromirle of magnesium which they contain. It is very probable that the hygienic and soeial influences which surround these places and render them attractive, are to be eredited with most of the good that they do. Aran, after admitting that the water of Vieliy may exert some influence, thus pointedly expresses himself with reference to the others: "Whatever be their composition, in whatever countries they may be found, I know of no work in which we can find an approximation to a demonstration in their faror."

No other general means compares in result with a change of abode and corresponding elange of air, habits, and associations. A removal, for example, to the seaside, where bathing ean be enjoyed, a sea voyage, or a resillence at an agreeable watering place, may accomplish much good. Mental depression predisposes to and aggravates this discase most markedly. Aran goes so far as to say that he has almost invariably found it present as an exeiting canse. However this be, eheerful and congenial company certainly proves one of the best nervons tonies in a therapeutic point of view, and should always be sought for. $A$ stay in a well regulated hydropathic establishment, where the patient ean have fure air, plain and mutritious fool, and agreeable society, together with the strict attention to the general rules of hyogiene which characterizes those institutions, will often produce the best effeets.

Depletion. - If vaginal touch and conjoined manipmlation discover the fact that the uterus is tender, the occusional abstraction of small amounts of bloor l,y puncture or searifieation will be beneficial. Not more than all ounce or two should be taken at once, unless amenorrhoa be a symp- 
tom. In case this be so, a more copious abstraction by lepelues, during the menstrual epoch, will often give great relief. At times leeeles them applied to the cervix will give great pain hy their bites. 'This is sometimes so severe as to lead to the apprehension that one has escaped into the eavity; lenee it is important that they should be comted before being placed in the speculum, and on their removal from it.

The three methods by which local depletion of the ecrvix can be best pratetised are lecehing, scarification, and cupping. 'Three or four large lecehes, or a suflieient number of small ones, to take from three to five ounces of blood, may be applied in the following manner: $A$ cylindrical speculum, of suflicient size to contain the entire vaginal portion of the eervix, being passed and the part thoroughly cleansed, a small pledget of cotton, to which a thread has been attached for removal, should be placed within the os, so as to prevent the entrance of the lecehes to the eavity above. A few slight punctures, sufficient to cause a flow of blood, should then be made in the cervix, and all the leeches to be employed thrown in, and the speculum filled at its extrenity by a dossil of cotton pushed towarls the bleeding surface. The speculum should be watehed until they cease sucking, for if left for a very short time, even with the mouth of the instrument filled with cotton, they will escape. After their removal all clots of blood slıould be removed by a sponge or a rod wrapped with cotton, the speculum withdrawn, a large sponge squeezed out of warm water placed over the vulva, and the patient directed to remain perfectly quict. Should scarification be employed, a very sharp and narrow bistoury or tenotomy linife may be introduced within the os, and drawn outward towards the vaginal edges of the cervix so as to sever all the superficial vessels over which it passes. I would recommend, in preference to this plan, acupuncture, which may be performed by an ordinary three-sided surgical needle held in the grasp of a pair of forceps, or, still better, by a little sprear, the invention of Dr. Buttles, of this eity.

FIG. 124.

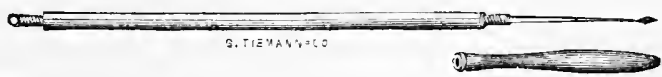

Buttles's spear-pointed scarificator.

This little instrument, when plunged about one-sixteenth of an inch into the cervix and given a rapid halt turn before removal, causes a very free flow of blood should congestion exist. If a suflicient flow does not occur from three or four of its punctures, this can be caused by dry cupping the cervix by a very simple instrument, made of vulcanite, which is introduced through the speculum, the medium size of the cylindrical variety being large enough to admit it. Being passed up to the cervix, the piston is retracted, and so perfect is the working of these instruments, when constructed of rulcanite, that a complete vacuum is produced. By 
using this for a few minutes, and then puncturing, with Buttles's spear, from two to four ounces of blood may readily be drawn. The exhauster should not be used after puncturing, lut before it. All that will be necessary afterwards will be to pass a moist sponge, attached to a spongeholder, over the punctured surface so as to prevent clotting in the mouths of the bleeding ressels. Dr. Joln Byrne, of Brooklyn, has drawn especial attention to still another methorl, which in some cases answers an excellent purpose. It consists in passing a long, delicate blade up the os internum, and eutting through the mucous membrane, its bloodvessels, and the superficial layer of muscular tissue, as it is withdrawn through the os externum. Local depletion by one of these methods should be practised cautiously, the patient for twenty-four hours after its adoption being kept perfectly quiet in bed.

FIG. 125.

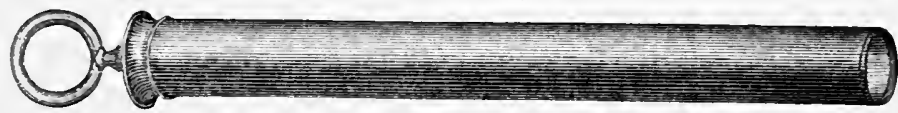

Hard rubber cylinder for dry cupping the cervix uteri.

It is surprising to observe how steadily depletion by all these means has been, during the last ten years, going out of rogue in New York. Many gynecologists with large practices have entirely given it up, and in the Womau's Ilospital it has almost completely passed ont of use. It must be remembered, however, that the same statement would hold good in reference to abstraction of blood in every other department of medicine.

I aginal Injections. - A great deal of adrantage accrues in these cases, from the systematic use of very copions vaginal injections of water as lot as the patient can bear them. They should be employed for from fifteen to twenty minutes at a time and once in every twelve hours. Their use quiets pain, improves the pelvic cireulation, remores irritating secretions, and unruestionably stimulates the absorption of effised material.

Local Alteratives.-The best local alterative is the compound tincture of jodine, which, by means of a brush of pig's bristles, should be carried up to the os internum or even to the fundus, should endometritis exist, and over the whole cervix; then, wating for complete drying, this process should be repeated. After these applications a wal of cotton, to which a string has been attached in sueh a way as to lave its surface flat, should be saturated with grlycerine and laid against the corvix. This acts as a local hydragogue, and disgorges the tissues. 'These local applications shonld he repeated once a week, but others should be made of tener by the patient herself ly means of varrinal injections, by which the drugs just montinned may be bronght in contact with the cervix.

Should it appear to the practitioner that persistent liyperamia requires more energetic means than those mentioned, resort may be lad to counter- 
irritants which vesicate and destroy the mucous membrane of the vaginal cervix, and thus cause a free How of serum. Such cases grow smaller and smaller in my practice as I grow older in experience, and although I anluit the occasional neeessity of these means, I caution the realer anainst a constant or too early resort to their use. They cannot diminish the absolute size of the enlarged organ, and should not be used with any such view. They ean remove congestion and nervous exaltation, and in certain exceptional cases may be employed for these purproses.

One of the best methods for practising counter-irritation upon the cervix uteri is by blistering, a means for which we are indebted, I believe, to Aran, of Paris. To blister the cervix, a large cylindrical speculum should be used which will take the whole part into its field. The cervix having been cleansed and dried by a soft sponge or dossil of cotton, a camel'shair brush is dipped into vesicating collodion, which consists of ortinary collodion, commonly known as liquid cuticle in this country, containing in suspension cantharides, and painted over the whole vaginal cervix, no effort being made to avoid the os. There are two preparations of vesieating collodion, one made with ether, the other with acetic acid. The second is the more powerful and the less likely to affect the vagina. In a few seconds after it is painted on the cervix, it forms a hard, insoluble covering, upon which two or three other coats may be at once applied.

The whole is then exposed to the air by kecping the speculum in place for a few minutes, a stream of cold water projected upon it, to prevent any escape into the vagina, and the process is finished. In from eight to twelve hours the epithelial covering of the cervix is entirely removed by this, and a free flow of serum takes place as from a blister elsewhere applied. After this the patient should be kept perfectly quiet for several days, cleansing the vagina by warm injections, and as soon as the discharge shows a tendency to cessation, the blistering should be repeated. The only objections to this method of counter-irritation are the liability to vaginitis and cystitis from escape of the blistering fluid into the vagina and mouth of the urethra, which can readily be aroided, and the pain which is experienced in some cases while vesication is taking place.

After blistering, pledgets of cotton saturated with glycerine should be applied for the hydragogue effects of that drug.

Vesication may be easily produced by still another method which is both effectnal and simple. By means of a solid stick of nitrate of silver, which is rubbed gently over the whole vaginal portion of the cervix, its epithelial covering is destroyed, soon sloughs off, and leaves a granulating surface, which may be dressed with any of the alterative substances mentioned above, or with glycerine.

Mild and lacking in vigor as this course may appear, let any one test it side by side with the plan of using the acid nitrate of mercury, potassa fusa, and potassa cum calce, and the actual cautery; of swabbing out the 
uterine cavity with chemically pure nitric acid, or of leaving a piece of solid nitrate of silver to melt within it; and, unless his experience greatly differ from mine, he will feel that in the former he has reached a resting place for his fith in the treatment of the most important of all the forms of uterine disease. He will see proof daily spring up before him that his capacity for benefiting his patients has greatly increased, while his liability to injuring them has as markedly diminished.

Dr. August Martin, of Berlin, advocates amputation of one lip of the cervix for the induction of a species of involution in cases of areolar hyperplasia. Some time ago lic reported seventy-two such operations, in only seven of which did any inflammatory symptoms show themselves, and which were invariably followed by a diminution in the capacity of the uterus of from two to three centimetres. In a discussion which followed a paper by Martin, Kehrer, Schroeler, and Olshausen agreed with it. This method possesses none of the advantages of trachelorrhaphy, to which it is inferior in every respect. Both operations are usually employed where laceration of the cervix exists as a cause of the hyperplasia.

\section{H A P T E X XI.}

\section{GRANUlar AND CYSTIC DEgENERATION OF THE CERVIX UTERI.}

No subject in connection with gynecology has attracted more attention within the past fifty years than inflammatory uleeration of the cervix uteri. Lintil a comparatively late period it was fully believed in, but, as more careful observation has been practised, the fact has been recognized that unless affeeted by direct pressure or friction from some solid body the cervix uteri is little prone to simple ulceration. It is, of course, everywhere admitted that cancerous and syphilitic uicerations may affect this part, but no one would propose to style these inflammatory uleers. It is likewise admitted, that in a prolapsed uterus, frietion against a pessary or the elothing, commonly produces true inflammatory ulceration. But these armissions do not touch the point at issue, and it is fully agreed to-day that the condition lately styled inflammatory ulceration, by Dr. Henry bemet and his school, was not one of ulceration at all, but one of exuberant growth of the tissues of the cervix with or without laceration of this part, which is much more correctly described under the names which head this chapter.

It not unfrequently happens that one symptom of a disease will so distress and harass a patient that remedial measures must be entirely directed to it, ahthongh the practitioner be aware of the fact that it depends on dis- 
eases elsewhere located. An example of this is frequently prosenterl in the morbid state muler consideration, which, in itself, proves so annoying by its profuse diseharge, and interference with the functions of the uterus and with locomotion, as to call for prompt relief.

'The vaginal surface of the cervix uteri is covered by a smooth mucous nembrane, which is continnous below with that of the vagina, and extenting throngh the cervical canal joins that of the body, which differs widely from it, at the os internum. 'This membrune is covered over by numerous papilla which become visible when a sufliciently strong glass is used. One or more slender bloodvessels pass into each and form at their extremities vascular loops, then return, and at their bases pass into adjoining ones. They are completely eovered by parement epithelium and basement membrane. Thronghout the cervical canal mucous erypts or follicles exist, which are likewise found seattered over the vaginal portion of the eervix, and even within the eavity of the uterus itself. The diseases of two of these elements of cervical mucous membrane are now to engage our attention.

\section{Granular Degeneration of the Cervix.}

Definition.-This condition, which has been described under the names of erosion of the cervix, granular ulcer, and epithelial abrasion, consists, as its name implies, in the development of a surface of granular character on the smooth face of the cervix and just within the os.

Frequency. - It is an affection of great frequency, attending all the diseases of the uterus which result in leucorrhea, and being commonly a concomitant of most of the diseased conditions of the parenchyma and lining membrane. Very often it exists for a length of time without any suspicion of its presence arising in the mind of patient or plysician, and sometimes without causing symptoms which prove in any great degree annoying. At others, grave constitutional signs may be traced to it and entirely removed by its cure.

Cuuses.-The predisposing causes are:-

Enfeebled general health;

Sjanæmia;

The scrofubous diathesis;

The syphilitic diathesis.

Those which are exciting are the existence of -

Displacements ;

Endometritis;

Laceration of cervix;

Areolar hyperplasia ;

Abuse of sexual intercourse;

Vaginal lencorrloca;

Pessaries which touch the vaginal face of the cervx. 
From this array of causes it will appear that it is rarely a disease which stands alone, but that it is usually engrafted upon some other affection of greater moment. Although this is true, it will not do in practice to carry the view too far. At the same time that it must be admitted that granular degeneration, even of aggravated character and considerable proportions, affecting the vaginal face of the cervix, and the distal extremity of the cervical canal, is commonly a consequence of some pre-existing disease, the fact must not be lost sight of, that this affeetion of itself keeps up a hyperamia in the subjacent and neighboring parts of the uterus, and even extends a reflex influenee to the ovaries.

By almost all writers upon this subject since Réeamier's time, too much stress has been laid upon the theory that it depends upon an "indurated and hypertrophied condition of the parenchyma of the eervix." That it results from this no one would deny, but it is equally true that it often arises from other causes, and itself induces this one. In general terms we may say that it is usually produeed by, 1st, any disorder which keeps the mucous membrane of the cervix constantly bathed with ichorous fluids for a length of time; $2 \mathrm{~d}$, by anything which keeps up friction against the cervix; $3 \mathrm{~d}$, by any influence producing and perpetuating congestion of the uterus. Let the reader turn to the list of predisposing eauses and he will see that they are just such as to favor these morbid influences, and that the exciting ones are those which absolutely produce them. For example, displacements keep up congestion of parenchyma and mucous membrane, and produce uterine leucorrhœa, and cause friction between the cervix, thus engorged and excoriated, and the vaginal surface. Hyperplasia produces displacement with all its results, furnishing in advance a tissue peeuliarly prone to hyperamia, and already abnormal in character. Laceration of the eervix is a fruitful souree of cervieal hyperplasia, and the eversion of mucous membrane which attends it establishes frietion which results in leucorrhoea and increase of hyperamia. But it is unnecessary to apply remarks which are so obvious to each of the eauses mentioned.

Before Emmet pointed out the pathological bearing of laceration of the cervix, a great many eases of that aceident were regarded as granular degeneration. A careful differentiation must be jractised with reference to the two affections, while at the same time a proper degree of weight should be given to the fact that granular degeneration often oceurs in virgins and involves the whole vaginal face of the cervix.

Symptoms.-Should granular degeneration exist with but trivial disorder of the uterus of any other kind, very few symptoms may be present. Indeed, profuse leneorrhoa is sometimes the only one of which the patient will complain. The fact that other and more serious symptoms generally show themselves, is a corroboration of the statement, that graver disease of the uterus constitutes an important element in sueh cases. Ordinarily, 
these are the syuptoms which will be noticed in a case of the more serious kind:-
Profise blooly and purulent leucorrhea;
Pain and hemorrhage after intercourse;
Nenorrhagia or metrorrhagia;
Pain on locomotion;
Fixed pain in batek and loins;
Tendency to spanamia;
Nervous disorders and perhaps hysteria.

Physical Sigus._- Vaginal touch alone might serve as a diagnostic means, for by it the cervix is felt to be covered by a velvety or granular surface, which, to the practised finger, is at once recognizable. But the speeulum offers the fullest corroboration or corrects any error committed by this means. By it, the cervix, more especially near the os, is seen to be covered by a mass of pus, which being removed lays bare an intensely red, granular, hemorrhagic-looking space of greater or less extent, closely resembling the inner surface of the eyelids when affected by granular degeneration. The diseased surface does not appear depressed below, but is sometimes even elevated above the surrounding mucous membrane.

Course and Duration.- The disease is unlimited. If the general liealth improve, it is possible that nature may effect a cure without the aid of local treatment, but such a result should not be anticipated. The degenerated surface may go on for an unlimited time pouring out pus, and thus greatly impoverish the blood and eause grave constitutional results.

Pathology.-According to Ruge and Teit, the maceration of the cervical mucous membrane in ichorous fluids results in the desquamation of epithelium to such an extent that only one layer of cells exists, through the diaphanous structure of which the red colored tissue beneath is visible, with its exaggerated vascular supply.

Very soon from the epithelial layer prolongations project in wards, dividing the subjacent tissue into villi or processes, such as are formed in the vesical and uterine mucous membrane. These villous projections are new formations, not hypertrophied papilla. They are covered with epithelium, richly supplied with superficial bloodvessels, and liable to increase to large masses. 'To these the names of raricose and bleeding ulcer and cock'scomb granulation have been given.

Prognosis.-The prognosis in this affection is almays good, though it may require a great deal of time to effect a cure, for this will not be permanent unless that of the coexisting disease be accomplished.

T'reatment.-Before treatment for this condition is commenced, let me urge the practitioner to examine carefully as to whether he is really dealing with a case of granular degeneration or with one of cervical laceration. The two conditions elosely resemble each other; the former often com- 
plicates the latter; and a treatment which is appropriate to the one is utterly insufficient for the other.

Granular degeneration heing generally a secondary disorder engrafted upon a pre-existing one, before treatment is adopted, the primary disease should be sought for, and both should be treated simultaneously.

Should displacement, endometritis, vaginitis, or areolar hyperplasia exist, attention should be directed to their relief at the same time that this one of their results is treated. It may be asked, if this be true, how is it that the mere application of caustics to the discased surface will so often effect a recovery without regard to other disease? An influence which commonly induces granular degeneration is congestion of the mucous and submucous tissues at the vaginal extremity of the cervix. The solution of continuity to which the causties are applied, acts, after their application, as an issue, and they by derivative and alterative influence effect good. It is precisely in accordance with this principle that the practitioner, if called to treat a very obstinate case of cervical hyperplasia, which is unattended by such solution of continuity, creates it by abrading the surface by a blister, and then cures the issue thus caused by such caustics as the nitrate of silver or cluromic acid. It is common to hear physicians remark that they are more successful in treating cases of cervical enlargement accompanied by granular degeneration, than those which are free from it. The key to the explanation is, I think, the one here given.

Ilaving presented these remarks and sufficiently insisted upon their importance, I now proceed to the eonsideration of the special treatment of the eondition itself. Before commencing treatment, the general health should receive especial attention; those tonies and hygienic directions which appear hest snited to the particular case being given. These indications should from the eommencement be as far as possible fulfilled: 1st, the granular surface sloould be put beyond the influence of friction; 2.1, it should be protected from contact with ichrous discharges; 3d, a steady alterative influence should be exerted upon it by local applications; and $4 t h$, congestion of the uterus and of the especial part diseased should be prevented.

To accomplish the first indication the uterus, if displaced, should be put and kept in position by a well-fitting pessary. Even if its axis be normal, it is often excellent practice to lift it out of the pelvis by an elastic ring. At the same time such support prevents a tendency to congestion of the organ, and may be rendered more effectual by careful removal of all weight from the abdomen, by tightly fitting or heavy clothing. Let no one who las not tried this as an adjuvant, undervalue it, for there can be no question of its great utility.

Frre use of copions raginal injections should be practised twice daily, to remove all leucorrliwal discharge, and should this arise from endome- 
tritis, that condition should be treated. This indication maty further be accomplished by the application of the styptie colloid of Richardson, which eonsists of a strong solution of tamin in gun-cotton collodion. I know of no means better calenlated than this to accomplish all four of the indications enumerated. It appears to act not only as a direct alterative, but, forming a protective crust over the surface, constitutes for it a slield agrainst friction and uterine discharges, while at the same time, by its compression of the excoriated villi, permeated by their loops of vossels, and of the submueous tissue with its increased vascular supply, it diminishes local congestion.

The nerves governing nutrition and circnlation in the part should be impressed with a new influence by direct alterative applications. The best solid ones are the stick of nitrate of silver or sulphlate of copper ; and the most effectual fluid applications, saturated solution of carbolic acid; chromic acid $\overline{3}$ ss to water $\mathbf{z} \mathbf{j}$; compound tincture of iodine ; equal parts of tannin and glyeerine, left in contact with the part on pledgets of lint or cotton; iodoform; and saturated solution of persulphate of iron, pure or diluted with equal parts of glycerine.

It is a good routine plan to begin with a thorough application of solid nitrate of silver, and follow this immediately by a protective coating of styptic colloid.

When an exuberant development of villi, called by Evory Kennedy, I think, cock's-comb granulation, exists, it is well to snip the growths as close as possible to the mucous membrane by a pair of long-handled scissors, or even to scrape the surface until it is smooth, by means of the steel curctte, before applying the caustic. After this the same substances may be used as for ordinary degeneration.

Should simple eversion of the cervix exist, the hemorrhoidal mucous membrane should be at once removed by the scissors or destroyed by fuming nitric acid. When this is excessive, and due to laceration of the eanal by parturition, the condition may be cured by an operation which consists in paring with long scissors the edges of the cervical fissure, and passing deep sutures of silver wire so as to approximate them thoroughly. By this means the os is restored to its integrity, and the ererted mucous surfaces being placed face to face, friction against them is prevented.

The last indication in enumeration, but not in importance, is the prevention of congestion, local and general. To a certain extent this is aceomplished, locally, by all the alterative and astringent applications alluded to, and the same thing may be furthered by vaginal suppositories and injections. Should any ease prove very obstinate, this end may be more decidedly attained by taking a sharp-pointed, curved bistoury, and begiming as high up the cervix as the disease extends, cutting through the mucous membrane and submucous tissue, extending the incision outside the os as far as the surface is affected. Five or six such superficial 
and painless incisions sever the netrork of little vessels in the submucous tissue, and, for the time at least, interfere with the circulation.

Congestion of the whole uterus is greatly relieved by removal of weight from it by abdominal and skirt supporters; avoidance of muscular efforts; the use of a pessary; careful regulation of the bowels; rest, especially during menstruation; and the use of copious warm vaginal injections.

Applications should be male not only by the physician, who will probably use the speculum not oftener than once a week, but also by the patient, who should make them daily by injections and suppositories. The former should be thus employed : every night and morning a gallon of warm water, containing one ounce of glycerine and one drachm of sulphate of zinc, or two of sulphate of alum, acetate of lead, or tannin, should be injected for a period varying from ten to twenty minutes. Or if it be found necessary to employ a stronger astringent solution, a gallon of pure water may be used first, for the time mentioned, and then a medieated solution, one quart in amount, be used for a short time afterwards.

Vaginal suppositories are by some practitioners employed under these circumstances. A suppository may be made to contain three grains of oxide of zinc, or of sulphate of alum ; ten grains of mercurial ointment; five grains of iodide of lead; or two grains of tannin. To any one of these, should an anodyne be needed, one grain of the extract of belladonna, or of opium, may be added. These substances may be made into a mass with powdered gum tragacanth, starch, or slippery elm, and glycerine, and the whole covered with cocoa butter. They may be introduced hy the finger, but by the use of the vaginal suppository tube, elsewhere mentioned, there is much greater certainty of their coming in contact with the diseased surface. Suppositories may be employed once or twice a day.

Surprise may be felt at the small amount of medicinal substance which I propose to add to each suppository. A great deal of discomfort often arises from larger doses than I have mentioned. I have repeatedly scen patients for whom two grains of tannin thus administered was too large a dose, and who had in consequence to cut each suppository in half before cmploying it.

\section{Cystic or Follicular Degeneration of the Cervix.}

Definition.-This form of discase, though not so frequent as that last mentioned, is by no means rare. It consists in an inflammation of mucous follicles, which resemble those of the cervical canal, and which are scattered over the vaginal face of the eervix, and exist even in the cavity of the womb. "The cervical mucous cysts," says Farre, "are lined by epithelium and basement-membrane. They contain a small quantity of mucus together with granule-cells. Those upon or near the margin of the os uteri may be sometimes observed to contain short papillæ within their 
margin." A recollection of these facts is essential to a full understanding of the stages of this form of degeneration.

Pathology.-Follicular disease of the cervix shows three entirely different phases: 1st. A number of vesicles, equal in size to a millet secol and filled with a fluid like honey, is noticed covering the part. These are due to repletion from retention of the secretion of the follicles. 2al. 'These cysts are seen open, $i$. e, they have burst, and a depression marks the former site of each. 3d. The papilla which they contain undergo hypertrophy and cause the appearance of red, elevated, hemorrhagic-looking tubercles in place of the depressions just mentioned. For the thorough knowledge of this subject we are indebted, as for so much else relating to the anatomy and pathology of the uterus, to Dr. Arthur Farre. Usually the cervix is seen studded over by little globular bodies about as large as a hemp seed, with here and there a depression, and here and there a prominence of red and irritable looking character.

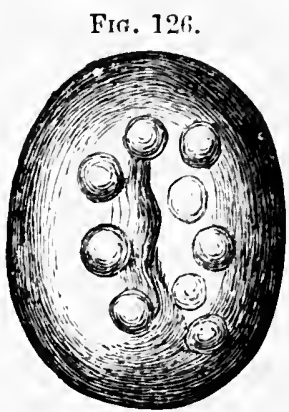

Cystic degeneration of the cervix.

Synonyms._It will now be readily appreciated why a variety of names should have been applied to this disease when examined at different stages. Follicular disease is supposed to be the source of the eruptive affections described by authors as acne, herpes, and aphtha of the uterus.

Causes.-Anything which keeps up congestion in the cervical mucous membrane may give rise to this affection of the mucous glands of the vaginal cervix. Among the chief are :-

Cervical endometritis ;

Granular degeneration ;

Cervical hyperplasia ;

Laceration of the cervix.

Prognosis.-If a few scattered cysts appear, the prognosis is decidedly favorable; but in certain rare cases, where the whole of the extremity of the cervix is filled by them, nothing but amputation of the part containing them accomplishes cure.

Treatment.-The contents of all the cysts should be evacuated by a bistoury, and their cavities thoroughly cauterized by a sharp point of nitrate of silver, chromic acid, or the acid nitrate of mercury. Should the second or third stage exist, the diseased surface should be treated upon very much the same plan as that arlvisel for granular degeneration.

Should a great amount of cystic degeneration exist, and cure not follow evacuation and cauterization of the cysts, the vaginal face of the cervix should be removed by the galvano-caustic wire, or by bistoury or scissors. Here, as in cervical endometritis of cystic character, the rule of surgery which inculcates the ablation of a part which is the habitat of a disease which proves incurable by minor means, should be followed. 


\section{CHA P TER XXII.}

\section{SYPHILITIC VLCER OF THE CERVIX UTERI.}

Frequency-_Syphilis may affect the cervix uteri either as a primary or secondary disorder, though in neither form is it by any means common. It is now a settled fact that true chancre may locate itself upon the cervix, but not the less certain is it that it rarely does so. I lave seen but one case which I felt satisfied was of this character. This was proved by inoculation, the most certain way in which a strictly reliable conclusion can be arrived at, and by corroborative evidence existing in the presence of syphilitic roseola without primary disease elsewhere. Dr. Bennet ${ }^{1}$ states that in his own practice it has been very rarely met with, and quotes in confirmation of his own experience that of Ricord, Cullerier, Gibert, Dupareque, and others. MI. Bernutz, who has made, according to Becquerel, a special study of this subject in the hospitals of Paris, describes chancres of the os minutely, dividing them into Hunterian, diphtheritic, and ulcerous, which resemble phagedenic very closely. With regard to secondary affections on the cervix, there has been considerable discussion, some regarding them as quite common, others as rery rare. Beequerel, after careful research in l'Ourcine Hospital at Paris, was convinced of their occurrence, and Bernutz describes mucous patches, vegetations, erosions, tubercles, and gummy tumors. I know of no more significant evidence of the rarity of these affections upon the cervix than the fact, that in a recent work upon syphilis, a work remarkable for the thorough and eomprehensive style with which it deals with all relating to that subject, almost no mention is made of syphilitic affections of the cervix. I allude to the work of the late Prof. Bumstead. ${ }^{3}$ The anthor investigates the character of syphilis when affecting all parts of the body, even the lachrymal sacs, the membrana tympani, etc., but nowhere is any mention made of the disease appearing on the cervix, except a cursory statement, that at Bellerue Hospital he had seen some remarkable instances of mucous patches thus located. The sign of the secondary disorder which we would most naturally expect to find in this site would be the mucons patch, as it is one of the most frequent of all the manifestations of that stage; but we are informed by MII. Davasse and Deville,*

1 Bennent on the Cterus, p. 350.

2 Mal. de l'Uterus, vol. i. p. 169.

a Bumstearl on Venereal Diseases.

4 Iavasse and Deville, Des Plaques IIuqueuses: Arch. Gén. de Méd., 1845, t. ix. et $x$. 
that of one hundred and eighty-six women affected by syphilis. ant axamined in reference to the location of its lesions, they were found on the? cervix uteri but once.

Conrse and Termination._-'The primary affection being located on the cervix, the general system becomes affected as firom a ehanere on any other part, and, as M. Gosselin has pointed ont, instead of passing off rapidly, as it sometimes does, it may assume the fungous type. During its course the cervical chancre las a marked tendeney to become covered by false membrane, which Robert ${ }^{2}$ first noted, and Bernutz subsequently corroborated. Unless a fact corroborated by Förster ${ }^{2}$ be carefilly borne in mind by the diagnostician, a grievous error may oeeur in the differentiation of this form of ulcer from malignant disease. He declares that syphilitic ulcers sometimes destroy tissue so freely as to penetrate into the bladder or reetum.

Differentiation.-For evident reasons this is a matter of great importance, not only as regards therapentics, but beeause it may involve a delieate legal question affeeting the ehastity of the woman.

These are the means of diagnosis in eases of chancre:-

Border of ulcer preeipitous;

Surface of ulcer depressed;

Great tendency to bleed;

Great tendency to false membranous covering;

Rapid development of constitutional symptoms;

Early appearance of roseola ;

Transmission by inoeulation.

All of these signs are of value, but the only ones upon which a positive opinion eould be based are the last three.

Secondary eruptions, as for example, mucous patches, vegetations, ete., which appear here will be known by

Their rapid development ;

Their connection with constitutional signs ;

Simultaneous affection of the vagina;

Absenee of chronie cervical inflammation ;

The peculiar appearance of secondary eruptions.

Treatment._-This will eonsist in eases of chancre of the ordinary treatment adopted when such an ulcer affects any other part. In cases of seeondary affections the patient shonld be put upon a mercurial course, the surface cauterized, and subsequent dressings made of mercurial preparations, of whieh the black or yellow wash, mercurial ointment, and ealomel, are the best. 


\title{
C II A PTER X X III.
}

\author{
UTERINE FUNGOSITIES.
}

History.- The fact that the lining membrane of the uterus becomes covered over to a greater or less degree with fungous masses, which have a marked tendency to bleed, was announced by Récamier, who not only deseriber them, but gave us the best method yet devised for their relief. After attention was called to the subject by_him, theses were written upon it in Paris and Strasbourg, by Rouyer and Goldschmidt, and the subject attracted. a great deal of notice in France, and received the attention of such men as Marjolin, Robert, Trousseau, Nélaton, Maisonneuve and Nonat, who not only adopted Récamier's pathologieal views but endorsed and practised his method of treatment. After many years of trial this contribution of the great French gynecologist may be regarded as by no means the least raluable of the many which he has made to this department. For a long time kept sub judice, it has of late years found its way into the text-books.

Definition.-Cterine fungosities may be defined as fungous projections from the endometrium, the result of prolonged congestion from any cause, or of the organization of portions of placenta remaining attached to the surface. Under this head, of eourse, carcinoma and sareoma of the endometrium might through an error in diagnosis be brought, but the nature of these grave disorders being once recognized, no one would think of classifying them under it. Upon theoretical grounds objection might be raised to elassifying under the same head hyperplasia of the lining membrane of the uterus and remains of the placenta, but as the symptoms and treatment of the two conditions are identical, and there is no means of differentiating one from the other, it seems better for practical purposes to convisler them together.

Frequency-_Fungoid degeneration of the endometrium is an affection of great frequency: one which plays the part of an important factor in menorrhagia and metrorrhagia, and which often saps the health of patients in whom its existenee remains for years unsuspecterl. The practitioner who reengnizes the important bearing of this subject will find himself prepared to cope with many eases of chronic endometritis, menorrhagia, metrorrhagia, and uterine enkargement which before proved entirely rebellious to treatment.

Synomyms. - The disorder is sometimes described as granular hyper- 
plastic, or polypoid endometritis, or, as Slarjanky styles it, "internal villous metritis."

Pathology.—Uterine fungosities will usually be found to exist as a consequence of uterine engorgenent, however kept up; or of abortion or labor. I have also repeatedly seen them in young women at the age when menstruation is establishing itself, and found then under those cirenmstances produce a most excessive and dangerous degree of hemorrlage. In the first condition mentioned, prolonged congestion creates a liypergenesis of tissue which results in hyperplastic growths upon the endometrium. In the second, if a large portion of placenta remained attaclied in utero, what is sometimes styled a placental polypus would be created, but small portions only being here and there attached, these little fungosities are the result. In the third condition, the great impetus given by puberty to sexual growth in the developing girl seems to affect the uterine lining so as to produce localized lypertrophies upon its surface.

Under the microscope these growths if the result of hyperplasia and not of retention of small portions of placenta are found to consist, according to Dr. F. Delatield, who has repeatedly examined them for me, of hypertrophied elements of the mucous membrane, dilated follicles, enlarged bloodvessels, and exaggerated cell growth. Sometimes the amount of material removed at one time will amount to one, two, or three drachms, and its appearance will make one instinctively dread the existence of a malignant basis; but the microscope will commonly even in such cases convey the comforting assurance to the contrary.

Cuuses.-The causes may be enumerated as follows:-

Abortion or labor at full term;

Endometritis;

Subinvolution;

Laceration of the cervix;

Uterine displacement of any variety;

Fibromata, submucous or interstitial.

All these, except the first, seem to produce the condition by exaggerating formative development, or by keeping up engorgement of the uterine lining membrane.

Symptoms.-There is but one symptom which has any significance, that is uterine hemorrhage. This may consist only in a great exaggeration of the menstrual flow, or in profuse metrorrhagia. Whenever either or both of these is present, without other assignable cause, these growths should be suspected. For example, a patient has lost a great deal of blood from the uterus, and an abnormal condition is strongly suspected as the cause of the excessive flow ; no solution of continuity is found to exist, no neoplasm of any kind is discovered, and no large portion of placenta is supposed to be in utero; under these circumstances fungosities should always be suspected, and their existence determined by physical examination. The 
method of deciding the question is so simple that it should, under these circumstances, be unhesitatingly employed.

Physical Signs.-Fungosities being suspected to exist, the patient should be examined with Sims's speculum. After its introduction, the cervix sliould be lield by the tenaeulum, and if the os externum or cervical canal be very small, it should be gently opened by the introduetion of two or three graduated uterine dilators until it will admit the little wire curette to be shown further on in this clapter. An ordinary looped wire answers very well, and I have often made a loop of a lady's hairpin, bound it with waxed thread in the bite of the foreeps, and employed that.

All being now prepared, the loop of the wire curette, or the loop of wire, is passed in and drawn gently down the anterior face of the uterine eavity, then of the posterior, and then of each horn. As it is withdrawn after making each exploration, it is examined to see if it has dislodged a fungosity. If there be any within the eavity, and the instrument be not held in very unskilful hands, one or more will be looped off. These may, for greater certainty of diagnosis, be put under the microscope. In some cases a mamilloid proeess of mucous membrane will be found covered over with epithelium, placed edgewise upon it with great regularity; in others, a piece of placenta will be seen; while in a few eases the tale will be told of commeneing eancer or sareoma, which will yield to no treatment whatever.

It has been said that the curette gently passed over the endometrial surface will reveal little irregularities, even if it do not remore them; and in very marked eases this is true, but he who relies upon this as a erucial test will pass over many minor cases requiring diagnosis and treatment scarcely less than they. The wire hook should be regarded as a valuable diagnostic resource in all endometrial outgrowths. Employed as such, as freely as I make use of it, I have yet to see an accident follow its introduetion if applied with caution. I have seen the uterine sound excite peritonitis, but never the wire loop used gently for the purpose merely of diagnosis. By its instrumentality the powerful aid of the microscope is put at our service, and many an obseure case will be mate clear, many a doubtful one set at rest by the combination.

Course, Duration, and Termination.-These growths may last, produeing their evil results for years; not increasing at all, but not diminishing. If the patient become pregnant, the clianges of parturition seem in some cases to destroy their activity, but even this they at times resist, and after delivery the case goes on as before.

Sometimes the little growths will be east off and appear in the menstrual discharge. But this casting out does not go on to eure. If' not interfered with, they will commonly annoy and weaken the patient until the menofause, when, notwithstanding their presenee, the uterine flow will usually cease. I say usually, for the reason that in some cases it will obstinately continue at irregular intervals for years after its occurrence. 
The remedy to which I have made allusion as having bern introlued by liecamier, is the use of the curette, which meets the requirements of the condition perfectly. It must not, however, be supposed that one, or even several applications of the curette, will miformly cure these cases; many of them will prove very obstinate, rebellions, and perplexing. Some years agro, I attended, with Dr. Fessenden, of Brooklyu, a young lady of sixteen, who, ever since the establishment of menstruation, hat lost blool so freely at her periods as to be alarmingly exsanguinated. I employed the wire eurette, and removed a great number of large growths, and she got up apparently well. In three months, however, her dangerous symptoms retnined, and the operation was repeated and followed by injection of eompound tincture of iodine into the uterine eavity. Again she got better, and arain had a relapse after a few montlss. Sims's cutting curette was then empioyed, and after its use nitrie acid was applied by Lombe Atlill's method. After this Dr. Fessenden oceasionally made an application of iodine to the uterine cavity, and she ultimately recovered.

In another case whieh I attended with Dr. L. M. Yale, of New York, the curette was, during the course of three years, used ten times, very large quantities of fungous growths being each time removed; and the application of the instrument, Sims's being sometimes employed, and at other times mine, followed by free applications of iodine or nitric acid. After a time we felt sure that sarcoma or cancer must be the basis of the affection, but Dr. Delafield eheered us with the assurance that this was not so, and the justice of his statements was verified by the entire recovery of our patient. In a great many cases I have had to repeat the operation of scraping about once a year for a long time, so that now I always guard my patients against this possibility for fear of their being disappointed at the result.

Another curious fact connected with this operation, which I am at a loss to account for, is the irregularity in menstruation which occasionally follows it. The period next suceeding the operation will possibly be as profuse as those before it, but after this the patient may menstruate very irregularly.

$$
\begin{aligned}
& \text { Results._Directly :- } \\
& \text { Menorrhagia; } \\
& \text { Metrorrhagia; } \\
& \text { Lencorrhoca. } \\
& \text { Indirectly : } \text { Spanonia ; } \\
& \text { Sterility ; } \\
& \text { Constitutional feebleness. }
\end{aligned}
$$

Prognosis.-This will depend in great degree upon the treatment adopted. If the practitioner be one of those who abhor a resort to even 
the simplest surgical procedures, and who rely upon constitutional treatment in all these affections, the prospects of the patient for recovery are poor. If, on the other hand, the procedure about to be described here be resorted to, recovery is as certain as the method is simple and safe.

Treatment.-Récamier advised the introduction into the uterus of a small scoop called the curette, by which these growths could be gently scraped off. Ilis advice, although followed by some able men, was not generally accepted, and his method excited a great deal of hostility which even now has not passed away. The reason for this was, I think, the fact that the instrument employed for the procedure was so rough and harsh. At a later period Sims introduced the steel curette shown in Fig. 128. This was an advance over Récamier's method in the superiority of the means for attaining the end. But even the use of Sims's cutting steel instrument was too dangerous, and the operation remained imperfect. For a number of years I lave employed the instrument shown in Fig. 129.

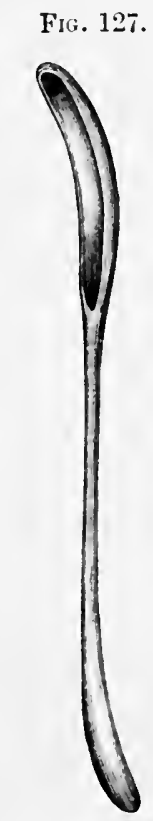

Récamier's curelte.
FIG. 128 .

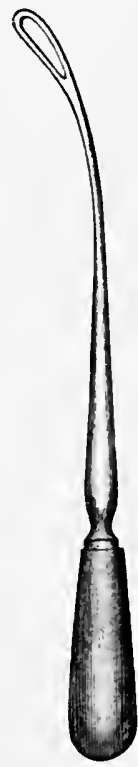

Sims's steel enrette.
FIG. 129.

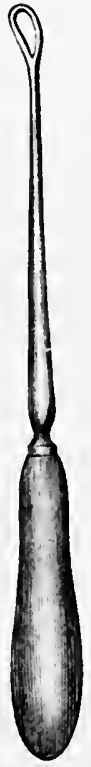

Thomas's wire curette.

It consists of a copper wire with a small loop at its extremity. The loop is slightly flattened at its edges, but still it is not a cutting instrument. Even if applied with force, it can do no serious damage. It removes the growths by looping them off, not by cutting or tearing the endometrium. I employ it very largely in practice, and never yet have I hand any accident follow its use in several hundred cases. Of course, as 
there are instances in which the passage of a uterine somm will cat1:e peritonitis, so there are those in which this operation may end fatally, hut I have never met with one, and no one could use it more freely than I do.

In a very few rare cases in which the wire eurette fails to effect a cure, I employ Sims's more powerful instrument, but never do I do this without good reason.

After the operation the patient should be kept perfectly quiet in bed for three or four days, and any tendency to inflammation at once met by the treatment appropriate to peritonitis.

Dangers of the Curette.-The dangers which attend upon the use of the curette are :-

\section{Peritonitis.}

\section{Cellulitis.}

Atresia of the cervical canal.

Hemorrhage some hours after operation.

I have seen the first follow the use of the steel eurette, never of the wire. It should be guarded against by eare after operation, perfect rest for several days, and the free use of opium in ease of pain. The second is likely to oceur in eases in which cellulitis has existed in chronic form before resort to the eurette. The third I have seen in one case after the whole corporeal and cervical lining was thoroughly scraped by the cutting curette. The fourth, which I have once met with, may readily be prevented by the use of a vaginal tampon.

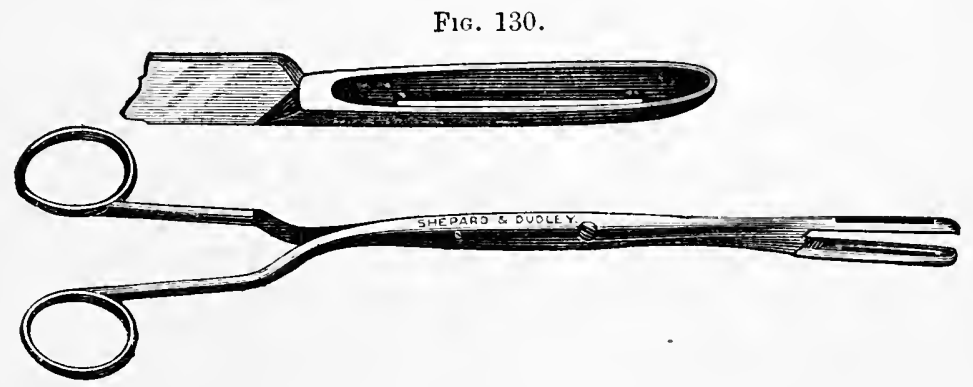

Emmet's curette forceps.

Emmet, in the hope of avoiding these dangers, recommends in place of the curette, the use of a pair of forceps with eutting edges shown in Fig. 130.

By these the fungoid growths are seized and removed by alternate separation and approximation of their blades. 


\section{II A PTER XXIV.}

\section{LACERATION OF THE CERVIX UTERI.}

Definition.-This consists in the tearing of the wall of the cervix uteri during labor either partly or entirely through the tissue which composes it.

History.-It has long been known that during the last part of the first stage of labor, as the presenting part of the child eseapes from the uterus and enters the vagina, the circular fibres of the os externum and of the raginal portion of the cervix not infrequently give way under the excessive distention which occurs, and lacerations in one, two, or more directions take place. In 1851 Sir James Simpson ${ }^{1}$ drew attention very fully to this subjeet, pointing ont the facts that lacerations of the cervix uteri are of very frequent ocenrrenee, that they are not the result of mismanagement, that they are so common after first labors as to be regarded as reliable signs of labor having oceurred, and that they may be complete or may involve only the mueous and middle coats of the cervix.

Some of the evil results of the eondition too were reeognized, as will be seen by reference to Dr. Gardner's work upon sterility, where it is eredited with the causation of liypertrophy of the eervix, ulceration, cervical eatarlh, sterility, and abortion.

But the important pathological bearings of this aceident upon disorders of the uterus, lias been aplyreciated only of late years. The eredit of having recognized the significance of the lesion, and of having furnished us with a safe and ellieient means of eure, belongs to Dr. T. A. Einmet. 'The future of his operation for its relief will unquestionably be a long and brilliant one, and its results will effeet a great deal of good for uterine patlology. Dr. Emmet, after having performed the operation for seven years, published his first paper upon it in 1869. It was not, lowever, until a second paper by him in 1874 that the importance of his discovery was fully appreciated. Since that period it las gradually risen in favor, although even now its great merits are not generally recognized. It is surely not too mueh to say of it that it eonstitutes one of the most important contributions to gynecology which has ever been made.

Frequency._No reliable statistics are at our disposal upon this subject, for the reason that lacerations of the cervix exist under two forms with

1 Binburgh Journ. of Med. Science, p. 488, and works of Sir J. Simpson, Am. (4.) [1. 152. 
reference to pathology : first, they may be important fictors; and second, their existenee is reeognized by inspection, but they prod!tee no evil results whatsoever. The question is not therefore merely how of ten the cervix is to a greater or less degree lacerated during parturition, but how often such laceration is productive of results which have an important bearing on uterine pathology. Simpson' declared that evidence of a certain derree of laceration is given by "almost every careful autopsy of women after delivery, whether assisted or not assisted during their labor." Emmet" says, "at least one half of the ailments among those who have borne children are to be attributed to lacerations of the cervix." Goodell ${ }^{3}$ estimates "that about one out of every six women suffering from utcrine trouble has an ununited laceration of the cervix." It may be taken for granted, first, that a certain degree of laceration of the vaginal extremity of the cervix uteri is the rule in first labors; second, that a certain number of these are entirely recovered from or exist with cicatrized surfaces without producing pathological consequences; and third, that in a large proportion they prove important factors of uterine disease.

The great reason for the varying results of laceration is this : if it interfere with involution of the body or cervix of the uterus, hyperplasia either local or general will result, with accompanying cystic degencration, catarrhal inflammation, eversion, and congestion; if, in spite of it, involution goes on to a successful issue, the parts give evidence of the accident only by physical examination, not by pathological results. Upon the recognition of this fact should rest the necessity for operative interference. If it become the rule of practice that all cervical lacerations should be closed without reference to their pathological influences, many women will be exposed to operation without cause and without compensation.

Synonyms._Lesser degrees of laceration are described as fissures, and cases attended by eversion of the cervical endometrium as ectropion.

larieties.-Laceration may be partial, where the mucous or middle coats of the cervix are torn through, the external being intact; and comlitete where the whole texture of the canal is involved in the rupture. It may likewise be bilateral, unilateral, or stellate.

Anctomy.-It must be remembered that this accident involves the lining membrane of the cervical canal, with its reticulated mucons membrane and immense number of Nabothian glands. Should it produce pathological results, they will primarily affect these parts, secondarily those which are more renote.

Puthology-Laceration of the cervix, occurring as it does during parturition, is very apt to interfere with involution of the cervix, of the body, or of the whole uterus. This interference may be very slight or very marked,

1 Op. cit., p. 152.

2 Op. cit., p. 480.

3 Lesson in Gyneculogy, p. 169. 
the degree generally depending upon the extent of the injury inflicted. As a result of the accident, the cervix or whole uterus remains enlarged; cystic hyperplasia affects the cervical andometrium, rich in glands; hypersecretion at onee takes place very markedly; and gramular degeneration with eversion of the lining membrane oceurs. This combination makes up the condition firmerly charaeterized as inflammatory ulceration of the cervix and treated by depletion and caustics.

I would not be understood as maintaining that moless laceration of the cervix produces subinvolution it therefore does no harm, but merely as asserting that it usually and ehicfly effects its results in that manner. This is the explanation of the fact that section of the non-parous cervix for removal of tumors or for the cure of sterility or dysmenorrhea very rarely results in any of the evils ordinarily attendant upon laceration, such as eversion, endometritis, or areolar or eystic hyperplasia. It is not to be denied, however, that laceration of the parous uterine neck, unattended by subinvolution, and section of the non-parous, sometimes, by slight eversion of the mucous membrane and the influence of frietion from the vaginal walls, eventuate in areolar or cystic hyperplasia with endometritis and granular degeneration. The last is not a necessary result of laceration, but is produced indirectly by the ichorous mucus which is secreted by the inflamed endometrium.

Cunses.-Every patient, when informed as to the existence and origin of this condition, instinctively turns in a direction to which the mind of woman has a natural proclivity, that of censuring the medical attendant for the unfortunate result. It becomes the bounden duty, at the present day, for the gynecologist to remove fully and completely all such disposition on the part of the patient, not as a matter of professional courtesy, but of simple justice. Let a patient be ever so well attended, this aecident may, as Prof. Simpson pointed out, occur even after a short and natural delivery. It will be noticed that I say that, "at the present day," no blame should be allowed to attach to the attending obstetrician. I feel sure that this will not be so in the future. It is true that even then prevention will prove impossible; but not so, carly recognition. Six weeks or two months after delivery every proturient woman shouh, with our present lights, be examined as to the conlition of the perineum and cervix uteri. It is an entirely fallacious position to asume that an examination just after labor reveals the real state of these parts. No one conld then thoroughly inform himself, except by an exploration the exposire attendant upon whiclo would defeat its practice. As far as the arvical injury is concerned, too, even if discosered just after labor, it could not then be operated on, and by the end of the feriod of involution it miglit have entirely disappeared. An examination at the time when a parturient woman should be discharged from the obstetrician's observation, the end of the period of involution, and not the ninth day, as is now gene- 
rally done, would reveal the true condition of things, and in a great many cases avoid for women lives of suffering and invalidisu. A laceration of the eervix being discovered, it would not follow that operation would be inevitable, but the obstetrician, being now forewarned, would be prepared to act for the best interests of his patient.

'The chief' causes of laceration of the cervix may thus be stated :-

Precipitate labor ;

Manual delivery;

Instrumental delivery ;

Labor with rigidity of 0 ; ;

Cicatricial material in tissue of cervix ;

Cancerous legeneration of cervix ;

Section of cervix during labor;

Too early evacuation of the liquor amnii ;

Abortion.

In my own experience $I$ lave met with every cause here stated as productive of this accilent, the first three recorded being infinitely the most fiequent. Head last labors, calling as they do for the very rapid passage through a badly dilated os of an uncompressed head, often induce it, but these I consider in the eategory of " manual delivery." Emmet considers criminal abortion a particularly frequent eause, though it is difficult to see why it slould be more so than that from aceidental causes.

Symptoms._-The rational signs of this condition are, as a rule, numerous and important :-

Pain in back and loins;

Sense of "bearing down;"

Leucorrhuca ;

Increase or diminution in menstruation;

Sometimes hemorrlage after coition;

Neuralgia of cervix ;

Sometimes sterility ;

Discomfort in locomotion;

Dyspareunia.

All these, of course, do not occur in any one case. Some cases present some of them, and some others.

Physical Signs._-The examination for this lesion should always be made with Sims's speculum or one of its modifications. By the cylindrical speculum, or by those valvular ones which distend the ragina sliglitly, it is often not recognizable, and always imperfectly appreciated. This furnishes a good illustration of the truth of the position elsewhere assumed in this work, that the gynecologist who habitually employs Sims's method of examination stands upon a vantage ground unattainable by one who does not do so.

The cervix, being exposed to view, will be seen to present somewhat the appearance shown in Figs. 131 and 132. 
Fig. 131.

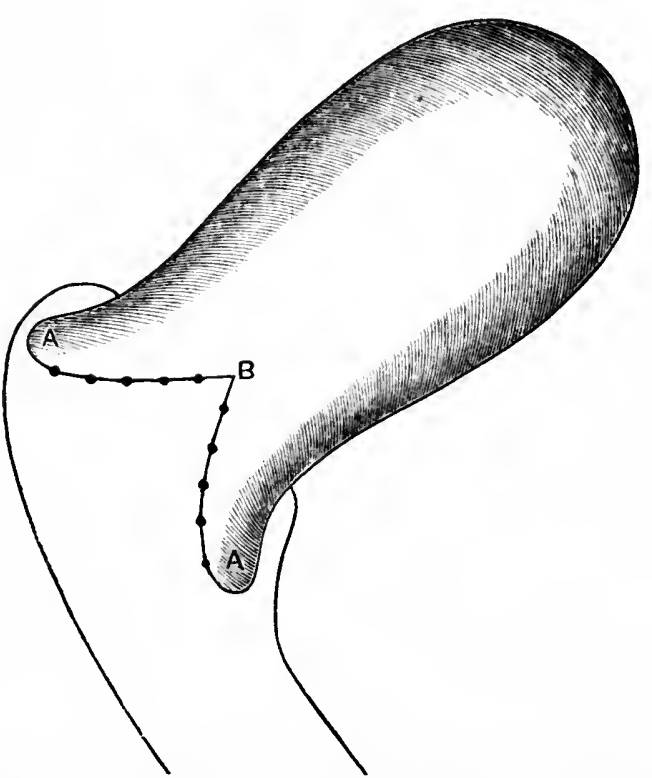

Bilateral laceration to vaginal junction. A, A, lips of the severed os externum. $B$, os internum.

Fig. 132.

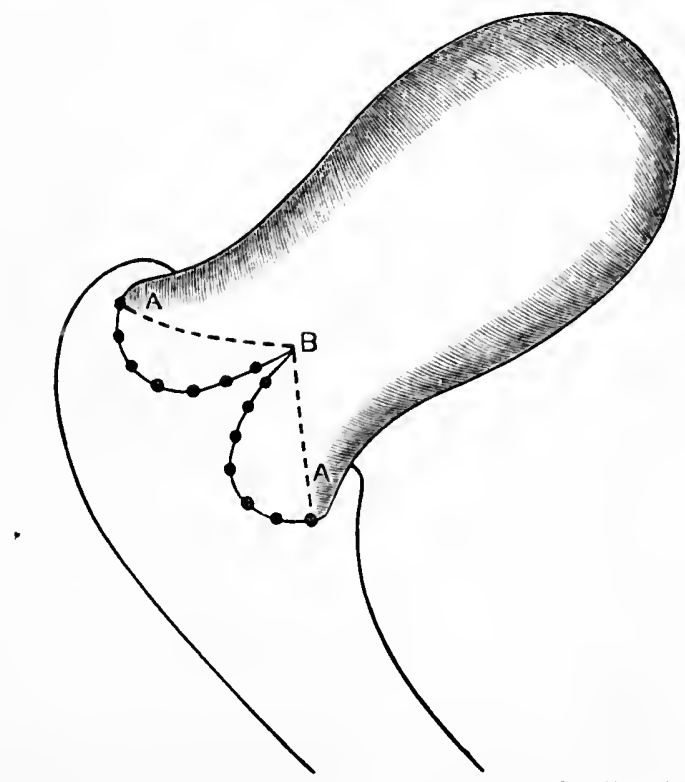

Bilateral laceration to vaginal junetion, with liyperplasia of enrvical malls. A, A, lips of severed os externum. B, os internum. 
In both these diagrams the round spots on the ecrvical walls represent enlarged Nabothian follieles; in the second the dotted lines must receive no attention, as they refer to something to eome hereafter. But these diagrams, although conveying correct ideas of the general nature of cervical lacerations, do not sufliciently portray the many variations which this interesting and important lesion may assume. Fig. 133 represents the

Fig. 133.

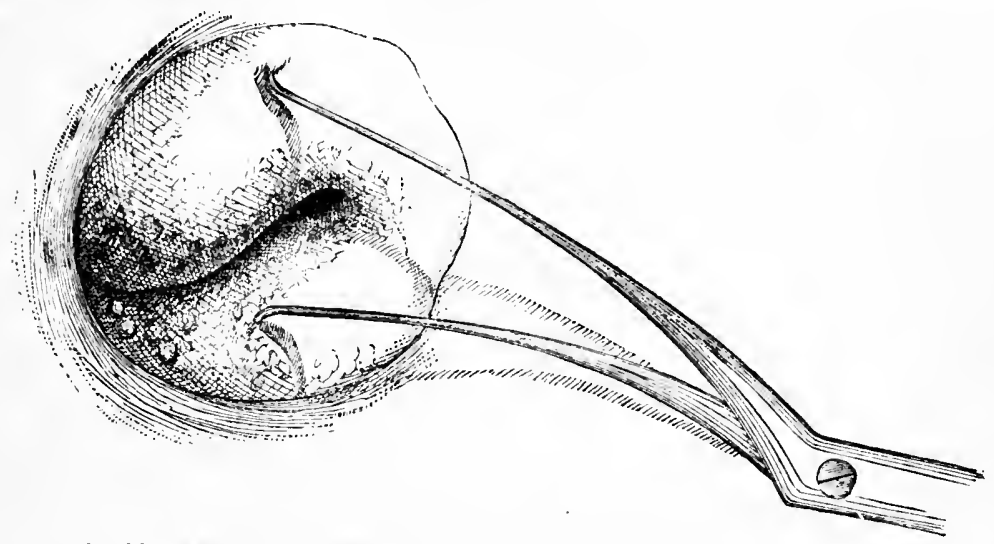

Double tenaculum separating the flaps of a [unilateral] laceration. (Emmet.)

more detailed outline of a unilateral laceration, the rent being posterior, and Fig. 134 of a muitiple or stellate rupture.

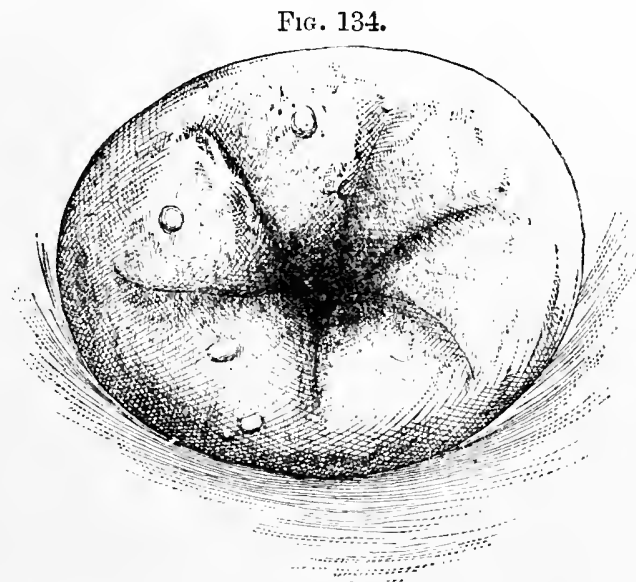

Multiple or stellate laceration of the cervix. (Emmet.)

Many cases of the varieties of cervical laceration which I have mentioned, unilateral, bilateral, and multiple, whether these be complete or partial, are obscured by hyperplasia and eversion of the endometrium, 
with its glands in a condition of cystic degeneration; by areolar hyperplasia of one or both lips of the tear; and by granular degeneration going on to development of extensive exuberant growths. These can only be recognized by careful aurl attentive examination. For excellent delineations of these and life-like representations of them, I would refer the reader to some colored lithographs by Dr. P. F. Mumlé.'

The parts being exposed to view by the speculmm, a tenaenlum should be fixed in each extremity of the serered cervix and its divided walls drawn together. As they come into contact, the normal shape of this part will present itself to view and at once be recognized unless, as in Fig. 134, so much hypertroplyy has occurred on the inner walls of the two sides as to render this impossible. Even then, however, an approximation to the truth may always be arrived at.

Differentiation.-The conditions from which laceration of the cervix will generally have to be differentiated are these:-

Granular degeneration;

Cystic degeneration;

Simple hyperplasia or hypertrophy;

Malignant lisease.

It will often prove by no means easy to arrive at certainty until the case has been kept for some time under oberration. From cancerous exuberation from the endometrium the microscope will sometimes prove the only certain method of differentiation.

Results._Nothing more trinmphantly displays the value of Emmet's contribution to gynecology in connection with eervical lacerations than a full exhibit of the evils which result from that condition. Its ordinary consequences are-

Clironie peri-uterine cellulitis ;

Epitlielioma ;

Subinvolution of a part or the whole of the uterus;

Sterility ;

Menstrual disorders;

Cerrical endometritis;

Granular and cystic degeneration ;

Fungosities of eorporeal endometrium;

Neuralgia of cervix ;

Dysparemia ;

Temlency to abortion;

Cterine displacements.

There can be, on the part of those who have heen properly impressed with the importance of this lesion, no question as to the trutl that all the conditions mestioned may originate from this aecident.

1 Am. Journ. Obstet. and Dis. of Women and Childrell, Jan. 1879, p. 134. 
No part of the borly of a woman is so liable to the developmont of cancer ats the uterus; no part of the nterus so liable to it as the neek; amb no tissue of the neck so liable to it as the glandular lining memblane. Exposure of this by eversion, the result of laceration, woukl, theoretically, be supposed to be a fruitful exciting cause of that aflection, and practieal observation abundantly supports theory in reference to the matter. My own observation has for several years made me feel sure of this, and that of Breiskey, Emmet, and Veit is recorded to the same effect. This alone oflirs a valid indication for the closure of lacerations attended by local engororements and irritation.

Prognosis.-As time passes, the raw surfaces of the lacerated cervix may gralually beeome cicatrized, its evil results diminish, hyperplasia disaplear, and the patient enjoy very good health, in spite of the fact that the condition still exists. This may occur without treatment, though the applieation of alteratives, escharotics, and astringents, as iodine, nitrate of silver, cantlariles, tannin, alım, zine, ete., unquestionably hastens and secures the result. Ordinarily the patient remains to a certain extent an invalid until the menopanse, when the occurrence of atrophy of the internal genitalia effects a removal of the consequences of the laceration.

Treatment.-This may be palliative or curative, the former being appropriate to cases in which from any cause the operation of trachelorrhaphy cannot be performed. Palliative treatment consists in the use of copious hot water vaginal injections, evacuation of cervical cysts by puncture, application of alteratives, such as iodine, nitrate of silver, glycerole of tamin, removal of all superincumbent weight, and direet support of the uterus by a pessary.

Curative treatment consists in repair of the laceration by trachelorrhaphy, after the patient's general condition has been rendered good and the affected parts have been properly prepared for operation by the palliative eourse just mentioned.

I will deseribe the operation as applied to a case of bilateral laceration. The patient being anesthetized and placed upon a table before a window, in Sims's position, his speculum slıonld be introduced, and two tenacula fixed, one in each flap of the laceration, and they should be approximated. It this can be effected, the operator determines exactly where his denurlation is to be made; if it be found to be impossible, he reconnizes the fact that the case will require a special plan of treatment, which is soon to be described. Ilaving decided where the denudation is to be made, the operator catches the lower side of one flap, and, by scissors, cuts away the mucous membrane and a small portion of the parenchyma as far as the angle made by the junction of the two flaps. Then seizing the other flap he treats it in the same way, the strip of separated tissue being now completely removed. The same process is gone through with on the of her side, the resultant of both being two long raw surfaces, one on each side 
of the laceration, with a strip of undenuded tissue exiending upwards to or towards the os internum. Fig. 135 will show this.

Fif. 135.

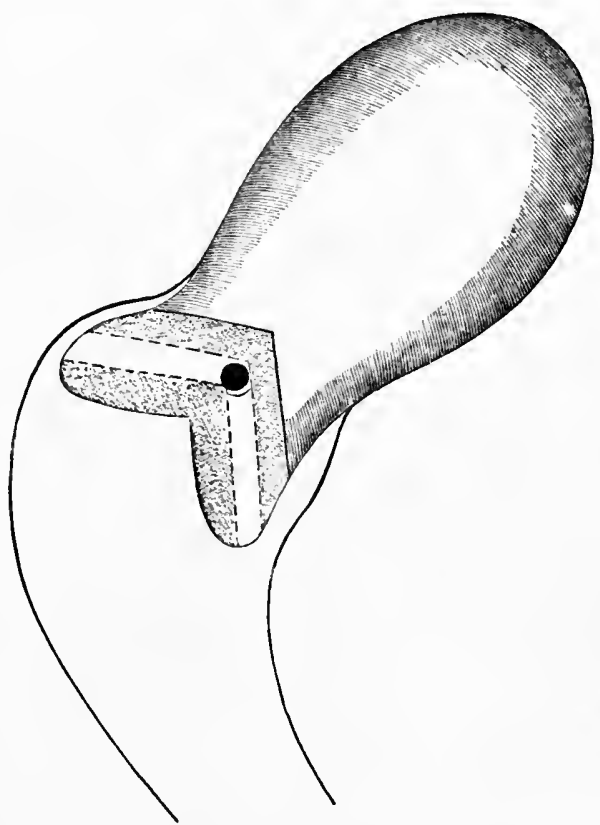

Lacerated cervix denuded, and strip of undenuded surface left to act as a cervical canal.

The flow of blood is now stanched, if necessary, by a tampon of linen or cotton left in place for five or ten minutes. The operator, again fixing the tenacula, aseertains by approximation of the opposing denudations that they will after passage of the sutures lie in contact with each other, and proceeds to the second step of the operation.

Fixing the tenaculum in the cervix near the upper angle of the lacera. tion, he now passes through one flap a sharp-pointed, short needle, held in the needle forceps. The needle is introduced about a quarter of an ineh from the edge of the denulation, passed through, and in the same way carried through the opposite lip. This needle is armed with a loop of silk by means of which a silver wire is drawn into place, the ends of which are placed muler the finger of the person holding the speeulum. One after the other wire sutures are passed from albove downwards, albout a third of an inch apart, nutil the lower extremity of the laceration is retehed. Then the other side is treated, if it be a bilateral laceration, in the same manner.

The sutures are now twisted one by one, the upper ones being first dealt with, until all are twisted, when each one is bent downwards so as 
Fig. 136.

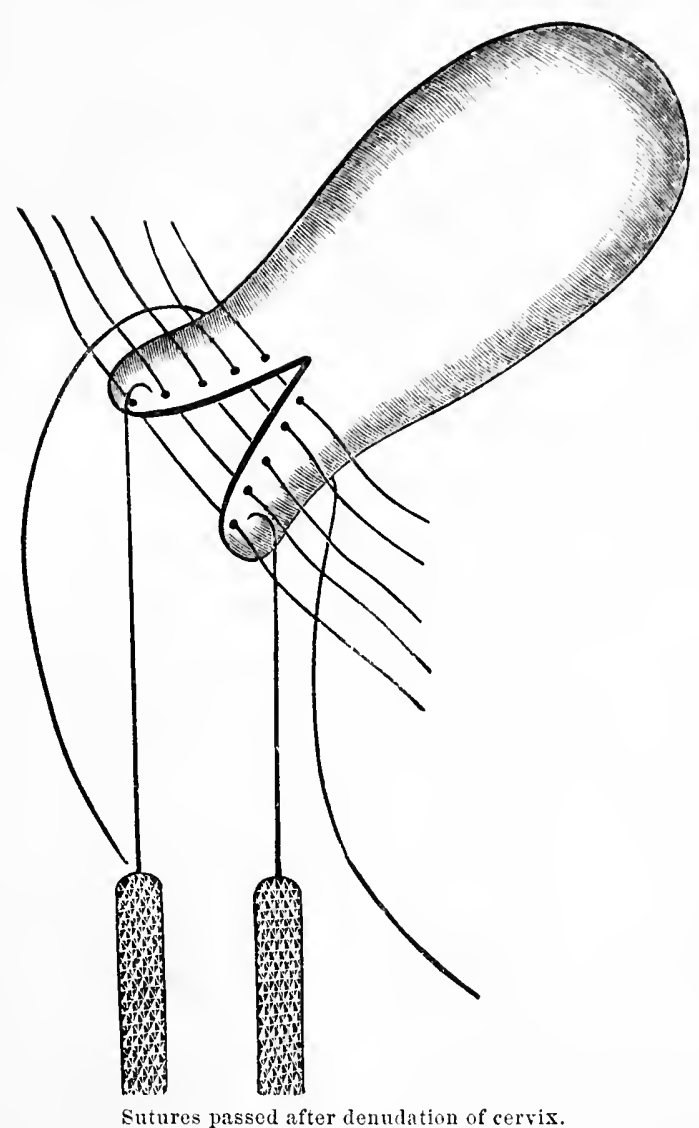

to lie flat against the wall of the cervix. 'The conclusion of this procedure is: shown in Fig. 137 .

In case the laceration is multiple or stellate like that shown in Fig. 134 , it is not proper to close each little fissure separately, but cutting up on each side to the vaginal junction so as to make the laceration one of bilateral variety, denuding still more so as to narrow the cervical canal. and then closing by suture as already described.

Still another class of cases must be mentioned. Sometimes hyperplasia of the inner walls of the cervix has occurred to such an extent as to prerent easy approximation of the opposing flaps, as shown in Fig. 132. Here it is necessary to cut away the hypertrophied tissue below the dotted lines, and then the cervical walls will readily come into apposition.

The patient, after the operation, should be confined to bed and kept upon low diet. The bowels may be moved every day, and the urine 
evacuated upon the bed-pan. Twice a day the vagina should be cleansed by a warm, carbolized injection, and on the eighth or ninth day the sutures should be very cautiously remored beginning with those above. If union have not occurred or seem very weak, the lower ones may be left for a fortnight.

\section{Fig. 137 .}

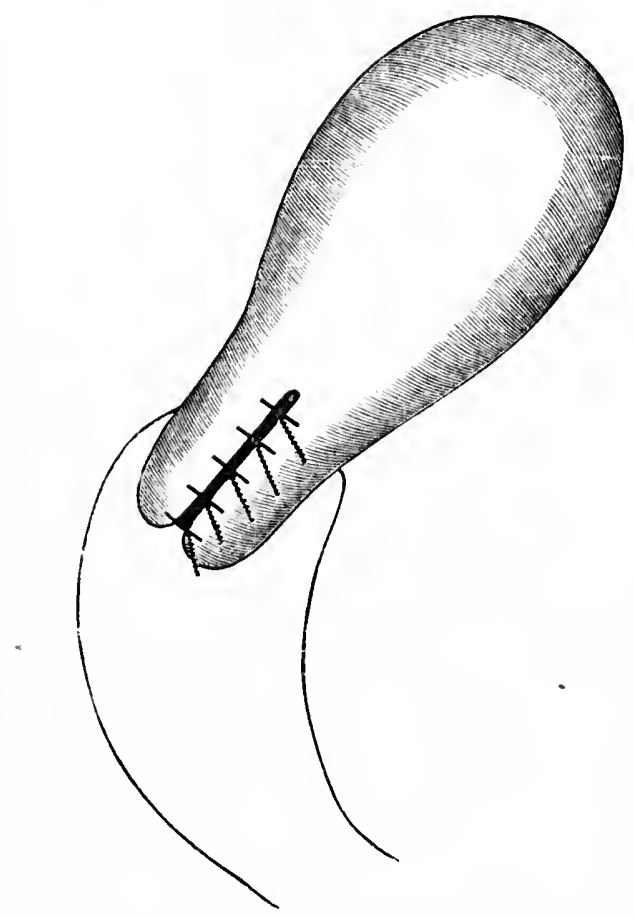

Sutures cwisted aud beut dowuwards against the wall of the cervix.

The operation sometimes, though very rarely, results in cellulitis or peritonitis, and considering the good which it accomplishes is remarkably free from risk. The use of a pessary to sustain the heavy uterus is often advisable for two or three monthis after recovery. 


\section{II A PTER XXV.}

\section{GENERAL CONSIDERATIONS UPON DISPLACENENTS OF THE UTERIS.}

Ilistory.-That the carliest practitioners of medicine were fimiliar with this subject is abmulantly attested by the writings of the Greek and Romin sehools. It is distinctly mentioned by Ilippocrates, and more clearly and exactly still by Galen and Moschion about the second century of the Christian era. This remark applies not only to prolapse, but also to versions, which were evidently understood. Hippocrates and Moschion even deseribed latero-version, a variety which has not been much noticed by modern writers, and Aetius ${ }^{1}$ in the sixth century indieates the method for reduction and retention in place of the retroverted womb. Although certain passages in the works of these old writers seem obscurely to refer to bending of the uterus upon itself, such for example as one in which Hippocrates speaks of cases in which "uterorum os conclusum, aut contortum fuerit," there is no satisfactory evidence that they understood the difference between versions and flexions.

Passing over many centuries, at the middle of the eighteenth we find gynecologists paying attention to versions, and even to flexions, of the pregnant uterus, but losing sight of these displacements in the non-pregnant organ. Versions were at that period described by Gartshore, W. Hunter, Jahu, and Desgranges; and flexions by Saxtorph, Wltczek, Bandelocque, and Böer. Gartshore describes a case of retroflexion complicated by retroversion, but the flexion appears to have made little impression upon him. In 1775 Saxtorph wrote an essay entitled "De Ischuria ex ntero retroftexo," describing a case with autopsy, but the words "orificium alte supra pubem reperi," show that it was not a true case. About the same time Witezek published an unquestionable case "de utero retroflexo," but it occurred during utero-gestation, and hence does not concern our inquiry. Both in England and France the subject of displacements attracted great attention at this period. "At this time Chopart upon his return from England, where he became well acquainted with W. Hunter, informed the Acacieny of Surgery what progress was being made in a subject which had attracted attention in France thirty years before."

1 Tetrabiblos, ch. lxxvii.

2 Cusco, "Thèse de l'Anteflexion et de la Retroflexion de l'Utérus," Paris, 1853. 
Denman was the first writer who described flexion of the non-pregnant uterus, which he did in reference to a ease of retroflexion, about the year 1800. The wanting link, the description of anterior flexure, was not supplied until M. Améline, of France, deseribed anteflexions in 1827. After this many others adled to the knowledge of the subject, which soon assumed its place in systematic medical literature. A great deal was done for it by the introduetion of the uterine sound as a means of diagnosis and of reposition.

In carefully perusing more modern literature with reference to its contributions to uterine flexions, I am impressed with the belief that we are indebted to none more fully than to Cuseo, whose very valuable thesis $I$ have alluded to, and Graily Hewitt, whose views are familiar to all.

In this country the profession is generally indebted for correct views upon the subject to Dewees, Meigs, and Hodge. More especially lias the last of these identified his name with it by important eontributions to pathology and treatment.

Pathological Significance of Versions and Flexions._-The ancients ascribed to these displacements many constitutional evils, as paralysis, hysteria, etc., and even until a very recent period they were eredited with a great deal of pelvic pain and functional uterine disturbance, which it was supposed almost universally attended them. Lntil 1854 this belief prevailed very generally, laving the powerful support and endorsement of such men as Velpeau, Simpson, and Valleix. It is true that it was contested by Cruveilhier and Dubois, ${ }^{1}$ before the period mentioned; but at that time a spirited discussion arose coneerning it in the Acalemy of Medicine of Paris, which not only threw much doubt upon it, but gave rise to a powerful opposition, in the ranks of which appeared Depaul, II. Bennet, Aran, Beequerel, and others equally eminent. They maintained that these displacements of the womb, if unaceompanied by textural lesion, produced no constitutional disturbanee; ereated, as a rule, no discomfort; and did not deserve the attention in treatment which had been bestowed upon them. They did not believe that the disloeation was the cause of suffering when this existed alone, but looked upon it, in such cases, as an epiphenomenon engrafted upon some important lesion. Consequently they were opposed to reliance being placed upon support by pessaries as one of the essentials of treatment, as had been done by the other sehool.

When views supposed to be false are repudiated, those arlopting new ones are always apt to run too far into an opposite extreme, and in this instance many have done so. Scanzoni ${ }^{2}$ sounds the keynote of this extreme party when he states, that ". flexiuns of the womb do not aequire any impor-

1 Goupil, B. \& r., op. rit.. p. 459.

2 Op. cit., Amer. ed., p. 112. 
tance, nor are followed by any serious dangers, save when they are complicated with an alteration in the texture of the organ."

The following propositions present the views upon this subjeet which I think will be found to bear the test of experience :-

1st. Versions and flexions of the womb may, but very rarely do, exist without causing any symptoms, for in themselves they do not constitute disease. Thus it is that in raye cases we see the uterus forced completely out of its place, without the production of morbirl signs.

2d. By interfering with escape of menstrual blood, by disordering uterine eirculation, and keeping up hyperamia, by eausing pressure and frietion from contact witl surrounding parts, and by creating a barrier to the entranee of seminal fluid, they become, as a general rule, of great importance and require special attention.

31. Often being the results, as they are sometimes the causes, of uterine and periuterine diseases, their treatment should be combined with efforts at the alleviation of these states.

4th. Treatment by pessaries, combined with means which remove the weight of the superincumbent intestines, is of great value. By it, even although the primary disease is not aflected, we may relieve one of its most troublesome symutoms, which often reacts for evil in aggravating and prolonging the affection which caused it. When the displacement has resulted from relaxation of the uterine ligaments, in consequence of increased weight or pressure from the ablominal viscera, pessaries prove a most useful and efficient means of treatment.

5th. One reason for the great prejudice existing against the use of pessaries in the minds of many is to be found in the fact that most of the enlargements of the uterus were attributed unhesitatingly to parenchymatous inflammation. Mechanically lifting an inflamed organ appeared repulsive to reason. So long as the existing inflammation was uncured, etforts appeared to be directed to a side issue, a result and not the root of the disorder. Since it is now known that what was supposed to be chronic metritis is really a vice of nutrition resulting in new formation of connective tissue, this theoretical objection falls to the ground.

6th. Another reason is this: it requires skill, and ingenuity, the result of practice, not only to do good with pessaries, but to apply them without doing absolute harm. In the hands of a physician who has made no special, or at·least careful, study of their use, and who habitually applies only a lialf-dozen in the course of every year, pessaries are elements of absolute danger. It would be as unreasonable to expect an untaught experimenter to fit the foot comfortably with a shoe, as to hope for etficiency, comfort, and safety from a pessary applied by ignorant hands.

7th. The gynecologist who to-day assumes the position that pessaries are useless or worse, and treats uterine displacements without their aid, 
will fail, by reason of the absence of other means to accomplish the existing indieations, to meet the requirements of his cases.

Definition and Synonyms. - The term displacement is applied by British and American writers to any decided removal of the nterus from its normal position, without reference to the direetion in which it has been moved; while French writers apply the term displacement only to ascent and deseent of the uterus, reserving that of deviations for versions and flexions.

Anatomy.-One of the salient points in the comprehension of this most important subject consists in a clear understanding of the natural position of the healthy uterus. But unfortunately, owing to the fact that the position of this organ varies constantly with inspiration and expiration, with museular effort and quietude, and with fulness and emptiness of the bladder and rectum, it is ditlicult to arrive at common ground with reference to a point apparently so easy of settlement. As this chapter progresses, I propose to jut before the reader a diagram of the normal position of the uterts when not influenced by any decided disturbing cause. It is the result of long and careful investigation, and represents the truth, I think, more accurately than any other with which I am acquainted.

Let any one examine a healthy uterus by means of Sims's speculum, and he will recognize that it is delieately and perfectly poised near the midlle of the pelvic eavity by sueh supporting influences that it is never, even for a few seconds, perfectly at rest. It aseends with expiration and descends with inspiration with such regularity and distinctness, that one operating upon the pelvic viscera can, by this up-and-down movement, recognize at once when an anxsthetic is affecting respiration badly. Under the influence of more decided factors, such as pregnancy, repletion of bladder or rectum, or violent muscular efforts, still more marked changes of position oceur to it. Nevertheless we must agree upon a medium position as the normal one for a liealthy uterus.

The mechanieal influences which sustain the uterus and preserve its pelvic equipoise are five in number. These are-

1:t. The retentive power of the abdominal carity.

21. The attachments to the areolar tissue of the pelvis.

3:. The juxtapowition of the other organs.

4th. The vaginal promontory upon which the neck rests.

ith. The following ligaments:-

a. The round ligaments, continuations of uterine tiswe, extending from uterine liorns to labia majora;

1. The utero-vesieal ligaments, bands of pelvic faseia. and uterine muscular tisue pasing between the blatder and the cervico orporeal junctim, where they attach themselves, and prevent retreat of cervix ;

c. The utero-sacral ligaments, formed of hyperastrie faseia, and the uterine and raginal tissue, extending from posterior surface of cervix, passing baekwards to be attached to saerum, and preventing pasage of cervix forwards; 
d. The broad ligaments, folds of peritoneum inclosing areolar tisuse, ovarian and round ligaments, and ovaries; preventing lateral, anterior, and posterior displacements.

None of these means of suspension are concerned in flexions and inversion, which are combated by forces of entirely different nature. The tissue of the normal, mimpregnated uterus is of such strong, resisting character in the adult female, as to prevent too great a curvature of the body upon the neck either anteriorly, laterally, or posteriorly. It is to this peculiarity of strueture that immunity from these conditions is due.

When stimulated by pregnancy, the uterine tissue develops rapidly into muscular strncture. This keejs the carity of the organ closed by tonic contraction, and removes the possibility of inversion unless it be accomplished by absolute violence. But when from any cause this contractile power is destroyed and the condition of tone is replaced by one of atony, flexion or inversion may occur.

Fig. 138.

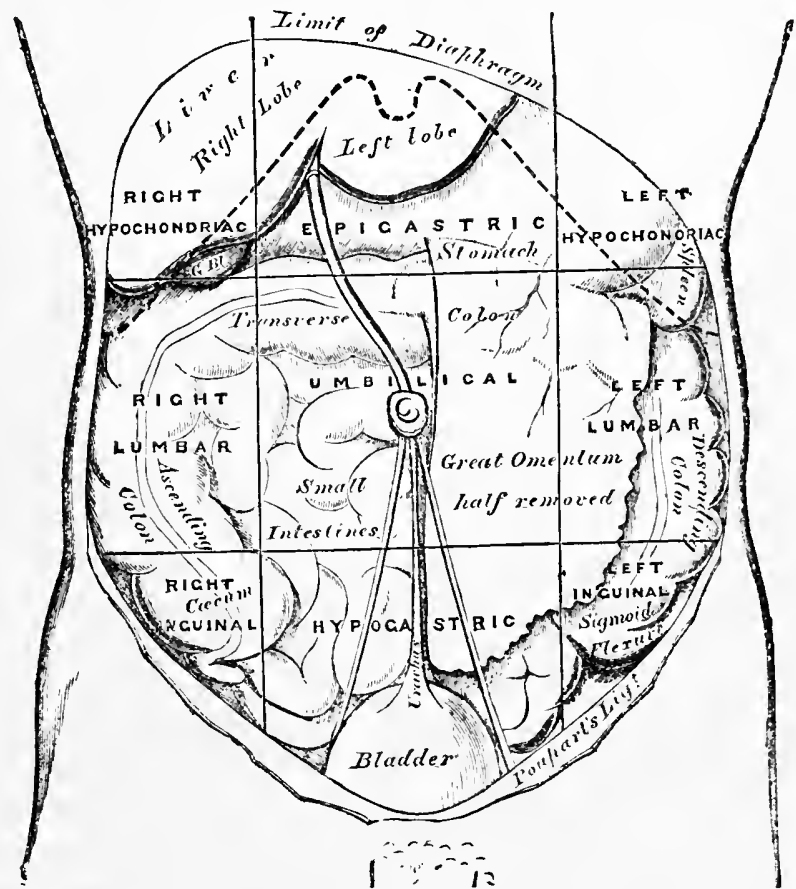

The regions of the abdomen and their contents. Edge of costal cartilages in dotted outlines.

(Gray.)

The retentive power of the abdomen is one of the most important influences for the support of the uterus, and one of the most neglected in consideration of this subject. Fig. 138 represents the abdominal viscera in 
their normal condition and place. The diaphragm, one of the muscles most essential to respiration, is located nearly midway in the trunk, across which it extends like a concavo-convex curtain. "Its action exactly resembles that of a piston in the cylinder of a pump." As it contracts it forces the abdominal viscera downwards directly upon those of the pelvis, and as it relaxes, and expiration occurs, the depressed abdominal viscera rise to their former place, drawing the pelvic viscera upwards. This up-and-down movement not only keeps the uterus in place, but it exerts a powerful stimulating influence upon its circulation, and prevents that tendeney to sluggishness which perfect quietude so markedly favors. Dr. Matthews Dunean ${ }^{2}$ has very ably treated of this important subject, and done a great deal of good with reference to it; an excellent contribution has been made to it by Dr. Busey, ${ }^{3}$ of Washington; and a remarkable work las been written upon it in its various aspects by Dr. Geo. H. Taylor, ${ }^{4}$ of New

F1G. 139.

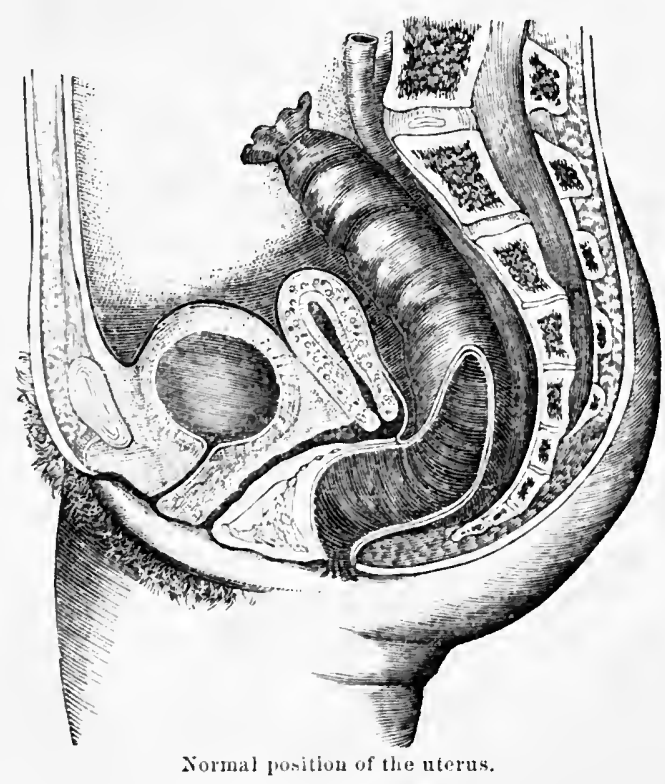

York. In my mind its importance cannot be over estimated, for I believe that more valuable contributions to the etiology of uterine displacements in the future will come from investigations in this direction than any other.

1 Course of Lectures on Physiology", by Prof. Küss, of Lniversity of Strashourg, p. 294.

2 Lesearches in Olstetries.

3 Amer. Journ. Obstet., Feliruary, 1872, p. 585.

4 Disease's of Women, 1871. 
Fig. 139 represents the results of my researches as to the normal position of the uterus, the bladeler and rectum not being entively ringty. I shall alluite in detail here to only one other factor in uterine support. The eervix will be observed to impinge slightly mon the anterior reetal wall, and to depress it a little. This a reetal examination will usually reveal as the rule. The perineal body being normal, the posterior vaginal wall will from this point be found, upon careful vacrinal toucl, to rise up below the cervix, which will thus rest in a very shallow well or depression, the anterior cervical wall being supported as if by a shelf, by the anterior projection of this. 'This anterior projection of the posterior vaginal wall is what $I$ have styled the vaginal promontory in the enumeration of the influences supporting the uterus. Like the third factor mentioned, it is not powerful, but, like it, it is too important to be overlooked. It must be borne in mind that the support of the uterus is not accomplished by one or two powerful factors alone, but by a combination of several, each working towarls a common end.

This very fact makes it manifest that a number of mechanical influences may force an organ thus sustained upwards, downwards, laterally, or even bend it upon itself or turn it completely inside out, and that the direction of the impelling force or nature of the loss of support will determine the elaaracter of the displacement. The displacements which may thus result lave received the following appellations :-

Ascent ;
Descent or prolapsus ;
Anterersion;
Anteflexion;
Retroversion;
Retroflexion;
Lateroversion ;
Lateroftexion;
Inversion.

These varieties should not be memorized by the student, for such an effort would be uncalled for. Let him suppose any pear-shaped bag, one of gutta-percha for instance, suspended by yielding supports in a eavity, and it must be evident that these and only these changes of position conld be impressed upon it.

Having said this much in a general way as to displacements, let me say a few words with special reference to uterine flexions.

Version, or turning of the uterus, signifies the fact that its long axis has changed its normal direction in the pelvis. Flexion signifies the bending of the uterus upon itself, so that a decided angle is created in its long axis. One condition is a displacement; the other a deformity in the organ. One may be likened to a dislocation of one of the long bones; the other to a fracture with angular union of the broken extremities. The 
treatment of one involves merely restoration of a dislocated organ; that of the other, rectification of a deformity which may lave lasted for years or may even have been congenital.

Frequenry.-Flexions of the uterus, that is, displacements, anteriorly, posteriorly, or laterally, in which the decidedly predominating feature is flexion and not version, are very common.

In 339 displacements Nonat found 67 flexions.

" 84 " Neadors " 54 "

As to the relative frequency of anterior and posterior flexions, the evidence is decidedly in favor of the former.

In 67 cases of flexion Nonatl found 33 anteflexions and 14 retroflexions.

" 54 " " Neadows " 20 " 20 and 34 "

" 54 " " Seanzoni " " 46 " " 40 and 8 "

" 23 " " Valleix" " " 11 " "

" 296 " " Hewitt " " $" 184$ " "

Oit of 1670 eases of flexion collected by Ludwig Joseph, ${ }^{6}$ of Breslau, 1100 were anterior and 570 posterior. Out of 345 cases of flexion, Emmet found 273 to be anteflexion, 29 to be retroflexion, and 43 to be lateroflexion.

Although the results are somewhat conflicting, the preponderance of evidence very decidedly favors anteflexion over retroflexion.

One reason why we should anticipate that retroflexion would be less frequent than anteflexion, is that the natural anterior obliquity of the uterus favors the latter and opposes the former displacement. Another is the fact that the former is more thoroughly guarded against by ligamentous support ; the round ligaments, ruming as they do from the horns of the uterus to the vulva, decidedly tending to prevent its occurrence. Not only do they do this; the uterus, being kept by them in anterior inclination, should softening of its structure oecur, or any direet force be exerted upon it, naturally bends forwards.

If this be so, it may be asked why areolar hyperplasia so frequently rcsults in retroflexion as well as in anteflexion. One reason is because the first effect of the increased uterine weight attending that disease is deseent of the uterus. 'This relaxes the round liganents, tends to briug the uterine axis in coincilence with that of the middle of the pelvis, and favors retroflexion. For a time the tendency is to descent and coincident retroversion. This continues until the progress of the cervix is checked

1 Mal. de l'l'térus, [. 416.

8 Klob, op. cit., p. 69.

s bis. of Women, $2 \mathrm{Am}$. el., p. 213.

The othar statisties refer to pure flexion.

${ }^{6}$ Br.rlin Britrïge zur Geburtshulfe und Gyü̈kologie, vol. ii. part 2, 1873.

I'rin. and Prac. of (iynecology. 
by the utero-sacral ligaments. Then the heavy body bends, the warkened tissue yielding at the os internum, and retroflexion results. Another reason is that flexion commonly follows parturition, at which time, attacking an organ with weakened tissues and relaxed ligaments, it meets with an eflicient ally in the nurse, who favors retroflexion at the expenso of anteflexion by zealously foreing the fundus backwards by a tight obstetric bandage.

'Thanks to the researches of Coste, Pouchet, Bischoff, and others, we are to-day well informed concerning the development of the uterus. Early in embryonic life a little duct shoots out from the external surface of each Wollian body. 'These pass downwards to unite and make a common eanal, which becones in time separated into uterus and vagina. Very soon a constriction appears, the neck of the uterus is formed, and becomes well developed, while a very small spot marks the point where the body is to show itself. The original canals become Fallopian tubes, and at the time of birth these, as well as the neck and body of the uterus, vagina, and other organs, have arrived at maturity. But it must not be supposed that the proportions of the adult uterus exist in that of infancy. The neck forms three-quarters of the organ, and the body, represented by a soft movable membrane, has no fixed position, but follows the bladder, if upon opening the abdomen it is drawn forwards, or the reetum, if that viscus is pushed backwards. Later in the life of the girl, even after she has reached puberty and menstruation has occurred, the uterus is curved forwards; and this anterior inflexion lasts through life, if a normal state continue, though it is generally dininished and sometimes overcome by puberty and utero-gestation.

In 1849 , Velpean, whose insight into gynecology was ecrtainly remarkable, in a discussion before the Academy of Medicine of Paris, declared that he had so often found an anterior inflexion of the uterus in healthy women, that he was inclined to look upon it as normal. Upon this hint two of his pupils, Boullard (1852), and Piachaud (1853), with great assiduity, investigated the subject, and determined that it is so in the child and virgin; the latter basing his deductions upon 107 cases. Boullarl found it to exist in 80 female fotuses, and in 27 adult females. Verneuil and Follin subsequently confirmed these observations.

'That this is the normal condition up to puberty is unquestionable; nor can it be denied that to a limited degree it is so even afterwards in the ummarried female. But, as Cusco has pointed out, it greatly diminishes at puberty, unless abnormal flexion is developed. Up to this time the neck of the uterus represents three-quarters of its entire bulk, and the whole organ is an insignificant element of the human body. At this time, however, it becomes an important organ. The body develops; its walls become thick, dense, and strong; "and," says Cusco, "this is an important point, if the development is regular its walls establish an equilibrium; 
the uterus straiglitens itself; its anterior concavity disappears; and there remains only a slight depression corresponding to the bladder." Up to this period of life curvature is unquestionably due to the want of tone and lower which characterizes undeveloped uterine tissue, for even when anteflexion does not exist, the organ is generally otherwise displaced. Thus, M. Soudry, in 71 post-mortem examinations of infants, found the uterus anteflexed $\$ 1$ times, anteverted 11 times, retroverted 15 times, retroflexed twice, and retroverted with anteflexion twice. We may then conclude from the evidence at present upon record-

$1 \mathrm{st}$. That anteflexion is the rule during early childhood;

21. 'That it is quite frequent, in slight degree, in nulliparous women, without constituting disease.

For the prevention of versions certain pelvic ligaments are very effectual, but they have no power to prevent bending of the uterus upon itself. This is accomplished by the inherent strength and resistance of the proper tissue of the organ. Remove a normal uterus from the cadaver, balance it upon the cervix, and it will sustain itself perfectly; press it down by applying force to the fundus, and its own resiliency will cause it to erect itself im. mediately. Suppose a uterus to be composed of gutta-percha instead of living tissue; the material forming the walls of the neck will support the fundus when the pear-shaped bag is held by the stem or narrow part. To carry the simile further, so long as the proper tissue of the stem or neck remains normally strong, flexion will be impossible unless its resistance be overeome by direct physical force exerted by pressure or traction. But if some influence be brought to bear locally, so as to soften the part sustaining the fundus, it is evident that, as the gntta-percha walls grow weak, there may be a flexion of the fundus from its own weight. It will he said that these views represent the uterus as supported by the varina, and leave out of consideration the broad ligaments which sustain the fundus. If these ligaments were tightly drawn cords, I could admit their action, but as they are merely lax folds which are not made tense by the bending of the uterus upon itself, I do not do so.

$A$ corroboration of this view is found in the frequency of flexions in the uteri of the aged which have lost tone and strength. "In aged women," says Klob, " with exceedingly relaxed uteri, the pressure of the intestines upon the posterior surface of the organ is sufficient to eause anteflexion."

Puthology._Flexions may be eongenital or aecidental. As the opposite walls develop, an excess of nutrition may be appropriated by one, which grows rapilly, while the other developing more slowly arrests the crection of the uterus, and, giving it an inflexion, ereates a concavity on one sile aml a convexity on the other. If the posterior wall develop most deciledly, an anteflexion results; if, as was the case in nineteen out of $\mathrm{M}$.

1 Aran, op. cit., 1. 981.

2 Op. cit., p. 61. 
Soudry's seventy-one autopsies of infants, posterior displacement exist, and the anterior wall receive the chicf amount of nutrition, a retroflexion is the consequence. But not only does the excessive growth of one wall create an inflexion on the opposite sile; the sile which is bent unlereres to a certain extent atrophy, and this increases the already growing lis-proportion. This, in all probability, is the source of congenital flexion, a condition always exceedingly difleult of cure, but fortumately one which does not ereate as much corporal congestion and constitutional disturbance as the more remediable form which is accidental.

In the supplement to the second volume of Herbert Spencer's work upon Biology, appear some remarks upon the influence of prevailing winds upon the growth of trees, which are interesting in this connection. The tree, says he, being habitually bent in one direction, its nutrition is, on the concave surtace, impaired, the ligneous material upon the convex portion is deposited in excess, and in consequence the lieart of the tree is not centrak, but considerably nearer to the concave than to the convex surface. Epon experimenting upon growing twigs by bending them to one or the other side, he found that he conld uniformly produce the same result. When the uterus is flexed, a similar change will be found to occur from a like cause.

Congenital anteflexion is much more common than congenital retroflexion. Cases of the latter are, lowever, by no means mnknown. Boivin aud Dugès' report two cases, Dubois one, Deville one, and Bell one in a very young girl. I have several times met with it.

Any influence which weakens the tissue constituting the uterine walls, creates flexion. If the posterior wall be chiefly affected, the body falls backwards; if the anterior, it inclines forwards; if both, the direetion of inclination is decided by extraneous forces. Rokitansky luas proved that such weakening is accomplished by endometritis, which creates an inward growth of the utricular glands into the submucous connective tissue, near the os internum, which in conseguence undergoes atrophy and enfeeblement ; or by cystic degeneration in the cervical glands, "which, from their increased size and subsequent pressure, canse the submucous stratum to become atrophied, and which ultimately bursting, thereby cause a collapse of tissue in the formerly dense framework of the uterus, leaving in its place a flaccid net-like areolar tissue incapable of sustaining the organ in its normal position." Both these occurrences, says Klob, take place quite frequently. Rokitansky says that in the anterior semicircle of the uterine tissue around the os internum of women who have borne many children, a large transverse vein is found, which, by its removal of tissue, weakens the wall.

But there are otker influences which may accomplish this result: 
abseess of the nterine tissue; development of fibroids which disorder the bloodvessels; varicose degeneration of the veins and sponginess of tissue engendered by prolonged traction upon the neck; disturbance of nutrition by flexure ereated suddenly by a blow or fall, or gradually by traction from false membranes; subinvolution, or areolar lyperplasia, which accomplishes, on a large seale, the substitution "for the dense framework of the nterus of a flaceid, net-like areolir tissue, ineapable of sustaining the organ," which Rokitansky declares occurs at the os internum in eystic degeneration.

This loss of power in one or both walls of the uterus is frequently, though not universally, the cause of flexions of accidental character. They are sometimes due to force sufficiently strong to overcome the resisting power of the uterine tissue, either suddenly or by slow degrees. Onee flexed, one wall soon undergoes degeneration, and thus two causes for a continuation of the condition are combined.

The point of greatest weakness is the point at which flexion occurs, and this is nsually opposite the os internum. In anteflexion it may oceur below this point, when the neck only is flexed, from prolonged and habitual constipation. In both retroflexions and anteflexions I have known it to occur at the middle of the body, and eseape superficial examination, or induce a belief in the existence of fibrous tumor. IN lob has noticed this but once, and has failed to find an analogous instance. Cnsco records one ease in his own experience where the body was equally divided by a flexion, and guotes $\Lambda$ shwell and Bell for others of similar character.

These are the influences under which flexion is induced. No sooner does it occur, than a marked elange takes place in the uterine circulation. The uterine bloolvessels arise from the arteria uterina hypogastrica, the arteria uterina aortica, and from the arteria spermatica exterma. ${ }^{2}$ The reins make up by their union two plexuses, the uterine and pampiniform. All these vessels go to and come from the uterus at its silles. A flexion of this organ to a certain extent ligates these vessels, as IJewitt expresses it, and interferes with circulation directly and immediately. The ineompresible arteries still earry blood to the body, but the compressible veins fail to return it to the general eirculation, and the conserquences are congettion, whema, and, in time, hypergenesis of tissue. This important fact IIewitt, in his recent admirable edition of his work ujon Diseases of Wimen, lays so much stress upon, as to make it the pivotal point of his pathological ereerl. There ean be no question of the truth of this view, nor of its extremely important pathological bearing. In bringing it frrminently forwarl, and insisting npon its frequent and striking effeets as a filctor in uterine disorders, IJewitt has, in my judgment, done a grean deal of grood. IIt is in error, however, in supposing that it had

10 p. cit., 1). 37.

2 Stricker's Manual of Ilistology. 
previously been unrecognized, as the following passage from liis work announees: "It is somewhat snrprising that the oecurrence of mechanical congestion of the body of the uterus, arising from mere ehange of slape of the organ, as above pointed out, should not have attracted the altention of uterine pathologists." Since the appearance of Klob's work on Pathologieal Anatony, published in 1868, ${ }^{1}$ it had especially attracterl my attention, and had eonstituted a prominent feature in my teachings. Klob ${ }^{2}$ declares that "a further" consequence of venous hyperania, arising from hindered reflux of blood at the point of flexion, is cedema with tumefaction and genuine hypertrophy of the body of the uterus. 'The reflux of blood from the uterine to the liypogastric veins is interrupted, and in consequenee of the collateral liyperamia, frequently a very considerable dilatation of the plexus pampiniformis takes place, because the blood can now only flow through the spermatic vein." Luder this mechanieal influence both neck and body become tumid, tender, and painful; the mucous lining is so congested as to give forth exeessive amounts of mucus and blood; and the tissues of the organ, exeited to exeessive growth by prolonged blood stasis, undergo in time marked lyypergenesis.

At the point of flexion the cervical canal is always more or less closed by alposition of its walls. From this cause the ingress of fluids is prevented, and sterility commonly results, and the egress is interfered with to such an extent that dysmenorrloea, hematometra, hydrometra, and accumulations of mucus take place. Of course such accumulations cannot occur with impunity; they result in the production of endometritis and even in hematocele by regurgitation.

In congenital flexion the circulation of the uterns is so gradually interfered with that marked congestion is not so likely to oecur as it is when the organ is suddenly bent upon itself, nor is occlusion of the cervix ordinarily so complete.

Results and Complications.-Already the reader can enumerate for himself many of the consequences arising from flexion of the uterus; and a list of them placed before him will need little further explanation as to the mode of their production. They are the following:-

Congestion;

IIypergenesis of tissue;

Sterility;

Dysmenorrhoa ;

Menorrhagia ;

Endometritis ;

Tentency to abortion;

1 Hewitt's riews were furst pullished in an article read before the British Mulical Association at Leeds in $1 \leq \pi$ U.

2 Op. cit., p. 60. 


\author{
Hematocele; \\ Oraritis and Salpingitis; \\ Pelvic peritonitis ; \\ Fluid accumulations in utero ; \\ Uterine neuralgia ; \\ Cystitis and Rectitis ; \\ Granular degeneration.
}

When it is remembered that each of these affections sets up symptoms and complications of its own, it will be appreciated that flexion of the uterus is a disorder which, apparently insignificant in itself, is the souree of many grave results.

Deranged uterine circulation produces menstrual disorder. Usually this consists in excessive flow, but sometimes the opposite condition exists.

Ovarian congestion, neuralgia, and enlargements, as, likewise, catarh of the Fallopian tubes, are probably due to a reflex influence transmitted through the intimate and sensitive nervons connections between the uterus and these organs. Rigby attributed them to pressure, but this does not appear to account for those conditions.

Peritonitis results from pressure and friction by the displaced fundus, and, in some eases, from reflux through the tubes of imprisoned fluids. It is by no means rare; so common is it, indeed, that Virchow regards traction by false membranes as the chief cause of anteflexions. That this pathologist is in error upon this point is the belief of all others with whose views I am fimiliar.

Etiology of Lterine Displacements.-Both in didactic and clinical teaching I have for many years grouped the causes of uterine displacement in the manner alout to be described. Enlarged experience with the method leads me to regard it with increased favor, and I would urge its claims to adoption, by teachers and students. By it no influence prodncing displacement escapes classification, and it induces him who employs it to arrange the subject systematieally in lis mint.

The general causes of uterine displacement may thus be tabulated:-

1st. Any influenee which inereases the weight of the uterns;

2d. Any influence which enfeebles the supports of the uterus;

3d. Any influence which displaces the uterus by pressure;

4th. Any influence which displaces the uterus by traction.

To state this more fully in other words:-

1st. The uterine supports are equal to sustinining the organ when of norrand weight; but when its weight is increased they naturally fail in their takk.

2d. Even if the uterus be no heavier than it shouhl be, it may become

1 Kiwiscle reports a case of hyidremetra. 
displaced from depreeiation of that support to which it is entitled, and which was made to sustain it.

3d. If both the uterus and its sustaining powers be perfeetly normal, it is evident that direct or powerful pressure may overeone the latter, and force the organ from its place.

4th. It is equally evident, that, as, by a tenaculum fastened in the uterus of the cadaver, we may drag it from its position, so may contracting lymph or a prolapsed vagina eflect this in a living body.

All these finets having been premised, a concise view of the special eauses of displaeements may be thus presented.

1. Influences increasing weight of uterus.

Congestion ;

Tumors in the walls or cavity;

Pregnancy ;

Excessive growth of any of its component parts ;

Subinvolution ;

Fluid retained in cavity;

Masses of eaneer or tubercle.

2. Influences weakening uterine supports.

Rupture of the perineum;

Weakening of vaginal walls ; 1

Stretching of uterine ligaments;

Want of tone in uterine tissue;

Degeneration of uterine tissue;

Abnormally large pelvis ;

Any influence impairing sustaining power of abdomen.

3. Influences pressing the uterus out of place.

Tight clothing;

Heary elothing supported on the abdomen;

IIuseular efforts ;

Aseites ;

Abdominal tumors;

Abscesses or masses of lymph.

Repletion of the bladder.

4. Influences exerting traction on the uterus.

Lymph deposited in pelvic areolar tissue;

Lymph deposited on peritoneum of pelvic viscera ;

Cieatrices in raginal walls;

Shortening of uterine ligaments ;

Natural shortness of ragina ;

Prolapse of vagina, bladder, or reetum.

1 Such weakening from subinvolution or any other cause destroys the supporting power of the vaginal promuntory. 
The mode of action of each of these causes is so evident as to require no special mention at this time, but they will be particularly alluded to hereafter.

No circumstance combines so many of these causes of displacement as utero-gestation and parturition. Should involution follow these without interruption, no tendency to displacement results. But the process of inrolution is frequently interfered with. Then, as consequences of the arrest of retrograde metamorphosis, the uterus remains large and heavy; the ragina voluminous and feeble; and the uterine ligaments, which owe their strength chiefly to the uterine tissue which they contain, lax and weak. As a result of parturition, too, the perineum is often enfeebled, which allows of prolapse of the vagina, which produces traction upon the uterus.

These remarks apply to true displacements of the uterus. To flexions or deformities of the organ itself, they do not so sufficiently apply as to render uncalled for some special remarks, which I now proceed to offer.

Predisposing Causes of Uterine Flexions.-Any cause which predisposes to enfeeblement of uterine tone, to the development of a force which overcomes this even when unimpaired, or still more one which combines the two evil influences, prepares the way for flexure of the uterus under the impulse given by a sudden or persistent exciting cause. They may be thus cnumerated :-

\section{Parturition ;}

Imporerishment of the blood;

Enfeebled nerve state;

Extreme youth or age;

Laborious occupation ;

Relaxation of abdominal walls ;

Influences altering pelvie axes.

Exciting Causes.-One of the functions of the cervix uteri is to support the body, and for the performance of this it is abunlantly competent, unless its powers be impaired by one of the following influences :-

Influences weakening uterine support.

Endometritis ;

Cystic degeneration near os intermum;

Pregnancy ;

Fatty degeneration ;

Areolar hyperplasia ;

Vascular degeneration in uterine walls.

Influences increasing the weight of the fundus.

Finlargement of the body ;

Pregnancy ;

Tumors ;

Accumulation of fluid in utero. 
Influences pushing the fundus or cervis forwards or backwards.

$\Lambda$ belominal or pelvie tumors ;

Ascites ;

Feeal accumulation;

Tight clothing;

MIuscular efforts.

Influences exerting traction forwards or backwards.

False membranes from pelvic peritonitis.

Of the first class of causes, inflammation affecting the mucous membrane of the neck and creating areolar hyperplasia in the parenchyma is, according to my experience, one of the most frequent. The hyperplasia thus arising results in atrophy of the muscular and submucous fibrous structures of the uterus and their replacement by hypertrophied areolar tissue, and produces a marked tendency to this deviation by thus substituting a lax and feeble for a dense and powerful substance. Kilob declares that this replacement of strong tissue by that which is weaker occurs more especially near the os internum. Virchow denies the agency of this condition as a causative influence, as he likewise does that of fatty degeneration, observed by Scanzoni, at the point of flexure. The influence of parturition, abortion, and pregnancy has been admitted by all authorities.

The varieties coming under the head of the second set of causes are all universally admitted, as are also those belonging to the third. Fecal impaction may possibly produce flexion of the body, and frequently causes the cervix to bend sharply forwards. The fourth set of causes is put beyond question, by the fact that in autopsies the uterus is often found thus bound in a state of flexion.

The etiology of cervical flexion is somewhat different from that of corporeal. It is, I feel satisfied, generally induced by pressure directly exerted upon the uterus by tight clothing, which forces it against the concave surface of the vagina. This surface gives the impinging part a slant forwards, and keeps it thus bent. Habitual constipation increases this vicious curve, and the two causes combined of ten result in this unmanageable form of the affection. This explains the fact, which all must have noticed, that in pure corporeal flexion the uterus is often high up in the pelvis, while in that of cervical form it is almost invariably low down. It likewise explains what my observation leads me to regard as a fact, that in mulliparons women the cervical and cervico-corporeal varieties preponderate in frequency over the corporeal form, which is generally met with in multiparous women.

There is still another pathological element which enters into the etiology of cervical flexions, and explains the phenomena with regard to them which I have just mentioned. The uterus being forced downwards by influences exerting themselves upon the abdomen, if the utero-vesical ligaments be lax and yielding, corporeal flexion will occur, the cervix 
retreating under pressure. If, however, these ligaments keep the cervix in close contact with the bladder, cervico-corporeal or pure cervical flexion will be developed. Parturition does more to stretch these ligaments than anything else, and thus cerrical flexion is not so generally met with in women who have gone through that process as in those who have not. Corporeal flexion is the variety seen after parturition; the cervical and cervico-corporeal forms, those which we see in nulliparous women. Not only is this fact interesting in reference to pathology; it has an imprrtant bearing upon the treatment of cervical flexions. He who would treat these cases successfully nust systematically stretch the ligaments which keep the cervix in an anterior position, and by this means strive to change the form of displacement to that of corporeal flexion, or of anteversion.

Retroflexion is most frequently the result of some influence which weakens the tone of the uterine walls, but, even when this is normal, any force directly applied may displace it and produce a flexure, whether such force is developed suddenly or gradually.

We have now pursued the study of flexions, as a whole, as far as it is profitable to do so; and from this point, they shall be considered under separate heads.

The uterus may be flexed upon itself anteriorly, posteriorly, or laterally, giving rise to the disorders known as-

\section{Anteflexion ; \\ Retroflexion; \\ Latero-flexion.}

The fundus in falling forwards or backwards does not always preserve the median line, but commonly falls oblicpuely to the right or left. This obliquity is freciuently created, even where the median line was orjgnally preserved, by the use of a pessary, and constitutes so prominent a difliculty in these cases that I employ a special instrument for its treatment.

Thus we may find a uterus flexed forwards and laterally; backwards and forwarls; backwards and laterally, etc.

These varieties are known as-

\section{Retro-anteflexion; \\ Retro-lateroflexion; \\ Ante-retroflexion ; \\ Latero-anteflexion, etc.}

The student nced not memorize these, but, merely keeping in mind the fact that such combinations are possible, he will readily recognize them at the bedside if he have mastered the three chief forms.

This is all that need be said upon the subject of utcrine displacements in general. I shall now proceed to complete the outline here sketched, and to go into the details connected with each variety of the affection. 


\title{
CII A P TER XXVI.
}

\author{
ASCENT ANI DINCINT OE TIE UTERUS.
}

\section{Ascent of the Uterus.}

Ix its normal condition the uterus deseends into the pelvic carity so as to asime a position abont two inches from the vulva. If its weight be augmented, it comes much lower than this, and continues to do so as its volume increases, until its derelopment becomes so great that it cannot be accommolated by the pelvis. Then it escapes from the cavity by ascending to a more capacious space above the superior strait. This change occurs in every normal pregnancy. During the first three montlis the uterus falls in the pelvis, being in a state of prolapse. As the fourth month approaches its volume becomes so great that it ean no longer be retained in the pelvic eavity, and then it escapes above the superior strait where sufhicient space is afforded for it to undergo full development. This is not only so in pregnancy; the uterus is similarly affected by morbid growths. When, under these circumstances, it leares the pelvis, the fact is expressed by the term ascent.

Ascent of the uterus is never an original disease, but the result of some important change connected with that organ, and requires merely a mention. It may occur whenever a tumor is developed in connection with the vaina, rectum, or recto-raginal cul-de-sac, when there exists a growth in the walls or cavity of the uterus which renders it too large for accommodation in the pelvis, or, when an abdominal tumor draws up the uterus. It never requires treatment, and is of importance only as exciting suspicion of pregnancy, or as an evidence of morbid growth in some way connected with the organs of generation.

\section{Descent or Prolapsus of the Uterus.}

Definition, Synonyms, and Frequenry.-The name of this disorder lefines its character with suflieient elearness. It is of frequent occurrence, and muler the name of Falling of the Womb is well known to women, and constitutes for them an object of especial dread. As almost all women, after the period of fruitfulness has passed, have an intuitive fear of cancer of the uterus, so do a large number before that time manifest an apprehension of prolapsus. In the one ease the anxiety is for life, in the other for usefulness and comfort.

Lnfortumately for the student of this subject, its nomenclature has been 
rendered somewhat obseure. By some, all cases of prolapsus in which the uterus does not escape from the vagina are termed ineomplete, while those in which it does are styled complete. By others, complete protrusion is denominated procidentia; and, by others still, a very slight descent without alteration of direction of axis has been designated by the very old name of squatting uterus. I lave striven to simplify the matter by applying the name prolapsus to all, and marking the degrees of descent by the terms 1st, 2d, and 3d.

Anatomy.-Those uterine supports which are especially active in preventing uterine deseent are the surrounding areolar tissue, which binds it to the bladder, the rectum, and the pelvic walls; the utero-vesical and utero-sacral ligaments; and the retentive power of the abdomen. About the sustaining influence of the vagina there is much difference of opinion; some, like Savage, denying it; while others, like Bennet, West, and Kiwisch, maintain it. My opinion is, that the promontory formed by the vagina in front of the cervix certainly effeets something in the way of support, although observation has led me to modify very much the belief which I once had in the general sustaining influence of the canal. Loss of tone in it, resulting in prolapsus vagina, is commonly attended by a similar prolapse in the uterus, but it does not follow that the uterus falls from want of support; it is more probably dragged down by the heary vagina. This view may be sustained by so many strong arguments that it need not invoke weak ones. A good deal of stress has been laid upon an experiment for which Aran credits Stoltz; that of cutting the ragina away without noting any descent of the uterus. A little reflection must show that this proves almost nothing. It merely demonstrates the fact that, without the vagina, other supports are sufficient to sustain the uterus. No one has ever maintained that the vagina was the only support which keeps the uterus up, nor that others were insufficient without it.

A great deal of support is unquestionably derived from the connective areolar tissue, which so elosely unites the uterus with the reetum, bladder, and pelvic walls, as to involve displacement of these viseera in its descent. Dr. Savage, dragging the uterus of a cadaver forcibly downwards by means of a vulsellum attached to the neck, found that after cutting its important ligaments, and overeoming by force the action of the vagina, it still would not advance. "The obstruction was found to be due to the subperitoneal pelvic cellular tissue, partieularly where it surrounds and aceompanies the uterine bloodvessels."

The most important factors in the prevention of prolapse are the uterosacral ligaments, which Aran eonsidered the only real ligaments of the werus. Arising from the point of junction of neek and boly, they usually embrace the rectum in their bifurcation posteriorly, and, diverging on each sille of it, terminate in the subperitoneal cellular tissue, as high up as the scond lumbar vertebra. They are exceptionally inserted into the rec- 
tum. It was the recognition of this anatomical arrangement of these important ligaments which led In lumbar, instearl of utero-sacral. They consist of the following clements: peritoneum, pelvic connective tissue, uterine cortex, and vaginal museular tibre. Their influenee, as likewise to a much less degree that of two similar bands connecting the cervix in front with the bladder, cannot be doubted.

These are probably all the factors which unite in the prevention of prolapsus in the first and second degrees. When they are entirely overcome and the descent has become complete, the round and broad or lateral ligatments come into action, but not until that has occurred.

Varieties.-This displacement may occur very suddenly and unexpectedly, or gradually and by successive steps. As the symptoms of the two varieties differ only in the rapidity and severity of their development, and the second is much the more frequent, I sliall direct my remarks cliefly to it, and describe the first in a few words in an appropriate place.

Prolapsus may exist either in the first, second, or third degree, the direction of the uterine axis in each of which is exhibited in Fig. 140.

In the first the uterine axis is bent forwards, the organ being somewhat anteverted and sunk in the pelvis. In the second the body has gone towards the sacrum, the cervix having come down to the

Fig. 140.

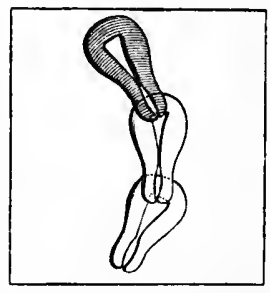

Diagram representing the uterine axis in the three degrees of prolapsus. ostium vaginx. In the third the last barrier has been overcome, and either a part or the whole of the uterus hangs between the thighs.

Causes._The causes which predispose to this accident are-

Child bearing;

Laborious occupations;

Advanced age ;

Habitual constipation.

I know of no way in which I can give so concise a summary of the exciting causes of prolapsus as by a reference to the elassification to which $I$ have already referred under general considerations upon displacements; for the exciting causes will be found to belong in every case to one of four classes: those increasing uterine weight; those enfeebling uterine supports; those forcing the uterus down by power applied above; and those drawing it down by traction from below.

a. Examples of causes connected with increased uterine weiglit :-

Tumors, submncous, subserous, or mural;

Pregnancy, (rare, but sometimes met with);

Hypertrophy or hyperplasia;

Retained fluid. 
b. Examples of causes connected with enfeeblement of uterine supports:-

Abnormally capacious pelvis ;

Destruction of power of the perineum;

Loss of tone in vaginal walls;

Loss of tone in uterine ligaments ;

Absorption of fat from pelvic areolar tissue;

Atony of abdominal muscles;

Diminution of power of respiratory muscles.

c. Examples of influences forcing the uterus downwards :-

Violent coughing ;

Tumors in abdomen ;

Ascites ;

Violent muscular efforts ;

Tight and heary elothing;

Straining at stool.

d. Examples of influences dragging the uterus down :-

Congenital or acquired shortness of the vagina;

Prolapse of vagina, bladder, or rectum ;

Uterine prolapsus.

I have already stated that these evil influences are most completely combined in the condition existing after parturition, when the uterus is heavier than normal, the recently distended vagina relaxed and feeble, the uterine ligaments very much stretched, and the sphincteric muscles of the vagina weakened. When, as so often happens, rupture of the perineum and of the cervix uteri occur, and are followed by subinvolution of vagina, uterus, and uterine ligaments, we lave in perfection all the conditions which give rise to this displacement. Of all the causes of prolapsus this combination is the most frequent, and hence the difficulties attending cure. It is for this reason that prolapse is found to be rare in women who have never borne clildren, less rare in those who have borne one only, and apprears to increase in frequency in proportion to the frequency of the parturient process. Scanzoni reports that in 114 cases of prolapsus 99 occurred in women who had borne children. Even the most complete prolapse, lıowever, will sometimes be met with in young and unmarried women. Within the past five years I have met with three snch eases, one in a virgin of nineteen, one in an old maid of about sixty, and the third in a healthy, laboring woman at the menopause.

Next in order of frequency will be found a condition which occurs in old women, a loss of vaginal power from atrophy of the vagina, and absorption of the padding of fat which normally oceupies parts of the pelvis, and helps to aid that canal in sustaining the uterus. This condition has been specially mentioned by some of the German pathologists, and attention lias been called to its importance by Dr. Barnes, of London. Here, 
although the uterus is atrophied, it descends in spite of its lightness, partly from loss of support from the vaginal promontory and party from traction excrted upon it by the prolapsing vaginal walls.

An important position as a pathological factor is assiumed by loss of tlee retentive power of the ablomen. Want of exercise exerpt in walling induees in women very commonly an atonic eondition of the thoracic and abdominal museles; and the respiratory act therefore becomes incflieient, and the piston function of the diaphragm feeble and impertect. $\Lambda$ s a consequence of this failure, the uterus rises in the pelvis at each expiration less perfectly than it ought; its eirculation, labking the stimulus of the abdominal rise and fall, becomes sluggish ; gradually it settles lower and lower in the pelvis, and becomes a readier prey to the action of other malign influences.

Relaxation of the abdominal walls probably also favors displacement by effecting an alteration of the direction of pressure transmitted to the uterus, bladder, and superior vaginal wall, and by permiting the free entrance of intestines into the anterior peritoneal prolongation or anterior uterine excavation.

Inereased uterine weight and pressure from above are so plainly active in ereating prolapsus, that no one will doubt their causative influence. By its instrumentality we see complete prolapsus occur with ovarian tumors, aseites, etc.

Pathology.-There is no variety of displacement about the pathology and mechanism of which gynecologists are more at variance than this, and yet none to which a greater amount of honest, scientific labor has been applied for the elucidation of these very points. As examples, I may eite the experimental researches of Aran, ${ }^{1}$ Legendre, ${ }^{2}$ IIuguier, ${ }^{3}$ Savage, and 'Taylor, ${ }^{5}$ to which the seeker after more elaborate data is referred.

Iy limited space will not permit me to go fully into the vicws of these in restigators, and I shall confine myself chiefly to a rather lormatic statement of my own opinions, at the same time acknowledging that they are, in great extent, founded upon the investigations alluded to.

It matters not whether the original cause of the displacement be inerease of uterine weight, depreciation of sustaining power, or direct force exerted upon the organ from above or below; an invariable result of its existence is diminution of the power of the uterine suplorts. 'The ligaments are stretclied, the vagina distended and doubled upon itself or everted, and the contractile power of the sphincterie museles inpaired.

1 Etudes Anatomiques et Anatomo-pathologique sur la Statique de l'V́térus, Paris, 1-58, Archiv. Gén. de Mél.

2 De la Chute de l'Utérus, Paris, 1860.

3 Les Allongements llypertrophiques du Col de l'Ltérus, Paris, 1859.

4 Female Pelvic Organs, Lumion, $2 d$ ed., 1870.

5 On Amputation of the Cervix Lteri, ete., New lork, 1869. 
The displaced organ is generally affected by congestion and inflammation of the nucous lining, its cavity is much enlarged, and solutions of continuity occur upon the cervix. The vaginal ruga are effaced, and the lining of the canal, exposed to atmospheric influences and frietion, looks like the cicatrized surface of scalled skin rather than mueous membrane.

"The tension of the aponeurotic fibres of the broad ligaments," says Legendre, "during uterine prolapse, results in compression of the hypogastric veins, at compression of the veins of the neck occurs, from tension of the cervical fascia, when the head is foreibly thrown backward. In this waly congestion of the uterus and other pelvic organs is kept up." Prolinpens, from its influence in thus producing hyperamia, is usually attended by lyperplasia of the areolar tissue of the uterus. This organ undergoes an absolute increase in size, and the tissue of the cervix is especially altered. Simultancously with hyperplasia, there is varicose degeneration of the bloodvessels of the cervix and absorption of its proper tissue. This increases the natural ductility of the part, and upon any traction being applied it stretches so as to produce the phenomenon of variation in the length of the uterus, mentioned under the head of physical signs. The walls of the vagina are found much thickened by proliferation of epithelium and hypertroplyy of the submucous layers of areolar tissue. Thus it becomes not only more eapacious, but lieavier and more voluminous than normal, and eren if its increase in volume and weight are consequences of uterine displacement, it drags upon the uterus and increases its tendency to descend.

The uterus may descend from its normal place in the pelvis under any one of the four influences which have been mentioned. It must not, however, be supposed that one only is usually active. On the contrary. two, three, and even four are often combined in furthering the result. For thoroughness of study they are examined apart, that course being also chosen from the fact that even if several causes are combined, one is usually especially prominent as a factor.

If a carefnl clinical study be mate of this interesting subject, the uterus will be found to descend in one of these ways:-

1:t. A woman who has previously been in good health begins to complain of dragging alont the loins, backache, and sense of fat tigne about the pelvis. An examination is made, and the nterus is found resting upon the floor of the pelvis, its axis little altered. There is no rupture of perineum. no redumlaney of vagina, and the habits of life of the patient preclude the posibility of muscular efforts or tight clothing being agents in the condition. A carefinl examination of the displaced uterus shows it to be lange and heavy from subinrolution, or discorers a fibrous tumor in its structure. The natural supports have been perfect, but they lave bern overtaxed and have yielded. Increased uterine weight is the prime mover in the li-order. 
But keep this case under olservation. The desernt alrealy eflietul has drawn down the blader, ansed pressure upon the rectum, istabli-berl a hyperania in the tisines of the vagina, and begm alreaty to rob the uterine ligaments of their power by stretehing them. Pressure on the reetum and dragging upon the bladker create irritation, the patient "bears down" in evacuating these viseera, and a new influence is developed: force from above. Very soon congestion of the vagina results in excessive areolar growth, this canal falls into its own distended chamnel, and another evil influenee is the result: traction npon the uterus from below. The uterus has now descended so that its os projects between the labia majora; if its ligaments were stretched before, how much more so must they be now !

2d. A uterus is found in the first legree of prolapsus. It is a healthy uterus, normal in size, weight, and consistency. Its supports appear perfect, and so influence exerts traction upon it from below. Everything is normal, but one-the uterus has descended. Examination proves that this woman has labored hard, lifting heary weights, and placing herself in a constrained attitude to do so ; or she has for weeks suffered from a spasmodic, violent cough; or from obstinate constipation which las caused tenesmus. The cause of the prolapse is evidently force applied to the uterus from above. But this remains the sole cause for a short time only. Very soon increased weight of the uterus from congestion, enfeeblement of uterine supports from prolonged tension, and traction by falling of the hypertrophied vagina and prolapsed bladder complete the vicious circle.

31. An examination of the uterus in a case exactly similar as to symptoms, demonstrates no increase of uterine weight, no force applied from above. The woman is found to liave a justo-major pelvis, which has always resulted in precipitate labors; or she is past sixty, and a senile atrophy is developing; or the perineum is ruptured, and the anterior and posterior vaginal walls are protruding in egg-like pouches at the vulva, not suficiently to drag upon the uterus, but enough to shorten the vagina by allowing its distal end to protrude, and thus the vaginal promontory is removed. The mischievous factor is loss of uterine support. The uterus is normal in weight and exposed to no evil influences from pressure or traction, but its feeble supports eren then are unfit for their functions, and the uterus falls. It deseends to the second degree, and, dragging upon the broad ligaments, their aponenrotic expansions compress the hypogastric veins, great eongestion results, and at once a new influence developsincreased uterine weight. Now rectal and vesical tenesmus and pressure by the displaced abdominal viscera ald another untoward element-force applied from above. And as the descending nterus everts still further the congested, voluminous, and heary vagina, it drags the oflending organ still more rapidly down.

4th. The reader wearied by repetition may crave a respite here, but he 
asks it just where it cannot be granted, for we come to the consileration of the most frequent and consequently most important of all the influences resulting in prolapsus uteri. P'rolapse of the uterus is sometimes a primary affection, but in the great majority of cases it is secondary, produced by prolapse of the ragina, which literally drags it from its position. There are two methods in which this occurs: 1 st. 'The perineum is ruptured, and by this the raginal walls lose the buttress against whieh they rest, and the power of the pubo-roceygens nuscle is diminished. 2d. A vagina developed by utero-gestation does not undergo involution, but remains a large, voluminous, and heary bag, the redundant walls of which overeome the resistance of the perineal hody and prolapse, dragging the uterus down, either before or simulaneously with their escape from the vulva.

Dr. Duncan, in an essay read before the Edinburgh Obstetrical Society, ${ }^{1}$ in 1871 , maintained that the perineum latul nothing to do with the support of the uterus, and that, therefore, laceration of this part is not a canse of prolapsus. I do not believe that the perinemu supports the uterus direetly, nor that upon the cadaver its section would result in prolapsus; but I believe that destruction of the perineal body wlich acts as a support to the vagina results in loss of support to both its posterior and anterior walls. These prolapse, their tissue becomes hypertrophied, and they drag down the bladder and then the uterus. Look at Fig. 56 and see how much support vagina and bladder obtain from the perineal boly, and the results of its rupture may be better appreciated. So long as the vagina is normal in volume and weight, and remains within the pelvis with its walls in apposition, it constitutes, by its ante-cervical projection, I think, a uterine support. So soon as it falls fiom the pelvie cavity, beromes hypertrophied, and has its walls separated, it not only loses this puwer, but degenerates into a uterine tractor.

'The same authority points to the fact that many cases of complete perineal laceration do not produce prolapsus uteri. This is true. Such laceration is usually the result of parturition. and is, I am satisfied, often a cause of subinvolution of the vagina. If this condition has resulted, the laceration is very generally followed by prolapsus vagina, and thus by descent of the uterus. If vaginal involution have not been interfered with, it is usually not so.

Aran points out the fact, that removal of the ragina from the calaver does not produce uterine prolapse, and I)r. Dunean deckares, "I have no doubt that, if, hy way of experiment, the periurum was cut through in a healthy woman, no tendency to prolapsus would be thereby produced." I freely accept both experiment and proposition, hut I cannot agree in the desluetions based upon them. When the uterine ligaments are strong, the uterus does not readily leare its position. Sometimes traction stearlily

1 Transactions, vol. ii. p. 269. 
exerted mpon the cervix fails to draw down the body, but streteles the neck so that the uterus measures by the somml between six and serem inches. Klob"declares, that " praxation of the utrine tissue is noticeable in the region of the external orifiee, and consequently in what was previonsly the vaginal portion and lower secrment of the cervix, which fart often assumes a spongy softuess. This relaxation must be attributed to the varicose condition of the bloodvessels, and absorption of the cervi"al tisile." This, and not hypertrophy, is probably the condition of this distented part. In many cases, before prolapse occurs, the uterus is aflected by areolar hyperplasia, or the local atrophic state engendered by flexion, which last $\mathrm{D}_{\mathrm{l}}$. IJewit regards as a frequent source of it, and when thus wakened it readily yields to traction. When the tractile force is checked by reposition of the uterus, the neek instantly contracts, aml the length of the whole organ greatly diminishes.

May this fact not explain the experience of IInguier, who found only two cases of true prolapse in sixty reported cases, and of Routh, who in a large experience met with only three? It seems to me highily probable that these investigators, making their measurements while the uterus was prolapsed to the third degree, concluded that hypertrophic elongation of the supra-vaginal portion existed, when in reality this peculiarly elastic tissue, which was the conseguence and not the cause of the descent, was the true pathological condition. Certainly some such explanation must account for the remarkable diserepancy which exists between the results of these two eminent gynecologists and the great majority, whose experi. ence is opposed to theirs.

In these cases the force of traction appears to expend itself upon the most powertul uterine ligaments, those inserted at the axis of rotation, the eervico-corporeal junction. They yield, and the cervix advances towards the vulva, but the uterus, supported though it is by factors of less power, resists steady traction, and remains in place. Legendre attached to the tervix uteri of a cadaver, a weight of fifteen kilogrammes, which was gratually increased to fifty during the period of an hour, then diminished to thirty, and kept up traction by that for two hours. At the commencement, the uterine canal measured by the sound five centimetres, and at its conchusion nine, the lengthening being cliefly in the cervix. In other experiments, a less weight kept in action for several days, caused complete prolapse with elongation of the cervix uteri.

Since the appearance of Huguier's essay upon supra- and infra-vaginal elongation of the cerrix as tonditions commonly mistaken for prolapsus, writers have commonly considered hypertrophic elongation of the cervix below the vaginal junction under this head. I shall not do so, because the propriety of such a course seems to me to be sustained neither by 
clinical obscrvation nor pathological investigation, and because true cervical lypertropluy will be elsewhere treated of.

That there is a form of hypertrophic elongation of the cervix uteri, which oecurs below the cervico-vaginal junction, and appears upon very superficial examination to resemble prolapsus, or even produces that condition by traction, I, of course, admit. But it appears to me erroneous to regard supra-vaginal elongation, which is marked by an attenuation of the tissues of the neck and "a spongy softness," according to Klob at tributable to a "varicose condition of the bloodressels and absorption of the cervical tissues," as true hypertrophy.

It is highly probable that this condition, the result of traction, may oceur during pregnancy, and exist as a source of great annoyance after it. 'The following deduetions by M. Gueniot ${ }^{1}$ substantiate this view :-

" 1 . In certain women there exists during pregnancy, and occasionally at the time of parturition, a special affection of the neck of the womb, which generally passes unrecognized, and has not hitherto been the subject of any description.

"2. This affection may be designated under the name of Gidematous Elongation with Prolapse of the Neck, which indicates the principal constituent traits. Hyperamia and turgesence of the organ, the arrangement of its cavity, which is transformed into a long and freely patent canal; the rapidity with which these symptoms mal disappear, and the great facility with which they may be reproduced under certain circumstances, are all so many fundamental characters of the affection. Ulceration of the os tinca, occlusion of the vagina, a thin and flaceid condition of the uterine walls, are also almost constant symptoms; as are also cireumpelvic pains, a feeling of general debility, and rariable disturbances in micturition.

" 3. The causes of this change in the neck of the uterus are complex; they are derived from two sources : certain anatomical dispositions of the organ, and various circumstances exerting upon it a prolonged mechanical action.

“4. Although very rare, cedematous elongation with prolayse of the neck is, without doubt, a less exceptional aflection than one would be inclined to imagine. Many observers lave erroncously assimilated it to hypertrophic elongation, or to simple prolapsus, to which aflections, in truth, it presents a great analogy, but from which it is essentially distinguished by proper and very important elaaracters."

Course, Duration, and Termination.-Prolapsus uteri is unlimited in its duration, and, unless relieved by art, will continue indefinitely. It impairs the patient's comfort and capacity for exertion, lut rarely has a fatal termination, unless by exeiting peritoneal inflammation, or pelvic 
cellulitis, as I have seen it do in scveral cases. Even in the chronic form of the disease, death has in very rare cases oceurred from arinania, the result of interferenee with the ureters. 'The trigone of the blather becoming displaced to such an extent that the orifices of the ureters are pressed firmly against the symphysis pubis by the mass behind it, they become obstructed and distended, and in time hydronephrosis may result. Virchow ${ }^{1}$ and Kiwisch ${ }^{2}$ both announce this fact. An interesting instance of death thus produced may be found in the twelfth rolume of the 'Transactions of the London Obstetrical Society, reported by Dr. Phillips. In a case of incarcerated uterus occurring in ny own experience, and which will receive further mention elsewhere in this article, I was compelled to resort to a degree of force in returning the displaced organ, which at the time of application I regarded as attended by extreme langer. Iaul my efforts not sneceeded, deatl would, I feel sure, have resulted; for the uterts and surrounding parts appeared to be about passing into a state of gangrene. This ease before $I$ saw it had resisted all the efforts which were applied by three competent physicians. After forcible replacement, the entire lining membrane of the vagina sloughed, and the patient narrowly esciped death from pcritonitis, which was excited and ran a violent course. Forcible taxis was resorted to, with a conviction on the part of the attending physicians and myself, that the issue involved either restitution of the uterus or death.

Symptoms.-The symptoms of prolapsus are dependent upon two results growing out of the displacement: the meelianical interference of the womb with surrounding parts, and alteration induced in its circulation and tissue by reason of its abnormal position. The uterus may remain even in the third degree of descent without any marked symptoms, but generally congestion, areolar hyperplasia, and granular degeneration occur, which render it sensitive and intolerant of pressure or friction. At the same time, by dragging upon the bladker, rectum, and all the pelvic areolar tissue and fascia, and by protruding between the labia, it produces discomfort and often imperes locomotion to a great extent. The most prominent of the symptoms thus created are the following:-

Sensation of dragging and weight in the pelvis;

Rectal and vesical irritation;

Pain in back and loins;

Great fatigue from walking;

Inability to lift weiglits ;

Leucorrhoea and other signs of congestion.

It is a very singular and striking fact, that in prolapsus, even of the third degree, there is very commonly no menstrual disorder, and equally remarkable that sterility does not ordinarily exist. These immunities 
are probably dependent upon the facts that the uterine catarrh which usually exists is rather the result of a passive congestion of the endometrium than of true inflammation, and that the axis of the organ, although altered in direction, is not bent upon itself so that an obstruction in it is created.

Pliysical Signs.-All the symptoms detailed will only excite suspicion and prompt an examination which will fully elucidate the case. Should the affection exist only in the first degree, the finger passed up the vagina will meet with the os low down in the pelvis and pressing upon its floor. As it is slid upward in front of the cervix and along the base of the bladder, the resisting anterior wall of the uterus will be clearly distinguished, and it may be found that anterersion or anteflexion exists, complicating prolapsus.

If the second degree have been reached, the os will be found at the ostium vagina, prevented from escaping only by the resistance of the sphincteric muscles, and the body, instead of lying forwards, will be to some extent retroverted. To determine the degree of prolapsus, more especially in this stage, the patient should be examined standing.

Sight and touch will combine in making a diagnosis in the third degree of prolapse rapid and casy, but even here $I$ have known very grierous mistakes committed. The apparent ease of the diagnosis sometimes causes error by inducing negleet of that eaution and watchfulness which, even in the simplest eases of disease, constitute the only safeguard of the physieian.

One very eurious pluenomenon which in the physical investigation of these cases must have struck every practitioner is this: the uterus being proeident and a sound introduced, it passes up for the distanee of five or six inches. The organ now being replaced, and again examined by the sound, it is found to measure only three or four, and this experiment may be reprated any number of times with the same result. The explanation of this fact is given in connection with the subjeet of pathology.

Differentiation.-In any of its varieties prolapsus uteri may be confounted with fibrous polypus, inversion of the uterus, and hypertrophic elongation of the neek, from all of which, however, it is readily distingruished if the practitioner be awake to the possibility of error. From the first it is known by the presence of the os and cervix, and the general slape of the mats. From the second, hy the presence of the os and cervix, and absence of the signs of inversion. The third will realily be recoornized by the great length of the cervix, the impossibility of replacing the supposed prolapsed organ, and the great depth of the uterus discovered ly the uterine probe, after it has been restored to the pelvis.

Prognosis. - In most cases a great doal of relief can he effected by molisal and minor surgieal means. In a fow in which the displacement is secondary to the existence of a large abdominal or perhaps uterine tumor, 
nothing ean be done either for relief or cure. In many in which descent of the uterus is secondary, due to traction upon it by the prolapsed vagina. bladder, and rectum, cure can be efleeted, even where the third dearee lats been reached, by surgical procedures appropriate to the cure of the primary displacements which produce traction upon the uterus.

In cases existing only in the first and even the second degree cure may, in fatrorable cases, be accomplished by mere removal of the canses which are gradually depressing the uterus.

Complications.-Prolapsus of the uterus in its first and second degrees, and still more freeqnently in its third, produces the following complications:-

Congestion of the nterus and its appendages;

Endometritis and Fallopian salpingitis;

Ilyperplasia of uterns;

Hypertrophic elongation of the cervix ;

Cystocele;

Rectocele.

As soon as the uterus descends into complete prolapse, and to a less extent when it has reached only the first and second degrees, its tissue becomes congested, and appears swollen, œelematous, soft, and relaxed. In time this passive lyyperemia induces hyperplasia, which especially atfiects the connective tissue. As a consequence the uterus is enlarged, and increased in weight and capacity. Not only do congestion and liyperplasia affect the parenchyma of the uterus; the mucous membrane and submucous tissue are likewise disordered, and endometritis is an almost invariable consecquence of prolapse. It has been already stated that peculiar changes occur in the cervix. This part becomes particularly soft and relaxed; its vessels become varicose, and the muscular tissue is often absorbed in great degree.

In consequence of these secondary morbid states we generally have as concomitant symptoms, leucorrhca, dilatation and eversion of the cervix, disorders of the bladder and rectum, and sometimes eystitis. Eversion of the cervix is too important a feature of the condition to be passed by without special mention. As the uterus descends it inverts the vagina. This, by its cervical attachment, which now becomes depressed to a point far below its upper portion, makes constant traction upon the os externum; the principle being the same as that by which the colpenrynter is made to dilate this part for the establishing or expediting the first stage of labor. As this action is prolonged and increased by further descent of the uterus and inversion of the vagina, the ccrvical canal is rolled out, so as to become completely everted, and the os internum becomes literally the external and only os uteri, the real os externum having disappeared by expansion.

Dislocation of the bladier is accomplished by uterine descent to such an extent that if a catheter be introduced it will pass downwards and 
backwards. This complication is important, for not only do traction and dislocation tend to the production of eystitis; it is further induced by reflex irritation and by decomposition of urine oceurring from retention, after urination, in the pocket formed by the inverted wall of the bladder. By a similar process prolapse of the anterior wall of the rectum occurs, and results in fecal impaction at this point.

Sudden or Acute Prolapsus may come on from any great effort, a fall, or violent contraction of the abdominal muscles, acting upon a uterus which is enlarged by hyperplasia, subinvolution, pregnancy, or tumors. It may even occur to a uterus normal in size and consistency. In an instant the patient feels that something lias given way within her, becomes prostrate and much alarmed, and suffers pain of an expulsive character, as if desirous of forcing something from the pelvis. I lave twice seen it oceur within a fortnight after delivery from sudden and violent muscular effort: and once in a nulliparous girl of nineteen years, in consequence of a violent muscular effort made to lift a heavy weight, the cervix was driven out of the vulva, the body being arrested by the sphincter vaginæe and perineal septum. The last patient I saw a year alter the accident. She had suffered intensely from the displacement, but from false modesty had never told of it. I discovered distinct traces of the hymen, which I had every reason, both physical and moral, to believe had not been ruptured by sexual congress.

In such a ease as this it appears to me highly probable that the uterosacral ligaments are ruptured. This supposition, the difficulty of proving which by necropsy is apparent, may lave attracted attention, but the only allusion to it which I lave met with is the following from Courty, who, in speaking of the utero-sacral ligaments, says, "if they are stretehed or broken, the entire organ falls."

In acute prolapsus, should reduction not be affected at once, violent pain will be felt over the sacrum and groins, and the degree of traction exerted upon the pelvic peritoneum may result in dangerous inflammation.

Treatment.-The first indieation as to treatment is to return the displaced organ to its normal position; the second, to keep it there.

Methods of Replacing the Uterus._-In general no diffieulty will attend the performance of the first indication, hut in some cases careful and intelligent taxis will be necessary. The best method for applying this is the following: the pationt, after thorough evacuation of the bladder and reetum, if this be possible, should be placed in the genu-pectoral position, in order to cause gravitation of the pelvic and aldominal viseera towards the diaphragm. She should not kneel upon a soft or yiekling bed, into which the knees would sink, but upon the floor or a table, for the object of the wosture is to elevate the buttocks and depress the thorax as much as possible. Ten or fifteen minutes should then be allowed to elapse before any efliorts are made at reduction. In this time the intense congestion which 
exists in the pelvic viseera will greatly dimini-h. The operator then taking the cervix into the grasp of his index, mindle, amb ring fingers, pushes the uterus firmly and foreibly upwards in enincidence with the axis of the inferior strait. While the right land is thus employerl, the left rests upon the back of the patient aur stealies lor borly. No sudden or violent force is exerted, but by stealy pressure, kept up, it necessary, for fifteen, twenty, or thirty minutes, the nterus is restored to its place.

Few eases will resist this kind of eflort at reduetion, althongl some may 'do so. For example, I have alrealy referred to a ease in which an in. careerated uterus, which appeared "yon the point of becoming gangrenous, condd not be redueed by the method described, and in which, as no time was to be lost, I produced complete anasthesia, and then, taking the organ firmly in the extrenities of the thumb and three ingers, I carried it by main forre into position.

Methods of Sustuining the Lterns.-Before pursuing any special course of treatment for this end, the practitioner should emleavor to discover the cause of the descent. If it be due to inerease in the weight of the uterus, or to pressure exerted upon it from above, it is evident that the indication will be very different from what it would be if the cause were traction by a prolapsed vagina. Unfortunately, however, after the disease has existed for some time, it is often impossible to fix definitely upon the cause ; for even if it were originally increase of uterine weight, the lengthy inversion of the vagina, and stretching of the uterine ligaments involved in its descent, will have destroyed all power in these parts.

As far as possible, however, the original eamse should be ascertained, and if it be properly sought for it will, in a number of eases, be discovered. For example, suppose that there be no excessive enlargement or prolapse of the vagina, no evidence of excessive downward pressure, and yet the uterus lies upon the pelrie floor. Strength should be given to its normal supports.

Suppose, on the other hand, that the vagina be found to be in its normal state, and the prolapsed uterus to be very heary, weighing, perhaps, three times what it should. This inerease of weight should reeeive especial attention.

If, again, the insignificant, atrophied uterus of an old woman of seventy be prolapsed into a large, flabby, non-contractile ragina, traction by this vagina may safely be accredited with the uterine displacement.

Lastly, if the common coincidence of rupture of the perinenm, with subinvolution, and prolapse of the vagina and uterus be encountered, it may be assumed that increase of uterine weight, loss of support, and traction, have all combined to bring about the issue.

It should be the care of the physician to keep every one of the indications suggested by these factors in mind; and in every case attend first to 
that which coneerns the primary and most important; afterwards, to those which are secondary and ereated by the displacement itself.

A very important question offers itself for consideration here: Is it possible to give relief in an aggravated case of prolapse in the third degree without resort to operative procedure? The position has of late been taken by high authority that surgery must always be invoked as our final resort in such cases, and that less radical treatment should be looked upon as palliative and in great degree preparatory. This $I$ regard as a doctrine calculated to do great harn, and one which entirely misrepresents the true requirements of the subject. I should state the matter thus: In a very large majority of cases of prolapse of the uterus, whether in the first, the second, or the third degree, relief may be obtained without resort to operation; in a certain number of cases where traction by the prolapsed vagina, reetum, or bladder is the cause of the uterine displacement, it should be our ehief resource. Now it may be said in reply to this that even if such traction was not a primary factor in the displacement, it is always a secondary one, and, like a great many theoretical observations, this will earry weight. But it is not really a valid argument at the bedside for him who studies these eases from a scientific standpoint, howerer powerful it may be in the mind of the empirical gynecologist. If the perineum have lost all power, and a loose, flabby condition exist in the vagina from subinvolution or hyperplasia the consequence of prolonged congestion, and the resulting vaginal, resical, and reetal prolapse has dragged the uterus down, operation merely fulfils the important indication of removing the cause of the trouble, and logically presents itself as an important resource. If, on the other hand, a heavy uterus presses down of its own weight, or a normal one is foreed down by pressure from above, closing the perineum, or contracting the vagina by eolporrhaphy, is illogical, umecessary, and empirical. I wonld conclude this part of the subject by repeating, that operative procedure for uterine prolapse should be only exceptionally resorted to, and then to fulfil an indication, not to comply with a dogmatic rule.

I lave at this moment under observation a number of eases in which entire relief to complete prolapse has been afforded by means which will soon be mentioned here. So complete is this that the patients thus relieved would not listen to the proposal of operation. It is true, that complete cure hats not been eflected, but complete relief has. If the operative procedlires for such cases were simple, entirely free from danger, and certain ats to result, a universal resort to them would be indieated; but they are not so. I would not willingly alppear to oppose operation in these eases, for I favor it and constantly practise it. I merely urge the application to th' $\cdot$ of of the orlinary rules which govern the scientifie surgeon elsewhere.

I will now consider in order the methods most appropriate for resisting each of the pathological conditions which result in uterine prolapse. 
The means adapted to prevention of pressure from abore are-

Removing weight of elothing by nse of skirt-supporters;

Removing weight of intestines by prolibition of tiglit rlothing, use of an abdominal supporter, and avoidance of injurious muscular effiorts;

Preventing aceumulation of urine and feces.

The skirt-supporter is merely a pair of suspenders that may be contrived by any woman of ordinary ingennity, and which entables the patient to carry the whole weight of the under-garments upon the shoulders. A representation of a very good one will be found in Fig. 141. Or the skirts may be affixed to a waist, which replaees the corset, by buttons, as slown in Fig. 142.

Fig. 141.

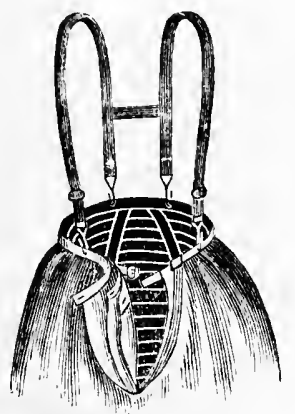

Skirt-supporter.
Fig. 112 .

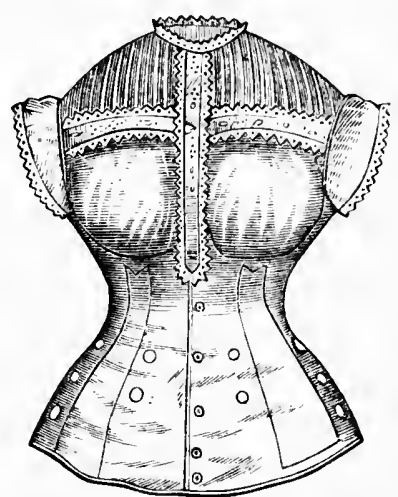

Waist with buttons for support of skirts.

There are many varieties of the abdominal supporter, some of whieh, unfortunately, are so eonstructed as to do absolute liarm. Shonld eompression be exerted by them upon the abdomen above the navel, it will tend to inerease pressure upon the uterus, or at least to annul all the benefit of that exerted below this point. The prineiple upon which these supporters should act is this-they should do just what the patient's hands do when she places them above the pubes, and lifts the abdominal viseera. Some of them are composed simply of bands of thick cloth, others are pads or disks of horn or metal, with encircling bands like those of the liernial truss. The physician may choose intelligently, if lie only bears in mind what it is that he desires to aceomplish by them.

During the eontinuance of treatment the patient should be limited as to exercise and confined to bed during menstrual epochs, when the uterns is known to be heavier than at other times. Should the aceident hare immediately followed parturition, she should be kept in the reeumbent posture to favor the accomplishment of involution. 


\section{Means adapted to diminution of uterine weight are-}

Removing polypi, tumors, etc., by operation;

Removing uterine inflammation, hypertrophy, and congestion, by appropriate treatment;

Amputation of the neck of the womb;

Repairing laceration of the neck.

Sometimes, by applying appropriate treatment to an enlarged cervix, the uterus is in time so much lightened by cure of attendant hyperemia that relief is effected, but in other cases the hyperemia is so persistent and rebellious that these means fail, and resort must be had to more powerful ones. A lacerated cervix will often prove a focus of irritation, and thus a cause of uterine congestion and hyperplasia, which may result in descent of the uterus. Under these circumstances closure of the laceration will often effeet a complete cure, and it should without delay be performed.

In some cases, even when parturition has never occurred, hypertrophy of the cervix occurs and proves a canse of prolapsus. For this, resort has been had to amputation of the neck. M. Huguier, of Paris, was, in 1848, the first to perform this operation for prolapsus, though it has long been resorted to for cancer. Since that time it has been performed by many others, after methods which will be described in a chapter devoted to the operation. It must not be supposed that the mere remoral of superabundant tissue is relied upon for the diminution of uterine weight. It is rather the derivative and alterative influences set up by amputation of which the surgeon endearors to a vail himself.

Means for strengthening or supplementing uterine supports:-

The recumbent posture;

Local astringents and tonics;

General tonics;

Exercising the retentive powers of the abdomen;

Pessaries.

The recumbent posture, persistently persevered in. accomplishes a great deal of good in cases of prolapsus in the first, and sometimes even in the second degree. The buttocks being elevated, the uterus retreats from the pelvis. and its supports are left entirely at rest. Opportunity is thus afforded the weakened tissues to contract, to gain tone and strength, and in time to resume their functions. The results of posture may be materially increased by simultaneous employment of the following agents.

Astringents and Tonics.-By these means the pelvic tissues may be male to sustain the uterus for a time, and thus by keeping it ont of danger of congestion from interference with circulation, ofportunity is given for removal of engorgement or slight hypertrophy.

The astringents most commonly employed are tannin, alum, persulphate 
of iron, and the hark of the white oak. They may be injected into the vagina in solution or infusion, by means of the ordinary syringe. A rery excellent astringent moder these circumstances is the infusion of the sumach berry, which grows commonly by our roadsides throughout the coluitry.

Tonies may be locally applied by the use of cold hip-batlıs, donelies, sea-baths, and by copious vagrinal injections of cold water, salt and water, or sea-water.

General tonies, mineral and vegetable, should be employed. Anong these, ergot, stryelnia, and iron may be specially mentioned. Sea-hathing is peeuliarly beneficial for this purpose, for it not only acts loeally, but improves the tone of the whole system. In speaking generally of the influences which sustain the uterus, the peculiar retentive power of the abiomen las been mentioned very fully. IIabits of life, with reference to exercise, dress, ete., exert a marked influence over this power. The woman who rarely exercises so as to call for tull expansion of the lungs, gradually diminishes her breathing power, and in the end suffers from atony of the thoracie muscles. This renders diaphragmatic action feeble; the alternate rise and fall of the abdominal viscera is lessence ; they settle down upon the pelvie viscera; and the abdominal nuscles lose their power and activity. This result is produced not only by a life of inactivity, which enfeebles the museles which accomplish thoraeie and abdominal respiration by want of use, and thus indirectly lessens diapliragmatic action; any influence which directly interferes with the piston-like action of the diaphragm, or indirectly enfeebles by prolonged pressure the thoracic and abdoniual museles, tends to overeome this important function of the abdomen in supporting and keeping the uterus in good cirenlatory condition. Should any one doubt this, let him examine witl Sins's speculun sereral tightly-laced women, who, since childhood, have done all that art could do to amililate this sustaining power of the abdomen; and then the same number of women undeformed by the pernicious habit. Let him even examine the same woman with and then without corsets, and he cannot fail to recognize the slight uterine movement in the one case, and the active, vigorous rise and fall in the other. The influence of constriction at the waist will be readily appreciated by reference to Figs. 143 and 144 .

As the retentive power of the abdomen is destroyed by pernicions habits, it may with perseverance and judicious efforts be restored, and the importance of striving to accomplish its restoration in all cases of uterine displacement eannot be too strongly insisted on. This should be done first by freeing the trunk from all constriction and weight ; second, by causing free action of the diaphragm by general exercises which cause this muscle to work vigorously; and, third, by the practice of special exercises adapted 
to development of the thoracic and abdominal muscles. As excellent general exercises may be instanced, rowing in a light boat or upon a rowing machine, ${ }^{1}$ practising the "lift cure," the use of Goodyear's "parlor gymnasium," or calisthenics. Walking and riding, either in a velicle

FIc. 143.

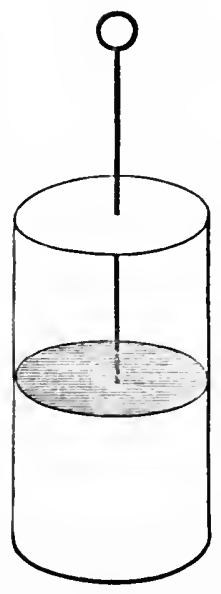

The action of the diaphragm, the parts in normal condution.
Fig. 144.

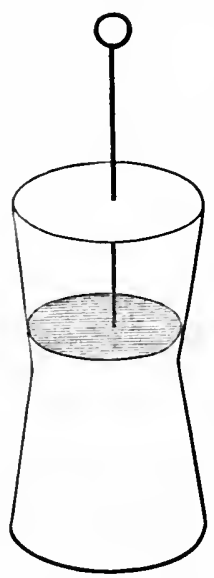

The action of the diaphragm, lhe parts deformed by tight and heary clothing.

or on horseback, are excellent in their results upon the general health. but they fail utterly in fulfilling the sprecial indication refuired. They improve nutrition and strengthen the muscles of the lower extremities, but not those of the upper portion of the trunk. Their sulstitution therefore for those just mentioned is an error. They may all to the general good accomplished, hut do not develop either the lost function or the muscles which should perform it.

There are also particular exercises adapted to the especial development of the abdominal muscles, at the same time that they excite an exagrerated action on the part of the diaphragm, and teml by that and by Eratritation to raise the pelvic viscera. For a fill exposition of this -uljoet I would refer the reader to a work by Dr. (ieorge II. Taylor. ${ }^{2}$ IIs directions for the speeial fulfitment of this indication I give in his wwn words. "The patient lies back downward on a horizontal conch, with the lands strongly clasped over the heal and presing on its crown; the feret drawn up so that the heels are in elose contact with the trunk, the soles of the feet resting on the conch, the knews and thighs being strongly flexed. By al moderate effort the patient raises the hips as ligh

1 Inplements for these exercises are on sale in all our large cities.

2 Dis. of Women, Naclean, N. Y., 1871. 
as she ean, or till the thighs and trunk form a straight line, the shoulders and the feet only resting on the couch; in this position the trunk must for a few moments be sustained. The hips and trunk are now allowed slowly to fall back to the commencing position on the couch. This action may be repeated a dozen or more times, a few noments of rest intervening."

Another exercise is this: "The invalid lies on a horizontal couch with face downwarl, the ellows resting firmly on the couch, the arms perpendienlar and supporting the upper portion of the trunk, the ankles strongly flexed, the toes, like the elbows, resting firmly on the couch. By a strong effort all the museles of the anterior portion, that is, the under side of the boly, are cansed to contract, the knees are straightened, the hips and whole body raised from the couch, and mate to form a horizontal line, touching the couch at no point but the elbows and toes."

Still another is the following: "Two stools or chairs are placed so far asunder that the patient, in lying face downward across them, will be supported by the chest resting upon one and the legs upon the other. While - thus lying the abdomen is unsupported and consequently gravitates towards the ground, causing retraction of the generative intestine. In this position, the patient must endeavor to maintain her body in a straight line, in opposition to the force of gravity acting on its central portion."

Pessuries._The plan of supporting the prolapsed uterus, vagina, bladder, and rectum by mechanical contrivances which supplement the enfeebled natural supports constitutes a method of great value, and one which should never be east aside. In a great many cases, objections, or advanced age on the part of the patient, want of skill on that of the physieian, and the uncertainty as to result which attaches to all surgieal procedures for the cure of prolapse, render a resort to a method which relieves very greatly, during even a long lifetime, one which is dictated by prudence and good sense. To support four organs, the vagina, uterus, bladder, and rectum, which are, and have been for a long time, prolapsed, by an artificial mechanieal means, frequently taxes the skill of the ablest gynceologist, and sometimes utterly defeats his best attempts. Let the general practitioner bear this undeniable fact in mind, and not become discouraged by difficulties, nor disheartened by repeated fruitless ettiorts. Let sueh a one who reads this believe too the assertion which $I$ here make, that $I$ advise no instrument merely because it has been generally accepted, and that I limit myself to the mention of those only which I daily employ in practice with good results.

In employing pessaries for all the varieties of prolapsus of the pelvic organs, the desideratum is an instrument which will not distend the vagina, at the same time that it will support the uterus. Such instruments as sustain the vagina without distending it, and thus allow it to regain something of its former tone and elasticity, are those which should 
be, as far as possible, selected. The great functions which, in the majority of eases, are required of a pessary in prolapsus are these : first, to supplement the action of the utero-sacral ligaments, the chief factors in sustaining the uterus; second, to keep the vagina, bladder, and rectum in place, so as to prevent them from perpetuating the uterine displacement by traction.

I have already said, that he who treats this condition, in any of its varieties, by rephacement and support by a pessary, must frequently meet with insuecess. Is it not illogical to suppose that by any mechanical contrivance, heary, congested, and prolapsed organs, of ten four in number, very generally three, can be, without preparation or the use of allied means, kept at once in normal position? Yet such a result is often anticipated. Betore resorting to a pessary at all, it is a good plan to keep the patient in the recumbent posture for a few days, or, if possible, a week, with the foot of the bedstead elevated twelve inehes, for the purpose of allowing congestion to pass off. During this time mild cathartics should be given to further this end by removal of feeal matter and stimulation of hepatic circulation, and the vagina should be systematically and copiously irrigated with astringent fluids to harden its tissues in preparation for a pessary, to effect support of the uterus, bladder, and rectum by a re-establishment of its sustaining power, and to cause contraction in its distended superficial bloodvessels. This time is not wasted, for the ease is sure to be a lengthy one. and at the end of it, the paticnt is much better able to begin treatment of a mechanical kind without meeting with mishaps, which, in the commencement, dishearten and discourage her. Nowhere is the statement more true than here, that a good beginning advances us half way to suecess.

The patient having risen, all of these means, except recumbency, should be continned throughout treatment, and others which are adjuvants to the pessary should be adopted, as, for example, removal of weight of clothing; avoidance of deleterious muscular efforts, long standing, and constrained postures; liminution of weight of uterus; development of retentive power of the abrlomen; and others which have been already enumerated. Having attended to all these points, the pessary presents itself as a valuable resource by which to complete and effect restoration of the parts: without attention to them it is, as a rule, too feeble to accomplish, unaided, the desired result.

Let us suppose that we are dealing with a case of prolapse in the first or second degree, what pessary should we choose? This will dejend upon the anomnt of weiglat to be sustained. If this be great, subinvolution of the uterus existing, and depressing the organ, very possibly no internal pesary will siecced; if it he molerate, almost any one of this list will do s-lleigs's elantic ring, Iforlge's, Smith's, Ilewitt's, or Thomas's pessaries, all of which are shown by diagrams in connection with retroversion. 
None should be used which distends the vagina, and that employed should be worn without any sense of discomfort ; slonlal be kept alan by irrigattion with astringent fluid every night, or night and morning; and shomb be aximined, at intervals, by the physician, to make snle that it is not injuring the tissues.

If the erreat weight of the nterus render these pessaries, which pass entirely inte the vagrina, ineffietual, or slonld the case be one of prolapses in the third degree, other's, which are in part rxternal and in part internal, should be employerl. I very rarely attempt to sustain a completely probaped uterus by an internal prisidy, berause I nsually despair of strecess, and becanse I have known such evil conserpences result from them in sueh cases, that I am moilling to let the patient pass out of my sight with one in place. It is sater, more effectual, and more comfortable for both physieian and patient that she should wear an instrument which she can remove at will, allow the parts to rest fluring the hours of recumbency, and replace upon rising.

There are three methods by which sueh support may be furnished, by a stem curling over the perinemm, by one passing out of the vagina over the symphysis pubis, and by one ending at the midlle of the vulvar opening, and resting upon a bandage passing beneath jt. Of these plans, the best is the first, and the next, in merit, the second. The thind is objectionable on account of the want of some point of support against which to fix the distal extremity of the stem, and to prevent motion in it.

F1G. 145.

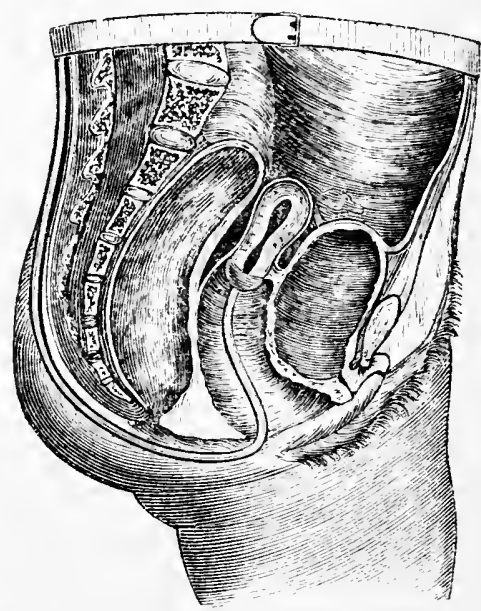

Culter's prolap-ns pessary in position.

Fic. 146.

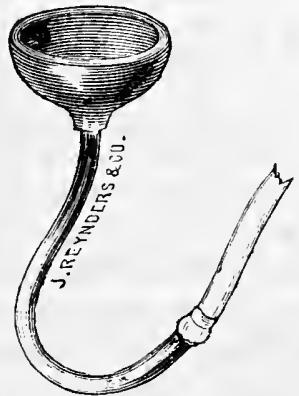

Cutter's prolapsus pessary.
Firi. 147 .

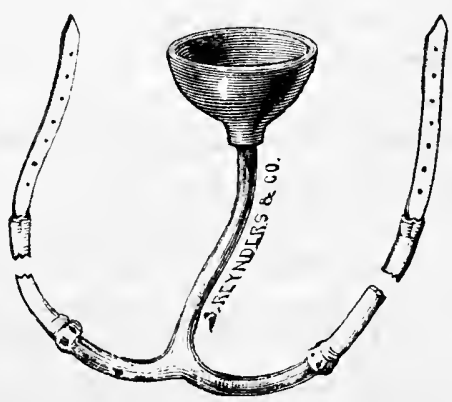

Thumas's modification. 
No pessary with which I am acquainted, so universally answers the indications of supplementing the action of the utero-sacral ligaments and sustaining the prolapsed vagina, reetum, and bladder as Cutter's admirable pessary, shown in Figs. 145 and 146. The eup at its upper extremity receives the cervix uteri, and the simplicity of the instrument enables the patient to remore and replace it with perfect facility. This should be done in the recumbent posture upon retiring at niglit and rising in the morning.

Means for preventing traction by the vagina:-

Perineal support;

Perineorrhaphy ;

Colporriaphy.

Perineal Support._I liave already pointed out the important function of the perineal body in closing the mouth of the vagina and offering a buttress for the support of its walls. When rupture of the perineun oecurs, its sphincteric powers are destroyed, and the result is sagging of one or both columns of the vagina and coincilent descent of the uterus. By firm pressure at the weak spot, by means of a pad or cushion filled with hair, cotton, or air, and combined with an abdominal supporter, to which it may be attached, partial relief is sometimes obtained.

Perineorrhaphy._. Much more complete and permanent support may be given to the vagina, and prolapse of its walls be much more certainly obviated, by restoration of the perineal body by the operation of perineorrhaphy. If the uterus be not very heavy, this operation often proves a very excellent means of relief, for it removes the tractile power, which pulls down this organ, and thus the cause of the aecident is taken away. But this operation, although efficient in these eases, is not likely to prove so where so heavy a weight, as a much enlarged uterus, requires support.

It must not be supposed that, in cases of prolapsed vagina, perineorrhaphy is limited to instances in which the perineal body is ruptured. It is equally applicable to those in which it has lost its power from any of those influences which are mentioned in the chapter upon the perineum; such as subinrolution, etc. etc.

In all eases, to be effectual, perineorrhaphy must restore the lost organ, the perineal body, and not simply shut the evil from sight by drawing before it at thin and nseless curtitin, which extends from the fourchette to the anus.

Should this operation not be suflicient to remove traction, eolpo-perineorrhaphy, or anterior or posterior eolporrhalphy, or a esmbination of these may be practised.

For these procedures the reader is referred to chapters which have gone before.

By there means traction is taken away from the uterus, and if this was 
the cause of its prolapse relief will probably follow, hut it is never safo to promise a good and permanent result from any of the operations of eolporrhaphy. If in a case of laceration of the cervix, relaxation of the vagina, and complete distention or rupture of the perineum, the patient is willing to submit to three operations-operation upon the cervix, colporrlaphy upon anterior wall, and elosure of the perineum-cure will often be complete and permanent. 'This is a trying ordeal, both mentally and physically ; nevertheless, most women afleeted by prolapsus in the third degree would unhesitatingly accept one of even greater severity with the prospect of cure.

Besides the operations here mentioned as praetised upon the vaginal walls, Episiorrhaply, which has been already deseribed, has at varions times been resorted to as a curative or palliative process for the affection of which we are treating. 'This, too, has been variously combined and moditied, as, for example, under the names of Inferior Elytrorrhaphy, Elytro-episiorrhaphy, Episio-perineorrhaphy, etc. For fear of confusing the subject by the introduction of details which, although highly interesting, are of no great practical value, I shall not describe these modified procedures, but pass them by with this mention.

Not only have efforts of this kind been made for narrowing the vagina and creating an artificial cicatricial anterior or posterior column for the support of the uterus; the actual cautery, mineral acids, escharotics, ulceration ereated by galvanic pessaries, and sloughing produced by pressure by forceps, have all been tried for the accomplishment of the much-desired end. I shall not go into the detail of describing these procedures, but refer the reader, who desires further information upon them, to Seanzoni's work upon the Diseases of Females. All these methods have the disadvantages of proving excessively painful, after anasthetic influence has passed off, and of being more mmanageable and less certain in their results than those here described.

\section{II A P T ER X XVII.}

\section{ANTERIOR DISPLACENENTS OF THE UTERLS.}

\section{Anteversion.}

Definition and Frequency.-This disorder of position consists in an anterior inclination of the uterus, so that the fundus approximates the symphysis pubis and the cervix retreats into the hollow of the sacrum. Although not so frequent as its kindred condition, anteflexion, it is by no means of rare occurrence. At times it presents itself as an annoying 
complication of areolar hyperplasia or fibroid growths, while at others it is produced without any alteration existing in the uterine parenclyma.

Dr. Clıurchill opens his clapiter upon this subject witl these words : "It may be thouglit somewhat out of place to treat of some of these displacements here, as they are so intimately connected with pregnancy and parturition; but as they do occur independently, it appears to me preferable to travel so far out of the way in order to complete the subject, rather than give a partial view, or omit it altogether." My own experience learls me to an entirely different conclusion from that liere recorded by the eminent Irish obstetrician. I meet with versions very commonly in the nonpuerperal state, although it must at the same time be admitted that anterior displacements generally assume the character of flexions. To give some idea of the relative frequency of the varions anterior and posterior displacements, I present the following tables. The first table is one constructed from a valuable statistical report by Dr. Meadows:-

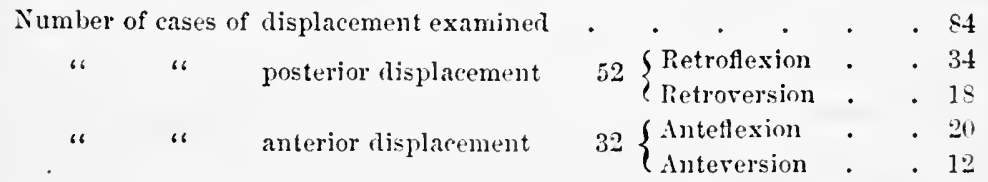

It is impossible to reconcile the discrepancy of the results obtained by statistical evidence accumulated by different observers. Thus, for example, out of 339 cases of displacement recorded by M. Nonat, ${ }^{2}$ the following were the number of anterior and posterior inclinations :-

$\begin{array}{lllllllll}\text { Anteversion } & . & . & . & . & . & . & . & 135 \\ \text { Anteflexion } & . & . & . & . & . & . & . & 33 \\ \text { Retroversion } & . & . & . & . & . & . & . & 17 \\ \text { Retroflexion } & . & . & . & . & . & . & . & 14\end{array}$

"Anteversion," says Klob, " in general is a rare form of displacement, and occurs much less frequently than retroversion."

Emmet, out of 5.5) cases of version, found 236 to be anteversion and 295 retroversion.

Suljects of this eharacter belong to that class npon which reasoning and theorizing aecomplish no good, but rather the contrary. The only way in which they can be settled is by earefully collected statistics, and one would suppose that this mothod would be conclusive. Yet we see in thre present case how far this is from being the fact. Dr. Meadows's most frepuent displaterment is .II. Nonat's and Scanzoni's least frequent! Nothing but discrepancy and doubt result from the comparison of the firures of these three conscientious observers. "There is nothing," said

I Iiseases of Women, Am. erl.

2 Mal. de l'Ltérus, p. 416.

3 Klob, l'atholog. Anat., P. 68. 
Sydney Smith, "so unreliable as figures, except ficts." After surh a comparison of statistical evidence one feels inclined to agree with him.

The normal position of the nterns is one of sliglit anterersion, the axis: of the bolly corresponding with that of the smperior strait, which is a line rumning from the umbilicus, or a little above it, to the aceyx.

The degree of this forward inclination maty be so increated by slight canses as to constitute a morbid state. As to the line which separates what is normal from what is abnormal, it is impossible to lay down any "xact rule; experience must be our guide. In general terms we may say, that when the long axis of the uterus is fomm lying across the pelvis, the fundus near the symphysis pubis, and the neek in the hollow of the sacrum, anterersion exists.

Predisposing Canses. - The predisposing canses of this allection are farturition, enfeebled museular condition, habits of indolence and inactivity, and loss of tone in the abdominal walls.

The exeiting causes may thus be presented.

Influences increasing the weight of the uteris.

Congestion ;

Hypertrophy or hyperplasia ;

Subinvolution ;

Fibroids ;

Pregnaney ;

Laceration of the cervix.

Influences forcing the fundus directly forucards.

Violent efforts ;

Abdominal effusions ;

Abdominal tumors;

Tight elothing.

Influences enfeebling uterine supports.

Ruptured perineum ;

Relaxation of ligaments ;

Destruction of the retentive power of the abrlomen. Cystocele.

Influences dragging the fundus directly foructer.

False membranes ;

Prolapsus vagina ;

Cystocele ;

Shortness of the round ligament; (?)

Anteflexion.

A large number of eases will be found due to areolar hyperplasia, a number by no means inconsilerable to fibrous tumors, some of the most irremediable eases to false menbranes, many to eystocele which takes away support at the same time that it produces traction, while a few will exist without other apparent eause than direct pressure from some power 
which forces down the abdominal viscera upon the fundus. The last cause is much aided by laxity of the abdominal walls, which robs the viscera of support.

One fruitful source of the condition is unquestionably the gradual destruction of the retentive power of the abdomen by habits which engender atony of the thoracic and abdominal respiratory muscles and enfeeblement of the action of the diaphragm.

Symptoms. - In a certain number of cases anteversion will be found to exist without creating any disturbance either constitutional or local. This, however, is a rare exception to a general rule. By pressure of the os against the posterior vaginal wall, anteversion commonly induces dysmenorrhoea and sterility, and by pressure of the fundus against the bladder, and the cervix against the rectum, these viscera are irritated and interfered with in their functions. The bladder more especially suffers, sometimes a state bordering upon cystitis being engendered. Pressure upon the rectum more rarely produces tenesmus and a painful, irritable state.

In exceptional cases it is surprising to see to how great an extent locomotion is affected by this condition. My experience furnishes me with four cases in which patients were for long periods confined to bed or the lounge on this account. In one of these the patient had not left the house for four years; in another she had scarcely assumed the upright posture for eight months; the third was the counterpart of the second; while in the fourth the patient for twelve years had never walked over a quarter of a mile without serious inconvenience. In each of these cases positive proof was afforded me of the agency of anteversion in producing the disability which existed, by its removal when the uterus was properly sustained by an anteversion pessary, and by relapse at once recurring when without her knowledge she was left without it. Not one of these women was suffering from that hysterical condition which so often misleads the physician as to the results of remedies.

Course, Duration, and Termination.-Even if the exciting cause of the condition be removed, it will usually continue, for the broad and uterovesical ligaments have by long distention become stretched and enfeebled, while there has been simultaneous contraction in the utero-sacral ligaments from long disuse. The first fail to aid the fallen organ; the last help to keep it out of position by lifting the cervix up against the rectun. Sometimes cure is affected by pregnancy, the displacement disappearing as involution is accomplished. Usually, however, unless the exeiting cause of the condition be removed, and the organ be kept in proper position for a year or more, the displacement will continue unabated.

I'arieties.-Anteversion may be complete or partial. While there are three degrees of retroversion and of prolapse, there are but two of this displacement, for the axis of the uterine boly is naturally inclined so much 
forwards as to prevent us from including slight increase of inclination under the head of discase.

Fig. 1.18 will show the varieties referred to; an inclination of 450 . 1. presenting the first degree, or partial anteversion, and that of 90 o the second degree, or complete anteversion.

FIG. 148.

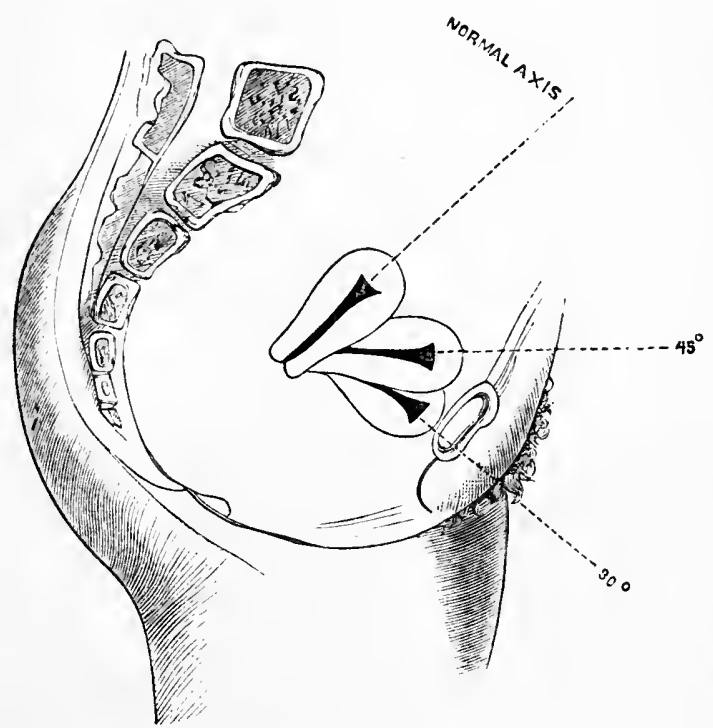

The degrees of anteversion.

Diagnosis. When in a case of this displacement raginal touch is practised, the patient lying on the back, the index finger passed into the fornix vagina discovers that the cervix is absent. A rapid investigation will prove that it is not to be found in the pubic or lateral regions of the pelvis, and rleep exploration with two finger's will discover it high up in the hollow of the sacrum. The finger being then passed towards the pubes will come in contact with a hard ridge, which will run towards the symphysis. Conjoined manipulation will prove this to be the hody of the uterus, and complete the diagnosis. Should further evidence be required, the uterine probe, very much eurved, may be passed into the carity, though this is rarely necessary and always difieult.

Differentiation.-Capuron tells us that Lerret mistook the first case he saw for stone in the blarlder, operated for this, and sacrificed the life of the patient. In spite of such a grave mistake at the lands of so great an authority, it may be stated that there is no diseased condition with which this should be confounded. The disease inducing the displacement may not be recognized, or some serions error may be made as to its nature, 
but that does not concern the present subject. 'The recognition of the mere fact of the anteversion is never difficult, if proper diagnostic means are brought to its elucilation.

Prognosis.-The prognosis as to any serious injury which will arise from the displacement is decidedly good, although there are many ineonvenicnees and discomforts connected with it, such, for example, as vesical and rectal irritation, neuralgia in eonsequence of compression of the nerves, and diffieulty in locomotion; none of these, however, go on to a dangerous degree of development. If the condition be not treated by mechanical means, it will prove entirely incurable; but by these the prospect of great improvement and even of complete cure is very gool. Important and early evidences of improvement resulting from mechanical treatment are frequently obtained in disappearance of dysmenorrhoea and sterility. It is often difficult to remove the exciting cause of anteversion, and even should this be accomplished, the uterus is so prone to retain the abnormal position in which it has long been kept, that great difliculty attends its retention in normal position. One of the reasons for this is the fact, already stated, that the uterine ligaments readily alter their proportions under certain influences. 'Thus during pregnancy they are all elongated; in posterior displacements the utcro-sacral ligaments are stretched $;$ and in anterior inclination the utero-vesieal liganients are similarly affected. As the antithesis of this fact, prolongel absence of function causes contraction in these struetures; thus in anterersion the utero-sacral ligaments are generally shortened, and there is no doubt that the round ligaments are similarly altered.

\section{Anteflexion.}

Definition.-This, which is one of the most fiequent of all uterine displacements, consists in a bending of the organ so that the fundus, the cervix, or both, are bent more or less sharply forwards.

Farieties.-There are three forms of anteflexion: first, corporeal thexion; second, cervical flexion; third, cervico-eorporeal flexion.

1st. The cervix being normal in position the body is flexed :

2d. The body being normal in position the cervix is thexed;

3(l. Both are flexed forwarls.

The lines represented in Fig. 150 will serve to show the dreviations which may atfect the axes of both body and ecrvix.

These varietirs are neither arbitrary nor unnecessary. The existence of each may readily be verified at the bedside, and treatment should always be materially molified by the peruliarity of the deviation. It appears to me that a neglect of them and the fixation of attention upon flexure of the body alone has serionsly retarded progress in treatment. No one ean intelligently treat anteflexion without regard being had to 
the variety of the disorder to which lee is called upon to adipt his mechanical appliances.

$$
\text { Fis. } 149 .
$$

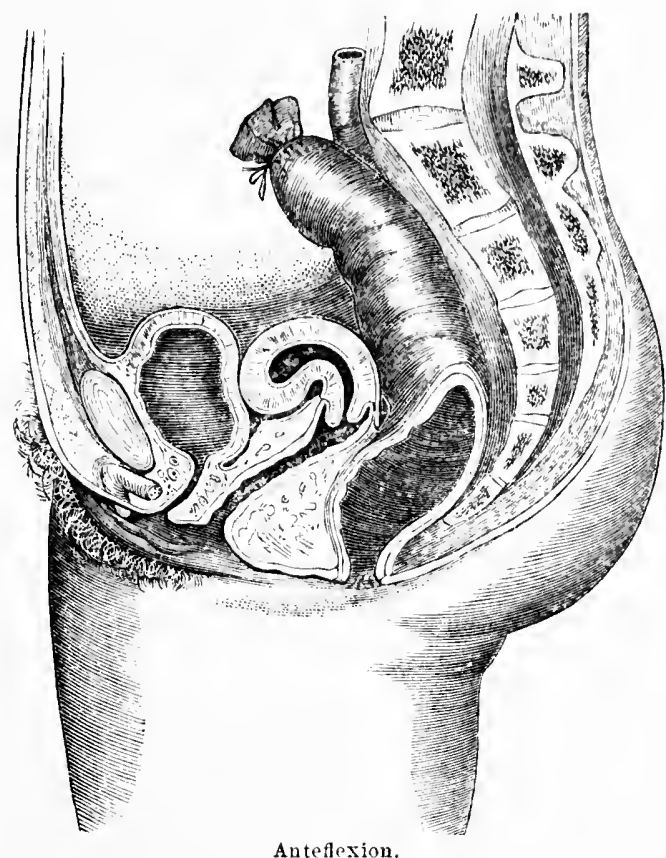

In addition to these there is a rare form in which the cervix is flexed forwards and the body backwards, but it is difficult to represent the axes of this variety in a diagram.

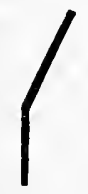

Normal axes.

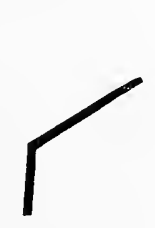

First variety of Hexion.

Fig, 150 .

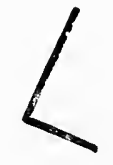

Seconl varioty of tjexion.

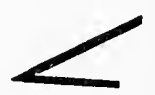

Third variety of Hexion.

Symsptoms.-A certain degree of this displacenent may exist for years without the development of symptoms. Very generally, however, obstruction to venous return at the point of flexure prodnces congestion which increases the displacement, disturbs the nervous system, and disorders uierine functions. Then the following symptoms develop themselves:-

Pain over hypogastrium and in groins and back;

Irritable bladder ;

Leucorrhora; 
Dysmenorrhœa ;

Sterility ;

Nervous disturbance and despondency;

Pain on locomotion;

Menorrhagia;

Tendency to abortion;

Pain on sexual intercourse;

Pelvic neuralgia ;

Sense of depression at the epigastrium.

In some cases there is a morbid and invincible aversion to walking, partly arising from physical and partly from mental causes. I have, in several cases, seen women who had been bedridden for three and four years rapidly restored to their powers of locomotion by restoration of the uterus to position, and its retention by an efficient pessary.

Dr. Hewitt mentions the retention of secundines after abortion in cases of anteflexion, and their putrefaction in utero, and advises as treatment restoring the organ to place, when expulsion at once occurs.

Physical Signs. - As the finger passes into the vagina and touches the cervix, nothing abnormal will usually be discovered. But as it sweeps along the anterior wall of the uterus, about the os internum a protuberance will be met with which presses upon the bladder. The finger which has thus far explored being kept in contact with this mass, the disengaged hand should then be laid upon the abdomen and made to depress the anterior abdominal wall so as to approximate the finger in the vagina. By this means the shape. size. and sensitiveness of the body may be ascertained. The diagnostician is, however, still in doubt whether the enlargement may not be one due to filsrous tumor or cellulitis. This point he settles by placing the patient on the side, introducing Sims's speculum, and gently probing the uterus to the fundus. Giving to the probe the curve which by vaginal touch he has been informed is that of the uterus, he carefully passes it in. Should it not proceed without obstruction, he withdraws it, aiters the curve, and tries again. Having sueceeded in introducing it, he learns the course of the uterine canal, its length, and the sensitiveness of its walls. Should the prohe lave entered the mass felt throngh the vagina, that mass is the uterine hody. Should it go in the normal axis or backwarls, it is not the uterine body, but some growth in eontact with it. In pure cervical flexion the neck will be felt sharply lent forwards and in the double form both neek and boly will be found flexirl.

Proguosis. - The prognosis as to cure will depend upon certain circumstances's which I will procesel to enumerate.

(a) It is better in multiparons than in nulliparous women, because the varina in the former more rearlily admits of the use of mechanical supports, and beeause it is acpuired and not congenital. 
(b) It is better in pure corporeal anteflexion than in those varietics in which the cervix is affected.

(c) Where the eervix is thrown far hark and lifted high in the pwis, the prognosis is decidedly unfavorable, and more especially if there exi-t only a scanty vaginal pouch anterior to the neck.

(d) If the flexion be of reducible kind, prognosis is favorable; if the contrary, it is by no means so.

(e) The prognosis of congenital flexion is almost a hopeless one, unles: the knife be resorted to.

$\left(f^{*}\right)$ Of all the cases except the last the prognosis is most unfavorable in those in which the vagina joins the cervix very low down, near the os externum, and where the uterus is held high in the pelvis.

The shibboleth of the subject of prognosis as to cure is, however, this: if the flexion be entirely reducible, the ease may be cured; if it be not so, it will in all probability prove incurable.

As regards the general health of the patient, the prognosis is not usually bad, but enlargement of the uterine body may result from anteflexion, and its consequences are commonly sterility, vesical irritability, dysmenorrhwea, and lencorrhoei.

Treatment of Anterior Displacements.-The first point which the practitioner should settle before commencing treatment, is whether the displacement is the main source of existing morbid phenomena, or whether these are due to some disease which underlies that condition. If he be led to regard it as merely a coincident or resulting condition which is producing no annoyance, of course the primary disorder must take precedence of it in treatment. It is, however, futile to assume the pasition that not the displacement, but its cause, must be the main object of attention; that, if endometritis, subinvolution, or a fihroid be its callse, they, and not it, must be treated. Nothing so surely prevents sulcess in the management of such cases as the earrying into practice of the theoretical view that support must be confined to cases of pure, uncomplicated displacement. It is very often required where this is a result or complication of other disease. We are called upon to alleviate one of the most annoying symptoms of disease here, as we are in so many other instances. Pessaries are frequently required by the uterus as splints are by a fractured bone, not absolutely as a means of eure, but as adjuvants in treatment, by which rest and freedom from pain can be procured while the healing process advances.

Means for Reduction.-In the restoration of an anteverted uterus to its place, difficulty will rarely be exprerienced, for, unlike retroversion, the displacement does not often become complete. Even when it does so, reduction may be easily accomplished. When it proves difficult, the bladder having been emptied hy the catheter, the patient should be placed upon her back on a hard bed or table, and all tight clothing removed 
from the abdomen. The operator having oiled two fingers should then pass them into the ragina, and press their tips against the body of the nterus, which will have forced the walls of the bladder down before it. The fingers of the left hand being thus employed, the right should be laid upon the abdomen, so as to push up the abdominal viscera and uterus when reduction is attempted. The patient is now directed to fill the lungs with air, and then to expel it gently by a prolonged expiratory act. As this expiration is being finished, the operator presses up the body of the uterus by the fingers in the ragina, and the abdominal viscera and fundus by the hand on the abdomen. ${ }^{1}$ He will generally succeed at once in replaeing the organ. Should he not do so, he should repeat the process as above described, until the end is attained. Of course where the dislocation is partial, restoration may be much more easily effected; but in this case it accomplishes nothing, for no sooner does the force applied eease, than the organ again falls out of place. As the fundus is lifted by bimanual manipulation, the hand on the abdomen keeping it up, the finger in the ragina should be placed behind the cervix, and this part be pulled forwards towards the sympliysis.

Some practitioners rely for cure upon the daily restoration of an anteverted or retroverted uterus, but hopes thus based will usually prove delnsive. Where the version is complete and sudden, a return to the normal position may be final; but rarely have $I$ seen it so result where the displacement was incomplete and chronic.

The method just described is, unless the uterus be bound down by false membranes, very generally successiul in anteversion. In anteflexion also, where the displacement is one of redncible character, it is often all that is required. But in cases of anteflexion irreducible in character or diflicult of reduction, more efficient means must be resorted to. These may be enumerated as the uterine sound, Elliott's reprositor, Jennison's sound, and Wallace's spring tent, or laminaria tents.

Of course such restoration is ouly temporary, hut even that benefits utrine circulation and improves the nutrition of the enfechled concave wall. I have elsewhere likened the flexed uterus to a bent twig. 'The replacement of the former may be compared with the straightening of such a twig by the forester, and the use of a pessary to the employment of the supporting splint which he binds to the growing tree and by whieh he strengthens its weak side.

The uterine somnd being introduced to the fundus, not much curved, but als straight as it can be made to pass, the haudle being loeld in one hand, the tips of the fingers of the other should be pressed anginst the shaft of the somd near the middle, and they being made a fulcrum, the handle

I The operator should he very sure that the anteverted uterus is not bound down by false nemblones before applying force for its replacement. 
should be carried to the symplysis. By this manemre the flexed fimdus is elevated, and at the same time carried towards the hollow of the sacrum. This point being reacherl, the somel should be very gontly rotaterl, and complete retroversion with partial retroflexion of the uterus accomplisherl. This should be done with the utmost gentleness, and as I have describerl, not by a sudden rotation of the flexed organ, which foreibly sweeps the findus around the superior strait of the pelvis.

Sims's speculum being introdueed and the cervix caught by a tenantlam, Elliott's sound, shown in Fig. 151, may be carried quite curved

Fig. 151 .

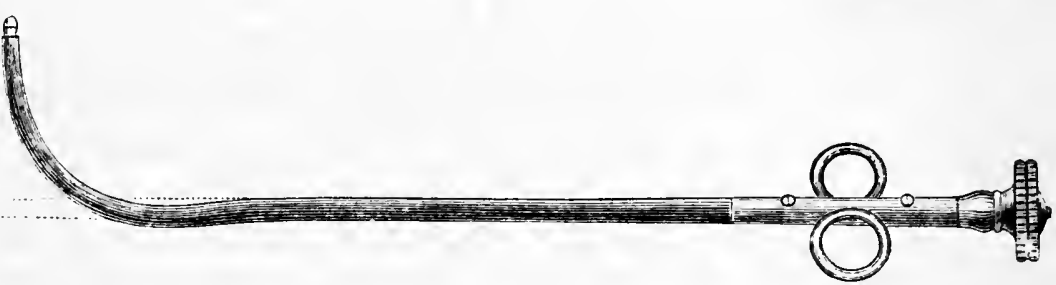

Elliott's utrine repositor.

into the flexed nterus and straightened by the action of the screw at its lower end.

A method of reposition which $I$ prefer to these in anteflexion is that by the use of Jemnison's sound, Fir. 152.

Fig. 152.

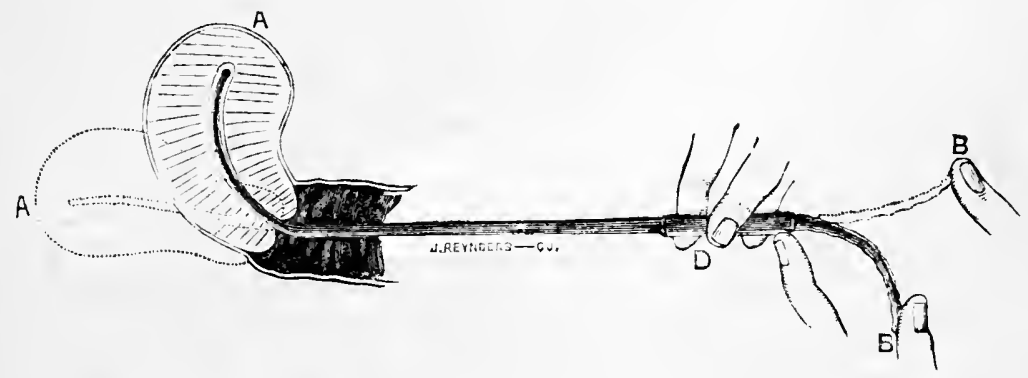

Jeunison's sound.

Pressure upon the lower extremity of this causes the upper to bend sharply so that it readily enters a flexed uterus. Then reversal of this pressure lifts the flexed body, and not only straightens the uterine axis but ereates retroflexion.

Every succeding exercise of the uterus in this straightening process renders reposition easier. improves the nutrition of the flexed wall, and benefits the circulation in the organ. After this has been done four or 
five times the second indication should be attempted, keeping the uterine body in position.

In a large number of cases of anteflexion, however, even these means of replacement prove unavailing, and the deformity of the uterus is susceptible of relief by two plans of treatment only: that which, by uterine tents and the intra-uterine stem, forcibly straightens the bent organ; and that which, by the knife or seissors, renders the eanal straight without reference to the relations of neck and body. Such cases being commonly congenital, one wall is well developed by excessive growth, while the other is dense, rigid, atrophic, and unyielding. They may, however, result from prolonged accidental flexion, with development of slight attacks of peritonitis; even without the last, indeed, for cicatricial retraction of the atrophied section of connective tissue has been found by Klob under these circumstances.

One of the most effectual means of meeting the difficulties of irreducible flexion is the use of the spring tent of Dr. Ellerslie Wallace, of Philadelphia. He passes through a canal made in a piece of carbolized sponge a small piece of watchspring and compresses the sponge so as to make the tent curved as represented in Fig. 153.

Fig. 153.

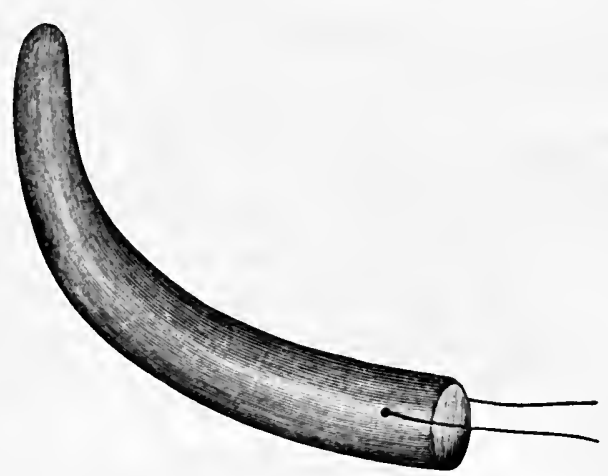

Ellerslie Wallace's spring tent.

In this condition it is passed into the flexed uterus, and as the sponge softens, the spring erects itself and straightens the uterus. $\Lambda$ ll the dangers attending the use of sponge tents attend the use of this, but no more. It may be practised once a week until three or four tents are used, or it may be used once and be followed by the intra-uterine stem.

The same end may be obtained by moistening in hot water a laminaria tent up, to the point of bending, and jas.ing this into the uterus, and keeping it there untii it fully expands.

One very important fact, however, which should be eonstantly borne in mind in connection with anteflexion is, that there is a class of cases of irredu- 
eible flexions which is incurable. The practitioner, unwilling to admit this to himself, or not appreciating the fact, begins treatment from a con rentimal idea that such is his duty. But the case proves far too obstinate for the ordinary local treatment; tents will not cure it, and trachelotomy, not filly meeting the mechanical indications, fails likewise. If the patient passes the ordeal without being attacked with peritonitis or cellulitis, she in time gives up all efforts at cure, or seeks the advice of another physician.

Means of Retention in Position of a Uterus Anteriorly Displaced.These should be based, like those adopted in all other uterine displacements, as far as possible upon antagonizing the influences which produce and perpetnate the aberration from the normal position. The repetition of this fact, and of the means for developing the principle in connection with the various displacements, may prove tedious, but I offer no apology for this, for the great alvantage which will result to the student from following this course will abundantly justify me. It will be sail too, by the many who prefer empirical to scientific methods, that the plan pursued is based upon theory which is not applicable at the bedside. Let this question be put to the test of experience, and the student will find that the mere direction of the mind into proper channels of thought and investigation will give the plan value and induce him to adopt it.

In every case of anterior displacement let the practitioner endeavor to find out which is the main element concerned in its production, but at the same time let him remember that this one has almost surely developed others which are scarcely less important as factors. In most cases, therefore, he will be called upon to direct his attention to all forms of the pathological influence about to be mentioned.

All increased weight of the uterus should be treated by appropriate means; inflammation and its results by methods already mentioned, liyperplasia and hypertrophy by means adapted to their management, and laceration of the cervix by trachelorrhaphy, etc. The fulfilment of this indication alone will sometimes effect a complete cure of anteversion. Whether it does so or not, the next should always receive attention.

Pressure from above should be removed by carrying the weight of the clothing upon the shoulders, by skirt-supporters; pressure of the intestines, by prohibition of tight clothing, the use of an abdominal supporter, and the avoidance of injurions muscular effort.

The dorsal decubitus in eases occurring suddenly, as, for example, during pregnaney or after labor, is of great va'ue, and even in chronic cases is an important adjurant to treatment by pessaries. In the commencement of such treatment at least, it should be always adopted, for two or three lours every day, at mid-day, for the purpose of affording a temporary rest to the parts.

In proportion to the disadvantages resulting from corsetting the upper segment of the trunk, are the advantages to be derived, in these cases, 
from thus acting upon the lower. When the abdominal walls are lax and yielding, and do not properly sustain the viscera, they fall upon the fundus uteri, and tend to produce and keep up anterior obliquity.

No one can deny that by a well-fitting abdominal supporter, tone is given to the lax walls, and that the intestines, not the uterus, are sustained. I have already stated that many are prejudiced against this means and decry it as absolutely injurious; but I see it too plainly and certainly productive of good results in daily practice to admit of any doubt in my mind concerning it. Dr. J. C. Nott offered a very plausible explanation of the fact that in some women benefit follows the use of abdominal supporters, while in others absolute injury results from their employment. "If the patient be emaciated," said he, " and the abdominal walls retracted or even flattened, the supporter will depress and not sustain the uterus. On the other hand, if the woman be corpulent, the greatest support will be yielded by its applieation." I have employed for this purpose with very great alvantage an abdominal pad or truss, which is at the same

FIG. 154.

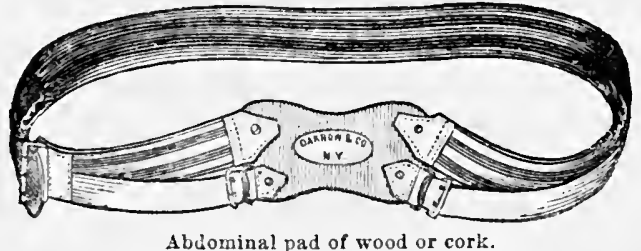

time simple, inexpensive, and efficient. It consists of an ovoid block of cedar, pine, or cork, five incles long by four inches wide. This is convex upon the surface to be placed next the body, and flat on the opposite side, and is held in place by an elastie band or slender strip of steel covered

F1G. 155.

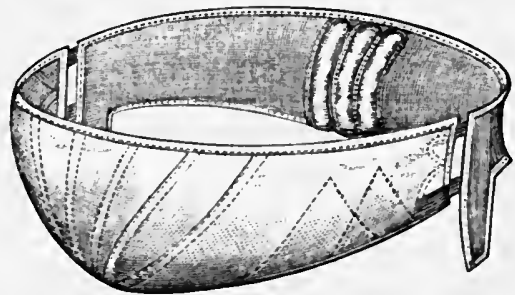

Abdominal supporter.

with leather, like an ordinary male truss. The pressure made resembles that of the hand, and, as soon as patients beeome accustomed to it, which it should be borne in mind may take a little time, gives great comfort. Another very efficient one is shown in Fig. 155. 
Traction upon the uterus from below, if fouml to exist, should be removed by perineorrhaphy alone or combined with colporrhaphy, or it may be obviated by the use of a pessary which sustains vagina, uterns, and bladder.

Fig. 156 shows how loss of power in the perineum will result in prolapse of the anterior raginal wall, how the hladter will in conserpuence prolapse, and how the upper portions of the uterus will follow it, anteversion resulting, and how perfeet repair of the perineum will remove all traction from the uterus, and allow it to resume its place in the pelvis.

Fig. 156.

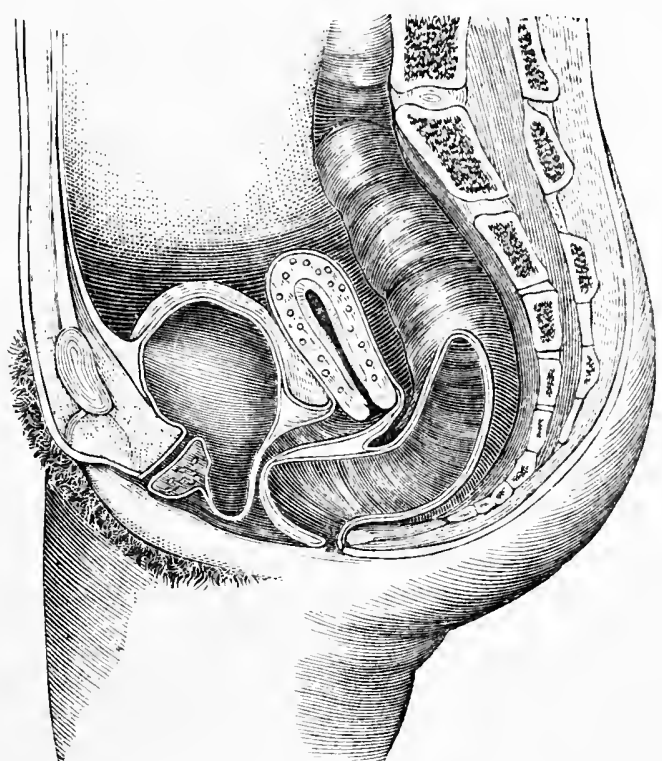

The perineal body destroyed, both rectal and vesical walls descend.

Loss of the normal supports of the uterus should be overeome by the use of general and local tonics, developing the retentive powers of the abdomen, and by the use of pessaries. Astringent vaginal injections, seabathing, and the internal use of vegetable and mineral tonies are unquestionably of value.

By the development of the retentive power of the abdomen, a great deal can be done for replacement and support of an anteverted uterus. Every morning and evening the patient should place herself flat upon the back upon her bed, with the hands clasped over the head and the heels touching the buttocks. Then she should raise the pelvis as ligh as possible, and sustain it for a few moments, the shoulders and soles of the feet alone touching the bed. Letting the pelvis slowly descend, she is to repeat this a half dozen times. The movement too for strengthening the 
abdominal muscles mentioned under treatment of prolapse should be praetised here, as well as the general exercises indieated there for the full development of the thoracic and dorsal muscles.

Pessaries.-What is desired of a pessary in sustaining the anteflexed or anteverted uterus is this: to make gentle pressure on the base of the bladder above the cervico-corporeal junction, and as near to the fundus as possible, to supplement the vesico-uterine ligaments, and at the same time not to injure the vagina by excessive pressure at this point. It is by no means easy to make an instrument answer these requirements; it may either keep the uterus in place at the expense of a degree of foree which will ereate a solution of continuity in the vagina, or it may, when possessed of too little power, allow the fundus in spite of it to fall forwards. The use of pessaries for this displacement requires a vast deal more skill, mechanical ingenuity, and patience than is necessary in those of posterior variety. Even with every precaution, cases will commonly occur in which the parts will be injured by pressure; and without preeautions the means is one which is attended by absolute danger. In cases in which pelvie peritonitis has preeeded the displacement, the danger is so marked that treatment by pessaries, either should not be adopted at all, or, if attempted, should be limited to the most cautious trials.

The diagnosis having been made, and it having been decided that retention of the uterus in position is not attended by danger on account of former pelvic peritonitis, and that the displacement results from no condition removable by operation, the treatment should be commenced in this way. The intestines should be evacuated by a cathartic, all weiglit removed from the fundus by abdominal and skirt supporters, and the patient enjoined to take very moderate exercise and to avoid all violent efforts. Every night and morning she should use the warm vaginal donche, not only at first, but throughout the duration of treatment, to prevent irritation from it. Before the introduction of a pessary, the uterus should have been several times replaced by conjomed manipuiation and held in position for two or three minutes at a time. At the end of this period, if the displacement is readily reducible, and it requires no great force to sustain the uterus, the anteversion pessary represented in Fir. 157 may be introduced, and the patient allowed to walk about. Should it give no pain, she may wear it home, even if going to a distanee from the practitioner's residence, for she can herself remove it on the first menace of injury. In three or four days the instrument should be examined. If it have given pain or have left its mark upon the vaginal walls, it should be changed at once; if not, it may be left for a week; then for two weeks; then for a month; and afterwards for a still longer time, two montlıs, for example, without examination. The pessary here advised is represented open for withdrawal by the dotted lines, and elosed 
as it should be in the ragina in introduction. The piece which sustains the fimlus is large and smootle, so as not to injorr the vitrinal wall. When the pessary is drawn upon by means of its lower hranch, this picee falls back of itself, and thus the instrument is suseeptible of removal. 'The

FIG. 157.

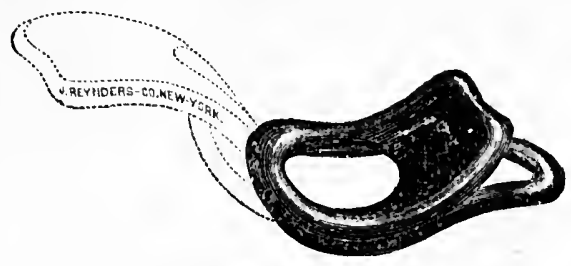

Thomas's anteversion and anteflexiun pessary.

possibility of removal by the patient is an important element in an anterersion pessary, for she may go away after its introluetion and suffer agony in a few hours, and, slould she be unable to remove it, inflammation miglit result. Even of she obtain meslical aid, it is often very difficult for a pliysician ignorant of the peculiar construction of one of these instruments to remove it. I never consent to a patient who is wearing one leaving my office to go out of the city without first making myself sure of her ability to remove it herself. The pessary here represented is introduced elosed and carried to and behind the cervix just as one for retroversion is. As the piece intenderl to support the fundus is resisted by the pubes, the perineum is depressed and it is carried under it. The instrument is opened as shown in the diagram, not for its insertion, but for its withdrawal. The anterior, projecting piece may be made longer or shorter as greater or less elevation of the uterus becomes neeessary. Fig. 158 represents this instrument modifierl so as to consist of a permanent and immovable projection on the anterior face of a Holge or Smith pessary. In the case of a virgin it is often difficult to withdraw and introduce these, but in a married woman, and especially in a parous one, it is easy of application.

Fici. 158.

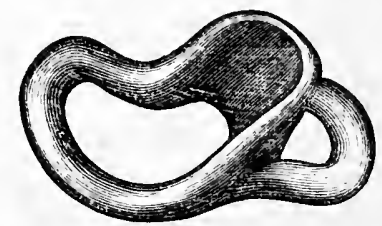

Thomas's anteversion pessary, with fixed projection.

Another instrument which I employ very commonly, both in anteversion and anteflexion, is that shown in Firs. 159, 160, and 161.

The instrument is here presented closed. 1 it is introduced open. Upon pulling upon the bow which presents at the mouth of the vagina, the piece which sustains the uterus falls baek, and it can reatlily be withdrawn by patient or physician. 
Fig. 162 represents a modification of the two instruments which precede it.

Frg. 159.

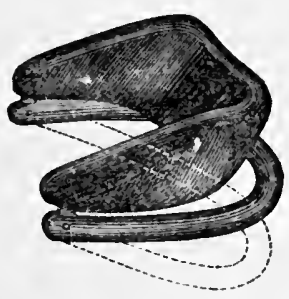

Thomas's anteversion pessary as it appears in the vagina.
FIs. 160.

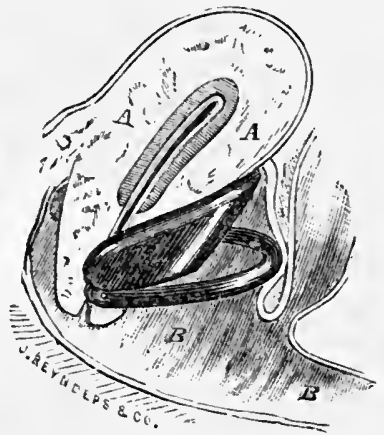

The same instrument in position.
Fig. 161.

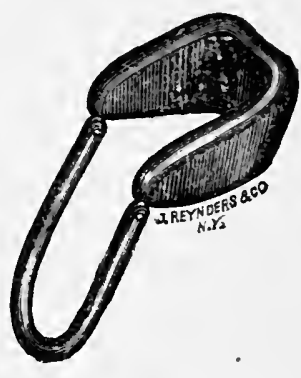

The same instrument as it appears on removal.

Fig. 163 represents an elastic pessary for anterior displacements, made of spiral wire and strips of whalebone covered with gutta-percha, by Otto and Sons, of this city. The whole pessary is so pliable that it can be introduced and withdrawn with perfect ease.

Fic. 162.

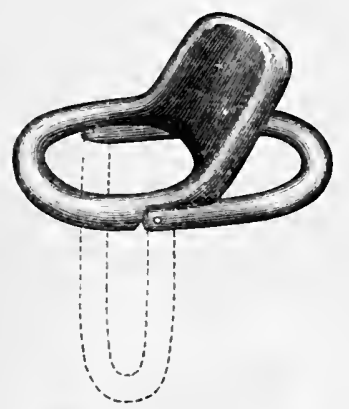

Thumas's auterersion and anteflesion jessary.
FIG. 163.

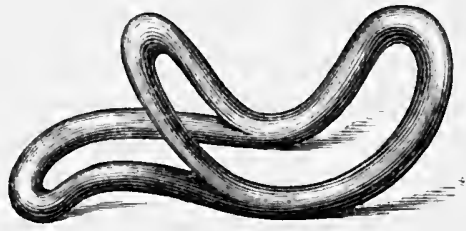

Thomas's elastic jessary for anterior displacenents.

If the attending physician possess only little skill in the use of pessaries, or if the uterus be replaced with difliculty, and sustaining it appear to require foree, he had better not employ an internal pessary, but limit himself to one connecting externally with a band. Support may be given to such a pessary by a stem arching over the perineum, as shown in Fig. 161. This displatys in position a modification of Cutter's retrosersion pessary.

The "lper extremity of this form of Cutter's pessary has a bulb attached to it, and is so bent forwards as to strike the base of the bladder, anterior 
to the cervix. This is introduced by the practitioner, and its mothon of introduction and removal fully explained to the patient. She is instructed how to remove it upon retiring every night, and to replace it before rising in the morning. By it the eervix is pulled forwards, the utero-sacral lima-

FIg. 164.

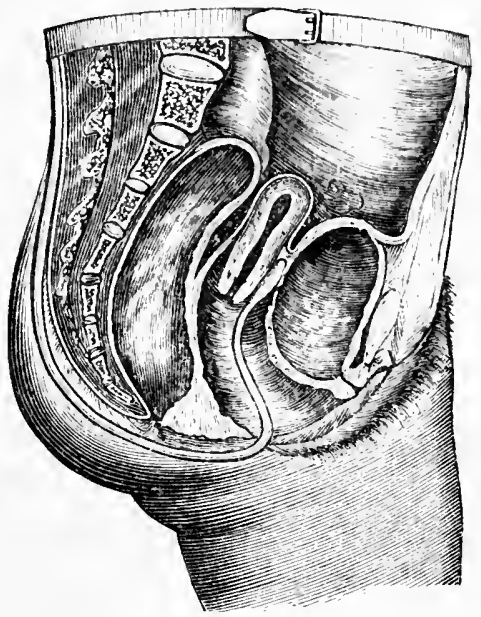

Anteversion pessary supporting uterus.

ments streteled, a tolerance of a foreign body established, and a pouch or poeket ereated anterior to the cervix, which will aceommodate in time the pessaries already depicted, if the praetitioner desires to try them. The bulb pessary with external attaehment may in any ease be used as preparatory to an internal instrument. After the former has been used for a

FIG. 165.

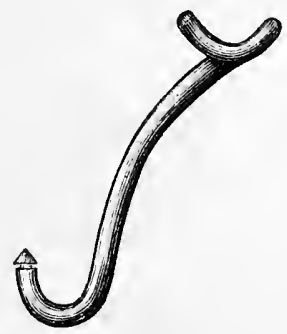

Cutter's T pessary for anterior displacements.
FIg, 166.

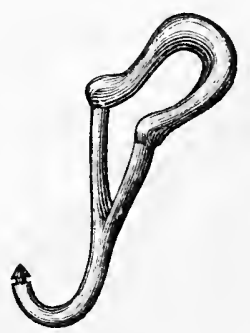

Thomas's modification of Cutter's pessary.

month or so, the latter will generally be applicable. One having experience with these two instruments ean almost always tell without experimentation which will be appropriate. It there be a pouch anterior to the eervix when the base of the bladder is pressed up by the finger, the in- 
ternal pessary will be tolerated. If there be none, and the tissue resist pressure by the finger, it cannot be employed until space las been created by the other instrument.

To facilitate the proper introduction of this instrument, and to prevent the supporting portion from being placed behind the uterus instead of in front of it, Dr. Cutter has devised the instrument shown in Fig. 165, and I have modified it as shown in Fig. 166.

Even if the patient made an effort to place these instruments incorrectly, it would be accomplished with difficulty. Their benefieial results in these cases are unquestionable except by those whose prejudices or incapacity lave defeated them.

Cases will occasionally be met with in which the parts are so sensitire that the hard bulb of these pessaries cannot be borne. Under these circumstances, they can be with great advantage replaced by soft balls of very fine sponge, until the reposition of the uterus and remoral of congestion which is thus efleeted render solid bulbs tolerable.

FjG. 167.

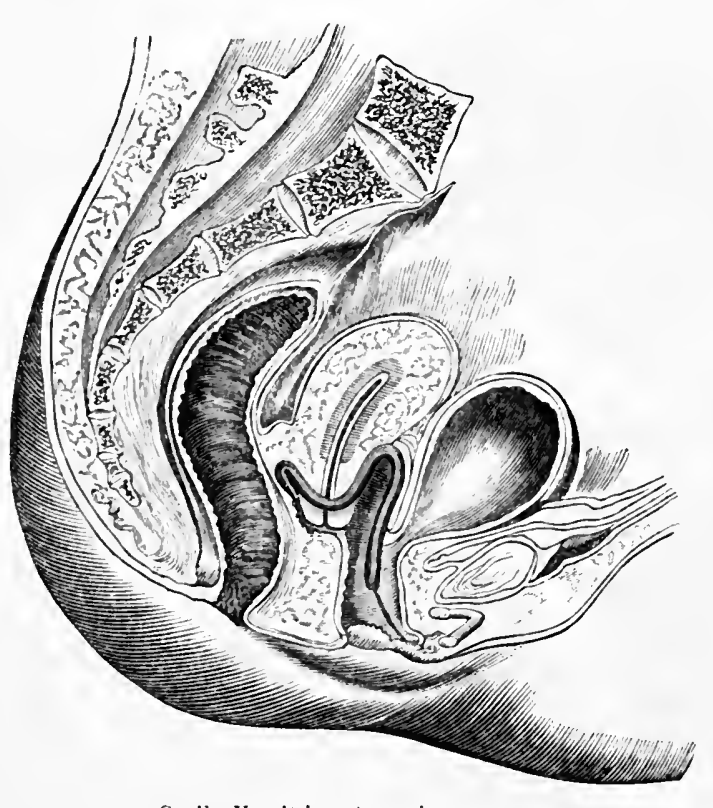

Graily Hewitt's auterersion iessary.

Fig. 167 represents the very exeellent pessary of Dr. Graily Hewitt. I have employed it very extensively, and esteem it higlily.

I have also in some cases found the pessaries of Guerung and Fowler answer very well in anterior displacements. The latter of these is shown in Fig. 168. 
Ile who expects from these methorls extraordinary results will surely be disappointed. In a certain number of cases failure will attend all means thus far devised, not excepting surgical procedures. My experience, however, warrants me in saying that a persevering resort to the treatment here advised will reward the gynecologist by success in many cases. After overcoming this form of flexion, a Meigs's ring pessary should be worn for a long time to prevent relapse. After overcoming this, and all other forms of flexion, it is well to dilate the cervical canal by means

Fig. 168.

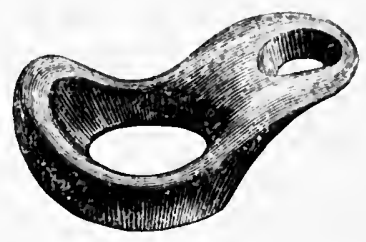

Fowler's pessary for anterior displacemeuts. of graluated sounds, as there is generally more or less contraction of it.

I would especially impress the importance of not relying exclusively upon any one of these pessaries or internal supporters. Their use slould be combined with external means calculated to remove pressure from the fundus. By this combination the happiest results may be confidently anticipated from efforts at relief of this often distressing accilent.

Before concluding, let me recapitulate the most important of the maxims embodied in this chapter.

1st. Never begin treating an anteverted uterus mechanically until satisfied that no periuterine inflammation exists; that bad symptoms present are due to the disflacement ; and that no condition susceptible of removal by medical or surgical means requires carlier and more prominent attention than retention of the uterus in position.

2d. Before using a pessary, act thoroughly on the intestinal cạnal, use warm vaginal injections fireely, and replace the uterus repeatedly.

31. Do not rely upon vaginal support alone, but aid it by aroilance of all pressure from above, and by using an abdominal pal.

4th. Pessaries are of the greatest value in treating anteversion, but require muel more skill, are attended by greater danger, and are more apt to need frequent alteration than when used in posterior displacements. There is no comparison in the relative amount of difficulty in applying this means to the two varieties of displacement.

5th. Never use an anteversion pessary which the patient cannot remove, unless she keep within reach of your aid ; always examine frequently to see if injury is being done to the vaginal walls, and never let a patient wearing one pass entirely out of observation.

6th. If no suffieient pouch exist anterior to the cervix for the accommodation of an internal pessary, create one by use of the external bulb pessary.

At the same time that I speak so strongly of the difficulties surrounding the treatment of these cases, and so repeatedly point out the dangers attending it, I must make this statement for those who lave been dis- 
couraged by repeated failures: were I asked from the treatment of what class of uterine diseases $I$ experienced the greatest satisfaetion, and felt that I had accomplished most good for my patients, I should unhesitatingly reply-anterior displacements of the uterus.

In many cases of this variety of displacement, a great deal of relief may be obtained from merely lifting up the displaced organ in the pelvis without rectifying the anterior displacement, and for one who is not familiar with the use of anteversion pessaries, or has not at his command facilities for procuring good instruments, I really think that this, in the commencement of treatment, if not throughout its entire course, is the safer and better plan. Lifting the uterus may be accomplished by the ordinary ring pessary or Gariel's air pessary, and the simultaneous use of the abdominal pad of wood or cork. If the pad be used alone, and when the fundus uteri is behind the symphysis pubis, no good will result from it; but if the uterus be lifted so that the fundus becomes amenable to direct pressure, the benefit felt will be often very great.

As I have elsewhere stated, furnishing support to a uterus anteriorly displaced is much more difficult than to one which inclines posteriorly. As there are, therefore, men who to-day doult the efficacy of support for the latter forms of displacement, there must be many more who entirely oppose that for the former. To both classes of objectors I would say, with a confidence resulting from a large daily experience, that the hostility to mechanical support in both varieties of displacement arises partly from prejudice and partly from want of skill on the part of the practitioner, who charges to the mechanical process shortcomings which really lie at his own door.

On more than one occasion I have heard the most unmeasured denunciations against anteflexion pessaries upon the part of men who I found had been persistently using them upside down. Failing to give relief by instruments thus used, the illogical experimenters have been too willing to attribute to a method what was really due to an igmorant abuse of it.

In certain eases of anteflexion, notably those requring the energetie means recently mentioned for their reduction, pessaries resting in the vagina fail to accomplish the required purpose, and the use of more powerful means of support are resorted to.

Recognizing our porerty of resonrces in such cases M. Velpeau, ${ }^{1}$ between thirty and forty years ago, conceived the very plausible idea of restoring the uterine axis to its normal direetion, by introducing a stem to the fundus, and retaining it there. After experiment lie abandoned it, and subsequently Amussat followed in his steps, both in essaying and easting it aside. In 1848, Prof. Simpson again brought it into notice in versions and flexions, and met with a warm ally in M. Valleix, of Paris.

1 Discussion in Acad. de Méd., reported in Charleston Med. Jonrn. 1853. 
The instrument known as the intra-uterine or stem pessary, unquestionably counteraets directly and immediately all flexions of the uterus. But it was found to eause peritonitis and death in a number of instances, and in eonsequence it was, for a time, almost entirely abandoned. So deeidedly did experienee appear to weigh against it that it beeame difficult to explain the encomiums once showered upon it by its alvocates, and the remarkable eures reported from its use. Nonat declared that, carried away by enthusiasm, "ils se sont laissés aller trop facilement sur le terrain glis:ant des illusions." Nevertheless, the method was never entirely cast asicle, for none conld hesitate to indorse the sentiment expressed by Malgaigne, in the disenssion upon the subjeet in the Aealemy of Medieine in Paris, in 1852, that, "a treatment which Amussat, Velpeau, Simpson, Huguier, and Valleix harl trierl, cannot, should not, be considered as repuguant to common sense."

During the last ten years there has been evidenced, however, a growing inclination to return to this plan, and the last five have brought forth a number of reports favorable to it.

At a medieal convention held in Innsbruch, Germany, in September, 1869, this subject received some attention. Spæth, of Vienna, expressed his belief in the disadvantages of the intrauterine treatment of flexions, although he has found in some cases a total insensibility and an absence of reaction from the wearing of intrauterine instruments. IIugenberger, of St. Petersburg, advocated the use of Simpson's pessary in flexions, and declared his experience to be, that it was not only tolerated, but did great good when properly applied and retained for a suffieiently long time. More recently, Prof. Schultze, of Jena, advised the use of the intranterine stem in eertain obstinate cases, but, in a review of his publication, by Dr. Munde, in the American Journal of Obstetrics, it evidently appears that he does so with cattion and reserve.

Prof. Olshausen, of Halle, likewise published lis experience with the method. Of its character the reader can judge for limself, for the professor gives accurate data. Out of 297 cases of versions and flexions, 81 were treated by the stem and 5 were so treated for other conditions than displacement. Periuterine inflammation resulted in 7 cases; treatment was stopped on account of hemorrhage or pain 10 times; the stem could not be kept in place 3 times. Of 66 eases in which they did well, in 15 the results appeared to be permanent; in 18 improvement was great and lasted a long time ; and in 17 " doubtful pernanent results were obtained." In 11 sterility was cured. The stems were worn for periots varying from a few weeks to $22 \frac{1}{2}$ months.

Drs. Savage and Chambers have both reported very favorably upon this plan in the Obstetrical Journal of Great Britain and Ireland, to which the reader is referred for their interesting articles. I would likewise refer to 
excellent essay's by Dr. Routh', of London, and Dr. Van De Warker, ${ }^{2}$ of Symeuse.

Before the use of this method careful examination should be made as to the previons existence of periuterine inflammation. If any be found existing the uterine stem should be aroided.

A great variety of instruments have been employed for keeping the stem in place. Some are complicated, others stiff' and unyielding, while most are not susceptible of removal by the patient, and are therefore wanting in the main element of safety. I would recommend the instrument which I employ for this purpose as not subject to any of these objeetions. It consists of two parts, a stem of solid glass, two to two and a half inches long, and ending below in a round bulb as represented in Fig. 169. 'This being introduced into the uterus, it is supported by the anteflexion pessary shown in Fig. 169, or, if difficulty be found in using this, by an ordinary IIodge pessary, between the branches of which a eup has been placed, as shown in Fig. 197, or by a disk of vulcanite shaped like the Hodge or Smith pessary, as shown in Fig. 170.

- Fig. 169.

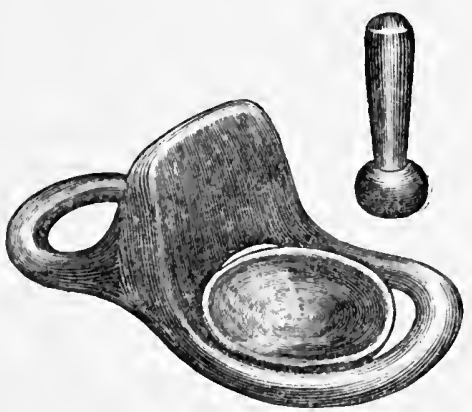

Anteflexion pessary supporting intra-uterine stem.
Fis. 170 .

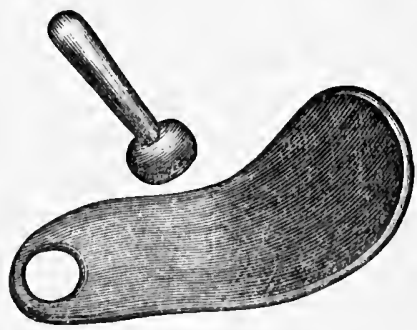

Glass filem supported by disc pessary.

The stem ending in a round bulb rests upon the surface of the pessary, and changes position with every movement of the uterus. It must be remembered that it is not used for anteversion hit for anteflexion, and that stability of the hase of the stem is not desirable. Just above the sloulder a small hole may be made through the stem through which a silk thread is passed which hangs from the vulva. Tron the first evidence of trouble the patient draws out the loosely fitting pessary, then making tration upon the thread removes the stem.

before introduction of the stem, the cervix, if found to be too contracted for it to pass, should be dilated by one or more tents, which for the time straighten the uterus and dilate the eervieal canal. After introluction the fatient should be kept in bed for three or four days, and, upon leaving it, should be careful in her movements for a week or two. She should be 
directed to remore the tent upon the ocmmence of pain, chilliness, or feeling of general languor or liscomfort. Even the mont ardent alvocates of stem pessaries will admit the propriety of these precatutions, and even their bitterest opponents must allow that with them as a safeguard, in certain cases they should he resorted to. To east them entirely aside when such high authority recomnends them, would be irrational and unjustifialle. To use them freely in the faee of such evidence as we possess would be reckless and unwarrantable.

It requires skill in introducing the pessary after introduction of the stem before the latter fills from its place. A Sims's speculum is a sine qua non; the stem should be held in place by Sims's depressor, and the pessary be slid into place upon this. In this way the mancurre is easy.

I am opposed to the exhibition of instruments which I have not myself fully tried, but the stem pessary of Dr. II. F. Camplell impresses me so favorably that $I$ depart from my rule and present it here.

Fig. 171.

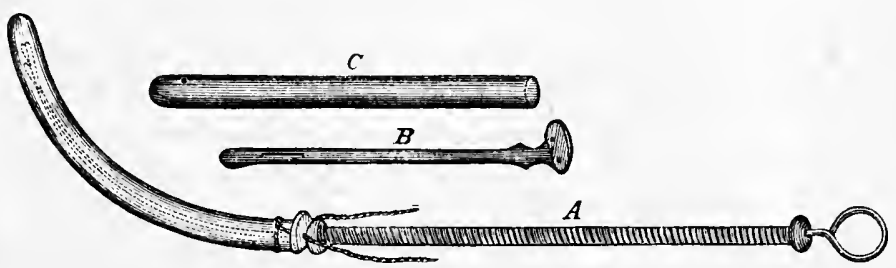

Campbell's soft-rubber spriug-stem pessary. $A$. The soft-rnbber stem and spring prepared for iutroduction. $B$. Shows the spring separately. $C$. The rubber cap or hood.

It will be seen that this consists of a soft-rubber tube and watch-spring. It is introduced bent upon itself by means of a sounl, and this being withdrawn it straightens itself under the influence of the protected spring.

But in a certain number of cases even the intra-uterine stem fails. Then the gynecological surgeon, following the example of the general surgeon, gires up striving after an end unattainable by minor means, and resorts to the knife for relief.

Should the patient not tolerate the intra-uterine pessary with comfort, should the flexion not yield to the treatment by it, or should the practitioner prefer to adopt operative procedures, an operation devised by Sims is at his disposal not intended to eure the displacement, but to remedy its resulting cervical obstruction, leaving the disorder of position unchanged.

Operation for Irreducible Cervicul, Corporeal, or Cercico-Corporeal Flexion.-If a piece of stiff tubing be bent, the calibre of its canal will be obliterated at the point of flexure in proportion to the acuteness of the angle created. In the same manner is the uterine canal affected by the lesion under consideration. The obstruction ereated in this way prevents the free escape of menstrual blood, which distends the eavity of the uterus and forms elots within it, and these at each menstrual period are expelled 
by uterine tenesmus. In consequence of this, inflammation of the mucous lining of the uterus arises, that in time may produce areolar hyperplasia, which favors further displacement by the increase of uterine weight attending it. The effort required for expelling clotted menstrual blood creates painful menstruation, and the same obstruction which retards egress of fluids interferes with ingress and prevents conception.

Having been forced to accept the displacement as an irremediable evil, we now endeavor to strike at one of the sources of the pathological series which results from it by overcoming obstruction at the point of flexure; in other words, by substituting a straiglit for a crooked canal. This can be

Fig. 172 .

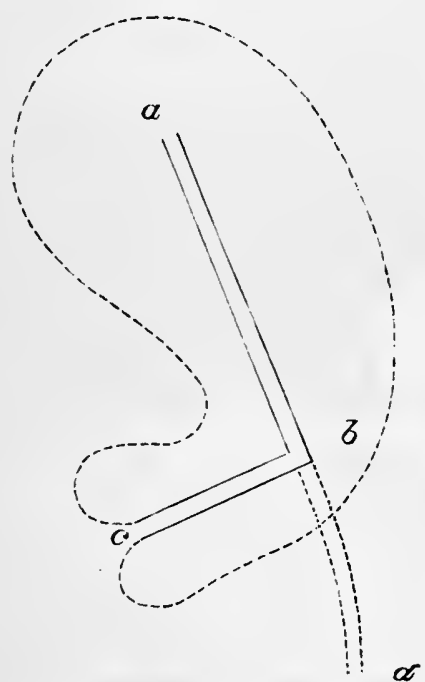

Schematic diagram, showing the creation of new uterine axis. a $b$ represents the axis of the body; $l c$ represents the axis of the neck: $b d$ represents the axis created ly incision. accomplished by cutting through one wall of the cervix. Having thus overcome cervical obstruction and consequent accumulation of fluids in utero, do we at the same time remove the tendency to mechanical congestion of the body of the uterus? Not entirely, but if we secure the results of cervical section as we may ordinarily do by subsequent use of the intra-uterine stem, we accomplish to a certain extent both results.

If the posterior uterine wall, bent forward as shown by the line $c b$, Fig. 172, in a case of anteflexion, be cut towards the raginal junction so that a probe will pass into the uterus in the direction of the line $a d$, the obstruction resulting from the existence of an angle will be remored, and thus fluids would have free entrance and exit, for instead of turning the angle at $b$ and escaping at $c$, they would at once escape at $b$.

The operation which accomplishes this result is an exceedingly simple one, and is thus performed. The patient being placed in position, and Sims's speculum introdnced, the cervix is seized and drawn down by a tenaculum. Then, by a long slender knife, that of Sims's is the best, an incision is made as far as can be conveniently done without involving the vaginal junction, which will probably be above the point $b$ in Fig. 172. The hlade of Sims's knife, represented in Fig. 173 , is now introrluced through the os internum, and the tissues are cut so as to lay open the posterior wall of the cervix. $\Lambda$ little shoulder will, as Dr. Emmet has pointed out, be generally fonnd to exist on the anterior wall of the canal, just at the angle made by flexure of this wall. Towards this the blade of the knife should now be turned, and it should be eut through. 
Fis. 173.

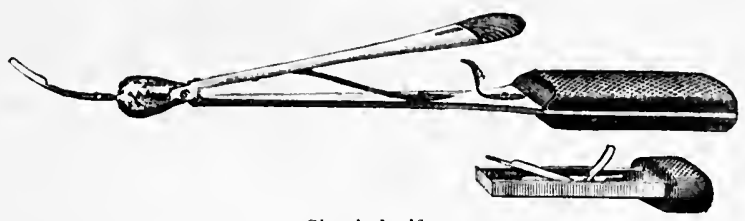

Sims's knife.

In this operation the knife alone should be used. None of the uterotomes are at all appropriate. Just after the operation the glass stem

Fig. 174 .

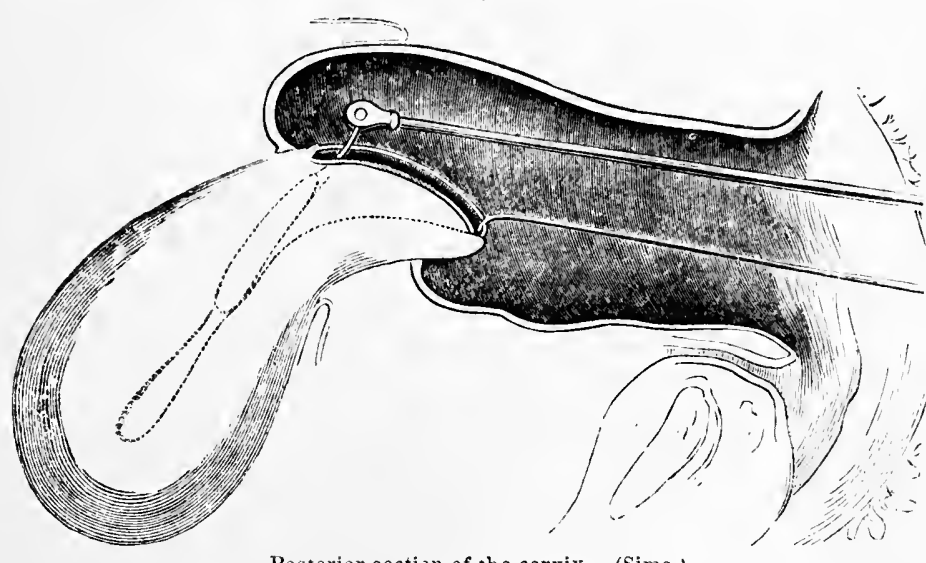

Posterior section of the cervix. (Sims.)

shown in Fig. 170 should be introduced so as to occupy the whole cervix from os internum to os externum. Under this a firm tampon of wet carbolized cotton should be placed. In forty-eight hours the tampon should be removed, and, if any sign of hemorrhage be present, reapplied. If not, one of the sustaining pessaries shown in Figs. 169, 170, or 197 should be introduced, the vagina be thoronghly syringed with warm earbolized water twice daily, and the patient be kept in bed for a fortnight. The stem and pessary should be worn, if no evil symptoms develop, for two or three months. Then, after cicatrization has fully occurred, they may be removed with a reasonable hope that the canal will remain pervious.

Suceess in this operation depends less on its method of performance than on the persistent wearing of the glass stem until cieatrization has been fully accomplished.

Should an error be made as to the etiology of the displacement or the reeognition of its complieations, and this apparently trifling operation be performed during the existence of perinterine eellulitis or peritonitis, the gravest results may follow, and the sufferings of the patient be greatly aggravated. Indeed, had all the fatal eases which have oceurred in consequence of this operation been published to the profession, as they should 
have been, the list would, I think, be a startling one. I myself know of several, and hare heard rumors of many others. It may be asked why this operation upon a part of the uterus which does not ordinarily resent surgical interference should so often be followed by dangerous consequences. My conviction is, that the operation per se is not attended by great danger. It is the performance of it when pelvic peritonitis exists in chronic form that has caused it to produce such bad results. Even a minor operation, performed in the face of a condition which should interdiet the use of the uterine probe, may set up a train of symptoms which may lead to a fatal issue.

After these procedures for the cure of anteflexion which has for a long time been irreducible and was very probably congenital, conception is by no means common. Operations for this condition often effect relief of menstrual and amelioration of circulatory disorders; and they may eren cure sterility, but he who practises them should beware how he makes promises to this effect.

It is very evident that at present a formidable wave of professional opinion is steadily advancing in opposition to this operation. Some of the very men who took exaggerated positions in reference to its value ten years ago are now emphatic in its denunciation. It is the old story of the swing of the pendulum! The operation should hold to-day just the position to which it was entitled ten years ago. Its merits are unquestionable; its place cannot in the interests of gynccology be left vacant. But as it did not deserve the encomiums of a formcr time, so it does not merit the depreciation which is aimed at it to-day.

One of its advantages has been, I think, lust sight of. Many cases of obstructive dy:menorrhœa, sterility, and inefficient menstruation, for which resort has been had to it with good effect, are due to an undeveloped state of the cerrix, which, eompared with the body of the uterus, is disproportionately small. Section, followed by the use of the glass cervical plug for two or three months, will often improve the nutrition of the cervix and result in its increased derelopunent.

\section{CIIA PTER XXVIII.}

POSTERIOR DISPLACEMENTS OF TIE LTERUS.

Retroversion and Retroflexion.

Definition and Fiequency.-Retroversion consists in a posterior inclimation of the uterus, so that the fundus, approaches the sacrum and the cervix allances torards the symphysis pubis. $\Lambda$ s an idiopathic primary lesion, it is not conmon, but it is frequently symptomatic of neoplasms, 
areolar hyperplasia, or other states which increase the weight of the uteris.

$$
\text { Fig. } 175 .
$$

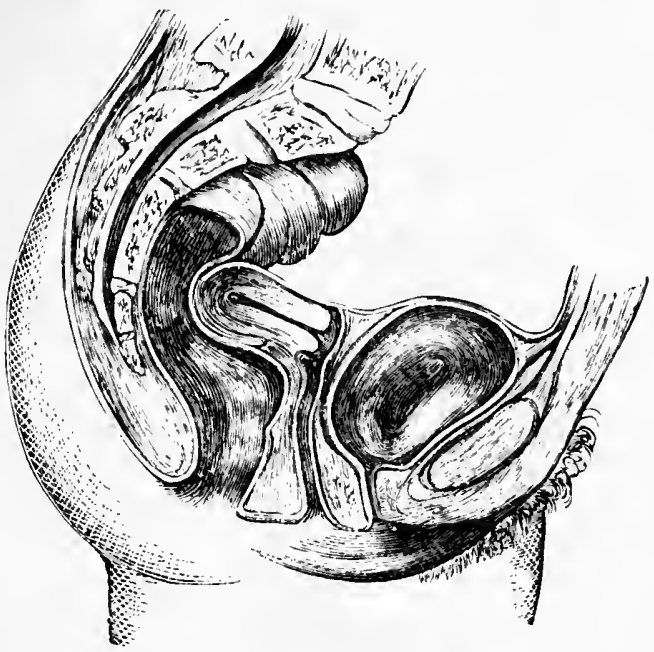

Retroversion of the uterus.

Retroflexion is said to exist when the body of the uterus is bent towards the sacrum so as to create an angle on the posterior wall.

Fig. 176.

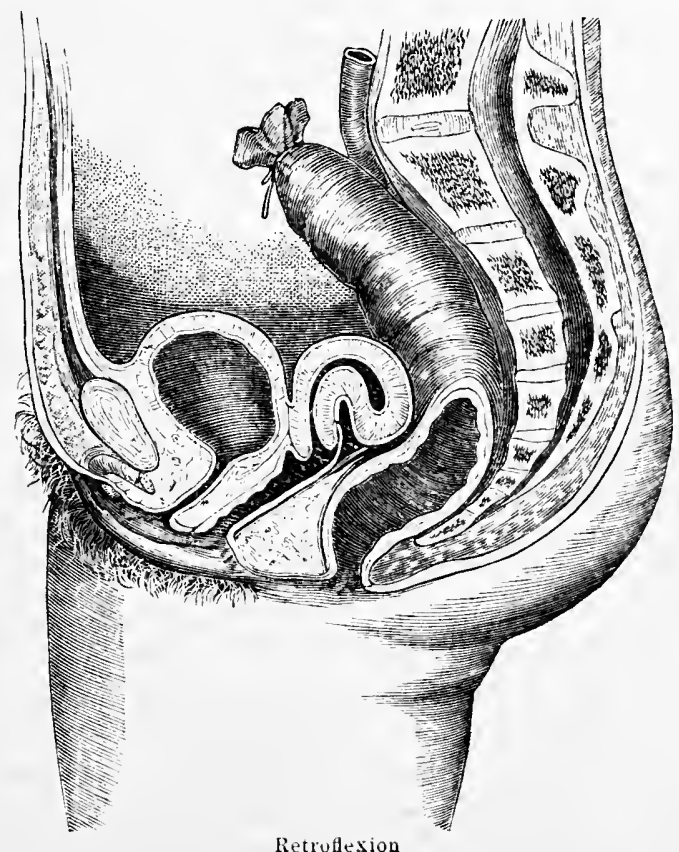


Predisposing Canses. - The predisposing causes of posterior displacements are parturition, general muscular debility, and habits of indolence and inactivity.

Exciting Causes._-These may be classified under four heads :-

Influences increasing uterine weight.

Fibroids;

Subinvolution ;

Areolar hyperplasia ;

Pregnancy ;

Congestion.

Influences dragging the uterus out of place.

Allhesions from pelvic pcritonitis or periuterine cellulitis ;

Rectocele;

Subinvolution of the vagina;

Prolapsus of posterior vaginal wall;

Retroflexion.

Influences forcibly displacing the uterus by direct pressure.

Severe succussion by blows or falls ;

Muscular efforts ;

Distended bladder ;

Tumors ;

'Tight landaging after parturition;

Tight and heavy clothing.

Influences weakening uterine supports.

Parturition;

Destruction of power of perineum ;

Prolapse of vagina.

Of all these causes the two most frequent are decidedly prolapse of the vagina, from subinsolution or ruptured perineum; and areolar hyperplasia, commonly the adranced stage of subinvolution of the uterus. All the others mentioned are sometimes met with, but, compared with these, they are insignificant as causes.

As might be presumed from the natural obliquity of the uterus, anterior displacements not unfrequently occur as idlopathic lesions resulting from pressure of superineumbent viseera forced down upon the fundus by tiglit clothing or muscular efforts. Retroversion oceurs in this way less frequently. It generally depends upon some pathrlogieal state in the nterns or its appendages. The third class of causes mentioned as displacing the organ by direct pressure may act through violent succussion, and induce sudlen displacement with symptons of most urgent character. Prolonged pressure from a distended bladder, or from a tumor anterior to or alove the uterus, may likewise induce gradual displacement. A little reflection will explain how the management of parturient women, by British and American practitioners at least, favors the occurrence of the 
accident. In the first place, it must be remembered that pregnancy anmbines in itself two of the influences which are prodnctive of this condition, inerease of uterine weight and relaxation of supports. It is no exaggeration to assert that the usual plan of management after parturition supplies one of the others which are mentioned above. The woman lying almost constantly upon her back, the heary fundus naturally temds to fall backwards into the hollow of the sacrum. Many nurses insist upon this position, and often for days refuse the patient the privilege of lying upon the sile. But this is not all, many a nurse's reputation among ladies rests upon her eapacity for "preserving the figure" by tight bankaging. A powerful woman will often expend her whole foree in making the bandage as tight as possible to accomplish this purpose. No one who has watched the process can doubt its influence in displacing the uterus by direct pressure. There is no practice connected with the lying-in room to which so much of almost superstition attaches as to the use of the obstetric bandage for preservation of the figure and prevention of hemorrhage. This is a repertition of what $I$ have elsewhere stated, but the importance of the subjeet in my mind must be my excuse for dwelling upon it here.

If involution have gone on tardily and imperfectly, the woman is still more prone to have the uterus forced backwards. The round ligaments, which are composed of muscular structure similar to that of the uterus, are important agents in preventing.this. It is lighly probable that an arrest of retrograde metamorphosis affecting the uterus may likewise affect them, and leave them longer and less powerful than natural. "Hypertrophy of the two (round) ligaments," says Scanzoni," " constantly accompanies a natural pregnancy; while, as we have ourselves had an opportunity to determine, in the case of a bicorned uterus, biparted, or bilocular, the ligament corresponding to the side on which was the pregnancy, was alone hypertrophied. - . . We remember many cases of women who have died after metritis or puerperal peritonitis, with whom one or both of the round ligaments were notably hypertrophied, and presented a lively red color, with a serous infiltration."

Not ouly as a result of pregnancy do these ligaments develop a condition which renders them prone to yield to traction from an enlarged uterus -Boivin and Dugès have observed hypertrophy in them, with dilatation of their vessels from chronic engorgement, fibroids, and even from ovarian tumors.

Varieties of Retroversion.-Retroversion may exist in slight degree, the uterine axis inclining so as to make with that of the superior strait an angle of $45^{\circ}$; or it may incline to $90^{\circ}$, thus lying across the pelvis; or the cervix may be thrown up and the fundus descend so as to form an angle of $135^{\circ}$. 
These varieties constitute the first, second, and third degrees of retroversion.

Retroflexion also has been divided into varieties dependent upon the degree of intensity, but these are so entirely arbitrary that they may as well be ignored.

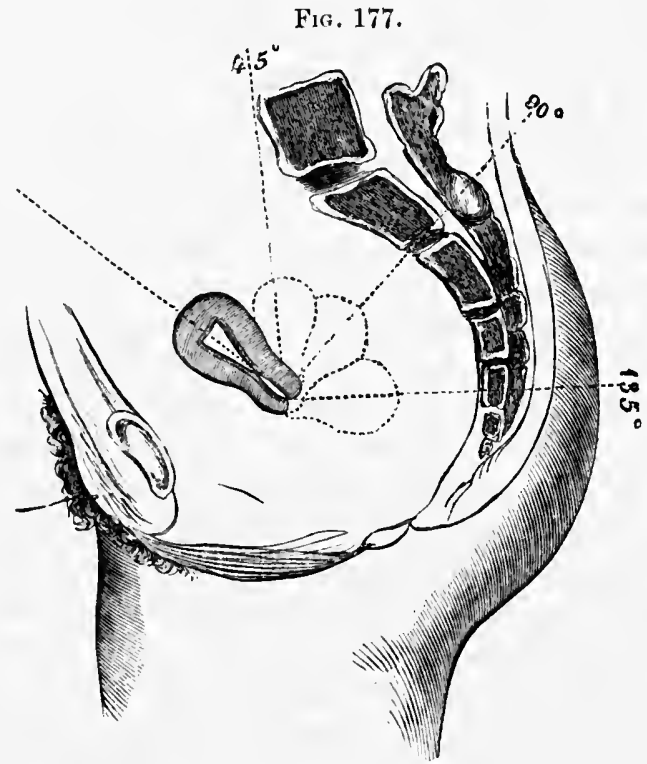

The deyrees of retroversion.

Symptoms.-Posterior displacements produce annoying symptoms by creating congestion of the uterine body, obstructing the cervical canal, and causing pressure on the reetum, congestion of the ovaries, and reflex nerrous manifestations. Through so many aremues of approach it may well be supposed that the symptoms are numerous. They are usually as follows :-

Severe backache;

Wreight in rectum with tesnesmus;

Leucorrhora ;

Dysmenorrhea ;

Nervous disturbances;

Diflieult locomotion ;

IIenorrhagia ;

Tendency to abortion;

Pain on sexual intereourse;

Pelvie neuralgia ;

Epigatstric depression; 
Gastric derangement;

Uterine colic or tenesmus;

Sterility.

Many of these symptoms prorluce epiphenomena of their own, aurl thins increase a list which is alrealy long.

Physical Signs._-The diagnosis is made by the following means :-

Vaginal touch;

Conjoined manipulation ;

Rectal touch;

The uterine probe.

The patient lying on the back, the index finger is introduced to the eervix, which is found in its normal place. It is then swept over the base of the bladker, where nothing abnormal is observed. Then it is passed into the fornix vagine, and here a round tumor continuous with the ridge of the cervix is discovered. The disengaged hand is then placed on the abrlomen, and made to approximate the finger in the vagina, so as to grasp the body of the uterus. If the abdominal walls be lax, this will yield good results, but not otherwise. The finger should now be earried into the rectum, in order to study further the eharacter of the tumor pressing upon this eanal. The patient being then placed upon her side and the speculum introduced, the uterine probe, which has been curved in accordance with the direction impressed on the mind by the sense of touch, is gently passed into the uterine eavity to the fundus, which completes the diagnosis.

Differentiation.-This displacement may be enfounded with feeal impaction, fibrous tumors, cellulitis or peritonitis, extra-uterine gestation, a prolapsed and enlarged ovary, and prolapsed kidney. The careful practice of the four diagnostic methods mentioned will remove all donbts.

In certain very rare cases the kidney has been known to prolapse into Douglas's eul-de-site and produce the most anomalons symptoms. In a ease of my own in which a very obseure tumor existed posterior to the uterus, this diagnosis was made by Dr. Noeggerath in eonsultation. In aceordance with his advice I placed the patient in the knee-chest position, and applied a good deal of upward pressure, when the tumor suddenly escaped into the abdomen. Support was given by a bulb pessary, and for a time my patient was relieved, but upon her return to her home in Virginia a complete relapse oceurred. Dr. Noeggerath tells me that he has met with but one other such ease. Of course the correctness of the diagnosis is doubtful. I am inelined to almit it from the peculiar symptoms exhibited, and by the fact that post-mortem examination proves that such a prolapse of a floating kidney sometimes occurs. The following account of such a case may be found in Braitluwaite's Retrospect.

"Examining the body of a man who had died of phthisis, aged thirty-five, Dr. Isaacs found the left kidney located in the pelvis, its upper end being in 
contact with the bifureation of the aorta, and its lower touching the posterior surface of the bladder, and lying on the ifth lumbar vertebra, and first, second, and third pieces of the saerum. Its right edge was in contact with the rectum, and the left with the iliae portion of the brim of the pelvis. There were three renal arteries, one coming from the aorta, and two others from the right common iliac. The kidney was of the ordinary size, but the supra-renal capsule was twice its natural size, and of the shape of a fig-leaf, and it oceupied its normal position in the lumbar region."

Consequences of Posterior Displacements.-The post-uterine peritoneal space being much more extensive than the anterior, they proceed to a more aggravated degree than anterior displacements. The body sometimes descends to the upper extremity of the vagina, and instances are recorded by Rokitansky and Schott in which it penetrated the walls of the rectum and vagina, and forced itself into these canals. This of course is a very rare occurrence, but it is worthy of mention as showing how great is the pressure which a retroflexed uterus may exert. The ordinary consequences of the affection are-

\section{Dysmenorrlıœa ; \\ Endometritis ; \\ Sterility ; \\ Areolar hyperplasia ; \\ Pelvic peritonitis.}

As rare complications may also he recorded, hematometra ani hydrometra from imprisonment of fluids by obliteration of the canal by flexure at the os internum. Slould pregnancy oceur during the existence of this deviation, or retroflexion complicate pregnancy, and the funclus be incareerated below the promontory of the sacrum, abortion will result. This cause of that accident is so very common that it should be suspected and examined for in every case of habitual abortion.

Prognosis.-There are three conditions which render the prognosis of this condition unfavorable: where the uterus is bound down by strong adhesions; where the organ contains in its parenchyma a fibrous tumor; and where the vagina is at tacher to the cervix so near the cxtermal os that no pessiry can rest posterior to the cervix to sustain the uterus after it is replacer. This form of utero-vaginal junction is important as giving ground for a very grave prognosis as to the eure of all anterior and posterior displacements.

Trertment.-The first indication is to restore the uterus to its place, the second to prevent its again becoming displaced.

Metlords of Rednction. - In an ordinary case in which the uterus is not firnly linl in retroversion ly the surroumling parts, the patient should he pliserd on the left sile as for an orlinary exanination with Sims's spenlum. The operator then lubricating the index and middle finger of the right hand introduces them, he standing at the patient's back, and 
faeing her hearl, and the palmar surfaecs of the fingers being directerl to the reetum. 'The body of the uterus is then lifted npon the tips of the fingers mutil it becomes ereet, then their dorsal surfares, which will rablly be the backs of the naik, are male to push the organ orer into normal position. As the uterus becomes elevated the mildle finger is still kept in the post-uterine space to mantain what is ganed, while the index finger is carried in front of the cervix, and this part is by pressure forcenl back towarls the sacrum. The middle finger is now likewise placed in front of the eervix, aud by both fingers this part is forced towarls the sacrum and kept there for a short time. This method of replacing a uterus which has fallen backwards is superior to any other that I know of. I would urge a trial of it exactly as here described, and will answer for its efficiency.

But sometimes the uterus is irreducible by any but the most powerful methods. In such a case, the bladder and reetum having been evaeuated, and the elothing loosened, the patient is made to kneel upon a hard surface, and to place the sternum as elosely as possible in eontaet with the plane which supports her. The practitioner then lubricating two fingers of the right hand earries them into the vagina and against the fundus. He then directs the patient to fill the ehest with air, and expel it completely. As she does so, he foreibly elevates the fundus and restores it to its place. Should this plan fail, the buttocks should be still more elevated by placing cushions under the knees, and the attempt repeated with two fingers in the rectum instead of in the vagina.

Should these powerful and usually efficient methods fail, I would strongly urge against efforts being made by introduction into the uterus of instruments for restitution. If they exert less force, they will not be effeetual ; if more, they may penetrate the uterus and create peritonitis. Besides, in a case resisting the plan detailed, there will probably be found to be adhesions as the source of the difficulty. Under these eircumstances, Kuchenmeister ${ }^{1}$ has, from extended experience, advised the introduction of the colpeurynter filled with water every day, for as long a time as the patient ean bear it. Steady hydrostatic pressure often in this way aceomplishes safely what sudden force would do with danger to the patient.

In cases requiring the application of much less force, Sims's repositor is an excellent instrument for the purpose, and should be employed. This instrument, which is represented by Fig. 178, consists of a short metal souml, terminating in a ball. The ball is elasped by a straight shaft, moves upon a pivot ruming through its centre, and is perforated by seven holes. Through the shaft runs a rod which is projected by a concealel spring, that is governed by the finger passed through the ring. The ball can be made to revolve so that the sound describes a half eircle, 
by withlrawing the stop-rod which runs through the shaft, and depressing the instrument.

FIG. 178.

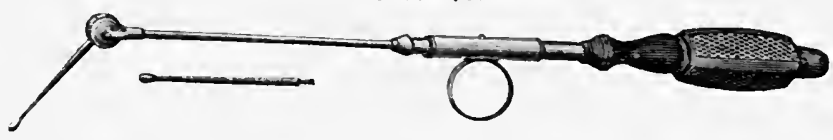

Sims's uterine repositor.

In the majority of instances reposition is perfectly practicable by comjoined manipulation or rectal taxis, or by means of a sponge fixed in a sponge-holder and pressed into the fornix vagina.

Good results will often attend carrying one sponge staff up the reetum and another up the vagina, so as to make pressure upon the displaced fundus, after the plan adopted by Dr. Bond, of Philadelphia, in his ingenious repositor, which is represented in Prof. Meigs's work on Midwifery. In replacing a nterus in this or any other malposition, the operator should never forget that inflammatory action may have caused an effusion of lymph around it which resists its removal, and that if these adhesions be violently ruptured cellulitis or peritonitis may result.

As early as 1820 , von Ritgen, of Giessen, recommended the kneechest position for the automatic replacement of the retroflexed womb, and since his time the method has been often resorted to as an adjurant to replacement. To Dr. II. F. Camplell, however, belongs the eredit of systematizing it as a method of "pnemmatic self-replacement," and putting it at the disposal of the gynecologist for daily use. "Campbell's method" never does harm, generally effects great good as an adjurant to other treatment, and in rare cases proves in itself sutheient for complete relief. It consists simply in the reversal of gravity by placing the patient in the attitude represented in Figs. 179 and 180, an examination of which will at onee show the action of the method upon intestines and uterus. Dr. Camphell likewise directs that a small glass tube, about as large as the largest sized test-tule, should be introrluced into the vagina by the patient while in the "genu-peetoral" position, to secure the admission of air and its action as a repositor.

During the treatment of all uterine displacements, except inversion and irredueible flexion, the patient may, with advantage, be directed to practive this automatic method of replacement for five or ten minutes upon retiring at night and upon rising in the morning. If a pessary be worn, it will be, by this plan, relieved of much of the pressure which it bears, congestion of the pelvic viseera will be lessened, and the organs of the ablomen, heirg displaced upwards, will not immediately descend and depress those of the pelvis. 
Fia, 179.
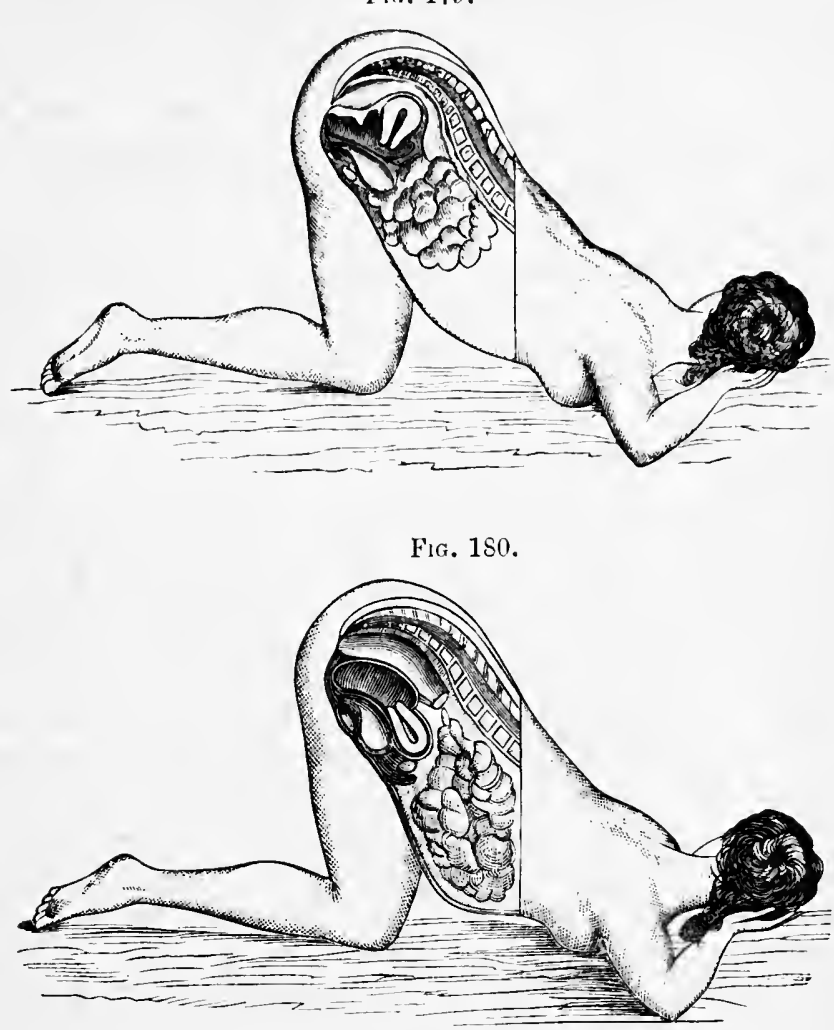

The genu-pectoral position; showing its action in retroversion.

After replacement has been effected by any one of these methods, the sound may be employed to make sure of its thoroughness and to inerease it. It slould never be used for this purpose before manual replacement, and even after it it should be employed very cautiously and by the following steps:-

1st. It should be introduced, but slightly bent, to the fundus.

2d. Holding the handle in his left liand, the operator should place the tips of the fingers of the right hand upon the sliaft and carry it towards the perineum as far as possible.

$3 \mathrm{~d}$. The uterus being now, to a certain degree, straightened and elevated, the sound should be rotated so as to throw the fundus forwards, and the handle of the instrument held in one hand be carried towards the patient's back so as to advance the tip as far as possible towards the abdominal walls.

Rearling a procedure thus described often leaves the impression that it is a complicated one, and, perhaps, that the directions given are unimpor- 
tant. Let one who has habitually used the sound simply as a rotator fairly try this more delicate and rational employment of it, and I am sure that he will adhere to it, even although prejudiced against it originally.

Sims's repositor, likewise, answer's a good purpose in rendering replacement complete after partial replacement by the fingers.

Means for Retcining the Uterus in Position.-Having replaced the uterus, the question which arises is, How are we to prevent the recurrence of displacement at a very early period? Careful attention should immediatrly be paid to the following points : 1 , all pressure from above should be removed by the use of the skirt supporter, the abdominal supporter, and avoidance of injurious muscular efforts; 2 , increased weight of the uterus should be diminisher by the adoption of means already pointed ont for the fulfilment of this indication; 3 , feebleness of the uterine supports should be remedied by exercises calculated to develop the retentive powers of the abdomen and by general and local tonies; and 4, all traction upon the uterus should be removed by perineorrhaphy, or this combined witl colporrhaphy. The fulfilment of one or of all these indications may at once bring relief to a case in which less radical and more desultory efforts might be indefinitely prolonged with only partial bencfit. As the means for fulfilling these indications have been already fully pointed out, I shall not repeat them liere.

All causes which originally excited and still perpetuate the accident having been as far as possible combated, the chief and most immediate indications are clearly to replace the displaced uterine body and to keep it in position.

For the purpose of fully exhibiting the method of treating a chronic ease of this disorder, I will suppose that we are dealing with one of rebellions character, in which there is considerable tenderness about the uterus, so that it will not tolerate the pressure of a pessary sufficiently powerful to kcep it in position. The bowels should loe evacuated; the vagina thoroughly syringed with warm water night and morning; all weight taken from the aldomen by a skirt supporter, an abdominal supporter, and avoudance of all muscular efforts; and the uterus be replaced and held in the condition of complete anteversion for two or three minutes, once in every forty-eight hours, for a week or more. As an additional preparation for the permanent support of the displaced organ, a tampon of carbolized cotton should be applicul in the following way: the uterus being pushed into a state of complete anteversion, a roll of cotton about the size of a small hen's egog, or an egr-sponge moistened with earbolized glycerine, should be carefully pushed as far as it will go into the fornix vagine. Then a large roll of cotton should be placed below the cervix and a little anterior to it (not behind it, as the first one wass), but so arranged as to lift this part up into the hollow of the sacrum against the roll, which has now become invisible, in the fornix vagine. The subcervical tampon not only puslies back the cervix, 
which was before its introduction near the symphysis pubis, but it still further elevates the supra-cervical roll, which thus pushes the fundus farther and farther upwards until it topples over forwarls by its own weight, uninterfered with as it is by pressure from above, and aided by the ablominal decubitus which should he observed by the patient. The aceompanying diagram will explain the action of these two portions of

Fir: 181.

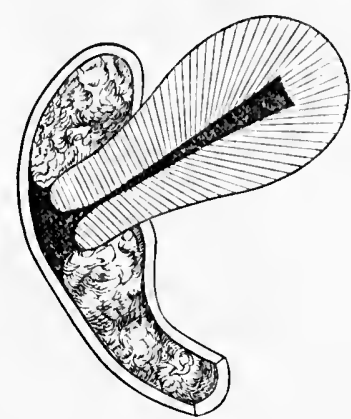

the tampon when properly applied. If, instead of being thus applied, the ordinary tampon be employed, and the lower portion of the ragina be filled, nothing is accomplished but elevation of the retroverted organ. What we desire to produce is anteversion. After the introduction of the cervical pad as shown in the figure, the vagina is filled with cotton to keep this in place, as well as to elevate the whole uterus, and bring gravitation to our aid in throwing the body forwards. I do not look upon the abdominal decubitus as a valuable resource in the treatment of retroversion, but merely as an adjurant to other means, which directly straighten the axis of the uterus. Lift the retroverted organ, and it has a certain legree of efficacy, as an adjuvant, which it does not possess while the displacement is in existence. The tampon may be retained for fortyeight hours withont inconvenience, if the material of which it is composed be properly prepared by means of antiseptic drugs.

Cotton impregnated with antiseptic and alterative substances, such as bor:ax, carbolic and salicylic acids, zinc, copper, alum, iron, etc., nay now realily be obtained from druggists, so that the physician need not charge himself with its preparation.

During the use of this means the patient may go about and attend to her usual arocations, although sometimes it is better to confine her to bed.

I sometimes effect the same result by introdncing a Hoffman's or Inurd's inflated rubber pessary, and then placing under this a tampon, which will press it firmly up against the displaced fundus.

Should the residence of the patient be out of the city, or her pecuniary 
condition render it impossible for her to be treated as here advised, the

Fig. 182.

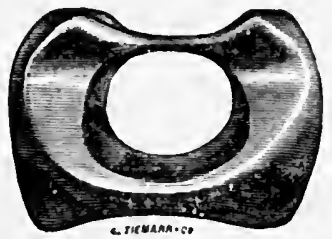

Hoffman's inflated, soft-rubber pessary. plan may be imitaterl by one which is very effectual, and mueh less troublesome to patient and physieian. The uterus being thrown into anteversion by the repositor, or two fingers introduced into the fornix, while the patient is in the left lateral position, a sponge-pessary, which eonsists in the attachment of a soft egg-sponge, instead of a bulb, to the stem of Cutter's pessary, Fig. 191, should be left in position. The sponge fits in the vaginal eul-de-sac, is steadily pushed upwards against the uterus by the elastic dorsal strap, and foreibly, but gently, keeps the organ in normal position. For such cases as those just indieated, and for others in which the retroversion is so obstinate that it recurs in spite of a pessary passed entirely into the vagina, this constitutes a means of such great value that $I$ urge its trial in all diffieult cases. By it $I$ have controlled many eases which had resisted all other plans of mechanieal treatment, and feel assured that it will not fail to produee in the hands of others as good results as it has yielded me. Of course, it is only a temporary and preparatory means, for sponge is, at all times, an objectionable substance to leave in the vagina. It should, in this ease, be removed, washed, and replaced by the patient onee in every twelve hours.

After the methods tluns far deseribed have been pursued for a month or two, even the worst cases will generally tolerate a well-adjusted permanent pessary; but where this tolerance is not established, the medieated tampon, or sponge pessary should be continued until it becomes so.

One important point in eonnection with this method of replaeing the uterus is this. The round ligaments are attached to the horns of the organ, and at the vnlra. If the retroverted or retrotlexed uterus be left in malposition and simply pushed up, the ligaments will inevitably inerease and insure the continuance of the displacement. If, on the other hand, the body be thrown forwarls and kept in anterior position until the organ be lifted, the round ligaments, becoming tense, tend to ate remedially on posterior deviations. A little thought will convince the reader of the truth of this statement. It is upon this action of the round ligaments that I in part depend for the benefit of the plan which I am deseribing.

It nay be asked whether $I$ propose to treat all eases of retroversion in this manner in the beginning. By no means so. I prefaced these remarks upon preparatory treatment by stating that I supposed the practitioner to be dealing with an aggrarated ease and one intolerant of support. Most eases will at once admit of the use of a retroversion pessary, and require no preparatory treatment. There are, however, many others which do require it and in which immediate resort to artifieial support proves inju- 
dicious and even dangerons. Some may suppose that a great deal of time must be consumed by this preparatory treatment which is not absolutely necessary for the relief of the case. If preparatory treatment be not necessary, it should not be resorted to; if it be necessary, time will be gained and not lost by its adoption. At least let me urge this advice: when the most carefully arjusted pessaries create diseomfort, let a month be devoted to the preparatory treatment which I have describer, and at its end let pessaries be anain tried. Many eases will then be found to yield to meehinical treatment which were rebellions to it before, and more certainly so if the means recommended for removing pressure upon the fundus from aluove be faithfully put in practice. Some of the most gratifying results of gynecolony will be foumd to arise from a cautions, patient, and philosophical treatment of these eases. But let no one suppose that a eareless fultilment of the directions given is likely to perform all this. If the plan which $I$ am urging be used unintelligently and ronghly, it will do larm and not good, and result in annoyance and not comfort to the patient.

It lias now been decided, we will suppose, to try the effects of a retroversion pessary. Which of the many varieties at our command shall be selected? The oldest and most generally known of these instruments, IIorge's pessary, still holds its place in professional esteem, and is slown in Fig. 183.

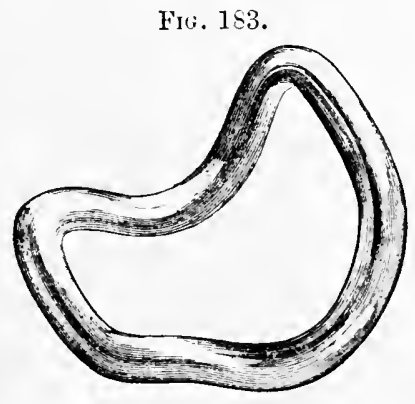

IIodges closed lever pessary.

To IIodge's pessary there are two objections: one is that it lacks a point of resistance at the outlet of the pelvis, which prevents it from turning around; the other is that it does not earry the body of the uterus high enough up in some cases. These defects Dr. Albert Smith has well met in the modification of Hodge's instrument which is shown in Fig. 184.

I likewise very commonly employ, in cases in which I desire to carry the retroflexed fundus very high in the pelvis, the instrument shown in Fig. 18.5.

It is a long and narrow instrument, surmounted at its upper extremity by a bull, and measures between its branches at the widest part seveneighths of an inch in the smallest sizes, and one and one-eighth of an inch 
in the largest; upon its upper extremity is a bulb which prevents eutting of the tissues; its lower extremity rests against the tissues under the pubes; and it is five incles long in the largest sizes, and four and a quar-

FIG. 184.
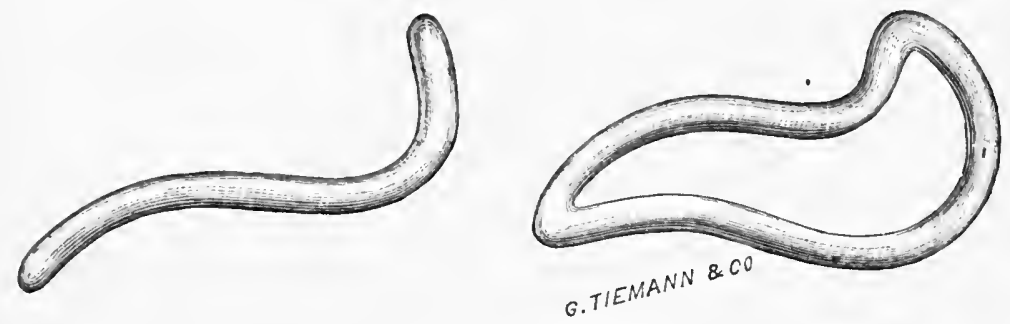

Albert Smith's pessary.

ter in the smallest, measured along the ontside curve of the branches. Spamning the pelvis, this narrow instrument stretehes the vagina without distending it, and pushes the fundus to a higher point than any other with which I am familiar. Its retention depends not upon its size bnt its relation to the pelvis, for it is prevented from escaping not by separation of its branches, hut by the lengtl and degree of the post-uterine curve, and by the retention established by the tissues under the pubes against the downward curved lower extremity.

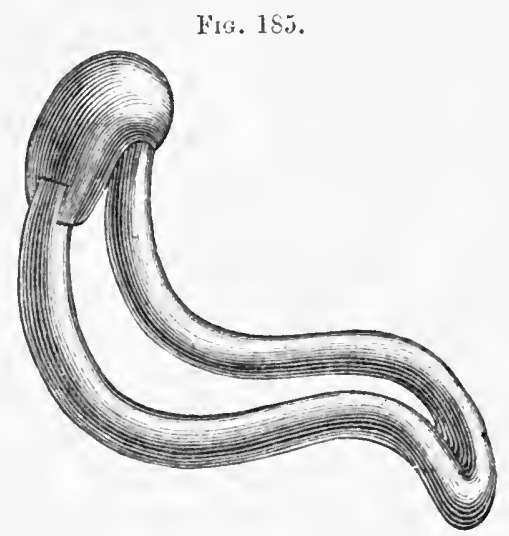

Thomas's retroflexion pessary.

The same instrument is also very cleverly made by Mr. Otto, of this eity, of elatic spiral wire, covered with soft rubber, and ending in at solt rublere cushion or bulb at its upper extremity, as shown in Fig. 186.

To a limited degree support may in these eases be obtained by the elastic ring pessary of Mejogs, which has been as variously altered as the lever of Hodge, but this instrument in posterior and anterior displacements is only palliative and imlerfect in mechanism. 
Nevertheless this instrument, imperfeet as it is, cannot be discarded hy the gynecologist, for in some cases it answers a pmpose which no other

Fit. 180.

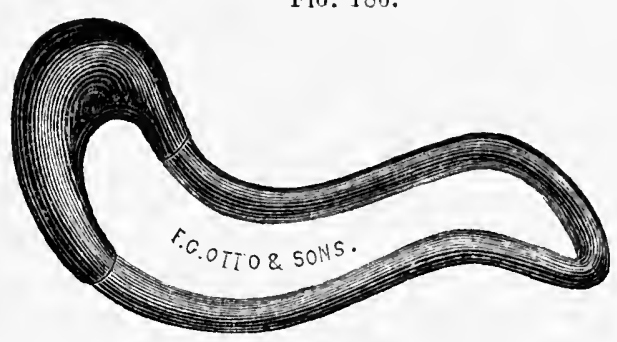

Elastic lull pessary.

instrument can be made to do. To one unacenstomed to the use of pessaries the simplicity and elasticity of this instrument will prove very seductive, and lead to a belief in its perfeet harmlessness. Such a reliance will prove utterly delusive. Even the most elastic instrument will often cut through the vaginal walls when it is a little too large. It is indeed more liable to produce this result than any other variety of pessary.

Sometimes the posterior uterine wall becomes the site of a fibrous tumor, FIG. 187.

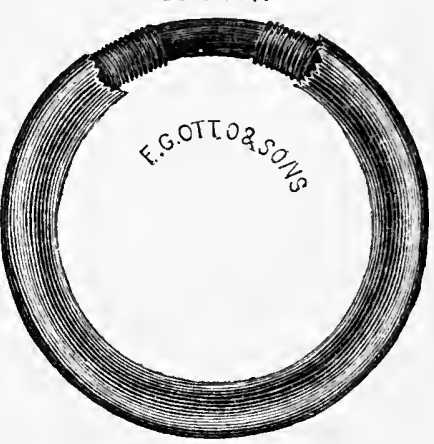

Meigrs's elastic ring pessary. which, by keeping up eongestion by its presence as well as by the flexion which it induees or aggrarates, renders the whole fundus so tender, that

Fic. 1:8.

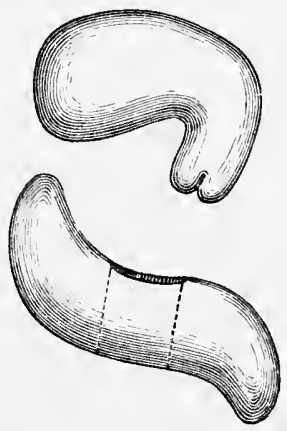

Hurd"s pessary.
Fig. 189.

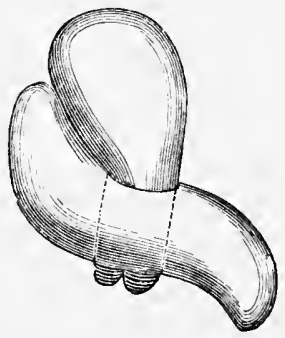

Retroflexed uterus in Hurd's pessary.

an ordinary pessary cannot be tolerated. In such cases the bulb should be removed from the modified Cutter's pessary and replaced by a soft sponge, 
and by this the uterus may be supported. Under these circumstanees Hurd's pessary, Fig. 188, will be found to answer a good purpose, and the inflated, soft rubber pessary of IIoffman, Fig. 182, is also a serviceable temporary resort, alone or combined with the tampon, which greatly inereases their effieiency. Where tenderness is excessive, it will often be found to be a wiser course to pack the fornix with medicated cotton or sponge, and elerate the whole uterus, as already adrised. By employing this method for a time, a pessary will soon be tolerated.

These are the instruments which I employ in ordinary cases of posterior displacement of the uterus. There are other varieties, however, which

Fig. 190.

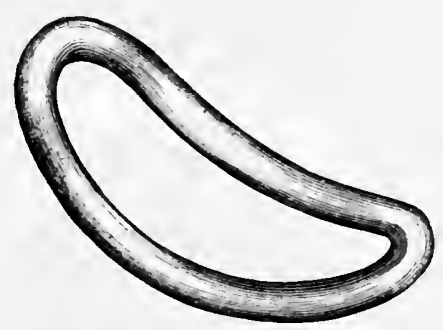

Hewitt's jessary. often answer an execllent purpose. Hewitt's pessary is an excellent one, if the weight to be sustained be slight. If it be at all great, this instrument is utterly inadequate to cope with it. It is not simply inefficient; it is in such cases a dangerous insstrument, for resting against the soft parts covering the symphysis pubis it may, as I lave seen it do, cut direetly through.

In a certain number of cases the displaced uterine body is so heavy and presses so forcibly downwards that a pessary of ordinary size is driven out of the vagina, or so low down as to allow descent of the fundus. This might ve obviated by employing an instrument of large size and great expansion of limbs, but this the vagina cannot tolerate. It sets up ulceration and creates pain from pressure and distension. In other words; without a very firm base the uterus forees out the instrument; with a sufficiently firm base to resist this, ulceration from excessive pressure results. In some eases indeed, so very great is the pressure exerted by the displaced uterus, that no purely internai support will answer the purpose of sustaining it, for the point against which either the pubic or uterine extremity of the instrument rests will, in splite of every preeantion, become uleerated. Under these cireumstanees I lave obtained the most gratifying results from the use of a modification of Cutter's retroversion pessary, intended to obviate a diffienlty which I found attended that excellent instrument, that of cutting through the vagina. If no great amount of pressure is to he borne, Cutter's pessary answers very well for this purpose; if great pressure is to be borne, the foint of his instrument endangers the tissues. For this reason I have affixed to the top of Cutter's pessary bulbs of different sizes_-some as large as at hickory nut-for the object is not only to prevent cutting of the vagina, but to place behind the displaced funths a mass which will make it fall forwards by displacement, and not by pressure. My alteration of this in- 
strument is insignificant ; the entire eredit of it belongs to Dr. Cutter, to whom the profession is indebted for aflording it so valuable and simple a method for meeting the difliculties of agrravated retroversion. Had I space, I could eite a number of very bad cases of this difficulty, which

Fig. 191.

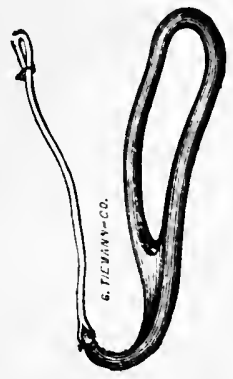

Cutter's pessary.
Fig. 192.

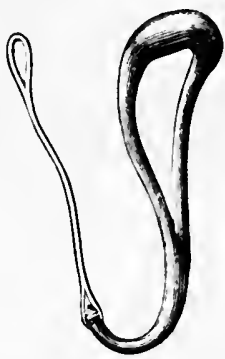

Thomas's modification of Cutter's pessary.

had for years resisted treatment by ordinary pessaries, and which have readily yielded to the use of Cutter's instrument, or this modifieation of it. The inferior extremity of this pessary arches backwards over the coccyx, and attaches to an elastic cord which passes upwards over the sacrum to a girdle around the waist. It is a painless and effieient method of giving support, and will gain a high reputation on account of these qualities in posterior displacements. The class of cases to which it is especially applicable, is that in which the displacement is due to prolapse of the posterior vaginal wall from rupture of the perineum or other eause. When employed for posterior displacements, the upper extremity of the instrument simply lies in the fornix vagina, the cervix of course not entering the fenestra.

This instrument should be removed every night and reinserted every morning. It may be said that this will prove diffieult of aceomplishment for the patient. Out of several hundred eases in which I have used it, I have never found an instanee of failure in this respect. The patient will very often become disaffeeted towards the instrument from its chafing the perinemm. By a little patience, covering the points which rub with greased lint, and leaving the pessary out until the irritated part be healed, the feeling will soon pass away.

It will be observed, that thus far we have dealt, in treating of the mechanical means for sustaining the flexed uterine body, with those which directly push the fundus upwards, in the hope that in time it will fall forwards of its own weight and assume a natural position. In some eases this is not enough; we are forced to do that at the same time that we elevate as far as possible the cervix into the hollow of the sacrum, and thus inerease the liability of the uterine body to fall forwards. In other words, 
there are two forces which may, through a pessary, overcome retroflexion: first, that which pushes the corpus uteri upwards and forwards; seeond,

Fı. 193.

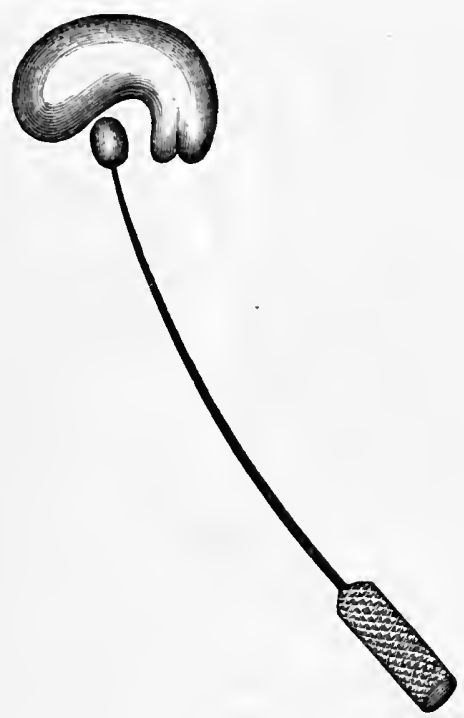

Force applied to uterine body aloue. that which pushes the cervix upwards and backwards. The first of these often proves quite sufficient without the second, but sometimes the direct and steady pressure upon the uterine body involved in it becomes intolerable. Then is it that the second, whieh alone is never sufficient, comes into play as an efficient adjurant. I have often seen the practice of the double method effect cures which seemed to have been impossible by that of a single one. I deem this point of sufficient importance to illustrate it by sehematic diagrams.

This double action is developed by the post-cervical and ante-cervical tampon, by the sponge and tampon, and by Hurd's pessary and a tam-

Fig. 194.

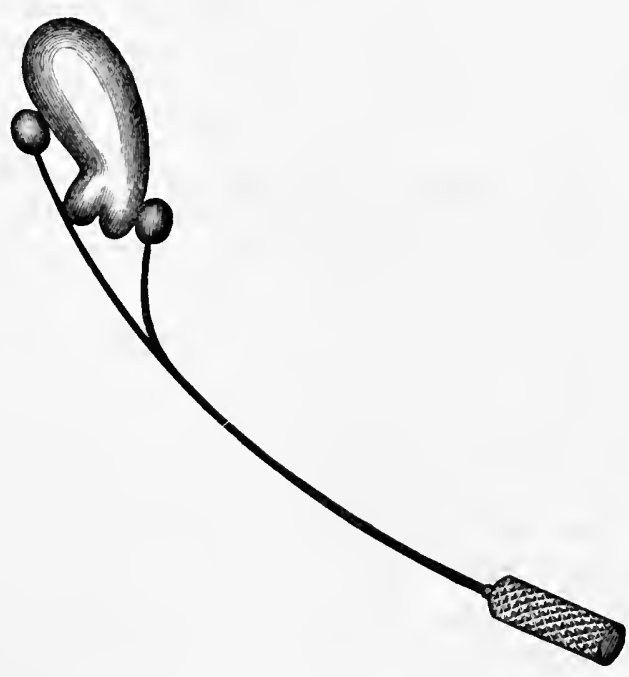

Force simnltancously applied to cervix and body.

pon. I now show two pessaries which accomplish the same end, one an addition to the IIodge pessary, the other a modification of the Cutter. 
The second is so unconth in appearance that one instinctively feels prejudieed against it, but I would atsk for it a fair trial, and assure my reaters that it has proved, in my hanels, at most valuable resource in at elitsis of calses of most intractable charalcter.

Fig. 195.

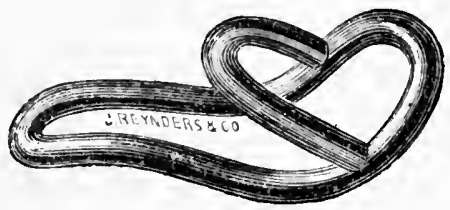

Retrotlexion pessary with cervieal rest.
Fig. 196.

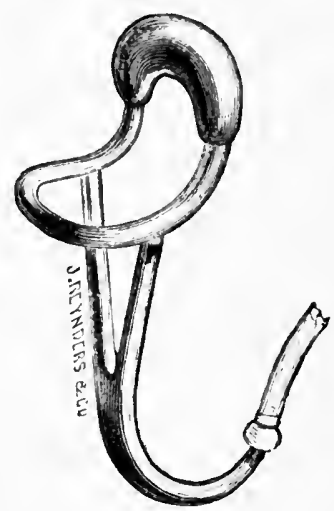

Modification of Cucter's pessary with cervical rest.

It will be at onee appreciated that the anterior arm in each of these instruments lifts the cervix upwards, as the anterior ball does in Fig. 194.

by these means a uterus affected by a redueible retroflexion may, in all conditions excepting the unfarorable ones already mentioned, be restored to its place and kept there without resort to the intra-uterine stem or a cutting operation. These unfavorable conditions we will now consider.

When the vagina unites itself to the cervix so near its lowest point as to leare almost no post-cervical space, it is impossible to sustain the uterus loy any vaginal pessary. Under these cireumstances, and these alone, I believe the intra-nterine stem to be necessary in posterior displacement. Those which were recommended in anteflexion will answer here.

Anteftexion is probably often a congenital condition, or continues for so long a period during the life of the girl before it is discovered, that the anterior inflexion becomes an irredncible nterine deformity. This is sometimes, thongh much less frequently, so in retroflexion, which is usually reducible, unless the flexed body be hound down by false membranes, the result of slight peritonitis. It is sometimes difficult in a given case to decide the cause of the permaneney of the displacement. In a general way it may he said, that, if it be due to filse membranous attachment, the uterns will not move from its position in the pelvis; if it be due to contraction in the tissue of the uterus itself, the organ will change its pelvic relations, but not the abmormal ones existing between body and neck.

In case the flexion be found due to parenchymatous alteration, no sur- 
gical procedure should be adopted; but the body should be cautiously bent torwards once or twice a week by means of the sound or repositor, and kept in anterior inclination by means of the retroflexion pessary shown in Fig. 195, or by the modified Cutter's pessary.

If the uterus be found fixed in the position of retroflexion by false membranous attachments not of recent origin, and the patient be not suffering to such an extent from the displacement as to render reposition urgently necessary, it had better be left undisturbed in its unnatural place. Should the disorder, however, be aftiecting the health, or cansing such pain and discomfort as to render the incurring of the risk of peritonitis warrantable, reduction should be accomplished in this way. The patient having been anesthetized and placed in the left lateral position, the sphineter ani should be stretched by the thumbs. Then the index and middle fingers of the right hand should be passed, with the palmar surfaces towards the sacrum, up the rectum to the flexed uterine body. Steady pressure should then be made upon it until the organ is lifted upright, when, the fingers being made to describe the arc of a cirele towards the pubes, the outer surfaces of the finger-nails will be in contact with the uterine body, and by them it will be pushed over into an anterior position. After this the fornix should be filled with a soft, moist sponge, and this be forced up so as to sustain the body by a tampon of cotton in the vagina. After this the patient should be kept very quict for a week, and all pain should be soothed by free use of opium, as a preventive of peritonitis.

\section{Lateroflexion.}

Sometimes the uterus is flexed to the right or left side as a consequence of disease of its proper tissue or of direet pressure. This variety of displace-

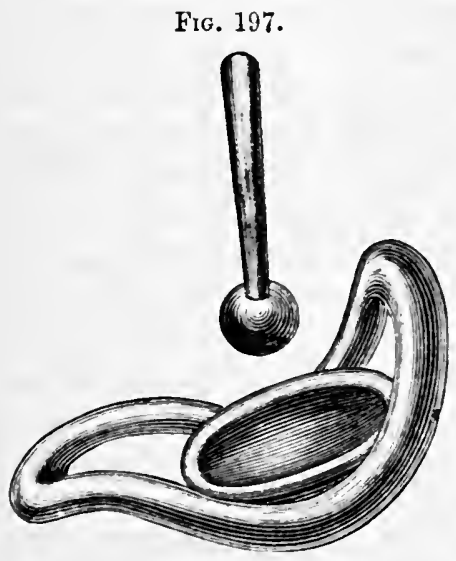
ment rarely attains to such a degree, however, as to result in obstruction of the uterine canal. Its chief importance is connected with diagnosis, for it may readily be mistaken for, periuterine inflammation or a fibrous tumor. The practice of conjoined manipulation and the use of the uterine probe will always settle the point.

The treatment of lateroflexion should be conducter upon precisely the same principles which guide us in reference to anteflexion and retroflexion. Or all varieties of flexion this is the most likely to require the use of the intrauterine stem, for it is exceedingly difficult, I may even say rarely possible, to overeome it by a vaginal instrument. When this necessity presents 
itself, either in retroflexion or lateroflexion, I employ the intra-uterine stem represented in Fig. 197. The fundus is in part sustained by thr. pessary, not entirely by the stem.

After the introduction of every pessary, the position of the uterine bolly should be at once examined, either by the probe, by conjoined manipulittion, or by both, to ascertain whether the instrument be efficient or not. If' it be not so, it is imperfect, for the object is not to go through the form of introducing a pessary; it is to rectify the malposition of the uterus. At the next and at every subsequent visit of the patient, this examination should be made before removal of the instrument, in order to test the effect of time and movement upon the position of the supported uterus.

\section{II A P E R X X X.}

INVERSION OF THE UTERUS.

Definition.-This dangerous and infrequent form of displacement consists in the turning of the uterus inside out. As the bottom of a bag may be pushed through its mouth, so that the inner surface becomes the outer, so may that of the uterus, and the occurrence of such an accident constitutes the disease which we are considering.

Varieties.-Writers differ in classifying the varieties of the affeetion, some describing three and some four forms. For practical purposes all

F1G. 198.

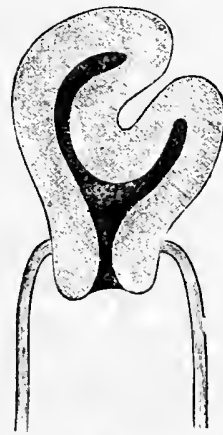

Partial inversion.
Fig. 199.

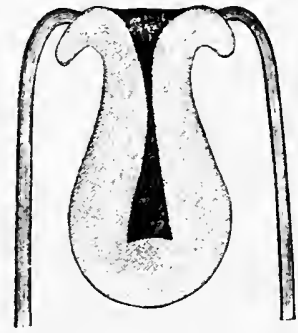

Complete inversion.

these may be brought under two heads-partial and complete. In the first the body lias become depressed, but has not passed through the os. In the second the uterns has been turned completely inside out, and the inverted fundus and body hang in the vagina or between the thighs, 
"velut scrotum," as it has been expressed by Hippocrates. Fig. 198 represents the first, and Fig. 199 the seeond form of the aceident.

In addition to these varieties the accident must be divided into acute and chronic, or sudden and gradual inversion, as it occurs rapidly or slowly.

Anatomy.-In treating of flexions of the uterus, it was remarked that they are chiefly prevented by the resisting nature of the parenelyma of the cervix which supports the fundus and body. A similar function on the part of the entire uterine structure keeps the cavities of the neck and hody elosed, and prevents inversion. Should that power, which in the pregnant uterus we call contractility, and in the non-pregnant, tone, be to any great degree impaired, the body of the organ, bereft of support, will incline forwards or backwards. Should it be entirely abolished, the fundus under the influence of traetion or downward pressure may pass through the unresisting os and escape into the vagina, eonstituting inversion. I once saw this perfectly illustrated in a cadaver upon which I was called to perform version soon after death. $\Lambda$ s I extracted the child the flaceid uterus followed it directly and was completely inverted, the placenta still adhering.

Pathology.-The aceident depends for its production upon two elements-

1st. Relaxation and inertia of the uterine walls;

2d. Downward traction or pressure.

The first of these may be a primary and original state, or it may be induced by the second after months of exhausting action. For example, after labor the uterine walls may remain lax and atonic from inherent inertia; or their tissue in the non-pregnant state may be firm and resisting, yet in time be overcome by the traction and dilatation exerted by a large fibrous polypus attached to the fundus.

In the limited space which I can allot to this subject it is impossible to present the various theories which have been advanced for the explanation of the mechanism of inversion; nor would it be beneficial for the student that I should do so. In place of such an eflort I shall mention those which appear to me to possess a really important and practical bearing upon the subject.

The three views to which I shall direct attention are the following:-

1.t. That some part of the relaxed body prolapses, and passing out of the cervix drags the entire uterine borly with it.

21. That some part of the relaxed body prolapsing, acts as an exeitant of uterine contraction which forces the remaining portion through the cervix, and thus inverts the whole organ.

31. That lateral traction and direct pressure on a cervix the tissue of which is abnormally soft, causes eversion of this part and gradually of the whole uterus. 
The first of these is the oldest and even at present the most genorally received view as to the mechanism of inversion. According to it, it was generally supposed that the part of the fundus which first underenes inversion is the middle. This is denied by Oldhan and Kiwisch, who maintain that one horn first inverts itself and is followed by the fimdus, the other horn, and then the entire body. I have net with one case which proves incontestably that, even if this be not a rule, inversion at least occurs in this manner sometimes. A patient who for seceral years had suffered from menorrhagia applied to Prof. C. A. Budd, of this eity, for treatment. Upon examination he discovered what he supposed to be a fibrous polypus equal in size to a hen's egg attached to the uterine cavity near the entrance of the right Fallopian tube. Carefully differentiating this, as he supposed, from partial inversion, he applied the ecrasenr and removerl it, when he diseovered that he had removed one horn of the uterus with a part of the corresponding Fallopian tube and round ligament. 'The case, which was one of partial inversion, was not susceptible of diagnosis. The menorrhagia attending it was entirely relieved by the operation, the patient rapidly recovering.

When the accident begins in this way, the inverted horn pulls down the other parts, with greater or less rapidity, and thus the method of occurrence may be lost sight of: Rokitansky, in speaking of irregular postpartum uterine contraction, thus describes partial inversion, with which he has twice met: "We must here mention a very singular circumstance which may, on account of the consequent danger, become important, and may even be misunderstood in post-mortem examinations; it is paralysis of the placental portion of the uterus occurring at the same time that the surrounding parts go through the ordinary processes of reduction. It induces a very peculiar appearance. The part which gave attachment to the placenta is forced into the cavity of the uterus by the contraction of the surroumding tissue, so as to project in the shape of a conical tumor, and a slight indentation is noticed at the corresponding point of the external uterine surface. The close resemblance of the paralyzed segment of the uterus to a fibrous polypus may easily induce a mistake in the diagiosis, and nothing but a minute examination of the tissue can solve the question. The affection always causes hemorrhage, which lasts for several weeks after childbirth, and proves fatal by the consequert exhaustion."

Since the days of Astruc, the theory has been at various times maintained that active contraction of the uterus sometimes produces inversion. "Sometimes," says Astruc. "it is produced from contraction of the womb, which forces the bottom inside out, through the mouth of the womb, which is not yet closed." Regular uterine contraction, however violent it may be, would only tend to complete closure of the uterine cavity. If, however, such a partial inversion or internal projection as that alluded to by Rokitansky, in the quotation recently made, occur, it acts as the placenta, 
the hand of the obstetrician, or any other body in the cavity, by exciting expulsive efforts which may succeed in driving it out of the os externum. Should they do so, complete inversion is the result; should they fail, the projection may persist as a partial inversion. This view, which was advocated by the late Dr. Tyler Smith, appears to me to explain the apparent paradox of inversion with tonic contractions of the uterus more satisfactorily than any other which has been advanced. I have met with one case occurring after delivery, which convinces me, that sometimes, at least, what $I$ have just described really takes place.

Still another and very ingenious theory has been advanced by Prof. I. E. Taylor for explaining the occurrence of inversion. It is that inversion sometimes begins at the cervix, this part undergoing eversion as in prolapsus, and this going on to the complete inversion of the entire organ.

In previous literature, allusions to the possibility of inversion after this method may be found. Klob alludes to it in these words: "A very remarkable cliss of cases of inversion are those in which, without efficient cause, an inversion of the cervix into the vagina takes place, drawing the fornix of the latter with it, and thus forming a polypus-like tumor in the cavity of the ragina, which may reach down to the vulva, at the lower part of which the internal orifice is situated." A very striking case was publisleed by Mr. William Lawrence in the London Medical Gazette, Dec. 5, 1838, under the hear of "Spontaneous Partial Inversion of the Uterus." But the credit of having drawn proper attention to the subject and having proclaimed its probable pathological bearings, unquestionably belongs to Taylor. I say "probable," for the reason that it is not yet proved. I accept it, because my own observation leads me to believe that Dr. Taylor's deductions are probably correct.

Predisposing Canses._Every influence which destroys the tone and resistance of the uterine parenchyma proves a predisposing cause of this condition. As examples, may be inentioned-

Parturition;

Distention of uterus by retained fluids ;

Distention of uterus by tumors;

Spongy softening of tissue in prolapsus (?).

Exciting Couses. $-\Lambda$ uterus in which the tone of the walls has been destroyed by physiological, pathological, or mechanical causes has lost all its normal safeguards against inversion. Thus, we may say, that anything which produces distention and relaxation of the tissue of the uterus prepares the way for inversion so completely that a very trifling exciting cause may produce it. For example, any decided traction or pressure exerted upon the fundus of a uterus thus affected, even to a limited degree, may directly result in it. The exciting causes are thus presented:- 
Traction on placenta ;

Traction by polypi or tumors;

Sudden delivery of child by traction;

Muscular eflorts when relaxation exists;

Prolapsus uteri(?).

Instanees of its production by all these causes are on record, though by far the greatest number of eases has followed parturition. Of 400 eases collected by Dr. Crosse, of Norwich, Eugland, 350 followed delivery, and of the remaining 50, forty were due to polypi. This disproportionate frequency does not, however, invalidate the fact that the other causes mentioned have resulted and may result in the accident. Most frequently it oceurs very soon after delivery, though Ané and Baudelocque report its having taken place on the third, and Leblanc on the tenth day.

Traction and relaxation, when combined, are evidently sufficient for the induction of the accident, and it is generally to a union of the two that it is due. The question now arises whether either of them alone can calse it. With reference to the efficiency of the second element, the answer may be aflirmative, since, with complete relaxation, inversion may occur from a very insignificant exciting cause, as coughing, sneezing, or a change of posture. As to the possibility of any amount of force inverting the non-pregnant and undilated uterus, much doubt has been expressed. At first thought, every one will feel inclined to express a decidedly negative opinion, bat the evidence on record in faror of such a possibility is too strong to be entirely ignored. A portion of it is therefore laid before the reader.

Puzos, ${ }^{1}$ in 1744 , read before the Academy of Medicine of Paris a memoir in whicls he declared that lie latd seen the accident in women who had never borne clildren. Boyer ${ }^{2}$ cites a similar example in a female whose uterus contained no foreign body, and Daillez $z^{3}$ tells us that Baudolocque met with a case in a girl fifteen years of age, in whom clandestine delivery could not have occurred, since a perfect hymen existed.

Prof: Willard Parker, of New York, furnishes me with the listory of the following case. A young woman who had borne one child, seven or eicht years previonsly, and had never had any recognized uterine disease, while making a violent effort in rolling tenpins, suddenly felt sometling give way within her, after which she suffered the most intense pain and became completely disabler. Dr. Parker being called to see lier, after a hasty examination coincided with the opinion of the attending plysician, that a polypus had been suddenly expelled and was hanging in the vagina. Impressed with this belief he renoved the whole mass, when, to his surprise, he found that he heid in liis hands the inverted uterus with its tubes

1 Colombat on Females. Meigs, p. 182.

$\&$ Traité des Mal. Chirurgicales.

3 Colombat, op. cit. 
and ligaments. The patient recovered without any bad symptoms, and subsequently menstruated regularly.

Menstruation, after amputation of the uterus, is by no means rare. It must he remembered that in such an operation the whole uterus is not removel. It is from the remaining stump that the flow occurs.

It is certainly diflicult to admit the occurrence of inversion beginning in the body of an undilated uterus. It may be that in these cases some distemling influenee which escaped observation preceded the accident. The suggestion of Colombat is certainly very plausible, that hydrometra, physometra, or retention of the menses must, in such cases, have produced dilatation, which, being followed by pressure just after the escape of the contained air or fluid, gave rise to the displacement. It may be that inversion begins in such cases at the cervix and becomes complete in the method suggested by Taylor.

After all, there is nothing more astounding in the fact of spontaneous inversion of an undistended uterus than there is in the spontaneous reposition of one which has been long inverted, and this we lave, with the positive testimony of scientific and reliable men now on record, no possible justification for doubting. Of late the validity of both these phenomena has been denied. There is nothing easier than the rejection of the testimony of others, and the discrediting of deductions which we onrselves have not drawn. When De La Bare presented his ease of spontancons reposition to the Academy of Surgery, Baudelocque was appointed a committes to examine into it, and reported that it was " totally false." Some years afterwards he met with a very similar case, and yielded to the evidence of his own senses a credence which he had presumptuously denied to the assertions of another.

Symptoms._Should inversion occur suddenly, as for instance after delivery. the patient will complain of discomfort ahout the vulva, faintmess and nervons disturbance. Hemorrhage and tendency to collapse will show themselves, and unless proper treatment be adopted at an early perion, death may ensue. A physieal examination will at once settle the diagnosis, for a large, flabby, grobular mass, perhaps with the placenta attached to it, will be foumd between the thighs of the gatient if inversion be complete. But very often no diagnosis will have been made at the time of its weenrence, and months, perhaps years, afterwarls, the physician will he called mon to determine the charaeter of the case, which will probably present the following symptoms:-

Occasional or constant hemorrhatge ;

Dragging fains in back and loins;

Difficulty in locomotion;

Difficuly in defecation and micturition;

Anamiat and its accompanying evils. 
Physical Signs.-All these symptoms belong as much to polypus, fibrous tumor, and cancer, as to inversion, and to determine their true cause, physical exploration is indispensable. Slould the inversion be complete, the finger being introdueed into the vagina will meet with a tumor which the examiner will at onee know is either the displaced horly of the uterus or a polypus, and his attention will be directed to their diflorentiation.

IF IT BE A POLY'P'S.

The probe will usually pass by its sicle into the uterus;

Conjoined manipulation will reveal the uterine body.

Rectal examination will reveal the uterus in siluि;

Recto-vesical exploration will reveal the uterus;

Acupuncture will give no pain.
IF IT BE INVTRSIOS.

The probe will le arresterl at the neck ;

Conjoined manipulation will reveal a ring where the uterus should he;

Rectal examination will not reveal the uterus in sitú;

Recto-vesical exploration will not reveal the uterus;

Acupuncture will give pain.

In certain very rare cases, a large fibrous tumor growing from one lip of the cervix, will lead to the belief in inversion in the following manner: the pediele setting up inflammation in the cervical canal, complete alhesion takes place, so that a probe can nowhere be passed. An examination

FIt. 200.

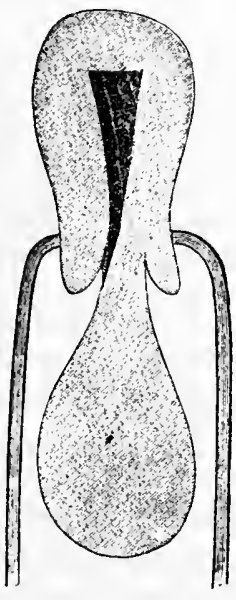

Polypur.
Fig. 201.

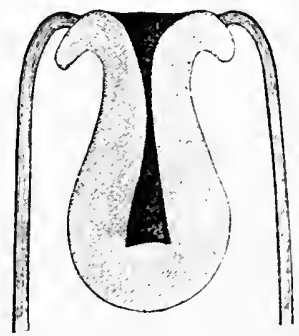

lnversion.

of Fig. 200 will readily explain how such a state of things miglt arise and prove excecdingly perplexing. I have seen two such cases, one with Dr. Byrne, of Brooklyn, and another with Dr. Ross at my clinique, in both of which recognition of the presence of the uterine body above, emboldened

1 Gueniot, Arch. Gén. de Méd., 1868, t. ii. p. 393. 
me to work the probe through the tissue around the pedicle of the growth, eausing it to enter the uterus, and thus prove ineontestably the nature of the ease.

Should the inversion be incomplete, diagnosis will always prove difficult, and in fat women particularly so. Differentiation from a fibrous tumor will depend upon the following signs :-

IF IT BE A FIBROID GIROTTI.

The probe will show increase of uterine carity ;

Conjoined manipulation and Simon's method will reveal rotund body of nterus;

It will have come on very gradually ;

It will have no reference to parturition; Acupuncture is painless.
IF IT BE PARTIAT INVERSION.

The probe will show diminution of uterine cavity ;

Conjoined manipulation and Simon's method will reveal small abdominal ring; It will have occurred more suddenly; It usually follows parturition; Acupuncture gives pain.

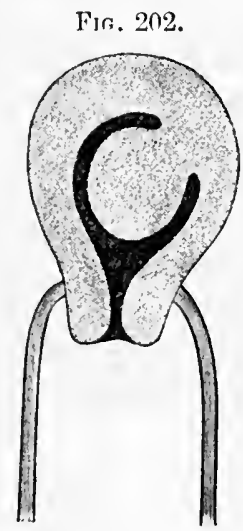

Fibrous polypus.
F1G. 203.

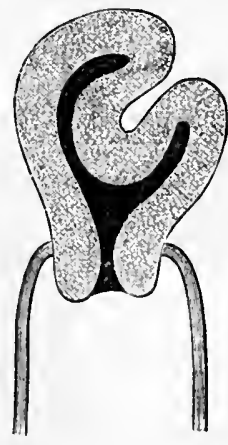

Partial inversion.

Course, Duration, and T'ermination.-All these are very variable. The accident occurring after delivery may rajidly, unless relieved, produce deatlı by hemorrhage and exlıaustion; or it may continue for many years, giving very little annoyance; or, again, it may render the life of the patient miserable on accomnt of hemorrhage and other attending symptoms, and nevertleless last for years. As a rule, it may be stated that inversion continues until relieved by treatment, and yet even this is not without exceptions. The womb has been known under these circumstances to replace itself by its own contractions, years after its occurrence, when the accident has happened after delivery. Twelve such eases have now been placed upon record: three by Meigs, and one by each of the following observers: Spiegelberg, ${ }^{2}$ Leroux, ${ }^{2}$ De la Barre, ${ }^{2}$ 'Thatelıer, ${ }^{2}$ Rendu, ${ }^{2}$ Shaw, ${ }^{2}$

1 Olstetrics.

2 Articl" by Prof. Spiegelberg, "Archiv für Gynäkologie," Am. Journ. Obstet., Aug. 1873 . 
Beaudelocque, ${ }^{1}$ Foujen, ${ }^{2}$ and IIuekins. ${ }^{3}$ Even almitting the undoulted antlienticity of these cases, spontaneous reduetion must be regarded only as a curiosity, and not as a process to be anticipaterl.

Prognosis.-The prognosis of chronic inversion is at all times grave. Repeated and prolonged hemorrhages prostrate the paticnt, and expose lier to all the risks of the worst forms of uterine polypus. But not only is she exposed to dangers inherent to the displacement from which she suffers; those attendant upon an erroneous diagnosis are very great. To one alive to the possibility of confounding the condition with fibrous polypus, the methods of differentiation are numerous and reliable; but to the rapid and careless diagnostician, who does not allow the possibility of error to enter his mind, and consequently does not carefully weigh the evidence, there is a great likelihood of it.

One who is aware of the great frequency with which amputation of the inverted uterus has been practised, under the impression that a fibrous polypus was being removed, cannot but wonder that errors of diagnosis have so often occurred, when so many methods of differentiation were at command. The explanation is that to whieh I lave referred, namely, that the possibility of error was not entertained. Out of fifty-eight cases of inversion of which a report is given in the "Beitrage zur Geburtskunde und Gynäkologie," and in which amputation was practised, seven were mistaken for polypi.

I have treated personally nine cases of inversion, of which six resulted from parturition and three from traction by sessile polypi. Of these, seven were cured by replacement; one, in the case of a very old and feeble woman, was left unreplaced, after removal of a sessile fibroid, which gave complete relief; and one case after replacement ended fatally from peritonitis.

Even where a correct diagnosis has been made, still another danger menaces the patient: that of rupture of the vagina in attempts at reduction of the inverted organ. A small hand, a cautious, unexcitable mind, and constant vigilance during all the efforts by taxis, must be combined with thorough knowledge of the subject, to aroid this imminent danger. Even with this eombination, it is a matter of surprise to me, from my experience with these cases, that the aceident has not occurred much oftener. I confess that I should prefer to trust a patient in whom I felt great interest to the operation of abdominal section, which is hereafter described, than to that of prolonged taxis at the hands of a rough, unintelligent, and inexperienced practitioner. To one thinking upon this subject for the first time, this position will appear exaggerated and indefensible; but $I$ assume it after mature reflection.

I Daillez, Thesis.

2 Weiss, Des Réductions de l'Inversion, etc.

3 Letter to author from Dr. Jason Huckins, of Maine, U. S. 
When the prospect of returning the uterus seems brigltest, the practitioner is sometimes disappointed by the existence of adhesions. Thus Velpeau, ${ }^{1}$ after the removal of a polypus attached to an inverted uterus, was completely foiled in restoring it, and the patient died from peritonitis.

Treatment.-.In the treatment of inversion, three methods may be adopted.

1st. The organ may be left in malposition; hemorrhage being controlled by hemostatic means.

$2 \mathrm{~d}$. The inversion may be reduced by taxis, by elastic raginal pressure, or by a combination of the two.

$3 \mathrm{~d}$. All these failing to give relief, the uterus may be amputated.

Methods of Checking Hemorrhage, the Uterus being left in sitû.Should the operator fail in repeated attempts at reduction, it becomes a question whether he should amputate the displaced organ or leave it in its abnormal position and endeavor to combat the evils resulting. The greatest of these is unquestionably hemorrhage, which steadily exhausts the patient; but others of less moment arise from dragging of the uterus upon its ligaments and the mechanical inconvenience of a tumor in the vagina. If the patient be near the menopause, both of these may diminish by atrophy and cessation of menstruation. Should she be young, artificial means may, in a limited degree, aceomplish the same results.

The most vascular growths, sueh, for example, as hemorrhoids and nævi, may be diminished in size and rendered non-hemorrhagic by astringents or eaustics, which destroy their superficial varieose vessels and leave a less vascular tissue beneath. The inverted uterus may be similarly acted upon, not only in ehecking hemorrhage, but in producing atrophy, and thus removing, to a certain extent, the two sources of suffering.

Solutions of alum, tannin, persulphate of iron, or acetate of lead may with advantage be injected into the vagina so as to bathe the uterus freely, or they may be placed in contact with it by means of pledgets of cotton. Slould these fail in checking the flow, a plan, proposed by Aran, of applying eaustics to the whole bleeding surface, may be resorted to. The tumor being drawn down and exposed to view as much as possible, its surface is seared by the actual cantery or touched by potassa cum ealce or the mineral acids. The organ, after being bathed in a neutralizing fluid, is then enveloped in lint, so as to protect the vaginal walls, and placed within the pelvis. I have never seen the method employed, but would not hesitate in an appropriate case to venture upon it. Aran declares that not only is hemorrhage eliecked by it but great diminution of the tumor effected. The procedure recommends itself as eminently rational, and when it is remenbered that the only recognized alternative is amputation, the propriety of giving it consileration must be admitted.

1 Becquerel, op. cit., p. 306. 
Many cases are on record in which the nterine nucous mombrane hats become altered so as to resemble skin, and in which the pationts laaw lived without suffering for many years. Dr. Alexander H. Stevens had one case under observation for more than thirty yoars. Dr. Charles $A$. Lee diagnosticated one which had remained mudetected for twenty-five years; and the works of older writers ofler many other examples. If we can bring about a similar condition by artiticial means and avoid the operation of ablation, we will certainly be acting in the best interests of the patient. It is for this purpose that cautrization offers itself as a resonrce.

Methods of Replacin! the Uterus.-It is not certainly known whether the condition of inversion of the uterus was properly understood before the time of Ambrose P'aré. Since his eproch it has been fully deseribed by his successors, and all its pathological teatures, its various symptoms, and its manifold langers, have been thoroughly appreciated. From the time of P'aré, who lived abont the middle of the seventeenth century, to our own, atthough great advances were made in the scientific department of the subject, very little was attained in the way of treatment. The possibility of replacing by taxis a uterus recently inverted was known, but for cases in which the organ had been displaced for years, or even for months, no resource existed except amputation.

It is certainly one of the many triumplis of which the gynecology of the nineteenth century ean boast, that this accident has been proved to be amenable to conservative measures, and that taxis has been shown to be capable of effecting a cure, and preventing a resort to a mutilating surgical procedure.

So fur as I have been able to ascertain, the first cases of chronic inversion which were successfully reduced by taxis are those mentioned by Colombat ${ }^{1}$ in the following passage: "Dr. Daillez reports in his dissertation that the surgeon, Labarre De Benzeville, had effected the reduction as late as the eighth month, and Baudelocque after eight years." In later times the first successful ease occurred in $1847 . .^{3}$ The inversion had lasted more than a year, when M. Valentin, by introducing one hand into the ragina, and making counter-pressure by the other over the abdomen, succeeded in reducing the displaced fundus in ten minutes. In 18.52, Mr. Canney ${ }^{3}$ in the same manner effected reduction in a case of five months' standing, and in the same year M. Barrier accomplished it in one which latd existed for fifteen months.

L $p$ to the year 1858 , the reposition of inverted uteri may be said to hare been limited to replacement, within short periods after pariurition. It is true that occasional cases had occurred in winch chronic inversion

1 Colombat, Am. ed., p. 186.

2 Daillez's Thesis appeared in 1803.

3 Quoted from Ranking's Abstract, vol. 7 , by G. Hewitt.

4 Conr'ty, Mai. de I'Utérus, p. 797. 
had been overcome hy taxis and pressure, but these held the position of accidental and anomalous feats in treatment, not that of systematic procedures, which it was incumbent upon the practitioner to essay in every case. At this period two eases of elronic inversion were reduced, one of twelve years' standing by Prof. Tyler Smith, of London, by elastic pressure and taxis; the other of almost six months' standing by Prof. James P. White, of Buffalo, U. S., by taxis alone. Each of these gentlemen worked without the knowledge of what the other was doing; and to them belongs the great eredit of having systematized, and made subservient to science and humanity, a method which before had been practised in a loose and desultory manner. Soon after their publications, eases of cure affected by taxis alone, or eombined with pressure by bags of air or water placed in the vagina, were rapilly reported from different parts of the world. Most notable among these were the eases of Noeggerath, of 13 years' standing; Teale, of $2 \frac{1}{2}$ years; West, of 1 year; White of 15 years; and Bockendalıl, of 6 years. When it is stated that all these occurred in 1859 , it will be fully appreciated how great an impetus was given to this subjeet by the suceesses of Smith and White. Within the past ten years cures lave multiplied so rapidly as to preclude the mention of individual eases in a work of the eharacter of this; and, although I cannot go so far as to endorse the sanguine predietion of White, made in 1872 , that "well directed pressure upon the fundus, if continued long enougl, will, in all cases where there are no adhesions, result in restoration or reposition," I do believe that the day has passed when any practitioner would be held blameless by a jury of his peers, who has either left untouched, or amputated a uterus in the condition of chronic inversion without some speeial reason apart from the mere displacement itself:

The best methods at our command for replacing an inverted uterus I shall now proceed to describe, premising this description with the statement that I do not propose to mention all methods which have been adopted, but only those whieh are most worthy of reliance. They may thus be presented at a glance:-

Methods for effecting gradual reduction

Methods for effecting rapid reduction
Elastic pressure hy vaginal stem and eup or bulb;

Elastic pressure by vaginal water-bag combined with taxis;

Elastic pressure by vaginal water-bags alone;

A stream of cold water.

C Manipulation by Viardel's nethod;

\begin{tabular}{|c|c|c|}
\hline " & “ Einimet's & \\
\hline$\therefore$ & “ Baturier's & 6 \\
\hline 6. & “ Noeggerath's & \\
\hline 6 & "Courty's & \\
\hline “ & “" 'Thomas's & \\
\hline 6 & " White's & \\
\hline
\end{tabular}


None of these methods are free from danger; in several cases even elastic pressure las excited fatal peritonitis. But gradual reposition is certainly mueh safer than rapid reduetion.

Before the practice of any of them certain preparatory measures calculated to relax the ecrvical parenchyma, or render its resistance less de:cided, may be essayed. One of these is the use of bellatomna by the vagina in the form of vaginal injections of the infusion, of ointment smeared around the uterine neck, or of hypodermic injection; or by the rectum in form of suppository. 'The other is the making of two or three longitudinal incisions through the superficial layers of the parenchyma of the neck. 'Whis method is a very old one, dating back to Millot' in 1773. Since his time it has been repeatedly advised; for example, by Colombat, Gross, Sims, Barnes, and others. Of the benefit of the first of these methods there is little doubt; of that of the second there is none.

Gradual Reduction by Repositor.-This method dates back to Yon Siebold, ${ }^{2}$ who employed a curved stem surmounted by a fine'sponge, the

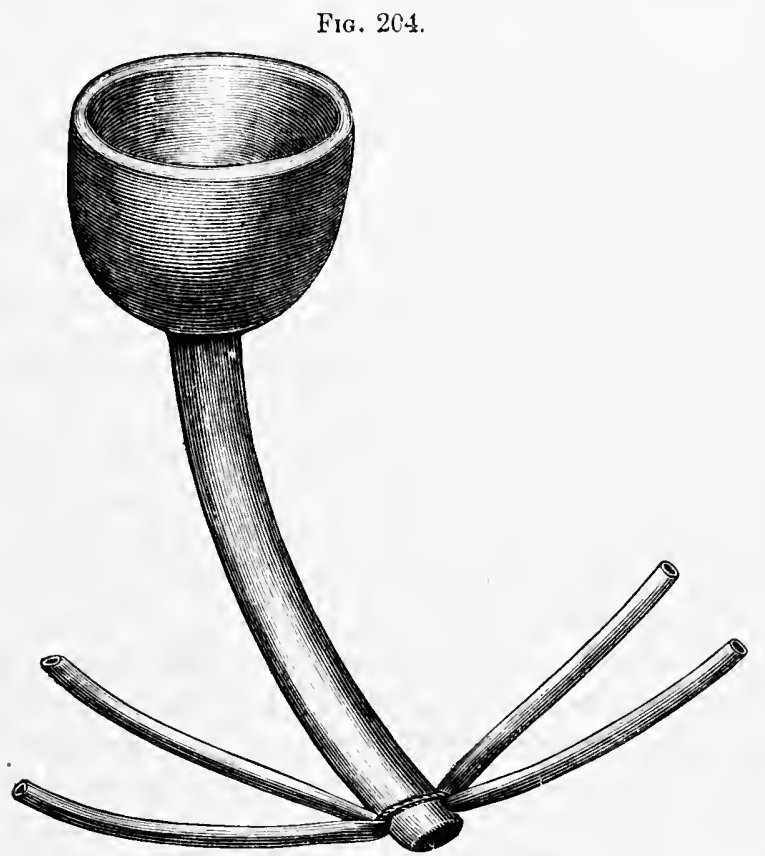

Cup and stem for making continuous pressure in replacing the inverted uterus.

stem being held in sitû by a T-bandage. After him it was repeatedly and successfully employed, and to-day it is coming again into favor, having been very recently recommended by Drs. ITicks and Barnes, of

1 Taylor, op, cit.

${ }^{2}$ Ch. F. Weiss, Paris, op. cit. 
London. The former employs a solid stethoseope, the large extremity covered by India-rubber; the latter, a hollow caoutchone cup, fixed to a curved stem. Both of these are supported by a $T$-bandage.

Before the eup is adjusted, a long compress, consisting of a bag of muslin stuffed loosely with cotton, should be placed across the hypogastrium, so as to extend from the anterior superior spinous process of one ilium to the other, and to lie just above the symplhysis pubis. This should be fixed in position by a band of adhesive plaster made to encircle the body entirely. The compress, being about eight inehes in eirenmference, forms a firm ridge across the pelvis, and furnishes counter-pressure against the retreating uterus. The bands represented as attaelied to the stem of the instrument may eonsist of India-rubber tubing or of Indiarubber elastic bands, by which gentle, steady, and gradually inereasing pressure may be kept up.

This constitutes one of the best, if not the very best, of all the means at our disposal for effecting gradual reduction of the inverted uterus. One point requires special attention; sometimes, when the vagina is abnor. mally voluminous, the uterus gets out of the line of pressure, it bends upon itself above the edges of the cup, and not only does the pressure exerted aceomplish no good-it absolutely does harm, and creates the danger of inflanmation of the tissue of the uterus. This should be prevented by tamponing around the cup, after it is adjusted, with earbolized cotton, as explained in connection with elastic pressure by the water-bag.

The force exerted by the elastic bands should not be great, for we should look for the desired result not to great but to gradual and steadily sustained pressure.

Elastic Pressure by Vaginal Water-bag.-The demonstration of the important fact, the most important, indeed, conneeted with this subjeet, that elastic pressure was capable of greatly aiding reposition of an inverted uterus, belongs to the late Dr. 'Tyler Smith. I say "greatly aiding," for le combined taxis with it. It was left for Bockendahl, of Germany, to prove that it could effect reduction unaided. Smith's plan eonsists in passing the hand into the ragina, night and morning, and kneading the uterus for ten minutes, and during all the intervening period keeping an air pessary in the canal. Bockendahl simply trusts to elastic pressure alone, thus making an important improvement upon Smith's plam.

The best method for employing elastic pressure I have found to be this: Pass a Sims' speculum and tampon around the uterus firmly with earbolized cotton soaked in glycerine, so as to keep it from slipping out of the line of pressure. Then introduce an India-rubber bag, and fill it with water. Cut a strip of adhesive plaster two and a half inches wide, and of suflicient length to extend from the lumbar region between the thighs of the patient and as high n, as the navel. Two holes should be cut in it, one for the tube of the rubber bag to pass through, the other to leave the 
urethra free. After the bag is introduced into the vaginat, this strip of plaster is heated and attached to the surface. The bag may afterwarls be rendered more tense by pumping in water, or the amount of its contrnts may be diminished by turning the stopeock, which prevents its escape. While the method is in operation, the patient should be kept in bed, and all pain quieted by the use of opinm. The bladder shoukl be emptied by the eatheter, and the bowels, previously thoronghly evacuated, be kept constipated.

A Streum of Cold I'ater.-This method has not been sufficiently tested to command confidence, but it is worthy of mention an:l consideration. Dr. Charles Martin, ${ }^{1}$ of France, sueceeded in effecting relluction in a case which proved rebellious to other means by this, which he tried in the following manner: he introduced the speculum around the inverted uterus twice a day and threw upon the fundus, with force, by means of a syringe, a strean of cold water. Then filling the speculum with cold water, he kept the uterus immersed for three or four minutes. My impression is that, simple as this method is, we shall hear of it again.

There is no limit to the time during which efforts at gradual reduction may be persevered in. Such a limit is established solely by the patient's tolerance of the method tried. A case is mentioned in this chapter in which elastie pressure was kept up for eighteen days with successful result. Sometimes, however, the patient cannot tolerate elastic pressure, or that by a repositor, for symptoms of peritonitis result from their use. Then it is that anæsthesia and rapid reduction offer themselves as valuable resources.

Rapid Reduction by the Old Methods of Taxis.-Taxis has been practised for the reduction of chronic inversion certainly since the beginning of this century, and perhaps before that time, in two entirely distinet methods. First, the manipulations of the operator are directed to the constricting cervix, in order to overcome resistance there, and to return first the parts which last escaped. Second, these manipulations are directed to the body, in order to return first the parts which escaped first. The first of these methods is thus described by Capuron :" "If the orifice be not suffieiently dilated to allow the inverted portion to return easily, it is a better plan to take the tumor in the palm of the hand, with the fingers distributed around it pedicle, and to reduce first the portion which was inverted last, as if we were dealing with a hernia." "We encounter at this point," says Aran, "two opinions which have arisen in relation to the reduction of the uterus inverted during labor; one party desiring to return first the parts which escaped last, subjecting the uterus to a general compression, so as to soften it to a certain extent and force it to pass the orifice

1 Gaz. des Hôp., 1853.

2 Mal. des Femmes, 2d ed., p. 510.

3 Mal. de l'Ltérus, p. 901. 
little by little, commencing with the least voluminous parts.

Arrived at the tumor, if the operator wishes to employ the first method, he kneads it so as to soften it, and cause it to pass more easily through the constricted orifice in which he engages his fingers." Becquerel ${ }^{1}$ describes it thus: "It is adrisable, as far as practicable, to return first the parts which last escaped; for in this way we dilate in advance the muscular fibres which oppose reduction. (P. Dubois Danyau.) . . . . II. Velpeau considers this the best method."

The second method of taxis consists, not in manipulating the "constricted orifice in which he engages his fingers," so as to "dilate in advance the muscular fibres which oppose reduction," as Aran and Becquerel express it; but in dimpling or indenting the fundus itself, so as to make of the indented or invaginated portion a species of wedge, which is forced into the cervical constriction. In recent cases of inversion, occurring, as the vast majority of these cases do, after labor, 350 ont of 400 reported by Crosse having done so, the centre of the fundus may be indented and carried up through the cervical canal; and even in chronic eases such an inragination has been attempted. My impression is that the manipulations practised on the fundus in chronic cases act not in this way, but in overcoming cervical resistance, and thus accomplishing in a more indirect and imperfect way what the French method, styled the method of Viardel by Becquerel, does by engagement of the fingers within, and direct expransion of, the cervical constriction. It is scarcely applicable to other than recent cases.

The diagnosis liaving been clearly made and reduction determined upon, the bowels and bladker should be emptied, and the patient put under the influence of an anxsthetic, and laid on her back upon a strong table. The operator should always be attended by three or four reliable counsellors, upon whom he may call not only for adrice but physical aid. As the late Prof. Elliot has pointed out, the strength of one man will often fail to accomplish what that of several, replacing each other in rapid succession, will readily effect. Having thoroughly oiled one hand, the nails of which lave been pared, the operator should slowly dilate the vagina so as to introrluce it, and grasp in its fralm the entire tumor. The other hand should be laid upon the abdomen so as to press just over the ring which marks the non-inverted cervix, and oppose the force exerted through the vagina, so as to prevent too great stretching of this canal.

In a case of four years' standing, which I attended with Dr. Joseph Worster, of this eity, and which had been subjected to eight attempts previous to my seeing it, each varying in duration from two to three hours, I sliggested substituting for the hand a cone of boxwood four inches long. The patient being very thin, this could readily be inserted into the 
ablominal ring of the uterus, and it was gradually forced lown into the inverted fundus for such a distance as to dilate the cervix and allow reposition. Since the experience gained in that case I have always rmployed this abdominal phug for comter-pressure, except in fat women, and this course has likewise been adopted by Ihyrne and others.

In attempting reduction by the hand in the vagina elasping the inverted uterus, the operator should not arlhere too bong to one plan of manipulation, but try one after the other the methods of manipulation which will now be mentioned.

Eimmet's Method.-This consists in giving to the finger encircling the cervix a decided motion of extension, while connter-pressure is actively kept up by the fingers over the abdominal ring so as to expand this by the conjoined action of the two hands. I had supposed this method to be identical with that of 'Viardel, but its proposer declares it to be different from it in many essential respeets, and speaks highly of its merits. A full exposition of it will be found in his work upon "The Principles and Practice of Gynecology."

Barrier's Method consists in spreading the four fingers around the uterus, pressing the thumb against the fundus, and forcing the neek against the curve of the sacrum as a point of resistance.

Noeggerath's Method consists in placing the index finger upon one horn of the uterus, the thumb upon the other, and so compressing as to invert one or both cormal. Before seinversion of the neck it should not be tried. For redueing the body after the neck has yielded it is a most valuable plan. I have succeeded by it in three out of five cases which I have treated.

Courty's Method consists in passing the index and middle finger up the rectum, dipping them into the cervical ring, and thus gaining a point of resistance. It is one of the best at our command, and may be combined with Noegreath's method, one being directed to reduction of the neck, the other to that of the body.

Thomas's Method consists in abdominal section over the cervical ring, dilatation with a steel instrument, made like a glove-stretcher, and reposition of the inverted uterus by any one of the methods mentioned, by the hand in the vagina. Fig. 205 will render this clear.

This procelure, let it be remembered, is not offered as a method of treating inversion of the uterus, but as a substitute for amplntation. Few cases will, I think, resist elastic pressure and judicious taxis; but that some will do so camnot be questioned. It is to save these few cases from amputation that I suggest abdominal section.

One of the cases operated on in this way has proved fatal. Let it not be forgotten that a certain number of those cases treated by elastic pressure and by taxis likewise do so, for, as in my second case, these operations are often performed upon exsanguinated women whose blood is impore- 
rished. One instance of death after reduction by elastic pressure is recorded by Dr. Tait in the eleventh volume of the London Obstetrical 'Transactions, while one of the earliest cases on record reduced by taxis, that of Dr. White, of Buffalo, likewise ended fatally.

FIG. 205

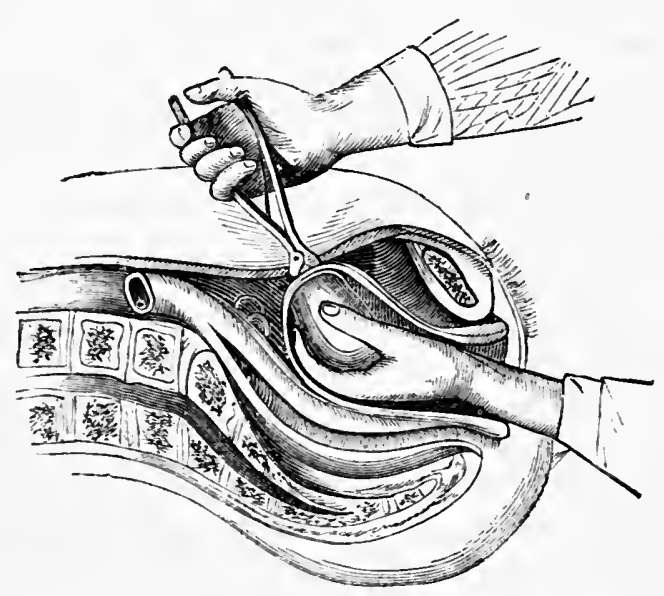

Replacement of uterus by dilatation throngh abdomen.

If a case shonld prove rebellious to taxis repeatedly and intelligently applied, and to prolonged and powerful elastic pressure, what is to be done? Only two courses lave been open to us; one to leave the case unrelieved, the other to perform amputation. In an elaborate report of cases of inversion given in the Amcrican Journal of Obstetrics for August, 1868, the results in fifty-eight cases of amputation are given. By this statement it will be seen that nearly one-third of all operated upon died, and let it not be forgotten that this number died, not in being eured, not in an effort, even, at attuining perfect health, but in an attempt at purehasing immunity from a series of dangerous and annoying symptoms at the price of that organ of which IIippocrates says, "Propter uterum est mulier."

It is ineumbent on me to state that this method has not received the endorsenent of the profession. Appreciating this I should have omitted it entirely from enumeration here, did I not feel that in the future it will receive more favorable consideration and prove of real value.

The use of a reprositor by which to make direet pressure and aid in reduction has been resorted to by Depaul and others. P'rof. J. P. White hat successfully employed one which by its simplieity and eflicacy makes it wortly of especial mention. Fig. 206 shows this instrument, and, likewise, makes evident the method of reduetion whieh the experience of nine cabes extending over a period of fifteen years has led him to adopt. 
Excellent repositors lave likewise bern invented by $A$ whing and Byrne. 'The latter of these is constructed upon the best mechanieal principle whech las ever been applied to this process, consisting of a cup which is mate shallower and less capacions by the action of a serew at its lower extremity, as the inverted uterus gradually returns to its place. I have employed it with perfect suecess in one case, and esteem it very highly.

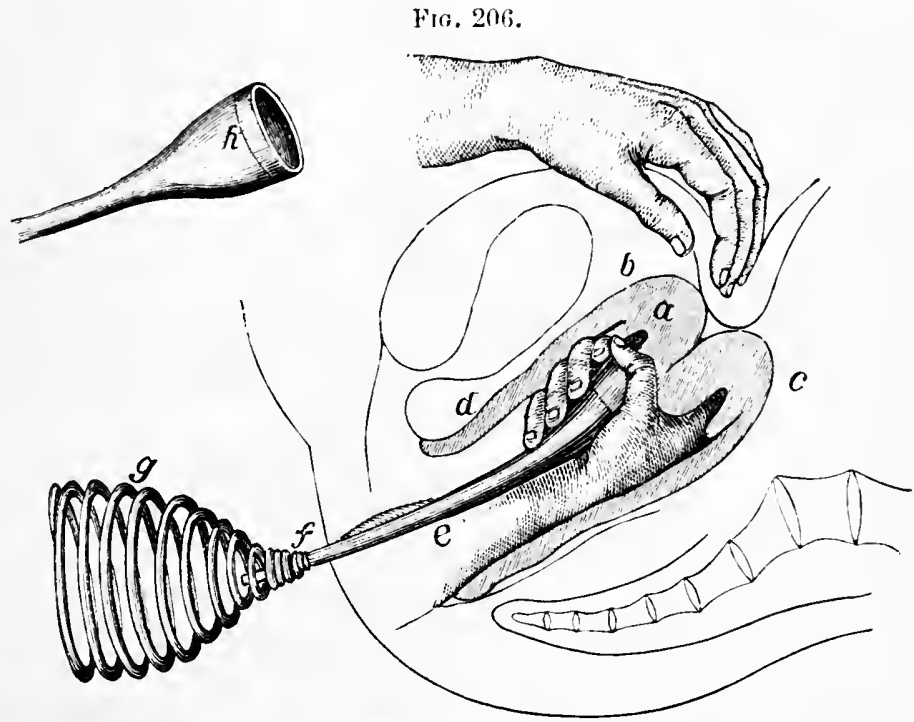

Rapid reduction by White's method. Operator grasps uterus, $a$, and presses his chest agaiust spiral spriug, $g, f$, which forces cup of repositor agaiust fundus.

It is impossible to set an absolute limit to the time which should be allotted to one attempt at immediate reduction, but these efforts cannot be persisted in much longer than one or two hours without great danger of cellulitis or peritonitis. It is true that numbers of successful cases are on record in which from three to five hours have been spent in continuous exertion before suecess was accomplished, and in which no unfarorable symptoms late arisen; but a safer and more judicious course would be to desist after a reasonable effort, secure what has been gained by placing a caotutehoue bag in the vagina, or closing the os uteri by silver sutures as practised by Emmet, after the method shown in Fig. 207, administer a large dose of opium, and make another attempt in thirty-six or forty-eight hours. Manipulation should then be cautiously repeated for about the same period, and again, in ease of failure, followed by the air bag, or elosire by suture.

Methods of Amputating.-Although it cannot be denied that instances may present themselves in which, from impossibility of returning the inverted uterus, removal of the whole organ is indicated, it is equally 
undeniable that the operation has been resorted to very often upon insuffcient grounds and betore eflorts at reduction had been fairly tried. Tyler Smith succeeded after persevering with elastic pressure for eiglit days,

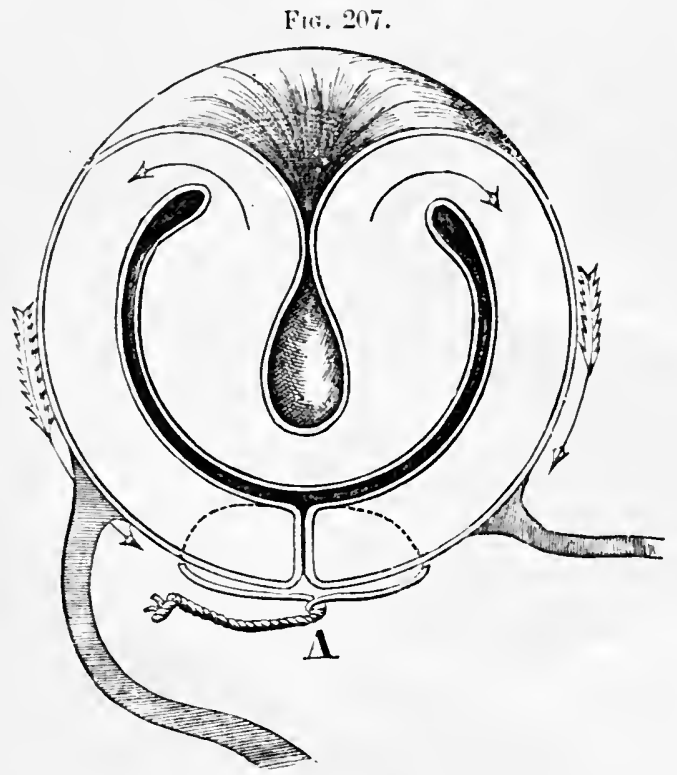

Partially restored uterus sustained by closnre of os externum (Emmet.)

and Dr. F. A. Ramsay, ${ }^{1}$ of Knoxville, Tennessee, after seventeen or eighteen days of effort. Does any one doubt that in the hands of many less persevering practitioners both these cases would have been treated by amputation before success was attained? Amputation of the inverted uterus will surely he less frequently performed in the future than it has been in the past. It is destined to assume among operative procelures its proper place as a last resort. In addition to its own manifest and inherent langers it must ever present these great oljections:-

1st. Hernia of the abdominal or pelvic viscera may have taken place into the inverted sae;

21. It frequently produces emansio-mensium and its train of evils;

8il. It necessarily results in sterility.

It is impossible to conceive of eireumstances which would justify the procedure before full consultation with the most able counsel attainable.

Removal of the uterus, although attended by great danger, often ends in reeovery. This will not be wondered at when it is borne in mind that even tearing away of the organ has been several times recovered from. Riadford, J. C. Clarke, ${ }^{2}$ and others have reported eases in which an in- 
verted utems has slonghed off from strangulation withent a fatal issure, and Osiander for many years showed a patient in his lecture-room from whom, atter delivery, the millwife tore away not only the placenta but the inverted uterus to which it was attacherl. A case of similar kind is recorderl in the (iazette des Iloppitanx for 18.2. One chilal being born, the miclwite felt the breech of another as she supposed. Aromed it she parsed a handkerehiet, pulled with all her force, and dragged away uterus and anmexar. The patient recovereal!

A comprehensive view of the results of amputation is presented by Dr. irest in the following table:-

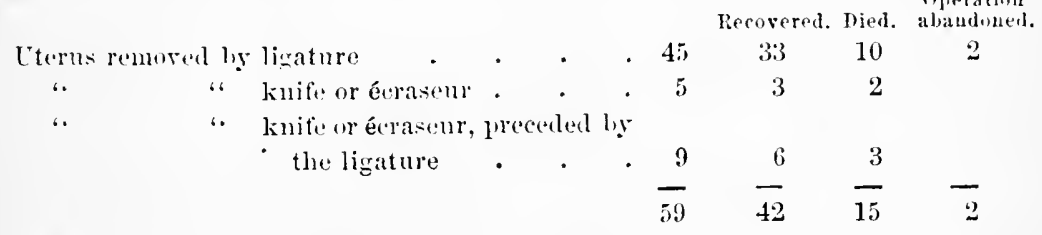

Out of 58 cases of amputation collected in the report in the German journal recently alluded to, 18 were fatal-nearly one-third.

Should it be deemed advisable to resort to this procedure in spite of the dangers incident to it, there are four methods by which it may be performed : the knife or scissors preceded by the ligature; the écraseur, preceded by the ligature; the elastic ligature; and the galvano-cautery.

Experience proves that removal of an inverted uterus by the knife, or even the écraseur, is likely to be followed by profuse and dangerous hemorrlage. To aroid this, a method advised by Dr. MeClintock, of Dublin, may be adopted. It consists in the application of a strong ligature for from two to three days before the operation. This obliterates the ressels, and, just about the time that decomposition of the strangulated organ begins, amputation is practised. Fven should the galvano-cautery be resorted to, so great is the danger of immediate and remote hemorrhage, that it is advisable to precede its use by that of the ligature for a few days. Courty strongly recommends ligature of the neck of the inverted organ by a rubber ligature, which he tightens on the second day as much as possible. The uterus is amputated by this on the twelfth or fourteenth day. During the use of all these methorls pain and nervous disturbance shonld be quieted by the hypodermic use of morphia, and septicamia obviated by antiseptic vaginal injections.

Hegar and Kaltenbach ${ }^{\mathrm{I}}$ recommend the following plan for amputation. Sutures of metal or silk are passed througln the cervix, high up, and tiglitly drawn so as to constrict all vessels, and completely close the peritoneal cavity. Then, by any means which the operator may select, the body of 
the uterus is amputated. By this procedure hemorrhage is kept under control, and the parts are so arranged as to favor subsequent unjon.

Removal of the uterus by ligature alone should never be attempted. Not only have we better and safer means; statistics prove this to be an especially dangerous method. Out of 33 cases thus operated upon, 17, over laalf, ended fatally.

Resumé of Plans of 'Treatment.-Let us suppose that a case of chronic inversion alplies for treatment to a general practitioner, what are the methods by which he could most easily and safely test the question of his ability to overcome the difficulty without resorting to the aid of a specialist? I wonld advise the following course as having these advantages-it is often equal to the accomplishment of replacement; even when it does not prove so, it is safe; and it does not ordinarily alienate the co-operation of the latient, as an injudicious course may very readily do by the discomfort which it induces.

1st. The bowels should be thoroughly evacuated by a course of mild cathartics; vaginal irritation and engorgement be relieved by copious hot vaginal injections; and uterine congestion, which always exists, be overcome by rest.

2d. Pressure by the cup and stem should then be fully tried for a fortnight, hot vaginal injections and inunetion of the cervix with belladonna being employed at the same time.

3d. Elastic pressure by vaginal water-bags should then be tried, the uterus being kept in the line of pressure by means of a tampon of antiseptic cotton saturated with glycerine.

4th. Should this not produce good results in a week, and no untoward symptoms lave developed, taxis slould be tried for a short tine once or twice a day.

5th. Should success not now erown his efforts, the practitioner might try the use of a stream of cold water projected against the inverted fundus, or this might be combined with elastic pressure, taxis, and the other means just mentioned.

All these means failing, resort to more radical, efficient, and hazardous ones will now become necessary. But let the practitioner remember that so long as the temperature and pulse remain normal, or nearly so, and there is absence of severe pain, he may with safety persist in the mild eflorts at reduction which have been mentioned, even for several weeks. Should every general practitioner do this systematically and intelligently, few, very few cases of this accident would fall into the hands of the specialist, and a geat deal of fame now concentrated upon a few would be distributed amongr many.

The day for rapid and brilliant replacements of the uterus in condition of clironic inversion las passed and gone. There are unquestionably cases which may call for inmediate or at least for rapid replacement, and others 
which will demand the most heroie resonrees of surgery, from the fact that all milder ones have failed. But the rule should, with our present light "pon the subject, be positively and unhesitatingly accepted, that gontle, slow, and safe methods should always take precedence over rapid, harsh, and dangerous ones. As a very general rule time is here a matter of no moment. Certainty of result and freedom from dauger are the great desiderata. A case of ehronic inversion presenting jtielf under the eireumstanees which are ordinarily atteudant upon the eondition, the surgeon who selects the plim of rapid over that of gradual retuction is exposing his patient to risks which might have been avoided in the attainment of a result which would have been as likcly under the safe as under the dangerons course. If all goes well after adoption of the latter, neither surgeon nor patient will cuestion the wislom of the choice; but supposing that a fatal issue oceurs!

It must be alpreciated that I do not undervalue the serions procedures which have been recommended and practised for ohstinate cases of inversion. I wonld unlesitatingly resort to them after failure with safer and less eflicient procedures. It is a resort to them as a matter of election, and before the milder means have been tried, that I deprecate-a willingness to weigh the safety and interests of the patient against any other consideration that I condemn.

As one looks back upon lis experience in surgery, he can see many cases which, if he could have availed himself in them of knowledge which did not exist a few years ago, would in all probability have had a favorable instead of a fatal result, and he feels regret. If he have at his disposal resources which could have produced such a happy change in the record, and which he from eloice did not use, regret is apt, in the mind of a conscientious minn, to merge painfully into remorse.

\section{II A P T E XXX.}

\section{PERICTERINE CELLLIITIS.}

History.-The history of this affection presents one of those examples, which are often repeated in medical literature, of a subject which was onee understoor being subsequently completely overlooked and forgotten.

There can be little doubt that it is to this disease that allusion was made by Arehigenes, who flourished in the second century, and whose acconnt of it was subsequently repeated by Oribasius in the fourth, and Aetius and Paul of Egina in the sixth and seventl. The last two undquestionably refer to it under the head of "Abseess of the Womb," for 
in one passage Paulus especially speaks of cases in which the "aposteme is seated about the mouth of the uterus."

The morlern history of the subject may be thus stated :-

\begin{tabular}{|c|c|c|}
\hline i & $\begin{array}{l}\text { Richard Wiseman,' England, as "Distempers } \\
\text { of the uterus in childbed,". }\end{array}$ & 1679 \\
\hline .. & Nichs. Puzos ${ }^{2}$ France. as "Dépôts Laiteux," & 1743 \\
\hline . & $\begin{array}{l}\text { Bourdou, a pupil of Récamier, as "Fluetu- } \\
\text { ating tumor of true pelvis," }\end{array}$ & 1841 \\
\hline .* & $\begin{array}{l}\text { Doherty, Ircland, as "Chronie inflammation } \\
\text { of the appendages of uterus," }\end{array}$ & 843 \\
\hline “ & $\begin{array}{l}\text { Marchal de Calvi, as "Intra-pelvic phlegmo- } \\
\text { nous abscess," . }\end{array}$ & \\
\hline " & $\begin{array}{l}\text { Churehill, }{ }^{3} \text { Ireland, as " } A \text { bseess of uterine } \\
\text { appendages," . }\end{array}$ & \\
\hline " & Lever, England, & \\
\hline
\end{tabular}

It will thus be seen that after being appreciated, then entirely forgotten, then for a second time brouglat into notice, the knowledge of this affection languished for nearly two centuries, to be suddenly restored by the efforts of four investigators who entered the field almost simultaneously. It would be unjust to a conscientious observer, M. Auguste Nonat, not to mention the great influence which his writings have had in advancing our knowledge ; but when he commenced his investigations in Hôpital Cochin, in 18.46 , the morbid state which he subsequently did so mueh to elucidate had alrealy received considerable attention in Great Britain.

Definition, Synonyms, and Frequency.-This disease, which is now known to be of frequent oecurrenee, consists in an inflammation of the adlipose and areolar tissue lying behind, in front of, and at the sides of the uterus, and extending up between the layers of serous nembrane which make the broad ligamants. It has been described by different writers under the following titles: parametritis, periuterine phlegmon, inflammation of the broarl ligaments, pelvie alscess, and pelvic cellulitis. The last term, which was applied to it hy Sir bames Simpon, indicates the nature and seat of the disease; hut it is open to the grave oljection of being too general in its application, and not sufficiently confining witlin proper limits a distinct and well-defined affection.

Anutomy._" "The sub-peritomeal pelvie tissue," says Dr. Savage," in his work on the Female Pelvic Organs, "tills up all that part of the pelvie avity between the pelvic "roof" and floor of the pelvis, which is not ocen-

1 Viclintrok, "Diseases of Women," p. 1.

2 brs. Wist aurl Mcclintock date the appearancr of Puzos, "Traite d'Accouchemint," 1759. They are probably in error, as Beruntz and Nonat both date it $17+3$.

3 W"ut, "I)iseasess of Wonen," Am. ed., p. 310.

4 sitwace, op, cit. 
pied by the viscera, and is the sole bond of union between them." Any one ean satisty himself ats to the abumdance of loose crelhuar tis-lue in the pelvis, by even a rough dissection. It will be found in the hroml ligaments in great abmulanee splating their contents, betwen the vaginat

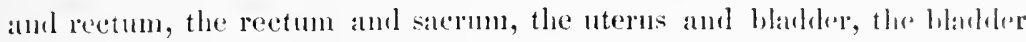
and aldominal parietes, and investing the psoas and iliac muscles. 'llhe relations of the urethra and rectum to this tissue are peenliar, carh being isolated in a sheath or canal which may be remored with ealice.

Everywhere around the pelvic organs cellular tissue exists except between the peritomsum and uterus. Here solittle is discoverable that some have ventured to deny its existence, while all admit that over the borly of that oran it is diflienlt of demonstration. Dr. Farre deelares that along the median line and over the whole fundus he has found the peritonem inseparable from the uterus, except after prolonged maceration. On the sides of the orom and at the cervix the connection is not so intimate, loose celhular tissue existing at these points to such an extent as to permit of the investing membrane gliding upon the uterus. M. Goupil, ${ }^{2}$ who has made a special study of this tissue, declares that it is so small in amount at the point of contact of the peritonem and vagina, and in front and rear of the uterus, that " its presence can scarcely be determined."

Puthology.-According to the wile range given to the affection by the majority of English pathologists, this areolar tissue is the seat of the lisease nuder consideration, which may affect any or all of its parts. Drs. West, Simpson, and most British writers, except Dr. Bennet, adopt this view, and regald as instances of the affection any inflammation of the cellular tissue within the pelvis. But this evidently leads to great confusion. It is certainly not conducive to clearness of comprehension to blend the description of iliac, psoas, and perirectal abscesses with this disease.

French writers, ${ }^{3}$ on the contrary, regard as instances of periuterine cellulitis only inflammation of the cellular tissue of the broad ligaments and of that immediately in contact with the uterus at its junction with the vagina and bladder. While admitting that inflammation originating here may spread, by continuity of structure, to other areolar tracts in the pelvis, they rrgard these as complications, designating them by different appellations, and do not admit them as elements of this affection. This is the definition which I would adopt, and to express it alearly have employed the term periuterine, in place of pelvie, cellulitis.

Periuterine cellulitis has three stages: 1st, the stage of active congestion; $2 \mathrm{~d}$, that of effusion of liquor sanguinis; $3 \mathrm{~d}$, that of suppuration. In its course it may be likened to an ordinary furnncle; at first there is simple congestion accompanied ly pain, heat, and swelling; then liquor san-

1 Cyc. Anat. and Phys., Sup., p. 631.

$\&$ Becquerel, p. 441, rol. i.

3 Aran, Mal. de l'Ctérus, p. 675. 
guinis is effused, which ereates hardness and tension, and lastly suppuration oceurs, and ends the morbid process, unless one of two other terminations takes place. Resolution may oceur, or, in place of suppuration, the areolar tissue involved may be destroyed, as it so generally is in anthrax and phlegmonous erysipelas, and come forth as a sloughing mass.

The term phlegmon, now almost obsolete with us, but still in use on the continent of Europe, signifying inflammation of areolar tissue, is strictly applicable to this affeetion. Its source is similar to that of areolar inflammations in other parts of the body, and its three stages are identical with theirs.

The most common seat of periuterine cellulitis is the areolar tissue of the broad ligaments, and generally that of one side only is affeeted.

In a certain number of cases where no affection of the areolar tissue of the broad ligaments exists, cireumscribed tumors, in immediate contact with the womb, have long been noticed. Lisfrane supposed them to be due to partial parenchymatous metritis, "engorgements," which had resulted in enlargements of one part of the organ ; and no one contradieted lim until M. Nonat, ${ }^{1}$ about the year 1849 , deseribed them as being due to phlegmonous inflammation in the areolar tissue immediately around the uterus, $i . e$, between the cervix and reetum, the cervix and bladder, and immediately by the side of the neck. The existence of this variety of cellulitis has been denied by M. Bernutz, who sustains his position by abundant argument. In reference to it, I will merely say here, that there are, so far as my knowledge extends, only two cases of such limited cellulitis substantiated by autopsic evidence, one reported by M. Demar(yuay, ${ }^{2}$ the other by M. Simon. ${ }^{3}$ Nevertheless, judging from elinical observation, one is inclined to side with the view of Nonat rather than with that of Bermutz. There are many cases in which abseesses in the broad ligaments point and discharge anteriorly or posteriorly to the cervix, but these come within a different eategory. The broad ligaments and their entire contents, cellular tissue, ovaries, and Fallopian tubes, are more frequently affeeted than any other parts, and M. Aran goes so far as to say that the collections of pus oceurring in periuterine cellulitis " belong more particularly to the oraries and tubes." In post-mortem examinations these parts are often found imbedded in a mass of effused material, the ovaries, one or both, in a state of suppuration, and the tubes inflamed and filled with pus, or constrictel at both uterine and ovarian extremities and dilated by sero-purulent material so as to eonstitute tubal dropsy. I have examined the post-mortem reports of eases by a number of authorities with reference to this point, and, rejecting only those in which the examination was made in too eareless a maner to allow of their admission, I present them in the following table:-

1 op. cit., p. 237.

2 Gazelte des Hopitaux, April 17, 1858.

3 Bull. de la soc. Anat. de Paris. 
No. of ciase. Authority.

I. M. Nonat.

2. M. Nomat.

3. M. Noniat.

4. M. Nunat.

5. Dr. West.

6. Ir. West.

7. Mr. Wrast.

8. Mr. Mcllintock.

9. M. Demarquay.

10. M. Simon.
Sorat of l'urulent find action.

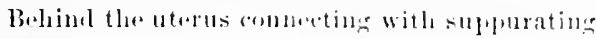
ryst ju left ovary; small alscerss in right wary.

Behind uterus and rectum extending into l,roud ligranents of loth siales.

On left side extemling from uterus to ilinu.

Behind uterus and ragina extrueling juto ledt broal ligament; another the sime of a hen's erer just belind the nterus, opening into a third, very large, extending to signoid tlexure and into broad ligament.

Left broad ligament.

Opposite right sacro-iliac synchondrosis unier psoas muscle, another to the left of and behind the rectum.

Left lroad ligament.

Left broad ligament.

In cellular tissue between uterus and rectum and also in recto-uterine poucl of peritoneum.

Size of a small orange, between the bladder and uterus, sending conoidal prolongation into left broad ligament. Its limits were as follows: base of bladder in front; neck and body of uterus behind; peritoneum above; vagina below; at the sides it ran off into the broad ligaments.

Left broad ligament.

Left ovary, right tube, with pelvic adlesions throughout.

Size of an apple in left broad ligament.

At side of uterus and in the left broad ligament.

13. M. Bonrion.

14. M. Aran.

It will thus be seen that of this number, which is large when it is remembered that the discase rarely ends in death, but two eases present instances of cellulitis, uncomplicated by lisease of the cellular tissue of the broad ligaments, ovaries, or tubes. One of these, that of Simon, is conclusive of the possibility of sueh disease; that of Demarquay is doubtful, for with the abscess in the cellular tissue, there was also one in the cul-de-sac of Douglas. The purulent collections in this disease may be results of morbid action in the cellular tissue, the ovaries, or the Fallopian tubes. In other words, with the disease known as cellulitis we often, indeed generally, have other affections, some of them, in the present state of our knowledge, not separable from it, which attend upon it as eomplications.

Complications.-The complications of perinterine cellulitis arePelvic peritonitis;

Oraritis; 


\section{Fallopian salpingitis ; \\ Endometritis ; \\ Uterine displacement.}

The occurrence of these complications with cellulitis is so frequent that they may, at least the first three, almost be regarded as elements of it, when it exists in severity. They are, indeed, universally present where the tissue of the broad ligaments is seriously involved, as will be seen by reference to antopsic evidence contained in any of the works upon the sulject. The fact of the frequent coexistence of endometritis should be especially noted, for great injury may be done by local treatment of it, under the supposition that it is the cause of symptoms which in reality are the results of cellulitis.

Course, Duration, and Termination.-It is necessary that I should here inform the reader that the account which I shall give of this part of our suljject will differ essentially from that generally found in systematic works, for the reason that, regarding pelvic cellulitis and pelvie peritonitis, which are nsually treated of synonymously, as different affections, I shall attempt to deseribe them separately. Cellulitis proper, that is, uncomplicated ly other diseases, rarely passes into a ehronic state, but usually in the course of two or three weeks passes off by resolution or ends in suppuration, the former being much the more frequent termination. Any one of its usual complications, however-peritonitis, endometritis, ovaritis, or salpingitis-may become chronic, and thus leave the impression upon the mind of the observer that the original affection has done so. Or one or more abscesses may discharge themselves by long sinuses which fail to allow of their complete eracuation, and may continue to pour out pus for montlis or even years. In saying that eellulitis rarely beeomes chronic, I look upon chronic pelvie abseess rather as one of its results than one of its stages. If the case be of acute character and occur as a sequel of parturition, suppuration may take place in a few days, but ordinarily, even under these eircumstances, it does not oceur for two or three weeks. In a chronie case the effused matter may remain hard, resisting, and ligneons for months without showing signs of softening, but such iustances are exceptions to the rule. After suppuration has occurred the disease may follow one of three courses :-

1st. The accumulated pus may discharge itself and the alscess gradually dry up and disappear.

21. The empty sae, lined by pyogenic membrane, may for an unlimited time go on pouring out pus.

31. Small abscesses may form and diseharge in one part, then others may do so in another, until the whole pelvie areolar tissue is perforated ly them and by fistulous tracts connecting them.

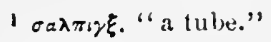


There are various outlets for the imprisoned purulent aceumulation :-

1st. Throngh the abdominal walls or saphenous openings;

2d. Throngh the pelvie viseera, bladler, rectmm, vagina, urethra, or uterus;

3d. Through the floor of the pelvis near the anus;

4th. Throngh the pelvic foramina, obturator, or sacro-isehiatie;

5th. 'Through the pelvic roof' into the peritoneal eavity.

Sometimes the purulent collection burrows into the surronnding tissues and evacuates itself at a distance. In one ease which I saw with ir. Echeverria, it passed through the seiatic foramen, and, burrowing upwards and forwards, came forth near the great trochanter. It may thus take so ecentric a conrse as to mislead the practitioner as to the seat of the abseess.

The most frequent channels of evacuation are the vagina and rectum, in the non-puerperal form, and probably the abdominal walls in the puerperal, or at least the results of Dr. McClintock's ${ }^{1}$ carefully noted cases would lead us to believe so. In 37 puerperal cases treated by him which ended in suppuration, 20 abseesses discharged in the iliae regions, 2 above the pubes, 1 in the inguinal region, and 1 beside the anus. Of the remaining 13,6 were discharged per vaginam, 5 per anum, and 2 burst into the bladder. In the non-puerperal variety it is extremely rare for the abseess to discharge externally, and fortunately in both forms it is rare for it to burst into the perineum.

Prognosis.-A guarded prognosis should always be made as to the time of recovery, for no amount of experience can foresee the course of the affection; whether the effused liquor sanguinis will disappear by absorption in three weeks; whether the lischarge of one abseess will end the patient's suffering; or whether a chronic induration will exist for a great length of time. But fortunately it may be stated, thiat the prospects as to life are decidedly favorable, though in cases occurring just after parturition, there is always some danger from general peritonitis.

Causes.-CThe disease usually oceurs as a result of one of the following causes :-

Parturition or abortion;

Influnmation of uterus or ovaries;

Direet injury from coition, calustics, pessaries, operations, or blows.

Parturition or abortion produces, according to statistics, from one-half to two-thirds of all the cases. Even this large proportion I believe to fall short of the truth, from the fact that those collecting the statistics from which the deductions were drawn made no distinetion between this disease and pelvic peritonitis. Cellulitis will very rarely be met with, except after the parturient process. It is true that, when the puerperal state 
exists as a predisposing eause, exposure to cold, fatigue, over-exertion, etc., will excite it ; but under these circumstances they are merely immediate and exciting influenees.

Inflammation of the Ovaries or Cterus. It is rare to meet with the affection in a non-puerperal patient, as the result of exposure, unless she be suffering from disease of these organs. Aran believes disease in the ovaries to be "almost always the eause." It is eertain that these organs are generally diseased where the affection exists, but it is difficult to determine whether as a complication, or as the first link in the chain. In the histories of fourteen autopsies which I have collected, the state of the ovaries is mentioned in ten. Out of these they were affected by inflammation in seven. In some of the seven cases, abscesses existed; in others their tissue was in part destroyed, and in others they had entirely disappeared. Any chronic or acute disease of either the uterine parenehyma or mueous lining, may also result in it, and $I$ have more than once seen it follow applications of mild character to the cavity of the uterus.

Direct injury is by no means a rare cause in non-puerperal cases, though it generally proves active in those suffering from previous uterine or ovarian disorders. Thus it may follow operations upon the neek or body of the uterus, slitting the neck for flexion or contraction, for example, or simple dilatation by a tent. It may result from efforts at removal of intra-uterine growths, and one fatal case that I have met followed the ligation of hæmorrhoids.

The important fact, that this disease is usually not an idiopathic affection, but one symptomatic of uterine or ovarian inflammation, has been especially insisted on by Dr. Aathews Dunean, who first drew attention to it as early as 18.3.

Symptoms.-The acute form, and more especially that occurring after parturition, is usually ushered in by very decided symptoms, of which the most constant are the following :-

Clill ;

Inereased thermometric range;

Pain ;

Fever;

Dysuria;

Netrorrhagia.

The chill, though sometimes absent, is a rery general symptom. No sooner does it pass off than the pulse rises to 110 or 120 , increased heat is felt in the hypogastrie region, and pain, which for a number of hours or perliaps days before was just perceptible, eomes on with considerable violence. The thermometer shows narked increase of animal heat, the mercury rising to $108^{\circ}$ or $104^{\circ}$, and, in severe cases, even highler. With these general symptoms there will be others pointing to the rectum and 1) ladder, and should the affection exist in a menstruating woman the flow 
may be much increased. Even when the patient is not menstruating, utcrine hemorrhage sometimes, thongh not fiequently, comes on.

lint he who awaits these symptoms for diagnosis will be led into many errors of omission, for subatute eases very grenerally, and acute cals sometimes, fully develop themselves without them.

All cases maty be brought under three heads as to severity of symptoms:-

1st. Cases accompanied by chill, fever, pain, and ordinary signs of inflammation;

2d. Those accompanied by pain without chill or fever;

34. Those marked by scarcely any symptoms except extreme feebleness and some sense of pulsation and weight about the pelvis, with hectic fever towarls evening.

Cases which have assumed the chronic form will present themselves with such a history as this: a patient who was clelivered one, two, or three months ago has not recovered her strength, but is very feeble, has no alpetite, and feels nerrous, depressed, and teverish towards evening. She las no absolute pains, but fears that something is wrong about the womb, for now and then she feels a sensation of throbbing, tension, ancl weight about that organ, which is increased by defecation, urination, and walking. This prompts to physical exploration, which establishes the diagnosis.

Pleysical Signs._-Physical exploration is the means on which we must rely for a rapicl and certain determination of the character of these cases. Should the finger be introduced into the vagina during the first stage, the parts will be found to be very warm, and perhaps a swollen and cellematous spot may be detected. Upon pressing in different directions great sensitiveness will be observerl, and by conjoined manipulation a particularly sensitive point will be detected, usually on one sille of the uterus.

As the second stage, or stage of effusion, arlvances, induration occurs in the areolar tissue affected, and then, by careful vaginal tonch combined with external nanipulation, a tumor as large as a walnut, a goose's egg, or an orange, may be detected in one of the broad ligaments, or in the tissue around the cervix.

But the examiner must not suppose that the mere introduction of the finger into the vagina will accomplish a discovery which often requires the greatest care and most thonghtful attention in examination. The finger being passed up to the cervix, and the other hand placed upon the lyyogastrium so as to make counter-pressure, it slould be carefully pressed aguinst Douglas's cul-de-sac and all around the cervix orer the base of the blatdler and as far as possible towarls the fundus. Then it should be marle in a similarly eareful manner to traverse the sides of the pelvis where tue broad ligaments are placed, and last of all, those parts below the pelvic roof. For one suficiently practised in this kind of examination 
this procedure will generally be sufficient to determine the existence of even a very small point of induration on the sides or in front of the uterus. Sometimes, where it is posterior to that organ, a rectal exploration will throw much additional light upon the case.

Should the disease have alvanced to its third stage, in addition to the signs alrealy noted, the uterus, which, as already mentioned, is generally displaced, is now pushed from its normal position, in a direction opposite to the accumulated pus. Sometimes it lies upon the floor of the pelvis, at others it is in a state of anteversion, retroversion, or lateroversion, and. more rarely, sharply flexed, the body having remained movable after the cervix has become fixed.

Into whatever malposition it has been forced it remains to a certain extent immovable, from fixation by adhesive lymph. But this fixation is by no means so complete, so universal, as in pelvic peritonitis. I feel satisfied that $I$ have seen two unquestionable cases in which no fixation of the uterus existed at all. This, however, is very rare. Nonat has even gone so far as to declare that the phlegmonous mass itself may be movable, and Dr. Duncan reports one case which appears to verify this statement. I have never seen an instance in which this mass was not firmly fixed.

Differentiation._-The diseases with which it may be confounded areFibrous tumors;

Hematocele;

Pelvic peritonitis ;

Early pregnaney.

Fibrous tumors are painless, free from tenderness, and movable in the pelvis. They are unaceompanied by chill, fever, and other signs of inflammation, and are closely attached to the uterus, so as to form part of it. The tumors resulting from cellulitis are the contrary of all this, and appear firmly attached, like bony growths, to the walls of the pelvis.

Hematocele occurs suddenly with uterine hemorrhage, and is marker by prostration, coldness, and other symptoms of loss of blood. The tumor created is soft in the beginning and grows hard; that of eellulitis is hard in the begiming and tends to softening.

Pelvic peritonitis shows the ordinary signs of peritoneal inflammation, great tendeney to relapse at menstrual periods, excessive pain and tenderness, and produces no distinct tumor in the beginning, but hardening of the whole pelvic roof. Later, a small tumor may be discovered, but it is usually posterior to the uterus and not on one side of it. The uterus is less movable than in cellulitis, and when the body is fixed the cervix sometimes moves under pressure.

1)r. Gro. Engelman' has drawn attention to a rare class of cases in which early pregnaney simulates this disorder very closely. 
Consequences of Cellulitis. - The remote results of this affection are so grave, that even if there were no danger's immediately connected with it, they would stamp its oecurrence as a great disaster. The ovaries are at times destroyed by suppurative action; at others they mulergo an atrophy, the result of inflammation, and the Fallopian tubes are of ten left impervious. The uterns is often permanently displaced in consequence of strong adhesions which bind it in a had position. From this results the fact that, although the disease be cured, the patient is often left incapacieated for some of the most important physiologieal functions. Sterility, amenorrho:a, dysmenorrhoa, menorrhagia, tubal dropsy, ${ }^{1}$ and displacement may remain to attest the gravity of the original disease, and eontinue for an unlinited time a source of suffering for the patient and diseonragement for the phissician.

Treatment._. Should the practitioner be called in the acute stage of cellulitis, the patient should be at once completely quieted by opium. If pain be violent, the hypodermie method should be employed in its alministration; if not, it should be given by mouth or rectum. 'This drug throughout the acute stage of the affection should be steadily kept up. It accomplishes these results: it relieves pain, diminishes the severity of the inflammatory process, keeps the bowels constipated, produces sleep, and ereates general nervous quietude. If when first seen the patient be suffering very severcly, ten drops of Magendie's solution of morphia may be injected by the hypodermic syringe into the cellular tissue of the arm.

Absolute rest should be enjoined, the patient not being allowed to sit up in bed for a moment, upon any pretext whatever. Were I limited to one remedial resource in this affection, I should choose rest in preference to all others, but to accomplish anything it must be absolutely enforced.

The diet of the patient should be mild and unstimulating, consisting of milk with farinaceous substances, and tea or coffee.

If the ease be seen very early, before the stage of effusion las occurred, a bladder of crushed ice should be laid over the hypogastrium in the hope of arresting the advanee of the disease. But if the disease has advanced beyond the point where this seems possible, warm poultices of powdered linseed should be applied every third or fourth hour over the hypogastrium, the bowels be kept constipated, and febrile action, should it exist. be quieted by refrigerants and direet sedatives, as tineture of veratrum viride, tineture of aconite, or tineture of gelseminum.

As soon as the acute symptoms liave passed, and vaginal touch informs us that the effused material is becoming thoronghly organized, a further effort should be made to break up the morbid train before it passes on to suppuration or into chronic induration, by the applieation of a blister, six by eight inches, over the hypogastrium. This should not be applied he- 
fore febrile action and the most acute symptoms have disappeared. Some excellent authorities, among others Sir James Simpson, object to blistering for fear of strangury resulting. I have never had to do otherwise than congratulate myself on its employment. Should the case tend to an acute course, and suppuration be impending, this should be encouraged by constant poulticing.

As soon as the acuteness of the attack has passed, until which time attention should be turned to quieting the general symptoms of inflammation, it is advised by the best authorities that the iodide or bromide of potassium should be alministered, the former in five-grain doses repeated every third or fourth hour, or the latter in doses of ten, fifteen, or even twenty grains, at the same intervals. At the same time that $I$ am not prepared to deny the utility of these drugs, I confess that I lave never been able to persuade myself that they really accomplish any good result.

'There is no more certain method of disgorging the veins of the pelvis and lower bowel than by acting upon the liver, which governs the outlet of the portal system, with which they are connected, and this ean most readily be done by mercurial catlartics. Thus occasionally used, the mercurials prove of great benefit in relieving congestion, which is a leading elenent of the disease. But in doing this we are not developing the specific action of these medicines, which here act as a subordinate, and not the chief element of treatment. The production of ptyalism should be aroided, since it is ly no means certain that it is of any benefit, and by impoverishing the blood at the commeneement of what may becone an exhausting disease it may do absolute injury. As the acuteness of the affection subsides the bowels slould be kept free by laxative medicines, and the occasional use of a mercurial in this capacity is indicated. It may be necessary to repeat the application of the blister before the case ends in suppuration or passes into the chronic stage.

While the patient remains in bed, warm poultiees, or towels wrung out of warm water and covered hy oil silk, should be worn over the hypogastrium. An additional emollient remedy of great value is the persevering use of the warm douche for fifteen or twenty minutes, night and morning, after Emmet's method, alrealy described. The fluid nsed should be as warm as the patient can bear it, and may be slightly medicated in the later stages by the addition of eliloride of sodium, tincture of iodine, or iorlide of potassium. The injections stimulate the absorbents, and, at the same time, quiet inflammatory action, in the performance of which functions they are invaluable in these eases.

As the third stage of the disease, or the stage of suppuration, merges into pelvic abscess, it will be best to postpone the consideration of its managenent to the chajter in which that subject is treated. I will merely state here that after an abscess has formed and evacuated itself, great care 
should be taken not to allow the patient to exert herself for several weeks, for fear of a relapse, and even after she has left the house and begrun to exereise regularly, during two or three menstrual periods she should confine herself to bed.

\section{H A P T ER XXXI.}

\section{PELVIC PERITONITIS.}

Definition.-Inflammation involving the peritoneum covering the female pelvic viscera, and limited to it, receives the name of pelvic peritonitis. It must not be supposed that by this definition is meant simply that form of peritoneal inflammation arising in the pelvis and spreading into general peritonitis, which has long been described as metro-peritonitis. The disease that we are now considering is one usually strictly limited to the pelvis, presenting symptoms peculiar to itself, and rarely passing into the gencral form of the same disorler.

History-Long before pelvic cellulitis was known, peritonitis, limited to the serous covering of the pelvic organs, had attracted attention, and its clinical resemblance to cellulitis, as subsequently described, fully noted. Thus Morgagni ${ }^{1}$ relates a case in which, thirty days after delivery, the riglit ovary and tube were adherent to the colon and almost destroyed by an abscess. Nauche, in his work on Diseases of the Uterus, published at Paris in 1816, described inflammation of the uterus as affecting, first, the mucous membrane; second, the parenchyma; and, third, the serous covering. In 1828, Mad. Boivin credited the adhesions resulting from this affection and binding the uterus down with a large number of abortions attributed to other causes; and, in 1833, she described immobility of the uterus, for which she gave as causes, peritonitis, metro-peritonitis, and pelvic abscess. In 1839, Grisolle distinctly stated, that "there are cases of circumscribed peritonitis which, producing a tumor appreciable to sight and to touch, may lead to the belief in the existence of phlegmon," $i$. e., at tumor the result of inflammation of areolar tissue. Lisfranc, ${ }^{3}$ writing ten years after Boivin and Dugès, copies their description very closely in his article on "Fixité de la Matrice," withont referring to them, and like them attributes it to peritonitis or metro-peritonitis.

Although these facts were known and universally admitted, they

1 Artic. 22, epist. 46. Nonat, op. cit., p. 234.

2 Bernutz and (roupil, op. cit., p. 398.

${ }^{8}$ Clin. Ned., vol. iii. p 514. 
attracted little notice, and after the description of pelvic cellulitis by Doherty and Marehal de Calvi, pelvic peritonitis was almost entirely lost sight of. This was due to the fact that the enthusiasm created by the description of a long-forgotten affection caused observers to look upon the results of peritonitis as those of cellulitis, and to deseribe them as such. Thus the matter rested until $185 \bar{j}$, when M. Bernutz, in a treatise written in concert with M. Goupil, not only drew especial notice to it, but took the position that inflammation of the cellular tissue immediately around the uterus, described by Nonat as "plulegmon périutérin," or what would strictly be termed, in our nomenclature, "periuterine cellulitis," did not exist as a pathological reality, but that the lesions aseribed to it were absolutely due to pelvie peritonitis.

These views, published at first in the "Archir. Gén. de Méd.," are fully elaborated in the admirable work ${ }^{2}$ of these observers more recently brought forth. They do not touch the general subject of periuterine cellulitis as it exists in the broad ligaments, subperitoneal tissue, ant around the rectum, but only that variety supposed to have its seat in the areolar tissue between the uterus and peritoneum.

It has been already stated that MI. Bernutz was incited to his investigations by certain views adranced by M. Nonat as to the pathology of periuterine induration, which sometimes goes on to suppuration. But his researches served not merely to settle this comparatively unimportant point, they proved the fact, for which the investigator appears to have been himself entirely unprepared in the beginning, that many of those cases regarded as instances of non-puerperal cellulitis are in reality not phlegmonous but peritoneal inflanmations. Since the publication of these views I have directed my attention partieularly to this point, and from careful observation, both clinical and post-mortem, feel warranted in recording the conclusions at which I have arrived in the following propositions :-

1st. Periuterine cellulitis is rare in the non-parous woman, while pelvie peritonitis is execedingly common;

2d. A very large proportion of the cases now regarded as instances of cellulitis are really those of pelvie peritonitis;

3ł. The two affections are entirely distinet from each other, and should not be eonfounded simply beeause they of ten complicate eaeh other. They maly be compared to serous and parenchymatous inflammation of the lungs, - pleurisy and pneumonia. Like them they are separate and distinet, like them affect different kinds of strueture, and like them generally complicate each other.

4th. They may usually be differentiated from each other, and a neglect

1 Archir. Gén., $185 \%$.

\& Clin. Méd. des Femmes, 1862. 
of the effort at such thorough diagnosis is as reprehensilule as a rimilar want of eare in determining between periearditis and endorarditis.

M. Bernutz cites the results of tive autopsies ${ }^{1}$ hy himself, and between twenty and thirty by others which presented all the signs of protvie peritonitis and noue of cellulitis, although during life the symptoms and signs gencrally attributed to the latter disease were present. $\Lambda$ s an example conveying some idea of the close clinical resemblance between his eases found in antopsy to be peritonitis and those ordinarily regarded as eellulitis, I quote the salient points in his sixth observation.

P'atient 33, lymphatic temperament, entered hospital November 24 th for feebleness, pain in the back, emaciation, and dysmenorrhea. After a while loss of appetite, increase of pain, and chills appeared. By touch the uterus was found completely fixed, low down in the pelvis and inclined to the right side, and attached to it a very sensitive tumor the size of a hen's egg, exterrling behind the womb. On the 15 th of December this tumor wals ats large as a turkey's egg. February 1st: tumor only the size of a pigeon's egg; a circumscribed tumor on the left attached to uterus and to the walls of the pelvis. March 23d, uterus movable and tumor reduced to the size of a little nut. $\Lambda_{\text {pril }} 4$ th, she died; and autopsy showed tubercular pelvie peritonitis, evidenced by tubercular deposit, lympl, pus, firm old adlesions, oraries imbedded in false membrane and nearly destroyed.

I laad often been struck by the great similarity between peritonitis and many of the cases of what, until enlightened by M. Bernutz, I lad regarded as cellulitis, and by the fact that they occasionally ran into general peritonitis without any apparent emptying of purulent collections into the peritoneal sac, but I never had an opportunity of examining such a case post mortem until the following presented itself :-

Mrs. M., aged 35, married, but never pregnant, had been under my care, during the winter, at the Woman's Hospital, for anteflexion of the uterus, the result, as I supposed, of periuterine cellulitis. Anguat 6th, I was called to see her in consultation with Dr. Roth, her family physieian, and found her suffering from severe pelvie pain, constant vomiting, and fever. Upon vaginal touch I found the uterus immovably fixed and the pelvie roof as hard as a board. The pelvie tissue was everywhere hard and resisting, and the physical signs of what I had habitually styled cellulitis were present. About a week afterwards the patient died suddenly and unexpectedly, and I made an autopsy in presence of Drs. Roth and J. C. Smitl. No general peritonitis existed : the left ovary presented a sae the size of a hen's egg, filled with pus; the pelvic peritoneum was intensely inflamed and the uterus bound down by old false membranes, bands of

1 I have rejected a number of the cases reported, because not sufficiently conclusive. 
which matted all the parts together. The vermiform appendage was bound to the right ovary and the eaput coli lay just below the uterus. No trace of inflammation could be discovered in the pelvic cellular tissue except, of course, that in immediate contact with the ovary.

The fixation of the uterus, observed during life, was due to lymph effused upon the pelvic peritoneum, and no trace of inflammatory action in the pelvic areolar tissue could be discovered as accounting for it. It is true that the left ovary, enveloped by the layers of the broad ligament, was inflamed, and that a certain amount of inflammation existed in the cellular tissue immediately surrounding it, but this did not extend.

Frequency.-A reference to the autopsic notes of cases of cellulitis, for example those recorded by West, Nonat, Aran, and McClintock, will give abundant evidence of the almost universal attendance of this complication upon it. But, even without the existence of that disease, Aran found it in greater or less degree in fifty-five per cent. of eadarers of women examined in his service. This proves that peritonitis, limited to the pelvic viscera, is a common affection, and one which is very generally orerlooked. It is probably to its occurrence that are lue so many of those attacks of violent hypogastric pain occurring with menstruation, or just after it, accompanied by vomiting and slight febrile action, and which are generally treated by domestic remedies and viewed as cramps or uterine colic.

Puthology.-The disease runs its course here, as peritoneal inflammation does elsewhere, in three stages. In the first there are simple engorgement and turgeseence of the ressels, producing redness, dryness, and pain.

Fig. 208.

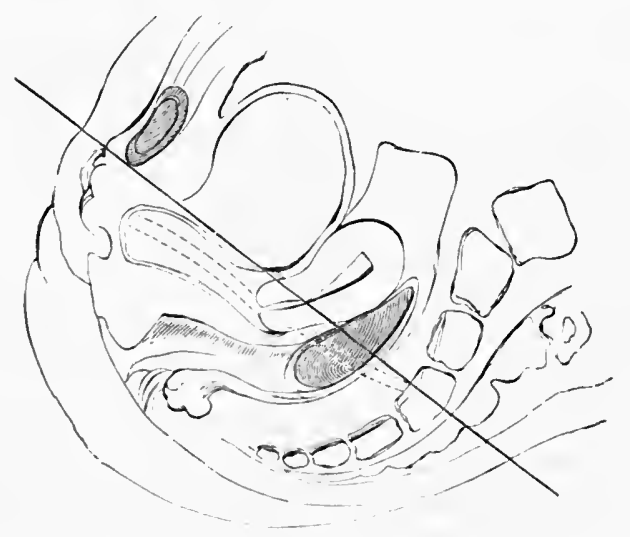

The straight line represents approximately the roof of the pelvis: the dotted liue represents it more exactly.

In the second stage an entirely different state of things will be found to exist, to comprehend which fully, the reader must hear in mind what is meant by the "roof of the pelvis." If a plane be passed backwards from 
a point just under the pulsic areh, through the cervix utreri at the attate hment of the vagina, to the sacrum at the attachment of the ntenesu-sactal ligaments, it will correctly represent this roof, which is thus formed by thes vesieo-vaginal septum, the lower extremity of the uterus, which projects, as it were, through a hole in the roof, the npper part of the fornix vaginat, and the utero-sacmal ligaments. Above the plane, the organs of reprodnetion float, as Nonat expresses it, "in an atmosphere of cellular tissue." Let the realer suppose that instead of this yielding, springy tissne, these organs were fixed in their places by having a fluid mixtme of plaster of Paris poured around, among, and over them, which had afterwards become solid, and he may form a correet idea of what raginal exploration will yiekl to the sense of touch in the second stage. The roof of the pelvis is hard, ligneous, and as if composed of a "deal board," to which Prof. Doherty likens it. The uterus, which is generally much displaced, is immovable, and all its appendages appear fixed by some solid surrounding element.

This, the second, stage consists in a collection of plastie lympl on the surface of the peritoneum, and of serous, purulent, or sero-purnlent fluid in its most dependent parts.

In the third stage the fluid, if serous, is absorbed; if purulent, discharged, and the exuded lymph undergoes organization and subsequently contraction. This binds the uterus, its appendages, and some of the intestines together in a mass, which yields all the physical signs of a tumor.

Causes.-Its causes are the following :-

Periuterine cellulitis ;

Parturition or abortion ;

Gonorrhœa ;

Endometritis, ovaritis, or salpingitis ;

Eseape of fluids into the peritoneum;

Traumatic influences;

Inırudenee during menstruation;

Tuberculous or cancerous deposit;

Uterine displacement.

Its frequent dependence on the first needs no further mention.

As a result of parturition or abortion, it is so well known as to make the exlibition of proof here almost unneeessary. Reference may be made, however, to 53 antopsies by Aran, ${ }^{1}$ in which, out of 38 women who had borne children, 24 presented evidences of its previous existence, while out of 15 who were nulliparous, only 5 did so.

Gonorrhoa, by passing into the uterus and through the Fallopian tubes, is a fruitful source of the affection. According to M. Bernutz, 28 out of 99 of his eases had this origin. I have seen a number of severe eases due 
to it, and the great importance attached to this cause by Noeggerath is elsewhere fully stated.

It would be strange if ovaritis and endometritis did not, at times, cause pelvie peritonitis. Tlat they frequently do so, is abundantly demonstrated by autopsies made after their existence both in the puerperal and nonpuerperal states.

Salpingitis causes it not only by the extension of inflammation along the mueous, into the serons membrane which is continuous with it, but by emptying its accumulated pus into the peritoneal cavity.

Escape of fluid into the peritoneum is an undisputed cause of this, as of general peritonitis. I myself produced a well-marked case, which almost terminaterl fatally, by injecting a solution of persulphate of iron into the uterine carity. The prassage of the fluil through the tubes could not be questioned, for agonizing pain came on in less than three minutes, and continued up to the development of inflammation. This danger has eaused the almost entire abandonment of intra-nterine injections on the part of the majority of practitioners, unless the cervix be previously dilated by tents. list many other sourecs from which fluid may enter the peritoneum exist; as, for example, rupture of an ovarian cyst, discharge of tulal dropsy, or of a pelvic abseess, intra-peritoneal hemorihage, regurgitation of obstructed menstrual blood, ete.

Traumatic ageneies, as blows, falls, injury during labor, punctures, etc., may result in partial, as they do in general, inflammation of the peritoneum.

During the performanee of menstruation, a plyysiological function which involves ovarian rupture and produces hemorrhage, which must pass to the uterus by a narrow tube not permanently in immediate contact with the ovary, any degree of exposure must evidently tend to inflammation in the investing peritoneum. Of M. Bernutz's 99 cases, 20 were thus produererl.

Tubercles deposited in the part, either on the peritoneum or in the tisste of the tubes or uteris, may, as they do elsewhere, result in secomlary inflammation; and eancerous or cancroid degeneration would be still more likily to produce the same result.

In certain peculiar states of the system this affection is excited by the most trivial eircumstances, and very commonly the plyysician is held to a severe account for the fatal issue of all aflection which he as little expected to arise from his interference as the fricnds of the pationt did. I have sern it cacited hy the passage of the uterine sound, the use of a small sponge tent, and, in one case, from the passage of water, used by raginal injretion, into the uterus. Dr. Barnes, in his late exeellent work on the "Dixenses of Women," says, "I have seen fatal peritonitis follow the simple alphlication of nitrate of silver to the cervix uteri." It shonld be the duty of every fhysician to shield an unfortunate brother practitioner 
by the protection which these facts legitimately afford him; lut it shonlul equally be the duty of each to remember this paragraph, the whole of which is italicized in Dr. Savage's work upon the Fomale Sexual (O)gants — "No surgical proeeding whatever, tourhing any part of the uterine systrm, should be unattended by the precantions oberved in operations of a grave elaracter there or rlsewhere; in certain states of the general system, unforeshadowed by any reeognizable peculiarity, the most trivial operation las been specdily followed by fatal peritonitis."

Larieties.-This affection may assume either an aeute or chronic form, though when it constitutes the principal disease it generally, in the heginning. presents the features of the former. When it oceurs as a complication of tubereulosis or uterine disease, it often assumes from the beginning the chronic type. Besides these varieties there are two others which cannot be passed without notice-menstrual pelvic peritonitis which becomes agrarated at periods of ovulation, and recurrent peritonitis which lasts for many years, giving, lowever, immunity for long periods, and then recurring with great violence from a trivial cause. I have had siveral such eases, one of which lasted ten and another eight years. For eight, ten, or twelve montlss these patients enjoy an almost absolute immunity from the disorder: then, excited by some apparently insignifieant cause, a severe and excessively painful attack comes on. Sometimes these attacks arc complicated by cellulitis, and a purulent accumulation frequently discharges itself through the pelvis as a consequence of them.

Symptoms._. The acute form shows itself by-

Pelvic pain and tenderness;

Sometimes great vesical irritation;

Lsually increased thermometric range;

Nausea and romiting;

Anxious facies ;

Mental disturbance;

Tympanites.

When a severe acute attack sets in, it may cause either a chill, or a sensation of coldness so slight that the patient will not recall its oceurrence unless her attention be especially directed to it; or pain and fever may slow themselves without this symptom.

Pain is at times only moderate, but at others most severe. It may occur in paroxysms, which create the greatest agony and prostrate the patient by their severity. I have seen it amount to agony equal to that arising from the passage of a biliary calculus. causing the patient to roll in herl, ceize the bedclothes in the teeth, and cry aloud most piteously. As a rule, it is not so violent as this. Pain may show itself quite early in the disease, or may be preceded for several days by pelvic uneasiness and weight.

Tenderness over the whole lypogastrimm accompanies it to such a de- 
gree, that even the weight of the bedclothes is intolerable, and the patient, to relieve it, lies upon the back with the legs flexed in order to relax the abdominal muscles.

The pulse shows in slight cases very little, and in severe cases a considerable amount of febrile action. It is small and wiry, and increases in rapidity to 110 or 120 to the minute.

The thermometric range is likewise variable. In the heginning of an attack, which may become a severe one, the range may be normal, or even below the normal stanlard. "Sub-normal temperatures are especially common in peritonitis," says Wunderlich, "and always suspicious; death may follow them closely. High and rising temperatures do not add, per se, arguments for an unfavorable termination, although adding another dangerous element to the case. It is not so much the actual height, as its constancy, which must be feared; as are, also, great and irregular fluctıations between very high and very low temperatures." When, however, a case commences with a temperature of $106^{\circ}$, it is greatly to be feared that it will run a violent and dangerous course. On the other hand, even a normal temperature should not give complete security, although a decidedly favorable angury may usually be drawn from it. In general terms it may be said that for him who implicitly trusts to the revelations of the thermometer in this affection, it will prove an unreliable guide; but to him who looks upon them merely as aids to diagnosis and prognosis, it will give decided assistance.

Nausea and romiting are common symptoms, though they do not generally exist to such a degree as to prove very annoying.

The facies is peculiarly anxious, and is sometimes rendered very striking by the appearance of dark circles around the eyes.

I have generally noticed in acute cases that the mind is markelly dis. turbed, as if the patient instinctively dreaded some serious disease, and even in chronic cases there is a decided tendency to slight mental alienation. In sereral cases I have seen this advance to absolute insanity.

It may be justly observed that these are the symptoms which mark general peritonitis. This is true; it is merely the slighter degree of severity and the localization of pain and tenderness, which will point to the partial nature of the affection.

With reference to general peritonitis, it may be stated that, on the one hand, it, of all diseases, may declare itself by the most numerous and charateristic symptoms, or, on the other, run its fearful course with the greate-t obscurity, so as to mislead the most careful diagnostician, even up to its latest stages. If this be true as to the general disorder, how much more must it be so as to the local. Thus it is that we find the subacute and chronic forms passing off without recognition, and the fact that they have existed is known only by the discovery of firm adhesions over the 
whole pelyie roof in post-mortem examinations. In these varietien, there is less pain and tenderness and less tendency to namsan and fibrile antion than in the acute. Sometimes, inderel, there is merely a sense of lowal discomfort, increasing to pain at menstrual periods, accompanied by fiever towards evening, by diflenlty in locomotion, and by a gemeral semse of ferbleness and malaise. This remarkable abschee of symptoms in pelvis: peritonitis was announced by Aran, and Dr. Duncan ${ }^{1}$ expresses limself upon it in these worls: "I might alduee cases of gonorlheal ovaritis commeneing in lowalthy young girls, and ending in the fusion of all the parts in the pelvis into a solid, immovable mass, without the patient losing a cheerful, and even gay visage, or making any great complaint of pain. unless interrogated elosely, and then alleging the clief suffering to be from irritable bladder."

Plysical Signs.-Should an examination be made during the first stage, nothing will be ascertained hut the existence of sensitiveness upon pressure in the vaginal cul-de-sac and upon lifting the uterus. Tenderness will likewise be denonstrated by pressure on the hypogastrium. None of that doughy, sedematous, puffy feel which accompanies cellulitis will be discovered by vaginal touch. Should the disease run its course as one of those very insignificant attacks, which produce no grave symptoms and are scarcely recognizable, no other pluysical signs will present themselves at this or any other period. Should it be one of graver character, a sense of resistance merely, or a tumefaction like an ill-defined tumor, may be felt in the recto-raginal space or at the side of the uterus. Or if very little lymph and much sero-pus lare been the result of the inflammatory action, a sense of fluctuation may be detected very early. 'The uterus is always more or less interfered with in its mobility, and in severe eases it is absolutely fixed. This explains how Lisfranc and Boivin applied to it the name of "fixity" or "immobility" of the uterus.

I lave stated that a tumor is commonly felt posterior to, or at one side of the uterus. This tumor, which is formed by agglutination of the pelvic and abdominal viscera, is extremely sensitive to touch.

If the disease go on to formation of pus, the sense of tumefaction may disappear as this discharges, itself; but if the effused lympll become thoroughly organized, it remains lard and resisting for a length of time. This accumulation almost invariably displaces the uterus, sometimes by pressing it in an opposite direetion, sometimes by drawing it towards itself as the lymph contracts.

In a case which I saw some years ago with the late Prof. G. T. Elliot, we were much puzzled for a short time before its fatal issue, by the existence in the fornix vaginæ of a pouch, aplarently filled with fluid, all the 
surrounding parts being unattached and no sense of tumefaction or resistance being discoverable. The patient died suddenly from general peritonitis, and upon post-mortem examination, conducted by Prof. J. W. S. Gouley, we found, first, a small liece of fetid placento in utero, the result of a recent abortion; second, an abscess of the right ovary, which had created general peritonitis by emptying itself into the peritoneum; and, third, pelvic peritonitis, which had evidently existed for more than a week. It had created a purulent collection in Douglas's cul-de-sac, which was limited to this space ly false membranes, that formed for it a complete roof. This accumulation it was which gave the sensation above described.

In another case, sent to me hy Prof. J. C. Hutchinson, of Brooklyn, the uterus was found firmly bound to the sacrum by a hard, resisting mass, which was very sensitive. There was considerable corporeal endometritis, and I incautiously applied to the uterine cavity tincture of iodine, and as a result the most violent pelvic peritonitis developed itself, which almost became general. In ten days after its inception, a soft, fluctuating pouch formed in the fornix vagina, which became so painful that I tapped it with an exploring needle and drew off about an ounce of clear serum, much to the patient's relief.

Course, Duration, and Termination.-In no disease can these be more variable and uncertain than in that under consideration. A great similarity exists between its phases and those of pleuritis. As in that affection we have shades of difference, varying from the ordinary "stitch in the side," which results from inflammation of a portion of the pleura not larger perhaps than a silver lialf dollar, to empyema and tubercular pleuritis, which may continue till death by pulmonary consumption or pneumothorax closes the scene, so may we have in pelvic peritonitis like variations. It may run its course unobserved, leaving evidence of its existence only in adhesions found post morten. It may jass through its first two stages in three or four weeks, leaving the uterus permanently displaced by the continuance of the third. It may reappear with a certain amount of acuteness at menstrual periods, causing them to be very painful. It may, if due to tubercular deposit, continue so as to exhaust the patient slowly. It may produce a purnlent collection, which, by emptying itself into the peritoneum through the allhesions thrown around it, may create general peritonitis, or this last may result from the spread of morbid action from the pelvic to the general serous membrane.

Differentiation. - The diseases with which this is most likely to be confounded are-

Periuterine cellulitis ;

Pelvic hematocele;

Fibrous tumors;

Fecal impaction. 
Periuterine Cellulitis._-Differentiation between these two affections is in some cases simple conough, but in others it is impossible. I)iflenlty will occur when cellulitis aflects, and is confined to, the tissue most immerliate to the uterus, but this we know to be very rare. Our suspicions will often be turned into the proper chammel by the cause of the attack. Cellulitis will very rarely occur except after parturition, abortion, or an operation on the pelvic visecra. Peritonitis will usually result from exposure during menstruation, disease of the ovaries, or escape of fluid into the peritonemm. Should the attack oecur as a result of gonorrhoca, it is probibly due to serous and not cellular inflammation, a fact which the anatonical relations would lead us à priori to anticipate, and which is fully substantiated by statistics. West and Aran credit gonorrhoca with the eausation of cellulitis in from one to two cases in a hundred, and Bernutz declares it active in twenty-eight out of a liundred of peritonitis.

Pelvic Hematocele.-From this it may be distinguished by the great suddenness of appearanee of hematocele, absence of signs of inflammation in the beginning, presence of those of hemorrhage, and by the much greater dimensions of the tumor, which, unlike that of peritonitis, is at first rather soft and gradually becomes hard. The occurrence of free bloody flow will likewise point to hematocele, though such an occurrence, to a limited extent, often takes place in peritonitis. Hematocele often excites peritonitis, and thus both frequently exist together.

Fibrous Tumors._These will generally be known by their producing no pain, presenting no sensitiveness on pressure, no sense of cedema, no signs of inflummation nor rapidity of development. They are likewise usually movalle, and cause no fixation of the uterus.

Fecal Impaction.-After pelvic peritonitis and cellulitis have existed for some time, and have lost their features of acuteness, and more especially after opium has been long used to allay the jain which attends them, they are very apt to be complicated by fecal impaction. Not only is this a complication, $X$ have known it exist long after the inflammatory affection which preceded it has passed away, and give rise to the belief that this still continues, the pain which it creates being attributed to the primary condition. I have met with several very striking cases in which, after four or five months of intense suffering fiom supposed periuterine inflammation, which was treated by free use of opium, I discovered great fecal impaction, the removal of which afforded complete and permanent relief. So frequent do I consider the development of this condition as a result and complication of periuterine inflanmation, or as an independent state which is mistaken for it, that I never take clarge of a ease which has been under the previous treatment of others without examining for its existence, and in the management of cases from the commencement under my charge, always carefully guard agairst its oceurrence. 
Importance of differentiating Peritonitis from Cellulitis.-The importance of differentiating this disease from cellulitis rests in part upon the fact that it adnits of less loeal interference. Sometimes the passage of a uterine sound, an applieation to the earity, or even the use of a vaginal injection which by accident lias entered the uterus, has been known to destroy life by causing peritonitis which has extended to the whole peritoneum. It is likewise important in reference to prognosis as to the course of the affection and its remote results. Lastly, it should not be forgotten that progress in the comprehension of the diseases of all organs must be preceled by a careful and systematic separation of them, one from the other. As the study of acute eardiac affections under the common name of earlitis could never have accomplished what that of each of its varieties has done, so could not investigation of these affections, undivided into their proper classes.

Prognosis.-If the case follow parturition or abortion, the prognosis will be rendered graver by that fact. Otherwise it will be governed in great degree by the general symptoms. Should these show great intensity of inflammation, and constitutional disturbance be evidenced by excessive nausea and romiting, quick pulse, anxious facies, etc.; in other words, should the symptons point to the probable spread of the disease over the whole serous sac, the ordinary prognosis of peritonitis may be made. In cases of chronic type, occurring in the non-puerperal state, it is decidedly favorable, unless the disease exist in a scrofulous or tuberculous patient, or show a tendency to severe periodical relapses. Another fact, which will increase the gravity of prognosis, is the existence of purulent effusion in place of lymph and serum as the result of the inflammatory action.

Results.-The common results of the disease, which remain long after it lias passed away, or perhapls permanently, are injury of the oraries by abscess or atrophy; obliteration or dropsy of the tubes of Fallopius; and fixation of the womb in malposition, by organization of false membranes. $A$ s consequences of these lesions follow very naturally, amenorrhoca, dysmenorrhca, and sterility.

Treatment.-Pelvic peritonitis usually announces its advent by severe pain, elevation of temperature, rapidity of julse, and other symptoms which leave the practitioner in no doubt as to its development. The rule of treatment should be based upon the following indications: first, entire prevention of pain during its eourse; second, complete control of the temperature; thirl, the strict observance of absolute quietude. The patient's prospect for life and for escape from the clironic results of the disease, if recovery occurs, will greatly dejend upon the thoroughess with which these indications are fultilled.

In the very commencement of the attack pain should be relieved by opium andunistered hy the hypodermic syringe, the mouth, or the rectum. The first method is an excellent one to begin with, but its frequent use is 
so apt to engender a morbid taste that it is better after pain has onec been completely subdued to continue the narcotic influence by opium or morphia by mouth or rectum. But opium should be regarded not only as a means of relieving pain, it aids in fultilling also the indication of preserving perfect quietude, and limiting inflammatory action by its influence on the nervous system. 'The sovereign remedy for peritonitis is opium, not in small, but in large and repeated doses, carried to the point of produeing the quietude which is necessary for the favorable progress of the case. Sometimes this condition will be produced by one grain of opium, in powder, or quarter of a grain of sulphate of morphia every two or three hours, but in many cases half a grain of sulphate of morphia will be repeated every two or three hours for a long time before perfect ease is obtained. The inexperienced employer of this drug in these doses will fear dangerous narcotism, but in New York, under the tuition of Alonzo Clark, to whom we are indebted for this practice, we employ it with the greatest confidence. Let the physician avoid all other drugs and give opium thus freely in one or two cases of this affection, and he will appreciate its value.

In a certain number of diseases death is in great degree due to the very high temperature which attends them. Examples of such are sunstroke, typhoid fever, septicæmia, and peritonitis. In all these, the greatest advantage results from keeping the temperature at or near the normal standard. 'This being done the altered blood state, and its remote influences upon the tissues, composing the nervous system and important viscera, which result from an exaltation of the animal heat, are avoided, and thus, although death may come through some other avenue of approach, this one is obstructed. 'The best method of controlling ligh temperature is cutaneous refrigeration by Kibbee's plan, which is described under the aftertreatment of ovariotomy, to which the reader is referred for details of its praetice.

Perfect quietude should be observed. Not an approximation to it, but a stillness which should interdict the action of every voluntary muscle. A nurse should watch the patient night and day, antieipate every want, and supervise every function. The patient should not converse with her, and no one else should be habitually in the chamber. The bowels will be quieted by the opium employerl. No cathartic medicine should be given, as it interferes with quietude, and it is well to keep the bladder empty by the catheter, if urination is not easy. Milk, beef-tea, and other plain, nutritious, and unstimulating food should be prescribed, but no solid food should be allowed. Should the pulse be strong, rapid, and resisting, the tincture of veratrum viride should be given in doses of five drops, in water, every four hours, until the specific action of the drug is developed.

In the second and third stages, where lymph has been the chief and perhaps the only product of inflammation, we must rely upon counter-irritants, and I know of none to be compared with the blister. One made of 
Spanish flies, four by six inches in dimensions, should be applied over the hypogastrium and the abrasion which it produces dressed with savine ointment. As soon as it heals entirely, another should be applied directly over the newly-formed skin, and this may be repeated every ten or fourteen lays with great advantage. I have known patients who dreaded them in the beginning beg for them after experiencing the relief which they gare. The blister is to pelvic peritonitis in its later stages what it is to pleuritis, the most rapid and efficient of remedial agencies.

Another very excellent method for producing counter-irritation is by tincture of iodine painted over the hypogastrium once in twenty-four hours for weeks.

Treatment of Chronic Cases.-The affection having passed into the clironic stage, or originated with all the appearances of chronic disease, a different course of management becomes advisable. The patient should not be so strictly confined to bed nor dieted. She has entered upon an invalid course which may last for months or for years, and in making a strenuous effort to cure her local disorder we may sap her general health and do her irretrievable injury. On the other hand, she should not attend to her household cares, nor take exercise to any great degree; but remaining in bed or on a lounge most of the time, go out in the fresh air for an hour or two daily. Her diet should be of the most nutritious character, stimulants should be allowed in moderation, and the impoverished blood resulting from a combination of circumstances prejudicial to hematosis, combated by change of air and the use of vegetable and mineral tonics, especially iron.

One of the most important questions in the management of chronic cases is that of the amount of exercise to be allowed, and the strictness of confinement to be practised. No absolute rule can be laid down in reference to these points, for each case will call for special guidance, based upon careful experiment. In general terms it may be stated that when motion does not produce pain or discomfort, the patient should ride in an easy carriage for two or three hours daily. In those cases which are still nore free from local trouble, she may walk with moderation; while in others which present elements of acuteness, no motion whatever should be allowed. Sometimes the patient will even bear renoval from home to the sea-side or some watering-place during the summer. If this be so, a locality should be chosen that is accessible by easy travel. One great and ever recurring difficulty in this comnection arises from the great tendency of patients, allowed to take exercise, to commit indiscretions by overtaxing themselves. 'This becomes so great at times, as to make it advisable to confine to bed one who would be benefited by molerate exercise, in order to a void langer from her imprudence. The fact slould never be lost sight of that the pelvic peritoneum forms a part, a sheath, as it were, of the suspensory ligaments of the uterus. The fibrous structure of the round, 
broal, sacral, and vesical ligaments is covered by it, so that dragring of the nterus upon them puts the peritoneum upon the stretch and strongly tends to excite renewed action there.

Ot all influenees which act in a directly prejudicial manner upon these cases, sexual intercourse is the most decided, and its strict limitation should be made one of the first rules laid down for their management.

Should acute exacerbations occur in chronic cases, the use of local depletion is advised by high authority; but, as a plan to be strictly pursued with referenee to eure, it is highly objectionable on ac"ount of the spanamia which it induces.

If it be deemed advisalble to keep up the use of the iodide or bromide of jotassium, the results of which are, however, doubtful, they may, with advantage, be combined with iron and regetable tonics, as in the following prescriptions :-

R. Potassii jodidi, 3iij.

Ferri iodidi syr. $\zeta_{i j}$.

Tr. calombe, žj. - H.

A dessertspoonful ( $5 \mathrm{ij})$ in water three times a day.

R. Potassii bromicli, 3 r.

Vini ferri dulcis, żir.

Tr. calombæ, 亏̈iv.-W.

A dessertspoonful in water three times a day.

Should collections of pus or serum be evacuated? The important bearing: of this question are manifest, but unfortunately no definite answer can be given to it. In evacuating these collections the peritoneal cavity is not exposed to entrance of air, for a false, membranous roof covers the collection, but there is always danger in perforating the delicate and easily inflamed serous sac. I have elsewhere reported a case in which I drew off one or two ounces of serum under these circumstances, to the great relief of the patient, who rapidly improved and did well. It is not the only case in which I have ventured to invade the peritoneum under these circumstances. The safest rule for practice will be this: if in spite of the sero-purulent collection the patient be doing well and do not suffer from the local trouble, it should be left to empty itself spontaneously. If, on the other hand, the patient suffer from the collection, be not progressing favorably, and the evacuation be perfectly practicable, it should be accomplished.

Methods of Evacuation. - Evacuation may be accomplished by the aspirator, a small trocar and canula, or by a guarded bistoury or tenotomy knife. After evacuation the sac may be carefully washed out with a weak solution of carbolic acid in warm water, or of tr. of iodine in the same menstruum. 


\section{CHA PTER XXXII.}

\section{PELVIC ABSCESS.}

SurPrise may be felt at the appropriation of a special chapter to this subject. The opinions of several reviewers have already been expressed to this effect, and the propriety of making it an addendum to that on cellulitis or peritonitis has been suggested. How conld this, however, with propriety be done, when pelvic abscess arises from other than those inflammatory processes; from ovaritis, perirectitis, psoas discase, disease of the pelvic bones, etc.? It appears to me a matter of importance to impress the fact that it should be viewed from a more general standpoint and not be limited to the results of two affections. I know of no surer way of effecting this object than that which I here pursue.

Definition.- Upon this point little need be said, as any purulent colleetion originating in, and not simply passing through, the pelvis, comes under this head, regardless of its cause.

Puthology.-There are three sources of pelvic abscess: 1st, breaking down of tubereulous material deposited in any of the tissues of the pelvis; 2d, suppurative action taking place in the walls of a cavity formed by an hematocele or ovarian eyst ; 3d, inflammatory suppuration in the areolar tissue, the ovaries, the tubes, the pelvic peritoneum, or the parenchyma of the uterus itself. Of all these sourees the third is decidedly the most frequently met with, and is most generally the result of cellulitis, occurring after parturition or in the non-puerperal state. Under the latter cireumstances cellular inflammation may be primary, or sceondary to irritation from some foreign boly, as the debris of an extra-uterine foctus, a lard substance in the vermiform appendix, a fibrous tumor of the uterus, or caries of the pelvic bones.

Canses.-Any influence which induces cellulitis, or either of the other two pathological conditions mentionerl, may prove immediately causative of abscess. As remote causes may be mentioned the tubereulous, serofulous, and syphilitic diathesis; great depression of the vital energies from any cause, as impure air, like that of a hospital; the puerperal state; and pyemia.

Symptrms. - These will not differ esscutially from those of abscess elsewhere. When pus is forming, violent chills, followed by fever, with pro. fuse sweating, are likely to occur. Then a feeling of prostration with throblung min in the pelvis, pressure upon the reetum and bladrler, and sonetines interference with urination, present themselves. Pain down 
the thigh, which may be mistaken for sciatica, will also at times be noticed.

Physical Signs,-By abdominal palpation, combined with rectal or varinal touch, a fluetuating tumor will be felt, presenting the ordinary physical signs of purulent collections elsewhere.

Course, Duration, and Termination.-Pelvic alsscesses may evacuate themsel ses through any part of the floor of the pelvis, through its roof into the peritoneum, through any one of its walls by means of foramina, through any of the pelvie viseera, or by several of these channels at the same time. They may open by free outlet or by a long, sinuous tract, which renders prognosis as to eure extremely grave. The most favorable points for evacuation are through the vagina and rectum. Next to these comes, in point of farorable prognosis, evacuation through the abclominal walls. Nonat declares that when the collection "opens simultaneously into the intestine and bladder, death is almost inevitable." In the Charleston Medical Journal, for 1853, I published a fatal ease of this character with autopsy. Sometimes, when left to themselves, these abseesses will go on to recovery without delay, opening into, and discharging themselves through some of the parts mentioned, and gradually contracting and disappearing. Sometimes, if deprived of the assistance of art, they may burrow deeply into the tissues, open by long, fistulous tracts into some organ, as the large intestine or sigmoid flexure, or discharge into the peritonemn.

König has instituted some very interesting experiments on the cadarer, to show the most probable routes which these accumulations may take:-

1st. Injecting air or water beneath the peritoneum near the ovary or tubes, the injection ran along psoas and iliac muscles into pelvis.

2u. Beneath lateral ligament near cervix, it filled the same sirle of pelvis, ran along round ligament towards Poupart's ligament, and to the iliac fossa.

3d. Beneath broad ligament behind cervix, it filled posterior and lateral part of pelvis, and passed along psoas and iliac muscles into pelvis.

Sometimes, even when the opening at first is large, it contracts so as to allow only an imperfect discharge of the contents of the sac. Then hectic ferer arises, and the patient either leads a miserable existence for years from the constant fetid flow, or is worn out by exhaustion or septicemia. At other times these collections of pus will remain imprisoned for a long period, without any attempt at escape.

Differentiation.-The morbid states with which this condition may be coufounded are these:-

\footnotetext{
Pelvic hematocele;

Extra-uterine pregnancy;

Displaced ovarian cyst;

Hydrometra ;

Tubal dropsy.
} 
The first of these, being a liemorrhage, gives certain symptoms characteristic of that accident, as prostration, coldness of the surface, suddenness of appearance, etc.; and absence of chill, heat, fever, and other signs which are likely to accompany abscess.

With the seeond, the signs of pregnancy exist, and as early as the fourth month foctal movements maly be detected, while the perfect health of th: patient with absence of menstruation will excite suspicion as to the chat racter of the affection.

Around abscesses, even of tubercular character, there is always a wall of lymph thrown up which wonld not be present in a displaced ovarian cyst. All the rational signs of suppuration would likewise be absent in the latter.

He who confounds the distended body of the womb with abscess would surely be very culpable, for the spherical shape of the body and the light obtainable from the uterine probe should be guides by which to avoid error

'Tubal dropsy is generally the result of inflammatory action affecting the Fallopian tubes and closing both uterine and ovarian extremities, at the same time that it causes a secretion, which distends the intermediate canal. The fluctuating tumor thus resulting, being produced by inflammation, and being often attached, in consequence, to the surrounding parts, would offer difliculties in diagnosis which might well prove insurmountable. If an error were made, however, no evil wonld result from it.

Prognosis.-The prognosis will depend upon the following circumstances: It will be favcrable if the abscess be superficial, point upon a mucous tract, open low down in the pelvis by free exit, and give forth pus which has un offensive odlor. Should it be deep-seated, open by a long tract, give forth fetid pus, open ligh up and by two points of exit, as, for example, the bladder and bowel, the prognosis is decidelly unfavorable, !nless the case can be so affected by surgical interference as to change its character.

Treatment.-Nothing can be done in these cases by specific medication, by which I mean that directed esprecially to relief of the existing morbil condition. All of our efforts should be directed to supporting the vital forces, which are always much prostrated by the process of suppuration. The patient should take the most untritious diet, as much animal food as she ean digest, eggs, milk, fresh vegrtables, and malt liquors. Whiskey or brandy should be allowed her, and the blood state shonld be improved at much as possible by regetable and mineral tonics. Those most espe(ially suited to the condition are preparations of cincliona, and of iron, as, for instance, the following pill :-

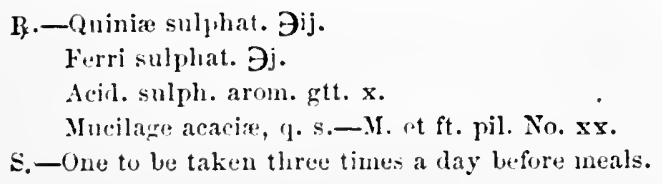


But it is to surgery that we must losk most conficlently for airl, and in this connection arises the important question ats to the properiety of opening such abseesses, the best point for evacuation, and the time for interference.

Should an abseess in the pelvis show a rapid tendency to point and discharge through a firvorable channel, at the sime time that no distressing or dangerous symptoms show themselves, it would be the part of wistum to await the action of nature, for all must armit that there are few localities in the body into which it is more hazardons to cut than this. Even uncter these sireumstinees, however, there is tiunger in delay. Sir James Simpson relates a case which he saw with Dr. Zeigler one day when the abscess pointed decidedly towards the vagina and reetum very low down. Feeling sure that it must soon discharge, they left it till the next day, but before that time, to their surprise, it had burst into the peritoneum. This danger, ats evideneed ly statistics, is not great, and as experience goes to prove that the knife is often employed too early, rather than too late, i should strongly recommend the delay of surgical interference until the presence of pus is an absolute certainty. If it be thus delayed, the tissues intervening between the pus and the point of introduction of the instrument become broken down, and a tract or sinus is avoided; if two or three abscesses exist near ealch other, we give time for them to coalesce; and the mass of lymph poured out is liquefied by the suppurative proeess. Should evacuation be resorted to too soon, all these advantages will be lost.

Iet us suppose a different case, that the patient is suffering grave constitutional sigus from the abseess. The answer to the question of the propriety of interference resolves itself into this: if the pus can be certainly reached, it should be evneuated. Should the abscess be deeply seated, on the other hand, so as to make the operation difficult and uncertain, it would expose the patient to hazards greater than those attendant upon delity.

Dr. Savage believes that "puncture should be practised early and per vaginam." Spencer Wells declares from an experience in opening as many as from twenty to thirty pelvic abscesses that he has known of no fatal result. "I have known," says he, "several cases of death where no puncture has been made-some of them very painful cases-when I had urged puncture and was overruled." As a rule he punctures per vaginam.

Prof. Brickell, of New Orleans, has recently taken strong ground in faror of the early evacuation of pelvie accumulations, and, as I especially desire to lay before the reader an unbiassed view of the present state of professional opinion upon this important subject, I give his conclusions in full :-

"1. I have no doubt at all that there are two distinet forms of pelvic inflammation-serous and phlegmonous, or suppurative. An attack of 
either may be abortive-that is, may fail to result in formation of pus or effusion of serum. But, should either pus or serumi be deposited, then,

2. I am sure that evacuation is the proper practice; and,

3. Either should be evacuated per vaginam.

4. The presence of pus in any portion of the body is not to be tolerated by the surgeon. I contend that the presence of effused serum in the pelvis is not to be tolerated either. As long as it is present, in addition to the pain and prostration present, there is the abiding stimulus to repeated inflammations, and the pelvis can and will be ravaged.

5. Topical applications and internal remedies have no influence on pelvic and serous effusions, according to my observation."

For my part, I feel very sure that this subject is one upon which no fixed rule ean be given. The surgeon must weigh the dangers of operation with those of delay, and decide by the indications presenting in eaeh individual case. Were the determination of the existence and locality of purulent accumulation really as easy at the bedside as one might be led to regard it from the literature of the subject, I should strongly advocate a uniform resort to evacuation. But this not being by any means the case, I am ind uced to do otherwise. Nor must it be imagined that seeking for pus hidden away in the pelvic areolar tissue is an entirely sate procedure. The following fatal case, due in all probability to an entrance of air into the veins, will prove interesting in this conneetion:-

"In the ease reported," aspiration some three months before, for the removal of a quantity of pus from the pelvis, had been followed by much relief. The symptoms having returned, the needle was again introdueed through the ragina to the left of the uterus, a distance of three-fourths of an inch. As soon as the pumping was commeneed the patient manifested lain, became convulsed, and grew purple. Congestion of all the snperficial veins follower, though the needle was immediately withdrawn as soon as the symptoms began, when no more than four or five strokes had been made. In three minutes the patient was comatose, and in ten minutes the heart ceased to pulsate.

"The autopsy revealed a small punctured wound on the left side of the ragina, one and a laalf inches before its juncture with the uterus. The probe passed upward and to the left threc-fourths of an inch in the direction of a soft tumor in the uterus. Around the track followed by the probe was no more than a teaspoonful of clotted blood. A close network of small veins was traversed by the puncture just outsids of the vagina, but after the most diligent seareh it was seen that no important bloodressel hat been touched. The areolar tissue about the uterus contained air. The left lung was much eongested. The right ehambers of the heart were filled with air, and contained no blool. The left chambers were

1 Boston Med. and Surgo. Journ., rol. cii. No. 17. 
empty. The valves were normal. The veins of the stomach were distended with air, presenting the appearanee of pale round worms.",

The Best Point for Evacuation. - To whatever surlace the point of the abscess is nearest, that will, as a general rule, be the best for its evacuation. If there be a choice, the loeations at whieh it will most likely point should be chosen in this order: 1st, the vagina; $2 \mathrm{~d}$, the reetum; $3 d$, the abdominal walls.

1). Savage reports the points of opening, artificial or spontaneous, in 19 cases; they were as follows:-

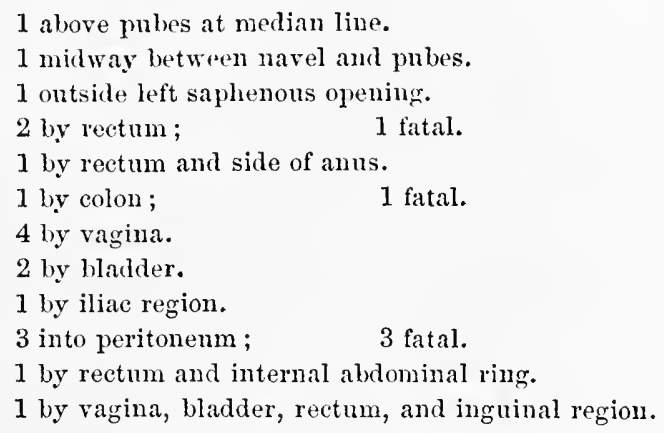

It will be seen that out of 19 cases 5 proved fatal-3 by emptying into the peritoneum, and 2 by causing colitis and rectitis.

Methods of Operating.-The propriety of opening the abscess having been determined upon, the operator, if he intend reaching it through the vagina or rectum, should carefully investigate, by tonch, as to the presence upon their walls of large bloodvessels, the opening of which might prove a source of serious hemorrhage. The patient being placed on the left side and Sims's speculum introduced, if there exist the slightest doubt as to the contents of the sac the needle of a hypodermic syringe should be plunged into it and the point decided. 'If this be not done, an ordinary exploring needle should be passed into the tissues until pus is seen to flow along its groove. Then the operator, feeling sure of his ability to reach pus, holds the needle in one hand, while with the other be slides the point of a bistoury along its gutter and passes it to the place of accumulation. This is a method at once safe, certain, and effectual, and I should recommend it in preference to any other except that which comes next to be eonsidered. The aspirator affords an easy and effectual means of emptying these accumulations, and at the same time one that is to a great extent free from danger. After it has removed all the fluid which will flow, its action may be reversed, the sae filled with warm carbolized water, and this at once drawn off again. Should reacumulation take place, the situation and certainty of the purulent collection being established, it may be evacuated by a bistoury. If the opening made be large enough to admit the finger, it should be passed in, and sy it any tract leading into 
an adjoining abscess should be enlarged, and any sloughing tissue met, removed. After this, should there be any fear of closure of the canal just opened, its walls may be touched by nitrate of silver, or painted with solution of persulphate of iron, or a piece of gum-elastic catheter or rubber tubing may be left in it.

If it be thought best to select the abdominal surface as the point of evacuation, all danger of escape of pus into the peritoneum may be aroided by following the suggestion of Récamier with reference to hepatic cysts, namely, cansing adhesions of the layers of the serous membrane by a nitric acid issue orer the point of selection. A trocar, the needle of the aspirator, or a bistoury guided by an exploring needle, may be plunged through the centre of the issue without the danger just mentioned.

Means for Causing Closure of the Sac.-Cometimes, after the evacuation of these abseesses, their sacs will not close, but, remaining open for months and even years, go on pouring out large quantities of pus.

The causes of their not closing are these: the existence of sinuses, which will not allow their complete evacuation; a peculiar condition of their walls from the existence of a membrane, called by Delpech pyogenic, which tends to prolong suppuration; or the passage into the sae of air or feces from the intestines, or urine from the bladder.

Of these the first is decidedly the most frequent, and should be met by dilatation of the tract lealing to the abscess, by tents of laminaria, or enlargement by the knife.

Should the abscess have a short and free outlet, the sae should be injected two or three times a week with tincture of iodine, at first in solution, afterwards pure; or by solution of earbolic acid.

In case of entrance of feces, air, or urine into the diseased part, a counter-opening should be made which will allow their free eseape, and the part kept as clean as possible by injection of tepid water. Then the fecal or urinary fistula allowing the vicarious discharge should be cured by appropriate means.

Before practising any operation for evacuation of pelvic abscesses an anasthetic should always be administered, as perfect quietude is essential to satety. 


\section{II A P T E R X X I II.}

\section{PELVIC IIEMATOCFLE.}

Definition and Synonyms.-Under this and the synonymons titles of retro-uterine hematocele, periuterine hematoma, and bloody tumor of the pelvis, has been deseribed an accumulation of blood in the pelvic carity either above or helow the peritoneum.

History-_ Although an attempt has been made to prove that the ancients were cognizant of this affection, the proof of such a fact is not satisfactory. The carliest allusion made to it is contained in the works of Ruyseh, of Amsterdam, who wrote in 1737. After this, little attention was paid to it until the time of Récamier, although mention of it wals made by Frank, Deneux, and some others.

In 1831, Récamier, under the impression that he was opening an abscess, cut into a tumor behind the uterus and gave exit to a large amount of black, grumous blood, and about ten years afterwards Bourdon, one of his pupils, published another case occurring in his practice.

A tabular view of the names of those who have been chiefly instrumental in elucidating the subject and sytematizing our knowledge upon it is here presented :-

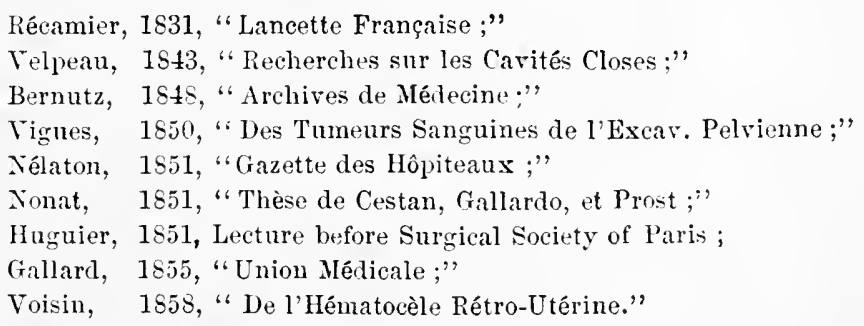

I have not endeavored to record the names of all who have marle valuable eontributions in France, for had I done so. the list would have been a long one. Those only are referred to who have bcen foremost in adrancing our knowledge.

It will thus be seen that we are indebted to France for the early literature of pelvic hematocele. Germany has of later years contributed a great deal towards it through the labors of Olshansen, Credé, Braun, Hegar, Virchow, Schroeder, Seiffert, and others; and England through those of Madge, McClintock, and Tuekwell. In America, Prof. Gunning S. Bedford reporterl the first ease which I can find recorded. IIore recently, we were indebted to Dr. Byrne, of Brooklyn, for a faithful report of several 
cases. Prior to the year 1851, although it had attracted some attention, it was not well understood even in France, for, in 1850, we find Malgaigne cutting into a hematocele under the impression that he was enueleating a fibrous tumor, and losing his patient from hemorrhage.

Frequency.-This subject is not fully settled, a good deal of diserepancy of opinion existing concerning it. Prof. Olshausen, of Ilalle, declares that in 1145 gynecological cases he saw 34 hematoceles, and Seiffert, of Pragne, reports 66 seen in 1272 eases of pelvie female diseases. In ten years Dr. Barnes has met with 53 cases, and in twenty years Dr. Tilt has seen but 12 .

I do not regard the disease as being, by any means, very rare, but my experience assures me that many cases of cellulitis and a certain number of nterine and periuterine tumors are reported as those of hematocele.

Pathology._-The definition of hematocele has no relation whatever to the cause of the hemorrhage which gives material for the bloorly tumor. The disease consists in the collection of a mass of blood in the pelvis, either above or below its roof. Whatever be its source, such a collection constitutes the affection which engages us. Ordinarily, we find that the flow giving rise to it takes its origin from one of the three following sources:-

1st. Direct escape of blood from vessels in or near the pelvis;

2d. Reflux of hlood from the uterus or pubes;

31. Transudation of blood in consequence of dyscrasia or peritonitis.

It is evident that hematocele is not a disease, but a symptom of a number of pathological conditions. As, however, the source of the hemorrhage which results in the bloody tumor very often cannot be ascertained, we are forced to deal with its most prominent and significant sign, taking this as an exponent of a state which is beyond the possibility of diagnosis.

In works upon practice written twenty years ago, we find dropsy treated of as a disease. In those of to-day it is regarded only as a legitimate result of renal, cardiac, or bepatic disease. Obstetric writers, even as late as ten years ago, deseribed puerperal convulsions as a disease incident to parturition. Those writing ten years hence will probably regard them, as many do to-day, as one of the numerous consequences of renal disease. We may with good reason hope that the time will come when a similar improvement in deseription, basel upon an advanee in our knowledge of lathology, may connect itself with hematocele, but at present the discovery of the souree of the hemorrhage is usually impossible.

The special sources of the hemorrhage inducing the affection, which lave bern revealed by post-mortem examinations, may thus be presented at a glance:-

1. Rinture of bloodressels in the pelvis.

Itero-ovarian;

Varicose reins of broad ligaments; 
Aneurism of artery ;

Vessels of extra-uterine ovisac.

2. Rupture of pelic viscera.

Oraries ;

Fallopian tubes ;

literus.

3. Reflux of blood from the uterus.

lieflux of menstrual blood.

4. Transudation from bloodvessels.

Purpura ;

Scorbutus;

Chlorosis ;

Ilemorrlagie peritonitis.

All of these canses have been proverl by post-mortem research to have resulted in hematocele, but it cannot be questioned that rupture of any bloodvessel which empties its contents into the peritoneum might also to so. Blood poured into the peritoneum from rupture of the spleen, for example, would gravitate towards Douglas's cul-de-sac, because it is the most dependent portion of that membrane, and coagulating would give all the signs of a bloody tumor in that locality. At times the affection is indicative of serious internal lesion, rupture of the ovary or tube; at others it results merely from imperviousness of the cervical or tubal eanal, which prevents the advance of menstrual blood and causes it to regurgitate into the peritoneum; while in still a third class of cases, it is created by pouring out of blood from the vessels of the peritoneum. The last condition has been described as hemorrhagic peritonitis, and especially pointed out by Virelow. Schroder believes that peritonitis always preedes the occurrence of liematocele. That it usually accompanies it is unquestionable, but if it be a precursor of this affection, which suddenly bursts forth upon a patient apparently in good health, it tells badly for our means of diagnosis of pelvic peritonitis. It is undeniable, however, that in some cases hematocele does follow and not precede the peritonitis.

Whatever be the source of the blood, it collects either in the most dependent part of the peritoneum, or in the pelvic areolar tissue beneath it. Here it remains for a time fluid, then undergoes partial coagulation, becoming a grumous mass like currant jelly, and lastly, all the fluid being absorbed, a hard, resisting tumor composed of fibrinous material remains. Should the collection have occurred in the peritoneum, its boundaries will be the walls of that cavity laterally and below, while a localized peritonitis forms for it a roof of effused lymph. If it collect in the areolar tissue of the pelvis, the effised blood will make its own nidus by percolating the loose structure and mechanically creating a space in it.

In either of these positions it is entirely absorbed and reduced to a hard, firm tumor, which remains for a long time, or is discharged by the vagina 
or rectum, or into the peritoneum. The last point of evacuation is fortunately rare. Nonat ${ }^{1}$ quotes Dupuytren for the following very ingenious and plausible explanation of the method of such absorption, which he likens to the process of digestion. The vessels of the cyst which are in contact with the mass remove its fluid portion, and thus its hard surface comes in apposition with the sac. This excites effusion of serum, which softens the fibrinous wall and renders it susceptible of absorption, which soon oceurs. Then again contact excites a flow of fluid, and again this is removed, until the whole mass is diminished or completely absorbed.

Causes.-A glance at the reconnized causes of the disease will make it evident that congestion of the pelvic organs must, in an eminent degree, predispose to it. This explains the fact that it has been found to have oceurred most frequently during the period of ovarian activity and especially during a menstrual epoch.

The predisposing causes are-

The period of ovarian activity, 15 to 45 ;

Disordered blood state, plethora or anamia ;

The menstrual epoch ;

Chronic uterine or ovarian disease;

The hemorrhagic diathesis.

The exciting causes are-

Sulden eheeking of menstrual flow ;

Blows or falls ;

Excessive or intemperate coition;

Ohstruction of cervical canal;

Obstruction of Fallopian tubes;

Violent efforts.

I crieties.-There are two forms of the affection, subperitoneal and peritoneal. In the latter the blood tumor forms within the peritonemm, Where it in time becomes encysted unless death oecur at an early period. In the former, it occurs in the arcolar tissue of the pelvis, under the peritoneum.

'The propriety of the consideration of the former under the same heal as the latter has been contested by Aran, Bernutz, and Voisin, but from a elinieal standpoint it appears to be quite valid. Not only have distinct instances of subperitoneal hrmatocele been recorterl by such obsorvers at Simpson, Olshausen, Tuckwell, and Barnes; eases have, likrwise, presented themselves, which rommencing as subperitoneal ones have ruptured the peritoneal eovering of the pelvis, and thus broken down the theoretical barrier which pathohgists have been inched to establish between the two varieties.

Ot the two varietiss, the peritoneal is much the more frequent, at the

$$
\text { ' op. cit., 1. } 3+4 .
$$


Firi. 2019.

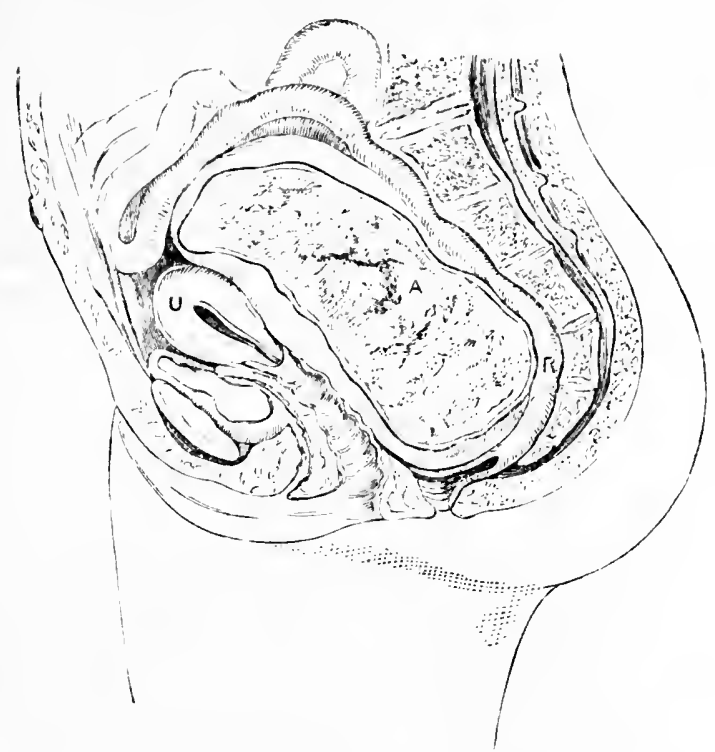

Peritoncal hematucele. (Barnes.)

Fig. 210.

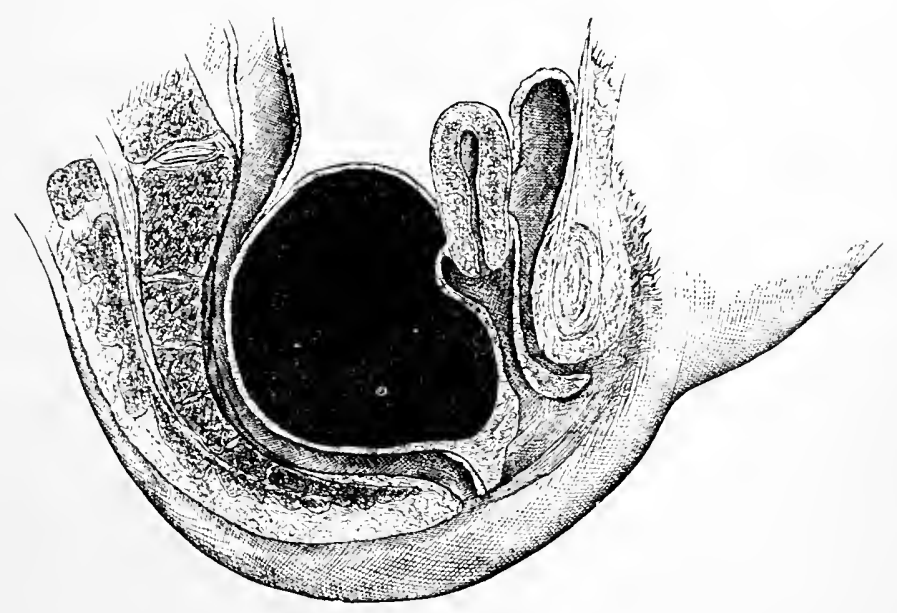

Snhperitoneal hematucele. (Eromet.)

same time that it is the more grave. In 41 autopsies Tuckwell found the tumor to be peritoneal in thirty-eight. In a case which I saw with Dr. Emmet, we were mable to make a diagnosis of a tumor which lay obliguely anterior to the uterus. In twenty-four hours the patient fell into a state of collapse. and as we saw her thus, the nature of the tumor, which 
we were doubtful about on the previous day, hecame evident. Upon a post-mortem exanination an ante-uterine hematocele as large as a goose's egg was found under the peritoneum, through which it had broken, discharged a portion of its contents into the peritoneum, and caused collapse and deatl. This is the only ante-uterine, but not the only subperitoneal, hematocele with which I have met.

Symptoms. - The absolute oceurrence of hemorrhage is generally preceded by symptoms which are premonitory, as fixed, dull pain over the ovaries, derangement of menstruation, metrorrhagia, or prolongation of the menstrual discharge. The symptoms of the actual escape of blood will depend in great degree upon the nature and gravity of the accident which has given rise to it.

Sometimes the affection occurs without any violent symptoms and almost without warning. It will be appreciated that this would be so if it were due to gradual reflux of blood on account of constricted cervix, or transudation, the result of purpura. Frequently a sudden manifestation of symptoms occurs, and the accident is announced as rapidly as is cerebral apoplexy.

It is evident, then, that the symptons must differ widely in cases marked by very great and sulden loss of blood, and those aecompanied by very little. In the first there are evidences of profuse abstraction of vital fluid, great peritoneal shoek, and excessive prostration. In the second these may all be so slight as to escape the notice of non-observant patients. The best course which can be pursued in reference to the matter is, I think, to take, as an exanple, a case of moderate severity, and gnard the reader against supposing that all attacks give the same degree of intensity of symptoms.

Most prominent among the symptoms are-

Severe pain in the pelvis;

Pallor, faintuess, and coldness of extremities;

Sense of exhaustion;

Ninsea aud romiting;

Netrorrhagia;

Cterine tene:mus;

Tympanites;

Interference with bindler and rectum;

Sinall and rapiel pulse;

Depressed thermometric range.

The patient feels as if' a large and heary body exists in the pelvis, and instinctively strives to expel it hy the vagina. At tines the pain complained of is very acute; at others, it is a dull and heavy aching.

Aftre a variable time, generally within forty-eight hours, a reaction from this state of prostration oecurs. Sometimes this is slight; at others lecided. It is rependent chiefly upon the degree of inflammation set up 
by the sanguineous accumulation acting as a foregen benly. This in us aatly matked by the following symptoms:-

Temleney to elilliness;

Constipallion ;

Suppression of mojue ;

Gireat tympanites;

Ileat of skin ;

Iligh thermometric range;

Rapicl julse ;

'Tenteruess over abdomen.

All these symptoms point to two facts: ist, sudelen and excessive loss of blool ; 21, the existence of some substance in the pelvis which mechanically intertieres with its viscera. A part of them might be produced by menorlarga, a lat by sudflen retroversion; but a union of the whole will strongly excite suspicion of hematocele, and call for a plysical exploration.

Pleysiral Signs. - Vaginal touch reveals a tumor usually posterior to uterus and vagina, and generally partially elosing the latter. The mass thus felt, if the examination be made very soon after its formation, will be foumd to be soft, smooth, and obscurely fluctuating. If a number of days hare elapsed before it be touched, it will give the impression of a smooth, dense, solid body. The uterus will be found pressed out of its position, generally upwards and forwards, so that the cervix will be above the symphysis. Sometimes, though rarely, it is forced oat of the median line to one sille.

Nonat dogmatically announces that the uterus is never found between the tumor and the rectum, that is to say, behind the mass of blood; but Chassaignat ${ }^{2}$ reports a case in which the sanguineous eollection existed entirely between the bladder and uterus, and conseruently must have forced that organ backwards; and similar cases are recorded by G. Brann, Olshatsen, Barnes, Emmet, myself, and others.

Rectal touch will show that the bowel is partially dosed by pressure from the tumor.

Abelominal palpation will reveal the presence of a hard mass which may extend only up to the superior strait, or as high as the navel. In cases where a small quantity of blood has been effused, and more especially where this has collected under and not in the peritonetum, an abdominal tumor may not be discovered.

By the aid of conjoined manipulation the shaje, extent, and character of the mass may be further ascertained.

Differentiation. - The diseases vith which hematocele may be confounded are- 
Peivic cellulitis or abscess;

Retroversion;

Extra-uterine pregnancy ;

Fibrous tumor;

Dislocated ovarian cyst.

The mass created by cellulitis and abscess is usually found at the side of the uterus, and not posterior to that organ; it develops less suddenly than hematocele; is hard at first, and gradually softens; is exquisitely painful to touch; does not lift the uterus and press it forwards; and is not usually accompanied by metrorrhagia.

Retroversion may present the signs due to the mechanical results of hematocele, but not those due to loss of blood. If pregnancy coexist, conjoined manipulation will usually suffice for diagnosis. If it should not, the uterine probe will elucidate the case.

Extra-uterine pregnancy does not develop suddenly, but slowly, and is characterized by many of the signs of preguancy. In place of metrorrhagia there is usually, though not always, amenorrhoea.

Fibrous tumors grow slowly, are painless, and move with the uterus. They are irregular and hard, and do not usually push the uterus so far forwarls and upwards.

Displaced ovarian cysts are painless, show no signs of hemorrhage, and canse no constitutional disturbance or metrorrhagia.

Course, Duration, and Termination.-Hemorrhage from the sources enunciated as those of hematocele may be so great as to destroy life immediately. Five such instances are recorded by Voisin, and Ollivier d'Angers' mentions two in which deatl oceurred in half an hour from rupture of a varicose utero-ovarian vein. Such a termination is, however, decidedly exceptional. The tumor generally disappears by absorption, is discharged by the rectum or vagina, or remains a hard, indurated mass long afterwarls. Discharge is most frequently followed by recovery, but sometimes putrefaction occurs in the walls of the sac, septicamia takes flace, and death ensues. The process of absorption may be accomplished in three weeks, or six months may elapse before it is complete.

In some cases a slow and stealy hemorrhage appears to go on for weeks. and render the blooty tumor gratually larger. In others hemorrhages sulsiguent to the first take place after this has become encapsulated. After subsilence of the symptoms of reaction, chill, fever, and sweating often come on late, marking suppuration in the mass, and slight septic alsorption.

Prognosis._The proguosis of hematocele must be governed in great degree by the amount of hood lost, the degree of constitutional shock resulting, and the intensity of reaction excited. $\Lambda$ s a rule it is farorable; 
especially so, I shonld say, when treated npon the expectint plin, and not by immediate surgical interforence.

In cases of peritoncal form a graver prognosis is called for than in the subperitoneal, for evident reasons; and where a grrat deal of bloon hats been lost the dangers are greater than where the amonnt has bedo nore

, limited. This is true not only from the fact that an exessive flow might ealuse deatl from exhaustion, but because the removal of so latrge an amount of coagulum, whether by absorytion or discharge, must necesarily exprose the patient to great dangers.

When death occurs it is usually a consequence of loss of blood, shock from sudden invasion of the peritoneum, peritonitis, rupture of the encapsulated mass into the peritoneum, or septicamial.

T'reutment.-The physician will rarely be called npon to resort to treatment before the amomnt of blood which is destined to be lost has collected in the pelvis. Ile will, however, often be present to witness the great constitutional disturbance and excessive prostration and pain which immediately follow the hemorrhage. The diagnosis being made, the indica. tions for treatment will be simple enongh :-

1st. To eheek tendency to further loss;

2d. To prevent death from prostration;

3d. To relieve pain.

These indications should, as fur as possible, be met simultaneously, for the dangers to be eombated all occur at one and the same moment. The patient should at once, withont the delay attendant upon changing the clothing, etc., be put in a condition of perfect rest, and a full dose of morphia be administered hypodermically. A bladder of cruslied ice or cloths wrung out of iced water should be laid over the hypogatrium, and hottles of hot water or warm bricks wrapped in flamel should be put to the soles of the feet. Should the stomach not be very irritable, brandy and water or iced champagne should be given freely by the mouth.

If prostration be so alarming as to threaten collapse, and the stomach be intolerant of ingesta, brandy or sulphuric ether in loses, the former of two drachms, and the latter of half a drachm, should be injected subcutaneously by the hypodermic syringe.

Reaction having taken place, the most perfect quieturle should be observed, pain should be relieved and nerrous shock prevented by the free use of opium or one of its salts, and the diet should consist of milk, animal broths, and gruels of farina, sago, or indian meal.

And now will arise the important question, whether the accumulated blood should be left for removal by nature, or should be evacuated by surgical means. Récamier, in introducing the subject to the profession, inaugurated the practice of evacuating such tunırs, and Nélaton indorsed and popularized it. But experience tanght Yélaton that the procedure was not judicious, and "to-day he proscribes it in an almost absolute 
manner." Immediate surgical interference presses its claims in consideration of the facts that-

1st. It is eapable of eutting short a lengthy and dangerous disorder;

2d. It may save the patient from the dangers incident to absorption as well as diseharge.

31. It removes from the peritoneum or pelvic cellular tissue a foreign body, which, undisturbed, would prove the foeus of inflammation.

It is not surprising that it was the farorite plan in the infancy of the subjeet. When, however, pathologists had had an opportunity of studying the natural history of the affection, it was as naturally abandoned, for the following reasons:-

1st. It was discovered that, when not interfered with, hematocele very generally passes away rapidly.

2d. It was discovered that the dangers of puneture were greater than those of the tumor left undisturbed;

3d. Nedical means were found to exert a marked controlling influence over its complications.

With the light which experience has thrown upon this point, it appears to me that, without being dogmatic, we may safely adopt this rule. The mere presence of a large amount of blood in the peritoneum does not warrant eracuation. If, as time passes, suppuration within the sac, which has then pretty certainly become eneipsulated, and septic absorption are manifested by chills, febrile action, and profuse sweating, the softening mass should be discharged by incision. In other words, so long as the aceumnlated blood appears to be doing no deeided harm and nature seems to be eausing its absorption, it should be left alone. But so soon as evidences of septicemia are observed, it should be eracuated. Lnder these circumstances, a negleet of surgical interference would be culpable. Without such inlications it should be aroided, and relianee placed upon medical resources, for it should be borne in mind that the collection of blood is usually in the peritoneum, and that ineision of this membrane, in addition to its own inherent dangers, would always expose to those arising from almission of air.

Methorls of Operuting.-The patient being placed upon the back, as if for lithotomy, a trocar and eanula may be hell in the right hand, guided to the most fluetuating and dependent part of the mass, and phunged in. Or, the patient lying on the left side, the perineum and posterior vaginal wall may be lifted by Sims's speeuhm, and an incision made into the wall of the tumor by a tenotomy knife or small bistoury. Through the opening thus made, one or two fingers shonld be introduced and the clots remoral. After eraenation by either method, the nozzle of a syringe should be introluced into the sac, and a stream of tepirl water, or of this with a 
very small amonnt of carbolic acid, slonld be very gently and cantionsly male to wash out the eavity remaining. 'This should be reineded one or twice in twenty-four hours, for prevention of septicamia. All this should, as far as possible, be done under the antiseptie methor.

Alter the abatement of acute symptoms, a blister, four by six inches, should, unless some contra-indication exists, be applied over the hyporastrium, and this may with advantage be repeated every ten or twelve days. Its results will often be very marked, and, although apparently harsh practice, it prevents much suffering, while it eauses but little.

As time passes and pain is relieved, quinine, alone or combined with sulphuric acid, in full doses will prove a valuable remedy, and should be kept up perseveringly.

\section{II A P T R XXXIV.}

\section{MYO-FIBROMATA OR FIBROID TUMORS OF THE UTERLS.}

Definition and Synonyms.-The parenchyma of the uterus is liable to undergo a loealized hypertrophy, wlich results in the production of two varicties of tumors; the fibrous and the fibro-eystic. The first, which is one of the most frequent pathologieal conditions to which this organ is subject, will now receive attention, while the second and much rarer form will be treated of in a separate section.

By the older writers fibrous tumors were styled tubercula, steatomata, sarcomata, etc. Since their true nature has been more carefully studied by aid of the microscope and been understood, they have been described under the names of fibrous tumors, uterine fibroids, fibroma, and more recently, by Virehow, myoma. I have adopted the terms which head this elapter, following the example of Billroth for the first, and of Klob for the second, for the reason that neither that of fibroma nor myoma alone expresses the existing pathological condition. Billroth ${ }^{1}$ rejects the latter name, which signifies that these growths eonsist in hypertrophy of musenlar substanec; and at the same time he refuses to almit the former, as that conveys the equally ineorrect idea that they are construeted of connective tissue. Fibroid (fibrosus and $\varepsilon \_\delta$ ) ), resembling fibrous tissue, is at least not calculated to mislead, while myo-fibroma expresses the exact trutl.

History._Until the time of Dr. William Hunter, who wrote towards the elose of the eighteenth century, the true nature of uterine tibroids was 
not appreciated. 'They were confounded with maligiant growths, of which they were regarded as a variety. He described them under the name of Heshy tubercle, and contributed greatly to the knowledge of their pathology; but it was not until the writings of Chambon, ${ }^{1}$ Baillie, Bayle, and others that the subject was fully elucidated. Sir Charles Clark, in 1814, wrote an excellent chapter upon them, which would almost answer the requirements of our day.

Pathology.-Surprise that any confusion should have existed between these tumors and cancerous growths, will cease when we consider that their identity is boldly assumed by so careful an observer as Dr. Ashwell, as late as 1844. He gives fire reasons for his belief, which he declares appear to him "conclusive." His reasoning has failed to convince others, no writer since his time having adopted the view which Dr. Hunter succeeled in abolishing, and no fact in gynecology is now more fully settled than that of the non-malignancy of these tumors.

Lntil recently the question has not been settled as to the possibility of their undergoing cancerous degeneration. Bayle and Lobstein have declared that they never do so, and the researches of Cruveilhier and Lebert tend to support the riew ; while Kiwisch, Dupuytren, Atlee, ${ }^{2}$ and Simpson believe that malignant degeneration occurs in rare cases. The weighty authority of Virehow $^{3}$ is east into the seale favoring the possibility of both carcinomatous and sarcomatous degeneration, and Klob agrees in this assertion. "In 1862," says the latter author, "a singular specimen was added to the Salzburg Mfuseum. From a fibroid tumor the size of a child's head, situated in the posterior walls of the uterus, carcinoma had undoubtedly been developed without any other portion of the body being affected, and I am therefore constrained to allow the possibility of such a transition, although I cannot recall a second case of this kind either in the literature of the subject or in my rather extensive experience."

Although this case seems to settle the matter of possibility, at least, it must not be forgotten that beyond doubt such a change of type is exceeringly rare. It is in this connection a fact worthy of note that in the negress, in whom fibroid tumors are so common as to be regarded by some as almost universally met with after the thirtieth year, carcinomatous atfections of the uterus are very rarely seen.

I have met with two cases in which uterine fibroids which had been known to exist for eight and ten years, and had behaved like benign growths, suddenly took upon themselves the aspect of sarcoma, and led to a fatal termination. In one case the tumor was removed post-mortem, and in the other ante-mortem with great relief to symptoms.

1 . Wal. de LUtérus.

2 M.Clintock, Diseases of Women.

3 Pathclorie des Tumeurs, Paris, 1871. 
Eterine fi!robls may develop singly, when ordinarily thry do not attain to at very great size. Sometimes, howerer, they exist in great numbleps. and grow to a very large size. Courty reports one weighing fifty pundis, and I have removed one, with nterus and both ovariss, of the same wright. Some years ago I exhibited to the New York lathological Society, the uterus of a negress which contaned thirty-five tumors of every size leetweru that of at fietal heard and that of a marble.

Fibrods may develop in any part of the nterus; hut the usual site is in the body or fundus. Mr. S. Lee examined seventy-four preparations in the Lomrlon museums, and fonnd that the rarest of all locations for them is the cervix. A very interesting instance of a large tumor developed below the os internum is reported by Dr. Nurray, in the sixth volume of the London Obstetrient Transactions. I have myself removed several of this chatucter from the parenchyma of the eervix, the body of the uterus being in 110 wise involverl.

Their structure varies very greatly, not only from their original development being different, but from their being susceptible of several diseased states, which will very soon be mentioned, and which produce their characteristic alterations. The typical form is that of hard, resisting fibrous tissue, which ereaks under the knife. Under the microscope this is foumd to consist of long, fine fibres, generally united in bundles; of fusiform fibre-cells analogous to fibro-plastic elements; and of round or elliptic granules of small size; the whole being bound together by fine intercellular substance.

They consist of the hypertrophier elements of the uterns, to which organ they are strictly homologons. In the majority of cases, it is declared by recent pathological investigators, that connective tissue preponderates in their construction, but there is always a certain degree of muscular hypertrophy concerned in their development; hence Billroth's objection to the terms fibroma and myoma. In some cases the amount of muscular exceeds that of connective tissue in their construction. This, which may be styled the normal type of the uterine fibroid, is departed from by formation of eysts in the midst of the tibrous tissue, which constitutes the tumor one of fibro-cystic character.

Eterine fibroids are liable to a variety of diseases, among which the most frequent are celema; inflammation; gangrene; fatty, colloid, and calcutreous degeneration; and apoplexy. The last consists in rupture of snull bloodvessels within the mass, and consequent acemmulation of blood.

Very rarely the whole mass becomes a ball of calcareous matter, which, projecting in utero and becoming detached, is sometimes discharged per raginam. This is the disease which was described by old writers as uterine calculus. The viterine attachment of fibroids of compound character is sometimes the seat of a species of varicose degeneration of the small 
ressels, which canses the structure to resemble erectile tissue. Tumors thus affected have been styled by Virchow, telangiectatic tumors. This rascular structure readily bleeds, and in one case I saw it the cause of a small

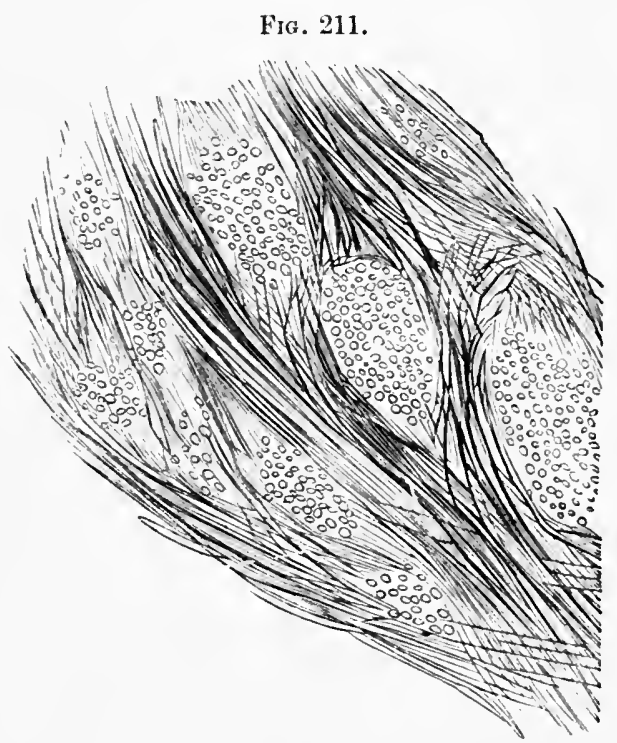

Cterine fibroma. Oblique longitudinal section of muscular ccll-bundles. (Billroth.)

hematocele. But large vessels are likewise discovered in the pedicles of fibroids; Caillard reporting one the size of the radial artery. Klob has met with but one such vessel, which was the size of the uterine artery.

Varieties.-Klob divides these growths into two classes_simple and compound. The first consists of one tumor, which is generally spherical, and which is connected by loose connective tissue with the uterus. The second is a compound tumor, made up of a number of small fibroids, connected by loose connective tissue. The second variety is more vascular than the first, and its surface is nodulated and not smooth. Both these classes present themselves clinically in three varieties, which are created by the locality of the growths in the walls of the uterus. If they lie under the mucous membrane projecting into the uterus, they are called submucous; if under the peritoneum, subserous; if in the wall of the uterus, interstitial.

If a tumor be situated in the wall of the uterus, it may remain there until it assumes large dimensions. Should it be near the mucous or serous lining, it is subjected to contractile efforts on the part of the surrounding parenchyma, which are excited by its presence, and which often in time force it towards the uterine or abdominal ravity. Sometimes its connec- 
fion with the mother tissue is kept up by a broal base; sometimes it is limited to a loner, slender peetiche, which, in the ease of the subperitomeal varicties, allows of great mobility. Should the mass be forced into the uterine cavity, and gradually assume a slender, perhuclated attachnent, it receives the name of fibrous polypus, whith is therefore a variety of submucons fibroid.

'These neoplasms of ten affect the uterus very curiously. The interstitial varieties protuce every form of displacement; the sub-mucous sometimes produce complete inversion of uterus and vagina; and the sub-peritoneal, Virchow declares, by dragging the findus upwards not only draw ont the cervix so as to make it resemble the urethra, but absolutely canse "the spontancous separation of the neck from the body of the uterus." The last variety, too, sometimes shows most singular migrations. 'The pediele being broken, they have at times been found rolling about freely in the peritoneum, and at others, having set up adhesive inflammation, they have been found detached from the uterus, and attached to some other abdominal viscus.

Causes._The predisposing causes, or rather those generally regarded as such, are-

Race, the $A$ frican being peeuliarly liable;

Age, from thirty to forty-five;

Nulliparity ;

Menstrual disorders of long standing.

Concerning the exciting causes, one writing in the year 1874 may, unfortumately, quote the words of Sir Charles Clarke, recorded in 1814: "Nothing is known respecting the cause of this disease." Sixty years of research have thrown no light upon its etiology.

Complications.-The most frequent of the complications which show themselves in the course of the disease are-

Endometritis ;

Displacement ;

Cystitis ;

Obstruction of the rectum ;

Hemorrhoids ;

Pelvic peritonitis ;

Areolar hyperplasia ;

Atrophy of uterine walls ;

Grave menstrual disorders.

Every one who has made autopsies upon cases, in which uterine fibroids have existed, must have been struck by the fact of the varied appearance of the walls of the uterus. Where several tumors exist the uterine carity is sometimes so perverted and rendered so tortuous that it cannot be traced, while in cases where a large number of tumors are formed, the 
whole uterus seems to have disappeared, its place being usurped by tumors. In the case already cited, in which I counted thirty-five tumors, no trace of the uterus could be discovered by the naked eye, above the os internum. In some cases the vice of nutrition set up by the presence of these growths results in thickening of the uterine walls by the establishment of interstitial hypertrophy, in others localized points of thickening exist, while in others still the wall of the uterus may become so attenuated by distention and atrophy as to leave only a thin film to represent it. This distended and attenuated organ is that which Walter has styled the "membranous uterus."

Symptoms.-The enumeration of complications just given is a sufficient explanation of the great number of rational signs which present themselves, for not only do we meet with the symptoms of fibroid tumors, but with those of a variety of disorders which they excite. Most prominent among the symptoms are-

II norrhagia or metrorrhagia ;

Irritability of bladder and rectum;

Pain thronghout the pelvis;

Uterine tenesmus;

Profuse leucorrlicea ;

Dysmenorrhuea ;

Signs of pressure on crural nerves and vessels ;

Watery discharge from uterus.

These symptoms are not equally common to the three varieties of the affection. Subperitoneal tumors often, and interstitial tumors sometimes, are accompanied by none, or at least by very few, of them. It is the submucons variety which most constantly and prominentiy develops them.

The immediate effects of uterine fibroids are exerted upon the system through the following means:-

1st. They produce excessive menstrual discharge and profuse leucorrhea, which impoverish the blood.

24. They press upon and derange the innervation of neighboring parts.

3d. They, in some way, interfere with hematosis and the funetions of the ganglionic nervous system.

4th. They disorder the mind by creation of depression of spirits, from the fact that the patient recurs with gloomy apprehension to their existence almost constantly.

Plysical Sigms.-Although the rational signs are so numerous and striking, they can never do more than exeite a suspicion, which leads to investigation by physical means.

In the case of a large tumor no difficulty in diagnosis will present itself; for the results of varinal tonch, abdominal palpation, and conjoined manipulation will be so decided as to settle the character of the case defini- 


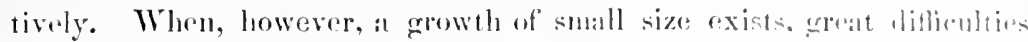

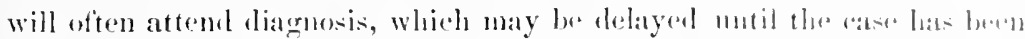
moler observation for a long time. A thomongh examination invelues fult

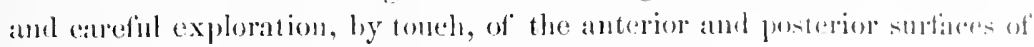
the utrorns, as well als of its cavity to the fimhlus.

'To examine the external surfaces of the uterus, the fationt should lio npon the bark with the thighs flexed. All eonstrietion should be remosed from the waist, and the blabler and rectum emptiol. 'The raminer then, depressing the utroms by the right hand placed over the hypegastrium, should sweep the index finger of the other as high up as possible over the posterior wall, first hy raginal and then by rectal tonch. While the tinger in the vigina or rectum lifts the uterus, the tips of the fingers placed on the abkomen should be foreed behind the fundus, and downwards over the posterior uterine wall so as to approale the finger within the pelvis. By these means the posterior wall will be superficially examined in women with tense abdominal muscles, thoroughly in those in whom they are thin andralaximl.

The finger in the ragina now drawing the cervix forwarls, the fingers of the hand on the abromen slould be marle to depress its walls so as to swep from the funlus over the anterior surface down to the cervix. The finger under the cervix lifting it up will offer itself as an opposing force to the hand on the abdomen. This manocurre will fully expose to examination the anterior surface of the uterus, unless the patient be very fat. Should she be so, a tenaculum may be fastened in the cervix, and the uterus drawn down by it, so that the posterior wall will he better within reach of rectal totich, and the anterior wall within that of vacinal rxplonation when the finger is pressed firmly against the base of the hadder.

When, in a case in which it is of importance that a certain diagnosis sionld be arrived at, it proves impossible to do so by nse of the means thus far mentioned, the morlifiontion of Simon's method, muntioned in the chipler npon Diagnosis, may be resorted to with great contidence as to the re-ults whieh it will yield.

For investigating the interior surface of the uterus, the neck should be finlly dilated by tents, and inmediately upon their removal. the uterus being depresced as for examination of the outer surface, the finger should be carried into the cavity of the horly.

Differentiation.-The disenses which may be contomded with fibrous timor's are-

Pregnaney :

Periuterine cellulitis or abseess;

Pelvie hematoecle;

Anteflexion or retroflexion:

Ovarian tumor:;

Fecal impaction. 
In pregnaney, amenorrlice and other signs of utero-gestation exist, while in uterine fibroids there is usually a tendeney to menorrhagia. In pregnancy the uterus is symmetrical, in fibroids usually asymmetrical. The tumor found in pregnancy is generally softer than in fibroids, and more uniformly median in position. In a doubtful case time, with its development of fotal movements, will always settle the point.

The tumor ereated by eellulitis is usually immorable, very sensitive, accompanied by fever, eomes on suddenly, and fixes the uterus. $A$ fibroid tumor is the opposite of this in every respeet.

Itematocele generally oceurs suddenly and with violent symptoms. The tumor is sensitive and immovable, at first semi-fluid, and aceompanied by tympanites and constitutional disturbance. Fibroid tumors show no such symptoms.

Flexion may be determined by the uterine probe, and differentiation estahlished between it and fibroids by conjoined manipulation and rectal tonel.

Orarian tumors of solid form are the only ones which usually give diffculty in diagnosis, and these are rare. They are unacempanied by menorrhagia, can be pushed from side to side without affecting the position of the uterus as ascertained by raginal touch, and are less affected by movement of the uterus by means of the uterine sound. In eases where an ovarian tumor is firmly attached to the uterus, differentiation is not only difficult, but often impossible.

Fecal impaction presents a tumor which ean often be indented by pressure, is generally in the eaput coli, does not move with the uterus, gives severe intestinal pain and disorder, and exerts little influence on the functions of the uterus.

From this rapid disposal of the subjeet of differentiation it must not be supposed that it is always an easy matter. In many cases only carefinl watehing will enable the diagnostician to arrive at a certain conclusion.

Prognosis.-The practitioner cannot be too catutious or display too much reticence in pronouncing the prognosis of uterine fibroids. There ane few diseases in which the young physieian will be led into greater error or be made to regret more decidedly an over-contident prediction. Fibroid umors, unless of great size. rarely end fatally, however gloony the prospeet may alplear when they are tirst discovered. And yet death from them is not so infrequent as to warrant an entirely favorable prognosis.

Frequrncy.-These statements are to a certain degree corroborated by an examination into their frequency. Were they as dangerous as is sometimes sulposed, a large number of deaths would be annually produced by them, for, to use the worls of MeClintock, " without question the most frepuent orratic discase of the uterns, if we except inflammation and its effect., is fibrons tumor." bayle estimated that of all women dying be- 
youd thirty-five years of age, twenty per cent. were thus atfecterl. Lirn supposing that this assumption was an exaggerated one, an illea of the frequency of the aflection may be gathered from the fact of his venturing upon it, and surprise at it will be modified when the following extract is reacl from Klob." In speaking of their frequency, he says, " $\Lambda$ t the climacteric periol, it is such that undoubtedly 40 per cent. of the uteri of females, who die after the fiftieth year, contain fibroid tumors."

Let the diagnostician who has discovered a uterine fibroid, and feels prompted to give a grave prognosis concerning it, bear these facts in mind, and he may be prevented from injuring his patient's comfort and his own reputation by so doingr.

Conrse, Duration, and Termination._As already stated, these growths may attain the enormons weight of fifty pounds. Fortumately they rery rarely reach such dimensions, but even when they do not, they sometimes exhaust the patient by metrorrhagia, leucorrhoa, hydrorrhoa, and a low grade of constitutional irritation, often attended by hectic fever. But this termination, like the preceding, is exceptional. Having attained a moderate size they generally remain stationary, or increase slowly until the menopanse, creating considerable inconvenience and depreciating the patient's strength by hemorrlage. Then undergoing a certain degree of atrophy with the cessation of uterine and ovarian functions, they cease to be, to any degree, a source of annoyance, or at least of danger. Even cluring the age of uterine aetivity, nature may, unaided, effect a cure by the following means :-

Absorption or atropliy;

Direct expulsion by rupture of attacliment;

Sloughing, from deprivation of nutrition, or inflammation;

Calcareous degeneration;

Gangrene.

The tumor is sometimes deprived of nutrition by inflammatory action occurring in the rascular structure of the uterine attachment, which has already been described, collections of pus being sometimes discorered in it.

Throughout their existence these tumors sympathize in the uterine changes which attend upon these three conditions: menstruation, uterogestation, and the menopause. With the occurrence of menstruation they, like the tissuc of the uterus, become congested, enlarged, and sensitive. During pregnancy their component muscular fibres grow, and probably undergo retrograde metamorphosis after delivery. As senile atrophy succeeds the menopanse, their nutrition is impaired, and fatty and calcareous degeneration sometimes occur.

Sometimes fluid collections take place within these masses, some morbid process destroying their tissue as if by hiquefaction. The fluid thus col- 
lecting may be purulent, watery, or sanguineous. In some cases a colloid degeneration is said by pathologists to occur in or near the centre of the mass, which softens down and liquefies the fibroil tissue. In others, an apoplexy takes place, which creates the initial carity, and this is sulsequently found filled with the débris of the clot and with turbid serum.

Pallintive Treatment.- In the vast majority of cases of interstitial and subserous fibroids, the efforts of the practitioner should be limited to palliation of the evils resulting from these growths. These evils will generally be due to either one or all of the three following conditions which result from them: displacement of the uterus; pressure on surrounding organs and parts; and menorrhagia or metrorrhagia. The first will of ten he greatly relieved by restitution of the displaced organ, and its retention at, or even above, the superior strait. This may be accomplished by the ordinary means of replacement, and the use of the bulb pessary (Fig. 192), in difficult eases, or of one of the varieties of intra-raginal anteversion or retrurersion pessaries, in less obstinate ones. By a properly adjusted pessary, aider by complete removal of weight and constriction from the abdomen, ant the use of an eflicient abdominal pad, the second set of evils may be ameliorated. Relief of hemorrhage generally proves difficult, and not rarely impossible. The presence of the fibroid in utero keeps up congestion of the endometrium, and this results in leucorrhoa, hydrorrhea, and menorrhagia. Fortunately, good cin generally be, to a limited extent, at least, effecterl by rest in the recumbent posture during the menstrua! periods; the use of hemostatic agents, as elixir of vitriol, ergot, viscum album, cammabis indica, gallic acid, cte. ; and the use of the tampon atter at sufficient loss has oceurred to meet the demands of ovulation. The practice of applying a tampon of earbolized cotton impregnated with solution of alum after a menorrhagic flow has, under these circumstances, lasted for four or five days, I often resort to, and never with any but grool results. Without some sueh controlling intluence, the patient will commonly become greatly exalnguinatel. While these means are being alopted the bowels should be kept regular, and the functions of the skin aut liver carefilly sujervised.

In some cases the engorged conlition of the mucous membrane lining the uterus causes it to become covered by little fingoid growths, which keep up and greatly increase the amount of hemorrhage. Lnder these circmustances, the applieation of the wire curette is of great service. Even if there shonld be an error in diagnosis, this treatment will accomplish grow by severing the distemded ressels of the mueons membrane, and relieving congestion.

Should it be foum that by this means aven. liemorrhage is not sufticiently controlled, resort should be promptly had to palliative resources of a mare dereidedly surgical character. These may prove effieient as 
hemostatics, while at the same time they prepare the way for curative means, if they should be in time deemed neessary.

It has been found that hemorrhage due to uterine fibroils is often greatly diminished by section of the uterine neek, a praetice which was first inaugurated by Amussat, and imitated by Nélaton, Brown, and IICClintock. In some not very explicable manner, cutting through the cervical canal by deep incisions on its sides exerts a good influence in controlling this form of hemorrhage. A still more powerful effect will follow incision direetly through the investing coat of the tumor itself, so as to cut its capsule, its superficial layer of fibres, and its superficial bloodvessels, and thus diminish its vascular supply. When, however, the tumor becomes so accessible as to render this possible, complete removal becomes so likewise, and should be preferred.

Curative Medicinal Means. - Whether absorption of these neoplasms can be excited by any of those medicines styled absorbents, is not certainly ascertained. Tumors have in some instances been known to disalplear while such drugs have been employed, and perhaps they did so in consequence of their use. But no such effect can be looked for with any confilence. Indeed, with our present experience, such a result must be regarded as decidedly exceptional. Scanzoni, after advising those medicines which are most popular as stimulants of absorption, says, "We do not remember a single case in which, with the means indicated, or with others, we have obtained the complete cure of a fibrous body." If such drugs be tried for this purpose, they should be continued for many months, and even a year or two, before the trial can be considered fairly made, for their action is never immediate. Those in greatest esteem are iodine, the iodicle and bromide of potassium; that class of drugs supposed to possess the power of inducing fatty degeneration, as arsenie, phosphorus, and lead, "steatogenic" drugs, as they have been styled; preparations of lime; and the waters of certain mineral springs, as Kreuznach, Kissingen, Krankenheil, etc. Some of these waters may be employed externally in the form of baths as well as internally.

About eight years ago, a series of eight cases of uterine fibroids was published by Hildebrandt, ${ }^{1}$ of Königsberg, in which the only treatment alopted consisted in the subcutaneous injection of ergot. In seven, an extraordinary improvement took place. The theory of the plan is this: compression of the tumor by ergotic contraction of uterine fibre interferes with nutrition; fatty degeneration in consequence occurs; and the tumor is thus rendered susceptible of absorption. The results obtained by Hildebrandt were so favorable, that even the most sanguine were led to fear that future experience might not prove as successful. His method has, how-

I Berlin Klin. Wochenschrift. Amer. Journ. Obstet., Nov. 1872. 34 
ever, been so far tested by others that it must be conceded that it promises better results than any other which has been employed.

'The following is a condensed synopsis of some of Hildebrandt's cases:-

CASE 1. Patient æt. 31 ; tumor for three years; uterus as large as at seventh month of pregnancy; hemorrhages frequent and copious. Injections of ergotine practised daily for sis weeks, when meuses became regular and painless. Injections continued daily for fifteen weeks more, when tumor, which had been growing smaller from week to week, was found to have disappeared.

CASE 2. Under use of injections uterus "diminished in volume by absorption of the intrauterine tumor; menstruation became regular; and pain and leucorrhoea disappeared."

CaSE 3. Patient $x$. 30; profuse sanguineous discharges, sometimes lasting from six to eight months, since the age of sixteen. Anæmia and emaciation extreme; fundus of uterus nearly midway between pubis and umbilicus; by tonch, tumor distinguished in the anterior wall of uterus. Subcutaneous injections daily from January 17th to March 5th, when the patient was discharged ; menses regular; general condition improved; and uterus notably diminished in size, the vaginal portion having in great part returned to its normal volume.

Case 6. Patient ret. 45; uterus reached to umbilicus ; anteverted ; large fibroid in anterior wall; hemorrhage; and irregular menses. After resort to injections, improvement was well marked; fundus descending to a point midway between umbilicus and pubes.

The solution used by the hypodermic syringe consisted of three parts of the aqueous extract of ergot to seren and a half of glycerine and the same of water. The point of puncture was the hypogastric region. At each injection three grains of the extract were used.

In some cases this treatment produces severe ergotism at so early a period that it has to be desisted from, while at others it results in the production of small abscesses of painful character. Hildebrandt declares that the introduction of the needle straight down into the subcutaneous areolar tissue obviates the occurrence of abscesses. Should the subcutaneous method disagree with the patient, as it did in two out of Hildebrandt's nine cases, ergot may be given by month or rectum, with the prospect of exciting tonic uterine contraction, diminishing vascularity, and lessening sanguineous and mucous discharges, and subsequent growth of the tumor.

Although the experience of others with this practice has not been so good as that of Prof. Hildebrandt, all who have tested it must admit that his method possesses great merit, and fills a place in treatment which has heretofore been unoccupied. Ergot not only acts by exciting uterine action and thus interfering with the growth and retention of the neoplasm, but it likewise canses contraction of the bloodvessels themselves, and thus impairs nutrition and limits development. Its advantages as a palliative 
means have been already mentioned; in that eapacity it also acts in the two ways, of constrictor of uterine fibre and of arterial muscle. 'This explains its results in hemoptysis and other varieties of hemorrhage. Prof: Hildebrandt, in the American Journal of Obstetries, gives an account of 19 cases, and in the Berlin Klin. Wochenschrift of 8 cases, in which he has treated fibrous tumors of the uterus by hypodermie injections of ergotine. Ont of the number 3 were eured; 11 were diminished in size, and the metrorrhagia and leneorrhoea cured; 4 showed no effect from the treatment; and in 9 the tumor was not affected, although the hemorrhage was relieved. One tumor of very large size extending above the umbilicus entirely disappeared.

IIe considers the treatment most likely to result farorably-

1st. When the tumor is submueons;

2d. When the tumor is richly provided with museular tissue, and possesses the consistence and feel of a tense, elastic cyst;

3d. When the walls of the utcrus are sound and capable of vigorous contraction;

4til. When the ehronic metritis or parametritis has been removed by proper treatment;

5th. When the tumor has colleeted no capsule.

Byford has collected 101 cases from various sources; of these he report:-

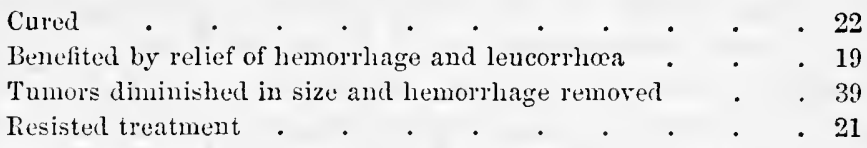

The best preparations for hypodermic injection that I know of are Squibl's ergotine dissolved in glycerine and water, Merek's ergotine, and Bartholow's solution.

These should be used fresh, the needle should be previously washed in earbolized water, the fluid thrown well down into the subcutaneous cellular tissue, and the part gently rubbed with the palm of the laand after injection until all tumefaction disappears. The injections should be given from three to seven times a week.

Subperitoneal tumors are not nearly so favorably affected by this method as interstitial and submucous growths. In the last variety the danger of the ereation of sloughing at a time when the rigidly contracted state of the os prevents resort to surgical procedure for immediate removal should not be overlooked. I lave seen quite a number of fatal eases from this cause.

Hildelrandt's method is a very trying one for the patient. Many suffer from abseesses, some from severe uterine pains, while others positively object to the pain and annoyance of repeated punctures to such an extent as to cause the physician to desist from treatment. 
Dr. Ephraim Cutter, of Boston, has obtained excellent results in these cases from a strictly animal diet of the most nutritious character, and the passage of the galvanic current through the tumor by puncture on each side of the abdomen by strong steel electrodes. He declares that very little constitutional disturbance follows these punctures, and that great diminution of size commonly results, with occasional complete cures.

In April, 1880, Dr. Cutter reported to the Boston Gynecological Society the following results:-

\begin{tabular}{|c|c|c|}
\hline No. of cases treated by el & ectrolysis & \\
\hline No in which growth was & arrested. & • \\
\hline No. in which growth was & not arrested & • \\
\hline No. which ended fatally & - & - \\
\hline No. which were cured & . $\quad$. & . \\
\hline No. which were relieved & nerely & • \\
\hline
\end{tabular}

Before taking up the consideration of the surgical resources applicable to uterine fibroids, I would sum up the general management of their varieties in the following manner:-

1st. With the means at present at our command, all the varieties of fibroids, the subserous, the submucous, and the interstitial, are amenable to extirpation; but the danger of removing thle first by laparotomy is so great that this should not be resorted to unless life be threatened by the non-removal of the tumor.

2d. If an interstitial fibroid be readily aceessible by cutting throngh its investing tissues, it shonld be removed.

3d. Submucous fibroids divide themselves into two classes, thus: if the os internum be obliterated, and the tumor present at or within the os externum, the case is most favorable for removal; if the os internum be unyielding, and the cervical canal undilated, danger will always attend dilatation preliminary to removal of the growth.

4 th. In cases unfarorable for removal it is best to resort to good diet, tonics, ergot, and means ealculated to palliate symptoms, and await an alteration in existing eircumstances which may prove more farorable to a resort to radical treatment.

Curative Surgical Procedures. - The gynecologist of to-day in recognizing the important allances in his department, signalized by the discovery of ovariotomy, the cure of vesico-vaginal fistula and reparative operations upon the perineum, the uterus, and the raginal walls, often forgets low much has been done in reference to the extirpation of uterine filbroids of all three varieties. Prior to the present century, and even during the first half of it, the operation of laparotomy for subperitoneal tumors of this class was unknown; interstitial tumors were uninterfered with; and he who studies the methods of those who attacked submucous growths by the constricting ligature, will at once appreciate how hazardons. difficult, and uneertain were the means at the disposal of the surgeon of the olden time for dealing with them. 
The key-note to the modern alvance in this subject was struck by the late Dr. W. L. Atlee, of Philadelphia, when in the year 18.53 he presented to the American Iedical Association an essaly entitled, "The Surgical Treatment of Certain Fibrons 'Tunors of the Uterus heretofore considered beyond the Resources of Art." This essay received the prize of the association, and to-day stands as the pioneer article in the surgical literature of these grave and otherwise irremediable cases.

Both in this country and in Europe the lead of this bold surgeon has been followed, and the methods which he advocated a quarter of a century ago, and which slowly battled with a pretty deeided opposition, have come to be recognized as legitimate surgical resources.

The riews of Atlee, as published in 1853, may be epitomized in these three propositions :-

First-If a non-pediculated tumor cannot, from the nature of its attachment and envelopes, be expelled or drawn by mechanical means through a dilated os uteri, it is advisable to make by the linife a means of escape for it into the uterine carity, through its capsule or enveloping tissues.

Second_-If the tumor thus offered an outlet eannot be removed, it should be forced into and out of the uterine eavity by eutting the cervix, and persistently using ergot.

Third-The tumor, once coming within reach, it should as soon as practicable be enucleated or detached, and removed by the surgeon.

That this method of treating such cases is attended by the great dangers of septicamia, peritonitis, hemorrhage, and exhaustion, is not to be denied. But it must be borne in mind that while heroic interferenee is environed by risks, a Fabian course, a policy of watching, waiting, and inactivity, is by no means always a safe one. The growing tumor ereates exhausting hemorrhages, dangerous mental depression and anxiety, and disturbance of the functions of nutrition and exeretion, which slowly drag the patient down to death.

The dangers attending strangulation of a uterine tumor by a constricting ligature are now recognized as of so grave a character as to render every cautious surgeon arerse to the employment of this method, and although the boldness of the plans recommended by Atlee may appal the timid practitioner, it is now pretty generally appreciated that in apparent temerity there is a degree of safety not to be found in measures which are ostensibly milder and safer.

The plans now usually adopted for the extirpation of subuneous and interstitial fibroids may thus be summarized :-

Excision ;

Étrasement;

Avulsion;

Enucleation ;

The production of sloughing. 
The two elements which govern success in the removal of these growths by the surgical processes which now eome to be eonsidered are these : 1st, the degree of projection of the tumor into the uterine cavity ; $2 \mathrm{l}$, the degree of dilatation of the cervical eanal. I do not say that they decide the propriety of operation. Removal may be practised where the tumor is to a great extent interstitial, only causing slight protrusion inwards of the mucous membrane, and where the eervical eanal is completely contracted. But in such eases it is more difficult of accomplishment, and much more dangerous to the life of the patient. An interstitial fibroid exeites uterine contraetions, which in time usually extrude it, making it either subserous or submucous. In both cases it carries with it a covering of uterine tissue, which when it enters the uterine cavity is one of the influences which prevent its expulsion into the ragina; the elosure of the cervix being another. In some cases nature unaided overcomes these obstaeles. When they are too powerful for her, art eomes to her aid and removes them.

If the cervical canal be sufficiently dilated to allow of immediate aceess to the tumor, much danger, delay, and trouble are avoided by that condition. If it be deemed lest to force open the way to the neoplasm, the cervical canal may be distended by entting through it up to the vaginal junction, and giving ergot to expand it; by dilating it gradually by tents; and by foreibly dilating it by water bags, or by graduated dilators. Hydrostatic dilatation is applicable only when the part is dilatable, and offers little resistanee.

The ordinary water bags known as Barnes's dilators are not powertul enough for the expansion of the cervix of the non-puerperal uterus, and besides this they dilate irregularly. Molesworth's dilators, shown in Fig. 212, are by far more efficient in these eases. This instrument consists of

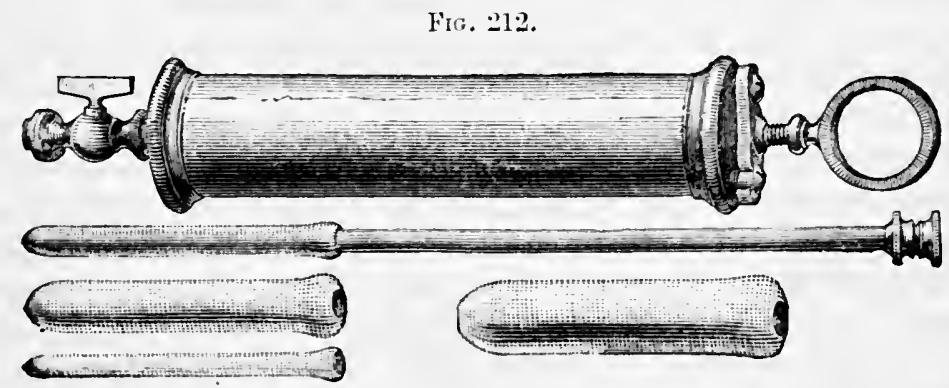

Molesworth's cervical dilators.

a scries of long bags of purc rubber, constructed in such a manner as to secure lateral expansion without elongation, and a niekel-plated force[mun, workerl by screw power, by which water or air can be foreed into the bag, to dilate it ats rapilly or as slowly as desired. Each instrument 
has a small stopcock, enabling the operator, if he desire, to remove the pump, leave the bag in position, and thus continue dilatation for any length of time.

Each instrument has several hags, the smallest of which is one-eighth of an inch in diameter, and capable of being dilated to from one-half to three-fourths of an inch. The largest bag is one-fourth of an inch, and can be dilated to from one to one and a half inclies.

The method which I have found safest and most certain for preparatory dilatation of the cervix is that of cutting through its walls laterally by Paquelin's thermo-eantery in the direction shown by the dotted lines in Fig. 213, and then keeping the patient under the hypodermic use of ergot.

Excision._Should a small submucous fibroid project into the uterine carity, it

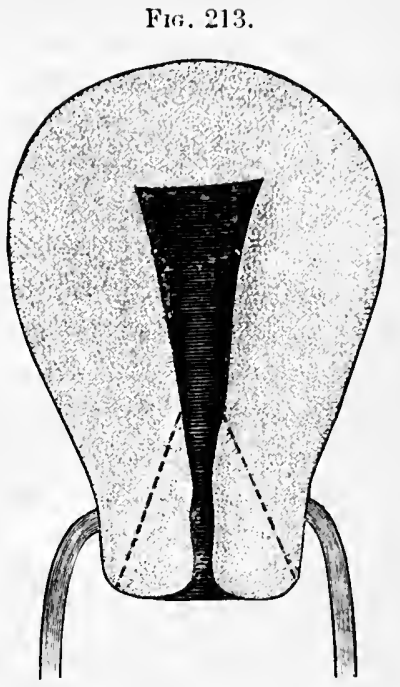

Incision of cervix by Paquelin's knife for the accomplishinent of dilatation.

may be removed by the severance of its attachment by means of the knife, scissors, or other cutting instrument. If it be within reach of the knife or scissors, it may be removed by them. In case it be attached higher in the uterine cavity, the polyptome of Aveling may be made to answer a good purpose (Fig. 214).

FiG. 214.

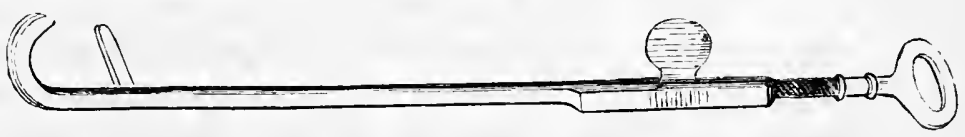

A reling's polyptome.

Removal may likewise be accomplished by the forceps of Nélaton, represented in Fig. 215, or by long-handled, curred scissors, by which as

FIG. 215.

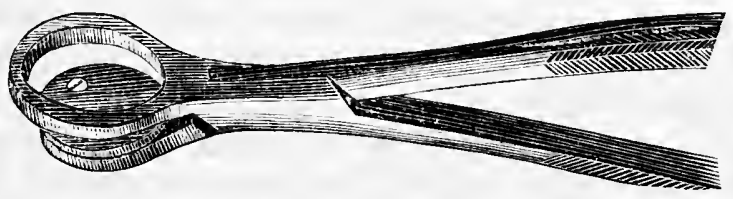

Nélatou's forceps.

much as can be got within their blades should be cut away. In this way, piece by piece, a large portion or the whole of the grow th may be excised. 
Écrasement._In many cases in which excision may be practised, écrasement becomes possible and should be preferred. The operation consists in cutting off the mass, as near its attachment as possible, by the écraseur. This instrument, the invention of M. Chassaignac, of Paris, consists of a

Fig. 216.

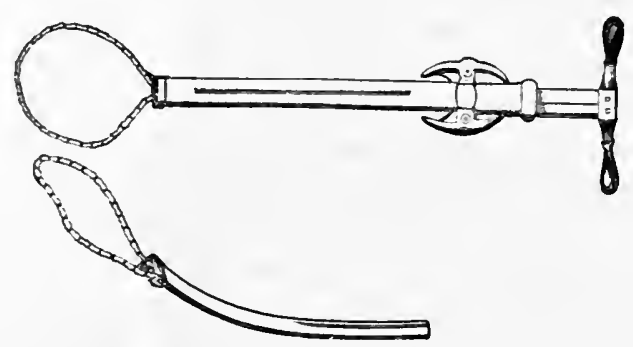

The écrascur, straight and curved.

flattened tube of steel which has two rods of the same metal passing through it to its upper extremity (Fig. 216). To the end of each of these

Fig. 217.

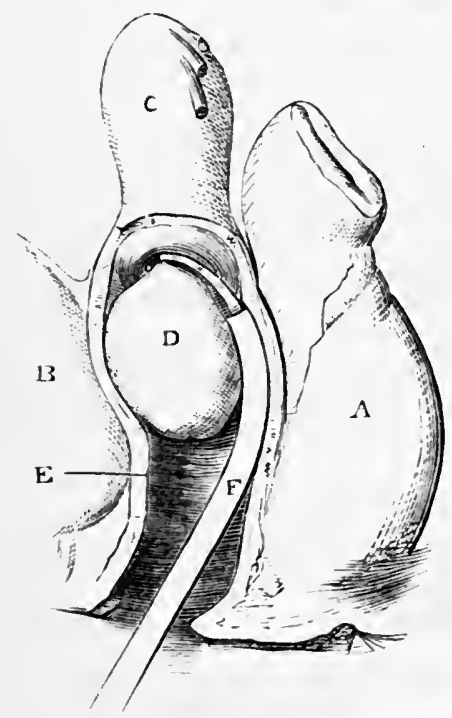

The icraseur at work. the extremity of a chain is attached. This is passed around the part to be cut off, and the rods are retracted by a ratchet movement at the other extremity. Stearlily and slowly the chain tightens around the mass and euts its way through ir. The écraseur not only presents the great adrantage of prevent ing hemorrhage, but experience proves that after its use inflanmatory action is much less likely to occur than after that of cutting instruments. Should the tumor be small and have passed out of the uterus into the vagina, the chain of the écraseur may be jasserl over it as a noose, by the fingers. If it be small and inside the uterus, or if the tumor be of great size, whether in the vagina or uterus, it may be necessary first to pass a cord around it by means of callulae, and in this way to draw in place the chain, which may be subsequently attached to the écaseur.

In many case the use of the écrasenr is so difficult that it becomes ineffectual. Under these circumstances the wire rope écraseur of Dr. Braxton Ilicks answers a most excellent purpose. Its constricting wire is stiff, 
small, and manageable, and thus we may be able to ensnare a tumor which was unattainable by Chassaignae's instrument.

Should the tumor be very large and fill the vagina completely, there are two methods by which it may be entirely removed: 1st, it may he drawn down by obstetric forceps and delivered; $2 d$, it may be cut away, piece by piece, until its base be reached. By the first plan the uterus is temporarily inverted, the morbid growth removed by the knife, scissors, galvano-cautery, or écraseur, and the uterus replaced, after the stump, should it bleed, has been seared by the red-hot iron. Of these I greatly prefer the second, which I have often practised, and never with hemorrhage as a result.

Avulsion. - The cerrix being dilated, the tumor is seized by vulsellum forceps and firm traction, with slight rotatory movement, made upon it. Under this tractile force its uterine attachments may be ruptured and the tumor come away. If it do not do so, the operator passes one hand into the vagina and two fingers into the uterus, by which he ruptures the attachments of the growth and thus frees it. Meantime the hand of an assistant is placed over the hypogastrium to steady and depress the uterus. Dr. West," writing in 1864 , says, "The foreible avulsion of polypi is a rough and hazardous proceeding, a relic of barbarous surgery."

Enucleation.-Where the attachments of the tumor are so extensive, or where it is so much embedded in the uterine parenchyma, as to render it impossible to practise upon it any of the procedures already described, the operation of enucleation offers itself as a most efficient and valuable resource. It has been stated that the attachment of submucous and even interstitial fibroids to the uterine wall is not firm, they being surrounded by a layer of loose cellular tissue. This fact suggested many years ago, to the mind of Velpeau, the possibility of enucleating them, and in $1840 \mathrm{M}$. Amussat put the theory into practice. At the same time that it must be regarded as a valuable resource in many difficult cases, it cannot be denied that it is one attended by great hazard, as it may be destructive to life by inducing exhanstion, hemorrhage, perforation of the uterus, pyamia, or inflammation of the pelvic viscera. Dr. West reports twenty-eight cases in which it was performed, fourteen of which proved fatal.

"Peritonitis, phlebitis, and pyæmia," says Dr. West, ${ }^{1}$ in estimating the prospects of success held out by enucleation, "the consequences of violence done to the uterus of women exhausted by large and frequently repeated floodings, are dangers from which but few have altogether eseaped; under which I fear that correct statistics will show that most have succumbed." The dangers attending its performance should not deter the surgeon from resort to it in suitable cases which absolutely require aid. They should merely induce him to exhaust all palliative means before resorting to this. 
Enucleation may be practised by two methods: immediate, in which the fingers of the operator at one sitting accomplish the removal of the tumor; and gradual, in which the fingers of the operator merely inaugurate the process which contractions of the uterus are excited to complete.

If the first plan is to be pursued, the patient, after previous complete dilatation of the cervical canal, is placed upon her back upon a strong table, the legs being held by assistants. An assistant firmly depresses the uterus by pressure on the abdomen, and the operator, by means of a pair of scissors, guided by two fingers, cuts into the capsule. Into this opening he passes the index finger and fixes the tumor. By means of scissors or a probe-pointed bistoury a crucial incision is then made through the capsule as freely as circumstances will admit. Passing one liand cautiously into the ragina, and forcing the uterus towards the vulva by his other hand and that of an assistant, he now proceeds to peel back the capsule and gradually to enucleate the mass. Usually the desired result will be accomplished, and an artifieial os thus offered for escape of the tumor from its capsule. If the vagina be not very dilatable, it latd better be prepared for these manipulations by copious warm raginal injections and gradual distention by water bags.

If the second plan ${ }^{1}$ is decided upon, the os being dilated or incised, a long crucial incision is made over the presenting part of the tumor, the lips of the capsule separated by the finger, and the patient put upon the steady and systematic use of ergot, in the hope that the body of the tumor may present through this species of os, and be expelled by uterine efforts.

Production of Sloughing.-Baker Brown and others adopted for the remoral of these growths plans for mutilating them, and thus•establishing the process of sloughing by which, a partial liquefaction of their tissue being effected, they could be more readily discharged by uterine efforts or remored manually. I mention the plan only to inveigh against it in the strongest terms. It slionld be cast aside for the reasons that it is attended by very great dangers, and that much better ones are at our disposal.

Althongh these methods are, as I have stated, far in advance of strangulation by ligature, to all of them serious objections and deficiencies attach. Excision, from the fact that it is, except in the case of pediculated growths. diflicult to reach the point of uterine attachment by knife, scissors, or polyptome, is often impracticable. Torsion can be applied only to pediculaterl tumors. Avulsion and enucleation are difficult of accomplishment, slow of performance, and so exhausting to the patient that she is in dan-

1 An excellent résumé of this subject, including loth the immediate and gradual forms of enucleation, will be found in the Med. Times and Gaz., Aug. 1857, by Mr. .J. IIutchinson. I mention this particularly because some more recent writers ajevear to regard this node of dealing with fibroids as entirely new. 
ger of siuking in consequence. Écrasement frequently fails to remove the entire growth, and leaves the uterine attachment to decompose and cause septicamia. And the removal of uterine tumors by the establishment of the process of sloughing, insures so certainly, as las just been stated, the great dangers of septic poisoning, that this method should, in view of the ficet that mueh safer ones are at our disposal, be now regarded as unwarrantable. Instead of the occurrence of sloughing being conrted by the surgeon, it should in these cases be feared, and avoided by all the means by which he ean oppose its development. One of the great objections to the use of ergot as at means of causing the enucleation or expulsion of large submucous growths is the tendency of the compressing influence of the uterine fibres to impair the nutrition of the neoplasm so completely as to produce its deatl and decomposition.

Dr. Emmet advocates very strongly the removal of fibroids projecting into the uterine cavity by firm traction, which he thinks causes the uterine parenchyma to expel the tumor in imitation of a natural process, and then eutting off the most prominent part attainable in the ragina by curved scissors. In this way he reports the successful removal of a number of large fibroids.

I now proceed to lay before the reader a plan which experience leads me to regard as superior to any of these, and which I believe will supersede them with all who are willing to give it a fair trial. This method consists in seizing the tumor at its most dependent and accessible point with strong vulsellum forceps, passing up along its sides the spoon-saw or serrated scoop depicted in Fig. 218, and by a gentle, pendulum motion from side to side sa wing through the attachments of the tumor and freeing it entirely from its connections with the uterus.

This instrument consists of a steel spoon with a strong handle, twelve or thirteen inches long. The spoon itself is slightly convex upon its outer, and concave upon its immer surface, while its borders are serrated. The saw teeth are blunt and not slanted in either direction, but perpendicular. The outer convex surface protects the uterine wall entirely, while the inner and concave canses the instrument to hug the tumor and run along its surfice as it cuts its way laterally and upwards.

The advantages which experience teaches me attach to this instrument are the following: 1st, the attachments of the tumor are separated by a saw, which greatly limits hemorrhage; $2 \mathrm{~d}$, the shape of the spoon, convex without and concave within,

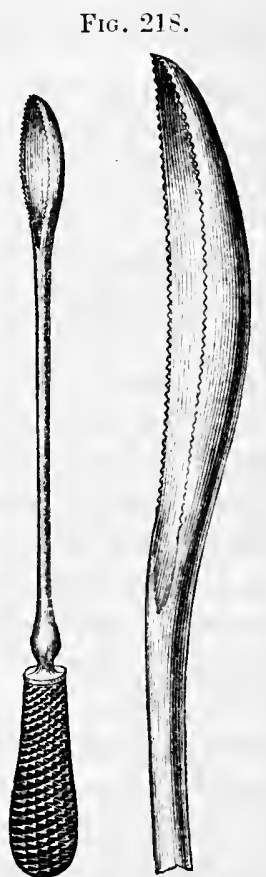

The spoon-saw. 
causes it to follow of itself the contour of the tumer unless this be very lobulated, and protect the enveloping uterine tissues from injury; $3 \mathrm{~d}$, the highest points of attachment of the tumor are as readily reached as the lowest, the freel growth descending under traction as the saw severs its adhesions in successive sweeps around it; 4 th, the saw action gives to the process of separation, whether the growth be interstitial or submucous, sessile or pediculated, rapidity and certainty ; and 5th and last, though by no means least, the nature of the spoon-saw secures separation of a grow th at the highest point of its attachment, leaving no peduncle to decompose.

Before endeavoring to remove a sessile uterine fibroid, it is always advantageous to learn as much as possible about the degree of its attachment. Not that even universal attachment should prevent the removal of the neoplasm liy means of the spoon-saw, but because here as elsewliere "knowledge gives power," and creates confidence. I have, after trying various methods of doing this, settled upon the use of the flat, elastic whalebone sound, which is represented in Fig. 219.

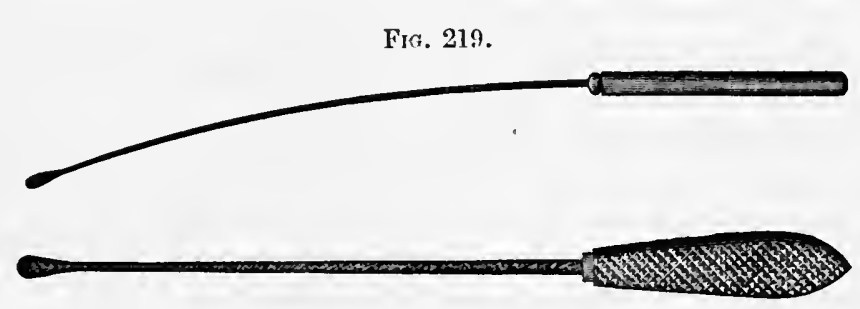

Elastic flat whalebone probe.

The manner in which I came to employ this was the following: Going to the country to remove a submucous fibroid, I endeavored by means of Simpson's sound, Sims's probe, and my own round, elastic wlialebone sound to discover the extent of attachment of the growth, but for some reason could not succed. Talking then a flat piece of whatebone about six inches long, which one of the ladies present removed on the instant from her dress, I put a knob upon it by touching it repeatedly with melted sealing-wax, and I employed this with perfect success. This improvised sound I took away with me, and for a year or more enployed it on sinilar occasions. After that I had one made artistically, which is represented in Fig. 219.

This somd is used in this way: The index finger of the left hand is placed on the most accessible part of the tumor; then the sonnd, held in the right hand, is slid up on one side between the tunor and the uterine wall until arrested, when the index of the left hand is placed upon its shaft at the es externum uteri. The sound being then withdrawn, and the finger kept upon $\mathrm{it}$, it is laid upon a sheet of paper or against a blackboard, and being curved, a line is drawn from its tip to the indicating 
fingrer. Then the somd is passed on the other side, and a similar transfer of its course is made to the sheet or boarl.

In this way it is possible not only to approxinate the turth, but to be womlerfully exact as to it. I have repeatedly demonstrated the efliciency of this sound to classes of students and to medical men, and I feel sure that it leaves nothing to be desired in reference to the determination of the dergree of attachment of any uterine fibroid which can be fully tonched by the finger. Without this possibility the method is mreliable.

'There is no method by which I could so surely lay the claims of this instrument before the realer, and at the same time demonstrate its application, as that of reciting two average cases in which I have employed it; one a case of submucous and one of interstitial fibroid:

CAs: 1.-In June, 1876, I was called by Dr. Joln Burke, of this city, to see with him Mrs. A., a lady forty-seven years of age, who had been for four years suffering from a very profuse menorrhagia and metrorrlagia. To such an extent had she been reduced by loss of blood that she was generally confind to her chamber, and suffered from oedema jedum, palpitation of the heart and dyspma mon the slightest exertion. Iler appearance was that of one suffering from an exaggerated degree of antmia, which was rapidly heing agcravated by repeated and severe lemorrhages. The liver was found to be very much enlarged, as was likewise the spleen; the former, as we supposed, from fatty degeneration, the latter from malarial poisoning.

Mrs. A. had been examined repeatedly as to the uterine condition during this period, and twelve months before I saw her Dr. Burke had discovered the existence of a submucous uterine fibroid, supposed to be as large as the egg of a goose. At no time up to June, 1876, did he consider lier in a condition fit to admit of an effort at the remoral of this, but at that time he called me to decide whether it would not then be possible.

When I first saw her I found the uterus, by conjoined manipulation, as large as it would be in pregnancy at the fourth month, admitting a sound to a distance of five inches, and the tip of the index finger, when foree was used, so that a hard, pyriform tumor could be touehed in the uterine earity.

The patient was so much exsanguinated, so much exluasted, and her nerrous system so profoundly depressed, that I decided against operation, and she was fully sustained by diet and fresh air, in the hope that a few months would so improve her state as to render operation possible.

I saw her several times after this with Dr. Burke, but instead of getting better, she steadily grew worse, and in September general dropsy set in, affecting the peritoneum and the cellular tissue of the body. We now thought the case decided, and gave up all hope of removal of the uterine growth. In tine, however, all the etlused fluid disappeared, and about 
the beginning of January she was so far restored that the question of operation was again agitated. On the 15th interference was decided upon, and on the 28th the tumor was detached and removed.

The following diagram represents the attacliments of this tumor:-

It was free upon one wall only; attached throughout the other to within an inch of the os internum.

At midday, on the 28th of Jannary, detachment and extraction were practised in the presence and with the assistance of Drs. Burke, Walker,

FIG. 220.

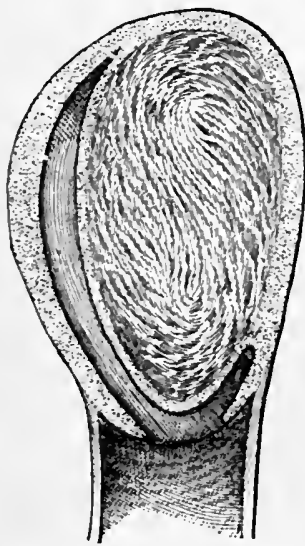

Attachment of fibroid in Mrs. A. 's case. and Jones. The patient, being etherized, was placed in Sims's position, and his speculum was introduced. The cervix being then caught with the tenaculum, its lips were severed on cach side, so as to open the way to the tumor, which could by the finger be felt above before this was done, but now could be quite freely manipulated. A pawerful vulsellum forceps was then firmly fixed in the growth, and securely locked. Then, with the spoon-saiv, the uterine attachments were rapidly and very easily severed.

I was equally surprised and pleased, as were also my assistants, at the rapidity, ease, and certainty with which the sawing motion given to this instrument by the right liand separated the tumor from the uterus, even at the fundus. In a very few minutes I had succeeded in detaching and delivering a tumor which by methods which $I$ have heretofore adopted would have taken, I think, at least a half hour. Indeed I must say that $I$ believe that in the enfeebled state of the patient by no other method could it lave been removed without great risk of fatal exhaustion.

The tumor weighed seven aid a half ounces, and measured, in its long diameter, four inches, and in its short, three. It resembled in slape and size a large goose-egg, and was composed of the orlinary tissue which characterizes these myomata.

The patient entirely recovered, and is now enjoying good health.

CASE: II._Georgiana P., at. thirty-six years, who has been married fourteen years, and lath one elild twelve years ago, since which time conception hats not oecurred, was atmitted to my service in the Woman's Hospital, Dee. 20, 1879. The patient was perfectly well until $A$ pril, 1879, when, just after a menstrual period, she was sudlenly seized with profuse uterine hemorrhage, aceompanied hy severe uterine tenesmus. This lasted only twenty-four hours, but it exlansted her very much indeed. At every inenstrual "poch which has occurred since that time she has had profuse lu'morrlatge, with what she styles "bearing-down pains." This has lasted 
usually about nine days. During the months of July and August she suffered very much from dysuria and rectal tenesmus. For the last four or five months before admission she had been almost entirely unable to walk, because locomotion created the "bearing-down pains" already alluded to. She declared that up to $A_{\text {pril, }} 1879$, slie was in excellent health. She was anamic, very pale, and extremely weak. During the month of Oetober, hemorrhage was so severe that a vaginal tampon had to be applied repeatedly to check the excessive discharge of bloot.

Upon physical examination the uterus was found very large, the fundus extending up to a point midway between the umbilicus and ensiform cartilage. The cerrical canal was distended so as to admit the tip of the index finger freely. The posterior uterine wall, including the cervix, was immensely hypertrophied, and out of all proportion to the anterior. 'The uterine carity, measured by an elastic sound, was found to lave a depth of nine and a laalf inches, the sound passing upwards and then inclining somewhat backwards towards the spinal column. The following diagram will convey a more correct idea to the mind of the reader than a much more lengthy description in words would accomplish.

The patient, with her husband, had come from Colorado Springs, and was exceedingly desirous to have some curative treatment adopted, for experience had taught her the inutility of the treatment by ergot, preparations of lime, and the various other therapeutical resources which are ordinarily adopted in cases such as hers. Accordingly she was seen with me in consultation by a number of my colleagues of the hospital staff, before whose consideration I laid the operation which I shall now describe; and I was thoroughly sustained in the resort to it.

The propriety of the operation and the urgent demand for prompt action in this case were from the first quite clear Fig. 221.

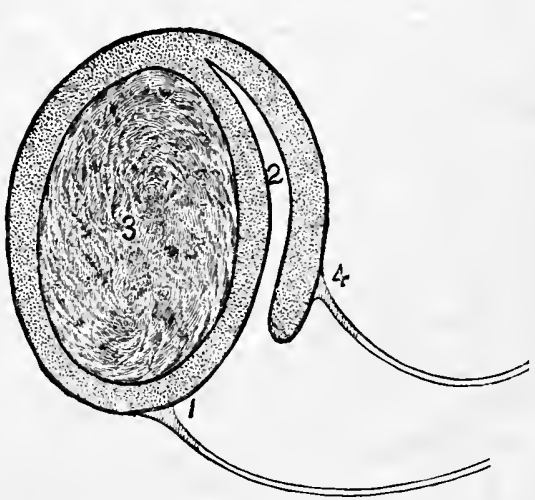

Diagram representing the tamor imbedded in the posterior wall of the uterus. 1 shows the projecting posterior wall ; 2 , the uterine cavity ; 3 . the tumor; 4 , anterior uterine wall at the point of attachment of the anterior vaginal wall. to my mind, and at no time did any doubts as to the justice of this conclusion present themselves. The reasons for my convictions were the following :-

1st. My experience with the spoon-saw in a large number of cases made me feel confident that success would crown my efforts as to the mere surgical part of the work. 
2d. The tumor, already large, was growing fast, and, in a few months, the abdomen would have had to be opened to give exit to it.

3d. The patient was losing large amounts of blood, and growing, of course, steadily weaker, and progressively more despondent.

4th. She lived in Colorado, far away from any surgical centre, and, if she were sent away now, it was highly improbable that, weakened by hemorrhage, discouraged by fuilure to obtain relief from surgery, and alarmed by the great and inereasing size of the abdomen, she would ever again make an attempt to save lier life. In the present $I$ saw a courageous and comparatively strong and healthy woman, with a fairly good blood state, unimpaired nerve condition, efficient digestive function, and a tumor weighing two pounds, not willing merely, but eager for operation. In the future I foresaw an anamic, feeble, and despordent one with impaired digestion, an exhausted nervous system, and a tumor weighing eiglit or ten pounds, still willing to submit to operation perhaps, but doing so with diminished hope and lessened enthusiasm.

On the 5th of January I proceeded to remove the tumor in the following manner, and in the presence of Prof. Alfred C. Post, and Drs. Emmet. C. C. Lee, J. B. Hunter, C. S. Ward, H. D. Nicoll, S. B. Jones, and the house staff of the hospital. The patient, having been etherized. was placed in Sims's position upon a strong table before a window admitting a good light. During the steps of the operation I was ably assisted by the assistant surgeons in my department, Drs. Ward and Nicoll. Sims's largest speeulum having been introduced, and the perineum and posterior wall of the ragina lifted by it, I canglit the uterine wall at the point marked by the figure 1 (Fig. 221), and, by means of a pair of long-handled scissors, snipped a piece out of it, extending deeply into its structure. Upon this a very free flow of blood occurred, but I disregarded it, and as I proceeded with the operation it very soon ceased. Keeping a strong tenaculum fixed in the uterine tissue between the figure 1 and the posterior vaginal walls, I now passed my right index finger into the opening which $I$ had made, and in this way enlarged it somewhat. Then taking a very strong and large grooved director, $I$ forced it upwards towards the figure 2, and sliding a knife in its groove, I slit the enveloping uterine wall high up into the uterine cavity. By the finger I now enlarged the opening thus made, and was at once gratified by the sight of the white fibrous strueture of the tumor of which $I$ was in search. Into this $I$ at once fixed a powerful pair of vulsellum foreeps, and taking the spoon-saw swept it around, and detached the tumor from its uterine bed for about an inch and a half or two inches all atround.

I now made traction upon it with the vulsellum, but found that the tumor was too large to be dragged down into the pelvis. Taking. then, a pair of long-handled scissors, I cut out the portion of the tumor within the bite of the forceps, remoring a piece about as large as a lien's egg. 
Then seizing another portion of the tumor, I cut it out, and continuing in this way I removd, piecemeal, all that portion which I had detached by the spoon-saw.

I now seized the tumor again with the vulsellum foreeps, and detach ing, by meatus of the spoon-silw, about an inch and a hall more of it, I removed it pircemeal by the scissors as alrealy described. This process I repeated till about one-thirl of the tumor only remained, when I detached the entire mass with the spoon-saw, and drew it away.

The operation lasted one hour and twenty minutes. After the first incision it was accompanied by almost no hemorrhage, and the patient bore it remarkably well. At its conclusion the large carity left by the removal of the tumor was syringed out with strongly carbolized water, and stuffed to its full capacity with carbolized cotton. The patient was put to bed; given a full dose of morphia hypodermically; kept very warm by the application of artificial heat; as soon as she could swallow, given brandy and water in small amounts at short intervals, and kept upon the greneral regimen usually adopted as preventive of shock.

I shall not weary the reader with a detailed account of the progress of the case; suffice it to say, that no bad symptoms developed themselves, and that just one month after the performanee of the operation, the patient left the hospital for her home.

'The tumor weighed exactiy two pounds, and was a good example of the ordinary myo-fibroma. It must be remembered that its duration is unknown. 'True, it was discovered in April, 1879 , but it is highly probable that it had existed long before that time.

At the conclusion of the operation, an eminent surgeon who was present remarked that he was surprised that $I$ had cepended so little upon the spoon-saw in its performance. My own feeling in regard to the matter is this: without the spoon-saw nothing would have induced me to touch this case; with it at my disposal, I would willingly undertake to cope with any number of similar ones. After having detached segment after segment of the lower portion of the tumor, dismemberment and removal of parts of it were easy. An attempt to excise and remove the growth before detachment would, I think, have very soon been followed by the filling of the raginal canal with intestines.

I have now operated more than twenty times with the spoon-saw, and its etficiency becomes more and more apparent with increasing experience. At present I resort to no other means for removal of intra-uterine growths which atre firm and large enongh to almit of traction by the vulsellum forceps.

Laparotomy.-One of the great questions of the future in gynecology is to be not the propriety but the proper limitation of the operation of laparotomy for the removal of uterine fibroids, involving, as it very commonly does, the ablation of a part or the whole of the uterus. Indeed, no operator should undertake gastrotomy for at uterine fibroid without being pre- 
pared, if necessary, to remove the uterus with the tumor, for the connection is often so intimate that a determination of the attacluments of the tumor is ont of the power of the most skilful diagnostician. Indeed, even after removal of the mass from the body, its relations to the uterus are often discovered only after patient and intelligent search. Dr. Farre tells of a specimen preserved in one of the London museums as a solid ovarian tumor which, upon careful examination, he proved to be uterine by tracing the Fallopian tubes into it. It was also in this way that the nature of a tumor removed by Dr. Storer was identified; Prof. Ellis, after a very minute examination, distinctly discovering the entrance of the tubes into the eavity of the body, and thus settling the matter.

I have said that the future would concern " not the propriety" of the operation of uterine extirpation for fibroids, for, although all eonservative men nust condemn the reckless resort to the operation, which is sometimes practised at present, all progressive men should, I think, be agreed that under certain circumstances it is not only an admissible but a necessary procedure. The point of difference should be, to-day, not the legitimacy but the indications for the operation.

"Seeing the results of the operation in this country," says Emmet, "no surgeon is justified in attempting to remove the uterus for the growth of a fibrous tumor except as a forlorn hope." "At present," says Barnes, "there is little ground for enthusiastic advocacy of the practice. The case may best be summed up by stating that the question is ad hoc sub judice." These two eminent gynecologists may be said to reflect the general conservative sentiment of the profession. And yet this adverse inclination in the professional mind is no more marked than it was a quarter of a century ago with reference to ovariotomy, the crowning glory of gynecologieal surgery. It must be remembered, on the one hand, that many cases in which removal of a large fibroid, which has involved the ablation of the whole uterus, have recovered, and it must be apprceiated, on the other, that the surgeon who refuses the chances of operation to one who is failing from the existence of a uterine fibroid, should panse when he reflects that a tumor, the removal of which appears to be exceedingly difficult, may prove upon experiment to be extremely easy. Two eases of my own will illustrate this remark. Fifteen years ago Prof. F. N. Otis brougint to me for consultation a patient who had a very large uterine fibroid, and I deeided against the advisability of operation. In time the patient died, and a colosial tumor was found mattached in the abdomen, connected with the uterus by a small pedicle, which could easily have been severed. Five months ago a Swedish woman jiresented herself in my service in the Woman's Ilospital with an abclominal tumor, weighing about fifty pounds, whieh had undoubtedly existed for twenty-three years. Of this fact we had prositive proof, apart from her own statement. I felt inclined to iegard the tumor as a uterine fibro-cyst, and operated with the belief that I should 
have to remove the whole uterus. The tumor proved to be ovarian, aud the patient rapidly recovered.

The warmest aclvocate of uterine ablation for fibroids has been M. P'éan, the celebrated surgeon of Paris. In 1873 lie published statistics, which will soon be cited, and made the following declarations: "Amputation of the supra-raginal portion of the uterus is not an operation of much graver character than extirpation of ovarian cysts complicated by adhesions." . . . . "Ablation of the uterus is a perfectly justifiable operation, which the surgeon is as much warranted in undertaking under certain circumstances as ovariotomy." At that time he reported nine operations, with seven recoveries, and yet during the past seven years no further report has emanated from him.

Statistics.-No reliable statistical report on the subject exists, so far as my knowledge goes, so that I shall have to content myself with fragmentary evidence.

\begin{tabular}{|c|c|c|c|c|c|c|c|c|c|}
\hline Péan' & collocted & 44 & cases, & of which & 14 & recovered & and & 30 & died \\
\hline Pozzi² & ، & 119 & "، & "6 & 42 & 6 & “ & 77 & ، \\
\hline Boinet & “ & 46 & “ & " & 12 & ، & ، & 34 & \\
\hline A. Leblond ${ }^{3}$ & “" & 12 & “ & " & 8 & "، & "، & 4 & “" \\
\hline Storer 4 & " & 24 & “ & “ & 6 & “ & $" 6$ & 18 & \\
\hline Thomas $^{5}$ & “ & 12 & “ & 16 & 1 & “" & $" 6$ & 11 & " \\
\hline Sehroeder 6 & "6 & 108 & "6 & "، & 30 & " & 6" & 78 & "6 \\
\hline
\end{tabular}

Of Schroeder's eases, 73 with removal of the uterus gave 55 deaths and 18 recoveries $\left(24 \frac{66}{100}\right.$ per eent. $)$; while 35 operations, without removal of the uterus, gave 23 deaths and 12 recoveries $\left(34_{10}^{3}\right.$ per cent.)

It would not be safe to generalize from all these cases, for without doubt many of the same cases liave entered into the calculations of several authorities. Having at liand no better material, I present this in its erude state.

Let us remember that antiseptic surgery has just dawned upon seience, and let us hope that the statisties of the future will show a great adrance over those of the past.

Supported by sueh statistical evidence, it is certairly not venturing too much to say, that, if a fibroid be pedunculated and unattached, its removal is not much more dangerons than the ordinary operation of ovariotomy was a few years ago; that, if it be completely amalgamated with the uterus, or so bound to neighboring parts that removal proves very difficult, the operation may be abandoned, the patient having, without great risk, availed herself of the only chanee of cure; and that, even if the removal of the tumor involve that of the uterus and ovaries, we may

1 Hystérotomie, par J. Péan et L. Urdy, Paris, 1873.

2 Pozzi, Thèse d'agrégation, 1875.

3 Traité Elem. de Chirurg. Gynecol., Paris, 1878.

4 Successful Removal of Womb and both Ovaries, 1866.

5 Dis. of Women, 1874.

6 Dis. of Female Sexual Organs. 
still indulge in a fair hope of saving our patient. Surely, when ablation of the entire uterus, as an addendum to the Cresarean scction and as a remedy for cancer, is winning the position of a warrantable procedure by reason of the success attending it, he who allows deatl to occur from uterine fibroids without offering his patient the chance of safety possible from gastrotomy, is assuming a responsibility far greater than that which would attend an honest and well directed effort to save life.

The same arguments which can be urged in favor of ovariotomy do not, however, apply to this procedure. Ovarian tumors almost always run a rapid course toward death; fibroid tumors do so only exceptionally. The former are not ameliorated by the menopause; the latter are usually greatly benefited by it.

The accidents which have generally produced a fatal termination in cases of gastrotomy are as follows :-

1st. Primary or secondary shock or collapse;

2d. Hemorrhage;

3d. Peritonitis;

4th. Septicania.

We are now possessed of means for limiting the first; the improved methods of hemostasis at our command diminish the danger of the second ; and the knowledge of the fact that antiseptic surgery markedly diminishes the probability of the occurrence of the third and fourth, will in future aid in aroiding them.

Metleods of Remoral.-I shall now proceed to describe three operative procedures, the first that of I'éan; the second that of Schroeder; and the third my own.

Péan's Operation.-This is divided into three stages. The first one consists in making an abdominal incision through the median line, extending downwards to one inch above the symphysis pubis, and upwards towards the umbilicus as short a distance as is compatible with exposure of the surface of the tumor.

Second Stage.--If any fluid exist in the tumor it should be evacuated by puncture by a trocar or canula. If it be small enough, either before or alter this, to be drawn through an abdominal opening of moderate size, this should be done, and the operator may at once proeed to the third stage. If it be solid and too large to he drawn out, it shonld be removed piecemeal in the following manner. By means of a long, curved needle, two or three strong wires are carried deeply into the tumor and tightly twisted, so as to eonstrict the vessels, and the intervening mass is cut away. Then another portion is similarly treated until the tumor is small rnough to be drawn out. Adhesions are then carefully tied and broken, and the tumor is delivered.

Third Stagr. - The tumor being held up by one assistant, while another closes the alddominal wound to prevent escape of the intestines; the uterus 
is penetrated by the long, curved needle near the os intermum, or even lower if the tumor extend clownwards; wires are drawn into place; the two halves of the cervix are compressed by twisting them; the tumor is cut off; and the pedicle thus formed is fixed in the wound.

The wound is then closed, and the pediele, which is kept in the abdominal wound by means of the instruments by which the wires were twisted, is treated as after ovariotony.

Schroeder's Operation. '- The abdominal incision having been made in the median line, and the uterus and tumor exposed to view, a needle is passed at the os internum and strong ligatures applied. This cuts off the blood supply to the tumor, which is cut to pieces as we would cut a melon and removed. The incision by which the uterus is removed is wedgeshaped, and the edges of the wound are approximated by deep and artiticial sutures, so that the opposing edges of the peritoneum come into contact, and the stump thus arranged is dropped into the peritoneum. Schroeder has operated for tumors of the uterus six times, with five recoveries. German operators seem to be pretty uniformly agreed that return of the pedicle to the abdominal eavity and complete closure of this is an essential to a successful system in this operation. The validity of this position is, however, by no means proved. Very surely, the external treatment of the pedicle does not invalidate the perfect practice of Lister's antiseptic methods where proper precautions are used in renewal of the dressings.

Thomas's Operation.-The abdominal walls are incised as for ovariotomy, and all cystic formations emptied by the trocar and canula. The lowest portion of the tumor is then manipulated so that a strong cord, a piece of cod line, for example, is passed under it. By this the pelvic extremity of the tumor is lifted so that one limb of the clamp, slown in Figs. 222 and 223, which measures nine and a half inches in length, can be passed under it. The second limb of the clamp is then screwed to the first, the tumor cut through, the severed end of it drawn down by vulsella, and, the entrance of blood to the peritoncal cavity being prevented by stuffing napkins under and around the bleeding surface, the mass is diminished in size by the knife, and removed as rapjdly as possible. The pedicle is then examined, and, if it be found practicable, a second clamp is placed lower down, the first removed, and additional tissue cut away above the lower one. 'The clamp is kept in place during the progress of the case as alter ovariotomy.

Should this mancurre be found to be impossible from the great bulk of the lower segment of the tumor, the incision is prolonged to such an extent that the tumor can be delivered with a certain degree of force. Two assistants then lift it as ligh in the air as possible, and the attachment of the bladder to the tumor being examined by a catheter, the former is detached from the latter if this be found necessary. As near to the vaginal

' Amer. Journ. Obstet., Jan. '1879. 
junction as it ean be placed, the large clamp is then applied and screwed so firmly as to control hemorrhage.

Fis. 222.

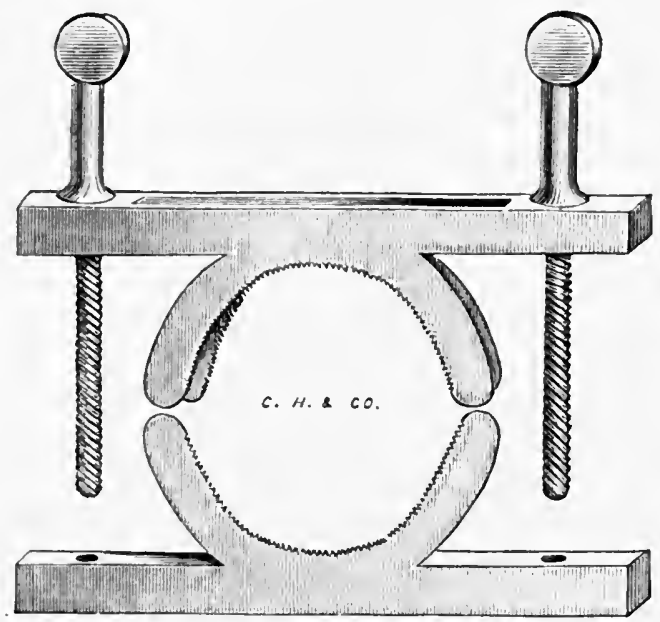

Thomas's c]amp, open.

Fig. 223.

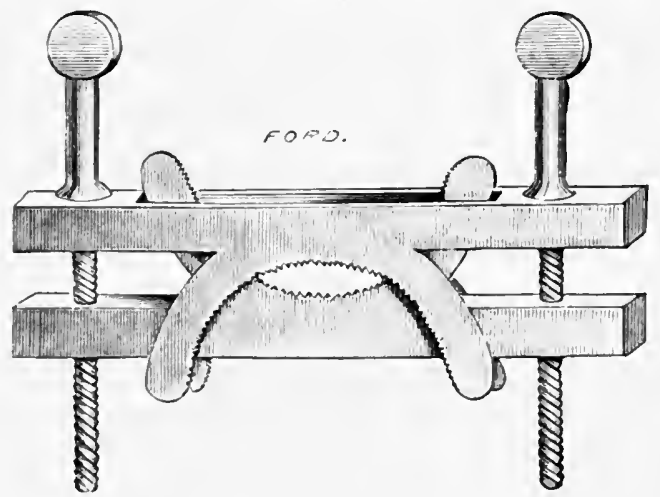

Thomas's clamp, closed.

By this means the portion of the tumor which is to be used as a pedicle is compressed, and as far as possible diminished in bulk. The tumor and as much of the uterus as is above the clamp is now cut off. The clamp is thus far used as the main hemostatic agent; but it is not to be thus employed permanently. Three or four steel knitting needles are now passed through the tissue just above the clamp, at right angles, so as to support the part after the clamp is loosened. Then by larece cautery irons the tissue above clanpl and needles is thoroughly eliared. This is the permanent hemostatie power upon which dependence is placed, and to render it reliable the whole inch of pedicle above. the clanp, should be completely charred. The 
clamp is now loos(need, the ordinary antiseptic dressing applied, and the patient put to bed and closely watched for evidences of hemorrhage or shock. 'The first should be met by tightening the screws of the elamp; the second by hypodermic injections of morphia, brandy, and ether, and by warmth to the entire body, and especially to the soles of the feet and jalms of the lainds.

I lave now removed the uterus, in whole or in great part, on account of tumors seven times, with four recoveries and three deaths. In no case was the operation one of election; in every case it was a matter of necessity, the patients in every instance having the choice between uterine extirpation and deatl.

These operations, like all others in abdominal surgery, should, with the light which we at present have upon the subject, be performed under the antiseptic methorl.

On the twelfth or fourteenth day the elamp may be cautiously removed. During the last two months I have twice removed the entire uterus by this nethod, with the recovery of both patients.

Oöphorectomy.-Extirpation of the ovaries, castration, Battey's operation, has been now repeatedly performed for the premature induction of the menopause, for the control of the exhausting hemorrhage which so commonly marks these cases.

The operation has been performed for the fulfilment of this indication, where uterine tumors have existed, as follows :-

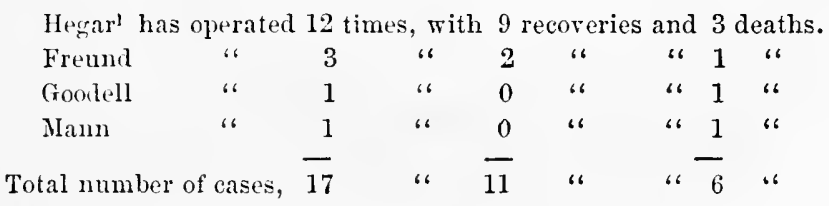

Hegar, whose experience with the operation is greater than that of any other authority, regards its eflicacy in very large tibroids as doubtful.

\section{CHA P TER XXXV.}

CYSTO-FIBROMATA, OR FIBRO-CYSTIC TUMORS OF THE UTERUS.

Definition, Synonyms, and Frequency.-The form of compound uterine tumor which we are now considering las been described by different authors under the names of cysto-fibroma, cysto-sarcoma, cysto-myoma, cystoid and fibro-cystic tumor.

1 See, with reference to this suljest, a paper by Dr. Mann, Archiv of Hed., vol. iv. No. 1, Feb. 1880. 
Our knowledge of these tumors is but recently acquired, and is even now exceedingly elementary. In two of its most important aspects, diagnosis and differentiation from other forms of abdominal tumor, we have been very deficient, and from this have resulted frequent and serious errors. Considerable attention is, however, being now directed to the subject, and already we are possessed of means which were wanting only a few years ago for arriving at correct and certain conclusions concerning them.

Cysts may develop in connection with the uterus in two entirely different ways: first, a cyst may grow and become very large, being enveloped by a layer of uterine tissue; second, solid tumors of the uterus, whether benign or maliguant, may undergo cystic degeneration, that is to say, within the structure of a solid tumor cysts may develop, which, distending the spaces in which they first forn, gradually increase in size, and it may be in number, until what was formerly a solid growth becomes in certain parts filled with fluid. Thus we may have eysto-sarcoma, cysto-fibroma, cysto-chondroma, or cysto-carcinoma.

It must not be supposed that this rariety of tumor compares in frequency with the simple fibroid, or that cystic degeneration often affects that. It is not a matter of rery common occurrence, but it is certainly sufficiently common to denand especial consideration at the hands of the gyneeologist. As has been the ease too with many other aflections, as soon as special attention has been direeted to it, it has been found to be much more frequent in occurrence than was previously supposed. Up to the year 1869, Koberlét tells us that only fourteen cases had been recorded, of which two were discovered post mortem. Dr. C. C. Lee, ${ }^{2}$ however, in that year, collected the reports of nineteen cases, nine in this country, eight in England, and two in France. Dr. E. R. Peaslee, ${ }^{3}$ writing in 1872 , says, "I have myself met with ten cases in the last two years, and have seen not less than fifty since my first operation of ovariotomy in 1850."

Puthology.-Pathologists deseribe a varicty of methods by which spaces may be ereated within fibroid tumors, which, subsequently becoming liued by a fluid-secreting membrane, are filled with serous, sero-sanguinolent, or (o)loid material. "Within some fibroid tumors," says Klob," "eavities may be found, which may have oeeurred in several ways. They either result from a dropsical conlition, or the connective tissue of the tumor undergoes colloil metamorphosis (mueous degreneration), commencing at the centre of the tumor, and in consequence of which its substance liquefies into an albumino-serou: fluicl. Finally, hemorrhages into thesubstance of a tumor may lead to the formation of eavities similar to the so-ealled "apoplectic cy:ts.", In speaking of neoplatic eysts, Billroth"says, "These

1 Giazette Ifelydom., No. 16, 1869.

2 Remark - "pon Diagnosis of Uvarian from Fibro-Cystic Tumors.

${ }^{3}$ Ovarian Tumors, p. 107:' 'Op. cit. $\quad$ S Op. cit., p. 621. 
result mostly from softening of tissue previously diseased by cell-infiltration, or a firm tumor substance. As soon as the new formation has separated into sac and fluil contents, in some cases a secretion from the inner wall of the sac begins, so that the softening eyst becomes a secretion or exulation eyst, and thus grows. Any tissue rich in cells may be transformed into a cyst by nucous metamorphosis of the protoplasm, or, as others express it, by separation of the mucous substance through eells without any connection with development of mucous glands." He then goes on to liken the process by which fluid spaces are created in ehondromata and fibromata to the formation of the joints in the limbs of the foctus by mucous softening of the cartilage tissue, of which the bones of the limbs are formed. Furthermore he declares, that "the often slit-shaped, smooth-walled cysts with serous, or sero-mucous contents which oceur in uterine myomata, are possibly enormonsly dilated lymph spaces," a view which was first adraneed by Crureillier.

It will be seen that the term eystic degeneration is rather loosely applied to this affection, for the fluid collections taking place are rather results of liquefaction than of true cyst development. Nevertheless I shall adhere to its use.

Cystic degeneration affects submucous or interstitial fibroids much less frepuently than those which are subserous. The following case reported by Dr. Sins, which he considers one of this degeneration in a submucous fibroid, is worthy of citation. It is described by him in these words : "I passed a trocar into it at its lowest point, and in the direction of its long axis, and there were discharged more than twenty ounces of a colored serum. The puncture was enlarged for two inches to prevent its elosing. There was at once a sensible diminution in the size and tension of the abdomen. The discharge kept up for some time; and this, together with occasional injections into the very fundus of the uterus, with the liquor ferri persulplatis, diluted with three or four parts of water, arrested very promptly the hemorrhages, and the patient. was dismissed in two months in a very comfortable condition, and with strength enough to walk six or eiglit miles."

As the records of cases of fibro-cystic tumors are not very commonly met with in the literature of this subject, I shall make reference to a few of them. Kiwiseh12 described one which filled the whole pelvic cavity, and extended as high as the ensiform cartilage. It took its rise from the posterior uterine wall; had as its base a fibroid tumor the size of the head, which was enveloped in uterine substance; and weighed forty-six pounds. Cruveilhier ${ }^{2}$ mentions a similar one. Spencer Wells speaks of two cases. In one the tumor was connected with the right side of the fundus by a

' Qunted by kloh, op. cit.. p. 182.

2 Klob, op. cit., p. 182.

3 Diseases of Ovaries, p. 354. 
broad banı ; its solid portion weighed sixteen pounds; its fluid portion twenty-six; and a semifluid material four pounds. The uterus was twice its natural size. In the other there were two tumors, botls of which lad a uterine attacliment, and consisted of solid and fluid elements. A very striking instance of this affection I saw submitted to operation by Dr. James L. Little of this city. The tumor, which yielded very obscure fluctuation, filled the entire abdominal cavity, and was composed of a network of fibrous tissue, constituting spaces varying in size from that of an apple to that of a cocoanut, which were filled with colloid material. This growth sprung from the neck of the uterus. It took its origin from the post-cervical wall, and the tumor growing from this pedicle filled the whole abdominal caxity, and was before operation regarded as orarian.

Symptoms._Fibro-cystic tumors do not vary in symptoms from subperitoneal fibroid growths of equal size. Like them they produce-

Displacements of the uterus;

Pressure on rectum and bladder;

Nenorrlagia in some eases.

Physical Signs._The uterus is usually found to be enlarged from excess of nutrition resulting from the formative irritation clue to the propinquity and connections of the tumor, and to be elevated and lie in front of it. The sensation yielded by bimanual manipulation and by palpation is not that of a lard, solid, and resisting mass, but an obscurely fluctuating sensation is discoverel. It is common in such cases to find a certain number of examiners inclining to the theory of fluidity, and others to that of solidity in the growtl. If an explorative tapping be practised by the hypodermic syringe, a very small anount of fluid, which is usually viseid or turbid, will be withdrawn from some places, while no fluid whatever will appear from others, and if a trocal or a large needle of the aspirator be employed a quart or two of thick stratw-colored fluid may be drawn off; leaving, usually, solid elements remaining. In rare eases of large uterine cysts the sac may be entirely emptied, and even these signs be wanting.

Differentiation.-Many competent anthorities have declared that the diagnosis of this form of tunor and its differentiation from ovarian eyst is inpossible. Kócherlé says, "the diagnosis of fibro-cystic tumors las, up to the present time, been declared imposible by almost every author," and Baker Brown acknowledges that he knows of "no distinguishing marks between the two." Even after ineision Spencer Wells declares that he knows of nothing but a darker lue of the sac-wall to put the operator on his guard. The result of this difliculty is illustrated by the fact that out of Lee's nineteen cases eighteen were operated on muder a mi-taken diagnosis of ovarian eyt.

'The comblitions with which this form of tumor will most likely be confounded are- 
Pregnancy;

Fibroid tumor of the nterns;

Ovarian cyst.

From the first it may be known by absence of the gastric and mamuary symptoms of that condition, by menstruation not only continuing but perhaps showing a tendency to increase in amount and frequency, by absence of fietal movements and heart sounds, and by the duration of the tumor beyoud nine montlss.

From fibroid tumor it may be known by its yielding obseure fluctuation, its assuming usually larger proportions, its more rapid growth, and, beyond everything else, by its yielding fluid to the exploring trocar.

From ovarian cyst diagnosis is usually diflieult and often impossible; the chief grounds upon which it will always depend, and upon which it maty sometimes be marle, are the following:-

Shape and density of the tumor;

Its connection with the uterus;

The depth of the uterus;

The rapidity of growth and effect on health;

The effects of tapping;

The characters of the fluid withdrawn ;

The elevated position of the uterus in the pelvis.

There are other differential signs, but these are the really reliable ones. A great array of symptoms often confuses rather than helps the inexperienced diagnostician, and I wish to analyze the subject here as it should be analyzed at the bedside.

When a differential diagnosis is arrived at, it is ordinarily done in the following way :-

1st. The examiner in palpating has been struck by the fact that the surface of the tumor which he supposes to be ovarian is peculiarly irregular and resisting to the touch, and that fluctuation is obscurely yielded in certain places only. This renders him suspicious, and he determines to investigate fully before committing himself to the diagnosis of ovarian tumor which at first suggested itself.

2d. He now examines the uterus and finds that the sound proves it to be much deeper than normal; that as he rotates this organ upon the sound it appears united to the tumor; that posteriorly to the uterus the tumor seems to join it and grow from it; and that ats an assistant lifts, depresses, and rolls the tumor, the uterus moves distinctly. IIis suspicions are strengthened.

3d. He now questions the patient more elosely, finds that she is over thirty, fibro-cystic tumors rarely appear before thirty, and that this tumor lias been slowly but steadily growing for four or five years without materially impairing her health. He feels the necessity for further information, and resorts to removal of the fluid by the aspirator or trocar. 
4th. The fluid which pours away is transparent and straw-colored, and as it ceases to flow he discovers that the sae only in part collapses. 'Testing the matter, he finds that this is not due to the existence of other cysts, but that solid elements prevent collapse.

5th. IIe now examines the fluid withdrawn, and finds that it coagulates spontaneously as well as under heat. The whole contents of the tube give a large coagulum like that of the blood elot in consistence though not in color. Placed under the microscope, a peculiar fibre cell may be discovered which is characteristic, according to Dr. Atlee, of the fluid of fibrocystic and not of ovarian tumors. It is a product derived from the tissue in which the eyst forms itself, the muscular tissue of the uterus.

F19. 224.

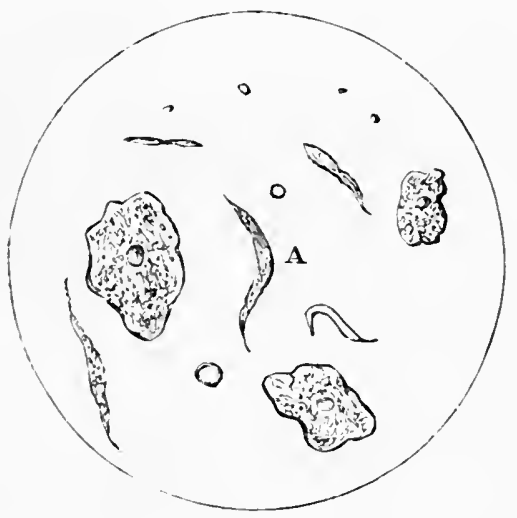

The fihre cell (A) characteristic of fibro-cyslic tumors. (Atlee.)

6th. Anxious now to test as completely as possible the relation of tumor and uterus, he practises the methol of IIegar and Schult.. The patient is anesthetized and laid upon the back; one assistant pulls the cervix down by means of a tenaeulum, and another seizes the tumor and alternately lifts and depresses it, while the examiner, by means of two fingers earried high $u$ the rectum, seeks to find out how intimate is the relation of uterus and tumor.

Even from this apparently copious supply of diagnostic means in many cases only a doubtful conclusion cain be drawn, for every one of them is often fallacious in typical calses, and always so in large cysts unaccompanied by any fibrons structure exeept that constituting their walls. The tumor may not be irregular nor hard; it nay develop with great rapidity ; the uterus may not increase in depth, may move independently of the tumor; and tapping may empty it. On the other hand, cases of true ovarian tumor are not rarely met with in which the uterus is increased in depth, the tumor and uterus move synchronously under slight impulse, tapping only partially empties the sae, leaving solid masses remaning, and 
the growth of the tumor is slow and hats little influence upon the general health. The late Dr. W. L. Atlee most truly remarked, that " no amount of experience will avail the surgeon in making a differential diagnosis by the ordinary methods of examination." "But," said that eminent ovariotomist in alluding to his past errors of diagnosis, "such errors need not be repeated." He believed that we had arrived at a period when, hy meaus of the fibre cell, diagnosis becomes at once simple and positive. Should the diagnostic method which he has furnished us bear the test of experience, a most important result will indeed have been attained. Dr. Atlee relies upon the physical properties of the fluid withdrawn from these sacs for diagnosis of their origin, whether uterine, ovarian, or of the broad ligaments. The characters of fibro-cystic fluid are these. It is transparent, of a deep amber color, and very thin when first drawn, but forms a hard and firm coagulum in a little while, which in a few hours shrinks and separates into a clot and a thin watery serum. It coagulates by heat, and resembles in every respect the liquor sanguinis. Under the microscope few cells appear in it. There are epithelium, oil globules, and a fibre cell, represented at $A$ in Fig. 224. This is eharacteristic of the structure in which the cyst originated.

Course, Duration, and Termination.-This form of tumor runs a very slow course. Much graver and more rapid in development than the pure tibroid, it develops more slowly than ovarian cyst. I had reeently under observation two very large tumors supposed to be of this kind. One of them had existed for eleven years, and yet the patient still performed the functions of nurse in a hospital. It is true that her abdomen was immensely distended, and that she moved about with diffienlty, but thus far she had not been completely incapacitated. In the second case the tumor had existed for about five years. It was quite large, when the patient, alter an attack of illness which was supposed by her physician to be peritonitis, began to improve, and is now reported to me as being better than she has been for many years.

Although this is the slow course of the affeetion in some cases, in others it exhausts the patient by constitutional irritation, the result of mechanical interference with other organs; menorrhagia; and deprivation of exercise and fresh air.

Prognosis.-The prognosis is unfavorable. Relief by medication is in the present state of therapentics unattainable, and the operation of laparotomy is much less promising when performed for uterine than for ovarian tumors.

Treatment.- Nothing more need be stated in reference to this subject than has been already said in connection with uterine fibroids, and will be said in spealing of ovariotomy. 


\title{
CHA P TER XXXVI.
}

\author{
UTERINE POLYPI.
}

Definition.-A uterine polypus is a tumor covered by the mucous membrane of the uterus, attached to that organ by a pedicle or stem, and originating in a lyppertrophy or hyperplasia of some of its proper tissues. Portions of placenta, the fibrinous remains of blood clots, and parts of the fotal envelopes, sometimes remain in utero, and take upon themselves the shape and develop the symptoms of true polypi. They might, with justice, be described as pseudo-polypi, but the true polypus originates in morbid growth of the tissues of the organ from which it springs, and it retards progress in pathology to confound these conditions with that to which this chapter is devoted.

History._While so many uterine disorders of great obscurity are described by the earliest medical writers, this, the diagnosis of which is often so self-evident and positive, attracted little attention. Hippocrates, Celsus, Galen, and even Aëtins make no mention of it. By Moschion it was described in the third century, and called pulps or polypus, but it was certainly neither well understood nor treated in his time, and we get no elear aecounts of it until the revival of this branch of learning by the French School in the seventeenth century. Then Guillemeau, and subsequently Levret, threw much light upon it, and in the latter part of the eighteenth and beginning of the nineteenth centuries many others contributed to place our knowledge upon its present basis.

Varieties.-The student will meet with much difficulty in arriving at definite ideas concerning the varieties of uterine polypi. Almost all authors differ in their classification, and the number of names which have at various times been applied to them is too large even for repetition. Let it be borne in mind that, since these tumors are formed by excessive development of one of the tissues existing in the nterus, there are but three elements which can give rise to them : the muscular tissne; the connective tissue; or the glands of the organ. It is true that by some a species of vascular polypus former from development of the bloorlvessels, a species of telangiectasis, has been described, but it is probable that this is only a form of the cellular or mucons variety. All classifications of these growths are to a great extent arbitrary, and hence in the present state of pathology none can become universal. That which I shall adopt is this :-

1st. Cellular polypi ;

2l. Glandular "6

3d. Fibrous "6 
These varieties are subjeet to morbid changes which create other forms; as, for example, fatty, calcareons, and malignant polypi. Colombat refers to a large, hollow polypus which, when removed, leads the op"rator at first to fear that he has mistaken an inverted uterus for a polypus. II states that Richerand and Jules Clogurt were once thus deceived, until the subsecquent death of the patient enabled them to correct their error by post-mortem inspection. Ime. Boivin represents one of this character, in Plate 19 of her work. She calls it a hollow polypus; declares that, before its removal by M. Dubois, it was regarded as inversion by several physicians, and atecounts for it by supposing that some plastic element hath eoated the uterus and been ripped off, except at its cervical attachment, and had become inverted by menstrual fluid colleeted above. Some years ago Dr. Henschel presented to the New York Obstetrical Society a hollow polypus which was attached to the cervix hy three points. It was referred to Dr. Noeggerath for examination and report, and his method of accounting for it was similar to that of Mme. Boivin in the case just mentioned.

Pathological Anatomy.-The cellular polypus is a tumor, generally of pear shape, varying in size from a marble to a hen's egg. It is covered over by mucous membrane, and consists within of connective tissue in a state of hypertrophy or hypergenesis. Its attach-

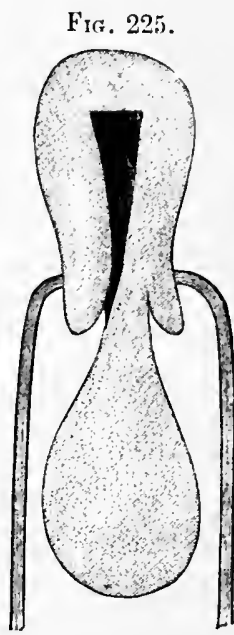

Celiular polypus. ment is generally, though not always, to one wall of the cervix, and in its strueture there appears a certain amount of cervical fibrous tissue. Sometinues the pediele of this variety is very long and slender, so that it hangs outside of the vulva.

The glandular polypus consists in hypertrophy of the Nabothian glands, or, according to Dr. Farre, of the utricular follieles. Several follicles are enlarged, and, being bound together by connective tissue, make up a tumor of pediculated form. It may arise either from the cervix or body, but very generally grows from the former, and is commonly gregarious, a large number of very small ones often studding the walls of the cervical cantl. The most remarkable instance of this variety with which $I$ have ever met is that represented in $\mathrm{Fig}$. 226. The whole growtl measured in length $4 \frac{1}{2}$ inches, and in longest dianeter $2 \frac{7}{8}$ inches. It filled the ragina completely, grew from the inner wall and lip of the cervix, caused no symptom except leucorrhcea and pelvic neuralgia, and was not known to exist until difficulty in sexual intercourse caused the patient to apply for examination. The mass was examined after removal by Dr. F. Delafield, and found to consist of enlarged cervical follicles, the grape-like masses shown in the diagram, which was copied from nature by Dr. J. B. Hunter, bound 
together by connective tissue. I removed it with great ease by the écraseur.

The fibrous polypus is a submueous fibroid. resembling closely those

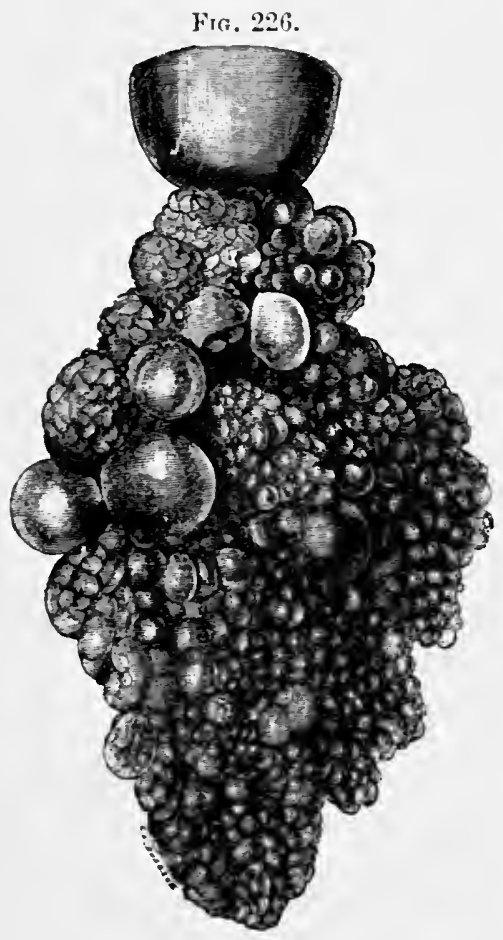

Glandular polypus.

FIfi. 227 .

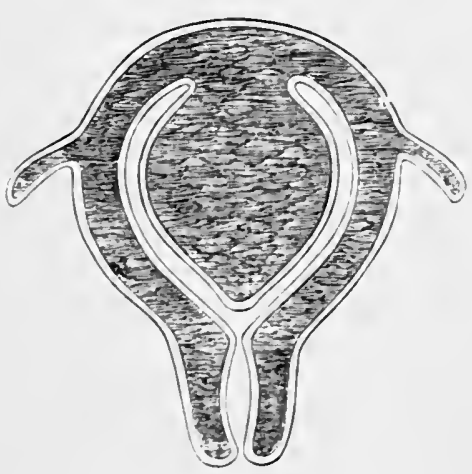

A aubmucone filroid being gradually tranafurmed into a fibrous polypus. which are subserous and interstitial. Slowly extruded from the uterine parenchyma by its contraction, the tumor gradually acquires a pedicle and becomes the form of polypus under consideration. Fibrous polypi usually arise from the body of the uterus, though they are sometimes attached to the rim of the os.

Causes.-Any ehronic inflammatory action, any obstruction to escape of menstrual blood which causes uterine tenesmus, or any influence tending to keep up uterine congestion, will predispose to hypergenesis of the elements of the mucous membrane. But as for fibroids, so for fibrous polypi, no positive canse is known.

Symptoms.-Polypi oecasion two classes of symptoms; one dependent upon the congestion which their presence excites, the other upon the mechanical obstruction which they offer to the escape of menstrual blood. These two influences result in the following signs:-

Lencorrhoea ;

Pain in back and loins;

Menorrhagia ;

Metrorrlıagia ;

Ilydrorrhcea ;

I)ysmenorrlioxa.

The last of these is not a freguent sign, but sometimes presents itself prominently, as it did in the following case, which occurred before we understood the use of tents as we do at present. A larly came from a distance to put herself under Dr. Metcalfe's care for dysmenor- 
rloca, claracterized by severe tenesmus and expulsion of clots. These symptoms had lasted for years, and lad resulted in emaciation, and great nervonsuess and irritability. In time she came under my care, was treated by me for nearly a year, and went home umelieved. At her next menstrual period she sent for the physician of the ncighborhood, who examined by touch, detected in the ragina a small polypus which lung by a stem from the uterus, and $t w i s t e d$ it off, to her complete and permanent relief. This had been at last expelled after having rested upon the os internum, and acted as a ball valve for years. 'The uterus had been repeatedly examined before, but nothing could be discovered.

Physical Signs.-CThese will depend in great degree upon the size and location of the growth. Should it be in the eavity of the body, and small, no sigus will be afforded by the tonch or speculum, and the uterine sound will give no evidence of its presence. The cavity will be discovered to be much congested, and a copions flow of blood will often follow the withdrawal of the instrument. Should the tumor be large, the uterus will often be found to be displaced, and increased in size, and the cervix somewhat rlilated. Should the attachment of the tumor be cervical, it can often be felt hanging from the canal or in the os uteri. But no examination for uterine polypi can be considered complete until the ecrvix has been fully dilated by tents, and eareful exploration been made by touch. Even then small growths will sometimes escape research.

By any other means than dilatation and touch it is often very difficult to determine whether a small neoplasm exist in utero or not. This statement, the history of the following cases which have occurred in my practice very recently, will illustrate :-

Miss B., a spinster, aged thirty-eight years, had suffered from profuse menorrhagia and metrorrhagia for three years, and upon examination I found the uterus enlarged and measuring internally four inclies. I made the diagnosis of intra-uterine neoplasm, dilated with tupelo tents, and found only fungosities to exist.

MIs. MI., aged thirty-seven years, married thirteen years, sterile, suffering from marked dysnenorrhœa, was submitted to the operation of bilateral tracheotomy, on account of constriction and tortuosity of the neck, which rendered the introduction of the sound almost impossible. On the tenth day after the operation hemorrhage occurred, and upon examination I found a hard, fibrous polypus as large as a pigeon's egg presenting at the os, which I very readily removed.

Differentiation.-Polypi must be differentiated from fibrous tumors even after the discovery of an intra-uterine growth las been made. The symptoms to which these affections give rise are very similar, and it is by pliysical means alone that differentiation can be effected. These means are the use of tents, the sound, and touch. By them, the mobility of the 
tumor, the point of its attachment, and the breadth of its base, may usually all be determined.

Course and Termination.- Nature may cure a uterine polypus by ejecting the mass with so much foree as to fracture its attachment and diseonneet it from the uterus ; or caleification, fatty degeneration, uleeration, or sloughing may oecur. But none of these results can be looked for with any ennfidence. In the majority of instances, without surgieal interference, steadily advaneing anæmia ultimately destroys life.

Prognosis.-The prognosis is generally good; depending, of course, upon the possibility of removal.

Complications.-Polypi, if so small as not to greatly inerease the weight of the uterus, create but two complications, leucorrhœa and metrorrlagia, which may go on to the production of fatal anæmia. If they be so large as to increase the size and weight of the uterus, displacements, with their attendant irritation of rectum and bladder, may show themselves, and even inversion has been known to occur.

Treatment.-This may be either palliative or eurative, and it is as necessary for the practitioner to familiarize himself with one as with the other plan. Many a patient suffering from intra-corporeal polypus has had life cut short by intemperate efforts at its removal, who by a systematic and patient eourse of palliative treatment miglit not only have lived for years but have ended her disease by expelling the tumor into the vagina and rendering it accessible to safe removal. There are few men of large experience, who cannot recall such instances of the unfortunate results of injudicious practice, either in their own experience or that of others. The dietum of Gooch that, "when hemorrhages from the uterus arise from a polypus, medicines are useless. The only effectual way to cure the hemorrhages is to remove the polypus," is undeniably sound. Lives have, however, been sacrificed to just such a style of assertion both in this and other diseases. When the young fractitioner reads the brilliant record of an os dilated, an instrument carried to the fundus, a tumor removed, and a ease of metrorrlagia eured, he foels almost culpable if he have a case under treatment and do not follow a similar course, and as he sees his patient's pale face every day demanding a cure, he is often lutried into a resolve to run every risk to effect one. But he who is familiar with this kind of practice knows that it in reality inrolves many dangers, and that successful eases have a proneness for creeping into literature which does not characterize fatal issule:s.

I would be distinctly understood, as not undervaluing the practice of dilating the cervix and removing intra-corporeal polypi by instruments carried to the fundus. I merely desire to insist upon the fact that such a course is necesarily dangerous; that it slould be undertaken only after carreful consideration; and that its proper performance requires skill and experience. 
Whenerer it is practicable to do so, all manipulation should be delayed until expulsion of the tumor into the vagina is accomplished; but, unfortunately, operative procedure is often called for before this can be effected. 'Then the operator has no choice. He is forced to proceed to removal of the growth even at a disadvantage and at a risk to his patient. If the os interuum be fully dilated, the opening of the external os will not prove diflicult of accomplishment. Slitting the neck or dilating it will usually be suflicient to bring the growth within reach of a tenaculum which will draw it forth. But where both are to be opened danger is involved in the process, for not only are we called upon to assume that conneeted with and dependent upon the use of tents : we have to do so in a pathological condition peculiarly liable to be complicated by endometritis and pelvic peritonitis. I have seen several deaths due to these efforts, and I always inaugurate them with a certain amount of anxiety.

Palliative Treatment.-As I have said a great deal in connection with the treatment of submucous fibroids, which would have to be repeated here if I went into the detailed consideration of this subject, I shall limit myself to a eoncise recapitulation.

1st. Replace the uterus if it be displaced, and keep it in position by means of an appropriate pessary, at the same time that all pressure is taken from the fundus by avoidance of tight clothing and all violent muscular efforts, and by the use of skirt and abdominal supporters.

$2 \mathrm{~d}$. Keep the patient in bed at menstrual periods, urging her to aroid war'm drinks, and to nse cold and acid ones. Give viscum album, cannabis indica, opium, gallic acid, ergot, or elixir of vitriol freely during the periods. After a menstrual epoch has lasted four or five days, use a tampon saturated with solution of alum or tannin, removing it immediately if there be any evidence of regurgitation through the tubes.

$3 \mathrm{~d}$. Keep the bowels regular, and aroid fatigue and over-exertion at all times.

4th. Repair the damage done to the blood by nutritious food, and that done to the nervous system by bitter tonics and nerrines, avoiding the use of iron and quinine, which inerease the tendency to hemorrhage.

jth. During the inter-menstrual periods give ergot freely, to favor extrusion of the growth.

Curative Treatment.--There are three positions in which a polypus may be found: above the contracted os internum, above the contracted os externum, or in the vagina. The first position presents the gravest diffieulties in the management of these cases, the second presents much less serious difliculties, while the third may, with our present appliances, be almost said to present none.

If it be discovered that the cervical canal has been dilated by the weight and wedge-like aetion of the polypus aided by uterine contraction, the walls of the cervix may be slit on each side nearly to the vaginal 
junction, and a tenaculum or vulsellum fixed in the tumor by which it may be drawn out of the uterus. Or by means of tents the resisting os may be dilated so as to admit the smallest size of Molesworth's dilator, and by this further expansion may be effected. After this, if the tumor can be seized, it may be drawn out, or ergot in full doses may be given to cause its expulsion. If it be found necessary to seek the pedicle at or near the fundus, it may be severed by the same means which we adopt in case the tumor hang in the vagina, namely-

Excision ;

Torsion and traction;

Ecrasement ;

The galvano-caustic wire;

The spoon-saw.

Should the pedicle be within reach of knife or scissors, it may be divided; or if higher in the uterus, the polyptome (Fig. 228) may be employed. Should the growths be so small as not to be susceptible of seizure, they may be scraped from their attachment by a large steel curette; and should they be small and possess slender pedicles, they may be seized with forceps and twisted off. Should they be so small and slippery as to defeat this plan, or should they be numerous, or return very soon after removal, the cervix should be slightly dilated, cleansed of mucus and blood, and thoroughly painted over by fuming nitric acid, as recomncouled by Dr. Lombe Athill in disease of the lining membrane.

FIG. 228.

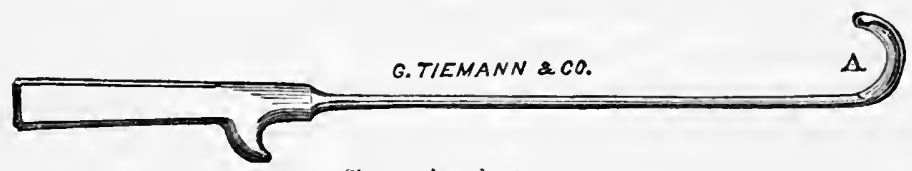

Simpson's polyptome.

The ligature, once so popular, should never be employed; the tardiness of its aetion, and the fetid discharge which it excites, rendering it objectionable and dangerous. Ecrasement constitutes sometimes a safe and expeditious operation. Sometimes, however, great difliculty attends the encircling of the tumor by the chain of the instrument. To effeet this, it is often necessary to encircle the mass first by means of a ligature passed by Gooch's canulæ, and then to draw the chain into position by tying it to the end of this, as represented in the chapter on fibroids. Lnder these circumstances Hicks's wire rope écraseur (Fig. 229) constitutes an excellent substitute. The polyptome of Simpson or that of Aveling often answers a good purpose in these cases.

When the polypus is of hard, fibrous character, and fills the uterus so completely that the pedicle cannot be reached, those portions which are within reach may be cut away piecemeal by Nélaton's forceps, constructed 
for this purpose, or by ordinary curved scissors. Dr. Gooch long ago announced that when a ligature was applied around one of these growths, that part above as well as below its constriction often died. It is with a hope of such a result that we make use of this means. I lave, however,

Fig. 229.

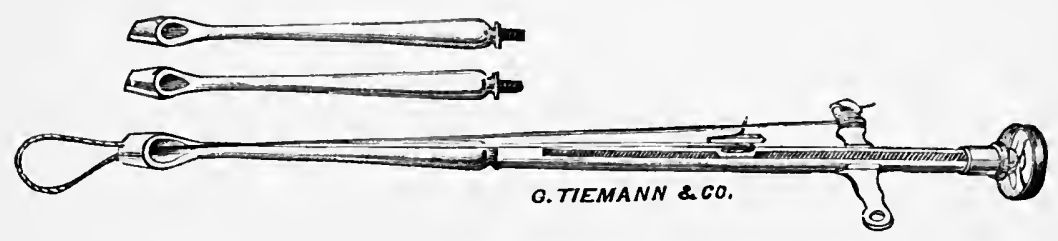

Hieks's wire rope écraseur.

ent through the centre of a fibrous polypus and found the attached portion continue to flourish as before operation.

When a large fibrous polypus presents its pedicle in such a way that it can be encircled by the galvano-caustic wire, this instrument may be employed. It not only cuts without the application of force through the hardest tissue, but, being brought to a white heat by the electric current which passes through it, it sears the open vessels, checks hemorrhage, and prevents septicamia.

I have deemed it my duty to place before the reader all the methods at our disposal for the removal of these neoplasms, that he may exercise his choice as to a selection. In my own practice I have given them all up for the spoon-saw, which is fully described under the head of uterine fibroids. A very small spoon-saw will readily pass through a partially dilated os internum and without difficulty slip up to the attachment of the polypus and sever it without the creation of hemorrhage, while it is kept in a state of tension by tration upon its most dependent part by the vulsellum forceps.

Should a very large fibrous polypus have escaped from the uterine cavity in whole or in part, the lowest portions should be cut away by scissors, and the tumor delivered piecemeal.

In conclusion, I offér a résumé of the methods of treatment recommended in this chapter.

1st. If a polypus exist in utero and the cervical canal be firmly closed, avoid inmediate attempts at its removal unless the symptoms be so grave as to make that course advisable. Temporize by employing palliative means until dilatation of the cervix and perhaps expulsion of the growth into the vagina are effected.

2d. To facilitate expulsion, dilate by tents or incise the walls of the cervix laterally and use ergot steadily, either internally or hypodermically.

$3 \mathrm{~d}$. If the os internum be fully dilated, remove the polypus at once, for 
the operation is one attended by little danger even if the cervix requires incision.

4th. If the cervix be dilated and the tumor be in utero, seize it with a vulsellum at its lowest extremity, and make a cautious but rapid attempt at its removal by torsion and traction. Lengthy manipulations carried on in utero are always very lazarlous.

5th. If it camnot be removed in this way, slide up along the wall of the tumor, npon which steady traction is made, the spoon-saw, sever the stem, and deliver the growth.

\section{CH A P TER XXXVII.}

\section{SARCOMA AND ADENOMA OF THE UTERUS.}

History.—Scattered through medieal literature may be found descriptions of a tumor growing from the eavity of the uterus, which appears to occupy a middle ground between myo-fibroma on the one hand and true eancer on the other. Presenting in many respeets the ordinary plyysical aspects of benign fibroid growths in their early periods, these tumors demonstrate a marked tendeney to return after ablation. Even after repeated and thorough removal, they again and again reeur, and in many cases their real character is in this way discovered. Another peeuliar and dangerons characteristie, which marks their differenee from benign fibroids, consists in their tendency to throw out fungoid growths, which show a marked tendency to undergo molecular death and disappear by ulceration, which process saps the vital forees of the patient by repeated and prolonged hemorrhages, and by opening the mouths of absorbent vessels for the entrance of septic elements into the blood.

The elinieal features of such growths will be found recorded in English literature by Callender, ${ }^{1}$ Iutchinson, ${ }^{2}$ Oldham, ${ }^{3}$ and $\mathrm{West}^{4}{ }^{4}$ to whose interesting accounts the reader is referred. Of course pathologists were struck by these two fats in connection with such tumors: first, their marked tendeney to return atter ablation, and second, the absence of micrographic evidences of cancer in pathological developments showing many of the features of malignancy. Paget gromped them under three hearls, malignant fibrous tumors, recurrent fibroids, and myeloid tumors, while Lebert described them under the name of fibro-plastie tumors, and Rokitansky under that of faseiculated cancer. Not until the time of

l'athological Trausactions, vol. ix.

3 Wilks, Pathological Auatomy, p. 464 .
2 Ibid., vol. viii.

4 Op. cit., art. Recurrent Fibroid. 
Virchow were they described under the old and previously loosely applied terin of sarcoma. 'This pathologist clearly defined the disease and placed it in a distinct class, apart from developments somewhat similar in elinical features, but some of which were entirely benign and others truly eancerons.

Definition, Frequency, and Synonyms._-Sarcoma," says Virchow, " is for me a prodnction easily definable. I mean by it a growth the tissue of which, following the general gronp, belongs to the connective tissue series, and which is distinguishable from marked varieties of the groups of connective tissues only by the predominant development of cellular elements." They possess, he declares, the characters of incomplete, rudimental, or embryonic development, and not those of perfect tissue. This peculiarity existing in the original tumor becomes more and more marked as recurrence takes place after successive removals.

Were I to draw my deductions from my own experience, I would say that sarcoma of the uterus was not very rare. Many cases which have been regarded as cancer, and not a few of supposed fatal fibroid tumor or polypus, have been unquestionably of this affection. Virchow, ${ }^{2}$ however, expresses a different opinion. "The production of sarcoma on the mucous lining of the uterus," says he, "is often spoken of, and even in his first work Lebert describes a fibro-plastic polypus. Nevertheless, from my observation sarcoma is very rare at this point, and the majority of tumors described as such are of a simply hyperplastic nature. True sarcoma, howerer, does originate in the uterine mucous membrane in medullary form diflicult of recognition, often very soft, and with round cells, sometimes with all the characteristics of myo-sarcona; the tissue may become in places more compact, and may form larger masses, and attain a degree of firmness so great that $I$ have seen the best diagnosticians deceived as to the nature of the affection, and take it for a fibrois." Before my attention was especially called to this subject, I confounded such cases with medullary cancer. Since that time I have net with many cases which, both from clinical and microscopic evidence, I am forced to regara as sarcomatons developments. None were confoumled with simple hyperplastic growths, as Virchow suggests, for all encled fatally.

Pathology.-Pathologists have commonly confounded sarcoma of the uterus with cancer. The reasons for this are probably these : after the former begins to ulcerate, it resembles the latter in many clinical features, both have a marked tendency to return, and they sometimes mite in the same tumor. 'The time has certainly arrived, however, when they should be separated both clinically and pathologically.

1 Pathol. des Tumeurs, par R. Virchow, traduit par P. Aronsohn, rol. ii. p. 173.

2 op. cit., vol. ii. p. $3+4$. 
Of late years uterine sarcoma, as a disease apart from eancer, has received careful study in Germany, excellent reports of eases being furnished by Ahlfield, Hegar, Winckel, Gusserow, Spiegelberg, and others.

Unlike myo-fibromata, sarcomatous tumors have no capsules, but are immediately connected with the uterine connective tissue. Virchow declares that, "in accordance with their density, sarcomata may be, like all morbid tissues, divided into two groups : soft and hard sarcomata." As the disease consists merely in a multiplication of normal cells, homologous to the tissue in which it develops, and subject to no other disorder than hypertrophy, it is characterized by one of the cells typical of the connective tissue group. Thus we may have spindle, round, and stellate celled sarcoma, the second being the most frequent, and the first the rarest in the uterus. In some cases the cells are so large as to cause the name "giant-celled" to be given to the growth. "We may," says Virchow, "divide all sarcomata, and not simply those rich in cells, into two groups: the one with large, and the other with small cells." These cells are merely exaggerated reproductions of those of the mother tissue, and "behave like cells of parenchyma, not like surface cells (epithelium, cancer)," which are heteroplastic to the mother tissue. Between these cells the intercellular substance is always preserved, while in cancer we find cells of epithelial type pressed elosely together in alveoli formed of trabeculie created by connective tissue.

Sarcoma, usually primary, is sometimes engrafted upon myo-fibroma by the process styled metaplasia, and a true sarcomatous tumor may itself be affected by cancer. Sarcomata into which a great deal of fibrous tissue enters are dense, like myo-fibroma, and Hegar ${ }^{1}$ admits a transition form, a fibro- and myo-sarcoma. Schroeder gives an illustration representing a sarcomatous polypus growing from a carcinomatous cervix.

Virchow divides all sarcomata into hard and soft in a general way, and then gives a great many subdivisions, as fibro-sarcoma, myxo-sareoma, glio-sarcoma, melano-sarcoma, chondro-sarcoma, and osteo-sarcoma.

These growths are so rich in vessels that Virchow declares that this feature is characteristic of them. To this vascularity is due their tendency to give forth a watery flow, to bleed freely, and to absorb septic materials.

Clinically, uterine sareoma presents itself under two forms, which are often very distinct from each other, and yet between which in many cases an absolute line cannot be drawn. These are the hard and diffuse forms. In the one case a dense, solid, tense, and elastic tissue is presented to the touch, the chief anatomical character of which is the existence of fusiform cells. In the other a diffuse, a fungous-like structure is found, which is characterized by small round cells. When the parenchyma of the uterus is affected by the hard variety, pain, according to my experience, is very 
severe. When a purely diffuse, endometrial form of the discase exists, there is very often none. The second variety will sometinses till and listend the uterus to a great degree. The growth being removed by the curette, the patient greatly imp,roves, but very soon the uterus refills and operative procedure is again called for. I have known patients live very comfortably for years through the relief afforded by this course, ultimately dying, however, of the continually returning affection.

Causes._With referenee especially to uterine sareoma, little ean with positiveness be said on this point. Virchow alludes, in speaking of sarcoma in general, to injuries, youth and old age, primitive debility in the part affected, inflammations, etc.; but whether uterine sarcoma has ever been traced to these I do not know.

Symptoms._These may be thus presented:-

Pain ;

Nenorrhagia or metrorrhagia ;

Offensive mucous discharge;

Pinkish watery discharge;

Dischiarge of shreds or portions of the tumor ;

Pressure on rectum and bladder;

Uterine tenesmus ;

Constitutional depreciation.

Gusserow declares that pain is constant and early, but Hegar denies this. My experience would lead me to indorse the opinion of the latter, though I have seen it very severe.

Physical Signs.-These will depend to a certain degree upon the individual peculiarities of the case. Sareoma usually develops in the cavity of the uterus. One case has been reported by Veit in which the cervix was primarily affected, two by Kunert, and $I$ have now under my care an uncuestionable ease of fibro-sareoma having this origin. The growth usually arises from the uterine wall by a broad base and projects into the cavity. In time, uterine contractions dilate the cervix, and a portion of the mass is foreed through the os.

In rare cases sarcoma assumes a polypoid form, and in others, coincidently with the uterine development, an extra-uterine growth projects into Douglas's poueh or one iliac fossa. Another way in which sarcoma affiets the uterus is by diffuse infiltration into one or both walls. This may affect mucous or submucous tissues alone, or even the museular structure itself.' 'This surfice soon nlcerates and gives forth a fetid diseharge. In some cases this diffuse infiltration may affect the whole uterus, giving it the appearance of symmetrical enlargement.

If the tumor can be touched, it is usually found to be soft, spongy, and friable, though in some cases it is hard and firm like myo-fibroma. By conjoined manipulation the uterus is found to be large and usually irregular in shape as if the seat of fibroid tumors. The uterine sound indicates 
enlargement of this organ. It is very common for the cervix to be dilated and portions of the mass to be expelled.

Differentiation.-Although these symptoms and physical signs will strongly point to the existence of sareoma, the microscope alone will distinguish it from cancer, myo-fibroma, and simple hyperplastic growths.

Conrse, Duration, and Termination.-It runs a much slower course than true cancer; a much more serious one than fibroids and hyperplastic growtlis. In rare cases it terminates rapidly, but it has frequently been known to last for five or six years. The patient gradually sinks under the following morbid influences: hemorrlage, septicamia, spread of the disease to neighlboring abdominal viscera, disturbance of nutrition, or peritonitis.

Prognosis.-This is invariably unfavorable; a fatal issue is a question merely of time, whether the growth be removed or left uninterfered with.

The nicroscope, to a certain extent, aids us in predicting the probable rapidity of the affection. The more nearly it approaches a hard growth, the preponderating element of which is fibrous tissue, the slower will be its course; the more it partakes of a soft character and shows itself rich in eellular elements, the more rapid will be its progress in molecular death. Again, the small-celled varieties show a more marked tendeney to rapidity of production than those which are characterized by large cells.

Treatment.- If the cervix be dilated, and a sessile growth be discovered in the uterine cavity, it should be entirely removed by the spoon-saw, galvano-cautery, écrasement, or the large curette, and the base of the growth thoroughly cauterized with chemieally pure nitric acid. If the cervix be not dilated, this may be accomplished by the use of tents, and the disease attacked by the surgical means reeommended.

Should the disease affeet the parenchyma, and not especially the endometrium, the propriety of uterine ablation should certainly be considered. The fatet that this disease is much less liable to return atter removal than cancer would recommend it more strongly than in that disorder; and if sarcoma were confined to the uterus, the prospeet of success from operation would be far greater.

Adenoma of the Cterus.-The lining nembrane of the uterus, in addition to sarcoma, cancer, benign fungosities, and polypoil tumors, is sometimes the seat of adenoma, a disease eonsisting of hypertrophy of its glandular structure.

This affection develop's the same symptoms as the others just mentioned, chief among which is hemorrlage. The diagnosis is established by exposure of a portion of the discased tissue, removed by the curette, to the nicroscope.

The treatment of adenoma consists in entire removal by the curette, after dilatition of the ecrvical canal, and the application to the surface, from which it has been scrapest, of tuming nitric acid. 
It has a marked tendency to return, though much less so thatn sareoma and eancer. 'This fact should teach us, however, the lesson that in dealing with it the entire endometrium should be thoroughly scraped in orter to prevent the rapid generation of some remaining portion of the growtl.

I have seen but one uncuestionable case of this discase, and in this the curette during a period of four or five years was used very thoroughly fourteen times, compound tincture of iodine and nitric acid having been repeatedly applied after its use. After that the patient entirely recovered, and has now remained well for a number of years.

The growths removed in this case were examined repeatedly by Dr. F. Delafield, who for some time feared malignancy, but finally decided that they were of the cliaracter mentioned above.

Very recently I have seen a case with Dr. Moller, upon which, during seven years, he has repeatedly employed the curette for an abundant and steadily reeurring growth. A portion of it, being examined by Dr. W. H. Welch, the pathologist of the Woman's Hospital, was pronounced to be a mixture of sarconsa and adenoma.

\section{II A P T R XXXVIII.}

\section{CANCER OF THE UTERUS.}

Definition.-Between cancer of the uterus and the same affection in other parts of the system there are no marked differences. As in other organs, it may be defined as a disease which is characterized by great proliferation of connective tissue, excessive generation of cells of epithelial type, and marked tendency to extension to neighboring parts, to molecular death, and to return after removal. Waldeyer ${ }^{1}$ concisely defines cancer as "an atypical epithelial neoplasm."

Mistory._M. Becquerel asserts that, " in spite of its great frequency, cancer of the uterus is not a disease of which the history has been long known." 'That it was not understood as we understand it to-day, is most true; but the ancients surely had a certain degree of knowledge concerning its clinical features. Hippoerates_de Morbis Mulierum_deseribes it at length, declaring it to be incurable. Archigenes wrote a chapter upon it, describing the ulceratel and non-uleerated forms and the peculiarities of the discharges. His article is preserved by Aëtius, who entitles it, "De Cancris Uteri," and is copied verbatim by Paul of Agina without the slightest acknowledgment. The Arabians likewise were familiar with

1 Billroth, Surg. Pathol., Am. ed. 
it, Alsaharavius, Haly Abbas, and Rhazes all alluding to its prognosis and treatment in a manner which leads us to believe that they understood its true nature.

Upon the revival of gynecology in France, the disease was confounded with fibrous tumors and areolar hyperplasia. Astruc described "scirrluus" as the result of abortion, in 1766 , and the confusion which attached to his description extended long after him. It characterized the times of Récamier and Lisfranc, and even so late as our own period we see the view endorsed by Ashwell, Montgomery, Duparcque, and many others. Blatin and Nivet, ${ }^{1}$ in expressing their belief that scirrhus results from chronic inflammation of the parenclyma, append the following footnote: "Paul of Egina, Galen, Andral, Broussais, Breschet and Ferrus, Piorry, Bouilland, etc., place scirrhus among the terminations of chronic inflammation; some of them, howerer, admit the existence of a predisposition." Although it was known to the physicians of the most ancient times, 'we are indebted to them for little in connection with it, except portions of the imperfect nomenclature which now attaches to it. It is beyond question that within the last half century much more has been accomplished for the thorough understanding of the subject than ever has been done at any former time, and yet, even now, much doubt and uncertainty exist as to its varieties, and its pathological characteristics.

Pathology.- With regard to the pathology of cancer the views of pathologists have, of late, undergone considerable modification. Formerly, the prevailing opinion was that it was always the local manifestation of a general blood state. At present, opinion is divided; many still adhering to the old view, while others are yielding to the cogent reasoning of those who regard it as originally a local affection, one of the most striking features of which is a tendency rapidly to intoxicate the system. In an exceedingly able and interesting discussion upon this subject before the London Pathological Society in March, 1874, the former of these views was maintained by MIessrs. De Morgan, Hutchinson, Moxon, Arnott, and others; the latter by Sir James Paget, Sir W. Jenner, Dr. Greenhow, and others. So equally was the society divided in opinion that a commentator remarks that " in point of numbers the constitutionalists almost equalled the localists."

Whatever be the peculiar state which gires rise to cancerous deposit, it is certain that any form of the affection may arise from one and the same disorler. This is proved by the facts that several deposits of different varicties may coineidently exist, that one form may change into another, and that one being removed by surgical means a different one may replace it.

As there is doubt as to the origin of cancer, so is there as to the method

1 Mal. des Femmes, Paris, 1842. 
in which the local deposit takes place. Certain pathologists, of whom M. Robin, of Paris, may be taken as a representative, belicve that, under the influence of a constitutional vice, which exerts a baneful influence over untrition and formation, a fluid blastema is transmitted from the blood into the connective tissue of the part. From this molecules arrange themselves and form the anatomical elements of cancer. Another party, of which Virchow was the founder, maintains that the proliteration of connective tissue and hypergenesis of cells both arise from repeated subdivision of connective tissue corpuscles. These go, some to creation of tissue, some to filling brood-spaces, and others to formation of epithelium. Still another party, headed by Remak and Waldeyer, hold that all cancerous discase in the uterus takes its origin from the epithelium lining glands which dip into the parenchyma. The cancer cells are due to perverted action of normal epithelial production, while the stroma comes from proliferation of the interstitial substance or connective tissue of the part. "Only Thiersch, and recently Waldeyer," says Billroth, "maintain, as I do, the strict boundary between epithelial and connective tissue cells. - . I only call those tumors true carcinomata which have a formation similar to that of true epithelial glands (not the lymphatic glands), and whose cells are mostly actual derivatives from true epithelium."

If the cervix uteri las been first affected, the disease spreads from this point, invades the whole neck, and sometimes the body of the uterus, the ovaries, vagina, bladder, and intermediate tissue. Even the bones of the pelvis may be attacked. For a varying length of time the deposition goes on, then without assignable cause the lowly organized mass begins to die, and ulceration or molecular death occurs. The detritus gives rise to a fetid, ichorous, and bloody discharge, which excoriates the vulva and thighs, and renders the patient disagreeable to herself and all around her.

The disease extends to neighboring and distant organs by several methods : first, by continuous growth; second, by absorption of contagious fluirl or cell elements from the cancer by the lymplatics and transmission to the glands and other parts; and third, by venons absorption.

Tarieties.' - Cancer may attack the uterus in any one of the following forms :-

1st. Scirrhus ; fibrous, or chronic cancer ;

2d. Encephaloid; or acute cancer ;

3d. Epithelioma ; cancroid, or epithelial cancer.

In addition to the varieties of cancer thus far recorded, a fourth, the colloid, is often mentioned. It is now very generally regarded as incor-

1 Although to be systematic I have deemed it best to adopt these conventional terms, the student must not imagine that it is always an easy matter to classify a uterine eancer under one of them. Very commonly a growth will be met with, which occupies a middle ground between these varieties, and is neither pure scirrhus, encephaloid, nor yet epithelioma. 
rect to look upon this as a true variety of cancer, for it is rather a mucoid degeneration of one of the preceding varieties. The same kind of degeneration may affect other growths; and, if the mere presence of colloid matter were used as the test of malignancy, many errors would result. Virchow declares in reference to this important point, "you may, therefore, say colloid cancer, colloid sarcoma, colloid fibroma. Here colloid meaus nothing more than jelly-like." When this change has affected one of the other varieties of cancer, the alveoli are found very large and filled with jelly-like, structureless material.

Cancerous and cancroid affections should not, with the light which we at present possess, be separated. In both we find the characteristics of malignaney, and the microseope shows the same type of cell and connective tissue structure. It is certain too, that the physical aspects of the varieties of cancer depend merely upon varying proportions and anatomical arrangement of their component parts. Before proceeding then to the details of this subject let me premise this fact, that all the affections to be here treated of, whether they be called cancer, cancroid, or epithelioma, are really malignant in character, and differ as to malignancy only in degree; and that in all, if allowed to proceed uninterfered with, systemic intoxicution is only a question of time.

Frequency.-Cancer is an affection of frequent occurrence, and is more frequently seen in the uterus than in any other organ. According to Rokitankiy, the following average scale may be adopted as representing the preference of cancer for various organs. "First, the uterus, the femalc breast, the stomach, the large intestines, and especially the rectum; next comes cancer of the lymplatic glands," etc. The following quotations will fully display the relative frequency of cancer of the uterus :-

Of all cases of cancer in females, the uterus is affected in 3 , Kiwisch. ${ }^{2}$

\begin{tabular}{|c|c|c|c|c|c|c|}
\hline “9118 & "، & "6 & “" & was & ." & 2996 , Tanchon. ${ }^{3}$ \\
\hline $87+40$ & " & " & " & "“ & "6 & 3000, Simpson. 4 \\
\hline 5122 & ، & ، & " & " & 6 & 113 , Wagner. 5 \\
\hline
\end{tabular}

Statistics prove that cancer is nearly three times more frequent in women than in men, and more than three times more frecuently met with in the uterus than in any other organ of the female.

Riflative Frequency of the I arieties._-Virchow regards cancroid affections as eonstituting the majority of so-called uterine caneers. Ilewitt declares that "the form of eancer usually witnessed in the uterus is the medullary cancer. 'The 'epithelial' comes next in order of frequency."

\footnotetext{
1 Sydrnham Trans., vol. i. p. 198, Am. ed.

${ }^{2}$ Klob, op. cit., p. 205.

3 liech. sur les 'Tnueur du sinin, p. 218.

4 Clin. Lect., p. 42.

5 Xew York Med. Journ., vol, ix. p. 561.

6 Lusli:s resume, N. Y. Hed. Journ., Sept. 1869, p. 56 .

7 Op. cit., p. 575.
} 
Court $y^{1}$ begins his remarks upon this snlject thus: "Epithelioma of the vaginal portion of the neek, perlayps the most frequent of uterine cancers," ete.

So rare is it to meet with the scirrhous form of uterine cancer that some? writers have doubted its existener. Rokitansky almits the possibility of its occurrence, but regards it as extremely uncommon. The reason of this is the fact that scirrlus is probably the earliest form assumed by the disease, and at this perion few symptoms showing themselves, no cxamination is songht by either physician or patient. I have met with several undonbted instances of it; to the history of one of which I shall make allusion.

Dr. Treskatis brought to ny elinique at the College of Physicians and Surgeons a woman between forty and fifty years of age who has been for some time sutlering from lencorthea and menorrlagia. Upon examination by tonch, I found the cervix very large and exceedingly hard and resisting. The speculum revealed no abrasion, except two little points about the size of pin-heads, which bled freely when brushed with a sponge. From the facts that the patient had shown no previous symptoms of uterine disease which could have resulted in areolar hyperplasia, that there was no intrauterine cause for menorrhagia discoverable, and that the hardness of the neck was excessive, I ventured upon the diagnosis of scirrhous eancer. This case was kept under observation by Dr. Treskatis, who subsequently reported that it had fully developed itself in to an unquestionable one of carcinoma, as evidenced by softening, ulceration, the microscopic signs, etc. Kloh" maintains that the disease "in the majority of cases occurs in a fibrous medullary form, that is, in the rare cases in which we are enabled to recognize and study the primary condition of the carcinomatous growth in the dead body, we find that form which is described under the name of fibrous carcinoma or scirrhus, whilst in those cases in which the disease proves fatal we generally meet with the distinct medullary variety of carcinoma."

After the first or hard and fibrous stage of the disease has lasted for some time, prolific generation of cells oceurs. These fill the alveolar spaces in the framework of connective tissue, which spaces burst and communicate with each other, and the whole mass grows large and soft. After still greater growth, these overcrowded cell spaces open, the large vessels supplying them give forth blood freely, and ulceration becomes established. As this last stage advances, the bladder is affected by an extension of the morbid matter to its base. Then the rectum, the lymphatic vessels and glands of the pelvis, and the neurilemma of the sacral nerves may become invaled, and the morbid action spread to all the tissues of the pelvic carity. The fiequency with which different parts are secon-

1 Traité prat. dess Mal. de l'L'térus, ete., p. 875.

2 Op. cit., p. 192. 
darily affecter may be judged of by the following facts given by Dr. Arnott, ${ }^{1}$ of the Middlesex Hospital :-

\begin{tabular}{|c|c|c|c|c|c|}
\hline \multicolumn{6}{|c|}{ affection of lymphatic glands. } \\
\hline 5 & ، & "6 & “ & “ & the ovaries. \\
\hline 3 & “ & “6 & “" & “" & the liver. \\
\hline 2 & “ & “ & "، & “ & the lungs. \\
\hline 1 & “، & “ & “ & “" & the heart. \\
\hline 1 & "“ & "6 & " & “" & the breasts. \\
\hline 1 & “ & “6 & " & "، & the peritoneum. \\
\hline
\end{tabular}

Scirrhons cancer presents as its predominant anatomical characteristic the large amount of connective tissue and the small amount of cellular elements of which it is composed; and as its chief clinical feature, its gradual development and comparative slowness of growth and progress. The abunlant stroma alluded to soon contracts, and in so doing checks epithelial generation, causes atrophy of almost all but peripheral cells, and by compressing bloodvessels limits vascular supply. These growths offer to the examniner, before ulceration has occurred, a hard, nodular, and resisting surface.

Fig. 230.

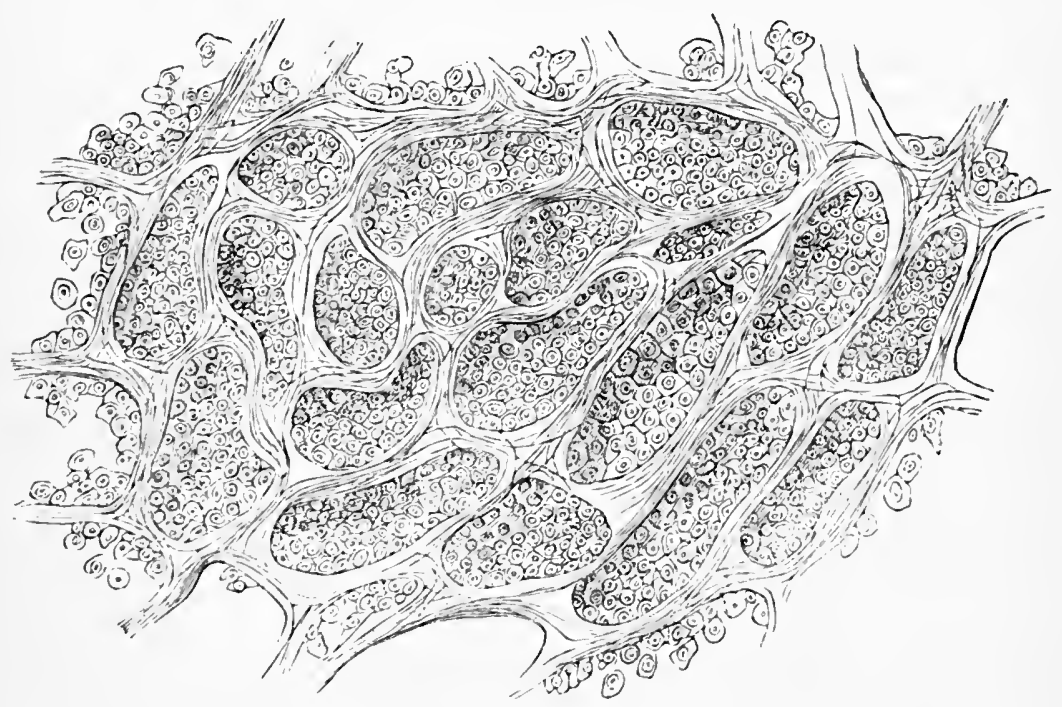

Cancer of mamma; stroma and cells. (Billroth.)

Encepleriloid cancer of the cervix is characterized by a small amount of stroma and a large amount of cells. Clinically it is marked by its rapid 
growth, tendency to hemorrhage, and early disintegration. Upon physical examination during life it presents a soft, lobulated, elastic surface.

Figs. 230 and 231, after Billroth, showing the arrangement of cellular and eonnective tissue clements, will prove instructive.

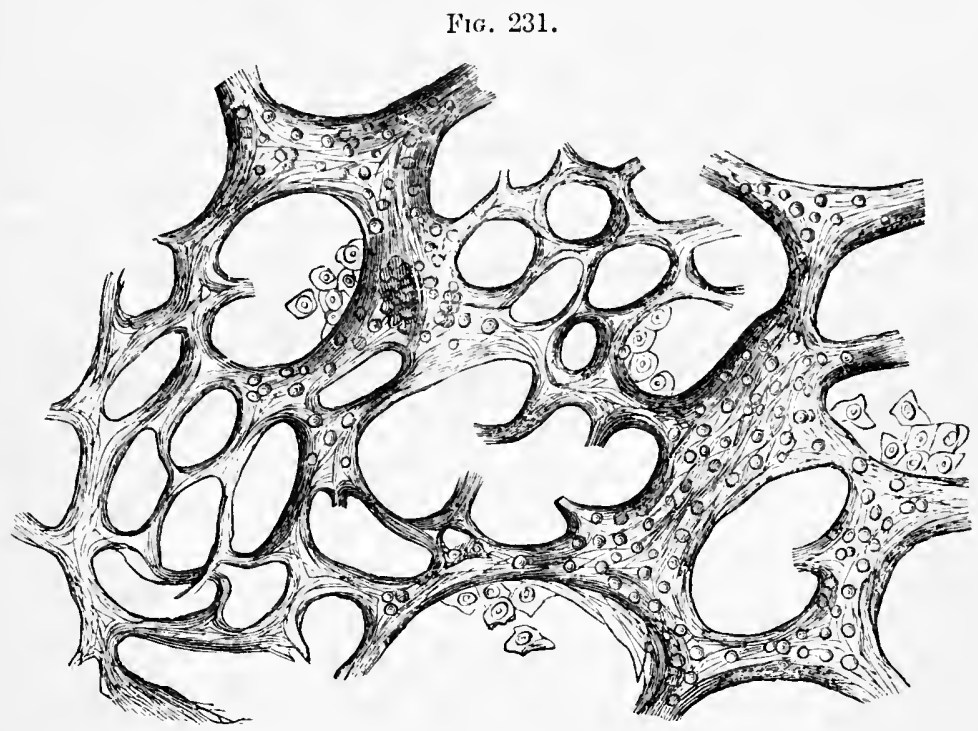

Connective tissue framework of cancer of mamma. Brushed-out alcohol preparation.

(Billroth.)

Epithelial cancer differs greatly both in anatomical and elinical features from the forms just enumerated, and claims espeeial consideration. Commeneing by excessive generation of the cells which characterize the part upon which the morbid influence is excited, it develops itself always in connection with epithelial covered surfaces-skin or mucous membrane. In some cases the stroma is very abundant; in others it is almost entirely wanting. As the cells increase in this, they arrange themselves into epithelial brood nests or spaces.

The importance of the distinction between this form of eancer and those previously mentioned is at present not as generally accepted as it was twenty years ago. At that time pathologists thought it necessary to divide cancers into two separate classes: those which were essentially true eaneer, and those which were ( $\varepsilon \delta \delta \circ$ ) like unto, though not identical with, that terrible malady. In 1846 , Lebert gare to these growths the name of "eancroid" for the reason just given; and in 1852, Hannover, from the fact that this variety of disease was known to consist in a morbid hypergenesis of normal epithelium, ealled them "epithelioma."

For a long time the current of opinion appeared to set in favor of making a wide distinction between the two affeetions; one being looked 
upon as a disease having its origin in a peculiar condition of the system, and the other as one of local nature only. More recently a different feeling has prevailed, pathologists strongly inclining to the view that cancroid growths are really members of the family of cancers, differing from them histologically chiefly in the features which $I$ have mentioned. On their part, clinicists noticed very marked differences, chief among which are tardiness of systemic poisoning in cancroids, and slighter tendeney to return of the disease after amputation. Rokitansky' said of them: "In many cases, however, notwithstanding precisely the same morphological and chemical relations, they accord so entirely in all their manifestations with the cancers, that we classify them with these as a further variety of medullary carcinoma, to which in their lineaments also they approximate

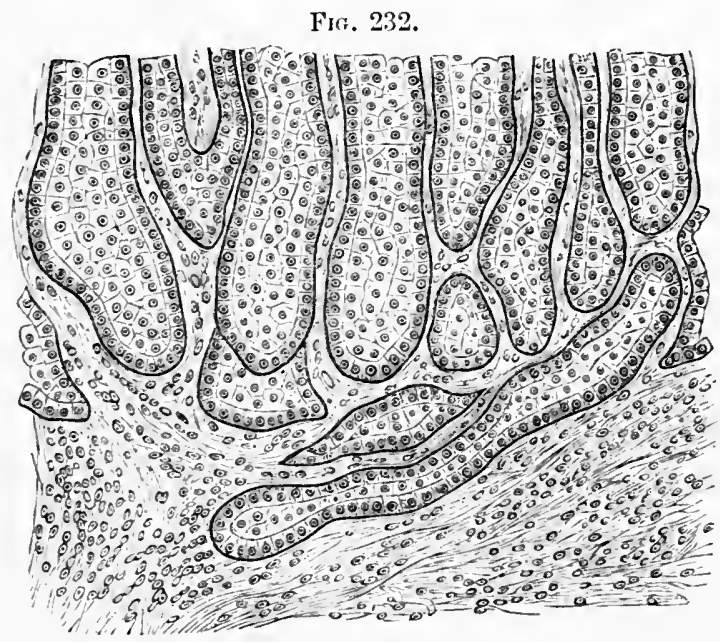

Flat epithelial cancer of cheek. Glandular ingrowth of rete Ialpighii into connective tissue. (Bill roth.)

the most nearly. This occurrence we believe to be limited to the mucous membranes and the common integuments." Virchow, whose investigations liave been later than those of Rokitansky, regards epithelioma as well as cancer as due to a generation of normal cells excited into a morbid activity by the unk nown influence which constitutes the eause of eancerous affections. II ${ }^{2}$ has demonstrated the development of cancroid substance within the uterine wall as well as upon its mucous membrane.

In the eommencement of each variety of malignant disease the clinical differences would be easily recognized; but as epithelioma advances, and the deeprer tissues become involved, a differentiation will often become not only difficult but impossible. 
Epithelial cancer may affect the uterus in two entirely different forms. The first is characterized by a strong tendency to ulceration; the sceomel by formation of a tumor, or fungus-like mass, which at a later period is attacked by ulceration. These forms lave been designated as-

Uleerating epithelioma;

Vegetating epithelioma.

The term corroding ulcer was applied by Dr. John Clarke, of London, and subsequently by his brother Sir Charles Mansfield Clarke, to a form of ulcer of the cervix in which nothing but rapid destruction of tissue is noticed as a pathologieal lesion; in which there is no hardness of the part affected, no induration nor inflammation of surromnding organs; nothing but molecular death in the cervix uteri, and disappearanee of its strueture as if by liquefaction. It las been described under the names of rodent ulcer, diffuse ulcerative cancer, epithelial cancer, and cancroid of the uterus.

All anthorities agree that this affection is eomparatively rare. Dr. Ashwell' remarks: "For one case of corroding ulcer we meet with ninety or a hundred of cancer of the uterus ;" and he further states that in the appropriate ward at Guy's Hospital at the time of his writing, not one example of this malady had appeared. In five hundred recorded eases of uterine disease in that hospital not one case of corroding uleer was to be found. This is the experience of all authors who make their reports, not from clinical but from eareful post-mortem evidenee. Those who rely upon clinical observations alone report the disease much more frequently; but it is highly probable that, as Scanzoni ${ }^{2}$ remarks, an error has been made in such cases with reference to its anatomieal characteristics. It should be borne in mind that many cases, proved by the microseope in post-mortem inspeetion to be unquestionable carcinoma, lave run a course very similar to that of this affeetion. Ashwell states that on several oecasions where a diagnosis of corroding ulcer had been made, post-mortem examination gave evidence of other forms of eancer; and Scanzoni tells of a case, occurring in the cinique at Prague, in which at an autopsy all present were inclined to reverse their diagnosis of carcinoma and adopt that of corroding ulcer, until the matter was settled by necropsy.

Pathologists are now very generally agreed that this affeetion is a variety of epithelial cancer, as the following tab!e will prove. In preparing it no author is quoted who wrote over thrrty years ago.

1 Dis. of Women, p. 318.

2 Op. cit., p. 21 i. 


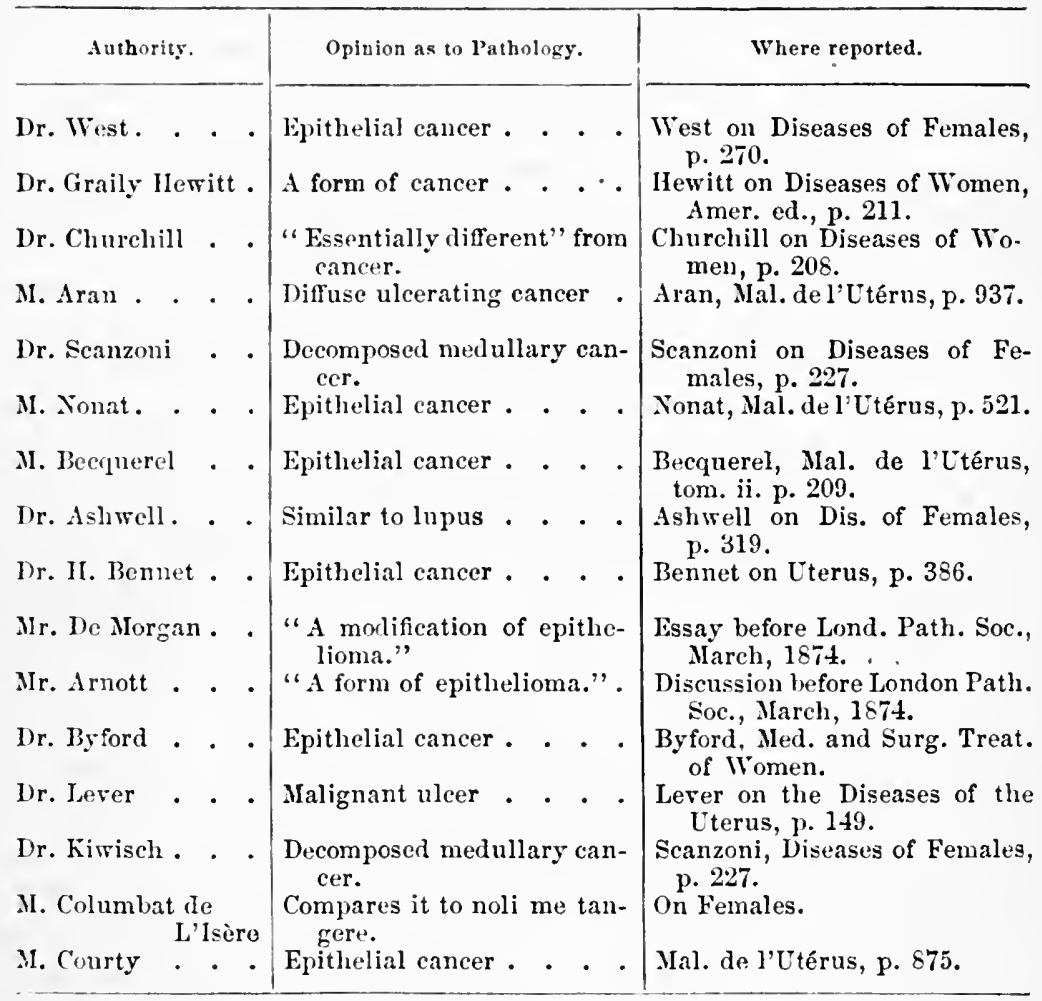

Rokitansky" alludes to the disense thus: "We also find primary and syphilitic uleers, cancerous ulcers that have resulted from the fusion of cancerous morbid growths, the so-ealled phagedenic uleer of the os tince, Clarke's eorroding ulcer. The latter may be compared to the phagedenic, cancerous sore of the skin; without having a morbid growth for its base it grarlually destroys the cervix and even the greater part of the uterus, and may extend to the rectum and bladder."

"In some dissections that I had made," says Mr. Arnott," "it seemed to me that rodent ulcer was a form of epithelioma, for one sees deep down an appearance like the cells of the rete mucosum, and oecasionally the bird's-nest body; the cells are more closely eoherent than in epithelioma, because they resemble more the cells of the rete mucosum, not the epidermis eells; therefore they have a still lower malignancy than any ordinary epithelioma."

The tendency of the newly formed cells is to rapid death. As the process of destruction adrances through the mucous membrane into the

1 Path. Anat., Sydenham ed., vol ii. p. 220.

\& Discussion Ixfore London l'ath. Soc. 
parenehyma beneath it, and profuse hemorrhages occur, the patient is gradually exlaausted; and as the peritoneum in time becomes invader, peritonitis of fatal type is exciter. Unlike other cancers, however, its course is often slow, and years may pass before death results. All varieties of cancer ultimately ulcerate. The prefix, "ulcerating," as here employed, applies only to that variety whose primary feature is to break down in this way.

That form of epithelioma called "vegetating," and which has been at different times deseribed under a varicty of names, has the following characteristic features : it consists in the growth of a lowly organized tumor, which creates hemorrhage, fetid discharge, and hydrorrhoca. There is an extraordinary development of cervical villi, an increase of their vessels, and a great activity in the growth of the cells which cover them; a "proliferation," as it is termed by Virchow. A morbid influence, the nature of which is unknown to us, stimulates the activity of cell growth, so that cells thickly cover the villi. "These growths," says Prof. J. H. Bennet, "speaking generally, are almost wholly composed of epithelial scales."

FIG. 233.

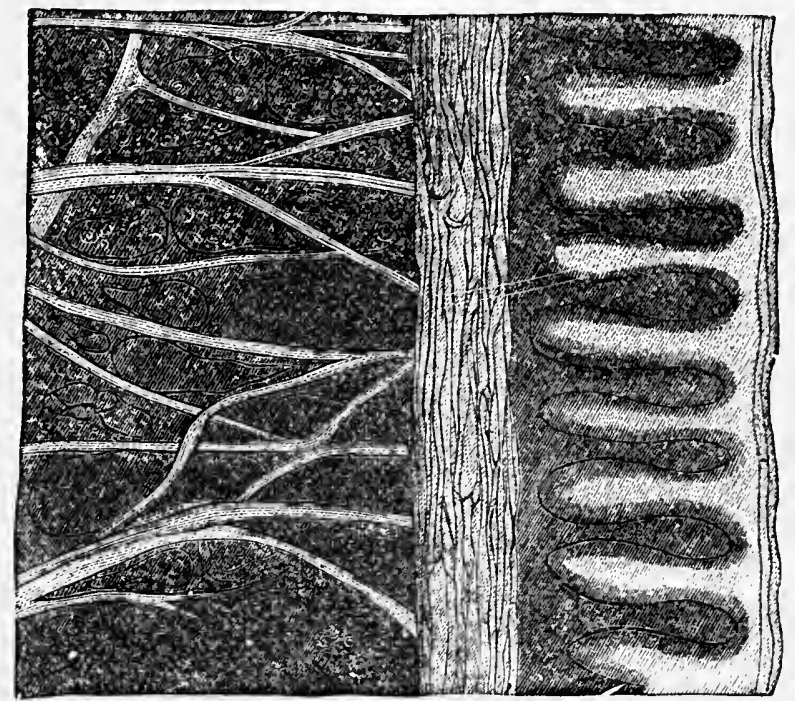

Transverse section of a vegetating epithelioma. (Virchow.)

In addition, the villi increase in size and length, their bloodvessels enlarge, and a true papilloma or papillary tumor is inaugurated. "The gall-nut which arises in consequence of the puncture of an insect, the tuberous swellings which mark the spots on a tree when a bough has been cut off, and the wall-like elevation which forms around the border of the wounded surface, produced by cutting down a tree, and which ultimately 
corers in the surface, all of them depend upon a proliferation of cells just as abundant, and often just as rapid as that which ve perceive in a tumor of a proliferating part of the human body." Fig. 233 represents one of these growths in section.

It must not be supposed that these masses are supplied with blood only by the vessels of the villi. These ramify outside of their proper canals, and, rumning into the masses of cells, allow of transudation of serum, which constitutes the watery discharge so characteristic of the disease, ant, being ruptured, give forth a profuse flow of blool.

These tumors, commeneing as papillary hypertrophies on the cervix or 0 , are at first local, but in time affect the constitution. They are sometimes engrafted upon true cancerous deposit in the cervical parenchyma.

Their most frequent site is the raginal portion of the cervix, but from this point the morbid process may spread into the uterine eavity or down into the vagina. An important, indeed a vital question as to such growths is this: is every cauliflower exerescence a malignant disease? Virchow, than whom we know of no better authority, is decidedly of opinion that it is not. "The pathological importance of a papillary tumor," says he, " is, at least as far as I know, determined by the condition of its basis-substance, or by that of the parenchyma of the villi themselves; and a formation can only be pronounced to be cancroid or carcinoma when, in addition to the growth of the surface, the peculiar degenerations which characterize these two kinds of tumors take place also in the deeper layers or in the villi themselves." Virchow then believes that some tumors, resembling in every outward aspect vegetating epithelioma, are really non-malignant papillomata. The difference between these and the real epithelioma is to be found by microscopic examination of the submucous tissue. In the one case it is lealthy, in the otler diseased. " Whilst," says Klob, " in the benign form, simply an arborescent framework is covered by a more or less thick layer of basement-epithelium, in the cancroid tumor, so-called cuncroid alceoli are developed in the substance proper of the tumor, and also in the 'parent tissue,' which is affected with lyyperplasia of comnective tissue." It is a notewortly and interesting fact that this opinion, arrived at by these learned German pathologists by careful microscopic research, was maintained as a result of elinical observation many years ago by Gooch, who said: "I do not believe that any man can tell infallibly by touch whethor a tumor in the vagina is a malignant excrescence, which is to grow again, or a benign one, which, if remored, will never return."

The pathological condition that we have thus far lescribed may be styled the first stage of the discase. In time ulceration oceurs in the ma-s thus created, which, rapilly breaking down its tissue, opens large 
and numerous vessels, and destroys life by long continued and profuse hemorrhages.

Klob describes two forms of malignant papilloma; one which goes on to the ereation of a tumor of some size and then breaks down; the other, which consists merely of small nodules upon the eervix, which rapidly ulcerate and eat away this part, and in time the body of the uterus. 'These tumors may grow from the vaginal portion of the eervix, from the cervical canal, or from the mucous membrane of the boly of the uterus.

'The authority of Virchow has been already quoted to prove how difficult is a differentiation of malignant from benign papilloma. Indeed, Scanzoni declares that Virchow is of opinion that "the excrescence is at first a sinple papillary tumor, which afterwards passes into a cancroid state." At the same time that differentiation is difficult in such a case, its great importance, as affecting the validity of deductions as to the results of treatment, must be evident. The following quotation from Graily Hewitt's ${ }^{2}$ excellent work will illustrate this remark. In speaking of the fatality

Fig. 234.

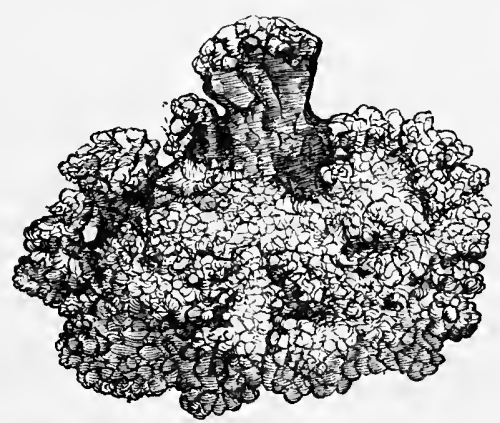

Vegetating epithelioma. (Simpson.)

and duration of cancerous and cancroid affections, he says, "One of the most valuable facts in this connection is given by Sir J. Y. Simpson in his 'Lectures on Diseases of Women.' The patient, the subject of the case, had a large cauliflower excrescence, the size of an egg, removed eighteen years previously. Since that period she has had five children, and was still alive. With reference to this case it should be stated that no 'caudate or spindle-shaped bodies' were found in the tumor removed." Now if we are to accept the revelations upon this subject made by recent investigators, of what real value is such a case? It is more likely to mislead than to guide the practitioner eorrectly. Klob, while guarding against the fallacy of judging by external appearances, gives this method of differentiaition by the microscope. "In simple papilloma there is a

$$
\text { 1 Op. cit., p. } 189 . \quad 2 \text { Op. cit., p. } 578 . \quad 3 \text { Op. cit., p. } 187 .
$$


framework covered merely by a thick layer of basement-epithelium; in malignant papilloma there are alveoli filled with cells eonstituting the socalled 'brood-cavities."

Predisposing Causes.-Those predisposing causes which are generally admitted may be thus enumerated:-

IIereditary tendeney;

Middle or advanced life;

Race, the African enjoying partial immunity;

Repeated parturition;

General depreciation of vital forces.

Hereditary tendency, once generally admitted as a fruitful predisposing cause, is now questioned by many.

Lebert found eridences of hereditary tendency in 14 out of 102 cases.

$\begin{array}{lllllll}\text { Paget " " } & \text { " } & 7 & 78 & \text { " } & 322 & \text { " } \\ \text { Sibley } & \text { " } & \text { " } & 33 & \text { " } & 305 & \text { " }\end{array}$

More recently Sir James Paget declares that in his experience about one case in three has been hereditary.

Although cases liave been reported at the extremes of womanhood, it is generally admitted that few occur before twenty and after sixty. The most fruitful period is from 40 to 50 ; the next from 30 to 40 ; the next from 20 to 30 ; and the next from 50 to 60 .

Scamzoni gives the ages of 108 cases treated by lim.

$\begin{array}{rrr}4 \text { were between } 20 \text { and } 25 . \\ 4 \text { " } \\ 17 \text { " } & 25 \text { and } 30 . \\ 18 & \text { " } & 30 \text { and } 35 .\end{array}$

The youngest was 23 and the oldest 59 years of age.

The black races appear to enjoy to a limited extent immunity from this disease when compared with the white.

Prof. Barker, in an interesting essay upon this subject, published in the Transactions of the New York Academy of Medicine for 1870 , cites the following statistics by Prof. Chisholm, of Baltimore :-

Registrar's report in South Carolina for 1859-

In 2423 deaths among whites, 20 were of cancer;

In 7277 " " blacks, 29 " "

Judging from these statistics, the exemption of the black races is by no means so complete as the general impressions of many practitioners appear to argue.

Cancer of the uterus is more frequently observed among multiparx than nullipare. Of Scanzoni's 108 cases- 


\begin{tabular}{|c|c|c|c|c|}
\hline \multicolumn{5}{|c|}{8 had been delivered 11 times } \\
\hline 3 & “" & “" & 10 & ، \\
\hline 4 & “ & “ & 8 & “" \\
\hline 13 & " & “ & 7 & “ \\
\hline 21 & “ & "، & 6 & “" \\
\hline & “ & “ & 5 & “ \\
\hline & “ & “ & 4 & “ \\
\hline
\end{tabular}

The results of Mr. Sibley's investigations in the Middlesex Hospital go to prove this fact. He found that the average number of children borne by women suffering from this disease was 30 per cent. in advance of the average number of all marriages.

Although it is maintained by some, that eaneer as commonly affects persons in perfeet lealth as it does the weak, it is generally admitted that depreciating influences exerted upon the general system have a predisposing effect. Among these may be especially mentioned grief and mental anxiety, (observed by Seanzoni 84 times in 108 eases,) overlactation, the existence of any diathetic state, life in a large eity, and the state of spanamia engendered by hard labor, exposure, insufficient food, or vicious labits.

Exciting Causes.-As has been already stated, the view onee entertained by many, that cancer is often a result of chronic inflammation, is now generally repudiated. In my own experience I have yet to find a case eren remotely sustaining such a position. There is, however, believed to exist, to use the words of Paget, " a local and a constitutional origin of cancer." Mr. Hutchinson humorously styles cancer "a rebellion of cells." It is the eause which incites this rebellion which has thus far eluded the search of pathologists and elinieists in general medicine and surgery.

With reference to uterine eaneer, my experience eertainly goes strongly to sustain the opinions of Breisky, Emmet, and other's, that epithelioma of the eervix very generally engrafts itself upon a laceration. Laceration exposes the complieated cervical endometrium, with its thousands of Nabothian follicles, to great irritation, which in time produces this untoward result in a certain number of cases. This constitutes of itself a valid reason for a resort to Emmet's operation in cervical laceration.

Symptoms._-The disease may pass through its period of inception and make considerable progress towards a fatal issue without developing any symptoms which attract the attention of the patient. Or only slight leucorrhœa and hemorrhage may exist, which may have been passed over as trivial circumstanees, not deserving treatment or investigation. Usually the following symptoms develop themselves and become more and more prominent as molecular death advances :-

Pain through the pelvis;

Tenderness upon movement or coition;

Menorrhagia and metrorrhagia ; 


\section{Iehorous and fetid leucorrhoea;}

Hydrorrhœa ;

Dark, grumous discharge;

Constitutional debility ;

Pallor and eachectic facies;

Vesico-vaginal or recto-vaginal fistulæ.

Pain and tenderness are not nearly so constant or severe as is often supposed, and they may both be entirely absent.

Menorrhagia and metrorrhagia may exist even before ulceration has occurred, resulting then from congestion of the mucous membrane. But it is not until after the inauguration of the process of destruction that they become alarming or excessive.

Iehorous, watery, and grumous discharges very generally mark the advance of the disease. The first of these discharges produces erythema, erosions, vaginitis, and sometimes ${ }^{1}$ a strong sexual appetite. The second exliausts the patient by draughts made upon the serum of the blood. The third creates fetor, and sometimes results in septicæmia, for the material giving color and odor to the flow is a putrilage formed by the detritus from the decaying uterus.

Constitutional debility and cachectic facies are the results, in part, of the malignant toxamia which is the basis of the disorder, in part of exliaustion produced by loss of blood or some of the elements. Slioull the walls of the rectum and bladder become implicated, as they very often do, the functions of these viscera are deranged, and the feces or urine, or both, pour out through the vagina, increasing the misery of the patient.

Pliysical Signs.-_Suspicion is generally first aroused and physical exploration prompted by these three symptoms : menorrhagia, fetid disclarge, and ichorous leucorrhas. They belong to the second or ulcerative stage of the affection, and, as Dr. IIenry Bennet has well established, it is almost invarially in this stage that the physician is consulted. Before the occurrenee of this stage no symptom usually exists which calls for physieal exploration.

As I have already stated I have seen but two eases which I am positive were incipient or non-nlecrated scirrhous eancer. In these the diagnosis was made by the peculiarly hard, norlular sensation yielded by the cervix, and in one by the coincident implication of the vagina. I feel sure, however. that be who ventures upon a decision as to the nature of the disease at this stage must expose himself to great risk of error. The mere fact of the cervix being excessively hard and nodular is not enough to warrant a diagnosis. This must be accompanied by other reliable signs, as menorrhagia, hydrorrha:a, and constitutional failure, to make a positive conclusion arlmissible. 
For this period of the disease, a period at which diagnosis is of extreme importance, in view of the fact that then ablation offers the greatest hope for permanent or temporary relief, Spiegelberg offers a valuable resource in the nse of sponge tents. If the induration of the tissue be benign, the dilating influence of the tent will produce a degree of softening, while, if it be due to malignant disease, the tissue will remain unyielling and larel.

After uleeration las occurred, diagnosis, to an experienced exrminer, is as simple and certain as it is obseure and uncertain beiore it. The finger discovers an absolute destruction of tissue, and finds the walls of the deep and ragged ulcer producing it eovered over with a crumbling, brittle mass, interference with which eauses hemorrlage. The uterus is often fixed by secondary inflammation, or diffuse deposit of cancerous matter, and the walls of the vagina near the uterine junction partieipate in the deposit. Sometines there is a stricture of the rectum, which especially engages the attention of the patient, who suspects no disease of the uterus or vagina.

It is diflieult to deseribe to another the peculiar sensation yielded by an ulcerating eancer, but it is easy to appreciate it by touch. He who carefully explores one case, and marks the hard, unyielding border and brittle surface, with its marked tendency to crumble and prodnce hemorrhage, will rarely fail to recognize another.

Nevertheless, it is in all cases safe, and in some essential, to remove a small portion of the eancerous material if it can be done without creating great flow of blood, for examination with the mieroscope. And now arises the question, what are the microseopic tests of eaneer? This subject is one which I cannot leave unnoticet, and yet one with which I must deal as cursorily as is consistent with a concise statement of the existing views of pathologists upon it. This can, I think, most readily be done by a series of propositions.

1st. There is no typical cancer eell, which, separated from its surroundings and viewed as an entity, enables a mieroscopist to pronounce upon a growtll.

2d. There are certain combinations of cells, alveoli, and stroma which do enable a microscopist to pronounce an opinion as to the benignity or malignancy of a growth.

3d. 'This combination eonsists, in general terms, in the existence of a fibrous stroma, containing ovoid alveolar spaces, tilled with masses of eells with large single or multiple nuclei, and all bearing more or less closely a resemblanee to epithelium.

Differentiation.-Upon theoretical grounds it might be supposed that the diagnosis of ulcerated cancer would be so simple that few errors would oceur in reference to it. This is far from the truth. A skilful diagnostician would, indeed, generally arrive at a correct conclusion, but I know 
of no disease of the genital organs of the female, unless it be pelvic peritonitis, which so frequently gives rise to errors of diagnosis with the inexperienced. It may be confounded with-

Eversion of cervix from laceration;

Papillary hypertrophy of the cervix, (cock's-comb ulcer;)

Sloughing fibrous polypus;

Lterine fibroids;

Syphilitic ulcer;

Areolar hyperplasia of cervix with metrorrhagia;

Sarcoma of the uterus;

Retention of products of conception.

From these a differentiation should be arriced at by careful study of the progress of the case, by the degree of constitutional implication, by the results of microscopic examination, and by the development of a tendeney to return after remoral. A positive conclusion is not always easy, or, without delay, even practicable. An intelligent decision of the question must depend upon care in investigation, thoroughness of examination, and upon time, which in most cases will clear up all doubt. It should be remembered that the diagnostician, however skilful he may be, who bases an opinion upon the sensation of hardness and resistance in the cervix, is running a great risk of error. Let it be borne in mind, too, that syphilitic uleers have been known to eat into the bladder and rectum and create very much such a state of things in the vagina as carcinoma develops.

Prognosis.-The prognosis is pre-eminently unfavorable. Not only is it so from the fact that the disorder is cancerous, but because that form which often affects the uterus belongs to the most rapid and dangerous of its varieties. "Metullary carcinoma," says Rokitansky, "is, both in its development and in its subsequent course, the most acute of all cancers."

In some eases death will ensue in from three to six months, while in others it may not oceur for five, six, or seven years. The prognosis should be governed in great degree by the character of the initial affection : true carcinoma, which begins with profound implication of subjacent parenchyma, runs a more rapirl course than epithelioma, which of ten involves only superficial portions of it. The general experience as to the duration of cancer of the uterus may be inferred from the following citation of authorities:-

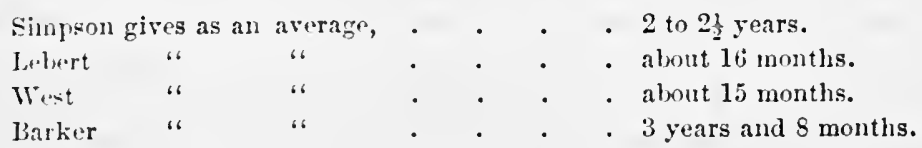

The termination of cancer of the uterus, if the disease be uninterfered with, is very generally a fatal one, although it is admitted that there is a 
possibility that the mass may slough away, the surface heal over, and the patient recover. Scanzoni, Rokitansky, Kiwisch, Virchow, and Klob, all announce this fact, strange thongh it may appear to one who has always taken a more gloomy view. "The cases of spontaneous recovery from uterine cancer," says Rokitansky," "are of extreme rarity, but they do occur." "In opposition to the above phenomena, which ineritably lead to death," says Klob, " the universally acknowledged possibility of. spontancous recovery from uterine cancer is interesting." Let it be remembered that these authors distinguish between cancer and cancroid, and are here writing of the former.

Under these circumstances the whole vaginal portion of the cervix usually sloughis ofl, and the os internum becomes the os externum. Instances of spontaneous recovery from true carcinoma are so rare and interesting that I refer the reader to the history of a case recorded by Prof. IIabit, of Vienna, which will be lound in the Syd. Soc. Year-Book for 1sct, at page 401.

When death, which is the almost inevitable issue of cancer, does occur, it is usually due to hemorrhage, irritative fever which assumes a typhoid form, septicemia, uramia, anamia, or some one or more of the numerous complications which I now come to enumerate.

Complications.-The following are the complications which most frequently accompany the disease :-

Septicamia from absorption of putrid fluid;

Cellulitis ;

IIydronephrosis ;

Peritonitis ;

Tetanus ;

Phlebitis ;

Embolism ;

Cancer in lymplatic glands or other organs.

In rare cases, as las been pointed out by Beatty, Cruveilhier, and others, cancerous degeneration obstructs the ureters, and produces in this, way uramic poisoning. Dr. Theophilus Parvin records an instance of this eliaracter in which for a week no urine found its way into the blad. der, and the symptoms of uræmia were well marked.

P'art of Lterus Affected.-Cancer much more frequently affects the neck than the body of the nterus, although sone authors, with whom 1 decidedly agree, look upon cancer of the body as much more common than is generally thought.

Although cancer developed in the body of the uterus has attracted very little attention, it is by no means cxceedingly rare. Dr. West has met witl it in two out of one hundred and twenty cases of maliguant uterine

$$
1 \text { Op. cit., vol. ii. p. } 228 . \quad 2 \text { Op. cit., 1. } 203 .
$$


disease, and Sir James Simpson looks upon its frequeney as represented by two out of every thirty cases.

The most marked feature of the affection thus making its appearance is the obscurity which attends diagnosis. For a long time, and perhaps throughout the ease, uterine hemorrhage and fetid discharges will be the only symptoms which will excite suspicion. These leading to further and fuller exploration, a portion of the morbid tissue will be removed by the eurette, examined by the microscope, and thus the diagnosis will be established.

Seirrhus, which is so rare as to be denied by some even in the neck, never affeets the body, and so rarely does encephaloid do so that some pathologists deelare that no unquestionable ease is on record. The supposed eases are, according to them, really instanees of sarcoma, tuberculosis, or sloughing fibroid growths. When malignant disease does originate in the cavity, it assumes the form of epithelioma.

Peculiar Features of Cancer of the Body.-The symptoms which mark the condition are :-

Ilemorrhage, especially if oceurring after the menopause;

Depreciation of vital forces;

Catchectic appearance;

Fetid diseharge;

Pains of severe and lancinating eharacter.

These symptoms having led to examination of the uterus, the following plyysieal signs will probably be recognized :-

Enlargement and hardening of uterine body noticed by bi-manual palpation ;

Increased capacity of uterus ascertained by the probe;

Profuse hemorrhage upon probing;

Lterine tenesmus witl dilatation of os ;

Recognition of peeuliar intra-uterine growth by introduction of finger;

Microseppic evidences of eancer.

Differentiation of Cuncer of the Body.-When the rational and physieal signs here enumerated are carefully developed and considered, a very probable diagnosis may be arrived at. Nevertheless, errors of diagnosis are common in reference to this disease at the hands of practitioners who are not familiar with the subjeet, or who rely too firmly upon one or two of these signs or symptoms. I lave seen each one of the following conditions mistaken for cancer of the body, and some of them I have knewn to lave repeatedly caused erroneous diagnosis:-

A slougling fibroid;

$A$ retained placenta ;

1 Courty, op. cit., p. 580 . 
A sponge left by accident in utero;

Syphilitic disease of pelvic bones;

Perinterine cellulitis or peritonitis ;

Cystic degeneration of chorion (hydatids);

Fibroid tumors or polypi ;

Entero-uterine fistula;

Intra-luterine vegetations.

I do not deem it necessary to go into detail upon the means necessary for accomplishing the differentiation of these affections from malignant disease. It will suflice to say that in cases in which doubt exists after careful investigation by all the other means here recommended, removal of a small portion of a mass and its examination by the microscope will prove of the greatest assistance, and will probably decide the question. ${ }^{1}$

The removal of a portion of intranterine cancerous growth may be accomplished in three ways. The simplest, and consequently the best, is to introduce a silver catheter, turn it around once or twice, and then withdraw it. Upon blowing through the manual extremity a piece of the growth large enough for examination will generally be obtained, for these masses are usually very friable. Should none of the growth be obtained in this way, a curette may be passed gently into the nterus, and greater force applied for the detachment of a portion. Should even this fail the os should be dilated by tents, and the desired specimen obtained either by the tinger, a wire-loop curette, or Emmet's forceps.

Treutment.-The indications for treatment are these :-

To amputate or destroy the diseased part as completely as possible;

To check hemorrhage;

To relieve pain;

To secure perfect cleanliness and correction of fetor;

To sustain the general strength.

Review the complications of uterine cancer, and it will be seen that many of them are of a most fatal character, and at the same time entirely beyond the resources of art. $A$ certain number, however, which would prove fatal if not avoided or checked, are temporarily under the control of the pliysician. Examples of these are septicxmia, hemorrhage, exhaustion from pain, ichorous leucorrhœa, hydrorrhœa, excessive constitutional debility from the depraved blood-state, and last, thouglı not least, the extreme mental depression which is the consequence of bereaving the unfortunate sufferer of all hope.

No single plan fulfils so many of the indications for alleviating these as

1 It may be of service to practitioners at a distance from cities in which competent microscopists reside, to state that, in sending specimens for examination, the best preservative menstrum consists of glycerine diluted with water. Alcohol, carbolic acid, and similar fluids contract and harden the structures to such an extent as to ronder them unfit for examination. 
removal or destruction of the growth, but no practice in reference to this disease can be so pernicious as that based upon the idea that because there is cancer of the uterus some surgical procedure must be resorted to. The same reasoning which applies to malignant diseases in other parts of the borly should do so here. If the operator be convinced that decided benefit is to accrue to the patient from surgical interference, it should be practised; not otherwise. Should the disease be detected early, and sufficient grounds be discovered for a positive diagnosis, the propriety of complete remoral of the cervix by amputation cannot be questioned. If the disease be scirrhous or encephaloid cancer, and not epithelioma, the operative procedure will generally fail in effecting a cure, but will probably not hasten a fatal issue. If it be the latter, a cure may possibly be accomplished.

In the great majority of cases, patients suffering from uterine cancer are scen so late that surgical interference, established with a vicw to cure, necessarily fails to effect it ; although, practised for relief of certain symptoms, and thus for a prolongation of life, it is frequently of a great deal of benefit. Should amputation of the neck promise entire removal of the morbid tissue, it should at once be accomplished, for by it cure may be effected. Even where complete removal is not practicable, ablation of all thic superficial portions of the growth tends greatly to the amelioration of symptoms.

There are several surgical procedures by which removal of the diseased structure may be effected. One of these will be most applicable to one case, one to another; that being always selected which in the particular ease will accomplish the end with the greatest thoroughness. Let it always be borne in mind that the hope of prolonged freedom from relapse depends upon thoroughness of ablation and upon that alone.

I will describe three operations for removal of the cancerous cervix uteri.

1st. Simple amputation by the galvano-caustic wire.

2d. Amputation by the galvano-caustic wire followed by the use of Simon's scoop, the knife or the scissors.

31. Removal of the diseased texture by Simon's scoop, and of all the hard subjacent structures which can with safety be removed by the knife or scissors, followed by searing the exposed surface thoroughly with Paquelin's thermo-cautery.

In the selection of the appropriate operation for malignant disease of the cervix uteri, the operator should, as far as possible, ascertain the extent to which the tissnes above the cervico-vaginal junction are involved. To ascertain this the cervical canal should be dilated by tents so that the finger can pass freely up, and a careful rectal examination should also be marle. The information thus obtained is not entirely reliable, but is, nevertheless, of great value. Having o'stained the desired information in 
this way, the special operation to be resorted to should be selected upon the following grounds.

It the disease be found to limit itself to the cervix below a line which would represent the course which would be followed by the galvano-caustic wire, amputation by that instrunent would be the most appropriate operations.

If the endometrium be foumd to be diseased above this point, the presumption being, of course, that the morbid action involves, to a greater or less degree, the subjacent parenchyma hkewise, while the circumferential tissues of the cervix admit of a safe resting place for the galvano-caustic wire, amputation by it might be adopted, followed by removal of a cone of diseased tissue by Simon's seoop, or Sims's knife; or the operation next to be mentioned might be preferred.

Should the circumference of the cervix be involved up to the raginal junction, the softened, friable tissue gives so poor a basis for fixation of the wire, that galvano-cautery proves under these cireumstances a most unsatisfactory procedure, and should be replaced by the scoop, the scissors, the knife, or a combination of the three instruments.

One of the great objections to the use of the galvano-caustic wire for amputation of the cervix uteri is, that it deludes the operator into the belief that the whole cervix is being removed while in reality the wire slips down and a mere scalping process is gone through with. This I have succeeded in entirely preventing by the instrument shown in Fig. 23j.

Fı. 235.

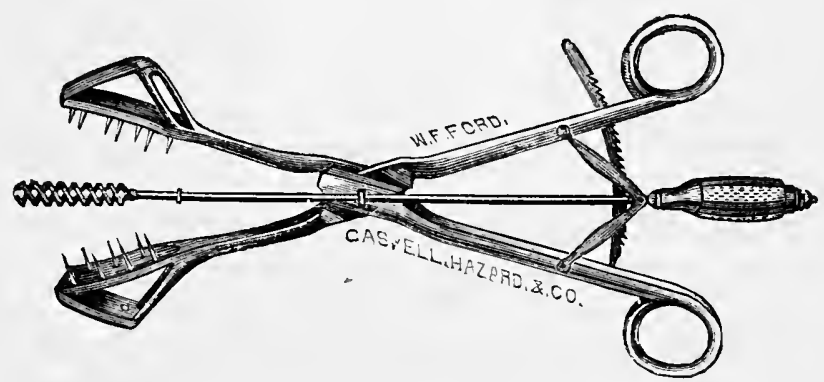

Forceps for amputating the cervix.

By the screw, which slides up and down, the cervix is pulled down into the bite of the forceps, which is then closed and clamped and the screw is reversed and lowered. The wire loop is then passed over the most prominent part of the diamond-shaped sides of the forceps, and, being tightened, slides to its highest point.

This part of the procedure is best performed with the patient anæsthetized and lying in Sims's position, and his largest sized speculum in 
place. If this be found very difficult of performance, the operator may, by vulsella, pull the uterus down to the vulva.

The best and simplest batteries for this purpose are those of Byrne, of Brooklyu, and Dawson, of New York. Both of them are very small, compact, and reliable.

If, after the incandescent wire has cut through the circumferential tissues of the cervix, traction be made, the gradually weakening structure will yield, and the result will be a conical amputation, as Dr. Byrne has pointed out, somewhat resembling the diagram exhibited in Fig. 236, though of course the cone removerl will be much less extensive.

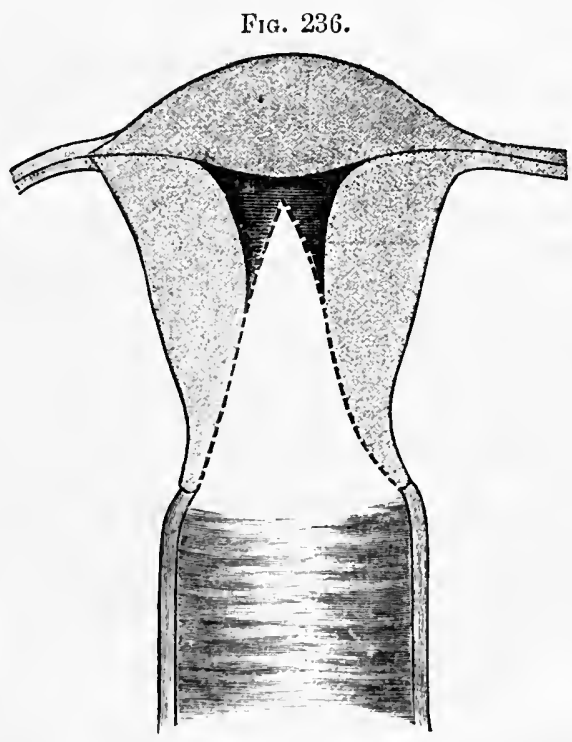

Cervix amputated and parts above cut out.

It has been said that the cold knife is better in the performance of this operation than the incandeseent one, lecause the former allows the operator to test by his fingers the existence of diseased tissue, and then guide him as to the propriety of its removal. 'This is a specious argument, for as much tissue should be removed in every case as the operator thinks compatible with safety.

I have operated in this way on many occasions, and I cannot imagine any more complete method for acconphlshing the end in view in the class of cases which I have eited.

$\Lambda$ fter every such operation the vagina should be securely tamponed with styptic carbolized or thymolized cotton for at least ten days, a tampon being introluced once in twenty-four or thirty-six hours. This is troublesome, but I have seen the most dangerons hemorrlage occur under 
these circumstances on the ninth day after operation. Indeed it must be borne in mind by every operator that reliance upon the henostatie powers of electro-cautery in this operation is a delusion, and a most hazardous one.

Should it be found that sufficient tissue has not been removed ly this proeedure, the second should be added to it. The central portion of the stump being seized by a tenaculum, its core should be removed, to as great an extent as the operator deems safe, by Simon's scoop, the longhatudled scissors, or Sims's knife, so as to make the uterus resemble the schematic diagram shown in Fig. 236.

But cases not rarely show themselves in which the soft, friable, malignant material offers no rest for the wire of the galvano-eaustic battery, and in whieh it is difficult to draw down the eervix by a tenaculum. Here all the softer cancerous masses should be scooped out after Simon's methud by his scoop shown in Fig. 237. The hemorrlage which occurs

FIG. 237.

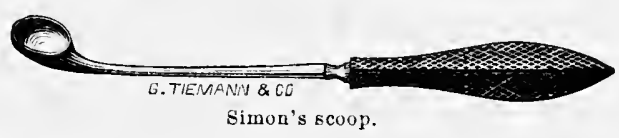

is often alarming. Its control depends upon two things, rapidity and boldness on the part of the operator. So soon as all the eancerous material is removed, the flow of blood will cease, or rather greatly diminish. Let such removal then be accomplished as rapidly as possible.

After removal of all the soft tissue which the seoop can remove, the cervix should be cut away by scissors or knife up to the raginal junetion, and all hard tissues above which are susceptible of safe removal should in the same manner be taken away. Then the cavity of the body should be thoroughly scraped with Sims's cutting curette.

All hemorrhage should then be controlled, and all exposed tissues seared, by means of Paquelin's thermo-cautery at a red heat.

The heat reflected from the thermo-cautery is often very objectionable. To protect against this, Dr. Wilson, of Baltimore, has invented an ingenious little shield which obviates the difficulty entirely.

It will be seen that all these means lead up to one issue. That will always be best which is most thorough, and, as all offer the opportunity for great thoroughness, it follows that success in their application will depend much more upon the hand which applies the method, than upon the method itself.

All the cancerous material which can be removed haring been taken away by any of the plans mentioned, the surgeon should not regard his task as yet finished. The bleeding stump should be thoroughly cauterized by the actual cautery, nitric, or chromic acid. But just after the operation, blood oozes too freely for either of the two fluid acids mentioned to 
be used. It has, therefore, been advised to tampon the excarated eervix by means of cotton saturated witl strong solutions of zinc, bromine, etc. The unmanageable character of such tampons, however, as to the degree of sloughing which they produce, renders them highly objectionable, and the scientific surgeon feels too surely that he is imitating the erratic practices of the "cancer curer." Paquelin's thermo-cautery, brought to a red heat, may be used to check hemorrhage and to destroy the base upon which the cancer grew. Should it stop the hemorrhage entirely, it may be followed by one of the acids mentioned; if not, by a tanpon, which being removed in twenty-four hours, cauterization by the acid may be practised.

After all these operations I would recommend putting two or three silver wire stitches on each side, so as to make the two halves of the stump face each other. They will probably not unite by first intention. That is not the object of the proeedure. The granulating stump will be protected from friction by partial union, and will progress mueh better than it will do if left entirely exposed. After doing this, and at the end of twelve or fourteen days removing the sutures, I have been surprised to see how perfect the mutilated parts appeared. This is only an imitation of Sims's procedure for covering the stump and securing union by first intention after his amputation.

Although eancer of the uterus is in itself no more malignant in type than that of other parts, the mamma, for instance, it is much more difficult of entire removal, for the reason that its existence is generally ascertained later in the progress of the ease, and thus it has involved deeper layers of parenchyma and has encroached more upon neighboring organs.

Where it is decided not to resort to surgical resource, great advantage often acerues from destruction of the superficial layer of diseased tissue by chemically pure nitrie acid. To apply this the cervix should be exposed by Sims's speculum, cleansed by a stream of water from a syringe, and thoroughly dried by dossils of eotton or sponge. Then the acid should. by means of cotton wrapped around a rod, be thoroughly applied to the whole diseased surface. After this a stream of water should be again projected upon the cervix, and a pal of cotton saturated with glycerine made to envelop it. The caustic applieation produces a decided slough, which destroys many of the bloodvessels which have proved the source of lemorrhage. I regard this as one of the best methods for accomplishing partial destruction of a cervix affected by cancer, and resort to it frequently in practice with excellent results. Such an application may be repeated once in two or three months; and it is curious to see how patients will urge a repetition of it. I can fully indorse the statement of Dr. Churchill, who thus speaks of the use of strong nitric acid as a caustie: "I have found it relieve pain. arrest hemorrhage, and restrain the discharges. In one case, hopeless when I first saw her, life was prolonged for three years under this treatment." 
If ehemically pure acid be obtained and efficiently applied, it will fulfil every indication required of an escharotie. I have discarded in its fawor all the nore violent ones, such as potassa fusa, the actual catutery, etc.

'The injection of escharotics into cancerous growths, by means of the hypodermic syringe, has of late years been practised, and gained some fivor. But, with the caustics which we possess, complete destruction of any malignant growth upon the cervix or in the body of the uterus is so easy and simple a matter that it is difficult to conceive why a resort to "parenchymatous injections" should ever become necessary.

Neans which destroy the superficies of the cancerous mass have a decided influence in controlling hemorrhage. It may further be controlled by rest during menstruation and by astringent raginal injections. The most appropriate styptics are the sulphates of alum, zinc, and copper, alone or combined, in about the strength of one or two draelims to the pint of water.

The relief of pain should be accomplished by the free, unrestricted use of opium by the mouth, the rectum, or under the skin. I often encourage my pratients to become opium eaters, and urge them to obtain as complete relief as the use of this drug can afford. In place of opium, other narcotics may be tried, but there is none which eompares with it for effieiency. In some cases the hydrate of chloral in scruple doses will be found to answer an excellent purpose, either as an alternate or a substitute for opium. It produces sleep, quiets pain, and is free from those consequences which frequently render opium objectionable.

When opium produces the painful results noticed where an idiosyncrasy exists against it, the persistent use of it will often effect a tolerance. In these cases the hypodermic use of morphia often becomes the greatest boon.

It is wonderful to see what large amounts of opium may be consumed, not only without danger, but with absolute benefit, for relief of the pains of cancer. Pinel is said to have administered to a woman at La Charité 120 grains of solid opium in twenty-four hours; Marc allowed a patient to talke 62 grains of morphine in the same time; and Monges and La Roche, of Philadelphia, gave three pints of laudanum in twenty-four hours, and lept up its administration at this rate for three months. Dr. Knight, of New Haven, had a patient who consumed three draclims of morphine in twenty-four hours, and continued the use of this drug for a considerable time in amounts almost equal to this. ${ }^{1}$

The fetor of the discharges may be, to a great extent, corrected by the use of raginal injections containing disinfectant substances in solution. A solution of carbolic acid or thymol, Labarraque's solution of soda, powdered persulphate of iron or sulphate of copper, or a weak solution of the iodide

1 These facts are recorded in Dr. Calkin's raluable work on "Opium and the Opium Habit." Lippincott \& Co., Philadelphia. 
of lead, will prove very useful. Of all these, carbolic acid is the most certain and eflectual.

Constitutional Treatment.-Wothing is more important for a practitioner in the treatment of morbid states than to have in his mind a clear and distinct line drawn between those means which repair the ravages of disease, sustain and soothe the system under its deleterious influences, and put it in condition to allow nature to strive for recovery on the one hand; and those which by some specific action cure the affection on the other. A confusion of these two ideas has done mischief in causing hypermedication, and in creating erroneous conclusions as to the value of drugs. In cancer a variety of drugs has at various times since the birth of Christ, and indeed before it, been vaunted as exerting a specific influence. As examples, for I have not space to mention one tithe of the whole, mercury, iodine, arsenic, bemlock, bromine, gold, silver, and other drugs, have had their day. After a fair trial liaving been given to each, but one conclusion can be drawn by a writer of the present time, namely, that we appear to be as far removed from the discovery of a cure for cancer as were the contemporaries of Hippocrates.

While this is true as to specific medieation, a much more gratifying statement must be made as to remedies calculated to stay the progress and combat the ravages of cancer.

The general strength should be maintained by fresh air, residence in the country, generous food, alcoholic stimulants, iron, and bitter tonics, while the mind slould he kept cheerful by lively company, and avoidance of the society of those who encourage conversation concerning the existing disease. As the digestion is weak, the most digestible substances should constitute the staple diet, and very often a patient who will become emaciated upon solid food and a mixed diet will improve upon the exclusive use of milk, beef-tea, and similar substances. So marked is this fact, that the milk diet strictly alliered to las been regarded, by many non-professional persons, as a means of cure for cancer.

Among bitter tonics, I have found Huxham's Tincture an excellent one to stimulate the appetite and sustain the strength, and for the impoverished blood-state created by hemorrlage the hypophosphites answer an excellent purpose.

Extirpation of the Uterus.-Of late, the extirpation of the entire uterus for malignant disease confined to it has not only been advocated, but repeatedly practised. The procedure which has been followed has been that of Prof. Freund, of Breslau, the greatest advocate of the operation. The "Chicago Medical Gazet te," quoting from "Schmidt's Jahırbucher," gives the following statistics of complete uterine extirpation for malignant disease of the uterus. Freund las performed 14 operations with 8 deaths, 5 recoveries, 1 incomplete operation. Of the five recoveries one died from a return of the cancer, one from pleuritis, and a third is now suffering from 
a return of the eancer. Of the remaining 25 operations of whieh the results are known, which have been reeorded by various operators, 19 died, 5 recovered, and in one case the operation was incomplete. Of these five suceessful cases, in three the cancer returned.

The procedure of Prof. Freund is the following. An incision being made through the median line, the intestines covering the uterus are held up out of the pelvis by means of a soft linen eloth soaked in warm, earbolized water, until the operation is finished. One thread is passed through the fundus uteri, and another through the peritoneum of the anterior part of the pelvis, to prevent its collapse, and held by assistants. Each broad ligament is now ligated in three portions, the upper ligature transfixes the Fallopian tube and the ovarian ligament, the middle one passes through the ovarian ligament by the side of the upper ligature and returns through the round ligament; the lower pierces the round ligament and is earried twiee through the vaginal wall-first through the antero-lateral part of the vaginal roof into the vagina, and then back through the postero-lateral part of the vaginal cul-de-sac behind the base of the lateral ligament into Douglas's pouch. The uterus is then removed, and after drawing the ends of the ligature into the vagina the peritoneal opening is closed, and, the intestines having been replaced, the abdominal incision is treated as after ovariotomy.

Freund ${ }^{1}$ has more recently made certain modifications in his operation. I. To avoid accidental detachment of the peritoneum from the anterior wall of the pelvis during the operation, the ineision throngh the peritoneum is to be shorter than that through the skin, so that the peritoneum at the inferior extremity of the wound may be stitehed to the skin. II. Instead of passing a looped wire through the body of the uterus, for the purpose of steadying it, he uses the fenestrated ovariotomy forceps. III. By means of a trocar needle a ligature is passed from the peritoneal cavity to the ragina on one side of each broad ligament and then from the vagina to the peritoneal cavity on the other side. This ligature is made to enter and to leave the vagina at points very near together in the utero-vaginal attachment, so as to include as little vaginal tissue as possible. This ligature does not include the Fallopian tubes, the orarian ligament, or the round ligament. It is tied and the ends are cut off. IV. To distinguish between the ligatures of the Fallopian tubes, of the ovarian ligaments, and of the round ligaments, he attaches to the end of the superior a slender piece of metal, to the next below a shorter pieee, to the other none at all. This also facilitates the passage of the ligatures through the vaginal wound. V. He passes loops through the peritoneal flaps to facilitate the dissection of the uterus therefrom. VI. When the dissection along the anterior wall of the uterus is nearly complete, he makes a small ineision from the vagina through the utero-vaginal attachment, and dilates this ineision until it will 
admit one or two fingers of the left hand. Then passing these fingers through this opening he inserts them into the uterine eanal to faeilitate the laandling of the organ during the remaining part of its extirpation.

Such is Freund's operation for ablation of the uterus affected by malignant disease. Those who have thus far performed this operation for malignant disease have been Freund, Martin, Mueller, Olshansen, Baunıgaertner, Schroeder, Winckel, Kiocks, Credé, Oelschlläger, and Noeggerath. Seliroeder' declared at a meeting of the German Gynecological Society in 1878 that if five times out of six the disease should return, he would still operate. In this conclusion he will find few conservative surgeons to agree with him. Freund's operation is adhoc sub judice. Time will decide as to its value.

At the risk of becoming terious by repetition, I offer the following résumé of the methods of fulfilling the indications in treating this affection.

1st. Secure cleanliness, prevention of fetor, and diminution of hemorrlage and pain by the free use of warn raginal injections of antiseptic and astringent character such as the following:-

$$
\begin{aligned}
& \text { R. Acidi carbolici (sol. sat.), Żijss. } \\
& \text { Glycerinæ, Oj. } \\
& \text { Aluminis sulphatis, } 3 \text { ×iv. } \\
& \text { Morphiæ sulphatis, gr. xvj.-Mr. }
\end{aligned}
$$

S.-Aild one tablespoonful to tro quarts of warm water, and use as a vaginal injection morning and evening by Davidson's or the fountain syringe. 2

21. Give an abundance of food which the system can appropriate, at regular intervals, hearing in mind that nutrition consists in the introduction into the blood, not into the stomach alone, of nutrient materials.

3d. Do not indulge in, what appears to be to a certain order of medical mind, the grim pleasure of making a fatal prognosis. As long as possible let the patient enjoy the "fleasures of hope." It is not the duty of the physician to hold constantly before her eyes the gloomy pieture of a speedy and certain death which he is powerless to avert. No deception should be practised, and none need he, for these patients always suspect the truth and do not seek to be informed. Immerliate relatives shonk have the fuets plainly stated to them.

4th. Quict pain by the sy:tematic use of opium or one of its alkaloids. The use of the hypodermic syringe at a fixed hour every day is the most certain and frequently the most agreeable plan.

5 th. If possible, remove the diseased part completely by surgical means.

6th. If complete removal be impminle, and the vagina, bladder, rectum, or pelvic tissues be involved, as a rule asoid surgical interference entirely.

1 Am. Journ. of Obstetrics, Jan. 1879.

2 A syringe of linglish manufacture, which I regard as superior to thow abore mentioned, has just been introduced here under the name of the syphon enema syringe. 
7th. If the disease be confined to the uterus, and complete removal be impossible, practise partial removal or destruction of the growth by galvano-cautery, the scissors, scoop, or curette, or by actual cautery or fuming nitric acid.

8th. If the affection be entirely confined to the uterus, the propricty of its complete removal by laparotomy should be considered. 'This operation has, however, been thus far too little tested to render an absolute decision with reference to the propriety of its adoption possible.

Althongh, of course, there is a great deal of discomfort and of suffering inherent to the progress of this dreadful malady, it is surprising to see to how great an extent these may be mitigated by forethouglit and intelligent attention to detail. In one case we see a woman suffering almost constant pain, breathing an atmosphere vitiated by sickening odors, associating with persons whose every word and look are productive of increased sadness and depression, and looking forward with unvarying gaze to the grave as an issue for her troubles, scarcely more gloomy than her present place of abode. In another the ability and care of the physician have changed all this. The patient looks forward for the visit of her medical attendant with the certainty that a full dose of morphia liypodermically administered will give her twenty-four hours of freedom from severe pain. Experience has taught her that the antiseptic injections which she employs every four or five hours lave the unquestionable power of almost entirely annihilating disagreeable odors, and that the well-regulated circulation of air and the repeated flushing of one chamber during the course of the day while she occupies another will give her pure and fresh air to breathe. She recognizes the fact that some influence other than her own has surrounded her with associates who prefer exaggerating the silver lining of the cloud which liangs over her, to contemplating its gloom, and the cultivation of thoughts calculated to create cheerful resignation, quiets and sustains the mind. Then, too, in the very depths of her heart flickers still a faint ray of hope. The worst is not known to her, and she lives in comparative comfort until the elosing scene.

'There is a peculiar nervous condition which develops in women, which deserves the name of carcinophobia. A dread of cancer suddenly seizes the woman, either from some physical reason like the recognition of some point of induration, or a moral one like the recent death of a friend from that disease, and losing all reason she becomes panic-stricken to a degree which renders her and all those who surround her utterly wretched. The assurances of the plysician are either doubted or disregarded, and the unlappy patient falls into a state of despondency bordering upon acute hypochondriasis. Some yaars ago a very timid and sensitive lady, whose mother had died of cancer, came to me, from one of the largest cities of this country, by the alvice of her plysician, to be operated upon for cancer of the cervix uteri. She appeared so completely dazed by the announce- 
ment of the diagnosis and prognosis on the part of her medical attendant, that she was scarcely aroused by the statement on my part, that she had no trace of cancer, and that the laceration of the cervix and fungoid degeneration, which had been mistaken for it, could be readily and certainly curel. In two weeks from the time that $I$ first saw her she was seen with me by Dr. Choate, and was removed to his private asylum at Pleasantville, where, after six months' residence, she entirely recovered from a mental aberration which, in the opinion of Dr. Choate and myself, was wholly due to the injudicious announcement to her of an incorrect diagnosis.

\section{H A P TER XXXIX.}

\section{DISEASES RESULTING FROM RETENTION AND ALTERATION OF TIIE FETAL ENVELOPES.}

\section{Uterine Moles.}

Definition.-By this term is meant the existence in the cavity of the uterus of a fleshy mass which cannot with propriety be classed among tumors or polypi, and which consists in the retention of a part or the whole of the factal shell, or of the placenta.

The appellation of mole is neither elegant nor appropriate, but it is sanctioned by use for so great a length of time that it is difficult to alter, and impossible to diseard it.

Ilistory.-Ancient medical literature teems with theories, hypotheses, I might also say fables, upon this subject. It would be unprofitable even to enumerate the extravagant and baseless surmises indulged in upon it, but as an example I will mention that Aristotle, ${ }^{1}$ IIippocrates, Galen, and the Latin authors regarded moles as due to a want of virtue in the seminal fluid, or to a superabundance of menstrual blood.

$\Lambda$ certain superstition has attached to them even in modern times; thus, Capuron quotes Malion for the following very curious assertion: "The housewives believe that moles not only take the forms of certain animals, but that they even walk, run, fly, try to hide themselves, even to re-enter the womb from which they eame; indeed, if no obstaele be offered they will kill the woman just delivered of them." Levret pointed out the fact that they are only the fectal shell, which by the establishment of a low grade of nutrition continues to exist.

I'utholngy. - As the foctus passes into the uterus it is enveloped by its proper membranes, the amnion and chorion, and these are surrounded by a prolongation of the hypertrophied mucous lining of the organ, called the decidua reflexa. Between the end of the second and the end of the third

1 Capuron, Mal. des Femmes, p. 268. 
month the placenta is formed, and the villi of the chorion not engaged in its development become atrophied. Before that time the foctal shell is (quite thick, and is everywhere in close communication with the uterine walls.

Many adverse influences may destroy the life of the foetus, and generally as a result, the whole of the products of conception are swept away by uterine contraction. But sometimes the shell of membranes clings to its attachment, and for an unlimited period holds its position in utero. 'This, absorbing nourishment from the uterine vessels, becomes to a certain extent organized, and constitutes the disease under consideration. When expelled from the uterus a mole is usually found to be somewhat ovoid in shape, and to resemble the product of coneeption at the sccond month. It differs from this, however, in its dark brown color and apparent lack of vitality.

Canses.- There are many intrauterine growths and collections which, being cast off, may be mistaken for moles, as, for example, masses of coagulated blood, polypi, decidual membranes, etc., but a true mole never exists except as a result of conception.

Symptoms.-The condition generally announces itself by these symptolns :-

Menorrhagia or metrorrhagia ;

Hypogastrie, weight and uneasiness ;

Uterine tenesmus;

Slight constitutional disturbance;

Cessation of signs of pregnancy.

Physical Signs.-The diagnosis of uterine moles is very obscure and often uncertain. When a patient who has exhibited all the siglis of pregnancy suddenly ceases to do so and presents those just enumerated, a mole may be suspected. Vaginal touch will reveal the fact that the uterus is enlarged, and the uterine probe may assure us that its eavity contains some solid substance, but the removal and examination by the microscope of a portion of the mass, will alone enlighten us as to its character. The condition being suspected, the cervix should be dilated by tents, and uterine action excited by ergot in order to settle the question.

Differentiation._This disease may be confounded with_-

Submucous fibroid ;

Sareoma or cancer of the uterine body;

Subinvolution.

To the finger passed into the uterus, a fibrous tumor is usually hard, smooth, and resisting; while a mole is soft, spongy, and yielding to the touch, but this may prove deceptive.

Sarcoma and cancer may be known by the peculiar sensation yielded to touch, their fetid discharges, the constitutional depreciation attending then, and their microscopical characteristics. 
Subinrolution demonstrates upon exploration the fact that the uterus is empty. It also frequently follows delivery at full term, while a mole rarely does so.

From all these conditions the differentiation may be positively accomplished in one way and one way only; dilatation of the cervix, removal of a small portion of the mass, and examination of this by the mieroscope.

Prognosis. - The prognosis is favorable.

T'reatment.-The cervical canal should be fully dilated and an effort made to arouse uterine contraction by persistent use of ergot. Should this fail, the mass should be cautiously removed by the large uterine scoop, or by traction by means of the placental forceps.

\section{Cystic Degeneration of the Chorion, or Uterine Hydatids.}

Definition.- The chorion, remaining attached to the uterine walls after expulsion or death of the embryo, sometimes undergoes a peculiar metamorphosis which receives this appellation. True hydatids, that is, cysts due to the presence of the acephalocyst, are very ravely met with in the uterus. Their extreme rarity may be judged of from the fact that Rokitansky declares that he has never discovered them but once. Dr. Graily Hewit ${ }^{1}$ believes, that, when they exist in the uterine cavity, it is probable that they are discharged into the peritoneum from rupture of a eyst in the liver, and then pass through the uterine wall. Not only do the grape-like cysts, making up what is commonly known as uterine hydatids, difler from true hydatids in absence of the acephalocyst, they are also unlike them in their appearance and formation. The former consist of little saes in a series, as if strung together; the latter are closed sacs, one within another.

Synonyms.-This aflection has been described under the names alrealy given, and under those of vesicular mole, in contra-distinction to fleshy mole just considered; hydatidiform mole; and hydatid pregnancy. In most works it is described only as a variety of mole.

Pathology.-Remaining in connection with the uterine walls after the expulsion of the foctus, and absorbing nourishment which it no longer appropriates, the villi of the chorion undergo a kind of dropsical swelling, which results in the grape-like bodies styled lyylatids.

It is probable that after the mul of the third month, no such degeneration can occur in the secundines, for after that period the placenta is formed, the villi which existed at its site hecome vascular, and those over ctler parts of the surface of the foctal sac undergo atrophy. It is awe that at parturition at full term, masses of these sacs have, in rare instances, been cxpelled; but in such cases it is probable that some portion of tho chorion hat begun to degenerate at an early period of conception.

$10_{1}$. cit., 1. 75 . 
('auses. - we know of no influences which exeite this form of degeneration in a retained chorion.

Fig. 238.

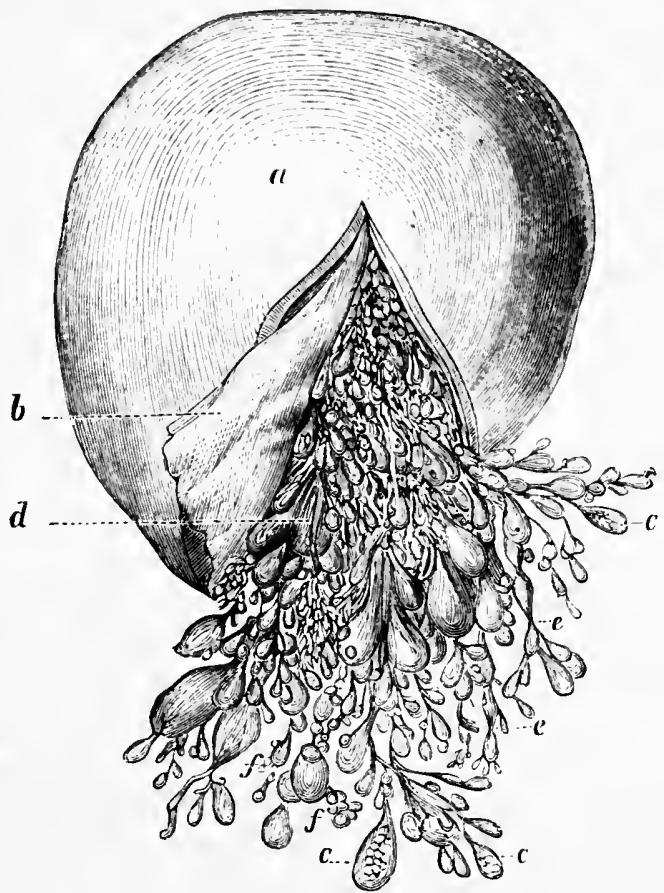

Cystic degeneration of chorion. (Boivin and Dugès.)

Symptoms._-Sometimes the disease demonstrates its presence by all the signs of pregnancy, abdominal enlargement being one of the most prominent. Suspicion of the existence of something abnormal is very generally excited at an early period by some or all of the following signs:-

\section{Nausea ;}

Discharge of clear or bloody water;

Ilemorrhage;

Cterine tenesmus;

Constitutional disturbance;

Discharge of little eysts.

Plysical Signs.- Yaginal touch will reveal the uterus enlarged, and the os patulous, as if the cavity of the organ were fillerl with something, and conjoined manipulation will prove this to be fluid and not solid.

If with these signs the fact could be ascertained that cysts liad been discharged, the diagnosis would be complete. If not, the cervix shonld 
be dilated, in order that the cavity of the body may be explored by touch, or that a portion of the mass may be removed for inspection.

Differentiation._-This disease might very readily be confounded withPregnancy;

Polypus ;

Sarcoma or eancer of the body of the uterus.

From pregnancy it could generally be distinguished by the very rapid development of the uterus, the presence of watery and bloody discharges, and the absence of quickening, ballottement, and other signs of that state.

From polypus a differentiation could readily be made by tents, the uterine sound, and the microscope.

Sarcoma and cancer would be known by fetid discharge, great constitutional decadence, and the smaller size of the uterus than in hydatids.

Prognosis.-If the case were one of true hydatids due to the acephaloeyst, the prognosis would be very grave. If it were proved to be one of cystic degeneration of the chorion, it would be favorable.

Treatment.-The treatment should consist, 1st, in full dilatation of the os and cervix uteri by tents, and then, if necessary, by hydrostatic dilators; and, $2 \mathrm{~d}$, in excitation of the expulsive powers of the uterus by the free use of ergot. Should this drug fail in establishing the desired contraction, a large scoop, or, if possible, the hand, should be gently passed into the uterus, and the mass be evacuated. During this time, should alarming hemorrhage occur, it should be controlled by the tampon and by tannic acid, or sulphuric acid given internally.

In the management of such cases the difficulties do not lie in the way of treatment, lut in that of diagnosis. This being once fully established, treatment becomes simple.

\section{A P T E R X L.}

DYSMIENORRHEAA.

WE have now arrived at the most appropriate place for the consileration of the derangements of the process on menstruation; and first among these we take up that of which the name heads this chapter.

'The process of menstruation, by which the human female discharges from the nterus a certain amount of blood once in every lunar montl, depends upon three phenomena which are intimately connected together: 1 st, the spontaneous escape of one or more ovules from the ovaries; $2 \mathrm{ll}$, engorgencint of the ereetile vascular stratum surrounding and supplying the uterus; and, $3 d$, rupture of the vessels supplying the endometrium, 
together with rapid desquamation of its epithelial cells. Until the year 1821, when Power first broached the subject, the connection between ovulation and menstruation was unsuspected. Even then it was not established until the writings of Negrier in 1840. After this the investigations of l'ouchet, Bischofl', Coste, and Raciborski carried conviction to the minds of most, and caused the general acceptance of the theory. There are now those who doubt the connection of the two phenomena, but I belicve that I an correct in saying that they are decidedly in the minority, and that the ovular theory is at present almost universally admitted. That menstruation sometimes occurs after removal of both ovaries I know by experience in one of my own eases of ovariotomy, and Dr. Ritchie ${ }^{1}$ has proved that it may occur without ovulation, as ovulation often takes place without it. But this is not the time for an examination into the merits of the lengthy discussion which lias taken place concerning the subject. I prefer to avoid it, and to express the view which I believe now to prevail, and to which $I$ give my own adherence.

We assume, then, that the extrusion of one or more ovules from the ovaries, which takes place under some unknown influence, is the exciting cause of menstruation; let us inquire into its mode of action. The uterus is surrounded by a network of fine and tortuous vessels, which envelop it as a stratum or layer, extending through the broad ligaments to the ovaries. Outside of this vascular network delicate muscular fibres, extending from the uterus, run, encircling its ressels. When an ovule begins to approach the circumference of the ovary, congestion of this organ occurs in consequence of irritation. This irritant effect is transmitted to the muscular layer surrounding the vascular network in and around the uterus. It contracts, impedes sanguineous flow, and causes engorgement, which in the membrane lining the uterus, and in all probability in that lining the tubes, causes a rupture and flow of blood into the uterine cavity. This engorgement constitutes the "erection" alluded to by Rouget in lis "Récherches sur les Organes érectiles de la Femme." Blood flowing from ruptured vessels collects in utero, whence it flows through the cervix into the vagina and from thence it passes out of the vulva.

When all the elements conneeted with this process are in a perfectly normal state, it oceurs without creating other discomfort than a sense of fulness about the pelvis, slight pain in the back and loins, and a general sense of lethargy. But if an abnormal condition should exist, either in the structure from which the blood pours into the uterus; in any of the surrounding parts or organs which undergo congestion; or in the canal by which it passes into the vagina, menstruation often becomes excessively painful, and in some cases undermines the health by the intensity of suffering which it induces. This state receives the name of dysmenorrhøea, a term derived from $\delta v_{s}$, difficult, $\mu \eta \eta$, a month, and $\rho \in \omega$, I flow. 
Pathology.-Any condition, whether general or local, affecting the structure of the uterine walls, the ovaries, or the surrounding areolar or serous tissues, so as to render the nerves supplying these parts morbidly sensitive; may produce pain in eonnection with the first part of the process. Anything impeding the escape of blood from the uterus or vagina may produce it by interference with the second part. For example, a general condition resulting in neuralgia of the uterine or pelvic nerves, or a local inflammation altering their state, miglt readily create pain in the first stage, while either a natural or acquired stricture of the eervix would probably do so in the second.

As a general rule, dysmenorrhca is due to one or more of the three following factors : 1st, a depreciated condition of the constitution, beginning usually either in the nerrous system or blood, which ereates a tendeney to neuralgia ; 21 , an abnormal state of the uterus; or $3 d$, a diseased state of the ovaries. In a woman in whom the nervous system, the uterus, and the ovaries are normal, it is highly improbable that this condition would ever arise. Every practitioner can recall numerous instances in which any one of the three conditions mentioned has sufficed to establish it, and as this is true of each of them separately it is more so of a combination of the three.

Every case should be examined from this standpoint in practice, and the treatment adopted should be governed by the discorery of the existence of one or more of these conditions as causative agents :-

Varieties of Dysmenorrhaea.-For convenience of stuly, dysmenorrhoea may be divided into the following varieties:-

Neuralgic dysmenorrhoea;

Congestive or inflammatory dysmenorrboa ;

Obstructive dysmenorrhoca;

Membranous " "

Orarian " "

Seat of Pain in Dysmenorrhxa.-Upon this point our knowledge is not certain. It is probable that in the first three varieties the pain is seated in the uterus, in the ovaries, or in the cellular tissue or peritoneum surrounding the pelvic viscera. Some of the most intractable cases with which I have met have been due to pelvic peritonitis, whieh, even after inflammatory action has subsided, has left the nerves supplying these parts in so scnsitive a state that pain, or even a recrudescence of inflammation styled menstrual pelvic peritonitis, is exeited in them by the process of menstrual congestion. It is often very difficult to decide as to the exaet seat of pain. Even a plyysical exploration instituted during the menstrual period may fail to enlighten us.

The practitioner who regarts dysmenorrlıea as a disease, and applies to every case a uniform plan of treatment, will rarely meet with success in its management. He should view it as a syuptom of an abnormal con- 
dition which should, as far possible, be discovered and removed. Although, even when aeting thus, eases will be met with in whieh he will be baffled, it will be gratifying to pereeive how rarely these will oecur. The great importance of diflerentiating the varietics mentioned, and adopting appropriate plans of treatment, calls for a separate study of each.

\section{Neuralgic Dysmenorrhere.}

This variety depends upon no appreciable organic disorder of the uterus or its appendages, but merely upon a peculiar state of the nerves, which, under the stimulating influence of congestion, produees pain.

Causes.-There are many agencies which at times so alter the healthy state of the nerves of the stomach as to produce in them, at each period of digestion, pain, which is called gastralgia or gastrodynia. Similar agencies may oceasion neuralgia of the nerves of the eye, or of those supplying the tissues of the head and face. In like manner they may affeet the uterine nerves whenever these are inordinately exeited from menstrual congestion. The same patient who from slight exeitement or fatigue develops supra-orbital neuralgia, will often, from the same causes, suffer from neuralgic dysmenorrhœa.

The causes which generally induee it are-

The neuralgic diathesis;

Chlorosis or plethora :

Certain blood states, as those of malaria, gout, and rheumatism ;

Luxurious and enervating habits;

Habits deteriorating the nervous system, as onanism or excessive venery.

Symptoms.-Pain may show itself before the flow has been established, and disappear as soon as it comes on; or it may continue with varying intensity throughout the duration of the menstrual discharge. The patient usually complains of a sharp, fixed pain over the pelvis, down the loins, or in some distant part of the body. I once saw a patient who, during each period, suffered intensely from neuralgic pain on the outer side of one little finger, and another who before the flow was established experienced for several days a violent pain at the root of the nose.

In some cases the pain seizes the patient very suddenly, and becomes so agonizing in character as to render her almost delirious. She will toss wildly upon her bed, and give evidence of the most serere physical suffering. Then in a few hours the pain will almost as suddenly abate, and for the rest of the menstrual period exist only in very moderate degree.

Differentiation.-When the pain is felt in the uterus, it presents nothing expulsive in its eharacter; the flow of blood is steady, and not interrupted; no clots are disebarged by spasmodie efforts, and physical examination discovers no obstruction. These facts generally distinguish neuralgic from 
obstructive dysmenorrhœa, though sometimes differentiation is very difdifficult.

From the congestive form it is differentiated by absence of constitutional disturbance, and by its being habitual and not exceptional. It may be distinguished from the inflammatory variety, by absence of the ordinary signs of endometritis, and of orarian and periuterine inflammation. There is also absence of leucorrhwe and pain, as well as of the physical signs of inflammation, in the intervils of menstruation.

Prognosis.-If a patient affected by neuralgic dysmenorrhœa be able and willing to effect a decided alteration in her mode of life, the prospect of recovery is good. Should no such change be attainable, it is decidedly unfarorable.

Treatment.-The first duty of the physician should be to discover the cause of the development of neuralgia in the performance of the menstrual function, and the second to endeavor to remove this. Neuralgia of the face and head is rarely a primary affection, and consequently resists remedies directed especially to it. It generally results from some focus of irritation, as, for example, a decayed tooth, or a plug of hard wax in the ear, or from some blood poisoning; and when the cause is removed it disappears. So with the disorder which we are considering. If the rheumatic or gouty diathesis exist, it should be treated by colchicum, guaiae, and vapor baths. The skin should be kęt warm and active by wearing flannel over the whole body in winter, and a mild, equable climate should be chosen during the cold months of the year. Should a delicate state of the nervous system have been engendered by habits of luxury, indolence, or dissipation, the patient should be sent to the country, where an out-of-door life, horseback exercise, early hours of retiring, and plain, wholesome food, may exert a decidedly alterative influence. Chlorosis and plethora should be treated, the one by ferruginous and nervous tonics, fresh air, foorl, and cheerful surroundings; the other by strict diet, venesection, eathartics, and other depletory means. Malarial toxæmia should be treated by change of residence, quinine, and iron. $\Lambda$ sea royage will often accomplish an excellent result in neuralgic dysmenorrhcea by its alterative influence, whatever be the cause of the neuralgic state, and the same nay be said of surf bathing.

In addition to these general means, benefit may be obtained from the use of some which are local. The occasional passage to the fundus of the uterus of a uterine sound, the retention in utero of the galvanic pessary, which will be described when speaking of amenorrhea, the use of tents, and the systematic employment of the continuous or galvanic current, one pole over the sacrum or against the cerrix and the other over the hypogastrium, will often prove very serviceable.

Parturition often accomplishes an cxcellent result, and in many cases cures the affection entirely. 
Besides these means there are certain anti-neuralgic remedies whicli act more or less as specifies in this form of dysmenorrhœa. Foremost amongrst these is apiol, a yellowish, oily substance, obtained from the petroselinum sativum by the action of alcohol and filtration with animal charcoal. It is preparel by Joret and IIomolle, of France, in the form of eapsules, and is sold by druggists throughout this conntry. The dose of these is one capsule night and morning during menstruation. The tineture of eannabis indica, in doses of twenty-five drops every fourth hour while pain is severe, is also beneficial, as is also the hydrate of chloral in ten grain doses every eight lours. Where a spasmodic element appears to exist in addition to the neuralgic, suppositories of butter of cocon containing each a quarter of a grain of extract of belladonna will often give great relief; they should not be repeated of tener than once in every eiglt hours. Under these eireumstances, too, great benefit will often follow the use of enemata of tincture of assafoctida, two to three drachms in a gill of warm water, or of ten grain doses of ehloral dissolved in half a pint of warm gruel. Placing the patient in a very warm general bath, for from twenty to thirty minutes, is likewise often productive of great relief.

\section{Congestive or Inflammatory Dysmenorrhœa.}

Definition.-At each menstrual epoch an active congestion oceurs in the nucous membranes of the Fallopian tubes and uterus as well as in the ovaries, and, probably, to a less degree in all the pelvic tissues. When any abnormal influence renders this excessive, it naturally produces pain in the nerves intervening between the distended vessels. This excessive hyperemia, which may result from a mechanical cause, as displacement of the uterus, or from a vital cause, as the peculiar condition which we know as inflammation, gives rise to a variety of painful menstruation which has been styled congestive or inflammatory, and which has been synonymously styled accidental in contra-distinction to those forms which are habitual.

The state of inflammation which so alters the condition of the nerves immediately affected by ovulation or menstruation, may exist in or around the uterus, in the peritoneum covering it, in the ligaments which sustain it, or in the areolar tissue of the pelvis.

In a great many eases inflammation of the uterine mucous membrane is the cause of this form of dysmenorrhcea. The existence of disease in this part causes, perhaps, little pain until the erythism engendered by menstruation occurs. Then great local excitement takes place and dysnenorrhoea shows itself.

Causes.-It may result from almost any pelvic inflammation, or from any influence which exaggerates and prolongs the congestion excited by ovulation. Chief among these may be mentioned- 
General plethora ;

Exposure to cold and moisture;

Sudden mental disturbance ;

Sluggishness of portal circulation ;

Displacement of the uterus ;

Fibrous tumors;

Areolar hyperplasia;

Endometritis ;

Periuterine cellulitis ;

Pelvic peritonitis.

Some of these causes, even without exciting true inflammation, may keep up a state of hyperemia in the uterine vessels, which, being augmented at menstrual epochs, creates pressure upon the neighboring nerves and consequently pain.

Symptoms. - A patient who has previously menstruated painlessly is seized during a period with severe pelvic pain accompanied by diminution or cessation of the discharge and considerable constitutional disturbance. The pulse becomes full and rapid, the skin hot and dry, and the eyes suffused. There is severe pain in the head, with nervousness, restlessness, and sometimes, though rarely, a little delirium. There may be in addition rectal and vesical tenesmus and diarrhœa. In cases in which a local inflammation exists, as the flow begins, or before that time, the patient suffers from dull, heary, fixed pelvic pain, which lasts until the process is ended, and often even after it has done so.

Differentiation.-If the attack be due to hyperæmia merely, without inflammation, the constitutional disturbance and suddenness which characterize it will mark its difference from the neuralgic and obstructive forms, as the absence of signs of inflammation in the intervals will do from the inflammatory. If it be due to the influence of existing pelvic inflammation, it will usually be marked by pain during the inter-menstrual periods, difficult locomotion, fatigue after exertion, leucorrhœa, etc.

Prognosis.-This will depend upon the prognosis of the condition which has given rise to it. If that can be removed, the dysmenorrhoa, which is one of its symptoms, will disappear; if not, it will continue without material diminution. If the cause of the symptoms be a fibrous tumor, pelvic peritonitis or periuterine cellulitis, or even an irremediable displacement, the probability of relief is, of course, not at all great.

Treatment.-As in the neuralgic variety, the source of the evil should be carefully ascertainerl before remedial measures are adopted. If it be due to plethora, the lancet, catharties, strict diet, exercise, and fresh air will be indicated. Should the attack be accidental and have oceurred from exposure to cold and moisture, opiates, diaphoretics, and sedatives will give speedy relief. In case a sluggishness of the portal circulation exists, this should be stimulated to greater energy by mercurial eathartics 
and a change in the habits of life from sendentary to active. $\Lambda$ displaeed uterus is of ten kept in a constant state of congestion, which ean be relieved only by properly sustaining the organ. This, according to my experienee, is the most frequent of all the causes for congestive dysmenorrlicea. In some eases a slight degree of retroversion or anteversion will produce it, while in others direet descent will be found to be its cause. In many of these cases it will, upon recognition of the displacement, be scarcely credited by the practitioner that it is suflicient to be productive of the result. Yet replacement of the uterus, and removal of superincumbent weight by meaus of a skirt supporter and abdominal pad, will give such complete relief as to put all doubts at rest. If a fibrous tumor be the cause, a cure will depend upon its susceptibility of removal.

Should any local inflammation be discovered as the cause of the evil, this, and not one of its many results, should be the subject of treatment.

\section{Obstructive Dysmenorrhoea.}

If, after the collection of blood in the uterus, any obstruction exist which prevents its eseape into and through the vagina, a violent spasmodic pain is excited which often amounts to uterine tenesmus. To this form of painful menstruation the name of obstructive dysmenorrhea has been applied. The obstruction may exist in the os or cervix uteri, in the ragina, or at the vulva, where that canal is partially closed by the hymen.

Pathology.-If any organ be filled with fluid beyond the point of tolerance, as, for example, the bladder, stomach, or large intestine, violent contractions of the distended fibres, which make up its walls, are excited, and spasmodic efforts, which have received the name of tenesmus, are established. If evacuation result from these, relief is obtained; if not, contractions continue for a long time. When occurring in the uterus, they present the symptoms which characterize the affection which now encrages us.

Cuuses.-The special causes of such obstruction are-

Congenital or acquired contraction of the cervical canal;

Flexion or version of the uterus;

Vaginal stricture;

Small polypus in utero;

Obturator hymen ;

A fibroid in the parenchyma of the neck.

Any one of these causes may produce the result by partially occluding the cervical canal, so as to allow of the escape of fluid imperfectly and painfully. Contraction of the cervix may be congenital, or may result from inflammation of the mucous lining of the canal, or diminution of its calibre by contraction of the parenchyma, from the use of strong caustics within the os, or other cause. The last cause is a prolific one, the con- 
dition commonly resulting from the passage of the actual eautery or potassa cum calce into the canal of the cervix. Flexion obstructs the canal by creating an angle in its course. Let a tube of gutta-percla be slightly curved and no obstruction will exist, but if it be sharply bent upon itself complete occlusion will occur. Versions much more rarely produce the difliculty, but sometimes, the os being, by reason of the displacement, pressed very firmly against one wall of the vagina, a partial obstruction is produced.

Some time ago a young girl presented herself at my clinique, at the College of Physicians and Surgeons, declaring that at every menstrual epoch she suffered from the most intense bearing-down pains, which exliausted her greatly. Upon examination I found a partial closure of the vagina, the result of sloughing during typhus fever, which had produced an accumulation of blood above it. This excited uterine contraction, and each effort caused the expulsion of a small amount of the fluid collected above the stricture. In like manner the hymen may prevent free escape and produce uterine tenesmus.

Sometimes a small polypus comes down to the os internum and rests upon it, obstructing the egress of fluid, but permitting the passage of a probe into the uterine body. It acts upon the principle of the ball valve, and by so doing produces the worst features of obstructive dysmenorrhoca.

Symptoms.-After menstruation has continued for some hours, and sufficient blood has been collected in the uterus to distend it, a severe spasmodic pain occurs over the pelvis, which has been styled "uterine colic." This rapidly passes into a violent expulsive effort like the contractions attending miscarriage, which in time causes the passage of a certain amount of blood. Then severe pain ceases for a time, until further distention and obstruction occur, when the process by which the uterus empties itself is repeated.

It will be clear to the observer that the difficulty develops itself by three steps:-

1st. Some obstruction causes a collection of blood in the uterus;

2d. This excites uterine contraction by distention;

8d. Uterine contraction, to a limited degree, frees the uterus and gives ealse.

This is the pathology of the condition, whether the obstruction exist in the vagina, at the vulva, or in the cervical canal. If it exist at the last point, the efforts of the uterus will generally expel a small elot, and then a gush of imprisoned blood will follow, much to the patient's relief.

Differentiation.-The symptons just relatel are so marked and decided that little difficulty will generally be experienced in determining as to the patholocy of the case. Before such a decision is arrived at, however, physical exploration will usually place the matter beyond a doubt. The absolute obstruction may generally be demonstrated by difficulty in the 
introduction of a probe into the cavity of the uterus. Should the obstruction exist in the vagina, the finger will detect it, and, if in the cervix, the probe will do so with almost as great precision.

It cannot be denied, however, that in exceptional cases a degree of constriction at the internal os which will admit the sound may, by some spasmodic action occurring at menstruation, offer an obstruction to escape of Llood. Indeed, I feel that, in all the varieties of dysmenorrlina, spasm of the fibres of the os internum plays a much more important rôle than is generally appreciated. It is this fact which explains the occurrence of severe pain at certain periods, while at others there is little or none. In some women there appears to be a regularity about this irregularity, the pain occurring without assignable reason every second montl.

Prognosis._This will depend entirely upon our ability to overcome the mechanical obstacle. Should it not be possible to remove this, the constantly repeated distention of the uterine cavity and consequent effort required for emptying it, will frequently result in endometritis. If uterine displacement exist, it slould be treated by meehanical means; any narrowing of the vagina should be overcome; and if possible any obstructing neoplasm removed. If the indication in a given case can be completely fulfilled, the prognosis is good, but not otherwise.

Treatment of Cervical Constriction.-Should it be discovered that the cause of difficulty consists in congenital or acquired constriction of the cervical canal, the condition may be remedied by two methods, dilatation and incision, the means for accomplishing which may be thus presented at a glance:-

Dilatation.

By sounds ;

By tents ;

By expanding instruments. Incision.

Simpson's method;

Simss metlod;

Combined method.

If the constriction be due, as it very commonly is, to flexion forwards of the body or neck of the uterus, the point of stricture will usually be found near the os internum; if it be due to congenital deformity without flexion, it will usually be found at the os externum; while if an escharotic have created the difficulty, the entire length of the canal may be found deficient in calibre.

About the year 1832, Dr. Mackintosh, of Edinburgh, established the practice of dilating the constricted cervical canal by metallic rods, as is done in stricture of the urethra. His plan was to introduce a very small sound, leave it for a short time in position, and then follow it by others gradually increasing in volume. He declares, in reporting upon the practice, that 
out of twenty-seren cases, $t$ wenty-four cures were effected. The sounds by which dilatation may be best accomplished are graduated ones of metal of three or four sizes. Those of Kanmerer are very convenient. Dilatation by their means should be slowly and cautiously accomplished. A sound being passed should be left in position for several minutes, and upon its removal another should be inserted, until the distention deemed practicable at one sitting is attained. There can be no question as to the efficacy of this plan, though it is probable that some of the cases relieved by Dr. Mackintosh were instances of neuralgic and not obstructive dysmenorrheea.

When this method is to be adopted the patient should be anæsthetized, and by means of graduated sounds the cervix, which has been held by a tenaculum, should be dilated by the application of a little foree.

The same result may be accomplished by the use of tents of sea-tangle or tupelo, but the danger attending this method should always be considered belore it is selected.

Another method, which has been adopted with advantage in many cases, consists in the dilatation of the constriction by means of expanding instruments. Cne of the best of these is shown in Fig. 239.

Fig. 239.

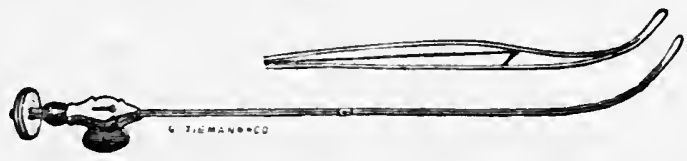

Priestly's dilator for the cervix.

A modification of Holt's stricture dilator is likewise employed for this purpose, and every surgical instrument maker's shop will display many others.

Ball of Brooklyn, and Ellinger of Germany, accomplish complete cervical dilatation by the use of powerful divulsors, which, the patient being anxsthetized, stretch the canal widely open at the expense of the tissues which form it. I have seen the operation performed, and must say that it is to all appearances shockingly brutal, and seems to be a dangerous procedure. Excellent reports are neverthcless made of its results, and the day has passed when any one should allow prejudice to bias his judgment in reference to any surgical procedure, the danger of which may possibly exist only in appearance.

Although a great deal has been said by high authority of late years against dilatation and in favor of incision in these eases, an opposite position was taken by many proninent men in a debate before the American Gynecological Society in 1878. Schultze, of Jena, combines the use of laminaria tents with decided dilatation by means of the instrument shown in Fig. 240. After full dilatation by tents of laminaria, the dilated cer- 
vix is still further distendet by the two-branched instrument just shown. The entire procedure is accomplished uniler Lister's antiseptic method.

Fig. 240.

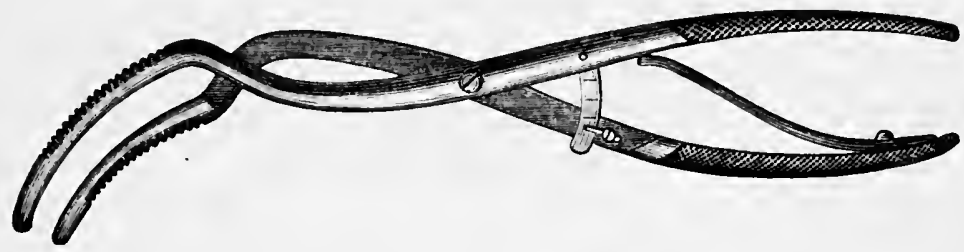

Schultze'g dilator.

I have satisfied myself that the suecess of these methods, like that of the cutting operations adopted for the same purpose, depends not on the way in which they are performed, but upon the lengthy maintenance of dilatation after then by retention in the cervical canal of a glass plug an inch and a half or an inch and three-quarters long. By this the dilatation obtained by operation is perpetuated until a permanently free cervical canal is secured. It matters not whether the original distention was accomplished by one method or by another.

Whatever plan be adopted, the antiseptic method, with the exception of the spray, should be observed strictly.

In 1843, Prof. Simpson, of Edinburgh, advocated and practised cutting through the walls of the cervix, and thus gaining space without dilatation. He employed a single-bladed hysterotome, represented in Fig. 241.

Fig. 241.

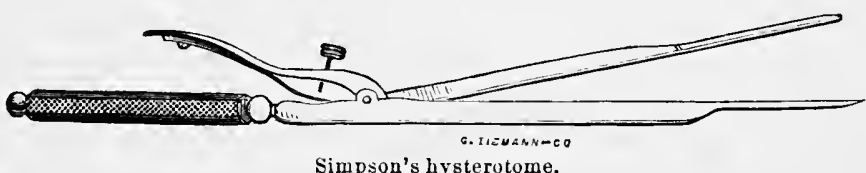

This instrument is introduced without a speculum, the patient lying on her left side. The hysterotome, with its blade concealed, is guided by the index finger up to, and if necessary, as is very rarely the ease, through the os internum. If the cervieal eanal be too small to admit it, previous dilatation should be practised by tents. Being placed in position the blade is thrown out, the force being increased as it is withdrawn to the os externum. By thus increasing the pressure upon the hancle of the blade, the incision is made wider at the lower than at the upper end of the canal. The instrument is then reintroduced and the other side incised in a similar manner, and the surface is brushed over with the solution of persulphate of iron.

To accomplish the incision of both sides simultaneously, a number of . 
double hysterotomes have been devised with two blades instead of one. That of Dr. Greenhalgh, of London, has become popular. A very simple one devised by Mr. Stohlmann, of this eity, is represented in Fig. 242, and a very excellent hysterotome is that of White, shown in Fig. 243.

FIG. 242.

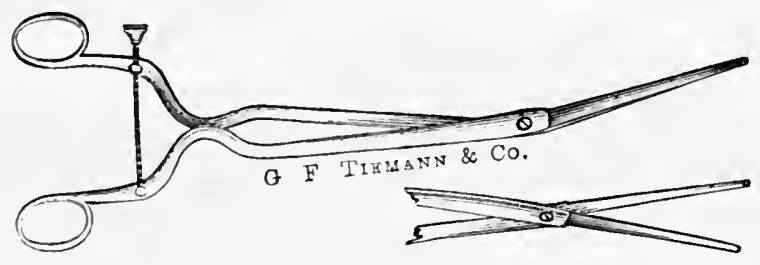

Stohlmann's hysterotome.

Since Dr. Simpson introduced this plan of treatment, several modifications of it have been recommended, but very little improvement had been attained until the introduction of Dr. Marion Sims's method. This con. sists in exposing the parts fully to view and replacing the bistourje caché

Fig. 243.

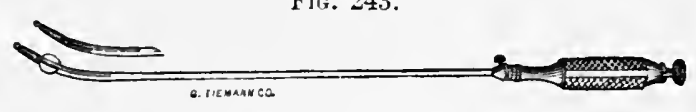

White's hysterotome.

by the knife or scissors, guided by the eye of the operator. It is an axiom that whatever secures clearness of observation conduces to good surgery. Darkness and bad surgery go hand in hand. For this reason Sims's method is far superior to Simpson's. It puts this operation on a level with those practised in other departments of surgery, and lifts it out of the field of uncertainty.

The operation which I proceed to describe is that which I perform, and is almost identieal with the original operation of Sims. The ragina having been thoroughly syringed out with a 1 to 30 solution of carbolic acid, the patient is placed in Sims's position and his speculum is introduced. The ragina is then filled with carbolized water, which remains in it all throngh the operation, and if the operator is careful the operation may be performed almost under water, so thoroughly does it bathe the raginal cervix.

The cervix is now drawn well down by a tenaculum, and, by means of a long, slender bistoury, like that of Sims, an incision is made from and a little above the os internum uteri through the cervical tissue and through the ns externum, so as to cut entirely through the vaginal portion of the rervix at its lowest part. Then the other side is similarly cut, and a glass fluy one and a half inches long is, as soon as active hemorrhage has ceased, pushed by the finger through the severed os internum, and kept 
in place by a tampon. The upper portion of this has been saturated with the following antiseptic and astringent solution:-

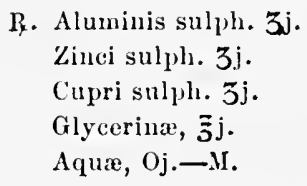

The lower portion of the tampon consists merely of carbolized cotton.

There is very little danger from hemorrhage wlen the cervix is not cut up to the vaginal junction, and the patient is carefully watehed.

The tampon is removed in thirty-six hours, the vagina thoronghly carbolized, and a pessary, small and loosely fitting, like that shown in Fig. 170, is put in position. After this, carbolized vaginal injeetions should be used twice in every twenty-four hours, the patient is kept in bed for a fortnight, and the glass stem and pessary are kept in position for two montlis. The former does not interfere with menstruation, and when it is removed the healing process has finished, and contraction is much less likely to occur than it would be if no stem were employed, or one were kept in place for ten days only.

The influence which invalidates this operation is, I am convinced, the contraction which attends the reparative process. Let this process go on to completion, contraction being rendered impossible, and a full and wide canal will be secured as a result of the operation. The stem goes only within the os internum; not into the body of the uterus; and I lave seldom seen it do harm; nevertheless, it slould be carefully watched.

Like all other operations, whether bloody or bloodless, upon the uterus, antisepsis should be observed, with the exception of the spray.

The results of incision of the cervix, when practised in suitable cases, are sometimes very gratifying. In cases, however, in which the cervical tissue has undergone atrophy, or become hard and contracted, it is often impossible to keep the canal pervious. It gradually contracts in spite of all that can be done to oppose its doing so.

Treatment of Cases Dependent upon Flexion or Version.-Should version be the cause of dysmenorrhœa, it should be relieved not by operation, but by the means already mentioned when speaking of that displacement. If the diffieulty be due to flexion, and more particularly to anteflexion, two indications offer themselves for its relief: 1st, to straighten the bent canal by keeping the body of the uterus erect; $2 d$, to effect the same end by surgical operation.

If a uterus be flexed below the raginal junction, it is evident that obstruction to the menstrual flow will oceur at the point of flexure, and equally evident that an incision through both sides of the canal would not overeome this by straightening it, while a single incision through the posterior wall would do so. In 1862 Dr. Sims conceived and practised such 
an operation successfully. This will be found described in the chapter on flexion. It is unquestionably the procedure most applicable to the relief of dysmenorrhoca due to anteflexion.

Treatment of Vaginal Stricture.-This condition, which may be congenital, or be induced by syphilitic or eancerous disease, or by sloughing, if so complete as entirely to obstruct the canal, produces amenorrhoea. If it be a pervious strieture, it may result in dysmenorrhoea.

The affection may be treated by three methods: dilatation by large bougies, dilatation by tents, and incision. If syphilis be ascertained to be the basis of the local disorder, constitutional means shonld at the same time be resorted to.

Treutment of Dysmenorrhoe from Polypus. — Should the presence of a small polypus be discosered, the cervix should be dilated by tents and the growth removed.

Treatment of Obturator Hymen and Fibroids.-The first should be ineised with extreme caution, and the second removed, if possible, by one of the methods mentioned under the head of fibroids.

\section{Membranous Dysmenorrhæa.}

Definition.-This variety of dysmenorrhoca consists in the expulsion of organized material from the uterine carity, at menstrual periods, which is found upon microscopical examination to consist of the lining membrane of the uterus itself. This may consist of a sac, representing the triangular cavity of the body of the uterus with its three openings, or it may come away piecemeal as slireds or strips of mucous membrane.

Observers, since the time of Morgagni, have recognized this form of disordered menstruation, but looked upon the mould cast off as formed of fulse membrane, and as being a result of croupy or diphtheritic endometritis. For the true explanation of the phenomenon we are indebted to Simpson, Oldham, and Virchow.

Pathology.-Dr. Oldham's opinion, which strikes me as the most rational, not only upon theoretieal grounds, but from close observation of those eases which have come under my notice, is that at some time during the inter. menstrual period, the entire lining membrane of the uterus is lifted from its lase and separated, so as to be ready for extrusion at one of the next menstrual crises. Virchow deelares that a deciduons membrane, similar to that of pregnaney, forms, and for this membrane he proposes the name of the "menstrual decidua." Dr. Ohllam believed that congestion of the ovaries gave rise to this remarkable phenomenon, by transmitting an irritant influence to the uterus. IIowever inaugurated, this process appears to prepare the membrane gralually for complete detachment and extrusion at a menstrual period, when it is expelled. Simpson, denying the eausative influence of inflammation in the production of the menstrual decidua, 
regards it as a prodnct natural to the uterus as to function, but unnatural as to time, circumstances, and frequency of development.

An entire membranous cast, when washed and examined by the naked eye, is found to be triangular, with three openings, two at its upper angles and one at its lower. Its external face is soft and irregular, and everywhere shows small perforations, which are openings of utricular follicles. The inner face is free from inequalities, and feels like mucous membrane. These sacs are usually extruded as they lie in utero, but sometimes they are inverted. In one instanee $I$ have known such a sac to become inverted and expelled into the vagina, but the cervical extremity holding its attachment at the os internum, the inverted bag lung like a polypus in the vagina. A similar ease is recorded by Mme. Boivin.

Lnder the nicroscope the east is found to consist of the lining membrane of the uterus, hypertrophied in all its elements almost exactly as it is in pregnancy. Indeed, as I shall soon show, the most skilful microscopist cannot distinguish one from the other. The vessels of the mucous membrane are increased in size, capacity, and number, a proliferation has taken place in its epithelial cells, and great development has occurred in the utrieular glands, the mouths of which are visible even to the naked eye.

Etiology.-This part of our subject constitutes one of its most important and interesting points, but, unfortunately, that diversity of opinion which always characterizes unsettled questions is found to exist here. Our want of accurate information depends upon the fact that the true pathology of the condition is not known. Some, with Oldham and Tilt, regard it as a result of ovarian disease; others, with Raciborski, Lebert, IIandfield Jones, and Simpson, look upon it as a pure desquamation or exfoliation of the uterine mucous membrane for which no cause can be assigned; while Klob and others are convinced that it is an exudation, the result of endometritis, thus returning to the position assumed by our forefathers. In further reference to etiology I shall give a résumé of the views which have been and are received, and mention some of the authorities who adhere to them.

1. It was formerly believed that a layer of plastic lymph was, as a result of endometritis, thrown out over the uterine wall, which, becoming organized, constituted the east of the uterus. This belief was entertained by Montgomery, Dewees, Siebold, Frank, Naegelé, Desormeaux, and others.

2. It is now regarded as an exfoliation of the entire mucous membrane of the uterine body, due to congestion and irritation transmitted to the uterus. This view, conceived by Oldham, is allered to by Semelaigne and others.

3. The pathologieal explanation just mentioned being adopted, the cause of the occurrence of the exfoliation is attributed, in the words of 
Scanzoni," to "a considerable hyperamia of the walls of the uterus, which is followed by an excess in the development of the mucous membrane." This theory is adopted by Courty, Hegar, Eigenbrodt, and others. The last two authorities have proposed for it the name of "dysmenorrhcea apoplectica."'

4. l'rof. Simpson attributed the exfoliation "to an exaggeration of a normal condition, or to an exalted degree of a physiological action." Mandl declares that Rokitansky, Robin, Mayer, and others adopt this view. He fiurther attributes the same belief to Klob, Courty, and Braun, but in this I think that he is in error.

5. It is regarded as due to an inflammatory condition by Klob, who declares that "those pathologists were not far from the truth who described such cases as endometritis." This view is indorsed by Tilt, ${ }^{5}$ Braun, ${ }^{6}$ and others.

6. By some the membrane is regarded as due to a deciduous formation excited by conception which has just been established, or is ovular in its character. The first of these views is maintained by Hausman, ${ }^{7}$ and admitted in some cases by Rokitansky $;^{8}$ and the second was adranced by Raciborski.

From my olservation of this affection, I cannot attribute it to endometritis, for evidence of the existence of that disease was entirely wanting in four cases out of five. Even if endometritis exist with marked displacement, it must not be concluded that these conditions have necessarily prorluced exfoliation, for they are commonly present as results in cases in which dysmenorrhoa of membranous type has lasted long without evidence of their existence.

Frequency.-I cannot regard the disease as one of frequent occurrence, for in my experience $I$ have met with it but fire times. It is true that I have seen a number of eases which had been regarded as of this eharacter, but most of them proved not to be so upon closer examination. Scanzoni reports twenty-one cases.

Differcntiation._The diseases with which this may be confounded areEarly abortions ;

Blood casts, or fibrinous moulds of the uterus;

Exfoliation of the vaginal mucous nembrane;

Diphtheritic endometritis.

1 Op. cit., p. 348.

2 Fur any citation of authorities on this subject, especially those of Germany, I rely upon a very valuable article by Ir. Mandl, of Vienua, translated in the $\mathrm{X}$. Y. Olstet. Journ., vol. ii. P. 402. To this essay I am much indebted.

3 Clin. Lect. on Iis. of Women, Am. ed., p. 109.

- Op. cit., p. 237 .

5 Lancet, 1853.

- Iixpression of opinion in Dr. Mandl's case. See his article, p. 413.

7 Masdl's article, p. 407.

8 klob, op. cit., p. 237. 
From the first of these the differentiation can be accomplished liy the progress of the case, the repetition of the process, and the entire absenes of the symptoms of pregnancy. The great difficulty which attends determination of the character of one specimen may be gathered from two (quotations from Dr. Mandl's article, already often alluded to. They are from reports by Wedl and Rokitansky, who exposed specimens from the same patient to the mieroscope. Wedl's' report ends in these words: "This proves that the membranes belong to the decidua and chorion, and are parts of an ovum of the first weeks of pregnancy." Rokitansky's report contains this passage: "The development of the mucous membrane is in exeess of its usual menstrual degree. It is not, however, connected with conception."

Blood easts will readily be recognized by the microscope. No elements of uterine mueous membrane are discovered.

The microscope, ton, will readily slow the nature of false membranous casts of the uterine body, and of exfoliations of the vagina due to what Dr. Tyler Smith las styled epithelial vaginitis, or to contact witl perchloricle or persulphate of iron.

Symptoms. With the conanencement of the menstrual flow there are steady pains, which increase as this progresses until they become violent and expulsive like those of abortion. In a patient whom I have seen with Dr. Walser, of Staten Island, they are so excessive that she cannot find words to express her dread of their recurrence. Under these the os gradually dilates, and the membrane is forced out into the vagina. Then there is commonly a tendency to menorrhagia, which, however, soon disappears, and the patient has passed through the attack. For some time after it lias passed off there are symptoms of endometritis, and purulent and sanguineo-purulent discharges. Sometimes, accorling to IIuchard and Labadie-Lagrave, who have written an excellent article upon this subject in the Archives Générales for July, 1870, membranous dysmenorrhoa becomes complicated by diplitheritic endonetritis, which is engrafted upon an attack of endometritis set up by the affection which we are considering.

Pain occurring with the commencement of menstruation ends only witl the discharge of the exfoliated membrane. This membrane, as has been already mentioned, is pathognomonic of the kind of dysmenorrhcea which exists, and serves to differentiate it clearly from all other varieties. The appearance of the membrane is represented in Fig. 244.

Prognosis.-The prognosis as to cure is extremely unfavorable, although cases, not only of complete cure, but instances in which in adranced stages of the disease conception has occurred, have been reported by Sie- 
bold, ${ }^{1}$ Tyler Smith, D'Outrepont, and others. Two such eases have come under my own observation.

Fis. 244.

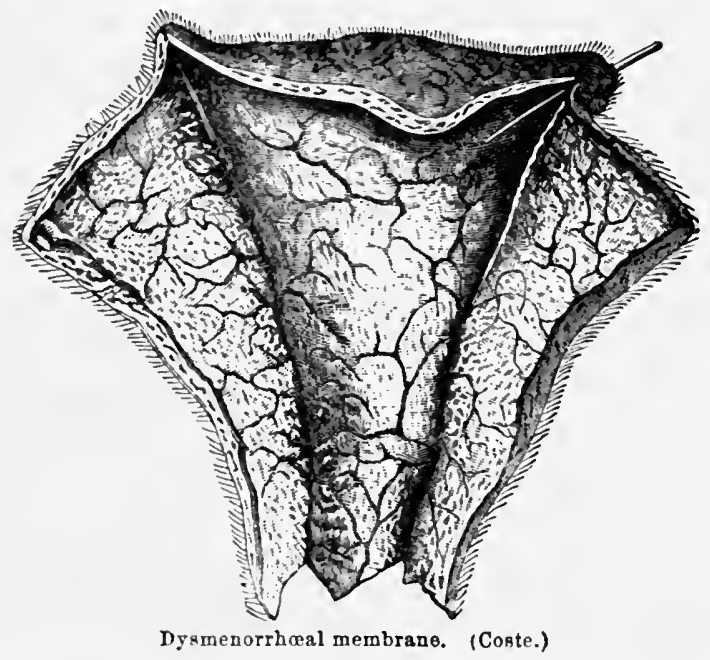

Treatment.-When the etiology and pathogenesis of a disease are unknown, it is astonishing to see how various, contradictory and energetic, treatment usually is. Deficiency of knowledge in these respects rarely results in an expectant plan of treatment. It commonly induces excessive vigor of interference. In the disease which we are now considering, the actual cautery has been freely applied to the cervix, while solid nitrate of silver and other caustics have been carried up to the fundus.

Cncertain as we are as to the pathology of the disorder, little can be said with any positiveness as to treatment. For relief of the violent pains which attend the attack, nothing compares in quickness, certainty, and efficiency, with the injection of morphia by the hypodermic syringe. If this use of the drug be not inarlmissible on account of constitutional intolerance, it should be resorted to once in every eight or every twelve hours. Should there be any objection to its use, the pains of the attack should be quieted by inhalations of sulphuric ether carried only to the point of producing quieseence of the nervous system, not sleep or unconsciousness.

If uterine or ovarian disease be detected, it slould be treated in aceordance with general rules. If no such cause for the exfoliation be discovered applications of alterative claracter may be made to the uterine mucous membrane. as tincture of iodine, chromic or carbolie acid, solution of nitrate of silver, or solution of persulphate of iron. Dr. Fordyce Barker

1 Mandl, loc. cit., p. 423. 
reports very satisfactory results from passing into the cavity of the borly an ointment containing from one to three grains of iodoform, to the amount introduced. Should displacement exist, it should be relieved, upon the prineiple that if we camnot enre a disorder, it is at least wise to relieve its most prominent complications and disagreeable symptoms. The meagreness of this advice as to the treatment of so distressing a malary is but too apparent, but there is no help for it, as it arises from an absolute want of knowledge as to more certain therapeutic resources.

\section{Ovarian Dysmenorrlica.}

Definition.-In a number of cases, unfortunately by no means small, no depreciated condition of the nerrous system will be found to account for habitual dysmenorrhœa; and the most careful exploration of the pelvis will fail to discover uterine or periuterine disorder. In such eases, if by conjoined manipulation the regions to the side of and behind the uterus be investigated, a globular, slightly compressed mass, about the size of a large walnut or small egg, will often be found in the cul-de-sac of Douglas, or on one or both sides of the uterus, low down, and in close proximity to it. If the patient be now placed in the left lateral position, and two fingers of the right hand be carried up the ragina, their palmar surfaces looking backwards, the presence of these smooth and movable bodies will be still better ascertained. They are the ovaries, enlarged, congested, tender, and prolapsed.

In some cases their disordered condition will be accompanied merely by dysmenorrhoca; but in others it will be marked by hysteria, amenorrhœa alternating with menorrhagia, and even by true epilepsy. Whether epilepsy is in such cases due to the existing ovarian disease, I am unpreplared to state; but $I$ have so often seen it accompany it that $I$ freely confess my belief that it is sometimes caused by it. This is the condition commonly styled chronie oraritis; which consists in congestion as its first stage, and hyperplasia of tissue with excessive nervous hyperesthesia as its second. In several of these cases, where I have had an opportunity of examining the ovaries, I have found them filled with numerous small eysts.

Symptoms.-It would be difficult to make the diagnosis of this form of painful menstruation by rational signs alone. It should rest upon a union of rational and physical signs; but a suspicion as to the nature of the case would generally be formed from the former. The pain precedes the bloody flow by several days, and diminishes as it is established. It is of a dull character, extends down the thighs, is peculiarly likely to be accompanied by nervous manifestations, and to create depression of spirits. The breasts often sympathize, becoming painful and tender to the touch.

One very curious phenomenon which now and then marks these cases is the occurrence of intermenstrual, or "intermediate pain," as it has been styled by Dr. Priestley. At times this occurs with wonderful regularity 
on a given day. In one case in my experience it occurred on the ninth day after menstruation had ceased; in another on the fourteenth; and in a third it commenced one week after the menstrual act, and continued for five or six days.

It must not be supposed that in every case in which the ovaries are discovered to be large, tender, and prolapsed, dysmenorrhœa will necessarily exist; nor that they will always be found in this condition where there are other reasons for suspecting ovarian dysmenorrhœa. The rule is as I have stated, but it is by no means without exceptions.

Pathology.-It is possible that the process of ovulation in a diseased ovary may excite, through its extensive and decided nervous connections, congestion and nervous hyperasthesia in the uterus, which would create disordered menstruation of the congestive or neuralgic type. Ordinarily, however, the pain seems to be in the diseased ovaries themselves, and to depend upon the dehiscence of the follicles of De Graaf. This can be proven by touching these organs during the early periods of menstruation, and is made evident in cases in which ovulation occurs without menstruation, in cases of atresia or absence of the uterus.

Prognosis.-The prognosis of dysmenorrhnea due to this cause is very bad. In a young girl in whom ovarian disorder has advanced only to congestion, recovery may rapidly take place; but in a woman further advanced in life, and in whom chronic enlargement of the ovaries las occurred, and become associated with great tenderness and prolapse, the prospects of cure are very unpromising.

Treatment.-In such cases sterility is, I think, the rule. If uterogestation should be inaugurated, the nine months of inactivity and repose secured by it to the ovaries, is likely to be of great service. I have yet to meet with a case of chronic character in which I have effected a cure by purely medicinal means. By anodynes and nervines, of course pain may be annihilated, but this is far from effeeting enre, and their use possesses the additional disadvantage of exposing the patient to the dangers of contracting a bad habit in reference to their future employment.

All means calculated to soothe local irritation, to give tone to the nervous system, and to combat singuineous exeitement, should be resorted to. Change of air and scene, a visit to the mineral springs and baths of Germany and France, and removal of all influences which severely or disagreeably tax either mind or horly, will often accomplish great good. Warm sitz baths and warm and soothing vaginal injections slould be employed, and complete rest in bed, or great guietude if the paticut objects to bed, should be prescribed during menstrual periods and for three or four days after them. Internally $I$ know of no means which are so effieacious as the free use of the bromides of potasium and ammonium, commenced a week before the menstrual act and continued until its close.

During menstruation, opiates, alcoholic stimulants, and anæsthetics 
should, as far as possible, be avoiled. Their use will probably give relief; and ats a consequence they will be resorted to once a moith thereatter. The tanger of such a course is apparent. In place of them the tincture of cannabis Indica, hyoseyanus, and camphor, or five grain dowes of the monobromate of eamphor, may be employed. In some cases I have known a rectal suppository of tive grains of iodoform give great relief.

I an unwilling to convey the idea that even these means are prolifie of good results in such cares. They are by no means so, and are merely oftered as the best with which I am acquainted. My own experience leads me to dreal the application for relief of one of these obstinate and unsatisfactory eases.

Before learing this subject I must put the reader upon his guard in reference to the following point. In treating of the subject of dysmenorrhoea I have accepted all the varicties which are generally indicated by anthorities, becanse I believe that by their adoption a more thorongh investigation of the subjeet is seeured, and because experience leads me to think that a recollection of them at the bedside will aid the praetitioner in elassification and treatment. It must not, however, be supposed that every case of dysmenorrloea will prove susceptible of strict limitation to one of these varieties. Sueh an anticipation will lead to disappointment and distrust of this classification. Many, indeed most, cases demonstrate the existence of more than one disturbing element. Thus, for example, retroversion oecurring in a debilitated, weak, and nervous woman, whose blood is impoverished, might cause a dysmenorrhœa, due in part to mechanical obstruction, in part to neuralgia, in part to congestion, and perhaps even to a certain extent to a secondary endometritis. Too much must not be expected from any classification, and it must be borne in mind that one of the great ends in view, in alopting this style of arrangement, is the attainment of thoronghness of investigation and facility of remembranee.

In view of the fact which $I$ have just mentioned, it is well for the practitioner to have at his disposal some general plan of treatment whiel may be resorted to in eases not reallily susceptible of elassifieation. The following is one whieh I think will be found effectual. As soon as menstruation begins, or some hours before if its approach can be recognized, the patient should go to bed and apply warmth, by bottles of warm water, warm bricks wrapped in dry flannel, or, as is better, by bags of Indiarubber filled with warm water, to the feet, abdomen, and saerum alternately. She should then take by the rectum an enema composed as follows:-

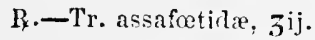

Tr. belladonnæ, gtt. $x x$.

Tr. opii, gtt. $x$.

Aqux tepidx, żijss.-II.

$\mathrm{S}$ - Throw the whole into the rectum and retain. 
If the patient have any decided objection to the use of an enema, the following prescription will be found very useful :-

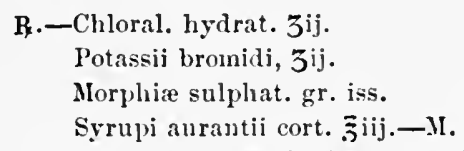

S.-A dessertspoonfnl in a wineglassful of sweetened water every four hours while in pain.

The following suppository will sometimes prove useful in place of the enema :-

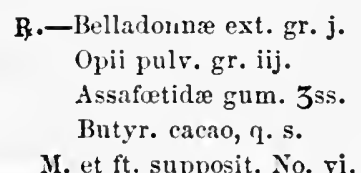

S.-One by the bowel night and morning while suffering.

I must again reiterate that one great care of the physician in these cases should be to aroid ereating in the patient a eraving for opiates and stimulants. Barnes writes upon this so ably and justly, that I cannot refrain from referring the reader to lis excellent work.

\section{II A P T E R XI.}

\section{MENORRIHGLA AND METRORRHAGIA.}

Definition.-The first of these terms is employed for the designation of a profuse and excessive flow of blood at the menstrual periods; the second for any flow of blood, whether profuse or not, during the intervals. A patient who menstruates too profusely is said to suffer from menorrhagia, while one who loses blood not only at menstrual periods but in the intervals is said to suffer from metrorrhagia.

Frequency.-Both of these conditions are necessarily frequent, for they are both symptomatic of a large number of both functional and organic affections of the uterus. The uterus is the only organ in the body from which blood flows as a physiological process. Many organs and all the erectile tissues are subject to normal congestions, but from none except the uterus is a flow of blood ever other than a morbid process. It is not then astonishing than in this orgin slight and numerous eauses are alt to excite hemorrhage.

Prethology.—1st, any condition which induces a state of active or passive congrestion of the uterine parenclyma or lining membrane; $2 d$, any influence creating a solution of continuity upon its mucous surface; $3 \mathrm{~d}$, any 
growth which, having a vascular connection with the uterine vessels, allows of a percolation through its tissues and from its circumference; and 4 th, any agency producing dyserasia of the blood may result in these disorders. Any one of these eouditions existing alone may produce the flow ; several combined are still more certain to do so. It must, however, be admitted, that very violent hemorrhages will sometimes take place from the non-pregnant uterus without our being able to determine their eause, none of the eonditions just mentioned being recognizable.

Cuuses.-The conditions which most frequently occasion menorrhagia and metrorrhagia are-

General plethora ;

Areolar lyyperplasia ;

Polypus ;

Fecal impaction;

Granular degeneration;

Fibrous tumors;

Chronic ovaritis ;

Caneer or sareoma ;

Retained products of conception;

Fungous degeneration of uterine mucous membrane;

Hematocele ;

Subinvolution ;

Any displacement of the uterus.

Congestion of the uterus is very common at the period of the menopause, or as a result of violent muscular efforts. It may likewise oceur as a consequence of abortion, an impeded hepatic cireulation, endometritis, areolar hyperplasia, displacements, ehronic ovaritis, or fecal impaction.

Retention of some of the products of eonception is very frequently a cause. The placenta may remain in part or in whole, the foctal shell may become a mole, or the ehorion may undergo degeneration, and uterine hydatids, as they are erroneously called, collect within the uterus.

Simple hyperplasia of the lining membrane of the uterus, styled vegetation or fungous degeneration, is the most frequent source of both varieties of hemorrliage. The vegetations thus ereated were deseribed by Récamier, who advised and practised scraping them off by means of a steel instrument. M. Aran, who has written an excellent article upon them in lis work on the Diseases of the Uterus, thus deseribes them. "They present themselves in two entirely different forms. In the first and most common form they are tumors, ordinarily sessile, continuous with the mucous membrane by a base sometimes as large as themselves. 'They vary in size from that of a grain of wheat or a little pea to that of a large pea and even of a small strawberry or a large raspberry. The last are often pediculated." These are styled cellulo-vascular vegetations, and may exist in any part of the cavity of the uterus. Generally they do not 
exceed two or three in number, and are found in the carity of the body. "In the second form they are a species of perliculated vegeiations resembling in appearance those follicular polypi which are so common in the neck of the nterus. They vary in size from that of a grain of wheat to that of a pea." These are called cellulo-fibrons regetations. Both rarieties generally result from chronic engorgement of the mucous lining of the uterus. As a consequence of subinvolution they are very frequently met with, and markerlly complieate that eondition.

Sometimes after an abortion, at other times after labor at full term, hemorrhage will steadily continue without any assignable cause. If the cervical canal be dilated, little fungoid growths will be found attached to a circumscribed portion of the uterine wall, which being removed by the curette, the flow will at once cease. This variety of fungoid growths follows so closely upon the parturient act, that it appears probable that they arise from minute portions of placenta, which, remaining attached, draw their nourishment from the uterine ressels. I have no positive evidence of the truth of this view, for, although I have often had these growths mieroscopically examined, I have not obtained it in this way. Klob mentions a peculiar kind of flat rascular elevation which occurs upon the mucous membrane of the uterus which I have never seen. "These puffed elevations are red, shiny, velvety, and smooth; on scraping them with a knife a milky fluid exudes from them, which, under the microscope, exhibits nothing but the glandular epithelium of the uterus, sometimes transparent vesicles and colloid boldies of varying size." They are very vascular. Klob declares that in the case of a woman 36 years of age death occurred from metrorrhagia. He examined the uterus post mortem, and "was unable to find anything exeept such a regetation of mucous membrane, about one inch thick and one and a half inches in diameter."

It is astonishing how profise and constant a flow will sometimes result from very small and apparently insignificant regetations. Some years ago I had an opportunity of examining post mortem a patient of Dr. Louis Elsberg, of this eity, of whom this history was given. The patient had suffered for years from menorrhagia and oceasionally from metrorrhagia. On many oceasions Dr. Elsberg had resorted to the tampon, and on several had been foreed to plug the cervix with considerable force to prevent death from the excessive flow. Lpon inspection I found nothing to account for the condition but three fingous projections, which were situated just above the os internum. They resembled somewhat the warty growths sometimes seen upon the glans penis, except that their papillary character was not so markel. Lnfortunately they were destroyed before they could be examined by the microscope. It may be suggested that some other eause might have existed, but none such was 
discovered upon careful investigation. The uterus, ovaries, and pelvic tissues appeared to be in a perfectly normal condition.

Chronic ovaritis often results in great menstrual irregularity, sometimes for months the menstrual discharge does not oceur, and then without any apparent exciting cause a dangerously profise hemorrhage occurs which requires the most energetic means to control it.

My experience furnishes me with a number of cases in which fecal impaction produced prolonged metrorhagia, which was cured by its removal.

Differentiation.-This is at once the most important and most difficult of the physician's duties in reference to the symptoms which we are considering. If lie be too easily persuaded to look upon the loss as one of the results of the "change of lif'e," or even of primary idiopathic congestion, much time may be lost before his error is corrected. Should he forget that he is dealing with a symptom, and look upon the condition as a disense, he will often not merely lose time, but, in the end, entirely fail in giving relief; for the empirical practice of confining such patients to bed and relying upon astringents, coll applications, and narcotics, will commonly be found to be ineffectual. In every case, unless the cause be palpable, it is advisable to examine systematically the entire uterus and its surrounding tissues in the following manner:-

1st. The cervix should be investigated by touch, the speculum, and the uterine probe.

2d. The anterior and posterior walls, and the fundus and sides of the uterus, should be examined by conjoined manipulation, rectal touch, and palpation.

3d. The whole pelvis should be explored by conjoined manipulation, rectal touch, and palpation.

4th. The cervix should be dilated by tents, and the cavity of the body explored by the introduction of the index finger, by the uterine sound, and the curette.

In many instances a diagnosis can be made only by these means; but by their aid, if fully developed, very few cases will baffle research.

Tents offer us a most valuable means for diagnosis and treatment, but the practitioner must be very sure to open the os internum by them so that the finger may pass to the fundus. In many cases, when it is supposed that a full investigation of the uterine cavity has been made, the os internum has never been passed by the finger, which consequently explores only the cervical canal. It will not infrequently require three and even four tents to open the cavity of the boty fully to the finger. But such an exploration, although very thorough and satisfactory, is not free from langer. It may, therefore, be very generally replaced by the passage of a loop of wire over the endometrium. If any small tumor exists, it will in this way be discovered, and, if uterine fungosities exist, the removal of one or more will very surely disclose the fact. 
Prognosis.-This will depend upon the cause of the affection. Should this be elearly ascertainable and eurable, it will, of course, differ very much from what it would be if the cause were obscure and difficult of removal.

Results._Menorrhagia, and, more markedly still, metrorrhagia, if uncheeked, may result in-

\author{
Sterility; \\ Hydramia ; \\ Hysteria; \\ Dyspepsia; \\ Extreme emaciation; \\ Death.
}

Treatment.-This is palliatice and curative. The treatment of a profuse flow of blood from the uterus, as from any other part of the body, should always consist primarily in checking it. In a case of menorrhagia, the patient should be kept perfectly quiet upon her back; cloths wrung out of cold water should be laid over the uterus, vulva, and thighs; cold, acidulated drinks, as iced lemonade, solution of elixir of ritriol in icewater, etc., should be given freely; and the ingestion of all warm fluids strictly interdicted. In addition, the apartment should be kept cool, the foot of the bedstead elevated about ten inches, the nervous system quieted by opium, or an appropriate substitute, and all conversation prolibited. Certain general hemostatics should always be tried; among the chief of which are gallic acid, ergot, and tincture of cannabis indica. The last is one of the best at our command.

In mild eases this treatment may suffice, but in severe ones it will not. In these the speculum should be introdnced and the vagina filled with a tampon. This will rarely fail; but in certain cases, as, for instance, those of cancer of the neck, it will do so. Under these circumstances the tampon of cotton should be removed, and replaced by one consisting of the same material saturated with a strong solution of alum, or with the officinal solution of persulphate of iron diluted with four times its bulk of water. A stronger solution may canse slonghing of the raginal mucous membrane. $A$ solution of full strength has been known to produce gangrene of the vaginal walls themselves. Instead of using these solutions a small linen bag may be filled with powdered :llum, placed in contact with the eervix, and held in place by a tampon; or two drachms of tannin may be left free against the part. To these means almost all cases will yield temporarily, but some will be met with which will not do so, and in which eren more energetic ones are called for to prevent death from loss of blood. In these exceptional cases the cavity of the body of the uterus should be freely injectecl, after dilatation of the cervical canal. with the tincture of iodine, or a strong solution of alum.

Before a case of menorrhagia is subjected to this course of management, 
this point must be carefully considered: some women naturally flow very freely at menstrual epoehs, and are not injured by the loss. It is their peculiarity, and not an evidence of an abnormal state, and it should be decided whether or not treatment be required. In reference to metrorrhagia, it is equally important to bear in mind that some women, during the early months of pregriancy, have a steady flow of blood, and before a tent is employed, or probing the uterus is resorted to, this state should be earefully eliminated.

Curative Treatment.-One great reason for the fact that this often proves firutless is that the existing disorder, and not the disease which produces it, is kept before the mind of the praetitioner. It should be borne in mind that the exeessive hemorrhage is a symptom, and that the morbid state which creates it must be sought for and eradicated. I am confilent that the statement already made that one of four great pathological factors will usually be found to be the souree of excessive or prolonged uterine hemorrhage, will stand the test of experience at the bedside. I therefore place before the reader at a glanee the ordinary causes of uterine congestion, solution of continuity, growths from uterine mucous surface, and blood dyscrasia. That there are other conditions, such as pelvic peritonitis, hematocele, etc., which may cause uterine hemorrhage, I do not deny; but when a bloody flow marks the existence of such grave diseases, it is overshadowed by them and requires no special treatment. I here give those which ordinarily produce a flow which requires treatment from its prominenee and importance, although I am almost repeating myself.

\begin{tabular}{|c|c|}
\hline & ar hyperplasia; \\
\hline & volution ; \\
\hline & Fibroids ; \\
\hline Congestion of uterine tissue may be & General plethora ; \\
\hline ie to & Displacement ; \\
\hline & Fecal impaction; \\
\hline & Chronic ovaritis ; \\
\hline & Laceration of the cervix. \\
\hline Solution of continuity may be created & $\begin{array}{l}\text { Cleeration; } \\
\text { Granular degeneration; }\end{array}$ \\
\hline by & $\begin{array}{l}\text { Cancer ; } \\
\text { Sarcoma. }\end{array}$ \\
\hline & $\begin{array}{l}\text { Laceration of the cervix. } \\
\text { Polypi; }\end{array}$ \\
\hline & Fungous growths ; \\
\hline $\begin{array}{l}\text { Growths from uterine walls may con- } \\
\text { ist in }\end{array}$ & $\begin{array}{l}\text { Adhering produets of eoncep- } \\
\text { tion; }\end{array}$ \\
\hline & $\begin{array}{l}\text { Fibroids ; } \\
\text { Sarcoma or cancer. }\end{array}$ \\
\hline
\end{tabular}


Blood dyscrasia may be due to

$$
\left\{\begin{array}{l}
\text { Scorbutus; } \\
\text { Chlorosis; } \\
\text { Spanamia from uræmia or } \\
\text { other grave constitutional } \\
\text { disease. }
\end{array}\right.
$$

If the source of the disorder be discovered, its treatment is often very simple and effectual, and as the management of most of the conditions here recorded is familiar to every reader upon general medicine, or is given in other parts of this work, little more need be said except upon one or two points.

In a case of subinvolution, the free use of ergot will be found a raluable adjuxant to the means already enumerated for palliative treatment, and it may prove serviceable as a curative agent. The same remark applies to the fluid extract of viscum album, which may be well employed alternately with, or instead of, ergot. In the treatment of all uterine congestions the occasional use of an active purgative, or the systematic and steady employment of the same class of medicines in small doses, will often prove highly beneficial.

Treatment of Fungous Degeneration of the Uterine Mucous Membrane.If this condition be elearly diagnostieated, not surmised, but fully determined upon by rational and physieal signs; the first eonsisting in prolonged hemorrhage, without the existence of other disease; and the second in evidence afforded by the detachment or expulsion of some of these masses, the whole lining membrane of the uterine body should be thoroughly but gently scraped by the curette represented in Fig. 245.

$$
\text { FIG. } 245 .
$$

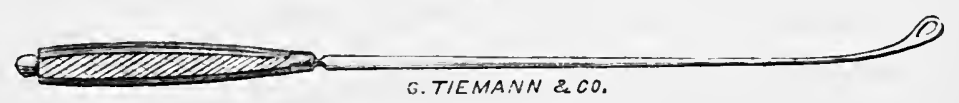

Thomas 's wire curetle.

Should the cervical eanal he narrow, it may be necessary to dilate it by a sea-tangle tent; but, orlinarily, no previous dilatation is necessary for the use of this instrument, which should be passed with a slight degree of seraping action over the entire surface of the uterine body.

In recommending the curette as a most valuable resource in the treatment of menorrhagia due to fungous decgeneration of the uterine lining mrmbrane, I do so from very extensive aud eonstantly increasing experience with it. I employ it frepuenty in private practice, and in the Woman's Hospital it is commonly used by most of my colleagurs. as well as by myelf. Not only las it proved in my hands a very efficient instrument, hint one attended by little danger unless employed in cases proviously affected by peritonitis or eellulitis. For one using it with such results it is difficult to comprehend how it should be so unfarorably regarded 
by many able practitioners. The late M. Aran ${ }^{1}$ was bitterly opposed to a resort to it; and Gallard ${ }^{2}$ styles its use a "detestable operation." The latter author then goes on to speak of the "perfect harmlessness of intrauterine injections" in menorrhagia! Truly, experience does not teach to all men the same lessons, though all may sincerely strive to read its teaching.s aright.

In place of the curette the lining membrane of the uterine borly may be modified by the applicition of pure nitrie acid, after the plan of Kidd and Athill, of Dublin, or by the injection of the uterine eavity by pure tincture of iodine, solution of nitrate of silver, or solution of persulphate of iron diluted with two or three equivalents of water. As a full discussion as to the dangers of intraterine injections will be found elsewhere, I shall not enter upon the subject here.

Should caustic treatment by strong acid be determined upon, the cervieal speeulum should be passed through the neek to protect this part, and preserve the acid for energetic action on the lining membrane of the body.

In many cases replacement and support of a displaced uterus will serve to relieve a prolonged metrorrlagiat, while the same results will be produced in others by cure of a granular and bleeding cervix, or the repair of a lacerated one.

All disorder of the blood should be combaterl by appropriate constitutional means, even where it is secondary to the loss, and not a primary cause of it. Where the hemorrhage is due to a polypus, the resulting impoverishment of the blood renders escape of the vital fluid more easy and rapid.

In very obstinate cases a change from a warm to a cold climate, and from the lowlands to a mountainous region, often aceomplishes a great deal of good.

I feel very sure that in menorrhagia a great deal of liarm results from the frequent use of iron and quinine. These drugs are given to repair the danage done to the bloot, but both of them increase uterine congestion, and tend to aggravate the flow.

\section{CHAPTER XLII.}

\section{AMENORRHGE.}

Definition.-Amenorrhœa, a term derived from a, privative, $\mu \eta \eta$ "a month," and $\varepsilon_{\varepsilon \omega}$, "I flow," implies an absence of the menstrual flow in a woman in whom it shonld naturally exist. Such an absence before puberty, after the menopause, or during pregnancy and lactation, is the normal condition, and hence does not come within the definition.

1 Op. cit., p. 473.

2 Op. cit., p. 242.

3 Op. cit., p. 254. 
Frequency.-It is an affection of great frequency among women who live luxurious and indolent lives, and disorder the nervous and sanguineous systems by neglect of those habits which keep them in a state of health. Hence it is very frequently eneountered among the members of the higher classes of civilized society all over the world.

Varieties.-If the habitual monthly discharge be suddenly checked, the disorder is styled suppressio-mensium; and if the discharge have never appeared in a woman who ought to menstruate regularly, it is called emansio-mensium.

Puthology._-That the discharge of blood, which, occurring at monthly periods, constitutes menstruation, is a true hemorrhage dependent upor. the process of ovulation, is now regarded as a settled fact by most physiologists. In accordance with a law of nature which we recognize in its effeets but cannot explain, once in every twenty-eight days one or more orules in each ovary burst their envelopes, and entering the Fallopian tubes pass downwards to the uterus. This eruption of orules produces in the ovaries congestion and nervous exaltation, which continue until the process is completed.

No sooner are these organs thus affected than, through the instrumentality of the ganglionic system of nerves connecting them with the uterus, that organ sympathetically undergoes congestion likewise. The whole uterus becomes heary and descends perceptibly in the pelvis; its mueous membrane is swollen and turgid, and the vessels which supply it dilate under an excessive hyperamia, as do those of the conjunctiva in conjunctivitis; then a rupture occur's and relief is obtained by hemorrhage. For the proper performance of the function three elements must exist in a perfect state of integrity: 1st, the uterus, oraries, and vagina must be perfect in form and vigor; $2 \mathrm{~d}$, the blood must be in its normal state; and $3 d$, the nervous system governing the relations between the uterus and oraries must be unimpaired in tone.

Any influence disordering one or more of these may check ovulation, the great moving cause of the function; prevent the degree of sympathetic congestion necessary for rupture of uterine vessels; or oppose the discharge of blood which has been effused.

The non-performance of the function of menstruation was formerly, and even now is by some, regarded as productive of many constitutional evils, as, for example, chlorosis, phthisis, dropsical effusions, etc. It is highly probatble that in these deductions the eflect has been mistaken for the cause. The impoverished blood, and nerrous derangement attendant upon these affections, result in failure of that function. No proof exists which can substantiate the view that anenorrhoa ever induces permanent lesion of any organ in the body.

Canses.-After what has been already stated, the causes of the affection may be tabulated without fear of confusing the reader. 
Amenorrhœa may result from any of the following conditions:-

Abnormal states of organs of generation.

Absence of uterus or ovaries ;

Rudimentary uterus or ovaries;

Occlusion of uterus or vagina ;

Uterine atrophy;

Pelvic peritonitis ;

Atrophy of both ovaries ;

Cystic degeneration of both ovaries.

Abnormal states of the blood.

Chlorosis ;

Plethora;

Blood state of plithisis ;

" " of cirrhosis;

" " of Bright's disease, etc.

Abnormal state of ganglionic nervous system.

Atony from mental depression;

" " indolence and luxury ;

" " want of fresh air and exercise ;

" " constitutional diseases, as phthisis, etc.

Complete absence of the internal organs of generation is very infrequent, though a rudimentary condition is less rare. With reference to absence of the uterus, Scanzoni remarks: "On carefully analyzing the reported cases of entire absence of the womb, we find that almost always some rudiments of this organ still exist, so that authenticated and unquestionable instances of this anomaly are extremely rare." He further declares that he has never been able to authenticate a single case. I have seen one instance presented by Prof. I. E. Taylor to the Obstetrical Society of this city, in which no trace of the uterus could be detected upon the closest scrutiny of the parts removed post mortem.

Absence of both oraries is quite rare. They are most frequently found to be in a rudimentary condition resembling their foctal state.

The vagina may be occluded by an obturator hymen, contraction from inflammation and sloughing, or from congenital or acquired atresia.

So likewise may the canal of the cervix uteri be congenitally or accidentally closed.

What I have styled atony of the nervous system has been well described by Prof. Hodge, of Philadelphia, under the name of sedation. It consists in a decrease of the excitability, rigor, and activity of the nervous agency which controls the functions of different organs, and has for its cause physical and moral influences, some of which have been enumerated. Some of the functions which are under the control of the ganglionic system are, the action of the heart, digestion, peristalsis, and regulation of animal heat. In one leading a natural and healthy life, in the country for ex- 
ample, all these are likely to be normally performed; but if the same individual remove to a crowded eity, lead the life of a student, exhaust his nerve power by late hours, bad air, and mental efforts, all of them rapidly become deranged. He suffers from palpitation of the heart, dyspepsia, coldness of hands and feet, and constipation. This change usually occurs slowly, but sometimes it does so rapidly, as from a sea-voyage or any very violent mental strain. In a similar manner the processes of ovulation and menstruation are affected by it, in some cases gradually, in others with great rapidity.

Differentiation.-Before treatment is instituted for this condition, it must be carefully differentiated from-

\section{Pregnancy ; \\ The menopause; \\ Tardy menstruation.}

The first will be readily recognized by its characteristic signs, if suspicion be awakened, and they be investigated. Very often no such suspicion arising, the criminal desires of some women are gratified, and the hopes of others blighted through the unintentional induction of abortion by the treatment adopted.

The law with regard to the menopause is, that it should occur between the ages of forty and fifty, but it is sometimes delayed until sixty or seventy, and at others take place at a very early age. It may occur as early as the twenty-first year, and in twenty-seven out of forty-nine cases of early cessation collected by Dr. Tilt, ${ }^{1}$ it took place from the twentyserenth to the thirty-ninth year. The absence of sensations of discomfort at the periods when the menses should occur, will help to lead the practitioner to a correct conclusion as to the eharacter of the case.

Sometimes mothers will be much alarmed by absence of the function in girls at fifteen or sixteen years. It should be remembered that it is not very rare for it to be delayed until those ages. Differentiation should be accomplished under these eircumstances as under the last mentioned.

Treatment.-From what has been already said, it is manifest that amenorrhora is not a disease, but a symptom of some local or general disorder, and it follows that all efforts directed simply to re-establishment of the absent function, must necessarily be empirical. The cause should be discovered, and, if possible, removed. Should it be susceptible of removal, the method appropriate for aceomplishing this will be evident, while if it depend upon an incurable condition, great benefit will be gained by the avoidance of means previously praetised in the rain hope of establishing the flow, and by our ability to place the mind of the patient beyond the harassing influence of suspense.

If the uterus be found to be absent, all that can be done will be to ab-

1 On Cterine and Ovarian Inflammation, p. 54. 
stract a sufficient amount of blood from the arm by renesection, if necessary, to relieve the urgent symptoms attending each epoch.

Ocelusion of the vagina or cervix should be treated by surgical moans, the barrier being overcome by the knife, seissors, or trocar.

In ease a rudimentary or atrophied uterus be diseovered as the souree of the affection, attempts shonld be made to deselop it by local stimulation and distention. At short intervals it should be fully distended by a tent, in orler that an increase of mutrition and consequent increase of volume and capacity may be excited. When this plan is not in operation, an intrauterine galvanic pessary may be kept in utero for the furtherance of the same end. It is astonishing how much development may be obtained by a persevering practice of this plan. In many instances it will restore the uterts to its original size, and cause a return of the menstrual flow. But it often requires considerable time to bring about so favorable a result ; even years may elapse before it is fully attained.

If it be decided that the non-performance of the function is due to plethora, anamia, or chlorosis, these states should be treated; the first by venesection, strict diet, exereise, and a life in the open air; the second and third by change of air, rich food, exercise, and ferruginous tonics. In plethora, Prof. Bedford speaks highly of the abstraction of blood from the arm at intervals of a month, the abstraction being performed between the menstrual epochs.

Should some grave constitutional condition like tuberculosis or the others mentioned, be found to be the main morbid state, it, and not its resulting synutom, should attract attention.

An atonic state of the nervous system governing menstruation should be treated by a resort to a general tonic comrse. Among the means applicable to its removal may be especially mentioned, exercise on foot and horseback, rowing, ealisthenies, sea-bathing, nutritious food, and nervous tonics of medieal character, as nux vomica, strychnine, quinine, and the general use of eleetricity. It is in this class of cases that many drugs and prescriptions styled enmenagogue have often succeded in restoring the function even when used empirically. A state of general nerrous atony is frequently attended by clilorosis and always by constipation. The nerrous disorder and two of its resulting symptoms may be favorably affected by the stereotyped combination of aloes, iron, and myrrh or nux vomica ; and the sluggish nerve power nay be temporarily excited to the performance of its duties by the administration of tansy, rue, ergot, or savine. But it is not through desultory means of this charaeter that a cure can be anticipated with any confidence. A more comprehensive plan directed to the improvement of the patient's constitution should be adopted and systematically pursued. As general means those already mentioned will always be found highly useful. If the patient while at home cannot be prevailed upon to practise sufficient self-denial to aroid what is injurious, 
or be made to develop the energy necessary to follow a course which requires effort, she may, with great adrantage, be placed for a time in a well-regulated hydropathic establishment, where the early hours of retiring, simple food, exercise, society, pure air, and bathing, will accomplish a roborant effect which will prove of great value in the cure of the affection.

But not merely should constitutional means be adopted. After the general condition has been improved, local stimuli may be resorted to with great benefit. Those which will be found to be most efficient are-

Passage of the sound;

Tents ;

Cupping;

Electricity;

Stimulating enemata;

Baths.

In their action these nieans probably exert an influence not only on the uterus, but sometimes by their stimulating effects exeite the process of orulation. The sound should be passed up to the fundus once every day for three or four days before the expected flow; or if the process of ovulation do not demonstrate its existence, it may be passed once a week throughout the month. At the same periods tents of tupelo or sea-tangle may be used, the dangers attending them being always borne in mind during their employment.

The cervix uteri may, by the application of an exhauster or dry cup, hare a marked hyperemia exeited within it, which extends to the uterine body and replaces that which should have occurred from physiologieal causes. A very simple method for producing it is to enclose the cervix within the mouth of the eylinder of hard rubber represented in Fig. 246, and then exhaust the air by withdrawing the piston.

Fig. 246.

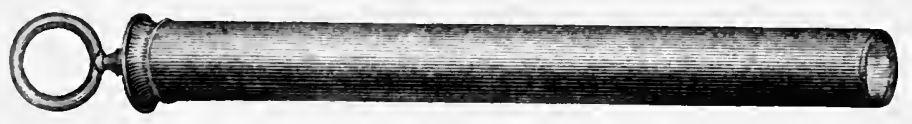

Syringe for dry cupping the cervix.

Before the introduction of this instrument the uterus should be exposed hy means of the speculum. In this way I have repeatedly drawn, without effort, one or two drachms of blood throught the mucous lining of the neck.

Flectricity is a means of great ralue. One pole of a battery may be applied over the lower portion of the spine and the other passed over the hylogastrium, placed in contact with the cervix, or even carried, by means of a wire covered, except for its terminal three inches, with a gumelastic catheter, up to the fundus of the uterus. For the purpose of keeping up a mild but steady current within the uterus, Prof. Simpson has 
advised a stem eomposed of copper for one half its length and rine for the other half, which is passed up to the fundus. It has an oveill disk at it: lower extremity upon which the cervix rests. Dr. Noeggerath hats made an improvement in this by having the stem composed of two patallel pieces of eopper and zine, insteal of two short pieces of these metals united at the eentre of the strm. As these instruments must be left in phace while the patient walks about, there is always danger of their irritating the watls of the uterus to too graat an extent. To aroid this I have employed a stem composed of alternate beads of copper and zine, held together by a small wire rope, which passes through the centre of each, and is secured to the uppermost and to the raginal clisk below. This maly, hy any morrment of the uterus, be bent at the required angle, and consequently can do no injury. (Fig. 2.77.) The disk or bulb of this instrument should be made globular so as to rest in the cup held between the branches of a Ilodge or Smith pessary, as shown in Fig. 197.

As an excitant of the menstrual flow, enemata of very warm water impregnated with chloride of sodium, aloes, or soap, constitute a valuable resource. Not only does the medicinal substance irritate the uterine nerves, the warm fluid brought into elose contact with the uterus also

Fig, 247 .

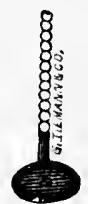

Galvanic pessary. excites a flow of bloot to it. Hip-baths and pediluvia have long been resorted to for the purpose of exciting menstruation. They should be prolonged, and as warm as the patient can bear them. In addition to these means, copious injections of warm water may with benefit be thrown into the vagina, one or two gallons being, by means of a proper syringe, projected against the os uteri.

Reasoning from analogy and from our knowledge of the physiology of menstruation, we are unquestionably warranted in the deduction that in a certain number of cases amenorrhoca is due to non-performance of the function of orulation. It is not possible to give clinical evidence of the fact, but it may be strongly surmised when none of the symptoms usually attendant upon this process present themselves at monthly periods. The means by which it should be treated are those already advised, for any of the causes mentioned may produce that variety of the affection which is due to non-performance of ovarian functions, in the same manner that they give rise to that form depending upon the incapacity of the uterus.

In many cases where, in spite of well directed efforts, eight, ten, and twelve months will elapse without signs of menstruation, and this on repeated occasions, it is useless to continue efforts such as those which have been mentioned. The case is often better left to nature. 


\section{II A P T ER XLIII.}

\section{LEUCORRIICA.}

Ix my anxiety to impress the importance of regarding and treating this condition as a symptom of uterine or vaginal disease, and not as a primary affection, I have been in great doubt as to the propriety of devoting a separate chapter to it. In doing so I confess that I yield to a conventional practice which I do not fully indorse, and I offer this fact as an explanation of any superficiality in the treatment of the subject which may strike the reader. I feel very sure that the writer of fifty years hence will omit the separate consideration of this symptom entirely.

Definition.-This affection, the name of which is derived from $\lambda \in v \times 0$, "white," and ¡\&w. "I flow," consists in a whitish, yellowish, or greenish mucons discharge from the vagina.

Synonyms.-It has been, in modern times, described under the names of fluor albus, blemorrhoa, pertes blanches, fleurs blanches, and whites. In aneient literature the variety of names which was applied to it may be julged of when it is stated that orer fifty appellations were at different times employed in designating it.

Frequency._- No discase or symptom in the whole list of female ills is so common. Probahly no woman ever goes through life without at some period, and for a variable time, suffering from it. It is only when it becomes anmoying by its constancy, abundanee, or irritating properties that it attrats attention and causes the patient to seek assistance.

Ifistory.-In the arliust writings of the Greek school and throughout Roman and Arabuan medical literature, abmdant descriptions of this disorder may le fomm. IIjprocrates drscribed it, pointing out as among its sympoms, puffiness of the fice, paleness, and enlargement of the abdomen. He evinces a familiatrity with its treatment by an admission of the difliculty of euring it. Arotiens of ('apparlocia, in the first eentury, mentioned the varietios of lencorrhoxa, at to color, quantity, etc., and $\Lambda$ etius and Paul of Regina speak of two forms of the affection, red and white flux. For the latter, Aetius recommends gestation, vociferation, watking, ete. The Arabians, Ialy Abhas and Alsabaravius, wrote upon the subject, bat advanced nothing new.

As in ancient times, so also in morlern, it lias attracted a great deal of attention, and mutil the establishment of the present school of gynecology by liécamier, was treated of as a discase rather than as a symptom. Even 
lorgy after this period it wats eommonly regarded as a disease; the result of constitutional debility, or the index of an impure blood state. For the views which are now entertained concerning it, we are indebted to no one so much as to Dr. J. II. Benuct, of London, who, by his forcible reasoning, supported by elinical evidence, clearly demonstrated its ordinary dependence as a symptom upon some local lesion. Dr. Tyler Smith, in an elaborate essaty upon the sunject, has also done much to elueidate certain points in its pathology, which before his time had been undeveloped.

Pathology.-As a discharge of mucus or muco-pus is a sym!tom of urethritis, bronchitis, nasal catarrh, and faueitis, so is it a symptom of inflammation of the vagina and lining membrane of the uterus and Fallopian tubes. Whaterer influence is capable of creating it elsewhere may give rise to it here, and in this position it is, as it is elsewhere, only an isolated sign of a pathological state. It is not by any means, however, always an evidence of inflanmatory action. As many individuals upon exposure to cold will freely discharge mucus from the nostrils without any inflummation existing, so will many women suffer from leucorrluca from any eause producing a temporary congestion of the mucous membrane. But in these cases the disense is temporary, following or preeeding the menstrual congestion, or arising from fatigue or exhaustion. When it becomes permanent and the discharge grows profuse or acrid, its connection with a morbid state is rendered probable. At such times it is always a symptom of some abnormal condition of the uterus, Fallopian tubes, or vagina, and its presence should lead to an investigation of these organs,

Any agency which moderately increases vascular activity in a secreting organ tends to angment the amount of its secretion. I say moderately increases, becuuse an excessive turgescence, such as attends upon acute inflanmation, checks secretion entirely. Such an influence being exerted upon any part of the mucous covering of the generative canal of the female, an excessive flow of plasma, together with a rapid exfoliation of epithelial cells and the formation of pus-corpuscles, results.

Iarieties.-Leucorrhoul is divided into two rarieties, according to its origin-vaginal and uterine. Either of these may exist separately, or the two may coexist. If it be raginal, it may continue as such for a length of time. If the inflammatory action producing the discharge be confined to the uterine mucous membrane, it may remain so without implieating the ragina, but that eamal receiving the products of uterine secretion is gencrally excited into morbid action. A similar result may frequently be observed in nasal catarrh in children, the upper lip being bereft of its epithelial investment, and a papular or vesicular eruption exected over the neighboring parts of the face.

Vaginal leucorrhora consists of a white, creamy, purulent looking fluid, 
which is compesed, atecording to Dr. Tyler Smith, of the following clements :-
Acid plasma ;
Sealy epithelium ;
Pus corpuseles;
. Biood globules;
Fatty matter.

Lnder the microscope it appears as represented in Fig. 248.

Fig. 248.

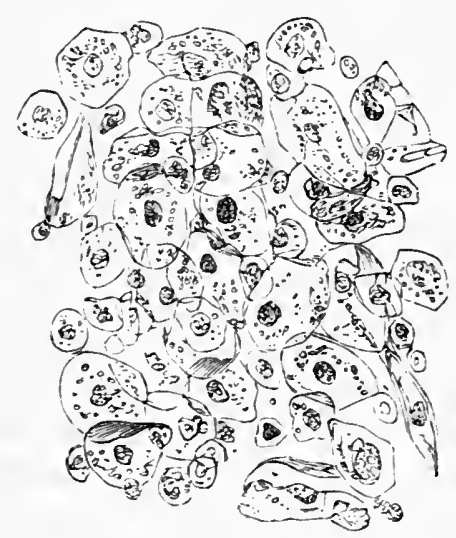

Vacinal leucorrhea uuder the microscope. (Smith.)

That arising from the canal of the cervix is thick, tenacious, and ropy, like the white of an egg, and consists of-

Alkaline plasma ;

Mucous corpuseles ;

Altered cylindrical epithelium;

Pus corpuscles:

Blood globules:

Fatty jarticles.

Examined by the microscope it presents the appearance shown in Fig. $24 !$.

That arising from the boly of the uterus resembles the eervical form, rexcept that it is less gelatinous, less ropy, and more likely to be tinged with blood.

Crueses.-Any pathological state which keeps up in the uterus a condition of engorgement ending in inflammation, or simply in retarderl and enterbled circulation, may ereate leucorrhua as at symptom. P'rominent annong tlese nay le mentioned-

Sulinvolution of uterus;

Suppressed menstruation;

Fibroids, polypi, or fungous veretations; 
Prolonged lactation;

(iestation and parturition;

Excessire coition ;

Anamiar ;

Uteriue displacement ;

Laceration and eversion of cervix ;

Endometritis, eorporeal or cervical ;

Gramular decreneration ;

Syphilitic ulceration ;

Varginitis, speeific or simple;

IIalitual constipation ;

Toximia from malaria, uramia, or gout.

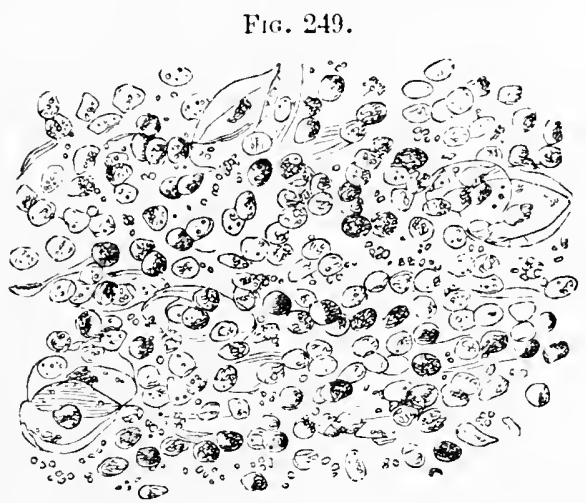

Corvical leucorrhoa under the microseope. (Smith)

It will thus be seen that the disorder may in some instances be a trivial matter, whieh, by a judicious combination of general and local means, will rapidly disappear, while in many others it is an attendant circumstance of sone grave pathological state of the uterus or vagina, and consequently diflicult of cure.

Prognosis._This will depend in great degree upon the cause. If this can be readily removed, the prognosis will be favorable; while if it be connected with some serions organic lesion, it will not be so.

Results._- Cterine lencorrlıa may result in-

Sterility ;

Vaginitis ;

Pruritus vulvix;

Vulvitis ;

Salpingitis ;

Gramular degeneration.

Treatment.-When a patient applies to a practitioner for the eure of leucorrhoea, it should be his first endeavor to discover the cause of the mueo-purulent flow. A suspicion as to the source of the difficulty may 
ordinarily be based upon examination into the rational signs, but a diagnosis of the condition which gives rise to the symptom which has excited anxiety in the mind of the patient can be more certainly arrived at by physical exploration. If upon this, disease of the uterus, ragina, or Fallopian tubes be diseovered to exist, either in the form of inflammation or congestion, this affection should receive appropriate treatment. To recapitulate the plans which should be pursued would here be entirely out of place, for they are laid down in other parts of this work in connection with the special disorders of these parts. Suffice it liere to say that the condition underlying the symptom leucorrhoa should receive treatment always. Sometimes the applieation of the eurette, the operation of trachelotomy or of trachelorrbaphy, the replacement of a displaced uterus, or the renoval of a submucous tumor will cut short a treatment which might otherwise be prolonged for years.

As to general treatment, a course especially adapted to giving tone to the dilatef bloodressels of the mucous membrane, and overcoming the tendency to excessive creation of cells and exudation of blood plasma, should in addition be adopted. To begin with, the patient sliould be put upon general tonic treatment, such as the use of quinine, Perurian bark, strychnine, and iron; sea-bathing; change of air and scene; and the substitution of quiet and eheerful social influences for those which are exciting or depressing. The diet shonld also be made nutritious and simple, and all stimulants, spices, and condiments be strictly avoided.

When the vagina is affected, that canal, after having been carefully cleansed, should, by means of a rod wrapped with cotton, be thoroughly washed over with a solution of the nitrate of silver, one part to eight or ten of water. After this a tampon of cotton saturated with glycerine shonld be left in the canal for twenty-four hours and removed by the patient, a thread being attached to it for this purpose. Then copious astringent and soothing vaginal injections should be employed night and morning. The best astringents for this purpose are alum, tannin, infusion of oak bark, zinc, and lead. As examples of good combinations, I give the following:-

$$
\begin{aligned}
& \text { R.-Acidi tanniei, } \tilde{\jmath} \mathrm{iv.} \\
& \text { Glycerine, } \tilde{\jmath} \times \mathrm{vj} . \mathrm{M} \text {. }
\end{aligned}
$$

S.-A tahlespoonful to a quart of tejid water, to be used as a vaginal injection for five minutes every night and morning by means of one of the syringes recommended.

$$
\begin{aligned}
& \text { R.-Cupri sulphat. 3jss. } \\
& \text { Ziuei sulphat. 3jss. } \\
& \text { Alummis sul,hat. } 3 \text { jss. } \\
& \text { Glycerine, 3ry.-MI. }
\end{aligned}
$$

Follow same directions as those given above.

One drachm of boracic acid to a pint of warm water, half a drachm of hydrate of ehoral or ialf an ounce of the fluid extract of pinus Canadensis to the same also answer an excellent purpose. 
Once a week the application of the solution of nitrate of silver, in diminishing strength, should be repeated and followed by the uies of the tampon of cotton soaked in glycerine, or glycerine and tannin, until the letucorrhea is eured. Cure will conmonly be effeeted by these means, if no other disorder exist to reproduce a symptom which it has once proved itself eflicient to establish. If such a condition exist and be overlooken by the practitioner, it will inevitally cause again what it did before. Neither plan should be despised-treatment of the cansative disorder nor that of the resulting symptom; and by a combination of the two plans better results will be obtained than could be aceomplished by an exclusive adherenee to either:

In cases of chronic raginitis, astringents sometimes appear to do harm, and infusions of flaxseed, slippery elm, and similar substances of ten prove beneficial. On the other hand, in the treatment of chronic endometritis, it will often be found of benefit to use astringent injections which act not only by securing cleanliness, but by hardening the vaginal mucous membrane and preventing the complication of vaginitis as a result of uterine caturh.

As a general outline, the following may be given as a plan of treatment:-

1st. Keep the uterus in perfect position by a pessary if it be decidedly displaced ;

2d. By appropriate cathartics, keep the portal cireulation free and the rectum emptied of feces;

3l. Cure laceration of the cervix if it exist, and remove polypi and fungosities;

4th. Remove all weight from the uterus from above, and all traction from it from below;

5th. Keep the cutaneous circulation active by baths, friction, exercise, and pure air ;

6th. Keep the blood and nerve states normal by tonics, exercise, etc.;

7 th. Counteract all toxamic influences, such as malarial, (whether palludal or from sewer emanations), uræmic, scorbutie, rheumatic, or arthritie ;

Sth. Keep the menstrual function normal by careful supervision;

9th. In case cardiac disease, aneurism, hepatic disease, pelvic peritonitis, or perimetric cellulitis are primary causes of it, recognize the futility of local treatment, and do not annoy the patient by a resort to it.

To enter more minutely into the treatment of leucorrhoea would be to defeat the main object which I have had in view, that of subordinating the consideration of this disorder to that of the diseased states which produce it. 


\title{
CHA PTER XLIV.
}

\author{
STERILITY.
}

Definition and Synonyms.-This term, which is derived from ozвpвos, "barren," and implies an incapacity for conception, is synonymously entitled barrenness and infecundity.

History.-Throughout medical literature, from the earliest periods to the present, it has attracted special attention, and been the subject of dissertations by all authors who have touched upon the affections peculiar to females. The frequent reference made to it by Biblical writers as a reproach to women, is too well known to require special mention.

Causes.-To comprehend the pathology of sterility, the physiology of conception must be clearly understood. In the act of coition the male organ, being introduced into the ragina, projects into and against the cervix a fluid, consisting of a thick, watery portion, holding in suspension large numbers of eiliated cells which have the power of moving by ciliary action. The bulk of this fluid pours down into the vagina, but many of the cells which it contains pass mpwards into the body of the uterus, and through the Fallopian tubes as fir as the ovaries. Should they come in contact with an ovule, impregnation may take place in the ovaries, Fallopian tubes, or uterus. When the impregnated ovule at taches itself to the uterus, the mucous membrane of this organ undergoes exuberant development, and throws around it an envelope called the decidua reflexa. Further than this, the process does not concern us, for conception has then followed impregnation, fixation of the impregnated ovum liaving occurred.

These faets being kept in mind, it becomes evident that a variety of influenees may interfere with the performance of this delicate and subtle process. For its accomplishment four things are necessary as far as the woman is eoncerned.

1st. The possbility of the entrance of seminal fluid into the uterus;

2d. The possibility of the production of a healthy orule;

31. The possibility of the entrance of an ovule into the uterus;

4 th. The absence of influences in utero destructive to the vitality of the s'men, and preventive of fixation of the orum upon the uterine wall.

Should these four conditions exist, no woman will be sterile. She may not bear children, but the incapacity may attach to the male and not to her ; or, having corceiverl, she may have suffered from consecutive abortions, which have been mistaken for attacks of menorrhagia. 
The special eauses of sterility, or those interfering with these conlitions, may be thus presented :-

1st. Cuuses proventing entrance of semen into the uterus.

Absence of the uterus or vagina;

Obturator liymen;

Vagrinismus;

Atresia vagina;

Occlusion of cervical canal ;

Conical shape of cervix ;

Cervical endometritis ;

Polypi or fibroids ;

Displiacements ;

Very small os internum or externum.

21. Causes preventing the production of a healthy ovule.

C'hronic ovaritis ;

Cystic disease of both ovaries;

Cellulitis or peritonitis;

Absence of ovaries.

3d. Causes preventing passage of ovule into uterus.

Stricture or obliteration of Fallopian tubes;

Absence of Fallopian tubes;

Detachments and displacements of Fallopian tubes.

4th. Causes destroying vitality of semen or preventing fixation of impregnated orum.

Corporeal or cervical endometritis ;

Membranous dysmenorrhœa ;

Menorrlagia or metrorrhagia ;

Abnormal growths;

Areolar hyperplasia.

The mode of action of most of these causes is so self-erident as to make anything more than their mention unnecessary. Some of them, however, require special explanation.

Vaginismus is an appellation which has been given of late years to it hyperasthetic state of the ostium ragina, which results in spasm of its splincter. This interferes with the entrance of the male organ, and consequently of seminal fluid into the raginal canal; indeed, in aggravated eases, it entirely precludes sexual approaches. The affection is by no means rare, and is a fruitfinl source of sterility.

An abnormal shape of the cervix has been pointed out by Dr. Sims as a frequent cause of infecundity. If this part be too long, so as to curl or hend upon itself, it is evident that it may not admit seminal fluid through its canal. But even a slighter degree of elongation, in which the cerrix has a conical siape, has been observed to be frequently followed by that 
eondition. Fig. 250 represents the variety of eonoidal cervix generally met with as productive of sterility.

Endometritis, whether it be cervical or corporeal, fills the uterine canal with a thick, tenaeious mucus, which often prevents the entrance of seminal fluid or destroys its vitality.

Flexions of the uterus, by producing bending of the cervical canal, and

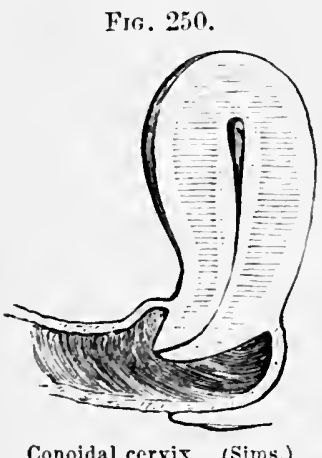

Conoidal cervix. (Sims.) versions, by pressing the os against one wall of the vagina, so as to close it as if by a valve, may entirely obstruct the passage to the uterus.

Obliteration and displacement of the tubes frequently result from pelvic peritonitis, and thus that affection often entails sterility of the most irremediable character. The second stage of the disease consists in effusion of lymph, which in time undergoes contraction, and either closes these canals or draws them out of place.

Membranous dysmenorrhea, or rather the tendency to exfoliation of uterine mueous membrane which characterizes it, so alters the uterine surlace as to render it inapt for the fixation of the orum.

Menorrlagia and metrorrhagia may result in the washing away of the orum after impregnation and before fixation. The normal menstrual hemorrhage oceurs before the entrance of the orule into the uterus. If it be excessive and prolonged, it may remove the ovule entirely, and in the same way metrorrhagia may remove the impregnated orum. An abortion does not occur under these circumstanees, for although impregnation may have taken place, conception has not done so.

Abnormal growths of any form which fill the uterine cavity, as, for example, fibroids, polypi, liylatids, or moles, may so interfere with the attachment of the orum to the uterus, as to prevent conception even when impregnation has oceurred.

Although it is impossible to give positive proof of the fact that serious chronic disease of the ovaries results in a blighting influence upon the orule, such a conclusion is rendered highly probable by the results of experience in such eases. Such a result is often found to attend ehronie ovaritis, general pelvic peritonitis or cellulitis, and double eystic disease.

Some of the eauses here enumerated are much more frequent than others. I would enumerate the most common causes in the order of their frequency in the following sequence. First, glandular eervieal endometritis; second, areolar hyperplasia, the result of subinvolution of the uterus; thirl, conoid cervix, with contracted os ; fourth, flexion and version of the uterus; fifth, contraction of os externum ; sixth, fibroids, interstitial, or subnueous; seventl, menorrhagia or metrorrhagia; and eighth, ovarian incajacity from elironie ovaritis or pelvic peritonitis. I do not 
state this sequenee dogmatically, but merely to convey an idea of my impressions with reference to the matter.

Differentiation.-Before it is determined that a woman is sterile, the sexual eapacity of the hushond should be asecrtained. Men are averse to the confession of impotence, and will often allow the supposition of sterility on the part of their wives to be maintained rather than admit the truth. In two cases I have used an anesthetie, ruptured the hymen, and distended the vigrina, under the impression that sterility of several years' standing was due to the impossibility of the aceomplishment of intercourse, and have subsequently, discovered that the husbands of my patients were entircly impotent, and had been so before marriage.

Prognosis.-In reference to a disorder which may be produced by such a varicty of causes, no positive prognosis can be given, for its cure will entirely depend upon the removal of the ageney which produces it. Mueh, too, will depend upon the thorough investigation of the causes by the plysician, and a proper understanding, on his part, of the treatment. Enquestionably a large proportion of sterile women may, by appropriate treatment, be made fruitful.

Results.-No pliysical results are produced by sterility, but its existence will frequently depress the spirits and sadden a disposition which, under other circumstanees, would have been cheerful and equable. The married woman has always regarded and will forever view this incapacity as a reproateh to her womanhood, and no amount of argument can make her aceept it with resignation.

Treatment.-The treatment of sterility consists in the removal of its eanse. Many of these causes are not suseeptible of remedy, while the means of treating others are so evident that special mention may be confined to a few. Obturator hymen, vaginisnus, atresia vagina, and ocelusion of the cervical canal should be treated by the surgical operations appropriate to eaclı.

In case the vaginal cervix should, to only a limited extent, be too projecting or conical, the bilateral operation for its enlargement should be pratised after the method elsewhere described. If a slight constriction of the cervical canal appear to be the cause of the condition, dilatation may he essayed in place of a surgical procedure. In an aggravated case, when the neck projects markedly and is decidedly conoidal in shape, both these means are insufficient; amputation then beeomes necessary. After this has been recovered from, the bilateral operation for cervical hysterotomy is often neeessary before cure is effeeted. In this conneetion the chapters upon dysmenorrhœa and amputation of the cervix should be referrel to. Endometritis slould be appropriately treated, and abnormal growths should be dealt with as if sterility did not exist.

If a displacement be discovered and replacement and retention be possible, they should be practised. But if in case of flexion this be impos- 
sible, the uterine canal should be rendered as straight as is praeticable, by the ecrvical incision recommended by Dr. Sims for dysmenorrhœa. Menorrhagia and metrorrhagia should be treated upon the plan recommended in the chapter upon those subjeets, and the patient be advised to keep very quiet and to avoid warm and stimulating beverages during menstrual epochs.

A remark made in connection with the treatment of leueorrbœa may with propriety be repeated here, namely, that to enter more minutely into the study of special remedial measures would tend to divert the mind of the reader from a point which I regard as of paramount importance; that this affection is commonly only a symptom which should be reached through the malady which induces it.

As I have elsewhere stated, glandular endometritis and tortnosities of the uterine neck are among the most frequent of the canses of sterility. The first of these is a disorder which is often incurable, and the surgieal operations practised for the latter very commonly fail of result. And so with regard to other conditions resulting in sterility. If at the end of a large experience every one would compare the number of his failures in treating sterility with that of his successes, his results would not be regarded as very satisfactory. Unfortunately, the unsuecessful eases soon sink beneath the mental horizon, while the suecessful ones stand out prominently, and thus many a practitioner, by his evidence, unintentionally misleads others and produces disappointment.

\section{CHA P T E X XV.}

\section{AMPLTATION OF THE NECK OF THE LTERUS.}

ALTHocgir the recognition of the important role played by laceration of the cervix in uterine pathology will certainly circumscribe very much the field of the operation, there are nevertlieless eonditions which will still call for a resort to it as the most eflective surgical resource. As a full description of the operation lats not yet been elicited by previous chapters of this work, it will be well to consider it here before leaving the consideration of uterine and taking up that of ovarian diseases.

History.-Ambrose P'arét wals the first surgeon who advised amputation of the cervix. He recommended it in malignant growths of the part, to which, he says, "we may apply the speculum matricis, in order to see more "asily." It is reported, upon insufficient authority, to lave been performed as early as 16,22 , by 'Tulpius, of Amsterdam, and in 1766 , by

I Eurres d'Ambroise Paré, lih. xxir. p. 1012. 
Lat l'eyronie. Daniel Turner, of Lonlon, in 17:36, reported an instance in which the neck of a prolapsed uterus was amputated by means of a razor in the hands of the patient herself, who wats insane. The recovery of the woman was evidently regarded ats a wonderful ciremmstance. In $1 \times(0)$, the operation was systematized by Osiander, who performed it twenty-three times, and after this it was resorted to by Dupuytren, Récamier, Hervez de Chegoin, and others. It wats, however, in the hands of Lisfrane that it attracted special attention, and in consequence of his enthusiatm it was for a time regarded as a means which was destined to accomplish a vast deal of goor. Ilis reports of its results were most favorable, and he described its dangers as slight. But soon after his publications upon it there appeared a counter-report from the young physician ${ }^{2}$ who took chlarge of many of his cases and was familiar with all, which ast discredit upon all the master's statements. By Pauly, the truth was, as Beequerel expresses it, "brutally revealed," and it was entirely at variance with the representations of Lisfranc. Since that time the operation has: to a certain extent fallen into disrepute, but is still resorted to in appropriate cases.

Dangers._The dangers of the procedure are the following :-

Primary hemorrhage;

Secondary liemorrhage;

Peritonitis ;

Cellulitis;

Tetanus.

The statisties of the operation liave not as yet been carefully eolleeted. Lisfranc reported 99 operations and only two deaths, but these statements Paniy renders more than donbtful. Huguier reports 13 operations and no deatlss; Sims over 50 operations and one deatls; and Simpson 8 operations and one death.

Even these reports, farorable as they are, refer to the results of amputation by the knife. By galvano-cautery much hetter results are obtained. It is really surprising to see how little eonstitutional disturbance follows this operation. Out of the large experience of Dr. Byrne, of Brooklyn, with it, no fatal case is reported: and only one bad result lias occurred in my own practice in over fifty amputations of the whole cervix.

Conditions demanding Amputation.- The conditions which ordinarily call for removal of the cervix are the following:-

Malignant disease;

Great enlargement from cervieal hyperplasia ;

Longitudinal cervical lyypertrophy;

Conical and projecting cervix ;

Granular or cystic degeneration of intractable eharacter.

1 New York Med, Journ., vol. v. No. 5.

2 Panly, Maladies de l'Utérus, Paris, 1836. 
One of these conditions, longitudinal cervical hypertropliy, not having previously reeeived special mention, requires it here. The cervix may be congenitally very much elongated below the vaginal junetion. Generally it undergoes hypertrophic elongation from a simple formative irritation, a low grade of eervical endometritis, congestion long kept up, or prolapsus in the third degree. Under these eireumstances the neck grows very long, so as to rest between the labia or even to project for a number of inclies from the body, and it has in some instances been mistaken for the penis. By means of the touch, eonjoined manipulation, the speeulum, and the probe, a diagnosis ean readily be made. M. Huguier, some years ago, maintained that this condition often deceived practitioners into the belief in prolapsus uteri.

Varieties of the Operation.-In some cases, as in cancer, for example, it is necessary to remove the entire cervix and even as much tissue as possible from that portion of the organ above the vaginal attaelinent. In others, only lalf of the vaginal portion requires ablation, while in still another set of cases, only the removal of a thin section of the hypertrophied lips is called for.

Methods of Performance.-The operation may be performed by the following methods:-

By the bistoury or seissors;

By the éeraseur ;

By the galvano-caustic battery.

Operation by Bistoury or Scissors.-When performed by the first methor, the patient should be placed upon the left side and Sims's speeulum employed. The corvix being slit bilaterally, one lip is seized and eut off as near the varinal junction ats is deemed advisable, and then the other is removed in a similar manner. Formerly the operation was completed at this point, hut Dr. Sims has introduced the practice of drawing down the mucous membrame and stitehing it, with silver sutures, so as to cover the stump, as that of the arm or thigh is covered by skin after amputation of those parts. When the stmmp is covered by mueous menbrane, after this plan, recovery is much more rapis than when granulation is allowed to accomplish the cure. 'Tlis operation is often a bloody one.

Operation by the Ecrasenr.-In operating by this method, if the uterus be prolapsed, if the degree of longitulinal hypertrophy be so exeessive a to cause full protrusion of the cervix, or if such protrusion be attainablo by moderate traction, the patient may be placed on the back. If the uterus be high up in the pelvis and strong traction be necessary to depress it. the lest position will be fomel to be that arlvised when seissors or the bistoury are employed, the speculum heing used. 'The passage of the clain will be found to he very simple, and the part should be slowly cut thromerh.

In using the écraseur for this purpose, great care should be observed 
not to allow of too great dragging of the clain upon the neck withont cutting. If attention be not given to this point, the peritcaetam may be opened or the blatder involved.

I describe the operation by the écrasenr, although I regard it as inferior in merit to both the other methoils mentioned. I do this beeause the operation is often called for far from surrical centres, where it is very difficult to procure a battery, and where no operator of suflicient skill can be found to perform amputation by cutting instruments.

Operation by Gulvano-cautery-CThe galvano-caustic apparatus consists simply of an instrument which enables the opcrator to engage any part in a loop of wire which, being connected with a powerful galvanic battery, becomes red hot and cuts its way through. The instruments generally

FIG. 251.

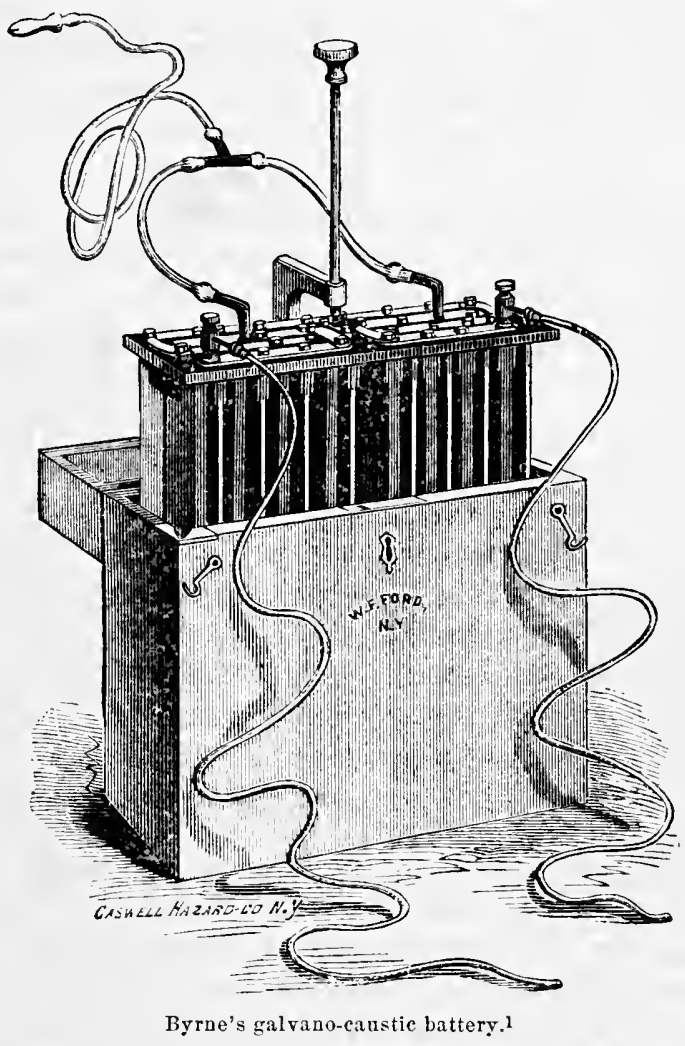

employed here are a German battery, Middledorpf's ; or Grennett's, a very compact instrument made in London; and one constructed by W. F. Ford,

1 For details concerning this instrument I refer the reader to Dr. Byrne's interesting brochure entitled liectro-cautery in Uterine Surgery, Wm. Wood \& Co. 
of New York, after a method suggested by Dr. John Byrne. It would be out of place here to give details concerning these instruments; all of them answer the purpose in view very well. That of Dr. Byrne is, for an American, most attainable, and is certainly a very eflicient and reliable apparatus. It is slown in Fig. 2:1.

In amputating the neek in this way, the patient may be placed upon the back, and the uterus drawn down between the labia; or, if this depression of it be diflicult, she may be placed upon the side, and Sims's speeulum employed. By one of these procedures the part to be amputated is fairly exposed to view and manipulation. The wire loop of the galvano-cautery is passed around the neck as ligh up as is deemed safe, and tightened until it is fixed in the tissues so as not to slip. Then the current of electricity is made to pass through it, and the loop being slowly tightened by the turuing of a serew by the operator the cervix is amputated.

Sometimes the removal of the portion of the cervix desired is difficult of attainment, a sealping proeess being substituted for a complete amputation. To accomplish the operation completely, I have devised the forceps shown in Fig. 235. By the long, sliding screw between the blades, the cervix is drawn into their grasp and fixed by closing them. Then the serew is withdrawn, and the cold wire slid over the projecting portions and tightened, and, the electric eurrent passing, a red, and not a white, heat being established, the cervix is completely removed.

By this methor immediate hemorrhage is usually controlled, but not so remote hemorrhage. Sometimes on the fifth, sixth, or even the tenth day a most active flow takes place in spite of every precaution. For this reason the tampon should be used after such an amputation, and the fatient's convaleseence be carefully watched.

\section{II A P T E X X VI.}

\section{DISEASES OF THE OVARIES.}

Ilistory.-Aneient literature is singularly barren upon the subject of ovarian diseases. 'That the functions of' these orcrans were known to early anatomists, there is no doubt, for as early as $2011 \mathrm{~B}$. C. the operation of castration of female animals is alluded to by Aristotle, and in the second entury A. C. they were described by Galen under the name of "testes muichres." As to the influence excrual by them upon menstruation, they were not informesl, for they attributed that process, according to Aristotle, to a superfluity in the blood, an opinion which was entertained 
even by Ilippocrates. The works of Aëtius make no mention whatever of ovarian disorlers, and those of Paul of Ainina are equally silent. When it is borne in mind that the ovular theory of menstruation dates baek for its origrin to the labors of Négrier, Gendrin, Bischoff; Pouehet, and others of our own time, and that the operation of ovalriotomy was never systematieally performed before the year 1809 , it will be appreciated how recently the profession even in modern times has fully grappled with the subject.

During the past twenty years full amends have been made for this delay in progress, for in that time no portion of the field of gynecology has received more attention or been more thoroughly investigated than that which now engages us. Not only have most of the diseased conditions of the ovaries been satisfactorily investigated, and the diagnosis of them reduced to a scientific system; for the nost frequent and important of them surgieal means have been instituted with such success as to have given proeedures of the most appalling character and undoubted dangers the position of legitimate and justifiable operations. The reeent literature of ovarian pathology and surgery is now enriehed by the contributions of so many capable observers, that it is almost invidious to particularize the most prominent. Unfortunately there is one set of ovarian affections with reference to which these statements are not true; those of inflammatory character. Our means of diagnosis of ovaritis, both acute and chronie, is, in spite of all the advances alluded to, so elementary and unreliable that the result is discordance of riews, and uncertainty as to pathology and therapeutics. It was probably the contemplation of this fact which led Seanzoni to open his article upon diseases of the ovaries with the following sentence: "If we felieitate ourselves upon the progress which has been made during the last few years, in the diagnosis and treatment of the diseases of the uterus, we should, on the other hand, remember that the labors of gynecologists in respect to the diseases of the ovaries have been almost fruitless in practical results."

In illustration of the difficulties attending the diagnosis of ovarian diseases, I introduce a table which I have constructed from Hennig's ${ }^{1}$ report of one hundred post-mortem examinations made by him, with special reference to this point. "If we now turn our attention," says he, "to the diseases of the ovaries, it is a fact of great value, in reference to diagnosis, that in ten out of one hundred cases, the diseased state of the ovary was, or might have been, recognized during life-more frequently by rectal exploration than by vaginal or abdominal." On the other hand, out of 81 bodies, a diseased eondition of the ovaries was found in 53 , a proof of how frequently disease of the oraries cannot be recognized during life. The diseased condition was more frequent in one ovary alone than in both; this being found in three-fourths of the cases.

' Catarrh of Sexual Organs of the Female. By Carl Hennig. 


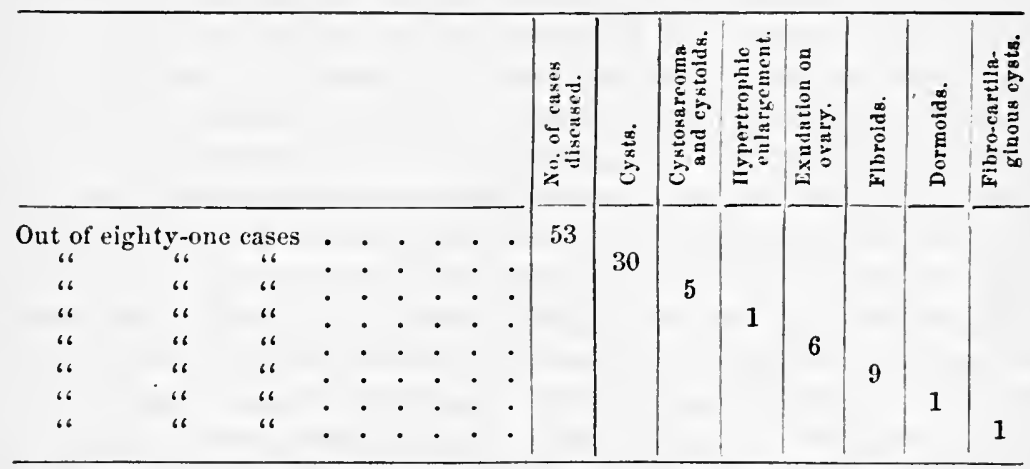

Anatomy of the Oraries. - The ovaries are two follicular glands about the shape and size of small almonds, situated one on each side of the uterus. So dejendent are they upon the position of the uterus and surrounding viseera that they have really no fixed place. They are usually found in the lateral and posterior parts of the true pelvis, about an inch from the uterus, and just below the point where the Fallopian tubes enter that organ, the left being in close proximity with the rectum. Each ovary is attached to the peritoneum, which eonnects it with adjacent structures, and is firmly united with the uterus by means of a fibrous cord arising from the horn of each side.

The Fallopian tube of each sile is connected with the orary by one fimbria, and acts at Ieriods of ovulation as its excretory duct. The surface of the ovary is not covered by peritoneum, for, arrived at the cireumference of these organs, this membrane loses its characteristic appearances, and the only trace of it which is discorerable is a layer of basementepithelium. ${ }^{1}$ Around the circumference of the ovaries a cortical portion exists, whose duty it is to generate the Graafian follicles. Within this is a fibrous structure, composed of muscular fibres, cellular tissue, ressels, and nerves, which receives the name of stroma. Renoved from the stroma and examined with rare by the microscope, each of the Gratian vesicles is found to consist of a sar, ealled the tunic, which is filled with fluid, the liquor follieuli, in which is contained the ovum or egg which is the female contribution to conception.

It is now accepted as a fitct by most physiologists, although still contested by some, that the periodical discharge of blood from the uterus, which is called menstruation, is merely a uterine symptom of the discharge of one of the ova from the ovary ly rupture of a follicle. After the period of pulerty has arriverl, one or more of the follicles of each ovary burst every month by the following process: a congestion or hyperamia occur-

1 For details with regard to these curious and recently discorered facts, the reader is referred to essays by Otto Schrone, Henle, and Sappey. 
ring in the ovary for some reason beyond our comprehension, canses an excessive secretion by the walls of the follicle, in which a miniature dropsy takes place. This gocs on to rupture, and escape of the liquor follieuli, blood, gramular cells lining the ovisac, and the ovum. The nerve supply to both uterus and ovaries is excited by this process, and one of the results of such excitement is contraction of the delieate middle layer of uterine fibres which surround the network of minute vessels enveloping and penetrating the uterine strueture. This throws the vascular apparatus into a state of eretion. Great engorgement oecurs on the surfice of the uterine mucous membrane, and probably on that lining the Fallopian tubes; they rupture, and a flow of blood takes place. Three elements are concerned in this discharge: 1st, ovarian irritation excited by ovulation and transmitted to the nerves governing the muscles constituting the midule coat of uterine fibres; $2 \mathrm{~d}$, erection of the uterine vasenlar system; $3 \mathrm{~d}$, consequent rupture of the bloodvessels of the mucous membrane of the uterus and escape of blood. The ovisac being thus emptied, a elot of blood soon forms within it, then an hypertrophy of the cells lining it occurs, and the corpus luteum is formed.

If the examiner hold up one of the broad ligaments between himself and the light, a small plexus of white, erooked tubes will be seen forming a cone, the apex of which is directed towards the hilus of the ovary. It measures about an inch in breadth, and consists of about twenty tulues which are filled with a clear fluid. This is the organ of Rosenmuiller, which has recently been minutely deseribed by Kobelt under the name of the par-ovarium, and is supposed by him to be an exaggeration of the Wollian body. The exact location of the par-oraria is this : they lie beneath the ovaries and between the ultimate folds of the peritoneum covering the fimbriated extremities of the Fallopian tubes, which have received the name of the alie respertilionum.

The ovaries are supplied with blood through the spermatic arteries, which, upon arriving at the margin of the pelvis, pass inwards between the layers of the broad ligaments, and thus reach their lower border. Their nervous supply is not extensive, and is derived from the renal plexis.

The ovary presents its most perfect type in the young virgin, when its dimensions are greatest and its surface undeformed by the numerous eicatrices which appear at a later period. The dimensions of this organ are greater than they are during early virgin life only during and for six weeks after the process of ntero-gestation. Hennig, who has made a special and exceedingly minute study of this point, declares that preguancy increases the length but not the breadth nor the thickness of the organ. Utero-gestation, which leaves the uterus larger than it was before, has the contrary effect upon t!le ovaries, which after its accomplishment diminish in size, never again to attain their former dimensions while in a state of health. 
Vtrieties of Orarian Disease.-Any one or all of the tissues which have been mentioned may be affeeted by disease, or the position of the ovary may be altered to such an extent as to constitute a morbid state. The following table presents a list of the disorders of these glands which will now receive special attention :-

Absence;

Imperfeet development;

Atrophy ;

Inflammation ;

Neoplasms.

\begin{abstract}
Absence.
One or both of the ovaries may be congenitally absent, but such a condition is very rare. When it does exist, it is generally only a part of a complete want of genital development which is manifested not only by these organs but by the parts making up the vulva, the vagina, and the uterus. Kiwisch declares that it has been most frequently observed in the bodies of newly-born infants who were not viable on account of complicated deformities. Where there is congenital absence of the ovaries the woman is generally small in stature, her figure undeveloped, as if the period of girlhood were abnormally prolonged, and the genital system imperfeet, as already mentioned. In some cases the mind is very leficient, a condition bordering upon idiocy sometimes existing. In others this is not the case, but the patient suffers from depression of spirits, and appears to lack vigor both of mind and body. Development into womanhood has never arrived for her, and she remains a child without the vivacity and eheerfulness of childhood.

Although certainty can only be arrived at post mortem, a diagnosis mey be marle during life by the use of Simon's method, which may guide us in prognosis and treatment. Inderd, one of the greatest benefits which can accrue from a correct eonclusion will consist in the avoidance of all efforts which, being vainly addressed to exciting the performance of the functions of the ovaries, deteriorate the state of the patient. Should the general condition of the patient, the undeveloped state of the vulva, vagina, aud uterus, and the entire absence of the menstrual erisis combine as evidences of the condition, a diagnosis is admissible.
\end{abstract}

\title{
Imperfect Development.
}

This condition, which consists in persistence of the fotal state of these organs after the period of puberty when rapid development should have occurred, is by no means so rare as that just mentioned. It may exist on one side only, though it generally affects both. As in the case of absence of the ovaries, a certain conclusion is not easy, and as in that ease, also, we draw a presumptive conclusion from want of development in the other 
organs of generation, absence of the usual signs of the menstrual erisis, and lack of general constitutional vigor and development.

As examples of ease's susceptible of such an explanation, I record the histories of two with which I have recently met. 'The first is that of Miss F., referred to me l,y Dr. Rodenstein, of Manhattanville. She is twenty-four years of age, and yet has the aplearance of a girl of thirteen. Indeed, it is diflicult to believe the statement that she is more than that age. The features, limbs, mode of expression, and general deportment are those of a chihl. She has never menstruated nor shown any evidences of a tendeney to do so. Physical exploration shows the vulva in the state of early girlhood, the mons veneris destitute of hair, the labia thin, and the vagina so small and narrow that the little finger only can be introduced, and that causes great suffering. The canal being short as well as narrow, the uterus can be touched, and is found like a little nut in the vagina, so light that its weight is scarcely perceptible.

'The second ease is one which I saw with Prof. W. H. Thompson. The patient is eighteen years old, and has never menstruated. Previous to the treatment established by Dr. Thompson, she snffered greatly from epileptic seizures, which have evidently impaired the force of her intellect, but during the two months before I saw her she had been firee from them. The girl is slow in her movements, childish in manner, and stupid in replying to questions. Upon physical exploration, the vulva, vagina, and uterus are found fully and perfectly developed, the latter giving by measurement, with the uterine probe, two and a half inches. Nothing can be elicited with reference to the ovaries by physical means, but the rational signs mentioned, together with the fact that all the appearances of girlhood arc combined with entire absence of any apparent effort at orulation, render the supposition that the oraries are undeveloped, or foetal, highly probable.

Sometimes cases will be met with in which masculine development, enansio-mensium, and sterility will lead to a diagnosis of absence of the ovaries, but which will subsequently undergo a change and give all the evidences of the presence and efficiency of these organs. One such case, which occurred in the practice of Dr. Metcalfe and myself, is worthy of record. Mrs. B., a large, musenlar, and haudsome woman, had menstruated very irregularly and scantily for ten or fifteen years. Sometimes the menstrual discharge would be entirely absent for months, then it would at long and irregular intervals slow itself for a day. Her health was not affected by this in any way. She presented, however, many signs of masculinity; the voice was harsh, the breasts flat, and the chin covered with a sparse beard. After laving been married for years she became pregnant, and in due time bore a child, subsequent to which she menstruated more regularly and plentifully, and has since borne two ehildren.

Treatment.-Should the ovaries be congenitally absent, it is evident that art can do nothing to remedy the evil. Should they exist in an 
undeveloped or fortal state, it is possible that, by a proper stimulus applied to them by the most direct mearis in our power, growth and maturity may be fostered, unless the condition be one of aggravated arrest of development. The means which are most likely to accomplish this are-

General tonics ;

Uterine irritation;

Electrieity ;

Marriage.

The sanguineous and nerrous systems slould both be brought into as perfect a state of health as possible by ferruginous and bitter tonics, fresh air, exercise, change of scene, and a general observance of the laws of hygiene.

The most direct method for irritating the ovaries is through the uterus, with which so elose a sympathy exists. For this purpose tents may be oceasionally resorted to, as often, for instance, as once or twice a montl. This not only prepares the uterus for its part of the process of menstruation, but causes a hyperamia in the ovaries, which we know to be the physiologieal forerunner of ovulation.

Electricity may be employed by placing one pole of a battery over the spine and one over the ovaries, or, more effectually, by carrying one pole, protected where it touches the vagina, to the cervix uteri, eonnecting this with a battery, and passing the other pole over the ovaries. An intrauterine galvanic pessary may likewise answer a good purpose, when worn steadily and persistently.

The ovarian irritation and congestion incident to the marital act will sometimes excite ovulation, not at the moment of coition, as was formerly supposed, but remotely.

\section{Atrophy of the Ovaries.}

At a period, varying from the forticth to the fiftieth year, the oraries are destined to undergo atrophy. They diminish in volume, become wrinkled, the Gratian follicles disapjear, and the stroma beeomes dense and non-vascular. This is a physiological process, and marks what is termed the menopanse, or periol of menstrual cessation. Sometimes this proeess sets in at a very carly period, owing to some abnormal condition which has excited it, and produces the same results as those following it when it takes place at the normal time.

Causes. - With regard to the special eauses of this oceurrence very little is absolutely known, further than the fact that it sometimes oceurs from pelvic inflammations. It is probable that acute ovaritis may produce it, and it is eertain that, at times, it results from pelvic peritonitis and cellulitis.

The following ease which presented itself at my elinique some time ago is illustrative of this fact. Mary G., a healthy young Irish woman, aged 
24 years, stated that she had a miscarriage at the thirl menstrual period, five years betore, in Albany. Three days atter the product of eonception lad been cast ofl, she was taken with a chill, with violent pain over the abdomen, and was declared by her physician to have inflammation of the bowels. Of this attack she nearly died, but after a confinement to bed for six weeks grew better. For two years after this she had irregular, painful, and profise menstruation. As she expressed it, whenever she became fatigued or excited, flooding wonld come on. $\Lambda$ fter this time the menstrual periods disappearen, and she now applied for relief on account of amenorrho:a of three years' standing. Physical exploration revealed the uterus in normal position, though diminished in size to about two inches. Nothing could be ascertained about the ovaries.

The view which 1 took of the case was that pelvic peritonitis and acute ovaritis originally existed; these left the parts in such a state that for two years metrorrhagia and menorrhagia ocenred; then subsequent contraction occurring in the effused lymph in and around the ovaries, atrophy resulted with its usual consequence, amenor rhwa.

The peculiarly destructive influence exerted upon the ovaries by pelvic peritonitis will be impressed upon any one who makes an autopsy in a patient who has died of that affection, or who reads the reports of others. Very often the ovaries cannot be discorered in the mass of "putrilage" which ocenpies their site.

Treatment.-An attempt may be made, by the means recommended in the treatment of undeveloped ovaries, to excite ovulation in any part of the glands which may still be eapable of performing the funetion. But it should not be persisted in if not at once attended by good results, for inflammatory action may be excited by it. When these means are essayed, great caution shonld be observed and their influence developed only to a limited degree.

\section{Ovarian Apoplexy.}

Definition.-The word apoplexy is very loosely employed in reference to sangnineons effusions in all the organs of the body, some signifying by it sudden vascular rupture, while others apply it to interstitial hemorrhage occurring even very slowly. This las ereated confusion of deseription, and certainly added difficulty to the clear comprehension of the pathological states to which it lias been synonymously applied. Thus, in deseribing ovarian apoplexy, Kiwisch divides it into primary and secondary, considering as examples of the latter, hemorrhage from the walls of a eyst which fills it slowly with blood, or hemorrhage the result of tapping. The two conditions should be regarded as essentially different, and I would offer this as the proper definition of our subject. Apoplexy of the ovary 
consists in a rapid effusion into its tissue of blood, which results from rupture of one or more of its larger vessels.

The ovaries present the only example in the animal economy of apoplexy occurring as a physiologieal act. At each menstrual period, as an ovule leaves its nidus, an apoplexy from the vessels of the tunic of the ovisac occurs as a necessary conseçuence. It is this which, upon subsequent alteration, constitutes the corpus luteum. Generally these hemorrhages are self-limiting, and their effeets rapidly disappear; in some cases, however, the bleeding continues too long or returns after cessation, and then the collection of blood sometimes reaches the size of a man's fist or of a child's head.' In some instances the tunica albuginea of the ovary is completely ruptured, when the effused blood pours into the most dependent portion of the pelvic carity, constituting pelvic hematocele.

Symptoms._-The occurrence of apoplexy is often ascertained only in autopsy, no signs existing during life by which it can be positively diagnosticated. The symptoms which will usually point to its existence are sudden and violent pain over the region of one orary, with sense of great exhaustion, nausea, and romiting. These symptoms, if combined with enlargement and tenderness of one ovary, as ascertained by conjoined manipulation, will be suffieient to render a diagnosis warrantable if the patient's health has previously been good.

Prognosis.-WThe great danger from the aceident is peritonitis, arising either from implication of the peritoneal fold which makes the broad ligament, or from rupture of the cortical portion of the ovary and occurrence of hematocele.

Treatment._-Should there be symptoms of peritonitis, the treatment elsewhere recommented should be adopted. Beyond this, all that can be done is to keep the patient quiet in the recumbent posture, and prevent all muscular effort until absorption oceurs.

\section{Displacement of the Ovaries.}

The extreme mobility of these glands and the laxity of their supports have already been remarked upon. Any influence which increases their weight, draws upon them directly, or acts upon them by traetion through a neighboring organ, may cause them to leave their position, and even in rare cases to pass out of the pelvis in the form of hernia. For example, they may be displaced by inflammation, hypertrophy, ovarian futation, etc, which catuse increase of weight ; or they may be acted upon by contractions of effused lymph, resulting from pelvic peritonitis; contraction of the ovarian ligaments, ete., drawing them out of place; or they may be atfected by displacement of the uterus, pregnancy, or hernia of any

1 Kiwisch, op cit., p. 232. 
of the abdominal viseera acting upon them by means of traction. $A$ hernia of the ovary alone is very rare; it is almost always attended by hernia of the Fallopian tube, or some portion of the intestines or omentum.

The ovaries often fall, when their weight is increased, into the eul-de-sac of Douglas. More rarely they pass into the inguinal canals, or through them into the dartoid saes of the labia majora. Here they show a monthly intumescence, which creates great local disturbance, and keeps the part swollen, heated, and tender, until ovulation is passed. Deneux ${ }^{1}$ deelares that they may enter the femoral, umbilical, and ischiatic openings, or form a part of ventral hernia, and Liwisch has reported a ease in which one entered the foramen ovale. The aceident is rarely important in its results except in reference to exclucling the suspicion of other forms of tumor, and avoiding the danger of surgical interference under a mistaken diagnosis.

Treatment.- The treatment consists in returning the displaced part by taxis, and keeping it in situ by a properly constructed truss, pessary, or bandage. Should the gland be bound in its false position by strong membranes, the propriety of its removal might be considered, in case scrious inconvenience resulted from the displacement.

\section{Ovaritis.}

Definition.-By this term is meant an inflammation of the tissue comprising the ovaries, which has been deseribed by some authors under the name of Oöphoritis. A dogmatic treatise upon ovaritis in the non-puerperal woman is, in the present state of science, impossible. So much concerning the disease is unsettlet, and such utterly discordant views are entertained upon it by the most reliable authorities, that too great caution cannot be obscrved in treating of the subject, lest theories constructed upon analogical reasoning be mate to pass current in the mind of the reader for facts faithfully observed at the bedside and in the dead-house. No writer should attempt its description without determining as $A$ ran did, when he penned the following sentence: "I leave out of consideration all the fantastic clescriptions of ovaritis which have been constructed in the library by physicians who were more remarkable for brilliancy of imagination than knowledge of the disease." Our knowledge of the subject is at least so far adranced as to make a theoretical essay upon it entirely inadmissible.

Varieties._Ovaritis may be either puerperal or non-puerperal. The first does not concern our present investigation, and we put it ont of consideration. The non-puerperal form of the disease has been divided into acute and chronic, which will now engage us in order. 


\section{Acute Ovaritis.}

This affection, though very common as a result of parturition or abortion, is, exeept as a complication of pelvic peritonitis or cellulitis, quite rare in the non-puerperal woman. Mme. Boivin ${ }^{1}$ even goes so far as to say that, "it would be dificult to point to a single well-authenticated case out of the condition of pregnancy." Dr. West ${ }^{2}$ remarks that, " acute inflammation of the substance of the unimpregnated ovary is of such rare occurrence that no ease lias come under my own eare, and but one has presented itself to my observation." Prof. Fordyce Barker ${ }^{3}$ says, "I doubt very much if I have ever seen a clear, well-marked case, and I have been for years looking for its existence in the dead-house." 'There can be no question of the truth of these statements as regards pure uncomplicated inflammation of the ovary, but oraritis of acute charaeter going on to suppuration or production of a diffluent state of the stroma, is by no means rare as a complication of pelvic cellulitis or peritonitis. One of the greatest dangers to be feared from these diseases is injury or destruction of the ovaries, and it is probable that few cases of cellulitis and none of peritonitis run their course without involving them to a greater or less extent. It is likewise probable that pelvie peritonitis is frequently excited by some trouble originating in the ovaries, which are elosely in contact with the peritoneum making up the broad ligaments and covering the pelvie roof. The intimate relation of these parts, the ovaries, the pelvic peritoneum, and the pelvie areolar tissue, accounts for the fact that uncomplicated acute oraritis is rarely met with.

In proof of this statement let me point to the conditions of the ovaries in the autopsies of periuterine cellulitis reported by Aran. In alnost all instances they were diseased, and they generally contained pus. So common was this lesion that Aran was persuaded that "the purulent eollections which, as a consequence of periuterine inflammation, discharge themselves into the peritoneum or into the organs in the neighborhood of which they are plaeed, rectum, bladder, vagina, ete., sometimes even by the surface, belong more particularly to the ovary or tube."

Since the writings of $\Lambda \mathrm{ran}$, no one has done more to put in a strong and proper light the intimate relations existing between inflammation of the ovaries, suppuration, and pelvic peritonitis and cellulitis than Dr. Mattlews Dunean. IIe regards these periuterine inflammations as always symptomatic affections; as secondary to uterine, tubal, or ovarian disease, or noxious discharges entering the peritoneal eavity through the tubes. At the same time that 1 differ from Dor. Dunean, in looking upon reriuterine inflammation as not infrecuently primary, and as commonly

\footnotetext{
1 or. ait.

2 Op. cit., p. 473.

3 Jul. X. Y. Acad. Ned., vol. i. p. 549.
} 
resulting in acute or chronic ovaritis and abscess, I admit that the. sequence of events is often that which he states.

Authors have divided acute ovaritis into parenchymatous, follicular, and peritoneal, but in an affection, the mere recognition of which is so diflicult, it is hardly wise to refine upon its peculiarities. The form of the affection styled peritoneal is really not ovaritis, but peritonitis of the very character of which we are speaking; from which to parenchymatous and follicular disease there is only one step. As an example of ovaritis complicated with peritonitis in a non-pregnant woman, I a wail myself of the kindness of Dr. Roth, and record the following history prepared by him.

"M. S., xt. 35, married ten years, had a miscarriage nine years ago. Since that time has suffered from dysmenorrhoa and gastrie disorder, which was styled dyspepsia. Two years ago she applied to me, and I found her suffering trom profuse fluor albus and retrottexion of the womb. Under use of causties and tonics she improved very much, and treatment was stopped. I did not see her again until August 1, 1866, when I found her in a convulsion. After it had passed off she vomited constantly, complained of great pain in the bowels, was very thirsty, and the pulse was near a hundred. Opium was freely administered. On the next day the pulse was over one liundred; skin hot and dry; and she complained of severe pain in back and loins, and over left iliac fossa. I made a raginal examination by touch, but could discover nothing, except that the ragina was very hot and dry. Aug. 3. No great change, except that the abdomen became tympanitic. Aug. 4 . She lost about five ounces of blood per raginam; symptoms unchanged. Aug. 6 . She was scen in consultation by Prof.' Thomas, who diagnosticated pelvic peritonitis with probable acute oraritis on left side, and anticipated formation of an abseess near or in the ovary. By his advice a large blister was applied over the hypogastrium, and opium given in very large doses. The case went on in this way until Aug. 11th, when she suddenly vomited a large amount of bile, became collapsed, and died that night.

"Autopsy eighteen hours after death.-The peritoneum covering the pelvic viscera was eovered with a recent lymph, and between the organs a great deal of puriform serum existed. Abdominal peritoneum healthy. The left ovary, which was agglutinated to the intestines, tube, and uterus, was about the size of a hen's egg. In its removal it was broken, and several ounces of pure pus eseaped. No evidences of cellulitis could be discovered upon careful disseetion. Other organs healthy."

Pathology. - This is not clearly male out, though it appears safe to accept the stages described by Mme. Boivin: first stage, congestion, with increase of wcight and rotundity; second stage, the organ double, triple, or quadruple its normal size, tissue soft and infiltrated with yellow and violet-colored serum, with slight effusion of blood; third stage, suppura- 
tion, pus infiltrated or collected in spots; fourth stage, gray softening, disorganization, the gland leecoming diffluent.

Causes.-C'The causes of the disease may be thus enumerated:-

Pelvic peritonitis ;

Periuterine cellulitis;

Gonorrhica ;

Disturbance of menstruation.

Any of the causes which lave been spoken of as sufficient to cause the first two diseases mentioned may through them produce oraritis. A form of ovaritis called btemnorrhagic is admitted by most authors as corresponding with blennorrhagic orehitis in the male. It is difficult to see how even the progress of gonorrheal inflammation along the tubes would cause discase of an organ not connected with the extremities of these tubes, but let it be remembered that gonorrhoa is in this way one of the most firuitful sourees of pelvic peritonitis, and an exploration of ovaritis as a seeondary result will suggest itself. Suppression of menstruation, or any sudden and riolent shock given to the ovaries while orulation is progressing and the walls of the organ are about being broken through, may likewise induce it.

Symptoms.-The symptoms of this affection are so intimately associated with those of peritonitis and cellulitis that it is impossible to separate them. There is severe pain in one or other iliac fossa, with inerease of lieat, fever, and perhaps chill. Pressure shows the most exquisite sensitiveness, and when the part is examined by conjoined manipulation this is excessive. By that means the ovary is felt enlarged and generally depressed in the pelris. These symptoms may subside upon the occurrence of resolution in four or five days; or pus forming within the grland may be discharged into the peritoneum, the rectum, the vagina, or the bladker.

Differentiation.-This is generally impossible. The association of the disease with those which have been mentioned as being at times its causes, at others its consequences, is usually too intimate for its distinction from them. Should conjoinerl manipulation discover the ovary as a round ball, very sensitive, and unassociated with fixation of the uterus, a diagnosis would be aldmissible. I have never met with such a case of acute eharacter, nor is it likely that it often ocenrs, thougl in subacute or chronic ovaritis these pliysical signs are common.

Prognosis.-The prognosis is favorable, though ncver free from an element of doubt.

Treatment.-Leeches may be applied around the anus, over the diseased organ, or at the groin. Should its weight not give pain, a poultiee should thron be place? over the hyogastrium, aud opium freely administered by mouth or rectum. The patient should be kept perfectly quiet, and not allowed to rise from her bed even for relief to the ealls of nature. Espe- 
cial eare in this regard should he observed if it be supposed that suppuration has ocenred, for then a very slight eflort might eause a rupture of the abscess into the peritoneum.

\section{Chronic Ovaritis.}

Chronic inflammation of the ovaries is an affection of common occurrence, thongh very little has been ascertained as to the exact frequency of the disease. So great is the sympathy existing between the uterus and these organs, that uterine disorders excite ovarian pain very commonly, and give rise to many symptoms which are regarded as characteristic of this disease. Again, it is a well-ascertained fact that sliglit attacks of chronic pelvie peritonitis are extremely common, and unfortunately we possess no certain means for distinguishing such a disorder, in the vicinity of an ovary, from chronic ovaritis.

In the great majority of cases of uterine disense the patient will complain of pain, of dull, aching character, over one or both ovaries, and this will very likely be augmented by menstruation. But it is by no means to be concluded that this sympathetic pain, even if dependent, as it very often is, upon congestion, is due to chronic oraritis. As well might it be believed that mammary pains excited in the same namner are due to mammitis.

As a primary affection which creates secondary uterine disorder and results in dysmenorrlowa, sterility, and hysteria, it is by no means rare. Many cases supposed to be obscure and unmanageable ones of uterine disorder, many in which the pliysician is sorely puzzled in accounting for the wonderful disproportion between the existing symptoms and the degree of uterine disorder discoverable, are due to this affection. Instances will not rarely be met with in which with slight uterine displacement, and a catarrls of no great moment, a patient will be entirely unable to stand or walk, except for very short periods of time. will for years prove sterile, and will suffer from agonizing dysmenorrhoea from this cause. The reviral of uterine pathology has drawn off attention too completely from the ovaries. The coming decennium will, I feel convinced, prove that in many cases disease of these most important organs in the female economy is the source of many ills now attributed to that less important viseus the uterus. It is in the study of orarian, not uterine, pathology, that the next great advances in gynecology are to be made.

Symptoms. - The symptoms of chronic ovaritis are numerous and often perplexing; no two cases of the affection presenting the same features. In some they are physical entirely, while in others the mind and nerrous system are decidedly involved. In several cases in my experience true epilepsy las existed, whether as a consequence or not I canrot say, but certainly as a very suspicious complication. 
The rational signs may be enumerated as-

I)ysmenorrhoea ;

Fixed pain over one or both ovaries;

Tendency to hysteria ;

Rarely inability to stand or walk;

Sometimes pain on sexual intercourse;

Pain and exhaustion after defecation;

Pain in rectum and down thighs;

Irregular menstruation;

Frequently leucorrhœa;

Sterility if both ovaries are diseased.

Dysmenorrlœea often precedes menstruation by several days. At other times it oceurs just after the cessation of the menstrual discharge; while in a few cases it occurs in the interval between the menstrual periods. The last constitutes the intermediate dysmenorrhoea of Dr. Priestly, and is a most interesting symptom. At times it occurs with great regularity. In one ease which oceurred in my practice it showed itself invariably on the ninth day, and in another on the fourteenth. Ovarian dysmenorrhøa produces great nervous disturbance, which renders the patient peculiarly prone to seek relief in the use of opium.

I have met with several eases of this disease in which the patients have been unable to stand or walk, except for a few minutes.

If the orary be prolapsed, sexual intercourse often proves a source of pain, but not otherwise.

The menstrual discharge is sometimes very irregular, remaining absent for months, and then showing itself as an alarming hemorrhage. In many cases it is quite regular both as to time of occurrence and amount.

The continued uterine irritation kept up by elironic ovaritis often engenders uterine catarrh, which proves, in eonsequence of its cause, very intractable to treatment.

That in many cases the patients become pregnant cannot be questioned, but, as a rule, where both ovaries are diseased sterility exists. It is highly probable that the diseased organs produce diseased or imperfect ova.

Physiral Signs._-The patient heing examined by touch and conjoined manipulation. the uterus will, for some reason which I cannot appreciate, be usually found to deviate from its normal axis, laterally, anteriorly, or posteriorly, and from the cervical canal a thick, mucous plug will often be found to hang. In Doughts's cul-tle-sac, on one. or on each side of the uterus, a rouml. soft, tender bouly, about as large as a walnut, will be found. This, when caught between the fingers, in conjoined manipulation. will prove very sensitive to pressure, which will often produoe namsea and tembeney to lyyteria ; and even after it has been desisted from, a dull aching fain will generally remam. 
Prognosis.-I know of few curable disorders which I dreal so much to meet as this. The day will probably eome when our treatlient for it will be sittisfictory and eflicient, but it has not yet done so by any means. Matuy eases will entirely baflle treatment, while all will prove little antenable to it. That they often in time recover is true, but recoveries have, in my experienee, but little comection with treatment.

T'reatment.-I have nothing better to offer than the following course, the meagreness of which I regret. If the ovaries be found prolapsed they should be carefully sustained by a light, elastic ring pessary, and if the displaced uterus press upon them it should be kept in position. Sexual intercourse should be limited as far as possible. If seanty menstruation exist as a symptom, one or two leeches shonld be applied every month to the eervix uteri. Rest should be prescribed during menstrual epochs, when the diseased glands are eongested and in a state of nervous exeitement. Serere exercise or fatigning oceupations slould be avoided, and all influences calculated to depress the vital forees carefully guarded against. Counter-irritation, by means of small blisters, tincture of iodine, or issues of nitric aeid, should be kept up over the diseased organs for months at a time, and once or twice a week the cervix uteri and the whole upper part of the ragina should be painted orer with tineture of iodine. Every niglit and morning the patient should be directed to use eopious injections of warm water into the vagina in the manner elsewhere explained. For the various nervous symptoms which accompany the affection the bromide of potassium in ten to fifteen grain doses will be found very beneficial. Ctero-gestation, which secures the ovaries from monthly congestions for nine months, is always mueh to be desired under these eircumstances.

Slonld evidence be elicited that small cysts exist in the enlarged and tender ovaries, they may with advantage be punetured and evacuated by the smallest needle of the aspirator, the operation being performed antiseptically.

It is now six years sinee the publication of the last edition of this work, and during that time no disease has more especially commanded my close scrutiny than this, and yet, in an amended edition after that lapse of time, I find myself unable to offer any improvement upon what was written then! 


\section{CHA PTER XLVII.}

\section{OVARIAN TUMORS.}

Witur the last twenty-five years important advanees have been made in our knowledge of those pathologieal derelopments ealled tumors. The progress, which about the beginning of that period Rokitansky inaugurated, has since enlminated in the eminent labors of Virchow. Had we now reached a standpoint which gave eomplete satisfaction to pathologists, it would be an easy matter to offer a simple digest of the whole subject for the contemplation of the student. But this is far from being the present aspect of the subject. Changes are constantly being made in nomenclature ; views as to pathology are daily being altered ; and elassification is in consequence undergoing frequent alterations. This presents evident difficulties for one who, not being entitled by personal researches to original views, is foreed to rely upon the workers in pathological anatomy for his authority. All who have really studied the subject of tumors will almit the force of this statement, and from such I have no fears of a severe judyment upon the table by which I here endeavor to display at a glance the varieties of ovarian tumors. I am fully aware of its imperfections, but 1 know of no better method for simplifying a diflicult subject so as to make it easily comprehensible to the general reader, and none which will prove so useful in elinical investigation.

For the purpose of facilitating the clinical study of ovarian tumors, it is probably best to consider them under two heads: first, those which are solid and free from eystic development; second, those which are eharacterized by such development.

The following table presents at a glance these genera and those of their species which are met with at the bodside, not as pathological curiosities, but as diseased conditions requiring surgical interference. Certain forms which are rarely met with, even by the most industrious morbid anatomists, will receive casual mention, bnt I cannot believe that good arises from blenling these in description with others which are constantly presenting themselves to the attention of the practitioner. I also introluce here a table presenting other pelvic eysts resembling ovarian cysts so closely that a differentiation is exceedingly difficult. 
Ovarian $\left\{\begin{array}{l}\text { Solid tmmors } \\ \text { Cymors } \\ \text { Cystic tumors }\end{array}\right.$

Pelvie eysts closely resembling ovarian
( Carcinoma ;

I Fibrona.

Cysto-carcinoma :

('ysto-fibroma or silroma ;

Dormoid cysts;

${ }^{1}$ Orarian cysts and cystomata.

Cysts of broad ligaments ;

Parasitic eysts ;

IIylro-salpinx ;

Lterine cysts and fibro-cysts;

Encysted peritoneal dropsy;

Subperitoneal cysts ;

Cysts connected with the spinal cord;

(Renal, splenic, and lepatic eysts.

Under the head of solid tumors, enchondroma and osteoma have been reported, but the authenticity of the few cases noted is very doubthil. Under that of cystic tumors might be mentioned hydrops folliculorum, which sometimes creates a sac as large as a child's head, and Rindfleiseh describes a rare form of cysto-colloid degeneration of botl ovaries growing larger than a man's fist, to which he applies the name of struma ovarii. These affections, of great interest to the pathologist, I have not thought it best to classify with the more frequent forms of ovarian disease which commonly call, not for diagnosis merely, but for surgical interference, for fear of uselessly complicating the already difficult subject of diagnosis.

Curcinoma.-CThe ovary may be affected by several varieties of cancerous deposit, which are here placed before the reader:-

1. It may be affected by true scirrhous degeneration. This form of cancer is less common than others, occurs usually after middle life, and may create a tumor of large dimensions. It develops slowly, and presents the physical appearance of scirrlious disease in other organs; it may be a primary malignant development; or it may occur in the ovary secondarily, its primary development having been previously recognized in some other part of the system.

2. The ovary may be the seat of medullary cancerous deposit, which may originate in the vesicles of De Graaf; in a corpus hiteum, as Rokitansky once saw it do ; or in the stroma of the organ. Distention sometimes causes rupture of the tunica albuginea of the ovary, and then exuberant medulary growth develops in contact with the peritoneum and abdominal viscera.

1 A cyst is a collection of fluid developed within a pre-existing sac; a cystoma one which creates its own sac. 
3. Seirrhous or medullary eancer may alone or united attack the wall of a cyst, and develop either as an endogenous or exogenous production. The cancerous matter so eompletely invades the cyst walls in some eases as to make it appear that eystic degeneration lad oceurred secondarily to its deposit.

4. From the wall of a cyst, vaseular, arborescent villi may project, lining the cavity, and, in time, filling and distending it so as to eause the muture of its walls. 'Then the exuberant cancerous element develops in immediate contact with the peritoneum, and produces either a dangerous peritonitis or abundant abdominal dropsy.

With this form of eancer colloid degeneration is often associated, when it constitutes that variety which has been deseribed by Cruveillier as alveolar cancer.

The recognition of the faet that the ovarian disease which affects a patient partakes of the elaraeter of any one of the forms of cancer just enumerated, must ever be a matter of great moment, for upon it must depend not only our prognosis, but in some cases the determination to adopt or reject the operation of ovariotomy. Even if the ease be one of maligniunt disease, however, operative procedure may aecomplish good by prolongattion of life.

The symptoms which generally point to the malignant charaeter of an ovarian tumor are these :-

1. The rapid development of a solid tumor in an ovary, with-

2. Marked depreciation of the strength, vital forces, spirits, and general condition of the patient.

3. The oceurrence of cedema pedum and spanamia with a small tumor, which are consequently dependent upon a general blood state, and not the results of pressure by the tumor.

4. Lancinating and burning pains through the tumor.

5. Cacheetic appearanee.

6. The occurrence of ascites without evidences of eirrhosis or other hepatic disease; organic disease of the kidneys, or heart; or ehronic peritonitis.

Cystic degeneration of the ovary sometimes advanees with great rapidity, and is aecomplanied in its course by rapid emaciation, narked physical prostration, ascites, and a cacheetic appeamee. It may be asked whether a ease thus eomplieated would not present the very conditions which have been pointed out as furnishing grounds for the diagnosis of malignant disase. Unquestionably it would. Let it be remembered that while these symptoms are mentioned as valuable aids to diagnosis, I do not pretend to maintain that they will always enable the diagnostician to avoid error. Arain, in eiting ascites with a solid tumor as a most important symptom of maligrnant ovarian disease, I do not allude to slight or even moderate effi-ion with a large growth, lut a markedly disproportionate amount of fluid, a great deal of abslominal effusion with a very small tumor. 
Besides the condition just mentioned there are two others which may ereate dillieulty in diflerentiation from ovarian eancer : one is preconancy in the mildle or latter months, complicated by peritoneal effusion; the other, a nterine fibroid existing with attendant dropsy. The first maty generally be known by its characteristic symptoms; while the second, althongh it might be recominzed by the physical and rational signs of uterine fibroids, would rery likely give considerable trouble in diagnosis.

When diflicult and obscure eases present themselves in which a positive diagnosis becomes impossible by ordinary means, paraecntesis, explorative incision, or both, should be resorted to rather than that the patient should be deprived of the prospeet for eure held ont to her by ovariotomy. Very of ten the most doubtful ease may be satisfactorily settled by evacuating the abdominal effusion, and passing the index finger or the hand through a small opening in the peritoneum so as to touch the morlsid growth. In certain rare cases eren this would not suffice to remove all doubt.

by the means mentioned I lave suceeded in making a correct diagnosis in many cases of true ovarian cancer, but in relying upon them I have twice fitiled entirely, pronouncing as cancer what afterwards turned out to be benign growths. Cystic ovarian tumors may unquestionably produce excessive ascites and all of the other rational signs which I have here recorded as evidences of cancer.

Fortunately we are not ealled upon now to rely upon these imperfect means. A very valuable addition to our means for diagnosticating carcinoma of the ovary has within the last three years been put at our disposal by Drs. Foulis of Edinburgh, and Thiornton of London, each working without knowledge of the other's labors. They have found that if the peritoneal fluid which has been in contact with malignant orarian tumors be examined microscopically, it will be very generally found to contain germs which will announce the fact and put us on our guard as to the nature of the disease. Their statements may be found in the British Medieal Journal for July and September, 1877, and are well worth careful study.

Fibroma, or Fibrons Tumor._. This form of tumor is rarely met with in the ovary, and never attains a very great size. Kiwisch reports two cases, one the size of a child's, and the other the size of a small adult head. Dr. Farre discredits the reports of large ovarian fibroids which are upon record, and believes then to have been in reality either cancerous tumors or growths connected with the uterus, which so encroached upon the ovaries as to seem to have sprming from them. Periuterine fibroids which spring, not from the uterus itself, but from the extension of uterine fibres into the broad and utero-sacral ligaments, have probably often given rise to errors in reports of such tumors. Many of the reported eases of ovarian fibroids lave likewise been due to confusion of this form of tumor with cysto-tibroma. When the disease does affect the ovary, it differs in no essential degree from the same affection of the uterus, except 
that pedieulation does not occur as in the latter organ, and that the growth of the tumor is mueh more liniterl.

The reader must be reminded that these remarks apply to the pure fibroid and not the fibro-eystic ovarian tumor, which may attain an immense size, and is always to be regarded as a serious disease. They likewise apply to the development of fibroid tissue into true fibromata, for in the walls of cystic and cystomatous grow ths fibroid tissue is commonly developed.

Virchow belicves that of the well-authenticated cases of true orarian fibroma, the size has varied between that of a hen's egg and that of a elild's head. Larger ones he regards as cases of cysto-fibroma. Forster reports, however, one case in which the tumor was as large as a man's head; and Seanzoni and Van Buren similar ones. Dr. Peaslee ${ }^{1}$ records a case where a tumor of this hind of equal size was removed by me in 1864 , but I cannot agree in his elassification. It was, according to my view, a true eysto-fibroma. The following was the report of it published soon after its removal: "The tumor, when placed upon a table and palpated, was so deecptive in its apparent yielding of fluetuation, that it was eren then declared to contain fluid which had not been reaehed by the trocar, and this view was entertained until it was bisected. It was found that it consisted of loose fibrous elements, forming numerous loculi, about the size of a hickory-nut, which were filled with a honey-like material. After section had allowed what was computed as about three pounds of this material to flow away, the tumor weighed a little more than fourteen pounds."

Within the last year, however, I have removed an unquestionable ovarian fibroid as large as the largest man's head.

If in one of the solid tumors just mentioned eysts develop themselves as essential parts of the growths, we give them the names of cysto-fibroma, cysto-sarcoma, or cysto-carcinoma.

Cysto-curcinoma.-The formation of fluid eollections may oceur with cancer of the ovary in three ways: 1st, cysts may develop in the structure of scirrhous and medullary eaneers, as they do in that of sareomata; $2 d$, a fluid or eystic tumor, primitively benign, may develop malignant material in its eyst-wall ; 3l, a large medullary cancer may, by cell infiltration and disintegration at its centre, form within itself a mass of fluid. The condition may consist then in cancer complicating eystic degeneration or in eystic degeneration complieating cancer. According to Scanzoni, the cancerons mass may deselop in the tisue of the cyst walls and projeet either internally or externally, or it may grow from the walls by pediculated or sessile tumors filled with medullary material, which are soft, tumefierl, and very vascular. In the same tumor both colloid degeneration and medullary cancer may be met witl. 
The ovarian limits do not always confine these fatal growths. At times they pass them, and aflicet the peritonem or other neighboring parts. This tendency to eceentric development accomts for the protuberances, the size of the fist, so often serving as a means of diagnosis of oxarian cancer. The distinguishing chatracteristic of cystic eancer is its rapillity of development. In a tew montlss it often reaches a size which sarcoma or eren eystic deageneration would not attain for several years.

The frequency of these and other ovarian tumors may be judged of from reference to some statistics accunulated by Scanzoni, which lave been already referred to :-

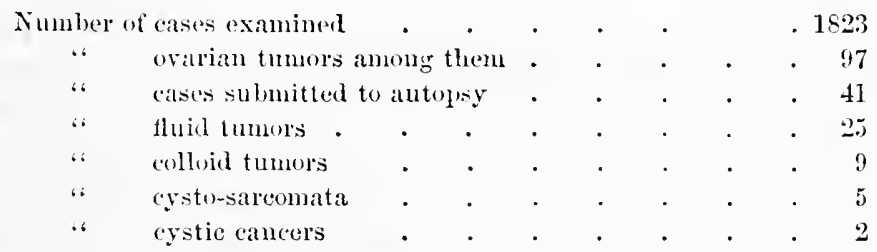

From this it will be seen that the affection which we are now considering is arer than sareoma and very much rarer than colloid or alveolar de. grenelution.

Surgical treatment holds out little hope in these cases. According to my experience, ovariotomy performed npon patients thus affected almost invariably results fitally. Nevertheless, even as a forlorn hope, its propriety should be considered.

The prognosis in this disease is graver, and the limit of life shorter than in any other affection of the ovaries.

Cysto-fibroma or Cysto-surcoma.-Between sarcoma and fibroma of the uterus a very broad distinction is now made by pathologists and clinicists, but at present these two terms are in reference to the ovaries used synonymously. That they have really been so for a long time in works upon gynecology, is evident from an examination with relerence to the subject. Thus Scanzoni defines fibrous tumors of the ovaries to be "tumors formed of cellular tissue," and cysto-sarcomata as "tumors composed of cellular tissue in the middle of which are formed more or less considerable cavities." Peaslee refers to cysto-fibroma, and makes no mention of cysto-sareoma, while Barnes and G. Braun treat of eysto-sarcoma without alluding to cysto-fibroma. It must be rememberel that, even in reference to these affections in general, Rindfleisch says, "I cannot separate the fibroma from the sarcoma; . . . we distinguish three principal varieties of sarcoma, namely: round-celled sarcoma, spindlecelled sarcoma, and fibroma." "By cysto-sarcomata," says Lüeke, "those large tumors are especiaily meant which consist of solid masses, papillary 
proliferations, and numerous elosed and open cavities, such as are found in the mamme, ovary, and testicle." In some cascs the first step in disease is adenoma; then, this being affected by sarcoma, which undergoes cystic degeneration, the result is a combination to which Lücke gives the name adeno-cysto-sarcoma.

These cysts often grow to a very large size. In Mr. Wells's ninetyfirst case of ovariotomy the operation was preceded by tapping, which removed thirty-eight pints of thin, dark fluid containing much cholesterine. Dr. Fox, who examined the tumor, states that the cysts which were emptied by tapping represented one-balf the bulk of the mass, which. even after this, weighed thirteen pounds. The structure of the solid portion of the tumor was very complex, the cysts being of every variety of size and grouped together in great confusion. In some the fluid was clear, and in others like pea soup. The proportion between the cystic and fibrous elements governs the character of these masses to such an extent that it is often difficult to classify them. When the former is much in the ascendency, the growth resembles a fluid tumor; when the latter predominates, it appears perfectly solid.

The contents of the cyst may be colloid, purulent, serous, or sanguinolent, and blood is sometimes effused between the fibrous interstices so as to cause a rapid increase in size. The cystie sarcoma sometimes attains very large, or, as Kiwisch expresses it, " colossal," dimensions.

In Mr. Wells's case just alluded to, the tumor filled the whole abdomen, and extended two inches above the ensiform cartilage by its upper margin, but its growth was not nearly so rapid as that of pure cystic disease. This case had lasted for seven or eight years, slowly inereasing until 1863, when it dereloped at the following rate: June to July, one inch; July to August, one inch; Augrist to September, one inch; September to October, laalf an inch; October to November, one inch.

Should one or more large eysts be detected, relief to many of the synuptoms arising from mechanical interference may be obtained by tapping. The results of the operation are, however, more dangerous than in fluid tumors, hemorrhage and subsequent inflammation often taking place in consequence of it. Another disadvantage attending it is that the operator is more limited as to choiee of the point to puncture. Besides this means our efforts at palliation must consist in relieving symptoms as they oceur, in giving support to the mass by an abrominal bandage, and in enjoining quictude during me'nstrual epochs.

Thor only curative treatme'nt with which we are acquainted that arails anything for this form of tumor is removal by ovariotomy. The operation is not so fromising as in eatse of cystic degeneration, and should not be mulertaken until the evil results of the disease and its tendency to destruction of life are fully manifested. It requires, generally, the long abdominal incision, and is very likely to be rendered diffieult by adhesions; still 
the prospeet of sueeess is such as to render the operation in many eases of grave prognosis not only almissible, but incumbent upon us.

Dermoid Cysts. - In varions parts of the boly, the orbit, the floor of the: mouth, the brain, the eye, the anterior mediastinum, the lungs, the mesentery, the testicles, and the ovaries, a peenliar eyst containing fat, teeth, latir, cholesterine, cartilage, and bone is sometimes found. Its wall gives evidences of the existence of sweat glands, sebaceous follicles, papillar, and an investing epithelium, so that the microseopic appearances of the wall resemble closely those of the skin. Many fanciful theories have been indulged in as to the origin of these peculiar growths. It is now generally believed that they are the result of an irregular and ecentric development of the tissues of the foutus during intra-uterine life. It was Lebert who advanced the theory that from the elements present, spontameous generation of a portion of skin oceurs, and this being given, we have, as Dr. Farre expresses it, "the basis out of which many of those products spring."

M. Pigné has analyzed eighteen cases with reference to the period of life at which they were found, with the following results :-

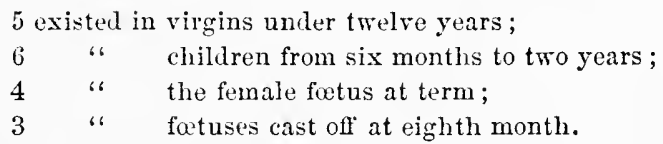

Dermoid tumors vary in size from that of a hen's egg to that of the adult heal, but very rarely grow larger. They are hard and generally globular. One ovary is usually affected, and by only one tumor; but instances are on record where a single ovary contained a large number. They usually consist of fat, long hairs, teeth, skin, and traces of bone intermixed. The teeth are usually imbedded in the cyst wall or attached to pieces of bone, and are sometimes very numerous. Sclinabel records a case in which they exceeded one hundred in number, and Ploucquet ${ }^{2}$ one in which they amounted to three hundred.

Histories of such cases are so rare that I transfer the following from Prof: Kiwisch's work: "A girl, serenteen years of age, was attacked with a swelling of the left ovary which, after twenty-one years, measured four ells in eireumference, and reached below the knee. After her death, which took place in her thirty-eighth year, it was found that the sac alone of the ovary weighed fourteen pounds, and contained forty poumls of a thick, adipose, honey-like mass, which was mixed with many hairs of different lengtlıs, among which curls were found two inches long, and as thick as a thumb, very like elf locks; the internal surface of the sac was set with short hairs. There were also found eight bony concretions of irregiular shape, one of which was seven and another ten inches

1 Kiwisch, op. cit.

2 Becquerel, op. cit. 
long, and about two incles broad; the form of one of these bones was polygonal, ant set with six molar teeth and one incisor, and nine separate bones were present besides. 'The teeth had the size, perfectness, and firmmess which they generally have in a girl twenty years of age."

Although in themselves innocuous, and not likely to increase rapidly or to attain any great development, they sometimes set up very serious and even fatal disturbance by one of three methods: by creating suppuration and abscess on account of the irritation kept up by a foreign mass; by perforation and discharge into the peritoneum; or by the cyst which contains the dermoid elements secreting fluid and changing its character to that of a fluid tumor. Out of one hundred and fifty ovarian tumors removed by me, four were large cysts having as bases dermoid tumors contianing fit and hair, and in one case a small fragment of bone. In these cases the cysts containing the dermoid elements were not in communication with the large eysts filled with fluid colloid, which constituted the mass of the tumor. In two cases the tumor was nearly removed when a cyst filled with fluid, fat, etc., was opened into. The large cysts appeared exactly like ordinary multilocular cystoma.

Very often they are discovered by aceident only. Physical exploration reveals a hard, round mass, painless upon tonch, and, unless the size present it, perfectly movable. When of smail size they require no special treatment, unless, as once happened in a case of Dr. Ramshotlam's, they obstruct parturition. When the eyst wall undergoes suppurative action and the mass points, it should be managed upon the same principles as a pelvic abscess. When a large eyst or cysts develop, they should be treated as the ordinary cystoma orarii.

We have now reached the proper point for the consideration of the subject of orarian cysts and cystomata, which ealls, on aceount of its faramount importance, for the elosest investigation on the part of the gynecologist. That it may receive this I leave its sturly for a separate chapter. Inautime, before leaving this part of our sulject, it appears best to me to saly a few worls upon colloid degeneration of the ovary, an affection which at present holds in the minds of many a doubtful position. as to malignancy. For a long time the generally accepted opinion with

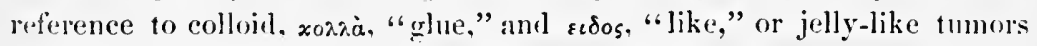
was that they were of eancerous nature, but hoth in their minute structure and in their clinical fieatures they are so far removed from true malignant diwase that the belief is becoming very prevalent that they are not necessarily of that eharacter. This view is now adopted by Drs. Farre, G. IJewitt. Kiwiseh, Collis, ${ }^{1}$ Becquerel, and most of the more recent writers "upn the sulyject. In speaking of ovarian colloid tumors, IIewit remarks: "The latter designation (eolloid cancer) is not a good one, for an attentive 
consideration of the facts leads to the conclusion that the atliction is net cancer" at all." M. Beequerel seems to have placed the qunestion in it: proper light when he says, "Several diseases have bern contonded under the indetinite name of colloid ayts; it is therelore essential, befonce anlvancing, to distinguish these diflerent varieties. We slatl now emleavor to do this after them (Virchow and Scanzoni), previonsly remarking that muler the name of colloid matter some have not at all intended to signify a cancerons product, while others have assigned it such an origin." Virehow strongly expresses himself upon this point. In speaking of the diflerence botween the form and nature of growths, he says, "You may therefore say, eolloid eancer, colloid sareoma, colloid fibroma. Ilree colloid means nothing more than jelly-like." Ite then gross on to remark that no confision should exist between sneh growths as colloid eancer and colloid degeneration of the thyroid gland ats to pathologieal significance. Ilis description of the so-ealled alveolat eaneer is thus quoted by beequerel: "Small pouches, which are filled with gelatinous matter and whose walls are lined by a layer of epithelium, are found in the parenchymat of the ovary. These vesicles develop in every direction, but more especially at the periphery of the ovaries, where they form masses of irregular sliape. Some of them are isolated, while others are grouped together in the following mamner. The walls of these vesicles disappear by atrophy of cellular tissue, when they are only formed by their epithelial lining. This becomes infiltrated with fat, and the walls forming the comeetion are easily ruptured. Those of the large cyst remain intact and become hypertrophied. . . . . . In other eases the vesicles rupture by over-distention; from this results hemorrhage, and hlood is found in the vesieles." Kiwisch describes it as a breaking up of the stroma of the ovaries into cellular cavities, alveoli, elosely aggregated together and inclosing a jelly-like, semifluid mass. By others it hals been likened to a sponge or a honeycomb.

It is sate to conclude, from the present aspect of the suliject, that, while colloid deposit may eoexist in the ovary with true cancer, the peculiar breaking up of the stroma into alveoli whieh we have just deseribed is not in itself a malignant affeetion. but one which seems to eonstitute a eonnecting link between cancer and the benign degenerations. It frequently complicates eancer, sarcoma, and fluid tumors. "We have observed," atys Kiwisch, "alveolar degeneration of eonsiderable extent remain in the system for a long series of years, withont any remarkably bad effects."

Should a large eyst be discovered anywhere, and the size of the tumor require diminution on account of interference with surrounding parts, paracentesis may be practised; but in a pure alveolar tumor, such an aceu- 
mulation is not common. Lnder these eireumstances, if the disease steadily adrance and the constitution suffer in consequence, we should be eneouraged by recognition of its non-malignant nature to perform orariotomy.

\section{A P E R XLVIII.}

\section{OVARIAN CYSTS AND CYSTOMATA.}

Turs disease consists in the derelopment of cysts within the orary without coincident growth of solid elements, such as fibroma or carcinoma. Of all the varieties of ovarian tumor it is the most commonly met with, and hence for the practitioner it is the most important. It is fortunately, too, that which above all others is most susceptible of relief by surgery.

Pathologists are still at variance with reference to the origin of ovarian eysts. While some with Wilson Fox agree, that "all the forms of cysts met with in the ovary originated from the Graafian follicles, and that the multilocular forms are not the results of any special degeneration of the stroma;" others, like Wedl, doubt their follicular origin entirely; and others still, with Rindfleisch, admit two different sources of cystic formation-one, the follicles, the other, the interstices of the stroma.

"In many cases," says Rokitansky," "they are undoubtedly formed from the Graafian follicles, and it appears that an inflammatory process is farticularly liable to give the first impulse to this metamorphosis. They are probably, however, as often new formations from the beginning."

"It was formerly very generally supposed," says Wedl, " that the eysts in the parenclyma of the ovary originated in the Graafian follicles, but no direct proof of this was ever given."

Liicke, ${ }^{4}$ one of the latest and most reliable authorities, takes even stronger ground against it than Wedl did. After quoting Rokitansky's views he goes on to say: "But we have already stated that cysts ean only form in the connective tissue, and only after a long continued irritation; and that it does not look at all probable that such eysts should form by spontaneous exudation. As far at the cystoids of the ovary are eoncerned, theory certainly is not almissible. These tumors are essentially cysts from broken down tissue."

While experimental pathologists are testing this question, we may for

1 Med. Chirurg. Trans., 1864.

2 Op. cit., p. 249.

3 Will's Path. Ifistol., p. 462.

' (hapter on Tumors in Billruth and Pitha's Nanual of General and Special Surgery. 
the time assume that there are two entirely different pathological processes by which true ovatrian eysts are generated :-

1st. 'The follicles of be (inat become filled with a colloid material, due to abnormal secretion from their walls, and, according to lonkitansky and Rindfleisch, probably the result of inflammatory disease of the wall of the follicle. This is not the insignificant hydrops folliculorum which creates small eysts, but a true colloid degeneration of the follicle of mueh more serious import.

21. A development of cysts may oecur in the stroma of the ovary withont connection with the follicles. In this case, according to Wedl, "the cyst consists in an cxcessive augmentation of volume of the areola of the areolar tissue and of the papillary new formations conposed of connective tisine." In this view Wahleyer coincides in his excellent treatise upon ovarian tumors."

Lïcke nrakes Rokitansky's view as to the mode of formation of these cysts in the stroma so clear that I use his words instead of quoting the original: "Cysts may also be generated by exudation into new formed comective tisste-the fluid distending the different bundles, and as they intersect in all directions, the globular form is the result; thus numerous small spaces communicate with each other, from their walls new cysts start, and thus very complex tumors can be formed." Rindtleisch ${ }^{3}$ aceepts both of these sources of ovarian eystoma in the following words: "An exact investigation also proves that at least the majority of all orarian cysts proceeds from Graatian follicles; while, upon the other hand, until further information, a different mode of origin must be accepted for a iroup of cysts, although not so large, yet, at the least, just as important."

The development of a substance resembling the glandular element of the ovaries, and constituting the nidus of cysts, has recently attracted considerable attention. In $1862 \mathrm{Mr}$. Speneer Wells proposed for this the name of "adenoma" or "allenoid tumor." Further investigations appear to have satisfied pathologists that a degree of adenoid development occurs in every true ovarian cystoma. Mr. Wells limself, in his recent work on Diseases of the Ovaries, considers under the hearl of adenoid tumors all simple, multiple, and proliferous cysts; and Delafield" declares, that "in the ovaries most of the compound eysts are adenomata, with dilatation of the follicles." Klebs strongly advoeates this view. As adenoma is then a frequent element of ovarian eystomata, it requires no separate and special consideration.

Until a recent period considerable attention has been paid to the character of ovarian cysts, based upon the existence of a few and of many cysts. Pathologists are beginning to lay less stress upon this feature than

I Pp. cit., p. 515.

3 Op. cit., p. 515.
\& Walleyer, Eierstock und Ei., Leipzig, 1870 .

4 Pust-mortem Exaninations and Morbid Anatomy. 
they formerly did. Rindfleisch declares that all are multilocular in the beginning, and that they become paucilecular, and, even in rare cases, unilocular, by fusion of adjacent cysts by breaking down of diviling septia. It must be admitted, however, that there is one class of tumors, the distinguishing characteristie of which is the existence of a few cysts only, one or two of which are nsually very large, and another which is specially marked by numerous small eysts. The first constitutes the olygocystic tumor of Peaslee; the latter the polycystic tumor; or, as they are likewise styled, paucilocular and multilocular.

Each class has usually certain well-marked features, the recognition of which is of value in a practical point of view. The first is thus described by Rindfleisch: "Multilocular tumors up to the size of a man's head, or unilocular eysts up to two feet in diameter, with smooth, but little adhering surface, and comparatively thick, fibrinous walls, which are very commorly corered at their inner side with ciuliflower-like or more tuberous papillary excrescences." This is the form of tumor which he regards as due to colloid degeneration of the Graatian follicles.

The second variety he describes in these words: " $\Lambda \mathrm{t}$ the place of one ovary (the other, as a rule, is healthy, while in the first form the disease is often of both sides) there lies a tumor, not infrequently far above the size of a man's head, which is composed of several large, and very many smaller, and even the snullest eysts. The larger eysts are often constricted, and exhibit, at these places, the remains of former partition walls in the form of fenestrated membranes, or ranified vascular strands, which evidently succumb to a gradual maceration. The surface of the tumor is probably always connectel with the peritoneum by a large number of inflammatory adhesions, upon which larger renous ressels run to and fro. The walls of the crsts are comparatively thin, and easily torn." These tumors he regards as due to colloild degeneration of the stroma.

While the statement of Rinufleisch that no "fundamental simnificance" "an be attributed to the unilocular or multilocular character of these tumors is correct from an anatomical point of view, it is not the less :o that the practitioner is greatly aided in prognosis and treatment by a recognition of the difference between the two forms of tumors just described; and also of that which exists between them and another, which, being composed of both cystic and solid (dements, receives the name of compount. We, therefore, proced to consider the virieties of these growths in reference to the points mentioned, and to recapitulate suecinetly what has been alrealy saicl.

Ovirian eysts are characterized hy three marked features: first, eysts with one or very few large comparturuts; second, cysts with a great many small compartments divided by thin cyst walls or thick trabeenlar; and third, cysts which are composed of solid and fluid elements in varying 
proportions. The first constitute the chass styled the monocystic, uniloculat, patuciloculat, or olygocystic tumor; the secoml, that known at the multilocular or polycystic tumor ; and the third that which is commonly styled the compound ovarian tumor. "All eystoids are multilocular" at the comneneement," says Rindfleiseh, but milocularization he declares is especially fresurent in those tunors arising from colloid degeneration of the Ciratian resieles. A true monocyst is rare, though it may grow to the size of the uterus in the ninth month of pregnancy. Kivisel ${ }^{1}$ has met with one whose contents weighed over forty pounds. In the compound tumor, eysts having formed in the solit tissue, the presence of solid and thuid elements is detected by examination. These eysts result chicfly from softening of tissue, or, as it is expressed, by licpuefaction. " $\Lambda$ s soon," says bilhroth, "ats the new formation hats separated into sac and fluid contents, in some eases a secretion from the inner wall of the sac begins, so that the eyst from liqurefaction becomes a secretion or exudation cyst and thus grows."

Dr. Noeggerath has been led to assume, by his microscopical investigations, that "the proliferating cystoma, or adenoma-cylindro-cellulare, the origin of which is at the present time generally associated with the formation of Ptliiger's ducts, is to a large extent the result of a degeneration of ovarian bloodvessels.

These alterations consist-

1st. Of a hyaline degeneration of arteries and veins.

2d. Of a cell proliferation and secondary softening of the media of arteries.

3d. Of an endarteritis destruens.

4 th. Of an alteration of all the elements constituting the large arterial sinuses, and secondary enlargement of the same.

5th. Oí a metamorphosis of eapillaries into epithelial tubes."

The walls of ovarian eysts consist of a corering of peritoneum, the proper tunic, tunica albuginea, of the ovary, and an epithelial layer. The peritoneum sometimes undergoes great hypertrophy, in rare eases being half an inch thick.

The size to which ovarian cysts will grow is truly wonderful. It has been already stated that unilocular or monocystic tumors are rarely seen of very great size, but instances are on recorl of multilocular tumors containing orer one liundred pounds of fluid, and Dr. Copland, in the Dict. of Pract. Merl. tells of an instance in which five hundred pints of fluid were drawn off by repeated tappings, in twelve montlis.

One or both of the ovaries may be affected, the right being that most frequently selected by the disease. The comparative frequency with 
which the right and left ovary are affected is shown by the following table :-

\begin{tabular}{|c|c|c|c|c|c|c|c|c|c|c|}
\hline \multicolumn{7}{|c|}{ Authority. } & No. of cases. & $\begin{array}{l}\text { Right side } \\
\text { aflected. }\end{array}$ & $\begin{array}{l}\text { Left side } \\
\text { atfected. }\end{array}$ & Both sides. \\
\hline $\begin{array}{l}\text { Safford Lee } \\
\text { Chéleau. } \\
\text { Scanzomi. }\end{array}$ & . & : & $\begin{array}{l}\dot{ } \\
\dot{ } \\
\text {. }\end{array}$ & $\begin{array}{l}\cdot \\
\text {. }\end{array}$ & $\begin{array}{l}\cdot \\
\cdot \\
\cdot\end{array}$ & $\begin{array}{ll}\cdot & \cdot \\
\cdot & \cdot \\
\cdot & \cdot\end{array}$ & $\begin{array}{r}93 \\
215 \\
41\end{array}$ & $\begin{array}{r}50 \\
109 \\
14\end{array}$ & $\begin{array}{l}35 \\
78 \\
13\end{array}$ & $\begin{array}{r}8 \\
28 \\
14\end{array}$ \\
\hline
\end{tabular}

Contents of Orarian Cysts. - This subject has been exhaustively investigated by Scherer and Eischwald. By the latter it has been so minutely dealt with that little is left to be desired as to the chemistry of such fluids.

These contents vary very much, between a clear, albuminous, serous fluid and a thick, gelatinous material which will flow througl no canula, and has to be manually removed. The speeific gravity may be as low as 1017 , though usually it is 1018 or 1020 . The most important chemical constituent is an albuminate, termed colloid, which is usually more dense in polycystic than olygocystic tumors, and denser in small olygocysts than in the same after laving assumed a large size. Tapping appears to increase the density of this fluid in olygocysts.

Accorling to Eischwald, two ehemical transformations go on in the fluids of cysts simultaneously. Colloid material changes into muco-peptone, while the albuminates transuding from the blood are converted into allumino-peptone. $\Lambda$ species of digestion of the raw material goes on muler the lieat of the body, as Rindfleisch expresses it, and consequently the larger and older the tumor the more fluid are the contents likely to be. Fischwald found these fluids chemically to consist of the following elements :-

Of the mucous order-

Substance of colloid particles ;

Mucin;

Colloirl substance;

Mruco-peptone.

Of the albuminoms order-

Albumen (and fibrin);

Paralbumen;

Metalbumen ;

Allumino-peptone (and fibro-peptone).

As an example of the quantitative analysis, the following from one of Eischwall's cases will serve. 1000 pruts contained-

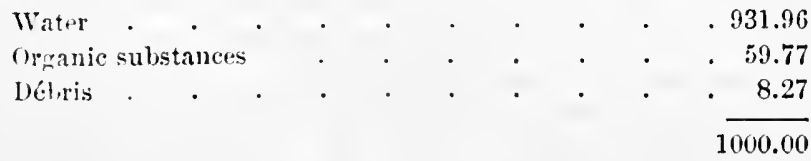

1 Würzburger Medizinische Ziitschrift, 1864. 
The débris (8.27) containol-

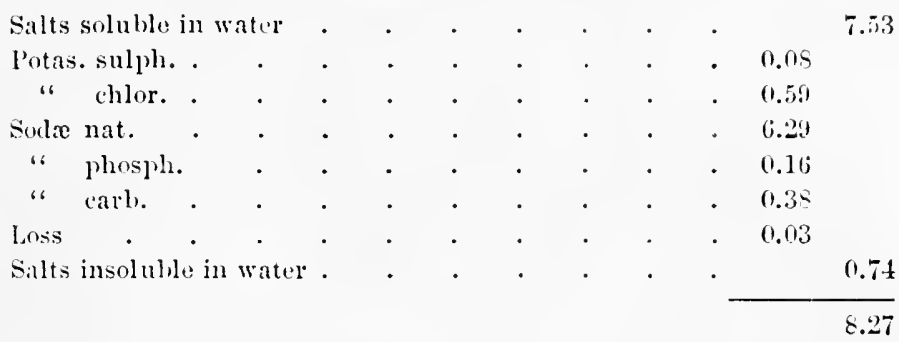

Test for. Paralbumen._-Leave the fluid at rest in a cool place, filter or decant, and thus separate sediment firom supernatant fluid. l'alss a stream of carbonic acid gas through this fluid, and instantly a precipitate of fine floceuli of paralbumen will occur.

Test for Metalbumen.-Digest another part of this fluid with absolnte alcohol for three days. Filter off the precipitate, and heat with distilled water. Filter again, and metalbumen may be precipitated by sulphate of magnesia. Paralbumen is preeipitated from this fluid by a few drops of dilute acetic acid and redissolved by an excess.

To the naked eye the fluids of ovarian cysts present various appearances, as they are tinged with blood or pus from hemorrhage or suppuration of the cyst walls. The varieties generally met with are the following: a light colored fluid like larley water : a light brown fluid like infusion of linseed; a dark red, bloody looking fluid; a greenish-yellow, semi-solid gelatine; a purulent fluid of very offensive character closely resembling pea-soup in appearance; rery rarely an intensely black fluid; and in dermoid cysts a grumous, gruel-like mass.

Does a true orarian cyst large enough to call for surgical interference, that is to say, larger than the size of a child's head to which hydrops follieulorum sometimes attains, ever contain fluid free from albumen? This is evidently a question of a great deal of importance. Wells and Barnes make three groups of ovarian fluid, the first of which they declare are deroid of fat and albumen. "Heat and nitric acid," says the former, "will neither coagulate nor precipitate them." W. L. Atlee relied upon absence of albumen as a sign that a cyst is not ovarian, and the following interesting ease reported by J. L. Atlee will show the estimation in which this point is held by lim.

"I operated upon Mrs. MI., aged over fifty years, in October, 1870. She had labored under abdominal enlargement from the presence of a thuid for several years, and had been tapped about twenty-seren times, filling rapidly after each operation. After the last two or three tappings a small tumor remained in the right iliac and pelvic regions; but at no time could albu-

1 Dis. of Ovaries, Am. ed., p. 92.

2 Essay by Dr. Drysdale, Trans. Amer. Med. Asso. 
men he detected in the fluid by the ordinary tests of heat and nitrie acid ; hence I diagnosed the ease to be one of serons cyst attached to the broad ligament. The presence of the tumor, as large as a turkey's egg, in the right iliac region, an unusual thing in serous cysts, cast a doubt as to its true character; but the inability to detect albumen by the above tests decided me against the operation, and the patient was sent home. Under these ciremustances, a portion of the fluid obtained from the last tapping was sent to Dr. Drystale, who gare a very decided opinion that the tluid was from an ovarian eyst. Cpon the strength of this opinion I told the friends of the patient that I wonld operate if she filled again.

"Accordingly, on the 14th of October, 1870, I removed a cyst weighing, with the contained fluid, fifteen pounds, and of an unusual charaeter. The upper half of the eyst was very thin and of a scrous nature. Below the umbilietus the eyst was much thicker, and, deseending to the pelvis, proved to be the right ovarim, having one large eyst filling the abdomen above, with an aggregation of very small eysts constituting the iliae and pelvie tumor:

"The peculiarity of this case consisted in the rupture, probably at an early period of the disease, and before I saw her, of the tunica propria, or albugineous coat of the ovary, leaving the peritoneal covering intact, and of suflicient strength to retain, not only the small portion of the ovarian secretion, but of the serum secreted by the peritoneal coat. This also accounted, in some measure, for the very rapid filling after each tapping."

The correctness of the explanation given by Dr. Atlee is open to doubt, but his reliance upon presence of albumen as a sign of ovarian cyst is fully shown. Peaslee ${ }^{1}$ expresses himself in these words, "the fluid of an ovarian cystoma will probably always be found to contain albumen if it be limpid enough to flow through the fine tube of the exploring trocar." I can safely say that I lave nerer met with a true ovarian fluid which did not eontain alloumen.

The solid elements of the fluid of orarian cysts consist of the results of hemorrhage, and descuamation and fatty degeneration of epithelial strueturcs. In them are found cholesterine, fat globules, blood corpuseles, and pigment cells.

Nicroscopiral Appearance of Orarian Fluids.-The thinner, serous fluids present in comparison with those of eolloid character few cellular elements. In the latter, under a power of from 300 to 5.50 Eisehwald $^{2}$ found such an amount of morphological elements that the fluid had to be diluted with water hetore it eould be examined. Ile then found fatty elements of various size; round cells, some serrated; large, colloid cells; round cells similar to the pyoid bodies of Lebert, or the exulative corpuseles of Itenle; globular aggregations varying in size; scales of horny equithelium ; crystals of eholesterine; dark brown pigment; ete.

"On placing a drop of the fluid removed from an ovarian cyst under the microscope," says I)rysdale, " "we usually find a number of granular cells,

10 . cit., 1. 110.

2 (1). cit.

3 Op. cit. 
E, some free granular matter, c, and small oil globules, n; and frequently, in adlition to these, epithelial cells of various forms, $A$, and crystals of cholesteriue, D. These, torrether with blood-corpuseles, F, the intammatory globules of Gluge, I, the pus cells, G II, and disintegrated blood and other cells, may all be sometimes seen floating in either a clear or a turbid tluid."
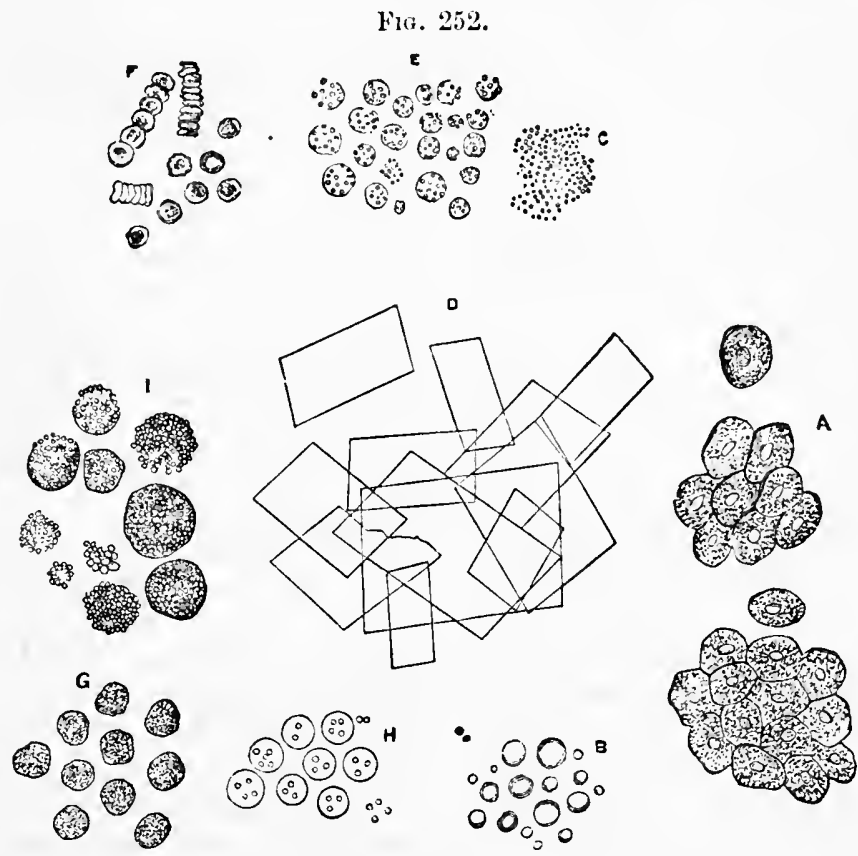

Microscopic appearance of ovarian fluid. (Drysdale.)

For the microscopist and pathologist all these are of interest. For the ovariotomist this is the chief point of importance: is there any characteristic, pathognomonic cell or element upon the presence of which a positive diagnosis of orarian cyst may be based? When this question can be unreservedly answered in the affirmative, a great adrance will have been male in this important matter. Spiegelberg, in an interesting lecture upon the diagnosis of orarian tumors, enumerates cylindrical epithelium, colloid cells, cholesterine, ete., and appears to rely upon the character of cells furnished by the part from which the material was secreted rather than upon any particular cell.

Long ago, Nunn pointed out the existence of the "gorged granule," though not as a diagnostic point, and Paget, Bennett, Gluge, and others speak of the "granular corpusele," the "compound granular cell," and the "inflammation globules." In an essay, already referred to, Dr. T. M. Drysdale, of Philadelphia, has recently described a cell which he calls "the ovarian gianular cell," which, when found in pelvic tumors, he 
regards as pathognomonic of ovarian disease, and, as such, he looks upon its diagnostic value as very great. 'This matter is of so great importance, that I prefer to describe this cell in Dr. Drysdale's words. In referring to the cells shown in Fig. 252 he says:-

"To find them all present in one specimen, however, is rare; more commonly we can discover but three or four of them in the fluid. But no matter achat other cells may be present or absent, the cell which is almost intaricebly frem in these fluids is the granular cell.

"This gramular cell, E, in ovarian fluid, is generally round, but sometimes a little oval in form, is very delicate, transparent, and contains a number of tine granules, but no nucleus. The granules have a clear, well-defined outline. These cells differ greatly in size, but the structure is always the same. They may be seen as small as the one five-thousandth of an inch in diameter, and from this to the one two-thousandth of an inch. In some instances I have found them much larger, but the size most commonly met with is about that of a pus cell.

"The addition of acetic acid causes the granules to become more distinet, while the eell becomes more transparent. When ether is added the granules becone nearly transparent, but the appearance of the ecll is not changed.

"This granular cell may be distinguished from the pus cell, lymplo corpuscle, white blood cell, and other cells which resemble them, both by the appearance of the cell and by its behavior with acetic acid.

"The pus and other cells, G, which have just been named, have often a distinctly granular appearance; but the granules are not so clearly defined as in the granular cell found in ovarian disease, owing to the partial opacity of these cells; and when the granular cell of ovarian disease and the pus eell are placed together under the microscope, this difference is very apparent. In addition to the opacity of these cells, we frecquently find their eell wall appearing wrinkled rather than granular; and further, in the fresh state, they are often seen to contain a body resembling a nucleus.

"But. if there is doubt as to the nature of the cell, the addition of acetic acid dispels it; for, if it is a pus cell, or any of the cells named above, it will, on adding this acid, be seen to increase in size, become very transparent, and nuclei, varying in number from one to four, will become vixible. (Sce a, pus cell before adding acid; and II, pus cell after adding acid.) Should the eell, however, be an ovarian granular cell, the addition of this acid will merely increase its transparency and show the granules more distinetly.

"The compound gr:mular cell, I, the granule eell of Paget and others, or inflammation corpuscle of Gluge, is also occasionally present in these fluids, and might possibly be mistaken for the ovarian granular cell; but it is not difficult to distinguish them from each other. Gluge's cell is un ually much larger and more opatque than the ovarian ecll, and has the aplearance of an aggregation of minute oil globules, sometimes inclosed in al cerll wall. and at others deficient in this respect. The granules are coarser, and vary in size, while the granules of the ovarian cell are more 
miform and very small. liy comparing them in the drawing these differences will be apparent. Arath, the behavior of these cells on the addition of ether will at once decide the question ; for, while the ovarian eell remains nearly maflected by it, or, at most, has its gramules made paler, the eell of Ciluge loses its gramular appearanee, and sometimes entirely disappears through the solution of its contents by the ether.

"That the discovery of at grautalu cell in ovarian lluid is new, I do not assert, as J. Hughes bennett and other writers have described granulat eells which they have seen in these fluids; but, with one exception, their

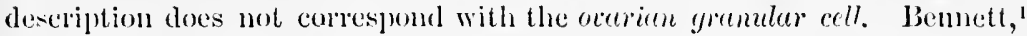
for instance, states that the granular cell which he saw exhibited a distinct nucleus on the addition of acetic acid, which is not the ease with this. Other writers have deseribed the eells which they found as pus and pyoid cells; and yet others confound them with the compound grannlar eell, or intlammation globules. The exception referted to above is found in lieale's description of the mieroscopic appearance of ovalian tluid."'2

The description given by Beale he declares to correspond closely to that of his "ovarian gramular cell, but it is incomplete, and no test is giren by which to distinguish it from other granular cells." Dr. Drysdale, therefore, clains to have been the first to describe a cell which has never been accurately described before, and to have given the tests by which it may be distinguished from others, such as the pus cell, the white blood corpuscle, and the compound granule cell, which elosely resembles it. He sums up in these words :-

"I claim, then, that a gr"anular cell has been discovered by me in ovarian fluid, which difiers in its behavior with acetic acid and ether from any other known granular cell found in the abdominal cavity, and which, by means of these reagents, can be readily recognized as the cell which has becn described; and, further, that by the use of the microscope, assisted by these tests, we may distinguish the fluid removed from ovarian eysts fiom all other abdominal dropsical fluids."

Microscopists are by no means agreed as to the validity of Drysdale's corpuseles as pathognomonic of ovarian eyst. Indeed I may say that, so far as my knowlerlge goes, a very general scepticism with regard to it prevails. Time will soon settle this matter, which as yet cannot be regarded as at rest, for the subject is now receiving the attention which it long ago deserved.

Cuuses. - Very little is positively known upon this subject. The predisposing causes which are generally admitted are the following:-

1 Ed. Med. and Surg. Journ., rol. 1xv. p. $280,1846$.

2 The fricroscope in its Aplltcation to l'ractical Medicine. By Lionel s. Beale, I.B., F.R.S., ete. 3 d edit., p. 179.

3 The views of Dr. Drysdale are not yet verified. The matter is at present sub judice. 
Age ;

Childbearing ;

Chlorosis ;

Scrofulous diathesis ;

Menstrual disorders ;

Depreciation from poor living.

It should be borne in mind that even as to some of these there is doubt and variance of opinion among gynecologists.

The great predisposing cause is age, the affection commonly showing itself during the period of ovarian activity, and very generally during that of the most vigorous aetivity. It is rare under twenty and over fifty, the most common period of its occurrence being between twenty and forty. It may, however, oceur in infancy, and as late as eiglity. $\Lambda$ case has reently been recorded in which ovariotomy was successfully performed upon a child of six years of age.'

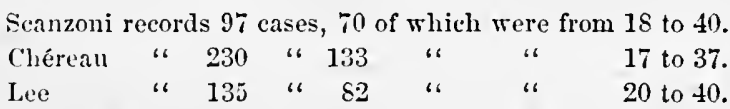

Of Scanzoni's cases five were between fifty-five and sixty; of Lee's one hundred and thirty-five cases, eighty-eight were married, thirty-seren unmarried, and eleven widows.

The much greater frequency of the disease among women who have become enfeebled by hard labor, poor diet, or depressing surroundings, than among those better circumstanced, must lave struck every one of large experience.

The uncertainty existing as to the exciting causes is even greater than this. All those influences which theoretically would be likely to excite cystic growth, as ovaritis, lolows, checking of menstruation, excess of coition, libidinous desires without gratification, have been advanced by authors as scientific certainties. But proof is wanting, however plausible the theoretical reasoning appears, and they cannot in the present state of science he arlmitted. In the great majority of cases these tumors devolop in women who have led rational and quiet lives, in whom no prejudicial influence can be discovered as laving existed, and who have detected the growth of the tumor when imagining themselves in rery fair health.

Certainly nothing can with satety be assumed beyond this, that it is probable that those infuences which keep up and intensify ovarian congestion, and intertere with rupture of the follicles of De Graaf, tend to produce cystic and follieular degreneration. Kiwiselı, Rokitansky, and Rindlleisch all agree in thinking it probable that inflammation affecting the walls of the resicles has an influence on the production of the disease. 
Nuturul Itistoryof Orariun Cysts._Ovarian cystic tumors develop cither by one or by a number of eysts. In the first case the eyst may luenme finly distended by thide, reach a point where its growth eeases and remain quiescent, only annoying the patient by the mechanical results of its [rescure and the appehension that it ma increase and create trouble. There are no groumls for doubting the evidence that such tumors may remain without increase for even forty or fifty years, but such cases are rare exceptions to a general rule. "Much mischief has resulted, however," says IIewitt, "from looking on such eases as the typical ones, while the large majority of the cases, the end of which is naturally death in a much shorter time, have been considered as the exceptional ones."

We now and then meet with pulmonary tuberculosis which goes on to formation of a large cavity, and then for some unaccountable reason ceases to adrance. The cavity, which is distinctly discernible, remains quiescent, and the patient may live for years. As this is an exception to a rule in the natural history of phthisis, so is the tardy conrse of ovarian dropsy just alluded to an exeeption to the usual course of that affection. The olygocystic tumor grows much more slowly than the polycystic, and this is the more marked as it approaches the monocystic type. I remored one which had been under my own observation for nine years, and only at the end of this time did its existence affect the constitution.

If its type be multilocular, the tumor adrances more rapidly, certainly, and uncontrollably, than in the case just mentioned. The prognosis of ovarian dropsy not interfered with by art, and by this we mean surgical art, as medicine has no controlling or curative power in the disease, is always unfaromble. The average duration of the eases of both types is supposed by the best modern authorities to be about three years of life after the inception of the affection.

Mr. Safford Lee has collected statistics as to the duration of the disease in 123 cases, not subjected to any curative surgical treatment.

\begin{tabular}{|c|c|c|c|c|c|c|c|c|c|c|c|}
\hline \multicolumn{4}{|c|}{ In 38 the duration was } & . & . & - & . & - & . & & year. \\
\hline " & 16 & " & " & & . & . & . & . & . & & years. \\
\hline$\because 17$ & "، & " & " & & . & . & & & & 3 & "، \\
\hline$" 10$ & “ & $\therefore$ & " & & . & . & . & & & 4 & " \\
\hline & " & “ & " & • & . & & & & . & 5 & ، \\
\hline ". & " & " & " & & . & . & se & & & 6 & " \\
\hline "4 4 & ، & 6 & "، & . & . & & & & & 7 & 6 \\
\hline " 3 & "، & : & " & & . & & & & . & S & "6 \\
\hline " ד & 6 & "6 & "، & & & & & & 9 to 5 & & " \\
\hline
\end{tabular}

From this it will be seen that out of 123 cases 80 terminated within three, and 94 within five years. At the same time that the fact must not be lost sight of that 17 out of 123 cases lasted over nine years, and that some, the number of which is not stated, terminated at the end of fifty, it must not be accepted as certain that these were cases of true ovarian 
cystoma. Experience in this affection leads to the suspicion that these were instances of dermoid eysts, or of some variety of abdominal tumor which, while it closely simulates ovarian cystoma, runs a mueh more benign course.

I have removed an undoubted mutilocular ovarian cyst whieb had lasted, the evidenee in favor of duration being medical and perfectly reliable, for twenty-three years; another for twelve and a half years; another for ten, and another for nine years.

Spontaneous Cures of Orarian Cysts._-Sometimes nature effects a cure in one of the following ways. The eyst may discharge into the peritoneum, and absorption oceur. Of this accident Dr. Tilt has collected 71 cases, of which 30 recovered, 19 were improved, and 21 died. I have met with four instances of such rupture, two of which proved fatal by peritonitis. The cyst walls may undergo ealcareous degeneration, which ehecks advance. The cyst may discharge externally by the abdominal or dorsal surfaces, or into the rectum, bladler, vagina, or uterus by means of the Fallopian tubes. Instances of the last occurrence are mentioned by Morgagni, Frank, Follin, and Boivin, and Richard records five eases.

With reference to nature's power alone, or aided by absorbents, to remove the accumulated fluid, Kiwisch declares, "We must express our dissent from the opinion of those practitioners who assume that an ovarian cyst ean be completely removed by simple absorption. So far as we know, this process has not been satisfactorily demonstrated by a single case." It is the opinion of many that absorption of the contents of these cysts does oecur, and numerous instances are cited in proof ; but, in these cases, the doubt arises whether a true cystoma ovarii existed, or one of the periuterine eysts which so closely resemble it.

Diseased Conditions affecting Ocarian Cysts.-I have already alluded to suppurative inflammation of the cyst walls, which may occur in consequence of tapping, or without operative interference. The pulse and temperature become elevated, the patient restless and depressed, profuse perspirations occur, diarrluea sets in, and, unless relieved, the patient dies with lectic symptoms. In a number of instances ovariotomy has been successfully performed under these circumstances. One such case is recorded by lieith, the suppurative action occurring seven days after tapping; three by Wells; one by Peaslee; and one by Teale.' I have several times operated npon cases in which ovariotomy was undertaken only as a last resort, where the contents of the eysts were excessively fetid, and the patient very ill at the time of the operation, and which have nevertheless done well.

Twisting of the pedicle is another accirlent which sometimes takes flace. Gallez, in referring to this, says, "This very curious and haply

1 Ionion Lancet, Am. reprint, Sept. 1873.

2 L. Giallez, Histoire des hystes de l'Ovaire, Bruxelles, 1873, p. 150. 
termination of ovarian rests is unfortumately very rare, and likewise very ditlicult of artificial accomplishment; its eflect is to produce strangulation of the tumor." Where the interference thus established in the vascular supply of the tumor goes just far enough to produce gratual atrophy, cure may be eflected, aud post-mortem evidence of such an oceasional occurrence exists. Ordinarily strangulation and death of the tumor oceur, which destroy life nuless ovariotomy should intervene. In 166.j lokitansky published an essay upon this subject, and sinee that tine it has attracted considerable attention. He cited the details of thirteen cases, and Spencer Wells mentions two deaths thus caused before operation, and twelve cases discovered ly him upon performanec of ovariotomy. Klob reports an instance in which a tumor turned upon its perlicle five times; and in a case of fital hemorrhage into the cyst Patruban found in autopsy torsion of the pedicle ereating venous stenosis and rupture.' Crane and 'Tait ${ }^{3}$ record eases in which small cysts were thus rendered gangrenous, in consequence of which the patients died of septicamia.

Sometimes an ovarian cyst increases very suddenly in dimensions, great pain from distention ocenrs, and symptoms of loss of blood derelop themselves. This is due to hemorhage from the cyst wall. In two cases in my experience it las occurred; in one orariotomy demonstrated the source of the difliculty; and in the other aspiration, adopted on acconnt of the severe suffering from distention, did so. Parry records a case which almost proved fatal from this cause, and Patruban ${ }^{5}$ one which did so. In the latter case torsion of the pedicle seemed to have produced the rupture of vessels. Wonder at such an occurrence will cease when it is remembered that veins ${ }^{6}$ as large as the little finger have been found between the outer and middle layer of cysts.

Conditions likely to complicate Orarian Cysts. - They may be complicated by pregnancy; ascites ; feeal impaction; Bright's disease ; pleuritic effusion; peritonitis with adhesions; a low type of gastritis marked by intensely red tongue, constant vomiting, and tenderness of the stomach; a low grade of septicamia; diarrboa; inguinal, umbilical, and crural hernia, etc.

Methods in wlich Death is produced.-There are several modes in which ovarian dropsy produces its usual fatal results when uninterfered with by surgical means.

1st. A cyst may rupture and produce peritonitis, either before or after suppurative inflammation of its walls.

2l. Intlammation of the eyst wall may result in the filling of the eyst with pus, which produces hectie and in time exhaustion and death.

1 London Lancet, Am. reprint, Sept. 1873.

2 Amer. Hed. Month!y, April, $1 \& 61$.

3 Edin. Med. Journal, 18631.

4 .Im. Journ. Obstet., Nov. $1 \varepsilon 71$.

5 Gallez, op. cit., p. 150.

6 T. s. Lee. 
3d. Fatal hemorrhage may occur into the eyst.

4 th. Prolonged interference with the functions of nutrition and respiration may sap the powers of life.

5th. Death of the cyst may occur from twisting or rupture of the pedicle and cause septicamia.

6th. A low grade of gastritis, pleuritis, ${ }^{1}$ or enteritis may produce exlaustion.

7th. Finally, from the combined depreeiating influences of this condition, gradual or sudden prostration of strength may close the scene by death.

Every one haring charge of a case of ovarian tumor should recollect that of ten the only hope of saving life, threatened by the accidents here recorded, consists in an immediate resort to ovariotomy. Eren ncute peritonitis has been thus cut short, and patients with a temperature of $105^{\circ}$ from suppuration of the sac have been saved. Spencer Wells arrived just too late to save two eases in which death resulted from hemorrhage into the sac, and Wiltshire in time to sare one, and I operated with a successful result in a patient nearly completely collapsed from sudden rupture of a large eyst.

We now approach the important subject of symptomatology of ovarian cysts and their differentiation from other morbid conditions met with in the abdomen. As the study of that subject will frequently involve allusion to pelvic cysts closely resembling ovarian but yet entirely distinct from the ovaries, I deem it best to take a rapid survey of them liere.

Cysts of the Broad Ligaments.-Cysts of considerable size sometimes form between the layers of peritoneum making up the envelopes of the broad ligaments. They are supposed to arise from the collection of fluid in the meshes of areolar tissue of the ligaments; or from the parovaria or bodies of Rosenmüller. Within the external margin of the broad ligament, where the two walls of the peritoneum pass from the fimbria of the tulbe to the ovary, exists the body of Rosenmuiller, parovarium, or Wolffian body, to which allusion has already been made as consisting of a number of little, tortuous cords, some of which are perforated by canals. The slight secretion oceurring from the walls of these tubes sometimes becomes greatly increased, and the containing walls becoming proportionately distended, a tumor is created. These eysts may attain a large size, though they do not generally do so.

One of the most interesting cases of cyst of the broad ligament which I have seen in practice was in a larly from Mobile, upon whom ovariotomy was successfully performed hy the late Dr. Nott, of this city. He liad tapperl her, and drawn off a large amount of limpill fluill four years before

1 I have seen two cases in which hydrothorax proved a great source of prostration. 
the operation, and the eyst had for about three years appeared to late closed. After that time, however, it had refilled, and wats, whan I tirst saw her in consultation with Dr. Nott, quite tense, and the abdomen appeared of about the size of that of a woman in the seventh month of pregnancy. Operation was determined upon, but delayed for three months in consecuenee of the heat of the weather. When it was performed, both ovaries were found to be perfect in size and slape, and the eyst wats fonnd to occupy the left broad ligament, the peritoneal walls of which were immensely distended over its surface.

The peculiar features which have been found to characterize cysts of the broad ligaments are the following: They contain a clear, limpicl, very slightly albuminous liquid, which takes on a purplish tinge when exposed to the rays of the sun; tapping generally, though not always, eures them; after tapping no eyst can be felt; they are always milocular; and they have been found to contain in their walls nonstriated muscular fibre, which the walls of orarian cysts never contain.

Parasitic or Hydatid Cysts._- Althongh eases of these cysts, developed in consequence of the presence of the echinococeus hominis and cysticereus cellulose, are reported as having occurred in the ovaries, it is doubtful whether such reports are authentic. These parasites may, howerer, develop in the mesentery, the omentum majus, and even in the cellular tissue; the vesicle of which the parasite consists becoming surrounded by a neoplastic sac. "I have seen," says Billrotl, "cysticercus vesicles removed from the tongue and nose, echinococens vesicles renoved from the back and thigh." Spiegelberg reports a case of retro-uterine, left sided parasitic cyst, simulating orarian cyst, in which he ent down and removed some of the characteristic contents. This procedure and tapping or aspiration are the only means of diagnosis which are at all reliable.

Tubal Dropsy._-This condition, which is deseribed under the names. of hydrops tube, salpingian dropsy, and hydrosalpinx, consists in the distention of the Fallopian tubes by muco-serous fluil.--It arises in this manner: some influence, for example, acute or chronic salpingitis, pelvic peritonitis, or cellulitis, occludes both extremities of the tube. The inflammation of the mucous membrane of the tube creating a muco-serous fluid, the canal is distended by this, generally irregularly, to the size of the finger or small intestine. Thus far the affection does not concern our present investigation, for there is no probability that such a growtl would resemble ovarian tumor so closely as to leal to an error in diagnosis. But as this distention goes on, the mucous lining of the tube takes on the anatomical and physiological charaeters of a serous membrane, and secretes plentifully a serous, straw-colored, and slightly flocculent fluid. At times the distention of

1 This cyst is now in my possession. Dried and stuffed with cotton, it measures 26 inches in circumference. 
the walls of the tube proeeeds so far that the fluetuating tumor which results gives all the physical signs of ovarian dropsy.

The testimony of authorities is almost unanimous that between this condition and ovarian dropsy there are no means of diagnosis without withdrawal of some of the fluid. M. Aran sounds the key-note to the general belief when lie declares that, " the tube distended by liquid, I am perfectly assured, does not give a sufficiently clear sensation to allow us to diagnosticate its existence." Prof. Simpson, lowever, assumes a different position. ${ }^{2}$ Ile declares that, although " in practice this form of tumor is usually altogether overlooked or is mistaken for some other kind of tumor," it is really diagnosticable by the following means: "1st, its free and independent mobility ; $2 \mathrm{~d}$, its elongated form ; and 3d, its wary outline." Let any one examine the shape of a large tubal dropsy, like that represented at Fig. 258 , for instance, and he will see that both the shape and wary

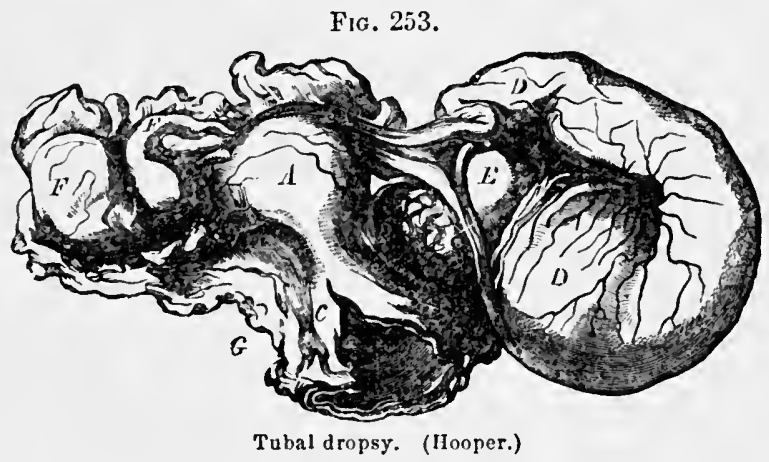

outline will fail him. When it is remembered that the affeetion frequently results from pelvie peritonitis, it will be apparent that the freedom of motion will be often delusive. "The diseased tube," says Courty, " is rarely free and without alteration at its periphery: generally it bears signs of old inflammation, which is adhesive, and this fixes it to the neighboring parts." I have met with the affection four or five times in autopsies, and this statement has always been sustainerl.

The means of diagnosis just mentioned would be applieable to slight tubal distention, which is rarely productive of symptoms calling for examination. Few instances of diagnosis are on record, and even in cases where tapping lias been supposed to substantiate it, it is by no means sure that such a disease existed. I'rof. Simpson reports but one case in lis extensive experience in which he was able to come to a conclusion. Ile denies the possibility of great enlargement of these tumors, declaring that they rarely grow larger than a foctal liead, and that we may justly be allowerl to be sceptical as to cases reported as being much larger. Dr.

$$
1 \text { Op. cit., p. } 633 . \quad 2 \text { Op. cit., p. } 432 . \quad 3 \text { Op. cit., p. } 987 .
$$


Arthur Farre, ${ }^{1}$ however, willingly admits the well-known cases of Bonnet and be Hacn; the first of which contained thirteen pounds of fluid and the second thirty-two pounds. Seanzoni circumstantially reports an instance in which the sae attained the size of the head of a ehild of ten years of age.

Subperitoneal Cysts._Cystic degeneration is much more likely to occur in those organs which have, as component parts of their structure, minute cavities lined hy epithelium. Thus, the kidncys and ovaries are peeuliarly liable to be affected in this way. Cysts thus formed lave been styled by Virchow eysts by retention. But eystic degeneration is by no means limited to such structures. It may oceur in areolar tissue anywhere, and those organs which, like the thyroid and mammary glands, are prone to production of new growths having areolar tissue as their basis, are likewise especially liable to it.

It is believel by pathologists that under these circumstances the cyst is merely an expansion of the areola of the areolar tissue. In various parts of the abdominal eavity such cysts are found under the peritoneum and classed uuder the head of subperitoneal cysts. Mr. Safford Lee reports one case of a tumor which filled the abdomen, and destroyed life, after having lasted for twenty-five years. On post-mortem inspection a large cyst was found behind the peritonemm, which had originated under the pancreas. Ife reports another which began on the right side of the ablomen, was tapped forty-eight times, and was found by autopsy to be omental.

Cysts connected with the Spinal Cord.-In November, 1870, a woman aged 36 years entered the Woman's Hospital in this eity, and came under the care of Dr. Emmet. ${ }^{2}$ He found a large cyst filling the hollow of the sacrum and there firmly fixed. To aid in diagnosis, an ounce of fluid was drawn off by aspiration. This was clear and limpid, free from albumen, and revealed under the microscope only a few oil globules. The patient died, and Dr. F. Delafield on making an autopsy found a cyst, which contained some three quarts of fluid, filling completely the pelvic cavity and extending up to a level with the second lumbar vertebra. This communicated with the spinal cord by a funnel-shaped passage, which had as its lower outlet an oval opening extending from the upper margin of the second sacral foramen on the right to the position of the coceyx, which was wanting. Over the surface of the sac was a network of nerve tissue, extending posteriorly and to the right side. The sac was supposed to be one of spina bificla or hydrorachis.

Symptoms.-During the earlier periods of the development of ovarian cysts, very few symptoms ordinarily show themselves. As enlargement

1 Supplement Cyc. Anat. and Phys., p. 619.

2 This case is described in the Amer. Journal of Obstetrics, Feb. 1871. 
goes on the patient becomes struck by the fact that her abdomen has increased in size, and, if both ovaries be affected, menstruation sometimes ceases, and she may imagine she has beeome pregnant. Pressure of the small but increasing tumor will sometimes create dragging sensations about the pelvis, irritability of the bladder, and, if the growth occupy the retro-uterine space, as it often does, pain in the back. 'This is, however, by no means all the inconvenience which may be experienced. $A$ small, movable eyst, which may be pushed about in the abdomen, will sometimes cause severe pain. In one such ease which I saw with Dr. Noeggerath, the account of which is published in Dr. Atlee's work on the Oraries, ovariotomy was necessitated, when the cyst was no larger than a cocoanut, by excessive pain.

As the tumor grows and fills the abdomen, rising above the navel, a sense of distention is complained of, dyspnca begins to show itself upon exertion, the patient feels more feeble than usual, and slight emaciation is observed. As it increases and begins to press upon the large viscera beneath the diaphragm, these symptoms increase, and the patient's face wears a peculiar expression, which has been styled by Mr. Wells, the "facies ovariana." This is created by an absorption of adipose tissue, an exaggeration of the natual furrows of the face, and an expression of anxiety and apprehension. To one who has studied this expression, an imperfect description such as this will recall it; but to one who has not become clinically faniliar with it, it is impossible to convey a clear conception of it. 'To these symptoms the mammary and gastric symptoms of pregnincy sometimes, though rarely, add themselves.

Pressure upon the kidneys creates eongestion of these organs, and scanty secretion is a common result. Occasional attacks of localized peritonitis are by no means rare, and hence, in many eases, ascites becomes a complication of the affection.

As the decadence of strength, the emaciation, and the impoverishment of the blood incident to this grave disorder increase with time, digestive and intestinal disorders show themselves, œdema of the feet and legs occurs, great feebleness appears, and the patient dies from progressive exhaustion.

A summary of the rational signs which may arise in consequence of ovarian cysts from the commencement of their growth to full development may thus be given; irritability of the hladder, dysmenorrhoca, constijation, hemorrhoids, pelvie pains of neuralgic character, symptoms of pregnancy, seanty urinary secretion, intestinal and digestive disorder, deranged respiratory function, peculiar facies, emaciation, cedema, venous distention on surface, ascites, vomiting, diarrlıea, cardiae irregularity, alphthous stomatitis, and hectic. In cases advanced in the last stage, all the last of these may show thenselves, and in early cases, all the first mentioned; 
but, in many instames, some of the most prominent of these signs are entirely wauting.

Plyssical Signs._The symptoms thus far enumerated are nerer sulticient for diagnosis. They are usually only suflicient to suggest pliysieal examination, by which reliable signs will probably be discovered, and the diagnosis be mate complete.

The pliysical sigus of ovarian cysts are, therefore, of the greatest importance, and the full capacity of physical exploration should in every case be developed, for to it we must look for answers to the following questions:-

\section{1st. Does a tumor exist?}

2.1. If so, is it ovarian?

Does a tumor exist?-To decide this question, the patient should be placed upon her back upon a flat, resisting surface, the abdomen uncorered, all eonstriction removed from the waist, and the knees drawn up so as to relix the abdominal muscles. It is of primary importance that she shonld be calm, and give herself up to the examination in the full desire of aicling the physician in arriving at a diagnosis. In some cases the patient, from nerrousness, in some fiom pain created by pressure, and in otlers from in desire to mislead and deceive, will not be able or willing to do this, but, by suddenly contracting the abdominal walls, will place a serious, pcrhapis insurmountable, obstacle in his way. Under such circumstances ether should be employed as an anasthetic, and full investigation made. The abdominal museles being entirely relaxed, careful palpation and deep, stealy, and prolonged pressure should be made by both hands over the whole abdomen, downwards towards the spine, and especially orer the pelvie region. By this means at more or less resisting mass may be discorered, which produces an abdominal enlargement visible upon inspection.

Thus far very little has been learned; merely that an abnormal enlargement exists in the abdomen. It may not deserve the significant name of tumor, but be due to one of these states:-

1st. Abnormal thickness of abdominal walls;

2d. Tonic sprasm of abdominal muscles;

3u. Intestinal distention ;

4 th. Distention of urinary bladder;

5tlı. Pregnancy.

With care and caution each of these conditions may usually be eliminated by means which we shall soon consider. A neglect of such means has often resulted in great and needless alarm to patients, and a painfully humiliating and often ludicrous exposure of the practitioner.

It having been now decided that the patient has an abdominal tumor, or, in other words, an abdominal swelling due to a morbific cause of serious nature, it next becomes important to decide whether it be ovarian or not. 
Is the tumor ovarian? - It has been already stated that any abdominal tumor may, unless careful means of differentiation are adopted, be confonded with ovarian growths. The truth of this will be appreciated by reference to the valuable tables of Dr. Jolın Clay, the translator of Kiwisch on the Ovaries. He las colleeted twenty-three cases of attempted ovariotomy in which the operation was abandoned because the tumor proved not to be ovarian. The tumor's were of the following characters:-

12 were uterine;

2 " omental;

2 " results of chronic peritonitis;

2 " not discoverable;

1 was tubal pregnancy;

1 " obesity;

1 " mesenteric;

1 6 splenic;

1 " not stated.

So great did the difficulties of diagnosis for a long time prove, that they were urged by the opponents of the operation as a valid objection to it as a surgical procedure. At the same time that they are still acknowledged, and that it is admitted that the most cautious and skilful diagnostician nay be defeated by them, it can be confidently asserted that every year's experience greatly diminishes them, and that with the improved means now at command, an experienced examiner will rarely be misled. Let me, however, again insist upon the fact that immunity from oft repeated errors can be obtained, even by such an one, only by strict adherence to a conseientious and exhaustive examination of every case, a resort to all the known means of diaguosis, and a methodical exelusion of all comlitions calculated to mislead.

It is a fact which I daily see demonstrated that an inexperienced diagnostician usually arrives at a conclusion by the application of a much smaller number of tests than a veteran examiner would dare to do. The latter las been so often deceived that he knows his weakness; the former has yet to learn.

The means of physical exploration which are at our disposal are the following :-

Inspection and manipulation ;

Mensuration ;

Pallpation ;

Pereussion ;

Ausculation;

Vaginal touch ;

Rectal toueh ;

The uterine sound;

Aspiration or paracentesis ; 
Cliemical and microscopieal examination of thuids of the tumor ;

Explorative incision.

Solid ovarian tumor's are rare and seldom assume very lange proportions, and although ovariotomy is sometimes demanded for their removal, the operation is suecially adlipted to cystic tumors. We therefore pass to the more careful consileration of the diagnosis of these, and their diflerentiation from other ablominal enlargements.

An ovarian cyst usuitly develops markedly on one sille of the abdomen, and if multilocular the abdominal distention is not symmetrical even in alvanced periods. $A$ s it increases, the eyst pushes the intestines aside into the hypochondriac regions. The aseending and transverse colon alone approximate their nornal positions, and the omentum majus is usually pusherd up over the front of the tumor. While the eyst is in the pelvis, the uterus usually lies in front of it, but as increase of growth occurs it is ordinarily pushed behind it. There are, lowever, exceptions to both these statements. In rare cases, fortunately for the ovariotomist, a portion of intestine runs across the face of the tumor, being fixed there by adhesion. The uterus, even late in the development of a large cyst, may be found in front of it or latero-flexed, latero-verted, or cren drawn completely above the pelvic brim. Curious as it may appear, great diversity of statement exists concerning the relation of cyst and uterus among writers on this subject. "Simpson's remark," says Peaslee," "that, "if" the sound show a tumor in front of the uterus, the disease is eertainly not ovarian,' is incorrect. The uterus is in front of an ovarian tumor only in exceptional cases; but is of ten so in cases of uterine filbroma and fibro-cyst. Boinet mentions the fact as a remarkable one that Cruveilhier found the uterus behind an ovarian cyst in three instances." My observation certainly agrees with that of Dr. Atlee," that "the uterus may be dragged up, or tilted up out of the pelvic cavity by the tumor; or, through these influences, it may be found on either side, or displaced forward or backward within the pelvis. It may also be crowded downward against the perineum, or entirely extruded through the vulvar orifice. So that there is no general rule as regards the position of the uterus in ovarian tumors."

When the tumor hats ascended above the umbilicus, as the patient lies upon the back, the abdomen will appear rotund, a decided protuberance existing, and very little flattening out by sagging of fluid to the flanks occurring. As the liands are laid upon the surface, and manipulation is practised, a firm, dense mass will be felt, which yields fluctuation, not usually of a superficial character like ascites, but less superficial and perce,tible. Percussion will yield dulness all over the surface of the tumor and in one flank, but in the other resonance will generally exist. The surface of the tumor will often feel irregular and lobulated, and in multi- 
locular tumors be more voluminous on one side than the other. If pressure be made upon the tumor, as the patient lies upon the back, it will resist like a full sac, and not yield, and the pulsations of the aorta may be felt obseurely through it. By raginal and rectal touch the lower surface of the tumor may be felt and obscure fluctuation elicited.

Mensuration practised from the umbilicus to the sternum, and the umbilicus to the anterior superior spinous processes of the ileum, will generally slow a marked difference between the two sides in polycysts and less difierence in monocysts. In ascites the two sides are symmetrical. Auscultation serves to exclude pregnancy. By vaginal touch the position of the uterus as well as its mobility is ascertained, and when combined with conjoined manipulation the solid or cystic claracter of a small or even a large tumor may be determined by it. Should the tumor be found low in the pelvis in the later periorls of growth, it is probable that a short pedicie exists, and also probably adhesions. Should it have risen out of the pelvis the pedicle is probably, but by no means certainly, a long one.

The uterine sound informs us as to the capacity, the mobility, and the sensitiveness of the uterus, as well as, to a limited degree, its relations to the tumor.

Simon's method of rectal exploration, modified by the introduction of the hand without the thumb into the bowel, constitutes one of the most valuable means of diagnosis and differentiation at our command. By it the point of origin of the tumor, as well as its general characters, may be very accurately ascertained.

Emptying the cysts of the tumor of fluid by aspiration or tapping is likewise a most useful means of gaining information; and of great moment is the careful and intelligent examination of the fluids removed.

Of late it has been proposed to determine as to the nature of such fluid by the discovery in it of "luteine," a yellow substance found in the blood, the egg, and the fluid contents of ovarian tumors. As yet, this test has been too little investigated to enable us to decide what weiglit is to be given to it.

Lastly, we reach the crucial test of explorative incision, the ralue of which eamnot be exaggerated, but which is attended by consilerable danger.

These are the means by which the positive signs of ovarian cystoma may be elicited, but, before a diagnosis is arrived at by deductions based upon them, many other abdominal enlargements must be carefully considered and excluded. If this be necessary merely in arriving at a correet diagnusis where no operation is to be practised, how much more so is it in view of the grave procedure of ovariotomy. Any one of the following conditions may mislead the investigator, and each of them must be in turn considered by him who desires to do his full duty to his patient and limelf. 


\begin{tabular}{|c|c|}
\hline \multirow{5}{*}{$\begin{array}{l}\text { Abnormal thickness or ten- } \\
\text { sion of abrlominal walls }\end{array}$} & \\
\hline & Obesity ; \\
\hline & (Eidemal ; \\
\hline & Elephantiasis ; \\
\hline & 'Tonic spasur. \\
\hline \multirow{7}{*}{$\begin{array}{l}\text { Distention of abdominal vis- } \\
\text { cera }\end{array}$} & 'Tymunanites; \\
\hline & Fecul tumor ; \\
\hline & Dilatation of stomach ; \\
\hline & Distended blatder; \\
\hline & Physometra; \\
\hline & Cystic chorion ; \\
\hline & Ilydrosalpinx. \\
\hline
\end{tabular}

Fluid accumulation within the
peritoneum Areites ;

Eneysted dropsy ;

IIematocele;

Colloid accumulation.

Cyst of broad ligament ;

Renal eyst;

Splenic cyst ;

Cystic disease of other parts Hepatic cyst; in the abdomen

Parasitic cyst ;

Subperitoneal cyst;

Uterine cyst ;

Uterine eysto-fibroma.

Excessive development or displacement of other viscera of the abdomen

Cterine fibroma;

Enlarged spleen;

Enlarged liver ;

Fibro-plastic tumor of peritoneum ;

Sarcoma of abdominal glands;

Malignant disease;

Omental tumor;

Displaced lidney ;

Displaced liver.

Normal ;

Extra-uterine $\left\{\begin{array}{l}\text { Tentral; } \\ \text { Tubal; } \\ \text { Interstitial ; }\end{array}\right.$

With amniotic dropsy ;

With ovarian dropsy ;

With dead child.

Discased states of pelric walls

Enchondroma ;

and areolar tissue

Encephaloid of bones ;

Pelvic abscess.

1 A most remarkable and interesting instance of this is recorded by Dr. Reeres Jackson, of Chicago. 
Abnormal Thickness or Tension of Abdominal Walls._Obesity will be recognized by obscure resonanee on percussion over the whole abdomen; by absence of a detined, resisting outline to the supposed tumor; by the possibility of catching the fatty walls between the two hands, lifting them, and rolling them over the museular floor beneath; by the deep depression which can be made when the patient is anresthetized; and by the pendulous folds ereated by assumption of the sitting posture. It would be inexeusable in an expert to mistake this condition for orarian tumor, but for an inexperienced examiner not at all to. I see numerous eases every year in which such an error is committed by very competent practitioners.

Eilema will be known by pitting upon pressure; by the existence of the same condition in the areolar tissue of the feet or face; and by its generally attending uremia, chlorosis, or cardiae disease.

Elephantiasis, of which Dr. Atlee records a remarkable ease, would be reeognized by the peeuliar structural alterations of the skin which characterize it.

Tonic spasm of the aldominal muscles has more than once led, as has indeed obesity, to abdominal section for removal of a tumor. It often oeeurs under the name of "phantom tumor" in very hysterieal women, and is not rare as a reflex result of earies of the vertebre. It may be diagnosticated by resonanee on pereussion; absence of fluetuation ; and absence of all signs of tumor under anasthesia. In case of doubt, anasthesia should always be resorted to. In addition to these signs, the unaltered position of the uterus eonstitutes an important one.

Distention of Abdominal Viscera._Even without abdominal spasm a large amount of air sometimes aecumulates in the intestines from hysteria, digestive disorder, or great obstruetion in the canal. It may be known by resonanee on perenssion ; absence of fluetuation; absence of all signs of tumor "Ion examination under anrsthesia; and the normal position of the uterus. By firm, steady pressure downwards towards the spine, kept up and increased after each expiration, resistance will be overcome, and deep exploration prove the absence of a tumor. This method was systematized by licederer.

Fecal tumor will be marked by absence of fluetuation; a peculiar "doughly" sensation upon manipulation; pain upon pressure; constijation ; violent eolic ; and. most valualle sign of all, the creation of a distinct pit or depression when stearly pressure is made at one point, the fatient being anasthetized. 'The action of catharties and enemata is often entirely clelusive as a test of feeal tumor.

Dr. Atlee relates a case of distention of the stomach in a man, in which that organ filled the entire abdominal carity, and covered, like an apron, all the other aldominal organs. "Ilan the patient been a female," says lee, "I should at once have pronomcel it an orarian cyst." Explorative incision would alone lave aceomplished diagnosis. 
It may be thought mulikely that a distended bladler condel be mistaken for an ovarian cyst, but it often gives the appearance of one. In one rate in which this ditliculty had existed for three werks, I fomd the badrler distended so ats to reach above the mmbilieus, its neck being compresend by the meck of a retroverted pregnant nterus. Suspicion as to the mature of the tumor will be excited by interference with urination, constant involuntary discharge of mine taking place, and the very frequent concurrenee, aceomling to my experience, of retroversion of the preguant uterus. Should aspiration he practised, the physical and chemical foatures of the urine will suggest a resort to the eatheter, which will settle the question of diagnosis.

In considering the differentiation of hematometra, plysometra, and cystic degeneration of the chorion, little reliance should be placed upon rational signs in comparison with physical. Cessation of menstruation and many of the other signs of pregnancy will be discovered in most cases, and, in physometra and cystic chorion, characteristic discharges will usually attend-air in the former, and blooty sermm in the latter. The enlarged uterus will be recognized as the tumos in question by conjoined manipulation and Simon's method; but the decisive test of these conditions consists in the passage of the uterine sound, or of a silver catheter to the fundus, in order to allow of escape of jmprisoned material, which, being collected, may be submitted to chemical and microscopieal examination.

Iydrosalpinx sometimes develops into a large tumor. De Haen describes one which weighed seven pounds. To differentiate snch a condition from ovarian cyst, bnt two methols can be relied upon: first, the removal of fluid, and examination by chemical means and the microscope; and second, explorative incision.

Finid Peritoncal Accumulations.-It is often exceedingly difficult to differentiate betwen ascites and ovarian dropsy. The means which ordinarily enable us to do so are here stated. It must, however, be borne in mind that there are cases in which even the most important may be tiansposed. For example, an ovarian cyst sometimes establishes communication with the intestines, and becomes resonant; while, in ascites, where the amount of fluid is excessive and the mesentery short, dulness exists over the front of the abdomen. The rule is here athered to, but the exceptions must not be lost sight of.

Is Orariax Dropsr.

1st. A small, round tumor will often have shown itself in the begimning in one iliac fossa;

21. In supine posture a rotundity is observed in the abdumen;

\section{IN Ascites.}

1st. The enlargement will have shown no small tumor at any point ;

2l. In supine posture the fluid gravitates to sides of abiomen, and the abdominal surface is tlattened; 
IN OYariax Dropst.

3d. Percussion made in supine posture gives dulness orer surface of abdomen;

4th. Change of posture alters area of dulness but little ;

5th. Noevideuces of cardiac, renal, or hepatic disease exist as a rule;

ith. Skin is uormal as to color, moisture, etc. ;

7th. Edema of the feet is absent until a late period, when the patient has become exhausted;

Eth. Health fails slowly;

!tlt. Sitting posture affects shape of abdomen but little;

10th. Fluctuation ordinarily not so superficial, lerel fixed to great extent, ceases where intestinal resonance begins;

11th. Aortic pulsation transmitted;

12th. Fluid usually amber colored and tenacious, often like syrup, of various hues in polycysts, not spontaneously coagulable, always sticky when rubbed between fingers. Shors cylindrical epithelium, granular cells and matter, oil globules, and cholesterine, and contains paralbumen and metalbumen. The granular cell is distinguishable from other ceels by its merely becoming transparent by acetic acicl others increase in $\operatorname{siz} ; 1$

Specific grarity, 1.018 to 1.024 .
Is Ascites.

3d. Percussien gives resonance over abdominal surface because the intestines float on the fluid;

4th. Change of posture alters area of dulness markedly ;

5th. Eridences of cardiac, renal, or hepatic disease almost always exist;

ith. Skin, in majority of cases, gires evidences of cirrhosis by its parchment feel and jaundiced liue;

7th. Edema of the feet exists as an early sign;

Eth. Health fails carly and rapilly;

9th. Produces bulging often in Douglas's pouch and throngh navel;

10th. More superficial, level changes with change of posture, perceived eren where intestinal resonance exists.

11th. Not so.

12th. Fluid of light straw-color; spontaneously coagulable from containing fibrin ; without sediment usually; shows to microscope squamous epithelial cells, oil globules, pus cells, and amneboid bodies; does not contain paralbumen, metalbumen, or cholesterine;

Specific gravity, 1.010 to 1.015 .

Sometimes, however, peritoneal aecumulations are sacculated by eneompassing lymph in one protion of the peritoneum; among the intestines matted together by effused lymph; or, as in a case recorder by West, enveloped by the omentum. "Between four and five quarts," says he, "of a dark fluid were found collected between the folds of the peritoneum." The amount of fluid thus imprisoned is often rery large, and hence the difficulties of diagnosis which have led Mr. Wells" to assert, "I am aware of no means by which such cases are to be distinguished from ovarian dropsy." II.Dowell himself once opened an ahdomen in such a case under the belief that an ovarian tumor existed. The intestines do not rise above the fhuil as in simple ascites. but there is less rotundity to the mass, and les: intertienence with espiration than are found to exist with orarian cyst. 
Diacnosis in these ditlicult eaters nunt depeme upon the results of aspira. tion, eximination of contained fluids, simon's method, and explorative incision.

The sudden appeanance of hematocele, the immediate and often urgent symptoms which it excites, and the remoral of a little fluid by aspiration will settle the question of diagnosis.

Colloid disease sometimes atlects the whole peritoneal cavity. In some cases it appears to escape into it from a ruptured orarim eyst ; in others it originates there. Removal of a small amount of the characteristic material by tapping is the only means of diagnosis.

Cystic Diserse of other Parts in the Abdomen.-Cysts of the broat ligament so closely resemble milocular orarian cysts as to be diagnosticable only by explorative incision or aspiration. Their character might be suspected from superficiality of fluctuation, slight implication of general health, absence of emaciation, and slowness of growth; but the chemical and microscopical features of the contained fluid would alone decide positively. This fluid is as clear and pure in appearance as distilled water, showing when boiled after aldition of acetic acid only a trace of albunen as an albuminate; is loaded with ehloride of sodium; and contains only a few fat and blood globules. After evacuation the cyst walls cannot be felt, and tapping often proves curative. Spiegelberg removed such a cyst in 1869, the walls of which, unlike those of ovarian tumors, contained muscular fibres, and the fluid of which contained albumen.

Renal cysts hare several times deceired the most skilful diagnosticians. 'Their characteristies are these: they ordinarily push the intestines for wards and not backwards; pus, blood, and albumen usually occur in the urine; these tumors grow from above downwards; they are rare and grow slowly; may be pushed up so that resonance occurs between tumor and pelvis; and the fluid contained shows none of the microscopical features of orarian cyst, while it shows the chemical and microscopical elements of urine. Sometimes eehinococci, which are frequent in renal cysts and unknown in ovarian, are found. The tumor is apt to be crossed by the descending colon or to lie outside of the ascending colon; it is usually marked by renal and not by menstrual derangement; and is usually unilateral.

Sometimes, however, a renal eyst occupies a median position; extends like an ovarian tumor into the pelvis; is attached to the pelvic organs; pushes the intestines aside like an ovarian cyst; contains fluid free from elements of urine; and eren presents cholesterine and paralbumen. In such cases the determination of the point of attachment by Simon's method constitutes a most valuable resource.

Siplenic and hepatic eysts are rare, grow from above downwards, give an area of dulness between tumor and pelvis, and in the fluid of the latter 
the echinococcus is often discovered. In both Simon's method is of great value as a means of differentiation.

Paraitic cysts, the result of the presenee of the echinococcus, may develop in any of the organs or tissues of the abdomen. Should the position of the tumor be such as to lead to doubt as to differentiation between it and owrian cyst, diagnosis would be attainalle only by aspiration and examination by the mieroscope and cliemical means. The former would show the presence of the parasite.

Sulperitoneal eysts are distinguishable from orarian only ly physical features of contained fluid and explorative incision.

Cyits growing from the uterus itself are not common. They may be reeognized by Simon's method, by the chemical examination of their contents, and by the curative effects of tapping. Atlee reports three eases thws cured. Furthermore, the fluid which they contain separates into a coagulum and a pinkish or bright red portion which does not coagulate, and the peenliar cells of ovarian fluid do not appear in it. Ovarian fluid never spontaneously coagulates.

Fibro-cystic tumors are diflicult of differentiation from ovarian cystomata, but when we comprare our present position with reference to this sulject with what it was only a few years ago we have great cause for congratulation. I here give only the most prominent differences between the two diseases, and hence those upon which reliance can really be placed. To many of these even, however, there are exceptions; to several there are none.

Utense Fibo-crst.

Grows slowly and occurs usually after thirty years of age.

Corine carity generally enlugent.

Conuection of tumor and uterus usually, though not always, intimate.

l'luid spontaneonsly and quickly coagulates.

Cterus sometimes lifted alwow pultes aml out of pelvis, often in front of tumor.

Ifralth remains geond for years.

Mirroscope shows fithe cell (1)rystale).

\section{Ovariax Crst.}

Grows more rapidly and is less governed by age.

Lterine cavity not usmally enlarged.

Cterus more inklependent of tmuor.

Never does so.

Uterus generally hehind tumor.

Conerally fails within three years.

Shows the preculiar gramular aul epithelial cells of ovarian cyst.

Although these signs are all of some value, those which should be regarden as most reliable are the following: spontaneous coagulability of comtanerl fluill presenee of the fibre cell; increased capateity of the utern; and the determination of its comnection with the tmmor by mans of simen's methon of rectal exploration. Explorative ineision should not ramk high as a diagnostic method, for simple section of the abdominal walls is not anough, and the explomtion which is further required to decirle the proint exposes the patient to great danger. 
Excessice Development or Displacement of other Tiscera.-If ascites lo not attend hepatic and splenie enlargenent, there will never be any great dilliculty in distingrushingr them from ovarian eystoma. Should it do so, tippling should be resorted to.

Vterine fibroma may be recognized by its peculiar hardness, slowness of erowth, absence of fluctuation, continuance of grood health and alsence of enaciation, tendeney to increased menstrual flow, irregular surfice, intinate connection with uterns, increase in capacity of this organ, and absenee of fluid upon aspiration or tapping. It nust not be forgotten, however, that the uterus may be normal in size, and the tumor entirely independent of it.

"The symptoms caused by the growth of large, tatty, and fibro-plastic tumors fiom various parts of the peritoneum or mesentery," says Spencer Wells," "so much resemble those of true ovarian disease, that their real nature can only be determined in some cases by an exploratory incision or lappingr." Should fluid be removed from them it would lack the peculiar ovarian cellular elements, and would spontaneously coagulate, and Simon's method would in some cases demonstrate the fact that the point of origin is not the ovary.

A movable or floating kidney might be mistalien for an ovarian cyst, but for so small a one that the question of ovariotomy would not arise in connection with it. Time would prove that it was not a growing ovarian cyst.

Dr. J. K. Dile, ${ }^{2}$ of Little Rock, Arkansas, reports an interesting case of tumor supposed to be ovarian, but which upon explorative incision was found to be the liver, which was " free and movable, very much enlarged, oceupying the right half' of the pelvis, encroaehing upon the bladder and rectum, and interfering very materially with the due performance of their respective functions." I had myscli precisely the same experience in a case in which I made an explorative incision in New Haren, in presence of Drs. Whittemore, Jewett, and others.

Pregnancy.-The ordinary signs of utero-gestation, both rational and physical, should be carchully considered in eliminating normal and interstitial pregrnaney. More than one woman has died from the passage of a trocal and cinula into the pregnant uterus after abdominal incision, an accident certainly scarcely more deplorable for the patient than for the unfortunate practitioner whose carelessness causes it. I say carelessness, for the reason that the passage of the uterine sound as a means of differentiation would always prevent error. True, this would result in premature labor in normal pregnaney, but how mnch better this, even at the sacrifice of the child's life, than the terrible mishap just alluded to.

During the past eighteen montlis three cases of pregnancy at full term 
have been referred to me as ovarian eysts, and this not by ignorant men but by very eapable practitioners. Two out of the three pregnancies were illegitimate, and the examiners were misled by relying upon rational instead of physical signs. Reliance should be placed especially upon discovery of the foctal body and movements by careful palpation; upon ballottement between the fifth and seventh months; upon recognition, by vaginal toueh, of the movable presenting part after that time; and upon the foctal heart sounds and placental bruit. The gastric, mammary, and nerrous symptoms of pregnancy sometimes result from orarian disease.

Should the clild be dead many of these symptoms will be absent, and if it be retained in utero, as it sometimes is, for many years, diagnosis must depend upon the history of the case, Simon's method, the uterine sound, and dilatation of the cervix so as to admit of digital exploration. In tubal or ventral pregnancy diagnosis would prove more diffienlt, but the same means will aid in making it, for even when the foetus is developed out of the uterus that organ enlarges deeidedly.

Not only should a differential diagnosis be made between pregnancy and ovarian tumor; even after recognition of the latter, the former should always be eliminated as a coincident condition.

Dropsy of the amnion gives very superficial fluctuation, and might deceive one not careful in diagnosis. A patient investigation of the ease, and consideration of its history would ordinarily remove all doubt. The fibres of the cervix uteri are usually expanded, the cervix moves as the tumor is rolled in the abdomen, and the nterine sound passes far up into the cavity above. Should aspiration have been resorted to, the fluid remored will be found to present the following features. It is alkaline, with specific gravity 1005 to 1010 , eontains albumen but no fibrin, and presents to the microseope epithelial cells and oil globules. Meconium and blood alter these features.

Diseased States of Pelvic Walls and Areolar Tissue.-Enchondroma or encephaloid disease of the pelvic walls is lard, free from fluctuation, and firmly fixed and united to the part from which it grows. Rectal exploration and abdominal palpation will prove these facts, and if aspiration be attempted the absenee of fluid will be evideneed.

Pelvic abseess usually results from cellulitis, which presents marked symptoms. It rarely extends to the umbilicus, hardness will be felt in one or other iliac fossa, it is fixed in the pelvis, and aspiration gives evidenee of pus. Exeessive pain attends it, with throbbing and pain down one thigh, and the outline of the mass is obseure and unsatisfactory. There is often a tendency to point, there is pain upon pressure, and there are generally chills and fever.

In the early days of ovariotomy, when adhesions were regarded as a bar to extirpation of these tumors, the question of the existence of arthesions possessed important bearings. Now, however, when even the firmest 
attachments are broken not only with impunity, but with results which are ofter better than those which follow the removal of a tumor from a healthy peritonenm, it sinks into comparative insignificanee. This is a most fortunate fact, for the reason that the eletermination of the existence of athesions is little more than guess-work. Beyond a few very ereneral facts by which we may venture to form a surmise, all is empirical prealiction with reference to the matter.

If the case have developed very rapidly and be believed to be unilocular, there are probably no adhesions.

If there have been symptoms of peritonitis, there are probably adhesions. If the case have been painless, there are probably none.

Should the abdominal walls roll fieely over the tumor, the patient lying upon her back, and should the tumor fall low in the abdomen as she suddenly sits up, there are probably no anterior adhesions. But posterior ones may exist, and not be suspected from this examination.

If, upon vaginal examination, the uterus and base of the tumor exlithit immobility such as is found in pelvic peritonitis, and if, upon change of posture from erect to supine, these parts do not retreat from the finger in the vagina, there are in all probability strong pelvic adhesions.

All these signs are unrelialsle, and disappointment will surely follow any great degree of confidence which is reposed in them, but a compensation is to be found in the fact already stated that even firm adhesions do not eontraindicate removal.

It is always desirable to know the length of the pedicle. This point can be approximatively settled, in a certain number of cases, by the means recommended by 'Tixier, ${ }^{1}$ of Strasbourg. IIe says :-

"Practice and observation have enabled us to diagnose, in certain cases, the probable length and variety of the pedicle. Certain objective and subjective signs may guide the practitioner and facilitate his diagnosis; a very important matter, sinee on the length of the pedicle often depends the success of the operation.

"We have hitherto been able to diagnose with almost perfect certainty three varieties: the long, short, and twisted pedicle.

"The long pacticle. - The form of the abdomen has a peculiar aspect; this is the form en besece. The hypogastric portion of the abdominal wall is applied to the internal surfaces of the thighs, and the ovarian tumor, forcibly projected forwards, seems to be remored from the superior entrance of the pelvis. A vaginal examination reveals an elevation of the cervix uteri, and the index finger passed into the pelvic excavation does not meet with the tumor at any point. The womb is very morable and can be readily displaced. The collection of these symptoms induces one to presume that there is an elongated condition of the broad ligament and of the

1 Le Pédicule et son Traitement après l'operation de l'Ovariotomie, Strasbourg, 1 1s 9 ; Archives Générales de Mlédecine, Juillet, 1870. 
Fallopian tube, a condition favorable for forcing the pedicle without the abdominal wound.

"The shoit preticle.-The existence of the short pedicle may be assumed in the presence of the following symptoms: in the first place, the form of the abromen diflers from that described above; one may observe a lateral extension without pronounced prominence of the median portion. In attempting $t$ o introduce the tip of the finger between the tumor and the pules, one feels through the skin that the growth passes into the pelvie excavation; its base seems to be seated over the pelvie opening. The raginal tnuch denotes a sinking of the eervix uteri, and a more or less pronounced immobility of the womb. If the pelvic excaration be then explowel with the finger, one feels that it is not free, and that certain parts of the tumor are contained within it. In the presence of these facts the surgenn may assume that there is a greater or less degree of shortening of the pedicle.

"The teristed lecliele. $-A t$ first sight this torsion seems difficult to determinc. It may, howerer, under certain conditions, be diagnosed with greater certainty than the two preceding varieties. Its existence may be concluded whenerer the following symptoms have been observed:-

.. The patients experience at intervals very acute pains radiating downwarls along the vein corresponding to the affected ovary, and upwards to the lumbar region on the same side. These pains are excited by work and fittigue. They break out also when the patient is in bed, and when she wishes to change her position. One hear's also from these patients of very stroug uterine cramps analogous to those occasioned by deligation of the pedicle. The cystic tluid is more or less deep in color, presenting a hemorrhatic appearance. The touch in these eases gives no precise indication. One can only accuire the idea of the existence of an habitually long and thin pediele in cases of this kind."

Although I have not been able to draw as positive and certain conclusions in reference to the determination of the length and character of the pedicle, by aid of these meams, as M. Tixier has, I nevertheless regatrd his sugrestions as valuable, and well wortly of application to every case in which ovariotomy is contemplated. One rule which I have found very reliable is this-if the tumor be found far up, ont of the pelvis, upon raginal examination, the pedicle cannot be very short. If a tumor which is not very large be fixcel in the pelvis so that it cunnot be pushed out, the perliele is probably a short one. The value of this sign may be increased by rxamining in the knee-elbow position.

When doults exist upon any of the points here stated, which eannot be removed hy those means of investigation which are limited by the abrominal walls and pelvie roof; which, in other words, extend to, but not byoul, the peritoneum in their immerliate application, there exist three unethent: of exploration which bring the explorer into direct contact with the interior of the abdomen and of the tumor. Those positive and reliable 
moans, which may justly he styled the erucial tests of ahhominal munors, are the following :-

\section{Aspiration ;}

T:upling;

Explorative ineision.

To these a certain amount of danger undoubtrdly attaches; but when compared with the great danger arising from operation upon an meertain diagunsis, it becomes trivial. Many an inappropriate case has been submitted to the operation of orariotomy which would have been spared it, with the promise of a protongation of life, had one of these metherls been previonsly employed. They are of course not to be confined to the determination of the chanater of at tumor alone, but that of the origin, attachments, and complications of any ablominal growtl.

Aspiration.-The introduction of aspiration into use for the liagnosis of ovarian tumors constitutes a decided aldumee. The instrument generally employed in this comntry is that of Dieulafoy, shown in Fig. 28. By this a delicate, hollow needle is passed into the tumor, and powertul suction applied through an India-rubber tube comeeted with a strong syringe, in which a vaeum is created by an upward movement of the piston. Through the most delicate needle clear fluids will pass, and through the langest, which is very small when eompared witl an ordinary trocar and eanula, very tenacious colloid material may be drawn. By this beautiful instrument a large polyeystic tumor filled with tenacious, syrupy fluid may be readily emptied by turning the needle into new eysts as those first punctured are eraenated. And when eomplete evacuation is not desired, it furnishes a supply of fluid for chemical and nieroscopical examination. It greatly diminishes the dangers of such evacuation as compared with those resulting from tapping. The dangers attending that operation are the following: 1st, hemorrhage from a bloodvessel in the abdominal or erst wall; 21, admission of air to the cavity of the sac and decomposition of flud, which may ereate inflammation of the cyst wall and septicamia; $3 d$, subsequent escape of the eontents of the tumor into the peritoneum; and the futal injury from wounding of an intestine or solid organ. Spencer Wells mentions a ease in which an aequaintance of his tapped a patient who died soun after. Lpon antopsy two and al lalt' (quarts of blood, which had esalpul from a wounded variense vein, were found in the peritoneal carity. All these dangers are considerable from ordinary tapping; decidedly less so trom aspiration.

It may then satcly be said that aspiration aceomplishes all that tapping does, at infinitely less risk, and that the former should, when practicable, alway be preterred to the latter procedure. Unfortunately the eost of the aspirator is large, and it may not be attainable, or the fluid may be too thick to flow throngh it. When it is desired merely to obtain a small amount of fluid for eximination, the hypodermic syringe may be employed, 
even in preference to the aspirator. The use of this instrument, which was suggested by Dr. H. F. Walker and practised by myself before our knowledge of that just deseribed, consists simply in plunging the needle with syringe attacled through the abdominal walls at different points, drawing out as much fluid as possible, and expelling this into a test-tube for examination. This method serves to determine the following points : 1 st, whether a tumor is fluid or solid; $2 \mathrm{~d}$, whether it contains clear, slightly albuminous fluid or ichorous and irritating material ; $3 \mathrm{~d}$, by means of several punctures whether it be multilocular or not. In 1875 , Dr. Peaslee declared that he did not regard the aspirator as safer than the trocar. Surely an instrument with which we venture to tap the distended intestines, the pericardium, and the bladder, must be safer than one which leaves so large a hole as the trocar.

Although it has been stated that aspiration is much less dangerous than tapping, it must not be regarded as free from danger. Death has repeat. edly resulted from it, and it should be regarded as an axiom that all abstraction of fluid from an ovarian eyst, by whatever means it is accomplished, is attended by danger. The smaller the puncture made, lowever, the less the danger, I think. Cases of peritonitis, some of them fatal, after aspiration, are recorded by Atlee, Little, Lusk, Munde, Gillette, and Jenks; cases of decomposition of sac contents and septic fever are reported from the same eause by Goodell, Perujji, Schnetter, Skene, and myself ; and a case of peritonitis and adhesions after diagnostic puncture by a hypodermic needle by Fauntleroy of Virginia.

Tapping.-Tapping is a means of great value in the diagnosis of ovarian cyst, and, where the aspirator is not attainable, should never be lightly disregarded. Atlee, Wells, Peaslee, Spiegelberg, and many other leading ovariotomists of our day place great stress upon its value, and although some, like Stilling, have entitled it, in the warmth of deprecation, "a crime," it may safely be said to have overcome the greater part of the objections once urged against it, and to have fully establislied its claim to consideration as a valuable diagnostic and palliative measure. Wells has proved that it does not consilerably increase the mortality of ovariotomy. It is often even an excellent preparation for that operation, and, when practised with proper precautions, its dangers are greatly diminished. It must not be forgotten, however, that it is attended by dangers, which are not matters of speculation, but of fact established by statistical evidence. Of 130 instances of first tappings analyzed by Kiwisch, 17 per cent. of the cases died within a few hours or days after the operation. ${ }^{2}$ This is certainly a mortality to be greatly dreaded, espeeially when the operative prorelure which induces it is not curative, but one resorted to merely for galliation or the accomplishnent of diagnosis.

1 Op. cit., p. 275.

2 Hewitt, op. cit., p. 637. 
The operation of paracentesis, or tapping, eonsists of the introduction of a trocar and canula through the walls of a sac contaising fluid, and allowing this to flow away. Of all the operations for relief of ovarian dropsy this is the oldest, and the one which has been most frrdun'ntly performed. The adrantages which it offers are facility of performance, quickness of relief, and immunity, to a certain extent, from the dangers which attend more radieal procedures adopted in these eases.

Althongh, in a limited number of cases, it has been declared to have proved eurative, it should never be pratised with any reliance upon its doing so, for donbt exists as to the authenticity of the facts. Furthermore, it is attended by the immediate dingers recently mentioned, and by the more remote one of exhansting discharge from the sac, which may continue so long as to wear out the patient's strength. M. Courty collates one humbred and thirty eases treated in this way by Kiwisch, Lee, and Southam, of which these are the results:-

$$
\begin{array}{llll}
46 & \text { died after the } 1 \text { st tapping. } \\
10 & \text { " } & 2 \text { d "6 } \\
26 & \text { " } & \text { " } & 3 \text { d to } 6 \text { th tapping. } \\
15 & \text { " } & \text { " } & \text { ith to } 12 \text { th " } \\
13 & \text { " } & 12 \text { th tapping. }
\end{array}
$$

Of 21 of these cases treated by $M I$. Southam, 4 died within a few hours after the operation, 3 within the first month, and 14 within nine montlss. Kiwiseh lost 9 out of 64 within twenty-four hours after the first tapping. Dr. Fock, ${ }^{1}$ of Berlin, gives the following table, displaying the dates at which death occurred after first operations in 132 patients :-

$$
\begin{aligned}
& 25 \text { died within a few days. } \\
& 24 \text { " " } 6 \text { months. } \\
& 22 \text { " " } 12 \text { " } 12 \\
& 21 \text { " " } 624 \text { " } \\
& 11 \text { " " } 36 \\
& 29 \text { only were alive at end of last date. }
\end{aligned}
$$

132

It will thus be seen that reliable statistical evidence places this procedure in the position of a palliative measure which is generally followed by advance of the disease, and not rarely by immediate evil results. Still it must not be lost sight of that death may be warded off by the operation, many existing evils alleviated through the course of a period varying from ten to twenty-five years, and that, in a few cases, complete cure may have been effected. Dr. Ramsbotham records an instance in which one lundred and twenty-nine tappings were performed in eight years, and four lundred and sixty-one gallons of fluid removed; and Dr. Martineau another, in which eigity operations evacuated in twenty-five years seven

$$
1 \text { Simpson, op. cit., p. } 347 .
$$


hundred and twenty-nine gallons. I had recently under my care a patient who for tive years has had a large cyst which has been tapped forty-five times.

I have stated that a considerable number of cases are on record in which it is asserted that simple tapping has cured ovarian cystoma. It is a matter of great doubt whether the cases thus cured were true ovarian eysts, or eysts of the broad ligament, which are often thus cured. Linowing of no well-authenticated case in which orarian cyst has been thus permanently cured, we are not warranted in regarding this measure as anytling more than a valuable diagnostic means and a palliative resource, which often saves life when it is threatened by one of the consequences of the cystic disease.

In case the contents of the cyst do not appear to be those of true ovarian cystoma, but jresent the characters of the fluid of cyst of the broad ligament, tapping may be practised with a reasonable hope of curative results.

The circumstances which ordinarily indicate the propriety of paracentesis as a jalliative measure are, rapid accumulation which interferes with some important function; coexistence of orarian discase with pregnancy; solitary eharacter of the cyst ; firm adhesions which bind the tumor down so as to prohilitit a more radical procedure; great doubt as to diagnosis; or constitutional debility, which prevents the tolerance of a more serious operation. The operation may be performed throngh the abdominal, vaginal, or rectal wall.

Tapping throngh the Abdominal Wall.-The patient being placed upon the side, a many-tailed londage, such as is emploged in paracentesis abdominis, is pased around the borly. Its ends heing held by assistants, traction upon them malses firm pressure, evaenates the tumor, and prevents syncope. $\Lambda$ fold of skin being now pinched up between two fingers, it is penetrated by a lanect or bistoury upon the linea alba, midway between the symplysis pubis and umbilicus. The trocar and canula are then flunged throngh the two layers of peritoneum and the wall of the cyst. Thromgl the cantal thes introduced a tlow of fluid will take place, which, if sueh an in-trunent as that represented in Fig. 254 be employed, will be conducted by an India-rubler tube attached to the canula into at tul, placed by the side of the bet upon which the patient lies. 'The free' extremity of this tube is kept carefully immersed in water in the tub, to prevent entrance of air into the sace.

Shonk other evsts be felt through the abdominal wall after emptying the inain one, the canula may be made to empty them, by pressing it firmly arainist them.

The following rules should be owerved in abdominal tapping of ovarian "yst; for it is highly probahle that a strict adherence to them would very fitrombly atlect the statisties of the operation. 
1st. Never talp while the paticnt site, but alway: as she lies npon the side or batck.

2t. C'nt the skin with a lancet, and employ a trocar and camula, with tube inmersed in water, so as to prevent entrance of air.

Fic. 254.
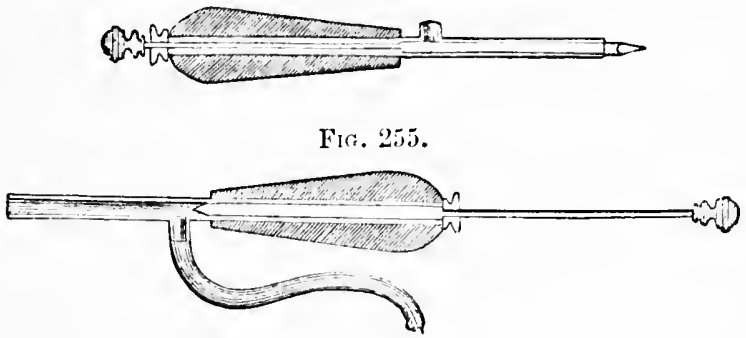

31. When the fluid withdrawn is viscid, always wash out the cavity of the sale, if it be empticd, with warm, earbolized water.

1th. Should there be oozing of blood from the puncture, pass a hatrelip pin deeply through its lips, and affix a figure-eight ligature.

5 th. Keep the patient recumbent and rery quiet for two or three days.

Tapping through the liall of the Tagina.-This operation has been more or less in rogue for a long time. According to Kiwisch, it was first performed by Callisen in 1775 , but has received little notice until modern times. Velpetul declares that he advised it in 1831, and that it wats adopted a few years afterwards by Neumann and Récamier. In Germany it hats of late years been frequently resorted to, and Scanzoni gives the following reasons for preferring it to abdominal paracentesis. It "more often produces a radieal eure than the other method just considered, and that especially becase the cyst, opened in its lowest part, can empty itself more completely. If the puncture by the vagina were always posible, the abdominal puncture would soon entirely disappear from chirurgical practice; but unfortunately, this is not the case, for the conditions neeessary for this operation are met with in but few patients; in fact, it is rare that the lower portion of the tumor descends sulliciently low into the pelvis to be accessible to raginal toueh, and, furthermore, in miny eases where the tumor can be reached, it does not present in its lower portion any eavity filled with liquid, but only solid masses of a sarcomatous, colloid, or cancerous nature." Kiwisel declares that he "unconditionally" prefer: it to ablominal tapping, whenever it is practicable.

by this method, the arlvantages of which are thus strongly stated by the authorities just mentioned. two of the diangers of tapping, secondary escape of fluid into the peritenemm, and consergnent peritonitis, are unquestionably 
lessened, but others are as surely increased, namely, those of injury to portions of the intestine, and entrance of air into the sac, with consequent decomposition of eontents, septiexmia, and inflammation of the sac walls. My experience with the metlod is not large, but it leads me to agree with Spencer Wells that, "as a rule, air enters the cyst, the opening fills up, and the fluid remaining in the cyst, or that freshly secreted, putrefies. Suppurative inflammation of the lining membrane of the cyst comes on, and is accompanied by a low form of exhaustive fever or pyxmia." Where a eyst is firmly fixed in the pelvis, however, this method, followed by drainage and antiseptic injections, is one of great value.

The operation is thus performed : the bladder and rectum having been carefully emptied, and the patient anxsthetized, she should be placed upon a table in the position for lithotomy. The operator then introducing the index, or, as is better, the jndex and middle fingers of the left hand, places them against the most dependent and accessible part of the tumor. Upon the finger or fingers, a canula ten inches long is passed up and pressed against the tumor, the point of the troear being drawn in a little. The operator then plunges the trocar through the vaginal walls into the tumor, and withdrawing it allows the fluid to flow away through the canula. The patient is then put to bed, quieted by opium, and guarded against all influences which might induce inflammation as long as such an accident is probable.

Explorative Incision.-Of all the means for definite and certain settlement of the question of diagnosis in abdominal tumors, I esteem explorative incision most highly. As, however, it involves not only opening the peritoneal cavity, but usually considerable manipulation of its contents, it neeessarily involves a certain amount of danger. While the other methods may be practised several days or even weeks before the operation of ovariotony, this should constitnte, or rather be merged into, its first step. If it yield information which makes the surgeon deeide against operation, the opening marle should be closed; if the light which it throws upon diagnosis favors the radieal procedure, the incision should be at once enlarged and prolonged into the final abdominal opening.

Explorative incision should be thus performed. The patient having been prepared for the procedure exactly as if we lad determined upon ovariotomy, she is placed upon the table and surrounded by assistants, etc., as in the case of the radieal operation. An incision is then made by the bistoury upon the median line, one inch in length. This is earried down to the tumor, and the finger is at once gently swept over this in every direction, so as to ascertain its character. The tumor may be emptied with a very smoll trocur, so small that the opening made maty be readily elosed if it be deemed best to desist from ranlical operation, or by the aspirator. If the sac be emptied by this means, the hand is then passed into the abrlominal cavity and complete exploration made. If it be not completely 
emptied, a sound should be passed into the uterus and two fingers or the hand carried down through the abdominal opening to the fundus uteri, to aseertain as aceurately as possible the origin and attachments of the solid mass. In ease abdominal effusion have existed, this of course at once flows away, and any growth existing in the abdomen comes within the reach of the finger.

Before leaving this part of my subject let me lay before the reader a few rules, the observance of whieh will diminish very greatly the ehances of his falling into errors of diagnosis in operating for ovarian tumors.

1st. Never perform ovariotomy without carefully exploring the uterus by the somnd, if this be possible.

2d. Before operation, should doubt exist as to diagnosis, always remove a small amount of fluid by the hypodermic syringe or aspirator for chemical and microscopical examination.

3l. If any doubt whatever exist as to diagnosis, anæsthetize the patient and examine carefully.

4th. If doubt still exist, empty the cyst or eysts by aspiration or t:spping.

5th. Should all doubts not be cleared up at the moment of operation, begin it as an explorative incision and proceed or not as instrueted by what is discovered.

Spiegelberg ${ }^{1}$ makes the important declaration that when upon drawing off fluid either from a cyst of the broad ligament or an ovarian cyst, it is found to be of low density and of serous nature, it may be taken as evidence that the eyst wall has ceased to grow actively, and is merely being distended by accumulation of its contents. He opposes operation under such circumstances, declaring that emptying the cyst will of itself often effect a radical eure.

Treatment.- The medical treatment of ovarian dropsy by diuretics, hydragogue cathartics, diaphoretics, mercurials, absorbents, mineral waters, etc., has now been faithfully tested and found to be ineflicacious. After a eareful search through the recorts of the subject, one is forced to the conclusion that there is a lack of evidence substantiating the possibility of the accomplishment of absorption by these means. All that can be anticipated in these cases from medication is sustaining the nerrous and sanguineous systems by tonjes and stimulants; regulating disordered functions by diaphoretics, cathartics, diuretics, and anti-emetics; and relieving local inflammations by the ordinary means usually resorted to under such circumstances. I am the more urgent in insisting upon the fact of the inefficacy of constitutional treatment, because $I$ so often meet with fully developed cases of ovarian dropsy which bear evidence of a variety of attempts by cupping, leeching, inunction, painting with iodine,

I A rchiv für Gynäkologie, vol. xiv. s. 175 . 
and correspondingly active internal treatment, to dissipate the accumulation. There is but meagre proof extant that such means have effected cures, and there is nothing more certain than that they lower the tone of the system and depreciate the vital forces. A recognition of this fact led Dr. W. Hunter, before the introduction into practice of the present methods of surgical treatment, to say that, "the patient will have the best chance of living long under it (ovarian dropsy) who does the least to get rid of it."

Not only is it to surgery alone that we must look for aid, but to one surgical procedure-ovariotomy. Even after the acceptance of ovariotomy as an operation, the medical profession strove, and very properly, too, against its universal adoption in cases of ovarian tumor, and endeavored to discover less radical processes which were to share the field with it. Thus up to a late day were tried, and even now, in rare cases, are tried, tapping, drainage, incision, and injection of the sac. I do not give the details of these procedures here, for the reason that I question the propriety of their adoption. In the present state of our knowledge, whether the tumor be large or small, simple or complex, the attempt to employ other curative means than ovariotomy can scarcely be regarded as warrantable, in view of the dangers attaching to them and their uncertainty of suecess, and, on the other hand, the hope of good results which is held out if the patient is sustained until complete extirpation can be accomplished.

\section{CHA P TER XLIX.}

\section{OVARIOTOMY.}

Definition.-Orariotomy consists in the extirpation of the diseased oraries.

History.-The history of the operation goes back only to a very recent date. It has become customary for those who have written upon it to cite ancient authors to prowe that even as long ago as the time of the early Greeks the ovaries were often removed in the inferior animals as is done in our own time. The writings of Aristotle put this beyond question. It is even asserted that among the Ifylians castration of the human female was practiser in order to enable them to serve as eunuchs. In more recent periods, we are toll by Wierus that a Hungarian swineherd, incensed by the lasciviousness of his danghter, removed her ovaries, in hope of reformation, after the manner in which he was in the labit of spaying his swine. Towards the close of the eighteenth century both ovaries, 
which had descended into the inguinal canals, were removed by 1)r. Percival Pott, of England. But all this, though interesting as a unatter of physiology, las little to do with the operation of ovariotomy, accorling to the true signification of the term. In the ouc case a minute and healthy glamd, which is sparsely supplied with blood, was removed from a liealthy preritoneal cavity. In the other a huge sac, which is supplied by lance bloodressels, and has in many instances contracted adhesions to a diseased peritoneum, requires extirpation.

The idea of removing large ovarian cysts, even, is not new, since it was discussed in 16 \&.) by Schorkoptf, in 17222 by Schlenker, in $1731 \mathrm{ly}$ Willius, in 17.51 by Peyer, and in 1752 by Targioni. In 1758, Delaporte even went so far as formally to propose the operation to the Royal Acalemy of Surgery. As the eigliteentli century approached its close, the suggestions of the writers already mentioned were not forgotten, but were from time to time repeated ; among others by John Hunter in 1787, and later still by William IInnter. In 1798, Chambon ventured to prophesy that it would in time become a recognized resource in surgery ; and in 1808, Simmel d'Escher, a student of Montpellier, proposed a specific plan for its performance based upon the teachings of one of his masters, M. Thumin.

In 1786 , one observer stood upon the very verge of the great discovery, very much nearer than Laumonier, by some supposed to be the discoverer, ever did, and yet failed to systematize it as a surgical resource. Like many a man before and since lis time, he recognized and appreciated a fact, but failed to connect this with a law. The following is a quotation from a work written by Thomas Kirkland, an Englishman, and publislied in London in 1786. It is entitled, "An Inquiry into the Present State of Medical Surgerv.",

"A woman, betwixt twenty and thirty years of age, had been tapped twice for an ascites, and a large quantity of water taken away at each time; but after the last operation the puncture clid not heal, and, in a little time, a substance they did not understand protruding, I was desired to see leer. It was evidently a part of a eyst, and, as it had already dilated the sore, I persuaded her to let it alone till the opening became larger, in hope of a better opportmity of afiording relief. Accordingly, in ten days or a fortnight the protruison was much larger, and by the help of a dry cloth a cyst, that would contain five or six gallons of water, was gradually extracterl. Yore than a quart of matter immediately followed, and more was daily discharged for some time, yet the woman recovered without further trouble than keeping the parts clean, and atterwards bore several children."

Later on in his work he says :-

"We have given an instance, p. 195, where a cyst being taken away cured an ascites; and, seeing medicines do not a vail in eneysted dropsies

I Wieland and Dubrisay, French translation of Churchill on Dis. of Women.

2 Med. Record, June 15, 1867, from Exchange. 
of the abdomen, is it not worth our while to consider whether, when they are unconnected with the aljacent parts, after taking away the water, the patient might not sometimes be eured by enlarging the puncture, pressing the eyst forward, and drawing it out?"

He then proceeds to examine the difficulties in the way and the objections which may be brought against the operation, and thus concludes :-

"At present, I offer these hints to those who think the subject deserving attention, and time will probably determine the question.",

Thus, as we advance from more remote periods to the beginning of the nineteenth century, we find the minds of physicians being grachally jrepared for the reception of ovariotomy, as its consummation was step by step approached. But all that we find accomplished up to this time is the womulgation of ideas, prophecies, and propositions, and the performance of accidental operations, or of those upon healthy ovaries.

In 1809 , the first real case of orariotomy ever undertaken was successfully performed by Dr. Ephraim McDowell, of Kentucky. His first case was successful, the patient living twenty-five years afterwards. Subsequently he operated thirteen times, twith eight favorable results. It may confidently be asserted that the history of no operation has been more thoroughly sifted than this, and that, up to the present time, nothing can be elearer than the fact that to McDowell belongs the eredit of priority of performance. It is interesting to examine the competitive claims which have been put forwarl in reference to the matter. First, in chronological order, is that of Dr. Houstoun,' of Scotland, who operated in 1701, and whose case, says Mr. Wells, ${ }^{2}$ makes it "appear that ovariotomy originated with British surgery, on British ground." This statement will excite wonder, and the claims of the operator fail to attract attention when it is stated that nowhere does Houstoun claim to have removed the cyst, or even a part of it. He merely treated a case of ovarian cyst successfully by incision.

The second is that of Laumonier, of France. Of him Baker Brown says: "The first who attrmpted extirpation appears to have been Aumonier, of Rouen, in 1782, and he was succesful." In this statement, as Dr. Parvin has pointerl out, Mr. Brown was wrong in three points: first, as to the fact; second, as to the name of the operator; and third, as to the date. The supposed ovariotomy was performed in 1776 , by Laumonier, and was really the opening of a pelvic alscess.

The third is that of Dzondi, of Ilalle. As the patient was a boy, the claim refuires no further consideration.

In 1821. Dr. Nathan Simith, of this country, operated snceessfully. In 1.2.3 Dr. Lizars endeavored to introduce the operation into Scotland, and

I Amer. Jonrn. of Merl. Sciences, vol. vii., 1849, p. 534. $\quad 2$ Op. cit., p. 299. 
operated four times, but his results were bad. In one case the tumor was uterine and was not removed; in one no tumor could be discovered after abdominal section; and one of the two cases upon which ovariotomy was performed lied.

Since this period, Atlee, Peaslee, Kimball, and Dunlap have been most influential in establishing the operation in America. In Engrand, Dr. Charles Clay, in 1840, pressed it upon the notice of the profession, and he was soon ably sustained by Lane, Wells, Keith, Bryant, Baker Brown, and many others, whose names have become famous in eonnection with it.

"It is only within the last five years," says Grenser, writing in 1871 , "that much progress has been made in Germany in this operation." Untortunately, for many years insucess appeared to attend it, and thus the voices of the most eminent and authoritative were raised against it. Of the first three patients ever operatel upon there (by Chrysmar, in Wurtemberg), two died. Clurysmar commenced operating in 1819, and lis results were certainly not such as to popularize a new and dangerous procedure. In 1828 the alverse criticism of the great Dieffenbach was pronounced in these strong terms: "Whoever' considers the opening of the abdominal cavity as a light matter, and, as Lizars seems to believe, that the difficulties are small, whoever thinks that this operation is accompanied by no more dangers than other operations, must be very thoughtless; for me, my one case is suffieient." The "one ease" to which he refers, and from which he drew so illogical and hasty a conclusion, was an incomplete operation. In spite of the adverse weight of this opinion, in 1835 Quittenbaum, in 1841 Stilling, and in 1851 Martin, operated in a few cases, and with varying suceess. Writing of the operation at this time, when overclouded by repeated insuccesses, it had failed to command the confidence of the profession, Grenser says: "Most of the ovariotomies performed within the last forty years had a fital termination, and as a consequence reliance could not be felt in it, and confidence in it was altogether shattered when the celebrated Dieffenbach took ground against the operation." Diefenenbach's opinion in 1828 has been given; let us see how the experience of twenty years affected it. In 1848 he wrote: "The operation does not benefit either patient or plyysician; the idea of opening into the abdomen of a sick, cachectic woman, affected with a hard tumor of the ovary, or even employing Lizars' method with cross-incisions, in orler to remove the tumor by force, seems neither reascnable nor useful." lle moditied his opinion somewhat where the tumor was fluid, of small size, and movable. 'Thus wrote the great surgieal light of Germany, and while he wrote American and English surgeons were gaining great results for humanity and for science in this same field. It must not be supposed that even in his own country advances were not being made, for Stilling,

1 Grenser, Report on Ovariotomy in Germany. 
Büring, and others were carrying on the work. In 1850 the latter announced an important advance, namely, that adlicsions should not be considered as a contra-indication to removal.

In 18.52 Edward Martin declared that the question was no longer as to the propriety and efficiency of ovariotomy, but of circumstances favorable to success. Martin's rules for operating, read even by our present lights, are most of them excellent.

About this time the voice of liwisch was raised against the operation. II ${ }^{1}$ collected the statisties of 54 eases, of which 51 ended fatally, and concluded that certainly over half of all submitted to operation died. It was soon after this that Scanzoni and Gustav Simon gave their evidence against the operation, and increased its disfavor to such a degree that, as Grenser says, "its very existence was threatened." This opposition seems to have lasted up to 1864 , when the tide appeared to turn in its favor, and it soon numbered among its advocates Breslau, Gusserow, Hildebrandt, Spiegelberg, Martin, Stilling, Veit, Wagner, and Billroth. Grenser collected in 1871 the statistics of 129 operations performed in Germany, of which 60, a little less than half, recovered. When these results are compared with English and American statistics of that period, they show that Germany had much to make up. That she has done this is proved by the excellent results obtained by Schroeder and other operators of the present time, and to-day it must be conceded that in this department of surgery she stands fully abreast with other countries.

According to Grenser we owe to Germany two of the most important of the improvements which have taken place in the operation since the days of McDowell : first, the adoption of the short incision and tapping the sac in situ, which originated with Quittenbaum; second, the external treatment of the pedicle, which he declares was first resorted to and its advantages insisted npon by Stilling in 1841, and not by Duffin in 1850 . In 1819, Martin first secured the pedicle in the lips of the wound. There are other arlvances which have been made in Germany; but I mention only those which have had a decided influence on the operation.

Into France the operation was introduced, or as some Frenclı writers express it, " reintroduced," by Dr. Woyerkowski, in 1844. It was subsequently performed by Vaullegeard, in 1847 , and later still by Nélaton, Maisonneuve, Jobert, D'marquay, and other surgeons of Paris. The results of these attempts, however, had the effect of casting diseredit on the operation, from which it is only now emerging, thanks to the writings of Jules Worms, Ollier, Laballhary, Vegas, and more especially to those of Koeberlé, of Strasbourg. When it is stated that all these writers have published since 1862 , it will be appreciated how reent is the favorable reception of the operation in France.

1 Grenser, loc. cit.

2 Wieland and Dubrisay, the French translators of Churchill. 
M. Boinet, in 1867 , read an essay before the Academy of Medieine, strongly advocating it, and "reprobuting the timidiy of French surgeons who have so long recoiled betore it."

$\mathrm{U}_{\mathrm{p}}$ to July, 1868, P'itul, of Paris, had had seven recoveries out of ten cases, and in 1870 and ' 71 , ont of thirty-two operatione, twenty-six recoveries took place. In 1873, he wrote a work upon IIysterotomy for Fibroids and Fibro-Cysts, in which he elaims seven recoveries for nine operations. Nothing could more surcly mark the advance of the operation, as well as the rapidly increasing boldness and skill of French surgeons, than this announcement.

It is needless to point out the fact that to-day all opposition to the operation has disappeared, and that in every eivilized country of the globe it stands among the proudest achievements of surgery.

In concluding the history of ovariotomy, it may be said that the conception of the operation in all its steps is over a hundred years old, and is of European origin; that for its accomplishment we are indebted to what Mr. Piorry once styled, "une audace Américaine," which was supplied by Ephraim MeDowell; and that many of the important improvements which have since been introduced, we owe to Great Britain. Pre-eninently an Anglo-American procedure, it has only within the last decade assumed its legitinate place in Germany and France, but in both countries it is not merely maintaining itself, but being improved and advanced towards perfection.

larieties.-There are two forms of the operation: one, abdominal ovariotomy, in which the eyst is removed through the incised abdominal walls; the other, vaginal ovariotomy, in which a small eyst is removed by incision through the fornix vagine. Incomplete eases, or those in which only at portion of the sac is removed, have also been grouped under the first liead, but very improperly so, for less than complete removal constitutes an entirely different operation, which is known as partial excision.

Dangers.-The dangers which attend it are numerous and grave. The following table, construeted by Dr. Peaslee upon the post-nirtem evidence of 50 cases, will exhibit them at a glance:-

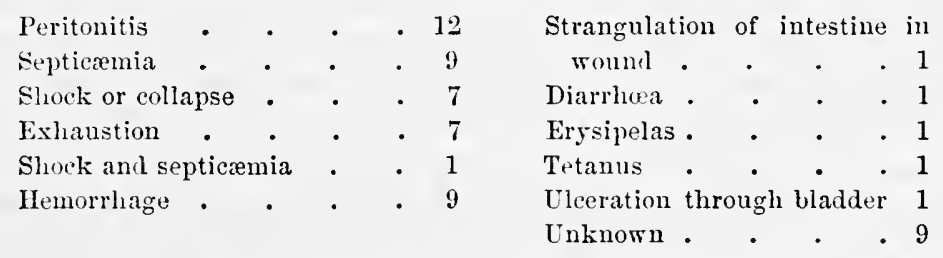

It will be seen from this table that peritonitis destroyed one-quarter of all who died from the operation; and septicæmia, or absorption of putrid material, one-sixth. After these causes followed those directly resulting from the depressing influence of the operation upon the nervous system. 
Dr. John Clay makes the following analysis of the causes of death in 150 fatal cases, reported in his tables:-

\begin{tabular}{|c|c|c|c|c|}
\hline Shock or coll & apse'. & & - & \\
\hline Hemorrhage & . & & . & \\
\hline Peritonitis & - & & . & \\
\hline Phlebitis & . & & . & \\
\hline Tetanus & . & & . & \\
\hline Intestinal af & ections & & . & \\
\hline Abscess & . $\quad$. & & . & \\
\hline Chest disease & es . & & . & \\
\hline Congestion o & brain & & . & \\
\hline Diabetes & . $\quad$. & & . & \\
\hline Not stated & . & & . & \\
\hline
\end{tabular}

That in these lists many cases of septicxmia ending in peritonitis are eatalogned as peritonitis, I think is proved by the light which we now have on the subject. My own observation wonld lead me to put the causes of fatal issue after ovariotomy in the following order as to frequency and importance:-

\section{Septicamia ; \\ Peritonitis ; \\ IJemorrlage ; \\ Slioek.}

The first of these is the great evil to be feared, and combined with the second canses more deatlis than all the other causes added together and multiplied by ten.

Statistics._So hard was the struggle of ovariotomy for existence, so vigorous and malign the attacks made against it by the leaters of professional opinion all over the world, and so delieate the position of those bold and enterprising men who in the United States and England still clung to its fortunes, that up to a very recent period it was necessary to deal fully with statistical evidence endorsing it. That time has now happily passed, ovariotomy now stanting upon a basis every whit as firm as that of amputation of the leg or any other operation of general surgery. Then, too, a new era has dawned upon ovariotomy within the past five years which will almost surely greatly improve the statisties of the future. $\Lambda \mathrm{n}$ tiseptic surgery applied to this operation hats already accomplished a great deal; it will in all probability do in the future much more than it has done thus far.

\section{Conditions favoruble to the operation-}

Clearness and certainty of diagnosis;

Good eonstitutional condition ;

Paticut being hopeful and desirous of operation;

Paucilocular character of cysi; 
Absence of much solid matter in its structure;

Abrlominal walls not very thick;

Absence of strong pelvic: adliesions.

'The possibility of error in diagnosis lats been already suffieiently dwelt upon. The importance of elearly understanding the nature of the tumor eannot be over-estimated. 'The operator should, by repeated and nost careful examinations, alone or with counsel, endeavor to determine all the featmes of the case, not merely the fact that a tumor exists, but that it is ovarian and not uterine, that pregnancy does not exist with it, that it is not cancerous, that its contents are Huid, and that the fluid felt is all ovarian and none of it abdominal. In two eases I lave, in company with a number of others who eonsulted with me, been greatly deceived. In one ease, when upon the point of operating upon a large, multilocular tumor, the patient lying on the table, I discovered the eoexistence of pregnaney in the filth month. In another, which I supposed to be a large ovarian tumor, mpon eutting through the abdominal walls, an immense amount of fluid escaped, leaving for removal a solid tumor of the ovary not larger than the adult head. Cases are on record in which surgeons of great experience and skill have cut down upon uterine tibroids, eysts of the kidneys, the pregnant uterus, and other abdominal enlargements, under the inpression that ovarian eysts existed, and instances have occurred in which abdominal section discovered no tumor of any kind, the operator having been deceived by tynupanites.

As to the period at which the operation should be undertaken, there is, and probably always will be, a great deal of diversity of opinion. As the decision of this point will always involve a great deal of responsibility on the part of the operator, it will not be without interest to refer to the views of weighty authorities. Baker Brown operated quite early, as soon as the diagnosis was fully established, in order to avoid changes in the cyst and peritoneum. Peaslee and Tyler Smith waited for some degree of impairment of health and emaciation, as does Keith likewise. Wells operates when the patient eamnot waik a mile without diffieulty. Bryant does so when the tumor, by its size, inconveniences the patient and interferes with her donestic duties; while Greenhalgh postpones the operation as long as it is justifiable, in order to secure changes in the peritoneum which will render it less liable to trammatie peritonitis.

It appear's to me that the general rule slould be this: if a small eyst be discovered which is removable by the vagina, it should be removed as suon as possible, while one too large for this should be interfered with when it is evident that the patient is failing in strength, and beeoming emaciated, depressed, and nervous. To this rule there are, lowever, marked excentions. In a patient of calm, philosophic mind, who does not clafe at the knowledge that a tumor exists, delay is often advisalle in the ease of a tumor which, in a nervons, fretful, cowardly woman, who is 
rendered almost insane by such knowledge, should be removed at a much earlier period.

The following table, constructed by Dr. J. Clay, of 299 cases in which the general health was ascertained, displays the important fact that even great emaciation does not produce a very unfavorable result :-

\begin{tabular}{|c|c|c|c|c|c|}
\hline Class of cases. & Health good. & $\begin{array}{c}\text { IIealth } \\
\text { imparred. }\end{array}$ & $\begin{array}{c}\text { Much } \\
\text { emaciated. }\end{array}$ & $\begin{array}{c}\text { Complicated } \\
\text { with other } \\
\text { disease. }\end{array}$ & $\begin{array}{c}\text { Complicated } \\
\text { with } \\
\text { pregnancy. }\end{array}$ \\
\hline $\begin{array}{l}\text { Successful : }: \text {. } \\
\text { Unsuccessful : }\end{array}$ & $\begin{array}{l}21 \\
21\end{array}$ & $\begin{array}{l}17 \\
25\end{array}$ & $\begin{array}{l}47 \\
46\end{array}$ & $\begin{array}{l}21 \\
27\end{array}$ & $\begin{array}{l}2 \\
2\end{array}$ \\
\hline Total. . & 42 & 42 & 93 & 48 & 4 \\
\hline
\end{tabular}

The mental state of the patient has so marked an influence on the result that operators agree that a depressed and apprehensive condition commonly produces an unfavorable issue.

The greater the amount of solid matter in an ovarian tumor, the more favorable will be the prognosis as to rate of growth and the more unfarorable as to cure.

The following is Dr. Clay's table in reference to the character of the tumor:-

\begin{tabular}{r|c|c|c|c|c|c}
\hline Class of cases. & Monocystic. & Polycystic. & Solid. & small. & Mrdium. & Large. \\
\hline Succossful . . & 19 & 66 & 8 & 4 & 14 & 30 \\
Unsuccessful . & 25 & 106 & 13 & 3 & 17 & 18 \\
\hline Total . . . & 44 & 172 & 21 & 7 & 31 & 48 \\
\hline
\end{tabular}

The greater the thickness of the abdominal walls, the more extensive will be the surace which must unite to effect closure of the abdominal opening, and the greater the probability of suppuration occurring between the lips of the wound and pus pouring into the peritoneum.

The presence of adhesions to the abdominal viscera greatly complicates the case, but, as this can be determined only after abdominal section, its consideration will be postponed until that point in the description of the operation is reached.

Conditions unfarorable to the operation.-The following circumstances, although unfarorable to the operation, do not contraindicate it, unless they exist in the most exaggerated legree :-

Obseurity as to diagnosis;

Great constitutional impairment;

Gastric or intestinal disorder;

Depression of spirits;

Presence of much solid matter in tumor; 
Extensive and firm adhesions to viscera;

Complication with other diseases;

Great thickness of abdominal walls.

Vaginal Ovariotomy._In certain cases, rare ones I admit, in which a tumor not larger than the head of at child a year old falls down into Douglas's cul-de-sate, it will be possible to eut through the vagina, seize the sac, draw it down, ligate the pedicle, and fasten it by suture in the lips of the raginal opening. If this ean be done, a great deal of risk will be avoided, and the patient spared a lengthy period of suspense, with the prospeet of a serious eapital operation at the end. I will lay the steps of this operation before the reader by relating the first case in which it was resorted to by myself.

The patient having been etherized was placed in the knee-elbow position, and secured upon the apparatus of Dr. Bozeman. This apparatus not only completely fixes the patient in this position, by straps and braces, but makes the position perfectly comfortable for any length of time, and also favors the administration of an anæsthetic. It is shown in Fig. 256.

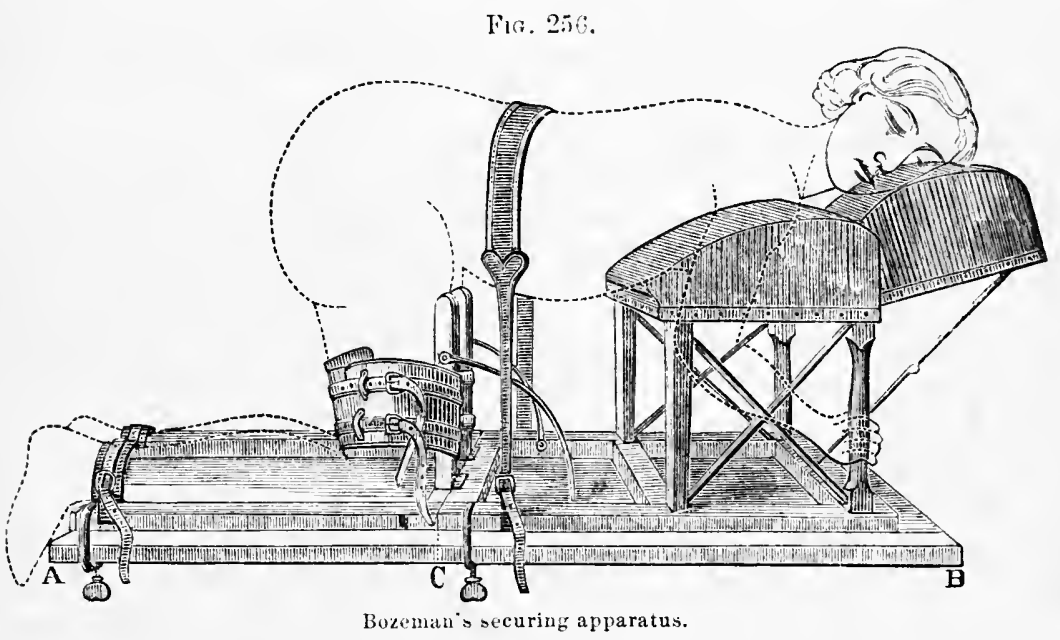

To prevent all possibility of the rectum falling into the line of incision, a rectal bougie was inserted for about five inehes. Sims's speculum being introduced, and the perineum and posterior raginal wall lifted, I caught the fornix vagine between the cervix and rectum with a tenaculum, drew it well down, and with a pair of long-handled scissors, one limb of which was placed against the rectum and the other against the cervix, cut into the peritoneum at one stroke.

The first step of the operation being aecomplished, I proceeded to the second. The patient's position was changed to the dorsal decubitus, and passing my finger through the raginal incision, I distinctly touched 
the tumor, which had fallen into the pelvis, and fastened a tenaculum in its wall. With a small trocar I punctured, one after the other, three cysts, which gave vent to about six or eight ounces of fluid which looked precisely like vomited bile. Drawing upon the cyst, it then passed without difficulty into the vagina.

For the third step of the operation the position of the patient was again changed. She was now placed in Sims's position on the left side and his speculum introduced. Passing through the pedicle at its point of exit from the vaginal roof, a needle, armed with a strong, double silk ligature, I tied each half of the penetrated tissue and cut off the cyst and ligature. The cul-de-sac of Douglas was then sponged, the pedicle returned to the abdominal cavity, the incision in the vagina closed by one silver suture, and the patient put to bed.

The entire operation occupied thirty-five minutes, and presented no difficulties other than those slight ones incidental to ligature of a pedicle at some distance up the ragina.

The only variation which increased experience would prompt in this course would be the fixing of the ligated pediele in the vaginal wound by silver suture, instead of returning it to the abdomen.

It is not my belief that the scope of this plan of performing ovariotomy will ever be very great; but I think that in cysts of small size, which are unattached, it will offer a valuable resource for the avoidance of years of mental suffering while the disease is progressing, and of the capital operation of abdominal ovariotomy in the end, with all its attendant dangers and uncertainties. Even in a doubtful case, vaginal ovariotomy may be resorted to as a tentative measure, which, in the event of failure from attachment of the cyst, would in all probability be recovered from.

I should urge upon any one who determines to essay it, not to trust to his general knowledge of the anatomy of the fornix vaginæ and peritoneum, but to rehearse the first step of the operation upon the cadaver before attempting it upon his patient. There is often considerable space between the roof of the vagina and the floor of the peritoneum, and it usually requires two strokes of the scissors to penetrate the abdominal cavity. The first severs the vagina: then through this opening a tenaculum should be passed, and the peritoncum drawn down and opened. In thin women, if the fornix be well drawn down by a tenaculum, one stroke will often open the peritoneum.

This operation has been now performed a number of times with the best results by Gilmore, IIamilton, Goodell, and others. I feel sure that it has before it a future of usefulness for the following reasons. It is fully as eaty of performance as abdominal ovariotomy; is evidently attended by much less danger; holds out to the pratient the opportunity of avoiding many weary months of suspense in anticipation of that more grave pro- 
cedure; is equally appliealle to multiloeular and to unilocular cysts ; and gives abundant facility for seeuring the peeliele.

Abdominal Ovariotomy._I have already expressed my belief that only a linited number of cases will be susceptible of the procedure just ileseribed. The great resouree in ovarian tumors is the ordinary opcration of ovariotony by the abdomen.

Previous to the operation the patient should be put upon a tonic course. Gencrous diet, iron, quinine, fresh air, eleerful surroumlings, and gentle exereise slould, unless impraetieable from some prenliarity of the ease, be preseribed. A visit to the country or some quiet watering place will prove of great advantage. Above all things, the mind of the patient should be made calm and cheerful, and every hope as to the result of the operation encouraged. After a eandid statement of the chanees of suceess hats been rendered her as material upon which to base her determination to aceept or reject the operation, no doubt ouglit thenceforth to be expressed as to the result by physician or friends.

The operation should be performed in a locality where the air is pure and salubrious-never, if it ean be avoiderl, in the wards of a erowded hospital, and if a choice be offered, in the country rather than the city. The day selected should be clear, and neither very hot nor very cold. If the weather be cool, the temperature of the apartment should be kept at from seventy-eight to eighty legrees. A thoroughly experienced nurse should be in readiness to take eharge of the patient.

After the operation it is essential that the bowels should be kept constipated for a week or ten days. That this may be done without ineonvenience they should be empty at the time of operation. To effeet this, during the week preceding it they should be acter? upon by a gentle laxative every second day, and the patient kept for two days previous to the operation upon animal broths, beef-tea, milk, and gruels like those of farina or Indian meal.

Five hours before operation I am in the habit of giving from twelve to fifteen grains of quinine with a quarter of a grain of morphia. The skin should be put into good eondition ly warm baths employed daily for a week or more, and its temperature kept equable during the operation by a flannel wrapper and drawers. As the time for operation arrices, the bladder should be earefully eracuated, the patient anisstletized, and laid upon her baek "ipon a table of suitable height and strength, which is eovered by folded counterpanes or blankets, and placed before a window affording a good light.

What the verdiet of the future will be in referenee to the full application of the antiseptic method to ovariotomy, no one caln now say. It is very possible that the use of the spraly may be disearded ; it is highly prohable that all the other steps of the procedure which so surely secure perfirct rleanliness and prevent contamination by disease-germs will live as 
long as surgery does. With our present lights, however, no man is justified in casting aside a method which promises so much of seeurity, and has already produced such exeellent results. Everything should therefore be prepared for full practice of the Listerian plan.

'The operator will require five assistants, one to administer the anæsthetic, one to stand opplosite to him and aid in manipulating the tumor and abdominal wall, one to take eharge of the instruments, one to apply ligatures, the actual eautery, etc., and a fifth to take charge of the atomizer. The nurse who is to take charge of the patient may look after the cleansing and supply of clean sponges wrung out of earbolized water.

The Operation.-Although this operation has of late years been so fully discussed and so free an interchange of sentiment concerning it las been aflorded, there is not one point eonneeted with it upon which operators are agreed. The extent of ineision, management of pedicle, elosure of wound, and the other steps which will be alluded to, are still subjeets upon which great rariety of opinion exists. I shall aroid discussion, and hoping to be jardoned for any applearance of dogmatisn which may result from so doing, give such a description as will, according to my view, best meet the requirements of practice.

The steps of the operation are these:-

1st. Incision through abdominal walls;

2d. 'Tapping tumor';

3d. Removal of the sae;

4 th. Securing the pedicle;

5 th. Cleansing the peritoneum;

6th. Establishing drainage, if necessary;

7th. Closing abdominal wound;

8th. Applying antiseptic dressing.

The incision is made by a bistoury held by the operator, who stands at the right side of the patient. It should pass directly through the linea alba, and should extend from a point at a varying distanee below the navel to one a little above the symplysis pubis. Passing through the skin and adlipose tissue, layer by layer, it is continued until the operator sees the fibrous sheath of the recti muscles. An inexperieneed operator may take this for the peritoneum. If any doult exist, it should not be incised until exposure to the air and pressure by forceps, fingers, or sponges, have eliecked the venous flow occurring from the vessels exposed ly the ablominal incision. Then the fibrous structure should be caught by a tenaculum, sniplend with seissors, and a grooved director passed under it, upon which it miy be slit. If this expose the belly of one of the reeti, it will be evident that the linea albat has not been struck by the incision. To rairle it, the director should he pushed under the shenth across the muscle, and it will be arrested at the linea, where the ineision should be made. All liemorriage having ecased, the parietal peritoneum should be lifted by 
the tenaculum, snipped, and slit upon the director for the length of the ineision.

During this part of the operation small vessels may pour forth blood quite freely. It is not necessary to ligate them, temporary compression by hemostatic forceps usually controlling their flow perfectly.

It maly be supposed that no difficulty conld arise in cutting through the abdominal walls, but this is not so. Operators will sometimes commit most serious errors even here. In two cases, one of wlich occurred to myself, and the other to a very skilful operator of this city, the incision was earried only down to the parietal peritoneum, when this was striped away from the muscles under the impression that it was an attached cyst wall. In other cases operators have become confused in searching for the linea alba, and, in others still, the incision which should open only the abdomen lays open the cyst itself, and allows its contents to flow away prematurely. By cutting at first only through skin and areolar tissue, and then applying the tenaculum to all doubtful tissues, these difficulties may be to a great extent avoided. It is hazardous to open the peritonenm by the knife, and always wise to lift it by the tenaculum, snip it with scissors, and slit it up upon a director. Sometimes a loop of intestine may be found over the anterior face of the tumor, as happened in one of Mr. Baker Brown's cases, where it wonld have been incised had the operator not slit the peritoneum upon a direetor with scissors. In one case, published by Dr. MeLine, of Troy, the bladder lay over the tumor, and was drawn up towards the umbilicus so far that both its walls were cut through by the ablominal seetion.

As a rule, the shorter the abdominal incision the better for the after progress of the case.

Mr. Brown has laid down, in reference to the abdominal section, this important rule: it should always be regarded originally as an exploritive incision. If any condition contraindicating the removal of the sac be found to exist, it may then be closed without exposure of the patient to great danger, while, if it be found advisable to enlarge it to proceed, this may be done to any necessary extent. Mr. Wells has removed one sac by an incision of one. ineh and a half, and rarely resorts to one of over five inches. On the other hand, Dr. Clay, whose favorable statistics have been alluded to, prefers the long ineision. The great drearl which has always been entertained of cutting into and exposing the peritoneum, lends a degree of fascination to the short incision. But when it is borne in mind that, for want of a sufficiently free incision, a tumor is often slowly and clumsily removed, bleeding ressels not detached, and an unelean peritoneum closed up in place of a clean one, it will be recognized that an operator may err in this direction as well as in the other.

The results of $\mathrm{Mr}$. Wells, as embodied in the following table, prove, however, that short incisions are greatly to be preferred to long ones. 


$\begin{array}{lcccc} & \text { No. of cases. } & \text { Recoveries. } & \text { Deaths. } & \text { Mortality. } \\ \text { Not exceeding } 6 \text { in., } & 440 & 337 & 103 & 23.4 \text { per cent. } \\ \text { Exceeding } 6 \text { in., } & 60 & 36 & 24 & 40 \text {." "6 }\end{array}$

It is equally worthy of note that the same surgeon operated on 17 cases by an incision of 3 inches, and lost 23.53 per cent., and on 203 cases by an ineision of 5 inches, and lost 19.7 per cent.

The most rational deduction to be drawn from these facts is this : that the shorter the incision by which the sac can be removed "tuto, cito, et jucunde," the better for prognosis. The effort to remove the sac, however, through an opening so small as to involve delay, uncertainty, and ineficient manipulation gives the patient a poorer prospect for recorery than the making of a longer incision would offer.

The shining wall of the cyst, covered by visceral peritoneum, being now under the fingers and eyes of the operator, he has an opportunity of verifying his diagnosis by palpation, visual examination, and removal of fluid by a very small trocar and canula or by the needle of the hypodermic syringe. Should connection with the uterus be suspected, before proceeding further its relations to this organ should be determined by passing the uterine sound, and rotating the uterus while two fingers are passed through the abdominal wound lown to the fundus uteri.

Before this, however, the operator may be checked in his progress by discovering that he is not in contact with the cyst wall, although the peritoneum be opened. In place of the smooth, shining wall of the cyst, he discovers a vascular membrane containing large vessels, which spreads over the tumor like an apron. To one who has never seen this covering it will prove very perplexing. It consists of the peritoneal walls or roof of the broad ligaments which have been syread out by the growing tumor and have undergone great hypertrophy. Tumors thus surrounded have, according to my experienee, broad and short pedicles, and their extirpation will be very difficult unless the vahuable method advised by Dr. Miner, of Buffalo, be adopted. It consists in cutting through the enrelope of the cyst. aroiding, as far as possible, the opening of large ressels, introducing the fingers, and enucleating the tumor. ${ }^{1}$ The sac which is left should then be opened, thoroughly eleansed, touched all over its oozing surface with solution of persulphate of iron, and, if large, tied around a drainage tube.

Should any doubt exist in the mind of the operator whether the structure which he sees throngh the incision is really the cyst wall or the peritoneum corering it, he may endearor to pass a finger thoroughly washed in

1 I have resorted to this method a great many times, with good results, in cases which would have proved unmanageable by other means. It appears to me to be me of the most valuable of all the contributions to ovariotomy which have enanated from this country. 
earbolized water between the eyst and peritonemon, or a steel somml may be gently swept around if it be possible.

Tapping.-belore tapping it is my habit to turn the patient on the silde towards the operator, whose special attention at this moment should be direted to two objects-one preventing the eseatye of even one drop of fluid into the peritoneal cavity, the other the avoidanee, ats lar ats posible, of the introduction of his hamels or fingers into it. 'Turning the pationt on the side greatly fiteilitates the second of these, and by no means increases the dillieulties of the first. The assistant opposite the operator, row standing at the back of the patient, steadies her body with his right hand, while with his letit he presses a soft, carbolized towel, or sponge, firmly against the abdominal wall just below the incision, so as to prevent ingress of fluid to the peritoneal eavity. The operator shoull now thoroughly cover the raw lips of the wound with carbolized raseline, or some other unctuons sulstance, to prevent absorption of the colloid, perhaps the decomposing, purulent fluid, of the sac, which is now to be tapped and withdrawn.

With a long curved trocar and canula, such as that shown in Fig. 2:5, the fluid of the sae is now allowed to flow away if it be not too tenicious to do so.

FIG. 257 .

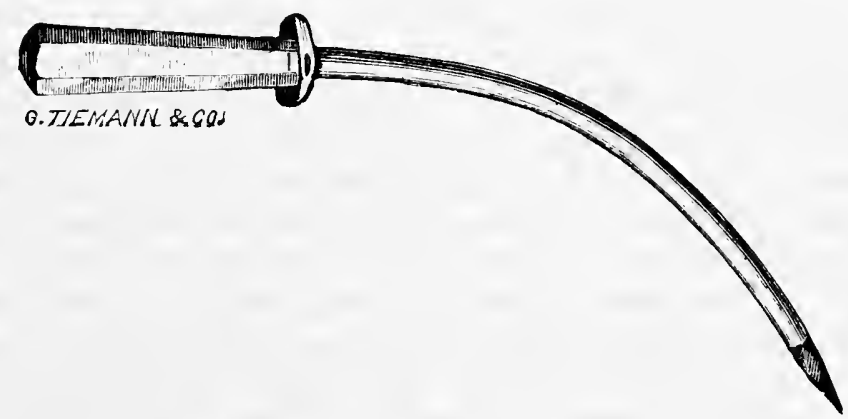

Emmet's trocar and cannla for tapping cysts.

I have cast aside entirely, and would alvise others to do so, the cumbrons attachments to trocars intended to carry off the fluid of the sac without woiling the surroundings of the patient. If a large wash-tub be placed upon the floor, and a little skill and care be displayed by the operator, no neeessity for them will be found to exist.

Let us suppose that the sac contents flow away easily and freely; the operator showhl wait until the visible portion of the sac protrudes a little through the ablominal opening; then he shonld fix a tenaculum in it and draw the opening in which rests the canula, just beyond the abclominal 
wound. In a few minutes a second tenaculum should be fixed in the sae, and very soon it will protrude decidedly. As soon as it is outside the abdomen, the canula may be with advantage withdrawn, and a free opening made into the sac by a pair of scissors, to prevent the waste of time which woull attend its slow evacuation through the eanula.

If one sac be emptied and another be felt, the operator may introduce the trocar into the canula, turn this obliquely, and plunge it into the remaining cyst or cysts ; or he may, and this is usually safer and better, pass one or two fingers, or the entire hand, into the main sac and rupture the remaining ones in this way and allow their eontents to flow out. In doing this the hand should never be passed into the peritoneal cavity, and great care should be observed not to break any remaining eyst so as to let it communicate with that cavity. This mancuvre is a very important and effectual one, and withal a very safe one, since the cyst walls protect the peritoneal cavity thoroughly. It is far safer than the plan of plunging a troear and canula blindly about in search of eysts, and than that of passing the liand into the peritoneum to find them.

While the fluid is pouring out, eompression of the abdominal walls against the tumor should be made by an assistant, who places one hand on each side of the abdominal incision, and the sac should be kept from slipping into the abdomen by strong forceps made to grasp its lips, if an ordinary canula be employed.

Suppose, however, that the fluid of the eyst is semi-solid colloid, that numerous very small cysts exist, or that a large amount of solid material jrevents evacuation of the tumor by trocar; what then is to be done? Passing two large and strong tenacula into the tumor at the extreme upper and lower extremities of the abdominal wound, and holding it firmily against it, the surface of the tumor between these tenacula should be cut through, and one finger, then two, and then the whole hand introduced, breaking up as it goes little cysts, and at once evacuating their contents. When the hand has well entered the tumor, a species of "conjoined manipulation," one hand on the abdomen and the other in the tumor, will serve to reveal the presence of all cysts not yet evacuated.

In this way inmmense tumors may be delivered without introducing the hand into the peritoneal eavity, without making a long abdominal incision, and without allowing the escape of sac contents within the abdomen.

Removal of the Sac.-The sac, being now drawn out by the tooth forceps, tenacula, or pincers, which have been fixed in it to prevent its escape into the abdomen, is seized by the fingers of the operator and grently drawn forth through the incision. This is the time for breaking athesions, and this is hest done, as a rule, hy stealy traction upon the sac. In the large majority of cases traction, stealy and even powerful traction, upon the sac is the best, most rapid, and safest method of severing attachments. Of course, this must not be rash or intemperate in degree, 
for by that serious dumare might le done; but it should be so firm and decided as to break all ordinary nttuchurents.

If an adhesion whinh resists the eflorts thus male to rupture the attachments hold the sne in the abdomen, this should be finly exposed, and severed by detaching it from the cyst wall by the fingers, which will now reach it rearlily; by the uctuat eautery, as suggested by MI. Jrown, if it be long enough to aroid cauterizntion of the abdominul wall; liy scissors, if a eutting instrument must be used ; or by a small ecrasenr, if it can l.e. applied. No rule can be given as to the best method, for cach cate will require the plan speeially adapted to its peculiar features. This maxim must be constantly horne in mind-that plan is best which severs attarlements without injuring viscera or leaving bloodvessels open, for these are the two evils to be fiared. If a flow of blood follow the severance of an arlhesion, the bleeding ressel should be exposed and ligated or touehed with the aetual cautery so lightly as not to ereate a slongl.

By the means recommended, adlesions may generally be severed without the application of ligatures, but now and then this is necessary. If it be so, silk should be unlesitatingly employed as a method of ligation. Metallic ligatures are unwieldy and unreliable, and none of the other animal ligatures compare favorably with silk. In some eases the cyst adheres so strongly to some viseus that it camnot be separated. Under these eircumstances a portion of the cyst wall slould be cut out and allowed to remain upon the surface to whieh it so pertinaciously clings. M. Boinet points out the propriety of removing the seereting surface of such a piece vefore leaving it.

Sometimes instead of adhesions here and there the cyst is found universally attached over the pelvis, and the operator sees eause to fear lest the removal of the whole eyst may prove impractieable. This condition of things may be dealt with in one of two ways. The operator may strip the envelopes of the sac away from it about three inches above the attached surface and enucleate its lower segment ; or if he find this impossible, or deem it to be very hazardous on account of hemorrhage, he may pass into the extremity of the sac a glass drainage tube, tie the sac firmly around this, and fixing both sac and tube between the lips of the abdominal wound drain it and inject with earholized fluid.

There are little mancurres which experience will teach the operator which will greatly assist in removal of the sac from the abdomen when difficulties present themselves. One of these, whieh I learned of Mr. Spencer Wells, consists in ignoring the attaeliments at the upper part of the sac. seizing its lowest, inner portion, pulling this out througl its moutl. and thus eompletely inverting it. Anofler consists in ligating the tumor, when much solid matter exists at its lower extremity, before complete emptying of it, turning it over, and delivering the pelvie extremity first. A third plan is applicable when the upper portion of the tumor is fluid, 
and that below the nmbilieus solid, and consists in passing the long troear throngh the solid portion obliquely upwards, emptying the upper sac, pulling this down and ont first, and then dragging ont the solid portion near the pelvis. By adopting these methods in suitable eases, it is surprising to see throngh how short an incision a colossal and semi-solid tumor may be extraeted. Very reeently I removed one in the Woman's IIospital weighing over sixty pounds, through an opening of less thạn five inches.

The tumor being freed from attachments is now drawn forth, and the pediele seized in the fingers. At this point there is usually a delay caused by the time required by the operator for determination as to the plan which will be best adapted to securing the pediele. There is often, too, some discussion upon this point, for no operator should be wedded to any single plan whieh he adopts in all cases. If the sac be left attaehed to

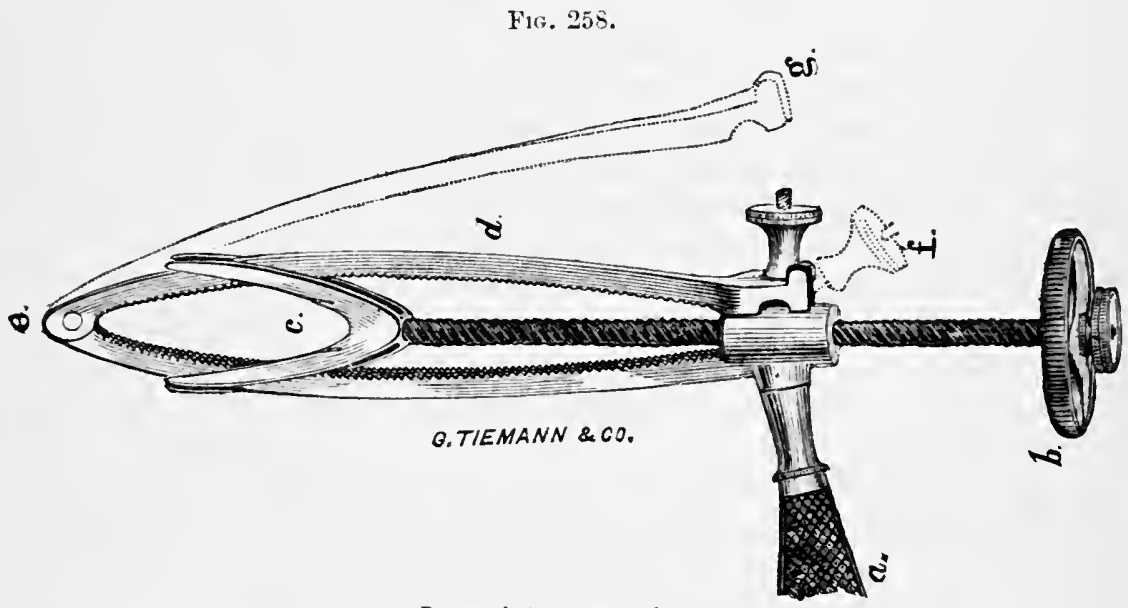

Dawson's temporary clamp.

the pedicle during this time, it is greatly in the way, drags heavily, soils the elothing, and usually forces entranee of its contents into the abdomen. I have been in the habit of rapidly encircling the mass some inches from the pediele with at strong ligature, eutting off the sae, and then at leisure examining the pedicle. Dr. B. F. Dawson has devised for this purpose the temporary clanp shown in lig. 258. By this the ressels of the pedicle are secured, and this part eompressed eirenlarly instead of laterally, while it is seeured by the means which are to be permanent.

Securing the Pedicle.-This, which eonstitutes one of the most important steps of the operation, is at times easily and satisfactorily aceomplished, while at of hers it is invested with great difliculties. Lnless the perlicle be exressively short, the sae may be drawn outside of the abdomen and its pedicle grasped by the fingers. When very shor: it has to be manipu- 
lated in the alodomen. It may be managed after one of the following methods, that one being selected which best meets the requirements of the particular case.

1st. The pedicle may be consitrieted by a elamp and held ontside of the abdominal cavity.

2d. The perlicle may be securely ligated and held between the lips of the wound by pins or sutures.

3d. The pediele nily be transfixed by double ligatures, which being eut short, it is dropped into the pelvic eavity.

4th. The tumor may be enueleated.

5th. The pedicle may be constricted by a temporary clamp and severed by the actual cautery.

$\Lambda$ large number of other methods have been advised and pratised, and to those interested in the matter, I would recommend the work of Ir. Peaslee on Ovirian Tumors where they are convidered at length. I mention here only those which appear to me deserving of special consideration and unquestionable reliance.

Fig. 259.

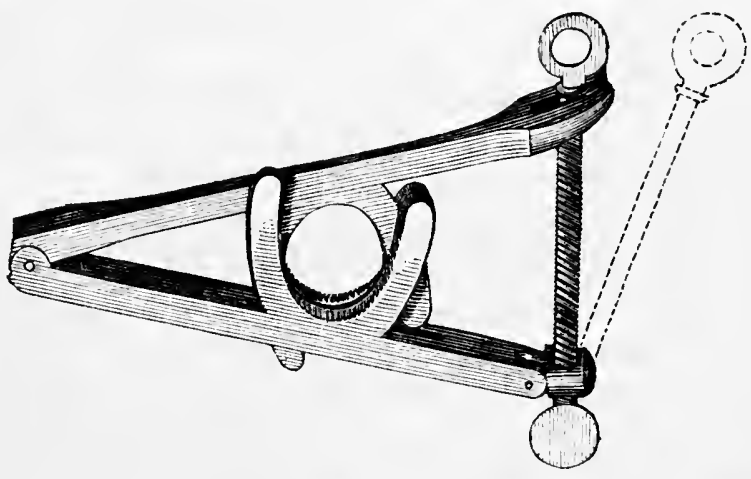

Thomas's clamp.

The prevention of hemorrhage by the ligature and elamp is evidently identical in principle. The elamp, however, has the advantage of being simpler and more easily applied. The elamp shown in Fig. 2.59 is that which I invariably employ. It appears to me to present all the advantages and few of the evils which attach to others.

It is thus employed: the peelicle or neek of the tumor being held in the fingers ; the clamp, Fig. 259, is adjusted so that one limb passes over one, and the other over the other side of it; the two branches are then closely approximated so as to obliterate the ressels, and the sac is amputated above this by a bistoury. The clamp is then laid flat upon the abdomen and the incision closed.

When the ligature is employed in the extra-peritoneal method, the sac 
is amputated and the stump phaced between the lips of the wound and transfixed by large pins, or the sutures which close this part of the ineision.

Dr. Tyler Smith was instrumental in rendering popular a method which was practised, according to Dr. Peaslee, as long ago as 1829 , by Dr. Rogers, and afterwards by Dr. Billington, of this eity. It consists in ligating the stump, cutting both ligature and pedicle as short as possible, returning them to the abdomen, and elosing the abdominal ineision. A great deal of prejudice has existed against this return of the pedicle. By theoretieal reasoning it is true that the practice can be made to appear very objectionable, but it is not theory which should deeide us in reference to so grave a matter; the results of practice should outweigh all theory, and no one should yield aught to mere feeling. This unwarrantable prejudice against the leaving of silk in the peritoneum, for so $I$ regard it, has been strengthened by the report of 34 cases of ovariotomy by Spencer Wells; of these, 4 were treated by return of ligature to the abdomen, and all died; 30 were treated by clamp, and all recovered. Peaslee, whose statistics were 17 recoveries out of 26 operations; Tyler Smith, who reported 14 successes in 17 operations; and Bradford, who saved 28 out of 31 cases, all employed this plan universally. I confess that I once shared in the prejudice to which I have made allusion, but experience has caused me to ehange my mind with regard to it. In $1878 \mathrm{Mr}$. Knowsley Thornton, of London, whose suecess as an ovariotomist entitles his opinion to great weight, reported very strongly in favor of the silk ligature and return of the pedicle.

An objection to the use of the ligature cut short and returned to the peritoneal cavity which has been raised upon theoretical grounds is, that gangrene of the portion of the stump distal to the ligature was likely to oceur, and prove a source of septicemia. Spiegelberg and Waldeyer have, however, proved that after the application of a ligature upon the horns of the uterus the portions of tissue distal to them do not become gangrenous, but are encapsilated by effused lymph.

Kublerlé, of Strasbourg, employed the clamp when the pedicle was long; but wlien short, he compressed the stump by a speeies of constrictor which tightens a metallic wire that surrounds the pedicle.

Enucleation will never prove applicable to a large number of cases, for where a pedicle can be treated by any of the methods thus far mentioned, it will offer no advantages. Where, however, there is no pedicle, it presents itself as a most valuable resouree, and comes into use in a class of anes to which no other plan is applicable.

The most remarkable results have attended the use of the actual cautery in the treatment of the pedicle, combined with the antiseptic method in the lands of Mr. Thomats Keith, of Edinburgh. Out of his last seventy ovariotomies, he has not had a death! 
No rule can be given with reference to a choice bretween all these methods other than this: when the pedicle is long and slemler, it dows not appear to matter very mueh which plan is selected, for all have yieldeel and are daily yielding excellent results; but when it is very shert, the external does not promise nearly so well as the intermal method of managing the stump.

Fiv. 260 .

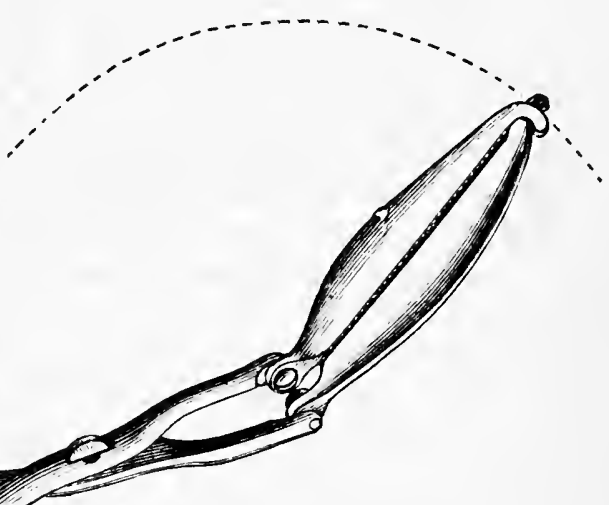

Storer"s clamp-shicld.

As to the special eases for aplyying the different plans, the following suggestions, not rules, nay be of service:-

a. The clamp is applieable to long pedieles, requiring powerful ligation, and presenting a large amount of tissue for suppuration and decay.

b. Ligation and return is apllicable to tnmors with pedicles too short for treatment by the elamp, and to slender pedicles.

$c$. Enueleation gives a method of removal of tunors which have no pedicles.

d. Sinee the experience of Mr. Keith, the use of the actual eautery should be again fully trier, for its utility may now be eonsidered beyond question. Where it is employed deep in the pelvis, Storer's elanpl-shield, Fig. 260, is an excellent adjuvant for prevention of hemorrhage during its use, and a good protection to the surromnling parts.

The statenent just nade as to its being immaterial whether the pedicle 
is returned or not, in ordinary cases, is based upon the comparative results of those who do not return it, with those of other operators who do.

The following analysis of a large number of cases is given with reference to this point by Dr. J. Clay :-

\begin{tabular}{|c|c|c|c|c|c|c|c|}
\hline Class of cases. & $\begin{array}{l}\text { Stated left } \\
\text { within the } \\
\text { abdomen. }\end{array}$ & $\begin{array}{l}\text { Inferred } \\
\text { left with- } \\
\text { in the } \\
\text { abdonen. }\end{array}$ & $\mid \begin{array}{c}\text { Kept } \\
\text { without } \\
\text { by various } \\
\text { inethods. }\end{array}$ & $\begin{array}{l}\text { Tied in } \\
\text { two or } \\
\text { more } \\
\text { portions. }\end{array}$ & $\underset{\text { ligatured. }}{\text { Simply }}$ & $\begin{array}{c}\text { Stitched } \\
\text { in } \\
\text { wound. }\end{array}$ & $\begin{array}{l}\text { Ecraseur } \\
\text { used to } \\
\text { divide it. }\end{array}$ \\
\hline $\begin{array}{l}\text { Successful . } \\
\text { Unsuccessful }\end{array}$ & $\begin{array}{r}113 \\
58\end{array}$ & 76 & $\begin{array}{l}20 \\
25\end{array}$ & $\begin{array}{r}122 \\
57\end{array}$ & $\begin{array}{l}22 \\
26\end{array}$ & $\begin{array}{l}3 \\
3\end{array}$ & $\begin{array}{l}2 \\
1\end{array}$ \\
\hline Total ... & 171 & 173 & 45 & 179 & 48 & 6 & 3 \\
\hline
\end{tabular}

Upon theoretical grounds it would appear that parturition in the future wonld be much less unfavorably affected atter the performance of ovariotomy with return of the pedicle to the abdominal eavity than after the same operation, the clamp being employed. Statistical evidence upon the subject is wanting. Dr. Walter F. Atlee ${ }^{1}$ relates a case where deatl occurred to mother and child from powerless labor, of which he says :-

"I think myself that the difficulty in this case arose from the irregularity of the contractions in a deformed womb. The left horn being fast to the abdominal wall at the lower end of the old cieatrix, which was just above the pubis, the womb, as it developed around the child, must have done so in a very different way from what occurs in ordinary cases. $A s$ it is, I have thouglit it well to report the case as bearing upon the question of the proper mode of securing the pedicle, when very short, in ovariotomy."

Before proceeding to the next step of the operation, the remaining orary should always be carefully examined as to the existence of disease. Upon the removal of a large ovarian cyst, it is very common to find very small cysts disseminated throughout the other ovary. If any of these have obtained considerable size, it is advisable that this should be remored. But if they be too small to call for this course, the matter may be compromised by puneture of them with a needle. Pippingskoeld, ${ }^{2}$ of Helsingford, Finland, advises that the small cysts should be punetured and their walls rapidly but efficiently cauterized with a pointed actual cautery. He de. clares that he has resorted to this plin in many eases and with uniformly good results.

Cleansing the Peritoneum.-The sae having been removed and hemorrhage checked, all fluids contained in the peritoneal eavity should be carefilly removed by soft sponges squeezed out of warm, earbolized water. Not only the intestines and aldominal walls, but espeeially the pelvis, shonld be completely and thoronghly cleansed. 'This is a point of great

1 Amer. Junru. Med. S.i., April, 1sen, p. 394.

1 Am. Jouru. Ohstetries, April, 1sso. 
importance, and may decide the issue of the case. Every particle of fluid left may undergo drcomposition, and expose to the great dangers of septicamia and peritonitis.

Establishing Drainage._No one familiar with ovariotomy will to-day doubt the assertion that the two factors which prove most fatal after it, septicannia and peritonitis, are both in great degree due to the retention of putreseent materials within the peritoneal carity. These materials may have escaped from the eyst during or before the operation, may consist of blood or serum oozing from vessels while the operation proceeds, or some lours after it has ended, or arise from emptying of pus into the peritoneum from inflammatory action. The importance of not only preventing the entrance of such elements into the peritoneum, and of removing them before elosing the abdominal opening, but also of giving them free vent during the period of convaleseence has attracted the attention of many ovariotomists. P'easlee introduced the plan of leaving a cloth tent in the lower angle of the wound in order to facilitate drainage in ease of the development of septicemia. Koberlé not only inserted clannels of metal through the abdomen, but even opened through the cul-de-sac of Douglas and inserted tubes, so as to drain per vaginam, and sims more recently has urged this plan as one very greatly calculated to diminish the liability to these conditions.

The removal of the cloth tent, fixed between the lips of the wound by congealed blood, is often difficult and painful, and the passage of a catheter or other tube down into Douglas's sac, the most dependent part of the peritoneum, is not rarely impossible after a slight effusion of lymph has oceurred.

Drainage per vaginam by means of tubes passed up into the peritoneum is, I think, calculated to increase the danger's of ovariotomy, by opening a way for putrid fluids from the peritoneum into the pelvic cellular tissue. I have practised it twice and seen it adopted many times, and it is upon the eril results thus far observed at the bedside that $\mathbf{I}$ base my estimate of its value.

For the past fifteen years, whenever, from the remaining of a portion of the sac in the pelvis, or from escape of fluids into the pelvic peritoneum, drainage has seemed advisable, I have, until recently, employed for this purpose a curved glass tube, which entered and rested in Douglas's pouch. 'This was kept elosed by a cork or by a roll of earbolized cotton, and through it the pelvie cavity was syringed out with carbolized water, carried in by a catheter if symptoms of septiciemia developed. Since the use of antiseptic dressings $I$ have, however, discarded this, and now employ a double tube with lateral branches, which pass out through the antiseptic dressings. This render's it unnecessary to disturb it when washing out the abdominal earity, and the rubber tubing with stopeocks arranged at the extremities of the lateral arms enables us to exclude air very perfectly. The two halves of the tube do not communicate. As it is forced in through 
one lateral branch, the fluid runs out at its lowest extremity, rises in the cavity, and escapes through the other tube. Obstructing the escape-tube will more completely fill the cavity with fluid, if this be considered desirable.

Fig. 261.

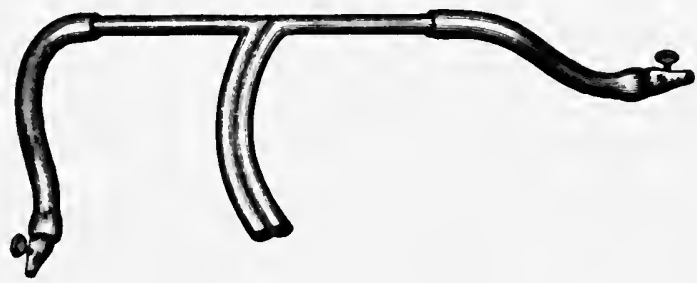

Thomas's drainage tube of metal, vulcanite, or glass.

Closing the Wound.-This is accomplished by two sets of sutures, the deep and superficial. The first, composed of silver, may be passed in the following manner: a thread of silver wire is passed at each of its extremities throngh a long and stout, straight needle. One of the needles, being grasped by strong needle-foreeps, is passed through the peritoneun of one abdoninal flap near the edge of the incision and made to emerge through the skin about an inch from the edge. Then the other needle is seized and passed through the other sile. The suture is then secured by twisting. These deep sutures, placed at the distanee of half an inch apart, will bring the whole incision into contact from the peritoneum to the skin, and favor healing by first intention.

A much better method is to pass through both walls of the abdomen a long needle with fixed handle and an eye near its point armed with a short loop of silk as recommented by Peaslee. Into this loop or into the eye of the needle a bit of metallic wire is fitted and immediately drawn into place.

Besides these, superficial sutures or pins like those employed for harelip, should be userl, which pass throngh the skin and areolar tissue, but do not involve the peritoneum. Aromd the pins thread is wrapped in figure of 8 .

The operation having been performed under Lister's method throughout, the wound is now covered with his antiseptic dressing, which is secured in place by a heary eovering of earbolized cotton, and this again by a firm bandage. Then the patient shonld be removed from the table to her bed, given a dose of opium or one of its salts, and covered up warmly, with warmth to the feet even in hot weather. It is well to move the patient now to another room. The temperature of the operating room should have been ahont 7.5 , that of the ehamber in which she is to remain should be less. This apartment should be kept at a temperature of $65^{\circ}$ to $68^{\circ}$ Falir., and thorongh ventilation should be secured, not by the unpleasant method of almitting cold, damp, and chilling air, but by the more philosophical 
one of causing the rapid escape of foul air. This can best he done by lighting a fire in the chimmey, by inmediate removal of offensive substances, and by general cleanliness.

$\Lambda$ (quiet, attentive nurse who understands the use of the catheter should be in attendance day and night.

The effeets of the operation upon the nervous system shonll be guarded against by the means just enumerated as general rules of management, and by administration of stimulants, as brandy or champagne, if the strength appear to be failing. In addition, the most complete quietude of mind and body should be afforded. All conversation and noise should be interdicted, the patient's hopefulness exeited and fostered, and all muscular eftiort avoided. For four or five days the catheter should be employed for eracuating the bladder, and the bowels be kept constipated by opium for ten days or a fortnight. 'The avoidance of cathartics during this time is essential to safety, a neglect of this precaution often producing a fatal issue. Some years ago I was present at the removal of an immense cystic sarcoma by the late Dr. John O'Reilly, who made an incision extending from the xiphoid cartilage to the symphysis, and after detaching many adhesions extirpated the mass. The patient did perfectly well for a week, and was in a fair way to recover. She was, however, very urgent that her bowels should be moved, and the doctor refusing to comply with her solicitations, she took surreptitiously a full dose of bitartrate of potash. This acted as a liydragogue catlartic, but its action was not limited as it usually is. Diarrhoa, and soon dysentery, supervened and destroyed the patient's life.

After the seventh or eighth day, tympanites may call for an alvine evacuation, which can be effected by an ordinary injection of soapsuds or an infusion of linseed, chamomile, or fennel.

The patient should be kept quiet and free from pain by opium, given either by the mouth or rectum, so soon as she has rallied from the anasthetic; or, in case of suffering, by the hypodermic method. Her nourishment should consist of milk, beef-juice, or gruel with milk. Even these digestible substances should be given in small amounts and with caution. Should there be a tendency to nausea and romiting, pieces of ice may be held in the mouth or swallowed, and if these symptoms be so severe as to threaten rupture of the sutures, the hypodermic use of morphia should be resorted to.

Should any marked irritability of the stomach exist, all efforts at giving nutriment by that riscus shonld at once be stopped, and the patient be nourished entirely by the rectum. From two to three ounces of mashed beef, bullock's blood, or strong meat essences, should be given every two hours. With this brandy or, as Mr. Thornton advises, port wine may be given, and if necessary the tincture of opium. I have, in many cases, had patients nourished almost entirely in this way from the time of operation until ten days' convalescence have been passsed.

The evils which are chiefly to be feared as sequels of the operation are, within the first twenty-four hours, hemorrhage; from second to fourth day, 
peritonitis ; from completion of operation to third or fourth day, nervous prostration; and from fourth to fourteenth day, septicemia.

Should hemorrhage be ascertained to be taking place, all dressings should be at once removed, and the stump, if out of the abdomen, securely ligated or touched with the actual cautery. If it have been returned to the abdominal eavity, there is but one course arailable, that is, opening the wound, ligating the bleeding vessel, and eleansing the peritoneal eavity. Such a necessity is very unfortunate, yet this course holds out the only prospect of success. Last year I had twiee to resort to this alternative, and both my patients recovered.

Septicamia, which is now admitted to be the most frequent cause of death after ovariotomy, is, when once fully established, a most dangerous'state. It is ushered in by dizziness; excessive muscular prostration; anorexia; great pallor; high temperature; small, rapid, and very weak pulse; sometimes a low delirium; dry tongue; and a sweetish orlor of the breath. It is this condition which is so often alluded to as a "typhoid state" after operations, and one cannot but suspect that many, if not most, of those cases quoted in Dr. Clay's tables as shock or collapse, occurring as late as the fifth, sixth, seventh, and tenth days, were really instances of this affection. In one of my fatal cases, the patient was doing quite well on the evening of the seventh day. On the morning of the eightl, I was struck by her wild, maniacal expression and cadaverous countenance; upon examination I found all the symptoms of septicamia present, and she very soon suceumbed to them.

The gravity of this sequel has rendered all operators anxious to possess the means to avoid or remedy it. Most of the methods of avoidance have been alrearly stated; the importance of the subjeet will, however, excuse my again referring to them as-

1st. Completely eleansing the peritoneum;

2l. Checking hemorrhage before elosing the abdominal wound;

3d. Establishing drainage, whenever fluids are likely to collect in the peritoneum ;

4th. Adhering strictly to Lister's method.

Septicemia, being the result, first, of the decomposition, and, seeond, of the absorption, of fluids in the peritoneum, is not likely to oceur for several days, but it may take place two or three weeks after the operation.

The development of peritonitis and septieamia should be earefully looked for. All the rational and physical signs which mark them sliould be constantly investigated, and their inception be met by appropriate therapeutic means. A written record of pulse-rate, temperature, and number of respirations should be systematically kept, an entry being made as to the three conditions at least as often as every six or eight hours. In case a competent assistant remain, at the bedside, it may be done more frequently, but never often enough to annoy or harass the patient.

After the lapse of twelve hours, in consequence of the anxsthetic, the 
voniting which this commonly induces, and the effeet of a capital surgical operation upon the nervous system, the pulse usually runs up to 110 or even 1:20, and the temperature to $102^{\circ}$ or $10: 3^{\circ}$, but as the irritative influence of these ageneies passes of a subsidence ordinarily occurs, the pulie ranging from 90 to 105 , and the temperature from $99^{\circ}$ to $101^{\circ}$ as convalescence proceeds.

If at any time the temperature should gradually or suddenly advance to $10.3^{\circ}, 104^{\circ}$, or $10.5^{\circ}$, except just as the patient rallies from the immediate effects of anasthesia and operation, fears should be entertained that peritonitis or septicemia is leveloping. If it oceur within four days after operation, it is likely to be the former. If after that time, the probabilities are greatly in favor of the latter. The pulse will usually become rapid at the same time whichever morbid condition is developing, and it must not be forgotten that the two are often combined.

I have alrealy stated that in cases in which fluid remains in the peritoneal cavity, or collects there subsequent to operation, it is my custom to pass to the very bottom of Douglas's cul-de-sac the tube elsewhere shown, 'Through this, should the temperature run up, I inject warm carbolized water once or twice in every twenty-four hours. In no instance have I seen evil result from this course. Even where a tube has not thus been left in place, when the temperature or pulse rises and the other symptoms of septicemia develop, such an injection may often, with advantage, be practised once in every eight hours. But without the tube left from the time of operation, it is diffieult and sometimes impossible to reach the most dependent part of the peritoneum, and hence I urge its employment.

The following tabulated record of temperature taken by Dr. Kuentzler, in a desperately bad ease of double ovariotomy occurring in my practice, will show what marked variations may occur, what elerations may be reached and yet the patient recover, and how decided is sometimes the effect of antiseptic injections into the pelvic cavity in rapidly lowering the animal heat.

Fig. 262.

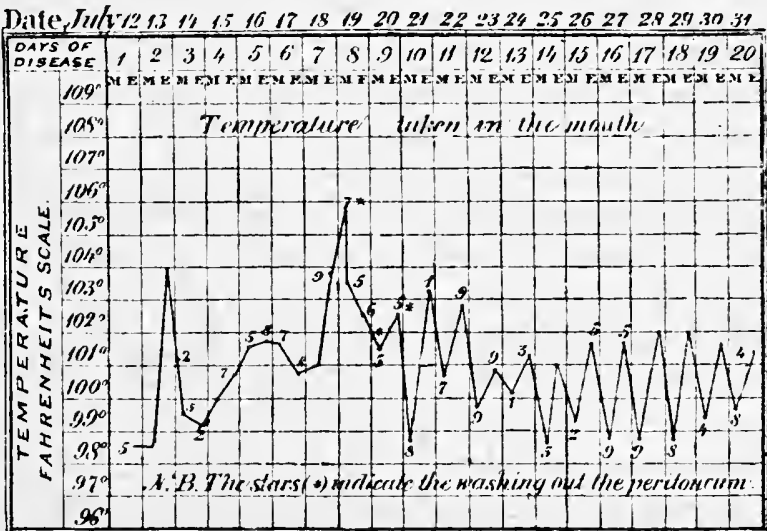


Fig. 263.

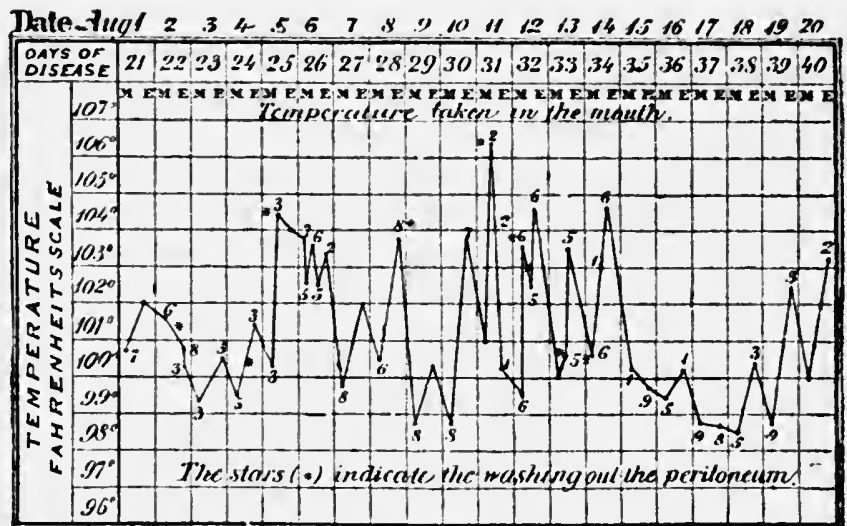

Fig. 264.

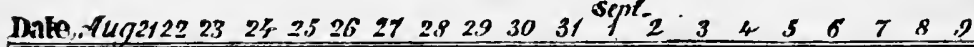

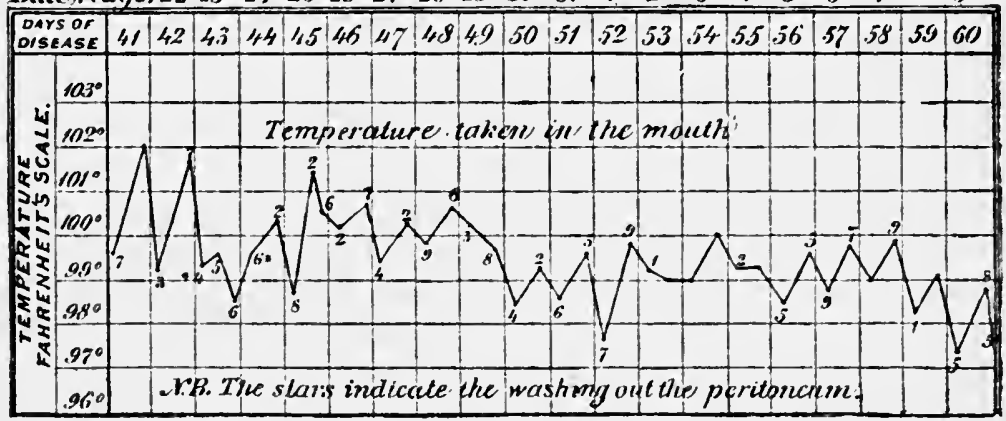

Let no one suppose that septicamia once established becomes irremediable. Experience disproves this ; it is the prolongation of ex posure to absorption of septic elements that constitutes the great danger of the condition.

This method of meeting in an effieient and satisfactory manner the most fruitful source of danger after ovariotomy, I regard as second in importance to no other improvement which lias been introduced since the discovery of the operation itself. It emanated from Dr. E. R. Peaslec, and las even now, I think, not assumed its legitimate position in the seale of importance.

It is a matter of moment, in reference to this method, to know how an experience of fifteen years in its use should have affected its originator towards jt. In an article written in 1870 , he expressed the following conclusions :-

"1. Intra-peritoneal injections of water, with the addition of liq. sorlx chlorinat. or carbolic acid, as before explained, are entirely safe after ovariotomy in the eonditions requiring them. 
"2. They should" be used with a curative intention in all cases of septicrmia alrearly developed, and in all cases for prevention where it is feared, from the presence alrealy of a thid in the peritoneal cavity, whose decomposition will produee it.

"3. Thus used, they will diminish the pereentage of deaths from septicania after ovariotomy from one-sixth (seventeen and eleven-seventeentlis per cent.) of all who die after it, to one-thirty-sixth (two and sixteenseventeenths per cent.); and increase the average suecess of ovariotomy firm seventy to screnty-four or seventy-five per cent.

"4. Intra-peritoncal injections are never to be tliought of except for the purpose of removing a fluid already in the peritoncal cavity, which cither has, or assuredly will have, produced septicæmia.

"5. A tent may be inserted for two to four days at the lower end of the incision, with cntire safety, in any ease of ovariotomy where the accunulation of such fluid is apprehended.

'6. Finally, septicamia would more rarely occur after ovariotomy if all fluid were removed from the peritoneal cavity by the most careful sponging before elosing the incision."

Peritonitis, which proves the cause of death to many of those who die from this operation, is bcst avoided by leaving as few ligatures as possible in the peritoneal cavity, by removal of all putrefactive matters, by keeping the abdominal viscera at rest by preventing vesical and rectal action, and by complete antisepsis.

Should peritonitis develop, it should be at once treated by free and steadily continued use of opium, after the plan of Alonzo Clark. The bowels should be kept strictly constipated, the patient perfectly quiet upon the back, the diet be restricted to milk, and no other medicine than opium be administered. A difference of opinion exists as to the benefit arising from applications over the abdomen. Mine is, that, as a rule, stupes of turpentine, bladders of ice, and warm poultices, alike do harm. In cases where the discase is limited to the pelvis the last often do good, but in general peritonitis the comfort of the patient appears to be favored by an avoidance of them.

Should peritonitis arise after the lapse of four or five days, it should, I think, be looked upon as a septic peritonitis duc to putrefaction of contained fluids, and it is a question whetler such cases should not be treated in their very inception by peritoneal injections. Should it arise still later, for instance, about the tenth or twelfth lay, it should be looked upon as a result of discharge into the peritonenm of encapsulated fluid material, and might likewise be met in this way, particularly if injection can be accomplished without reopening the abdominal wound. It is to avoid this necessity that $I$ employ a drainage tube in appropriate cases.

In a patient exposed to the dangers of ovariotomy the temperature is a matter of the greatest moment, and its excessive elevation often proves 
of itself, that is, without the full and fatal development of peritonitis or septicamia, the cause of death.

The establishment upon a firm and enduring basis of clinical thermometry, as an adjuvant to the practice of medicine and surgery, constitutes one of the most important advances which has marked the nineteenth century, prolific as it has been in progress. No longer like his forefathers, groping in the dark and dealing with surmises and conjectures, the practitioner of to-day finds the former, both in diagnosis and prognosis, replaced by certainty and the latter by scientific deduction. By the aid of this accurate method he watches his patient's progress from day to day, nay, even from hour to hour, with the calm confidence of one who has a reliable knowledge of the present and a certainty that he will be forewarned as to the future.

But it is not only in reference to diagnosis and prognosis that thermometry aids us at the bedside. It having been observed that prolonged high temperature kills; that, the animal heat being kept for days at $106^{\circ}$, the patient almost in rariably succumbs, the knowledge of this fact naturally suggested the adoption of means which, even although they did not cure the existing disorder, lowered the high. rate of temperature, and barred at least this arenue to the approach of death.

The importance of doing this has been recognized by ovariotomists, and partial results have been obtained by the use of quinine in large doses, the administration of salicylic acid, alone or in combination with soda, and the application to the head of the ice-bag of Wells. Struck by the very apparent inefliciency of these means, I have for some time been endeavoring to adopt some plan by which refrigeration of the trunk could be effected without the necessity of exhansting my patient by removal from the bed; and the "cold pack," sponging, and the apposition of wet cloths were, in turn, tried. The use of the cold bath I likewise considered, but the idea was at once abandoned; for the removal of a patient recently exposed to laparotomy from her bed to the tub was attended by risks which evidently must be mueh greater than those attending the same process in an ordinary case. The difficulties presenting themselves had well-nigh etused me to forego all hope of employing this means of combating hyperpyrexia, when the late Dr. G. W. Kibbee brought to my notice an ingenious device of his for accomplishing the desired result. Ile placed the patient upon what he ealled his "fever cot," which I here exhibit and describe in the words in which he advertised his invention.

Lpon this cot a folder blanket is laid so as to protect the patient's boly from cutting by the cords of the netting, and at one end is placed a pillow covered with India-rubber cloth, and a folted sheet is laid across the middle of the cot about two-thirds of its length. Cpon this the patient is now laid, ler elothing is lifted up to the armpits and the body enveloped by the folded sheet, which extends from the axilla to a little below the 
trochanters. The legs are covered by flannel drawers, and the feet hy warm woollen stockings, and against the soles of the latter bottles of warm

Fig. 265.

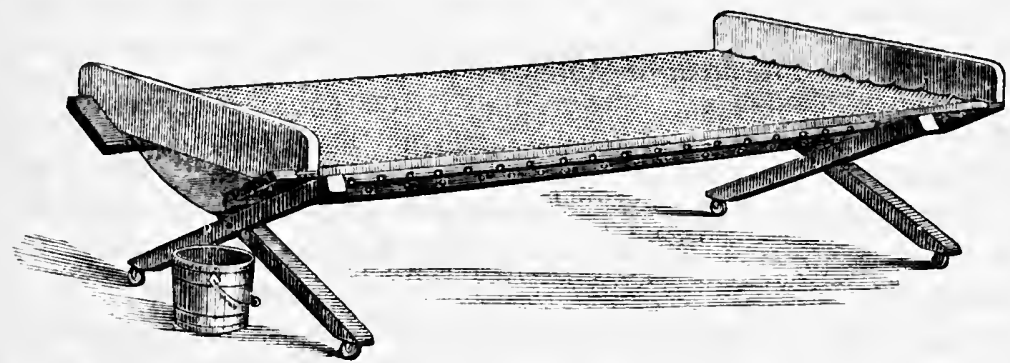

"The bet on whieh the patient lies consists of a strong elastic, cotton netting, mannfactured for the purpuse, throush which water readily passes to the botton below, which is of rubler cloth, so aljusterl as to convey it wa ressel at the foot. When not in use it can be close folded so as to oecupy but little space."

water are placed. Two blankets are then placed over her, and the application of water is made. 'Turning the blankets down below the pelvis, the physician now takes a large piteher of water at from $75^{\circ}$ to $80^{\circ}$ and pours it gently over the sheet. This it saturates, and then, pereolating the network, it is caught by the India-rubber apron beneath, and, running down the gutter formed by this, is received in a tub placed at the extremity of the cot for that purpose. Water at higher or lower degrees of heat than this may be used. As a rule, it is better to begin with a high temperature, $85^{\circ}$ or even $90^{\circ}$, and gradually diminish it.

The patient now lies in a thoroughly soaked sheet with warm bottles to her feet, and is covered up carefully with dry blankets. Neither the portion of the thorax above the shoulders nor the inferior extremities are wet at all. The water is applied only to the trunk. The first effect of the affusion is often to elevate the temperature, but the next affusion, practised at the end of an hour, pretty surely brings it down. It is better to pour water at a moderate degree of coldness over the surface for ten or fifteen minutes than to pour a colder fluid for a shorter time. The water slowly poured robs the boily of heat more surely than when used in the other way. The water colleeted in the tub at the foot of the bed, having passed orer the body, is usually $8^{\circ}$ or $10^{\circ}$ warmer than it was when poured from the pitcher. On one oceasion Dr. Van Vorst, late house-surgeon to the Woman's IIospital, tells me that it gained $12{ }^{\circ}$.

$\Lambda$ the end of every hour the result of the affusion is tester by the thermometer; and, if the temperature have not fallen, another affusion is praetised, and this is kept up until the temperature comes down to $100^{\circ}$ or even less.

It must be appreciated that the patient lies constantly in a cold, wet sheet; but this never beeomes a fomentation, for the reason that, as soon 
as it abstraets from the body sufficient heat to do so, it is again wet with eold water and goes on still with its work of heat abstraction. I have kept patients upon this cot enveloped in the wet sheet for two and three weeks without discomfort to them and with the most marked eontrol over the degree of animal heat. Ordinarily, after the temperature has come down to $99^{\circ}$ or $100^{\circ}$, four or five hours will pass before affusion again becomes necessary.

This device of Dr. Kibbee is so simple that one wonders that any perplexity attended his aecomplishing all that it does before it was shown to him, and at once the thought suggests itself how easily a substitute for it could be improvised. It is the old story of the egg of Columbus. The idea, once suggested, by its very simplicity assumes its place in the mind as a familiar one. Simple as it is, it affords the means of using a most important therapeutie resouree, and, in my estimation, leaves nothing to be desired in this respect. Recognizing in this a method by which cold could be applied to the surface for any length of time without fatigue or exhaustion to the patient and without the danger of exeessive chilling, sinee any great depression of temperature can be obviated by the affusion of warm water, I determined at once to adopt it after ovariotomy.

In adopting this plan of treatment after ovariotomy, and as I have in several eases done after parturition, I did not propose by it to check peritonitis, or to cut short septicemia, the great evils to be feared at this time. My hope was to rob these diseases of one of their ehief weapons of destruction-hyperpyrexia, and thus to resist the primary assault in the lope of bearing up against a more prolonged though less violent siege.

In all acute and grave diseases, the invasion of the disorder produces great commotion, which rapidly subsides as the system beeomes familiarized with the invading ailment. This is most marked in pneumonia-and to a less degree in peritonitis and septicomia, if the patient does not succumb very early. How often has every ovariotomist been surprised, in making an antopsy of a patient who has apparently died of acute peritonitis, to find only a slight field of pelvic peritonitis which most unsatisfactorily accounts for the destruction of life!

Robbed of its lengthy and wearing ligh temperature, which lasts for weeks, depraving the blood, altering the nerve centres, and degenerating the muscles, typhoid fever runs a much more manageable and less violent course. So septicamia and peritonitis, kept from the commencement of their courses within normal limits as to temperature, are wonderfully lifferent in their manifestations from the same diseases uninterfered with in this respect. Under these circumstances the system of the patient may be likened to a city exposed to attack from an armed foe. The great danger is from the first assanlt ; but, once having resisted that, its prospects of liolding out against a siege wonld be good, although in the end it might yield even to this. Still the prospects of suecessful defence would be 
greatly increased if the primary, most energetic, and most vigorous attack were defeated.

I have now employed this method very freely for more than a year, and my confidence in it increases with growing experience. I would alter but one statement concerning it which $I$ have formerly made; that is, I do not now often use water at very low temperatures, but usually at $90^{\circ}$, lowering it gradually to $80^{\circ}$.

As to the time at which the sutures should be removed, no fixed rule e:an be given, for it will depend upon the rapidity and completeness of union. Should union by first intention occur, some of them may be remored on the sixth, seventh, or eighth day. But great eare should always be observed, and only those at points where the union is strong should be withdrawn. After withdrawal the abdomen should be firmly supported by adhesive plaster. The clamp, if employed, or the ligature, if passed ont through the wound, should be removed when they lose their hold by reason of sloughing, and incline to fall off. No traction should be applied to them. A case was recently reported before a society in London in which too early removal of the elamp had resulted in obstinate protrusion of a knuckle of intestine, which prodnced fatal peritonitis. Mr. Wells used it as a text by which to urge that the elamp should always be left in place until it was ready to drop off. This will usually be about the ninth or tenth day.

The patient should be cautioned against rising too early after eonvalescence. Even after she is able to go about she should be very careful not to make any violent efforts, and for a year or two she should wear a wellfitting abdominal corset to guard against ventral hernia. I have had this occur in several eases. The abdominal walls were separated over a space measuring about four inches, and the intestines were supported only by skin, areolar tissue, and peritoneum. In one case these yielded to pressure, and one year after ovariotomy a tumor about the size of a kidney, with a mass of attached omentum, escaped.

The occurrence of ventral hernia is not the result of any bad management on the part of the operator. It may occur in any case, and sometimes comes on when no operation has been performed. 


\title{
C H A P T E R L
}

\author{
OÖPHORECTOMY.
}

Synonyms.-This operation has been styled female castration, spaying, and Battey's operation.

History.-As the creation of the male eunuch by remoral of the testicles has long been known as a procedure practised for other than seientific purposes, so probably has that of the female eunuch by remoral of the ovaries. The former procedure was, however, very commonly put into practice; the latter very rarely so. The former is substantiated by unquestionable evidence; the latter rests merely upon rague tradition, which asserts that a king of Lydia had it practised upon a lewd daughter, and that in India female eunuehs were thus created in the olden time.

In the lower orders of animals splaying has long been very extensively practised, and is so to-day.

In 1823 James Blundell, of London, formally suggested the practice of this operation in a paper presented to the Royal Society of Medicine and Surgery of London. In this he suggested that the extirpation of the healtliy ovaries would probably prove remedial for severe dysmenorrhou and for the menorrhagia which accompanies inversion of the uterus where amputation is not practicable.

In 1872 Dr. Robert Battey, of Georgia, performed the operation for removal of the healthy ovaries for the premature production of the menopause. He was soon followed by Hegar, of Germany, who has since not only contributed more than any other to the elinical history of the subject. but has likewise done more than any predecessor or contemporary for the scientific elucidation of the procedure. His name is indeed almost as much associated with the operation as that of its originator, Battey.

Theory of the Operation.-Dr. Battey, basing his reasoning upon the fact that orulation is the cause of menstruation, with all its accompanying pelvic engorgement and nerrous exaltation, drew the deduction that extirpation of the oraries by putting a stop to ovulation, would cheek its consequenee, menstruation, and that thus many evils dependent upon these two proeesses would by it be cured. Sueh was his conelusion, and to test the question he began practising the procedure. Very soon he was followed by others, so that now the operation is recognized as a surgical resoures in every civilized country, ant sufficient testimony is in existence from which to draw conelusions as to its propriety. 
Indications._Ovarian extirpation is recommended for the following conditions :-

Severe dysmenorihea;

Exeessive menorrhagia;

Insinity oceurring at timss of ovulation;

IIystero-epilepsy ;

Excessive hemorrhage with uterine tumors;

IIystero-neuroses, other than epilepsy of severe character;

Chronic ovaritis with severe symptoms;

Absenee of vagina or uterus, the ovaries being present.

Of course the surgeon would have to decide aceording to his judgment and his eonseience whether the evils for which he proposed operating were of so grave a character as to warrant his exposing his patient to a procedure of the gravity which the sequel will prove this to be.

The difliculties, the dangers, and the doubtful results of Battey's operation render it one to be avoided until all other resources have been tried, but when these have been exhausted and death, or what is oftentimes worse, a life of suffering, becomes the eertain fate of the patient, it offers itself as a resource of great value.

Results. ${ }^{1}$-In February last a table was published giving the results in 150 cases in which this operation has been performed, and since that time five others have been reported. Of these 106 recovered and 29 died, giving us a mortality of a little over 21 per cent.

Lnfortunately not all those who recovered from the operation were cured by it of the evils for which it was endured. Mundé very justly remarks, "if the positive benefits of the operation were as assured as its rate of recovery, the opposition to it would soon cease." Of 24 patients who recovered from the operation, Simpson ${ }^{2}$ reports that 2 received no benefit, that 11 were greatly improved, and that 9 only were entirely cured. Of the remaining 2 he makes no mention.

Names of those who hare operated.-In estimating the degree of favor with which a new operation has been received, a great deal can be gathered from a survey of the names of those who have performed it. The table which I here subjoin will present this at a glance, at the same time that it will show the number of times that laparotomy and elytrotomy have been selected.

1 Archives of Medicinr, vol. iv., No. 1, Feb. 1880.

2 British Hed. Jour., May 24, 1879. 


\begin{tabular}{|c|c|c|c|c|c|c|c|c|c|c|c|c|}
\hline & & & & & & & & & Lapar & rotomy. & Elytro & otomy. \\
\hline & & & & & & & & Total. & $\begin{array}{l}\text { Recov- } \\
\text { eries. }\end{array}$ & Deaths. & $\begin{array}{c}\text { Recov- } \\
\text { eries. }\end{array}$ & Deaths. \\
\hline Hegar & & . & . & . & . & . & . & 42 & 35 & 7 & & \\
\hline Scliroede & & . & . & . & . & . & . & 2 & 2 & & & \\
\hline Freund & & & . & . & . & . & . & 4 & 3 & 1 & & \\
\hline r. Lange & nbecl & & . & . & . & . & . & 1 & 1 & & & \\
\hline Martin & . & . & . & . & . & . & . & 3 & 3 & & & \\
\hline Müller & . & . & . & . & . & . & . & 3 & 3 & & & \\
\hline Czerny & & . & . & . & . & . & . & 3 & 2 & 1 & & \\
\hline Schncki & & . & . & . & . & . & . & 1 & 1 & & & \\
\hline Battey & & . & . & . & . & . & . & 12 & 2 & $\ldots$ & 8 & 2 \\
\hline Trenhol & & . & . & . & • & . & . & 2 & 1 & $\cdots$ & 1 & \\
\hline Goodell & & . & . & & . & . & . & 6 & 1 & 1 & 3 & 1 \\
\hline Sinıs & . & . & . & . & . & . & . & 7 & 2 & 1 & 4 & \\
\hline Englema & & . & . & . & . & . & . & 3 & $\ldots$ & 3 & & \\
\hline Thomas & . & . & & . & . & . & . & 2 & 1 & 1 & & \\
\hline Peaslee & . & . & 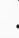 & . & • & . & . & 1 & $\ldots$ & 1 & & \\
\hline Sabine & . & . & & . & . & . & & 1 & 1 & & & \\
\hline Son Nus & sbau & & & . & . & . & . & 1 & 1 & & & \\
\hline Tauffer & . & . & . & . & . & . & . & 1 & 1 & & & \\
\hline Netzel & . & . & . & & . & . & . & 1 & $\ldots$ & 1 & & \\
\hline Pernice & . & . & . & . & . & . & . & 2 & 2 & & & \\
\hline Alberts & & & . & 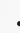 & . & . & . & 1 & $\ldots$ & 1 & & \\
\hline Spencer & Well & & . & . & . & . & . & 1 & 1 & & & \\
\hline Simpson & & . & . & & . & . & . & 1 & 1 & & & \\
\hline Kaltenly & eh & . & . & & . & . & . & 1 & $\ldots$ & 1 & & \\
\hline J. (xilno & & - & . & . & . & . & . & 1 & 1 & & & \\
\hline Martin & . & . & . & . & . & . & . & 2 & 2 & & & \\
\hline Pallen & & . & . & . & . & . & . & 1 & $\ldots$ & 1 & & \\
\hline E. Koels & rlé & . & . & . & . & . & . & 1 & 1 & & & \\
\hline W. C. F & rew & . & . & . & . & . & . & 1 & 1 & & & \\
\hline Prince & & . & . & . & . & . & . & 1 & $\ldots$ & $\ldots$ & $\ldots$ & 1 \\
\hline Welpone & & . & . & & . & . & . & 1 & 1 & & & \\
\hline Esmareh & & . & 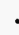 & . & . & . & . & 1 & 1 & & & \\
\hline Tait & . & . & . & . & • & . & . & 2 & 2 & & & \\
\hline West & . & . & . & . & . & . & . & 1 & $\ldots$ & ... & 1 & \\
\hline Sims & & . & . & & . & . & . & 3 & 3 & & & \\
\hline Noegger & ath & . & . & . & . & . & . & 11 & 8 & 3 & & \\
\hline Jlunter? & IICGu & aire & . & & . & . & & 2 & 2 & & & \\
\hline Lusk & . & . & . & . & . & . & . & 1 & $\ldots$ & 1 & & \\
\hline Tying & . & . & . & . & . & . & . & 1 & 1 & & & \\
\hline Savage & . & . & . & . & & . & . & 1 & 1 & & & \\
\hline Mann & . & . & . & . & . & . & . & 1 & $\ldots$ & 1 & & \\
\hline Börner & & - & . & • & . & & . & 1 & 1 & & & \\
\hline & & & & & & & & 135 & 89 & 23 & 17 & 4 \\
\hline
\end{tabular}

Mr. Lawson Tait reports in the British Medical Journal for July, 1880, 28 operations of oöphorectomy, which he had performed within the twelve months previous. Of these 25 were complete operations, with only 1 $\mathrm{d}$ eath ; in the other 2 cases he failed to remove the ovaries entirely, and of these 1 recovered and 1 died.

Wrthods of Operating.-The ovaries may be extirpated, either by eutting through the vagina into the peritoneal eavity, elytrotomy; or by cutting through the abdominal walls, laparotomy. The statistical evi- 
dence is somewhat in favor of the former of these, but the difliculties, the uncertilinty of success, and the possibility of cutting into the rectum make the latter decidedly preferable, except in certain exceptional cases which will soon be mentioned. In a number of cases, even after elytrotomy, it has been found impossible to remove the ovaries, which were hidden away under masses of effused lymph, and as a secondary procedure laparotomy lias been resorted to. I should, from my experience, offer this rnle as to the choice of operation. If the ovaries can be distinetly felt as movable bodies in the pouch of Douglas, elytrotomy should be preferred; if they cannot be felt there, and if signs of old pelvic inflammation can be discovered, laparotomy should be selected as the most reliable and safe procedıre.

Should elytrotomy be preferred, the patient may be placed in Bozeman's position, as shown in Fig. 256, and the perineum be lifted by Sims's speculum ; or upon the back, in a modified Simon's position, Fig. 102, and the perineum be drawn down by the same speculum. Then the ragina being pulled down by a tenaculum fixed in it near its junction with the cervix, it should be cut through by seissors, the ovaries hooked down by the finger, drawn into the vagina, their ligaments ligated by carbolized silk or eatgut, returned to the pelvis, and the vaginal opening closed by suture.

Laparotomy should be performed as in ovariotomy, the ovaries lifted, their ligaments tied, and the ligated pedicle dropped back into the abdomen.

The operation which is selected slould be performed under the antiseptic method, and the after treatment of the patients should be the same as atter ovariotony, to which the reader is referred for details.

Estimate of Battey's Operation.-In concluding this subject let me express my views concerning this procedure in a series of propositions.

1st. Battey's operation will, by reason of the fact that there is a class of cases, the great sufferings attuched to which can be relieved only by the cessation of ovulation and menstruation, survive all opposition, and exist in the future as a surgical resource of great value.

$2 \mathrm{~d}$. It is an operation attended by grave dangers, and by doubtful benefits. Nevertheless, the chances are greatly in favor of its affording relief.

3d. It will ever prove more difficult and dangerous than ovariotomy, because pelvic peritonitis will frequently be found to exist in cases demanding it; because the ligature of the pedicle must often take place deep down in the pelvis; because the abdominal walls, instead of being stretched as in ovariotomy, are contracted and resisting; because the removal of the ovary often involves tearing the surrounding tissues; and because the abdoninal peritoneum has not been prepared for interference by friction from a large tumor ats it has been before ovariotomy.

4th. While the practice of the operation for checking menstruation where vagina and uterus are absent is fully sustained, it is very doubtful whether benefit will result from it in cases of large uterine fibroids.

5th. A greater degree of surgical skill is necessary for the successful performance of this operation than for ovariotomy. 


\section{CHA PTER LI.}

\section{DISEASES OF THE FALLOPIAN TUBES.}

Anatomy.-The identity of structure of the Fallopian tubes and uterus will be appreciated by the study of the formation of these organs in the embryo, as described by recent observers, more especially by Leukart, Thierseh, and Kölliker.

In the walls of the Wolffian body, situated near the kidneys, on each side, in the female embryo, a narrow canal develops which ends below in the two horns of the uterus, while the distal extremity performs " a movement of rotation from before backwards, and from above downwards; the whole, together with the ligaments of the ovaries and the round ligaments, being enveloped in double folds of the peritoneum, which enlarge with the growth of the parts themselves, and constitute finally the broad ligaments of the uterus." Coming together at the median line these canals coalesee, or undergo fusion, forming the lower portion of the uterus, and the entire vagina down to the hymen. The fundal areh is now formed in all probability from fusion progressing from below upwards, although this is somewhat doubtful. Thierseh. ${ }^{2}$ thinks from observation on the embryos of sheep that it oecurs from below upwards; while Kölliker, who experimented on those of cattle, believes that it oecurs from the centre. Prof. Dohm, who experimented upon embryonic foxes, sheep, pigs, and cattle, concludes that it begins between the middle and lower third, and extends upwards and downwards. All this occurs very early in embryonic life; according to Dohm it is completed by the end of the second month. From the faet of this identity of strueture there naturally exists between these organs a elose sympathy in health and disease.

In the adult woman, accorling to Carl IIennig, ${ }^{3}$ the right tube is nine and a half centimetres (three and three-fourths inches), while the left measures only eight and a half. The abdominal extremity has attached to it five large and ten small fimbria. The walls of these tubes consist: 1st. Of peritoneum, which covers them to the fimbriated extremities. 2d. Of connectice tissue, in which are interspersed two sets of muscular

1 Treatise on lluman Physiology, ly J. C. Dalton, p. 645.

\& Prof. Dohm, of Marburg. Transac. Insbruck Convention, Olstet. Journ., vol. iii. ]. 167 .

3 Citcrine Catarrh. Translation in Ofstet. Journ. vol. iii. p. 468. 
fibres, external or longitudinal, and internal or transwerse, which are contimuations of the muscular tissue of the uterus and broad ligaments. At the point where these tubes enter the uterus, Hennig declares that the longitudinal and transverse layers of fibres both become greatly developerl, aurl that the latter forms here a distinet sphincter tube. 3d. We find within and lining the tube a mueous membrane, which is thrown into large and small folds, which are very evident near the fimbriated extremity, and gradually become insignitieant as we advanee towards the uterus. Within this membrane Mr. Bowman discovered tubal glands, which eonsist of grape-like struetures, extending downwards towards the subjacent muscular fibre. Thry differ from the muciparous follicles of the varina, the Nabothian glands of the cervix, and from the utricular follicles of the uterine cavity. Kölliker denies the existence of these, but IIennigr deseribes them very fully. These compound glands of the Fallopian tubes are lined with an epithelinm of basement form. The mucous membrane covering over the tubes, and not dipping down into these glands, is covered by a ciliated epithelium, the broom-like action of which is exerted towards the uterus. The object of this seems to be to sweep the products of the ovaries into the uterus, and to force in the same direction menstrual blood oozing into the tubes from their mucous lining, as a result of ovulation. The zoosperms, which are known to pass through the uterus and proceed as far as the ovaries, are themselves endowed with powerful eiliary action in the single cilia which each possesses, and by this they overcome the oplosing force of the tubal ciliax.

It is highly probable, to say the least, that the erectile condition induced in the mucous membrane of the uterus and tubes by contraction of the midlle coat of their muscular fibres produces in the latter, as in the former, rupture of bloodressels and consequent hemorrhage. Hennig declares that "during menstruation throughent its entire surface, it (the mucous membrane of the tubes) assumes a dark red color." Ruysch, an old anatomist of Amsterdam, who wrote in 1737, describes a post-mortem examination in which he discovered the Fallopian tubes containing blood. This has by some of the writers upon the history of hematocele been construed into a record of that affection, but the passage appears to refer merely to a condition which depends upon ovulation. Messrs. Bernutz and Goupil mention instances of the collection of blood in the Fallopian tubes in consequence of obstruction of these canals. Dr. Duncan ${ }^{4}$ admits that some blood may come from the tubes in natural menstruation. In two of my cases of ovariotomy in which I employed the clamp, the patients menstruated regularly throngh the tube for three periods, when at the same time menstruating per vaginam. The abdominal opening then

1 Loc. cit., p. 473.

3 Op. cit., voil. i.
2 Loc. cit., p. 470.

4 Fecundity, Fertility, and Sterility, p. 388. 
elosed, and the discharge was thereafter confined to the vagina. Other cases of the same kind are on reeord. Now as in these cases there was free exit of blood per vaginam, there ean be no reason for believing that a regurgitant action occurred. The blood flowing by the tube was more probably the result of hemorrhage into that canal, the uterine end of which was constricted by traction, effected by the confinement of the abdominal end in the wound.

The diseases by which the Fallopian tubes may be affected are the following :-

\section{Inflammation ; \\ Stricture ; \\ Distention ; \\ Displacements.}

Inflammation of the tubes, or salpingitis, consists in inflammation of their mucous membrane, and may be either acute or chronic.

'The acute variety generally results from puerperal endometritis, or from gonorrhcea, which has extended through the uterine mucous membrane. I have twice seen this disease almost destroy life by attacking the uterine mucous membrane, and subsequently producing pelvic peritonitis, doubtless reaching the peritoneum by traversing the tubes.

Chronic salpingitis is one of the sources of uterine lencorrhca, and commonly produces permanent interference with the ealibre of the tubes. In some cases it results in constrictions, while in others it produces dilatation. The latter condition it probably is which produces the discrepancy observed between the reports of various observers as to the dangers resulting from intra-uterine injections. When the splincterie action of the splincter tube of one or both sides is destroyed, fluid thrown into the uterus will sometimes enter the tubes, and produce in them contraction, spasm, and violent acute salyingitis, which may go on to the production of peritonitis and death. When dilatation has oceurred it is not at all rare for the uterine sound to be passed for several inches up the tube. I lave met with several unquestionable case's of this hind. I say unquestionable, because the sonnd must have followed one of two eourses-through the fundus into the peritoneum, or up the canal of one of the tubes.

As this subject has created some discussion, I will rapidly allude to two of these cases.

A physician, residing near this city, wrote to me concerning the case of lis wife, who had ehronic corporeal endometritis of several years' duration. Fon using the sound, he was alarmed at finding it pass into the uterus nearly six incles. The lady came down to me, and upon repeated measurement I found the sound pass a little over three inches. The patient went home, and her husband, surprised at my results, used the sound again, when, ats before in his laands, it passed in over five inches. To solve the para$d o x$ he at once came down with her, and when examning with hom I 
distinctly showed him the normal measurement, a little over three inches, and then twice passed the sound up one tube a distance of two inchen.

One of my clinical assistants pointed out to me at my clinique, as a fit subject for a lecture, a patient whose uterus measured five inches, and who presented no symptons exeept those of ordinary uterine catarrh. I had occasion to examinc this patient, after stating this measurement, before the chass, when I found that the sound jassed only three inches. Conlident, from the well-known aceuracy of my assistant, that he could not have erred, I at once stated to the class what I believed to be the cause of the discrepancy, and in its presenee passed the probe up the right tubr, making a measurement of five inches. 'To avoid all chance of error, I then requested my assistant to verify my two measurenents, when he also passed it first three inches to the fundus uteri, then two inehes up the right tube. IIildebrand ${ }^{1}$ relates two cases in which he passed a probe up the tube, and similar instances are recorded by Veit, ${ }^{2}$ Mathews Duncam, ${ }^{3}$ Noeggerath, ${ }^{4}$ and others.

The great danger in both acute and chronic salpingitis is pelvic peritonitis, which may spread and destroy life. This arises in part from escape of the contents of the inflamed tubes into the peritoneum.

Of the symptoms very little can be said. The chronic variety may continue for years, and result in dilatation of the tube with no symptons which arrest attention; while the acute form so quickly produces local peritonitis, that its symptoms are lost in those of that affection.

No special treatment is applicable to it except the adoption of means to prevent peritonitis, as rest, opiates, leeches, and strict avoidance of sexual intercourse.

The great obscurity of the diagnosis of tubal diseases renders the subject one upon which it is not profitable to speak further, although as a pathological study it is one of great interest.

Stricture.-The Fallopian tubes, which are often imperfect or wanting when the uterus is absent or undeveloped, may, even after full development, be affected by stricture. The condition may be produced by these causes :-

\author{
Calcific deposit ; \\ Senile atrophy; \\ Salpingitis ; \\ Pelvic peritonitis ; \\ Tubercle or fibrous tumors.
}

Partial obliteration of the eamal results in sterility if it affect both sides simultaneously, and sometimes, by causing the accumulation of fluids, it

1 Barnes's Report on Midwifery, Brit. and For. Med.-Chir. Review, Oct. 1868.

2 New York Ohstet. Journ., vol. i. p. 267.

3 Lilinburgh Med. Journ., 1856.

4 liemarks before Ostetrical society, New York. 
produces tubal dropsy. It is not rare for rupture of the tubes and consequent hematoecle and peritonitis to result from imprisonment of menstrual fluid in them. M. Puech analyzed two hundred and fifty-eight cases of congenital atresia of the genital organs, and found that in fifteen cases the Fallopian tubes were dilated, and in five were ruptured. The condition is rather a study for the pathological anatomist than for the gynecologist, for it can neither be diagnosticated nor relieved by treatment.

Distention.-The tubes may be distended by aceumulation of mucus, pus, menstrual blood, or a muco-serous material secreted by the altered mucous membrane accompanying great and prolonged distention. This condition invariably has as its moving cause stricture, which prevents the tube from emptying itself into the uterus. When very great distention takes place, the accumulated fluid either forces its way out of the uterine extremity, constituting the profluent dropsy of Rokitansky, or passes out of the fimbriated extremity into the peritoneum, or a rupture of the tube oceurs. Such an aceumulation may produce a tumor equal in size to the head of a child of ten years, and some say even much larger, though thels, is doubt as to the authenticity of the latter cases. Virehow has established a clitss of eysts which he styles eysts from retention, to which distention of the tube by sero-mucus properly belongs.

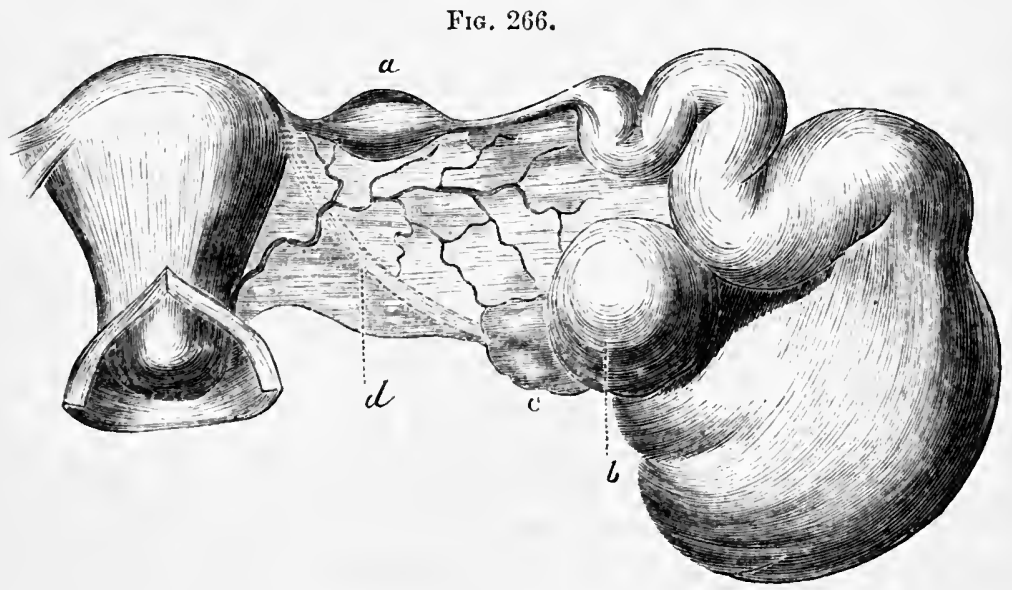

Tubal dropry. (Luiviu and Dugès.)

The diagnosis in alvanced cases, where, for example, the tumor las dereloperd to the extent just mentionerl, is difficult and of ten imposilble. Sometimes, lowever, it may be nates by the following means: An elongatted, fluctuating, mosable tumor is felt in the retro-uterine space a little to one side; in its ontlines the tumor is wary, and it can be separated from the uterus. Fieanzoni quotes kiwisch ats declaring that, in sueh cases, the presconce at the side of the fundus of a mammillated, elastic, and 
elongated tumor, justifies the diagnosis of tubal dropsy, but he differs from him, and regards the positive diagnosis as impossible. In case the diagnosis can be arrived at, the most appropriate treatment wonld consist in taplping per vaginam.

Displacements._-'The tubes may pass with hernial protrusions into the ingninal or erural openings, and, in ease of inversion of the uterus, may descend into the carity of the displaced organ. It is generally in company with the ovary that the tube leaves its place, but at times it descends alone. Dr. Scholler reports an instance in which, in a child who died twenty days after birth, a tumor was discovered which extended from the inguinal region to the riglit labium, and contained the Fallopian tube, which was non-adherent. A crural hernia of the tube alone which ended fattally is likewise recorded by M. liérard.

Prof. Rokitansky, ${ }^{2}$ and Dr. 'Turner, of Scotland, have both drawn attention to severance of the tube from the ovary by traction from inereased weight of the latter or from false nembranes. The former eites twelve instances in support of the fact.

Other Diseases of the Tubes.-In addition to these diseases the tubes are sometimes affected by cancer, tubercle, fibrous tumors, abscess, and aceumulation of blood in their canals from hemorrlage from the mucous membrane. There is so strong an analogy between these disorders and the same in other organs, that it is not deemed necessary to enter upon their consideration.

\section{CIA PTER LII.}

\section{EXTRA-UTERINE PREGNANCY.}

Ir is evident that to condense into the narrow limits of a short chapter a subject which would require a volume for its extended consideration, involves of necessity a superficial review of its essential points only.

It may even be thouglit by some that this subject is out of place in a work upon gynecology, and that it shonld have been left for one devoted to obstetries. Its admission here is proof of the fact that I do not share this feeling. Ectopic gestation, although theoretically falling in the domain of the obstetrician, in reality almost always claims the attention of the gyncologist from the fact that the existence of pregnancy is in these eases very generally not recognized, the patient being supposed to suffer from some pelvic tumor or obscure uterine or ovarian disorder. It is very frequently necessary to differentiate it from a variety of disorders which 
will soon be mentioned, and even its treatment involves rather a familiarity with the resources of gynecology than with those of obstetries.

Definition and Synonyms._Extra-uterine pregnancy, extra-uterine or ectopic gestation signifies the fixation and derelopment of the impregnated ovum outside of the uterine cavity.

Varieties._For the physiologist and pathologist there are many varieties of this abnormal gestation; for the gynecologist there are but three. For him the tubo-ovarian, tubo-abdominal, ovarian, and some other varieties are niceties beyond the appreciation of diagnosis, and he is foreed to limit himself as far as practice is concerned to the classifieation of all varieties into, 1st, tubal; 2d, interstitial ; and 3d, abdominal pregnancies. These by rational and physical signs lie may differentiate from each other, and in certain eases base the propriety of surgical interference upon his conclusions. These, and these only, then, are the varieties which we shall consider in this elapter.

Tubal pregnancy, the most dangerous of all varieties of extra-uterine gestation, consists in the arrest of the impregnated ovum in the Fallopian tuhe and its development there. It may be that instead of being absolutely in the tube the fruetified orum may derelop just where the fimbriated end of the tube clasps the ovary.

Interstitial pregnancy consists in an advance of the orum through the tube until it begins to pass through the uterine wall. Then an arrest taking place before the orum enters the uterus, it attaches itself, distends the parenchyma of the uterus to make its niclus, and eauses it to protrude partly towards the nterine cavity, partly towards the abdominal.

In abdominal pregnaney one of two things oceurs: either the tube loolding the impregnated ovm in its grasp breaks away from its orarian attachment, falls into the abdominal eavity, and remains there, while the orum easting out tentacula attaches itself to the peritoneum and grows; or. as some suppose possible, the impregnated egg falls out of the grasp of the tube, and, getting its nourishment from the peritoneum, develops independently of the lining membrane of the uterus which extends throughout the tubes.

Etiology.-It is a faet unirersally aceepted that in the human female, as in the lower order of animals, impregnation of the ovule often oceurs at or near the ovary. In some cases, by a stricture in the tube, due to lessening of its calibre by inflammation, the development of a little tumor, or contraction of lympli poured ont by pelvic peritonitis, an obstruetion is offered to the progress of the ovum towards the uterns. In contact with a muerous membrane closely resembling that of the uterus, it at once accommodates itself to its vicarious quarters, attaches itself, forms a placenta, and steadily grows. There are many points in pathology concerning which no one hals a right to an opinion who has not made researehes of a more or less personal charaeter in regard to them. The pathology of extra- 
uterine pregnancy is one of them, and although my experience in reference to this condition is quite large, as I shall soon show, I express nyself upon it with great hesitation.

Although extra-uterinc gestation has been divided by pathologists into abdominal, tubal, ovarian, interstitial, tubo-abdominal, and tubo-ovarian, it seems highly inprobable that the ovum at the moment of its impregnation could attach itself to any other tissue than the lining membrane of the uterus, which is so especially constructed to accommolate it. Once having undergone development in this connection, however, it rapidly invales arljoining structures, the omentum, peritoneum, etc., and forces them to nourish it.

Pathology.-Should the arrest of the ovum have occurred in one of the tubes, it develops rapidly and endeavors to furnish a uterus for the growing chilil. But the muscular structure of the tubes, being scanty compared with that of the uterus, although it develops to accommodate its contents, gradually grows thinner and thinner under distention until, towards the end of the first, second, or third month, it usually ruptures, and the contents of the ovum, as well as much blood escaping from the ruptured vessels of the tube, escape into the peritoneal cavity.

A true hematocele is thus created, the patient generally becoming collaysed, and dying, and very rarely escaping by absorption of the blood and by encapsulation or discharge of the fotus. Veit ${ }^{1}$ declares that about one-fifth of all cases of hematocele are due to the rupture of tubal pregnancies, and that recoveries occur under these circumstances much more commonly than is generally supposed. I do not agree with him as to the frequency of this cause of hematocele, but $I$ am quite sure that $I$ have seen it thus produced, and have seen recovery follow. These are the cases of hematocele which are classed by Barnes under the name of "cataclysmic." As a rule the violence of their onset entitles them to that name, but it is highly probable that some of those occurring at early periods of gestation develop with less violent and overwhelming symptoms.

Hecker reports 45 cases of tubal pregnancy. In 26 cases rupture occurred in the first month, in 11 cases in the third month, in 7 cases in the fourth, and once in the fifth month. Spiegelberg² reports a case of an orum advancing to maturity in the tube.

Interstitial pregnancy is much less frequent and less dangerous than the variety just mentioned. It is much more likely to alvance to full term, and while it may produce death by rupture and discharge into the peritoneum, it may, as in my fourteenth case, discharge into the uterus and be expelled through the natural passages. Dr. Lenox Hodge once succeeded in reeognizing the existence of such a case at full term, cut through the

1 Deutsche Zeit. für prakt. Med., No. 49, 1878.

\& Arch. f. Gyn., Bd. i. p. 406. 
layer of parenchyma which shut the fæetus off from the uterus, and conducted the case to a successful issue.

Although not attended by as great dangers as attach to tubal and interstitial pregnancies, the abdominal variety is a most serious aberration from normal gestation, and one which commonly destroys life. In the first two forms the rapidly developing ovum is imprisoned in tissues which are inapt for great distention, and which rupture under its influence. In the third the fuetal ball has at its disposal for expansion and growth the whole peritoneal cavity, the placenta encroaching in its search after nutriment upon the bladder, the omentum, the intestines, and any portion of the peritoneum within its reach. The events of this form of pregnancy are the following: First, the fotus unnaturally attached and nourished may die in the early months of its life, become encysted, and in time be east off through the rectum, the bladder, or through the abdominal walls. Secoud, the pregnancy may advance to the end of the ninth month, when, labor coming on, nature makes a persistent effort to expel the clild, but, on account of there being no way of exit, fails, and the child, with its enrelopes, is retained, and becoming encysterl remains in its nidus for years, creating no disturbance by its presence. Third, the child, shut up in its unopened shell, acts as a foreign body, ereates suppurative action in its envelopes, and becomes surrounded with pus in place of liquor amnii. Or, the liquor amnii being absorbed, the foetal bones become closely hugged by the walls of the eavity which contains them, and act as an intense irritant, which sets up formation of pus and in this way leads to hectic fever from absorption of septic material.

Hecker found that out of 132 cases of abdominal pregnancy, 76 terminated in recovery. Recovery took place in 28 cases after expulsion of foetus per anum, in 17 eases after formation of lithopxdion, in 15 eases after elimination through the abdominal wall, in 11 cases after laparotomy, in 3 eases following vaginal section, in 2 cases from undefined causes. Death followed from hectic in 18 cases, peritonitis in 12 cases, operations in 12 cases, rupture and hemorrhage in 7 cases, fecal vomiting in 2 cases, dropsy in 1 case, canse not dofined in 4 eases.

Ceurses of Death.-The causes of death in the various forms of extrauterine pregnancy may thus be presented:-

Shock ;

Hemorrhage;

Septicamia ;

Peritonitis ;

Hectic fever ;

Perforation of important riseera by bones.

Symptoms._-The suspicion of extra-nterine pregnancy is usually created in one of the following ways: 1 st. $\Lambda$ woman who has passed over one, two, or three menstrual epochs is suldenly seized with the symptoms of 
hematocele, agonizing pelvic pain, faintness, coldness of extremities, bathing of face with cold sweat, rapid and fechle heart action, and nausea and retching. She dies of overwhelming nerrous paresis, called " shock," of hemorrhage, of peritonitis, or of septicamia ; or she gets well, the diagnosis of pregnancy is regarded as a mistake, and she is said to have recovered from hematocele which was the result of temporary suppression of menstruation.

2l. $A$ woman who supposes herself to be pregnant becomes alarmed by the development of one, two, or three sets of abnormal symptoms: ( $a$ ) the oceurrenee of irregular, immoderate, sudden, and excessive gushes of bluod; (b) the rapid and disproportionate enlargement of the hypogastrium; or $(c)$ the manifestation of a dull, grinding pain, fixed in one iliae fossa or extending thence down the thighls, and, as time passes, becoming markedly paroxysmal and spasmodic.

Suspicion is thus excited, not of the existence of this vice of gestation, but of something being wrong, and a careful examination by rational and physical signs is instituted. Should such examination be made after rupture of the vicarious uterus, and eseape of its contents into the peritoneal earity, the ordinary physical signs of hematocele will be deteeted, and to their enumeration in the chapter deroted to that subject the reader is referred.

Physical Signs._-Besides the symptoms mentioned pointing to the advisability of a physical examination, the uterus is usually found enlarged, iifted up in the pelvis, and pressed forwards or laterally by a tumor which exists posterior to it or on one side. This tumor is found to be nearly immovable, very slightly sensitive upon pressure, and marked by a peculiar degree of hyperamia, which gives, to an exaggerated degree, the violet hue of gestation to the vagina. It is marked by a very rapid growth, so that a week's watching will show a decided inerease in its dimensions.

The tumor alone would not furnish sufficient grounds upon which to found a diagnosis of ectopie gestation, but a rapidly growing pelvic tumor accompanied $(a)$ by the gastrie and mammary symptoms of pregnancy, (b) by cessation of menstruation, (c) by enlargement of the uterus, $(d)$ by the purple liue of the vagina, and $(e)$ by the detection of ballottement in the tumor, would do so.

Differentiation.-The conditions with which extra-uterine gestation is most likely to be confounded are the following :-

Uterine fibroma or fibro-cyst;

Cyst of ovary or broad ligament;

Hematocele;

Double or bi-corned uterus with impregnation of one side.

Normal pregnancy with retroflexion;

Pelvic abscess.

The uterus is, in these eases, lined by decidua, and it is almost as mueh 
enlarged as in normal pregnancy. Before any decision is arrived at it is often wise to dilate the cervical canal with tents, so that the finger may be introduced to the fundus. By this measure normal pregnancy, if it exist, is interfered with, but the exigency requiring immediate diagnosis is so great, that this disadrantage must be accepted.

Dilatation of the cervical canal having served to exclude normal pregnaney, while all the symptoms of pregnancy exist with marked enlargement and softening of the uterus, and with the presence of a suspicious tumour in the pelvis, the probabilities in favor of extra-uterine futation become strengthened. Still the differentiation of this from the other conditions mentioned remains to be established, and it is often very difficult. It is only by the most careful consideration, patient research, and judicious delay that it can usually be accomplished. While these are being exercised, rupture of an extra-uterine foetal nest may occur, and a fatal issue be the consequence.

In some cases, ballottement, elear and distinct as that which is gotten in normal pregnancy, lends us its aid and makes diagnosis certain ; in others the aspirator clears up the case; while in others still, where, for example, the question lies between a eyst of the broad ligament and extra-uterine pregnancy, cutting into the sac by means of the incandescent knife will combine diagnosis and treatment in a most satisfactory manner.

Let me illustrate the difficulties and methods of diagnosis under these eireumstances by the relation of three cases.

CASE 1.-Mrs. A. suddenly ceased menstruating, and for three months suffered from nausea and romiting, and pelvic pain extending down one thigh, and beeame so enfeebled and emaciated that she could not stand without support. She came to me from Peekskill, and upon examination I found the uterus elevated and pushed to one side by a fluctuating tumor in one iliae fossa. Drs. Fordyce Barker and Noeggerath saw her in consultation with me, and we conld not decide whether it was a case of amenorrhoa with cyst of the broad ligament or tubal pregnancy. Immediate action was necessary, and I cut through the vaginal walls with Paquelin's thermoeautery and found the former condition existing.

Case 2._Mrs. B. was brought to Dr. Marion Sims and myself to deeide as to the cause of irregular menses, with violent pain in left iliac fossa. Physical examination showed uterus pushed upwards and laterally by a tumor attached to its left horn. The question lay between interstitial pregnancy and inflammatory product in left broad ligament. To decide it we fully dilated the uterus by tents, introduced the fingor fully to the fundus, and found the latter condition to exist.

CAsE 3.-Mrs. C. consulted me on atecount of a soft, fluetuating tumor posterior to the uterus, aceompanied by cessation of menstruation. I was doubtful whether it was a fixed ovarian cyst, a hematoma, or an abdominal pregnancy. Iler symptoms were so urgent that $I$ dared not delay for 
time to solve the question, so I passed through the mass a strong interrnpted eurrent which would have killed a futns had one existed. But it proved to be a hematoma, and was subsequently discharged through the rectnm.

The question of diagnosis bcing a very momentous one, it is generally alvisable to settle it hy crucial tests, which are not attended by great danger if the case be not one of pregnancy, and might prove curative if it were so.

Very often we hear of physicians being blamed on account of failure of diagnosis in these eases which suddenly die from rupture. Every medical man who eomntenanees sneh a charge demonstrates his want of experience or his want of professional loyalty by so doing. Very often there is nothing in these terrible cases to excite suspicion; very generally nothing to decide us positively even when suspicion is excited.

Symptoms of Approaching Rupture.-_The part containing the fotus and constituting a vicarious uterus begins to contract, and miniature uterine efforts show themselves in inereasing severity, a bloody flow takes place from the cervix, and very commonly a small pieee of deciduous membrane is expelled. These symptoms will very probably be supposed to point to alortion, and the ease is usually allowed to proceed until the suddenly developed symptoms of rupture of the sac serve to open the eyes of the practitioner to the truth, or at least excite in his mind a strong suspicion of it.

Recognition of the Varieties.-Nothing is easier in a written description or in the lecture-room than to point out the means of differentiating the three great varieties of ectopic gestation-abdominal, interstitial, and tubal. Nothing is more difficult, as every man of large experience in this difficulty will agree, than to do this at the bedside. In general terms it may be said that the interstitial form is very rare, that the tumor consists of an irregular enlargement of the uterine body, and that the tumor moves with the uterus, while at the same time this organ is empty: that tubal pregnancy gives an enlargement at the side of the uterus, yields ballottement more generally than the other forms, and is marked by a tumor somewhat separated from the uterus, and which does not decidedly more with it: and that abdominal pregnancy is generally detected late, at a period when the rolling of the child's body in the abdomen can be detected, while at the same time the uterus is found to be empty.

I lo not pretend to offer these differences between the rarieties as universal and reliable means of differentiation. Indeed, no such means will be oflered by any one whose experience is large; for such experience must have tanght him that none such exist. I have seen two eases of interstitial pregnancy, and have relied in the description which I have given very largely upon the signs presented in these.

Prognosis. - Whatever be the variety, the period, or the circumstanees connected with this vice of gestation, the prognosis is bad. True a large 
number of women escape death ; but this fact does not contradict the statement just made. The prognosis is most favorable in abdominal pregnaney when adhesion has oecurred from death of the foctus and subsequent inflammation between the sac wall and the parietal peritoneum; less favorable where no such adhesion exists and the peritoneal eavity is free in front of the fotal shell. It is more favorable in interstitial than in tubal pregnancy, and least favorable in the purely tubal rariety. In the tubal form it is much less farorable if the foetus be living than if it be dead. Kiwiseh ${ }^{1}$ reported 100 eases of extra-uterine pregnaneies, with 18 reeoveries; Pueeh 100 cases of tubal preguancy, 98 eases of rupture of tube, 2 of rupture of vein of broad ligament, 1 recovery; 199 cases of elimination of factus in the ovarian and abdominal form, 146 recoveries. (See Courty, p. 996.)

As my experience in this condition has been quite large, $I$ report it in full in the subjoined table:-

\begin{tabular}{|c|c|c|c|c|}
\hline : & With whom seen. & Variety. & $\begin{array}{l}\text { Remedial measures } \\
\text { adopted. }\end{array}$ & Termination. \\
\hline 1 & Dr. Mouraille. & Tubal. & & Death from rupture. \\
\hline 2 & Dr. Henschel. & Tubal. & $\begin{array}{c}\text { Aspiration by Dr. } \\
\text { Thomas. }\end{array}$ & $\begin{array}{l}\text { Death from septicx- } \\
\text { mia. }\end{array}$ \\
\hline 3 & Dr. Henschel. & Tubal. & ................ & Death from rupture. \\
\hline 4 & Dr. Giberson. & Tubal. & $\ldots \ldots \ldots \ldots$ & Death from rmpture. \\
\hline 5 & Dr. J. L. Brown. & Tubal. & $\begin{array}{l}\text { Aspiration by } \mathrm{Dr} \text {. } \\
\text { Thomas. }\end{array}$ & Death from rupture. \\
\hline 6 & $\begin{array}{l}\text { Drs. Green and } \\
\text { Crane. }\end{array}$ & Tubal. & $\begin{array}{l}\text { Elytrotomy by Dr. } \\
\text { Thomas by galvano } \\
\text { caustic knife and de- } \\
\text { livery of fotus. }\end{array}$ & Recovery. \\
\hline 7 & $\begin{array}{l}\text { Drs. Coates and } \\
\text { Barker. }\end{array}$ & Ablominal. & $\begin{array}{l}\text { Laparotomy by Dr. } \\
\text { Thomas. }\end{array}$ & Recovery. \\
\hline 8 & Dr. Chas. Young. & Abdominal. & $\begin{array}{l}\text { Lapiatrotomy by Dr. } \\
\text { Thomas. }\end{array}$ & Recovery. \\
\hline 9 & Dr. J. Hadden. & Abrominal. & $\begin{array}{l}\text { Laparotomy by Dr. } \\
\text { Thiomas. }\end{array}$ & Recorery. \\
\hline 10 & W. J. Walker. & Abdominal. & $\begin{array}{l}\text { Discharged by vagi- } \\
\text { na. }\end{array}$ & Recovery. \\
\hline 11 & Olcott. & Abrteminal. & Discharged by rectum. & Recorery. \\
\hline & $\begin{array}{l}\text { Drs. Barker, } \\
\text { Fisher, Lusk } \\
\text { and Mletealfe. }\end{array}$ & Tubal. & ............ & Death from rupture. \\
\hline 13 & Dr. Greell. & Interstitial. & ........... & $\begin{array}{l}\text { Died years after- } \\
\text { waris from pneu- } \\
\text { monia. }\end{array}$ \\
\hline 14 & $\begin{array}{l}\text { Drs. Emmet and } \\
\text { McBurney. }\end{array}$ & Interstitial. & $\begin{array}{l}\text { Life of fotus destroyed } \\
\text { ly electric current; } \\
\text { fetus discharged } \\
\text { through uterus. }\end{array}$ & Recovery. \\
\hline 15 & $\begin{array}{l}\text { Drs. Peaslee and } \\
\text { Janvrin. }\end{array}$ & & $\begin{array}{l}\text { Incision by Dr. Peas- } \\
\text { lee. }\end{array}$ & $\begin{array}{l}\text { Death from septicre- } \\
\text { mia. }\end{array}$ \\
\hline 16 & Dr. W. Frankel. & Abdominal. & & Still living: \\
\hline 17 & Dr. Harrison. & Abdominal. & $\begin{array}{l}\text { Electric current now } \\
\text { leing used. }\end{array}$ & Patient living. \\
\hline
\end{tabular}

1 Spiegelberg, Lehrbuch der Gel). IIülfe, 1877, p. 323. 
Of these 17 eases, 2 were interstitial and both recovered; 7 were tubal and 1 only recovered; so were abrominal and 5 recovered; while 2 are still doubthul. Ont of the 17 cases, 10 recovered and 7 died. This fact, however, must be noted: 2 patients still live, and the diagnosis may be jucorrect in their eases, or they may yet die of the condition it the diagnosis be correct. Out of the 17 women thus aflected, 9 were submitted to surgrical procedures, and out of these 6 recovered and 3 died.

Treretment.-In dealing with the treatment of extra-uterine gestation, I am possessed by a strong desire to avoid even the appearance of dogmatism. 'There is none in the whole list of subjects obstetrical and gynecological about which so little is absolutely settled and upon which practical men difter so widely. At one extrene stand able and conservative practitioners, who anpear to favor the position that, as a very general rule, we should stand calmly by with folded arms and accept without effort or resistance the terrible chances of death which attend these cases. At the other, we see enthusiastic ones with strong surgieal proclivities, who would apparently resort to laparotomy in every case in which diagnosis is possible. On a middle ground, one lying between these extremes, the truly conservative surgeon will find his appropriate position.

Let us in the beginning recognize the fact that, do what we will-remain utterly inactive, or use the greatest surgical enterprise-the issue of these untortumate cases will very likely be bad. And let every surgeon be sure that he does not shirk a dangerous operation beeause he fears the odium which will probably attach to a fatal result, and which he would avoid if he simply allowed his patient to die withont an effort.

He who cannot bear unjust eensure and endure without complaint an odium which he does not deserve, was not born to be a surgeon, one of the greatest functions of whose life this is ; and under the grave responsibilities which attach to the conduct of a case of ectopic gestation it is the bounden duty of such an one to place his patient's interests in stronger hands. The statement is true everywhere in surgery, but nowhere is its truth more strikingly apparent than in these casts, that every personal consideration, every private interest, should yield to the good of the patient ?

One point which may be regarded as entirely settled in the treatment of extra-uterine pregnancy is this: a secondary operation for discharge of the contents of the fictal sac is always sater than a primary one. But its antithesis must likewise be recognized_it may become hazardous to discard a primary operation and to expose a patient to the delay involved by waiting for a secondary one. The rule for interference should then be this: delay is wise so long as it is the offspring of prulence; it is culpable as soon as it becomes the dictate of timidity and indecision.

The only way in which justice can be done to this subject is by supposing 
certain conditions differing widely from each other, in which the patient may be seen :-

(a) The tumor being low in the pelvis, fluctuation distinct, and the diagnosis of extra-uterine pregnancy well established, the life of the foetus should be destroyed by means as certain and as free from danger as possible. There are three methods by which this may be done: 1st, by passing through the tumor a strong, interrupted current, one electrode in the rectum and the other on the most prominent part of the tumor, the judgment of the practitioner being the guide as to the power and duration of the current; $2 \mathrm{~d}$, by injecting through the vaginal or abdominal walls, by means of a long and slender hypodermic needle, ten to fifteen drops of Majendie's solution of morphia directly into the sac; and, 3d, by drawing off the liquor amnii by a very small aspirator needle with antiseptic precautions. In the last two operations mentioned the needle, first immersed in boiling water, should be thoroughly carbolized before being used, the solution employed should be carbolized, and the puncture brushed thoroughly with carbolized solution and painted with collodion.

The puncture of the extra-uterine ovisac has been performed in a number of instances with good results; viz., twice by Morton, and once each by Greenhalgh, Stoltz, and Koeberlé. I have resorted to this plan twice, and lost both patients. One died of septicemia; the other of hemorrhage in to the sac and rupture. Dr. Routh has recently reported a case which ended fatally after the same operation, as my second one did.

(b) The pregnancy being to all appearances one of tubal variety, and immediate action being demanded by severity of symptoms, two courses offer themselves. 1st, if the tumor be certainly accessible from the pelvis, it may be cut freely into by a dull, incandescent point, like the knife of Paquelin's thermo-eautery, the fotus removed, hemorrhage controlled by a firm tampon. septicemia prevented by antiseptic injections, and the placenta allowed to come away of itself; $2 d$, the operation of laparotomy may be pertormed, the broad and ovarian ligaments and the Fallopian tube be included as a pedicle in a ligature, and the foetal mass be removed.

From my present experience I should say that if the tumor be low in the pelvis, fluctuation in it be beyond donbt, and reaching the sac certain, the safest and best method of dealing with the case would be to introduce a large Sims's speculum, and, bringing the dull cautery of Paquelin's apparatus to a red heat, cut slowly into the sac. Then the foetus, but not the placenta, should be removed, a linen bag filled with cotton used as a compress fixed externally upon the abdomen over the site of the tumor with adhesive plaster, and the sac carefully filled with antiseptic cotton, which should be renewed once in every thirty-six hours. Listerism should be carefully observed. By these means hemorrhage can be completely controlled, and, this danger and septicxmia being put aside, it is difficult to conceive what 
more we can ask in that class of cases. In these cases also the fuctus may be destroyed by injections of morphia or by a strong, interrupted current, and subsequent events be waited for.

(c) Should the pregnancy minuestionably be abdominal, as proved by its atrance beyond the period ordinarily possible for tubal distention, and by the comparatively snall size of the uterus, it should not be interfered with until the completion of the full term. At that time an effort at labor usually oceurs and gives a signal for action. Slould this most fortunate event occur, the crowning triumph of obstetric surgery may be reached in the delivery of a living child from a living woman at full term, as was done by Jesop, of Leeds, in a case reported to the London Obstetrical Society a few years ago.

At the present day, when abdominal surgery is so thoroughly systematized and fully understood, and when the great contributions to it of the illustrious Lister have so completely altered its results, it is worse than useless to quote the statistics of laparotomy for extra-uterine pregnancy collected by Campbell and other's. A new departure must be made in the sulject, and the future must make its own record.

In these cases, where the head passes downwards into the pelvis, it sometimes becomes possible to cut through the vaginal wall, seize the presenting part by the obstetric forceps, and deliver a living child from a woman, only slightly endangered by the operation, almost per vias naturales. In the year 1816, Dr. John King, a country practitioner, residing upon Edisto Island, on the coast of South Carolina, met with just such a case as I have pictured, and being both a bold and original man, he followed the course to which I have alluded, with the result of saving mother and child. This case will be found published in the Med. Repository, 1817, and a pamphlet upon the subject by Dr. King is now in the possession of Dr. Pooley of Yonkers, N. Y.

(d) Should delivery at full term not be accomplished, a lithopædion or petrified infant may result and be retained for many years; suppurative action may occur in the fœetal envelopes, and laparotomy be subsequently resorted to as a secondary operation ; or, the liquor amnii being absorbed, the bones of the child may remain clasped by the foctal envelopes and produce dangerous inflammation and ulceration. Under these circumstances it requires a great deal of consideration as to the proper course to pursue'; whether to interfere or to leave matters to nature. Even if it be recognized that interferenee will surely become necessary, the question arises as to the time at which it should be practised. In the other varieties of extrauterine pregnancy the continued progress of gestation exposes the woman to constant and steadily increasing danger of sudden death. In the abdominal form it not only does not do this, but it is, as has been stated, often the wise course to allow the process to continue until the child arrives at full development. 
Let us suppose that either before or after full term of gestation the child has died, and it is pretty certain that the woman carries her dead offspring within the peritoneal cavity. Is it wise on this account at once to interfere by surgical means? I think not. One of the greatest dangers attaching to interference consists in hemorrhage. The longer time that the placenta remains attached after fotal death the more certain is it to become atrophied and consequently less vascular. Another great danger consists in septieamia. The more thoroughly the foetal envelopes become disgorged and atrophic from loss of function, the less likely is this dangerous complication to develop. Judicious delay and cautious waiting for symptoms indicative of approaching trouble are then, in my opinion, decidedly advisable.

But such delay, such waiting are by no means to be carried so far that symptoms of septic absorption shall occur. Non-interference carried as far as this is not less to be deprecated than a rashness which results in intemperate and premature resort to operation.

$A$ foctus remaining in the abdominal cavity long after the full term of gestation, laving lost its life, and being surrounded by intestines after atbsorption of the liquor amnii, or by a purulent fluid which has replaced it, is always an element of great danger which must become more and more aggravated as time passes. Its removal should be regarded only as a question of time, not of propriety. It is true that instances are on record where such contents have remained in the bodies of unfortunate women for thirty and forty years, but such cases are rare exceptions to the rule, and the impropriety of leaving these women for the remainder of their lives in such peril could be tolerated only in the dark days of abdominal surgery.

I have operated six times for extra-uterine pregnancy, but never liare I done so without good reason for believing that delay would be far more dangerous than immediate interference. Out of the six operations, four have saved lives which were in imminent peril. Nevertheless, I am willing to accept as the rule the precept that operative procedure in extrauterine pregnancy lad better, if possible, be delayed until nature points to the cliannel of extrusion which she selects. The nost dangerous of men, however, are those who implicitly, unthinkingly obey rules. The bold and wise surgeon is he who keeps the rule for general guidanee, breaking it unlesitatingly when an exceptional indication demands such a contse.

No fixerl rule can apply to all these cases. The following may guide the practitioner in general, he morlifying them to suit the varying indieations which may present themselves:-

Inefore full te.rm, should the child developing in the peritoneal cavity be alive, it: growth may be carefully watched, and the end of the ninth month be waited for in the hope of delivering at that time, either by laparotomy or elytrotomy, a liring child from a living woman. 
Should the child have died early in the pregnaney, delay in interference is alvisable, but this should not be carried to the developuent of septicamia or leetic.

Should the finl term be passed and the child be still imprisoned in its unnatural resting place, the rule should be to wait for evidences of constitutional disorder on the one hand, and to meet its development promptly and decisively by suecor on the other.

The most favorable condition for laparotony is when the foctal sac is adherent to the abdominal walls, and opening into the peritoneal cavity becomes unnecessary. When the sac is not thus adherent, its walls should be stitched to those of the abdomen, the peritoneum be shut off, and antiseptic injections practised.

If the pregnaney be interstitial, the uterine cavity should be dilated, so that palpation from within it could be practised, and the possibility of incision consideret.

In case of rupture of an extra-uterine sac with steadily progressing hemorrhage which threatens life, what course should be pursued? In 1867 Dr. Stephen Rogers, of this city, wrote a monograph strongly advocating laparotomy in these cases for the control of hemorrhage under these eireumstances. I feel very sure of the validity of his position, and yet experience proves to me that the field for such interference, from the difficulties of diagnosis, the possibility of the patient rallying, and the usually depreciated nerve state from shock, is a very limited one. In my personal experience of seventeen cases, I have seen but one in which it could have been justified. In that case a lady bled steadily for over forty-eight hours, and although I urged the diagnosis of tubal pregnaney and the propriety of laparotomy very strongly, I was orerruled as to both points by a strong consultation. A post-mortem examination showed a feetus near the fimbriated extremity of one tube surrounded by its liquor amnii. The sac was not ruptured, but one vessel on its circumference was, and from this a fatal flow had occurred. Laparatomy would almost surely have saved the life of this patient.

Abdominal surgery is too progressive, too steadily advancing to admit of the application to it of the maxim, "there is no better way of judging of the future than by the past." What was reprehensible in abdominal surgery five years ago, has become safe and practicable to-day, and it is almost certain that the near future will see cases of laparotomy successfully perforned for the cataclysmic symptoms resulting from the rupture of extra-uterine foetal cysts. So sure am I of this that $I$ would now assume laparotomy to be the only legitinate resource in these cases where sufficient delay las been practised to convince the practitioner that death is surely approaching. 


\section{II A PTER LIII.}

\section{CHLOROSIS.}

Definition and Synonyms.-This disease is probably a neurosis of the ganglionic system of nerves. Disordering the control which this system exerts over the functions of organic life, it produces, as symptoms of its existence, impoverishment of the blood, constipation, dyspepsia, palpitation, and menstrual derangements and irregularities.

Although it is probable that it may occur in the male as well as the female, that it is sometimes met with in women who have passed the age of puberty, and as an exceptional occurrence las been known to affect young children, the ordinary period of its invasion is the time of puberty, when the dormant functions of the ovaries are being aroused, and the girl is rapidly passing into the state of womanhood. This fact has led many observers to suppose that it is dependent upon some derangement in ovulation and menstruation, but it is more probable that torpidity of the uterus and ovaries is, like the peculiar blood state which is so characteristic of the disorder, merely a symptom of functional disease in the sympathetic system of nerves.

Chlorosis has becn described under a variety of names, as, for example, Anamia or Spanamia, a kindred disorder with which it has been commonly confounded by writers; Chloro-anamia, Green Sickness, Cachexia Virginum, Morbus Virginius, and many others.

Frequency.-It is an affection of great frequency in all civilized and refined communities. The greater the tendency developed by society to luxurious and enervating habits, the more frequently is it eneountered. Thus in large eities and the higher walks of life it is of much more common occurrence than in comtry places, and among the lower classes, where a more natural and healthy existence is passed.

History.-The characteristic feature of the disorder being readily recognizable, and of such a nature as to excite not only attention but anxiety, it has, from the remotest times, received some attention at the hands of physicians. Although, however, allusions to it will be found even in the writings of IIippocrates, Valleix declares that F. Hofman, ${ }^{1}$ who wrote in the millle of the eighteenth century, was the first who ever gave a full and satisfactory description of it. Sydenham, who flourished in the mid-

1 De Morb. Virgin.

2 Syd. Soc. Ed. of Works, vol. ii. p. 288. 
dle of the seventeenth century, deseribes "The Green Sickness," but disposes of the whole subject, symptomatology and treatment, in exactly ten lines. During the last eentury the subject has attracted great attention, and, thanks to the investigations of Andral, Becquerel, Rodier, and other's, our knowledge of the pathology of the condition has been greatly advanced.

Pathology and Symptoms.-Before approaching this part of our subjeet, special allusion must be made to a fiact which has been already mentioned, that chlorosis and antemia are frequently treated of as identieal aflections under the latter appellation. The pathologieal condition found to exist upon ehenical analysis of the blood in the two diseases is often the same, a diminisled amount of red corpuseles and in time diminution of all the solid elements of the blood. Many of their symptoms are also the same, as, for eximple, pallor, palpitation of the heart, dyspnoa, the existence of a loud, systolic, cardiac murmur, etc. In spite of these facts it will be noticed that even those writers who treat of the two eonditions under the name of anxmia are forced to note the circumstance that there is a peenliar form of the disease which occurs about the period of puberty, to females only, and which has characteristies not displayed under other circumstances. Prof. Flint, in treating of the etiology of anæmia, says:-

"The obvious causes may be arranged into the three classes just stated, viz. : First, causes which involve an actual loss of red globules, as in hemorrhages; Second, causes involving a defective supply of material for assimilation; Third, causes which oceasion expenditure of those constituents of the liquor sanguinis on which the production of red globules is dependent.

"The eauses are not always apparent. Anæmia is apt to occur in females at or near the age of puberty, when there has been no loss of blood, no deficiency in alimentary supplies, and no unusual expenditure of blood plasma. Under these ciremmstances it constitutes the affection to which the name Chlorosis was applied before the ancemic condition was fully understood. If the name be retained, it should be considered as denoting ansmia occurring under the circumstances just stated."

I have introduced this quotation not merely for the purpose of citing the views of the eminent author from whom it is drawn, but as illustrative of the position of those who look upon these disorders as identical as to pathology, and differing only in the period of life at which they are developed. As I proceed with the description of the symptoms, conrse, and treatment of clilorosis, I lope to be able to justify myself in following the example of Becqnerel, Valleix, and many other French writers, in looking upon them as essentially and entirely different in nature.

Several French pathologists, under the lead of Becquercl, of Paris, have

${ }^{1}$ Flint's Practice of Med., $2 d$ ed., p. 62. 
of late years advanced the view that chlorosis differs from anæmia mainly in this: that the latter is merely a blood state, while the former is a disease of the nervous system which may or may not produce the latter.

The most striking differences between the two diseases may be thus contrasted:

\section{AXEMIA}

Is merely impoverisliment of the blood due to want of nourishment, from some drain upon the system, or from some poison in the blood.

Can usually be acconnted for by discovery of some special cause.

Occurs at all periods of life, to men, wouten, and children.

Is readily curable by removal of cause, supply of good diet, and administration of iron.

Is always characterized by imporerishment of blood.

Proluces a puffy and pale appearance.

Does not ordiuarily produce salness or great nervous disquictude.

Is not especially accompanied by visceral neuralgia.

No special affection of solar plexus of nerves.

Iron always does good.

The cause of the disease being remored, patient will rapidly improve.

\section{CIILOROSIS}

Is a disease of the nervous system, and may occur with or without the production of its most common sympton, anrmia.

Cannot usually be accounted for by diseovery of special cause.

Oecurs in true type usually to girls about time of puberty.

Is affected farorably only by remodies which act upon the nervous system, as alteratives and tonics.

Sometimes exists without imporerishment of the blood.

Produces a light green color.

Commonly produces sadness and nerrous disquietude.

Is constantly accompanied by visceral neuralgia.

Pain, nneasiness, or distress commonly referred to solar plexus.

Iron often fails to benefit.

If supposed eause be removed, patient will often improve but slowly.

The rapid development by which the girl becomes a woman and the boy elianges to the man is at once one of the most striking, important, and interesting of the physiological processes which take place in the animal economy. The special alterations occurring at this time do not need enumeration here. All that it will be necessary to say is that all this change is coincilent with the development of the ovaries in the one case and the testicles in the other, so that the former organs become capable of casting off matured ovules, and the latter of secreting fructifying zoösperms. If any accident oceur so that growth and development do not take place in ovaries or testieles, the result is that the girl never becomes a fully developed woman, or the boy grows up a shrill-voieed, beardless, effeminate man.

In the lower order of animals, and more especially in the males of many species, interference by castration with development at puberty, gives us still more remarkable results. If two colts be bred in the same stable and from the same stock, and one be castrated and the other left entire, the former will develop into the gentle, slender gelding; while the latter will 
grow into the strong-neeked, majestic, and vieious stallion. $A$ still more striking contrast will be found to exist between the ox and the bull.

This process of development, which we term puberty, is under the control of the ganglionic, or sympathetic system of nerves, which, at that time, must neeessarily be in a condition of execssive suseeptibility. It is probahle that in that state of exaltation, it is, in the female, often affected by a functional derangement which ereates the eolleetion of symptoms to which we give the name of Chlorosis. I say it is probable, for it must be confessed that the theory which I have here stated is merely an hypothesis suggested by elinical observation of such eases, and not supported by postmorten or other physical evidenee.

'To state this view in other words; at the critical age of puberty, when a series of important and peculiar changes are being effected through the instrumentality of the sympathetic system of nerves, the system seems, in the female, to be liable to a morbid influence, which, in great degree, paralyzes it, and impairs its functions. Sadness, nerrousness, and iraseibility mark its onset; then neuralgia develops in the limbs, the liead, and the viscera; the appetite is impaired; digestion becomes weak, and dyspepsia, flatulence, and depraved tastes are encountered. The girl craves the most unpalatable and innutritious substances, as, for example, chalk, elay, slate, and other articles of alkaline character; while, at other times, the taste prompts her to consume acids, as vinegar, lemon-juice, pickled regetables, ete. Csually the process of blood-making is soon disordered, and anemia sets in, coincidently with amenorrhœa, constipation, palpitation of the heart, sensitiveness along the spine, distress in the solar plexus of nerves, coldness of the liands and feet, and irregular and excessive flushing of the face.

Rateiborski, from lis allusions to the affection in his work upon " Puberty and the Change of Life," evidently regards its pathology as due to disorler affecting the ganglionic nervous system:-

"Chlorosis is an affection very common with young women about the period of puberty. This is not the place for me to discuss the primary nature or the remote eause of this disease, to inquire if it commences in the alteration of the blood which characterizes it, or if, on the other hand, as appear's more probable, the alteration just alluded to is itself a consequence of an affection of an important part, such, for example, as the great sympathetic nerve, which, by its numerous relations, would explain at the same time both this alteration of the blood and various troubles in the digestive, respiratory, and genital organs, and all the disorders of general sensibility."

Upon pressing along the spine, a point of great sensitiveness will usually be found near the seventh eervical vertebra, and others are often dis-

1 De la puberté, and de l'age critique chez la femme, p. 240. 
covered above and below this. Auscultation reveals a loud, basie, systolic, cardiac murmur, and along the arteries the bruit de souffe can be detected. It is not rare to find the sternum and clavicles very sensitive to pressure; as, likewise, the intercostal spaces.

Most of these are symptoms which mark the effect of the disease upon the nerrous system. The peculiar blood state usually engendered has, however, received special attention, and been by many excellent authorities regarded as the main element of the disease. Becquerel, ${ }^{1}$ in his excellent article upon this subject, thus sums up the changes which are ordinarily effected in this fluid :-

"1st. The water of the blood is notably augmented, which diminishes the density of this fluid. The amount is represented by the same figures as in anæmia.

“2l. The proportion of the globules is diminished.

" $3 \mathrm{~d}$. The fibrin is usually found to be normal in amount.

" 4 th. The fatty and saline eonstituents retain their normal proportions, as does usually the albumen. In very severe and obstinate cases, however, the albumen is diminished, when we see dropsical swellings as a result."

German pathologists very generally appear to repudiate the nerrous theory of the production of chlorosis, and Rokitansky and Virchow have advanced the statement that severe and incurable cases are due to an aplasia, or, as Virchow would express it, a liypoplasia of the heart and large arteries, and a defective development of the genital system. According to them the disease is of congenital rather than acquired character.

Mode of Development._Chlorosis generally develops itself very insidiously. In a girl who has previously been in good health, languor, sadness, and aversion to company usually first attract attention. These are followed by palpitation of the heart after exertion, scantiness of the menstrual flow, and a characteristic pale or greenish complexion. Alarm is ordinarily excited by these evidences of approaching disease, and careful scrutiny soon discovers others which have been already alluded to. Aecording to my observation, the first suspicion which usually takes possession of the minds of the friends of the patient is, that pulmonary consumption, or heart disease, is about to develop itself. In some cases, an effusion of serum takes place into the areolar tissue of the body, into the pleural cavities, or into the peritoneum, when even the medical adviser is deceived, and fears that dropsy from Bright's disease, cardiac disease, or ehronic peritonitis is about to show itself.

If an error in diagnosis learl to neglect of appropriate treatment, or if, as is worse, the symptoms of the disease be mistaken for those of plethora, as I have more than once known them to be, the gravest features of the

1 Mal. de l'Ctérus, t. ii. p. 490. 
affection will show themselves, and a most critical condition be estabJished.

Causes.-The prolisposing eauses are well known to be sex and age; but those which absolutely excite the disorder are not so easily ascertained. The causes which are here recorded are probably those which most frequently prove active; but it must be specially stated that, in the majority of cases, no cause whatever can be assigned for the disease.

Great grief, or prolonged mental anxiety ;

Depressing lome influences ;

Great fear suddenly excited;

Deprivation of pure air, exercise, and light;

Disappointment in love;

Erotic excitement without gratification;

Prolonged watehing and loss of sleep;

Nostalgia ;

Excessive mental labor.

The most marked instances of the disease which have fallen under my observation have occurred under the influence of great grief for the loss of a relative, disappointment in love, or home-sickness. Dr. W. H. Hammond, in an interesting article upon this subject, published in the Psychological Journal for July, 1868, records a striking instance arising from sudden and extreme fear.

Before learing this part of the subject, it is proper that I should state that Becquerel, who has done more for the advancement of our knowledge of this interesting affection than any other modern authority, admits these causes with considerable reserve. They "can, if they do not produce, at least favor the development of chlorosis," says he in reference to most of those causes which I have recorded.

Varieties.-I know of no good reason for dividing chlorosis into rarieties. In one set of cases, eertain symptoms are predominant; in others, a different set of signs assume the ascendency. It may, however, prove useful to the reader to lay before him the six forms which have been adopted by Beequerel. They are as follows:-

1 st form, simple chlorosis ;

$2 d$ " chlorosis with predominance of cephalalgia ;

\begin{tabular}{|c|c|c|c|c|}
\hline $3 \mathrm{~d} \quad 6$ & 6 & 6 & 6 & dyspmoea and palpitation; \\
\hline 4 th 6 & “ & “6 & 6 & gastralgia ; \\
\hline oth ، & 6 & ، & “ & menstrual disorder ; \\
\hline 6 th 6 & 6 & 66 & 6 & general feebleness. \\
\hline
\end{tabular}

Differentiation.-An aggravated case of this disease may be confonnded with anemia, cardiac disease, tuberenlar pleuritis or peritonitis, or even with the first stage of tubercular phthisis. From all these a careful and intelligent search for the evidences of organic lesions will usually distin- 
guish it in time; but without watching the progress of the case for a considerable period, it is of ten impossible to decide as to the diagnosis.

The plysician is frequently deterred from arriving at a positive conclusion as to the existence of chlorosis, by imagining that the disorder is identical with anæmia. Drawing from the veins of the patient a drop of blood, he puts it under the microscope, and to his surprise finds it to contain red globules in normal amount, and concludes that his suspicions were incorrect. It is a well-known fact that the disease may exist in aggravated form with little or no blood ehange.

Complicutions._Chlorosis may be complicated by hysteria, hypochondriasis, hypertrophy of the heart, and tuberculosis. In one case which I have seen, chlorosis developed itself with most unmistakable symptoms, and then violent chorea showed itself, which proved fatal after lasting about two years.

Prognosis._- Unless some serious disorder complicate it, the prognosis is always good; but the course and duration of the disease cannot be predicted. If all the surroundings of the patient, both social and plysical, be altered, and all causative influences removed, recovery may be rapid and complete; but if these changes cannot be brought about, the affection may last for an indefinite time.

Treatment.-Treatment should consist, not in fruitless attempts to overcome one or even two of the results of the disease, amenorrhoea and anamia, for example, but in a systematic effort to accomplish these three ends :-

1st. To remove the cause of the disorder;

2d. To cure the neurosis itself;

3]. To repair the damage which it has effected in the systen.

If any one of the causes which have been enumerated be found to exist, it should, as far as possible, be promptly and entirely removed. In many cases the cause cannot be discovered, and in many, if discovered, camnot be removerl; but if seareh be always made for it, a sufficient number of successes will occur to reward the effort.

Even where the special cause cannot be detected, recovery may be attained by removing the patient from home, and sending her to a distance from objects and people connected with the sadness and depression attendant upon the inception of the attack. A visit to some agreeable watering place or lively country resort, if the patient live in a city, or to some large and busy eity, if she reside in the conntry, will often do more in the way of cure than can be effected by ally amount or kind of medication. $\Lambda$ sca-royage and visit to a foreign country will often produce a most excellent result, and sometimes cause complete cure.

Well-regulated exercise in the open air is of great importance. Horseback exercise, rowing, bowling, walking, playing at croquet, tennis, etc., constitutes some of our best nervous tonies. Sea-bathing, and more particularly surf-bathing, is very useful, and should, when attainable, be faithfully 
tried. All of these are, however, inferior in value to cheerful and congenial society. 'This accomplishes a change in the nervous system which nothing else so surely effects.

In the mean time, nervous tonies should be freely given. The best of these are the preparations of the hypophosphites, arsenic, strychnine, and quinine. Shonld the patient bear it well, the continuous electrie eurrent shonld be employed, and general electrization often proves very beneficial.

As anamia is usually a complication of the disease, iron is generally indicated. Some of the best preparations are, the saccharaterl carbonate, iron by hydrogen, dialyzed iron, and the bitter wine of iron. A very execllent combination is offered in the following preseription :-

$$
\text { B.--Ferri vini amari, } \zeta \text { vijss. }
$$

$\mathrm{Tr}$. nucis vomice, 3 iv.

Solut. potasse arsen. $3 \mathrm{ij}$.-M.

S.-A dessertspoonful in a claret-glassful of water just after each meal.

The diet should be extremely nutritious, consisting of meat, milk, animal broths, eggs, and regetables, with wine, whiskey, or malt liquors, if they appear to be well borne by the patient.

Should the pathology of severe cases be, as suggested by some of the most eminent German pathologists, an undeveloped state of some of the important oryans of the body, of course nothing will result from treatment except palliation by improvement of the existing blood and nerve states. 



\section{N D E X.}

$A$ BDOMEx, applieations to, in perianatomy, recriomal, of, 367

Alulominal ovariotomy, 733

pat in anterior displacements of the utorus, 418

palpation conjomed with use of the soumil, 90

in physital examination, 89

supporter after ovariotomy, 755

viscera, distention of, diflerentiated from orarian tumor, 706

Ablation of uterus, 545

cases, 546

nethorls of removal, 548

operation, l'étn's, 548

Schroeder's, 549

Thomas's, 549

statistics, 547

Abnormal growths a cause of sterility, 6.50

Abortion, induction of, a cause of disease among women, 50

Abscess and cyst of rulro-raginal gland, $\mathrm{I} 26$

Alscess, pelvic (see Pelric alscess), 502

Absence and rulinentary state of the ovaries, 119

of the uterus and ovaries, 115

of the vagina, 119 treatinent, 229

Acuc of the vulva, 128

Arlenoma of the uterus, 566 (sce Sarcoma of the uterus).

Air-pessiry rlescribed by the ancients, 21

Anenorrhoea, 635

causes, 636

definition, 635

differentiation, 638

frequency, $636^{\circ}$

minopause a canse of, 638

piltiology, $636^{\circ}$

tarly menstruation a cause of, 635

treiturent, general, 638

local, 640

baths, 641

eupping in, 641

electricity, 640

enemata, stimulating, 641

sounr, passage of, 640

tents, 640 . enorrlicat-
varictics, 630

Amputation of the neck of the nterus, 652

conditions demanding, 653

danerers, 653

listory, 6.52

operation by bistonry, 654

by écraseur, $65 \dot{4}$

by cralvano-cautery, $65 ;$

miethouls of performing, 654

seissols, 654

varieties of, 654

of the nterns for inversion, methods of, 471

objections to, 473

Amnssat's operation for atresia vagine, 230

Anæmia, distinguished from chlorosis, 780

Anresthesia in physical diagnosis, s7

Aluatomy of the ovaries, 658

Ancient specula, 23

Ancioma, venous, urethral, 150

Anomalies of nterine development auring childhood, 119

Antetlexion of the nterus, 410

axes of the nterus in different flexions, 411

definition, 410

incurable Hexions, 417

irreclucible flexions, 414 operation for, 429

plyysical signs, 412

prognosis, 412

reduction, means of, 413

statistics, $406^{\circ}$

symptoms, 411

varieties, 410

Anterior displacements of the uterus, 4(i.)

abdominal pad in, 418

supporter in, 418

antetlexion, 410

Elliot's uterine repositor, 415

Jennison's sound, 415

maxims for treating, 425

means for reduction, 413 of retention, 417,418

operation for irreducible flexjolls, $4: 3$ 
Anterior displacements of the nteruspessaries in, 4:0 intra-nterine, 413 maxims for nsing, 425 section of the cervix in, 431 Sims's knife nsed in, 431 Wallace's spring tent in, 410

Anterersion of the nterus, 405 causes, exeiting, 407 predisposing, 407 course, 408

definition, 405

degrees of, 409

diagnosis, 409

differentiation, 409

dorsal deculjitus in, 417

duration, 408

frequency, 405

intluences dragging fundus forwarts, 407

enfeebling nterine supports, 407

forcing fundus forwards, 407

increasing weight of uterus, 407

pessaries, 420

Cintter's, 4:0

Fuwler's, 425

Hewitt's, 4:4

'Tlomas's, $4 \cdot 21,422$

stem, $426,4: 28,4: 29$

pressure, removal of, 417

progursis, 410

recluction, means of, 413

statisties, 406

srmptoms, $40 \mathrm{~s}$

termination, 405

treatment, 413

varieties, 408

Apoplexy, ovarian, 663

definition, 6633

prognosis, litit

symptoms, 664t

treatment, bitis

Apparatus, Boz'man's securing, 431

Areolar hyperplasia of the uterus, 307 amputation, partial, of the eervix for, 336

Brek, Snow, on, 31;

Benuett. J. 11., on, 310

blisters in, 335

causes exciting, 324 predisposing, 323

cervical, physical signs of, 325 complications, 327,328

conserguent on subinvolution, 314,316

corpwreal, physieal signs of, 3:5)

erours. 321

enpiping the ervix for, 333

definition, 3018

differentiation, 320
Areolar hyperplasia of the uterusdue to non-puerperal eauses, 319

frequeney, 321

Gallard on, 317

Klob on, 320

nomenelature, 308

mineral waters in, 332

pathology, 313

resumé of article on, 320

physical sigus of cervieal, 325 of corporeal, 325

prognosis, 327

resumé of artiele on patliology of, 320

stages in, 320

symptoms, 324

termination, 321

treatment, 328

general, 332

indieations for, 330

loeal, alterative, 334

depletion, 332

injections, emollient, raginal, 334

vesication, 335

rest as a means of, 330

varieties, 321

West on, 315

Ascent of the uterus, 381

Ascites differentiated from ovarian dropsy, 707 .

Aspiration in diagnosis of ovarian tumor, 715

Aspirator as a means of diagnosis, 109

Dieulafoy's, 109

$A$ stringents in treatment of prolapsus uteri, 398

Atresia of the genital tract and retention

of blood and other tluids, $2 \cdot 20$

definition, 220

synonyms, 220

Atresia of the uterus, 221

causes, 221

definition, 221

diagnosis, 22:2

ditlerentiation, 222

frequeney, 2221

progurosis, 2:21

results, 2222

Atresia of the varina, 224

causes, $2 \cdot 25$

Dupuytren's operation for, 229 history, 224

pathology, 225

physical signs, 220

prognesis, 226

results, 220

symptoms, 225

treatment, $2 \cdot 27$

Auussat's operation, 230

Lefort's operation, 232

when due to closure by diaphragm or hymen, $2 \dot{2} 8$ 
Atresia of the vagina, trintmentwhere three is atresiat of the nterine neck, $2:-27$

where there jo closture or alsenere of valgina, 2.20 varietits, 2:-2t

Atresia, uterine, at as externmm, 2.23 at os intermun, 22:3

in one half of a clouble uterns, (2):3

Atrophy of the ovary, 662 (cillsises, titi:

treatment, (iti:)

Auscultation and peroussion as a means of diagnosis for pelvic disease, 111

Aveling's polyptomen, 535

Axes of the uterus, 411

Axis of the uterus in llexions, 430

0 ANDAGING, tiolit, after parturition, a frepuent somree of clisease among wome'n, 4t

Baths in amenorleora, 641

Battery, Byrne's galvano-caustic, 655

Battey s operation, 7.56 estimate of, 759

Bicorn nterus, 118

Bilateral laceration of the cervix nteri, 356

Bivalve speenlum, 2:3

Blatder, prolatpe of, 172

Bozeman's securincr apparatus, 731

Broall ligament, cysts of, $696^{\circ}$

Bulbs of the vestibule, anatomy, 130 rupture of, 130

CANCER of the nterus, 571

body, cancer of the, differentiation, 590

peculiar features of, 590

canses, exciting, $5 \subseteq 5$

prexlisposing, $58 t$

cervix, amputation of, 594

eomplications, 589

dotinition, 行

dillerentiation, 587

early views on, 26

encephativi, 576

epitlelial, 577

opinions about pathology of , $5=0$

vergetating, 581

epithelioma, vegetating, $5 \$ 3$

extirpation of the uterus for, 595

frequeney, 574

relative, of the varieties, 574

history, $\$ 71$

part of the nterus affected in, $5 \leq 9$
Cancer of the uterus-

patholory, 572

physical signs, 580

progrllosis, 5xt

scirrhous, 570

Simon's seoop, 595

symptoms, 5is.)

treatment, 591

roustitutional, 598

restimé of , 600

varieties, 573

Cancer, epithelial, of the cheek, 578

vecretatiuge, 581

Cancernus ulcerations of the uterus, 29

(ancinema of the ovary, $67: 3$

Caruncle, methral, irritable, 147

causes, 147

course, 148

differentiation, 148

dinration, 140

patlology, 147

physical signs, 148

prognosis, 148

treatment, 148

Catleter, Sims's sigmoid, 251

Callses of disease, exciting, tabulation of, 54

predisposing to diseases of women, 43

Cellular polypus, 559

Cellulitis, periuterine, 475 (see Periuterine cellulitis).

Cervical constriction, treatment of, 615

dilators, Molesworth's, 534

hyperplasia of the uterus, 321

lencorrhcea, microscopical appearance of, 645

mucous membrane, anatomy of, $276^{\circ}$

speculum, Wylies, 299

Cervix, conoj(lal, 650

dilator, 'rriestley's, for, 616

Cervix uteri, amputation of, 652 (see Amputation of the neck of the nterus).

for cancer, 594

cystic degeneration of, 342 (see Cystic degeneration of the cervix nteri).

follicular degeneration of, 342 (see Cystic dereneration of the cervix uteri).

forceps for amputating, 593

granular and cystic degeneration of, $33 i j$

Cervix uteri, granular, 337

causes, exciting, 3.77

prerlisposing, 337

conrse, 33:4

definition, 337

duration, 3:3!

fretuency, 337

pathology, 33!)

physical signs, 339

prognosis, 339 
Cervix uteri, granular-

symptoms, 338

treatment, 339

Cervix uteri, laceration of, 352

anatomy, 353

bilateral, $356^{\circ}$

causes, 354

definition, 352

demuded, 360

diflerentiation, 358

frequency, 352

history, 352

pathology, 353

physical signs, 355

prognosis, 359

results, 355

"stellate," 357

sutures passed in, 361

twisted in, 362

symptoms, 355

synonyms, 353

treatment, 359

unilateral, 357

virieties, $3: 3$

Cervix uteri, adematous elongation with prolapsus of the, 390

posterior section of, in flexions, 431 syphilitic nlcer of, 344 course, 345

differentiation, 345

frequency, 344

termination, 345

Chlorosis, 778 treatment, $3+5$

blood clianges in, 782

causes, 783

complications, 784

definition, its

developinent, mode of, 782

differentiation, 780,783

frequency, tio

history, 77 h

pathologe, 779

prognosis, 784

symptoms, 779

synonyuns, 778

treatment, 784

varieties, 783

Chronic eervical endometritis, 275 (see Eudometritis, chronic cervical). parenchymatous metritis, 307 (see Areolar liyperplasia of the nterils).

Clamp, Dawson's temporary, in ovariotomy, 740

Thomas's, for securing the pedicle in ovariotomy, $7 \pm 1$

used in removal of uteriue filoroid tumors, 550

Clitoris, anatouny of, 1:1

Clonurn of the vagina, 224 (see Atresia of the vagina).

Coceromlynia, 151

aucituny, 151
Coccyodynia-

causes, 152

definition, 151

differentiation, 151

frequenoy, 151

history, 151

pathology, 152

prognosis, 153

symptoms, 152

treatment, 153

Colloid degeneration of the ovary, 680

Colporrlaphy, $176^{2}$

Emmet's operation, 178

"posterior," 180

Sims's operation, 177

Colpo-perineorrliaphy, Jenks's operation, 203

Conception, prevention of, a cause of clisease, 50

Congenital and infantile malformations of the female sexual organs, 112

physical examination of, 117

malformations of generative organs, varieties, 114

misplacement of the uterus, 119

Constipation, luabitual, a cause of disease, 52

Corporeal hyperplasia of the uturus, $3: 1$ (see Areolar hyperplasia of the uterus).

Cup, Lente's, for fusing nitrate of silver, 287

and stem for gradual reduction of inverterl uterus, 465

Cupping in amenorrhoa, 640

cervix uteri, laard rubber cylinder for, 334

Curette, dangers of, 351

-forceps, Enmet's, 351

Recamier's, 27, 350

Sinus's 289

steel, 350

Thomas's wire, 350, 634

Cylinder of hard rubber for dry cmpping the cervix uteri, 334

Cyst of vulvo-vaginal gland, 126

Cystic degeneration of the cervix uteri, 343

causes, 343

definition, 342

pathology, 343

prognosis, 343

synonyus, 343

treatment, 343

Cystic degeneration of the chorion, 604, 605 (see Uterine hydatids).

Cysto-careinoma of the ovary, 676

Cistocele, 172

Cysto-fibroma of the ovary, 677

Cysto-filoromata, 551 (see Fibro-cystic tumors of the uterus).

Cystomata and cysts, ovarian, 682 (see Uvariall cysts and cystomata). 
Cysto-sareoma of the ovary, 677

Cysts, broal ligament, of the, 696 dermoid, of the ovary, 679 hylaticl, (i97 parasitic, 697 subperitoneal, 699

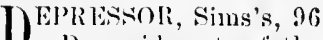

Delmoid rysts of the ovary, 679

lestent of the utrus, 381 (see l'rolapsus of the uterus).

Development of the grenerative organs, 113

uterine, in childlood, anomalies of $11 ! 9$

Diagnosis, aspirator as a means of, 109 'xploring neerle: as a means of, 109

Diagnosis of female liseases, 80 ancestresia, 87

examination, plyysical, managrement of pat iont during, st exploration, vesico-rectal, 92 manipulation, conjoined, 88,89 inspection, 90 palpation, abdominal, 89 conjoined with use of bimanual, 83 the soln nd, 90

plrysical diagnosis, means of, 86

signs, rational, 82

speculum, 93

touch, rectal, 91 vaciual, 87

Diagnosis, imperfect, a freqnent cause of nnsuecessfiul treatment of uterine disease, 62

micrusepe as a means of, 109

of pelvic clisease, recapitulation of means used in, 111

pliysical, means of, 86

Diaphragm, action of, in prolapsus of the uterus, 400

Dilator, Molesworth's nterine, 534

Priestley's, for constricted cervix, 616

Schultze's, for the cervix, 617

Diseases of the Fallopian tubes, 760

anatomy, 760

aisplacements, 765

distention, 764

intlammation of, 762

ot lier diseases of the tubes, 765 salpingritis, 762

stricture, 763

Diseases resulting from retention and alteration of the foetal envelopes, 602

of women, predisposing causes of, 42

Displacement a primary factor in uterine dicease, 33

Displacements of the nterus, 363 anatomy, 360
Displacements of the uterus-

antulexion, 410

anteversion, 405

camplications, 375

congenital, 373

doflinition, $366^{\circ}$

etiology of, 376

flexions, causes, exciting, 378

frequenty, 370 predisposing, 378

grileral considerations, 363

listory, 363

influences exciting traction on, 377,379

increasiug weiglit of, $37 \pi$, 378

pressing nterus ont of plate, 377,379

weakening nterine supports, 377,378

patlologrical signiticance of versions and tlexions, 364

patlology, 372

resililts, 375

synonyus, $366^{\circ}$

treatinent of anterior, 413 of posterior, 438

varieties, 369

Displacements, uterine, pathological views upon, 32

Distention of Fallopian tubes, 764

Diviled uterus, 118

Houble uterus, 118

1)rainage tube, Thomas's, 746

1)ress, improprieties of, a predisposing cause of distase in women, 45

1)ressing-force'ps, T'homas's, 74

Dropsy, tubal, 697,764

1npuytren's operation for atresia vaginae, $2: 29$

Dysmenorrlıa 606

pathologry, 608

seat of pain in, 608

varieties of, 608

Dysmenorrloea, congestive, 611

causes, 611

detinition, 611

diflerentiation, 612

prognosis, 612

symptoms, 612

treatment, 612

Dysmenorrluka, inflammatory, 611 (see

Dysuencrilnoea, congestive).

Dysmenorrloea, membranous, 620

definition, 620

diflerentiation, 622

etiolog $v, 621$

frequeney, 622

membrane in, 624

pathology, 620

prognosis, 623

symptoms, 622

treatment, 624

Dysmenorrhou, neuralgic, 609 
Dysmenorrhœa, neuralgiccauses, 609 differentiation, 609 prognosis, 610 symptoms, 609 treatment, 610

Dysmenorrhoa, obstructive, 613 causes, 613 cervical constriction, treatment of, 615

diflerentiation, 614

pathology, 613

prognosis, 615

symptoms, 614

treatment of cases cansed by fibroids, 620

by obturator hymen, $6: 20$

by polypus, 620

dependent on flexion or version, 619

raginal stricture, 620

Dysmenorrhnea, ovarian, 625

definition, 625

1)athology, 626

prognosis, 626

symptoms, 625

treatment, 626

Dysmenorrhceal membrane, 624

ÉCRASELR, 536

C wirte-rope, Hicks's, 565

Elastic sound, Jenks's, 102

Electricity in amenorrlea, 640

Elytro-episiorrhapliy, 405

Elytrorrhaphy, 176

inferior, 405

Emmet's treatument of laceration of the cerrix uteri, 37

Endometritis, acute, 208

calrises, 206?

complications, 272

course, 273

differentiation, 271

duration, 273

fretulency, 269

pathology, 271

physicil signs, 270

progruosis, 273

symptoms, 2100

symenyins, 269

termination, 273

treatment, 273

varieties, 269

Endometritis, (huronic cervical, 275)

anatomy of cervical mucous nembrane, $276^{\circ}$

cause's, ('x)'iting, 278 predisposing, 277

coursi, 277

curette, sims's, in, 289

definitim, 27ij

duration, $2>0$
Endonetritis, chronic cervical-

frequency, 275

pathology, 277

physical signs, 277

prognosis, 281

symptoms, 279

synonyms, 276

termination, 280

treatment, 281

applications, alteratire, 284

emollient, 283

diseased glands, destruction and ablation of, 288

general regimen, $28 \mathrm{I}$

villi of cervical canal, 276

Endometritis, chronic corporeal, 290

anatomy, 291

applications to uterine carity, 298

causes, exciting, 293

predisposing, 293

complications, 298

conrse, 297

duration, 297

frequency, 290

ointments, nse of, in, 300

pathology, 292

physical signs, 297

prognosis, 292

favorable and unfarorable, contrasted, 293

symptoms, 295

sinonyms, 290

termination, 297

treatment, 298

application of alteratives (solid) to endometriun, 300

injections into the uterine cavity, 301

intra-riterine injections, dangers of, 302

Molesworth's syringe for injecting uterine cavity, 306

substances nsed for intrauterine injections, 306

Endometrium, application of alteratives (solid) to, 3010

Enimata, stinulating, in amenorrhœa, 641

Linterocele, 173

Eipisio-perineorrhaphy, 405

Episiorrhaphy, 405

Fpitheliona, vegetating, 583

Erroneons prognosis a frequent cause of failure in treating uterine disease, $6: 2$

Liputive diseases of the vulva, 128

Ltiolony of the diseases peculiar to wonien, 41

lixamination, physical, management of patient during, 84 
Lixcessive hevelopment of the nervous Fibroid tumors of the uternssisterm a prodisjusing catuse of disribses of woment 44

Exriting callsts of eliseases of women, tabulation of , it

Exolecise and physical development, norlect of, a prodisposing teallse of diseristes of wollone +43

Exploring needle, as a means of diagllosis, I0s

lixternal organs of generation, tumors ot, 1.14

Extirpation of the uterus, 545 cistes, 540

methus of removal, 548

operation, l'éanls, 548

schroder s, jo

Thomas's, 549

stitisties, 547

Extra-nterino promancy, 765

ealses, 770

deatl, causes of, 768

delinition, 7 fit

ditlerentiation, 769

etiolong, 760

patlology, 767

pleysical signs, 769

prognosis, 771

rupture, apploaching, symptolus of, 771

symutums, 7 (is

s.rnollyms, T66

tilble ot cases, 772

treatment, 773

varjoties, 760

F

AILLRE of successful treatinent in uterime diseases, reasons for, 61

Frocal histulie, 265 (see Fistule, tecal).

Frmale pliysicians, 38

Firerecot, Kibluee's, 752, 753

Filure cell of tihro-erstie tumors, 5566

Fibro-cystic tumor's of the uterus, 551

collike, $5 ; 7$

definitim, 551

ditferentiation, 554

Auration, 557

filure call elratacteristic of, 556

frecfllency, 5.51

pathology, 553

pliy ical signs, 554

pognosis, 557

symptoms, 5it

symonyms, 5i)1

timuination, 557

treatilust, 557

Filmroicl, sulmucous, 560

Filnoils ausing obstuctive dysmenorrho:a, 620

Fibroid tumors of the uterus, 579

Atlues views on surerical treatment of, 533

avulsion, 537 cases illustratime removal ly

tho "spoou-siaw," 5.t1, 5.4."

eallses, 523

clamp, 'l'homas's, used in removal of, 550

complications, 523

course, 527

cusative merlicinal means, 529 surgical procidures, 532

Cutter's treatment of, 53:

definition, 519

diagrans of cases, 542,543

differentiation, 505

from partial inversion, 460

dilatation of the cervix uteri, $5: 34$

duration, 527

écrasene'nt, 536

elastic, flat whalebone probe for examining, 540

enucleation, 537

excision, 535

extirpation, plans for the, 533

forcels, Nelaton's, 535

frequeney, $5: 26$

llildebrandt's methor of treatment, 530

history, 519

laparotomy in, 545

Molesworth's dilators, 534

öpphorectomy in, 551

operation, Péan's, 548

Sch rocder's, 549

Thomas's, 549

Paunelin's thermo-cautery used in incising the cervix in, 535

pathology, 520

physical signs, 524

polyptome, Aveling's, 535

prognosis, 526

remowal, methods of, 548

sloughing, production of, 538

"spoun-saw," Thomas's, 539

statistics, $5+7$

symptoms, 524

symonyms. 519

termination, $5: 27$

traitment, $5: 28$

uterine fibroma, 522

rarieties, 5222

Filroma of the ovary, 675

Fibrous po'rpus, 560

tumors of the ovary, 675

Fistula, perineo-vagimatl, 267

peritoneo-vaginal, 207

Fistulie, blind vaginal, 267

entero-vitginal, 267

Fistulæ, feeal, 265

callses, 265

definition, 265

physical signs, 266

prognosis, $26 t^{\circ}$

syuiptons, 265 
Fistule, fecal-

treatment, 266

varieties, 265

Fistule of the female genital organs, 233 definition, $2: 33$

varieties, $2: 33$

simple vaginal, 267

definition, 257

perineo-raginal, 267

weritoneo-vacrinal, 267

uretero-uterine, 263

uretero-raginal, 263

Fistulæ, urinary, 233

bistoury for paring edges of, $2 \pm 6$

causes, 235, 236, 237

classes, 235

complications, 238

edges of, berelled, 247

elements of successtul treatment of, 240

elytroplasty, 258

fork for adjusting sutures in, 250

fulerum for supporting wire while twisting, 250

history, 23:

look for engaging needle in, 250 knlpokleisis, elin

means for oltaining a natural eure for , 244

needle forcelss used for repairing, 248

operation, after treatment, $25 \overrightarrow{6}$

Gosiet's, 2t]

Mretzlr.rs, 242

muthod of uniting edges, 256

Sinnon's. 252

Sims.s. 246

physical signs, 236

proguosis. $23-$

requiring slecial treatment, 201 scisiors curred for paring elges of. 240

sinuses, long, trortuons, capillary, remaining after operation, treatuntent of. 654

Sins's catluter nsed in, 251

sutures, noule of twisting, 250 twisterl, 25)

symptroms, 237

treatmunt, 24.5

by cautrization, 244

by sutures. 245)

ojeration, Sims's, 240

approximating

tolges and steeuring sutures. 250

laring edires of

fistula, $24+1,247$ passing sutures, 245,249
Fistulæ, urinary, operation-

preparation of the patient, 245

vivitying edges of, 254,255

uretero-uterine, 263

uretero-vaginal, 263

uretlıro-raginal, 234

vagina, closure of, 259

obliteration of, 260

vesico-uterine, 234, 261

resico-utero-vaginal, 234,262

resico-ragiual, 233

with extensive destruction of

the base of the bladder, $2 \cdot 2$

Fistulæ, vesico-uterine, 261

resico-utero-raginal, 262

with extensive destruction of the

base of the bladder, 262

Flexion of the uterus, influences cansing, 378,379 (see Displacement of the uterus, 363)

pathological signifieance of, 364 rarieties, 380

Foetal envelojes, diseases resulting from retention and alteration of, $6(12$

Follicular degeneration of the cervix uteri, 342 (see Cystic degeneration of the cersix uteri).

Follicular vulritis, 124 (see Vulvitis, follicular).

Food, insufficient, a cause of distase, 51 Forceps, Nélaton's, 536

Fossa navicularis, anatony of, 121

Fungosities, uterine, $3 \notin 6$

canses, 347

course, 348

curette, dangers of, $35 \mathrm{I}$

definition, $3+$ is

duration, 348

fretulency, 346

history, 346

pathology, 347

physical simns, 348

jognosis, 349

risults, 349

symptoms, 347

synouvms, 3413

termination, 345

treatment, 350, 634

Fungons degeneration of the nterine mucous nembrane, treatment of, 634

CALVAXIC pessary, 64]

G Cialvano-caustic hattery, Byrue's (6.5)

(iveratis" organs, decelopment of, 113

(ienital track, atresia of, and retention of menstrual blood. 220

"(Fenu-1uctoral" prsition, 441

(ilanfl, vulvo-raginal, cyst and abscess of, 126

Glands, Sabothian, 270 
filandular polypus, 559

(rontr)rha:a, 215

callsis, 215

complications, 218

drolinition, 215

diflerentiation, 216

duration, 217

patholory, 2lis

physieal signs, 216

syinptoms, :2li;

terminations, 217

"Granular cell" of lorysilate in ovarian fluil, (i)

Gianular deconeration of the cervix nteri, $3: 37$

callses, rxeitiug, $3: 37$

preclisposing, 337

collese, 33!

refinition, 337

duration, $33 !$

firerplutuey, 337

patholory, 339

physieal signs, 339

progmosis, 339

symptoms, 338

treatureut, 339

framular and eystic degeneratuon of the cervix uteri, 336

vaginitis, 235

(inowtlis, intra-uterine, ascertained by tlet soumil, 100

Gynecology, historical sketch of, 17

list of joumals elevoted to, 40

desirable works mpon, 39

therapentic resources of, 66

diet, tit

exercise, 66

pessaries, 67

flecautions for proventing sep-

ticemia and pyemia in operations, 70

tampon, 77

temperature, neans of controlling, is

vaginal injections, it

$\mathrm{H}$

ABITUAL constipation a cause of disease, 52

Hrematocele, pelvic, 509 (see Pelvic

hituriatocele).

peritomeal, 513

pudenulal, 131

causes, 133

detinition, 131

derelopment, 133

natulal course, 134

pathologry, 132

prognosis, 133

symptoms, 133

treatment, 134

suloperitoneal, 513

Hemorrhage, pultendal, 130

causes, 131
IIemorrhag", pudendal-

syolil,toms, 131

treatument, 131

Hernia, pudendal, 134

allatomy, 134

causes, 135

definition, 135

symptoms, 135

treatunent, 135

recto-vaginal, 172

vagilat, 173

supplenentary support in, 175 surgical procedures, 175

treaturent of, 173

Historical sketreh of gruecolory, 17

lluiter's specculum, !7

IIytatials, nterine 604 (see C'terine hydatids.

IIydracele, $136^{\circ}$

anatomy, 136

detinition, 136

differentiation, 137

frectilelley, 136

jathology, 136

treatment, 138

Hygiene and general manacement, inattention to, a causs of failure in treat-

ing uterine disease, 64

Hymen, anatomy of, 122

cansing atresia vacrinc. 226

imperforate, cansing listention of vagina by retainecl blook, $2 \cdot 24$

olstructive dysmenorhoea, treatment of, 620

llyperesthesia of the vulva, 145

cattses, $146^{\circ}$

definition, 145

differentiation, 146

frequency, 145

pathology, 145

symptons, 140

treatinent, 146

Hyperplasia, areolar, of the uterus, 307 (see Areolar hyperplasia of the uterus).

cervical, of the uterus, 321

IIysterotome, Simpson's, 617

Stohlman's, 618

White's, 6ils

IMPERFECT diagnosis in uterine dis-

eases, a freculent canse of fililure in their treatment, $6: 2$

Inflammatory ulceration of the uterus, 29

Injections, intra-nterine, dangers of, 302 in endometritis, 301

vaginal, 74

Inspection, a means of cliagnosis, no

Insufticient foor as a cause of disease anoug woment 51

Intestines, prolapse of, 173

Intra-uterine injections, dangers of, 302 
Intra-uterine injections-

important facts connected with, 305

substances used for, 306

Inversion of the uterus, 453

anatomy, 454

amputition of the uterus for, methods of, 471

objections to, 472

eauses, exciting, 456 predisposing, 456

complete, 453

conrse, 460

eil) and stem for gradual reduction, 465

definition, 453

dillerentiation, 459,460

duration, 460

elastic pressure by raginal water-bag, for reducing, $466^{\circ}$ gradnal reduction by a repositor, 465

methods of checking hemorrliage in, 462

of replacing, 463

taxis in, 467

Barrier's, 469

Courtey's, 469

Eummet's, 469

Noeggerath's, 469

Thomas's, 469

White's, 470, 47I

partial, 453

pathology, 454

lilysical signs, 459

prognosis, 461

rapil realuction by old methorls of taxis, 467

reduction by a stream of cold watel', 467

symptoms, 458

termination, 460

treatment, 462 resumé of plans, 474

varieties, 453

TENKS'S elastic sound, 102

Jonruals, list of, deroted to gyneco$\log y: 40$

TIFE, Sims's, 4.31

I Kolprokleisis, 200

T ABIA majora, anatomy of, 121 plilegmonoms intammition of, 1:99

syuptoms, 12?

tivitunent, $1: 29$

Lalia minora, anatomy of, 121

Lacerated princum, dangers arising from, $166^{\circ}$
Lacerated perineum-

efficts of, 165

evils arising from, 167

varieties, 186 (sce also Rupture of the perinemu), 182

Jaeeration of the eervix uteri, 352

anatomy, 353

bilateral, 356

causes, 354

definition, 352

denuded, 360

differentiation, 358

Emmet's operation for repair of, 37

frequency, 352

history, 352

pathology, 353

physical signs, 355

prognosis, 359

results, 358

"stellate," 357

sutures passed in operation for, 361

twisted in operation for, 362 symptoms, 355

synonyms, 353

treatment, 359

unilateral, 357

rarieties, 353

Latero-flexion, 452

Leueorrhoca, 642

eervical, mieroscopical appearance of, 645

definition, 642

frequency, 642

listory, $i 42$

pathology, 643

prognosis, 645

results, 645

synonyms, 642

triatment, 646

vacrinal, nicroscopical appearance of, $6 \pm 4$

varieties, 643

MALFORMATIONS, congenital and infantile, of the female sexual organs, 112

Mamma, eaneer of, stroma and cells, 576,577

Management, general and lygriene, inattention to, a cause of failure in treatiur uterino discase, (it

Manikin figure for teaching diagnosis, 112

Manipulation, conjoised, $88, \$ 9$

Iarriage witl existing uterine disease a "anse of tisease, 51

Means nsul in diarnosis of pelvie diseases. 111

of retaining position of uterus after anterior displacements, 417, 418, 419 
Mrnopanse a rause of amenorrloea, 638

Henorrhagra, 60s

callsiss, tizy

ledinition, $6: 28$

diflirentiation, 631

freriluency, lits

pat luolony, bizs

prormesis, 6322

lisults, $6: 3 ; 2$

treitmont, $6: 2) \cdot 2$

curative, $1: 33$

Menstrual blowl, retention of, etc., $2: 21$

Menstruation, improdumere during, a prolilic somre of discase anomg womin, 17

tarily, diflinentiated from anenorrliciat, 6335

Mrtallumen, tost fore, 687

Metritis, chlonie parelichymatous, 307 (nre Areolar liyperplasia of the uteruss).

Metrorrhagia, 628

('alss's, $6: 2 ?$ !)

telinition, 6:S

differentiation, 631

frexpleney, $6: 28$

patholory, 623

l'ownosis, 632

results, 632

treatuent, 632

eurative, 633

Microscope as a means of diagnosis, $10 ! 3$

Misplalement (eongenital) of the nterus, 11!

Mnles, uterine, 602 (see Uterine moles).

Molesworth's cervical dilators, 534

Mucous membrane, cervical, anatomy of, 276

Myo-fibromata, 519 (see Fibroid tumors of the uterus).

NABOTJILA glands, 276

D Neck of the uterus, amputation of, 6.2 (see Amputation of the neck of the uterus).

Nerelle-foreeps used in repairing urinary fistulie, 24!

Nerdle used in repairing urinary fistule, 249

Ninglect or non-recognition of iujuries tollowing parturition, a frequent cause of lisease in women, 50

Nélaton sorceps for removal of uterine fibroids, 53.5

Neurathenia, Weis Miteliell's treatment (i) 330

Non-reognition or neglect of injuries lue to parturition a freduent eause of lisease anollor women, 49

Nott's speculum, 97
QREMATOUS rlongation with pro lapse of the rack of the nterus, $3 ! \%$

Ointments, use of, in chrouje corporeal enclometritis, 300

Ö̈phurectomy, 750

estimate of operation, 759

history, 756

indieations, 757

means of treatmont of uterine filuroils, as a, 55l

methorls of opwrating, 758

names of operators, 758

results, 757

synouymus, 756

theory of operation, 756

Ovarian ajoplexy, (i6i)

definition, 663

progruosis, 664 t

svmptoms, fiti-t

tieatment, 6 tit.

Orarian cysts and cystomuata, 682

aspiration in, 715

broad ligaments, cysts of, 696

causes, 691

chemical comstituents of fluid trom, $686 ;$

conditions likely to complicate, 695

simulating, 705

contents of, 686

cure, spontaneous, of, 694

death, methorls by which produced, 695

diagnosis, rules for, 721

diflerentiation from almormal thickness or temsion of the abxominal walls, 706

from cystic aliseasto of oth.r parts of the abdomen, 7013

from diseased states of the prolvie walls and areolar tissue, 712

from rlistrution of abdominal riserea, 706

from excessive development or displacement of other visepra, 711

from fluid peritomeal aecumulations, 707

from filroerst, uterine, 7lo

from preminancy, 711

discased comblions aflecting, 694

"doe's a tumol "xist?" 701

explorative juesion in. 720

fluir, micloscopical appearance of. $6 \subseteq 5,689$

"gramular cell" of Drysdale, timo

hylatid cysts, 698

"is the timor orarian?" 702

meltalbumen, test for, 687 
Ovarian cysts and cystomatamicroscopical inrestigations of

Noeggerath, 685)

natural history of, 693

paralbumeli, test for, 687

jathologieal processes in, gene-

ration of, 683

pedicle in, long, 713

short, 714

twisterl, 714

physical exploration, means of, 702

signs, 701

spinal cord, cysts connected

with, 699

subperitoneal cysts, 699

symptoms, 699

table showing comparative frequency of affection of right and left ovary, 686

tapping in, $716^{\circ}$

through abdomen, 718

througl, vagrinal wall, 719

treatment, 721

tubal dropsy, 697

Orarian disease a cause of symptoms of uterine disease, 33

fluids, microscopical appearance of, 688

Orarian tumors, 672

carcinoma, 673

colloil, 680

cysto-carcinoma, 676

cysto-fibroma, 677

cysto-sarcoma, 677

dermoid cysts, 679

filroma, 675

malignant, symptoms of, 674

table of, 673

Oraries, absence of, 660

and rudimentary derelopment of, 115

state of, 119

atrophy of, 662

Oraries, disease's of, 656

absence of, 660

anatony, 658

at rophy of, causes, 662 triatment, $6(0 ; 3)$

development, imperfect, of, 660 treatment of, $6(j 1$

displacement of, 664 triaturant, $6(6)$

history, 6506

ovarian apeplexy, 663 (see ovarian a (oplexy).

ovaritis. 6665

d.+fiution of, 665

tw+atment of, 665

acute, 666 (sce Oraritis, ar:ute).

chromic, 669 (see Oraritis. (hromic).

Tilt's views upon, 34

Oraries, diseases of-

varieties, 660

Ovarióomy, 722

abdominal, 733

conditions favorable to opcration, 728

unfavorable, 730

dangers, 727

definition, 722

"fever cot," Kibbee's, after, 752, 753

history, 722

injections, antiseptic, after, 750

operation, after-treatment, 747 steps of, 734

applying antiseptic dress. ing, 746

cleansing peritoneum, 744 closing abdominal wound, 746

drainage (if necessary), es. tablishing, 745

incision thirough abdominal walls, 734

removal of sac, 738

securing pedicle, 740

tapping tumor, 737

peritonitis atter, 751

septicænia following, 748

methods of avoiding, $7 \neq 8$

statistics, 728

sutures, removal of, after operation, 755

temperature after, 749

vagiual, 731

varieties, 727

Oraritis, 665

definition, 665

varieties, 665

Ovaritis, acute, 666

causes, 668

differentiation, 668

prognosis, 668

symiptoms, 668

treatment, 668

Ovaritis, clyonic, 669

prognosis, 671

sigus, physical, 670 rational, 670

treatment, 671

Ovary, carcinoma of, 673

colloirl degeneration of, 680

cysto-carcinona of, 776

cysto-filroma of, 677

cysto-sarcoma of, 6i77

cyists (domunid) of, 679

filuroma of, $(7,5$

filorous tumors of, 675

DALPATION, abrominal, 89

conjoined with the use of the somurd, 90

limanual, 88 
Papille, filiform, of the vagina, 212

l'inuelin's thermo-eantery, 149, 535

l'aralbumen, tost for, 657

l'arturition, imprudence after, a frepuent Gune of alisease among woment 45

Pathologieal views of uterine disorders, 29

displacements, 32

latlology and treatmont, uterine. generil consirlarations npon, 54

l'éan's operation for removal of uterine filroid tumors, 540

lelvic abseess, 502

callsis, 502

closure of sac, means for causing, 5018

course, 503

definition, 502

ditlerentiation, 503

duration, 503

evacuation, best point for, 507

operating, methods of, 507

pathology, 502

physical signs, 503

prognosis, 504

puncture per vagina, 507

routes for discharge of, 503

sac, means of closure of, 507

symptoms, 502

termination, 503

treatment, 504

Pelvic hematocele, 509

causes, 512

conrse, 516

detinition, 509

dillerentiation, 515

duration, 516

frepuency, 510

history, 509

operating in, methods of, 518

pathology, 510

peritoneal, 513

physica' signs, 515

proguosis, 516

retlux of blood from the uterus, 511

rupture of bloodvessels in the pelvis, 510

of pelvie viscera, 511

subperitoneal, 513

symptoms, 514

symonyms, 509

termination, 516

transudation from bloodvessels, 511

treatment, 517

varicties, 512

Pelvic peritonitis, 487

cases, chronic, treatment of, 500

causes, 491

course, $496^{\circ}$

definition, 487

diflerentiation, 476
Pelvic peritonitis-

disation, 496

evacuation of pus and sorum, morles of, 501

frepluency, 490

liistory, $47 \mathrm{~s}$

importance of rifrerentiation from pelvic cellulitis, 498

patholocy 4 (\%)

plysical signs, 495

jrommosis, 498

results, 498

"roof of the pelvis," 490

symptoms, 493

termination, 496

treatment, 493

varieties, 493

Pelvis, roof of the, 490

Percussion and auseultation as a means of diagnosis in pelvic disease, 111

Perineal body, 158, 182

anatony, 183

descent of rectal and vesical walls after destruction of, 419

diacrams of, $160,161,163,183$, 184

surgical means for the restoration of, 182

Perineal laceration, 187

cause's, 187

natural history of, 187

operation, denudation for repair of, 194

diagrams of "triangle" to be united, 195

first part of, 192

instruments and appliances li seded for, 191

preparation of the patient, 191

schematic view of part to be denuded, 193

for complete, 198

demurled surface and sutures (diagramof) 201

diagrams, 198, 199, 200

rules to be observed in, 201

for partial, 192

dentist's "burr" used in, 196

method of securing encls of sutures. 198

profile view of recently clusert perinemu and sutures, 198

surface demuder and sutures in position (liagrams), 197

progmosis, 187

time for operation, 188 
Perineal laceration-

treatment of eases which have cicatrized, 190

varieties, 186

Perineal support in prolapsus of the uterus, 404

lerineorrliaplıy in cases of prolapsus of the uterus, 404

Perineum, 154

anatomy, 1.54

diagram of, 156

functions of, 159

physiology of, 159

improperly repaired, 185

Perineum, laceration of, 165 dangers arising from, 166 , 167

effects, 165

varicties, 186

Perineum, profile view of, 192

rupture of, 165

subinvolution of, 164

Peritoneal hematoeele. 513

Peritonitis, pelvic, 487 (see Pelric peritonitis).

Periuterine cellulitis, 475

anatomy, 476

cause's, 481

complications, 477

consequences, 455

course, 480

definition, 476

differentiation, 484

duration, 480

frequeney, 476

history, 475

pathology, 477

physical signs, 483

promosis, 481

symptoms, 482

synonyms, 476

termination, 480

treatment, 485

Pessaries in anterior displacements of the nterus, $420,421,422,423$, $425,428,42 ?$

in prolapsus of the uterus, 401

Pessary, Albert Smith's, $\mathbb{H 6}$

Camplell'ssoft-rubler, spring-stem, 429

Cutter's "T," for anterior displacements, 423

prolapsils, 403

modification of, with cervical rest, for posterior displacemonts, 451

rotroversion, 449

-lastic bulb, 447

Fowler's, for anterior displacenents, 425

galvanic: 461

Ilewjtt $s, 448$ antevision, 424

Ilorge's closerl lever, 445

\section{Pessary-}

Iloffman's inflated soft-rubber, for posterior displacements, $4 \mathbb{4 4}$

Hurd's, 447

intra-uterine stem for anteflexion, 428

glass stem for anterior displacements, 428

latero-flexion, for, 452

Meigs's elastic ring, 447

retrollexion, with cervical rest, 451

Thomas's anteversion, witl fixed projection, 442

elastic, for anterior displacements, 422

modification of Cutter's, 403, 423

for posterior displacements, 449

retroflexion, 446

Phlegmonous inflammation of the labia majora, 129

symptoms, 129

treatment, 129

Physical signs of uterine disease, 59

Polypi, uterime, 558 (see Uterine polypi)

Polyptome, Aveling's, 535

Simpson's, 564

Polypus, causing obstructive dysmenorrlica, treatment, 620

eellular, 559

filoroid, 560

glandular, 559

differentiation from inverted uterus, 459

Position, "genu-pectoral," 441

of patient for introducing Sims's speeulum, 99

Posterior displacements of the uterus, 432

causes, exciting, 434

predisposing, 434

consequences of, 438

definition, 432

ditferentiation, 437

forees applied in reduction, 450

frequency, 432

"genu-pectoral" position, 441

Ilollman's inflated soft-rubber pessary in, 44

means of retaining uterus in position. 442

methorls of reluetion, 438

pessaries, 444, 445, 446, 447, $448,449,451$

pliysical signs, 437

proguosis, 438

ritroversion, degrees of, 436

Sims's nterine repositor, 440

symptoms, 4336

tampon in, 443

treaturent, 438

varieties of retroversion, 435 
Posture, recumbent, in prolapsus of the l'rolajsns of the varina, 168 uterns, 3918

P'romancy, extra-uterine, 7tis) (ses lixtra-uterine prennamey).

Primary pathologioal conditions prohucing ritring distatse, 57,58

Probe, Budil's elastic, $2-1 ;$

leente's silver caustie, $2 \leq 7$

silver, sims's, tor applying medieated cotton to corvix interi, 288

Thomas's flat clastic whalebone, sto

Probing the nterus, methos] of, 101

Prognosis, erroneous at frecpuent cause of failure in treating uterine elisease, 62

in uterine atlections, 60

l'rolapse of the bladder, 172

of the intestines, 173

Prolipusus urethre, 150 tratment, 150

Prolapsus of the uterus, 381 acute, 394

analtomy, 382

astriugents in the treatment of, $3: 18$

callses, 383

complications, 393

(*) urite, 390

definition, 381

dianrams of, in the three degreeses of, 383

diaphragm, action of the, in, f(1)

difierentiation, 392

duration, 390

episiorrhaplyy for, 405

frepleney, 381

ne:ins to diminish nterine weight, 3 ! s

to prevent pressure from above, 397

to prevent traction by the vagina, 404

to strengthen or supplement uterine supports, 395

methods of replacing, 394

of sustaining, 395

nerlomatous elongation, with prolapse of the neek, 390

pathology, 385

perineal support, 404

perineorrhaphy, 404

pessaries, 401

physical signs, 392

1miture, recmulent, in, 398

promposis, 392

sullen, 394

symptoms, 391

synonyms, 381

termination, 390

tonics in the treatment of, 398

treatment, 394

varieties, 383

catuses, 170

contrise, 171

definition, 167

duration, 171

pathology, 170

promnosis, 171

symptoms, 171

symonyms, 169

tratment, 171

valieties, 171

Pruritus vulve, 138

causes, exciting, 140

preslisposing, 139

course, 138

detinition, 138

development, 138

patlology. 138

treatment, 141

Pubo-cocergeus muscle, 204

Pudendal hematocele, 131

causes, 133

detinition, 131

devolopment, 133

history, 132

natural course, 134

pathology, 132

prognosis, 133

symptoms, 133

treatment, 134

Pudendal hemorrhage, 130

causes, 131

symptoms, 131

treatme'nt, 131

Pudendal hernia, 134

anatomy, 134

causes, 135

definition, 135

symptoms, 135

treatment, 135

Purulent rulvitis, 122 (see Vulritis, purulent).

Pyæmia anl septicrmia, precautions against, in operations, 70

R EASONS for the frequencr of failure

$\mathcal{B}$ in the treatment of uterine diseases, 61

Récanjer's speculum, 25

Recapitulation of means nsed in diarnosis of pelvic disease, 111

Rectal touch, 91

Rectocele, 172

Recto-vaginal hernia, 172

Rertum, prolapse of, 172

Relation between nterine disease and constitutional depreejation, 31

Retrotlexion of the uterus, 432,433 (see Posterior displacements of the uterus).

Retroversion of the uterus, 432, 433 (see losterior displacements of the uterus).

Rod for making applications to cervix uteri, 285 
Rudimentary state and absence of the ovaries, 119

of the ragina, 119

Rules for the introduction of tents, 108

SALPINGITIS, 762

Sarcoma of the uterus, 566

causes, 569
course, 570
definition, 567
differentiation, 570
duration, 570
frequency, 567
history, 566
pathology, 567
physical signs, 569
prognosis, 570
symptoms, 569
synonyms, 567
termination, 570
treatment, 570

Scarificator, Buttles's spear-pointed, 333

Schroeder:s operation for removal of ute rine fibroid tumors, 549

Scissors, sharply curved, Emmet's, 192 slightly curved, 191

Scoop, Simon's, for removing cancer, 595

Screw for removing tampon, Sims's, 78

Sea-tangle tents, 103 adrantages of, 104

Septicemia and pyamia, precantions against, in operations, 70

Signoid catheter, Sims's, 251

Signs, physical, of nterine disease, 59

Simon's operation for urinary fistulæ, 252

adrantages of, 254

position of patient in, 253

Sims's operation for urinary fistulæ, 246 speculum, 37

advantares of, 37

an era in grnecology, 35

(and varieties of) introduction of, 98

Insition of patient in introduction, 99

Sinuses, treatment of long, tortuons, eapillary, remaining after operation, 2 it

Skirt supporter, 397

Sound, uterine, as a means of diagnosis, 100

difficulties and dangers attending its use, 100

facts ascertained $b y, 100$

J(11ks's rlastic, 102

Jeminisom's, 415

method of introdnction, 1 no

passage of, in amenorrhica, 640

simprin's and Sirns's, contrasted. 111

used by the ancrents, 24
Specula, ancient, 23

valvular and cylindrical, method of introduction, 98

Speculum, bivalve, 23

Cusco's, 94

Fergusson's, 93

Howard's modification of Cusco's, 95

Hunter's, 97

invented by Récamier, 25

mentioned by ancient writers, 24

Neugebaner's, 95

Nott's, 97

Sims's, 96 advantages of, 37 an era in gynecology, 35

(and varieties of) introduction of, 98

Thomas's modification of, 97

Thomas's telescopic, 94

trivalve, 23

Wylie's cervical, 299

Spinal cord, cysts connected with, 699

Sponge-lıolder, Sims's, 247

sponge-tents, 103

Spoon-saw, Thomas's, for remoral of uterine fibroids, 539

Sterility, 648

causes, 648

definition, 648

differentiation, 651

history, 648

prognosis, 651

results, 651

synonyms, 648

treatinent, 651

Stricture of Fallopian tubes, 763

Subperitoneal hematncele, 513

Symptoms of uterine disease dependent on orarian discase, 33

Syphilitic ulcer of the cervix uteri, 344 course, 345

differentiation, 345

frequency, 344

termination, 345

treatment, 345

Syringe, Davidson's, 76

for dry cupping the cervix, 640

for reinoving cervical mucus, $2 \$ 4$

Molesworth's double cannla and bulb for injecting the nterine carity, 306

vaginal, nozzle with reverse current, 76

TABLE, gynecological, Thomas's, 85, 8it

Tamunn, 7 it

in posterior displacements of the uterns, 443

Taxis, olrl methods for replacing inrerted uterus, 467

Taxis, rapid reduction of inversion of uterus by, 
Taxis, rapial roluction of inversion by-

Bitriere's nether1, 469

Courty's methenl, 4tis)

Emmet's metloml, 469

Noegrerath's mothorl, 469

Thomins's mether1, 469)

White's nethod, 470,471

Tenaculum for fixing the uterus, 106

'lemt, Wallatee's spring, 416

'T'unts, 102

dangers of using, 106

in anenorrhoa, 640

method of introsluction, 105

rules for the introduction of, 108

sea-tangle, 103

sponge, 103

tupelo, 105

Therafeutic resonrces of gynecology, liet and exercise, $66^{\circ}$

pessaries, 67

precautions for preventing septiccemia and pycemia in operations, 70

tampon, 77

temperature, means of controlling after operation, 78 varinal injections, 74

Therapeutics, inefficient or inappropriate, a cause of failure in treating nterine 1 lisease, 62

Thermo-cautery, Paquelin's, 149 incision of the cervix uteri by, 535

Thomas's operation for removal of uterine fibroid tumors, 549

Tight bandaging a cause of disease among women, 48

Tilt's views on ovarian disease, 34

Tonies, in tle treatment of prolapsus of the uterus, 398

Toothed forceps, Thomas's, 191

Trivalve speculum, 23

Trocar and canula, Emmet's, for tapping cysts, 737

for tapping ovarian cysts, 719

Tubal dropsy, 697, 764

'Tumors of the external organs of generation, 154

T'umors, fibrocystic, of the uterns, 551 (see Fibrocystic tumor's of the uterus).

fibroid of the uterus, 519 (see Fibroid tumors of the uterus).

ovarian, 672 (see Ovarian tumors). uterine, differentiation of, from displacements, by the use of the sound, 100

Tupelo tents, 105

JLCER, syphilitic, of the cervix nteri, 344 (see Syphilitic ulcer of the cervix nteri).

Ulcers of the uterus, Astrue on, 26

Ulcerations of the uterus, cancerous, 29
Uteerations of the uterus-

inflammatory, 29

Unicorn uterus, 118

Urethre, prolapsus, 150 troatment, 150

Urethral euruncle, irritable, $1+7$ caluses, 147

collose, 148

differentiation, 148

duration, 14s

pathology, 147

physical signs, 148

prognosis, 148

treatment, 145

Urethral venous angioma, 150

Urethro-vaginal fistula, 2:34

Urinary fistulæ, 233 (see Fistulæ, urinary).

Uteri, cervix, cystif degeneration of, 342 canses, $3+3$

definition, 342

pathology, 343

prognosis, 343

synonyms, 343

treatment, $3 \pm 3$

Uteri, cervix, granular degeneration of, 337

causes, exciting, 337 predisposing, 337

course, 339

definition, 337

duration, 339

frequency, 337

pathology, 339

physical signs, 339

prognosis, 339

symptoms, 338

treatment, 339

Uteri, cervix, laceration of, 352 (see

Laceration of the cervix).

syphilitic ulcer of, 344 (see Syphi-

litic ulcer of the eervix).

Uterine adenoma, 570 (sce Sarcoma of the uterus).

atresia at os extermum, 223

at os internum, 223

in one half of a double nterus, 223

canal, deviations of, determined by

the sound, 100

cancer, 571 (see Cancer of the ute-

rus).

cavity, applications to, in chronic corporeal endometritis, 298

injections into, in chronic corporeal endometritis, 301

development in childhood, anoma-

lies of, 119

disease in its relations to constitutional depreciation, 31

physical signs of, 59

primary pathological conditions causing, 57,58

progruosis in, 60 
Uterine-

disorlers, different pathologieal views on, 29

displacements, differentiation from tumors by the sound, 100 pathological views upon, 32 primary factors in uterine disease, 33

fibromata, 522

fungosities, 346 (see Fungosities, uterine).

hydatids, 604

causes, 605

definition, 604

diflerentiation, 606

pathology, 60.4

physical signs, 605

prognosis, 606

symptoms, 605

synonyms, 604

treatment, 506

moles, 602

causes, 603

definition, 602

differentiation, 603

history, 602

pathology, 602

physical signs, 603

prognosis, $6(14$

symptoms, 603

treatment, 604

pathology and treatment, general considerations upon, 54

polypi, 558

causes, 560

cellular, 559

complieations, 562

course, 562

Cefinition, 558

differentiation, 561

Ecraseur, Hicks's wire rope, 565

fibrous, 560

glandular, 560

history, 558

pathological anatomy, 559

physical signs, 561

polyptome, Areling's, 535

Simpson's, 564

prognosis, 562

symptoms, 560

termination, 562

treatment, 562 curative, 563

palliative, 563

varieties, 558

repositor, Elliot's, 415

Sims's. 440

sarema, 566 (see Sarcoma of the uterus).

sound, difficulties and dangers attending tlue use of, 100

facts ascertained hy, 100

means of diagnosis, as a, 100
Uterine sound-

method of introduction, 100

Simpson's and Sims's contraeted, 101

used by the ancients, 24

Uterus, ablation of, 545 (see Ablation of the uterus).

absence and rudimeutary development of, 115

amputation of the neek of, 652 (see Amputation of the neck of the uterus).

anteflexion of the, 410 (see Anteflexion of the uterus).

anteversion of the, 405 (see Anteversion of the uterus).

areolar hyperplasia of, 307 (see Areolar hyperplasia of the nterus).

atresia of, 221 (see Atresia of the uterus).

axes of the, in anteflexion, 411, 430

bicorn, 118

eancer of the, 571

early views on, 26

capacity of, ascertatined by use of the sound, 100

congenital misplacement of the, 119

divided, 118

double, 118

extirpation of the, 545

for eancer, 598

inflammation of, J. H. Bennet's views on, 28

inflammatory ulcerations of, 29

inversion of, 453 (see Inversion of the uterus).

method of probing, 101

mobility of, determined by the sound, 100

natural position of, 366,368

pathological signifieance of versions and flexions of the, 364

prolapsus of the, 381 (see Prolapsus of the uterus).

retroflexion of the, 432, 433 (see Posterior displacements of the uterus).

retroversion of the, 432, 433 (see Retroversion of the uterus).

ulcers of the, Astruc on, 26

unicorn, 118

Uterus and ovaries, alsence and rudimentary development of, 115

and vagina, distended with blood from imperforate hymen, 224

VAGINA, alsence and rudimentary state of, 119

aliatomy of, 211

atresia of, 224 (see Atresia of the varina).

closure of, treatment for, 229 
Vagina-

distended by blood from impreforate hymen, 22-4

filiform papilla of, 212

prolinssus of, lis

eauses, 170

cothrse, 171

detinition, 16i7

duration, 171

pathology, 170

prognesis, 171

symptous, 171

synonyus, 1699

treatrinent, 171

varieties, 171

transwerse section of, 1:7

Vagina and uterus distenderl with blood from imperforate lyymen, 224

Vaginal dilator, Sims's, 207

hernice, supplementary support in, 175

surerical procertures, 175

Iencorrluoa, microscopical appearance of, 644

ozariotomy, 731

prolapse, treatment of, 174

Vaginal stricture, treatment of, 620

touch, $8 \overrightarrow{7}$

water-hag for elastic pressure in inverted uterus, $466^{\circ}$

Vaginismus, 203

anatomy, 2014

causes, 205

conrse, 206

definition, 203

ditlerentiation, $206^{\circ}$

duration, 2016

frequency, 203

history, 204

operation, sims's, 209

Bums's, 210

pathology, 204

physical signs, 206

prognosis, 206

symptoms, $2(16$

treatuent, 207

Vaginitis, 211

anatomy of vagina, 211

detinition, 211

epithelium in, 214

granular, 218

causes, 219

definition, 219

pathology, 218

symptoms, 219

simonyms, 218

treatnent, 219

simple, 212

caltses, 213

complications, 215

definition, 212

ditlerentiation, 215

patliolory, 213

physical signs, 214

Varinitis, simple-
symptoms,

specitic, 215 symutomis, 214

caluses, 215

eomplications, 218

definition, 2I5)

diff.rentiation, 216

duration, 217

pathology, 215

physical signs, 216

syiuptoms, 216

termination, 217

symonyms, 211

treatment of, 219

varieties, 212

Valvular and ey lindrical specula, method of introrluction, 9s

Venons angioma, urethral, 150

Versions of the uterus, pathological signiticance of, 364

Vesico-vaginal fistulæ, 233 (see Fistule, urinary).

Vesico-uterine fistulæ, 234

Vesico-ntero-vaginal fistulie, 234

Vestibule, anatomy of, 121

Villi of canal of cervix uteri, 276

Vulva, diseases of, $1: 1$

eruptive diseases of, 128

treatment, 129

hyper'esthesia of, 145

causes, 146

definition, 145

differentiation, 146

frequency, 145

pathology, 145

symptoms, 146

treatuent, $146^{2}$

Vulve, pruritus, 138

causes, exciting, 140

pred isposingr, 139

course, 138

definition, 138

development, 138

pathology, 138

treatment, $1+1$

Vulvitis, detinition, 122

follicular, 12t

causes, 124

course, 125

definition, 124

duration, 125

plysical signs, 125

syniptous, 1:25

synumys, 124

treatment, 125

purulent, 122

causes, 123

course, 123

symptons, 123

ternination, 123

treatment, 123

varieties of, 122

Vulvo-raginal glands, abscess and cyst of, $120^{\circ}$ 
806

Vulro-raginal glands-

anatomy of, 126

inflaumation of, 127

causes, 127

course, 127

differentiation, 127

duration, 127

symptoms, 127

treatment, 127
INDEX .

IVA IST for supporting skirts, 397 Water-bed, Kibbee's 752,753

Water, stream of cold, for replacing inverted uterus, 467

Women, etiology of diseases peculiar to, 41

Works on gynecology, list of, 40 


\section{LEISHMAN'S MIDWIFERY-Just Ready.}

A SYSTEM OF MIDWEFEY, INCLUDING TIE DISEASESOF PREGNANCY AND

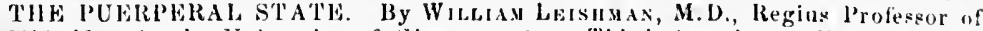
Midwifery in the Universily of Glasgow, elc. Third Ameriean edition, revistal by the nulhor, wilh aditions by Jons S. Panir, M. D., Obetelrician to the l'hila. llospital, ete. In one large and very handsome ocharo volume of $7 \% 3$ pages, with over 201 illust. Cloth, $\$ 450$; leather, $\$ 550$; very handsome half Russia, raised bitlds, $\$ 6$.

We flatly welcome the new edition of this ommending it. Ananexponont of the millwilery excetlent text-book of midrifery. 'The former of the prenent day it has no superior in the $t u_{5}$ editions have been mu: tavorably received by lish language. - Ganadre Lancit, Jan. 1850.

the profesaton on both sides of the Allantic. In thes preparation of che present elition thealthor has wade such a! terations ax the progress of ob. stetrical icleuce serems to regure, aud we eanuot bot aduire the dhility wi h whith the tank has been verformed. Wo conslder it an udmirable lexthook for silleats during their altendance upou lectares, and have great pleasare in rec-

Totlie American student the work before no muat prove admirably adapled, complete in all its parts, essentialiy modern in its teachings and witls demonstrations noted for clearnens aud precision, it whll galn in favor, and be recognized as a work of staudard merit. The work cannot rail to be popular, aud is cordially recommended. -N. O. Med. ani Sury. Journ, Intch, IsSo.

\section{PLAYFAIR'S MIDWIFERY－Just Ready.}

A TREATISE ON TIE SCIENCE AND PRACTICE OF MIDIFERY. By W. S. Playfalr, N.D., F.R.C.P., Professor of Medicine in King's College, etc. Edited, with adlitions, by Robert P. Hanus, M. D. In one handsome octavo volume of about 700 pages, with nearly 200 illustrations. Cloth, $\$ 4$; leather, $\$ 5$; very handsome half Russia, raised bands, $\$ 550$.

The rapidity with which one edition of this It certaialy is an admirablo exposilion of the work folluws another is proot alike of its excel- Science and Practice of Midwifory. Of conrse lence and of the estimate lhat the professiun has the additions made by the Anerican editor, Dr. formed of $t$. It is inleed so well known and so R. P. Harris, who never utersanidie wurd, and highly valued liat uothing nted be ould of it as whose stadions researches in some spetid dea winole. All things cousidered, we regard this partmeuls ol obstetrics are so well kuown tu the treatise as the very lest on Midwifery in the profession, are of great value.-The Am. PracEuglishlanguage.-N. X. Med.Journ., May, lsso. titioner, April, 1 sso.

\section{HODGE'S OBSTETRICS.}

TIIE PRINCIPLES AND PRACTICE OF OBSTETRICS By Hugh L. Hodge, M.D., Emeritus Professor of Midwifery in the University of Pennsylvania. [l] ustrated with large lithographic plates, containing one hundred and fifty-nine figures from original photographe, and with numerous wood.cuts. In one large and beautilully printed yuturto vol. of 550 double-columned pages strongly done up in cloth. $\$ 14$.

* Specimens of the plates and letter-press will be forwarled to any address free, by mail, on receipt of six cents in postage stamps.

\section{HODGE ON DISEASES OF WOMEN.}

UN DISEASES PECULIAR TO WOMEN : Including Displacements of the Uterus By Ilven L. IIODGE, MI.D., Emeritus Protessor of Oostetries in the Univ. of Penna. With original ilkustrations. Second edition, revised and enlarged. In one octaro volume of 031 pages. Cloth, $\$ 450$.

\section{RAMSBOTHAM'S MIDWIFERY.}

THE PRINCIPLES AND PRAC'TICE OF OBSTETRIC MEDICINE AND SURGERY, in relerence to the Process of Parturition. By F́maxis H. Rams Botian, M.D. A new and enlarged edition, thorougbly revised by the author. With additions by W. V. Kentiva, M.D., Prolessor ol Ubstetrics, in the Jefferson Med. Coll., Phila. In one large and bandsome imperial octavo volume of 650 pages, strongly bound in leither, with raised bands; with tit beautiful plates, and numerous wood-cuts in the text, culltaining in all neitrly 200 large and beautilul figures. $\$ 7$.

\section{SWAYNE'S OBSTETRIC APHORISMS.}

OBSTETRIC APHORISMS FOR TIE USE OF STUDENTS COMMENCING MID. W LEERY PRAC'TICE. By Joseph Griffiths Swayxa, M.D. Second American, from the filth and revised London edition, with additions by E. R. Ilurchiss, M. D. Wath illustrations. In one neat 12 mo. volume. Cloth, \$1 25. 
A COMPLETE PRACTICAL TREATISE ON THE DISEASES OF CHILDREN. By

J. Lewis SytTh, M.D., Clinical Professor of Diseases of Children in the Bellevue Hozpital Medical College, New York. Fourth edition, revised and enlarged. In one bandsome octavo volume of about 750 pages, with illustrations. Cloth, $\$ 450$; leather, $\$ 550$ : very handsoma half Rnssia, raised band, $\$ 6$.

In the perlod which has elapsed since the third editlon of the work, so extenslve hure been the a drances that wole chapters required to be rewritten. and hardly a paze could pass without e)me material correction or addition This labor has ncenpiad the writer closely, and he bas performed it conscientionsly so that the b rok may be considered a faithfa! portraiture of an exceptional'y wide clinical experience la iufantile disedae:, corrected by a rureful study of the recent literature, f the sabject - $\boldsymbol{M} \div \boldsymbol{d}$ and Surg. Reporter, April 5, 1879

It is scarealy necessary for as to say the work befire us is a standard work up in di-esses of children, and that no work has a bigher standingthan it upon thoreaffections. In c nrequence of it a thorough revision, the work has hee $\mathrm{mad}$ a of more ralue than ever, and may beregarded a* fully abreast of the times. WFe cordially com. mend it to stadents and physicians. There is no better work in the language on diseases of chil.

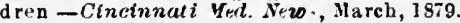

This excellent work is 80 well known that an extended notjce at this time would be superfinous. The anıhur has takon advantage of the demind for another new edjtion to revise in a inost careful manner the entire book; and the numerous corrections and addilions evince a determination on his part to keep folly abreast with the rapid progress that is being made in lbe knowledge and treatment of children's diseases. By the adoption of a somewhat closer type, an increa of only ibirty pages has been necessi. taled by the new - uhject-matter introdaced. Boston Med. and Sury. Journ., Yay 29, 1579

\section{CONDIE ON DISEASES OF CHILDREN.}

A PRACTICAL TREATISE ON DISEASES OF CHILDREY. By D. Frascis Con DIE, M.D., Fellow of the College of Physicians, etc. Sixth edition, revised and augmented. In one large octavo volume of nearly 800 pages. Cloth, $\$ 525$; leather, $\$ 625$.

\section{SMITH ON 'SHE WASTING DISEASES OF CHILDREN.}

TIE WASTING DISEASES OF INFANTS AND CIILDREN. By Eustace Smitu, M.D. Second American, from the secont and enlarged London edition. In one very handsome octavo volume of 266 pages. Extra cloth, $\$ 250$

\section{DUNCAN ON THE DISEASES OF WOMEN-Just Ready.}

CLINICAL LECTURES ON THE DISE ASES OF WOMEN. Delivered in St. Bartholomew's IInpital. By J. Matruews Duxcas, M.D., LL.D., F.R.S. In one very neat octavo volume of 173 pages. Cloth, $\$ 150$.

\section{WINCKEL ON CHILDBED.}

A COMPLETE TREATISE OF THE PATHOLOGY AND TREATMENT OF CIILD. BED, for Students and Practitioners. By F. Wiscket, Profeser and Direntir of the Gynæcological Clinic in the University of Rostock. Translated with the consent of the author, lrom the second German edition, by JAsks READ CuADWICK, M.D. In one oet ivo volume. Cloth, \$4. (Latcly Issued.)

\section{TANNER ON PREGNANCY.}

ON TIIE SIgNS AND DISEASES OF PREgNaNCY. By Tuovas H. Tayner, M.D. First American, Irom the second and enlarged Engliah edition. With four colsred plates, and a number of illustrations on wool. In one handsome octaro rulume of about 500 pages. Cloth, $\$ 425$. 


\section{HENRY C. LEA'S SON \& CO.'S}

(LATE HEXKY C. LEA)

\section{OIASSIFIFD OATALOGUE \\ OF \\ MEDICAL AND SURGICAL PUBLICATIONS.}

In asking the attention of the profission to the works advertised in the following pages, the publishers would state that no pains are spared to secure a contimuance of the comfitence earned for the publieations of the honse by their careful selection and accuracy and finish of execution.

The large number of inquiries received forom the profession for a finer class of bindings than is usually placer on medical bonks has induced us to put certain of our standard mullications in half Russia, and that the groving taste may be encouraged, the mices lawe been fixed at so small an advence oier the cost of sheep, as to place it within the merths of all to possess a hibrary that shall have attractions as well for the rye as for the mind of the reading practitioner.

The printed prices are those at which books can generally be supplied by booksellers timbughont the United States, who can readily procure for their customers any works not kept in stork. Where access to hookstores is not convenient, books will be sent by mail post-paid on receipt of the price, and as the limit of mailable weight has been irmoved, no difficulty will be experienced in obtaining through the post-office any work in this catalogue. No risks, lowever, are assumed either on the money or on the hooks, amel no publieations but our own are supplied, so that gentlemen will in most eases fiut it more converient to deal with the nearest bookseller.

An Imicstrated Catalogue, of 64 octavo pages, handsomely printed, will be forwarled by mail, post-paid, on receipt of ten cents.

HENRY C. LEA'S SON \& CO.

Nos. rof and g08 Saxson St., Pmimadetpmia, Oetober, 1880.

INCREASED INDUCEMENT FOR SUBSCRIBERS TO

\section{THE AIIERICAN JOURNAL OF THE MEIDICAL SCIENCES.}

\section{TWO MEDIOAL JOURNALS, containing nearly 2000 LARGE PAGES, Free of Postage, for FIVE DOLLARS Per Annum.}

TERMS FOR 1880.

The American Jourxal of tile Medcal Screxces, published f Five Dollars quarterly (1150 pages per ammm), with $\}$ per annum,

The Menical News axd Alsstract, monthly (768 pp. per annum), $\}$ in advance.

\section{SEIARATE SUBSCRIPTIONS TO}

Tine Americax Jovrisal of tile Medical Scinaces, when not paid for in alvance, Five Dollars.

The Mloncal News Axd Abstract, free of postage, in advance, Two Dollars and a halt.

* Alvance paying subscribers can obtain at the close of the year cloth covers, gilt-lettered, for each volume of the Journal (two annully), and of the News and Abstract (one ammually), free by mail, by remitting ten cents for each cover.

It will thus be seen that for the molerate sum of Frve Dollars in arlvance, the subcriber will receive, thee of postage, the equivalent of three or four large octaro volumes, stored with the choicest matter, original and selected, that can be furnished by the medieal literature of hoth hemispheres. Thus taken together, the "Journal," and the "XEWS AND ABSTPACT" combine the advantages of the elaborate preparation that can be revoted to the Quarterly with the prompt conveynee of intelligence hy the Monthly; while the whole beine uncler a single editorial supervision, the subsoriber is secured against the cluplication of matter inevitable when periodicals from different sources are taken together.

The puriodieals thus offered at this mnprecerlented rate are universally known for 
their high professional stauling.

I.

\section{THE AMERICAN JOURNAL OF THE MEDICAL SCIENCES,}

\section{Ented ib I. MINIS HAXS, M.D.,}

for more than half a century has maintained its position in the front rank of the medieal literature of the world. Cordially supported by the profession of Ameriea, it circulates wherever the language is read, and is universally regarded as a national exponent of American medieine-a position to which it is entitled by the distinguished names from every section of the Union which are to be found among its collaborators.* It is issued quarterly, in January, April, July, and October, each number containing about three lundred octavo pages, appropriately illustrated wherever necessary. A large portion of this space is devoted to Original Communieutions, embraeing papers from the most eminent members of the profession throughout the country.

Following this is the Revikw Departuext, containing extended reviews by competent writers of prominent new works and topies of the day, together with numerous elaborate Analytical and Bibliographieal Notiees, giving a fairly complete survey of medical literature.

Then follows the Quartercy Sumary of Improvemexts axd Discoveries ix the Mruical Scifxces, elassified and arranged under different heads, and furnishing a digest of medical progress, abroad and at home.

Thus during the year 1879 the "Jourxal" contained 67 Original Communications, mostly elaborate in character, 147 Reviews and Bibliograplical Notices, and 215 articles in the Quarterly Summaries, illustrated with 70 wood engravings.

That the eflorts thus made to maintain the high reputation of the "Jovrsal", are successful, is shown by the position accorded to it in both America and Europe as a leading organ of medical progress:-

This is nuiversally acknowledged as the leading Auerican Jonrnal, and has been conducted ly Dr. Hay alone until $1 \$ 69$, when his son was associaled career, was sncceeded in Is27 by the Americun will him. We quite agree with the critic, that thls Journal of the Medical sciences, a perlodical of fonrual is gecond to none in the language, and cheer- world-wide reputation; the ablest and one of the fully accord to it the first place, for 10 where ghall oldest periodicals in the world-a journal which has We flnd more able and nore impartial criticism, and an unsullied record.-Gross's History of Americun nowhere such a repertory of able orlginal articles. Med. Literature, 1876.

Indeed, now that the "British and Foreign If edico. The beat medical journaleverpublished in Enrope Chirnrgical Review" has terminuted its career, the or America.-Va. Med. Monthly, May, Is79.

Auerican Journal otands without a rival.-London Med. Times and Gazette, Nov. $2 t, 1677$.

The best medical jonrual on the continent.-Bo8ton Sted. and Surg. Journat, A pril, 1879.

The prevent number of the American Jonrnal is an cxceedingly good one, and gives every promise of maintaining the rell-earned reputation of the revlew. Our venerable contemporary has our best wishes, and we can only exprens the hope that it may continue its work with as much vigor aud excellence for the next fity years as it has exhibited in the yast. - Lundon Lancet, Nov. 24, Ist.

It is nniversally acknowledged to be the leading American medical jourual, and, in our opinion, second to none in the language.-Boston Med. and Surg. Journal, Oct. Isit.

This ls the medical journal of on conntry to which the American physician abroud wlil point with tie greatest satisfaction, as reflectlog the state of medical culture :ll his country. For a great many years it has been the medium throngh which our ablest writers have made known their discoveries and observations, - Address of L. P. Yandell, M.D., l. fore International Dfed. Congres8, Sept. 1876.

And that it was specifically included in the award of a medal of merit to the Publishers in the Vienna Exhibition in 1873.

The subscription price of the "Anemicax Jounxal of the Medical Screxces" has never been raised during its long eareer. It is still FIVE DOLLA Rer annum; and when paid for in advance, the subseriber receives in addition the "MeDrcal. Niws Axil Aistract," making in all nearly 2000 large octavo pages per anuum, free of postage.

II.

\section{THE MEDICAL NEIVS AND ABSTRACT.}

Thirty-seven years ago the "Menicar. Niws" was commenced as a monthly" to convey to the subscribers of the "Avkricax. Joursal" the elinical instruction and

* Cominnications are invitod from gentlemea in all parts of tho conutry. Elaborate articles ineerted by the Edisor are paid for by the pablisterk. 
current information which could not be acommorlated in the Quarterly. It consisted of sixtern puge's of such matter, together with sixteen more known as the library De'partment and devoted to the publishing of books. With the inereased progress of scienee, however, this was found insufficient, and some years since another periodical, known as the "Moxtricy Anstract," was started, and wis furnished at a moderate frice to subsiribers to the "AnEricax Jovrsal." These two monthlies will hereafter be consolidated, under the title of "Tine Medical News axi Austract," and will be furnished free of charge in connection with the "AMERICAN JoUnNal."

The "News ANI Anstiact" will consist of 64 pages monthly, in a neat eover. It

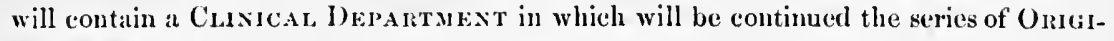
ral Ambrican Chisical hectures, by gentlemen of the highest reputation throughout the United States, together with a choice selection of forcign Lectures and Hospital Notes and Gleanings. 'Then will follow the Montuly ABstract, systemati(ally arranged and classified, and presenting five or six huntred articles yearly ; and each number will conclule with a NEws DEpartukxt, giving current professional intelligence, domestic and foreign, the whole fully indexed at the close of each volume, rendering it of permanent value for reference.

As stated above, the subscription price to the "News and ABstract" will be 'Two Dollars and a Half' per annum, invariably in advance, at which rate it will rank as one of the cheapest medical periodienls in the eountry. But it will also be furnished, free of all charge, in commutation with the "Amkricax Journal of The Mrical Sciexcles," to all who remit Five Dollars in advance, thus giving to the subseriber, for that very moderate sum, a complete record of medical progress throughout the world, in the compass of about two thousand large octaro pages.

In this effort to furnish so large an amount of practical information at a price so unpreciedentedly low, and thus place it within the reach of every member of the profession, the publishers confidently anticipate the friendly aid of all who feel an interest in the dissemination of sound medieal literature. They trust, especially, that the subseribers to the "Aniericar Medical Joursal," will call the attention of their acquaintanees to the advantages thus offered, and that they will be sustained in the endeavor to permanently establish medical periodical literature on a footing of cheapness never heretofore attenpted.

\section{PREMIUM FOR OBTAINING NEW SUBSCRIBERS TO THE "JOURNAL."}

Any gentleman who will remit the amount for two subscriptions for 1880 , one of which at least must be for a new subscriber, will receive as a Pinsium, free by mail, a copy of any one of the following recent works :-

"Barnes's Maxual of Midwifery" (see p. 24),

"Tilbury Fox's Epitome of Diseases uf tile Skis," new edition (see p. 18),

"Fotnergill's Axtagonism of Medicines" (see p. 16),

"Holdex's Landmarks, Medical axd Strgical" (see p. 6),

"Browne ox the USE of tile OpitThallioscope" (see p. 29),

“Flixt's Essays on Conservative Medicine”' (see p, 15),

"Sturges's Clinical Medicine" (see p. 14),

"Swayce's Obstetric Aphorisus," new edition (see p. 21),

"Taxier's Clinical Maxual" (seep. 5),

"West on Neryous Jisoriders of Cinldures" (see p. 20).

* * Gentlemen desiring to avail themselves of the atvantages thus offered will do weil to forward their subseriptions at an early day, in order to insure the receipt of romplete sets for the year 1880 .

The safest mode of remittanee is by bank cheek or postal money order, drawn to the order of the undersigned. Where these are not accessible, remittances for the "Jounxal" may be made at the risk of the publishers, by forwarding in REGIsTbised letters. Address,

Il kxry C. Lea's Sox \& Co., Nos. 706 and 708 Sansom St., Phila., Pa. 
UNGLISON (ROBLEY), M.D.,

Late Professor of Institutes of Medicine in Jefferson Medical College, Philadelphia.

MEDiCal LEXICON; A. Dictionary of Medical Science: Containing a concise explanation of the various Subjects and Terms of Anatomy, Physiology, Pathology, Hygiene, Therapeutics, Pharmacology, Pharmacy, Surgery, Obstetrics, Medical Jurisprudence, and Dentistry. Notices of Climate and of Mineral Waters; Fornulx for Officinal, Empirical, and Dietetic Preparations; with the Accentuation and Etymology of the Terms, and the French and other Synonymes; so as to constitute a French as well as English Medical Lexicon. A New Edition. Thoroughly Revised, and very greatly Mod. ified and dugmented. By RicharD J. lunolison, M.D. In one very large and band. some royaloctavo volnme of over 1100 pages. Cloth. $\$ 650$; leather, raised bands, $\$ 750$; half Russia, $\$ 8$. (Just Issued.)

The object of the anthor from the outset has not been to make the work a merelexlcon or dictionary of terms, but to afford, undereach, a condensed view of its varions medical relations, and thus to render the work an epitome of the existing condition of medical science. Starting with this view, the immense demand which has existed for the work has enabled him, in repeated revisions, to augmentits completeness and usefulness, until at length it has attained the position of a recognized and standard authority wherever the language is spoken.

Special pains have been taken in the preparation of the present edition to maintain this en. viable reputation. During the ten years which have elapsed gince the last revision, the additions to the nomen of the past, and up to the time of his death the authorlabored assiduously to incorporate every. thing requiring the attention of the student or practitioner. Since then, the editor has been equally industrious, so that the additions to the vocabulary are more numerous than in any previous revision. Especial attention has been bestowed on the accentuation, which will be found marked on every word. The typigraphical arrangement has been mucb improred, rendering reference much more easy, and every care has been taken with the meobanjeal execution. The work has been printed on new type, small but exceedingly clear, with an enlarged page, so that the additions have been incorporated with an increase of but little orer a hundred pages, and the volume now contains the matter of at least four ordinary octaros.

A book well known to our readers, and of which may safely confirm the hope ventured by the editor a thor of the work pased away, probably all of us ts an individualinterest, wlll be found worthy a con. feared lest the book should not maintain its place tinuance of the position so long accorded to it as a in the advancing science $w$ hose terms it defines. For- atandard authority."-Cincinnat, Clinic, Jan. 10, 1874. tunately, Dr. Kicbard J. Dunglison, haring aseisted his father in the revision of several editions of the work, and haring been, therefore, trained in the methods and imbued with the spirit of the book, has been able to edit it, not in the patchwork manner no dear to the heart of book editors, so repulsive to the taste of intelligent book readers, but to edit it as a work of the kind should be edited-to carry it on steadily, without jar or interruption, along the groover of thought it has travelled during its lifetime. To show the magnitude of the task which Dr. Dunglison has assumed and car. ried through,it is only necessary to state that more than six thousand new subjects bave been added in the present edition.-Phala. Med. Times, Jan. 3, 187 t.

$A$ bout the first book purchased by the medical stndent is the Yledica! Dictionary. The lexicon explanatory of technical terma is simply a sine qua non. In a science so extensire, and with such collaterals as medi. cine, it is as much a necessily s]so to the practislng physician. To meet the wants of students and most physfcisns, the dictionary must be condensed wbil. comprehensive, and prsctical while perspicacious. It was because Dunglison's met these indications thst it became at once the dictjonary of general use whererer medicine ws studied in the English language. In no former revision have thealterstions and additions been so great. Sorethan six thousand new subjects and terms have been added. The chlef terms hare been set in black letter, while the derivatives follow in amsll caps; an

It has the rare merlithat it certalnly has noriral in the English langaage for accaracyandextent of refereaces.-London Medical Aazette

As a standard work of reference, as one of the best, fol the very best. medical dictionary in the Eng. llsh la nguage, Danglison's work has been well known for about forty years, and needs no words of prales on our part to recommend it to the members of the medical, and, llkewise, of the pharmaceutical profession. The latter especlally are lo need of snch a work, which glreg ready and reliable laformation on thonsads of rabjects and terma whlch they are llable to encunater in parsuing their daily arocatlons, but with which they cannot be expected to be famliar. The work befire no fully sapplies this want.-Am. Journ. of Pharm., Feb. 1s71.

A valuable dictionary of the terms employed in medicine and the allied sciences, and of the relationg of the subjects treated nuder each hend. It relects great credit on Itr able American anthor, and well deserves the authority and popularlty it has obtained.-British Med. Jinurn.,Oct. 31, IS74.

Few works of thls class exhlbit a gragder monumeat of patlent research and of acienilfic lore. The extent of the sule of this lexicon is sufficlent to testify to lts a fefuineks, and to the great serrice conferred by Ur. Robley Dnagllson on the profesgion, and indeed on otvers, by its lssne.-London Lancet, Itay 13. 1h75.

HOBLYN (RICHARD D.), M.D.

A DICTIONARY OF THE TERMS USED IN MEDICINE AND TIIE COLLATERAL SCIENCES. Revised, with numerous additions, by IsaAc HaYs, M.D., Editor of the "American Journal of the Medical Sciences." In one large royal $12 \mathrm{mo}$. volume of over 500 double-columned pages; cloth, $\$ 150$; leather, $\$ 200$

It ta the bert book of deflations we have, and ought always to be apon the atudent's table. Southern Med. and Surg Journal.

ROD WELL (G.F.), F.R.A.S., \&..

A DICTIONARY OF SClesce: Comprising Astronomy, Chem. istry, Dynamics, Electricity, Heat, Hydrodynamics, Hydrostatice, Light, Magnetism, Mecbanice, Meteorology, Pnenmatics, Sound, nnd statics. Preceded by an Essay on the History of the Physical Sciences. In one handsome octavo volume of 694 pages, and many illustrations: cloth, $\$ 5$. 
A CENTURY OF AMERICAN MEDICINE, 1776-1876. By Doctors E. H. Clarke, II. J. Bigelow, S. D. Gross, T. G. Thomus, and J. S. Billings. In one very hand. some $12 \mathrm{mo}$. volume of about 350 pages: cloth, $\$ 225$. (Lately Issued.)

This work "ppeared in the pages of the American Journal of the Medioal sciencesduring the year 18iti. As a detailed account of the development of medical science in America, by gentlemen of the highest authurity in their respective depurtments, the profession will no doubt welcome it in a form adapted for preservation and reference.

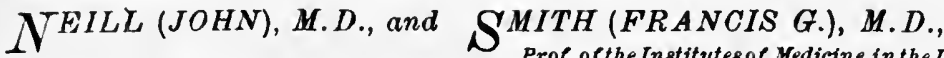

AN ANALYTICAL COMPENDIUM OF THE VARIOUS BRANCHES OF MEDICAL SCIENCE; for the Use and Examination of Students. A new edition, revised and improved. In one very large and bandsomely printed royal 12mo. volume, of about one thousand pages, with 374 wood-cuts, cloth, $\$ 4 ;$ strongly bound $n$ leather, witb raised bands, \$4 75 .

\section{HARTSHORNE (HENRY), M.D., \\ Professor of Hygient in the Oniversity of Pennsylvania.}

A CONSPECTUS OF THE MEDICAL SCIFNCES; containing Ilandbooks on Anatomy, Physiology, Chenistry, Materia Medica, Praotical Medicine, Surgery, and Obstetrics. Second Edition, thoroughly revised and improved. In one large royal $12 \mathrm{mo}$. volume of more than 1000 closely printell pages, with 477 illustrations on wood. Cloth, $\$ 425$; leatber, $\$ 500$. (Lately Issued.)

We can say with the strictest truth that it is the / worthy. If students must havea conspectns, they best work of the kind with which we areacquainted. wili be wise to procnre that of Dr. Hartshorne. It embodies in a condensed form all recent coutribntions to practical medicine, and is therefore useful to every busy pructitioner tbroughout our conatry, besides being admirably adapted to the nse of students of medicine. The book is faithfully and abiy executed.-Charteston Med. Journ., A prii, 1875

The work is intended as an aid to the medical student, and as such appears to admirably fulfil it 6 object by itsexceilent arrangement, the fuil compiiation of facts, the perspicuity aud terseness of language, and the clear and instructire itinstratione in some parts of the work-American Journ. of Pharmacy, Philadelphia, Juiy, 1874.

The voiume wili be found useful, not onty to stndents, hut to many otherswhomay desire torefresh their memories with the smaliest possible expendi. tare of time.-N. Y. Med. Journal, Sept. 1874.

Thestudent will find this the most conrenient and nsefui book of the kind on which he can lay his hand.-Pacific Med. and Surg. Journ., Ang. 1S74.

This is the best book of its kind that we haveever examined. It is an honest, accurate, and concise compend of redical sciences, us fairly as possible representing their present condition. The changes and the additions bave been eo judicions and thorough as to render it, 80 far as it goes, entirely trastDetroit Rev. of jód and Pharm., Ang. 1874.

The work before ns, however, has many redeem. ing features not possessed by otner6, and is the best we have eeen. Dr. Hartshorne exhihits mnch skill in condensation. It is weli adapted to the physician in active practice, who can give but timited time to the familiarlzing of himseif with the important changes which have been made since he attended lectures. The manual of physiology has also been improved and gives the most comprehensive view of the latest advances in the science possibie in the epace devoted to the subject. The mechanical exscntion of the book leaves nothing to be wished for.-Peninsular Journal of Medicine, Sept. 1874.

After carefuity looking throngh this conspectue, we are constrained to say that it is the most com. plete work, especiaily in its illnstrations, of its kind that we have seen.-Cincinnati Lancet, Sept. 1874.

The favor with which the first edition of this Compendinm was received, was an evidence of its various excellences. The present edition hears evidence of a careful and thorough revision. Dr. Hartshorne possesses a happy facuity of seizing npon the salient points of each subject, and of presenting them in a concise and yel perspicuons manner - Leaven worth Med. Heraid, Oct. 1574

\section{LODLOW (J.L.), M.D.}

A MANUAL OF EXAMINATIONS upon Anatomy, Physiology, Surgery, Praotice of Medicine, Obstetrics, Materia Medica, Chemistry, Pharmacy, and Therapeutics. To which is added a Medical Formulary. Third edition, thoroughly revised and greatly extended and enlarged. With 370 illustrations. In one handsome royal 12 zo. volume of 816 large pages, cloth, \$3 25 ; leather, \$375.

The arrangement of this volume in the form of question and auswer renders it especially suitble for the offce examination of students, and for those preparing for graduation.

TANNER (THOMAS HA WKES), M.D., \&c.

A MANUAL, OF CLINICAL MEDICINE AND PHYSICAL DIAG. NOSIS. Third American from the Second London Edition. Revised and Enlarged by Tilbury Fox, M. D., Physician to the Skin Department in University College Hospital, \&c. In one neat volume small 12 mo., of about 375 pages, clotb, $\$ 150$.

* * On page 3, it will be seen that this work is offered as a premium for procuring new subscribers to the "American Journal or the Medical Scienceg." 
GRAY (HENRY), F.R.S.,

Lecturer on Anatomy at St. George's Bospital, London.

ANATOMY, DESCRIPTIVE AND SURGICAL. The Drawings by H. V. Carter, M.D., and Dr. WestMacotr. The Dissectionsjointly by the A Dr. CARTER. With an Introduction on General Anatomy and Development by $T$. Howmas, M.A., Surgeon to St. George's llospital. A new American, from the eighth enlargec and improved London edition. To which is added "Lavmarks, Manical and Sirgical," by Luther Holdex, F.R.C.S., author of "Human Osteology," "A Manual of Dissections," etc. In one magnificent imperial octavo volume of 983 pages, with 522 large and elaborate engraving 8 on wood. Cloth, $\$ 6$; leather, raised basds, $\$ 7$; hilf Russia, $\$ 750$. (Just Ready.)

The author has endearored in this work to oover a more extendedrange of anbjects than is cus. tomary in the ordinary text-books, by giving not only the details necessary for the student, bet slso the application of those details in the practice of medicine and surgery, thus rendering it both a guide for the learner, and an admirable work of reference for the active practitioner. The en. gravings form a special feature in the work, many of them being the size of nature, nearly all original, and having the names of the various parts printed on the body of the cat, in place of figures of reference, with descriptions at the foot. They thus form a complete and splendid series, which will greatly assist the student in obtaining a clear idea of A natomy, and will also serve to refresh the memory of those who may find in the exigencies of practice the necessity of reealling the details of the dissecting room; while combining, as it does, a complete Atlas of A natomy, witb a thorough treatise on systematic, descriptive, and applied Anatomy, the work will be found of essential nse to all physicians who receive students in their offices, relieving both preceptor and pupil of much labor in laying the groundwork of a thorough medioal edncation.

Since the appearance of the last Anerican Edition, the work has received three revisions at the ha ads of its accomplished editor, Mr. Holmes, who has sedulously introduced whatever has seemed requisite to maintain its reputation as a complete and anthoritative standard text-book and work of reference. Still further to increase its usefulness, there has been appended to it the recent work by the distinguished anatomist, Mr. Lutber Holden- "Landmarks, Medical and Surgical" - which gives in a olear, condensed, and systematic way, all the information by which the practitioner can determine from the external surface of the body the position of internal parts. Thus complete, the work, it is believed, will furnish all the assistance that can be rendered by type and illustration in anatomical study. No pains hare been spared in the typographical execulion of the volume, which will be found in all respects snperior to former issues. Notwithstanding the increase of size, amounting to over 100 pages and 57 illustrations, it will be kept, as heretofore, at a price rendering it one of the cheapest works ever offered to the American profession.

The recent work of Mr Hulden, which wag no- to cunanlt his bogks on dnatomy. The work is ticed by us on p. 53 of this volutue, has been added slmply indiapensable, especially this present Ameras a appendix, so that, altogether, this is the mott ican edition.-Va. Ired. Monthly, Sept.1878.

practical and conplete anatomical treatise available to Americanstudents and phyicians. The former finds in it the necessary guide in making dissectioas; a very comprehensive chapter on minute anatomy; and ubont uil that can be tanght him on goneral and speeial anatomy; while the latter, in its treatment of each region from a surgical point of view, and in the raloable edition of Mir Holden, will fand all that will be essential to him in his practico.-Nevo Remedies, Aug 1878.

This work is as near perfection as one conld poseibly or reasonably expect any book intended as a lext-buok or a general reference book on anatomy to be. The American publisher deserves the thanks of the profession for appendiog the recent work of Mir. Holden, "Landmarks, Medical and Surgical," which has already been commended as a separate bunk. The latter work-trenting of topographical a patomy-has becorne an essentiat to the library of every intelligent practitioner. We know of no buok that can take its place, written as it is by a unoht distinguished anatomist. It would be simply wayte of words to say angthlog further in praise of Gray's Anatomy, the text-book in almost $\theta$ very wodlcai college in this contry, and the daily refer oce book of every practitioner who has vecation

The addition of the recent work of Mr. Holden, as an appendix, renders this the most practical and compiete trentise available to American students, who find in it a comprehensive chapter on uninute auatomy, about all that can be tanght on general und special anstomy, whlle its treatment of each region, frotn a surgical point of view, in the valuable section by Mr. Holden. is all that wlll be essen. tial to them in practice. - Ohio Medical Recorder, A ag $157 \mathrm{~S}$.

It is diffecult to speak in moderate terms of this new edition of "Gruy." It seems to be as neariy perfect as it is possible to make a book deroted to any branch of medical science. The labors of the eminent men who hare successively revined tho eight editions thrungh which it has pasked, wonld seem to leave notbing for future editors to do. The aldition of Holden's "Landmarks" will make it as indispenssble to the practitioner of medicine and surgery as it has been heretof sre to the student. As regarde completeness, ease of reference, ntility, beauty, and cheapnese, it has no rival. No student shonld enter a medical school without it; no physician can atford to have it abnent from his linrary - St. Louis Clin. Rtcord, Sept. 1S78.

ALSO FOR SALE SEPARATE-

HOLDEN (LUTHER), F.R.C.S.,

I Surgenn to St. Bartholomew's and the Founditig Hospituls.

LANDMARKS, MEDICAL AXND SURGICAL. From the 21 London Ed. In one bandsome volume, royal $12 \mathrm{mo}$ :, of 125 pages : cloth, 88 cents. (Now Ready.)

HEATH (CHRISTOPHER), F.R.C.S., Teacher of Operative Surgery in Unlversity College, London.

PRACTICAL ANA'TOMY: A Manual of Dissections. From the Second revised and improved London edition. Edited, with additions, by W. W. KeEr, M. D., Lecturer on Pathological Anatomy in the Jefferon Medical College, Philadelphia. In one handsome royal 12 mo.volume of $5 i \delta$ pages, with 247 il] uatrations. Cloth, $\$ 350$; leather, $\$ 400$. 
ALLEN (HARRISON), M.D.

Profissor of Physiology in the Univo of Pa

A STSTEM OF HUMAN ANATOMY: INCLUDING ITS MEDICAL and Surgical Relations. For the Uso of Practitioners and Studentsof Medicine. With $n$ Introductory Chupter on 11 istology. By E. O. ShAKESPEARE, M D, Ophthalmologist to the Phila. Ilosp. In one large and handeome quarto volune, with several hundred origrinal illustrations on lithographic plates, and numerous wood-cuts in the text. (In Press.)

In this elaborate work, whicl, has been in active preparation forseveral years, the author has sought togive, notonly the detnils of descriptive anatomy in a clearand condensed form, but also the practical applications of the science to medicine and surgery. The work thus has claims upon the attention of the general practitioner, as well as of thestudent, enabling him not only to refresh his recollections of the dissecing room, but also to recognize thesignificance of all variations from normal conditions The marked utility of the object thus sought by the author is self evident, and his long experience and ussiduous devotion to its thorough development are a sufficient guarantee of the manner in which his aims have beencarried nut. No pains have been spured with the illustrations. Those of normal anatomy are from original dissections, drawn on stone by Mr. Ilermann Faber, with the name of every part clearly engraved upon the figure, after the manner of "Holden" nnd "Gray." and in every typographical detail it will be the effort of the publisher to render the volume worthy of the very distinguished position which is anticipated for it.

\section{ELLIS (GEORGE VINER).}

\section{E. Emeritus I'rofessor of Analowy in Eniversity Crollege, London.}

DEMONSTRATIONS OF ANATOMY; Being a Guide to the Knowledge of the Human Body by Dissection. By George Vixer Ellis, Emeritus Professor of Anatomy in University College, London. From the Eighth and Revised London Edition. In one very handsome octivo volume of over 700 pages, with 256 illustrations. Cloth, \$4.25 ; leather, \$5.25. (Just Ready)

This work bas long been known in England as the leading authority on practical anatomy, and the favorite $f$ uifle in the dissecting-room, as is attested by the numerous editions through which it has passed. In the last revision, which has just appeared in Iondon, the acconplighed author has sought to bring it on a level with the inost recent advances of science by making the necessary changes in his account of the microscopic structure of the different organs, as developed by the latest researches in textural anatomy.

Ellis' Demonstrotions is the favorite text-book 1ts leadership over the English manuals upon dis. of the Euglish studenl of anatomy. In passing secting.-Phila. Med. Times, May 24, 1879.

throngh eight editions it has been so revised and adupted to the needs of the student hat it would seem that it had almost reached perfection in this speciat line. The descriptions are eteur, and the methods of pursuing anatomical investigations are given with oucb detail that the book is bonestly entitled to its name.-St. Louis Clinical Record: June, IS79.

The success of this old manual seems to be as well deserved in the present as in the pant volumes. practitioner of medicine who can possibly get it.The book seems destlued to maintain yet for years Va. Med. Monthly, Juie, $15 i 9$.

As a dissector, or a work to have in hand and studied while one is engaged in dissecting, we re gard it as the very best work extaut, which is certainty saying a very great deal. As a text-book to be studied in the dissecting-room, it 18 superior to a y of ibe works upon anatomy.-Cincinnuti Med. Newos, Hay 24,1879 .

We most nureservedly recommend it to every

\section{DILSON (ERASMUS), F.R.S.}

A SYSTEM OF HUMAN ANATOMY, General and Special. Edited by W. H. Goвrecut, M.D., Professor of General and Surgical Anatomy in the Medical Col. lege of Ohio. Illustrated with three hundred and ninety-seven engravings on wood. In one large and handsome octavo volume, of over 600 large pages; cloth, $\$ 4$; leather, $\$ 5$.
SMITH (HENRY H.), M.D.,
Prof. of Surgery in the Bniv. of Penna., \&c.
and ORNER (WILLIAM E.), M.D.,

AN ANATOMICAL ATLAS; illustrative of the Structure of the Human Body. In one volume, large imperial ootavo, cloth, with about six hundred and fifty beautiful figures. $\$ 450$.

SCHAFER (EDWARD ALBERT), H.D., Assistant Professor of Physiology in University College, London.

A COURSE OF PRACTICAL IISTOLOGY: Being an Introduction to the Use of the Microscope. In one handsome royal $12 \mathrm{mo}$. volume of 304 pages, with numerous illustrations: cloth, $\$ 200$. (Just Issued.)

HORNER'S SPECIAL ANATOMY AND HISTOLOGY. Eighth edition, extensively ravised and modifed. In 2 vols. Svo., of over 1000 pages, with 320 wood-cuts: cloth. $\$ 6$ no

SHARPEY AND QUAIN'S HUMAN ANATOMY. Revised, by Joseph Lkidr, H.D., Prot of A aat. in Uuiv. of Penn. In two octaro rols. of about 1300 pages, with 5l] illustrations Cloth, $\$ 60 t$. BELLAHY'S STUDENT'S GCIDE TO SURGICAL ANATOMY: A Text-book for Students prepaitig for their Pags Examination. With engravlugs on wood. In one bandsome royal $12 \mathrm{mo}$. volnme. Cloth. $\$ 225$.

CLELAND'S DIRECTORY FOR THE DISSECTION OF THE HUMAN BODY. In one Emall volume, ruyal $12 \mathrm{mo}$. of 182 pages: cloth $\$ 125$.

HARTSGORNE'S HANDBOOK OF ANATOMY AND PHYSIOLUGY. Second edition, revised. In ore royal 12 mo. vol., with 220 wood.cuts cloth, $\div 1 \div 5$. 
CARPENTER (WILLIAM B.), M.D., F.R.S., F.G.S., F.L.S.,

PRINCIPLES OF HUMAN PHYSTOLOGY; Edited by HENRY POWER, M.B. Lond., F.R.C.S., Examiner in Natural Sciences, University of Oxford. A new American from the Eighth Revised and Enlarged Englisb Edition, with Notes and Addi. tions, by Frascis G. Smita, M.D., Professor of the Institutes of Medicine in the Univer. sity of Pennsylvania, etc. In one very large and handsome octaro volume, of 1083 pages, with two plates and 373 engravings on wood; cloth, $\$ 550$; leather, $\$ 650$; half Russia, \$7. (Just Issued.)

We have been agreenbly surpriged tofod the vol- new a year or two ago. looks now as ifit had been a nme 80 complete in regard to the etractureand fonc. received and establixhed fact for years. In this encytione of tbe perrons system in all its relations, a clopxdic way it is unrivalied. II ere, as it seems to cubject that, in many reapects, is one of the most difi. us. is the great raine of the book; one is safe in sejuling calt of all, in tbe whole rubge of physiology. upon a student to it forinformation on slmost any given which to prodnce a full and satisfactory treatise of subject, perfectly certain of the fulness of information the class. to $w$ hich the one before ne belongs. The it will convey, and well satisfied of the accuracy with additions by the American editor give to the work as which it will there be found stated. - London Med. it is a consldersble valne beyond that of the last Times and Gazette, Feb. 17, 187. English edition. In conclnsion, we can give on cordial recommendation to the work as it now appears. work ob pliysiology in onr langage that, in the fall. est $80 \mathrm{~B} \times \mathrm{e}$ of the word, is the production of a philosopher as well 8 a physiologiet, bronght it ap as fully a s could be expected, if not desired, to the atandard of our knowledge of its sabject at the preeent day. It witl deservediy maintain the ploce it has 8 .lways bad in the favor of the medical profesion.-Journ. of Nervous and Mental Disease, Aprll, 1877.

Such enormousadvances have recently been made in our physiological knowledge, thst what was perfectly

The merits of "Carpenter'sPhyklology" are so widely know $n$ and appreciated that we need only allude briefy to the fact that in the latest edition will be found a com. prehensive embodiment of the results of recent physio. logical investigation. Care has been taken to preserve the practical character of the original work. In fact the entire work has been hrought up to date, and bears evidence of the amount of labor tbat has been begtowed upon it by its distingulsbed editor, Mr. Henry Power. The American editor has made the latest additions. in order fully to cover the time that has elapsed since the tast English editlon. $-N$. $Y$. Med. Journal, Jan. 18: :.

T'OSTER (MICHAEL), M.D., F.R.S., Prof. of Physiology in Cambridge Univ., England,

TEXT-BOOK OF PHYSIOLOGY. A new American, from the last English edition. Edited with notes and additions by EDwarn T. Reicrart, M.D., Dewonstrat or of Experimental Therapentics in Univ. of Penna In one handsome royal $12 \mathrm{mo}$. rolume of 1030 pages, with 259 illustrations. Cloth, $\$ 150$. Leather, $\$ 200$ (Just Ready.)

\section{Anerican Editor's Preyace.}

The high reputation acquired on both sides of the Atlantic by Dr. Foster's "Text-Book on Physiology, ' as a lucid exposition of functional physiology, in its most modern aspect, has seemed to call for an edition more thoroughly adapted to the wants of the American student. The plan of the author has presupposed an acquaintance with the details of physiological anatomy such as the student is accustomed to look to in his treatises on physiology. The absence of these details has rendered many parts of the work rague, if not altogether incomprehensible, and has therefore proved a serious drawback to the usefulness of the book as an accompaniment to lec. tures on physiology, as it is usually taughe in our scbools, and this defieciency the editor has endeavored to supply, by brief notes and the introduction of a large number of illustrations.

The almost limitless n mount of material accumulated by modern research has rendered diffi. cult the task of election and compression, without exceeding the ressonuble linits of a conrenient text-book. In his selection the editor bns been guided by his experience in the wants of students, und has endearored werely to present, in the mokt concise form, such facts ns would seem to be indispensable to a correct appreciation of the structure and function of the important organs. In accomplishing this, his additions have considerabiy exceeded his expectalions, a monnting to about 140 pages, including the illustrations which have been increased in number from 72 to 259 . If be shall thus bave succeded in rendering this admirable work better fitted for the wants of the American student, he will feel abundantly rewarded.

Nothing has been omitted from the English edition, and all additions have been distinguighed by insertions in brackets $[-]$.

The great popalarity of "Foster's Text-book of editor. So ably and so thoronghly bas tbe edit)r Physiolugy," both in England and in this country, performed his task, that we have no hesitancy in readersitunnecessary to kay anything forther re- gaying that, in onr oplaion, the American ediiton garding its merit. We shall, therefore, simply is far superior 10 its Engtisb cuotemporary. In its poial vat that, in the american edition, numerons present form we confideatly recommend this textimportant additions hare been made to the text of book to the stadent s; a clear, conctse, snd thorthe third Engtibh edition whereby the usefuiness of oughly rellable exposition of modern physiology. the work as text-buok for students has been greatig increased. - Phila. Med. and Surg. Reporter, A pril $2 t, 1580$.

The additions of the American editor are so copl. 0 s and in portant as to largely increase the book s spbere of nsefuloess. In notices of forner sditlons, we allnded to the absence of any reference to the iे ysiological anatomy of the different organs, and the dearih of fllastralions 88 serions drawbacks to the ralue sud general arefulness of lir. Fonter's work. These faults of onisslon have been inteli1. keatiy and qulte fally sapplied by the American

-Am. Journ. of Med Sriences, Jaly, 1880.

The matter of the lakt Englixh edition bas been transferred bodily to this, and there hare been added very many lllustrations and copious potes on histology and embryology by the merican edltor. The English editinns have been defective, so far an Amarican stadents are concerned, in their dearth of illustrations and the absence of all discaesion of physiologicsl abatoloy. There being anp. plled in thls edlition, the work is bow undoubtedly the best on physiology in the Eaglish language. Ohin Mert. Recorder, Jnne, $18 s 0$.

THE SAME. English Sturlent's Erlition, without notes or additions. Latest issue. In one small 12 mo. volume of 804 pages with 72 illustrations. C'loth, 75 cts. 
DALTON (J. C.), M.D., Professor of Physiology in the Gollege of Physteians and Surgenns, New York, ac.

A TREATISE ON IIUMAN PHYSIOLOGY. Designed for the use of Studentsand Practitioners of Medicine. Sixth edition, thoroughly reviged and enlarged, with three hundred and sixteen illustrations on wood. In one very beautiful ootavo vol. ume, of over 800 pages. Cloth, $\$ 550$; leather, $\$ 650$; half Russia, $\$ 7$. (Iately Issued.)

During the past few yearsseveral uew works on phy - notation and nomenclature have also been introduced alotogy, and new eilitions of old works, liave appeared, into the pregent edition. Notwithsianding the multicompering for the tavor of the nedical student, but ollcity of text-bonks on pbyslology, thls will lose none none will rival this new edition of balton. As now en- of its old time popularity. The mechanical execution targed, it witl be found also to be, in general, a satisfac- of the work is ali that could be desired.-Peninsular tory work of reference for the prastitioner.-Chicago Journal of Medicine, Dec. $18 \% 5$.

Vid. Journ. and Examiner, Jan.1876.

Prof. Dalton has discussed conflicting theories and This popular text.book on physiology comes to us in its sixth edition with the addition of about fifty per cent. of new matter, chiefly in the departments of pathofitirness, a fulness, and a conciseness which lend fresh. logical chemistry and the nervous system. where the ness and vigor to the entire book. But his discussions principal advances huve been realized. With so tho. have been an guarded by a refusal of admission to those rough revision and alditions, that keepthe work well Bpeculative and theoretical explanations, which at best up to the times, its continued pnpularity may be contiexist in the minds of obarrers themselves as only pro- dently predicted, notwithstanding the competitlon it babilities. that none of his readers need be led into may encounter. The publixher's work ja adinirably grave errors while naking them a study.-The Medical done.-St. Louis Med.and Surg. Journ., Dec. 1875. Record, Feb.19,1876.

The rerision of thisgreat work has, brought it forward with the physiologicul aivances of the day, and renders it. as it has ever been, the finest work for studentsextant.-Nashville Journ. of Med. and Surg., Jan. 1876.

For ctearness and perspiculty, Daltou's Physiology commended itself to the student years ago, and was a pleasant relief from the verbose productions which it supplanted. Physinligy has. however. made many adrances since then-and white the style has been pregerved intact, the work in the present elition has been brought up fully abreast of the times. The new chemical

We hesrtily welcome this, the aixth edition of this admirable text-book. than which thereare none of equal brevity more valuable. It iscordially recommended by the Professor of Physiology in the University of Louisi. ana. as by all competent teachers in the United States, and wherever the English language is read, this bonk has been appreriated. The present edition, with its 316 admirably executed illustrations. has been carefully revised and vary tu uch enlarged, although its bulk does not seem perceptibly increased.-New Orleans Medical and Surgical Journal, March, 1876.

\section{(YREENE (WILLIAM H.), M.D. Demonstrator of Chemistry in Med. Dept, Univ. of Penna.}

A MANUAL OF MEDICAI, CHEMISTRY. For the Use of Students. Based upon Bowman's Medical Chemistry. In one royal $12 \mathrm{mo}$. volume of 312 pages. With illustrations. Cloth, $\$ 175$. (Just Issued.)

It is well written, and give the latest views on vital chemistry, a subject with which most phy-iciaus are not sufficieatly familiar. To those who may wish to improve their knowledge in that direc tion, we can heartily recommend this work as being worthy of a carefn] pernsal. - Phila. Med. and $s u * g$. Reporter, A pril 21, 1850.

CLASSEN (ALEXANDER),

Profeseor in the Royal Polytechnic Schonl, Aix la-Chapelle.

ELEMENTARY QUAN'I'TATIVE ANALYSIS. Translated with notes and addition. by EDar I. Sur Towne Soientific School, Univ. of Penna. In one handsome royal $12 \mathrm{mo}$. volume, of 324 pages, with illustrations; cloth, $\$ 200$. (Just Ready.)

It is probably the best manal of an elementary / advancing to the analysia of minerais and such pronature extant, jnsomuch as its methods are the best. ducts as are met with in applied chemistry. It is It teacher hy examples, commencing with single an indlapensable book for stadents in chemistry.determinations, fotlowed by aeparations, and then | Boston Journ. of Chemistry, Oct. 1878.

Y $A L L O W A Y(R O B E R T), \vec{F} . C . S$. Prof of Applien Chemistry in the Royal College of Science for Ireland, etc.

A MANUAL OF QUATITATIVE ANALYSIS. From the Fifth London Edition. In one neat royal 12 mo. volume, with illustrations; cloth, $\$ 275$. (Lately Issued.)

TEMSEN $(I R A)$, M.D., Ph.D.,

PRINCIPLES OF THEORETICAL CHEUISTRY, with sperial reference to the Constitution of Chemical Compounds. In one handsome royal $12 \mathrm{mo}$. vol. of over 232 pages: cloth, $\$ 150$. (Just Issued.)

BOWMAN'S INTRODUCTION TO PRACTICAL CHEMISTRY, INCLIDING ANALYSIS. Sixth Americao, from the kixth tad revised London edition. With nomerous illustrutions. Iu one neat vol., royal $12 \mathrm{mo}$., cloth, $\$ 225$.

WOHLER AND FITTIG'S OUTLINES OF ORGANIC CHEMISTRY. Translated with additions from the Eighth German Edition. By IaA Remser. M D., Ph.D., Prof, of Chemistry and Physics in Willlams
College, Mass. In one volume, royal $12 \mathrm{mo}$. of 550 pp., ctoth, $\$ 3$.

LEHMANN'S MANUAL OF CHEMICAL PHYSIOL. OGY. Translated from the German, wlth Notea and Additione, by J. Cheston Morkis, M.D. With illustrations on wood. In one octaro rolume of 336 pages. Cloib, 225.

LEHMANN'S PHFSIOLOGICAL CHEMISTRY. COM. plete in two large octaro volumes of 1200 pages, with 200 illustrations; clotb, \$6. 
FOUNES (GEORGE), Ph.D.

A MANUAL OF ELEMENTARY CHEMISTRY; Theoretical and

Practical. Revised and corrected by HkxkY WArrs, B.A., F.R.S., nutbor of: A Diotionary of Chemistry," etc. With a oolored plate, and one hundred and seventy-seven illustrations. A new American, from the twelfth and enlarged London edjtion." Edited bJ RoBRt Bridezs, M.D. In one large royal $12 \mathrm{mo}$. volume, of over 1000 pages; cloth, \$2 75 ; leather, \$325. (Just Issued.)

Two careful revisions by Mr. Watts, since the appenrance of the last American edition of "Fownes," have so enlarged the work that in England it bas been divided into two volumes. In reprinting it, by the use of a sma!l and excedingly clear type, cast for the purpese, it bas been found possible to comprise the whole, without oinission, in one volume, not unhandy for study and reference. The enlargement of the work has induced the American Editor to confine bis additions to the narrowest compass, and he bas accordingly inserted only such discoveries as have been announced since the very recent appearance of the work in England, and bas ald ec the standards in popular use to the Decimal and Centigrade systerns employed in the original.

Among the additions to this edition will be found a rery handsome colored plate, representing a number of spectra in the spectroscope. Erery care has been taken in the typogriphical execution to render the volume worlhy in every respect of its bigh reputation and extencled use, and though it bas been enlarged by more than one hundred and fifty pages, its very moderate price will still maintain it as one of the cheapest volumes accessible to the chemical student.

This work, jnorganic and organic, is complete in one conrenient volume. In lts earliest editions it was fully up to the latest adrupcements und theories of that ifme. In its present form, It presents, is a remarkably convenieat and Batisfuctory mannur, the principles and leading facts of the chemlstry of to-day. Coucerning the mander in which the varjous eubjects are treated, innch deverves to be rald, aud mostly, too, in pralee of the book. A reriew of such a work at Forones's Chemistry within the lintis of a bcok-notice fur a medical neekly is simply ont of the question.-Cincinnnti Lancet and Clinic, D.c. 14, $15 \%$.

When we stute that, In onr opiaion, the present edition sustains in every renpect lie high repatation which lts predecesrors have arquired und eujoyed. we express therewib on fall belief in jis inirinsic valne as a text-bouk and work of reference. $-A m$. valne as a text-bouk abd work of Pharm., Ang. 1878 .

The couscientione care which has been bestowed npon it by the Americansnd Euglish edtors rencers it still, perhaps, the best book for the student aod the praclltivuer who would keep alive the acquibitions of his student days. It has, indeed, reached a some.

what formidable maguitude with its more than a thon:a ad pages, but with less than this no fair reprecentation of cheinistry as it now is can be giren. The type is small but very clear, a ad the sectione a re very lacidly urranged to facilitate otady and reference. Mrd and Surg. Repirter, Ang 3 , $15: 8$.

The work is too well known to American stadents to need ny exteuded notice; sn fifce it to say that the revinion by the Engll-beditor has been falthfolly done, and that Professor Bridges has added some frexh and valuable matter, espeoially in the inor. gavic chemfalry. The buok has alwuye beeu a fa* vorite in this conp:ry, and in its new shape bids fair to retuin allits foriner prestige.-Boston Jour. of Chemistry, Aag. 1578 .

It will be entlrely douecessary for os to make any remurks relatiug to the geueral character of Fuwnes, Ifanual. For over twenty years it has lield the foremont place as a text-book, and the elaborate and thorough revistons which hare been made from tIme to timelearellttle chance for a ay wide a wakerival to otep before it.-Cianadian Pharra. Jour., Ang. 1878. As a mannal of chemistry it is without a 6 perior In the langnage.-Mf. Med. Jour., Ang. 1578 .

\section{A TTFIELD (JOHN), Ph.D.,}

Professor of Practical Chemistry to the Pharmaceutical Soctety of Grent Britain, \&e.

CHEMISTRY, GENERAL, MEDICAL, AND PHARMACEUTICAI, including the Chemistry of the U. S. Pharmacopeia. A Mannal of the General Principles of the Science, and thejr Application to Medicine and Pharmacy. Eighth edition revised by the author. In one handsome royal $12 \mathrm{mo}$. volume of 700 pages, with illustrations. Clotlı, $\$ 250$; leather, $\$ 300$. (Just Ready.)

We have repertedly expresied onr farorable, of chemistry in all the wedical colleges in the opinion of thls work, and on the appearance of a United States. The present editjon contulns buch Dew edition of it, little remalns for us to $\mathrm{kay}$, ex- alteratlons and additionsas seemed oecessary for cept that we expect this elghtb edition to be as the demanstratlon of the latest derelopmeats of iodispanonble to us as the seventh and previous chemical principles, a vd the latest applicatione of editions have heen. While the general plan and chemietry to parmacy. It is scarcely necesary a rrangement have been adhered to, new matier for us to say that it exhibits chemlatry jn Its prehas been added covering the obeervatjun made sent advunced state.-Cincinnati Medieal Nens, bince the former edition The present differs frum Aprll, 1879.

the preoedlug ove chiefy in these alterallous and in about ten pages of areful trbles adjed in the a ppendlx - Am. Jour. of Pharmucy, May, $18 ; 9$.

A standard work like Attfeld's Chemlatry need only be uentloned by lts name, wlthont further comments The nresent edition ontains snch al teratlons and udditione as seemed necessary for the demonatration of the latest devetopmenth of chemical principles, and the latest applications of chemlntry to pharmacy. The author has bestowed ardnona labor on the revision, and tine exient of the laformation thu igtroduced may be estlmated from the fact that the Index contalns three bundred new references relatlog to additlonal materlal.-Jruggist8' Circular and Chemical Gistle. Мау, 1879

This very popnlar and morltorlons work bas now reaclied ita elghth edlthon, whlch fact speaks In the highert terms in cornmendatiod of its excel. lence. It has now becomethe princlpal lext-book

The popnlarjty which thls work has enjoyed js $o$ wing to the origical and clear dispositjon of the factiv of the relence, the accuracy of the detalls, and the omission of much wbich freights many tresities hearlly without brluging eorrespondinglnutrnetton to the resder. Dr. Attfield writes for etoreats, and primarily for medical otudents; be al ways bas an eye to the pharmacoprela and lif officinal preparatione; and be is continnally pntting the mutter in the text so that it responds to the questlons with which exch section is provided. Thas the stadent lesrns edslly, and can always refresh and tert his know ledge.- Med and Surg. Reporter, A prli $19,79$.

We noticed only abont two rears and a half ago the oublication of ibe precedlag edjtion. and ro. marked apou the exceptionally valnable cha recier of the work. The work now liolndes the whole of the cheinlstry of the pharmacoposia of the Unlied Stuter, Great Brituln, and Indla.-New Remedios. Iay, is79. 
BLOXAM (C. L.),

CHEMISTRY, INORGANIC AND ORGANIC. From the Second I,ondon Edition. In one very handsome octavo volume, of 700 pages, with about 300 illus. trations. Clotb, $\$ 400$; lenther, $\$ 500$. (Lately Issued.)

We have in this work a coun pleteand most excel- ? lent text-book for the une of schools, and can hexrt. Ily recommend it as $8 \mathrm{uch}$. - Boston Med. and Surg. Journ., May 28, IS74.

The above is thetltle of a work which we can most conscientiously recommend to students of chemistry. It is as easy as a work on chemintry could be made, at thesame tlme that it presents a full acconnt of that science as it now stands. We have spoken of the work as admirably adapted to the wants of otudents; it is quite as well sulted to the requirements of practitloners who wish to review theil chemistry, or hare occasion to refresh their meno. cies on any polnt relating to it. In a word, it is a book to be read by all whowish to know what is the chemlstry of the present day. -American Practitioner, Nov. 1573.

It would be diffeult for a practical chemist and teacher to find any material fanlt with this most ad. nıfrable treatise. The a uthor has gtven us almont a c) clopredia within the limits of a convenient volnat, and has done no without penning the useless paragraphs too commonly making up a great part of the bulk of many cumbious works. The progressire scientist is not disapjolated when be look $x$ for the record of new and valuable processes and discoveries, while the cantious conservattve does not find its pages monopolized by uncertain theories and speculations. A peculiar point of excellence lo the cryntallized form of expression in which great truths are expressed in very short paragraphs. One is 8 rprised at the brief space allotted to an important topic, and yet, after reading it, he feels that little, if any more should have been said. Altogether, it is keld om yon gee a text-book 80 nearly faultlese. - Cincinniti Lancet Nov. 1873 .

\section{CLOWES (FRANK), D.Sc., London.}

Senior Seience-Master at the High School, Newcastle-tunder Lyme, etc.

AN ELEMENTARY TREATISE ON PRACTICAL CHEMISTR I AND QUALITATIVE INORGANIC ANALYSIS. Specially adapted for Use in the Lahoratories of Sehonls and Colleges and by Beginners. From the Second and Revised English Edition, with about fifty illustrations on wood. In one rery handsome roy:l $12 \mathrm{mo}$. volume of 372 pages: cloth. $\$ 250$. (Just Issued.)

It is short, conclse, and eminently practical. We/are so simple, and yet concise, as to be interesting therefore heartily commendit to stridents, and espe. and intellig'ble. The work is noinenmbered with cially to those who are obliged to dispense with a theoretical deductions, dealing wholly with the master. Of conre, a teacher is in every way dest- practical matter, which it is the aim of thls comprerabie, but a good degree of technical skilland prac- hensive text-book to impart. The accn racy of the tical knowledge can be attained with no other analytical methods are vouched for from the fact instructor than the very valnable handbook now that they have all been worked through by the ander consideration.-St. Louis Clin. Record, Ock. anthor and the memabers of his class, from the 1877.

The work is sow ritten and arranged that it can he omprehended by the stadent withont a teacher, aud the descriptions and directions for the various work printed text. We can heartily recommend the work to the student of chemistry as being a reliable a od comvrobensive one.-Druggists' Advertiser, Oct. 15,1577 .

EN I PP'S TBCHNOLOGY; or Chemistry Applied to the Arts, and to Manufactnres. Wi:h American additions by Prof. Waltek R. JonNson. In two

very hit ndsame octavo volumes, with 500 wood engravings, cloth, $\$ 600$.

\section{PARRISH (EDWARD),}

\section{Late Professor of Mnterin Medica in the Philadelphia College of Pharmacy.}

A TREATISE ON PHARMACY. Designed as a Text-Book for the Student, and az a Guide for the Physician and Pharmacentist. With many Formulæ and Pregcriptions. Fourth Edition, thoroughly rerised, by Thomas S. WIEGAND. In one handsrime octaro volume of 977 pages, with 280 illustrations; cloth, $\$ 550$; leather, $\$ 650$; half Russia, \$7. (Lately Issued.)

Of Dr. Parrish's great work on pharmacy it only the work. not only to pharmacists, bnt also to the remains to be said that the editorhas accomplished multitude of medical practitioners who are obliged lis work so well as to mitintiln, in this fon rth edi- to compound their ow medicines. It willever hold tion, the bigh standard of excellence which it bad an honored place on on own bookshelves.-Dublin attainedin previouseditions. In der the editorship of it: accomplished author. This has not been accom. plished without muchlabor, and many additions and irnprovements, involving changes in the arrangement of the several parts of the work, and the addition of much new matter. With the modiflcations this effected it constitutes, as now presented, a com pendium of the ecience and art indirpensable to the pharmacist, and of the ntmost value to every practitioner of medicine desirous of familiarizing hinself with the pharmaceutical preparation of the articlesw wich he prescribes for his patients. - Chiergo Med. Journ., Jaly, Is74.

The wark is eminently practical, and has the rare merit of being readable and interesting, while lt prearves astrictly icientificcharacter. The wlrole work refleets the greatest credit on author, editor and onb. iisher. It will convey someided of the liberality which has been bestowed upon itsproduction when we menhas been bestowed upon itsproduction when we men- the public with all the mature experience of 1 ts an Illastrations. In conclusion, we hedrily recommend blood.-Lond. Pharm. Journal, Oct. 17, 1874.

We expressed onr opinion of a former edition in terms of nnqualified praise, and we are in no mood to detract from that opinion in reference to the pre. sent edition, the preparation of which has fallen in to conipetent hands. It is a book with which no pharma cist can dispense, and from which no physician can fail to derire much information of valne to him in practice.-Pacific Med. and Surg. Journ., Jnne,'74.

Perhaps one, if not the most important book npon pharmacy which has sppeared in the English lian. gnage has emanated from the transatlantic press. "Pdrrish's Plarmacy" is a well-known work on this side of the water, and the fact shows no that a realiy nseful work neverbecomes merely local in its fame. Thanks to the jndicious editing of Mr. Wiegand, the posthumons edition of "Parrish" has been sared to 
FARQUHARSON (ROBERT), M.D., Lecturer on Mnterin Medica at St. Mary's Hospital Medical Schnol.

A GUIDE TO THERAPEU'TICS AND MATERIA MEDICA. Second American edition, revised by the Author. Enlarged and adapted to the U.S.

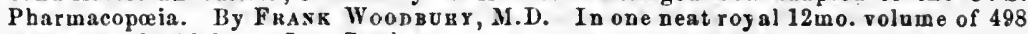
pages: cloth, \$2.25. (Just Ready.)

The appearsnce of a new edition of this conveDient aod bandy book in less tban two years may certalaly be taken as an Indication of its arefni ness. Its convenieat arrangement, and lis terveness, and, at the same time, comoleteness of the information given, make it a handy book of reference.-Am. Journ. of Pharmacy, Jnne, 2879.

This work oontains in moderate compass such well-digested facts conceraing the physiological and therapeuticsl action of remedies as are reason. ably establisbed np to the present time. By a convenient arrangement the corresponding effects of esch article in bealth and disease are presented in parallel colnmas, not ony renderiag reference ensier, bat aleo impressing the facts more strongly upon the mind of the reader. The hook has been sdapted to the wants of the Ameriesn atudent, and copious aotes havebeenintroduced, embodylag the Intest revision of tre Pharmacopeia, lngetber wi h the antidutes to the more promtuent poisons, and snch of the newer remedialagentis seemed aeces sirv to the completeness of the work. Tubles of weighta and messures, and a good alphabetical in dex end the volnme.-Druggists' Circutar and Chewical Gazette, June, 1879.

It is a plessnre to think that the rapldity with which a second edition is demanded may he takeo R8 an indication that the sense of appreciation of the value of reliable information regarding the nse of remedies 1- notentirels orerwhelmed in the cultivation of pathological studies, characteristic of the present day. This work certainly merits the snccess it has 80 quickly achiered.-Newo Remedies, Jaly, '79.

\section{STILLÉ (ALFRED), M.D.,} Professor of Theory and Practice of Medictne in the Unteersity of Penna.

THERA PEUTICS AND MATERIA MEDICA; a Systematic Treatise on the Action and Uses of Medicinal Agents, including their Description and History. Fourth edition, revised and enlarged. In twolarge and handsome $8 \mathrm{vo}$. vols. of about 2000 pages. Cloth, $\$ 10$; leather, $\$ 12$; half Rnssia, \$13. (Lately Issued.)

It is nnnecessary to do much more than to announce the uppearunce of the fourth edition of this well kaown abd excelleat work. -Brit. and For. Bfed.-Chir. Review, Oct. 1575.

For all whodeslreacomplete work on therapentics a d muteria medica for reference, iucasesinvolving medico-legal questions, ss well as fur information concerning remedial agents, Dr. Stille's is " war * $x$ celtence" the work. The work beingunt of prlat, by the axhanstion of former editions, the author has laja the profesaion ader renewed obligations, by the carefnl revision, importautadditionx, and timely re issuing a work not exactly supplemeated by any other in the English langange, if in any langnage. The mechanlcal execution handsomely astains the well-known skill snd good taste of the publisherSt.Louis Mert. and Surg. Journal, Dec. 1574.

From the poblication of the first aditton "Stille's Therapeutics" has been one of the classics; its whsence from our libraries wunld create a vacunm which could be filled by no other work in the langnage, and its presencesppplies, in the two volumes of the present edition, a whole cyclopedia of therapentics.-Chicago Medical Journal, Fob. 1575.

The rapid exbaustion of three editions and the nal. versul fovor with which the work has been received by the medical profession, are $b$ ufficient proof of 12 excellence as a repertory of practical a od usefal information for the physician. The edition before us olly \&uytainsthis rerdict, as the work has been care nlly revised and in some portions rewritten, bring ing it ap to the preseat time by the admission of chloral and cruton.chlural, nitrite of amyl, bicbloride of metbylone, methylic ether, lithium com ponods, gelseminnm, and other remedies. $-\Delta m$. Journ. of Pharmacy, Feb. 1875.

We can hardly admit tbat it hss \& rival in the multitnde of its citations and the fulness of its re search intoclioical histories, and we must assign it a place in the phybician's library; not, indeed, as fully representing the present stale of $\mathrm{knomledge} \mathrm{in}$ phariancodynamics, but as by far the most complete reatise upon the clinical and practical side of the question.-Boston Med. and. Surg.Journal, Nov. 5, 1574.

\section{GRIFFITH (ROBERT E.), M.D.}

A UNIVERSAL FORMULARY, Containing the Methods of Preparing and Administering Officinal and other Medicines. The whole adapted to Physiciars and Pharmacentists. Third edition, thoroughly rerised, with numerous additions, by Joux $\mathbf{M}$. MAiscn, Professor of Materia Medica in the Philadelphia College of Pharmacy. In one large and handsome octavo volnme of about $800 \mathrm{pp}$., cl., $\$ 450$; leather, $\$ 550$. (Lately Issued.)

To the dragglat a good formalary is simply iadis. pensable, and perhups no formulary bas been more exteasively used than the well-knowa work before us. Jany physicians have to ofliate, also, as drug. gists. This is trae especislly of the country physi. cisn, and a work which shall teach him the means by which to administer or comblae his reinedies in the most efflacious uad pleaxant manner, will always bold its place apon hisshelf. A formulary of

CHRISTISON'S DISPENSATORT. With coplons ad ditiona, and 213 large wood angrariogs. By $R$ Ealrapiaid Gripfith, M.D. One rol. Svo.pp. l000, cloth. 400 . aready sipplled with a stapdard work of the kind.

A more comptete formulurythan it is in iis pres ent form the pharmaciet or physiciun cunjd hardly desire. To the first some such work is indispenry. bls, in ad it jy bardly less essentiul to the practitioner who compounds his owa mediciaes. Mnch of what s contrined in the Introdaction onght to be coln. mitled to melary by every otodent of med ad donbtless rill make its way into librarles not - The Ameriean Practitioner, Lonisville, Jnly, '74.

CARPENTER'S PRIZB ESSAT ON THE USE OF A i, COHOLIC LIQTORB IN HBALTH AND Diskark. New edltion, with a Preface by D. F. Coxniz. M.D., and explsostions of scientificwords. In oneaestl $2 \mathrm{mo}$. volame, pp. 178, cloth. 60 cents. 
A JSCH (.JOHN M.). Ph.J...

Prof. of Mut. Med, and Rut in Phila. Coll. Pharmacy. Sucy.tothe Amorican Pharmuteutieal Association.

THE NATIONAL DISPENSATORY : Containing the Natural Iistory, Chemistry, Pharmacy, Actions and Uses of Medicines, including those recoguized in the Pharmacopoias of the United States, Great Britain, and Germany, with namer. ous references to the French $\mathrm{C}$ tedex. Second erlition, thoroughly revised, with numerous additions. In one very bandsome octavo volume of 1692 paqes, with 239 illustratinns. Extru cloth, $\$ 675$; leather, raised bands, $\$ 750$; half Russiil, raised bands and open back, \$5 25. (Now Ready)

Preface to tile Second Edtion.

The demand which bas exhausted in a few months an unusually large edition of the National Dispensatory is doubly gratifying to the authors, as showing that t'sey were correct in thinking that the want of such a work was felt by the inellical and rharmaceutical professinns, and that their efforts to supply that want have been acceptable. This appreciation of their labors has stimulated them in the revision to render the volume more worthy of the very marked favor with which it bas been received. The first edition of a work of cuch magnitude must necessarily be more or less imperfect; and thouph but little that is new and important bas been brought to light in the short interval since its publication, yet the length of time during which it was passing through the press rendered the earlier portions more in arrears than the later. The opportunity for a revision has enabled the authors to scrutinize the work as a whole, and to introduce alterations and additions whereve: there has seemed to be occasion for imnrovement or greater completeness. The principal changes to be noted are the introduction of seve. ral drugs under separate headings, and of a large number of drugs, chemicals, and pharmaceutieal preparations classifiel as allied drugs and preparations under the heading of more important or better known articles: these adilitions comprise in part nearly the entire German Pharmacopeia and numerous articles from the French Corlex. All new investigations which came to the autbors' notice up to the time of publication bave receired due consideration.

The series of illustrations has undergone a corresponding thorongh revision. A number have been added, and still more have been substituted for such as were deemed less satisfactory.

The new matter embraced in the text is equal to nearly one hundred pages of the first edition. Considerable as are these changes as a whole, they have been accommodated by an enlargement of the page without increasing unduly the size of the volume.

While numerous additions have been made to the sections which relate to the phssiological action of medicines and their use in the treatment of diseace, great care has been taken to make them as concise as was possible without rendering them incomplete or obscure. The doses have been expressed in the terms both of troy weight and of the metrical system, for the purpose of making those who employ the Dispensatory familiar w.th the latter, and paving the way for its introduction into general use.

The Therapeutical Index has been extended by about 2250 new references, making the total number in the present edition abnut 6000 .

The articles there ennmerated as remedies for particular diseases are not only those which, in the authors' opinion, are curative, or even beneficial, but tbose also which bave at any time been employed on the ground of popular belief or professional authority. It is often of as much consequence to be acquainted with the worthlessness of certain medicines or with the narrow limits of their power, as to know the well attested virtues of others and the conditions under which they are displayed. An alditional value posse sed by such an Index is, that it contains the elements of a natural classification of medicines, funnded upon an analysis of the results of experience, which is the only safe guide in the treacment of disease.

This evidence of success, seldom paralleled, showa clearly how well the authors have met the existing needs of the pharmacentical and inedical professions. Gratifying as it must be to them, they have embraced the opportnnity offered for a thorough revinion of the whole work, striving to em. brace within it all that might have been omitted in the former edition, and all that has newly appeared of snficient importance during the time of its collaboration, and the short interval elapsed since the previous publication. After having gone curefally throng the volume we must admit that the authors have lahored faithfully, and with success, in maintaining the high character of their work as a com. pendium meeting the requiresents of the day, to which one can safely turu in quest of the latest information couceroing everything worthy of notice in connection with Pharmacy, Materia Medica, and Therapeutics.-Am. Jour. of Pharmacy, Nov. 1879.

It is with great pleasure that we an nounce to onr readers the appearance of a second edition of the National Dispensatory. The total exhansion of the flrst edition in the short space of six mouths, is a suffied testimony to the value placed upon the work by the profession. It appears that the rapid sale of the flrst edition must have induced both the editors and the publisher to make preparations for a new edition immediately after the flrst had been lssued, for we find a large amount of new matter added and a good deal of the previons text altered and improved, which proves that the authors do not

intend to let the grass grow nader their feet, but to keep the work up to the time.-Nero Remeties, Nov. 1879.

This is a grat work by two of the ablest writers on materta medica in America The uthors have produced a work which. for accuracy and comprebensive. pess, is unsurpassed by any work on the aubject. There is no book in the English language which containa so much valuable information on the various articles of the materia medica. The work has cost the authors years of laborious stady, but they hare succeeded in producing a dispenatory which is not only national, but will be a lasting memorial of the learning and ability of the authors who produced it.-Elinburgh Medical Journal, Nnv. 1879.

It is hy far moreinternational or nuiversal than any other book of the kind in onr langurga, and mure comprebensive in every sense.-Pacific Med. mure comprehensive in ever

The National Dispensatory is beyond dispute the very best authority. It is thronghout complete in all the necexsary detalls, clear and lucid in Its explaparions, and replete with references to the most recent writings, where further particulars can be obtained, if desired. Its value is greatly enhanced by the extensive indices-a general in ex of materia medica, etc., and also an index of therapentics It would be a work of supererogation to say inor 3 about this well-known work. No practlsing physician ritn afford to be without the Natioal Disoen-atory.Canada Med. and Surg. Journ., Feb. ISSO. 
CORNIL $(V$.$) ,$

$A N D$

$R_{\text {ANVIER }}(L)$.

MANUAL OF PATHOLOGICAL HISTOLOGY. Translated, with Notes and Additions, by E. O. ShAKESPEARE, M.D., Pathologist and Ophthalmic Surgenn to Pbilala. Hospital, Lecturer on Refraction and Operative Ophthalmic Surgery in Unir. of Penna., and by Hexry C. Stses. M D., Demonstratcr of Patbological Histology in the Univ. of $\mathrm{Pa}$. In one very handsome octavo volume of over 700 pages, wilh orer 350 illustrations. Cloth, $\$ 550$; leather, $\$ 650$; balf Russia, \$7. (Just Ready.)

The work of Cornil nnd Ranvier is so well known as a lucid and accurate text-book on its important subject, that no apology is needed in presenting a translation of it to the American profession. It is only necessary to say that the labors of Drs. Shakespeare and Simes have been by no means confined to the task of rendering the work into English. As it appeared in France, in successive portions, between 1868 and 1876 , a part of it, at least, was somewhat in arrears of the present state of science, while the diffuseness of other portions rendered condensation desirable. The translators have, therefore, songht to bring the work up to the day, and, at the snme time, to reduce it in size, as far as practicable, withont innairing its oompleteness These changes will be found throughout the volume, the most extensive being in the sections devoted to Sarcoma, Carcinoma, Tubercolosis, the Bloodvessels, the Mammæ, and the classification of turcors. Corresponding modifications have been made in the very exten sire and beautiful series of illustrations, and every care has been taken in the typographical execution to render it one of the most attractive volumes which have issued from the American press.

We bave a besitation in cordially recommending the English translation of Cornil \& Ranvier's "Pathological Hiatolngy" as the best work of the kind In any ianguage, and as giving to its readers a trustworthy guide in obtalning a broad and solid hasle for the apprecistlon of the practical bearings of puthologicai anatomy.-Am. Journ. of Med. Sciences, A uril, 1550 .

This important work, In its Amerlcan dresa, is a welcome offering to all gtudenis of the snbjects which it treats. The great mass of material is s rranged asturally and comprehensirely. The classification of tamers la clear and full, bo far se the subject idinita of definition and this one chapter is worth the price of the bock. The jllustratfons are copions and well chosen. Withont the sllghtest hesitation, the translators deserve honest thanks for placlng this indispeasable work in the handr of American etudents.-Phila. Med. Times, April 2t, $35 \leqslant 0$

Thls volume we cordislly commend to the profesfion. It will prove a valuable, almest necessary, uddition to the libraries of etadents w bo are to be physiclans, and to the libraries of students who are phy dicia $18 .-$ A inerican Practitioner, Jane, 1850

Their bonk is not a collection of the work of others. but bas been written in the laboratory beside the microscope. It bears the marks of personal knowledge and investigatlon npon every page, controlled by and controlllng the work of others. . . In short, its translation bas made lt the best work in pathology attainable In our langag ge, one that every stadent certainly ought to have.-Arehives of 3 ed icine, $\Delta$ pril, 1850.

This work, in the original, bae for years past accupied a prominent place in the library of Frenci pathologiste, as we shonid naturally be led to be. ileve from the reputation of the distiogulshed an. thors Now that it has been preseoted to the Eng. lisb student for the first time, it will be perased with unususl interest. The fllustratlons are by no means the lesst valuable part of the work. Indis. pensable ss they sre to any work of this nature, in the work before ns the artint has sacceeded in producing cuts which will prove unueuslly valuable to the resder. The translation is well done, sad gives evidence throughout the volume that It was made by a person thoronghly converrant wlth the sulj ect.-N. Y. Med. Gazette, Feb. 28, isso.

GENWICK (SAMUEL), M.D. Assistant Physicine to the London Hospital.

THE STUDENT'S GUIDE 'TO MEDICAL DIAGNOSIS. From the Third Revised and Enlarged English Elition. With eighty-four illustrations on wood. In one very handsome volume, royal $12 \mathrm{mo}$, , cloth, $\$ 225$. (Just Issued.)

GREFIN (T. HFNR Y), H.D...

PATHOLOGY AND MORBID ANATOMY. 'T'hird American, from the Fourth and Enlarged and Revised English Edition. In one very handsome octavo volume of 332 pages, with 132 illustrations; cloth, $\$ 225$. (Now Ready.)

This is naquestionably one of the best rasanals on clently numerous, and nsual'y well made. In the the subject of pathology and norbid s astomy that perent edition, sich new matter bas been added an can be placed in the studeut's bands, and we are was necessary to eiribrece the later renutts in pathogisd to ree it kept up to the times by new editlons. lagical renearch. No doubt it will contioue to enjuy Enchedition is curefully revized hy the anthor, with the tavor it hus received at the hinds of the proter Ench edicionis curefally revised hy the anthor, with the view of rakiug it include the most recent $a d$ rances in patholigy, and of omltting whaterer rasy hitre become obsolete.-N. Y. Mtd. Jour., Feb. 1579

The treatize of Dr. Green is compaet, clearly expressed, up to the times, aud popular as a text.book. histh in England and Amerlca. The cuts are gnffi

GLUGE'S ATLAS OP PATHOLOGICAL HISTOLOGY Transisted, with Noter and Additions, by JOREPH Leint, M. D. In one rolume, very large imperia! quarto, with 320 copper-plate Agures, plain and colored. cloth. $\$$ ion

PAVI' TREATISF OX THE FUXCTIUN OF DI(;Estris: itm Diwiders and thelr Treutment. From the accond londun edilion In une handsome rolnme, minall t)cisvo, cloth, $\$ 200$.

LA ROCHE ON YELI, WW FEVER.consldered in it Hintorical. Pathological. Etjolngical, and Thers pentical Polation. I t two large and handrome octarc volumer of near? y $1500 \mathrm{pp}, \mathrm{cloth} . \$ 700$

For practical, ordlaary dally nse. this is nadoubt. edly the best treatlee that is offered to student of pathology and in robid a natomy.-Cincinnati Lancet and Clinic, Feb. S, 1579.

HOI.LAND'S MEDICAL NOTES AND REFLEC T10N8. 1 v01.8v0., Pp. 500 , elutb. $\$ 3: 0$

BARLOW'S MANUAL OF THE PRACTICB OF YEDICINE. With Additfuas by D. F. CONDI II D. 1 vol. 8vo., pp 600, cloth. $\$ 250$.

TODD'SCLINICAI LECTURES ON CERTAIN ACU' E DisBaser. In ode nest octsto volume, of $320 \mathrm{pp}$. cloth. \$2 5n

STOKES' LECTITRES ON FETER Fdiled by Jон WIt.i. A MonRy, M. D.. A-gialant Phymiclan to the (") rk Sirent Fever Hospital. Iu one neat 8 vo. vo.uue clulh, \$200. 
GTLIN'T ( A USTIN), M.D.,

Professor of the Principles and Practice of Medictne in Bellevue Med. College, N. Y.

A TREATISE ON THE PRINCIPLES AND PIRACTICE OF MWDICINE; designed for the use of Students and Practitioners of Medicine. Fifth edition, entirely rewritten and much improved. In one large and closely printed octavo volume of about 1100 pp. (In press)

Exthact rron the autuor's Preface.

In prepuring the fifth elition of this treatise, the anthor has been thorou hly mindful of the progress of medicine since the publication of the fourth edition in 1873. Time and labne bare not been spared in the endeavor to briog the work in all respects up to the present state of medical knowlerdge.

1r. Wiiliam II. Welch, Lecturer on Pathological IIistology in the Bellevue IIospital Medical College, has contributed in Part I. the first saven chapters, embraeing the general patholigy of the solid tissues and of the hloot. He has also revised. and in great part rewritten, the leserip tions of the anatomicnl characters of the diseases considered in the rest of the volume It is believer that these portions of the work will serve as a digest of the essential facts perlaining to general and specinl pathological anatomy, as far as this important branch of study bears upon practical medicine

In the other portions of the treatise many changes will be found, whigh have somewhat en. larged the size of the volume, in spite of the omission of a considerable amount of untter, ancl the rewriting of muny portionswith a special view to condensation. Among these changes may be inentionel numernus improvements in the arrangement, including the classification of the diseases of the nervous syslem on an anatomical in place of a symptomatic basis, and the consideration of various disea-es not embraced in previous editions. In short, the eliminations, substitutions, and ndditions reniler the present edition virtually n new work.

In making chinges, the author has not heen influenced by any sense of obligation to maintain eonsistency of views with the previous editions of this treatise, or with other works which he bas written. If statements be found to vary from those inade at a prior date, the simple explanation is that the latter, in the light of more recent reflection and eblarged knowlerge, seetas to him no longer tenable. He his endeavored to regard his own past writings, in this point of view, divested of the partiality of authorship, and to subject them to as critical an eximination as if they were the writings of another.

\section{$B^{Y}$ THE SAME AUTHOR.}

CLINICAL, MEDICINE; a Srstematic Treatise on the Diagnosis and Treatment of Diseases. Designed for Stadents and Practitioners of Medicine. In one large and handsome octavo volume of 795 pages; cloth, $\$ 450$; leather, $\$ 550$; balf Russia, \$6. (Now Ready.)

The enineat ieacher who has written the volame nuder consileration b s recognized the needs of the American profession, and the resnlt is thl that we could wish. The style in which it $i$, writien is pecnliarly the author's; it is clear and forcible, aud markel by those characteristies which have ren. deved bim one of the best writers and teachers this country baxever produced. We have nut kpace for fo futl a consideration of this remarkable work as

It is here that the skill aod learning of the great clinician are displayed He ha, gireu $n s$ a store honse of medical $\mathrm{knowledge.} \mathrm{excel!ent} \mathrm{for} \mathrm{the} \mathrm{sta.}$ dent, convenient for the pracitioner, the result of a long life of the most faitbfal clinical work. collected by an energy as vigilant snd systematic as untiring. sad reighed by a jutgment no less clear than his observation is close.-Archives of Medicine, Dec. $1 \leqslant 79$

we would desire. $\rightarrow$ S. Louis Clin. Record, Oct. 1879.

\section{B T THE SAME AUTHOR.}

ESSAYS ON CONSERVATIVE MEDICINE AND KINDRED TOPICS. In one very handsome royal $12 \mathrm{mo}$. volume. Cloth, $\$ 138$. (Just Iss ued.)

WATSON (THOMAS), M.D., \&c.

LECTURES ON THE PRINCIPLES AND PRACTICE OF PIIYSIC. Delivered at King's College, London. A new American, from the Fifth rerised and enlarged English edition. Edited, with additions, and several bundred illnstra. tions, by Henry Hartshorne, M.D., Professor of Hygiene in the University of Pennsylvania. In twolarge and handsome 8vo.vols. Cloth, $\$ 900$; leather, $\$ 1100$. (Lately Publeshed.)

AARTSHORNE (HENRF), M.D. Professor of Hygiane in the University of Pennsylvania

ESSENTIALS OF THE PRINCIPLES AND PRACTICE OF MEDICINE. A handy-book forStudents and Practitioners. Fourth edition, revised and im. proved. With abont one hundred illustrations. In one handsome royal $12 \mathrm{mo}$. volume, of about 550 pages, cloth, $\$ 263$; half bound, $\$ 288$. (Lately Issued.)

DAYTS'S CLINICAL LECTURES ON VARIOUS IMPORTANF DISEASES; being a collection of the Clinical L ctures deis vered in the lledical Wards of Marcy II ospi al, Chicago. Edited by Frask H Davis, II.D. Secund edition, enlarget. In one baud some roval 12 mo. volumie. Cloth, $\$ 175$.

THE CYCLOPADIA OF PRACTICAL MEDICINE: cinnrising Treatizas on the Nature and Trealmen of Diseases, Materix Medica and Therapentics, Dis. eases of Women and Children. Medical Jnrisprndence, etc. etc By DUsolison, Furber, Twerde, and Covolus. In four large super-royal octaro volumes, of $325 t$ double-colutnued p:iges, strongly and hat adomely boand in leather. $\$ 15 ;$ cloth, $\$ 1$ i STURGES'S INTRODUCTLOX TO THE STUDY OF CIINICAL MEDICINE. Belng a Guide to the In. restigation of Disease. In one liandsome 12mo. volume, cloth, \$1 25. (Lately Issued.) 
BRISTOWE (JOHN SYER), M.D., F.R.C.P.,

Physictan and Joint Lecturer on Medicine, St. Thomas's Hospital.

A TREA'TISE ON THE PRAC'TICE OF MEDICINE. Second American edition, revised by the Author. Edited, with Additions, by JAMEs II. II 0 rcH Issos, M.D., Physician to the Pennn. Hospital. In one bandsome octaro volume of nearly 1200 pages. With illustrations. Cloth, $\$ 500$; leather, $\$ 600$; balf Russia, $\$ 6$ 50. (Now Ready.)

The second edition of this excellent work, llke the from the best cources outside of the a uthor's own first, bas recelved the benebt of Dr. Hutchingon's long experieoce, and the ralnable portion relating aguotations, by which the phases of dixease which 10 general pathology, aid greatly in completing an are peculiar to this contry are indicated, and thus exceptlonally good book for purpones of reference a treatige which was Intended for British practi. and ingiruction - Boston Medical and Surgical tioners and'students is made more practically noful Journal, February, $18 s 0$.

on this side of the water. We ree no reason to What we said of the first edition, we can with modify the high opluion previonsly expressed with i ncreased emphssis, repeat concerning this: "Every regard to Dr. Bristowe's work, except by adding pagelscbarscterized by the ntterabces of a thonghtour appreciation of the carefal labors of the author, ful man. What bas been gaid, bas been well gaid, in following the lateral growth of medical science. and the book is a fair reflex of all ibat is certainly Tha chapter on diseases of the skin and of the nerv. known on the subiects considered." -Ohio Med. ous system, with a new one on insanity compiled $\begin{aligned} & \text { kecorder, Jan. 7, } 1850 . \\ & \text { Rer }\end{aligned}$

RICHARDSON (BENJ. T.), M.D., F.R.S., M.A., LL.D., F.S.A., .

PREVEN'TIVE MEDICINE. In one octavo volume of about 500 pages. (Iu Press.)

The immense strides taken by medical science during the last quarter of a century have had no more conspicuous field of progress than the causation of disease. Not only has this led to marked advance in therapenticz, but it has given rise to a virtually new department of medi. cine-the prevention of disenge-more important, perhaps, in its ultimate results than even the investigation of curative processes. Yet thus far there has been no attempt to gather into a srstematic and intelligible shape the accuinulation of knowledge tbus far acquired on this most interesting subject. Fortunately, the task hos been at last undertaken by a writer who of all others is, perhaps, best qualified for its performance, and the result of his labors can hardly fail to mark an epoch in the history of medical science. The plan adopted for the execution of this novel design can best be explained in his own words :-

"With the object here expressed I write this volume. I have nothing to say in it that has any relation to the cure of disease, but $I$ base it revertheless on the curative side of medical learning. In other words, I trace the diseases from their actual representation ns they exist before us, in their natural progress after their birth, ns far as I $\mathrm{nm}$ able, back to their origins, nnd try to seek the conditions out of which they spring. Thereupon I endeavor further to analyze those conditions, to see how far they are removable and how far they are avoidable."

HOTHERGILL (J. MILNER), M.D. Edin., M.R.C.P. Lond. Asst. Phys. to the West Lond Hosp.: Asst. Phys. to the City of Lond-Hosp.,etc.

THE PRAC'TITIONER'S II TIBOOK OF 'TREA'TMENT; Or, the Principles of Therapeutics. Second edition, revised nnd enlarged. In one very nent octavo rolume of ahout 650 pages. Cloth, $\$ 400$; very haudsome balf Russia, $\$ 550$. (Just Ready.)

The call for a zecond edition of Dr. Fothergill's work has been met by the author with a revision performed in no perfunctory inanner. The entire subject-matter hus been suhmitted to a most careful and exhaustire scrutiny, and much new material been added, including articles on "The Functional Disturhances of the Liver," "The Menns of Acting on the Respiratory Nerre Centres," "The Reflex Consequences of Orarian Irritation," "When Not to Give Iron," "Artificial Digestion," eto., thus presenting n complete reflex of the existing condition of therapeutical science.

$B^{Y}$ THE SAME AUTHOR.

THE A NTAGONISM OF TIIERA PEUTIC AGEXTS, A ND II H T IT TEACIIES. Being the Fothergillinn Prize Essny for 1878. In one neat volume, royal 12 mo. of 156 pagez; cloth, $\$ 100$. (Just Ready.)

JYODBURY (KRANK), M.D..

Pkyxician to the German Hospitat, Philadelphin, late Chief Asqist. to Med. Clinic, Jeff. College Hiskyital, tc.

A HANIBOOK OF THE PRINCIPLES AND PRAC'TICE OF Medicine; for the use of Students and Practitioners. Bnsed upon II ssband's Handbook of Practice. In one neat volume, royal 12 mo. (Preparing.)

HABERSHON (S. O.). M.D.

Senior Phystcion to and late Leclurer on the Principles and Practice of Medicine at Guy's Hispilat, etc.

ON TIE DISEASES OF THE ABNOMEN, COMPRISING THOSE of the Stomacb, and other parts of the Alimentary Canal, Esophagus, Cæcum, Intes. tines, and Peritoneum. Second Anerican. from the third enlarged nnd revised Eng. lish edition. With illuatrations. In one handsome actaro rolume of over 500 pages. Cloth, \$3 50. (Now Really.) 
REYNOLIDS (J. RUSSELLL), M.D.,

\section{Frof. "f the Principles and rractice of Medicine in Univ. College, Londin.}

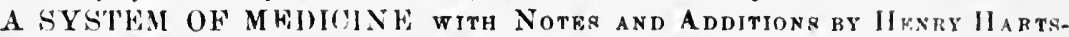
horne, M.D., late Professor of IIygiene in the University of Penna. In turee litrge and bandsome octaro rolumes, containing 3052 elosely printed double-columnerl pages. with numerous illustrations. Sold only by subsription. Price per vol., in cloth, $\$ 5.00$; in sheep, $\$ 6.00$ : half Russia, raised bands, $\$ 6.50$. Per set in cloth, $\$ 15 ;$ sheej, $\$ 18$; half Russiu, $\$ 19.50$

Vorume I. (just ready) contains Granerat, Diseases and Disfases of the Nrrvoly SYstey. Volum II. (just ready) contains Diseases OF Resplizatoly and Circulatohy Srsteas.

Voldme III. (just ready) contains Diseases of TIL Digestive and Bloon.GLanducar Systems, of the Urinary Organs, of the Female Reproductive Systea, and of tue Cutaneous System.

Reynolds's System of MedciNe, recently completed, has acquired, since the first appearance of the first volume, the well-deserved reputation of being the work in which modern British medicine is presented in its fullest and most practical form. This could scarce be otherwise in view of the fact thit it is the result of the collahoration of the leading ininds of the profession, each subject being trented by some gentleman who is regarded as its highest authority-as for instance, Diseases of the Bludder by Sir Henry Titospson, Malpositions of the Uterus by Grally Hewtt, Insanity by Henry Madesley, Consumption by J. Hugues Bennet, Diseases of the Spine by Cuaras Buand Ranclafe, Pericarditis by Fuances Sibson, Aleoholisin by Francis E. Anstie, Renal Affections by Willay Roberts, Agthina by Ilyde Sal,ter, Cerebral Affections by H Ciarlton Bastias, Gout and Rheumatism by AlFren Baring Gar. Ron, Constitutional Syphilis by Jonathan Hutcunson, Diseases of the Stomach by WiLson Fox, Diseases of the Skin by BalManno Squirk, Affections of the Larynx by Morpal, MaC. BENzte, Disenses of the Rectuin by Blizard Curline, Diabetes by Ladder Brunton, Intestinal Disenses by Joн Srer Bristowe, Catalepsy and Somnambulism by Tromas Kixg Chaм. Bers, A poplexy by J. Jlughlings Jackson, Angina Pectoris by Profegsor Gairdner, Emphysema of the Lungs by Sir WiLlias JENNer, etc. etc. All the leading schools in Grent Britain have contributed their best men in generous rivalry, to build up this monument of medical science. St. Bartholomew's, Guy's. St. Thomas's, University College, St Mary's in London, while the Edinburgh, Glasgow, and Manchester schools are equally well represented, the Army Medical School at Netley, the military and naval services, and the public bealth boards. That a work conceived in such a spirit, and carried out under such auspices should prove an indispensable treasury of facts and experience, suited to the ditily wants of the practitioner, was inevitable, and the success which it has enjoyed in Encland, and the reputation which it has acquired on this side of the Atlantic, have sealed it with the approbation of the two pre-eminently practical nations.

Its large size and high price having kept it beyond the rench of many practitioners in this country who desire to possess it, a demand has arisen for an edition at a price which shall render it accessible to all. To meet this demand the present edition has been undertaken. The five volumes and five thousand pages of the original have by the use of a smallertype and double columns, been compressed into three volumes of over three thousand pages, clearly and bandsomely printed, and offered at a price which renders it on $\theta$ of the cheapest works ever presented to the American profession.

But not only is the Americun edition more convenient and lower priced than the English; it is also better nnd more complete. Some years having elapsed since the appearance of a portion of the work, additions are required to bring up the subjects to the existing condition of sciellce. Some diseases, also, which are comparatively unimportant in England, require more elaborate treatment to adapt the articles devoted to them to the wente of the Ainerican physioian; ind there are points on which the received prastice in this country differs from that adopted abroad. The supplying of these deficiencies bas been undertaken by IIENRY HARTShorne, M.D., late Professor of Hygiene in the University of Pennsylvania, who has endeavored to render the work fully up to the day, and as useful to the American physician as it has proved to be to his English brethren. The number of illustrations has also been largely increased, and no effort spared to render the typographical execution unexceptionable in every respect.

Really too much praise can scareely be given to isnbjects with which he should be familiar:-Gailthis noble book. It is a cyclopedia of medicine written by some of the besi men of Europe. It is full of usetul information snch as one fivds frequent need of in one's dally work As a boin of refereace it is invaluable. It is up with the times. It is clear and concentrated in style, and its form is worthy of its famous publisher. - Louisville MIt dews, Jan. 31,1880 .

"Reynolds' System of Medicine" is jnctly considered the most popular work on the principles and practice of medicine in the Englisb langtage. The contributors to this work ale gentemen of well. known reputation on both sides of the Atlantic. Each gentleman has striven to make his pert of the work is practical as posible, and the information contalued is such as ls needed by the busy practitioner.-St. Louis Med. and Surg. Journ., Jan.'So.

Dr. Hartshorne bas made ample additions and revisionk, all of which give increased valne to the volume, and render it more nxefui to the American practitioner. There is no volume in Engliwb medical litecature more valuable, and every purchaner will, on beconing familiar with it, cougratnlate himcolf on the posesusion of this vaxt atore. houlie of information, in regard to so mauy of the lard's Med. Journ., Feh. 1880.

There is no medical work whicb we hare in times past wore frequently and fully consulted when perplexed by doubts as to treatment, or by having an. usual or apparently inexplicable symptoms pre. sented to us than "Reynold s' System of Medicine." Among its contributors are gentlemen who are se well known by reputation npon this side of the Atlantic as in Great Britain, and whose right to speak with anthority upon the subjects abont which they have written, is recognized the world over. They bave evidently striven to make their essays as practical as possible, and while these are sufficiently full to entitle them to the name of monographs, they are not loaded down with such an riuouut of detail as to render them wesrisome to the general reader. In a word, they contain just that kind of information which the busy practitioner frequenlly finds himself in need of. in orier that any deficiencies may be supplied, the publishers have committel the preparation of the book for the press to Dr. Henry Hartshorne. Whome judicious notes distribnted thronghout the rolnme afford abnn. dant evidence of the thoroughness of the revision to which he has subjected il. - Am. Jour. Afed. Seiences, Jan. 1850. 
BARTHOLOW (ROBERTS). A.M., M.D..LL.D.

Prof. of Materia Medica and General Therapeutics in the Jof $3 f e d$. Coll, of Phila, etc.

A PRAC'TICAL TREATISE ON ELECTRICITY. IN ITS APPLI. CATION TO MEDICINE. In one very handsome octavo volume of about 450 pages, with illugtrations. (In press.)

The constantly increasing therapeutic use of electricity, and the nbsence of a concise gaide cuited to the wants of the general practitioner, bave induced the suthor to prepare the present volume. Hix objeot has been to present the most adranced state of existing kuowletge in a form dirested of unnecessury technicalities, keeping constantly in view the practical needs of the student and physician.

As the volume is fuunded upon a course of lectures delivered in the Jefferson Medical College during the epring of 1880 , its ndaptation to its purpose is insured. Dr. Bartholow's power of lacid exposition is well known, and is particularly desirable in a subject such as this, treated from the standpoint of the general practitioner and. not of the speciulist.

RINLA YSON (JAMES), M.D.,

Physician and Lecturer on Clinical Medirine in the Glasgowo Western Infrmary, etc.

CLINICAL DIAGNOSIS; A Handbook for Stadents and Practitioners of Medicine. In one hnndsome $12 \mathrm{mo}$. volame, of 546 pages, with 85 illustrations. Cloth, $\$ 263$. (Just Isswet.)

The book is a excellent one, clear, concise, conve. tive from preface to the final page, and onght to be nient, practical. It Is replete with the very know- given s place on every office table, because il contalns ledge the student needs when he quits the lecture. In a condensed form ail that is valuable in semeiology roum and the laboratory for the ward and sick-room, and diagoostics to be found in bulkier volnmes, and aud does not lack in information that will meet the becanse in its arrangement and conplete index, it is wants of experienced and older men.-Phila. Mred. unasually convenient for quick reference in any Times, Jan. 4, 1879 .

This is one of the really asefnl books. It is at trac- - N. C. Med. Journ., Jsn. IS79.

\section{HAMLTO.N. ( ALIAN MrLANE), M.D.}

Attending Physicion at the IIospital for Epileptice and Paralyties, Blackwell's Island, N.Y., and at the Out-l'atients' Department of the New York Hospital.

NERTOUSDISEASES;THEIR DESCRIPTION AND TREATMENT. In one handsome octavo volume of 512 pages, with 53 illus.; cloth, $\$ 350$. (Just Issued.)

CHARCOT (J. M.).

Prefosgnr to the Fineulty of Med. Paris, Phys.to La Salpêtrière, ete.

LECTURES ON DISEASES OF THE NERVOUS SYSTEM. Translated from the Second Edition by George Sigerson, M.D., M.Cb., Lecturer on Biology, etc., Cath. Univ. of Ireland. With illustrations. 1 vol. 8 vo. of 288 pages. Cloth, $\$ 175$. (Just Ready.)

CLINICAL OBSERVATIONS ON FUNCTIONAL NERVOITS DISORDERS BV C. HANDPIELDJONE. if. D., Physician to St. Mary's Hospital, \&c. Sec.

ond American Edition. In onehandsome octavo volume of 3 is pagen, cloth, $\$ 325$.

\section{MORRIS (MALCOL.M). M.J).,}

SKIN DISEASES, Including their Definitions, Symptoms, Diagnosis, Prognosis, Morbid Anatomy, and Treatment. A Manual for Students and Practitinners. In one $12 \mathrm{mo}$. volume of over 300 pages. With illustrations. Cloth, \$1 75. (Now Ready.)

To physiciaps who would like to know something appliances of entaueong medicine. He has produced sheat skin dizea+ex, 80 tbst when a patient presents a plain, practical book, by aid of which, who so himelf for relief they can make a correct dianaosis chooses may trifn his eye to the recoguition of and prescribe rational trea'meot, we unhesitatingly light hat significant differences. The descriptions recommeud this littie book of Dr. Morris. The affec- sre velther too vague nor orer-refined; the directions of the skin are described in a terse, lucid man. tions for rreatment are clesr snd succinct.-London

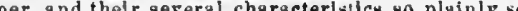
torth that diagoovis will be easy. The treatment in exch case is such $s \&$ the experience of the most eminent dermatsinalsts advike.-Cincinnati Medical Noves, April, 1550 .

This is emphatically a lestrer's book; for we can affely Ray, mo far as on jodement goes. that in the whnle range of medical literature of a like acope. there is an brok which fur clearnesg of expresslon and methodical urrangement is better ulupted to promote a rational conception of derinatology, brauch confexiedly difficalt and perp'exing to ilse hoginner. - St. Couis Courier of Modicine, April. $I \rightarrow 80$.

The anthor nfthla manosl hasevidently a full and Brain, April, Is8s

The suthor has handled his snbject in s clear and concixe manner, and us a text-bouk tn studenta his inanual will be fond nseful. - Medical and Surgieal Repwer, March 27, 1880.

The author's task has hean well done and han produced one of the best recent works upon the diffcult anbject of which it teats: there ia no wark published which given hetter view of the elemeotary facts and principieg of dermatology. - Nevo Orleans Medi. cal and Surgienl Journal, A pril, I880.

Thls excellent little book is the first work of a diatinguislied proil of Jonathan Hotchlngon: it recommend itzelf above all by its clearuess, method. intinate acqualntance with tbe llteratn of derma- de Syphiligraphie, 25 April, $15 S 0$.

tology, and with tho most recent developmentsand

GOX (TII.BUR Y). M.D., F.R.C.P., and T. C. FOX. B.A., M.R.C.S.,

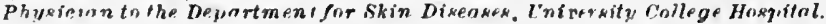

EPITOME OF SKIN DISEASES. WITH FORMULA. For STUDexts AND Practitionkrs. Second edition, thoronghly revised and grently enlarged. In one very handsoue $12 \mathrm{mo}$. volume of 216 pages. Cloth, $\$ 138$. (Just 1ssued.) 
$\boldsymbol{F}^{L I N T}(\operatorname{AUSTIN)}$, M.D.,

Professor of the Principles and Practice of Medictne in Betlevue Hospital Med. College, $N$. $Y$.

A MANUAL OF PERCUSSION AND AUSCUL'TATION; of the Physical Diagnosis of Diseases of the Lungs and Heart, and of Thoracic Aneurisu. Second edition. In one handsoun e royal $12 \mathrm{mo}$. volutue : eloth, $\$ 1$ 63. (Just liearly.)

Prof. Fliut is nо well kuown ин a medichl teacher, phystcigo's library.-Med. and Surg. Reporter, and writer that it xeems sipertlaous to stale that fiarch is, 1580.

thesuliject lias beeu treated in a thorongh and 8 ys- The little work before us bas already become a lemalic maner. In revising it for a second edtion standard one, and has become exlen-lvely alopted tho autlior has confued himself to nuch aldillons as as a text-book. There is certalaly uoge better. It seem likely to render it more useful. not only to contains the sabutance of the leysna which the students engaged In the practical study of the sub- anthor has fur miny searoglven, in connection with

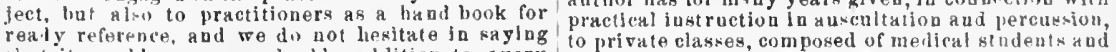
that it would prove a valuable addition to every practitlouers.-Cincinnati Med. News, Feb. 1580.

\section{$B^{Y}$ THE SAME AUTHOR.}

PIITHISIS: I'TS MORBID ANATOMY, ETIOLOGY, SYMPTOMATIC EVWNTS AND COMPLICATIONS, FATALITY AND PROGNOSIS, TREATMENT, AN1) PHYSICAL DIAGNOSIS; in a series of Clinical Studies. By Austix FLINT, M. D., Prof. of the Principles and Practice of Medicine in Bellevue IIospital Med. College, New York. In one handsome octavo volume: \$3 50. (Lutely Issued.)

\section{$B^{Y}$ THE SAME AUTHOR.}

A PRAC'TICAL TREATISE ON THE DIAGNOSIS, PATHOLOGY, AND TLEATMENT OF DISEASES OF THE HEART. Second revised and enlarged edition. In one octavo volume of 550 pages, with a plate, cloth, $\$ 4$.

Dr. Flin! chose a difficultsubject for his researches, i nd clearest practical treatise on thosesubjects, and and bas thown remarkable powers of observation should be in the hands of all practitionere and stn. ind reflection, as well as greatindnstry, in his treat- lents. It is a credit to American medical literature. ment of it. IIis book must be considered the fullest -Amer. Journ. of the Med. Sciences, Jnly, ISb0.

\section{B $T$ THE SAMF AUTHOR.}

A PRACTICAL TREATISE ON THE PHYSICAL EXPLORATION OF THE CHEST AND THE DIAGNOSIS OF DISEASES AFFECTING THE RESPIRATORY ORGANS. Second and revised edition. In one handsome octavo volume of 595 pages, cloth, $\$ 450$.

\section{BROWN (LENNOX), F.R.C.S. Ed.,}

Senior Surgeon to the Central London Throat and Ear Hospital, etc.

THE TIIROAT AND I'TS DISEASES. With one hundred Typical Illustrations in colors, and fifty wood engravings, designed and executed by the author. In one very handsome imperial octavo volume of 351 pages; cloth, $\$ 500$. (Just Ready.)

SEILER (CARL), M.D.,

Lecturer on Laryngoscopy at the Univ. of Penna., Chief of the Throat Dispensary at the Univ. Hospital, Philn., ete.

HANDBOOK OF DIAGNOSIS AND TREATMENT OF DISEASES OF THE THROAT AND NASAL CAVITIES. In one handsome royal 12mo. volume, of 156 pages, with 35 illustrations; cloth, $\$ 1$. (Just lieady.)

We most learlily commend this book as showing sound judgment in practice, and perfect familinrity with the literature of tire specialty it so ally epitomizes. Philada. Med. Times, July 5, 1879.

WIILIAMS'S PULMONARY CONSUMPTION; its Vature, Varieties, and Treatment. With an Ana.lyxis of One Thousand Cdxes to exemplify its duratiou. In one neat octaro volume of about 350 pages; clotb, $\$ 250$.

SLADE ON D] 'HTHERIA; its Nature and Treatment, with an deconnt of the History of its Prevalence in virious Conntries. Second and revised edition. In one neatroyal $12 \mathrm{mo}$. volume, cloth, \$1 25.

WALSHEON THE DISEASES OF THEHEART AND GREAT VESSELS. Third Anerican Edition. In 1 vol. Svo., 420 pp., cloth, $\$ 300$.

CHAMBERS'S MANUAL OF DIET AND REGIMEN IN HEAITH AND SICKNESS. In one handsome octavo volume. Cletb, \$2 75.

LA ROCHE ON PNEUMONIA. I vol.8vo., cloth, of 500 pages Prfee, \$300.

WILSONS STUDENT'S BOOK OF CUTANEOUS MEDICINE and MrEAsFs OF THE SKIS. In One $\nabla \in 1 y$ haddsome royal $12 \mathrm{mo}$ volume. \$3 50.
A convenient little handhook, clear, concise, and accurate in its melbod, and admirably folfilling its purpose of bringiug the subject of which it treals within the comprehension of the general practitioner. - N. C. Med. Jour., June, 1579.

FULLER ON DISEASES OF THE LUNGS AND AIRPASSAGES. Their Patbologs, Physical Diagnosis, Sympions, and Treatnent. From the second aud revised English edition. In oue hanitsome ocatvo volune of about 500 pages: cloth, $\$ 350$.

SMITH ON CONSUMPTION ; ITS EARLY AND RE. MEDIABLESTAGES. 1 vol. 8vo., pp. 254. \$225. BASHAM ON RENAL, DISEASES: a Clinical Guide to their Diagnosis and Treatment. With Illustrations. In one $12 \mathrm{mo}$. vol of 304 pages, clotb, $\$ 200$. LECTURES ON THE STUDY OF FEVER. BY A. Hengos, M.D., M.R.I.A., Physician to the Meatb Hospital. In one vol. Sro., cloth, \$2 50.

A TREATISE ON FETER. BY ROBERT D. LYON , K.C C. In one octavo voInme of 362 pages, cloth \$2 2.5.

HILLIER'S HANDBOOK OF SKIN DISEASES, for Students and rractitioners. Second $A m$ Ed In one royal $12 \mathrm{mo}$. vol. of $338 \mathrm{pp}$. Withillustrations. Cloth, \$2 25. 
RUMSTEAD (FREEMAN J.), M.D., LL.D., Professor of Venereal Diseases at the Col. of Phys and Surg., Nero York, \&c.

THE PATHOJOGY AND TREATMENT OF VENEREAL DIS. EASES. Including the results of recent inrestigations apon the subject. Fnurth edition, rerised and largoly rewritten with the co-operation of R. W. Taylor, M.D., of New York, Prof. of Dermatolngy in the Univ. of Vt. In one large and handsomenctavo volume of 835 pages, with 133 illustrations. Cloth, $\$ 475$; leather, $\$ 575$; half Russia, $\$ 625$. (Just Ready.)

This work, on its first appearance, immediately took the position of a standard aulhority on its subject wherever the language is spoken, and the success of an Italian translation sbows that it is regarded with equal favor on the Continent of Europe. In repeated editions the author labored sedulously to render it more worthy of its reputation, and in the present revision no pains hare been spared to perfect it as far as possible. Several years having elapsed since the publication of the third edition, wuch material has been accumulated during the interval by the iudustry of syphilologi-ts, and new views have been elunciated. All this sn far as confirmed by observation and experience, has been incorporated; many portions of the volume been rewritten, the series of illustrations has been enlarged and improved. and the whole may be regarded rather as a new work than as a new edition. It is confidently presented as fully on a level with the most advanced condition of syphilology, and as a work to which the practitioner miy refer with the certainty of finding clearly and succinctly set forth waterer falls within the scope of such a treatise.

We bave to congralulate our conntrymea apon will mare than repay him for the ontiay.-Archives the traly valuable addition which they have made of Medicine, April, isao.

to A mericna literature. The csrefal esitmate of the value of the volume, which we hare made, jnstifies ns in deciaring that tijis is the best treatise on venpreal disenres in the Englinh language, and, we might add, if there is a better in sny other tongue we cannot nane it; there are certainly no books in which the stadent or the general practitioner can find such a excellent résumé of the literalure of any topic, and such practical suggestions regarding the treatment of the vartons complications of every renereal direase. We take pleasare in repeating that we believe this to be the bert treatise on rene. real dikesee in the Euglish langunge. and we congratulate the anthors upon their brilliant addition to A neerican inedical liserature.-Chicagó Med. Journal and Examiner, February, 1850.

It is, without exception, the most raluable single work on 811 bruaches of the sabject of which it treats in any language. The pathology is sound, the work is, al the sume time, in the highest degree practical, and the hinte that he will get from it for the management of any one case, at all obscare or obstinate,

This a ow clussical work on venereal disease comes to us in fta fourth edition rewritten, enlarged, and materially improved in evary way. Dr. Taylor, ss we had every reason to expect, has performed this part of his work with unasual excellence. We feel that what bas been written has done but scanty jns. tice to the merits of this traly great treatise.-St. Louis Courior of Medicine, Feb. 1850

We find that we have bere prictically a new book - that the statemeut of the title-page, as to the fact that it has been larsely rewritien, is a sufficientiy modest aunon ncement for the important changes in the text. After a thorough examiantion of the pre. sent edition, we can assert confdeatly that the euormous labor we hare described has been here most faithfully and convcientiously performed. $\rightarrow$ Amer. Journ. Med. Sci., Jan. 1650.

It is one of the best geveral trestlses on veneres diseases with which we are scquainted, and is especialiy to be recommended as a guide to the trestment of sy philis.-London Practitioner, Jarch, 1850.

\section{CULLERIER (A.), and Surgeon to the Hopital du Midi.}

BUMSTEAD (FREEMAN J.),

Professor of Ventreal Diseases in the College of Plypicions and Surgeons. N. Y

AN ATLAS OF TENEREAI, DISEASES. 'Translated and Edited by

FreEsax.J. ВuмвтвAD. In one large imperial 4 to. volume of 328 pages, double.columns, with 26 plates, containing ahont 150 figures, beautifully colored, many of them the size of life; strongly bound in cloth. $\$ 1700$ : also, in five parts, stout wrappers, ai $\$ 3^{2}$ per part.

Anticipating a very largesale for this work. it is offered at the very low price of T н $R E$ EOL. LARs a Part, thus placing it within the reach of all who are interested in this department of practice. Gentlemen desiring early impressions of the plates would do well to order it without delay. A specimen of the plates and text sent free by mail, on receipt of 25 cents.

LEE'S LECTCRES ON SYPIHL'S AND SOME HILL OX SYPHILIS AND LOCAL CONTAGIOCS

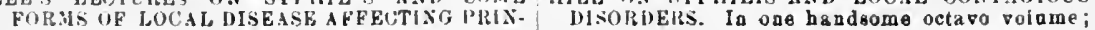
CIPALLY THE ORGANS OF GENERATION. In cloth $\$ 325$.

one haudscme octavo volame; cloth, 32 i.

WEST (CHARLES), M. T.., Physician to the Hospital for Sick Children, Londron, \&c.

I,ECTURES ON THE DISEASES OF INFANCY AND CHIID. HOOD. Fifth American from the sixth revised and enlarged English edition. In one large and handsome octaro volume of 678 pages. Cloth. $\$ 450$; leather, $\$ 550$. (Lately Isszed.)

$B^{Y}$ THE SAME ATTHOR.'(Lately IskUEd.)

ON SOME DISORDERS OF THE N ERTOUS SYSTEM IN CIIID. $1100 \mathrm{D}$; being the Lumleian Lectures deliverell at the Royal College of Phyrioians of London, in March, 1871. In one volume saall $12 m 0 .$, cloth, $\$ 100$.

$B^{Y}$ THE SA YE AUTHOR.

LECTURES ON THE DISEASES OF WOMEN. Third American, from the Third London edition. In one neat octavo volnme of about 550 pages, clotl, $\$ 375$; leather, \$4 75. 
SMITH (J. LEWIS), M.D.,

Clinical Professor of Diseases of Children in the Bellevue Hospttal Med. College, $N Y$.

A COMPLETE PRACTICAL TREATISE ON THE DISEASHS OF

CHILUREN. Fourth Edition, revised and enlarged. In one bandgome octavo volume $0 \cdot$ about 750 pages, with illustrations. Cloth, $\$ 450$; leather, $\$ 550$; half liusvia, $\$ 6$. (Now Reudy.)

The very marked fuvor with which this work has been received wherever the. English language is spoken, bas stimulated the author, in the prejaration of the Fourth Edition, to spare no pains in the endeavor to render it worthy in every respect of a continuance of profession:i] conflence. Many portions of the volume bave been rewritten, and untuch new untter intro. duced, but by an earnest effort at oondensation, the size of the work bas not been waterially increased.

In tie period which has elapsed since the third b th Americanand foreign, eapecially those beariog edition of the work, so extensive have been the ad- on therapenties. Altogether the book bas heen vauces that whole chapters required to be rewritten, greatly improved, wilile it bas not been greatly and hardly a puge conid pass without some materisi increased in size. - New Yurk Medicat Jonernal, correction or addition. This lahor bas occupied the June, 1879.

writer closely, and he has performed it conscien. This excellent work is so well known that an tionsly, so that the book may be considered a faith- ex ended notice at this time wonld be snperfaons. ful portrature of an exceptionally wide clinical The anthor bas taken advantage of the demand for experience in Infantide diseases, currected by a care. another new edit on to reviso in a most careful ful study of the recent literature of the subject. - manuer the entirebook; and the numerons correc. Med. and Surg. Reporter, April 5, 1879.

It is scarcely necessary for ue to 6 ay the work before us is a standard work upon diseakes of children, and that no work has a higherstanding than it upon thuse affectione. In conesquevce of its thorongh revision, the work has been made of more value than erer, and may be regarded as futiy abreast of the times. We cordially commend it to stadante and physiciaus. There is no better work in the language on diserses of cbildren.-Cincinnati Med. Neros, March, 1879 .

The anthor has evidently determined that it $k$ hall not lose ground in the esteem of the profession for want of the latest knowiedge on that important department of medicine. He bas g ccirdingly incorporated in the present edition the usefui and practical resuite of the latest etndy and experience, 1579.

tions and additious evince a determinition on his part to keep fully abreast with the rapid progress that is being made in the knowledge and treatment of children's diseases. By the adoption of a somewhat cloner ty pe, an increase in size of only thirty pages bas been necessitated by the new subject matter introduced.-Boston Med. and Surg.Jour., May 29. 1879.

Probably no other work ever published in this conntry upon a medicai subject has reached such a heighth of popuiarity as has this well-known trea-

tise. As a text and reference-birok it ik pre-eminenily the anthority upon direases of children. It atande deservedly higher in the estimation of the profession than any other work apon the same sub. ject.-Nashville Journ. of Med. and Surg., May,

SWA FNE (JOSEPH GRIFFITHS), M.D.,

Physician-Accoucheur to the British General Hospital, \&c.

OBSTETRIC APHORISMS FOR THE USE OF STUDENTS COMMENCING MIDWIFERY PRACTICE Second American, from the Fifth and Revised Lond on Edition, with Additions by E. R. Hutchiss, M.D. With Illustrations. In one neat 12no. volnme. Cloth, $\$ 125$. (Lately Issued.)

* * See p. 3 of this Catalogue for the terms on which this work is offered as a premium to oubscribers to the "American Journal of the Medical Sciences."

CHORCHILL ON THE PUERPERAL FEVER AND MEIGS ON THE NATURE, SIGNS, AND TREAT.

OTHER DISEASES PECULIARTO WOMEN. 1 VOI. 8 vo., pp. 450, cloth. $\$ 250$.

DEWEES'S TREATISE ON THE DISEASES OF FE

MALFS. With illustrations. Eleventh Edition.

with the Author's lastimprovementsand correc-

lions. In one octavo volume of 536 pages, with

piates, cloth. $\$ 300$.

HODGE (HUGH L.), M.D.,

Emeritus Professor of Obstetrics, \&c., In the University of Pennsylvania.

ON DISEASES PECULIAR TO WOMEN ; including Displicements of the Uterus. With original illustrations. Second edition, revised and eulurged. In one beautifully printed octavo volume of 531 pages, cloth, $\$ 450$.

CHURCHILL (FLEETWOOD), M.D., M.R.I.A.

ON THE THEORY AND PRACTICE OF MIDWIFERY. A new A merican from the fourth revised and enlarged London edition. Witb notes and additions by D. Fravcis Condie, M.D., author of a "Practioal Treatise on the Diseases of Children," \&c. With one hundred and ninety four illustrations. In one rery bandsome octavo volume of nearly 700 large pages. Cloth, $\$ 400$; leather, $\$ 500$.

MONTGOMERY'S EXPOSITION OF THE SIGNS AND SYIIPTONS OF PREGYANCY. With two exquisitecolored piateg, and aumerons wond-cuts. Tn 1 onl. 8vo.. of nearlvannnp..cloth. k3 7.

CONDIE'S PRACTICAL TREATISE ON THE DIS. EASES OF CHILDREX. Sixth edition, revised and augmented. In one large oclatro rolume of nearly 8ro closely.printed pazes, cloth, s5 25; leather $\$ 25$.
RIGBY'S SYSTEM OF MIDWIFERT. With notes and Additicnaj Illustrations. Second American adition. One volume octavo. cloth 422 pHges, *2 sn

SHITH'S PRACTICAL TREATISE ON THE WASTING DISEASES OF INFAXCY AND CH,LDH ICD. Second American, from the eecond revised and entarged Euslish edition. In one bandsome octa. vo voinme, olotb, $\$ 200$. 
THOMAS (T. GAILLARD), M.D., Prnfessor of Obstetrics, de.. in the College of. Physicians and Surgeons, N. Y., \&c.

A PRACTICAL TREATISE ON THE DISEASES OF WOMEN., Fifh edition, thoroughly revised and rewritten. In one lirge and handsome octavo volunie of over 850 pages, with nbout 270 illustrations. (In'Press.)

The author has taken advantage of the opportunity afforded by the call for a new edition of this work to render it worthy a continunnce of the very remarkable faror with which it bas leen received. Every portion of the work has been carefully revised, very much of it has been rewritten, and additions and alterations introduced wherever the advance of science and the increased experience of the author hare shown them desiratile. At the same time special care has been exercised to aroid undue increase in the size of the volume. To accommodate the numerous additions a more condensed but $v$ ry clear letter has been used, notwithstanding which, the number of pages bns been increased by more than fifty. The series of illustrations has been extensively changed; many which seemed to be superfluous have been omilted, and a large number of new and superior drawings have been inserted. In its improved form, therefore, it is boped that the volume will maintain the character it has acquired of a standard authority on every detail of its important suhject.

A few notices of the prerious edition are nppended.

A work which has reached a fonrth edition. and ing light and instruction. Dr. Thomas is a man with a that. ton. in the short space of five years, has nehieved very clearliead and deciced viows, and there scems to a reputation whicl places it almost beyond the reach be nothing which he so much dlslikes as bazy notions of criticism. and the favorable opiniong which we have of diasnosis and blind routlne and unreasanable therasiready expressed of the former elitions seem to re- pentics. The atudent wbo will thoroughly study this quire that we should do little more than announce book and test its principleg by clinical observation, will this new iswue. We cannot refrain from saying that, sertainly not be gailty of thesefaults. L London Lancet, as a praetical work, this is second to none in the Eng- Peb.13.1875.

lish. or. indeed, in any other language. The arrange- Relnctantly we are obllged to clnse this unsalis. ment of the contents, the admirably clear manner in 'actory notice of no excellent a work, and in concln. whict the subject of the dilferential diacnosis nf tion would remark that, as a teacher ofgyacology, geveral of the diseases is handled, leave nothing to be both diduc'lc and clinical, Prof. Thomashas certainly desired by the practitioner who wante a thoronghly both didac lc and clinical, Prof. Thomashas certainly clinical work, one to which he can refer in difficult anthor be certataly bas met with annual and mercases of doubtlul diagnosis with the certainty of gain. lited success, - Am. Journ. of Obstetrics, Nov. 157t.

BARNES (ROBERT), M.D., F.R.C.P.,

A CLINICAL EXPOSITION OF THE MEDICAL AND SURGI. CAL DISEASES OF WOMEN. Second American, from the Second Enlarged nnd Revised English Elition. In nne handenme netavn onlume. of 784 pages, with 181 illustrations. Cloth, $\$ 450$; leather, $\$ 550$; half Russia, $\$ 6$. (Just Ready.)

The call for a new edition of Dr. Barnes's work on the Diseases of Females has encouraged the authnr to make it even more worthy of the favor of the profession than before. By a rearrangement and careful pruning space has been found for a new chapter on the Gynæenlogical Kelations of the Blalder an 1 Bowel Disorders, without incrensing the size of the book, while many new illustrations have been introduced where experience has show $n$ thein to be needed. It is therefore hoped that the volume will be found to reflect thoroughly and accurately the present condition of gynæcological science.

Dr Buraes stads at the head of his profession in the work is a raluable one, and shonld be largely the old conntry, and tt reqnires but scant scrniny cun-nited by the profession.-Am. S:'pp Obstetricil of his book to whow that it has heen sketcbed by a Journ. Gt. Britain and Ireland, Oct. 1s78.

inaster. It is plain, pructical common renke; shows Noother gynacnloglcal work holds a higher posi. very deep revearcli wlthout belng pedantic; is eml- tho, baving become an anthority everywhere in nently ericulated to iampire enthusinsm withont fa- dlseases of women. The work has been bronght culcuting ra-hness: points ont the dangers to be fully ahreast of present knowledge. Every practlaroidrd as well us the nccess to he achiered in the lioner of medicine ahould have it upon the shelres various operutions connected with this hruacb of of his library, and thestndent will fiod lt a saperior medieine: nnd will do mnch to mooth the rugged text-book.- rineinnali Mred. Nevos, Oct. 157s.

path of the yonng gyasculogint and relleve the perplexity of lie in an of thature years. - Canadian Journ. of Meit. Science, Nov. ists.

We pito the doctor who, having any considerahie practice in diseafes of womea, has no copy of "Barnes" for daily consultation and instruction. It ik at once a book of great learning, resentch, and indivldual experience, and at the fame thme eminantip pructical. That it has heen appreciated hy the nrofsision, both in Graat Britaln aud in thig cuuniry, is show by the sfend edition following an woon upon the first,-Am. Practitioner, Nov. 1 1. 75 .

Dr. Bırnes's work is one of a practlcal character, largely illnktrated from cames in $h \mathrm{l} \times \mathrm{OW}$ n experience, bi by nomagn confined tn much, as will be lesrned from the fact that he quoted from ao le:s than 628 medieal anthors in numerons eonatrias. Coming

frora such an anthor. It iN not neceskary to way tbat Oct. Is78

This second revined edliton, of conrse, deserves all the commendation girea to its predeceser, with the additional onethat it appears to lacinde all or nearly all the additions to our $\mathrm{knowledge}$ of lis subject thit have been made mince the appearance of the first edition. The American references are, for an Englbs! work, expecially full and appreciative, and we cra cordially reeommend the votune to American read. ors. -Journ. of Nerpous and Mental Distuse, Oct. 1678.

This eecond editlon of Dr. Barnes's great work comes to us contuining many additions and improrements which briag it ap to dite la every feature. The excellences of the work are too well known to require enuraerution, and we bazard the prophecy that they wil for many yeara malatain ita high poalfion as a standard text-book and guidebook for wtidanik and practltloners, $-N$, C. Med. Journ.,

CHAD WICK (.JAJES R.), A.M., M.D.

A MINUAI, OF THE DISEASES PLCULTAR TO WOMEN. In one neat volume, royal $12 \mathrm{mo}$, , with illustrations. (Preparing.) 
W'WHET (THOMAS ADDIS), M.D.

Surgeon to the Woman's Hospilal, New York, etn.

'TIE PRINCIPLES AND PRAC'IICE OF GYNACOI,OGY, for the use of Students and Practitioners of Medicine. Second Edition. Thorougly Revised. In one large and very handsolue octavo volume of 875 pages, with 133 illustrations. Cloth, \$5; leather, \$6; half Russia, \$6.50. (Just Ready.)

\section{Pheface to the Secono Enition.}

The unusually rapid exhaustion of a large edition of this work, while flattering to the author as an evidence that his laburs bave proved acceptable, has in a great measure heightened his sense of responsibility. Ile has therefore endeavored to take full udvantage of the opportunity nfforded to him for its revision. Every page has received his enrnest scrutiny; the critioisms of his reviewers have been careftully weighed; and while no marked increase has been made in the size of the volume, several portions have been rewritten, and nuch new matter bas been added. In this minute and thorough revision, the labor involved has been much greater than is perhaps apparent in the results, but it has been cheerfully expended in the hope of rendering the work more worthy of the furor which has been accorded to it by the profession.

In no country of the world has gynacology re- not careless reading but profound stndy. Its valne ceived moreattention thulu America. It lo, iben, gs a contribution'ogyngcology is, perhaps, greater

witl a feeling of pleasure that we welcome a work than that of all previona literature on the subject on diseases of women from so emivent a gyaæcolo. gist as Dr. Emmet, and the work isessentially cliaical, and leaves a strong lmpress of the author's iu. dividnality. To eriticice, with the care it merits, the book thronghout, wonld deinaud far more space than is at our command. In paring, we can say that the work teems with orlginal jdeas, fresh and viluable methods of practice, and is written ln a clear aud elegant style, worthy of the literary reputaljon of the country of Lougfellow and Oliver Weadell Holmes.-Brit. Med. Journ., Feb. 21, Isso.

No gynæcological treatlse has appeared which contains an equal amount of nrigiual and useful matter; nor does the medical and surgical bistory of America Inclnde a book more novel and usefal. The tabular and sfatistical information which it coutaius is marvellons, hoth in quanity and accuricy, and cannot be otherwise than invaluable to future investigators. It is a work which demund combined.-Chicago Mrd Gaz., April 5, 1850

The wide repntatlon of the anthor makes lits pab. licatlon an event in the gynzecological world; and a glance throngh fts pages shows that it is a work to be studied with care. . . It must always be a work to be carefully studled and frequeutly consulted by those who practlse this branch of onr profession.-Lond. Med. Times and Gaz, Jan. 10, 1850.

The character of the work is too well known to require extended notice-xuffice it to say that no recent work upon any subject has atlained 8 ch great popnlarity to rapidly. As a work of geveral refarence upon the subjact of Diseases of Women i is inviluable. As a record of the largest clinical experience and observation it has no equal. No phystcian who pretends to keep up with the adrances of this department of medicine cau afford to be withoul it. - Nishville Journ. of Medicine and

$D^{U N C A N(J . ~ M A T T H E}$ WS), M.D., LL.D., F.R.S.E., etc.

CLINICAL LECTURES ON THE DISEASES OF WOMEN, Delivered in Saint Bartholomew's Hospital. In one very neat octavo volume of 173 pages. Cloth, \$1 50. (Just Ready.)

They are in every wy worthy of their author; The anthor is a remarkably clear lectnrer, and indeed, we look upon them as among tbe most valu- bis discassion of symptoms and treatiout is full abe of his contributions They are all np.s mat- and suggestive. It will he a work which will not ters of great interest to the general practitioner. fail to be read with beneft by practitioner:as well Sine of thein deal $\mathrm{wi}^{\text {th }}$ subjects that are not, as a as hy students. - Pliza. Bfed. and Surg. Reporter, rule, adequately handled in the text-books; others Feb. 7, 1850 .

of them, while bedring upon topics that are nsually we have read this hook with a great deal of treated of at length in sucb works, yet bear such a pleasure. It ls foll of good thiogs. The hints on stanp of individnality that, if widely read, as they pathology and treat meul scattered through the book

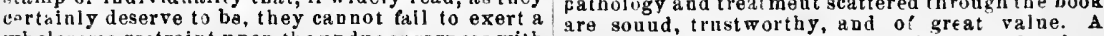
wholesome restraint upon tbe nodue eagerness with bealthy scepticlsm, a jarge experience, and a clear which many yong physicians keem bent upon fol- judgment are everywhere manifest. Instead of lusiug the wild teachings which so infest the gy ua- jwaglis cology of the present day. $-N$.. . Med. Journ., sound character, the book is in every respect a safe Iarch, 1580 .

gnide.-The London Lancet, Jan. 21, 1Ss?.

\section{$R_{\text {AMSBOTHAM (FRANCIS H.), M.D. }}$}

THE PRINCIPLES AND PRACTICE OF OBSTETRIC MEDI. CINE AND SURGERY, in reference to the Process of Parturition. A new and enlarged edition, thoroughly revised by the author. With additions by W. V. Kвativg, M. D., Professor of 0 bstetrics, dc., in the Jefferson Medical College, Philadelphia. In one l:trge and handsome imperial octavo volume of 650 pages, strongly bound in leather, with raised bands; with sixty-four beautiful plates, and numerous wood-cuts in the text, oontaining in all nearly 200 large and beautiful figures. $\$ 700$

WIVCKEL $(F$.$) ,$

Profesgrir and Director of the Gynceolngical Clinic in the Vniversity if Rostock.

A COMPLETE TREATISE ON THE PATHOLOGY AND TREATMENT OF CHILDBED, for Students and Practitioners. Translated, with the consent of the autbor, from the Second German Edition. by JAMES READ CHADWICK, M.D. In one octavo volume. Cloth, $\$ 400$. (Lately Issued.)

TANNER (THOMAS H.), M.D.

ON THE SIGNS AND DISEASES OF PREGNANCY. First Ameriran from the Second and Fnlarged Englisb Edition. With four colored plates and illustrotions on wood. In one handsome octaro rolume of about 500 pages, olotb, $\$ 425$. 
PLAYFAIR (W.S.), M.D., F.R.C.P.,

Prnfessor of Obstet ric Medicine in King's College, etc. etc.

A TREATISE ON THE SCIENCE AND JRACTICE OF MIDWIFERY.

Third American edition, revised by the author. Edited, with additions, by ROBERT P. IIARRIs, M.D. In one handsome octaro volume of about 700 pages, with nearly 260 illustrations. Cloth, \$4; leather, \$5; half Russia, \$5 50. (Just Ready.)

EXTRACT FROM THE AUTHOR'S PREFACE.

The second American edition of my work on Midwifery being exhausted before the corresponding English edition, I cannot better show my appreciation of the kind reception my book has received in the United States than by accerling to the publisher's request that I should myself undertake the issue of a third edicion. As little more than a year has elapsed sinoe the second edition was issued, there are naturally not many changes to make, but I hare, nevertheless, subjected the entire work to careful revision, and introduced into it a notice of most of the more importaot recent additions to obstetric science. To the operation of gastroelytrotomy-formerly described along with the Casarean section-I have now devoted a sepa. rate chapter. The editor of the Second American edition, Dr. Harris, enriched it with many valuable notes, of which, it will be observed, I have freely availed uyself.

Tine medical profesnion bas nuw the opportnuity a very intelligent idea of them, yet all detaits not of adding to their atock of standard medical works necerary for full anderktaoding of the anbject are one of the best volumes on midwifery ever published. part devoted to laborin all its various presentatious. the management and resulis, is admirably arranged, and the riews entertained will be found essentlally modern, and the opinions expressed trnstwurthy The work abonads with plates, illustrating rarious obstetrical positionx; they are admirably wrought, and afford great assistance to the student.-N. O. Med. and Surg. Journ., March, 1850.

If inquired of by a medical student what work on obstetrics we should recommend for him, as par excellence. We would a adoubtedly advise him to choose Playfair's. It is of coureoieut size, but what is of chief importance, its treatment of the varions subjects is concise and plaju. While the discussions and descriptions are sufficiently eluborate to render omitted.-Cincinnati Med. Nev8, Jan. 1880.

The rapidity with which one editton of this work follows another is proof alike of ils excellence and of the estimate that the professiun has formed of it. It is indeed so well known and so higbly valued that nothing need be said of it as a whole. All things considered, we regard this treatise as the very best on Midwifery in the Engiish langaage. $-N$. $Y$. Metical Josrnal, May, 1880.

It certainly is an admirable exposition of the Scieuct and Practice of Jildwifery. Of course the additions ulade by the American edilar, Dr. R. P. Harris, who never nttera an idle word, aud whose studions resenrches in some special departmente of obstecrics are 80 well known to the profession, are of great vilae - The American Practitioner, April, issu.

PARNES (FANCOURT), M.D., Physician to the General Lying.in Hospital, London.

A MANUAL OF MIDWIFERY FOR MIDWIVES AND MEDICAL STUDENTs. With 50 illustrations. In one neat, royal $12 \mathrm{mo}$. volume of 200 pages; cloth, \$1 25. (Now Ready.)

The book is written in plain, and as far as pos. will be popnlar with tbose for whom it bas been sible í nulecbnical langauge. Any jutelligent mid- prepared. The examining questions at the back wife or medical student ean easily comprebend the will be found very useful.-Cincinnati Med. Nevos, dírections. It will undoubtedly fll a want, and Ang. 1\&79.

\section{THE OBSTETRICAL JOURNAL. (Free of postagefor 1880.)}

THE OBSTETRICAL JOURNAL of Great Britain and Ireland; Including MidwerY, and the Diseases or Womar axd Ixpaxs. A montbly of 64 octaro pages, very handsomely printed. Subseription, Three Dollars per annum Single Numbers. 25 cents each.

With the January number will terminate Vol. VII. of the Obateirical Journal. The first No. of Vol. VIII. will be issued abont Feb. 1st; the "AMericas Supplemest" of 16 pages per No. will be diecontinued, and the periodical will thenceforth consist of 64 pages per number, at the exceedingly low price of Turee Dollaps per annuin, free of postage. For this trifling tum the subscriber will thus obtain more than 750 pages per annum, containing an extent and variety of information which may be estimated from the fact that Vol. VI. of the "OBstetaiCAL Jovreal" eontains in

Origisal Communications Hosirital Practice

Gentrat Correspondence KR.ViE:WS of BuOKs.

Procegdisg of Societips : 101 IN MONTULY SUM MaRY, OBSTETRiC 73

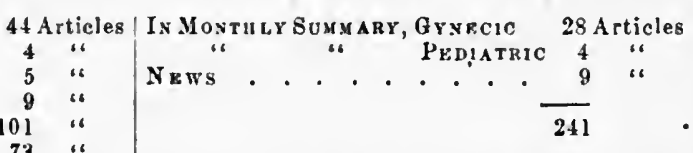

and that it numbers nmong its contributors the distinguished names of LomBe AtтиLt, J. H.

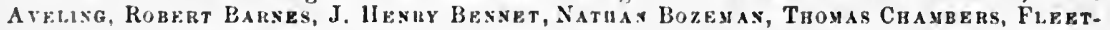
woun Culrchill. Changes Clay, John Clay, J. Matthews Duxcan, Arthur Farre, Robert Greenhalgh, W. M. Graity Hewitt, J. Braxton Hicks, Wilhia Leishan, anges Macdosald, alpred Meadows, Alex. Simpson, J. G. Swaye, Lawgon Tait, Eiward J. Tilt, E. H. Thesholye, T. SPexcer Wells, Artgur Wigglesworta, and many other digtinguished practitioners. Under such auspices it has amply fulfilled its object of presenting to the phywician all that is new and interesting in the rapid developwent of obstetrical and grnacological science.

As a very large increase in the aubreription lizt is anticipated under this reduction in price, gentlemen who propose to subscribe, and suberibers intending to renew their subscriptions, a re recontaended to lose no time in making thoir remittances, as the limited number printed Duas us any time be exhausted. 
LEISHMAN (WILLIAM), M.D.,

Regius Prufessor of Nidwifury in the Oniversty of Glasgov, \&c.

A SYSTEM OF MIOWIFERY, INCLUINTG THE DISEASES OF PREQNANCY AND THE PUERPERAL STATE. Third American edition, revied by the Author, witb additions by JoHn S. PARrY, M.D., Obstetrician to the Philadelphia Iospital, de. In one large and very handsome octavo volume, of 733 pages, wilh over two hundred illusirations. Cloth, $\$ 450$; leatber, $\$ 550$; balf Russia, $\$ 6$. (Just Ready.)

Few works on this suliject have met with as great rior in the English language._Canada Lancet, Jan. a demand ay tbis one appears to have. To judge IS80.

by the frequency with which its a uchor's views ale The hook is greatlyimproved, and as anch will be goted, and Its atstements referred to in obstetrical welcomed by those who are trying to keep posted in literature, one would judge that therearefew phy- the rapid advances which are being made jn the slclans devoting mach attention to obstetrics who study of obstetrics.-Boston Med.and surg Journ., gre withoutit. The author is evideatly a man of Nor $27,1879$.

ripe experlence and conervative views, and in no To the American stadent the work before ns mast branch of mediclae $x$ re these more valuable than in this.-New Remedies, Jan. 18 so.

We gladly welcome the new edition of this excellent text.book of uldwifery. The former editions have been most farorably recelved by the profen. siou on both sides of the Atlantic. In the preparathon of the present edition the author has made such alterations as the progress of obstetricsl science neems to require, aud we cannot but admire the abems to require, aud we cannot but admire the We consider it an admirable text-book for students daring their attendancc npon lectures, and have great pleasnre in recommending it. As au exponent of the midwifery of the present day it bas no snpeprove admirably adapted, complete in all $1 \mathrm{ts}$ parts, ensentrans noted for clearness and precision it will gain in favor and be recognized as a wouk of ktandard merit. The work canot fafl to be popnlar, and is cordially recommended. $-N$. O. Med. and Surg. Journ., March, I8So.

Leisbman'a is certainly one of the best systematic work? on midwilery. It is very complete in all the parta esenentis] for knch a treatie. To practitioner and students it 18 to be strongly recommeuded as a safe and reliable guide to the modern practice of mldwifery.-Canada Med. and Surg. Journal, March, 1Ss?

PARRI (JOHN S.), M.D., Obstrtrician to the Philadelphin Hospital, Vice-Prest. of the Obstet. S ciety of Philadelphia.

EXTRA-UTERINE PREGNANCY: ITS CLINICAL HISTORY, DIAGNOSIS, PROGNOSIS, AND TREATMENT. In one handsome ootavo volume. Cloth, \$2 50. (Lately Issued.)

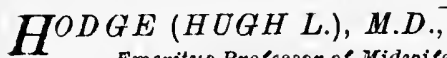

Emeritus Professor of Midwifery, \&c., in the University of Pennsylvania, \&c.

THE PRINCIPLES AND PRACTICE OF OBSTETRICS. Illustrated with large lithographic plates containing one bundred and fifty-nine fignresfrom original photographs, and with numerous wood-cuts. In one large and beautifnlly printed quarto volume of 550 double-columned pages, strongly bound in cloth, $\$ 14$.

The work of Dr. Hodge is something more than body in a ingle volume the whole scienceand art of a simple presentation of his particnlar views in the Obstetrics. An elaborate text is combined with acde artment of Obstetrics; it is something more cnrate and varied pictorial illustrations, fo that no than an ordinarytreatise on midwifery; it is, in fact, fact or principle ls left nnstated or nnexplained. a cyclopædis of midwifery. He has aimed to em- $\mid-A m$. Med. Times, Sept. 3, 1864 .

** Specimens of the plates and letter-press will be forwarded to any address, free by mail, on receipt of six cents in postage stamps.

STIMSON (LE IIIS A.), A.M., M.D., $\mathcal{S}$ Surgeon to the Presbyterian Hospital.

A MANUAL OF OPERATIVE SURGERY. In one very handsome royal $12 \mathrm{mo}$. volume of about 500 pages, with 332 illustrations; cloth, $\$ 250$. (Just Issued.)

The work before $n$ is is mell priated, profusely performing them. The work is handsomely illus11lustrated manal of over four huudred and seventy trated, and the decriptionsarecledrand well drawn. pages. The novice, by a perasal of the work, will It is a clever and useful volume; every student gain a good idea of the general domain of operative shonld possers one. The preparation of this work surgery, while the practical surgeon has presented does away with the nocessity of pondering over to hin within a very concise and intelligible form larger wurks on surgery for descripitions of opera. the latest and most approved selections of operative tions, a + it presents in a nut-6hell just what fs wanted procedure. Theprecision ard conciseness with which by the surgeon without an elaborate search to find the different operations are described enable the it-Md. Ned Journat, Aug. 1878.

author to compress an immense amount of practical The autbor's conciseness and the repleteness of information in a very small compass. $\rightarrow$ N. T. Metienl Recurd, Aug. 3,1878 .

This rolume is devoted entirely to operative snrgery, and is inteuded to famlliarize the student with the details of operations and the different modes of

SKEY'S OPERATIVE SURGERY. In I VOL. 850 . cl., of 650 pages; with about 100 wood-cuts. 325

COOPER'S LECTURES ON THE PRINCIPLESAND PRACTICE OP SURGERT. In I VOL. $\$$ Yo cl'h, $750 \mathrm{p}$. $\$ 2$.

GIBSON'SINSTITUTES AND PRACTICE OF SURGERY. Eighth edit'n, improved and altered. With thirty-four plates. In two handsome oc tavo vol. ames, about 1000 pp., leather. raised bandf. 50.

THE PRINCIPLES AND PRACTICE OF SURGERY.

By Willa y Pirrie, F. R.S.E., P'rofes'r of snrgery

in the University of A be rdeen. Edited by Jous the work with valuable illnstrations entitle it to be classed with the text-books for students of operative surgery, and as one of reference to the practitioner. - Cincinnati Lancet and Ctinic, July 27, 1878 .

NetLl, M.D., Professor of Surgery in the Penna. Medical College, Surg'n to the Pennaylvania Hospital, \&c. In vae rery hendsome octavo rol. of 750 pages, with 316 illust ratious, cloth, 375 .

MILLER'S PRIXCIPLESOF SURGERY. Fourth A mericsn, from the Third Edinburgh Edition. In one larre 8 ro. vol. of 700 pages, with 340 illustrations, cloth, $\$ 375$.

ITLLER'8 PRACTICE OF SURGERY. Fourth American, from the last kdinburgh kition kerised by the tmerican editor. In onelarge 8 vo. vol. of nearly 700 pages, with 364 illustrations: clotb, $\$ 375$. 
GROSS (SAMUEL D.), M.D., Professor of Surgery in the. Jefferson Medical College of Philadelphta.

SYSTEM OF SURGERY: Pathological; Diagnostic, Therapeutic, and Operative. Illustrated by npwards of Fourteen Hundred Engravings. Fifth edition carefully revised, and improved. In two large and beautifully printed imperial octavo volnmes of about 2300 pp., strongly bound in leatber, with raised bands; $\$ 15$; half Russia, raised bands, $\$ 16$.

The continued favor, shown by the exhanstion of successive largeeditions of this great work, proves that it has successfully supplied a want felt by American practitioners and students. In the present revision no pains have been spared by the author to bring it in every respect fully up tc the day. To effect this a large part of the work has been rewritten, and the whole enarged by nearly one-fourth, notwithstanding which the price bas been kept at its former very moderate rate. By the use of a close, though very legible type, an unusually large amount of matter is condensed in its pages, the two volumes containing as much as four or five ordinary octavos. This, combined with the most careful mechanical execution, and its very durable bind ing renders, it one of the cheapest works accessible to the profession. Every subject properly belonging to the lomain of surgery is treated in detail, so that the student who. possesse 8 this work may be said to have in it a surgical library.

We have now brought our task to a conclusion, and ejition of Gross's "Surgery," will confirm his title of have seldom read a work with the practical value of "Primus inter Pures." It is lesrned, scholar-like, niewhich we have been moreimpressed. Every chapter is thodical, precise, and exhaustive. Wo searcely thiuk so concisely put together, that the busy practitioner. sny liring mancould write socompletesnd faultless a when in difficulty, can at ouce find theinformation he treatise, or comprehend more solid, inatructive matter requires. His work, on the contrary, is cosmopolitan. in the given number of pages. The labor must have the surgery of the world being fully represented in it. been immense, and the work gives evidence of grest The work, in fact, is so historically nuprejudiced, and powers of mind, and the highest order of intellectual so eminently practical, that it is almost a false compli. discipline and methodical disposition, and arrangement meat to say that we believe it to be destined to occupy of acquired knowledge sad personslexperience.- N.Y. a foremost place as a work of reference, while a system Med.Journ., Feb.1873.

of surgery like the present system of surgery is the As a whole, we regard the work as the representative practice of surgeons. The printing and binding of the "System of Surgery" in the English language.-St. work is unexceptionable; indeed, it contrasts. in the latter respect, remarkably with English medical and surgical cloth-bound publications, which are generally so wretchedly stitched as to require re-binding before they are any time in use.-Dub. Journ. of Med. Sci. March, $18 \% 4$.

Dr. Gross's Surgery, a great work, has become still greater, both in size and merit, in its most recent form. The difference in actualnumber of pages is not more than 130 , but. the size of the page having been in. creased to what we believe is technically termed "elephant." there hss been room for considerableadditions, which, together with the alterations, are improvements.-Lond, Lancet, Nov.16,1872.

It combiaes. as perfectly as possible, the qualities of a text-book and work of reference. We think this last

Louis . Medical and Surg. Journ., Oct. 1872.

The two magnificent volumes before us a fford a very complete riew of the surgical knowledge of the day. Some yesrs ago we had the pleasure of presenting the first edition of Gross's Surgery to the profersion as a work of unrivalled excellence; and now we have the result of years of experience. labor.and stady, all condensed upon the great work before us. And to students or practitloners desirous of en riching theirlbbrary with a treasure of reference, we can simply commend the purchase of these two rolumes of immense research Gincinnati Lancet and Obsereer, Sept. 1572.

A completesystem of surgery - not s mere text-book of operations, but a scientific account of aurgical thecry and practicein all its departments.-Brit. and For. Med Chir. Rev., Jau. 1873.

\section{B $Y$ THE SAME A UTHOR.}

A PRACTICAL TREATISE ON THE DISEASES, INJURIES, and Malformations of the Urinary Bladder, the Prostate Gland. and the Urethra. Third Edition, thoroughly Revised and Condensed, by SAmuel W. Gross, M.D., Surgeon to the Philadelphia IIospital. In one handsome octavo volume of 574 pages, with 170 illns. trations: cloth, $\$ 450$. (Just Issued.)

For reference andgeneralinformation, the physician leses of the urinaryorgans,-Atlanta Med. Journ., Oct. oreureco can tind nowork that meets their necessities 1876 .

more thoroughly than this. a rerised edition of an ex. It is with pleasure we now again take up this old cellent treatise, and no medical library should be with- work in a decidedly nev dress. Indeed.it must be reout it. Replete with bandsome illustrations and good garded as a new book in rery many of its parta. The idens, it has the unasual adrantage of being easily chapters on "Disenses of the liladder," "l'rostate comprehended, by the reasonable and practical manner Body," and "Litlotomy." are splendid specimens of in which the various aubjects are syotematized and lescriptive writing: while the ehapter on "Stricture" arranged Weheartily recommend it to the profestinn is one of the most concise and clear that we have erer a a valuable addition to the important literature of dif- read.-New York M/td. Journ., Nov. 1876.

\section{$B^{T}$ THE SAMB AUTHOR}

A PRACTICAL TREATISE ON FOREIGN BODIES IN THE AIR-PASSAGES. In 1 vol. 8 vo., with illustrations, pp. 468 , cloth, $\$ 275$.

\section{ORUITT (ROBERT), M.R.C.S., \&c.}

TIE PRINCIPIES AND PRACTICE OF MODERN SURGERY.

A new and revised American, from the eighth enlarged and improved London edition. Illue. trated with four hundred and thirty-two wood engravings. In one rery handsome octaro volume, of nearly 700 large and closely printed pages, cloth, $\$ 400$; leather, $\$ 500$.

All that the surgical student or prsctitionerconld deslre -Dublin Quirterly Journat.

It it a most admirable book. We do not know Then wh hare examined one with more pleasure.Boston Mril. anit Surg. Journal.

In Mr Draltt'a book, thongh contalalngonly nome gevenhundred pager, both the principles sud the practice of aurgery are treated, and eo clearly and perbplcnonsly, as to elucidateovery importan l topic. We arve examined thebook most thorougbly, and cau is y that this anccessis well merited. His book moreover, possessea the 1 aestimahle advantsges of having the aubjects perfectly well arranged ard clnssifad and of belug wriuten in a st vle at once clear and succlact. -Am. Jourralof Med. Srience? 
CAMILTON (FRANK II.) M.D)., LI.I).

A PRACTICAL TREATISE ON FRACTURES AND DISIOCA-

TIONS Sixth edition, thoroughly revised, and mu.h improved. In one very bankone octaro volume of over 900 pages, with 352 illustrations. Cloth, $\$ 550$; leather, $\$ 6.50$;

half Russia, raised bands, $\$ 700$.

The demand which hus go specdily exhausted five large editions of this work, sbows that the uthor has succeded in supplying a wint, felt by the profession at lurge, of an exhautive treatise on a frequent and trubblesome class of acoidents. The nnanimons volice of the profes. sion abroal, as well ns at bome, has pronounced it the most complete work to which the surgeon can refer for information respecting the detnils of the subject. In the prepnrution of this new edition, the nuthor has added a cbnpter on General Prognosis: that on Frnctures of the Patella has been entirely rewritten, in order that the results of a recent exbaustive study of this sub. ject might be given, and, in fact, the entire matter of the book bas undergone most thorough revision. A number of illustrations bave been omitted to make place for new ones, and if few b:lve been inserted from the German edition, published at Göltingen in 1877.

A few notices of the previous edition are appended.

The volume letore us ix (we say it with a prag of a siugle compleie treatise on Fractnres and Disloca. wounded patriotlam) the best and bandiest beok un tions in the Euglisb language. It has reloained fior the snbject iu the Eiglish largoage. It le in vain our American brother to prodace a complete treatise to a tempt a reriew of it; nearly as vain 10 :eek apon the subject. - Londun Lancet.

for any sink, either of commission or omirsiun.Adinburgh Med. and Surg. Journal.

From the great labor and time bentowed upon its preparation, we had been led to aticipate a very thorongh and elaoorate monograph, aud an attentive perusal of ite pages has satisfled us that our expectations hdve been fully realized. The work is by far the most complete disqaisition on fractures and dislocations in the Elg loh language. It is not our inteution to present anything like a formsl a balysis of this work; to do so wonld carry us far beyoud the limits which we liare assigned 10 us, to sy nothing of the fact ihat it would be a matier of - upererogation, ioa: nuch as no intelligent practitioner will be likely to be without a copy of it for reddy nse. No library, however exiensive, will be complete without it - North American Mtdico('hirurgieal R+view.

This is a valuable contribntion to the surgery of mosc important affections, and is the more welcome, ind-much as at the preneut lime we do not possess

Aserery one kuows, this is the most complete and reliable work on tbe subjects of which it treats publlshed in any langnage, not even exceptiıg Jialgaigne's excellent aud staudard treatise. Hence it would be a wate of time and space further to attempt to convince our readers of its excellences. It remains only for us to add that, ta every respuct this flth edition has been thoroughly revised, and contains some fifty pages of new matter more ihan the fourth edition.-Va. Med. Monthly, Jan. Is7t.

For thoroughness, for completeness of defall, and for clearness of illustration, this work is withont its equal-without a rival indef -in its depart. ment of the medical Jiterature of our language. Its ralue is enhauced by the arti-tlc skili displayed in the mechanical execution of the volume.-Pacific Med. and Surg. Journ., Jan, 1576.

There is no better work on the subject in existence than that of Dr. Hamilion. It should be in the possession of every general practitioner and wur. geon.-The Am. Journ. of Obstetrics, Feb. 1576.

A SHHURST (JOHN, Jr.), M.D.,

Arof. of Clinical Surgery, Univ. of Pa., Surgeon to the Episenpal Hospital, Philadelphia.

THE PRINCFPLES AND PRACTICE OF SURGERY. Seeond

edition, enlarged and revised. In one very large and bandsome octarovolume of over 1000 pages, with 542 illustrations. Cloth, $\$ 6$; leather, $\$ 7$; half Russia, $\$ 7.50$ (Just Rea.dy.)

Conscientiousness and thoronghness are two very marked traits of character in the anthor of this book. Out of these traits largely has grown the success of his mental fruit in the past, and the present offer seems in nowise an exception to what has gane before. The general arrangement of the rolune is the sumeas in the first elftion, but every part has been caretuliy revired, and much new matter arded.-Phila. Hed. Times, Feb. 1, 1579.

We have previously spoken of Dr. Ashhurst's work in terms of pralse. We wish to reiterate those terins here, and to add that no more satixfactory representation of modern surgery has yet fallen frotu the press. In point of judicial tairness, of power of condensation, of accurary aud conciseness of expresion and thoroughly good Englinh, Prof. Asbburst has no superior a inong the surgical writers in America.-Am. Practitioner, Jan. 1579.

The attempt to embrace in a volume of 3000 pages the whole field of surgery, general and special, would be a hopeless tank unless through the most tireless industry in collatiog and nirunging, and

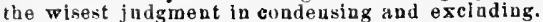
These facilities have been abundantly employed by the author, and he has given as a most excellent treatise, brought up by the revisiun for the second edition to the lintest dite. Of course this bouk is not Lesirned for specialists, but as a course of general surgical knowledge and for general practitioners, and as a text-book for students it is not surpassed by any that has $y$ et appeared, whether of lome or foreign authurship.-N. Carolina Med. Jinernal, Jav. J 579

Ashburit's Surgery is too well known in this conutry to requir special commendation frum us. Thls, its second edition, enlarged and thoroughly revised, brings it nearer our idea of a model textbork than any recently published treatike. Though numerous additions have been made, the size of the work is not materially inereased The main trouble of text-books of modern times is that they are too cumbersome. The student needs a book which will furainh him the most information in the shortent time In every respect this work of Ashburst is the model text-book - full, comprehensive and collpact.-. Yashville Jour. of Med. and Surg., Jan. '79.

The farorabie reption of the first edition is a girarautee of the popularity of this edition, which is fresh from the editur's hands with many enlargeinents and improvements. The author of this work is dexervediy popular as an editor and writer, and his contributions to the literature of surgery have gained for him wlde reputation. The volume now offered the protession will add new laurels to those already won by previons contributions. We can only add that the work is weil arrang, f, flled with practical matter, and coniains in briel and clear language all that is necessary to be tearned by the student of sulgery whilst in attendauce npon lectures, or the general practitioner in his daily routiue practice.-MA. Med. Journal, Jan. J 579.

The fitct that this work has reached a second edi. tion so very soon after the publication of the first we, speuks more highly of its merits than auything we might say in the way of commendation. It -pens lo have immediately gained the favor of stu. deuts and physiciaus.-Cincrn. Med. News, Jau. '79. 


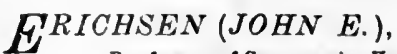

Professor of Surgery in University College, London, etc.

THE SCIENCE AND ART OF SURGERY; being a Treatise on Surgical Injuries, Diseases, and Operations. Carefully revised by the author from the Seventb and enlarged English Edition. Mlustrated by eight hundred and sixty two engravings on wood. Io two large and beautiful octaro volnmes of nearly 2000 pages : cloth, \$50; leather, $\$ 1050$; half Russia, \$11 50. (Nov Ready.)

In revising this standard work the anthor bas spared no pains to render it worthy of a continu. ance of the very marked favor which it has so long enjoyed, by bringing it thoroughly on a level with the advance in the ecience and art of surgery made since the appearance of the last edition. To accomplish this has required the addition of abont two hundred pages of text, while the illustrations have undergone a marked improvement. A hundred and fifty additional wood-cuts have been inserted, while about fifty other new ones bare been substituted for figures which were not deemed satisfactory. In its onlarged and improved form it is therefore presented with the confident anticipation that it will maintain its position in the front rank of text-books for the student, and of works of reference for the practitioner, while its exceedingly moderate price places it within the reach of all.

The geventh edition is before the world as the last word of Bargical science. There may be monography which excel it upon certain points, but as a cons pectus n pon enrgical principles and practice it is naripalled. It will well reward pructitioners to read it, for it has been a peculiar province of Mr. Erichsen to demcastrate the absolute interdependence of medical and anrgical science We need acarcely add, in conclusion, that we heartily com. mend the work to stadents that they may be groonded in a sonnd faith, and to practitioners as an invaluable guide at the bedside.-Am. Practitioner, A pril, 1878 .

It is nofile compliment to say that this fo the vest edition MIr. Erichsen hasever produced of his wellknown book. Besides inheriting the virtues of its predecessors, ir possesses excellences quite its own. Having stated that IIr. Ericheen bas incorporated into i bls edition every recent improvement in the science and art of surgery, it would be a supererogation to give a detalled criticism. In short, we uabesitatiogly arer that we know of no othersingle work where the student and practitloner can gain at once soclear an inaight into the principles of surgery, and 80 complete a knowludge of the exigencies of 8 rgical practice. - London Lancet, Feb. 14, 1579

For the past twenty years Erichsen's Surgery bas malntained itaplaceas the leadingtext-book, notonly in this contry, but la Great Britain. Thatitis able to hold fts gruund, I $\mathrm{s}$ aboudantly proven by the thoroughneks with which the present edition has been reviked, and by the large amount of raluable materisl that has been added. Aside from this, cne hundred and fifty $\mathrm{a} \theta \mathrm{w}$ illngtrations bave been inserted, includtug quite a number of microscopical appear. ances of pathisl igical procenвes. So marked is this change for the better, that the work almost appears a s a entirely new one.-Med. Record, Feb. 23, 157 .

Of the many treatises on Surgery which it has been our task to study, or our pleasure to resd there is none which in sll points has satisfed us so well as the classic treatise of Erichsen. His polished, clear style, his freedom from prejudice and hobbies, his nusurpassed grasp of his subject, and vast clinical experience. qualify bim admirably towrite a model text-book. When wewish, at the least cost of time, to learn the most of a topic in surgery, we turn, by preference, to his work. It is a pleasure, therefore, to see that the appreciation of it is general, and has led to the appearance of another edition.- Med. and Surg. Reporter, Feb, 2, 1878.

Notwithstanding the increase in size, we observe that much old matter has been omitted. The entire work has been thoroughiy written up, and not merely amended by a few extra chapters. A great improvement bas been made in the illustrations. One hundred and tifty new ones have been added, and many of the old ones have been redrswu. The author highly appreciates the fuvor wilh which his work has been received by $A$ merican surgeous, and has endestored to render his latert edition more than ever worthy of their approval. That he bas succeded admirably, must, we think, be the genersl opinion. We heartily recommend the book to both student and practitioner.-N. Y. Med. Journal, Feb. 18\%8.

Erichsen bas stood bo prominently forward for years as a writer on Surgery, that his reputation is wurld wide, and his a mo is as famillar to the med ical studentas to the accomplished and experienced anrgeon. The work in not a reprint of former eds tions, bat has in many places been entirely rewrit. ten. Recent improvements in sargery hare not escaped bis notice, varion new operations buve been thoroughly analyzed, and their meritu thoroughly discassed. One handred and fifty new wood-cats add to the value of this work. - N. O. Med. and Surg. Journet, Jarch, 1878

\section{HOLMES (TIMOTHY), M.D.,}

SURGERY, ITS PRINCIPLES AND PRACTICE. In one hand80 me octaro volnme of nearly 1000 pages, with 411 illustratione. Cloth, $\$ 6$; leather, $\$ 7$; half Russia, $\$ 7$ 50. (Just Issued.)

This is a work which has been looked for on both its force a nd diatinctuess. - N. Y. Med. Record, April -ides ofth Atlantic with mach taterest. Mr. HolmeB $14,1876$.

is a surgeon oflargeand virled experieace, and one It will befonad a most excellent epitome of sarof the best kaowa, and perbaps the mont billikat writer apon surgical inbjects in Eagland. It is a book for students-and an adpirableoue-and for the bang general practitioner. It will giveastudent all the knowledge needed to pans a rigid examina. tlon. The buok falriy jastiferthe high expectalioue that were formed of it. Itsatyle is clearand forcible, oreabrilliant at times, a ad the conclseness needed to briggit withinito properlimits bas aot lmpatred

gery by the reneral pructilioner wh has not the ime to gireariention to more minnie and extended works and to the medicalatudent. I f f ct. weknow of no one we ca a more cordialiy recommend. The wutbor bas succeeded well In glving a plain and practical accouat of each nargical injury and dis. tuse, and of the trestment whleh is most cominunly adrinable. It will nodoubt become a popnlar work in the profession, and especially as s textbook.-Cincinnat Med. New8, spril, 1576.

ASHTON ONTHE DISBASES, INJORIES, AKD JIAIFORMATIONS OF THE KECTUM AXD ANLS: with remarks on Hebitual Constipation. Second A inurican, from the fonrtb and enlarged London Edition. With ll]astrations. In one $\delta \mathbf{v o}$. vol. of 287 pages, cloth, 25.

SARGENT ON BANDAGING ANDOTHER OPERA. TIONS OF MINOR SURGERY. New edition, with a additional chapter on MHlitary Snrgery. One

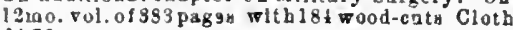
$\$ 175$. 

$B^{R Y A N T}$ Sirgeon to OuOMAS), F.R.C.S.,

THE PRACTICE OF SURGERY. Thirl American, from the Second and Revised English Edition. Thoroughly revised and much improved, by John B Roherts, M.D. In one large and very handsome imperial octuvo volume of over 1050 . pages, with 672 illustrations. (I" l'ress.)

WELLS (J.SOELBERG),

Professor of Ophthatmotogy in King's Gollege Hogpital, \&c.

A TREATISE ON DISEASES OF 'THE EYE. Thirl American, from the Third London Edition. Thoronghly revised, with copious additions, by Chas. S. Ball, M D., Surgeon and Pathologist tu the New York Eye and Ear Intirmary. Illustrated with about 250 engravings on wood, and six colored plates. Together with selections from the Test-types of Jaeger and Snellen. In one large ano very handsome octavo volume of 900 pages. Cloth, $\$ 5$; leather, $\$ 6$; balf Ruscia, raised bands, $\$ 6.50$. (Just Ready.)

The long-continued illness of the author, with its fatil termination, has kept this work for some time out of print, and has deprived it of the advantage of the revision which be sought to give it during the last years of bi: life. This edition has therefore been planed under the editorial supervision of Dr. Bull, who has labored earnestly to introduce in it all the advances which observation and experience have acquired for the theory and practice of ophthalmology since the appenrance of the last revision. To accompish this, considerable additions hare been required, and the work is now presented in the ennfidence that it will fully deserve a continuance of the very marked favor with which it has hilberto been greeted as a complete, but con. cise, exposition of the principles and facts of its important department of medicil science.

The additions made in the previnus American editions by Dr. Hays have been retained, including the very full serles of illustrations und the test-types of Jaeger and Snellen.

\section{NETTLESHIP (ED WARD), F.R.C.S., ophthimic Surg. and Lect. on Ophth. Surg, at St. Thomag' Hospitat. London.}

MANUAL OF OPHTHALMIC MEDICINE. In one royal $12 \mathrm{mo.}$ volume of over 350 pages, with 89 illustrations. Cloth, \$2. (Just Ready.)

The book is written in a cureful and logical manner, and though extremely concise, we have tailed to notice any evidence of ambiguity. It is rendered more compact and homogeneous by frequent references, by puge number, to other portions of the work; repetitions are thas avuided, and we have been surprised to find how much iuformation our memories in respect to the features of sume affecauthor has succeded in conveying in so small a tions.-Cincinnati Med. News, Jun 1580 .

space. A careful study of the book will weil repay The anthor is to be congratalated npouthe rery the geveral praetitiouer, even thongh it sbould enccessful mannerinwhich behas accomplished his serve only as a monitor. It is particularly usefnl task; he has succeeded in being concise withont in the latter regard, as the subject of reatment is sacrificiug clearness, and, inetuling the wbole presented in a thoroughly conselvative manner. - grouud cuvered by more roluminuus text.buoks, N. Y. Med. Recort, Maich 6, 1580 .

The author has snceeded in touching upon abont all the points, operatiuns, diseases ot the eye in relutiou to general diseases, and has prepared a very acceptible book.-Cincinnati Lancet ant Ctinic, Feb. 7, losu.

It is multum in parvo, contuiniug all the logdlog oints to be remembered in the pathology, description, and treatment of diseaser of the eye. It will be louud especially valuable in preparing for examnatiuns. Practltioners wlll find it convenlent as a grou ud covered by more voluminous text-buoks,
has given an excellent ressmé of all the practical iuturmation they contuin. We do not hesitale to prunounce Mr Nettleship's book the best manual on ophthalmic surgery for the use of students and "busy practitiouer." with which we are acquainled. -Am. Jiur. Med. Scitnc s, April, isso.

CARTER (R. BRUDENELL), F.R.C.S., Oplithalmic Surgeon to St. George's Hospital, fte.

A PRACTICAL TREA'TISE ON DISEASES OF THE EYE. Edited, with test-types and. Additions, by JohN GREeN, M.D. (of St. Louis, Mo.). In one handsome octavo volume of about 500 pages, and 124 illustrations. Cloth, $\$ 375$. (Just Issued.)

It is with great plensure that we can endorse the work / chapter is deroted to a discussion of the usesand selecas a most valuable contribution to prnctical ophthal- tion oispectacles, andis admirably compact. plain, and mology. Ir. Carter nererderiates from the end he bas usetul, especially the pgragraphs on the treatunent of iu view, and presents the subject in a clear and concist prexbyopia and myopia. In conclusion, our thanks are mander, easy of comprehension, and hence the mort due the author for many useful hintsin the great subraluable. We would especially commend, bowever, as ject of ophthalmic surgery and therapeutics, a feld worthy of high praise, the manner iu which the thara. where of tate years we glean but a few grninsof sound peutics of disease of the eye is elaborated, for here the wheat from a mass of chatf.-New Vork Medicai Record, author is particulurly elear and practionl, where other Oct. 2;3, 1575.

writers are unfortunately too often deficient. The final

BROWNE (EDGARA.)

surgeon to the Liverpool Eye and Ear Infirmary, and to the Dispensaryfor Skin Diseases.

HOW TO USE THE OPH'THALMOSCOPE. Being Elementary In. structions in 0 phthalmoscopy, arranged for the Use of Students. With thirty-fiveillustra. tions. In one small volume royal $12 \mathrm{mo}$. of 120 pages: cloth, $\$ 1$. (Now Ready.)

LAURENCE'S HANDY-BOOK OF OPHTHALMIC LAWSON'S INJURIES TO THE EYE, ORBIT, SURG ERY, for the use of Praetitloners. Secund edition, revised and enlarged With nnmerons Illnstrulions. ln one very haudsome octaro volume, cioth, $\$ 275$. In one very handoome octavo volume, cloth, $\$ 350$, 
BURNETT (CHARLES H.), M.A, M.D.,

Aursl surg to the Presb. Hoxp., Surgeon-in-eharge of the Infir for Dis. of the Ear, Phila.

THE EAR, I'TS ANA'TOMY. PHYSIOLOGY, AND BISEASES. A Practical Treatise for the Use of Medienl Students and Practilioners. In one hand. some octaro volume of 615 pages, with eighty-seven illustrations: cloth, $\$ 450$; leather, $\$ 550$; hall Russia, \$6 00. (Nono Reudy.)

Recent progress in the investigation of thestructures of the ear, and advances made in the modes of treating its disenses, would seeu to render desirnble a new work in which all the resources of the inost adranced science should be placed at the disposal of the praotitioner. This it bas been the nim of Dr. Burnett to accomplish, and the advantages whicb he hasenjoyed in the special study of the subject are a guarantee that the result of his labors will prove of service to the profession at large, as well as to the specialist in this department.

Foremost among the nomerous recent contribn- Iaedical studeut, and its atudy will well repay the tings to ancal Uteruture will be ranked thls work basy practitionerin the pleasare be will derive from of Dr. Burnett. It is impossble to do justice to the agreeable siyle In which many otherwise dry this volume of over 600 jages la a aecestarily brlel and mostly naknowa sabjects are treated. To the notice. It mast sofice to sdd that the book is pro- specialist the work Ja of the highest valne, and his fnely sad accarately llluxirated, the references иre betuse of gratitude to Dr. Burneit wlll, we hope, be cunacienticusly acknowledged, while the result has proportlonste to the amonat of benefl he can obtain been to produce a treatise which wlll lencefortb frotin the careinl stady of the book, and a constant rank with the classic writjngs of Wilde and Von reference to its trostwortby pagez.-Edinbuigh Trólsch. - The Lond. Practuliuner, Jay, 1579.

On acconat of the great advances which bave been made of late years in otology, und of the increased Intirest manlfested in it, the medical profesnion will welcone thls new work, which presents clearly and conclsely its present sapect, whilnt clearly ladl. cating the direction la which furtber researches cun be mont profiably carried on. Dr. Barn tt from his owa matured experience, and availing himself of the obrervstions and discoverlen of others, has prodaced a work, whlch as a text-book, stand fincile princeps la our language. We had marked sereral pa-gages as well worthy of quotation and the attention of the general practitloner, bat thelr $n$ umber and the space at oar command forbld. Pertaps li is betMed. Jour., A ug. 1578.

The book is deslgned especially for the use of sta. deuty and general practitioners, and places al their disposal nuch valuable insterial. Such a book as the present one, we think, haslongbeen needed, and we in ay cungratulate the sutbor on his saccesa In filling ithe gap. Both etudent and practitioner ean ktady the work whth 8 grest deal of benefit. It is profuvely and beantifully lluntrated, - N. Y. Hospital Gaztte, Oct 15, 1877 .

Dr. Burnett is to be commended for haring written the best book on the snbject in the English languge, and especlally for the care and atteation be has given to the reientlfic side of the subject.- $N$. $Y$. Med. Journ., Dec. 1877.

ter, as the book onght to be ln the hands of every

\section{TAYLOR (ALFRED S.), M.D.,} Lecturer on Med. Jurisp. and Chemistry in Guy's Hospital.

POISONS IN RELATION TO MEDICAL JURISPRUDENCE AND MEDICINE. Third American, from the Third and Revised English Edition. In one large octavo volume of 850 pages; cloth, $\$ 550$; leather, $\$ 650$. (Just Issued.)

The present la based pon the two previous edi-, beihg described which give rise to legalinvestigg * tlons;"balt the completererisiun rendered necesbary tions. - The Clinic, Nov. 6, 1875.

by lime bagcourerted lt lato a new work." This Dr. Taylorbas brougbttobear on the compilation siateusent from the preface cuntalar all that it lide- of this rolume, stures of learaing, experience, and sired to know in reference to the new edition. The practlcal acquai utance wlth blasubject, probshly far

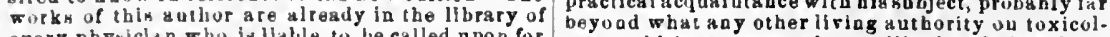
every phyricla $n$ wo is llable to be called apou for ogy could bave auasaed or nillized. He bas fally medicu-legultestimony (and whatenels not?), sothat sustafned his reputation by the consummate skill all that fr tequired to be $k$ now a about the present ad legal acumen he has displayed lu the arrangehuok in that the author bas kept it abreant with the ment of the subject-matter, and the renult is a work times. What makes it auw, as alwaym, enpeclally ou Poisous which will bejadispensabletoevery at araluable to the praciltloner in its concineuess anu dentor practitioner In ia $W$ and medicine. The Dub. practical characier, ouly those poisunounnubitances, lin Journ. of Med. Set., Oct. 1 S7.

\section{B THE SAME AUTHOR.}

MEDICAL JURISPRCDENCE. Eighth American Edition. Edited by Jous J. Reese, M.D., Prcf of Med. Jurisp. in the Univ. of Penn. In one large octavo rolume of nearly 900 pages. (In Press.)

rothe memberk of the legal aud medical profer. best anthorlty on this epecialtyinonilangutage. On alon, it is anuecensary to say anything cominenda. this polnt, bowever, we wllls y thatweconsider br. tury of Tayior's Medical Jarinpradeace. We might Taylor to be the ala fert medjco-legalauthority to fol. as well andertake to speak of the derit of Chitly's low, iageneral, with which we areaequaintedinany Pleallings. - Chicngo Legal Nirus, Oct. 16, 1873.

It is beyond question tbe mont attractlre an well a nont reliable manal uf medical Jurisprudeace publiabed la the Engliab langange.-Am. Juurnal if syphtingraphy, 0ct. 1873.

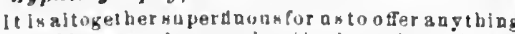
fa bealfota work on tredicaljorinprudencc by an

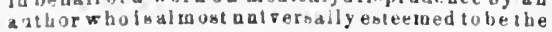

\section{$B^{Y} T H E S A M E A O T H O R$.}

THE PRINCIPLES ANI PRACTICE OF MEDICAL JURISPRU. DENCE. Second Eilition, Kevised, wilb numerous [l]ustrations. In two large octavo volumes, cloth, $\$ 1000$; leather, $\$ 1200$

Thisgreat work is now recognized in England as the fullest and mostauthoritative treatise on e cery department of its improrant subject. In litying it, in its improved form, beforeche $A$ mer. ian profession, the publi-bese trust that itwill assume the sume position in thir country 
Henry C. Lea's Son \& Co.'s Publications-(Miscellaneous).

ROBERTS ( WILLIAM), M.D.

Leeturer on Metictne in the Manchester School of Medicine, etc.

A PRACTICAI, TREA'TISE ON URINARY AND RENAL DIS. EASES, including Urinary Deposits. Illustrated by numerous cases and engravings. Third American, from the Thirlkevised and Enlarged London Edition. In one large and bandsome octavo volume of over 600 pnges. Cloth, \$4. (Just Ready.)

THOMPSON (SIR HENRY), Sirgeon and Professor of Clinicnl Surgery to University College Hospital.

LEC'TURES ON DISEASES OF THE URINARY ORGANS. With illustrations on wood. Second American from the Third English Edition. In one neat octavo volume. Cloth, $\$ 225$. ( ust Issued.)

B Y THESAME AUTHOR.

ON TIF PATHOLOGY AND TREATMENT OF STRICTURE OF TIE URETIIRA AND URINARY FISTULF. With plates and wood-cuts. From the third and revised English edition. In one very handsome octavo volume, cloth, $\$ 350$. (Litely Published.)

TUKE (DANIEL HACK), M.D., Joint author of "The Manual of Psychological Medicine," \&c.

ILLUSTRA'TIONS OF THE INFLUENCE OF THE MIND UPON TIIE BODY IN HEALTH AND DISEASE. Designed to illustrate the Action of the Imagination. In one handsome octavo volume ol 416 pages, cloth, \$325. (Lately Issued.)

BLANDFORD (G. FIELDING), M.D., F.R.C.P., Lecturer on Psychological Medicine at the School of St. Cleorge's Hospital, \&c.

INSANITY AND ITS TREA'IMEN'T: Lectures on the Treatment, Medical and Legal, of Insane Patients. With a Summary of the Laws in force in the United States on the Confinement of the Insane. By IsAAC RAY, M. D. In one very handsome octaro volume of 471 pages; cloth, $\$ 325$.

It eatisfieon want which muss bave been oorely/actnally seen in practice and the appropriate treat. felt bythe basy general practitioners of thisconntry. ment tor them, we find in Dr. Blandford's work a It takes the form of $a$ ta anul of clinicaldescription considerable advance over previons writings on the of the varions forms of insanity, wh a description subject. His pictures of the various forms of mentid of the mode of examining persons suspected of in- disease are so clear and good that no readercan fail 8anity. We call particularattention to this feature to be struck with their superiority to those giren in of the book, as givingit a unique valne to the gene- Jrdinary manuals in the Euglishlanguage or (sofar ral practitioner. If we pass from theoretical conside. ab onr own reading exlends)i nang other. - London rations to descriptions of the varieties of insanityas Practitioner, Feb. 1871.

CEA (HENRF C.).

SUPERSTITION AND FORCE: ESSAYS ON THE WAGER OF LAW, THE WAGER OF BATTLE, THE ORDEAL, AND TORTURE. Third Revised and Enlarged Edition. In one handsome royal $12 \mathrm{mo}$. volume of 552 pages. Cloth, $\$ 250$. (Just Ready.)

This valuable work is in reality a bistory of civi- more accurate than either of the preceding. but, lization as interpreted by the prigress of jurispru. from the thorough elaboration is more like a hardence. .. In "Saperbtition and Force" we have monious concertand less like a batch of stadies. a philosuphic survey of the long period intervening 1 The Nation, Aug. 1, 1878.

between primitire barbility and civi ized eulight enment. There is not a chapter in tbe work that should not be most calefully studied, and howerer webl versed the reader iny be in the scieace of jurisprudence, he will find much in Mr. Lea's rolume of which he was previously igaoraut. The book is a valuable addition to the literature of social science.-Westaninster Rtvitu, Jan. IS\$O.

The appearance of a new edition of Mr. Henry C. Lea's "Superstition and Force" is a sigu that our highest sebolar hip is not without hugor in its nd tive conntry. Mr. Lea has met every fresh demand for bis work with a caretui revision of it, and the present ecition is not only tuller and, if possible,

Many will be tempted to say that this, like the "Declineand Fall,"is one of the uncriticizable books. It tiacts are innumerable, ils deductions simple and inevitable, and its chevaux-de-frise of references bristling and dense enough to make the keenest, stoutest, and best equipped assuilant think twice before advancing. Nor is there anything controrersial in it to provuke assault. The author is no polemic. Thongh be obviously feels and thinks strougly, he succeede in attuining impartiality. Whetler looked on as a picture or a mirror, a work such as this has a lastiug value.-Lippincott"s Hagazine, Oct. Isis.

BY THE SAME AUTHOR. (Late'y Published.)

STUDIES IN CHURCH IISTORY-THE RISE OF THE TEM.

PORAL POWER-BENEFIT-OF CLERGY-EXCOMMUNICATION. In one large royal $12 \mathrm{mo}$. volume of $516 \mathrm{pp}$; $\mathrm{cloth}_{,} \$ 275$.

The story was nerer told more calmiy or with has a peculiarimportanceforthe Englishstadent,and greater learning or wiser thought. Weduubt, indeed, 18 a chapter on Ancient Law likely tobe regarded as If any other study of this feld can be compared wit tinal. We can hardly pass from our mention of snch this for clearness, accuracy, and power. - Chicago works as these-witb which that on"sacerdolal Examiner, Dec. 1570 . Mr. Lea's latest work, "St udiesin Church History,"literary phenomenon that the head of one of the first fally austidus the promise of the tirst. It deals with American housesisalso the writer of someofitemost chree subjects - the Temporal Power. Benefit of origiual books.-London Athenaum, Jan. 7, 1571.

Clergy, and Excommnuication, the recurd of which! 


\section{N D X TO CATALOGUE.}

$\Delta$ merlcan Jonral of the Medical Sclence Allen's Analomy

Anatomical Allas, by Sinitbind Horier. Ashton on the Rectam and Anas Atteld'b Chemistry

Ashwellon Diseasen of Femsles

* Ashbarst'o Surgery

Browne on Ophthalnoscope

Browne on the Throat

* Barnetion the Bur

* 3arnes ou Direaces of Women.

Barnes' Midwifery

Bellamy'x Surgical Anatomy

Bryant s Practice of surgery

Bloxarn'e Cheinlotry

biandford on lukanity.

Basham on Rezal Diseares.

Bariholow on Electricliy

burlow Practice ol Medicine

Bowman's (Jobn E.) Practical Chemistry.

* Bristowe's l'ractice

* Bamsiead on Tenereal

B 1 mstead and Cullerier's Atlas of Venereal

-Carpenter's Human Physlology

Carpenter on the Uee and Abuse of Alcohol * Cornil and Ranrier

Carter on the Eye.

Cleland's Dissector

Clanken's Chemistry

Clowes Chemixtry

Centary of A merican Medicine

Chad rick on Diseares of Women

Charcot on the Nervons System.

Chambers on Diet and Regimen

Christisonand Grifth's Dispenastory

Churchill's System of Midwifery

Charchill on Puerperal Fever

Condie on Diseases of Children:

Cooper's (B. B.) Lectareb on Surgery

Callerler's Atlas of Fenereal Diseaner

Cyclopadia of Practical Medlcine

Dancan on Diseases of Women

* Dailon's H ama Physiology

Da pis'r Clínical Lectures

Veweer on Diseases of Females.

Drait's Moderasurgery

* Danglison's Medical Diclionary

Eilis's Deulonstrations in Anatomy

* Erichsen's Syatem of Surgery

* Bmmet on Diseaser of Women

Furquharson's Tilerapeutica

Foster's Pby siology

Fentich's biagnests

Finlayson's Clinjcal Diagnosis

Plint on Respiratory Organs

Fint on the Heart

Fint ${ }^{\circ}$ Practice of Mediclne.

Fint's Eseays

* Filat"s Cirnical sedicine

Fint on Phthtsis

Flint on Percussion

Fotherzill's llandbook of Treatment

Fothergill's A atagonism of Therapeutic Agents F, w

Fox on Dimeanes of the Skjn

Fuller on the Lunga, \&c.

Green's Pathology s nd Morbid Anatomy

Greene's Medichl Chemistry

Gibeon' Surgery

Ginge's Patho,ogical Histology, by Leidy

*Gray'g Anstomy.

Galloway' Analysis

Grifth's (R.E.) Univereal Formulary

Gross on Urinary Qrgatrs

Gross on Forelgn Brdieg in Air.Passages

* Iroso" Syatem of Sorgery

Habershon on the Abromen

* Harnllion on Dis]ocationarad Prsctures.

Hartaborne'g Easentials of Medicine.

Hartanorve \& Conspectus of the Medical sciences

Hartiborae* Aastomy and Pbysiology

Hamilton on Nervons Dikeakes.

Hauth's l'ractich] Anatomy

Hoblyn' Medical Dictionary
PACR

Hodge on Women

Medical Noterand Retectione.

10 Holden's Landiarks

1 .

7

Horner's Anatomy and Histology: :

Hadson on Fever ${ }^{-} \cdot 19$

Hill on Fenereal Diseases: $\cdot{ }^{-} \cdot{ }^{-},{ }^{-}$

Hilller' Handbook of Skin Diseases

Jones (C. Handtleid) on Nervous Disorders. 18

Knapp's Chemical Technology. 11

Lea's Superstitionand Force : . : : 31

Lea ${ }^{\circ}$ Studies in Church History • • 31

Lee on Syphilis

Lelshman's Midwifery

La Roche on Pnenmonis, \&c.

Lanrence and Moon's Opbthalmic Surgery 29

Lawson on the Eye

Lebmann's Pbysiological Chemistry, 2 vols. . 9

hadion's Manal of Examination. ${ }^{*} \cdot{ }^{*}$

Lyon on Fever 19

Medical News and Abstract : : : : 2

Morris on Skin Dinezres . . . . . 1S

Melgr on Puerperal Fever. . : • . 21

Miller's Practice of Snrgery . . . . 25

Miller's Principles of Surgery . . • . 25

Montgomery on Pregnancy . . . . 2l

Nettleship's Ophthalmic Medtcine 29

veiliand Smith's Compendium of Med.

Obstetrical Journal • • 24

Parry on Extra-Uterine Pregnancy : : $\quad 25$

* Parrish' Practical Pharmacy.

Plrrie's System of Surgery.

* Playfalr's Midwlfery. . 24

Quain and Sharpey' Anatomy, by Leidy. $\quad 7$

Pichardaon's Preventire Medicine.

Roberts on Uriasy Dlsesses . . . . 31

Ramsbotham on Parturition $\quad \cdot \quad \cdot \quad \cdot \quad 23$

Rigby's Mtidwifery . . . 21

Rodwell's Dictionary of Sclence. . . . .

Silineon'в Operative Surgery : : : : 25

Swayne'r Obstetric Aphorism . . . .21

seiler on the Throat

argent's Minor surgery

Skey's Operative Surgery . . . . : 26

Siade on Diphtheria... . . 19

chífer's Histology • • • . • ?

* Smith (J. L.) on Chlldren * * 21

Smith (H. H.) and Horner's Anatomtcal Atias: 7

mith (Edward) on Consamption . • . 19

Etille's Therapentics. • : 12

Stille \& Maisch's Dispensatory. : . : 13

Starges on Clinical Mtgdicine . . . : 15

tokes on Fever. $\because 11$

anner's Mannal of Clinical

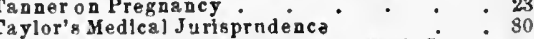

Taylor's Principles and Practice of Med Jurisp 30

Taytor on Poisons • . 30

Tuke on the Infuence of the Mind : . : 31

Thomar on Diseaser of Females: : : 22

Thompson on Uriuary Organs . $\quad \cdot \quad \cdot \quad 81$

holi p*on on Strictare.

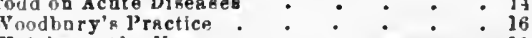

Walsbe on the Heart . . . . 19

Watson's Pructice of Physic * - . - 15

Vest on-Diseaser of Females

Werton Diseaser of Children $: \quad \cdot \quad \cdot \quad: 20$

West on Nervons Disorders of Children: : 20

Williamk on Consamption. 19

Wilson'b Hamandatomy. 7

Wilson's Handhook of Cataneous Medicine: 19

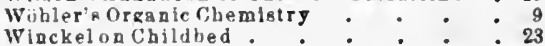

Books markert * are also bound in half Russia.

HENRY C. LEA'S SON \& CO.-Philadelphia. 



THE LIBRARY

UNIVERSITY OF CALIFORNIA

THIS BOOK IS DUE ON THE LAST DATE STAMPED BELOW.
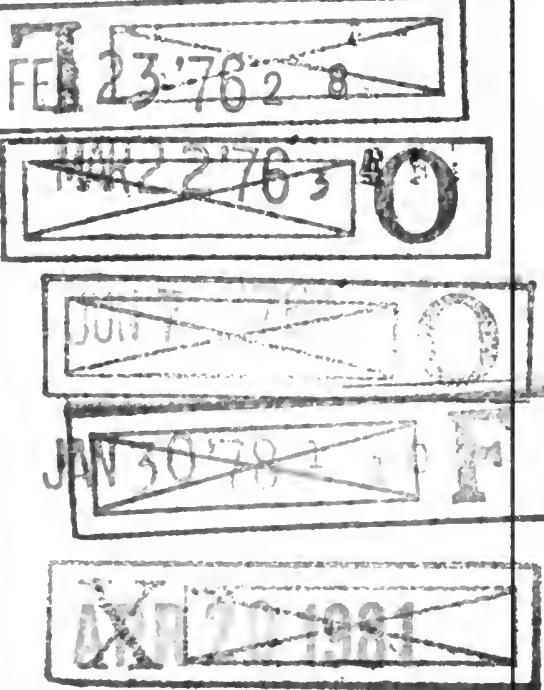


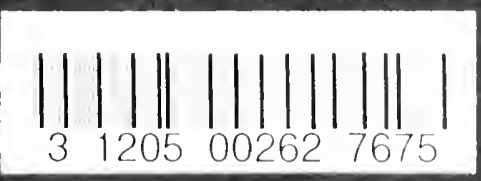

|||||||| | || || ||||| ||||||| $A A$ 
nos

H.

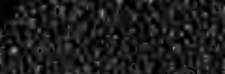

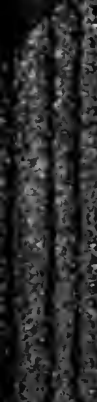

s,

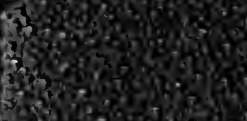

itcos:

ing

$x^{3}$

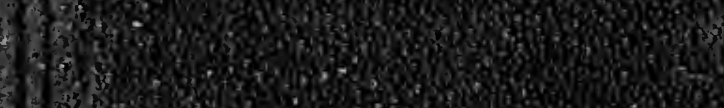

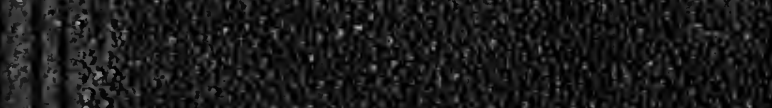

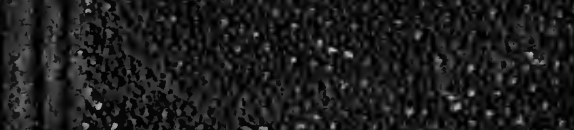

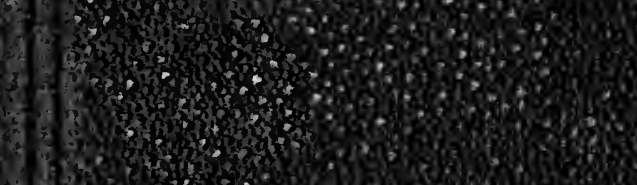

(3), 3 ,

$\frac{1}{3}+3$

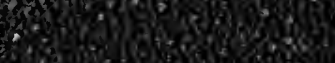

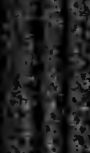

is

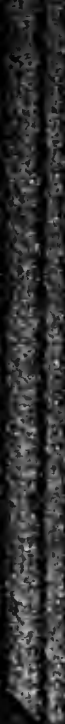

$2 \frac{1}{6}$

ces

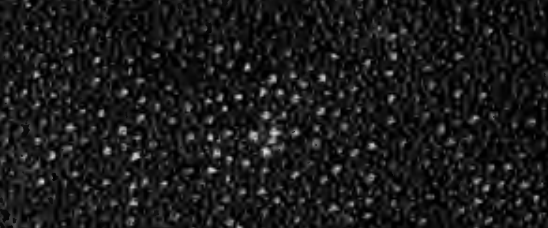

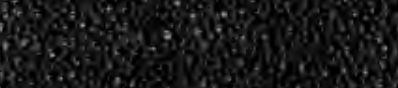

3. 30

130 ons 